\title{
ANÁLOGOS DE FENSTATINAS E ISOCOMBRETASTATINAS BASADOS EN PIRIDINA
}

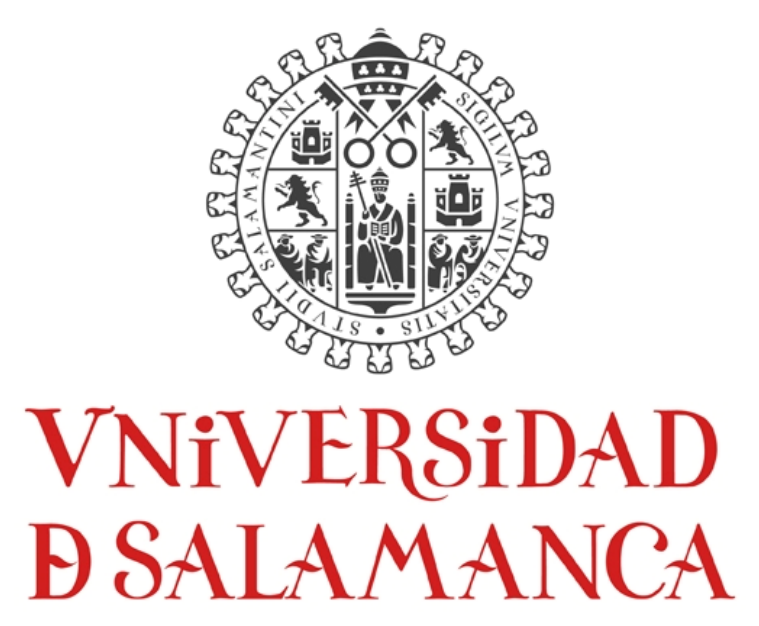

LAURA ARAMBURU VILLAR

TESIS DOCTORAL

FACVLTAD DE FARMACIA

DEPARTAMENTO DE QVIMICA FARMACÉVTICA 



\title{
UNIVERSIDAD DE SALAMANCA
}

\author{
FACULTAD DE FARMACIA
}

DEPARTAMENTO DE QUÍMICA FARMACÉUTICA

Trabajo Presentado Para Optar al Grado de Doctor en Farmacia por:

Laura Aramburu Villar

$\mathbf{V}^{\mathbf{0}} \mathbf{B}^{\mathbf{0}}$

Profesor Manuel Medarde Agustín

Director del Departamento de Química Farmacéutica 

Manuel Medarde Agustín, Catedrático de Química Orgánica, Rafael Peláez Lamamié de Clairac Arroyo, Profesor Titular de Química Orgánica y Raquel Álvarez Lozano, Profesora Ayudante Doctor, del Departamento de Química Farmacéutica, de la Facultad de Farmacia, de la Universidad de Salamanca,

\section{CERTIFICAN:}

Que la licenciada en Farmacia por la Universidad de Salamanca, Laura Aramburu Villar, ha realizado en este Departamento, bajo su dirección, el trabajo titulado "Análogos de Fenstatinas e Isocombretastatinas basados en piridina", para optar al grado de Doctor en Farmacia por la Universidad de Salamanca. Considerándolo finalizado, autorizan su presentación para que sea juzgado por el tribunal correspondiente.

Salamanca, Diciembre de 2014

Fdo. Manuel Medarde Fdo. Rafael Peláez Fdo. Raquel Álvarez 

La financiación de la investigación en este trabajo de Tesis Doctoral ha procedido de los siguientes proyectos:

- Síntesis y evaluación de nuevos agentes antitumorales basados en combretastatinas y fenstatinas: vectorización y modificación del mecanismo de acción. SAF2008-04242 (Ministerio de Ciencia e Innovación 2009-2011).

- Optimización de la aplicabilidad de fenstatinas mediante la combinación con complejos de platino: Diseño, síntesis y evaluación de nuevos agentes citotóxicos de acción doble. SA067A09 (Junta de Castilla y León 2009-2011).

- Heterociclos nitrogenados como constituyentes de nuevos agentes antimitóticos. A1/037364/11 (MAEC-AECID 2011-2013).

- Mejora de la solubilidad acuosa de agentes antimitóticos. Conversión de combrestastatinas, fenstatinas y compuestos relacionados en fármacos útiles para el tratamiento del cáncer. KAC8 (Universidad de Salamanca 2013).

- Optimización de antitumorales inhibidores de tubulina por mejora de propiedades farmacocinéticas. SA147U13 (Junta de Castilla y León (2013-2015).

Su realización ha sido posible gracias a:

- Ayuda para la formación de personal investigador de la Universidad de Salamanca financiada por el Banco Santander (2010-2014). 

Quiero agradecer a todas las personas que han compartido conmigo esta experiencia durante estos últimos años:

A mis directores de tesis, Manolo, Rafa y Raquel porque sin su apoyo y su confianza en mí no hubiera podido realizar este trabajo. Por tener siempre la puerta del despacho abierto para todas mis dudas.

Al Dr. Dominic Campopiano y a todo su grupo, en especial a Ashley Beattie, por acogerme en mi estancia en la Universidad de Edimburgo y hacerme sentir una más del grupo. A mis amigos Eva y Jaime, porque esos tres meses fueron geniales, y a Edimburgo por ser una ciudad perfecta.

A todos mis compañeros del Departamento, por hacerme sentir parte de la familia.

A mis amigos y compañeros de doctorado, Elena, Angie, Younes y los que han pasado por aquí, Carmen, Paula y Vicky. Por todo lo que hemos aprendido juntos. A TFG, TFM, y técnicos que han pasado por el laboratorio, en especial a Uge.

A Chufa, Rocío, Leti, Kope, Marta, Peku, Almu, Cris, por hacer que Salamanca sea la mejor ciudad del mundo. A mis paletos favoritos, por todo lo que hemos vivido y lo que nos queda. Que nunca se nos quiten las ganas de hacer lo que hacemos. A mis Antonias moralejanas (Dolo, Mer, Zule, Leti,..), y a las florecillas farmacéuticas, porque a pesar de la distancia seguimos como si tuviéramos clase juntas al día siguiente.

A mis padres, por confiar en mí, por apoyar siempre mis decisiones. A mi tía Tete, y a mi abuela Esther por ser una de las mejores personas que he conocido. A mis hermanos, sobrinos, y a mis amigas de Ribadesella.

A Chuchi, por todo.

Muchas gracias a todos. 

INDICE Y ABREVIATTVRAS 

A.1. Dominio de unión a colchicina 27

A.2. Compuestos que se unen en el sitio de la colchicina 29

A.3. Farmacóforo y relación estructura-actividad 32

- A.3.1 Modificaciones en el anillo A 33

- A.3.2 Modificaciones en el anillo B $\quad 35$

- A.3.3 Modificaciones en el puente $\quad 37$

B - PLANTEAMIENTO Y OBJETIVOS 39

B.1. Anillo A: anillo de piridina 41

B.2. Puente olefínico 43

B.3. Anillo B 43

B.4. Objetivos 42

C - MÉTODOS Y RESULTADOS $\quad 49$

C.1. Síntesis de fenstatinas 52

- C.1.1. Síntesis de materiales de partida 52

$\rightarrow$ C.1.1.1. Formación de derivados de piridina 53

C.1.1.1.1. Metoxilos como agentes nucleófilos 54

C.1.1.1.2. Metilsulfanilos como agentes nucleófilos $\quad 54$

C.1.1.1.3. Síntesis del ácido 2-metoxi-6- 55 (metilsulfanil)piridina-4-carboxílico

C.1.1.1.4. Síntesis de ácido 2-(dimetilamino)-6- 56 metoxipiridina-4-carboxílico

$\rightarrow$ C.1.1.2. Síntesis de bromoderivados $\quad 56$

- C.1.2. Síntesis de fenstatinas derivadas del ácido isonicotínico 57

$\rightarrow$ C.1.2.1. Reacción de transmetalación $\quad 57$

$\rightarrow$ C.1.2.2. Reacción con ácidos carboxílicos 58

C.2. Síntesis de isocombretastatinas 64

- C.2.1. Metodología general y resultados 64

$\begin{array}{ll}\text { C.3. Modificación de fenstatinas e isocombretastatinas } & 67\end{array}$

- C.3.1. Modificaciones en el anillo B 67

$\rightarrow$ C.3.1.1. Modificaciones en el $p$-metoxifenilo $\quad 68$

C.3.1.1.1. Nitración en posición $3 \quad 68$

C.3.1.1.2. Reducción del grupo nitro 69 
$\rightarrow$ C.3.1.2. Modificaciones en el anillo de indol $\quad 70$

C.3.1.2.1. Formilación $\quad 70$

C.3.1.2.2. Introducción de ácidos carboxílicos $\quad 73$

C.3.1.2.3. Preparación de carbonitrilos $\quad 73$

C.3.1.2.4. Síntesis de amidas $\quad 75$

- C.3.2. Modificaciones en el anillo A 76

$\rightarrow$ C.3.2.1. Oxidación del grupo metilsulfanilo $\quad 77$

$\rightarrow$ C.3.2.2. Introducción de un nuevo anillo aromático 78

- C.3.3. Modificaciones en el puente $\quad 79$

C.4. Síntesis de combretastatinas 83

- C.4.1. Preparación de sales de fosfonio a partir de ácidos 83 isonicotínicos

$\rightarrow$ C.4.1.1. Reducción del ácido a alcohol $\quad 84$

$\rightarrow$ C.4.1.2. Formación del bromoderivado 84

$\rightarrow$ C.4.1.3. Síntesis de las sales de fosfonio de derivados de 85 piridina

- C.4.2. Reacción de Wittig 85

$\begin{array}{ll}\text { C.5. Síntesis de oxadiazolinas } & 87\end{array}$

- C.5.1. Síntesis de 2-metilsulfanil-6 metoxipiridina carbohidrazida 87

- C.5.2. Síntesis de acilhidrazonas 88

- C.5.3. Formación de oxadiazolinas $\quad 89$

$\begin{array}{ll}\text { C.6. Actividad biológica } & 91\end{array}$

- C.6.1. Ensayos de inhibición de polimerización de tubulina 91

$\rightarrow$ C.6.1.1. Aislamiento de la proteína microtubular 91

$\rightarrow$ C.6.1.2. Ensayos de inhibición de polimerización de tubulina 92

$\rightarrow$ C.6.1.3. Determinación de la $\mathrm{IC}_{50} \quad 94$

$\rightarrow$ C.6.1.4. Análisis de los resultados $\quad 95$

C.6.1.4.1. Compuestos con p-metoxifenilo en el anillo B 96

C.6.1.4.2. Compuestos con N-metilindol en el anillo B $\quad 97$

C.6.1.4.3. Compuestos con otros sistemas aromáticos 100 en el anillo $B$

C.6.1.4.4. Compuestos con más de un átomo en el 100 puente

$\rightarrow$ C.6.1.5. Discusión de resultados

- C.6.2. Ensayos de citotoxicidad

$\rightarrow$ C.6.2.1. Análisis de los resultados 
C.6.2.1.1. Compuestos con p-metoxifenilo en el anillo B 106

C.6.2.1.2. Compuestos con $N$-metilindol en el anillo B 108

C.6.2.1.3. Compuestos con otros sistemas aromáticos 111 en el anillo $B$

C.6.2.1.3. Compuestos con más de un átomo en el puente

$\rightarrow$ C.6.2.2. Discusión de resultados $\quad 113$

C.7. Ensayo de solubilidad

117

D - PARTE EXPERIMENTAL

D.1. Técnicas generales

123

- D.1.1. Instrumentación 123

- D.1.2. Técnicas cromatográficas $\quad 124$

- D.1.3. Tratamiento de disolventes y reactivos 124

$\begin{array}{ll}\text { D.2. Métodos generales } & 126\end{array}$

$\begin{array}{ll}\text { D.3. Síntesis de materiales de partida } & 131\end{array}$

D.4. Síntesis de compuestos con un átomo en el puente $\quad 148$

- D.4.1. Síntesis de compuestos con p-metoxifenilo 148

- D.4.2. Síntesis de compuestos con indol 186

- D.4.3. Síntesis de compuestos con naftaleno 246

- D.4.4. Síntesis de compuestos con dimetilaminofenil 252

D.5. Síntesis de compuestos con más de un átomo en el puente $\quad 264$

- D.5.1. Síntesis de combretastatinas 264

- D.5.1. Síntesis de oxadiazolinas 269

$\begin{array}{ll}\text { D.6. Actividad biológica } & \mathbf{2 7 2}\end{array}$

- D.6.1. Ensayos de inhibición de polimerización de tubulina 272

$\rightarrow$ D.6.1.1. Aislamiento de la proteína microtubular 272

$\rightarrow$ D.6.1.2. Ensayos de inhibición de polimerización de tubulina $\quad 274$

$\rightarrow$ D.6.1.3. Determinación de la $\mathrm{IC}_{50} \quad 277$

- D.6.2. Ensayos de citotoxicidad 279

$\rightarrow$ D.6.2.1. Cultivo de células tumorales 279

$\rightarrow$ D.6.2.2. Ensayos de citotoxicidad 280

$\rightarrow$ D.6.2.3. Determinación de la $I C_{50}$ de citotoxicidad 282

D.7. Determinación de la solubilidad $\quad 284$

\begin{tabular}{lr} 
E - CONCLUSIONES & 287 \\
\hline
\end{tabular}

$\begin{array}{ll}F \text { - ESPECTROS } & 291\end{array}$ 


\section{LISTA DE SÍMBOLOS, ABREVIATURAS Y ACRÓNIMOS}

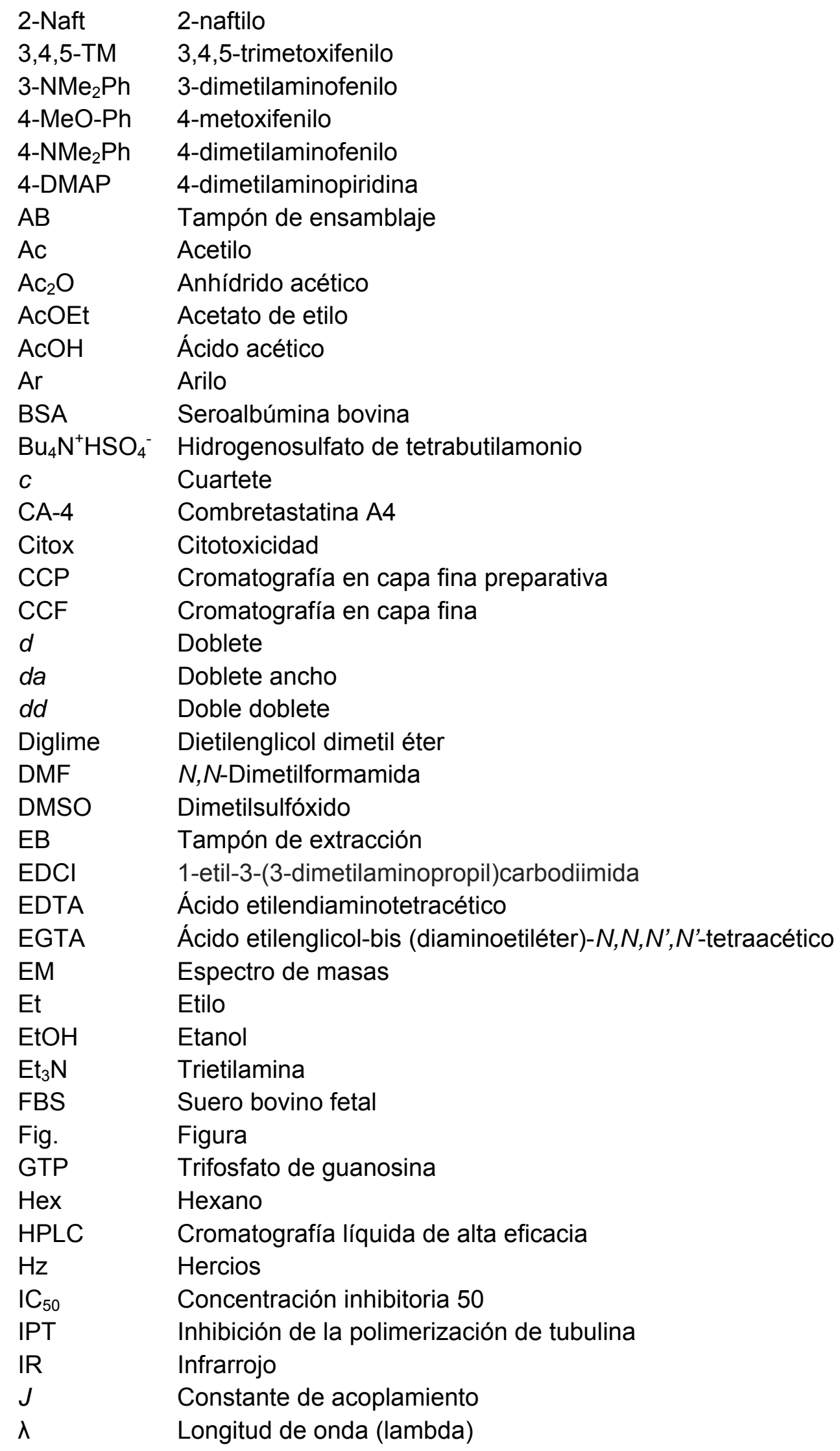




\begin{tabular}{|c|c|}
\hline$m$ & Multiplete \\
\hline$M^{+}$ & Ion molecular \\
\hline MAPs & Proteínas asociadas a microtúbulos \\
\hline $\mathrm{Me}$ & Metilo \\
\hline Mel & Yoduro de metilo \\
\hline $\mathrm{MeO}$ & Metoxilo \\
\hline $\mathrm{MeOH}$ & Metanol \\
\hline $\mathrm{MgCl}_{2}$ & Cloruro de magnesio \\
\hline MTP & Proteína microtubular \\
\hline $\mathrm{NaPi}$ & Tampón sodio fosfato \\
\hline$n$ BuLi & $n$-butillitio \\
\hline $\mathrm{NMe}_{2}$ & Dimetilamino \\
\hline NMeIND & $N$-metil-5-indolilo \\
\hline OMe & Metoxilo \\
\hline${ }^{\circ} \mathrm{C}$ & Grados Celsius \\
\hline$P$ & Grupos fosfato \\
\hline $\mathrm{Pd} / \mathrm{C}$ & Paladio sobre carbono \\
\hline $\mathrm{Pd}(\mathrm{OAc})_{2}$ & Acetato de Paladio II \\
\hline P.f. & Punto de fusión \\
\hline $\mathrm{Ph}$ & Fenilo \\
\hline PMSF & Fluoruro de fenilmetanosulfonilo \\
\hline $\mathrm{PPh}_{3}$ & Trifenilfosfina \\
\hline ppm & Partes por millón \\
\hline pyr & Piridina \\
\hline REA & Relación Estructura- Actividad \\
\hline $\mathrm{RMN}^{1} \mathrm{H}$ & Resonancia magnética nuclear de protón \\
\hline $\mathrm{RMN}{ }^{13} \mathrm{C}$ & Resonancia magnética nuclear de carbono 13 \\
\hline rpm & Revoluciones por minuto \\
\hline$s$ & Singlete \\
\hline sa & Singlete ancho \\
\hline SMe & Tiometoxilo \\
\hline$t$ & Triplete \\
\hline t.a. & Temperatura ambiente \\
\hline$t$-BuOK & terc-butóxido potásico \\
\hline$t-\mathrm{BuONa}$ & terc-butóxido sódico \\
\hline THF & Tetrahidrofurano \\
\hline$t_{R}$ & Tiempo de retención \\
\hline$\delta$ & Desplazamiento químico \\
\hline TB & Tampón de transporte \\
\hline UV & Ultravioleta \\
\hline XTT & Kit de proliferación celular \\
\hline XPhos & 2-diciclohexilfosfino-2', $4^{\prime}, 6^{\prime}$-triisopropilbifenilo \\
\hline
\end{tabular}




\section{RESUMEN}

El cáncer es una de las enfermedades con mayor mortalidad a nivel mundial, por ese motivo, durante los últimos años se han desarrollado multitud de compuestos antitumorales con capacidad para frenar la división anormal de estas células.

La Combretastatina A-4 es uno de los compuestos con estructura más sencilla y mayor potencia capaces de unirse a la tubulina en el sitio de unión de la colchicina, causando la muerte celular mediante la inhibición de la polimerización de esta proteína. Dos de los principales inconvenientes que presenta la CA-4 es su baja solubilidad acuosa y la inestabilidad del doble enlace cis, por este motivo, en nuestro grupo de investigación se diseñan, sintetizan y evalúan análogos de combretastatinas en los que diferentes anillos aromáticos se unen por un puente de un solo átomo en sustitución del doble enlace cis, de manera que se puedan solventar ambos inconvenientes.

En este trabajo nos hemos centrado en la síntesis y evaluación de fenstatinas e isocombretastatinas con anillos de piridina, en sustitución del anillo de trimetoxifenilo de la CA-4 que hasta ahora se consideraba indispensable para la actividad, en un intento de mejorar tanto la potencia como la solubilidad acuosa.

Sobre dicha estructura base, también se han realizado modificaciones en el otro anillo aromático, que se ha reemplazado por $p$-metoxifenilo o $\mathrm{N}$-metilindolilo, habiendo procedido a la introducción de grupos amino, aldehídos, nitrilos, oximas, etc.

La actividad de estos compuestos ha sido evaluada in vitro mediante ensayos de inhibición de polimerización de tubulina, y ensayos de citotoxicidad sobre cultivos celulares tumorales (Hela, HT29, HL60). Así mismo, también se ha determinado la solubilidad acuosa de los compuestos.

Los compuestos sintetizados presentan un notable incremento de la solubilidad acuosa y, en su mayor parte, mantienen una elevada potencia citotóxica y como inhibidores de la polimerización de la tubulina. 
Cancer is one of the diseases with highest mortality worldwide, for this reason, in the last years numerous antitumoral compounds have been developed to disrupt the abnormal division of these cells.

Structurally combretastatin A-4 is one of the simplest compounds with higher potency and capacity to bind to tubulin at the colchicine site, causing cell death by tubulin polymerization inhibition. Two of the major disadvantages of the CA-4 are their low aqueous solubility and the cis double bond instability. For this reason, our research group is focused in the design, synthesis and evaluation of combretastatin analogs constituted by different aromatic rings bonded through a single atom bridge replacing the cis double bond, in order to overcome these disadvantages.

In this work we have focused on the synthesis and evaluation of Phenstatins and Isocombretastatins with pyridine rings, replacing the trimethoxyphenyl ring of CA-4 that until now was considered essential for the activity, in an attempt to improve the potency and aqueous solubility.

Modifications in the other aromatic ring have been carried out by replacing it with a p-methoxyphenyl or $\mathrm{N}$-methylindolyl and by the introduction of amino groups, aldehydes, nitriles, oximes, etc.

The activity of these compounds has been evaluated in vitro in the tubulin polymerization and cytotoxicity assays on tumoral cell culture (Hela, HT29, HL60). Furthermore, the aqueous solubility of the compounds has also been determined.

The synthesized compounds show a noticeable increase of the aqueous solubility and, most of them, maintain a high potency as cytotoxic agents and tubulin polymerization inhibitors. 
<smiles>[R]c1cc([Y])nc([Y])c1</smiles>

\begin{tabular}{cccc|cccc} 
no & $\mathbf{X}$ & $\mathbf{Y}$ & $\mathbf{R}$ & $\mathbf{n} \mathbf{0}$ & $\mathbf{X}$ & $\mathbf{Y}$ & $\mathbf{R}$ \\
\hline $\mathbf{1}$ & $\mathrm{Cl}$ & $\mathrm{Cl}$ & $\mathrm{COOH}$ & $\mathbf{8}$ & $\mathrm{SMe}$ & $\mathrm{SMe}$ & $\mathrm{CH}_{2} \mathrm{OH}$ \\
$\mathbf{2}$ & $\mathrm{Cl}$ & $\mathrm{OMe}$ & $\mathrm{COOH}$ & $\mathbf{9}$ & $\mathrm{SMe}$ & $\mathrm{SMe}$ & $\mathrm{CH}_{2} \mathrm{Br}$ \\
$\mathbf{3}$ & $\mathrm{Cl}$ & $\mathrm{SMe}$ & $\mathrm{COOH}$ & $\mathbf{1 0}$ & $\mathrm{SMe}$ & $\mathrm{SMe}$ & $\mathrm{CH}_{2} \mathrm{PPh}_{3} \mathrm{Br}$ \\
$\mathbf{4}$ & $\mathrm{SMe}$ & $\mathrm{SMe}$ & $\mathrm{COOH}$ & $\mathbf{1 1}$ & $\mathrm{SMe}$ & $\mathrm{OMe}$ & $\mathrm{CH}_{2} \mathrm{OH}$ \\
$\mathbf{5}$ & $\mathrm{SMe}$ & $\mathrm{OMe}$ & $\mathrm{COOH}$ & $\mathbf{1 2}$ & $\mathrm{SMe}$ & $\mathrm{OMe}$ & $\mathrm{CH}_{2} \mathrm{Br}$ \\
$\mathbf{6}$ & $\mathrm{OMe}$ & $\mathrm{OMe}$ & $\mathrm{COOH}$ & $\mathbf{1 3}$ & $\mathrm{SMe}$ & $\mathrm{OMe}$ & $\mathrm{CH}_{2} \mathrm{PPh}_{3} \mathrm{Br}$ \\
$\mathbf{7}$ & $\mathrm{OMe}$ & $\mathrm{NMe}_{2}$ & $\mathrm{COOH}$ & & & &
\end{tabular}<smiles>[X]c1ccc2c([Y])n(C)cc2c1</smiles>

\begin{tabular}{c|cc} 
no & X & Y \\
\hline $\mathbf{1 4}$ & $\mathrm{CHO}$ & $\mathrm{H}$ \\
$\mathbf{1 5}$ & $\mathrm{Br}$ & $\mathrm{H}$ \\
$\mathbf{1 6}$ & $\mathrm{Br}$ & $\mathrm{CHO}$ \\
$\mathbf{1 7}$ & $\mathrm{Br}$ & $\mathrm{CH}=\mathrm{N}-\mathrm{OH}$ \\
$\mathbf{1 8}$ & $\mathrm{Br}$ & $\mathrm{CN}$
\end{tabular}

$\mathrm{CH}_{3} \stackrel{+}{\mathrm{PPh}_{3}} \overline{\mathrm{I}}$ 19<smiles>COc1c([N+](=O)[O-])cc(Br)cc1[N+](=O)[O-]</smiles><smiles>COc1cc(C(=O)NN)cc(SC)n1</smiles><smiles>[R]C=NNC(=O)c1cc(OC)nc(SC)c1</smiles>

$R: \xi \neg-N^{\prime} 22$

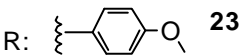

R: 24

COMPUESTOS CON p-METOXIFENILO EN ANILLO B (25-60)

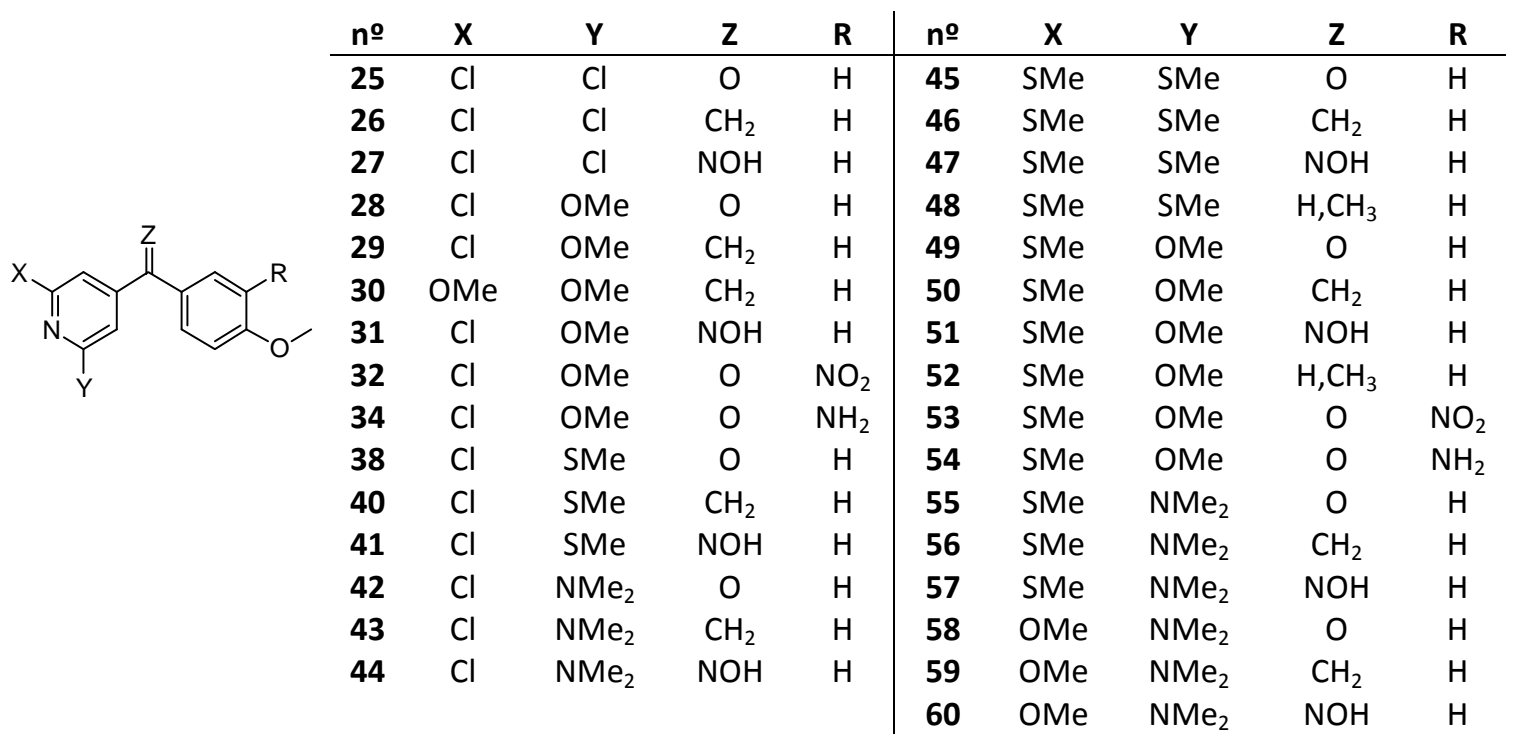<smiles>COc1cc(C(=O)c2cc(OC)c(OC)c([N+](=O)[O-])c2)cc(Cl)n1</smiles><smiles>COc1cc(C(=O)c2cc(N)c(OC)c(N)c2)cc(Cl)n1</smiles><smiles>COc1ccc(C(=O)c2cc(Cl)nc(Nc3ccccc3)c2)cc1</smiles><smiles>COc1ccc(C(=O)c2cc(Cl)nc(Nc3ccc(C)cc3)c2)cc1</smiles><smiles>CCOC(=O)CC(O)(c1ccc(OC)cc1)c1cc(Cl)nc(SC)c1</smiles> 


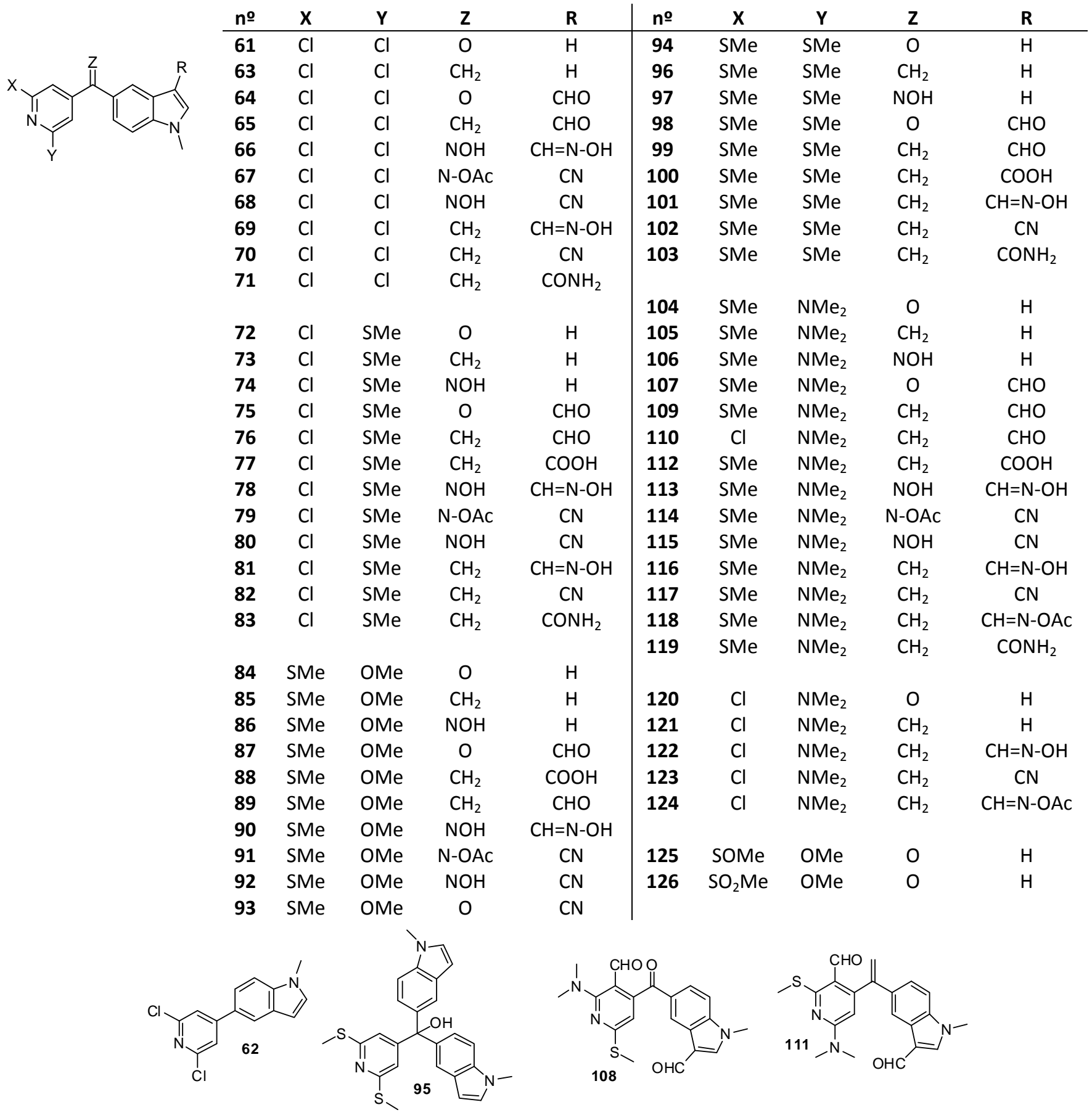

\section{OTROS COMPUESTOS (127-152)}

\begin{tabular}{|c|c|c|c|c|c|c|c|c|c|c|}
\hline & no & $x$ & $\mathbf{Y}$ & $\mathbf{Z}$ & Anillo B & no & $x$ & $\mathbf{Y}$ & $\mathbf{Z}$ & Anillo B \\
\hline & 127 & SMe & OMe & 0 & 2-Naft & 136 & SMe & SMe & $\mathrm{NOH}$ & $3-\mathrm{NMe}_{2} \mathrm{Ph}$ \\
\hline Anillo B & 128 & SOMe & OMe & $\mathrm{O}$ & 2-Naft & 137 & SMe & OMe & $\mathrm{O}$ & $4-\mathrm{NMe}_{2} \mathrm{Ph}$ \\
\hline & 129 & $\mathrm{SO}_{2} \mathrm{Me}$ & OMe & $\mathrm{O}$ & 2-Naft & 138 & SMe & OMe & $\mathrm{CH}_{2}$ & 4-NMe ${ }_{2} \mathrm{Ph}$ \\
\hline$Y$ & 130 & OMe & OMe & O & 2-Naft & 139 & SMe & OMe & $\mathrm{NOH}$ & $4-\mathrm{NMe}_{2} \mathrm{Ph}$ \\
\hline & 131 & SMe & SMe & 0 & 2-Naft & 140 & SMe & SMe & $\mathrm{O}$ & $4-\mathrm{NMe}_{2} \mathrm{Ph}$ \\
\hline & 132 & SMe & SMe & $\mathrm{CH}_{2}$ & 2-Naft & 142 & SMe & SMe & $\mathrm{CH}_{2}$ & $4-\mathrm{NMe}_{2} \mathrm{Ph}$ \\
\hline & 133 & SMe & SMe & $\mathrm{NOH}$ & 2-Naft & 143 & SMe & SMe & $\mathrm{NOH}$ & $4-\mathrm{NMe}_{2} \mathrm{Ph}$ \\
\hline & 134 & SMe & SMe & $\mathrm{O}$ & $3-\mathrm{NMe}_{2} \mathrm{Ph}$ & 144 & SMe & SMe & $\mathrm{O}$ & 6-NMe $\mathrm{N}_{2}$-pyr-3-il \\
\hline & 135 & SMe & SMe & $\mathrm{CH}_{2}$ & $3-\mathrm{NMe}_{2} \mathrm{Ph}$ & & & & & \\
\hline
\end{tabular}

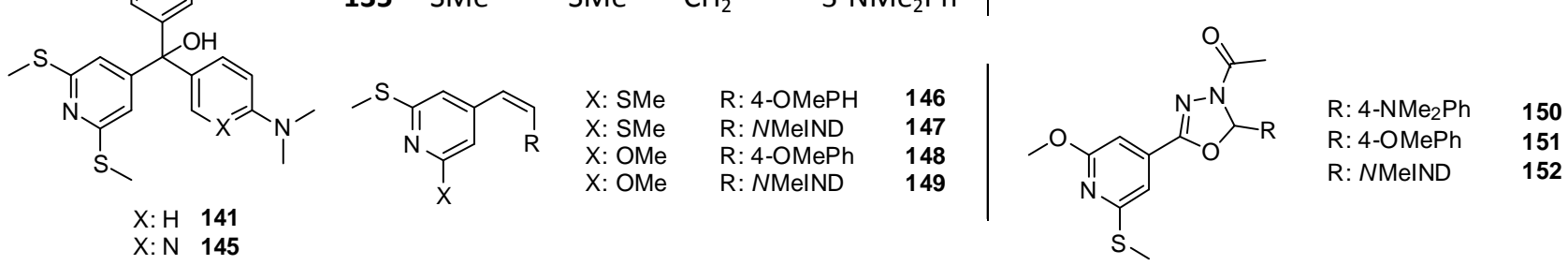


A — INTRODVCCi@́N 

El cáncer es un conjunto de enfermedades que se caracteriza por un crecimiento anormal de células debido a fallos en los sistemas de regulación ${ }^{1}$ que intervienen en los procesos de proliferación celular y de homeostasis. Estos fallos ${ }^{2}$ se deben a alteraciones en los genes que intervienen en el crecimiento y en la muerte celular, y pueden ser heredadas o adquiridas (factores de riesgo, virus, etc). Las células cancerosas pueden invadir otros tejidos a través de la sangre o del sistema linfático provocando metástasis.

Según la OMS, el cáncer es una de las primeras causas de muerte en el mundo. ${ }^{3}$ En 2012 se le estima 8,2 millones de defunciones, y se prevé que en 2030 esta cifra pueda llegar a los 12 millones.

En el tratamiento del cáncer es frecuente el uso de quimioterapia con fármacos que afectan a la división celular, alterando la función de elementos que participan en ella como los microtúbulos ${ }^{4}$, que son polímeros de proteínas que forman parte del citoesqueleto celular y tienen un papel fundamental durante la división celular ya que

\footnotetext{
${ }^{1}$ Hanahan D, Weinberg RA. The hallmarks of cancer. Cell, 2000, 100, 57-70.

${ }^{2}$ Instituto Nacional de Cáncer. Última actualización: 7 de marzo de 2014. http://www.cancer.gov/espanol/cancer/que-es

${ }^{3}$ Organización Mundial de la Salud. Última actualización: Febrero 2014. http://www.who.int/mediacentre/factsheets/fs297/en/

${ }^{4}$ Jordan MA, Wilson L. Microtubules as a target for anticancer drugs. Nat Rev Cancer, 2004, 4, 253-265.
} 
forman el huso acromático que permite la formación de dos células hijas a partir de una célula madre durante la mitosis celular. Además, participan en otros procesos celulares, como el transporte de orgánulos, señalización celular, etc.

Los microtúbulos son estructuras dinámicas ${ }^{5}$ compuestas por heterodímeros de a-tubulina y $\beta$-tubulina, que son codificadas por familias de genes que están relacionadas. Están formados por 13 protofilamentos lineares alrededor de un centro y tienen un extremo + o de crecimiento rápido donde se adicionan dímeros de tubulina, y un extremo - o de crecimiento lento donde se van liberando.

La estructura tridimensional del dímero de tubulina presenta varios sitios de unión $^{6}$, entre los que se encuentran los sitios de unión a compuestos naturales que alteran el funcionamiento de los microtúbulos. Tradicionalmente se han descrito: 2 sitios para GTP y GDP, el sitio del taxol, el sitio de colchicina, el sitio de los alcaloides de la vinca y recientemente se ha descrito el sitio de laulimalida y pelorusido $A{ }^{7} \mathrm{EI}$ mecanismo de acción antitumoral de los compuestos que se unen en el sitio del taxol se basa en la estabilización de la polimerización de la tubulina. Sin embargo, los compuestos que se unen en el sitio de la colchicina y en el sitio de los alcaloides de la vinca actúan inhibiendo la polimerización de la tubulina.

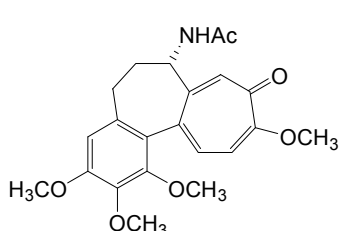

Colchicina

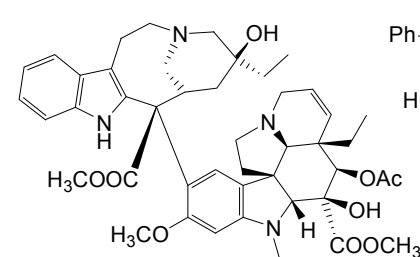

Vincristina

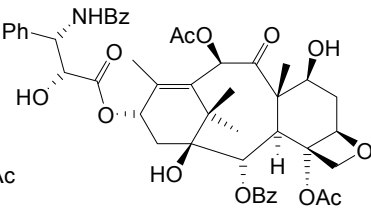

Taxol

Figura 1: Estructuras de colchicina, vincristina y taxol.

En este trabajo nos hemos centrado en la síntesis de compuestos que inhiben la polimerización de tubulina uniéndose en el sitio de unión a colchicina, por lo que a continuación se describen las características del dominio de unión.

\footnotetext{
${ }^{5}$ Cooper \& Hausman. La Célula. 4a edición. Editorial Marbán Libros. 2008.

${ }^{6}$ Jordan A, Hadfield JA, Lawrence NJ, McGown AT. Tubulin as a target for anticancer drugs: agents which interact with the mitotic spindle. Med Res Rev, 1998,18, 259-296.

${ }^{7}$ Prota AE, Bargsten K, Northcote PT, Marsh M, Altmann KH, Miller JH, et al. Structural basis of microtubule stabilization by laulimalide and peloruside A. Angew Chem, 2014, 53, 1621-1625.
} 


\section{A.1. DOMINIO DE UNIÓN A COLCHICINA}

El dominio de unión a colchicina ${ }^{8}$ se encuentra localizado en la interfase entre la subunidad alfa y beta del heterodimero de tubulina, y teniendo en cuenta las estructuras de rayos $X$ de los complejos de tubulina con diferentes ligandos, se han descrito tres zonas de interacción (zonas 1,2 y 3$)^{9}$ y un espaciador que comunica las zonas 1 y 2. La colchicina en complejo con la proteína únicamente ocupa las zonas 1 y 2. En la zona 1 se dispone el anillo de tropolona, que es el anillo de 7 miembros, mientras que en la zona 2 se coloca el anillo de trimetoxifenilo. Los ligandos descritos que interaccionan con la zona 3 poseen en la zona 2 un anillo aromático de menor tamaño que el trimetoxifenilo de la colchicina, de manera que permiten a la proteína adoptar una conformación que permite el acceso a la zona 3. A continuación se describen las tres zonas:

- Zona 1. Se encuentra localizada en la interfase con la subunidad alfa. Es una zona hidrofóbica, aunque tiene la posibilidad de establecer enlaces de $\mathrm{H}$ con los ligandos. En esta zona la colchicina acomoda el anillo de 7 miembros, y establece enlaces de Van der Waals con los aminoácidos Vala181, Sera178 y Vala315, además el carbonilo actúa como aceptor de enlaces de hidrógeno con Vala181.

- Zona central (Zona 2). Se encuentra localizada en la subunidad beta. Es una zona hidrofóbica, pero contiene una pequeña zona polar formada por la Cys $\beta 241$, que permite la formación de un enlace de hidrógeno. El anillo de trimetoxifenilo de la colchicina se encuentra encajado en esta zona estableciendo enlaces de Van der Waals con Lysß352, Asnß350, Leuß378, Alaß316, Leuß255, Lys $\beta 254$, Alaß250 y Leuß242. Además, los metoxilos establecen enlace de $\mathrm{H}$ con el tiol de la Cys $\beta 241$.

- Zona 3. Es una zona que se encuentra enterrada en la subunidad beta de la tubulina. Es un bolsillo hidrofóbico, pero conectado a una cavidad polar

\footnotetext{
${ }^{8}$ Massarotti A, Coluccia A, Silvestri R, Sorba G, Brancale A. The tubulin colchicine domain: a molecular modeling perspective. ChemMedChem, 2012, 7, 33-42.

${ }^{9}$ Álvarez R, Peláez R, Medarde M. Current Topics Med Chem, 2015, 0000.
} 
formada por diferentes aminoácidos como Asn $\beta 167$, Gluß200 y Tyrß202. Es la zona más polar del dominio de la colchicina, a diferencia de las otras dos zonas que se caracterizan por su alta hidrofobicidad. Uno de los ligandos que ocupan la zona 3 es la sulfonamida ABT-751, que además es el único ligando que se une en las tres zonas del dominio de la colchicina.

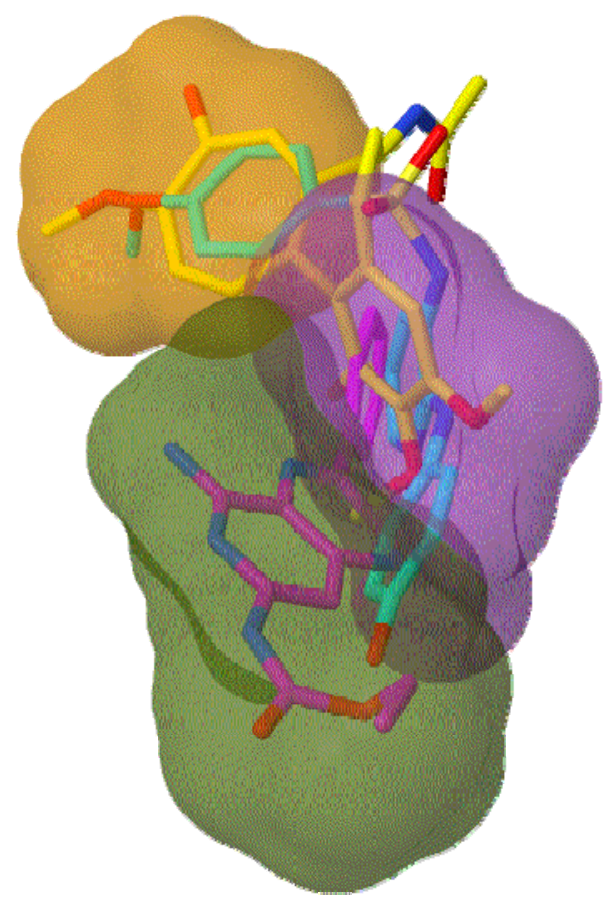

Figura 2. Superposición de las estructuras de colchicina, ABT-751 y G2N y representación esquemática de las partes de los compuestos que interaccionan con las diferentes zonas. La zona 1 está representada en color amarillo, la zona 2 en morado, y la zona 3 en verde.

Una vez descrito el dominio de unión, se van a detallar los diferentes compuestos que se unen y los requerimientos estructurales necesarios para que tengan actividad antitumoral. 


\section{A.2. COMPUESTOS QUE SE UNEN EN EL SITIO DE LA COLCHICINA}

La colchicina es un alcaloide soluble que se aísla de Colchicum Autumnale, y fue el primer agente desestabilizante de la tubulina conocido. ${ }^{6}$ A pesar de su actividad antitumoral, no se utiliza en clínica debido a sus efectos adversos ${ }^{10}$, como neutropenia, anemia, malestar gastrointestinal y daño en médula ósea. Debido a esto, se han sintetizado numerosos análogos de colchicina con el propósito de obtener compuestos que mantengan o incrementen su actividad desestabilizante de tubulina disminuyendo los efectos adversos.

Existen numerosos compuestos naturales y sintéticos que se unen a la tubulina en el dominio de unión de la colchicina ${ }^{10}$ con gran variedad estructural, como quinolonas, lignanos, benzofenonas (fenstatinas), combretastatinas, sulfonamidas, isocombretastatinas, etc; sin embargo ningún inhibidor en el sitio de la colchicina se utiliza actualmente en clínica para el tratamiento de cáncer.<smiles>C=C(c1ccc(OC)c(OC)c1)c1cc(OC)c(OC)c(OCC)c1</smiles><smiles>COc1cc(C2c3cc4c(cc3[C@@H](O)[C@@H]3COC(=O)[C@@H]23)OCO4)cc(OC)c1OC</smiles><smiles>COc1ccc(S(=O)(=O)Nc2ccc(O)cc2Nc2ccccn2)cc1</smiles>

ABT-751<smiles>COc1ccc(-c2ccc(OC)c(OC)c2OC)cc1</smiles>

MTC (bifenilo)<smiles>COc1ccc(OC)c(C(=O)/C(C)=C/c2ccc(N(C)C)cc2)c1</smiles>

Podofilotoxina (lignano)

Figura 3: Compuestos que se unen en el dominio de unión a colchicina.

\footnotetext{
${ }^{10}$ Lu Y, Chen J, Xiao M, Li W, Miller DD. An overview of tubulin inhibitors that interact with the colchicine binding site. Pharm Res, 2012, 29, 2943-2971.
} 
La mayoría de estos compuestos están formados por dos anillos aromáticos, habitualmente nombrados como $\mathrm{A}$ y $\mathrm{B}$, conectados por un puente de entre cero y tres átomos. El anillo $\mathrm{A}$ generalmente es un trimetoxifenilo mientras que el anillo $\mathrm{B}$ presenta mayor variedad estructural.

A pesar de que ningún inhibidor de tubulina se utilice en clínica en el tratamiento del cáncer, existen varios compuestos que se encuentran en avanzados ensayos clínicos, como la sulfonamida ABT-751 ${ }^{11}$ (fase II) y los fosfatos de combretastatina (CA-4-P y CA-1-P) que se encuentran en fase II/III en combinación con otros antitumorales $^{12} \mathrm{o}$ con radioterapia. Además, las combretastatinas presentan actividad antiangiogénica ${ }^{13}$, previenen la formación de nuevos vasos sanguíneos en el tumor mediante la inhibición del complejo VE-cadherina-ßcatenina, necesario para la adhesión de células en el endotelio.

AVE 8062 (Ombrabulina) es un derivado de la aminocombretastatina que mejora la solubilidad acuosa y la disposición oral de la CA-4, y ha demostrado en fase I ser bien tolerado junto a docetaxe ${ }^{14}$ en tumores sólidos avanzados. Actualmente se encuentra en fase III.

\footnotetext{
${ }^{11}$ a) Mauer AM, Cohen EE, Ma PC, Kozloff MF, Schwartzberg L, Coates Al, et al. A phase II study of ABT-751 in patients with advanced non-small cell lung cancer. J Thorac Oncol, 2008, 3, 631-636. b) Hande KR, Hagey A, Berlin J, Cai Y, Meek K, Kobayashi H, et al. The pharmacokinetics and safety of ABT-751, a novel, orally bioavailable sulfonamide antimitotic agent: results of a phase 1 study. Clin Cancer Res, 2006, 12, 2834-2840.

12 a) Study of Combretastatin and Paclitaxel/carboplatin in the treatment of Anaplastic Thyroid Cancer, US National Institutes of Health, http://clinicaltrials.gov/show/NCT00507429. Última actualización enero 2012. b) Zweifel M, Jayson GC, Reed NS, Osborne R, Hassan B, Ledermann J, et al. Phase II trial of combretastatin A4 phosphate, carboplatin, and paclitaxel in patients with platinum-resistant ovarian cancer. Ann Oncol, 2011, 22, 2036-2041.

${ }^{13}$ Tron GC, Pirali T, Sorba G, Pagliai F, Busacca S, Genazzani AA. Medicinal chemistry of combretastatin A4: present and future directions. J Med Chem, 2006, 49, 3033-3044.

14 a) Dose Escalation, Safety and Pharmacokinetic Study of AVE8062 Combined With Docetaxel in Patients With Advanced Solid Tumors. http://clinicaltrials.gov/ct2/show/NCT01907685 Última actualización: Julio $2013 . \quad$ b) http://clinicaltrials.gov/ct2/results?term=AVE+8062
} 
Uno de los avances más significativos para el desarrollo de nuevos fármacos análogos de colchicina fue la publicación de la estructura de rayos $X$ de la DAMAcolchicina (un análogo de colchicina ) unida a tubulina por Ravelli et al ${ }^{15}$ en 2004 , lo que ha dado lugar al inicio de estudios de modelado molecular ${ }^{16}$ de compuestos que se unen en este sitio. Además ha permitido la elaboración de un módelo de farmacóforo a partir de la selección de compuestos con variabilidad estructural que se unen al dominio de la colchicina y tienen actividad antitumoral. A continuación se detalla este modelo de farmacóforo.

\footnotetext{
${ }^{15}$ Ravelli RB, Gigant B, Curmi PA, Jourdain I, Lachkar S, Sobel A, et al. Insight into tubulin regulation from a complex with colchicine and a stathmin-like domain. Nature, 2004, 428, 198202.

${ }^{16}$ a) De Martino G, Edler MC, La Regina G, Coluccia A, Barbera MC, Barrow D, et al. New arylthioindoles: potent inhibitors of tubulin polymerization. 2 . Structure-activity relationships and molecular modeling studies. J Med Chem, 2006, 49, 947-954. b) Romagnoli R, Baraldi PG, Carrion MD, Cara CL, Cruz-Lopez O, Tolomeo M, et al. Design, synthesis and structure-activity relationship of 2-(3',4',5'-trimethoxybenzoyl)-benzo[b]furan derivatives as a novel class of inhibitors of tubulin polymerization. Bioorg Med Chem, 2009, 17, 6862-6871 c) Rappl C, Barbier P, Bourgarel-Rey V, Gregoire C, Gilli R, Carre M, et al. Interaction of 4-arylcoumarin analogues of combretastatins with microtubule network of HBL100 cells and binding to tubulin. Biochemistry, 2006, 45, 9210-9218.
} 


\section{A.3. FARMACÓFORO Y RELACIÓN ESTRUCTURA- ACTIVIDAD}

Las combretastatinas son compuestos naturales extraídos de Combretum caffrum $^{17}$ y son los análogos con estructura más simple, manteniendo una alta potencia citotóxica, que son capaces de unirse al sitio de la colchicina. Presentan el inconveniente de una baja solubilidad acuosa, y la isomerización del enlace cis, que provoca una pérdida en la actividad. Debido a esto se han desarrollado las fenstatinas, que son análogos de combretastatina pero sin la inestabilidad del doble enlace. Otros análogos que se han sintetizado son las isocombretastatinas, isómeros posicionales de las combretastatinas.<smiles>COc1ccc(/C=C\c2cc(OC)c(OC)c(OC)c2)cc1O</smiles>

Combretastatina A4<smiles>COc1ccc(C(=O)c2cc(OC)c(OC)c(OC)c2)cc1O</smiles>

Fenstatina<smiles>C=C(c1ccc(OC)c(O)c1)c1ccc(OC)c(OC)c1</smiles>

Isocombretastatina

Figura 4. Estructura de combretastatina, fenstatina e isocombretastatina.

Para el estudio de la relación estructura actividad de estos compuestos nos vamos a basar en un modelo del farmacóforo. Según el modelo ${ }^{18}$ descrito por Nguyen et al, este farmacóforo consiste en siete puntos organizados en 2 planos diferentes con un ángulo de $45^{\circ}$. Tres aceptores de enlace de hidrógeno (A1, $\left.A 2, A 3\right)$, un dador de enlace de hidrógeno (D1), dos centros hidrofóbicos (H1, H2), y un grupo plano (R1).

\footnotetext{
17 Tron GC, Pirali T, Sorba G, Pagliai F, Busacca S, Genazzani AA. Medicinal chemistry of combretastatin A4: Present and future directions. J Med Chem, 2006, 49, 3033-44.

${ }^{18}$ Nguyen TL, McGrath C, Hermone AR, Burnett JC, Zaharevitz DW, Day BW, et al. A common pharmacophore for a diverse set of colchicine site inhibitors using a structure-based approach. J Med Chem, 2005, 48, 6107-16.
} 


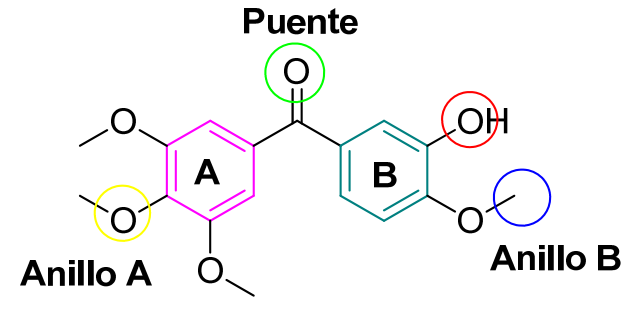

Fenstatinas<smiles>C=C(O)c1cc(OC)c(OC)c(OCCCCCOc2ccccc2)c1</smiles>

Isocombretastatinas

A1 A2 A3 D1 H1 H2 R1

Figura 5. Estructura de fenstatina e isocombretastatina con los puntos del farmacóforo de Nguyen et al.

El anillo $B$ tiene que tener un anillo plano $(\mathrm{R} 1)$, un centro hidrofóbico $(\mathrm{H} 1)$ como puede ser el grupo metoxilo, y un aceptor de enlaces de hidrógeno (A1). El anillo A tiene que tener un centro hidrofóbico $(\mathrm{H} 2)$ y un aceptor de enlaces de hidrogeno (A2). Hay dos puntos adicionales en el puente entre las dos zonas que corresponden a un dador (D1) y un aceptor (A3). Se considera que los puntos esenciales para la actividad son $\mathrm{A} 2, \mathrm{H} 1, \mathrm{H} 2$ y R1. Para la elaboración de este modelo sólo se han tenido en cuenta compuestos que se unen en el sitio de la colchicina en las zonas 1 y 2 .

A continuación se detallan las diferentes modificaciones que pueden llevarse a cabo en la estructura de los compuestos, con los correspondientes cambios en la actividad.

\section{A.3.1. MODIFICACIONES EN EL ANILLO A}

La mayoría de los compuestos que han sido sintetizados para inhibir la polimerización de tubulina tienen en el anillo $A$ un anillo de trimetoxifenilo ${ }^{19}$, ya que se consideraba fundamental para la actividad. Sin embargo, se han desarrollado nuevos compuestos que mantienen la actividad y que introducen modificaciones o carecen de este anillo.

${ }^{19}$ Gaukroger K, Hadfield JA, Lawrence NJ, Nolan S, McGown AT. Structural requirements for the interaction of combretastatins with tubulin: how important is the trimethoxy unit? Org Biomol Chem, 2003, 17, 3033-3037. 
Una de estas modificaciones es la sustitución por un anillo de piridina en posición meta ${ }^{20,21}$ y en posición para. ${ }^{22}$ Estos compuestos, que se colocan en la zona 1 y 2 del dominio de unión de la colchicina, presentan actividad citotóxica aunque no son tan potentes como combretastatina A-4.<smiles>COc1ccc(/C=C\c2cc(OC)c(OC)c(OC)c2)cc1O</smiles>

Combretastatina A4 $\mathrm{IC}_{50}$ IPT: $2-3 \mu \mathrm{M}$ $\mathrm{IC}_{50}$ Citox: $1 \mathrm{nM}$<smiles>COc1ccc(/C=C\c2cc(OC)nc(OC)c2)cc1</smiles><smiles>COc1cc(C(=O)c2ccc3c(ccn3C)c2)cc(OC)n1</smiles>

$\mathrm{IC}_{50} \mathrm{IPT}>20 \mu \mathrm{M}$

$\mathrm{IC}_{50} \mathrm{IPT}>20 \mu \mathrm{M}$<smiles>[R]n1c2ccccc2c2cc(S(=O)(=O)Nc3ccc(OC)nc3OC)ccc21</smiles>

R: Me IC ${ }_{50}$ Citox: $101 \mathrm{nM}$

R: Et IC $\mathrm{IC}_{50}$ Citox: $122 \mathrm{nM}$

Figura 6. Estructura y actividad biológica de compuestos con piridina en el anillo A y Combretastatina A4.

La sulfonamida ABT-751 que se encuentra actualmente en ensayos clínicos, incorpora otro anillo aromático que va unido al anillo $A$, y se une en la zona 3 del dominio de la colchicina. En la estructura de este compuesto se observa que carece de anillo de trimetoxifenilo y en su lugar hay un anillo de piridina, que como se ha visto anteriormente, al ser un anillo más pequeño permite cambiar la conformación de la proteína para que el nuevo anillo aromático se pueda acomodar en la zona 3.

\footnotetext{
${ }^{20}$ Shan G, Li Z, Hu L, Jiang J, Liu Z. N-(2,6-Dimeth-oxy-pyridin-3-yl)-9-methyl-9H-carbazole-3sulfonamide. Acta Crystallogr Sect E Struct Rep Online, 2013, 69, o584.

${ }^{21} \mathrm{Hu}$ L, Jiang JD, Qu J, Li Y, Jin J, Li ZR, et al. Novel potent antimitotic heterocyclic ketones: synthesis, antiproliferative activity, and structure-activity relationships. Bioorg Med Chem Lett, 2007, 17, 3613-3617.

${ }^{22}$ Miguel Lozano Alonso. Tesina de Licenciatura. Universidad de Salamanca 2007
} 
Adicionalmente, existen compuestos que tienen actividad y que no tienen en su estructura anillo $\mathrm{B}$. Estos compuestos están representados por $\mathrm{G} 2 \mathrm{~N}$ y K2N ${ }^{23}$ que son enantiómeros, y por TN16 ${ }^{24}$; y han sido cristalizados junto a tubulina, observándose en su estructura de rayos $X$ que se colocan en las zonas 2 y 3 del dominio. ${ }^{8}$ Recientemente, se han sintetizado compuestos $^{25}$, como el que aparece en la figura que tiene en su estructura un anillo de piridina y se une en la zona 2 y 3 del dominio con una potencia citotóxica $\left(\mathrm{GI}_{50}\right)$ de $200 \mathrm{~nm}$.<smiles>COc1ccc(S(=O)(=O)Nc2cccnc2Nc2ccc(O)cc2)cc1</smiles>

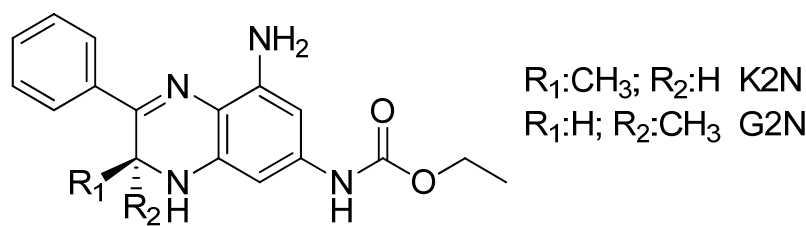<smiles>C/C(Nc1ccccc1)=C1/C(=O)NC(Cc2ccccc2)C1=O</smiles><smiles>COc1ccc(N(C)c2nc(Cl)ccc2C(C)=O)cc1</smiles>

$\mathrm{IC}_{50}$ Citox: 200nM

Figura 7. Estructura de compuestos que se unen en las zonas 2 y 3 del dominio de unión de colchicina.

\section{A.3.2. MODIFICACIONES EN EL ANILLO B}

El anillo de guayacol permite mayor número de modificaciones. Anteriormente en nuestro grupo de investigación se ha visto como la sustitución por un grupo naftaleno ${ }^{26}$

\footnotetext{
${ }^{23}$ de Inés C, Leynadier D, Barasoain I, Peyrot V, García $P$, Briand $C$, et al. Inhibition of microtubules and cell cycle arrest by a new 1-deaza-7,8-dihydropteridine antitumor drug, $\mathrm{Cl}$ 980, and by its chiral isomer, NSC 613863. Cancer Res, 1994, 54, 75-84.
}

${ }^{24}$ Arai T. Inhibition of microtubule assembly in vitro by TN-16, a synthetic antitumor drug. FEBS Lett, 1983, 155, 273-276.

${ }^{25}$ Wang XF, Ohkoshi E, Wang SB, Hamel E, Bastow KF, Morris-Natschke SL, et al. Synthesis and biological evaluation of $\mathrm{N}$-alkyl-N-(4-methoxyphenyl)pyridin-2-amines as a new class of tubulin polymerization inhibitors. Bioorg Med Chem, 2013, 21, 632-642.

26 a) Álvarez $\mathrm{C}$, Álvarez $\mathrm{R}$, Corchete $\mathrm{P}$, Pérez-Melero $\mathrm{C}$, Peláez $\mathrm{R}$, Medarde $\mathrm{M}$. Naphthylphenstatins as tubulin ligands: Synthesis and biological evaluation. Bioorg Med Chem, 2008, 16, 8999-9008. b) Maya AB, Pérez-Melero C, Mateo C, Alonso D, Fernández JL, Gajate $\mathrm{C}$, et al. Further naphthylcombretastatins. an investigation on the role of the naphthalene moiety. J Med Chem, 2005, 48, 556-68. c) Álvarez C, Álvarez R, Corchete P, Pérez-Melero C, 
mantiene una actividad semejante a la de combretastatina A-4. Los mejores resultados se han obtenido con la sustitución por un anillo de $\mathrm{N}$-metilindol ${ }^{27}$, con gran incremento de la actividad tanto en derivados de fenstatina como en isocombretastatinas. Este anillo permite la incorporación de grupos funcionales en posición 3 , como ácidos carboxílicos, carbonitrilos, amidas y aldehídos, que incrementen la solubilidad acuosa de los compuestos, y hace posible la conjugación con aminoácidos para la formación de profármacos.

Otros grupos de investigación han incorporado un anillo de piridina $28,29,30,31,32$ en este anillo, como puede observarse en la siguiente figura. Estos compuestos mantienen la actividad citotóxica, incluso alguno tiene su $\mathrm{IC}_{50}$ en rango nanomolar.

Peláez R, Medarde M. Synthesis and biological activity of naphthalene analogues of phenstatins: naphthylphenstatins. Bioorg Med Chem Lett, 2007, 17, 3417-3420.

${ }^{27}$ Álvarez R, Puebla P, Díaz JF, Bento AC, García-Navas R, de la Iglesia-Vicente J, et al. Endowing indole-based tubulin inhibitors with an anchor for derivatization: Highly potent 3substituted indolephenstatins and indoleisocombretastatins. J Med Chem, 2013, 56, 2813-27.

${ }^{28}$ Romagnoli R, Baraldi PG, Kimatrai Salvador M, Preti D, Aghazadeh Tabrizi M, Bassetto M, et al. Synthesis and biological evaluation of 2-(alkoxycarbonyl)-3-anilinobenzo[b]thiophenes and thieno[2,3-b]pyridines as new potent anticancer agents. J Med Chem, 2013, 56, 2606-2618.

${ }^{29}$ Romagnoli R, Baraldi PG, Carrion MD, Cruz-Lopez O, Cara CL, Tolomeo M, et al. Synthesis and biological evaluation of 2-amino-3-(3',4',5'-trimethoxybenzoyl)-6-substituted-4,5,6,7tetrahydrothieno[2,3 -c]pyridine derivatives as antimitotic agents and inhibitors of tubulin polymerization. Bioorg Med Chem Lett, 2008, 18, 5041-5045.

${ }^{30}$ Ohsumi K, Nakagawa R, Fukuda Y, Hatanaka T, Morinaga Y, Nihei Y, et al. Novel combretastatin analogues effective against murine solid tumors: Design and structure-activity relationships. J Med Chem, 1998, 41, 3022-3032.

${ }^{31}$ Hatanaka T, Fujita K, Ohsumi K, Nakagawa R, Fukuda Y, Nihei Y, et al. Novel B-ring modified combretastatin analogues: Syntheses and antineoplastic activity. Bioorg Med Chem Lett, 1998, 8, 3371-3374.

${ }^{32}$ Gwaltney SL,2nd, Imade HM, Barr KJ, Li Q, Gehrke L, Credo RB, et al. Novel sulfonate analogues of combretastatin A-4: Potent antimitotic agents. Bioorg Med Chem Lett, 2001, 11 , 871-874. 
<smiles>COC(=O)c1sc2nc(C)ccc2c1Nc1cc(OC)c(OC)c(OC)c1</smiles>

$\mathrm{IC}_{50}$ IPT: $0,2 \mathrm{nM}$ $\mathrm{IC}_{50}$ Citox: 0,7 $\mu \mathrm{M}$<smiles>COc1cc(C(=O)c2c(N)sc3cnccc23)cc(OC)c1OC</smiles>

$\mathrm{IC}_{50}$ IPT: $5,4 \mu \mathrm{M}$

$\mathrm{IC}_{50}$ Citox: $300-1000 \mathrm{nM}$<smiles>COc1ccc(/C=C(\C#N)c2cc(OC)c(OC)c(OC)c2)cn1</smiles>

$\mathrm{IC}_{50}$ IPT: $>20 \mu \mathrm{M}$

$\mathrm{IC}_{50}$ Citox: $1000 \mathrm{nM}$<smiles>COc1ccc(/C=C\c2cc(OC)c(OC)c(OC)c2)cn1</smiles>

IC $_{50}$ IPT: $2 \mu \mathrm{M}$

$\mathrm{IC}_{50}$ Citox: $20 \mathrm{nM}$<smiles>COc1cc(S(=O)(=O)Oc2ccn(C)c(=O)c2)cc(OC)c1OC</smiles>

$\mathrm{IC}_{50}$ Citox: $500 \mathrm{nM}$

Figura 8. Estructura y actividad biológica de compuestos con piridina en el anillo B.

\section{A.3.3. MODIFICACIONES EN EL PUENTE}

La función del puente en estos compuestos es permitir una posición no coplanar entre los dos anillos con un ángulo de $45^{\circ}$. Existe multitud de compuestos inhibidores de la polimerización de tubulina con diferentes longitudes en el puente, según el número de átomos. La colchicina y el MTC no tienen puente ya que los dos anillos aromáticos se unen directamente. En la podofilotoxina, fenstatinas e isocombretastatinas los anillos están unidos a través de un puente formado por un átomo. En las combretastatinas la distancia entre los anillos es de dos átomos, además en estos compuestos la conformación cis tiene mayor actividad que su isómero trans, por lo que la isomerización del doble enlace es uno de sus principales inconvenientes. Las chalconas y oxadiazolinas tienen un puente de tres átomos. 


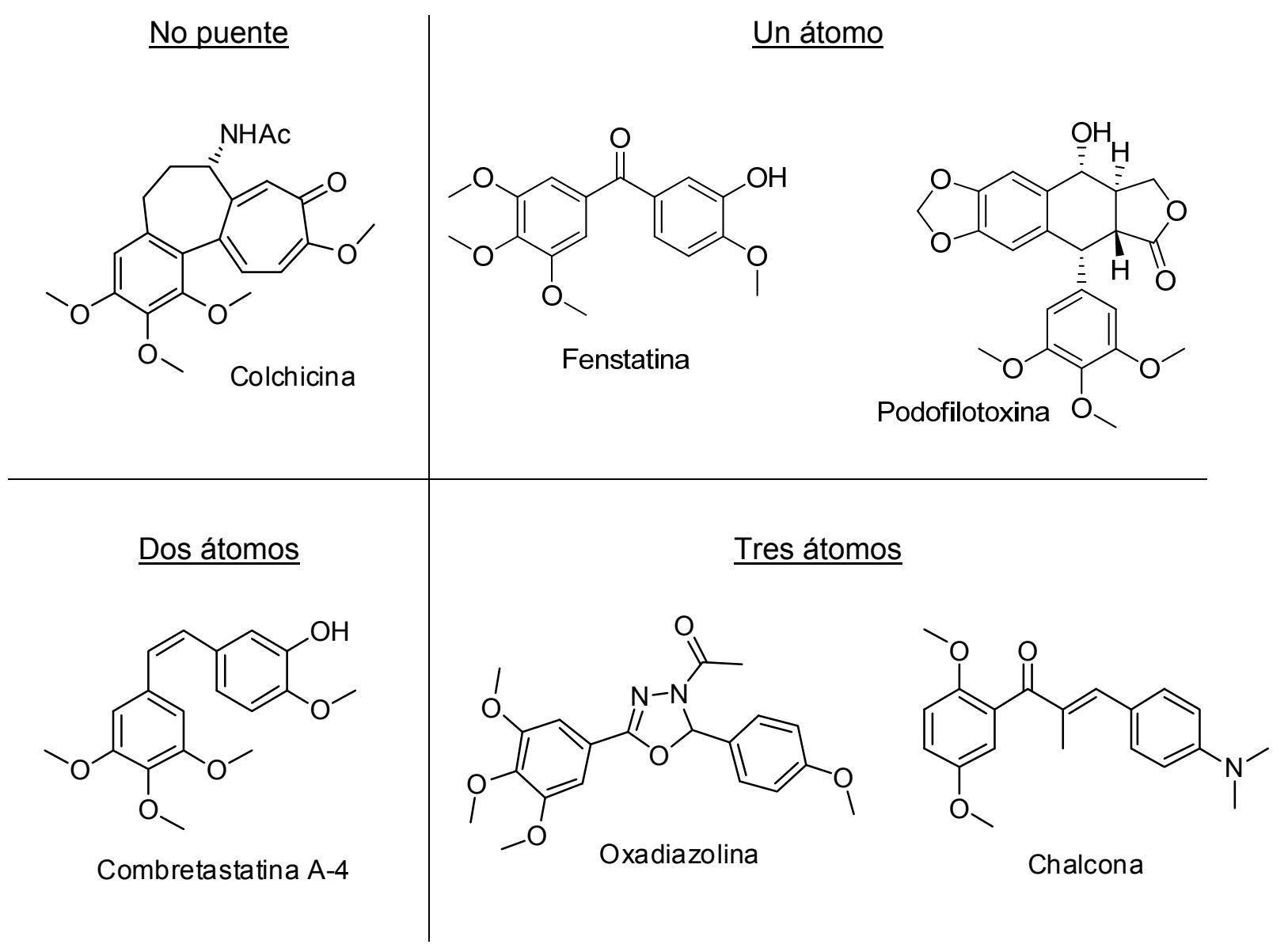

Figura 9: Estructura de los compuestos con diferente longitud en el puente. 


\section{B PLANTEAMIENTO Y OBJETIVOS}



El objetivo general de este trabajo es la síntesis y evaluación biológica de nuevos ligandos de tubulina que mejoren la potencia citotóxica y que incrementen la solubilidad acuosa, ya que es uno de los principales inconvenientes de estos compuestos. Basándonos en los antecedentes existentes, se van a sintetizar compuestos que contengan los siguientes elementos estructurales: un anillo de piridina (anillo A), un puente y un sistema aromático de uno o dos anillos (anillo B). La selección de estos elementos se discute a continuación:

\section{B.1. ANILLO A: ANILLO DE PIRIDINA}

Como se ha visto anteriormente, el anillo de trimetoxifenilo se consideraba imprescindible para la actividad de estos compuestos ${ }^{33}$, sin embargo se han sintetizado nuevos análogos que sustituyen este anillo por uno de menor volumen (ABT-751), como puede ser un anillo de piridina, o que carecen de este anillo (G2N, $\mathrm{K} 2 \mathrm{~N}$ ), y mantienen la actividad inhibitoria.

${ }^{33}$ Gaukroger K, Hadfield JA, Lawrence NJ, Nolan S, McGown AT. Structural requirements for the interaction of combretastatins with tubulin: how important is the trimethoxy unit? Org Biomol Chem, 2003, 17, 3033-3037. 
Aunque en los compuestos sintetizados anteriormente en el grupo de investigación con anillo de piridina y dos metoxilos en posición 2,6 se produce una pérdida de actividad ${ }^{34}$, se plantea la síntesis de nuevos análogos que tengan un anillo de piridina, pero cambiando el patrón de sustitución en estas posiciones, para ver el efecto producido por diferentes grupos. Una de las posibilidades es la sustitución por un grupo metilsulfanilo, que tiene un volumen similar al metoxilo, y puede mantener el enlace de hidrógeno con el tiol del residuo Cys $\beta 241$. Además, este grupo se puede oxidar formando sulfóxidos y sulfonas que aumenten la solubilidad acuosa.

El anillo de piridina tiene un volumen menor que el anillo de trimetoxifenilo, sin embargo, conserva los elementos necesarios para la interacción con el farmacóforo (puntos $\mathrm{H} 2$ y $\mathrm{A} 2$ ). Al disminuir el volumen en el anillo $\mathrm{A}$, se pueden introducir grupos que puedan acceder a la zona tres del dominio, como un grupo bencílico o fenílico. De esta manera, se puede explorar qué anillos pueden ser introducidos y los cambios que provoca esto en la actividad.

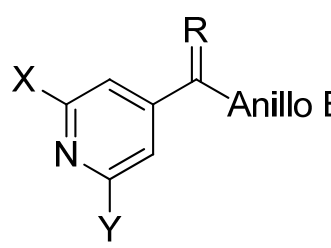

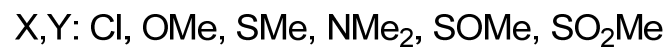

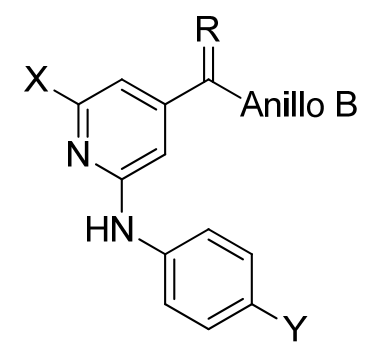

$\mathrm{X}: \mathrm{Cl}, \mathrm{OMe}, \mathrm{SMe}$

$\mathrm{Y}: \mathrm{H}, \mathrm{CH}_{3}$

Figura 10. Anillos de piridina disustituidos que van a ser introducidos en el anillo A.

Adicionalmente, el átomo de $\mathrm{N}$ de la piridina es susceptible de sufrir modificaciones que aumenten su polaridad, como la oxidación obteniéndose un $\mathrm{N}$ óxido, o la formación de sales solubles en agua gracias al carácter básico de las piridinas.

\footnotetext{
${ }^{34}$ Miguel Lozano Alonso. Tesina de Licenciatura. Universidad de Salamanca 2007
} 


\section{B.2. PUENTE OLEFÍNICO}

El puente entre los dos anillos puede tener una longitud entre cero y tres átomos de carbono. Las combretastatinas tienen la desventaja de la isomerización del doble enlace, por esta razón se plantea la síntesis de fenstatinas ${ }^{35}$ las cuales mantienen la actividad con igual patrón de sustitución en los anillos A y B. La incorporación de un grupo carbonilo en el puente introduce un grupo aceptor de enlaces de hidrógeno que es uno de los siete puntos propuestos en el farmacóforo $\mathrm{Nguyen}^{36}$ et al, lo que justificaría un aumento en la potencia de estos compuestos.

Otros compuestos que van a ser sintetizados son las isocombretastatinas, en las que se sustituye el grupo carbonilo por un grupo metileno, dando lugar a isómeros posicionales de las combretastatinas y provocando un gran aumento en la potencia ${ }^{37,38}$ de estos compuestos con respecto a sus análogos en fenstatinas y combretastatinas.

Para evaluar el efecto de la sustitución del anillo de trimetoxifenilo por un anillo de piridina, se van a sintetizar combretastatinas para comparar el efecto de esta sustitución con datos de otras combretastatinas publicadas en bibliografía.

\section{B.3. ANILLO B}

Dentro de los anillos B descritos anteriormente, hemos seleccionado el $\mathrm{N}$ metilindol porque tiene muy buenos resultados de actividad $^{31}$, y puede ser modificado mediante la introducción de grupos funcionales en posición 3 que incrementen su solubilidad acuosa, como grupos carboxilo, aldehído, amida y carbonitrilo. Otros anillos

\footnotetext{
${ }^{35}$ Liou JP, Chang CW, Song JS, Yang YN, Yeh CF, Tseng HY, et al. Synthesis and structureactivity relationship of 2-aminobenzophenone derivatives as antimitotic agents. J Med Chem, 2002, 45, 2556-62.

${ }^{36}$ Nguyen TL, McGrath C, Hermone AR, Burnett JC, Zaharevitz DW, Day BW, et al. A common pharmacophore for a diverse set of colchicine site inhibitors using a structure-based approach. J Med Chem, 2005, 48, 6107-16.

${ }^{37}$ a) Álvarez R, Puebla P, Díaz JF, Bento AC, García-Navas R, de la Iglesia-Vicente J, et al. Endowing indole-based tubulin inhibitors with an anchor for derivatization: Highly potent 3substituted indolephenstatins and indoleisocombretastatins. J Med Chem, 2013, 56, 2813-27.
} 
aromáticos que pueden sustituir al anillo de guayacol son el $p$-metoxifenilo ${ }^{38}$ y el naftaleno. $^{39}$

Adicionalmente, con el objetivo de incrementar la solubilidad, se plantea la síntesis de compuestos con anillos de piridina en el anillo $\mathrm{B}, \mathrm{y}$ anillos con dimetilamino.

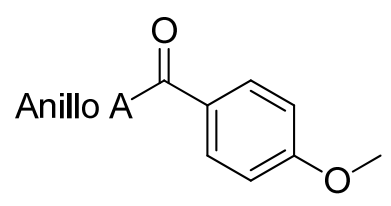<smiles>[R]c1cn(C)c2ccc(C(=O)O[Tl])cc12</smiles>

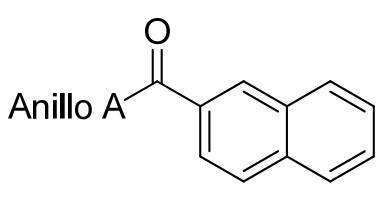

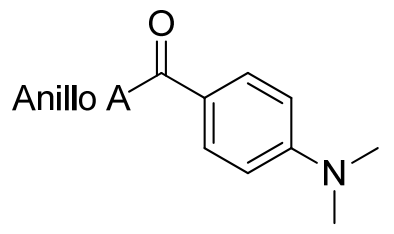

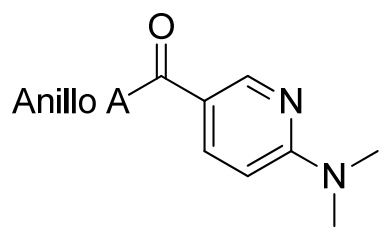

Figura 11. Anillos aromáticos introducidos en el anillo B.

\footnotetext{
${ }^{38}$ Álvarez R, Álvarez C, Mollinedo F, Sierra BG, Medarde M, Peláez R. Isocombretastatins A: 1,1-diarylethenes as potent inhibitors of tubulin polymerization and cytotoxic compounds. Bioorg Med Chem, 2009, 17, 6422-31.

39 a) Álvarez $C$, Álvarez R, Corchete $P$, Pérez-Melero $C$, Peláez R, Medarde $M$. Naphthylphenstatins as tubulin ligands: Synthesis and biological evaluation. Bioorg Med Chem, 2008, 16, 8999-9008. b) Maya AB, Pérez-Melero C, Mateo C, Alonso D, Fernández JL, Gajate $\mathrm{C}$, et al. Further naphthylcombretastatins. an investigation on the role of the naphthalene moiety. J Med Chem, 2005, 48, 556-68.
} 


\section{B.4. OBJETIVOS}

Una vez establecidos los antecedentes, los objetivos que se han seguido durante la realización de esta Tesis Doctoral son:

$\checkmark$ El primer objetivo consiste en la síntesis de ácidos piridina-4carboxílico sustituidos en posición 2 y 6 , como material de partida para la síntesis de fenstatinas e isocombretastatinas.

$\checkmark$ Síntesis de fenstatinas e isocombretastatinas con anillos de piridina en el anillo $\mathrm{A}$ y un anillo de p-metoxifenilo en el anillo $\mathrm{B}$. También se introducirán grupos nitro y amino en posición 3 . Se realizarán otras modificaciones en el puente como la introducción de oximas, o la hidrogenación del grupo metileno. Esto constituye el segundo objetivo.<smiles></smiles>

Adicionalmente se introducirá otro anillo aromático en posición 6 del anillo de piridina, con la intención de que se coloque en la zona 3 del dominio de la colchicina.<smiles>[R]c1ccc(Nc2cc(C(=O)c3ccc(OC)cc3)cc(Cl)n2)cc1</smiles>

$\mathrm{X}, \mathrm{Y}: \mathrm{Cl}, \mathrm{OMe}, \mathrm{SMe}, \mathrm{NMe}_{2}$ $\mathrm{Z}: \mathrm{O}, \mathrm{CH}_{2}, \mathrm{CH}-\mathrm{CH}_{3}, \mathrm{~N}-\mathrm{OH}$ R: $\mathrm{NO}_{2}, \mathrm{NH}_{2}$ 
Como tercer objetivo se plantea la síntesis de fenstatinas e isocombretastatinas que presenten un anillo de piridina sustituyendo al anillo de trimetoxifenilo, combinado con un anillo de $\mathrm{N}$-metilindol que puede ser modificado en posición tres mediante la introducción de grupos más polares como ácidos carboxílicos, aldehídos, amidas y carbonitrilos.<smiles></smiles>

En el cuarto objetivo se plantea la síntesis de fenstatinas e isocombretastatinas en los que el anillo $B$ esté constituido por otros sistemas aromáticos como naftaleno, dimetilaminofenil, y piridina, con la intención de evaluar el efecto de estos anillos sobre la actividad de los compuestos.<smiles>[X]c1cc(C([Z])c2ccc3ccccc3c2)cc([X])n1</smiles><smiles>[X]c1cc(C([Z])c2ccc(N(C)C)cc2)cc([Y])n1</smiles>
$\mathrm{X}, \mathrm{Y}: \mathrm{OMe}, \mathrm{SMe}$ $\mathrm{Z}: \mathrm{O}, \mathrm{CH}_{2}, \mathrm{~N}-\mathrm{OH}$ $R: H, N$

$\checkmark$ Además de la síntesis de compuestos con un puente olefínico de un solo átomo de carbono, también se plantea la síntesis de compuestos con una distancia de dos o tres átomos en el puente. Como quinto objetivo se van a sintetizar combretastatinas y oxadiazolinas con anillos de piridina en el anillo $A$.<smiles>[Y16]C=Cc1cc([Y])nc([Y])c1</smiles><smiles>[Y]c1cc(C2=NN(C(C)=O)C([Z17])O2)cc([X])n1</smiles> 
$\checkmark$ El sexto objetivo consiste en la realización de los ensayos de inhibición de polimerización de tubulina de todos los compuestos sintetizados. Los compuestos más potentes serán seleccionados para determinar el valor de su $\mathrm{IC}_{50}$.

$\checkmark$ Como séptimo objetivo se van a realizar cultivos celulares de diferentes tipos de células tumorales humanas para la posterior realización de los ensayos de citotoxicidad. Se van a cultivar células adherentes (Hela y HT-29) y células en suspensión (HL-60) y se va a realizar el ensayo de citotoxicidad de todos los compuestos sintetizados. Posteriormente se seleccionarán los mejores compuestos y se determinará el valor de $\mathrm{IC}_{50}$ en las tres líneas celulares.

$\checkmark$ El octavo y último objetivo es la determinación de la solubilidad de algún compuesto seleccionado por su estructura o por su actividad. Los datos de solubilidad, juntos a los de IPT y citotoxicidad serán evaluados para determinar cómo afectan los cambios estructurales en la actividad y en la solubilidad de estos compuestos. 

C — MÉTODOS Y RESVLTADOS 

Como se ha descrito anteriormente en el apartado de planteamiento y objetivos de este trabajo, se va a sintetizar una serie de compuestos con actividad sobre la polimerización de la tubulina. Estos compuestos pueden ser divididos en:

1. Compuestos con un solo átomo en el puente: Fenstatinas.

2. Compuestos con un solo átomo en el puente: Isocombretastatinas.

3. Compuestos con un solo átomo en el puente: Modificaciones estructurales de Fenstatinas e Isocombretastatinas.

4. Compuestos con dos átomos en el puente: Combretastatinas.

5. Compuestos con tres átomos en el puente: Oxadiazolinas. 


\section{C.1. SÍNTESIS DE FENSTATINAS}

El método utilizado para la síntesis de análogos de fenstatinas consiste en la preparación de un derivado organolítico, por tratamiento del correspondiente bromoderivado con $n$ BuLi. El derivado organolítico reacciona con un ácido carboxílico dando lugar directamente a la fenstatina. El esquema de preparación de estos compuestos es el siguiente:

$$
\mathrm{Ar}_{1}-\mathrm{Br} \underset{\text { THF seco }}{\stackrel{n \text { BuLi }}{\longrightarrow}} \mathrm{Ar}_{1}-\mathrm{Li} \stackrel{\mathrm{Ar}_{2}-\mathrm{COOH}}{\longrightarrow} \mathrm{Ar}_{1} \stackrel{\mathrm{O}}{\mathrm{Ar}_{2}}
$$

Esquema 1: Esquema de síntesis de fenstatinas

El primer paso para la síntesis de estos compuestos es la preparación de algunos materiales de partida.

\section{C.1.1. SÍNTESIS DE MATERIALES DE PARTIDA}

Para la preparación de estos análogos de fenstatinas es necesario disponer de diversos derivados del ácido isonicotínico (derivados de piridina) y de los bromoderivados requeridos en cada caso, algunos de los cuáles no son comercialmente asequibles y deben ser obtenidos previamente, según se describe a continuación.

\footnotetext{
* Todos los rendimientos que se indican en tablas y figuras corresponden a producto purificado por cristalización y/o cromatografía flash.
} 


\section{C.1.1.1. FORMACIÓN DE DERIVADOS DE PIRIDINA}

La primera parte de este trabajo consiste en la síntesis del anillo de piridina con diferentes sustituyentes en posición 2 y 6 , y con un ácido carboxílico en posición 4 . Para la síntesis de todos los derivados de piridina se parte de ácido citrazínico, un producto comercial y barato, el cual mediante reacción con oxicloruro de fósforo y cloruro de tetrametil amonio como catalizador, produce el derivado diclorado (1). El objetivo de este paso es facilitar la entrada de los diferentes sustituyentes en posición 2 y 6 ya que el cloro es un buen grupo saliente. A partir del derivado diclorado se pueden introducir diversos sustituyentes de forma secuencial mediante la utilización de agentes nucleofílicos y diversas condiciones de reacción.<smiles>O=C(O)c1cc(O)nc(Cl)c1</smiles>

Figura 12: Síntesis del compuesto diclorado 1.

Los compuestos de piridina que se han sintetizado utilizando esta metodología se resumen en la siguiente figura:

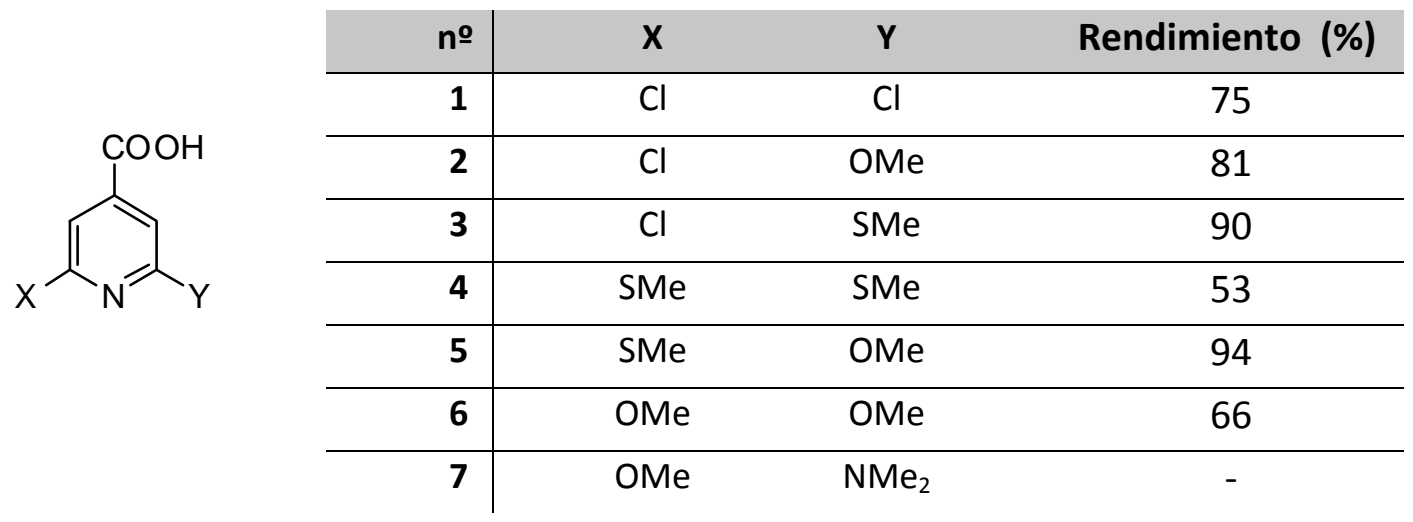

Tabla 1: Ácidos con anillo de piridina sintetizados. 


\section{C.1.1.1.1. Metoxilos como agentes nucleófilos}

Para la síntesis del derivado monometoxilado (2) se añade en exceso una disolución de metóxido sódico en metanol y se pone a reflujo durante 24 horas. La introducción del segundo grupo metoxilo está más impedido debido al efecto dador de electrones del primero. Para la obtención del derivado dimetoxilado (6) es necesario forzar las condiciones utilizando diglime como disolvente para aumentar la solubilidad del ácido, y poder subir la temperatura hasta 120 grados. Para facilitar la reacción, el $\mathrm{MeOH}$ se elimina con un dispositivo Dean Stark.<smiles>COc1cc(C(=O)O)cc(OC)n1</smiles>

6

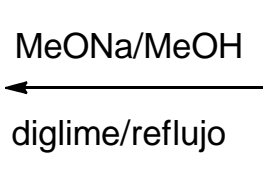

diglime/reflujo<smiles>O=C(O)c1cc(Cl)nc(Cl)c1</smiles>

1

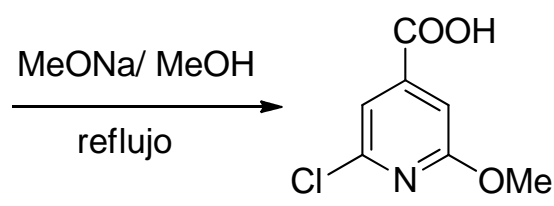

2

Figura 13: Síntesis de los compuestos 2 y 6.

\section{C.1.1.1.2. Metilsulfanilos como agentes nucleófilos}<smiles>O=C(O)c1cc(Cl)nc(Cl)c1</smiles>

1<smiles>COc1cc(C(=O)O)cc(Cl)n1</smiles>

3<smiles>Cc1cc(C(=O)O)cc(S(C)(=O)=O)n1</smiles>

4

Figura 14: Síntesis de los compuestos con grupo metilsulfanilo 3 y 4.

Para la introducción del primer grupo metilsulfanilo se añade 1,5 equivalentes de tiometóxido sódico por cada equivalente de ácido 2,6-dicloropiridina-4-carboxílico (1), y se calienta a reflujo durante 24-48 horas. En este caso es necesario añadir $\mathrm{KOH}$ que capte el $\mathrm{H}$ ácido y así evitar que lo haga el tiometóxido sódico. Para introducir el segundo grupo metilsulfanilo se añade tiometóxido sódico en exceso al derivado diclorado (1) o al derivado monosustituido (3). Estas reacciones utilizan como 
disolvente dimetilformamida ya que incrementa la solubilidad del ácido y permite temperaturas superiores a $100^{\circ} \mathrm{C}$, lo que aumenta la velocidad de la reacción.

\section{C.1.1.1.3. Síntesis del ácido 2-metilsulfanil-6-metoxipiridina-4-carboxílico}

Para la síntesis del ácido 2-metilsulfanil-6-metoxipiridina-4-carboxílico (5) se planteó la síntesis introduciendo primero el grupo metoxilo, y posteriormente el grupo metilsulfanilo. Partiendo del compuesto 2 se intentó introducir el grupo metilsulfanilo añadiendo $\mathrm{CH}_{3} \mathrm{SNa}$ en exceso y usando como disolvente $\mathrm{MeOH}$ o diglime en distintas condiciones, pero no se produjo la sustitución. Esto puede ser debido al efecto dador de electrones del grupo metoxilo.

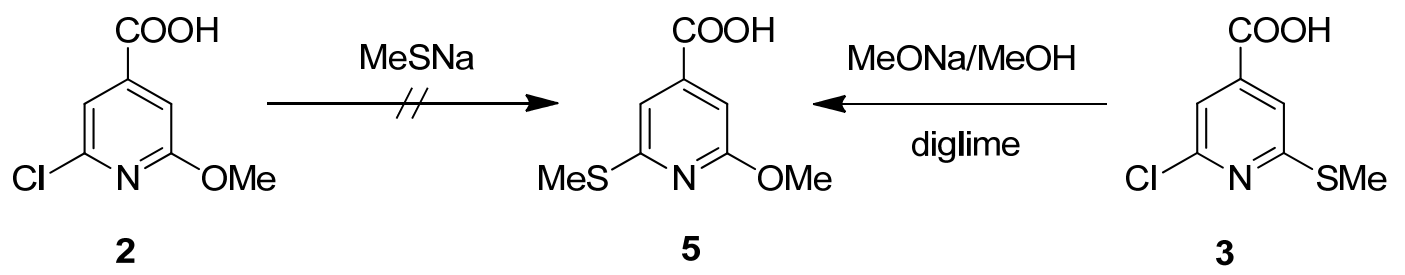

Figura 15: Síntesis del ácido 2-metilsulfanil-6-metoxipiridina-4-carboxílico.

Utilizando la ruta sintética alternativa, introduciendo primero el grupo metilsulfanilo y posteriormente el metoxilo, se obtiene el compuesto 5 con buenos rendimientos (94\%). A pesar de que la introducción de un segundo grupo nucleófilo sobre el anillo se encuentra desfavorecido debido al efecto dador de electrones del grupo metilsulfanilo en posición 6 , el uso de diglime como disolvente que permite elevar la temperatura, hace que se obtenga el compuesto planteado con un buen rendimiento. 


\section{C.1.1.1.4. Síntesis de ácido 2-(dimetilamino)-6-metoxipiridina-4-carboxílico}

Para la introducción de un grupo dimetilamino en el anillo de piridina, se utilizó como material de partida el derivado 2 con un grupo metoxilo, que se hace reaccionar con exceso de dimetilamina en $\mathrm{EtOH}$ al 33\% a reflujo.<smiles>COc1cc(C(=O)O)cc(Cl)n1</smiles>

2

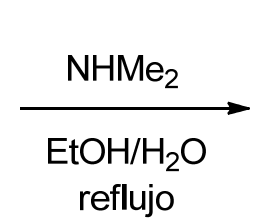<smiles>COc1cc(C(=O)O)cc(N(C)C)n1</smiles><smiles>[CH-]</smiles>

$7: 3$<smiles>CN(C)c1cc(C(=O)O)cc(N(C)C)n1</smiles>

$7 a$

Figura16: Introducción de grupos dimetilamino en el anillo de piridina.

Se obtiene mayoritariamente el compuesto buscado 7 y un pequeño porcentaje del compuesto $7 \mathrm{a}$, como resultado de una doble sustitución. En el espectro de RMN ${ }^{1} \mathrm{H}$ del producto de reacción se puede observar una señal singlete a 6,79 ppm, que corresponde a los dos protones de la piridina del compuesto simétrico 7a, y dos señales doblete a 7,12 y 7,37 ppm que corresponden a los dos $\mathrm{H}$ aromáticos del compuesto 7.

\section{C.1.1.2. SÍNTESIS DE BROMODERIVADOS}

Los derivados halogenados que se han utilizado han sido 1-bromo-4metoxibenceno, 5-bromo-1-metil- $1 \mathrm{H}$-indol (15), 2-bromonaftaleno, 3-bromo- $N, N$ dimetilanilina, 4-bromo- $N, N$-dimetilanilina y 5-bromo- $N, N$-dimetilpiridin-2-amina. Todos estos bromoderivados son productos comerciales, excepto el 5-bromo-1-metil- $1 H$-indol (15). 
Es necesaria la metilación del anillo indólico, debido al carácter ácido del protón del $\mathrm{NH}$, y porque se ha visto que la presencia del grupo metilo no disminuye la actividad citotóxica, sino que en algunos casos incluso la aumenta ${ }^{40}$.

La síntesis del derivado metilado se lleva a cabo mediante el tratamiento con bases $(\mathrm{NaOH})$, en presencia de un catalizador de transferencia de fase (hidrogeno sulfato de tetrabutil amonio) que facilita la formación del anión. Éste reacciona con un electrófilo adecuado, en nuestro caso yoduro de metilo, formándose el derivado $\mathrm{N}$ metilindólico 15 con un rendimiento del 95\%.<smiles>CO[N+](C)(O)O[Na]</smiles>

Figura 17: Metilación del anillo indólico.

\section{C.1.2. SÍNTESIS DE FENSTATINAS DERIVADAS DEL ÁCIDO ISONICOTÍNICO}

Una vez se han sintetizado los materiales de partida, se procede a la síntesis de fenstatinas. Como se ha comentado anteriormente, el primer paso consiste en la formación del organolítico, que posteriormente reacciona con el ácido carboxílico. Los dos pasos de esta transformación se llevan a cabo de forma consecutiva en el mismo matraz.

$$
\operatorname{Ar}_{1}-\mathrm{Br} \underset{\text { THF seco }}{\stackrel{n \text { BuLi }}{\longrightarrow}} \operatorname{Ar}_{1}-\mathrm{Li} \stackrel{\mathrm{Ar}_{2}-\mathrm{COOH}}{\longrightarrow} \mathrm{Ar}_{1} \stackrel{\mathrm{O}}{\mathrm{Ar}_{2}}
$$

Esquema 2: Esquema de síntesis de fenstatinas.

\footnotetext{
${ }^{40}$ Liou JP, Wu CY, Hsieh HP, Chang CY, Chen CM, Kuo CC, et al. 4- and 5-Aroylindoles as Novel Classes of Potent Antitubulin Agents. J Med Chem, 2007, 50, 4548-4552.
} 


\section{C.1.2.1. REACCIÓN DE TRANSMETALACIÓN}

Los organolíticos se forman mediante la adición lenta de $n$ BuLi sobre el derivado halogenado que ha sido previamente disuelto en THF seco a $-40^{\circ} \mathrm{C}$. En todos ellos la relación de $n$ BuLi con el derivado bromado que se añade es de 1:1, y a las bajas temperaturas empleadas no se ha observado en ninguna de estas reacciones productos de isomerización. Los organolíticos que se han sintetizado son los siguientes:<smiles>Cn1ccc2cc(Br)ccc21</smiles><smiles>COc1ccc(Br)cc1</smiles><smiles>Brc1ccc2ccccc2c1</smiles><smiles>[X]c1ccc(Br)cc1N(C)CCN</smiles><smiles>CCc1ccc2c(ccn2C)c1</smiles><smiles>COc1ccc(Cl)cc1</smiles><smiles>[Al]c1ccc2ccccc2c1</smiles><smiles>[X]c1ccc(N(C)C)cc1</smiles>

Figura 18: Formación de organolíticos a partir de bromoderivados.

\section{C.1.2.2. REACCIÓN CON ÁCIDOS CARBOXÍLICOS}

Una vez sintetizado el organolítico se adiciona lentamente el ácido carboxílico disuelto en THF seco. En esta reacción se consumen dos equivalentes de organolítico por cada equivalente de ácido, ya que un equivalente reacciona con el protón ácido, y el otro se adiciona al anión carboxilato. Alternativamente se puede preparar el carboxilato previamente por tratamiento con bases como $\mathrm{NaH}$. 


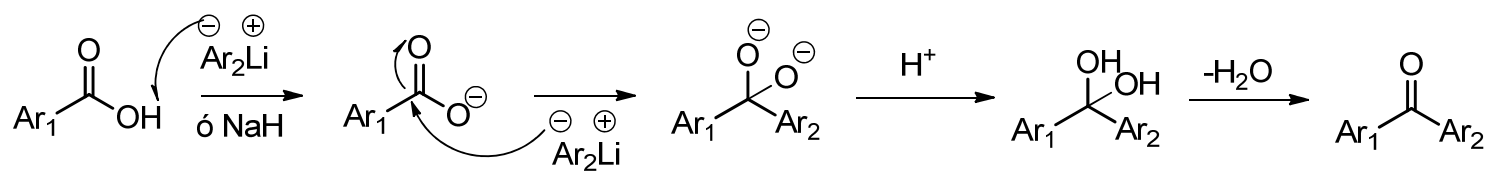

Esquema 3: Esquema de la reacción de adición-eliminación a un ácido carboxílico.

La formación de la fenstatina se confirma porque en el espectro de RMN ${ }^{13} \mathrm{C}$ se observa una señal a 190 ppm y en IR otra a $1645 \mathrm{~cm}^{-1}$ que son debidas al carbonilo, que también produce un apreciable desapantallamiento de las señales de los protones aromáticos en RMN ${ }^{1} \mathrm{H}$.

Para la síntesis de compuestos con anillo de p-metoxifenilo en el anillo $\mathrm{B}$, se utilizó 4-bromoanisaldehído comercial y los rendimientos de esta reacción variaron entre $17-59 \%$.

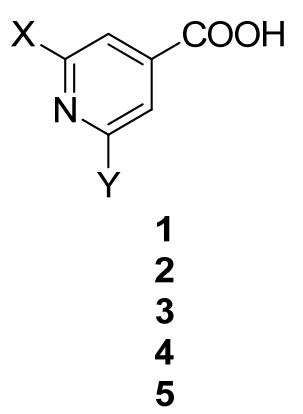<smiles>COc1ccc(Br)cc1</smiles>

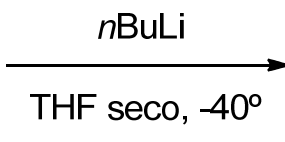

$\mathrm{X}, \mathrm{Y}: \mathrm{Cl}$

$\mathrm{X}: \mathrm{Cl} ; \mathrm{Y}: \mathrm{OMe}$

$\mathrm{X:Cl} ; \mathrm{Y}: \mathrm{SMe}$

$\mathrm{X}, \mathrm{Y}: \mathrm{SMe}$

$\mathrm{X}: \mathrm{SMe} ; \mathrm{Y}: \mathrm{OMe}$<smiles>[X]c1cc(C(=O)c2ccc(OC)cc2)cc([X])n1</smiles>
25 R: $17 \%$
28 R: $59 \%$
38 R: $24 \%$
45 R: $46 \%$
49 R: $51 \%$

Figura 19: Síntesis de los compuestos 25, 28, 38, 45 y 49.

En la síntesis del compuesto 38 además de obtener este compuesto en un rendimiento del $24 \%$, se obtuvo el compuesto 39 con un rendimiento del $32 \%$. Esto es debido a que en este caso no se añadió formiato de etilo para finalizar la reacción, por lo que se ha producido la reacción con el acetato de etilo utilizado para realizar la extracción líquido-líquido. 
<smiles>CCOC(=O)CC(O)(c1ccc(OC)cc1)c1cc(Cl)nc(SC)c1</smiles>

Figura 20: Estructura del compuesto 39.

En la síntesis del compuesto $\mathbf{5 8}$ se siguió el método general para la síntesis de las fenstatinas, sin embargo no se obtuvo el compuesto deseado.<smiles>COc1cc(C(=O)O)cc(N(C)C)n1</smiles>

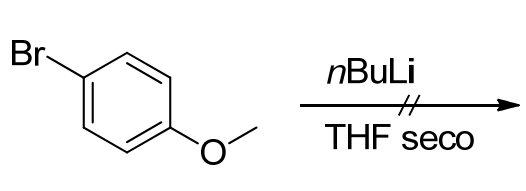<smiles>COc1ccc(C(=O)c2cc(OC)nc(N(C)C)c2)cc1</smiles>

Figura 21: Intento de síntesis del compuesto 58.

Debido a esto, las fenstatinas con grupos dimetilamino en el anillo de piridina se sintetizaron a partir de la propia fenstatina clorada, mediante una sustitución nucleofílica aromática con dimetilamina en $\mathrm{EtOH}$ al 33\%.<smiles>[X]c1cc(C(=O)c2ccc(OC)cc2)cc(Cl)n1</smiles>

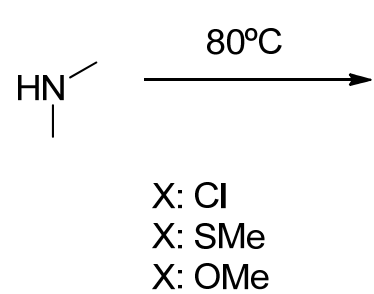

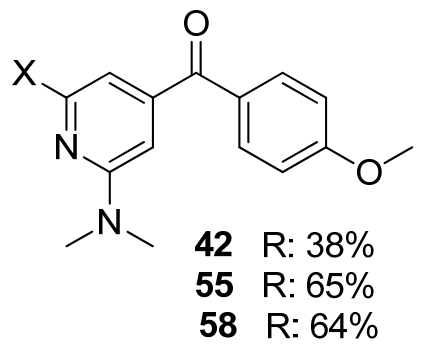

Figura 22: Fenstatinas sintetizadas con grupos dimetilamino en el anillo de piridina.

Para introducir solo un grupo dimetilamino se añade 1,3 equivalentes de dimetilamina por cada equivalente de fenstatina, como en el caso de la síntesis del compuesto 42. Sin embargo, para la síntesis del compuesto 55 y 58 se añade exceso 
de dimetilamina, ya que al tener grupos dadores de electrones en posición 6 , la segunda sustitución nucleofílica está menos favorecida.

En la síntesis de los compuestos con N-metilindol en el anillo B se utilizó 5bromo- $N$-metil- $1 H$-indol (15) y los rendimientos que se obtuvieron en estas reacciones fueron entre $20-50 \%$.<smiles>[X]c1cc(C(=O)O)cc([X])n1</smiles>

1
3
5
4<smiles>Cn1ccc2cc(Br)ccc21</smiles>

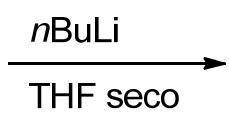

$\mathrm{X}, \mathrm{Y}: \mathrm{Cl}$

$\mathrm{X}: \mathrm{Cl} ; \mathrm{Y}: \mathrm{SMe}$ $X: S M e ; Y: O M e$ $\mathrm{X}, \mathrm{Y}: \mathrm{SMe}$<smiles>[X]c1cc(C(=O)c2ccc3c(ccn3C)c2)cc([X])n1</smiles>

61 R: $21 \%$

72 R: $35 \%$

84 R: $49 \%$

94 R: $33 \%$

Figura 23: Síntesis de los compuestos 61, 72, 84, 94.

En la síntesis del compuesto 61, además se obtuvo el compuesto 62 (8\%), en el que se ha producido un acoplamiento de los anillos aromáticos $\operatorname{Ar}_{1}$ y $\mathrm{Ar}_{2}$ con descarboxilación. Esta reacción de acoplamiento entre un derivado halogenado y un carboxilato se ha descrito mediante el empleo de metales (Cu, Pd). ${ }^{41}$<smiles>Cn1ccc2cc(-c3cc(Cl)nc(Cl)c3)ccc21</smiles>

Figura 24: Estructura del compuesto 62.

\footnotetext{
${ }^{41}$ a) Goossen LJ, Rodríguez N, Melzer B, Linder C, Deng G, Levy LM. Biaryl synthesis via Pdcatalyzed decarboxylative coupling of aromatic carboxylates with aryl halides. J Am Chem Soc, 2007, 129, 4824-4833. b) Haley CK, Gilmore CD, Stoltz BM. Development of a palladiumcatalyzed decarboxylative cross-coupling of (2-azaaryl)carboxylates with aryl halides. Tetrahedron, 2013, 69, 5732-5736. c) Rodríguez N, Goossen LJ. Decarboxylative coupling reactions: a modern strategy for C-C-bond formation. Chem Soc Rev, 2011, 40, 5030-5048.
} 
Como subproducto de la obtención del compuesto 94, se obtuvo el compuesto 95, que es producto de la introducción de dos organolíticos. En el espectro de RMN ${ }^{1} \mathrm{H}$ se observa que las señales que corresponden al anillo del indol integran por dos protones y en $\mathrm{RMN}{ }^{13} \mathrm{C}$ se aprecia la existencia de un carbono oxigenado tetrasustituido.<smiles>CSc1cc(C(O)(c2ccc3c(ccn3C)c2)c2ccc3c(ccn3C)c2)cc(SC)n1</smiles>

Figura 25: Estructura del compuesto 95.

Para la síntesis de las fenstatinas indólicas con dimetilamino en el anillo de piridina, debido a que la presencia de dicho grupo en el ácido piridina-4-carboxílico no dio resultado en la preparación del compuesto $\mathbf{5 8}$, se procede a la síntesis de las fenstatinas cloradas 72 y 61 , y posteriormente se introduce el grupo dimetilamino mediante sustitución nucleofílica aromática. Adicionando 1,3 equivalentes de dimetilamina al 33\% en etanol en el caso de la síntesis del compuesto 120, y añadiendo exceso para sintetizar el compuesto 104 , se obtuvieron las fenstatinas con rendimientos aceptables.<smiles>[X]c1cc(C(=O)c2ccc3c(ccn3C)c2)cc(Cl)n1</smiles>

72

61<smiles>CNCC(=O)O</smiles>

$\mathrm{X}: \mathrm{SMe}$

$\mathrm{X}: \mathrm{Cl}$<smiles>[X]c1cc(C(=O)c2ccc3c(ccn3C)c2)cc(N(C)C)n1</smiles>

104 R: $47 \%$

120 R: $39 \%$

Figura 26: Fenstatinas indólicas con grupos dimetilamino en el anillo de piridina. 
Por último, también se han sintetizado fenstatinas con otros sistemas aromáticos en el anillo B: grupos naftaleno (127 y 131), 3-dimetilaminofenilo (134) y 4dimetilaminofenilo (137 y 140).<smiles>CCCCOc1ccc2ccc(Br)cc2c1</smiles><smiles>[X]c1cc(C(=O)O)cc([Y])n1</smiles>

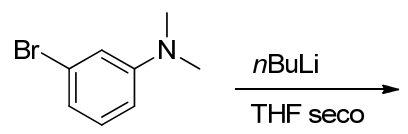

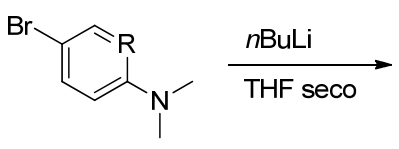<smiles>[X]c1cc(C(=O)c2ccc3ccccc3c2)cc([X])n1</smiles>

127 X:SMe; Y:OMe R: $24 \%$ $131 \mathrm{X}, \mathrm{Y}: \mathrm{SMe} \quad \mathrm{R}: 47 \%$<smiles>[R16]c1cccc(C(=O)c2cc([Y])nc([Y])c2)c1</smiles>

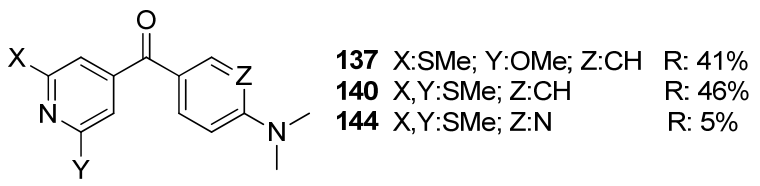

Figura 27: Fenstatinas sintetizadas con otros sistemas aromáticos en el anillo B.

En la síntesis de los compuestos 140 y 144, se han obtenido los productos 141 y 145, de la entrada de dos organolíticos. A pesar de que estructuralmente difieren de los compuestos diseñados, los productos de esta doble entrada también van a ser ensayados en los experimentos de actividad biológica, debido a que la plasticidad de la proteína en el sitio de unión de la colchicina puede permitir el acomodo de restos adicionales en diversas zonas.

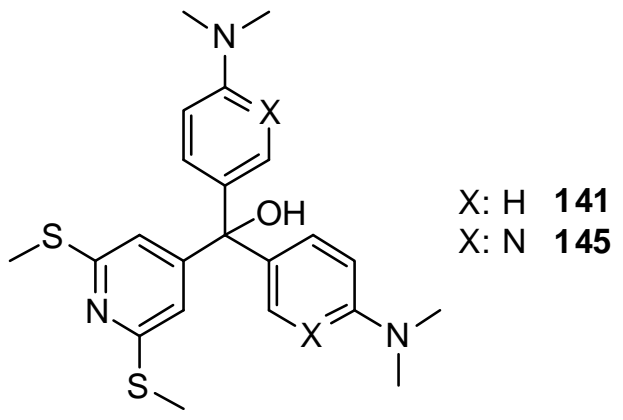

Figura 28: Estructura de los compuestos 141 y 145. 


\section{C.2. SÍNTESIS DE ISOCOMBRETASTATINAS}

Una vez que se han sintetizado las fenstatinas se procede a la síntesis de isocombretastatinas por medio de la reacción de Wittig.

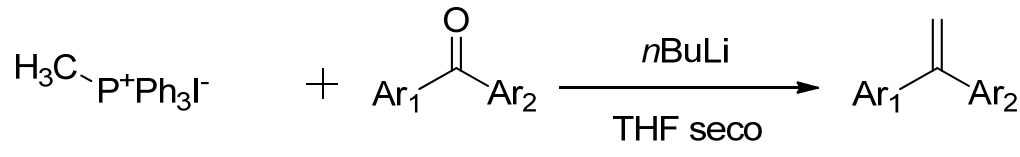

Esquema 3: Esquema de síntesis de Isocombretastatinas.

El primer paso es la síntesis de la sal de fosfonio, en nuestro caso yoduro de metiltrifenilfosfonio, que mediante tratamiento con una base fuerte como $n \mathrm{BuLi}$ forma el iluro de fosforo.

\section{C.2.1. METODOLOGÍA GENERAL Y RESULTADOS}

Según el procedimiento general descrito en la parte experimental, una vez preparado el iluro de metilenotrifenilfosfonio se procede a la adición de la cetona correspondiente previamente disuelta en THF seco y se deja subir la temperatura hasta alcanzar la temperatura ambiente.<smiles>[Y]c1cc(C(=C)[Al])cc([X])n1</smiles>

Figura 29: Metodología general de síntesis de Isocombretastatinas. 
El producto de reacción se purifica mediante cromatografía flash y se obtienen rendimientos que oscilan entre un 20-95\%. Esta variabilidad puede ser debida a que la sal de fosfonio no esté lo suficientemente seca, como ocurre en la síntesis del compuesto 29, que se obtiene con un rendimiento del 2\%. En la mayoría de estas reacciones se obtuvieron la isocombretastatina y material de partida sin reaccionar, que puede ser reutilizado.

Las isocombretastatinas que se han sintetizado se resumen en el siguiente cuadro, que incluye el rendimiento obtenido y las señales correspondientes al grupo $\mathrm{CH}_{2}$ del puente, características de este tipo de compuestos y que permiten confirmar su obtención.

\begin{tabular}{|c|c|c|c|c|c|}
\hline Producto & $x$ & $\mathbf{Y}$ & $\mathrm{Ar}$ & Rendimiento (\%) & $\begin{aligned} & \mathrm{RMN}^{1} \mathrm{H} \\
= & \mathrm{CH}_{2}(\mathrm{ppm})\end{aligned}$ \\
\hline 26 & $\mathrm{Cl}$ & $\mathrm{Cl}$ & 4-MeO-Ph & 32 & 5,$54 ; 5,60$ \\
\hline 29 & $\mathrm{Cl}$ & OMe & 4-MeO-Ph & 2 & 5,$47 ; 5,51$ \\
\hline 30 & OMe & OMe & 4-MeO-Ph & 0,8 & 5,$43 ; 5,45$ \\
\hline 40 & $\mathrm{Cl}$ & SMe & 4-MeO-Ph & 34 & 5,$47 ; 5,53$ \\
\hline 43 & $\mathrm{Cl}$ & $\mathrm{NMe}_{2}$ & 4-MeO-Ph & 38 & 5,$41 ; 5,47$ \\
\hline 46 & SMe & SMe & 4-MeO-Ph & 94 & 5,$42 ; 5,47$ \\
\hline 50 & SMe & OMe & 4-MeO-Ph & 49 & 5,$43 ; 5,47$ \\
\hline 56 & SMe & $\mathrm{NMe}_{2}$ & 4-MeO-Ph & 38 & 5,$38 ; 5,44$ \\
\hline 59 & OMe & $\mathrm{NMe}_{2}$ & 4-MeO-Ph & 13 & 5,$40 ; 5,43$ \\
\hline 63 & $\mathrm{Cl}$ & $\mathrm{Cl}$ & NMeIND & 59 & 5,$48 ; 5,56$ \\
\hline 73 & $\mathrm{Cl}$ & SMe & NMeIND & 23 & 5,$53 ; 5,61$ \\
\hline 85 & SMe & OMe & NMeIND & 31 & 5,$48 ; 5,54$ \\
\hline 96 & SMe & SMe & NMeIND & 47 & 5,$51 ; 5,59$ \\
\hline 105 & SMe & $\mathrm{NMe}_{2}$ & NMeIND & 80 & 5,$45 ; 5,53$ \\
\hline 121 & $\mathrm{Cl}$ & $\mathrm{NMe}_{2}$ & NMeIND & 37 & 5,$46 ; 5,54$ \\
\hline 132 & SMe & SMe & 2-Naft & 59 & 5,$53 ; 6,08$ \\
\hline 135 & SMe & SMe & $3-\mathrm{NMe}_{2} \mathrm{Ph}$ & 36 & 5,$52 ; 5,54$ \\
\hline 138 & SMe & OMe & $4-\mathrm{NMe}_{2} \mathrm{Ph}$ & 33 & 5,$32 ; 5,44$ \\
\hline 142 & $\mathrm{SMe}$ & $\mathrm{SMe}$ & $4-\mathrm{NMe}_{2} \mathrm{Ph}$ & 39 & 5,$31 ; 5,45$ \\
\hline
\end{tabular}

Tabla 2: Isocombretastatinas sintetizadas con el valor de rendimiento obtenido, y las señales de los protones del puente. 
En la mayoría de los compuestos, la diferencia de desplazamiento entre las dos señales del $\mathrm{CH}_{2}$ del puente va desde 0,03 a 0,08 ppm. Sin embargo, en el compuesto 132 que tiene un grupo naftilo, hay una diferencia de 0,55 ppm; y en los compuestos con 4-dimetilaminofenilo está diferencia es de 0,12-0,14 ppm. 


\section{C.3. MODIFICACIÓN DE FENSTATINAS E ISOCOMBRETASTATINAS}

\section{C.3.1. MODIFICACIONES EN EL ANILLO B}

Las fenstatinas e isocombretastatinas sintetizadas pueden ser modificadas con la introducción de grupos en diferentes posiciones. Estos cambios se producen con el propósito de mejorar el perfil farmacocinético de estos compuestos, con la inserción de grupos que aumenten la solubilidad acuosa y/o que puedan dar lugar a la formación de profármacos. En la mayoría de los casos el anillo A formado por un anillo de piridina disustuido no va a ser modificado, y los grupos van a ser introducidos en el anillo $B$, que como hemos visto anteriormente permite una mayor variabilidad estructural

\section{C.3.1.1. MODIFICACIONES EN $p$-METOXIFENILO}

Una de las modificaciones habituales para aumentar la solubilidad de combretastatinas, fenstatinas e isocombretastatinas es la introducción de un grupo amino en posición 3 del anillo B. Además, este grupo puede ser fácilmente convertido en sales de amonio y permite la unión de restos peptídicos y polihidroxialquilo, que convierten estas sustancias en profármacos solubles.

Para la introducción del grupo amino en posición 3 se sigue el procedimiento habitual de nitración seguido de reducción.<smiles>C=CC(=O)c1ccc(OC)c(N)c1</smiles><smiles>C=CC(=O)c1ccc(OC)c([N+](=O)[O-])c1</smiles><smiles>COc1ccc(C([14CH3])=O)cc1</smiles>

Esquema 4: Esquema retro-sintético de la introducción de grupos amino en el anillo de $p$ metoxifenilo. 


\section{C.3.1.1.1. Nitración en posición 3}

Puesto que el mecanismo mediante el cual se introduce un grupo nitro es una sustitución electrofílica aromática ${ }^{42}$, el grupo metoxilo activante que orienta a la posición orto y el carbonilo desactivante que orienta en posición meta, hacen que las posiciones susceptibles de nitración sean 3, y 5 en caso de dinitración.

El primer intento de nitración se realizó sobre el material de partida 4bromoanisol utilizando como disolvente $\mathrm{CH}_{2} \mathrm{Cl}_{2}$. Se añadieron 3 equivalentes de $\mathrm{HNO}_{3}$ al 60\% por cada equivalente de $p$-bromoanisol, sin embargo la reacción no tuvo lugar. Basándonos en experiencias anteriores del grupo de investigación, en un segundo intento se utilizó $\mathrm{H}_{2} \mathrm{SO}_{4}$ que favorece la formación de ión nitronio, que es el agente electrofílico de esta reacción, pero el exceso de ión nitronio en este caso ha favorecido la disustitución, obteniéndose el compuesto 20.

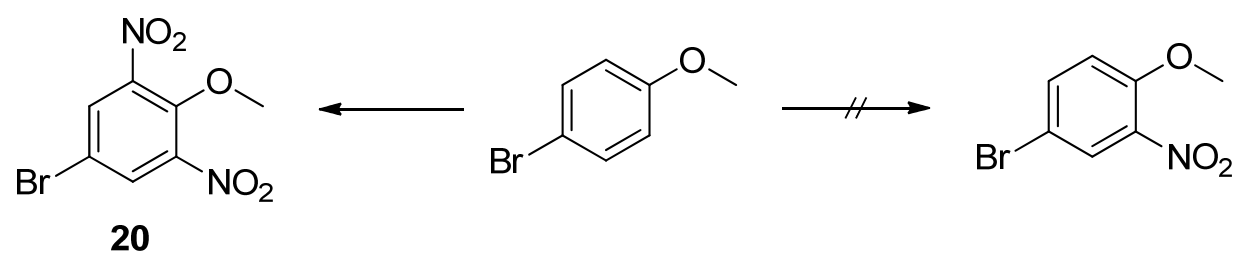

Figura 30: Intento de síntesis del compuesto con un grupo nitro en posición 3.

Para evitar la dinitración se decidió utilizar directamente como sustratos las fenstatinas, que están menos activadas. Empleando el compuesto 28 disuelto en $\mathrm{CH}_{2} \mathrm{Cl}_{2}$ y un equivalente de $\mathrm{HNO}_{3}$ al $60 \%$ calentando a reflujo no se obtuvo producto de nitración. Sin embargo, cuando se disuelve el compuesto 28 en $\mathrm{H}_{2} \mathrm{SO}_{4}$ en baño de hielo y se añade un equivalente de una dilución 1:5 de $\mathrm{HNO}_{3}$ en agua, se obtiene el compuesto deseado 32 con un rendimiento del $55 \%$. También se obtiene material de partida sin reaccionar y producto de disustitución. Estas mismas condiciones se han repetido para la síntesis del compuesto $\mathbf{5 3}$, que se obtiene con un rendimiento del $24 \%$.

\footnotetext{
${ }^{42}$ Francis A. Carey. Química Orgánica. Tercera edición. McGraw-Hill/Interamericana. 1999.
} 
<smiles>[Z6][R6]c1cc(C(=O)c2ccc(OC)cc2)cc(OC)n1</smiles>

49

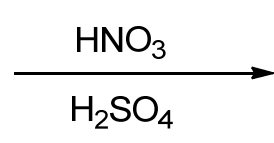

$\mathrm{X:Cl}$

$\mathrm{X}: \mathrm{SMe}$<smiles>[X]c1cc(C(=O)c2ccc(OC)c([N+](=O)[O-])c2)cc(OC)n1</smiles>

32 R: $55 \%$

53 R: $24 \%$

Figura 31: Fenstatinas sintetizadas con grupo nitro en posición 3.

\section{C.3.1.1.2. Reducción del grupo nitro}

La reducción del grupo nitro a amino se llevó a cabo utilizando Fe metal en medio ácido ${ }^{43}$. Los compuestos obtenidos por este método son 34 y 54, para los que se observa un apantallamiento en las señales debido a la reducción del grupo nitro. También es observada una señal en torno a $3300 \mathrm{~cm}^{-1}$ en IR.<smiles>[X]c1cc(C(=O)c2cc([R9])c(OC)c([N+](=O)[O-])c2)cc(OC)n1</smiles>

32

53<smiles>CCOC(=O)OCC</smiles>

$\mathrm{X}: \mathrm{Cl}$ $\mathrm{X}: \mathrm{SMe}$<smiles>[Y4]c1cc(N)c(OC)c(C(=O)c2cc([X])nc(OC)c2)c1</smiles>

34 R: $75 \%$

54 R: $24 \%$

Figura 32: Fenstatinas sintetizadas con grupos amino en posición 3.

${ }^{43}$ Liou JP, Chang CW, Song JS, Yang YN, Yeh CF, Tseng HY, et al. Synthesis and structureactivity relationship of 2-aminobenzophenone derivatives as antimitotic agents. J Med Chem, 2002, 45, 2556-2562. 


\section{C.3.1.2. MODIFICACIONES EN EL ANILLO DE INDOL}

En nuestro grupo de investigación se han sintetizado numerosos compuestos con anillos de $\mathrm{N}$-metilindol, y además se han introducido modificaciones en varias posiciones $^{44}$ con el objetivo de mejorar la solubilidad de estos compuestos con la presencia de determinados grupos funcionales como ácidos carboxílicos, aldehídos, carbonitrilos.

Las reacciones que van a ser llevadas en este anillo son sustituciones electrofílicas aromáticas en posición 3 del anillo indólico ${ }^{45}$, ya que además de ser la más reactiva, genera productos con mayor potencia y versatilidad, según se ha comprobado con anterioridad en nuestro grupo de investigación.

\section{C.3.1.2.1. Formilación}

Los compuestos con anillo de $N$-metilindol se han formilado en posición 3 mediante la reacción de Vilsmeier-Haack y los compuestos obtenidos se han utilizado como material de partida para la preparación de carbonitrilos.

En el método empleado se pone la DMF y se añaden $6 \mathrm{mmol}$ de oxicloruro de fósforo por cada mmol de compuesto a formilar, y se deja media hora en baño de hielo para que se forme el complejo de la DMF con $\mathrm{POCl}_{3}$, que da lugar a la formación del catión iminio ${ }^{46}$. Esta reacción es muy exotérmica, por eso es necesario el baño de hielo ${ }^{47}$. Posteriormente se añade el compuesto que va a ser formilado disuelto en DMF seca y se pone a reflujo, en caso de que el material de partida sean fenstatinas, o a temperatura ambiente en el caso de las isocombretastatinas, durante dos horas. Esta

\footnotetext{
${ }^{44}$ Álvarez R, Puebla P, Díaz JF, Bento AC, García-Navas R, de la Iglesia-Vicente J, et al. Endowing indole-based tubulin inhibitors with an anchor for derivatization: highly potent 3substituted indolephenstatins and indoleisocombretastatins. J Med Chem, 2013, 56, 2813-2827

${ }^{45}$ Davies D. Aromatic Heterocyclic Chemistry. Oxford University Press. 1999

46 Organic Chemistry Portal. http://www.organic-chemistry.org/namedreactions/vilsmeierreaction.shtm

${ }^{47}$ Campaigne E, Archer WL. Formylation of dimethylaniline. Org. Syn. Coll. 1963, 4, 331.
} 
diferencia es debida a que las isocombretastatinas son susceptibles de ser formiladas en el puente.

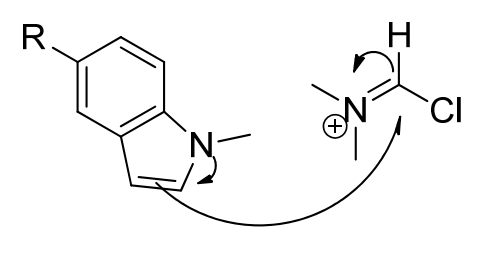<smiles></smiles><smiles>[R]c1ccc2c(c1)c(C=O)cn2C</smiles>

Figura 33: Mecanismo de formilación,

En general se obtienen los derivados formilados con un buen rendimiento, que oscila entre el 40 y el $90 \%$. Los compuestos sintetizados se resumen en la tabla siguiente:

\begin{tabular}{cc|cc|cc}
\multirow{2}{*}{} & \multicolumn{2}{c|}{ Fenstatina } & \multicolumn{2}{c}{ Isocombretastatina } \\
\cline { 3 - 7 } $\mathbf{X}$ & $\mathbf{Y}$ & Producto & Rendimiento (\%) & Producto & Rendimiento (\%) \\
\hline $\mathrm{Cl}$ & $\mathrm{Cl}$ & $\mathbf{6 4}$ & 84 & $\mathbf{6 5}$ & 92 \\
\hline $\mathrm{Cl}$ & $\mathrm{SMe}$ & $\mathbf{7 5}$ & 64 & $\mathbf{7 6}$ & 70 \\
\hline $\mathrm{SMe}$ & $\mathrm{OMe}$ & $\mathbf{8 7}$ & 51 & $\mathbf{8 9}$ & 59 \\
\hline $\mathrm{SMe}$ & $\mathrm{SMe}$ & $\mathbf{9 8}$ & 44 & $\mathbf{9 9}$ & 92 \\
\hline $\mathrm{SMe}$ & $\mathrm{NMe}_{2}$ & $\mathbf{1 0 7}$ & 47 & $\mathbf{1 0 9}$ & 54
\end{tabular}

Tabla 3: Compuestos sintetizados con grupos aldehído en el anillo B.

Los productos de formilación del indol se caracterizan en el espectro de RMN ${ }^{1} \mathrm{H}$ por la desaparición de la señal del protón $\mathrm{H}_{3}$ del indol, la aparición de un singlete del aldehído en torno a 10 ppm, y el desapantallamiento de la señal de los protones $\mathrm{H}_{2}$ y $\mathrm{H}_{4}$ del anillo indólico que son los que se encuentran más cercanos al grupo aldehído, como se aprecia en el compuesto 65. 


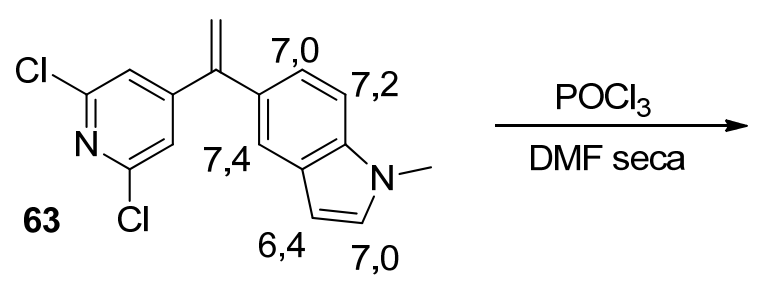

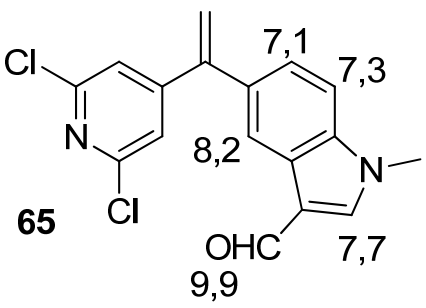

Figura 34: Señales de $\mathrm{RMN}^{1} \mathrm{H}$ de los protones del anillo indólico.

En algunas de estas reacciones se han obtenido productos de diformilación. Por ejemplo, en la síntesis del compuesto 107 se obtuvo el producto 108 , en el que se ha introducido un aldehído en el anillo de piridina, que en $\mathrm{RMN}{ }^{1} \mathrm{H}$ desdobla la señal de los protones del dimetilamino en dos señales singlete. En contraposición, en la síntesis del compuesto 109, también se obtiene el producto de diformilación 111 en el anillo de piridina, pero en la otra posición, por lo que la señal de dimetilamino sale como un singlete a 3,15 ppm.<smiles>CSc1cc(C(=O)c2ccc3c(c2)c(C=O)cn3C)c(C=O)c(N([13CH3])[R5](=O)[O-])n1</smiles>

108<smiles>C=C(c1ccc2c(c1)c(C=O)cn2C)c1cc(N([13CH3])[13CH3])nc(SC)c1C=O</smiles>

111

Figura 35: Compuestos obtenidos como resultado de diformilación.

Adicionalmente, en la síntesis del compuesto 109, en una de las repeticiones de esta reacción se obtiene el producto de la sustitución del grupo metilsulfanilo de la piridina por un cloro, obteniendo el compuesto 110. Esto puede ser debido a que los aniones cloro que se forman en la reacción de formilación, provocan una SNAr en el anillo de piridina introduciendo un grupo cloro. 


\section{C.3.1.2.2. Introducción de ácidos carboxílicos}

Para la incorporación de grupos carboxílicos en posición 3 del indol se utilizó fosgeno al $20 \%$ en tolueno y $\mathrm{CH}_{2} \mathrm{Cl}_{2}$ como disolvente. Se forma el derivado con cloruro de ácido que luego en contacto con agua se convierte en el ácido carboxílico.

Esta reacción solo ha sido llevada a cabo utilizando como material de partida las isocombretastatinas. Además de tener un bajo rendimiento (entre 5 y $27 \%$ ), en el crudo de reacción se obtiene material de partida sin reaccionar y se forma fenstatina debido a la rotura del alquenilo del puente.

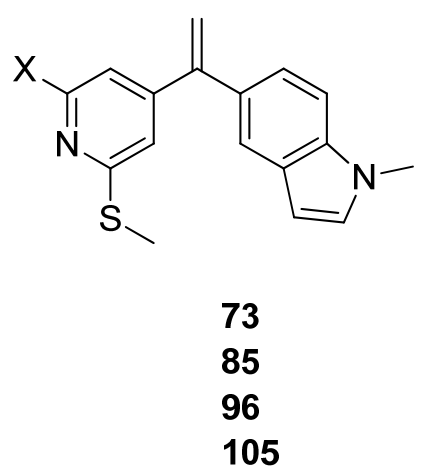<smiles>O=C(Cl)Cl</smiles><smiles>OCCCl</smiles>

$\mathrm{Cl}$ OMe $\mathrm{SMe}$ $\mathrm{NMe}_{2}$<smiles>C=C(c1cc(C)nc(SC)c1)c1ccc2c(c1)c(C(=O)O)cn2C</smiles>

77 R: $13 \%$

88 R: $27 \%$

100 R: $25 \%$

112 R: $5 \%$

Figura 36: Compuestos sintetizados con ácidos carboxílicos en posición 3 del anillo de indol.

\section{C.3.1.2.3. Preparación de carbonitrilos}

La síntesis de fenstatinas e isocombretastatinas indólicas con carbonitrilo en posición 3 se lleva a cabo en dos pasos a partir del aldehído. El primero consiste en la formación de las oximas, que mediante tratamiento con anhídrido acético dan lugar a la formación de los carbonitrilos.

Las oximas se sintetizan a partir de los aldehídos tratándolas con clorhidrato de hidroxilamina utilizando como disolvente metanol y unas gotas de piridina durante 24 horas a reflujo. En el crudo de reacción se obtiene, con buenos rendimientos, una mezcla de isómeros $E$ y $Z$ difícil de separar. Adicionalmente, cuando el material de 
partida es una fenstatina, también se forma la oxima en el puente, por lo que hay 4 isómeros diferentes, como ocurre con el compuesto 66 .<smiles>Cn1cc(C=O)c2cc(C(=O)c3cc(Cl)nc(Cl)c3)ccc21</smiles>

64

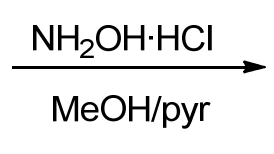

$\mathrm{MeOH} / \mathrm{pyr}$<smiles>Cn1cc(/C=N/O)c2cc(/C(=N\O)c3cc(Cl)nc(Cl)c3)ccc21</smiles>

Figura 37: Síntesis del compuesto 66.

Estos productos se utilizan directamente en el tratamiento con anhídrido acético en piridina para la formación de carbonitrilos. Cuando el material de partida es una isocombretastatina, se obtiene directamente el carbonitrilo con unos rendimientos que oscilan entre 20 y $74 \%$. En la síntesis de los compuestos 117 y 123, también se obtuvieron los derivados de acetoxima 118 con un rendimiento del $15 \%$, y 124 con un $5 \%$. Estos compuestos no han podido ser caracterizados porque se degradan en disolución.<smiles>[X]c1cc(C(=C)c2ccc3c(c2)c(/C=N/O)cn3C)cc([X])n1</smiles>

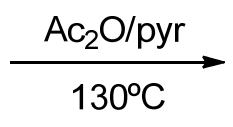

$\begin{array}{ll}69 & \mathrm{X}, \mathrm{Y}: \mathrm{Cl} \\ 81 & \mathrm{X}: \mathrm{Cl} ; \mathrm{Y}: \mathrm{SMe} \\ 101 & \mathrm{X}, \mathrm{Y}: \mathrm{SMe} \\ 116 & \mathrm{X}: \mathrm{SMe} ; \mathrm{Y}: \mathrm{NMe}_{2} \\ & \\ 122 & \mathrm{X}: \mathrm{Cl} ; \mathrm{Y}: \mathrm{NMe}_{2}\end{array}$<smiles>[Y]c1cc(C(=C)c2ccc3c(c2)c([Z])cn3C)cc([X])n1</smiles>

$70 \mathrm{Z}: \mathrm{CN}$
$82 \mathrm{Z}: \mathrm{CN}$
$102 \mathrm{Z}: \mathrm{CN}$
$117 \mathrm{Z}: \mathrm{CN}$
$118 \mathrm{Z}: \mathrm{CH}=\mathrm{N}-\mathrm{OAC}$
$123 \mathrm{Z}: \mathrm{CN}$
$124 \mathrm{Z}: \mathrm{CH}=\mathrm{N}-\mathrm{OAC}$

R: $20 \%$

R: $74 \%$

R: $39 \%$

R: $27 \%$

R: $15 \%$

R: $21 \%$

R: $5 \%$

Figura 38: Isocombretastatinas sintetizadas con carbonitrilo en posición 3 del anillo de indol. 
En la síntesis de carbonitrilos con fenstatinas como material de partida, se forma un intermedio de acetoxima en el puente, que en algunos casos se hidroliza durante en la reacción, y en otras ocasiones es necesario hidrolizarlo con $\mathrm{KOH} 5 \mathrm{~N}$ en $\mathrm{MeOH}$. El crudo de reacción se purifica mediante cromatografía flash obteniendo mezcla de isómeros $Z$ y $E$ y en algún caso un isómero aislado que se isomeriza en disolución.

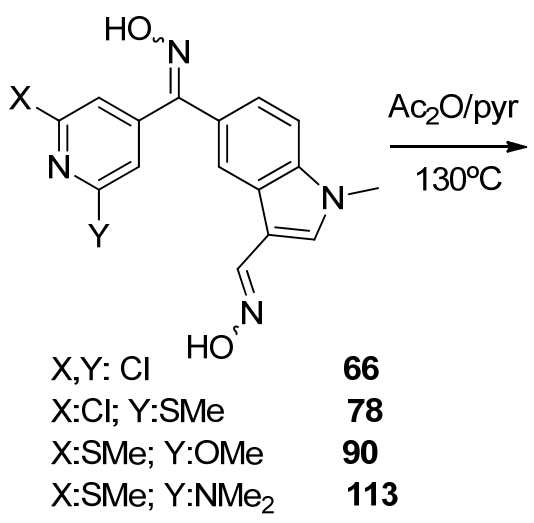

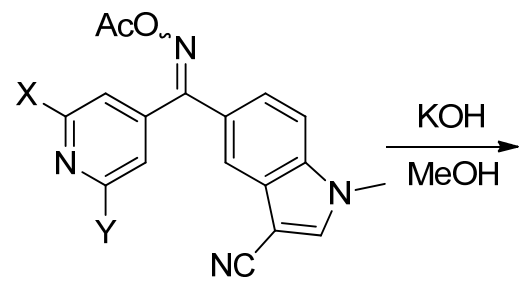

67 R: $42 \%$

79 R: $76 \%$

91 R: $42 \%$

114 R: $98 \%$<smiles>[X]c1cc(/C(=N\O)c2ccc3c(c2)c(C#N)cn3C)cc([X])n1</smiles>

68 R: $82 \%$

80 R: $50 \%$

92 R: $34 \%$

115 R: $85 \%$

Figura 39: Compuestos con oximas en el puente y carbonitrilo en posición 3 del anillo de indol.

El compuesto 92 es muy inestable en disolución, y la oxima del puente regenera la cetona formando el compuesto 93, por eso el compuesto que ha sido utilizado para en los ensayos de actividad biológica es la cetona. El compuesto 68 también sufre la misma hidrólisis en el puente en disolución clorofórmica.

Cabe destacar, en el espectro de $\mathrm{RMN}{ }^{13} \mathrm{C}$, el gran apantallamiento que sufre el carbono unido a carbonitrilo, que tiene un valor en torno a 86 ppm, a diferencia del compuesto con aldehído en esa posición que tiene un valor en torno a 120 ppm.

\section{C.3.1.2.4. Síntesis de amidas}

Para la introducción de amidas en posición 3 se intentó la hidrólisis del carbonitrilo. Las condiciones utilizadas fueron múltiples: hidrólisis en médio básico en $\mathrm{MeOH}$, hidrólisis en medio ácido con $\mathrm{HCl}$, con $\mathrm{H}_{2} \mathrm{SO}_{4}$, usando ácidos de Lewis (isopropóxido de aluminio), con ayuda de catalizadores (triflato de zinc). Sin embargo, ninguna de estas opciones tuvo el resultado buscado. 
<smiles>C=C(c1cc(Cl)nc(SC)c1)c1ccc2c(c1)c(C#N)cn2C</smiles><smiles>C=CC=CC</smiles>

Figura 40: Intento de síntesis de amidas a partir de carbonitrilos.

Debido a esto, se decidió introducir directamente el grupo amida utilizando las condiciones descritas por $\mathrm{Kim}$ et $\mathrm{al}^{48}$ modificadas, usando 1,2-dicloroetano como disolvente, 1,5 equivalentes de isocianato de clorosulfonilo durante $24 \mathrm{~h}$ a temperatura ambiente, obteniéndose el compuesto buscado con rendimientos que varían entre el 6 y el $31 \%$. En algunos casos también se obtiene en baja proporción el ácido carboxílico.<smiles>[X]c1cc(C(=C)c2ccc3c(ccn3C)c2)cc([Y])n1</smiles>

65

73

96

105
$\mathrm{X}, \mathrm{Y}: \mathrm{Cl}$

$\mathrm{X}: \mathrm{Cl} ; \mathrm{Y}: \mathrm{SMe}$

$\mathrm{X}, \mathrm{Y}: \mathrm{SMe}$

$\mathrm{X}: \mathrm{SMe} ; \mathrm{Y}: \mathrm{NMe}_{2}$<smiles>[Y]c1cc(C(=C)c2ccc3c(c2)c(C(N)=O)cn3C)cc([X])n1</smiles>

71 R: $6 \%$

83 R: $31 \%$

103 R: $31 \%$

119 R: $22 \%$

Figura 41: Compuestos sintetizados con carboxamidas en posición 3 del anillo de indol.

\section{C.3.2. MODIFICACIONES EN EL ANILLO A}

En la mayoría de los compuestos sintetizados, no se realizan cambios en el anillo A una vez se ha sintetizado la fenstatina, sin embargo, se han hecho algunas pruebas mediante la introducción de un nuevo anillo aromático y también se ha

\footnotetext{
${ }^{48}$ Pindur $\mathrm{U}, \mathrm{Kim} \mathrm{M}$. First reactions of vinylindoles with diethyl mesoxalate, nitrosobenzene, and chlorosulfonyl isocyanate: New functionalized and [b]annellated indoles. Tetrahedron, 1989, 45, 6427-6437.
} 
oxidado el grupo metilsufanilo en un intento de aumentar la solubilidad de los compuestos.

\section{C.3.2.1. OXIDACIÓN DEL GRUPO METILSULFANILO}

Los grupos sulfuro pueden ser oxidados a sulfóxidos y a sulfonas por medio de una serie de agentes oxidantes, como pueden ser peroxiácidos o peróxido de hidrógeno ${ }^{49}$. En nuestro caso se ha utilizado ácido meta-cloroperbenzóico (AMCPB) como agente oxidante, en $\mathrm{CH}_{2} \mathrm{Cl}_{2}$.

En la reacción con perácidos, el sulfuro ataca el enlace débil O-O del perácido a través de un mecanismo $\mathrm{SN}_{2}$. Este enlace se rompe, generando el ácido carboxílico y el sulfóxido. Esta reacción transcurre rápidamente y sin necesidad de catalizadores. La reacción de oxidación del sulfóxido a sulfona es similar, pero menos rápida que la oxidación de sulfuro a sulfóxido.

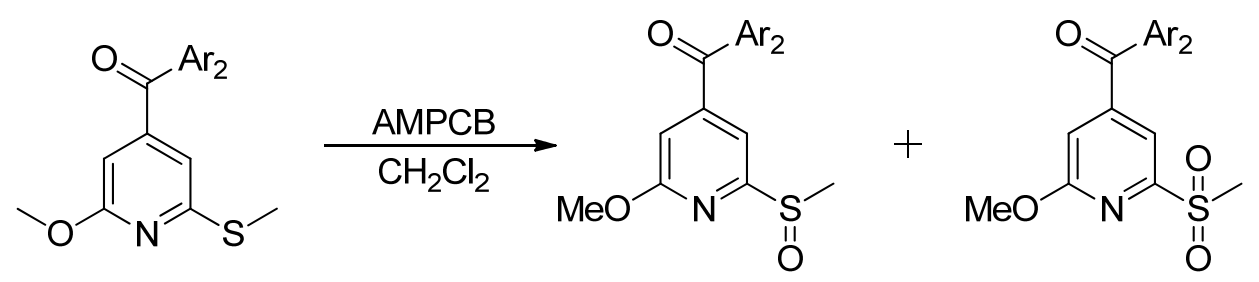

\begin{tabular}{c|cccc} 
Producto & $\mathbf{A r}_{\mathbf{2}}$ & Tipo de $\mathbf{S}$ & $\mathbf{R M N}^{\mathbf{1}} \mathbf{H ~ S C H}_{\mathbf{3}}$ (ppm) & Rendimiento (\%) \\
\hline $\mathbf{1 2 5}$ & NMeIND & Sulfóxido & 2,9 & 14 \\
\hline $\mathbf{1 2 6}$ & NMeIND & Sulfona & 3,24 & 3 \\
\hline $\mathbf{1 2 8}$ & $2-$-Naft & Sulfóxido & 2,91 & 26 \\
\hline $\mathbf{1 2 9}$ & $2-$ Naft & Sulfona & 3,26 & 11
\end{tabular}

Tabla 4: Compuestos sintetizados con sulfóxidos o sulfonas en el anillo de piridina.

La obtención de sulfóxidos o sulfonas depende de la cantidad de equivalentes de AMPCB que se añade. Por ejemplo, en la síntesis del compuesto 126 se añadieron

${ }^{49}$ Smith MB. Organic Synthesis. McGrawHill; London 1994. 
dos equivalentes, obteniendo la sulfona. Para obtener el sulfóxido 125 se repite la síntesis añadiendo solo un equivalente de AMCPB. En la síntesis de sulfóxido y sulfona con anillo de naftaleno como anillo $B$ añadiendo un equivalente de AMCPB, se obtiene mezcla de sulfóxido 128 y de sulfona 129.

Mediante RMN ${ }^{1} \mathrm{H}$ se puede diferenciar el sulfóxido y la sulfona según el desplazamiento químico del metilo unido a azufre. En el caso de la sulfonas, éste se desapantalla hasta 3,24-3,26 ppm, en el caso de los sulfóxidos la señal aparece a 2,90 ppm y en los materiales de partida este metilo resuena a 2,50-2,60 ppm.

\section{C.3.2.2. INTRODUCCIÓN DE UN NUEVO ANILLO AROMÁTICO}

Como se ha visto en la introducción, existen compuestos que se unen en el sitio de la colchicina que tienen un anillo aromático adicional que accede a la zona 3 del dominio. Es por esto que se decidió introducir un anillo aromático en posición 6 del anillo de piridina.

Inicialmente se intentó mediante la introducción de $p$-aminofenol mediante una sustitución nucleofílica aromática. Primero se llevo a cabo sobre el compuesto $\mathbf{2 8}$, que tiene un grupo metoxilo y utilizando diferentes condiciones (disolventes como DMF, diglime; añadiendo $\mathrm{NaH}$ ), y posteriormente sobre el compuesto diclorado 25 utilizando diglime como disolvente. En ninguno de estos casos se obtuvo el compuesto esperado.<smiles>[X]c1cc(C(=O)c2ccc(OC)cc2)cc(Cl)n1</smiles><smiles>CC(C)C</smiles><smiles>[X]c1cc(C(=O)c2ccc(OC)cc2)cc(Nc2ccc(O)cc2)n1</smiles>

\section{$\mathrm{X}: \mathrm{Cl}, \mathrm{OMe}$}

Figura 42: Intento de introducción de un nuevo anillo aromático. 
Por este motivo, se llevo a cabo la reacción mediante el método descrito por Brimble et $\mathrm{al}^{50}$, en el cual se realiza una $\mathrm{N}$-arilación utilizado un catalizador de $\mathrm{Pd}$. De esta manera se obtiene el compuesto 75 con un $12 \%$ de rendimiento. Este método también ha sido utilizado para la síntesis del compuesto 37 con p-toluidina.<smiles>COc1ccc(C(=O)c2cc(Cl)nc(Cl)c2)cc1</smiles><smiles>[R]OC(=O)OCCO[R16](=O)OCC</smiles><smiles>[R]c1ccc(Nc2cc(C(=O)c3ccc(OC)cc3)cc(Cl)n2)cc1</smiles>

$36 \mathrm{R}: \mathrm{H}$ $37 \mathrm{R}: \mathrm{CH}_{3}$

Figura 43: Síntesis de los compuestos 36 y 37.

\section{C.3.3. MODIFICACIONES EN EL PUENTE}

La mayoría de los compuestos que han sido sintetizados tienen en el puente una configuración $\mathrm{sp}_{2}$, sin embargo, también se han sintetizado con anterioridad en el grupo de investigación compuestos con configuración $\mathrm{sp}_{3}$ mediante la hidrogenación de las isocombretastatinas, obteniendo en algunos casos compuestos con buen perfil citotóxico. ${ }^{44}$ Por esta razón se han preparado los derivados hidrogenados de los compuestos 46 y 50 mediante hidrogenación.<smiles>[X]c1cc(C(=C)c2ccc(OC)cc2)cc(SC)n1</smiles>

46

50

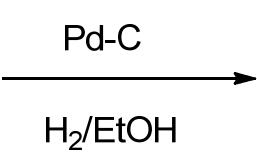

$\mathrm{X}: \mathrm{SMe}$

$\mathrm{X}: \mathrm{OMe}$<smiles>[X]c1cc(C(C)c2ccc(OC)cc2)cc(SC)n1</smiles>

48

Figura 44: Síntesis de derivados hidrogenados.

50 Lorimer AV, O'Connor PD, Brimble MA. Buchwald-Hartwig mono-N-arylation with 2,6dihaloisonicotinic acid derivatives: A convenient desymmetrization method. Synthesis, 2008, 17, 2764-2770. 
Esta reacción se controla mediante $\mathrm{CCF}$, transcurriendo con mucha lentitud (nueve días) y con bajos rendimientos por lo que no se ha realizado con más compuestos. En el espectro de $\mathrm{RMN}{ }^{1} \mathrm{H}$ aparecen las señales correspondientes al puente: un cuartete en torno a 3,9 ppm y un doblete a 1,55 ppm.

Otra modificación que se ha realizado en el puente, es la formación de oximas que mantienen la configuración $\mathrm{sp}_{2}$ y se ha visto con anterioridad que da lugar a compuestos que mantienen la potencia citotóxica. ${ }^{51} \mathrm{La}$ introducción de este grupo aumenta la probabilidad de establecer enlaces de hidrógeno, aumentando la solubilidad acuosa de estos compuestos. Además, la síntesis es muy sencilla y se obtienen buenos rendimientos. En esta reacción se disuelve la fenstatina de partida en metanol con 4 gotas de piridina, y se añade un exceso de clorhidrato de hidroxilamina.<smiles>[R16]C(=O)c1cc([X])nc([Y])c1</smiles>

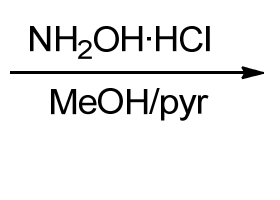<smiles>[Y16]/C(=N\O)c1cc([Y])nc([X])c1</smiles>

Figura 45: Síntesis de oximas en el puente.

El problema que presentan estos compuestos es la formación de mezclas de isómeros $E$ y $Z$ de difícil separación. En algunos casos, mediante cromatografía flash, se obtienen los isómeros por separado pero en disolución se vuelven a isomerizar. Debido a esto se utilizan mezclas de isómeros en los ensayos de actividad biológica.

En la siguiente tabla se resumen las oximas que han sido sintetizadas, junto con el rendimiento total de la reacción y el rendimiento de cada oxima por separado, en caso de haber sido separadas. Oxima A y B se refiere a los isómeros por separado pero no tienen asignada la configuración $E$ o $Z$. Las oximas en las que pone cristal, es porque han sido separadas mediante cristalización, mientras que si no pone nada es porque se han separado por cromatografía flash.

\footnotetext{
51 Álvarez C, Álvarez R, Corchete P, López JL, Pérez-Melero C, Peláez R, et al. Diarylmethyloxime and hydrazone derivatives with 5-indolyl moieties as potent inhibitors of tubulin polymerization. Bioorg Med Chem, 2008, 16, 5952-5961.
} 


\begin{tabular}{|c|c|c|c|c|c|c|}
\hline Comp & $x$ & $Y$ & $\mathrm{Ar}_{2}$ & $\begin{array}{c}\text { Rendimiento } \\
\text { Total }(a+b)\end{array}$ & Oxima A & Oxima B \\
\hline 27 & $\mathrm{Cl}$ & $\mathrm{Cl}$ & 4-MeO-Ph & 80 & $43 \%$ cristal & \\
\hline 31 & $\mathrm{Cl}$ & OMe & 4-MeO-Ph & 93 & cristal & \\
\hline 41 & $\mathrm{Cl}$ & SMe & 4-MeO-Ph & 89 & & \\
\hline 44 & $\mathrm{Cl}$ & $\mathrm{NMe}_{2}$ & 4-MeO-Ph & 97 & $28 \%$ cristal & \\
\hline 47 & SMe & SMe & 4-MeO-Ph & 83 & $7 \%$ & \\
\hline 51 & SMe & OMe & 4-MeO-Ph & 65 & $27 \%$ & $17 \%$ \\
\hline 57 & SMe & $\mathrm{NMe}_{2}$ & 4-MeO-Ph & 98 & & \\
\hline 60 & OMe & $\mathrm{NMe}_{2}$ & 4-MeO-Ph & 90 & $13 \%$ cristal & \\
\hline 74 & $\mathrm{Cl}$ & SMe & NMelND & & $12 \%$ cristal & \\
\hline 86 & SMe & $\mathrm{OMe}$ & NMeIND & 70 & $70 \%$ & \\
\hline 97 & SMe & SMe & NMeIND & 86 & $34 \%$ & $15 \%$ \\
\hline 106 & SMe & $\mathrm{NMe}_{2}$ & NMeIND & 89 & & \\
\hline 133 & SMe & SMe & 2-Naft & 99 & $50 \%$ & $31 \%$ \\
\hline 136 & SMe & SMe & $3-\mathrm{NMe}_{2} \mathrm{Ph}$ & 82 & $9 \%$ & \\
\hline 139 & SMe & $\mathrm{OMe}$ & $4-\mathrm{NMe}_{2} \mathrm{Ph}$ & 70 & & \\
\hline 143 & SMe & SMe & $4-\mathrm{NMe}_{2} \mathrm{Ph}$ & 69 & $10 \%$ & \\
\hline
\end{tabular}

Tabla 5: Compuestos sintetizados con oximas en el puente.

En la formación de oximas cabe destacar el ligero apantallamiento que sufren las señales de los protones que están próximos al puente como puede observarse en el compuesto 97.

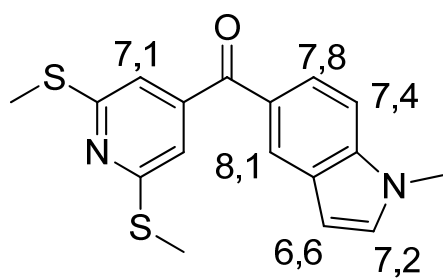

94

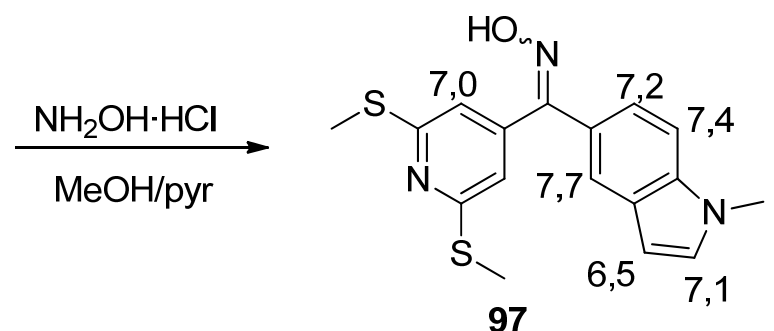

97

Figura 46: Señales de $\mathrm{RMN}{ }^{1} \mathrm{H}$ de los compuestos 94 y 97. 
Para la identificación de los isómeros $E$ y $Z$, se realizaron rayos $X$ de los cristales de uno de los isómeros aislados del compuesto 44, y tal como se observa en la siguiente imagen estos cristales corresponden al isómero $E$.

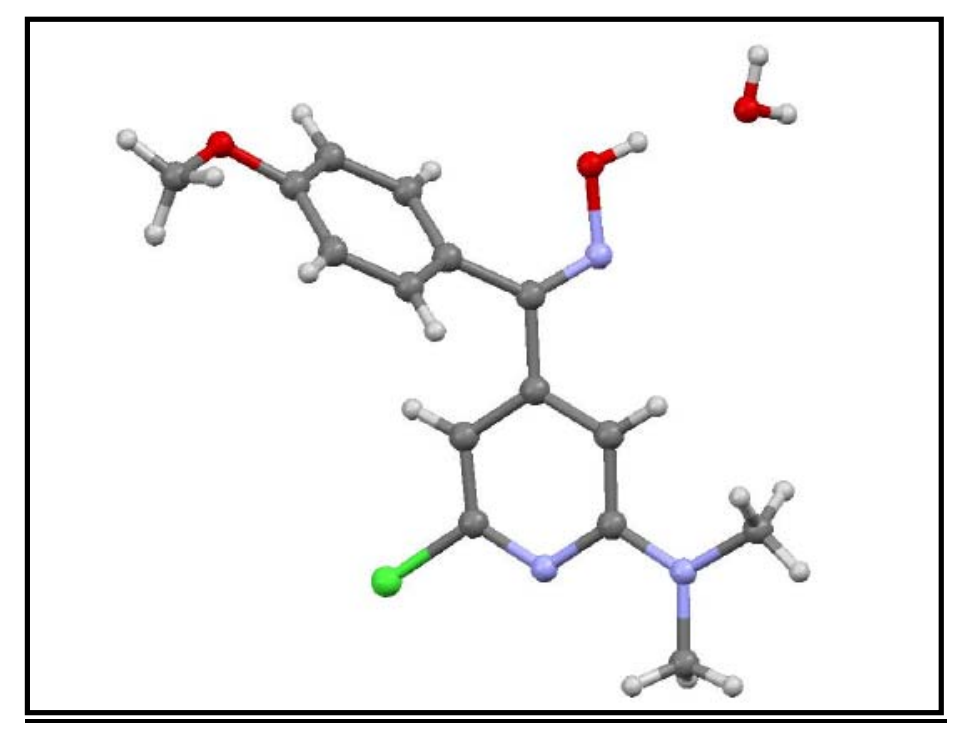

Figura 47: Estructura de rayos $X$ del compuesto 44E.

De esta manera, comparando las diferencias en las señales en los protones de piridina y en los protones del anillo de $p$-metoxifenilo en el compuesto 44 , se ha podido asignar los isómeros del resto de las oximas sintetizadas. En el isómero 44Z, en comparación con el isómero $44 E$, se observa un apantallamiento en las señales de los protones de piridina, debido a la proximidad de la oxima, y un desapantallamiento en los protones en orto del anillo de $p$-metoxifenilo debido al alejamiento.
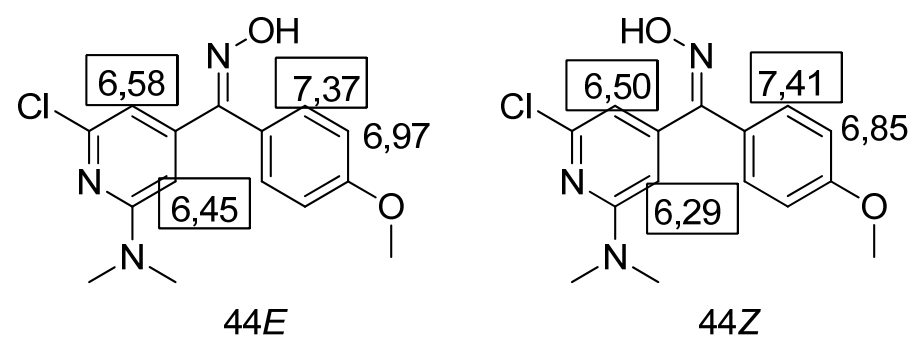

Figura 48: Diferencia de desplazamiento en los protones entre los isómeros $E$ y $Z$.

Para asignar los isómeros de todas las oximas sintetizadas nos hemos basado fundamentalmente en la diferencia en los protones de piridina, ya que es el patrón que más se cumple en todos los compuestos. 


\section{C.4. SÍNTESIS DE COMBRETASTATINAS}

En este trabajo se ha planteado la síntesis de combretastatinas con el objetivo de evaluar el efecto de la sustitución del anillo de trimetoxifenilo por un anillo equivalente de piridina. Para este estudio se ha decidido mantener los anillos de $p$ metoxifenilo y $\mathrm{N}$-metilindol en el sistema aromático $\mathrm{Ar}_{2}$ (Anillo B).

La síntesis de combretastatinas se realiza mediante una reacción de Wittig que produce la combretastatina como mezcla de isómeros $E$ y $Z$.

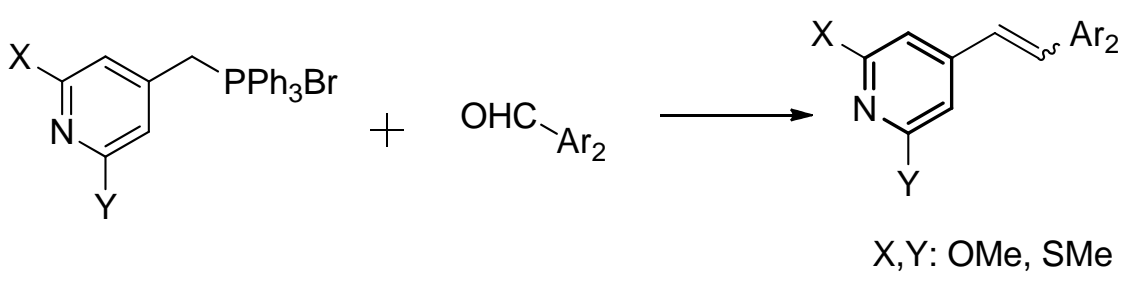

Figura 49: Reacción de Wittig para la síntesis de combretastatinas.

\section{C.4.1. PREPARACIÓN DE SALES DE FOSFONIO A PARTIR DE ÁCIDOS ISONICOTÍNICOS}

Como las sales de fosfonio de los derivados de piridina no son comerciales, se han preparado a partir de los ácidos isonicotínicos correspondientes según el siguiente esquema:<smiles>[X]c1cc(C[Pb]Br)cc(SC)n1</smiles>

Esquema 5: Esquema de preparación de las sales de fosfonio. 


\section{C.4.1.1. REDUCCIÓN DEL ÁCIDO A ALCOHOL}

Para la reducción del ácido carboxílico a alcohol se añaden 1,5 equivalentes de hidruro de aluminio y litio por cada equivalente de ácido. En el espectro de $\mathrm{RMN}^{1} \mathrm{H}$ destacan las señales del metileno que aparecen como un singlete a 4,58 ppm (compuesto 8) y a 4,55 (compuesto 11).

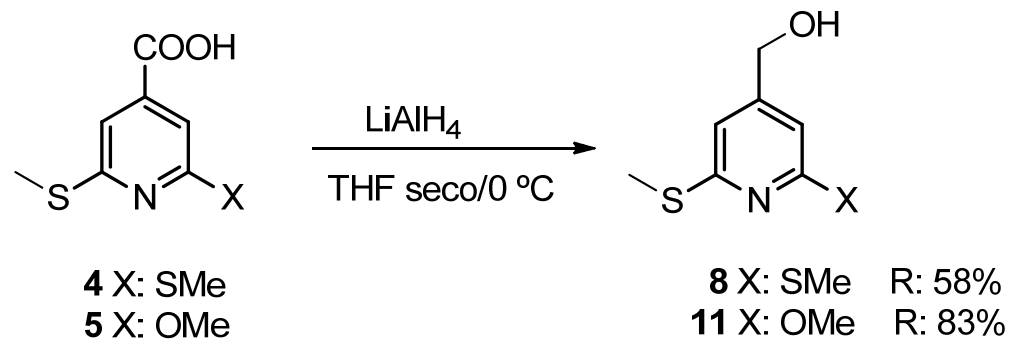

Figura 50: Reducción de ácido carboxílico a alcohol.

\section{C.4.1.2. FORMACIÓN DEL BROMODERIVADO}

La formación de un bromoderivado a partir de un alcohol con tribromuro de fósforo en éter a temperatura ambiente durante 24 horas no dio el producto buscado, posiblemente debido a que el material de partida no se disuelve bien en el éter. Posteriormente se utilizó bromuro de hidrógeno en ácido acético y baño de hielo durante 24 horas y se obtuvieron los productos 9 y 12 con buenos rendimientos (alrededor del $85 \%$ ).<smiles>[X]c1cc(CO)cc(SC)n1</smiles>

$8 \mathrm{X}: \mathrm{SMe}$

$11 \mathrm{X}$ : OMe

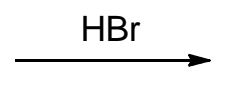<smiles>[X]c1cc(CBr)cc(SC)n1</smiles>

$9 \mathrm{X}: \mathrm{SMe}$ $12 X$ : OMe
R: $86 \%$

R: $84 \%$

Figura 51: Síntesis de los compuestos 9 y 12. 
En el espectro de RMN ${ }^{1} \mathrm{H}$ se ve reflejado este cambio por el desplazamiento en la señal de los protones del metileno de 4,48 y de 4,55 a 4,98 ppm.

\section{C.4.1.3. SÍNTESIS DE LAS SALES DE FOSFONIO DE DERIVADOS DE PIRIDINA}

A partir del derivado bromado, mediante reacción con trifenilfosfina utilizando como disolvente tolueno seco se forma, mediante un mecanismo $\mathrm{SN}_{2}$, la sal de fosfonio que precipita como un sólido de color blanquecino.<smiles>[X]c1cc(CBr)cc(SC)n1</smiles>

$9 \mathrm{X}: \mathrm{SMe}$

$12 \mathrm{X}$ : OMe

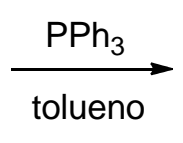

Figura 52: Sales de fosfonio sintetizadas con anillo de piridina.

\section{C.4.2. REACCIÓN DE WITTIG}

El último paso consiste en la reacción de Wittig, en la que se prepara una suspensión de la sal de fosfonio en THF seco a $-40{ }^{\circ} \mathrm{C}$, se añaden 1,1 equivalentes de $n$ BuLi y una vez se ha formado el iluro de fósforo se añade el aldehído correspondiente y se mantiene 24 horas dejando subir la temperatura lentamente. Se obtiene un crudo de reacción con mezcla de isómeros $E$ y $Z$ que son separados mediante cromatografía flash. El compuesto que es ensayado en los experimentos de actividad biológica es el cis ya que son los que presentan actividad sobre la polimerización de la tubulina, como se ha visto en el apartado de introdución. 

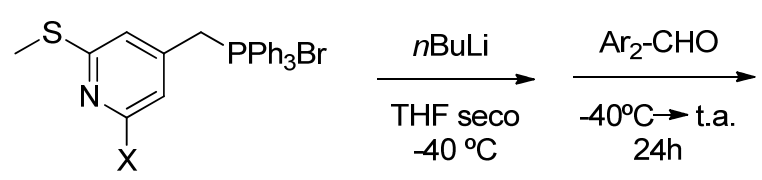<smiles>[Y10]C=Cc1cc([X])nc(SC)c1</smiles><smiles>[Z20]O[Se]</smiles>

Figura 53: Reacción de Wittig donde se forma mezcla de isómeros $Z$ y $E$.

En la siguiente tabla se detallan las combretastatinas que han sido sintetizadas, el rendimiento total de la mezcla de isómeros y el rendimiento parcial de cada isómero aislado. Sólo se ha conseguido aislar el isómero trans del compuesto 146, ya que en el resto de los casos siempre se recupera una mezcla $Z+E$.

\begin{tabular}{|c|c|c|c|c|c|}
\hline Comp & $x$ & $\mathrm{Ar}_{2}$ & $\begin{array}{l}\text { Rendimiento } \\
\text { total (\%) }\end{array}$ & $\begin{array}{c}\text { Isómero Z: RMN } \\
{ }^{1} \mathrm{H} \mathrm{CH}(\mathrm{ppm}) \text { y R } \\
\text { (\%) }\end{array}$ & $\begin{array}{c}\text { Isómero E: RMN } \\
{ }^{1} \mathrm{H} \mathrm{CH}(p p m) \text { y R } \\
\text { (\%) }\end{array}$ \\
\hline \multirow[t]{2}{*}{146} & SMe & 4-MeO-Ph & $71 \%$ & $6,25-6,75$ & $6,73-7,18$ \\
\hline & & & & $54 \%$ & $17 \%$ \\
\hline \multirow[t]{2}{*}{147} & SMe & NMelND & $40 \%$ & $6,26-6.86$ & - \\
\hline & & & & $14 \%$ & \\
\hline \multirow[t]{2}{*}{148} & OMe & 4-MeO-Ph & $50 \%$ & $6,28-6,62$ & - \\
\hline & & & & $10 \%$ & \\
\hline \multirow[t]{2}{*}{149} & OMe & NMeIND & $20 \%$ & $6,30-6,84$ & - \\
\hline & & & & $4 \%$ & \\
\hline
\end{tabular}

Tabla 6: Combretastatinas sintetizadas.

La estructura de cada isómero se establece a partir de los datos de $\mathrm{RMN}{ }^{1} \mathrm{H}$ teniendo en cuenta que:

- La constante de acoplamiento en los dos protones del puente tiene un valor de $12 \mathrm{~Hz}$ para el isómero cis, y $16 \mathrm{~Hz}$ para el isómero trans.

- En el isómero cis los protones del puente se encuentran más apantallados que en isómero trans. En nuestro caso, esta diferencia sólo es visible perfectamente en el caso de la síntesis del compuesto 146 ya que es el único en el que se han separado los dos isómeros, aunque pueden apreciarse estas diferencias en los espectros de la mezcla. Lo mismo ocurre con las señales correspondientes a los metilos del anillo de piridina. En el compuesto $146 Z$ el grupo SMe resuena a 2,49 y el OMe a 3,79, mientras que en el compuesto $146 E$ el SMe resuena a 2,61 y el grupo OMe a 3,84 ppm. 


\section{C.5. SÍNTESIS DE OXADIAZOLINAS}

Las oxadiazolinas son análogos de colchicina con tres átomos en el puente. La síntesis de estos compuestos se realiza en tres pasos diferentes que se resumen en la siguiente figura:<smiles>CC=NNC(=O)c1cc(OCC)nc(OCC=NNC(=O)CSc2cc(C(=O)NN)cc(OCC)n2)c1</smiles>

Esquema 6: Esquema general de síntesis de oxadiazolinas.

El primer paso consiste en la síntesis de la hidrazida, que posteriormente reacciona con un aldehído para dar una carbohidrazida. El último paso consiste en una ciclación mediante la cual se obtiene la oxadiazolina.

\section{C.5.1. SÍNTESIS DE 2-METILSULFANIL-6 METOXIPIRIDINA CARBOHIDRAZIDA}

Todas las oxadiazolinas sintetizadas tienen en el anillo de piridina los sustituyentes metoxilo y metilsulfanilo. El material de partida para esta reacción es el ácido 2-cloro-6-metoxipiridina-4-carboxílico, que se disuelve en $\mathrm{CH}_{2} \mathrm{Cl}_{2}$ y se añade EDCI (1-etil-3-(3-dimetilaminopropil)carbodiimida) y 4-DMAP (4-dimetilaminopiridina) y se deja una hora en agitación a temperatura. Posteriormente, se añade sobre una disolución de exceso de hidracina en $\mathrm{CH}_{2} \mathrm{Cl}_{2}$.<smiles>COc1cc(C(=O)O)cc(SC)n1</smiles>

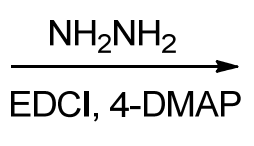<smiles>[R16][R5]</smiles>

Figura 54: Formación de la hidrazida. 
EDCI es una carbodiimida que actúa como grupo activante del ácido carboxílico a través del mecanismo siguiente:<smiles>COc1cc(C(=O)O)cc(SC)n1</smiles><smiles>CCN=C=NCCCN(C)C</smiles>

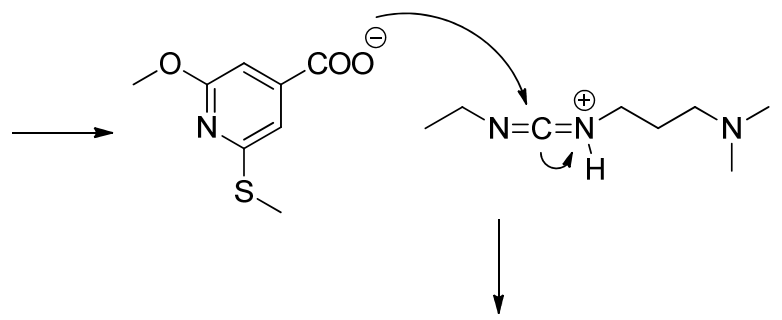<smiles>COc1cc(C(=O)NN)cc(SC)n1</smiles><smiles>CCNC(=O)NCCCN(C)C</smiles><smiles>CC/N=C(\NCCCN(C)C)OC(=O)c1cc(OC)nc(SC)c1</smiles>

Figura 55: Mecanismo de activación de EDCI.

\section{C.5.2. SÍNTESIS DE ACILHIDRAZONAS}

Para la síntesis de acilhidrazonas se utiliza como material de partida la hidrazida que ha sido sintetizada anteriormente, y un aldehído del sistema aromático que se va a introducir. El 4-(dimetilamino)benzaldehído y el anisaldehido son productos comerciales; sin embargo el $\mathrm{N}$-metil- $1 \mathrm{H}$-indol-5-carbaldelhído se sintetiza a partir de $1 H$-indol-5-carbaldehído, mediante alquilación con ioduro de metilo utilizando un catalizador de transferencia de fase (hidrogeno sulfato de tetrabutil amonio) y $\mathrm{NaOH}$.

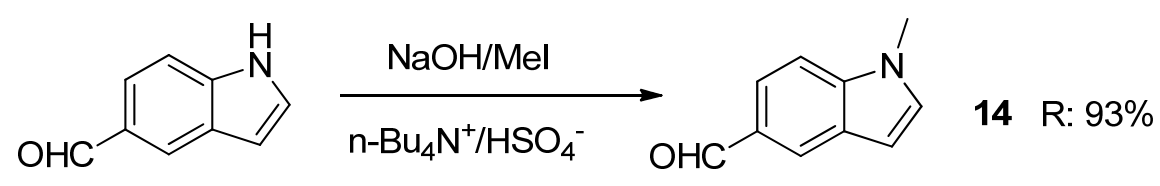

Figura 56: Metilación del anillo indólico. 
La síntesis de acilhidrazonas se realiza mediante el ataque del grupo $-\mathrm{NH}_{2}$ a un carbonilo $^{52}$ y se acelera mediante catálisis ácida; por ello se disuelve la hidrazida en una mezcla de EtOH/agua/AcOH en la proporción 25:5:0,2; y posteriormente se añade un equivalente del aldehído.

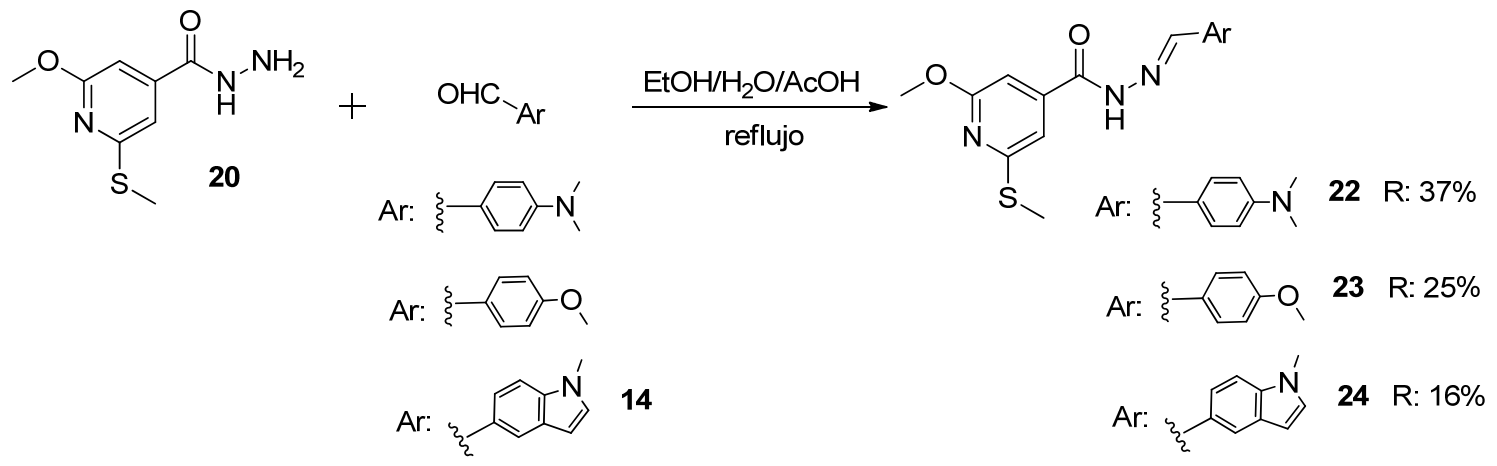

Figura 57: Síntesis de los compuestos 22, 23 y 24.

Una señal carácteristica de este compuesto en $\mathrm{RMN}{ }^{1} \mathrm{H}$ es la señal del $\mathrm{CH}$ de imina, que va desde 8,19-8,36 ppm.

\section{C.5.3. FORMACIÓN DE OXADIAZOLINAS}

El último paso consiste en la ciclación con anhídrido acético a reflujo de $160^{\circ} \mathrm{C}$ durante una hora.<smiles>COc1cc(C(=O)NN=CI)cc(SC)n1</smiles>

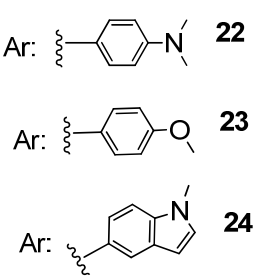

Figura 58 Oxadiazolinas sintetizadas.
$\mathrm{R}:$

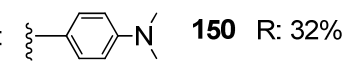

R:

R: 152 R: $46 \%$

${ }^{52}$ Francis A. Carey. Química Orgánica. Tercera edición. McGraw-Hill//nteramericana. 1999. Pag: 618-621 
El mecanismo de la reacción se detalla en la figura siguiente. Las oxadiazolinas sintetizadas se caracterizan por la aparición en $\mathrm{RMN}{ }^{1} \mathrm{H}$ de un singlete entre 7,00 y $7,19 \mathrm{ppm}$.

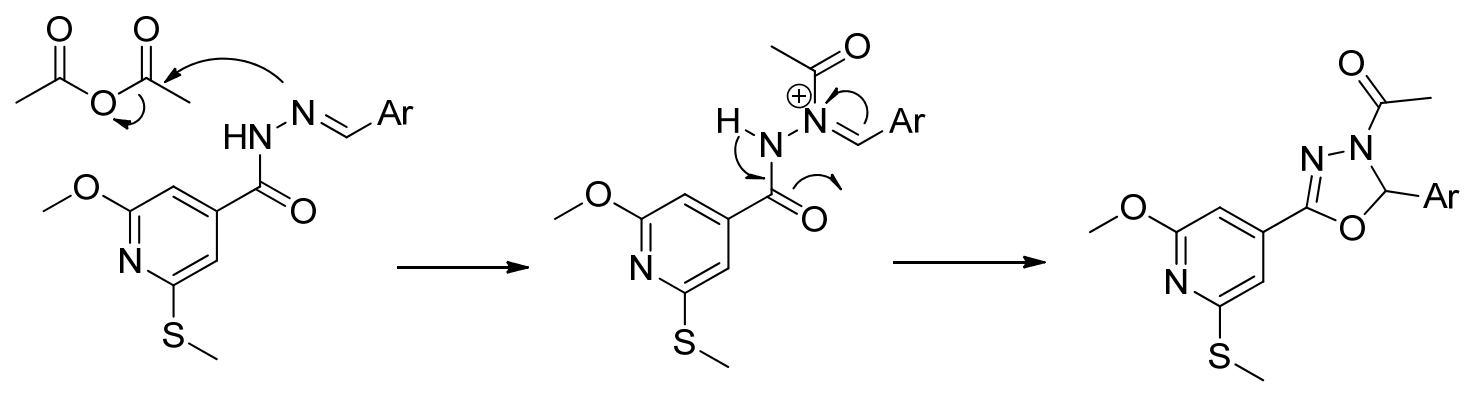

Figura 59: Mecanismo de ciclación para la formación de oxadiazolinas. 


\section{C.6. ACTIVIDAD BIOLÓGICA}

Los compuestos que han sido sintetizados en este trabajo han sido diseñados para que se unan a la tubulina en el sitio de la colchicina, por lo que debe evaluarse el efecto que producen sobre la polimerización de la proteína, y sobre la viabilidad celular. Por este motivo se van a realizar dos tipos de ensayos biológicos:

$>$ Ensayo de inhibición de polimerización de tubulina (IPT)

Ensayo de citotoxicidad sobre diferentes líneas celulares.

\section{C.6.1 ENSAYOS DE INHIBICIÓN DE POLIMERIZACIÓN DE TUBULINA}

En este ensayo se evalúa la capacidad que tienen los compuestos para inhibir la polimerización de la tubulina "in vitro", y se lleva a cabo sobre proteína microtubular (MTP). El proceso consta de tres etapas:

- Aislamiento de la proteína microtubular

- Medida de la actividad inhibitoria de los compuestos

- Determinación de la $\mathrm{IC}_{50}$

\section{C.6.1.1. AISLAMIENTO DE LA PROTEÍNA MICROTUBULAR}

La proteína microtubular (MTP) fue purificada de cerebros de terneros mediante dos ciclos de polimerización/despolimerización dependientes de temperatura, de acuerdo con el método de Shelanski ${ }^{53}$ con modificaciones.

53 Shelanski ML, Gaskin F, Cantor CR. Microtubule assembly in the absence of added nucleotides. Proc. Nat. Acad. Sci. 1973, 70, 765-768. 
En cada ciclo se lleva a cabo una polimerización inducida por la alta temperatura $\left(37^{\circ} \mathrm{C}\right)$ y el GTP, que permite recoger la proteína microtubular en el precipitado resultante por centrifugación. La proteína precipitada despolimeriza por enfriamiento a $0{ }^{\circ} \mathrm{C}$ y se vuelve a centrifugar, desechando en esta ocasión el precipitado. Tras 2 ciclos, se obtiene MTP de una composición adecuada para llevar a cabo los ensayos de inhibición de polimerización de tubulina. En esta proteína microtubular hay una mezcla de isotipos de tubulina (70\%) y MAPs (30\%) (proteínas asociadas a los microtúbulos).

\section{C.6.1.2. ENSAYO DE INHIBICIÓN DE POLIMERIZACIÓN DE TUBULINA}

El ensamblaje in vitro de tubulina se monitoriza a través de la medida a $450 \mathrm{~nm}$ (longitud de onda a la que los compuestos no presenta absorbancia) de la turbidez generada por la formación de microtúbulos. ${ }^{54}$ Cada ensayo incluye siempre un control sin ligando. Las muestras contienen $1,0 \mathrm{mg} / \mathrm{mL}$ de MTP y el ligando a la concentración deseada.

Todos los compuestos utilizados están disueltos en DMSO para evitar problemas de solubilidad. La concentración máxima de DMSO en los experimentos es del 4\%, concentración que no afecta a la polimerización de la tubulina. ${ }^{55}$

Inicialmente los ensayos se realizan a una concentración de $5 \mu \mathrm{M}$ con el fin de seleccionar los compuestos que presentan una $\mathrm{IC}_{50}$ igual $\mathrm{O}$ inferior a esta concentración, debido a que el objetivo es sintetizar compuestos que tengan una potencia igual o mejor que CA-4. ${ }^{56,57}$ La determinación de la $\mathrm{IC}_{50}$ se desarrolla en el siguiente apartado.

\footnotetext{
${ }^{54}$ Gaskin F, Cantor CR, Shelanski ML. Turbidimetric Studies of the in Vitro Assembly and Disassembly of Porcine Neurotubules. J. Mol. Biol. 1974, 89, 737-758.

${ }^{55}$ Dumortier C, Gorbunoff M, Andreu JM, Engelborghs Y. Different kinetic pathways of the binding of two biphenyl analogues of colchicine to tubulin. Biochemistry 1996, 35, 4387-4395.

${ }^{56}$ a) Tron GC, Pirali T, Sorba G, Pagliai F, Busacca S, Genazzani AA. Medicinal chemistry of combretastatin A4: present and future directions. J Med Chem, 2006, 49, 3033-3044.
} 
El grado de inhibición de la polimerización presentada por los ligandos se establece por comparación de la amplitud de la curva de polimerización de cada muestra con ligando con la de la muestra control, considerada como el $100 \%$ de polimerización. La relación entre ambas amplitudes (\%) es la capacidad de polimerización de la preparación de tubulina en presencia de ese ligando.

De esta manera, se realizó un primer screening de todos los compuestos sintetizados y se seleccionaron para medir las $I_{50}$ aquellos cuya inhibición era superior al 45\%. En la tabla siguiente se recogen los resultados de los compuestos cuya $\mathrm{IC}_{50}$ se prevé superior a $5 \mu \mathrm{M}$.

\begin{tabular}{ccc|ccc|ccc|} 
COMP & CONC $(\mu \mathrm{M})$ & \% INHIB & COMP & $\begin{array}{c}\text { CONC } \\
(\mu \mathrm{M})\end{array}$ & $\begin{array}{c}\text { \% } \\
\text { INHIB }\end{array}$ & COMP & CONC $(\mu \mathrm{M})$ & \% INHIB \\
\hline $\mathbf{2 5}$ & 5 & 0 & $\mathbf{6 0}$ & 5 & 2 & $\mathbf{1 2 8}$ & 10 & 18 \\
\hline $\mathbf{2 6}$ & 5 & 25 & $\mathbf{6 2}$ & 5 & 11 & $\mathbf{1 2 9}$ & 10 & 4 \\
\hline $\mathbf{2 7}$ & 5 & 31 & $\mathbf{6 4}$ & 5 & 0 & $\mathbf{1 3 0}$ & 10 & 0 \\
\hline $\mathbf{2 8}$ & 5 & 0 & $\mathbf{6 5}$ & 5 & 44 & $\mathbf{1 3 1}$ & 10 & 18 \\
\hline $\mathbf{2 9}$ & 5 & 22 & $\mathbf{1 1 8}$ & 6 & 26 & $\mathbf{1 3 2}$ & 20 & 4 \\
\hline $\mathbf{3 0}$ & 5 & 22 & $\mathbf{7 4}$ & 5 & 0 & $\mathbf{1 3 3}$ & 10 & 26 \\
\hline $\mathbf{3 1}$ & 5 & 0 & $\mathbf{7 5}$ & 5 & 14 & $\mathbf{1 3 4}$ & 5 & 20 \\
\hline $\mathbf{3 2}$ & 20 & 56 & $\mathbf{7 7}$ & 5 & 33 & $\mathbf{1 3 5}$ & 5 & 0 \\
\hline $\mathbf{3 6}$ & 5 & 11 & $\mathbf{8 4}$ & 5 & 7 & $\mathbf{1 3 6}$ & 5 & 9 \\
\hline $\mathbf{3 7}$ & 5 & 40 & $\mathbf{8 5}$ & 5 & 31 & $\mathbf{1 3 7}$ & 5 & 11 \\
\hline $\mathbf{3 8}$ & 6 & 21 & $\mathbf{8 7}$ & 5 & 0 & $\mathbf{1 3 8}$ & 5 & 43 \\
\hline $\mathbf{3 9}$ & 5 & 39 & $\mathbf{8 8}$ & 5 & 30 & $\mathbf{1 3 9}$ & 5 & 11 \\
\hline $\mathbf{4 2}$ & 5 & 34 & $\mathbf{9 5}$ & 5 & 44 & $\mathbf{1 4 0}$ & 5 & 0 \\
\hline $\mathbf{4 4}$ & 5 & 35 & $\mathbf{9 8}$ & 5 & 13 & $\mathbf{1 4 1}$ & 5 & 20 \\
\hline $\mathbf{4 5}$ & 5 & 39 & $\mathbf{1 0 6}$ & 5 & 27 & $\mathbf{1 4 4}$ & 5 & 0 \\
\hline $\mathbf{4 8}$ & 5 & 6 & $\mathbf{1 0 7}$ & 5 & 0 & $\mathbf{1 4 5}$ & 5 & 3 \\
\hline $\mathbf{4 9}$ & 5 & 21 & $\mathbf{1 0 8}$ & 5 & 7 & $\mathbf{1 4 6 e}$ & 5 & 24 \\
\hline $\mathbf{5 2}$ & 5 & 1 & $\mathbf{1 1 2}$ & 5 & 14 & $\mathbf{1 4 7 2}$ & 5 & 43 \\
\hline $\mathbf{5 3}$ & 5 & 0 & $\mathbf{1 2 4}$ & 5 & 33 & $\mathbf{1 5 0}$ & 10 & 4 \\
\hline $\mathbf{5 5}$ & 6 & 18 & $\mathbf{1 2 5}$ & 5 & 0 & $\mathbf{1 5 1}$ & 10 & 0 \\
\hline $\mathbf{5 7}$ & 5 & 32 & $\mathbf{1 2 6}$ & 10 & 27 & $\mathbf{1 5 2}$ & 10 & 8 \\
\hline $\mathbf{5 8}$ & 5 & 2 & $\mathbf{1 2 7}$ & 20 & 0 & & & \\
\hline & & & & & & 5 & 5 \\
\hline
\end{tabular}

Tabla 7. Compuestos no seleccionados para medir su $\mathrm{IC}_{50}$.

${ }^{57}$ Álvarez R, Álvarez C, Mollinedo F, Sierra BG, Medarde M, Peláez R. Isocombretastatins A: 1,1-diarylethenes as potent inhibitors of tubulin polymerization and cytotoxic compounds. Bioorg Med Chem, 2009, 17, 6422-6431. 
Los compuestos seleccionados para calcular la $\mathrm{IC}_{50}$, se muestran en la tabla siguiente:

\begin{tabular}{ccc|ccc|ccc} 
COMP & CONC $(\mu \mathrm{M})$ & \% INHIB & COMP & CONC $(\boldsymbol{\mu M})$ & \% INHIB & COMP & CONC $(\boldsymbol{\mu M})$ & \% INHIB \\
\hline $\mathbf{3 4}$ & 5 & $\mathbf{7 4}$ & $\mathbf{7 2}$ & 5 & $\mathbf{7 9}$ & $\mathbf{1 0 4}$ & 5 & 94 \\
\hline $\mathbf{4 0}$ & 5 & 100 & $\mathbf{7 3}$ & 5 & 100 & $\mathbf{1 0 5}$ & 5 & 100 \\
\hline $\mathbf{4 1}$ & 5 & 83 & $\mathbf{7 6}$ & 5 & 100 & $\mathbf{1 0 9}$ & 5 & 89 \\
\hline $\mathbf{4 3}$ & 5 & 100 & $\mathbf{8 0}$ & 5 & 92 & $\mathbf{1 1 0}$ & 5 & 100 \\
\hline $\mathbf{4 6}$ & 5 & 86 & $\mathbf{8 2}$ & 5 & 90 & $\mathbf{1 1 1}$ & 5 & 98 \\
\hline $\mathbf{4 7}$ & 5 & 80 & $\mathbf{8 3}$ & 5 & 87 & $\mathbf{1 1 5}$ & 5 & 89 \\
\hline $\mathbf{5 0}$ & 5 & 48 & $\mathbf{8 6}$ & 5 & 100 & $\mathbf{1 1 7}$ & 5 & $\mathbf{7 5}$ \\
\hline $\mathbf{5 1}$ & 5 & 89 & $\mathbf{8 9}$ & 5 & 80 & $\mathbf{1 1 9}$ & 5 & 45 \\
\hline $\mathbf{5 4}$ & 7 & 93 & $\mathbf{9 3}$ & 5 & 76 & $\mathbf{1 2 0}$ & 5 & 49 \\
\hline $\mathbf{5 6}$ & 5 & 97 & $\mathbf{9 4}$ & 5 & 58 & $\mathbf{1 2 1}$ & 5 & 91 \\
\hline $\mathbf{5 9}$ & 5 & 98 & $\mathbf{9 6}$ & 5 & 100 & $\mathbf{1 2 3}$ & 5 & 86 \\
\hline $\mathbf{6 1}$ & 5 & 46 & $\mathbf{9 7}$ & 5 & 49 & $\mathbf{1 4 2}$ & 5 & 89 \\
\hline $\mathbf{6 3}$ & 5 & 100 & $\mathbf{9 9}$ & 5 & 95 & $\mathbf{1 4 3}$ & 5 & 95 \\
\hline $\mathbf{6 8}$ & 5 & 63 & $\mathbf{1 0 0}$ & 5 & 95 & $\mathbf{1 4 6 z}$ & 5 & 70 \\
\hline $\mathbf{7 0}$ & 5 & 92 & $\mathbf{1 0 2}$ & 5 & 82 & $\mathbf{1 4 8 z}$ & 5 & 70 \\
\hline $\mathbf{7 1}$ & 5 & 63 & $\mathbf{1 0 3}$ & 5 & $\mathbf{7 9}$ & $\mathbf{1 4 9 z}$ & 5 & 80
\end{tabular}

Tabla 8. Compuestos con inhibición mayor del 45\%.

\section{C.6.1.3. DETERMINACIÓN DE LA IC I0 $_{50}$ DE INHIBICIÓN DE POLIMERIZACIÓN DE TUBULINA}

Con el fin de calcular el valor de $\mathrm{IC}_{50}$, definida como la concentración de compuesto que causa el $50 \%$ de la inhibición de polimerización, se ensayan los compuestos a diferentes concentraciones (generalmente 0,5, 1, 2, 5, 7 y $10 \mu \mathrm{M}$ ). Los porcentajes de polimerización para cada concentración de ligando se ajustan a una ecuación exponencial ${ }^{58}$, a partir de la cual se puede calcular el valor de $\mathrm{IC}_{50}$. En la siguiente tabla se muestran los resultados obtenidos:

${ }^{58}$ Origin $^{\circledR}$ 6.0: http://www.originlab.com/ 


\begin{tabular}{cc|cc|cc} 
COMP & $\mathrm{IC}_{50}(\boldsymbol{\mu M})$ & $\mathbf{C O M P}$ & $\mathrm{IC}_{50}(\boldsymbol{\mu M})$ & COMP & $\mathrm{IC}_{50}(\boldsymbol{\mu M})$ \\
\hline $\mathbf{3 4}$ & 2,5 & $\mathbf{7 2}$ & 2,4 & $\mathbf{1 0 4}$ & 2,4 \\
\hline $\mathbf{4 0}$ & 1,5 & $\mathbf{7 3}$ & 0,3 & $\mathbf{1 0 5}$ & 0,7 \\
\hline $\mathbf{4 1}$ & 4,6 & $\mathbf{7 6}$ & 1,6 & $\mathbf{1 0 9}$ & 2,4 \\
\hline $\mathbf{4 3}$ & 1,1 & $\mathbf{8 0}$ & 0,2 & $\mathbf{1 1 0}$ & 1,6 \\
\hline $\mathbf{4 6}$ & 2,0 & $\mathbf{8 2}$ & 0,6 & $\mathbf{1 1 1}$ & 3,2 \\
\hline $\mathbf{4 7}$ & 3,4 & $\mathbf{8 3}$ & 2,3 & $\mathbf{1 1 5}$ & 1,4 \\
\hline $\mathbf{5 0}$ & 4,1 & $\mathbf{8 6}$ & 1,6 & $\mathbf{1 1 7}$ & 1,0 \\
\hline $\mathbf{5 1}$ & 1,3 & $\mathbf{8 9}$ & 2,9 & $\mathbf{1 1 9}$ & 4,8 \\
\hline $\mathbf{5 4}$ & 0,9 & $\mathbf{9 3}$ & 2,9 & $\mathbf{1 2 1}$ & 1,9 \\
\hline $\mathbf{5 6}$ & 0,6 & $\mathbf{9 4}$ & 1,7 & $\mathbf{1 2 3}$ & 1,6 \\
\hline $\mathbf{5 9}$ & 1,4 & $\mathbf{9 6}$ & 1,1 & $\mathbf{1 4 2}$ & 3,8 \\
\hline $\mathbf{6 1}$ & 4,9 & $\mathbf{9 7}$ & 0,9 & $\mathbf{1 4 3}$ & 2,1 \\
\hline $\mathbf{6 3}$ & 0,9 & $\mathbf{9 9}$ & 1,2 & $\mathbf{1 4 6 z}$ & 3,8 \\
\hline $\mathbf{6 8}$ & 4 & $\mathbf{1 0 0}$ & 4,7 & $\mathbf{1 4 8 z}$ & 4,1 \\
\hline $\mathbf{7 0}$ & 2,5 & $\mathbf{1 0 2}$ & 0,4 & $\mathbf{1 4 9 z}$ & 1,0 \\
\hline $\mathbf{7 1}$ & 3,4 & $\mathbf{1 0 3}$ & 2,4 & $\mathbf{C A}-4$ & 3
\end{tabular}

Tabla 9. Valores de $\mathrm{IC}_{50}$ calculados.

\section{C.6.1.4. ANÁLISIS DE LOS RESULTADOS}

El análisis de los resultados obtenidos en inhibición de polimerización de tubulina, se va a realizar según el sistema aromático que tengan los compuestos en el anillo B. Así, tendremos tres tipos de familias:

- Compuestos con p-metoxifenilo en el anillo B con o sin sustituyentes

- Compuestos con $N$-metilindol en el anillo B con o sin sustituyentes

- Compuestos con otros sistemas aromáticos en el anillo B

Todos estos compuestos tienen un átomo de carbono en el puente entre los dos anillos. Sin embargo también se han sintetizado series de compuestos que tienen dos átomos en el puente (combretastatinas) o tres átomos (oxadiazolinas), y que se van a agrupar en la siguiente familia:

- Compuestos con más de un átomo en el puente 


\section{C.6.1.4.1. Compuestos con p-metoxifenilo en el anillo B con 0 sin sustituyentes}

Se han sintetizado un total de 36 compuestos con este sistema aromático en el anillo $B$, de los cuales sólo 11 compuestos tienen un valor por debajo de $5 \mu \mathrm{M}$ y se resumen en la siguiente tabla:<smiles>[X]c1cc(C([Z])c2ccc(OC)c([R])c2)cc([Y])n1</smiles>

\begin{tabular}{|c|c|c|c|c|c|c|c|c|c|c|c|}
\hline no & $x$ & $\mathbf{Y}$ & Z & $\mathbf{R}$ & $\begin{array}{c}I_{50} \\
(\mu \mathrm{M})\end{array}$ & $\mathrm{n}$ - & $x$ & $\mathbf{Y}$ & $\mathbf{Z}$ & $\mathbf{R}$ & $\begin{array}{c}I_{50} \\
(\mu \mathrm{M})\end{array}$ \\
\hline 25 & $\mathrm{Cl}$ & $\mathrm{Cl}$ & 0 & $\mathrm{H}$ & $>5$ & 43 & $\mathrm{Cl}$ & $\mathrm{NMe}_{2}$ & $\mathrm{CH}_{2}$ & $\mathrm{H}$ & 1,1 \\
\hline 26 & $\mathrm{Cl}$ & $\mathrm{Cl}$ & $\mathrm{CH}_{2}$ & $\mathrm{H}$ & $>5$ & 44 & $\mathrm{Cl}$ & $\mathrm{NMe}_{2}$ & $\mathrm{NOH}$ & $\mathrm{H}$ & $>5$ \\
\hline 27 & $\mathrm{Cl}$ & $\mathrm{Cl}$ & $\mathrm{NOH}$ & $\mathrm{H}$ & $>5$ & 45 & SMe & SMe & 0 & $\mathrm{H}$ & $>5$ \\
\hline 28 & $\mathrm{Cl}$ & OMe & 0 & $\mathrm{H}$ & $>5$ & 46 & SMe & SMe & $\mathrm{CH}_{2}$ & $\mathrm{H}$ & 2,0 \\
\hline 29 & $\mathrm{Cl}$ & OMe & $\mathrm{CH}_{2}$ & $\mathrm{H}$ & $>5$ & 47 & SMe & SMe & $\mathrm{NOH}$ & $\mathrm{H}$ & 3,4 \\
\hline 30 & OMe & OMe & $\mathrm{CH}_{2}$ & $\mathrm{H}$ & $>5$ & 48 & SMe & SMe & $\mathrm{H}, \mathrm{CH}_{3}$ & $\mathrm{H}$ & $>5$ \\
\hline 31 & $\mathrm{Cl}$ & OMe & $\mathrm{NOH}$ & $\mathrm{H}$ & $>5$ & 49 & SMe & OMe & 0 & $\mathrm{H}$ & $>5$ \\
\hline 32 & $\mathrm{Cl}$ & OMe & 0 & $\mathrm{NO}_{2}$ & $>5$ & 50 & SMe & OMe & $\mathrm{CH}_{2}$ & $\mathrm{H}$ & 4,1 \\
\hline 33 & $\mathrm{Cl}$ & OMe & 0 & $2\left(\mathrm{NO}_{2}\right)$ & $>5$ & 51 & SMe & OMe & $\mathrm{NOH}$ & $\mathrm{H}$ & 1,3 \\
\hline 34 & $\mathrm{Cl}$ & OMe & 0 & $\mathrm{NH}_{2}$ & 2,5 & 52 & SMe & OMe & $\mathrm{H}, \mathrm{CH}_{3}$ & $\mathrm{H}$ & $>5$ \\
\hline 35 & $\mathrm{Cl}$ & OMe & 0 & $2\left(\mathrm{NH}_{2}\right)$ & $>5$ & 53 & SMe & OMe & 0 & $\mathrm{NO}_{2}$ & $>5$ \\
\hline 36 & $\mathrm{Cl}$ & $\mathrm{Ph}-\mathrm{NH}$ & 0 & $\mathrm{H}$ & $>5$ & 54 & SMe & OMe & 0 & $\mathrm{NH}_{2}$ & 0,9 \\
\hline 37 & $\mathrm{Cl}$ & MePh-NH & 0 & $\mathrm{H}$ & $>5$ & 55 & SMe & $\mathrm{NMe}_{2}$ & 0 & $\mathrm{H}$ & $>5$ \\
\hline 38 & $\mathrm{Cl}$ & SMe & 0 & $\mathrm{H}$ & $>5$ & 56 & SMe & $\mathrm{NMe}_{2}$ & $\mathrm{CH}_{2}$ & $\mathrm{H}$ & 0,6 \\
\hline 39 & $\mathrm{Cl}$ & SMe & $\mathrm{AcO}, \mathrm{OH}$ & $\mathrm{H}$ & $>5$ & 57 & SMe & $\mathrm{NMe}_{2}$ & $\mathrm{NOH}$ & $\mathrm{H}$ & $>5$ \\
\hline 40 & $\mathrm{Cl}$ & SMe & $\mathrm{CH}_{2}$ & $\mathrm{H}$ & 1,5 & 58 & OMe & $\mathrm{NMe}_{2}$ & 0 & $\mathrm{H}$ & $>5$ \\
\hline 41 & $\mathrm{Cl}$ & SMe & $\mathrm{NOH}$ & $\mathrm{H}$ & 4,6 & 59 & OMe & $\mathrm{NMe}_{2}$ & $\mathrm{CH}_{2}$ & $\mathrm{H}$ & 1,4 \\
\hline 42 & $\mathrm{Cl}$ & $\mathrm{NMe}_{2}$ & 0 & $\mathrm{H}$ & $>5$ & 60 & OMe & $\mathrm{NMe}_{2}$ & $\mathrm{NOH}$ & $\mathrm{H}$ & $>5$ \\
\hline
\end{tabular}

Tabla 10: Resumen de todos los compuestos con anillo de $p$-metoxifenilo en el anillo $\mathrm{B}$, con sus características estructurales y sus valores de IC C $_{50}$ en IPT. Los valores de IPT de los compuestos que tienen un valor de $\mathrm{IC}_{50}$ por debajo de $5 \mu \mathrm{M}$ se han señalado en negrita.

Para analizar los resultados se va a clasificar según el elemento estructural: 
- Puente entre los dos anillos. Los compuestos más potentes son los que presentan una olefina en el puente (isocombretastatina), seguidas de las oximas (considerados conjuntamente ambos isómeros) con la excepción de la pareja 50/51, en la que es más potente la oxima. Las cetonas son menos potentes; con valores de $\mathrm{IC}_{50}$ por encima de $5 \mu \mathrm{M}$, salvo las que presentan grupos $-\mathrm{NH}_{2}$ en el anillo $\mathrm{B}$. Los compuestos que tienen un grupo metilo en el puente (compuestos 48 y 52 ) carecen de actividad.

- Anillo A. El mayor número de compuestos con un valor de $I_{50}$ por debajo de 5 $\mu \mathrm{M}$ se produce cuando hay presente un grupo metilsulfanilo, tanto en oximas como en isocombretastatinas, seguido del grupo dimetilamino. Estos sustituyentes no son los habituales en el anillo $A$ de fenstatinas $e$ isocombretastatinas ${ }^{57}$ en los que habitualmente los grupos metoxilo confieren una alta potencia en IPT. En estos compuestos con anillo de piridina, sin embargo, los grupos metoxilo conducen a derivados poco potentes (28-38), salvo en los compuestos $\mathbf{5 0}$ y $\mathbf{5 1}$ (combinación OMe-SMe) y cuando en el anillo $B$ hay un grupo $-\mathrm{NH}_{2}$ en meta (54 y 34).

- Sustituyentes en posición 3 del anillo B. Solo se han sintetizado compuestos con grupos nitro o amino en posición 3 , y todos ellos tienen un grupo carbonilo en el puente. Cabe destacar que los compuestos con grupo amino son de los más potentes, incluso con un valor de $\mathrm{IC}_{50}$ en escala submicromolar en el caso del compuesto 54. Sin embargo, los compuestos con grupo nitro carecen de actividad.

\section{C.6.1.4.2. Compuestos con $N$-metilindol en el anillo $B$ con 0 sin sustituyentes}

Se han sintetizado 51 compuestos con anillo de $\mathrm{N}$-metilindol en el anillo $\mathrm{B}$, de los cuales 31 tienen un valor de $\mathrm{IC}_{50}$ por debajo de $5 \mu \mathrm{M}$. Dentro de los 51 compuestos sintetizados existe una gran variabilidad estructural con diferentes sustituyentes en posición 2 y 6 en el anillo de piridina, y con varias combinaciones de grupos funcionales (aldehídos, carbonitrilos, amidas, ácidos carboxílicos) en la posición 3 del anillo indólico. 


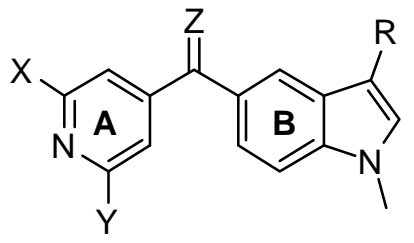

\begin{tabular}{|c|c|c|c|c|c|c|c|c|c|c|c|}
\hline no & $x$ & $Y$ & Z & $\mathbf{R}$ & $\begin{array}{c}I_{50} \\
(\mu \mathrm{M})\end{array}$ & $\mathrm{n}=$ & $x$ & $Y$ & Z & $\mathbf{R}$ & $\begin{array}{l}\mathrm{IC}_{50} \\
(\mu \mathrm{M})\end{array}$ \\
\hline 61 & $\mathrm{Cl}$ & $\mathrm{Cl}$ & 0 & $\mathrm{H}$ & 4,9 & 95 & SMe & $\mathrm{SMe}$ & $\mathrm{OH}$ & $\mathrm{H}$ & $>5$ \\
\hline 62 & $\mathrm{Cl}$ & $\mathrm{Cl}$ & - & $\mathrm{H}$ & $>5$ & 96 & SMe & SMe & $\mathrm{CH}_{2}$ & $\mathrm{H}$ & 1,1 \\
\hline 63 & $\mathrm{Cl}$ & $\mathrm{Cl}$ & $\mathrm{CH}_{2}$ & $\mathrm{H}$ & 0,9 & 97 & SMe & SMe & $\mathrm{NOH}$ & $\mathrm{H}$ & 1,0 \\
\hline 64 & $\mathrm{Cl}$ & $\mathrm{Cl}$ & 0 & $\mathrm{CHO}$ & $>5$ & 98 & SMe & SMe & 0 & $\mathrm{CHO}$ & $>5$ \\
\hline 65 & $\mathrm{Cl}$ & $\mathrm{Cl}$ & $\mathrm{CH}_{2}$ & $\mathrm{CHO}$ & $>5$ & 99 & SMe & SMe & $\mathrm{CH}_{2}$ & $\mathrm{CHO}$ & 1,2 \\
\hline 68 & $\mathrm{Cl}$ & $\mathrm{Cl}$ & $\mathrm{NOH}$ & $\mathrm{CN}$ & 4 & 100 & SMe & SMe & $\mathrm{CH}_{2}$ & $\mathrm{COOH}$ & 4,7 \\
\hline 70 & $\mathrm{Cl}$ & $\mathrm{Cl}$ & $\mathrm{CH}_{2}$ & $\mathrm{CN}$ & 2,5 & 102 & SMe & SMe & $\mathrm{CH}_{2}$ & $\mathrm{CN}$ & 0,4 \\
\hline 71 & $\mathrm{Cl}$ & $\mathrm{Cl}$ & $\mathrm{CH}_{2}$ & $\mathrm{CONH}_{2}$ & 3,4 & 103 & SMe & SMe & $\mathrm{CH}_{2}$ & $\mathrm{CONH}_{2}$ & 2,4 \\
\hline 72 & $\mathrm{Cl}$ & SMe & 0 & $\mathrm{H}$ & 2,4 & 104 & SMe & $\mathrm{NMe}_{2}$ & 0 & $\mathrm{H}$ & 2,4 \\
\hline 73 & $\mathrm{Cl}$ & SMe & $\mathrm{CH}_{2}$ & $\mathrm{H}$ & 0,3 & 105 & SMe & $\mathrm{NMe}_{2}$ & $\mathrm{CH}_{2}$ & $\mathrm{H}$ & 0,7 \\
\hline 74 & $\mathrm{Cl}$ & SMe & $\mathrm{NOH}$ & $\mathrm{H}$ & $>5$ & 106 & SMe & $\mathrm{NMe}_{2}$ & $\mathrm{NOH}$ & $\mathrm{H}$ & $>5$ \\
\hline 75 & $\mathrm{Cl}$ & SMe & 0 & $\mathrm{CHO}$ & $>5$ & 107 & SMe & $\mathrm{NMe}_{2}$ & 0 & $\mathrm{CHO}$ & $>5$ \\
\hline 76 & $\mathrm{Cl}$ & SMe & $\mathrm{CH}_{2}$ & $\mathrm{CHO}$ & 1,6 & $108^{*}$ & SMe & $\mathrm{NMe}_{2}$ & 0 & $\mathrm{CHO}$ & $>5$ \\
\hline 77 & $\mathrm{Cl}$ & SMe & $\mathrm{CH}_{2}$ & $\mathrm{COOH}$ & $>5$ & 109 & SMe & $\mathrm{NMe}_{2}$ & $\mathrm{CH}_{2}$ & $\mathrm{CHO}$ & 2,4 \\
\hline 80 & $\mathrm{Cl}$ & SMe & $\mathrm{NOH}$ & $\mathrm{CN}$ & 0,2 & 110 & $\mathrm{Cl}$ & $\mathrm{NMe}_{2}$ & $\mathrm{CH}_{2}$ & $\mathrm{CHO}$ & 1,6 \\
\hline 82 & $\mathrm{Cl}$ & SMe & $\mathrm{CH}_{2}$ & $\mathrm{CN}$ & 0,6 & $111^{*}$ & SMe & $\mathrm{NMe}_{2}$ & $\mathrm{CH}_{2}$ & $\mathrm{CHO}$ & 3,2 \\
\hline 83 & $\mathrm{Cl}$ & SMe & $\mathrm{CH}_{2}$ & $\mathrm{CONH}_{2}$ & 2,3 & 112 & SMe & $\mathrm{NMe}_{2}$ & $\mathrm{CH}_{2}$ & $\mathrm{COOH}$ & $>5$ \\
\hline 84 & SMe & OMe & 0 & $\mathrm{H}$ & $>5$ & 115 & SMe & $\mathrm{NMe}_{2}$ & $\mathrm{NOH}$ & $\mathrm{CN}$ & 1,4 \\
\hline 85 & SMe & OMe & $\mathrm{CH}_{2}$ & $\mathrm{H}$ & $>5$ & 117 & SMe & $\mathrm{NMe}_{2}$ & $\mathrm{CH}_{2}$ & $\mathrm{CN}$ & 1,0 \\
\hline 86 & SMe & OMe & $\mathrm{NOH}$ & $\mathrm{H}$ & 1,6 & 119 & SMe & $\mathrm{NMe}_{2}$ & $\mathrm{CH}_{2}$ & $\mathrm{CONH}_{2}$ & 4,8 \\
\hline 87 & SMe & OMe & 0 & $\mathrm{CHO}$ & $>5$ & 120 & $\mathrm{Cl}$ & $\mathrm{NMe}_{2}$ & 0 & $\mathrm{H}$ & $>5$ \\
\hline 88 & SMe & OMe & $\mathrm{CH}_{2}$ & $\mathrm{COOH}$ & $>5$ & 121 & $\mathrm{Cl}$ & $\mathrm{NMe}_{2}$ & $\mathrm{CH}_{2}$ & $\mathrm{H}$ & 1,9 \\
\hline 89 & SMe & OMe & $\mathrm{CH}_{2}$ & $\mathrm{CHO}$ & 2,9 & 123 & $\mathrm{Cl}$ & $\mathrm{NMe}_{2}$ & $\mathrm{CH}_{2}$ & $\mathrm{CN}$ & 1,6 \\
\hline 92 & SMe & OMe & $\mathrm{NOH}$ & $\mathrm{CN}$ & $>5$ & 125 & SOMe & $\mathrm{OMe}$ & 0 & $\mathrm{H}$ & $>5$ \\
\hline 93 & SMe & OMe & 0 & $\mathrm{CN}$ & 2,9 & 126 & $\mathrm{SO}_{2} \mathrm{Me}$ & OMe & 0 & $\mathrm{H}$ & $>5$ \\
\hline 94 & SMe & $\mathrm{SMe}$ & 0 & $\mathrm{H}$ & 1,7 & & & & & & \\
\hline
\end{tabular}

Tabla 11: Resumen de todos los compuestos con anillo de $N$-metilindol en el anillo $\mathrm{B}$, con sus características estructurales y sus valores de IC $\mathrm{IC}_{50}$ en IPT. Los valores de IPT de los compuestos que tienen un valor de $\mathrm{IC}_{50}$ por debajo de $5 \mu \mathrm{M}$ se han señalado en negrita. Los compuestos marcados ${ }^{\star}$ tienen un grupo carbaldehído en el anillo de piridina. El compuesto 62 tiene estructura de bifenilo. Ver lista de compuestos. 
El análisis de datos se ha llevado a cabo siguiendo la misma clasificación que en el apartado anterior:

- Puente entre los dos anillos. Los compuestos menos potentes ( $>5 \mu \mathrm{M})$ son aquellos que tienen un grupo carbonilo en el puente, mientras que las olefinas y las oximas presentan mayor actividad inhibitoria $(<5 \mu \mathrm{M})$ con valores de $\mathrm{IC}_{50}$ en IPT entre 0,3 - $2 \mu \mathrm{M}$ para las olefinas, y 1,0 - 1,6 $\mu \mathrm{M}$ para las oximas, sin sustituyentes en la posición 3 del indol.

- Anillo A. El mayor número de compuestos con un valor de $\mathrm{IC}_{50}$ por debajo de 5 $\mu \mathrm{M}$ se produce cuando hay presente un grupo metilsulfanilo en las tres familias de compuestos, seguido de dimetilamino en el caso de fenstatinas, y de cloro en el caso de isocombretastatinas. Ningún compuesto con sulfona o sulfóxido en el anillo de piridina tiene un valor de $\mathrm{IC}_{50}$ menor de $5 \mu \mathrm{M}$.

- Sustituyentes en posición 3 del anillo B. Existe una gran variabilidad en los resultados de IPT según el grupo funcional introducido en esta posición, aunque en general se produce una pérdida de actividad con respecto a su homólogo sin sustituyente. Los grupos que confieren mayor potencia son los carbonitrilos, seguidos de los aldehídos (con olefina en el puente), de las amidas y de los ácidos carboxílicos, en ese orden.

Mediante la introducción de carbonitrilos, se obtienen compuestos con valores que oscilan entre 0,4 y $2,5 \mu \mathrm{M}$ en el caso de isocombretastinas; y entre 0,2 y 4 $\mu \mathrm{M}$ en los compuestos con oximas en el puente.

Las fenstatinas con aldehído conduce a compuestos que pierden la potencia (excepto en el compuesto 111), sin embargo, cuando en el puente tenemos un derivado de isocombretastatina, la potencia se ve aumentada con respecto a su homólogo fenstatina, y varía entre 1,2 y 2,9 $\mu \mathrm{M}$.

Las amidas conducen a compuestos con valores de IC I0 $_{50}$ en IPT entre 2,3 y 4,8 $\mu \mathrm{M}, \mathrm{y}$ los ácidos carboxílicos tienen valores cercanos a $5 \mu \mathrm{M}$. 


\section{C.6.1.4.3. Compuestos con otros sistemas aromáticos en el anillo B}

Los compuestos que tienen un sistema naftaleno, 3-dimetilaminofenil, o piridina en el anillo B no mejoran la potencia antimitótica de las combretastatinas de referencia. Sin embargo, dos compuestos (142 y 143) con anillo de 4-dimetilaminofenil tienen un valor de $\mathrm{IC}_{50}$ por debajo de $5 \mu \mathrm{M}$. En estos compuestos se repite que los mejores sustituyentes en el anillo de piridina son dimetilsulfanilo, frente a metoximetilsulfanilo; y que las isocombretastatinas y las oximas son más potentes que las fenstatinas.

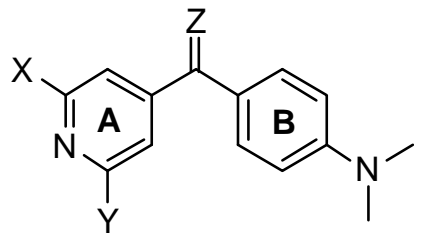

\begin{tabular}{c|cccc}
$\mathbf{n} \mathbf{0}$ & $\mathbf{X}$ & $\mathbf{Y}$ & $\mathbf{Z}$ & $\mathbf{I C}_{\mathbf{5 0}}(\boldsymbol{\mu M})$ \\
\hline $\mathbf{1 3 7}$ & $\mathrm{SMe}$ & $\mathrm{OMe}$ & $\mathrm{O}$ & $>5$ \\
\hline $\mathbf{1 3 8}$ & $\mathrm{SMe}$ & $\mathrm{OMe}$ & $\mathrm{CH}_{2}$ & $>5$ \\
\hline $\mathbf{1 3 9}$ & $\mathrm{SMe}$ & $\mathrm{OMe}$ & $\mathrm{NOH}$ & $>5$ \\
\hline $\mathbf{1 4 0}$ & $\mathrm{SMe}$ & $\mathrm{SMe}$ & $\mathrm{O}$ & $>5$ \\
\hline $\mathbf{1 4 2}$ & $\mathrm{SMe}$ & $\mathrm{SMe}$ & $\mathrm{CH}_{2}$ & $\mathbf{3 , 8}$ \\
\hline $\mathbf{1 4 3}$ & $\mathrm{SMe}$ & $\mathrm{SMe}$ & $\mathrm{NOH}$ & $\mathbf{2 , 1}$
\end{tabular}

Tabla 12: Resumen de todos los compuestos con anillo de 4-dimetilaminofenil.

\section{C.6.1.4.4. Compuestos con más de un átomo en el puente}

Se han sintetizado dos tipos de compuestos con más de un átomo en el puente: las oxadiazolinas y las combretastatinas. Las oxadiazolinas conducen a una pérdida de actividad, todo lo contrario a las combretastatinas que mantienen la potencia de las de referencia, especialmente la combretastatina $149 z$ que es más potente que la CA-4.

\begin{tabular}{|c|c|c|c|c|c|}
\hline & no & $x$ & $Y$ & Anillo B & $\mathrm{IC}_{50}(\mu \mathrm{M})$ \\
\hline & $146 z$ & SMe & SMe & 4-MeO-Ph & 3,8 \\
\hline B & $147 z$ & SMe & SMe & NMeIND & $>5$ \\
\hline$Y$ & $148 z$ & SMe & OMe & 4-MeO-Ph & 4,1 \\
\hline & $149 z$ & SMe & OMe & NMeIND & 1,0 \\
\hline
\end{tabular}

Tabla 13: Resumen de todas las combretastatinas sintetizadas con su valor de IPT. 


\section{C.6.1.5. DISCUSIÓN DE RESULTADOS}

Uno de los principales objetivos de este trabajo consiste en evaluar el efecto que produce la sustitución del anillo de 3,4,5-trimetoxifenilo, que se considera imprescindible para la actividad de los compuestos, por un anillo de piridina disustutido. Por este motivo, a continuación se van a comparar los resultados de actividad en inhibición de polimerización de tubulina de los compuestos sintetizados, con los compuestos sintetizados anteriormente en el grupo ${ }^{44,51,57}$, con anillos de 3,4,5trimetoxifenilo. Para ello se han tenido en cuenta las familias de compuestos que son idénticas, donde lo único que varía es el anillo $\mathrm{A}$.

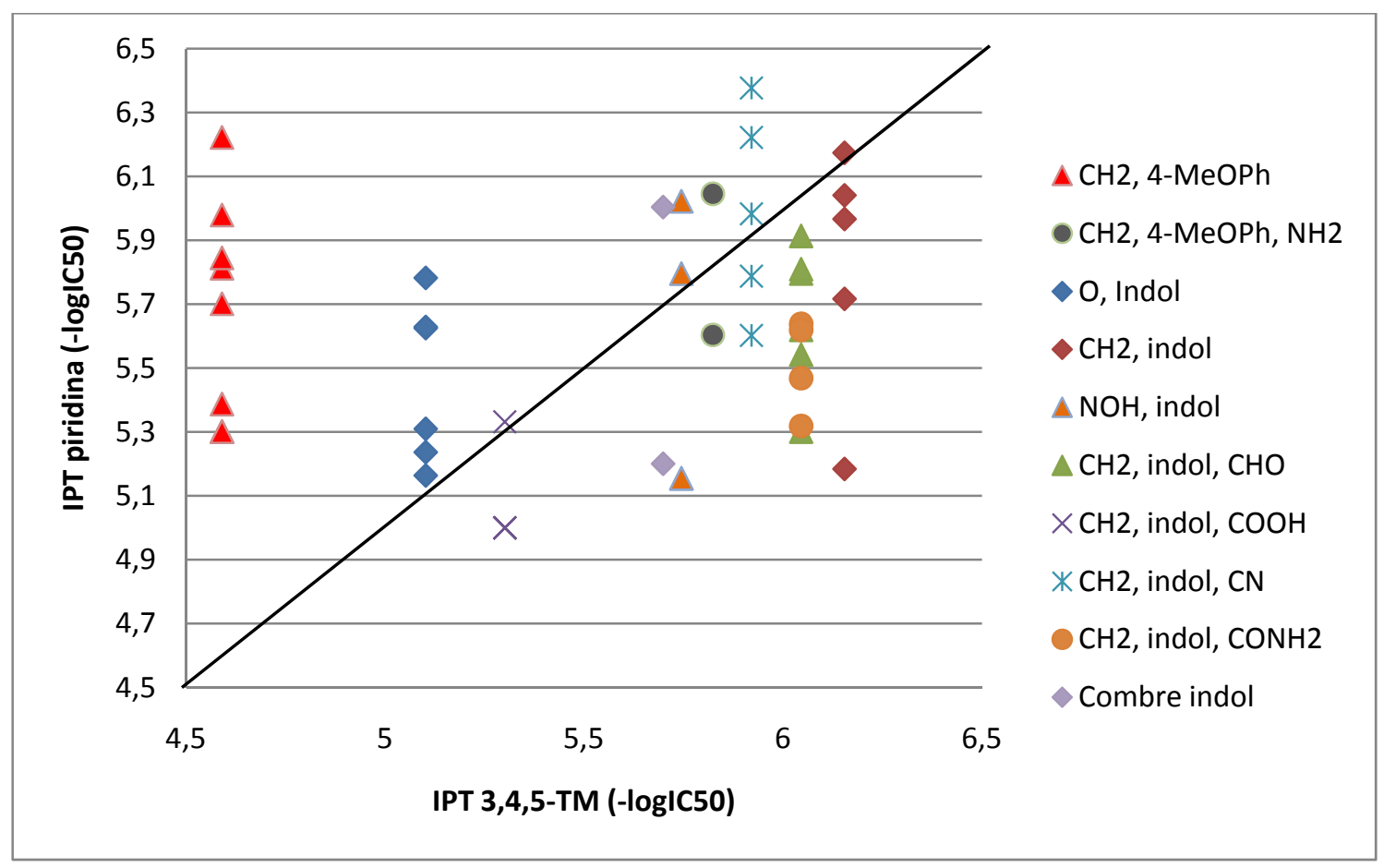

Figura 60. Representación de los valores de $I_{50}$ en IPT de compuestos con anillos de piridina bisustituidos frente a compuestos con 3,4,5-TM en anillo A. Cada serie corresponde a diferentes anillos en posición B (4-MeOPh, indol, indol con sustituyentes en posición 3) y con metilenos $u$ oximas en el puente entre los dos anillos. El anillo de piridina tiene diferentes sustituyentes, por este motivo cada valor de IPT en 3,4,5-TM tiene varios puntos en anillos de piridina.

En la figura se observa que la sustitución del anillo de 3,4,5-TM por un anillo de piridina produce en algunos casos un aumento de la potencia (isocombretastatinas con $p$-metoxifenilo en el anillo $\mathrm{B}, \mathrm{y}$ fenstatinas con $\mathrm{N}$-metilindol); y en otros casos una 
pérdida ( isocombretastatinas con carbaldehido o con carboxamidas en posición 3 del indol) aunque esta diferencia no es tan pronunciada ya que tienen el valor de $\mathrm{IC}_{50}$ por debajo de $5 \mu \mathrm{M}$. Adicionalmente, en otros compuestos la mejora de la actividad depende de los sustituyentes en posición 2 y 6 en piridina, como es el caso de las isocombretastatinas con carbonitrilo en posición 3 del indol, y en el caso de las oximas con indol. Por este motivo, se adjunta la figura siguiente donde se puede apreciar qué sustituyentes son los que producen aumento o pérdida de potencia:

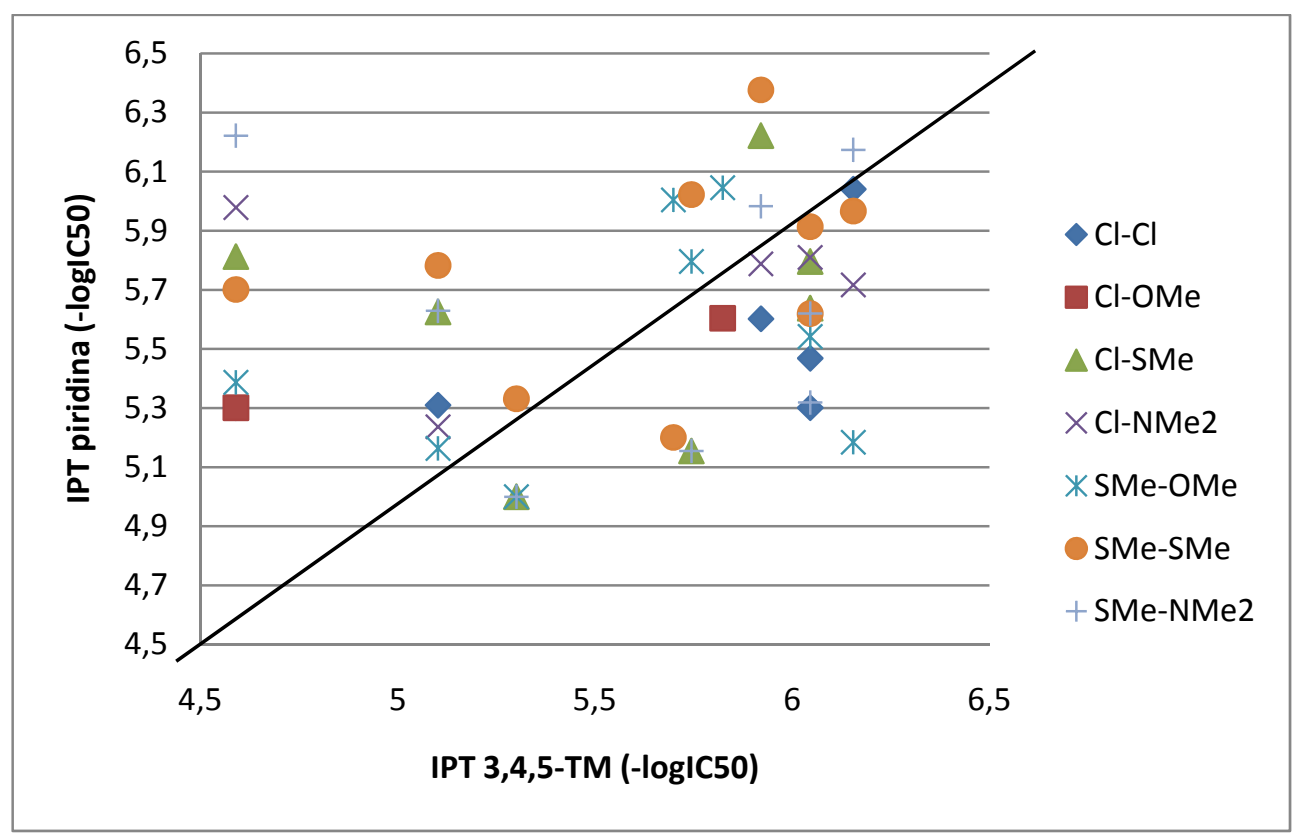

Figura 61. Representación de los valores de $I_{50}$ en IPT de compuestos con anillos de piridina bisustituidos frente a compuestos con 3,4,5-TM en anillo A. Cada serie corresponde a diferentes sustituciones en posición 2 y 6 del anillo de piridina.

Se observa que en general los compuestos con $\mathrm{Cl}-\mathrm{Cl}$ producen una disminución de la potencia, siendo los compuestos con SMe-SMe con los que se obtienen mejores resultados en $\mathrm{IC}_{50}$, aunque la dispersión de datos impide determinar un patrón en el comportamiento.

Como conclusión cabe destacar que el reemplazo del anillo de 3,4,5trimetoxifenilo por un anillo de piridina mantiene e incluso mejora la actividad, dependiendo de los demás elementos estructurales. 


\section{C.6.2. ENSAYOS DE CITOTOXICIDAD}

La toxicidad frente a líneas de células cancerosas de los compuestos sintetizados en este trabajo se ha llevado a cabo usando el test de viabilidad XTT de Roche ${ }^{\circledR}$. Este método fue utilizado por primera vez por Scudiero et al ${ }^{59}$ para la cuantificación espectrofotométrica de la viabilidad y crecimiento celular. Este ensayo consiste en la determinación de la actividad mitocondrial de las células mediante la adición de una sal de tetrazolio que en células vivas se transforma en formazan, un compuesto soluble y con un color naranja-rojizo cuya absorbancia se puede relacionar con la cantidad de células vivas.

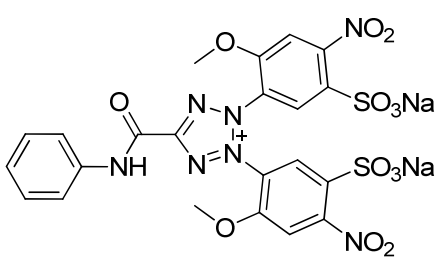

$\mathrm{XTT}$

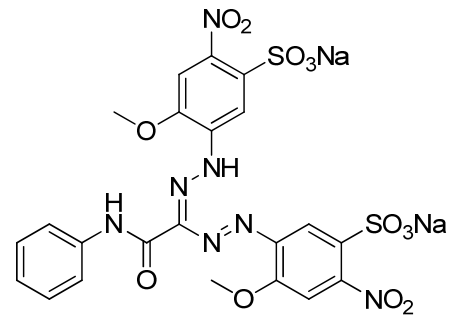

Formazan

Figura 62: Estructura de XTT y de Formazan.

Los compuestos se han ensayado frente a distintas líneas celulares para determinar la citotoxicidad. Con este fin se han utilizado los siguientes tipos de células:

HL-60: Leucemia mieloide humana.

HeLa: Carcinoma cervical humano.

HT-29: Carcinoma de colon humano.

Las células empleadas en los ensayos proceden de cultivos celulares en monocapa (HeLa y HT-29) o en suspensión (HL-60). Las células en fase exponencial de crecimiento se siembran en placas de 96 pocillos con la concentración apropiada* según la línea celular a ensayar, y tras incubarlas durante 72 horas con los

${ }^{59}$ a) Scudiero DA, Shoemaker RH, Paull KD, Monks A, Tierney S, Nofziger TH, et al. Evaluation of a soluble tetrazolium/formazan assay for cell growth and drug sensitivity in culture using human and other tumor cell lines. Cancer Research, 1988, 48, 4827-4833. b) Skehan P, Storeng R, Scudiero D, Monks A, McMahon J, Vistica D, Warren JT, Bokesch H, Kenney S, Boyd MR. New colorimetric cytotoxicity assay for anticancer-drug screening. J. Natl. Cancer Inst. 1990, 82, 1107-1112.

* Ensayo de densidad celular realizado previamente. 
compuestos, se añade el XTT y se incuba durante 4-24 horas. Las medidas de absorbancia se llevaron a cabo en un lector de pocillos ELISA. La diferencia en absorbancia varía según el número de células viables en cada pocillo. En este ensayo se utiliza un control positivo de células sin compuesto a las 72 de incubación, y un control negativo de células sin compuesto a las 0 horas de incubación. Para el resto de pocillos, se mide la absorbancia y por diferencia con la de referencia se determina la inhibición del crecimiento de los distintos compuestos a diferentes concentraciones, permitiendo el cálculo de la $\mathrm{IC}_{50}$.

En un primer screening se probaron 109 compuestos a concentraciones de $10^{-5}$, $10^{-6}, 10^{-7}, 10^{-8}, 10^{-9} \mathrm{M}$ y posteriormente, aquellos que se ha visto que inhiben el crecimiento a una concentración de $10^{-6} \mathrm{M}$, son seleccionados para repetir el ensayo por triplicado con el fin de calcular el valor de $I_{50}$. Los resultados obtenidos se recogen en la tabla siguiente y expresan la concentración que produce un $50 \%$ de inhibición de la proliferación celular $\left(\mathrm{IC}_{50}\right)$.

\begin{tabular}{|c|c|c|c|c|c|c|c|}
\hline COMP & $\begin{array}{c}\mathrm{IC}_{50} \text { Hela } \\
\left(10^{-6} \mathrm{M}\right)\end{array}$ & $\begin{array}{c}\mathrm{IC}_{50} \mathrm{HL60} \\
\left(10^{-6} \mathrm{M}\right)\end{array}$ & $\begin{array}{c}\mathrm{IC}_{50} \mathrm{HT} 29 \\
\left(10^{-6} \mathrm{M}\right)\end{array}$ & COMP & $\begin{array}{c}\mathrm{IC}_{50} \text { Hela } \\
\left(10^{-6} \mathrm{M}\right)\end{array}$ & $\begin{array}{c}\mathrm{IC}_{50} \mathrm{HL60} \\
\left(10^{-6} \mathrm{M}\right)\end{array}$ & $\begin{array}{c}\mathrm{IC}_{50} \mathrm{HT} 29 \\
\left(10^{-6} \mathrm{M}\right)\end{array}$ \\
\hline 25 & $\geq 1$ & $\geq 1$ & $\geq 1$ & 88 & $\geq 1$ & $\geq 1$ & $\geq 1$ \\
\hline 26 & $0,4 \pm 0,09$ & $0,6 \pm 0,2$ & $\geq 1$ & 89 & $0,4 \pm 0,01$ & $0,1 \pm 0,005$ & $0,7 \pm 0,07$ \\
\hline 27 & $\geq 1$ & $\geq 1$ & $\geq 1$ & 93 & $0,8 \pm 0,005$ & $0,2 \pm 0,02$ & $\geq 1$ \\
\hline 28 & $\geq 1$ & $\geq 1$ & $\geq 1$ & 94 & $0,2 \pm 0,08$ & $0,2 \pm 0,06$ & $0,5 \pm 0,07$ \\
\hline 29 & $\geq 1$ & $\geq 1$ & $\geq 1$ & 95 & $\geq 1$ & $\geq 1$ & $\geq 1$ \\
\hline 30 & $\geq 1$ & $\geq 1$ & $\geq 1$ & 96 & $0,5 \pm 0,1$ & $0,7 \pm 0,07$ & $0,2 \pm 0,03$ \\
\hline 31 & $\geq 1$ & $\geq 1$ & $\geq 1$ & 97 & $0,5 \pm 0,2$ & $0,2 \pm 0,07$ & $0,7 \pm 0,1$ \\
\hline 32 & $\geq 1$ & $\geq 1$ & $\geq 1$ & 98 & $\geq 1$ & $\geq 1$ & $\geq 1$ \\
\hline 34 & $0,03 \pm 0,004$ & $0,2 \pm 0,01$ & $\geq 1$ & 99 & $0,1 \pm 0,02$ & $0,3 \pm 0,006$ & $0,5 \pm 0,1$ \\
\hline 36 & $\geq 1$ & $\geq 1$ & $\geq 1$ & 100 & $\geq 1$ & $\geq 1$ & $\geq 1$ \\
\hline 37 & $\geq 1$ & $\geq 1$ & $\geq 1$ & 102 & $0,6 \pm 0,001$ & $0,6 \pm 0,1$ & $0,5 \pm 0,2$ \\
\hline 38 & $\geq 1$ & $\geq 1$ & $\geq 1$ & 103 & $0,6 \pm 0,2$ & $0,2 \pm 0,04$ & $0,2 \pm 0,06$ \\
\hline 39 & $\geq 1$ & $\geq 1$ & $\geq 1$ & 104 & $0,5 \pm 0,1$ & $0,3 \pm 0,1$ & $0,7 \pm 0,05$ \\
\hline 40 & $0,4 \pm 0,09$ & $0,4 \pm 0,06$ & $0,4 \pm 0,1$ & 105 & $0,2 \pm 0,03$ & $0,3 \pm 0,01$ & $0,5 \pm 0,1$ \\
\hline 41 & $0,5 \pm 0,03$ & $0,7 \pm 0,2$ & $\geq 1$ & 106 & $0,6 \pm 0,08$ & $0,6 \pm 0,1$ & $\geq 1$ \\
\hline 42 & $0,9 \pm 0,04$ & $\geq 1$ & $\geq 1$ & 107 & $\geq 1$ & $\geq 1$ & $\geq 1$ \\
\hline 43 & $0,3 \pm 0,02$ & $0,3 \pm 0,02$ & $0,2 \pm 0,04$ & 109 & $0,3 \pm 0,04$ & $0,9 \pm 0,08$ & $0,4 \pm 0,2$ \\
\hline 44 & $0,4 \pm 0,1$ & $\geq 1$ & $\geq 1$ & 110 & $\geq 1$ & $0,1, \pm 0,008$ & $\geq 1$ \\
\hline 45 & $\geq 1$ & $\geq 1$ & $\geq 1$ & 111 & $0,3 \pm 0,07$ & $0,2 \pm 0,008$ & $0,6 \pm 0,2$ \\
\hline 46 & $0,4 \pm 0,1$ & $0,3 \pm 0,1$ & $0,5 \pm 0,2$ & 112 & $0,7 \pm 0,1$ & $\geq 1$ & $\geq 1$ \\
\hline 47 & $0,4 \pm 0,1$ & $0,3 \pm 0,1$ & $0,2 \pm 0,08$ & 115 & $0,3 \pm 0,03$ & $0,5 \pm 0,1$ & $0,5 \pm 0,1$ \\
\hline
\end{tabular}


Métodos y resultados: Actividad Biológica. Ensayos de citotoxicidad

\begin{tabular}{|c|c|c|c|c|c|c|c|}
\hline 48 & $\geq 1$ & $\geq 1$ & $\geq 1$ & 117 & $0,6 \pm 0,07$ & $0,7 \pm 0,08$ & $0,6 \pm 0,1$ \\
\hline 49 & $\geq 1$ & $\geq 1$ & $\geq 1$ & 119 & $0,6 \pm 0,08$ & $0,3 \pm 0,05$ & $0,4 \pm 0,1$ \\
\hline 50 & $0,5 \pm 0,1$ & $0,3 \pm 0,01$ & $\geq 1$ & 120 & $\geq 1$ & $\geq 1$ & $\geq 1$ \\
\hline 51 & $0,2 \pm 0,05$ & $0,3 \pm 0,03$ & $0,2 \pm 0,005$ & 121 & $0,1 \pm 0,04$ & $0,3 \pm 0,1$ & $0,7 \pm 0,06$ \\
\hline 52 & $\geq 1$ & $\geq 1$ & $\geq 1$ & 123 & $0,6 \pm 0,1$ & $0,7 \pm 0,1$ & $0,4 \pm 0,09$ \\
\hline 53 & $\geq 1$ & $\geq 1$ & $\geq 1$ & 125 & $\geq 1$ & $\geq 1$ & $\geq 1$ \\
\hline 54 & $0,07 \pm 0,01$ & $0,06 \pm 0,02$ & $0,5 \pm 0,01$ & 126 & $\geq 1$ & $\geq 1$ & $\geq 1$ \\
\hline 55 & $\geq 1$ & $\geq 1$ & $\geq 1$ & 127 & $0,7 \pm 0,08$ & $\geq 1$ & $\geq 1$ \\
\hline 56 & $0,3 \pm 0,05$ & $0,2 \pm 0,04$ & $0,3 \pm 0,02$ & 128 & $\geq 1$ & $\geq 1$ & $\geq 1$ \\
\hline 57 & $0,5 \pm 0,1$ & $\geq 1$ & $\geq 1$ & 129 & $\geq 1$ & $\geq 1$ & $\geq 1$ \\
\hline 58 & $\geq 1$ & $\geq 1$ & $\geq 1$ & 130 & $\geq 1$ & $\geq 1$ & $\geq 1$ \\
\hline 59 & $0,4 \pm 0,006$ & $0,4 \pm 0,1$ & $0,3 \pm 0,03$ & 131 & $\geq 1$ & $\geq 1$ & $\geq 1$ \\
\hline 60 & $0,6 \pm 0,1$ & $\geq 1$ & $\geq 1$ & 132 & $\geq 1$ & $\geq 1$ & $\geq 1$ \\
\hline 61 & $0,8 \pm 0,02$ & $0,7 \pm 0,2$ & $\geq 1$ & 133 & $\geq 1$ & $\geq 1$ & $\geq 1$ \\
\hline 62 & $\geq 1$ & $\geq 1$ & $\geq 1$ & 134 & $\geq 1$ & $\geq 1$ & $\geq 1$ \\
\hline 63 & $0,04 \pm 0,01$ & $0,08 \pm 0,007$ & $0,4 \pm 0,12$ & 135 & $\geq 1$ & $\geq 1$ & $\geq 1$ \\
\hline 64 & $\geq 1$ & $\geq 1$ & $\geq 1$ & 136 & $\geq 1$ & $\geq 1$ & $\geq 1$ \\
\hline 65 & $0,2 \pm 0,06$ & $0,2 \pm 0,06$ & $\geq 1$ & 137 & $0,6 \pm 0,2$ & $0,5 \pm 0,2$ & $\geq 1$ \\
\hline 68 & $0,3 \pm 0,2$ & $0,07 \pm 0,02$ & $0,9 \pm 0,2$ & 138 & $0,5 \pm 0,2$ & $0,3 \pm 0,02$ & $\geq 1$ \\
\hline 70 & $0,08 \pm 0,01$ & $0,07 \pm 0,0004$ & $0,1 \pm 0,01$ & 139 & $0,6 \pm 0,2$ & $0,3 \pm 0,1$ & $\geq 1$ \\
\hline 71 & $0,05 \pm 0,02$ & $0,07 \pm 0,003$ & $0,09 \pm 0,01$ & 140 & $0,6 \pm 0,021$ & $0,4 \pm 0,2$ & $0,8 \pm 0,03$ \\
\hline 72 & $0,3 \pm 0,1$ & $0,4 \pm 0,09$ & $\geq 1$ & 141 & $\geq 1$ & $\geq 1$ & $\geq 1$ \\
\hline 73 & $0,1 \pm 0,02$ & $0,4 \pm 0,1$ & $0,5 \pm 0,2$ & 142 & $0,3 \pm 0,08$ & $0,4 \pm 0,2$ & $0,9 \pm 0,05$ \\
\hline 74 & $0,3 \pm 0,007$ & $0,2 \pm 0,03$ & $\geq 1$ & 143 & $0,2 \pm 0,03$ & $0,2 \pm 0,07$ & $0,8 \pm 0,1$ \\
\hline 75 & $\geq 1$ & $\geq 1$ & $\geq 1$ & 144 & $\geq 1$ & $\geq 1$ & $\geq 1$ \\
\hline 76 & $0,07 \pm 0,01$ & $0,04 \pm 0,001$ & $0,8 \pm 0,04$ & 145 & $\geq 1$ & $\geq 1$ & $\geq 1$ \\
\hline 77 & $\geq 1$ & $\geq 1$ & $\geq 1$ & $146 z$ & $\geq 1$ & $\geq 1$ & $\geq 1$ \\
\hline 80 & $0,06 \pm 0,01$ & $0,09 \pm 0,001$ & $0,1 \pm 0,002$ & $147 z$ & $\geq 1$ & $\geq 1$ & $0,6 \pm 0,2$ \\
\hline 82 & $0,1 \pm 0,05$ & $0,07 \pm 0,002$ & $0,3 \pm 0,1$ & $148 z$ & $\geq 1$ & $\geq 1$ & $\geq 1$ \\
\hline 83 & $0,08 \pm 0,003$ & $0,04 \pm 0,01$ & $0,3 \pm 0,008$ & $149 z$ & $0,3 \pm 0,09$ & $0,4 \pm 0,3$ & $0,4 \pm 0,03$ \\
\hline 84 & $0,2 \pm 0,03$ & $0,6 \pm 0,04$ & $\geq 1$ & 150 & $\geq 1$ & $\geq 1$ & $\geq 1$ \\
\hline 85 & $0,6 \pm 0,1$ & $0,3 \pm 0,1$ & $0,7 \pm 0,1$ & 151 & $\geq 1$ & $\geq 1$ & $\geq 1$ \\
\hline 86 & $0,2 \pm 0,04$ & $0,2 \pm 0,03$ & $\geq 1$ & 152 & $\geq 1$ & $\geq 1$ & $\geq 1$ \\
\hline 87 & $\geq 1$ & $\geq 1$ & $\geq 1$ & & & & \\
\hline
\end{tabular}

Tabla 14: Resultados obtenidos en los ensayos de citotoxicidad de los 109 compuestos preparados. 


\section{C.6.2.1. ANÁLISIS DE LOS RESULTADOS}

Al igual que en los ensayos de IPT, para el análisis de los resultados obtenidos en el ensayo de citotoxicidad se van a clasificar los compuestos según el sistema aromático en el anillo B.

\section{C.6.2.1.1. Compuestos con p-metoxifenilo en el anillo B}<smiles>[X]c1cc(C([Z])c2ccc(OC)c([R])c2)cc([Y])n1</smiles>

\begin{tabular}{|c|c|c|c|c|c|c|c|c|}
\hline no & $x$ & $\mathbf{Y}$ & z & $\mathbf{R}$ & $\begin{array}{c}\mathrm{IC}_{50} \text { Hela } \\
\left(10^{-6} \mathrm{M}\right)\end{array}$ & $\begin{array}{c}\mathrm{IC}_{50} \mathrm{HL60} \\
\left(10^{-6} \mathrm{M}\right)\end{array}$ & $\begin{array}{c}\mathrm{IC}_{50} \mathrm{HT} 29 \\
\left(10^{-6} \mathrm{M}\right)\end{array}$ & $\mathrm{IC}_{50} \mathrm{IPT}(\mu \mathrm{M})$ \\
\hline 25 & $\mathrm{Cl}$ & $\mathrm{Cl}$ & 0 & $\mathrm{H}$ & $\geq 1$ & $\geq 1$ & $\geq 1$ & $>5$ \\
\hline 26 & $\mathrm{Cl}$ & $\mathrm{Cl}$ & $\mathrm{CH}_{2}$ & $\mathrm{H}$ & $0,4 \pm 0,09$ & $0,6 \pm 0,2$ & $\geq 1$ & $>5$ \\
\hline 27 & $\mathrm{Cl}$ & $\mathrm{Cl}$ & $\mathrm{NOH}$ & $\mathrm{H}$ & $\geq 1$ & $\geq 1$ & $\geq 1$ & $>5$ \\
\hline 28 & $\mathrm{Cl}$ & OMe & 0 & $\mathrm{H}$ & $\geq 1$ & $\geq 1$ & $\geq 1$ & $>5$ \\
\hline 29 & $\mathrm{Cl}$ & OMe & $\mathrm{CH}_{2}$ & $\mathrm{H}$ & $\geq 1$ & $\geq 1$ & $\geq 1$ & $>5$ \\
\hline 30 & OMe & OMe & $\mathrm{CH}_{2}$ & $\mathrm{H}$ & $\geq 1$ & $\geq 1$ & $\geq 1$ & $>5$ \\
\hline 31 & $\mathrm{Cl}$ & OMe & $\mathrm{NOH}$ & $\mathrm{H}$ & $\geq 1$ & $\geq 1$ & $\geq 1$ & $>5$ \\
\hline 32 & $\mathrm{Cl}$ & OMe & 0 & $\mathrm{NO}_{2}$ & $\geq 1$ & $\geq 1$ & $\geq 1$ & $>5$ \\
\hline 33 & $\mathrm{Cl}$ & OMe & 0 & $2\left(\mathrm{NO}_{2}\right)$ & $\geq 1$ & $\geq 1$ & $\geq 1$ & $>5$ \\
\hline 34 & $\mathrm{Cl}$ & OMe & 0 & $\mathrm{NH}_{2}$ & $0,09 \pm 0,004$ & $0,2 \pm 0,01$ & $\geq 1$ & 2,5 \\
\hline 35 & $\mathrm{Cl}$ & OMe & 0 & $2\left(\mathrm{NH}_{2}\right)$ & $\geq 1$ & $\geq 1$ & $\geq 1$ & $>5$ \\
\hline 36 & $\mathrm{Cl}$ & $\mathrm{Ph}-\mathrm{NH}$ & 0 & $\mathrm{H}$ & $\geq 1$ & $\geq 1$ & $\geq 1$ & $>5$ \\
\hline 37 & $\mathrm{Cl}$ & MePh-NH & 0 & $\mathrm{H}$ & $\geq 1$ & $\geq 1$ & $\geq 1$ & $>5$ \\
\hline 38 & $\mathrm{Cl}$ & SMe & 0 & $\mathrm{H}$ & $\geq 1$ & $\geq 1$ & $\geq 1$ & $>5$ \\
\hline 39 & $\mathrm{Cl}$ & SMe & $\mathrm{AcO}, \mathrm{OH}$ & $\mathrm{H}$ & $\geq 1$ & $\geq 1$ & $\geq 1$ & $>5$ \\
\hline 40 & $\mathrm{Cl}$ & SMe & $\mathrm{CH}_{2}$ & $\mathrm{H}$ & $0,4 \pm 0,09$ & $0,4 \pm 0,06$ & $0,4 \pm 0,1$ & 1,5 \\
\hline 41 & $\mathrm{Cl}$ & SMe & $\mathrm{NOH}$ & $\mathrm{H}$ & $0,5 \pm 0,03$ & $0,7 \pm 0,2$ & $\geq 1$ & 4,6 \\
\hline 42 & $\mathrm{Cl}$ & $\mathrm{NMe}_{2}$ & 0 & $\mathrm{H}$ & $0,9 \pm 0,04$ & $\geq 1$ & $\geq 1$ & $>5$ \\
\hline 43 & $\mathrm{Cl}$ & $\mathrm{NMe}_{2}$ & $\mathrm{CH}_{2}$ & $\mathrm{H}$ & $0,3 \pm 0,02$ & $0,3 \pm 0,02$ & $0,2 \pm 0,04$ & 1,1 \\
\hline 44 & $\mathrm{Cl}$ & $\mathrm{NMe}_{2}$ & $\mathrm{NOH}$ & $\mathrm{H}$ & $0,4 \pm 0,1$ & $\geq 1$ & $\geq 1$ & $>5$ \\
\hline 45 & SMe & SMe & 0 & $\mathrm{H}$ & $\geq 1$ & $\geq 1$ & $\geq 1$ & $>5$ \\
\hline 46 & SMe & SMe & $\mathrm{CH}_{2}$ & $\mathrm{H}$ & $0,4 \pm 0,1$ & $0,3 \pm 0,1$ & $0,5 \pm 0,2$ & 2,0 \\
\hline
\end{tabular}




\begin{tabular}{c|llcccccc}
$\mathbf{4 7}$ & $\mathrm{SMe}$ & $\mathrm{SMe}$ & $\mathrm{NOH}$ & $\mathrm{H}$ & $0,4 \pm 0,09$ & $0,3 \pm 0,1$ & $0,2 \pm 0,08$ & 3, \\
\hline $\mathbf{4 8}$ & $\mathrm{SMe}$ & $\mathrm{SMe}$ & $\mathrm{H}, \mathrm{CH}_{3}$ & $\mathrm{H}$ & $\geq 1$ & $\geq 1$ & $\geq 1$ & $>5$ \\
\hline $\mathbf{4 9}$ & $\mathrm{SMe}$ & $\mathrm{OMe}$ & $\mathrm{O}$ & $\mathrm{H}$ & $\geq 1$ & $\geq 1$ & $\geq 1$ & $>5$ \\
\hline $\mathbf{5 0}$ & $\mathrm{SMe}$ & $\mathrm{OMe}$ & $\mathrm{CH}_{2}$ & $\mathrm{H}$ & $0,5 \pm 0,1$ & $0,3 \pm 0,01$ & $\geq 1$ & 4,1 \\
\hline $\mathbf{5 1}$ & $\mathrm{SMe}$ & $\mathrm{OMe}$ & $\mathrm{NOH}$ & $\mathrm{H}$ & $0,2 \pm 0,05$ & $0,3 \pm 0,04$ & $0,2 \pm 0,005$ & 1,3 \\
\hline $\mathbf{5 2}$ & $\mathrm{SMe}$ & $\mathrm{OMe}$ & $\mathrm{H}, \mathrm{CH}$ & $\mathrm{H}$ & $\geq 1$ & $\geq 1$ & $\geq 1$ & $>5$ \\
\hline $\mathbf{5 3}$ & $\mathrm{SMe}$ & $\mathrm{OMe}$ & $\mathrm{O}$ & $\mathrm{NO}_{2}$ & $\geq 1$ & $\geq 1$ & $\geq 1$ & $>5$ \\
\hline $\mathbf{5 4}$ & $\mathrm{SMe}$ & $\mathrm{OMe}^{2}$ & $\mathrm{O}$ & $\mathrm{NH}_{2}$ & $\mathbf{0 , 0 7} \pm 0,013$ & $\mathbf{0 , 0 6} \pm 0,02$ & $0,5 \pm 0,01$ & 0,9 \\
\hline $\mathbf{5 5}$ & $\mathrm{SMe}$ & $\mathrm{NMe}_{2}$ & $\mathrm{O}$ & $\mathrm{H}$ & $\geq 1$ & $\geq 1$ & $\geq 1$ & $>5$ \\
\hline $\mathbf{5 6}$ & $\mathrm{SMe}$ & $\mathrm{NMe}_{2}$ & $\mathrm{CH}$ & $\mathrm{H}$ & $0,3 \pm 0,05$ & $0,2 \pm 0,04$ & $0,3 \pm 0,02$ & 0,6 \\
\hline $\mathbf{5 7}$ & $\mathrm{SMe}$ & $\mathrm{NMe}_{2}$ & $\mathrm{NOH}$ & $\mathrm{H}$ & $0,5 \pm 0,1$ & $\geq 1$ & $\geq 1$ & $>5$ \\
\hline $\mathbf{5 8}$ & $\mathrm{OMe}$ & $\mathrm{NMe}_{2}$ & $\mathrm{O}$ & $\mathrm{H}$ & $\geq 1$ & $\geq 1$ & $\geq 1$ & $>5$ \\
\hline $\mathbf{5 9}$ & $\mathrm{OMe}$ & $\mathrm{NMe}_{2}$ & $\mathrm{CH}$ & $\mathrm{H}$ & $0,4 \pm 0,006$ & $0,4 \pm 0,1$ & $0,3 \pm 0,03$ & 1,4 \\
\hline $\mathbf{6 0}$ & $\mathrm{OMe}$ & $\mathrm{NMe}_{2}$ & $\mathrm{NOH}$ & $\mathrm{H}$ & $0,6 \pm 0,1$ & $\geq 1$ & $\geq 1$ & $>5$
\end{tabular}

Tabla 15. Resultados de actividad en citotoxicidad y en IPT de todos los compuestos con $p$ metoxifenilo. Los compuestos más potentes en citotoxicidad se han marcado en negrita.

Se han sintetizado 36 compuestos con anillo de $p$-metoxifenilo en el anillo $\mathrm{B}, \mathrm{y}$ 16 tienen un valor de $\mathrm{IC}_{50}$ inferior a $1 \mu \mathrm{M}$. De estos compuestos, 11 de ellos tienen un valor de $\mathrm{IC}_{50}$ en IPT por debajo de $5 \mu \mathrm{M}$, y los otros cinco restantes por encima de 5 $\mu \mathrm{M}$ (compuestos 26, 42, 44, 57 y 60). Estos cinco compuestos, sólo tienen actividad citotóxica submicromolar en Hela, y el compuesto 26 en HL60, careciendo de potencia citotóxica en la línea celular HT29.

Para observar mejor esta relación entre la actividad en IPT y en citotoxicidad, se representan a continuación los valores de $\mathrm{IC}_{50}$ en citotoxicidad de los compuestos que están por debajo de $1 \mu \mathrm{M}$, frente a los valores de IC $_{50}$ en IPT de los compuestos que están por debajo de $5 \mu \mathrm{M}$. La tendencia que se determina a partir de la gráfica, es que los compuestos con mejor actividad en IPT son más potentes en citotoxicidad. Este análisis se ha llevado a cabo en la línea celular Hela, ya que es la única que ha demostrado este comportamiento. En el resto tiene lugar una mayor dispersión de los datos. 


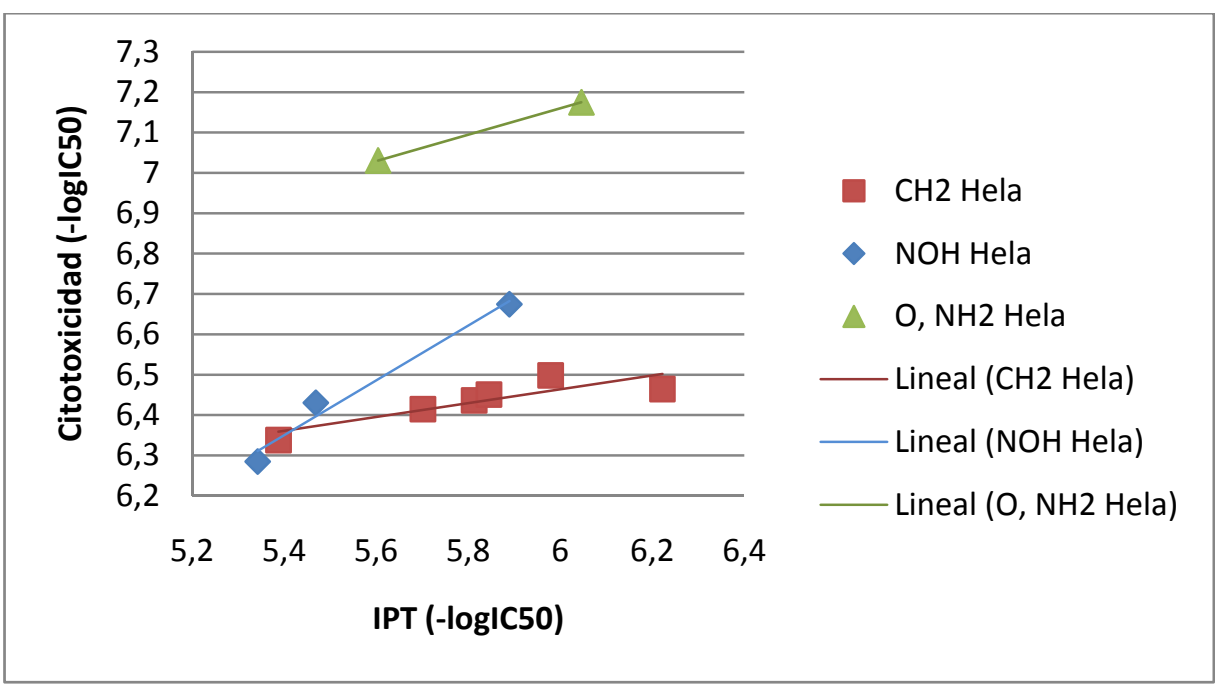

Figura 63. Correlación de las $I C_{50}$ de IPT con las $I_{50}$ de citotoxicidad en la línea celular Hela en compuestos con $p$-metoxifenilo en el anillo $\mathrm{B}$.

\section{C.6.2.1.2. Compuestos con $N$-metilindol en el anillo B}

\begin{tabular}{|c|c|c|c|c|c|c|c|c|}
\hline no & $x$ & $\mathbf{Y}$ & Z & $\mathbf{R}$ & $\begin{array}{l}\mathrm{IC}_{50} \text { Hela } \\
\left(10^{-6} \mathrm{M}\right)\end{array}$ & $\begin{array}{c}\mathrm{IC}_{50} \mathrm{HL60} \\
\left(10^{-6} \mathrm{M}\right)\end{array}$ & $\begin{array}{c}\mathrm{IC}_{50} \mathrm{HT} 29 \\
\left(10^{-6} \mathrm{M}\right)\end{array}$ & $\begin{array}{c}\mathrm{IC}_{50} \mathrm{IPT} \\
(\mu \mathrm{M})\end{array}$ \\
\hline 61 & $\mathrm{Cl}$ & $\mathrm{Cl}$ & 0 & $\mathrm{H}$ & $0,8 \pm 0,02$ & $0,7 \pm 0,2$ & $\geq 1$ & 5,0 \\
\hline 62 & $\mathrm{Cl}$ & $\mathrm{Cl}$ & - & $\mathrm{H}$ & $\geq 1$ & $\geq 1$ & $\geq 1$ & $>5$ \\
\hline 63 & $\mathrm{Cl}$ & $\mathrm{Cl}$ & $\mathrm{CH}_{2}$ & $\mathrm{H}$ & $\mathbf{0 , 0 4} \pm 0,01$ & $\mathbf{0 , 0 8} \pm 0,007$ & $0,4 \pm 0,2$ & 0,9 \\
\hline 64 & $\mathrm{Cl}$ & $\mathrm{Cl}$ & 0 & $\mathrm{CHO}$ & $\geq 1$ & $\geq 1$ & $\geq 1$ & $>5$ \\
\hline 65 & $\mathrm{Cl}$ & $\mathrm{Cl}$ & $\mathrm{CH}_{2}$ & $\mathrm{CHO}$ & $0,2 \pm 0,06$ & $0,2 \pm 0,06$ & $\geq 1$ & $>5$ \\
\hline 68 & $\mathrm{Cl}$ & $\mathrm{Cl}$ & $\mathrm{NOH}$ & $\mathrm{CN}$ & $0,3 \pm 0,2$ & $\mathbf{0 , 0 7} \pm 0,02$ & $0,9 \pm 0,2$ & 4 \\
\hline 70 & $\mathrm{Cl}$ & $\mathrm{Cl}$ & $\mathrm{CH}_{2}$ & $\mathrm{CN}$ & $\mathbf{0 , 0 8} \pm 0,01$ & $\mathbf{0 , 0 7} \pm 0,0004$ & $0,1 \pm 0,01$ & 2,5 \\
\hline 71 & $\mathrm{Cl}$ & $\mathrm{Cl}$ & $\mathrm{CH}_{2}$ & $\mathrm{CONH}_{2}$ & $\mathbf{0 , 0 5} \pm 0,02$ & $\mathbf{0 , 0 7} \pm 0,003$ & $\mathbf{0 , 0 9} \pm 0,01$ & 3,4 \\
\hline 72 & $\mathrm{Cl}$ & SMe & 0 & $\mathrm{H}$ & $0,3 \pm 0,1$ & $0,4 \pm 0,09$ & $\geq 1$ & 2,4 \\
\hline 73 & $\mathrm{Cl}$ & SMe & $\mathrm{CH}_{2}$ & $\mathrm{H}$ & $0,1 \pm 0,02$ & $0,4 \pm 0,1$ & $0,5 \pm 0,2$ & 0,3 \\
\hline 74 & $\mathrm{Cl}$ & SMe & $\mathrm{NOH}$ & $\mathrm{H}$ & $0,3 \pm 0,007$ & $0,2 \pm 0,03$ & $\geq 1$ & $>5$ \\
\hline 75 & $\mathrm{Cl}$ & SMe & 0 & $\mathrm{CHO}$ & $\geq 1$ & $\geq 1$ & $\geq 1$ & $>5$ \\
\hline 76 & $\mathrm{Cl}$ & SMe & $\mathrm{CH}_{2}$ & $\mathrm{CHO}$ & $\mathbf{0 , 0 7} \pm 0,01$ & $\mathbf{0 , 0 4} \pm 0,001$ & $0,8 \pm 0,04$ & 1,6 \\
\hline
\end{tabular}


Métodos y resultados: Actividad Biológica. Ensayos de citotoxicidad

\begin{tabular}{|c|c|c|c|c|c|c|c|c|}
\hline 77 & $\mathrm{Cl}$ & SMe & $\mathrm{CH}_{2}$ & $\mathrm{COOH}$ & $\geq 1$ & $\geq 1$ & $\geq 1$ & $>5$ \\
\hline 80 & $\mathrm{Cl}$ & SMe & $\mathrm{NOH}$ & $\mathrm{CN}$ & $0,06 \pm 0,01$ & $0,09 \pm 0,001$ & $0,1 \pm 0,002$ & 0,2 \\
\hline 82 & $\mathrm{Cl}$ & SMe & $\mathrm{CH}_{2}$ & $\mathrm{CN}$ & $0,1 \pm 0,05$ & $0,07 \pm 0,002$ & $0,3 \pm 0,1$ & 0,6 \\
\hline 83 & $\mathrm{Cl}$ & SMe & $\mathrm{CH}_{2}$ & $\mathrm{CONH}_{2}$ & $0,08 \pm 0,003$ & $\mathbf{0 , 0 4} \pm 0,01$ & $0,3 \pm 0,008$ & 2,3 \\
\hline 84 & SMe & OMe & 0 & $\mathrm{H}$ & $0,1 \pm 0,03$ & $0,6 \pm 0,04$ & $\geq 1$ & $>5$ \\
\hline 85 & SMe & OMe & $\mathrm{CH}_{2}$ & $\mathrm{H}$ & $0,6 \pm 0,1$ & $0,3 \pm 0,1$ & $0,7 \pm 0,1$ & $>5$ \\
\hline 86 & SMe & OMe & $\mathrm{NOH}$ & $\mathrm{H}$ & $0,2 \pm 0,04$ & $0,2 \pm 0,03$ & $\geq 1$ & 1,6 \\
\hline 87 & SMe & OMe & 0 & $\mathrm{CHO}$ & $\geq 1$ & $\geq 1$ & $\geq 1$ & $>5$ \\
\hline 88 & SMe & OMe & $\mathrm{CH}_{2}$ & $\mathrm{COOH}$ & $\geq 1$ & $\geq 1$ & $\geq 1$ & $>5$ \\
\hline 89 & SMe & OMe & $\mathrm{CH}_{2}$ & $\mathrm{CHO}$ & $0,4 \pm 0,01$ & $0,1 \pm 0,005$ & $0,7 \pm 0,07$ & 2,9 \\
\hline 92 & SMe & OMe & $\mathrm{NOH}$ & $\mathrm{CN}$ & $\geq 1$ & $\geq 1$ & $\geq 1$ & $>5$ \\
\hline 93 & SMe & OMe & 0 & $\mathrm{CN}$ & $0,8 \pm 0,005$ & $0,2 \pm 0,02$ & $\geq 1$ & 2,9 \\
\hline 94 & SMe & SMe & 0 & $\mathrm{H}$ & $0,2 \pm 0,08$ & $0,2 \pm 0,06$ & $0,5 \pm 0,07$ & 1,7 \\
\hline 95 & SMe & SMe & $\mathrm{OH}$ & $\mathrm{H}$ & $\geq 1$ & $\geq 1$ & $\geq 1$ & $>5$ \\
\hline 96 & SMe & SMe & $\mathrm{CH}_{2}$ & $\mathrm{H}$ & $0,5 \pm 0,1$ & $0,7 \pm 0,07$ & $0,2 \pm 0,03$ & 1,1 \\
\hline 97 & SMe & SMe & $\mathrm{NOH}$ & $\mathrm{H}$ & $0,5 \pm 0,2$ & $0,2 \pm 0,07$ & $0,7 \pm 0,1$ & 1,0 \\
\hline 98 & SMe & SMe & 0 & $\mathrm{CHO}$ & $\geq 1$ & $\geq 1$ & $\geq 1$ & $>5$ \\
\hline 99 & SMe & SMe & $\mathrm{CH}_{2}$ & $\mathrm{CHO}$ & $0,1 \pm 0,02$ & $0,3 \pm 0,006$ & $0,5 \pm 0,1$ & 1,2 \\
\hline 100 & SMe & SMe & $\mathrm{CH}_{2}$ & $\mathrm{COOH}$ & $\geq 1$ & $\geq 1$ & $\geq 1$ & 4,7 \\
\hline 102 & SMe & SMe & $\mathrm{CH}_{2}$ & $\mathrm{CN}$ & $0,6 \pm 0,001$ & $0,6 \pm 0,1$ & $0,5 \pm 0,2$ & 0,4 \\
\hline 103 & SMe & SMe & $\mathrm{CH}_{2}$ & $\mathrm{CONH}_{2}$ & $0,6 \pm 0,2$ & $0,2 \pm 0,04$ & $0,2 \pm 0,06$ & 2,4 \\
\hline 104 & SMe & $\mathrm{NMe}_{2}$ & 0 & $\mathrm{H}$ & $0,5 \pm 0,1$ & $0,3 \pm 0,1$ & $0,7 \pm 0,05$ & 2,4 \\
\hline 105 & SMe & $\mathrm{NMe}_{2}$ & $\mathrm{CH}_{2}$ & $\mathrm{H}$ & $0,2 \pm 0,03$ & $0,3 \pm 0,01$ & $0,5 \pm 0,1$ & 0,7 \\
\hline 106 & SMe & $\mathrm{NMe}_{2}$ & $\mathrm{NOH}$ & $\mathrm{H}$ & $0,6 \pm 0,08$ & $0,6 \pm 0,1$ & $\geq 1$ & $>5$ \\
\hline 107 & SMe & $\mathrm{NMe}_{2}$ & 0 & $\mathrm{CHO}$ & $\geq 1$ & $\geq 1$ & $\geq 1$ & $>5$ \\
\hline 108 & SMe & $\mathrm{NMe}_{2}$ & 0 & $2 \times(\mathrm{CHO})$ & $\geq 1$ & $\geq 1$ & $\geq 1$ & $>5$ \\
\hline 109 & SMe & $\mathrm{NMe}_{2}$ & $\mathrm{CH}_{2}$ & $\mathrm{CHO}$ & $0,3 \pm 0,04$ & $0,9 \pm 0,07$ & $0,4 \pm 0,2$ & 2,4 \\
\hline 110 & $\mathrm{Cl}$ & $\mathrm{NMe}_{2}$ & $\mathrm{CH}_{2}$ & $\mathrm{CHO}$ & $\geq 1$ & $0,1 \pm 0,008$ & $\geq 1$ & 1,6 \\
\hline 111 & SMe & $\mathrm{NMe}_{2}$ & $\mathrm{CH}_{2}$ & $2 \times(\mathrm{CHO})$ & $0,3 \pm 0,07$ & $0,2 \pm 0,008$ & $0,6 \pm 0,2$ & 3,2 \\
\hline 112 & SMe & $\mathrm{NMe}_{2}$ & $\mathrm{CH}_{2}$ & $\mathrm{COOH}$ & $0,7 \pm 0,1$ & $\geq 1$ & $\geq 1$ & $>5$ \\
\hline 115 & SMe & $\mathrm{NMe}_{2}$ & $\mathrm{NOH}$ & $\mathrm{CN}$ & $0,3 \pm 0,03$ & $0,5 \pm 0,1$ & $0,5 \pm 0,1$ & 1,4 \\
\hline 117 & SMe & $\mathrm{NMe}_{2}$ & $\mathrm{CH}_{2}$ & $\mathrm{CN}$ & $0,6 \pm 0,07$ & $0,7 \pm 0,08$ & $0,6 \pm 0,1$ & 1,0 \\
\hline 119 & SMe & $\mathrm{NMe}_{2}$ & $\mathrm{CH}_{2}$ & $\mathrm{CONH}_{2}$ & $0,6 \pm 0,08$ & $0,3 \pm 0,05$ & $0,4 \pm 0,1$ & 4,8 \\
\hline 120 & $\mathrm{Cl}$ & $\mathrm{NMe}_{2}$ & 0 & $\mathrm{H}$ & $\geq 1$ & $\geq 1$ & $\geq 1$ & $>5$ \\
\hline 121 & $\mathrm{Cl}$ & $\mathrm{NMe}_{2}$ & $\mathrm{CH}_{2}$ & $\mathrm{H}$ & $0,1 \pm 0,04$ & $0,3 \pm 0,1$ & $0,7 \pm 0,06$ & 1,9 \\
\hline 123 & $\mathrm{Cl}$ & $\mathrm{NMe}_{2}$ & $\mathrm{CH}_{2}$ & $\mathrm{CN}$ & $0,6 \pm 0,1$ & $0,7 \pm 0,2$ & $0,4 \pm 0,08$ & 1,6 \\
\hline 125 & SOMe & OMe & 0 & $\mathrm{H}$ & $\geq 1$ & $\geq 1$ & $\geq 1$ & $>5$ \\
\hline 126 & $\mathrm{SO}_{2} \mathrm{Me}$ & OMe & $\mathrm{O}$ & $\mathrm{H}$ & $\geq 1$ & $\geq 1$ & $\geq 1$ & $>5$ \\
\hline
\end{tabular}

Tabla 16. Resultados de actividad en citotoxicidad y en IPT de todos los compuestos con N-metilindol. Los compuestos más potentes en citotoxicidad se han marcado en negrita. 
Se han sintetizado 51 compuestos con anillo de $N$-metilindol en el anillo $\mathrm{B}$, de los cuales, 36 tienen un valor de $\mathrm{IC}_{50}$ menor de $1 \mu \mathrm{M}$. De estos 36 compuestos, 30 de ellos tienen un valor de $\mathrm{IC}_{50}$ en IPT menor de $5 \mu \mathrm{M}$. Además, todo lo contrario ocurre en el caso del compuesto 100 , que tiene un valor de $\mathrm{IC}_{50}$ en IPT de 4,66 $\mu \mathrm{M}$, pero no tiene actividad submicromolar sobre ninguna de las tres líneas celulares.

Al representar los valores de $I C_{50}$ en citotoxicidad frente a los valores de $I_{50}$ en IPT, se observa una tendencia similar a la obtenida para los compuestos con $p$ metoxifenilo. Los compuestos con mayor potencia en citotoxicidad presentan buen perfil en IPT (marcados en círculo azul), aunque existe alguna familia de compuestos donde no se cumple esta tendencia, como es el caso de algunas isocombretastatinas con carboxamida en posición 3 (compuestos 71 y 83), y de los compuesto 63, 70, 76 que son de los compuestos sintetizados con mejor potencia citotóxica, pero sin embargo su valor de $I_{50}$ en IPT no es destacable (marcados en círculo rojo). Lo contrario sucede en algunos compuestos de la familia de isocombretastatinas con carbonitrilo en posición 3 (compuestos 102 y 117), donde presentan buena potencia en IPT pero tienen peor perfil citotóxico (marcados con círculo verde).

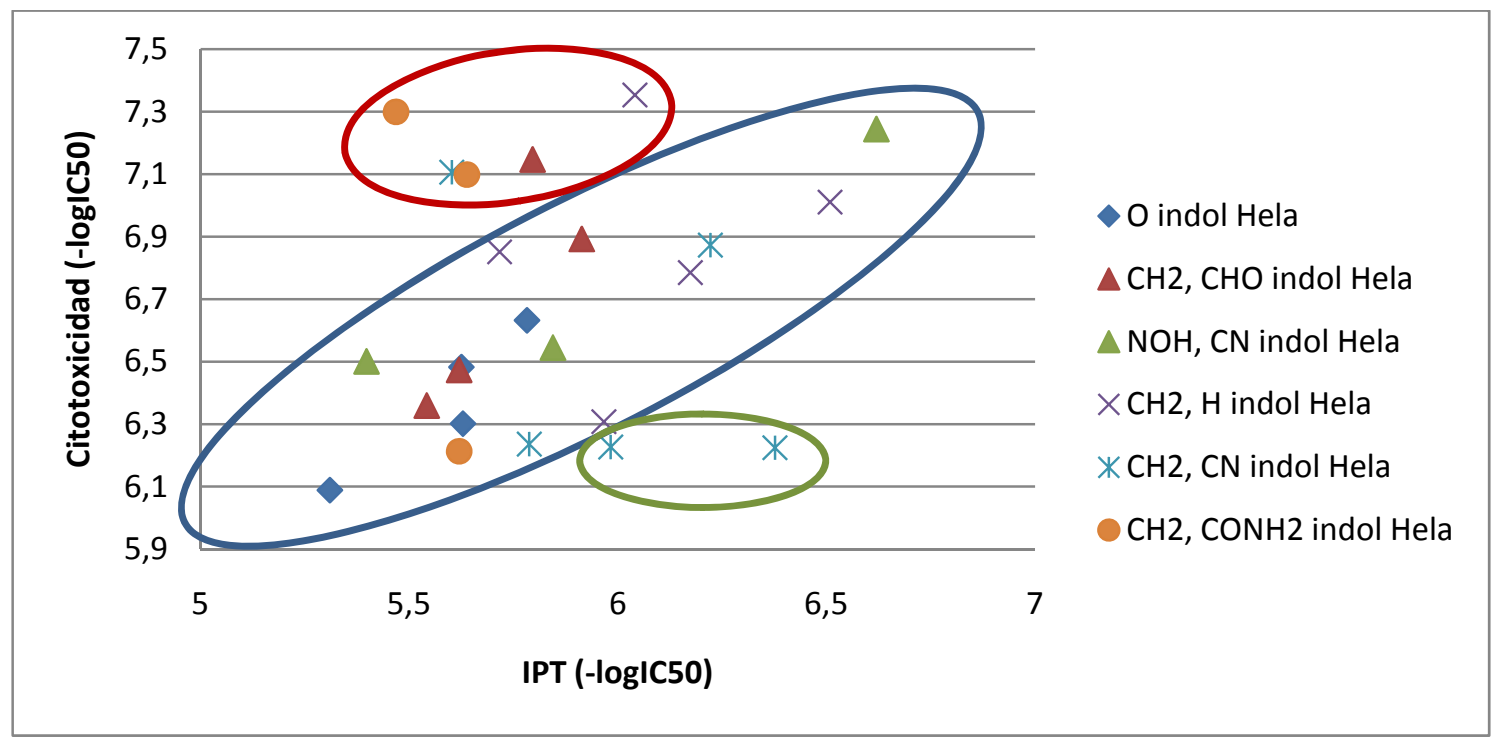

Figura 64. Correlación de las $I_{50}$ de IPT con las $I_{50}$ de citotoxicidad en la línea celular Hela en compuestos con $\mathrm{N}$-metilindol en el anillo B. 


\section{C.6.2.1.3. Compuestos con otros sistemas aromáticos en el anillo B}

Al igual que en IPT, los compuestos con 3-dimetilaminofenil, anillo de piridina y naftaleno (excepto el compuesto 127 en la línea celular Hela) en el anillo B, no tienen actividad citotóxica a las concentraciones ensayadas.

Los compuestos con 4-dimetilaminofenil sintetizados tienen todos actividad citotóxica en todas las líneas celulares ensayadas, excepto algunos de ellos en HT-29. El compuesto con mejor actividad es el 143, sin embargo no existen muchas diferencias entre estos compuestos.

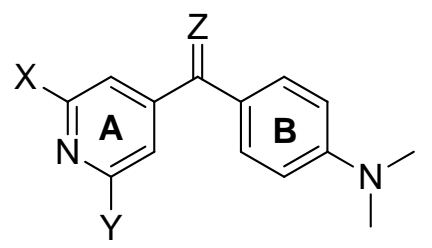

\begin{tabular}{|c|c|c|c|c|c|c|c|c|}
\hline no & $x$ & $\mathbf{Y}$ & Z & $\mathbf{R}$ & $\begin{array}{c}\mathrm{IC}_{50} \text { Hela } \\
\left(10^{-6} \mathrm{M}\right)\end{array}$ & $\begin{array}{c}\mathrm{IC}_{50} \mathrm{HL60} \\
\left(10^{-6} \mathrm{M}\right)\end{array}$ & $\begin{array}{c}\mathrm{IC}_{50} \mathrm{HT} 29 \\
\left(10^{-6} \mathrm{M}\right)\end{array}$ & $\begin{array}{c}I_{50} \text { IPT } \\
(\mu \mathrm{M})\end{array}$ \\
\hline 137 & SMe & OMe & 0 & $\mathrm{H}$ & $0,6 \pm 0,2$ & $0,5 \pm 0,2$ & $\geq 1$ & $>5$ \\
\hline 138 & SMe & OMe & $\mathrm{CH}_{2}$ & $\mathrm{H}$ & $0,5 \pm 0,2$ & $0,3 \pm 0,02$ & $\geq 1$ & $>5$ \\
\hline 139 & SMe & OMe & $\mathrm{NOH}$ & $\mathrm{H}$ & $0,6 \pm 0,2$ & $0,3 \pm 0,1$ & $\geq 1$ & $>5$ \\
\hline 140 & SMe & SMe & 0 & $\mathrm{H}$ & $0,6 \pm 0,02$ & $0,4 \pm 0,2$ & $0,8 \pm 0,03$ & $>5$ \\
\hline 142 & SMe & SMe & $\mathrm{CH}_{2}$ & $\mathrm{H}$ & $0,3 \pm 0,08$ & $0,4 \pm 0,2$ & $0,9 \pm 0,05$ & 3,8 \\
\hline 143 & SMe & SMe & $\mathrm{NOH}$ & $\mathrm{H}$ & $0,2 \pm 0,03$ & $0,2 \pm 0,07$ & $0,8 \pm 0,1$ & 2,1 \\
\hline
\end{tabular}

Tabla 17. Resultados de actividad en citotoxicidad y en IPT de todos los compuestos con 4dimetilaminofenil.

En estos compuestos se observa que a pesar de que algunos de ellos tienen poca actividad en ensayos de IPT, sí que tiene actividad citotóxica. 


\section{C.6.2.1.3. Compuestos con más de un átomo en el puente}

Ninguno de los compuestos con estructura de oxadiazolina tiene un valor de $\mathrm{IC}_{50}$ menor de $1 \mu \mathrm{M}$, sin embargo no ocurre lo mismo con las combretastatinas:

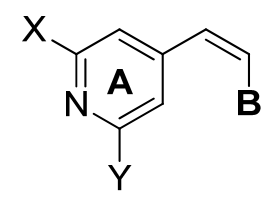

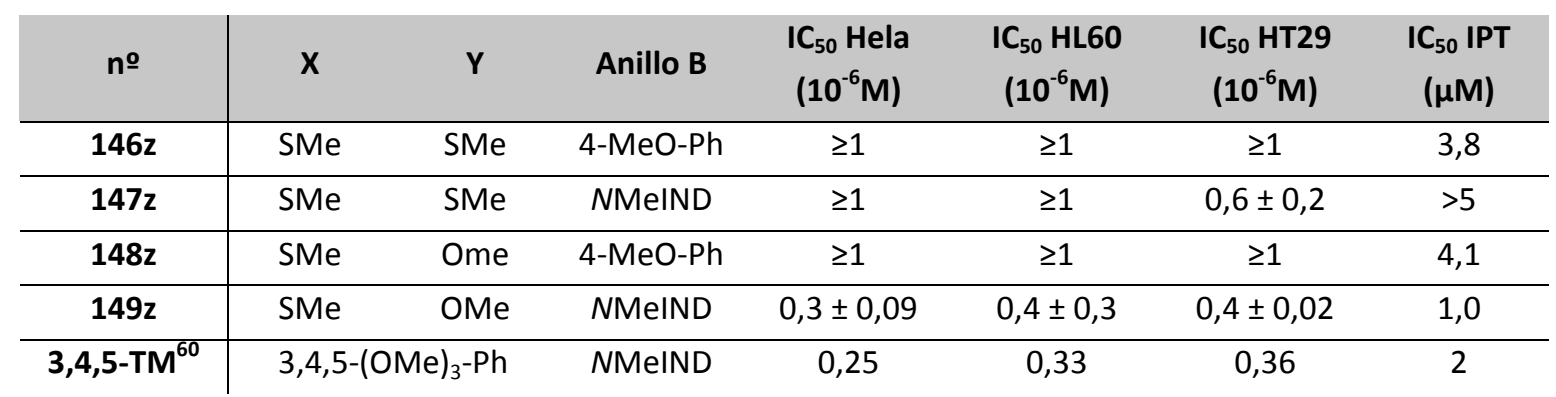

Tabla 18. Resultados de actividad en citotoxicidad y en IPT de las combretastatinas sintetizadas.

En las combretastatinas el único compuesto que tiene actividad sobre las tres líneas celulares es el compuesto $149 z$, y el compuesto $147 z$ sólo tiene actividad en la línea HT-29. Esto puede ser debido a la isomerización en disolución de los compuestos.

Al comparar los resultados del compuesto $149 \mathrm{z}$ con los de su compuesto de referencia $^{60}$ con 3,4,5-trimetoxifenilo en el anillo $A$, se observa que los resultados de citotoxicidad en las tres líneas celulares son muy similares, pero sin embargo, el compuesto $149 \mathrm{z}$ es más potente en IPT, lo que vuelve a indicar que este anillo no es indispensable para la actividad de los compuestos. Sin embargo, la mayor potencia en IPT del derivado piridínico no se traduce en una mayor potencia en los ensayos de citotoxicidad.

60 Maya AB, Pérez-Melero C, Mateo C, Alonso D, Fernández JL, Gajate C, et al. Further naphthylcombretastatins. An investigation on the role of the naphthalene moiety. J Med Chem, 2005, 48, 556-568. 


\section{C.6.2.2. DISCUSIÓN DE RESULTADOS}

En general, los compuestos que tienen un valor de $\mathrm{IC}_{50}$ en citotoxicidad menor de $1 \mu \mathrm{M}$, también tienen un valor de $\mathrm{IC}_{50}$ en IPT menor de $5 \mu \mathrm{M}$, lo que indica que, probablemente el mecanismo por el cual estos compuestos conducen a muerte celular es por la inhibición de la polimerización de la tubulina.

Para comparar el efecto que produce, en los valores de IPT y citotoxicidad, disponer de un anillo de $p$-metoxifenilo frente a un anillo de $N$-metilindol, se ha realizado un diagrama de barras en el que se comparan estos dos anillos, a igualdad del resto de elementos estructurales. Para poder incluir los compuestos que no fueron seleccionados para el cálculo del valor de $\mathrm{IC}_{50}$ en ambos ensayos, se les ha asignado un valor de $\mathrm{IC}_{50}$ de $10 \mu \mathrm{M}$ tanto en IPT como en citotoxicidad. 


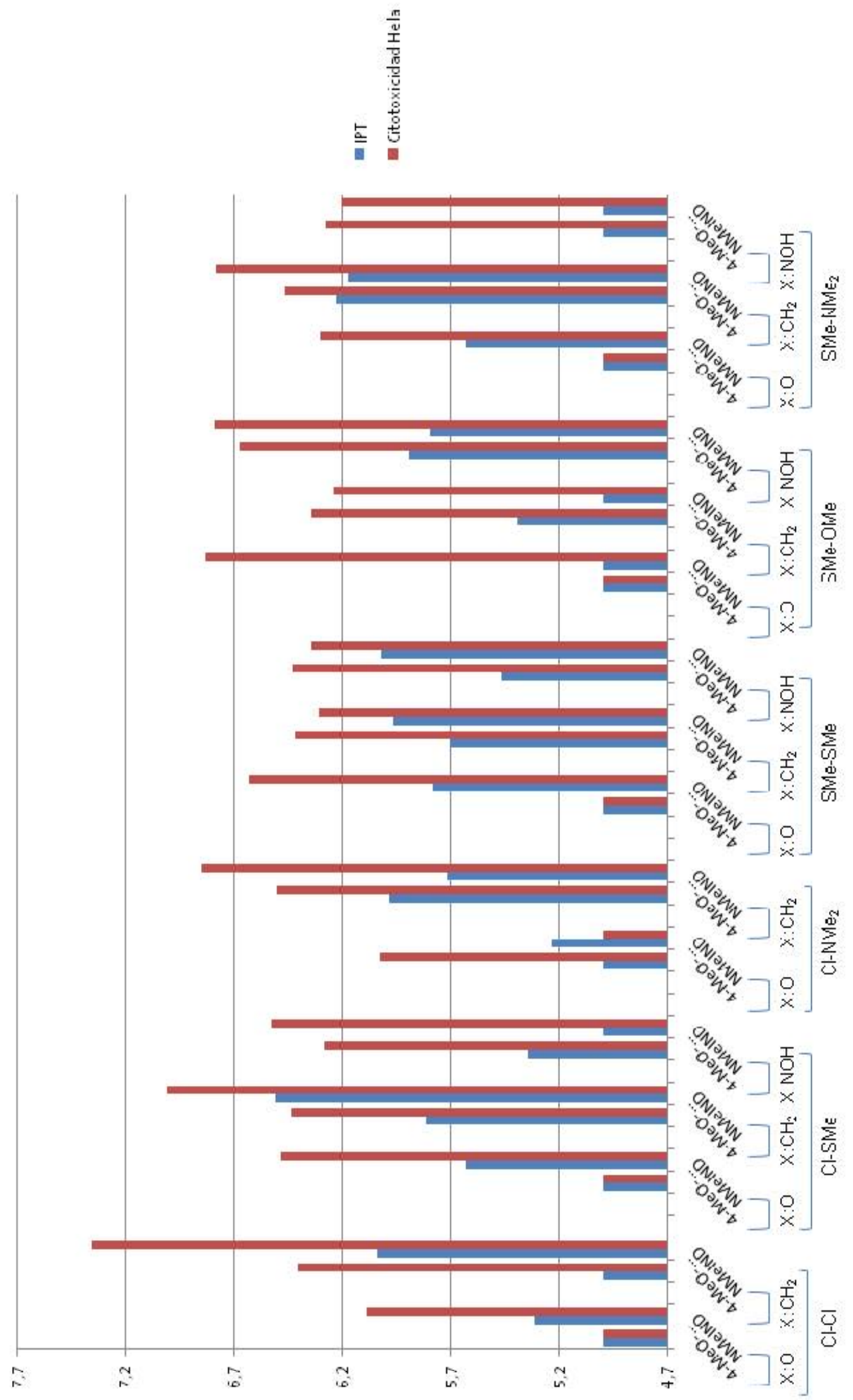

Figura 65. Representación de los valores de $\left(-\log \mathrm{I}_{50}\right)$ en IPT y citotoxicidad en Hela. 
En el diagrama se observa que en la mayoría de los casos son más potentes los compuestos con un anillo de $\mathrm{N}$-metilindol que con un anillo de $p$-metoxifenilo tanto en IPT como en citotoxicidad, observándose grandes diferencias de potencia citotóxica para las cetonas y menos para oximas y combretastatinas, salvo en dicloropiridinas (las más potentes en citotoxicidad). Este patrón es más irregular para los valores de IPT, reflejando una falta de correlación entre ambos valores (IPT y citotoxicidad). La gran diferencia observada para las cetonas se debe a que éstas son muy poco activas en la serie de $p$-metoxifenilo, pero más en la serie con $N$-metilindol. Cuando el anillo de $p$-metoxifenilo conduce a compuestos más potentes, la diferencia con los que tienen anillo de $N$-metilindol es muy pequeña.

Con respecto al puente entre los dos anillos, no existen grandes diferencias en citotoxicidad para isocombretastatinas, fenstatinas y oximas, salvo en el caso de las fenstatinas e isocombretastatinas con grupo $p$-metoxifenilo, debido a la baja potencia relativa de las primeras. Nuevamente, los valores de IPT presentan una variación diferente, observándose que en general las isocombretastatinas son más potentes que las fenstatinas. Las oximas son más parecidas a las isocombretastatinas.

Para observar mejor el efecto del puente en la actividad, se han analizado las familias de compuestos en las que se tienen sintetizados todas las posibilidades en el puente (carbonilo, metileno y oxima), y se ha calculado el porcentaje de compuestos que tienen un valor de IC $\mathrm{C}_{50}$ en IPT menor de $5 \mu \mathrm{M}$ (figura izquierda), y un valor de $\mathrm{IC}_{50}$ en citotoxicidad menor de $1 \mu \mathrm{M}$ (figura derecha) en la línea celular Hela.
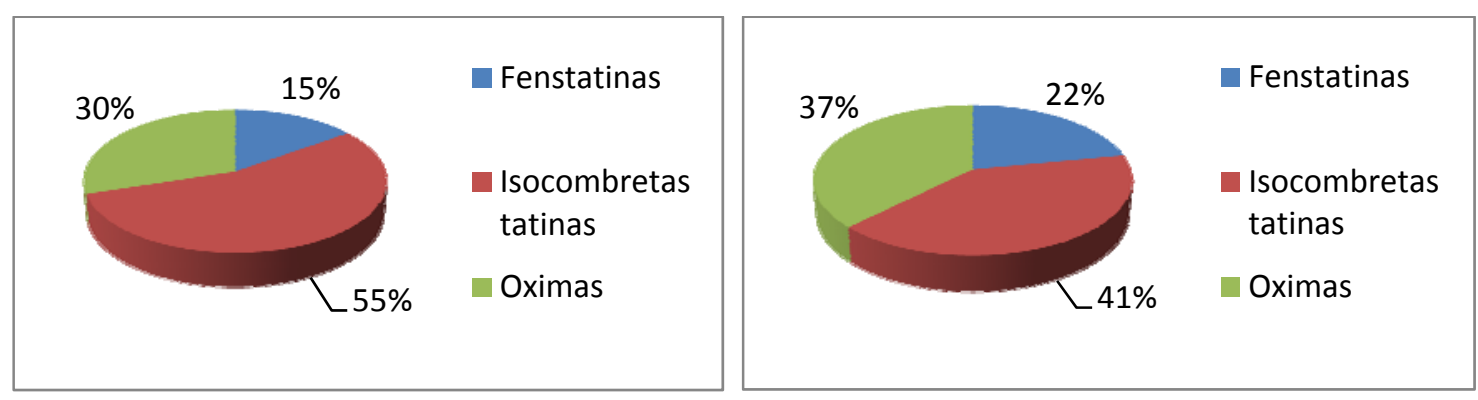

Figura 66: Representación de los porcentajes de compuestos con diferente estructura en el puente que tienen un valor de IC $\mathrm{C}_{50}$ en IPT por debajo de $5 \mu \mathrm{M}$ en IPT (izquierda) y debajo de 1 $\mu \mathrm{M}$ en citotoxicidad (derecha). 
Se observa que en ambos ensayos biológicos se repite el hecho de que los compuestos con mayor potencia son las isocombretastatinas, seguido de las oximas y por último las fenstatinas. 


\section{C.7. ENSAYO DE SOLUBILIDAD}

Como se ha visto en el planteamiento de este trabajo, los cambios estructurales que se han realizado en las moléculas tienen como objetivo aumentar la solubilidad acuosa de los derivados de combretastatina $A-4$, ya que es uno de los principales inconvenientes de este fármaco.

Por este motivo se ha determinado la solubilidad de algunos de los compuestos sintetizados. La selección se ha basado en la cantidad disponible de la molécula y las características estructurales.

El ensayo que se ha realizado consiste en medir la cantidad de fármaco que se disuelve en un tampón fosfato a pH 7 ( $\mathrm{pH}$ fisiológico) tras 48 horas en agitación continua. A continuación se filtra el tampón para eliminar el fármaco que no se ha disuelto y se determina espectrofotométricamente, a una longitud de onda determinada, la cantidad de fármaco que se ha disuelto en el tampón a partir de una recta de calibrado realizada anteriormente.

Los resultados que se han obtenido son los siguientes: 


\begin{tabular}{|c|c|c|c|c|c|c|c|c|c|c|c|c|c|}
\hline no & $x$ & $Y$ & z & Anillo B & $\mathbf{R}$ & $\begin{array}{c}S \\
(\mu \mathrm{g} / \mathrm{ml})\end{array}$ & no & $x$ & $\mathbf{Y}$ & z & Anillo B & $\mathbf{R}$ & $\begin{array}{c}S \\
(\mu \mathrm{g} / \mathrm{ml})\end{array}$ \\
\hline 25 & $\mathrm{Cl}$ & $\mathrm{Cl}$ & 0 & 4-MeO-Ph & $\mathrm{H}$ & 10,4 & 88 & $\mathrm{SMe}$ & OMe & $\mathrm{CH}_{2}$ & NMeIND & $\mathrm{COOH}$ & 151,9 \\
\hline 27 & $\mathrm{Cl}$ & $\mathrm{Cl}$ & $\mathrm{NOH}$ & 4-MeO-Ph & $\mathrm{H}$ & 29,5 & 93 & SMe & $\mathrm{OMe}$ & 0 & NMeIND & $\mathrm{CN}$ & 14,9 \\
\hline 34 & $\mathrm{Cl}$ & OMe & 0 & 4-MeO-Ph & $\mathrm{NH}_{2}$ & 56,2 & 98 & $\mathrm{SMe}$ & SMe & 0 & NMeIND & $\mathrm{CHO}$ & 230,2 \\
\hline 37 & $\mathrm{Cl}$ & MePh-NH & 0 & 4-MeO-Ph & $\mathrm{H}$ & 2,2 & 99 & SMe & SMe & $\mathrm{CH}_{2}$ & NMeIND & $\mathrm{CHO}$ & 7,6 \\
\hline 40 & $\mathrm{Cl}$ & SMe & $\mathrm{CH}_{2}$ & 4-MeO-Ph & $\mathrm{H}$ & 48,9 & 100 & SMe & SMe & $\mathrm{CH}_{2}$ & NMeIND & $\mathrm{COOH}$ & 102,7 \\
\hline 41 & $\mathrm{Cl}$ & SMe & $\mathrm{NOH}$ & 4-MeO-Ph & $\mathrm{H}$ & 41,7 & 102 & SMe & SMe & $\mathrm{CH}_{2}$ & NMeIND & $\mathrm{CN}$ & 46,3 \\
\hline 42 & $\mathrm{Cl}$ & $\mathrm{NMe}_{2}$ & 0 & 4-MeO-Ph & $\mathrm{H}$ & 10,7 & 104 & $\mathrm{SMe}$ & $\mathrm{NMe}_{2}$ & 0 & NMeIND & $\mathrm{H}$ & 8,2 \\
\hline 43 & $\mathrm{Cl}$ & $\mathrm{NMe}_{2}$ & $\mathrm{CH}_{2}$ & 4-MeO-Ph & $\mathrm{H}$ & 18,0 & 105 & SMe & $\mathrm{NMe}_{2}$ & $\mathrm{CH}_{2}$ & NMeIND & $\mathrm{H}$ & 0 \\
\hline 45 & SMe & SMe & 0 & 4-MeO-Ph & $\mathrm{H}$ & 1,5 & 108 & SMe & $\mathrm{NMe}_{2}$ & 0 & NMeIND & $\mathrm{CHO}$ & 47,6 \\
\hline 46 & $\mathrm{SMe}$ & SMe & $\mathrm{CH}_{2}$ & 4-MeO-Ph & $\mathrm{H}$ & 35,7 & 115 & SMe & $\mathrm{NMe}_{2}$ & $\mathrm{NOH}$ & NMeIND & $\mathrm{CN}$ & 5,3 \\
\hline 49 & SMe & OMe & 0 & 4-MeO-Ph & $\mathrm{H}$ & 17,0 & 123 & $\mathrm{Cl}$ & $\mathrm{NMe}_{2}$ & $\mathrm{CH}_{2}$ & NMeIND & $\mathrm{CN}$ & 6,0 \\
\hline 50 & $\mathrm{SMe}$ & OMe & $\mathrm{CH}_{2}$ & 4-MeO-Ph & $\mathrm{H}$ & 10,9 & 128 & SOMe & OMe & 0 & 2-Naft & $\mathrm{H}$ & 34,5 \\
\hline 54 & SMe & OMe & 0 & 4-MeO-Ph & $\mathrm{NH}_{2}$ & 37,3 & 132 & $\mathrm{SMe}$ & SMe & $\mathrm{CH}_{2}$ & 2-Naft & $\mathrm{H}$ & 1,9 \\
\hline 55 & SMe & $\mathrm{NMe}_{2}$ & 0 & 4-MeO-Ph & $\mathrm{H}$ & 7,4 & 134 & SMe & SMe & 0 & $3-\mathrm{NMe}_{2} \mathrm{Ph}$ & $\mathrm{H}$ & 1,3 \\
\hline 56 & $\mathrm{SMe}$ & $\mathrm{NMe}_{2}$ & $\mathrm{CH}_{2}$ & 4-MeO-Ph & $\mathrm{H}$ & 7,5 & 135 & SMe & SMe & $\mathrm{CH}_{2}$ & $3-\mathrm{NMe}_{2} \mathrm{Ph}$ & $\mathrm{H}$ & 2,4 \\
\hline 57 & SMe & $\mathrm{NMe}_{2}$ & $\mathrm{NOH}$ & 4-MeO-Ph & $\mathrm{H}$ & 4,5 & 136 & SMe & SMe & $\mathrm{NOH}$ & 3-NMe ${ }_{2} \mathrm{Ph}$ & $\mathrm{H}$ & 14,7 \\
\hline 58 & OMe & $\mathrm{NMe}_{2}$ & 0 & 4-MeO-Ph & $\mathrm{H}$ & 6,9 & 138 & SMe & OMe & $\mathrm{CH}_{2}$ & $4-\mathrm{NMe}_{2} \mathrm{Ph}$ & $\mathrm{H}$ & 43,8 \\
\hline 59 & OMe & $\mathrm{NMe}_{2}$ & $\mathrm{CH}_{2}$ & 4-MeO-Ph & $\mathrm{H}$ & 22,9 & 139 & SMe & $\mathrm{OMe}$ & $\mathrm{NOH}$ & $4-\mathrm{NMe}_{2} \mathrm{Ph}$ & $\mathrm{H}$ & 4,6 \\
\hline 73 & $\mathrm{Cl}$ & SMe & $\mathrm{CH}_{2}$ & NMeIND & $\mathrm{H}$ & 12,3 & 140 & SMe & SMe & 0 & $4-\mathrm{NMe}_{2} \mathrm{Ph}$ & $\mathrm{H}$ & 1,0 \\
\hline 74 & $\mathrm{Cl}$ & SMe & $\mathrm{NOH}$ & NMeIND & $\mathrm{H}$ & 14,8 & 142 & SMe & SMe & $\mathrm{CH}_{2}$ & $4-\mathrm{NMe}_{2} \mathrm{Ph}$ & $\mathrm{H}$ & 6,9 \\
\hline 76 & $\mathrm{Cl}$ & SMe & $\mathrm{CH}_{2}$ & NMeIND & $\mathrm{CHO}$ & 6,3 & 143 & SMe & SMe & $\mathrm{NOH}$ & $4-\mathrm{NMe}_{2} \mathrm{Ph}$ & $\mathrm{H}$ & 1,1 \\
\hline 80 & $\mathrm{Cl}$ & SMe & $\mathrm{NOH}$ & NMeIND & $\mathrm{CN}$ & 5,1 & 144 & SMe & SMe & 0 & Pyr & $\mathrm{H}$ & 47,1 \\
\hline 82 & $\mathrm{Cl}$ & SMe & $\mathrm{CH}_{2}$ & NMeIND & $\mathrm{CN}$ & 3,2 & $149 z$ & SMe & Ome & Combre & NMeIND & $\mathrm{H}$ & 19,1 \\
\hline 86 & SMe & OMe & $\mathrm{NOH}$ & NMeIND & $\mathrm{H}$ & 0 & 151 & SMe & Ome & Oxadiazo & 4-MeO-Ph & $\mathrm{H}$ & 9,8 \\
\hline 87 & $\mathrm{SMe}$ & OMe & 0 & NMeIND & $\mathrm{CHO}$ & 15,5 & 152 & SMe & Ome & Oxadiazo & NMeIND & $\mathrm{H}$ & 12,8 \\
\hline CA- $4^{61}$ & & & & & & 1 & & & & & & & \\
\hline
\end{tabular}

Tabla 19: Valores de solubilidad en un tampón NaPi 10 mM, pH=7 de los compuestos, junto a sus características estructurales

\footnotetext{
${ }^{61}$ Chen J, Wang Z, Li CM, Lu Y, Vaddady PK, Meibohm B, et al. Discovery of novel 2-aryl-4benzoyl-imidazoles targeting the colchicines binding site in tubulin as potential anticancer agents. J Med Chem, 2010, 53, 7414-7427.
} 
A la vista de los resultados obtenidos, la mayoría de los compuestos que se han ensayado tienen un valor de solubilidad mayor que el de la combretastatina A-4, siendo en algunos casos (compuestos $\mathbf{8 8}, \mathbf{9 8}, \mathbf{1 0 0}$ ) cien veces mayor. Los mejores resultados se han obtenido en los compuestos que tienen en el anillo $\mathrm{B}$ un sistema indólico con aldehídos y ácidos carboxílicos en posición 3. También se obtienen buenos resultados con anillo de p-metoxifenilo con grupo amino en posición 3 (compuestos 34 y 54). La introducción de estos grupos funcionales aumenta la solubilidad debido a la capacidad que tienen para establecer enlaces de hidrógeno con el agua. Respecto al grupo funcional en el puente entre los dos anillos, en general las oximas tienen un mayor valor de solubilidad que las fenstatinas y que las isocombretastatinas. Con respecto a los sustituyentes en posición 2 y 6 del anillo de piridina es difícil sacar un patrón, ya que hay mucha variabilidad dependiendo de los demás elementos estructurales.

Los tres compuestos con mayor solubilidad carecen de potencia citotóxica, sin embargo el cuarto compuesto con mejor solubilidad también es uno de los que tienen mayor potencia en la línea celular Hela. Se trata del compuesto 34, que tiene un valor de solubilidad de $56,2 \mu \mathrm{g} / \mathrm{ml}$ (50 veces más que CA-4) y tienen un valor de $\mathrm{IC}_{50}$ en Hela de $0,09 \mu \mathrm{M}$, por lo que se considera necesario continuar la síntesis de nuevos compuestos tomando éste como referencia. 



\section{PARTE EXPER IMMENTAL}





\section{D.1. TÉCNICAS GENERALES}

\section{D.1.1. INSTRUMENTACIÓN}

La instrumentación utilizada en cada caso es la que se cita a continuación:

Puntos de fusión: BUCHI 510, en baño de silicona y no fueron corregidos.

Espectros IR: Espectrofotómetro NICOLET Impact 410, en $\mathrm{KBr}$ al $1 \%$ ó en película. Los valores de la frecuencia de absorción se expresan en $\mathrm{cm}^{-1}$.

Espectros de RMN ${ }^{1} \mathbf{H}$ y de RMN ${ }^{13} \mathbf{C}$ : Espectrofotómetro BRUKER AC 200 (200 $\mathrm{MHz}$ ), Varian Mercury $200 \mathrm{MHz}$, Varian Mercury $400 \mathrm{MHz}$, BRUKER DRX 400 (400 $\mathrm{MHz}$ ), utilizando $\mathrm{CDCl}_{3}$ como disolvente, salvo indicación contraria, y TMS como referencia interna. Los valores de desplazamiento químico ( $\delta)$ se expresan en ppm y los de las constantes de acoplamiento $(\mathrm{J})$ en $\mathrm{Hz}$.

Espectrometría de masas (IE): Espectrómetro QSTAR XL, acoplado a un HPLC. 


\section{D.1.2. TÉCNICAS CROMATOGRÁFICAS}

Cromatografía flash. Se utilizó gel de sílice MERCK 60 (0,040-0,063 mm) en proporción 20-30 g de sílice por gramo de sustancia.

Cromatografía de capa fina. Se utilizaron láminas de poliéster prefabricadas POLYCHROM de 0,25 $\mathrm{mm}$ de espesor, con recubrimiento de gel de sílice con indicador fluorescente UV254. Para el revelado posterior se pulveriza con una disolución de ácido fosfomolíbdico al $10 \%$ en etanol, calentando a continuación a $110^{\circ} \mathrm{C}$ durante unos segundos.

HPLC. Se utilizó un equipo Agilent HP Series 1100, equipado con columnas Waters X-Terra®MS $C_{8}(5 \mu M, 4,6 \times 150 m m)$, Waters X-Terra®MS $C_{18}(5 \mu M$, $4,6 \times 150 \mathrm{~mm})$.

Cromatografía en capa fina preparativa (CCP). Se utilizaron placas PLC Silica gel $60 \mathrm{~F}_{254} \mathrm{MERCK} \circledast$ con $1 \mathrm{~mm}$ de espesor.

\section{D.1.3. TRATAMIENTO DE DISOLVENTES Y REACTIVOS}

Tolueno. El tolueno comercial se seca sobre láminas de $\mathrm{Na}$.

Cloruro de metileno. El $\mathrm{CH}_{2} \mathrm{Cl}_{2}$ comercial se seca sobre tamiz molecular.

Hexano. El hexano comercial se destila en columna de rectificación y se recoge sobre $\mathrm{CaCl}_{2}$. 
DMF seca. La DMF comercial se seca sobre tamiz molecular.

Tetrahidrofurano. EI THF comercial se destila inmediatamente antes de su uso sobre láminas de $\mathrm{Na}$, bajo atmósfera de argón, usando benzofenona como indicador. 


\section{D.2. MÉTODOS GENERALES}

\subsection{MÉTODO A. Formación de diarilcetonas}<smiles>[X]c1cc(C(=O)O)cc([Y])n1</smiles>

A una disolución del derivado bromado completamente disuelto en THF seco a $40^{\circ}$ y en atmósfera de argón, se le añade 1 equivalente de $n$ BuLi (1,6 $\mathrm{M}$ en hexano), y se deja en agitación una hora. Posteriormente se añaden 0,4 equivalentes, aproximadamente, del ácido carboxílico disuelto en THF seco y se mantiene $1 \mathrm{~h}$ más, después de la cual se deja subir la temperatura hasta $\mathrm{T}^{\mathrm{a}}$ ambiente. Pasadas $24 \mathrm{~h}$ se añade formiato de etilo, EtOAc y agua. La fase orgánica se evapora parcialmente, se lava con agua saturada con $\mathrm{NaCl}$ hasta $\mathrm{pH}$ neutro, se seca con $\mathrm{Na}_{2} \mathrm{SO}_{4}$, se filtra y se evapora a sequedad. El producto obtenido se purifica mediante cromatografía flash.

\subsection{MÉTODO B. Reacción de Wittig}

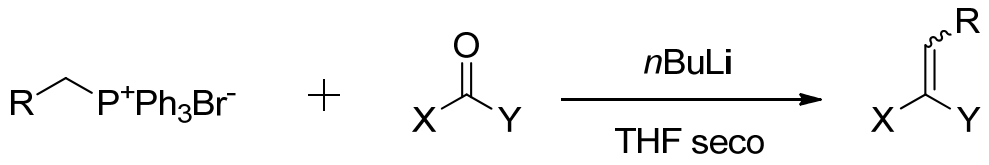

Una suspensión de la sal de fosfonio en THF seco se pone en agitación a $-40^{\circ}$ y atmósfera de argón, y se añaden 0,67 equivalentes de nBuLi (1,6 M en hexano). Se deja en agitación 1 hora y posteriormente se añaden 0,33 equivalentes del compuesto carbonílico disuelto en THF seco, y se deja que aumente la temperatura progresivamente hasta que alcance la temperatura ambiente. A las 24 horas se añade cloruro amónico y EtOAc, y la fase orgánica se evapora parcialmente. Se extrae con EtOAc, que se lava con agua saturada en $\mathrm{NaCl}$, se añade $\mathrm{Na}_{2} \mathrm{SO}_{4}$ y se filtra. El producto obtenido se purifica mediante cromatografía flash.

Para la formación de combretastatinas la reacción es la misma pero se cambian las proporciones de los reactivos: 


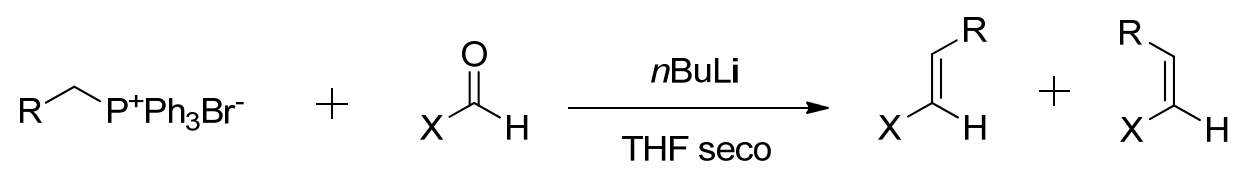

Se prepara una suspensión de la sal de fosfonio en THF seco y se añade 1,1 equivalentes de $n$ BuLi (1,6 M en hexano). Se deja en agitación 1 hora y posteriormente se añade 3 equivalentes del compuesto aldehídico, y se deja que aumente la temperatura progresivamente hasta que alcance la temperatura ambiente. Se obtienen mezclas de cis y trans que se separan mediante cromatografía en columna.

\subsection{MÉTODO C. Formación de acilhidrazonas}<smiles>COc1cc(C(=O)NN)cc(SC)n1</smiles><smiles>[3H]/C=N/NC(=O)c1cc(OC)nc(SC)c1</smiles>

Se disuelve la hidrazida en una disolución de $\mathrm{EtOH} / a g u a / \mathrm{AcOH}(25: 5: 0,2)$ y se añade 1 equivalente del aldehído y se deja $24 \mathrm{~h}$ a $90^{\circ} \mathrm{C}$. Se extrae con EtOAc, que se lava con agua saturada en $\mathrm{NaCl}$, se añade $\mathrm{Na}_{2} \mathrm{SO}_{4}$ y se filtra. El producto obtenido se purifica mediante cromatografía flash.

\subsection{MÉTODO D. Formación de 2,3-dihidro-1.3.4-oxadiazoles}<smiles>COc1cc(C(=O)N/N=C/[Al])cc(SC)n1</smiles><smiles>[Mg][Mg][Mg]</smiles><smiles>COc1cc(C2=NN(C(C)=O)C(Br)O2)cc(SC)n1</smiles>

Se disuelve la acilhidrazona en anhídrido acético y se pone a $160^{\circ} \mathrm{C}$ durante una hora. Se vierte sobre hielo y se extrae con EtOAc, lavándose con bicarbonato sódico hasta $\mathrm{pH}$ básico, y posteriormente se neutraliza con disolución saturada de $\mathrm{NaCl}$. Las 
fases orgánicas de secan con $\mathrm{Na}_{2} \mathrm{SO}_{4}$, se filtran y se evaporan a sequedad. El producto se purifica mediante cromatografía flash.

\subsection{MÉTODO E. Formación de oximas}

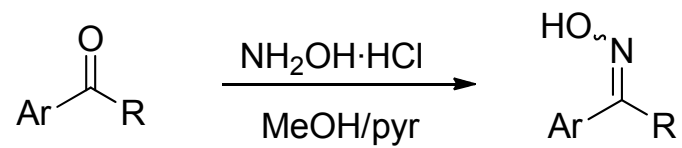

Se prepara una disolución del compuesto carbonílico en $\mathrm{MeOH}$ y se añaden 10 equivalentes de clorhidrato de hidroxilamina y 4 gotas de piridina. Se pone a reflujo durante 24 horas, se evapora el disolvente, se disuelve en $\mathrm{CH}_{2} \mathrm{Cl}_{2}$ y se lava con agua. La fase orgánica se lava con disolución saturada de $\mathrm{NaCl}$, se filtra y se evapora, obteniendo la mezcla de oximas ( $E$ y $Z$ ).

\subsection{MÉTODO F. Reacción de formilación}<smiles>[R]c1ccc2c(ccn2C)c1</smiles><smiles>[R]c1ccc2c(c1)c(C=O)cn2C</smiles>

Sobre DMF seca en tamiz molecular se añade a $0{ }^{\circ} \mathrm{C}$ el oxicloruro de fósforo $(6$ mmol por cada mmol de derivado indólico), y se mantiene en agitación durante media hora, tras la cual se adicionan el derivado indólico. Dependiendo de la naturaleza de $\mathrm{R}$, se calienta a $60^{\circ} \mathrm{C}$ durante $2-24 \mathrm{~h}$ (benzoilos), o se mantiene 2 horas a temperatura ambiente (alquenilos). Se vierte la solución resultante sobre agua con hielo y acetato sódico, y se deja precipitar en la nevera durante 24 horas. El precipitado se filtra, se redisuelve en $\mathrm{CH}_{2} \mathrm{Cl}_{2}$, se seca con $\mathrm{NaSO}_{4}$ anhidro, se filtra y se evapora a sequedad. 


\subsection{MÉTODO G. Reducción de ácidos a alcoholes}<smiles>[X]c1cc(CO)cc([Y])n1</smiles>

Se disuelve el ácido en THF seco con atmósfera de argón y sobre baño de hielo, y a continuación se añaden poco a poco 1,5 equivalentes de $\mathrm{LiAlH}_{4}$. Se deja reaccionar una hora en baño de hielo y luego se mantiene 24 horas a temperatura ambiente. Se vierte sobre EtOAc, se seca sobre $\mathrm{NaSO}_{4}$ anhidro, se filtra y se evapora a sequedad.

\subsection{MÉTODO H. Formación de bromoderivados}<smiles>[X]c1cc(CO)cc([Y])n1</smiles>

Se disuelve el alcohol correspondiente en un exceso de bromuro de hidrógeno (33\% peso en ácido acético) y se deja $24 \mathrm{~h}$ en baño de hielo. Se vierte la reacción sobre hielo, $\mathrm{NaHCO}_{3}$ y EtOAc, y se deja en agitación durante media hora. Se extrae con EtOAc y la fase orgánica se lava con disolución saturada de $\mathrm{NaCl}$, se filtra y se evapora.

\subsection{MÉTODO I. Preparación de sales de fosfonio}

$$
\mathrm{R}^{-\mathrm{Br}} \underset{\text { tolueno }}{\stackrel{\mathrm{PPh}_{3}}{\longrightarrow}} \mathrm{R}^{-\mathrm{PPh}_{3} \mathrm{Br}}
$$

Sobre una disolución del derivado bromado en tolueno seco y en agitación, se añaden 1,1 equivalentes de trifenilfosfina. Se mantiene en agitación y en atmósfera de argón durante 24-48 horas, observándose la formación de un precipitado. Si no se observa precipitado se introduce la mezcla en el congelador para favorecer la precipitación. Se filtra, obteniendo un sólido blanco. 


\subsection{MÉTODO J. Preparación de carbonitrilos}<smiles>[R]c1ccc2c(c1)c(/C=N/O)cn2C</smiles><smiles>CC(=O)OC(C)=O</smiles><smiles>[R]c1ccc2c(c1)c(C#N)cn2C</smiles>

Se disuelve la oxima en piridina y se añade un exceso de anhídrido acético. Se deja entre $24-48$ horas a $130^{\circ} \mathrm{C}$. Se vierte la reacción sobre hielo y posteriormente se extrae con $\mathrm{CH}_{2} \mathrm{Cl}_{2}$, se lava con $\mathrm{HCl} 2 \mathrm{~N}$, y posteriormente con $\mathrm{H}_{2} \mathrm{CO}_{3} 5 \%$. La fase orgánica se lava con disolución saturada de $\mathrm{NaCl}$ hasta $\mathrm{pH}$ neutro de las aguas de lavado. Se seca con $\mathrm{Na}_{2} \mathrm{SO}_{4}$, se filtra y se evapora a sequedad.

\subsection{MÉTODO K. Formación de amidas}<smiles>[R]c1ccc2[n-]ccc2c1</smiles><smiles>O=C=NS(=O)(=O)Cl</smiles>

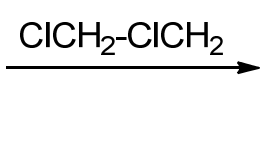<smiles>[R]c1ccc2c(c1)c(C(N)=O)cn2C</smiles>

Se disuelve el derivado indólico en 1,2-dicloroetano y se añaden 1,5 equivalentes de isocianato de clorosulfonilo. Se deja 24 horas a temperatura ambiente y se controla la reacción mediante CCF. Se vierte la reacción sobre hielo y se ajusta el $\mathrm{pH}$ a 8 añadiendo $\mathrm{NaOH} 4 \%$. Se extrae con EtOAc, se lava con agua saturada en $\mathrm{NaCl}$, se añade $\mathrm{Na}_{2} \mathrm{SO}_{4}$ y se filtra y evapora a sequedad. El producto obtenido se purifica mediante cromatografía flash en columna. 


\section{D.3. SÍNTESIS DE MATERIALES DE PARTIDA}

\section{Obtención de ácido 2,6-dicloropiridina-4-carboxílico}<smiles>O=C(O)c1cc(O)nc(Cl)c1</smiles>

Se suspenden 45,1 g de ácido citrazínico $(291 \mathrm{mmol}$ ) y $31 \mathrm{~g}$ de cloruro de tetrametilamonio $(282,8 \mathrm{mmol})$ en $\mathrm{POCl}_{3}(80 \mathrm{ml})$ y esta mezcla se calienta a $90{ }^{\circ} \mathrm{C}$ hasta la total disolución, tras lo cual, se aumenta poco a poco la $T^{\mathrm{a}}$ hasta alcanzar los $140{ }^{\circ} \mathrm{C}$ (temperatura del baño) manteniendo la agitación durante $24 \mathrm{~h}$. La mezcla se enfría hasta temperatura ambiente, se vierte sobre hielo y el contenido se deja en agitación durante dos horas. Los sólidos resultantes se filtran, se lavan con agua y se secan a vacío. El sólido se resuspende en EtOAc, se agita durante $15 \mathrm{~min}$, y se filtra para retirar el material insoluble (ácido citrazínico). La solución orgánica se seca sobre $\mathrm{Na}_{2} \mathrm{SO}_{4}$ y se evapora, obteniendo $42 \mathrm{~g}$ (218,8 mmol, 75,2 \%) de un sólido marrón pálido que corresponde al ácido 2,6-dicloropiridina-4-carboxílico.

Ácido 2,6-dicloropiridina-4-carboxílico (1):

P.f.: $203-204^{\circ} \mathrm{C}$

RMN ${ }^{1} \mathrm{H}\left(\mathrm{DMSO}^{\left.-\mathrm{D}_{6}\right)} \delta\right.$ (ppm): 7,83 (2H, s, Ar).

$\mathrm{RMN}{ }^{13} \mathrm{C}\left(\mathrm{CD}_{3} \mathrm{OD}\right) \delta(\mathrm{ppm}): 124,0(2 \mathrm{xCH}) ; 145,4$ (C); 152,2 (2xC); 165,0 (C).

IR (KBr): 1547, 1596, 1724, 2600-3300 cm-1

\section{Obtención de ácido 2-cloro-6-metoxipiridina-4-carboxílico}<smiles>COc1cc(C(=O)O)cc(Cl)n1</smiles> 
A una disolución de 10,3 g (53,6 mmol) de ácido 2,6-dicloropiridina-4-carboxílico (1) en $\mathrm{MeOH}(400 \mathrm{~mL})$, se añade una disolución de $\mathrm{MeONa} / \mathrm{MeOH}(200 \mathrm{~mL}$ ) en exceso. La mezcla se calienta a reflujo durante $24 \mathrm{~h}$. Posteriormente se enfría hasta temperatura ambiente, se añade $\mathrm{HCl}$ hasta $\mathrm{pH}$ ácido y se extrae con EtOAc lavando con $\mathrm{NaCl}$ hasta $\mathrm{pH}$ neutro. La fase orgánica se seca sobre $\mathrm{Na}_{2} \mathrm{SO}_{4}$, se filtra y evapora, obteniendo $8,1 \mathrm{~g}(43,2 \mathrm{mmol}, 81 \%)$ de producto limpio.

\section{Ácido 2-cloro-6-metoxipiridina-4-carboxílico (2):}

RMN ${ }^{1} \mathrm{H}\left(\mathrm{CD}_{3} \mathrm{OD}\right) \delta(\mathrm{ppm}): 3,83\left(3 \mathrm{H}, \mathrm{s}, \mathrm{OCH}_{3}\right) ; 7,10(1 \mathrm{H}, \mathrm{d}, \mathrm{J}=1,1 ; \mathrm{Ar}) ; 7,30(1 \mathrm{H}, \mathrm{d}$, $\mathrm{J}=1,1 ; \mathrm{Ar})$.

$\mathrm{RMN}{ }^{13} \mathrm{C}\left(\mathrm{CD}_{3} \mathrm{OD}\right) \delta(\mathrm{ppm}): 54,5\left(\mathrm{CH}_{3}\right) ; 109,4(\mathrm{CH}) ; 115,5(\mathrm{CH}) ; 144,3(\mathrm{C}) ; 148,1(\mathrm{C})$; $164,1(\mathrm{C}) ; 164,6(\mathrm{C})$.

IR (KBr): 1557, 1605, 1708, 2500-3200 $\mathrm{cm}^{-1}$

\section{Obtención de ácido 2-cloro-6-metilsulfanilpiridina-4-carboxílico}

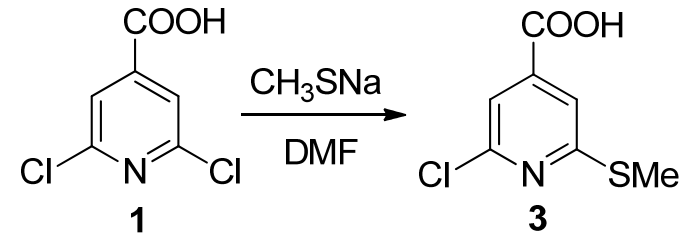

Se prepara una disolución de $7 \mathrm{~g}(36,5 \mathrm{mmol})$ de ácido 2,6-dicloropiridina-4carboxílico (1) en DMF seca $(50-100 \mathrm{~mL})$, y se añade $3,84 \mathrm{~g}(54,8 \mathrm{mmol})$ de $\mathrm{CH}_{3} \mathrm{SNa}$ y $1 \mathrm{~g} \mathrm{KOH}$, y se pone en agitación y reflujo durante 24-48 horas. Se extrae con $\mathrm{NaOH}$ hasta $\mathrm{pH}$ básico y después con $\mathrm{HCl}$ hasta $\mathrm{pH}$ ácido y EtOAc. Se lava varias veces con agua saturada de $\mathrm{NaCl}$. La fase orgánica se seca sobre $\mathrm{Na}_{2} \mathrm{SO}_{4}$ anhidro, se filtra y se evapora, obteniendo $6,71 \mathrm{~g} \mathrm{(32,9} \mathrm{mmol;} \mathrm{90,1 \% )} \mathrm{de} \mathrm{ácido} \mathrm{2-cloro-6-metilsulfanilpiridina-}$ 4-carboxílico.

Ácido 2-cloro-6-metilsulfanilpiridina-4-carboxílico (3):

$\mathrm{RMN}^{1} \mathrm{H}\left(\mathrm{CD}_{3} \mathrm{OD}\right) \delta(\mathrm{ppm}): 2,46\left(3 \mathrm{H}, \mathrm{s}, \mathrm{SCH}_{3}\right) ; 7,40(1 \mathrm{H}, \mathrm{d}, \mathrm{J}=1 \mathrm{~Hz}, \mathrm{Ar}) ; 7,54(1 \mathrm{H}, \mathrm{d}$, $\mathrm{J}=1 \mathrm{~Hz}, \mathrm{Ar})$.

$\mathrm{RMN}{ }^{13} \mathrm{C}\left(\mathrm{CD}_{3} \mathrm{OD}\right) \delta(\mathrm{ppm}): 13,7\left(\mathrm{CH}_{3}\right) ; 119,4(\mathrm{CH}) ; 120,3(\mathrm{CH}) ; 142,2(\mathrm{C}) ; 152,6(\mathrm{C})$; $163,7(\mathrm{C}) ; 166,2(\mathrm{C})$.

IR (película): 1545, 1588, 1706, $3100 \mathrm{~cm}^{-1}$ 


\section{Obtención de ácido 2,6-bis(metilsulfanil)piridina-4-carboxílico}

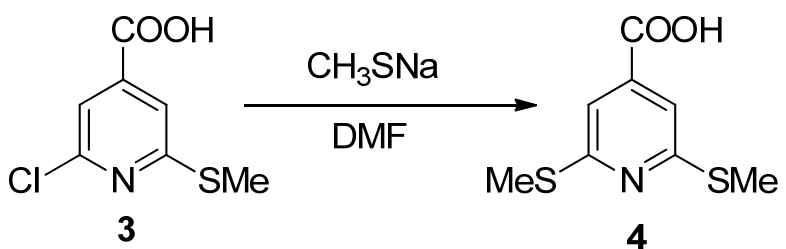

Se disuelven $390 \mathrm{mg}(1,92 \mathrm{mmol})$ de ácido 2-cloro-6-metilsulfanilpiridina-4carboxílico (3) en DMF seca (20 mL), y se añade exceso de $\mathrm{CH}_{3} \mathrm{SNa}$. Se pone a reflujo durante $72 \mathrm{~h}$. La mezcla se enfría hasta temperatura ambiente y se evapora el disolvente. El sólido se disuelve en agua y se acidifica hasta $\mathrm{pH}$ ácido con $\mathrm{HCl} 2 \mathrm{~N}$. Se hace extracción liquido-liquido con EtOAc. La fase orgánica se recupera y se seca con $\mathrm{Na}_{2} \mathrm{SO}_{4}$ anhidro, se filtra y se evapora, recuperándose $216 \mathrm{mg}(1,01 \mathrm{mmol}, 53 \%)$ de ácido 2,6-bis(metilsulfanil)piridina-4-carboxílico.

Ácido 2,6-bis(metilsulfanil)piridina-4-carboxílico (4):

$\mathrm{RMN}{ }^{1} \mathrm{H}\left(\mathrm{CD}_{3} \mathrm{OD}\right) \delta(\mathrm{ppm}): 2,48\left(6 \mathrm{H}, \mathrm{s}, \mathrm{SCH}_{3}\right) ; 7,25(2 \mathrm{H}, \mathrm{s}, \mathrm{Ar})$.

$\mathrm{RMN}{ }^{13} \mathrm{C}\left(\mathrm{CD}_{3} \mathrm{OD}\right) \delta(\mathrm{ppm}): 13,4\left(2 \mathrm{xCH}_{3}\right) ; 116,5(2 \times \mathrm{CH}) ; 139,5(\mathrm{C}) ; 162,2(2 \times \mathrm{C}) ; 167,5$ (C).

\section{Obtención de ácido 2-metilsulfanil-6-metoxipiridina-4-carboxílico}

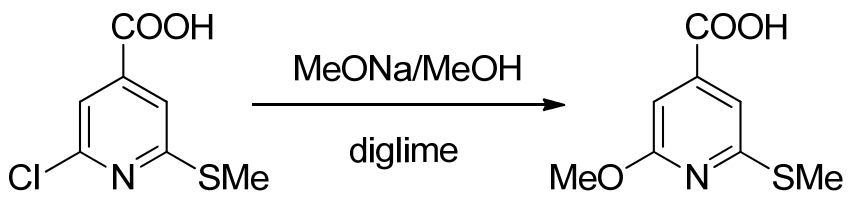

3

5

Se disuelven 5,53 g (27,2 $\mathrm{mmol})$ de ácido 2-cloro-6-metilsulfanilpiridina-4carboxílico (3) en diglime $(50-100 \mathrm{~mL})$ y se añade una mezcla saturada de $\mathrm{MeONa} / \mathrm{MeOH}$. Se pone a reflujo $24 \mathrm{~h}$ en un Dean-Stark, y se controla la reacción mediante $\mathrm{RMN}{ }^{1} \mathrm{H}$. Se va añadiendo $\mathrm{MeONa} / \mathrm{MeOH}$ según avanza la reacción. Cuando se observa la total desaparición del material de partida por $\mathrm{RMN}{ }^{1} \mathrm{H}$, se enfría la mezcla hasta temperatura ambiente y se evapora el diglime. Se extrae con $\mathrm{HCl} 2 \mathrm{~N}$ y EtOAc, y después se lava con $\mathrm{NaCl}$. La fase orgánica se seca sobre $\mathrm{Na}_{2} \mathrm{SO}_{4}$ anhidro, 
se filtra y se evapora, recuperándose $5,10 \mathrm{~g}$ (25,6 mmol, $94 \%)$ de ácido 2metilsulfanil-6-metoxipiridina-4-carboxílico, que se cristaliza en EtOAc.

Ácido 2-metilsulfanil-6-metoxipiridina-4-carboxílico (5):

P.f. (EtOAc): $178-179^{\circ} \mathrm{C}$

$\mathrm{RMN}^{1} \mathrm{H}\left(\mathrm{CD}_{3} \mathrm{OD}\right) \delta(\mathrm{ppm}): 2,47\left(3 \mathrm{H}, \mathrm{s}, \mathrm{SCH}_{3}\right) ; 3,86\left(3 \mathrm{H}, \mathrm{s}, \mathrm{OCH}_{3}\right) ; 6,81(1 \mathrm{H}, \mathrm{s}, \mathrm{Ar}) ;$ $7,16(1 \mathrm{H}, \mathrm{s}, \mathrm{Ar})$.

$\mathrm{RMN}{ }^{13} \mathrm{C}\left(\mathrm{CD}_{3} \mathrm{OD}\right) \delta(\mathrm{ppm}): 13,5\left(\mathrm{CH}_{3}\right) ; 54,3\left(\mathrm{CH}_{3}\right) ; 106,3(\mathrm{CH}) ; 113,7(\mathrm{CH}) ; 142,6(\mathrm{C})$; $160,3(\mathrm{C}) ; 165,6(\mathrm{C}) ; 167,4(\mathrm{C})$.

IR (película): 1557, 1597, 1703, $\mathrm{cm}^{-1}$

\section{Tratamiento del ácido 2-metilsulfanil-6-metoxipiridin-4-carboxílico con} metanol

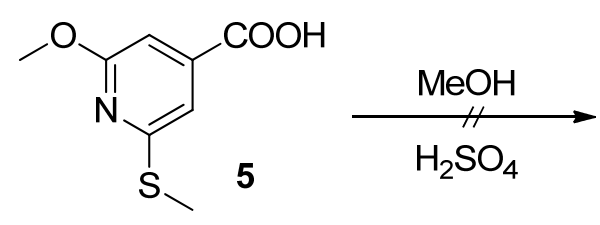<smiles>COC(=O)c1cc(OC)nc(SC)c1</smiles>

Se disuelven $5 \mathrm{~g}(25,1 \mathrm{mmol})$ de ácido 2-metilsulfanil-6-metoxipiridina-4carboxílico (5) en $\mathrm{MeOH}$ y se añaden 15 gotas de $\mathrm{H}_{2} \mathrm{SO}_{4}$ y se deja $72 \mathrm{~h}$ a Ta ambiente. Posteriormente se añade carbonato sódico anhidro, se filtra y evapora a sequedad obteniendo 4,8 g (22,5 mmol: $90 \%)$ de material de partida. 


\section{Obtención de ácido 2,6-dimetoxipiridina-4-carboxílico}<smiles>COc1cc(C(=O)O)cc(OC)n1</smiles>

Sobre una disolución de ácido 2,6-dicloropiridina-4-carboxílico (1) $(4,75$ g; 24,7 $\mathrm{mmol}$ ) en diglime, se añaden $60 \mathrm{~mL}$ de una disolución de $\mathrm{MeONa}$ en $\mathrm{MeOH}$. Esta mezcla se calienta a reflujo durante $24 \mathrm{~h}$, eliminándose el metanol mediante un Dean Stark. Posteriormente se añade una cantidad adicional de la solución de $\mathrm{MeONa} / \mathrm{MeOH}$ y se mantiene a reflujo durante 24 horas más. La mezcla se enfría hasta temperatura ambiente, se filtra y se evapora. El sólido se disuelve en agua, se acidifica con $\mathrm{HCl} 2 \mathrm{~N}$ y se extrae con EtOAc. La fase orgánica se seca sobre $\mathrm{Na}_{2} \mathrm{SO}_{4}$ anhidro, se filtra y se evapora, recuperándose 3,01 g (164 mmol, 66,4\%) de ácido 2,6dimetoxipiridina-4-carboxílico de color amarillento, que cristaliza en Hexano/EtOAc.

Ácido 2,6-dimetoxipiridina-4-carboxílico (6):

P.f. $\left(\mathrm{CH}_{2} \mathrm{Cl}_{2} / \mathrm{Hex}\right): 222-225^{\circ} \mathrm{C}$

$\mathrm{RMN}^{1} \mathrm{H}\left(\mathrm{CD}_{3} \mathrm{OD}\right) \delta(\mathrm{ppm}): 3,82\left(6 \mathrm{H}, \mathrm{s}, \mathrm{OCH}_{3}\right) ; 6,68(2 \mathrm{H}, \mathrm{s}, \mathrm{Ar})$.

$\mathrm{RMN}{ }^{13} \mathrm{C}\left(\mathrm{CD}_{3} \mathrm{OD}\right) \delta(\mathrm{ppm}): 54,1\left(2 \times \mathrm{CH}_{3}\right) ; 102,1(2 \times \mathrm{CH}) ; 145,0(\mathrm{C}) ; 165,1(2 \times \mathrm{C}) ; 167,8$ (C).

IR (película): 3354, 1704, $1619 \mathrm{~cm}^{-1}$

EM m/z (intensidad relativa, \%): $182(100), 183\left(\mathrm{M}^{+}, 85\right)$

\section{Obtención de ácido 2-(dimetilamino)-6-metoxipiridina-4-carboxílico}<smiles>COc1cc(Cl)cc(C(=O)O)n1</smiles><smiles>CCN(C)C</smiles><smiles>[3H]C(=O)c1cc(OC)nc(N(C)C)c1</smiles>

$70 \%$<smiles>CN(C)c1cc(C(=O)O)cc(N(C)C)n1</smiles>

$30 \%$ 
Se disuelven $680 \mathrm{mg}$ (3,62 mmol) de ácido 2-cloro-6-metoxipiridina-4-carboxílico (2) en una disolución de dimetilamina en $\mathrm{EtOH}$ al $33 \%(10 \mathrm{~mL})$ y se mantiene a reflujo durante $24 \mathrm{~h}$. Se obtienen $855 \mathrm{mg}$ de crudo de reacción que contiene en un $70 \%$ aproximadamente el producto esperado, y en un $30 \%$ se obtiene el producto de disustitución.

Ácido 2-(dimetilamino)-6-metoxipiridina-4-carboxílico (7):

$\mathrm{RMN}^{1} \mathrm{H}\left(\mathrm{CDCl}_{3}\right) \delta(\mathrm{ppm})$ : (Espectro $\left.7 \mathrm{H}\right) 2,68\left(6 \mathrm{H}, \mathrm{s}, \mathrm{NMe}_{2}\right) ; 3,94\left(3 \mathrm{H}, \mathrm{s}, \mathrm{OCH}_{3}\right) ; 7,12$ $(1 \mathrm{H}, \mathrm{d}, \mathrm{J}=1,0 ;$ pyr); $7,37(1 \mathrm{H}, \mathrm{d}, \mathrm{J}=1,0 ; \mathrm{pyr})$.

\section{Obtención de (2,6-bis(metilsulfanil)piridin-4-il)metanol}<smiles></smiles><smiles>CSc1cc(CO)cc(SCC(=O)O[Na])n1</smiles>

Siguiendo el método $\mathrm{G}$, se disuelven 1,098 $\mathrm{g}(5,10 \mathrm{mmol})$ de ácido 2,6bis(metilsulfanil)piridina-4-carboxílico (4) en THF seco $(50 \mathrm{~mL})$, y se añaden $290 \mathrm{mg}$ $(7,64 \mathrm{mmol})$ de $\mathrm{LiAlH}_{4}$. Se purifica mediante cromatografía flash usando como eluyente Hexano/EtOAc (9:1) y se obtienen $590,4 \mathrm{mg}(2,93 \mathrm{mmol} ; 58 \%)$ de (2,6bis(metilsulfanil)piridin-4-il)metanol.

\section{(2,6-bis(metilsulfanil)piridin-4-il)metanol (8):}

$\mathrm{RMN}^{1} \mathrm{H}\left(\mathrm{CDCl}_{3}\right) \delta$ (ppm): (Espectro $\left.8 \mathrm{H}\right) 2,57\left(6 \mathrm{H}, \mathrm{s}, \mathrm{SCH}_{3}\right) ; 4,58\left(2 \mathrm{H}, \mathrm{s}, \mathrm{CH}_{2}\right) ; 6,84$ $(2 \mathrm{H}, \mathrm{s}, \mathrm{pyr})$.

$\mathrm{RMN}{ }^{13} \mathrm{C}\left(\mathrm{CDCl}_{3}\right) \delta(\mathrm{ppm})$ : (Espectro $\left.8 \mathrm{C}\right) 13,4\left(2 \times \mathrm{CH}_{3}\right) ; 63,0\left(\mathrm{CH}_{2}\right) ; 113,8(2 \times \mathrm{CH})$; $150,3(\mathrm{C}) ; 159,5(2 \times C)$.

IR (película): 1539, 1581, $3351 \mathrm{~cm}^{-1}$ 


\section{Obtención de 4-(bromometil)-2,6-bis(metilsulfanil)piridina}

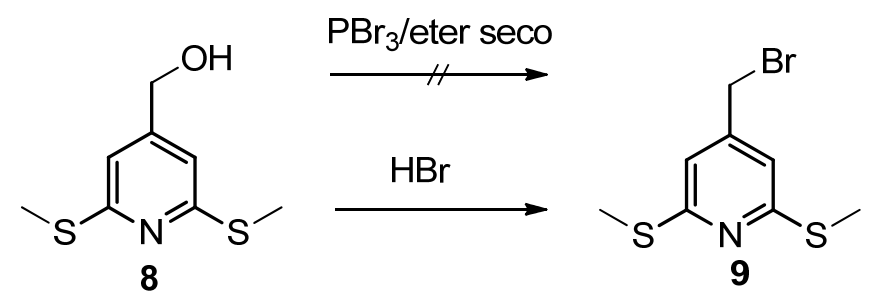

Se disuelven $584 \mathrm{mg}(2,90 \mathrm{mmol})$ de (2,6-bis(metilsulfanil)piridin-4-il)metanol (8) en éter seco $(50 \mathrm{~mL})$ a $-40^{\circ} \mathrm{C}$ y se añaden $304 \mu \mathrm{L}(3,219 \mathrm{mmol})$ de tribromuro de fósforo y se deja en agitación durante una hora. Posteriormente se vierte sobre una disolución de $\mathrm{NaHCO}_{3}$ al $5 \%$ y se extrae con EtOAc. Las fases orgánicas se lavan con agua saturada en $\mathrm{NaCl}$, se filtra y se evapora a sequedad, obteniendo $360 \mathrm{mg}(1,79$ mmol; 62\%) de material de partida sin reaccionar.

Siguiendo el método $\mathrm{H}$ se disuelven $360 \mathrm{mg}(1,79 \mathrm{mmol})$ de $(2,6-$ bis(metilsulfanil)piridin-4-il)metanol en exceso de bromuro de hidrógeno (10-20 mL) en ácido acético. Se extrae con EtOAc y la fase orgánica se lava con disolución saturada de $\mathrm{NaCl}$, se filtra y se evapora. Se obtienen $405 \mathrm{mg}(1,53 \mathrm{mmol} ; 86 \%)$ de 4(bromometil)-2,6-bis(metilsulfanil)piridina, que se utiliza sin purificar para la formación de la sal de fosfonio.

\section{4-(bromometil)-2,6-bis(metilsulfanil)piridina (9):}

$\mathrm{RMN}^{1} \mathrm{H}\left(\mathrm{CDCl}_{3}\right) \delta$ (ppm): (Espectro $\left.9 \mathrm{H}\right) 2,59\left(6 \mathrm{H}, \mathrm{s}, \mathrm{SCH}_{3}\right) ; 4,25\left(2 \mathrm{H}, \mathrm{s}, \mathrm{CH}_{2}\right) ; 6,87$ (2H, s, pyr).

RMN ${ }^{13} \mathrm{C}\left(\mathrm{CDCl}_{3}\right) \delta(\mathrm{ppm})$ : (Espectro 9C) 13,2 $\left(2 \times \mathrm{CH}_{3}\right) ; 30,5\left(\mathrm{CH}_{2}\right) ; 116,4(2 \times \mathrm{CH})$; $146,0(C) ; 156,0(2 \times C)$.

IR (película): 1431, 1540, $1581 \mathrm{~cm}^{-1}$

\section{Obtención de (2,6-bis(metilsulfanil)piridin-4-il)metiltrifenilfosfonio}<smiles>CSc1cc(CBr)cc(SC)n1</smiles> 
Se disuelven $355 \mathrm{mg}$ (1,34 mmol) de 4-(bromometil)-2,6-bis(metilsulfanil)piridina (9) en tolueno $(30 \mathrm{~mL})$ y se añaden $408 \mathrm{mg}(1,56 \mathrm{mmol})$ de trifenilfosfina siguiendo el método I. Se obtienen $323 \mathrm{mg}(0,61 \mathrm{mmol}$; 46\%) de (2,6-bis(metilsulfanil)piridin-4i)metiltrifenilfosfonio.

\section{(2,6-bis(metilsulfanil)piridin-4-il)metiltrifenilfosfonio (10):}

RMN ${ }^{1} \mathrm{H}\left(\mathrm{CDCl}_{3}\right) \delta$ (ppm): (Espectro $\left.10 \mathrm{H}\right)$ 2,39 (6H, s, $\left.\mathrm{SCH}_{3}\right) ; 5,65(2 \mathrm{H}, \mathrm{d}, \mathrm{J}=16,8$; $\left.\mathrm{CH}_{2}\right) ; 6,72(2 \mathrm{H}, \mathrm{s}, \mathrm{pyr}) ; 7,80\left(15 \mathrm{H}, \mathrm{m}, \mathrm{Ph}_{3}\right)$

IR (película): 1435, 1535, $1574 \mathrm{~cm}^{-1}$

\section{Obtención de (2-metilsulfanil-6-metoxipiridin-4-il)metanol}<smiles>COc1cc(CO)cc(SCc2nc(OC)cc(C(=O)O)n2)n1</smiles>

Siguiendo el método $\mathrm{G}$, se disuelven $1,127 \mathrm{~g}(5,66 \mathrm{mmol})$ de ácido 2metilsulfanil-6-metoxipiridina-4-carboxílico (5) en THF seco $(50 \mathrm{~mL})$, y se añaden 322 $\mathrm{mg}(8,48 \mathrm{mmol})$ de $\mathrm{LiAlH}_{4}$. Se obtienen $875 \mathrm{mg}(4,72 \mathrm{mmol} ; 83 \%)$ de (2-metilsulfanil-6metoxipiridin-4-il)metanol.

\section{(2-metilsulfanil-6-metoxipiridin-4-il)metanol (11):}

$\mathrm{RMN}^{1} \mathrm{H}\left(\mathrm{CDCl}_{3}\right) \delta(\mathrm{ppm})$ : (Espectro $\left.11 \mathrm{H}\right) 2,52\left(3 \mathrm{H}, \mathrm{s}, \mathrm{SCH}_{3}\right) ; 3,91\left(3 \mathrm{H}, \mathrm{s}, \mathrm{OCH}_{3}\right) ; 4,55$ $\left(2 \mathrm{H}, \mathrm{s}, \mathrm{CH}_{2}\right) ; 6,35(1 \mathrm{H}, \mathrm{s}, \mathrm{pyr}) ; 6,71(1 \mathrm{H}, \mathrm{s}, \mathrm{pyr})$.

$\mathrm{RMN}{ }^{13} \mathrm{C}\left(\mathrm{CDCl}_{3}\right) \delta(\mathrm{ppm})$ : (Espectro $\left.11 \mathrm{C}\right) 13,3\left(\mathrm{CH}_{3}\right) ; 53,5\left(\mathrm{CH}_{3}\right) ; 63,1\left(\mathrm{CH}_{2}\right) ; 102,3$ $(\mathrm{CH}) ; 111,0(\mathrm{CH}) ; 153,4(\mathrm{C}) ; 157,4(\mathrm{C}) ; 163,9(\mathrm{C})$.

IR (película): 1455, 1559, 1598, 3305, 3347, $3392 \mathrm{~cm}^{-1}$ 
Obtención de 4-(bromometil)-2-metilsulfanil-6-metoxipiridina<smiles>COc1cc(CO)cc(SC)n1</smiles>

11

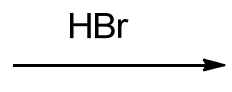<smiles>COc1cc(CBr)cc(SC)n1</smiles>

12

Se disuelven $875 \mathrm{mg}(4,72 \mathrm{mmol})$ de (2-metilsulfanil-6-metoxipiridin-4-il)metanol (11) en exceso de bromuro de hidrógeno en ácido acético $(10-20 \mathrm{~mL})$ siguiendo el método H. Se obtienen 984 mg (3,97 mmol; 84\%) de 4-(bromometil)-2-metilsulfanil-6metoxipiridina.

\section{4-(bromometil)-2-metilsulfanil-6-metoxipiridina (12):}

$\mathrm{RMN}^{1} \mathrm{H}\left(\mathrm{CDCl}_{3}\right) \delta$ (ppm): (Espectro $\left.12 \mathrm{H}\right) 2,53\left(3 \mathrm{H}, \mathrm{s}, \mathrm{SCH}_{3}\right) ; 3,92\left(3 \mathrm{H}, \mathrm{s}, \mathrm{OCH}_{3}\right) ; 4,98$ $\left(2 \mathrm{H}, \mathrm{s}, \mathrm{CH}_{2}\right) ; 6,34(1 \mathrm{H}, \mathrm{s}, \mathrm{pyr}) ; 6,70(1 \mathrm{H}, \mathrm{s}, \mathrm{pyr})$.

RMN ${ }^{13} \mathrm{C}\left(\mathrm{CDCl}_{3}\right) \delta(\mathrm{ppm})$ : (Espectro $\left.12 \mathrm{C}\right) 12,9\left(\mathrm{CH}_{3}\right) ; 53,2\left(\mathrm{CH}_{3}\right) ; 64,0\left(\mathrm{CH}_{2}\right) ; 103,3$ $(\mathrm{CH}) ; 111,5(\mathrm{CH}) ; 147,9(\mathrm{C}) ; 157,7(\mathrm{C}) ; 163,8(\mathrm{C})$.

IR (película): 1456, 1559, $1601 \mathrm{~cm}^{-1}$

Obtención de bromuro de (2-metilsulfanil-6-metoxipiridin-4-

\section{il)metiltrifenilfosfonio}<smiles>COc1cc(CBr)cc(SC)n1</smiles>

Se disuelven $985 \mathrm{mg}$ (3,97 mmol) de 4-(bromometil)-2-metilsulfanil-6metoxipiridina (12) en tolueno $(30 \mathrm{~mL})$ y se añaden $1,206 \mathrm{~g}(4,37 \mathrm{mmol}) \mathrm{de}$ trifenilfosfina siguiendo el método $\mathrm{I}$. No se produce la precipitación de la sal de fosfonio, por lo que se añaden otros $1,206 \mathrm{~g}(4,37 \mathrm{mmol})$ de trifenilfosfina. Se obtienen $375 \mathrm{mg}(0,73 \mathrm{mmol} ; 19 \%)$ de bromuro de (2-metilsulfanil-6-metoxipiridin-4i)metiltrifenilfosfonio. 
Bromuro de (2-metilsulfanil-6-metoxipiridin-4-il)metiltrifenilfosfonio (13):

$\mathrm{RMN}^{1} \mathrm{H}\left(\mathrm{CDCl}_{3}\right) \delta$ (ppm): (Espectro 13H) 2,13 (3H, s, $\left.\mathrm{SCH}_{3}\right) ; 3,78\left(3 \mathrm{H}, \mathrm{s}, \mathrm{OCH}_{3}\right) ; 5,50$ $\left(2 \mathrm{H}, \mathrm{d}, \mathrm{J}=16,2 ; \mathrm{CH}_{2}\right) ; 6,27(1 \mathrm{H}, \mathrm{s}, \mathrm{pyr}) ; 6,54(1 \mathrm{H}, \mathrm{s}, \mathrm{pyr}) ; 7,70\left(15 \mathrm{H}, \mathrm{m}, \mathrm{Ph}_{3}\right)$.

\section{Obtención de $N$-metil-1H-indol-5-carbaldehído}

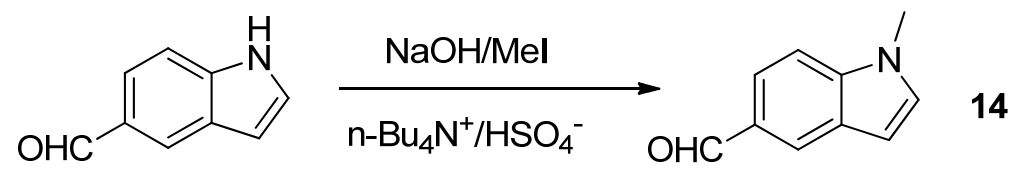

Se prepara una disolución de 1,56 g (10,8 mmol) de $1 H$-indol-5-carbaldehído en $\mathrm{CH}_{2} \mathrm{Cl}_{2}$, a la cual se añaden $0,86 \mathrm{~g}(21,6 \mathrm{mmol})$ de $\mathrm{NaOH}$ y $20 \mathrm{mg}$ de hidrogenosulfato de tetrabutilamonio y se mantiene en agitación. Después de 1 hora en agitación se añaden $2 \mathrm{~mL}(32,3 \mathrm{mmol})$ de iodometano. Se deja reaccionar $48 \mathrm{~h}$ a temperatura ambiente. El crudo de reacción se lava con una disolución saturada de $\mathrm{NaCl}$ hasta $\mathrm{pH}$ neutro. La fase orgánica, se seca sobre $\mathrm{Na}_{2} \mathrm{SO}_{4}$ anhidro, se filtra, y se evapora a vacío, obteniendo $1,60 \mathrm{~g}(93 \%)$ de $\mathrm{N}$-metil-1H-indol-5-carbaldehído.

\section{$N$-metil-1 $H$-indol-5-carbaldehído (14):}

$\mathrm{RMN}^{1} \mathrm{H}\left(\mathrm{CDCl}_{3}\right) \delta(\mathrm{ppm}): 3,76\left(3 \mathrm{H}, \mathrm{s}, \mathrm{CH}_{3}\right) ; 6,55\left(1 \mathrm{H}, \mathrm{d}, \mathrm{J}=3,3 ; \mathrm{H}_{3}\right) ; 7,10(1 \mathrm{H}, \mathrm{d}, \mathrm{J}=3,3$; $\left.\mathrm{H}_{2}\right) ; 7,41\left(1 \mathrm{H}, \mathrm{d}, \mathrm{J}=8,8 ; \mathrm{H}_{7}\right) ; 7,80\left(1 \mathrm{H}, \mathrm{dd}, \mathrm{J}=8,8 ; \mathrm{J}=1,9 ; \mathrm{H}_{6}\right) ; 8,05\left(1 \mathrm{H}, \mathrm{d}, \mathrm{J}=1,9 ; \mathrm{H}_{4}\right)$; $9,92(1 \mathrm{H}, \mathrm{s}, \mathrm{CHO})$.

$\mathrm{RMN}^{13} \mathrm{C}\left(\mathrm{CDCl}_{3}\right) \delta(\mathrm{ppm}): 32,6\left(\mathrm{CH}_{3}\right) ; 103,1(\mathrm{CH}) ; 109,8(\mathrm{CH}) ; 121,4(\mathrm{CH}) ; 126,1(\mathrm{CH}) ;$ 128,2 (C); 129,1 (C); 130,9 (CH); 139,8 (C); 192,3 (CHO).

\section{Obtención de 5-bromo- $N$-metil-1H-indol}<smiles>CO[N+]([O-])(O)O[Na]</smiles>

Se prepara una disolución de $9 \mathrm{~g}$ (45,9 mmol) de 5-bromo- $1 \mathrm{H}$-indol en $\mathrm{CH}_{2} \mathrm{Cl}_{2}$ (90 $\mathrm{mL})$, a la cual se añaden $6 \mathrm{~g}(150 \mathrm{mmol})$ de $\mathrm{NaOH}$ y 3 espátulas de hidrogeno sulfato de tetrabutilamonio y se mantiene en agitación. Después de 1 hora en agitación se añaden $3 \mathrm{~mL}(50,7 \mathrm{mmol})$ de iodometano. Se deja reaccionar $72 \mathrm{~h}$ a temperatura 
ambiente. El crudo de reacción se lava con una disolución saturada de $\mathrm{NaCl}$ hasta pH neutro. La fase orgánica, se seca sobre $\mathrm{Na}_{2} \mathrm{SO}_{4}$ anhidro, se filtra, y se evapora a vacío, obteniendo $9,21 \mathrm{~g}(43,8 \mathrm{mmol}, 95 \%)$ de 5-bromo- $N$-metil- $1 \mathrm{H}$-indol, que cristaliza en éter/hexano.

\section{5-bromo-N-metil-1H-indol (15):}

RMN ${ }^{1} \mathrm{H}\left(\mathrm{CD}_{3} \mathrm{OD}\right) \delta(\mathrm{ppm}): 3,76\left(3 \mathrm{H}, \mathrm{s}, \mathrm{CH}_{3}\right) ; 6,44\left(1 \mathrm{H}, \mathrm{da}, \mathrm{J}=2,7 ; \mathrm{H}_{3}\right) ; 7,05(1 \mathrm{H}, \mathrm{d}$, $\left.J=2,7 ; H_{2}\right) ; 7,19\left(1 \mathrm{H}, d, J=8,8 ; H_{7}\right) ; 7,29\left(1 \mathrm{H}, d d, J=8,8 ; J=1,8 ; H_{6}\right) ; 7,77(1 \mathrm{H}, d, J=1,8 ;$ $\mathrm{H}_{4}$ ).

$\operatorname{RMN}{ }^{13} \mathrm{C}\left(\mathrm{CDCl}_{3}\right) \delta(\mathrm{ppm}): 32,8\left(\mathrm{CH}_{3}\right) ; 100,8(\mathrm{CH}) ; 111,2(\mathrm{CH}) ; 112,9(\mathrm{C}) ; 123,4(\mathrm{CH}) ;$ $124,3(\mathrm{CH}) ; 130,5(\mathrm{CH}) ; 130,5(\mathrm{C}) ; 135,6(\mathrm{C})$.

IR (pelicula): $1051,793,775 \mathrm{~cm}^{-1}$

\section{Obtención de 5-bromo-1-metil-1H-indol-3 carbaldehído}<smiles>Cn1ccc2cc(Br)ccc21</smiles>

15

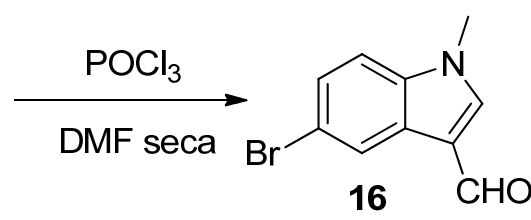

16

Se disuelven 6,83 g (32,52 mmol) de 5-bromo-1-metil-1H-indol (15) en DMF seca $(20 \mathrm{~mL})$, y se añaden $4,5 \mathrm{~mL}(48,8 \mathrm{mmol})$ de $\mathrm{POCl}_{3}$ siguiendo el método $\mathrm{F}$. Se obtienen $5,835 \mathrm{~g}(24,5 \mathrm{mmol} ; 75 \%)$ de un precipitado de 5-bromo-1-metil-1H-indol-3 carbaldehído.

\section{5-bromo-1-metil-1H-indol-3-carbaldehído (16):}

$\mathrm{RMN}^{1} \mathrm{H}\left(\mathrm{CDCl}_{3}\right) \delta$ (ppm): (Espectro 16H) 3,87 (3H, s, $\left.\mathrm{NCH}_{3}\right) ; 7,23\left(1 \mathrm{H}\right.$, da; J=8,6; $\mathrm{H}_{7}$ ); 7,46 $\left(1 \mathrm{H}, \mathrm{dd}, \mathrm{J}=2,0 ; \mathrm{J}=8,6 ; \mathrm{H}_{6}\right) ; 7,67\left(1 \mathrm{H}, \mathrm{s}, \mathrm{H}_{2}\right) ; 8,47\left(1 \mathrm{H}, \mathrm{d}, \mathrm{J}=2,0 ; \mathrm{H}_{4}\right) ; 9,96(1 \mathrm{H}, \mathrm{s}$, $\mathrm{CHO})$. 


\section{Obtención de las oximas del 5-bromo-1-metil-1H-indol-3-carbaldehído}<smiles>Cn1cc(C=O)c2cc(Br)ccc21</smiles>

16

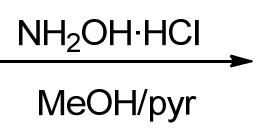

$\mathrm{MeOH} / \mathrm{pyr}$<smiles>Cn1cc(/C=N/O)c2cc(Br)ccc21</smiles>

Siguiendo el método $\mathrm{E}$, se disuelven 1,164 g (4,89 mmol) de 5-bromo-1-metil$1 \mathrm{H}$-indol-3-carbaldehído (16) en $\mathrm{MeOH}(20 \mathrm{~mL})$, y se añaden 3,8 g $(54,7 \mathrm{mmol}) \mathrm{de}$ clorhidrato de hidroxilamina. Se obtienen 1,164 g (4,60 mmol; 94\%) de mezcla de oximas, en proporción (6:4), que cristalizan en Hexano/EtOAc.

Oximas del 5-bromo-1-metil-1H-indol-3-carbaldehído (17):

P.f. ( Hex/EtOAc): $134-135^{\circ} \mathrm{C}$

$\mathrm{RMN}^{1} \mathrm{H}\left(\mathrm{CDCl}_{3}\right) \delta(\mathrm{ppm})$ : (Espectro $\left.17 \mathrm{H}\right) 3,78\left(3 \mathrm{H}, \mathrm{s}, \mathrm{NCH}_{3}\right) ; 3,84\left(3 \mathrm{H}, \mathrm{s}, \mathrm{NCH}_{3}\right) ; 7,16-$ 7-40 (m); 7,71 (1H, s); 7,89 (1H, d, J=1,6); 8,22-8,27 (m).

IR (película): 1422, 1467, 1520, $1636 \mathrm{~cm}^{-1}$

\section{Obtención de 5-bromo-1-metil-1H-indol-3-carbonitrilo}<smiles>CC(=O)OC(C)=O</smiles>

Se disuelven $136 \mathrm{mg}(0,54 \mathrm{mmol})$ de las oximas del 5-bromo-1-metil-1H-indol-3carbaldehído (17) en piridina $(10 \mathrm{~mL}$ ) y se añade $1 / 2 \mathrm{~mL}$ de anhídrido acético siguiendo el método J. Se obtiene $110 \mathrm{mg}(0,47 \mathrm{mmol} ; 87 \%)$ de 5-bromo-1-metil-1H-indol-3carbonitrilo.

\section{5-bromo-1-metil-1H-indol-3-carbonitrilo (18):}

$\mathrm{RMN}^{1} \mathrm{H}\left(\mathrm{CDCl}_{3}\right) \delta(\mathrm{ppm})$ : (Espectro $\left.18 \mathrm{H}\right) 3,84\left(3 \mathrm{H}, \mathrm{s}, \mathrm{NCH}_{3}\right) ; 7,24\left(1 \mathrm{H}\right.$, da; J=9,0; $\left.\mathrm{H}_{7}\right)$; 7,40 (1H, dd, J=2,0; J=9,0; $\left.\mathrm{H}_{6}\right) ; 7,52\left(1 \mathrm{H}, \mathrm{s}, \mathrm{H}_{2}\right) ; 7,84\left(1 \mathrm{H}, \mathrm{d}, \mathrm{J}=2,0 ; \mathrm{H}_{4}\right)$.

HRMS: Calculado (M+Na) 256,9690. Obtenido $\left(\mathrm{C}_{10} \mathrm{H}_{7} \mathrm{BrN}{ }_{2} \mathrm{Na}\right) 256,9679$. 


\section{Obtención de yoduro de metiltrifenilfosfonio}

$$
\mathrm{CH}_{3} \stackrel{\mathrm{PPh}_{3}}{\stackrel{\text { tolueno }}{\longrightarrow}} \mathrm{CH}_{19}^{\stackrel{+}{\mathrm{PPh}_{3} \mathrm{I}}}{ }^{-}
$$

Se prepara una disolución de $10 \mathrm{~mL}(169 \mathrm{mmol})$ de yoduro de metilo en tolueno seco y se añaden $10 \mathrm{~g}$ (38 mmol) de trifenilfosfina disuelta en tolueno seco. Se deja reaccionar $24 \mathrm{~h}$ a temperatura ambiente en agitación. Se forma un precipitado de color blanco, que se filtra en un Buchner obteniendo yoduro de metiltrifenilfosfonio de forma cuantitativa.

\section{Obtención de 4-bromo-1-metoxi-2-nitrobenceno}

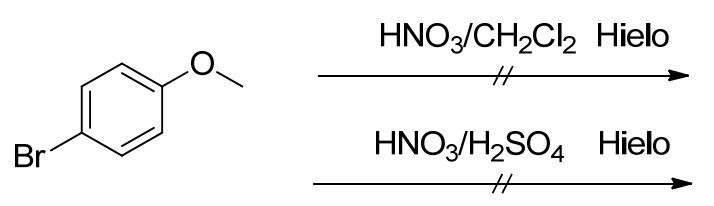<smiles>COc1ccc(Br)cc1[N+](=O)[O-]</smiles><smiles>COc1c(Br)cc(Br)cc1[N+](=O)[O-]</smiles>

Se disuelven $5 \mathrm{~g}$ (26 mmol) de 4-bromoanisol en $\mathrm{CH}_{2} \mathrm{Cl}_{2}(30 \mathrm{~mL})$ en baño de hielo y se añade poco a poco $4,6 \mathrm{~mL}(61 \mathrm{mmol})$ de $\mathrm{HNO}_{3}$ al $60 \%$ y se controla el avance de la reacción mediante CCF. No se observa avance de la reacción ni en placa ni en $\mathrm{RMN}^{1} \mathrm{H}$.

Se repite la reacción disolviendo $5 \mathrm{~g}(26 \mathrm{mmol})$ de 4-bromoanisol en $\mathrm{H}_{2} \mathrm{SO}_{4}$ (10 $\mathrm{mL}$ ) y se adiciona lentamente $2,02 \mathrm{~mL}(26 \mathrm{mmol})$ de $\mathrm{HNO}_{3}$ al $60 \%$. Se controla por placa, y cuando se ve que ha avanzado por completo se vierte la reacción sobre vaso con hielo y se filtra a vacio obteniendo un precipitado que se redisuelve con EtOAc y se añade carbonato sódico para eliminar el $\mathrm{H}_{2} \mathrm{SO}_{4}$. Se realiza extracción con EtOAc, y se lava la fase orgánica, hasta neutralidad, con una disolución saturada de $\mathrm{NaCl}$. Se seca con $\mathrm{Na}_{2} \mathrm{SO}_{4}$, se filtra y se evapora a sequedad obteniendo 5-bromo-2-metoxi-1,3nitrobenceno. 


\section{5-bromo-2-metoxi-1,3-nitrobenceno (20):}

$\mathrm{RMN}^{1} \mathrm{H}\left(\mathrm{CDCl}_{3}\right) \delta$ (ppm): (Espectro $\left.2 \mathrm{OH}\right) 4,07\left(3 \mathrm{H}, \mathrm{s}, \mathrm{OCH}_{3}\right) ; 8,17(2 \mathrm{H}, \mathrm{s}, \mathrm{Ar})$

$\mathrm{RMN}{ }^{13} \mathrm{C}\left(\mathrm{CDCl}_{3}\right) \delta$ (ppm): (Espectro 20C) 65,1 (2xCH$) ; 115,9(2 \times C) ; 127,3(\mathrm{C}) ; 132,1$ $(2 \times C H) ; 140,1(\mathrm{C})$.

\section{Obtención de 2-metilsulfanil-6-metoxipiridinacarbohidrazida}<smiles>COc1cc(C(=O)O)cc(SC)n1</smiles><smiles>NCCOC(=O)CNN</smiles><smiles>COc1cc(C(=O)NN)cc(SC)n1</smiles>

Se prepara una disolución de $2 \mathrm{~g}(13,16 \mathrm{mmol})$ de ácido 2-cloro-6-metoxipiridina4-carboxílico (5); 5,045 g (26,32 mmol) de EDCl; y $804 \mathrm{mg}(6,48 \mathrm{mmol})$ de 4-DMAP en $\mathrm{CH}_{2} \mathrm{Cl}_{2}$ y se deja en agitación durante una hora, tras la cual se adiciona sobre una disolución de $3,19 \mathrm{~mL}(65,8 \mathrm{mmol})$ de hidrazina en $\mathrm{CH}_{2} \mathrm{Cl}_{2}$ y se deja en agitación a temperatura ambiente durante $24 \mathrm{~h}$. Posteriormente se evapora el $\mathrm{CH}_{2} \mathrm{Cl}_{2}$, se disuelve en EtOAc y se extrae con $\mathrm{NaOH} 4 \%$, con $\mathrm{HCl} 2 \mathrm{~N}$ y posteriormente se neutraliza con $\mathrm{NaHCO}_{3}$ al $5 \%$. La fase orgánica se lava con agua saturada en $\mathrm{NaCl}$, se añade $\mathrm{Na}_{2} \mathrm{SO}_{4}$, se filtra y se evapora obteniendo $1,576 \mathrm{~g}(7,39 \mathrm{mmol} ; 56 \%)$ de 2-metilsulfanil6-metoxipiridinacarbohidrazida.

\section{2-metilsulfanil-6-metoxipiridinacarbohidrazida (21):}

$\mathrm{RMN}^{1} \mathrm{H}\left(\mathrm{CDCl}_{3}\right) \delta$ (ppm): (Espectro $\left.21 \mathrm{H}\right) 2.00\left(2 \mathrm{H}, \mathrm{s}, \mathrm{NH}_{2}\right) ; 2,51\left(3 \mathrm{H}, \mathrm{s}, \mathrm{SCH}_{3}\right) ; 3,90$ $\left(3 \mathrm{H}, \mathrm{s}, \mathrm{OCH}_{3}\right) ; 6,68(1 \mathrm{H}, \mathrm{d}, \mathrm{J}=1,1 ; \mathrm{pyr}) ; 7,05(1 \mathrm{H}, \mathrm{d}, \mathrm{J}=1,1 ; \mathrm{pyr}) ; 7,89\left(1 \mathrm{H}, \mathrm{s}, \mathrm{NH}_{2}\right)$.

RMN ${ }^{13} \mathrm{C}\left(\mathrm{CDCl}_{3}\right) \delta(\mathrm{ppm})$ : (Espectro 21C) 13,4 $\left(\mathrm{CH}_{3}\right) ; 53,9\left(\mathrm{CH}_{3}\right) ; 103,0(\mathrm{CH}) ; 110,9$ (CH); 142,6 (C); 159,2 (C); 164,2 (C); 166,7 (C).

IR (película): 1422, 1454, 1549, 1645, $3309 \mathrm{~cm}^{-1}$ HRMS: Calculado (M+Na) 236,0470. Obtenido $\left(\mathrm{C}_{8} \mathrm{H}_{11} \mathrm{~N}_{3} \mathrm{NaO}_{2} \mathrm{~S}\right) 236,0468$. 


\section{metoxipiridinacarbohidrazida}<smiles>COc1cc(C(=O)NN)cc(SC)n1</smiles>

Se disuelven $437 \quad \mathrm{mg} \quad(2,05 \quad \mathrm{mmol})$ de 2-metilsulfanil-6metoxipiridinacarbohidrazida (20) y $306 \quad \mathrm{mg} \quad(2,05 \quad \mathrm{mmol})$ de 4(dimetilamino)benzaldehído, en una disolución de $30 \mathrm{~mL}$ de $\mathrm{EtOH} / a g u a / A c O H$ $(25: 5: 0,2)$ siguiendo el método $C$. Se purifica mediante cromatografía flash, utilizando como eluyente Hexano/EtOAc (1:1) y se recogen $264 \mathrm{mg}(0,77 \mathrm{mmol} ; 37 \%)$ de $N^{\prime}$-(4(dimetilamino)benciliden)-2-metilsulfanil-6-metoxipiridinacarbohidrazida.

\section{$N^{\prime}$-(4-(dimetilamino)benciliden)-2-metilsulfanil-6-metoxipiridinacarbohidrazida} (22):

P.f. (Hex/EtOAc): $188-190^{\circ}$

$\mathrm{RMN}^{1} \mathrm{H}\left(\mathrm{CDCl}_{3}\right) \delta(\mathrm{ppm}):($ Espectro $22 \mathrm{H}) 2,53\left(3 \mathrm{H}, \mathrm{s}, \mathrm{SCH}_{3}\right) ; 2,98\left(6 \mathrm{H}, \mathrm{s}, \mathrm{NMe}_{2}\right) ; 3,93$ $\left(3 \mathrm{H}, \mathrm{s}, \mathrm{OCH}_{3}\right) ; 6,63(2 \mathrm{H}, \mathrm{d}, \mathrm{J}=8,6 ; \mathrm{Ar}) ; 6,79(1 \mathrm{H}, \mathrm{s}, \mathrm{pyr}) ; 7,15(1 \mathrm{H}, \mathrm{s}, \mathrm{pyr}) ; 7,57(2 \mathrm{H}, \mathrm{d}$, $\mathrm{J}=8,6 ; \mathrm{Ar}) ; 8,19(1 \mathrm{H}, \mathrm{s}, \mathrm{CH})$.

RMN ${ }^{13} \mathrm{C}\left(\mathrm{CDCl}_{3}\right) \delta(\mathrm{ppm})$ : (Espectro $\left.22 \mathrm{C}\right) 13,5\left(\mathrm{CH}_{3}\right) ; 40,4\left(2 \times \mathrm{CH}_{3}\right) ; 53,9\left(\mathrm{CH}_{3}\right) ; 103,4$ $(\mathrm{CH}) ; 111,3(\mathrm{CH}) ; 112,0(2 \times \mathrm{CH}) ; 121,3(\mathrm{C}) ; 129,6(2 \times \mathrm{CH}) ; 143,9(\mathrm{C}) ; 150,7(\mathrm{CH}) ; 151,8$ (C); 159,1 (C); 162,3 (C); 164,2 (C).

$\mathrm{IR}(\mathrm{KBr}): 1451,1529,1548,1592,1648 \mathrm{~cm}^{-1}$

HRMS: Calculado (M+Na) 367,1205. Obtenido $\left(\mathrm{C}_{17} \mathrm{H}_{20} \mathrm{~N}_{4} \mathrm{NaO}_{2} \mathrm{~S}\right) 367,1213$. 


\section{(metilsulfanil)piridinacarbohidrazida}<smiles>COc1ccc(/C=N/NC(=O)c2cc(OCCOc3ccc(C=O)cc3)nc(SC)c2)cc1</smiles>

Se disuelven $473 \mathrm{mg} \quad(2,22 \quad \mathrm{mmol})$ de 2-metilsulfanil-6metoxipiridinacarbohidrazida (20) y $0,26 \mathrm{~mL}(2,14 \mathrm{mmol})$ de anisaldehído, en una disolución de $30 \mathrm{~mL}$ de $\mathrm{EtOH} / a g u a / A c O H ~(25: 5: 0,2)$ siguiendo el método $\mathrm{C}$. Se purifica mediante cromatografía flash, utilizando como eluyente Hexano/EtOAc (1:1) y se recogen $174 \mathrm{mg}$ (0,53 mmol; $25 \%)$ de 2-metoxi- $N^{\prime}$-(4-metoxibenciliden)-6(metilsulfanil)piridinacarbohidrazida, que se cristaliza en $\mathrm{MeOH}$.

\section{2-metoxi- $N^{\prime}$-(4-metoxibenciliden)-6-(metilsulfanil)piridinacarbohidrazida (23):}

P.f. $(\mathrm{MeOH}): 175^{\circ}$

$\mathrm{RMN}^{1} \mathrm{H}\left(\mathrm{CDCl}_{3}\right) \delta(\mathrm{ppm}):($ Espectro $23 \mathrm{H}) 2,55\left(3 \mathrm{H}, \mathrm{s}, \mathrm{SCH}_{3}\right) ; 3,82\left(3 \mathrm{H}, \mathrm{s}, \mathrm{OCH}_{3}\right) ; 3,95$ $\left(3 \mathrm{H}, \mathrm{s}, \mathrm{OCH}_{3}\right) ; 6,76(1 \mathrm{H}, \mathrm{s}, \mathrm{pyr}) ; 6,87(2 \mathrm{H}, \mathrm{d}, \mathrm{J}=8,6 ; \mathrm{Ar}) ; 7,13(1 \mathrm{H}, \mathrm{s}, \mathrm{pyr}) ; 7,65(2 \mathrm{H}, \mathrm{d}$, $\mathrm{J}=8,6 ; \mathrm{Ar}) ; 8,25(1 \mathrm{H}, \mathrm{s}, \mathrm{CH})$.

RMN ${ }^{13} \mathrm{C}\left(\mathrm{CDCl}_{3}\right) \delta(\mathrm{ppm})$ : Espectro (23C) 13,4 $\left(\mathrm{CH}_{3}\right) ; 53,8\left(\mathrm{CH}_{3}\right) ; 55,3\left(\mathrm{CH}_{3}\right) ; 103,7$ (CH); 111,5 (CH); 114,1 (2xCH); 126,1 (C); 129,5 (2xCH); 143,4 (C); 150,6 (CH); 158,9 (C); 161,6 (C); 163,0 (C); 164,1 (C).

IR (KBr): 1422, 1457, 1512, 1549, 1604, $1652 \mathrm{~cm}^{-1}$

HRMS: Calculado (M+Na) 354,0888. Obtenido $\left(\mathrm{C}_{16} \mathrm{H}_{17} \mathrm{~N}_{3} \mathrm{NaO}_{3} \mathrm{~S}\right) 354,0889$. 


\section{metoxipiridinacarbohidrazida}<smiles>COc1cc(C(=O)NN)cc(SC)n1</smiles>

Se disuelven $382 \quad \mathrm{mg} \quad(1,79 \quad \mathrm{mmol})$ de 2-metilsulfanil-6metoxipiridinacarbohidrazida (20) y $285 \mathrm{mg}(1,79 \mathrm{mmol})$ de 1-metil-1H-indol-5carbaldelhído, en una disolución de $30 \mathrm{~mL}$ de $\mathrm{EtOH} / a g u a / A c O H ~(25: 5: 0,2)$ siguiendo el método $C$. Se purifica mediante cromatografía flash, utilizando como eluyente Hexano/EtOAc (1:1) y se recogen 103 mg (0,29 mmol; $16 \%)$ de 2-metilsulfanil- $N^{\prime}-((1-$ metil-1H-indol-5-il)metiliden)-6-metoxipiridinacarbohidrazida.

\section{2-metilsulfanil- $N^{\prime}$-((1-metil-1 $H$-indol-5-il)metiliden)-6-}

metoxipiridinacarbohidrazida (24):

$\mathrm{RMN}^{1} \mathrm{H}\left(\mathrm{CDCl}_{3}\right) \delta$ (ppm): (Espectro $\left.24 \mathrm{H}\right)$ 2,57 (3H, s, $\left.\mathrm{SCH}_{3}\right) ; 3,79\left(3 \mathrm{H}, \mathrm{s}, \mathrm{NCH}_{3}\right) ; 3,96$ $\left(3 \mathrm{H}, \mathrm{s}, \mathrm{OCH}_{3}\right) ; 6,50\left(1 \mathrm{H}, \mathrm{d}, \mathrm{J}=3,2, \mathrm{H}_{3}\right) ; 6,78(1 \mathrm{H}, \mathrm{s} ; \mathrm{pyr}) ; 7,06\left(1 \mathrm{H}, \mathrm{d}, \mathrm{J}=3,2, \mathrm{H}_{2}\right) ; 7,15$ $\left(1 \mathrm{H}, \mathrm{s} ;\right.$ pyr); 7,31 (1H, da, J=8,9; $\left.\mathrm{H}_{7}\right) ; 7,80\left(1 \mathrm{H}, \mathrm{da}, \mathrm{J}=8,9 ; \mathrm{H}_{6}\right) ; 7,87\left(1 \mathrm{H}, \mathrm{s} ; \mathrm{H}_{4}\right) ; 8,36$ $(1 \mathrm{H}, \mathrm{s}, \mathrm{CH})$.

RMN ${ }^{13} \mathrm{C}\left(\mathrm{CDCl}_{3}\right) \delta(\mathrm{ppm})$ : (Espectro $\left.24 \mathrm{C}\right) 13,4\left(\mathrm{CH}_{3}\right) ; 32,9\left(\mathrm{CH}_{3}\right) ; 53,9\left(\mathrm{CH}_{3}\right) ; 102,0$ $(\mathrm{CH}) ; 103,6(\mathrm{CH}) ; 109,8(\mathrm{CH}) ; 111,5(\mathrm{CH}) ; 120,5(\mathrm{CH}) ; 123,0(\mathrm{CH}) ; 125,0(\mathrm{C}) ; 128,2$ (C); 129,7 (CH); 138,0 (C); 143,7 (C); 152,3 (CH); 158,9 (C); 162,8 (C); 164,1 (C).

IR (película): 1405, 1459, $1648 \mathrm{~cm}^{-1}$

HRMS: Calculado (M+Na) 377,1048. Obtenido $\left(\mathrm{C}_{18} \mathrm{H}_{18} \mathrm{~N}_{4} \mathrm{NaO}_{2} \mathrm{~S}\right) 377,1043$. 


\section{D.4. SÍNTESIS DE COMPUESTOS CON UN ÁTOMO EN EL PUENTE}

\section{D.4.1. SÍNTESIS DE COMPUESTOS CON $p$-METOXIFENILO}

\section{Obtención de (2,6-dicloropiridin-4-il)(4-metoxifenil)metanona}<smiles>O=C(O)c1cc(Cl)nc(Cl)c1</smiles><smiles>CCCCCOc1ccc(Br)cc1</smiles><smiles>COc1ccc(C(=O)c2cc(Cl)nc(Cl)c2)cc1</smiles>

Sobre una disolución de $8,2 \mathrm{~mL}(65 \mathrm{mmol})$ de 4-bromoanisol en THF seco (20 $\mathrm{mL}$ ) se añaden $41 \mathrm{~mL}(65 \mathrm{mmol})$ de $n$ BuLi $1,6 \mathrm{M}$ en hexano siguiendo el método $A$. Posteriormente se añaden $5 \mathrm{~g}$ (26 mmol) de ácido 2,6-dicloropiridina-4-carboxílico (1) disuelto en THF seco $(20 \mathrm{~mL})$. Se purifica mediante cromatografía flash, utilizando como eluyente Hexano/EtOAc (95:5) y se recogen $1,234 \mathrm{~g}(4,4 \mathrm{mmol} ; 17 \%)$ de $(2,6-$ dicloropiridin-4-il)(4-metoxifenil)metanona.

(2,6-dicloropiridin-4-il)(4-metoxifenil)metanona (25):

$\mathrm{RMN}^{1} \mathrm{H}\left(\mathrm{CDCl}_{3}\right) \delta$ (ppm): (Espectro $\left.25 \mathrm{H}\right)$ 3,88 (3H, s, OCH $\left.\mathrm{OCH}_{3}\right) ; 6,97(2 \mathrm{H}, \mathrm{d}, \mathrm{J}=8,6 ; \mathrm{Ar})$; $7,44(2 \mathrm{H}, \mathrm{s} ; \mathrm{pyr}) ; 7,76(2 \mathrm{H}, \mathrm{d}, \mathrm{J}=8,6 ; \mathrm{Ar})$.

RMN ${ }^{13} \mathrm{C}\left(\mathrm{CDCl}_{3}\right) \delta$ (ppm): (Espectro 25C) 55,7 $\left(\mathrm{CH}_{3}\right) ; 114,3(2 \times \mathrm{CH}) ; 122,2(2 \times \mathrm{CH})$; 127,7 (C); 132,7 (2xCH); 150,7 (2xC); 151,0 (C); 164,6 (C); 190,6 (C).

IR (película): 1418, 1443, 1456, 1530, 1589, $1656 \mathrm{~cm}^{-1}$

HRMS: Calculado $(\mathrm{M}+\mathrm{H}) 282,0089$. Obtenido $\left(\mathrm{C}_{13} \mathrm{H}_{10} \mathrm{Cl}_{2} \mathrm{NO}_{2}\right) 282,0080$.

HPLC: Columna $C_{8} \quad t_{R}: 16,60 \mathrm{~min}$.

Columna $\mathrm{C}_{18} \quad \mathrm{t}_{\mathrm{R}}: 17,99 \mathrm{~min}$. 
Obtención de 2,6-dicloro-4-(1-(4-metoxifenil)vinil)piridina

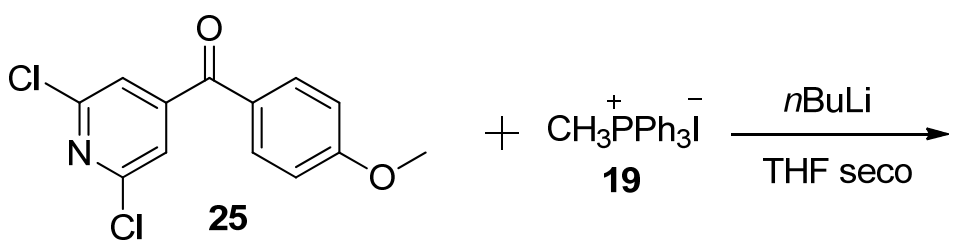<smiles>C=C(c1ccc(OC)cc1)c1cc(Cl)nc(Cl)c1</smiles>

A $266 \mathrm{mg}(0,66 \mathrm{mmol})$ de yoduro de metiltrifenilfosfonio (19) en THF seco (20 $\mathrm{mL})$ a $-40^{\circ} \mathrm{C}$ y en atmósfera de argón, se añaden $0,27 \mathrm{~mL}(0,43 \mathrm{mmol})$ de $n$ BuLi 1,6 $\mathrm{M}$ en hexano según el método $B$. Posteriormente se añaden $62 \mathrm{mg}(0,22 \mathrm{mmol})$ de $(2,6-$ dicloropiridin-4-il)(4-metoxifenil)metanona (25) disueltos en THF seco (10 mL). Se purifica mediante cromatografía flash, utilizando como eluyente Hexano/EtOAc (98:2) obteniendo $20 \mathrm{mg}(0,07 \mathrm{mmol}$; 32\%) de 2,6-dicloro-4-(1-(4-metoxifenil)vinil)piridina.

\section{2,6-dicloro-4-(1-(4-metoxifenil)vinil)piridina (26):}

RMN ${ }^{1} \mathrm{H}\left(\mathrm{CDCl}_{3}\right) \delta(\mathrm{ppm}):($ Espectro $26 \mathrm{H}) 3,85\left(3 \mathrm{H}, \mathrm{s}, \mathrm{OCH}_{3}\right) ; 5,54\left(1 \mathrm{H}, \mathrm{s} ; \mathrm{CH}_{2}\right) ; 5,60$ $\left(1 \mathrm{H}, \mathrm{s} ; \mathrm{CH}_{2}\right) ; 6,90(2 \mathrm{H}, \mathrm{d}, \mathrm{J}=8,6 ; \mathrm{Ar}) ; 7,19(2 \mathrm{H}, \mathrm{d}, \mathrm{J}=8,6 ; \mathrm{Ar}) ; 7,21(2 \mathrm{H}, \mathrm{s} ; \mathrm{pyr})$.

$\mathrm{RMN}{ }^{13} \mathrm{C}\left(\mathrm{CDCl}_{3}\right) \delta(\mathrm{ppm})$ : (Espectro $\left.26 \mathrm{C}\right) 55,4\left(\mathrm{CH}_{3}\right) ; 114,1(2 \times \mathrm{CH}) ; 117,5\left(\mathrm{CH}_{2}\right)$; 122,1 (2xCH); 129,3 (2xCH); 131,1 (C); 145,6 (C); 150,7 (2xC); 155,0 (C); 160,1 (C).

IR (película): 1418, 1459, 1519, 1578, $1606 \mathrm{~cm}^{-1}$

HRMS: Calculado $(\mathrm{M}+\mathrm{Na}) \quad 302,0115 \quad(100 \%), \quad 304,0086 \quad(63,9 \%) . \quad$ Obtenido $\left(\mathrm{C}_{14} \mathrm{H}_{11} \mathrm{Cl}_{2} \mathrm{NNaO}\right) 304,1926$.

HPLC: Columna $C_{8} \quad t_{R}: 20,15 \mathrm{~min}$.

Columna $\mathrm{C}_{18} \quad \mathrm{t}_{\mathrm{R}}: 21,53 \mathrm{~min}$.

Obtención de las oximas de (2,6-dicloropiridin-4-il)(4-

\section{metoxifenil)metanona}<smiles>COc1ccc(C(=O)c2cc(Cl)nc(Cl)c2)cc1</smiles> 
Siguiendo el método $\mathrm{E}$, se disuelven $156 \mathrm{mg}$ (0,55 mmol) de (2,6-dicloropiridin-4il)(4-metoxifenil)metanona (25) en $\mathrm{MeOH}(10 \mathrm{~mL})$ y se añaden $384 \mathrm{mg}(5,53 \mathrm{mmol})$ de clorhidrato de hidroxilamina. Se cristaliza en una mezcla de $\mathrm{Hexano} / \mathrm{CH}_{2} \mathrm{Cl}_{2}$, obteniendo $70 \mathrm{mg}(0,24 \mathrm{mmol} ; 43 \%)$ de cristales del isómero $Z$ y $61 \mathrm{mg}(0,20 ; 37 \%)$ de aguas madres con una mezcla de los dos isómeros de la oxima $(Z+E)$.

Oxima de (Z)-(2,6-dicloropiridin-4-il)(4-metoxifenil)metanona (27Z):

P.f. $\left(\mathrm{Hex} / \mathrm{CH}_{2} \mathrm{Cl}_{2}\right): 171-175^{\circ} \mathrm{C}$

$\mathrm{RMN}^{1} \mathrm{H}\left(\mathrm{CDCl}_{3}\right) \delta$ (ppm): (Espectro $\left.27 \mathrm{ZH}\right) 3,84\left(3 \mathrm{H}, \mathrm{s}, \mathrm{OCH}_{3}\right) ; 6,89(2 \mathrm{H}, \mathrm{d}, \mathrm{J}=8,9 ; \mathrm{Ar})$; $7,27(2 \mathrm{H}, \mathrm{s} ; \mathrm{pyr}) ; 7,34(2 \mathrm{H}, \mathrm{d}, \mathrm{J}=8,9 ; \mathrm{Ar})$.

RMN ${ }^{13} \mathrm{C}\left(\mathrm{CDCl}_{3}\right) \delta(\mathrm{ppm})$ : (Espectro 27ZC) 55,5 $\left(\mathrm{CH}_{3}\right) ; 114,3(2 \times \mathrm{CH}) ; 123,0(2 \times \mathrm{CH})$; 126,0 (C); 128,9 (2xCH); 146,3 (C); 150,9 (2xC); 153,5 (C); 161,5 (C).

IR (KBr): 1513, 1529, 1583, 1603, $3282 \mathrm{~cm}^{-1}$

HRMS: Calculado $(\mathrm{M}+\mathrm{H})$ 297,0198. Obtenido $\left(\mathrm{C}_{13} \mathrm{H}_{11} \mathrm{Cl}_{2} \mathrm{~N}_{2} \mathrm{O}_{2}\right) 297,0176$.

HPLC: Columna $C_{8} \quad t_{R}: 14,71$ min $t_{R}: 15,59 \min$.

Oxima de (E)-(2,6-dicloropiridin-4-il)(4-metoxifenil)metanona (27E):

$\mathrm{RMN}^{1} \mathrm{H}\left(\mathrm{CDCl}_{3}\right) \delta$ (ppm): (Espectro 27ZEH) 3,87 (3H, s, OCH $\left.\mathrm{OCH}_{3}\right) 7,01(2 \mathrm{H}, \mathrm{d}, \mathrm{J}=8,9$; Ar); 7,34 (2H, d, J=8,9; Ar). 7,35 (2H, s; pyr).

$\mathrm{RMN}{ }^{13} \mathrm{C}\left(\mathrm{CDCl}_{3}\right) \delta(\mathrm{ppm})$ : (Espectro 27ZEC) 55,5 $\left(\mathrm{CH}_{3}\right) ; 114,2(2 \times \mathrm{CH}) ; 121,5(2 \times \mathrm{CH})$; 122,0 (C); 130,9 (2xCH); 149,8 (C); 150,8 (2xC); 153,9 (C); 160,8 (C).

IR (película): 1527, 1580, 1603, $3265 \mathrm{~cm}^{-1}$

\section{Obtención de (2-cloro-6-metoxipiridin-4-il)(4-metoxifenil)metanona}<smiles>COc1cc(C(=O)O)cc(Cl)n1</smiles><smiles>COc1ccc(Br)cc1</smiles><smiles>CCCCCOC(=O)OCC</smiles><smiles>COc1ccc(C(=O)c2cc(Cl)nc(OC)c2)cc1</smiles>

Siguiendo el método A, se prepara una disolución de 11,3 $\mathrm{mL}(90,3 \mathrm{mmol})$ de 4bromoanisol en THF seco (30 mL), se añaden 56,6 mL (90,6 mmol) de $n$ BuLi 1,6 M en hexano y se deja media hora en agitación. A continuación se añaden 6,8 g (36,3 
mmol) de ácido 2-cloro-6-metoxipiridina-4-carboxílico (2) disuelto en THF seco (25 $\mathrm{mL}$ ). El producto obtenido se purifica mediante una cromatografía flash, utilizando como eluyente Hexano/EtOAc (9:1) y se recogen 5,947 g (21,4 mmol; 59\%) de (2cloro-6-metoxipiridin-4-il)(4-metoxifenil)metanona.

(2-cloro-6-metoxipiridin-4-il)(4-metoxifenil)metanona (28):

$\mathrm{RMN}^{1} \mathrm{H}\left(\mathrm{CDCl}_{3}\right) \delta$ (ppm): (Espectro $\left.28 \mathrm{H}\right)$ 3,85 (3H, s, OCH $)_{3} ; 3,95\left(3 \mathrm{H}, \mathrm{s}, \mathrm{OCH}_{3}\right) ; 6,82$ $(1 \mathrm{H}, \mathrm{d}, \mathrm{J}=1,1$; pyr); 6,92 (2H, d, J=8,9; Ar); 7,08 (1H, d, J=1,1; pyr); 7,77 (2H, d, J=8,9; Ar).

$\mathrm{RMN}{ }^{13} \mathrm{C}\left(\mathrm{CDCl}_{3}\right) \delta(\mathrm{ppm})$ : (Espectro 28C) 54,6 $\left(\mathrm{CH}_{3}\right) ; 55,7\left(\mathrm{CH}_{3}\right) ; 109,1(\mathrm{CH}) ; 114,1$ (2xCH); 115,6 (CH); 128,3 (C); 132,7 (2xCH); 149,0 (C); 150,7 (C); 164,0 (C); 164,3 (C); 192,2 (C).

IR (película): 1427, 1460, 1545, 1598, $1661 \mathrm{~cm}^{-1}$

HRMS: Calculado $(\mathrm{M}+\mathrm{H}) 278,0584$. Obtenido $\left(\mathrm{C}_{14} \mathrm{H}_{13} \mathrm{CINO}_{3}\right) 278,0606$.

HPLC: Columna $\mathrm{C}_{18} \mathrm{t}_{\mathrm{R}}: 19,34 \mathrm{~min}$.

\section{Obtención de 2-cloro-6-metoxi-4-(1-(4-metoxifenil)vinil)piridina}<smiles>C=C(c1ccc(OC)cc1)c1cc(Cl)nc(OC)c1</smiles>

A 2,15 g (5,33 mmol) de yoduro de metiltrifenilfosfonio (19) en THF seco (20-30 $\mathrm{mL})$ a $-40^{\circ} \mathrm{C}$ y en atmósfera de argón, se añaden $2,23 \mathrm{~mL}(3,57 \mathrm{mmol})$ de $n$ BuLi 1,6 M en hexano según método $B$. Posteriormente se añaden $495 \mathrm{mg}(1,78 \mathrm{mmol})$ de (2cloro-6-metoxipiridin-4-il)(4-metoxifenil)metanona (28) disueltos en THF seco (10 mL). Se purifica mediante cromatografía flash, utilizando como eluyente Hexano/EtOAc (97:3), y a $79 \mathrm{mg}$ de una mezcla de dos compuestos, se realiza una CCP con Hexano/EtOAc (9:1), y se obtienen $10 \mathrm{mg}$ (0,036 mmol; 2\%) de 2-cloro-6-metoxi-4-(1(4-metoxifenil)vinil)piridina (29), y $4 \mathrm{mg} \quad(0,015 \mathrm{mmol} ; 0,8 \%)$ del compuesto dimetoxilado (30). 
<smiles>C=C(c1ccc(OC)cc1)c1cc(OC)nc(OC)c1</smiles>

El bajo rendimiento se debe a que la sal de fosfonio se encontraba húmeda.

\section{2-cloro-6-metoxi-4-(1-(4-metoxifenil)vinil)piridina (29):}

$\mathrm{RMN}^{1} \mathrm{H}\left(\mathrm{CDCl}_{3}\right) \delta$ (ppm): (Espectro $\left.29 \mathrm{H}\right) 3,83\left(3 \mathrm{H}, \mathrm{s}, \mathrm{OCH}_{3}\right) ; 3,95\left(3 \mathrm{H}, \mathrm{s}, \mathrm{OCH}_{3}\right) ; 5,47$ $\left(1 \mathrm{H}, \mathrm{s} ; \mathrm{CH}_{2}\right) ; 5,51\left(1 \mathrm{H}, \mathrm{s} ; \mathrm{CH}_{2}\right) ; 6,60(1 \mathrm{H}, \mathrm{d}, \mathrm{J}=1,1 ; \mathrm{pyr}) ; 6,86(1 \mathrm{H}, \mathrm{d}, \mathrm{J}=1,1 ; \mathrm{pyr}) ; 6,88$ $(2 \mathrm{H}, \mathrm{d}, \mathrm{J}=8,6 ; \mathrm{Ar}) ; 7,21(2 \mathrm{H}, \mathrm{d}, \mathrm{J}=8,6 ; \mathrm{Ar})$.

$\mathrm{RMN}{ }^{13} \mathrm{C}\left(\mathrm{CDCl}_{3}\right) \delta(\mathrm{ppm})$ : (Espectro 29C) 54,1 $\left(\mathrm{CH}_{3}\right) ; 55,3\left(\mathrm{CH}_{3}\right) ; 108,3(\mathrm{CH}) ; 113,8$ (2xCH); 115,8 (CH); 115,8 $\left(\mathrm{CH}_{2}\right) ; 129,2$ (2xCH); 131,8 (C); 146,5 (C); 148,3 (C); 154,6 (C); 159,7 (C); 164,1 (C).

IR (película): 1460, 1513, 1539, $1600 \mathrm{~cm}^{-1}$

HRMS: Calculado $(\mathrm{M}+\mathrm{H}) 276,0791$. Obtenido $\left(\mathrm{C}_{15} \mathrm{H}_{15} \mathrm{CINO}_{2}\right) 276,0840$.

HPLC: Columna $\mathrm{C}_{18} \quad \mathrm{t}_{\mathrm{R}}: 22,92 \mathrm{~min}$.

\section{2,6-dimetoxi-4-(1-(4-metoxifenil)vinil)piridina (30):}

$\mathrm{RMN}^{1} \mathrm{H}\left(\mathrm{CDCl}_{3}\right) \delta(\mathrm{ppm}):($ Espectro $30 \mathrm{H}) 3,83\left(3 \mathrm{H}, \mathrm{s}, \mathrm{OCH}_{3}\right) ; 3,91\left(6 \mathrm{H}, \mathrm{s}, \mathrm{OCH}_{3}\right) ; 5,43$ $\left(1 \mathrm{H}, \mathrm{s} ; \mathrm{CH}_{2}\right) ; 5,45\left(1 \mathrm{H}, \mathrm{s} ; \mathrm{CH}_{2}\right) ; 6,27(2 \mathrm{H}, \mathrm{s} ; \mathrm{pyr}) ; 6,86(2 \mathrm{H}, \mathrm{d}, \mathrm{J}=8,6 ; \mathrm{Ar}) ; 7,24(2 \mathrm{H}, \mathrm{d}$, $\mathrm{J}=8,6 ; \mathrm{Ar})$.

$\mathrm{RMN}{ }^{13} \mathrm{C}\left(\mathrm{CDCl}_{3}\right) \delta$ (ppm): (Espectro 30C) 53,6 (2xCH$) ; 55,3\left(\mathrm{CH}_{3}\right) ; 100,7(2 \times \mathrm{CH})$; 113,6 (2xCH); 114,6 ( $\left.\mathrm{CH}_{2}\right) ; 129,2$ (2xCH); 132,5 (C); 147,6 (C); 159,2 (C); 159,5 (C); $163,2(2 \times C)$.

IR (película): 1451, 1554, $1609 \mathrm{~cm}^{-1}$

HRMS: Calculado $(\mathrm{M}+\mathrm{H}) 272,1287$. Obtenido $\left(\mathrm{C}_{16} \mathrm{H}_{18} \mathrm{NO}_{3}\right) 272,1393$.

HPLC: Columna $\mathrm{C}_{18} \mathrm{t}_{\mathrm{R}}: 22,57 \mathrm{~min}$. 
Obtención de las oximas de (2-cloro-6-metoxipiridin-4-il)(4metoxifenil)metanona<smiles>COc1ccc(C(=O)c2cc(Cl)nc(OC)c2)cc1</smiles>

Se disuelven $324 \mathrm{mg}(1,17 \mathrm{mmol})$ de (2-cloro-6-metoxipiridin-4-il)(4metoxifenil)metanona (28) en $\mathrm{MeOH}(20 \mathrm{~mL})$ y se añaden $90 \mathrm{mg}(1,30 \mathrm{mmol}) \mathrm{de}$ clorhidrato de hidroxilamina, siguiendo el método $\mathrm{E}$. Se purifica mediante cromatografía flash, utilizando como eluyente Hexano/EtOAc (7:3) obteniendo $319 \mathrm{mg}$ (1,09 mmol; 93\%) de mezcla de oximas, que cristalizan en $\mathrm{Hex} / \mathrm{CH}_{2} \mathrm{Cl}_{2}$, obteniendo cristales del isómero $E$.

Oximas de (2-cloro-6-metoxipiridin-4-il)(4-metoxifenil)metanona (31ZE):

P.f. $\left(\mathrm{Hex} / \mathrm{CH}_{2} \mathrm{Cl}_{2}\right): 113-115^{\circ}$

$\mathrm{RMN}^{1} \mathrm{H}\left(\mathrm{CDCl}_{3}\right) \delta$ (ppm): (Espectro 31EH) 3,87 (3H, s, OCH $)_{3} ; 3,93\left(3 \mathrm{H}, \mathrm{s}, \mathrm{OCH}_{3}\right)$; $6,66(1 \mathrm{H}, \mathrm{d}, \mathrm{J}=1,1 ; \mathrm{pyr}) ; 6,98(2 \mathrm{H}, \mathrm{d}, \mathrm{J}=8,6 ; \mathrm{Ar}) ; 7,08(1 \mathrm{H}, \mathrm{d}, \mathrm{J}=1,1 ; \mathrm{pyr}) ; 7,34(2 \mathrm{H}, \mathrm{d}$, $\mathrm{J}=8,6 ; \mathrm{Ar})$. Isómero $E$

RMN ${ }^{13} \mathrm{C}\left(\mathrm{CDCl}_{3}\right) \delta(\mathrm{ppm}):\left(\right.$ Espectro 31ZEC) 54,3 $\left(\mathrm{CH}_{3}\right) ; 55,5\left(\mathrm{CH}_{3}\right) ; 108,6(\mathrm{CH}) ; 109,4$ $(\mathrm{CH}) ; 113,9(2 \times \mathrm{CH}) ; 114,1(2 \times \mathrm{CH}) ; 115,0(\mathrm{CH}) ; 116,3(\mathrm{CH}) ; 122,6(\mathrm{C}) ; 128,9(\mathrm{CH})$; $131,0(2 \times C H) ; 148,7$ (C); 149,0 (C); 155,1 (C); 162,0 (C); 164,1 (C). Mezcla de isómeros $(Z+E)$.

IR (KBr): 1417, 1462, 1514, 1541, 1604, $3270 \mathrm{~cm}^{-1}$

HPLC: Columna $\mathrm{C}_{18} \mathrm{t}_{\mathrm{R}}: 17,58 \mathrm{~min}$. 


\section{Obtención de (2-cloro-6-metoxipiridin-4-il)(4-metoxi-3-nitrofenil)metanona}<smiles>COc1ccc(C(=O)c2cc(Cl)nc(OC)c2)cc1</smiles><smiles>COc1cc(C(=O)c2ccc(OC)c([N+](=O)[O-])c2)cc(Cl)n1</smiles>

a) Se disuelven $100 \mathrm{mg}(0,36 \mathrm{mmol})$ de (2-cloro-6-metoxipiridin-4-il)(4metoxifenil)metanona (28) en $\mathrm{CH}_{2} \mathrm{Cl}_{2}(10 \mathrm{~mL})$ y se añaden $0,27 \mathrm{~mL}(0,36 \mathrm{mmol})$ de $\mathrm{HNO}_{3}$ al $60 \%$ y se pone a reflujo $40^{\circ}$ sin verse avance de la reacción mediante CCF.

b) Se repite la reacción diluyendo $300 \mathrm{mg}(1,08 \mathrm{mmol})$ de (2-cloro-6-metoxipiridin4-il)(4-metoxifenil)metanona (28) en $\mathrm{H}_{2} \mathrm{SO}_{4}$ (3-5 $\mathrm{mL}$ ) en baño de hielo, y posteriormente se añaden $0,4 \mathrm{~mL}$ de una dilución 1:5 de $\mathrm{HNO}_{3}$ en $\mathrm{CH}_{2} \mathrm{Cl}_{2}(1,08$ mmol). A los 5 minutos se vierte sobre carbonato sódico anhidro y $\mathrm{CH}_{2} \mathrm{Cl}_{2}$, se filtra y se evapora a sequedad obteniendo el derivado dinitrado (33):<smiles>COc1cc(C(=O)c2cc(OC)c(OC)c([N+](=O)[O-])c2)cc(Cl)n1</smiles>

c) Se diluye $1,06 \mathrm{~g} \quad(3,82 \mathrm{mmol})$ de (2-cloro-6-metoxipiridin-4-il)(4 metoxifenil)metanona (28) en $\mathrm{H}_{2} \mathrm{SO}_{4}(5 \mathrm{~mL})$ en baño de hielo, y se añade posteriormente $1,04 \mathrm{~mL}$ de una dilución $1: 5$ de $\mathrm{HNO}_{3}$ en agua $(3,82 \mathrm{mmol})$; con las mismas condiciones descritas anteriormente obteniendo una mezcla de material de partida (28), compuesto mononitrado (32) y compuesto dinitrado (33). Esta mezcla se purifica mediante cromatografía flash, utilizando como eluyente Hexano/EtOAc (8:2) y se obtienen $677 \mathrm{mg} \mathrm{(2,10} \mathrm{mmol;55 \% )} \mathrm{de} \mathrm{(2-}$ cloro-6-metoxipiridin-4-il)(4-metoxi-3-nitrofenil)metanona (32) y $397 \mathrm{mg}$ de mezcla de material de partida (28) y compuesto dinitrado (33). Se cristaliza en EtOAc obteniendo $279 \mathrm{mg}$ de cristal. 
(2-cloro-6-metoxipiridin-4-il)(4-metoxi-3-nitrofenil)metanona (32):

P.f. (EtOAc): $100^{\circ}$

$\mathrm{RMN}^{1} \mathrm{H}\left(\mathrm{CDCl}_{3}\right) \delta(\mathrm{ppm})$ : (Espectro $\left.32 \mathrm{H}\right) 3,98\left(3 \mathrm{H}, \mathrm{s}, \mathrm{OCH}_{3}\right) ; 4,06\left(3 \mathrm{H}, \mathrm{s}, \mathrm{OCH}_{3}\right) ; 6,83$ $(1 \mathrm{H}, \mathrm{d}, \mathrm{J}=1,1 ; \mathrm{pyr}) ; 7,11(1 \mathrm{H}, \mathrm{d}, \mathrm{J}=1,1 ; \mathrm{pyr}) ; 7,20\left(1 \mathrm{H}, \mathrm{da}, \mathrm{J}=8,9 ; \mathrm{H}_{5}\right) ; 8,03(1 \mathrm{H}, \mathrm{dd}$, $\left.J=2,8 ; J=8,9 ; H_{6}\right) ; 8,27\left(1 \mathrm{H}, \mathrm{d}, \mathrm{J}=2,8 ; \mathrm{H}_{2}\right)$

$\mathrm{RMN}{ }^{13} \mathrm{C}\left(\mathrm{CDCl}_{3}\right) \delta(\mathrm{ppm})$ : (Espectro 32C) 54,6 $\left(\mathrm{CH}_{3}\right) ; 57,1\left(\mathrm{CH}_{3}\right) ; 109,0(\mathrm{CH}) ; 113,7$ $(\mathrm{CH}) ; 115,1(\mathrm{CH}) ; 127,6(\mathrm{CH}) ; 127,6(\mathrm{C}) ; 135,9(\mathrm{CH}) ; 139,2(\mathrm{C}) ; 148,9(\mathrm{C}) ; 149,2(\mathrm{C})$; 156,7 (C); 164,0 (C); 190,3 (C).

IR (KBr): 1421, 1463, 1536, 1608, $1670 \mathrm{~cm}^{-1}$

HRMS: Calculado $(\mathrm{M}+\mathrm{Na}) 345,0254$. Obtenido $\left(\mathrm{C}_{14} \mathrm{H}_{11} \mathrm{CIN}_{2} \mathrm{O}_{5} \mathrm{Na}\right) 345,0262$.

HPLC: Columna $\mathrm{C}_{18} \mathrm{t}_{\mathrm{R}}: 19,79 \mathrm{~min}$.

(2-cloro-6-metoxipiridin-4-il)(4-metoxi-3,5-dinitrofenil)metanona (33):

$\mathrm{RMN}^{1} \mathrm{H}\left(\mathrm{CDCl}_{3}\right) \delta$ (ppm): (Espectro 33H) 4,01 (3H, s, OCH $\left.\mathrm{OCH}_{3}\right) ; 4,14\left(3 \mathrm{H}, \mathrm{s}, \mathrm{OCH}_{3}\right) ; 6,85$ $(1 \mathrm{H}, \mathrm{d}, \mathrm{J}=1,1 ; \mathrm{pyr}) ; 7,14$ (1H, d, J=1,1; pyr); 8,42 (2H, s; Ar).

RMN ${ }^{13} \mathrm{C}\left(\mathrm{CDCl}_{3}\right) \delta(\mathrm{ppm})$ : (Espectro 33C) 55,7 $\left(\mathrm{CH}_{3}\right) ; 65,9\left(\mathrm{CH}_{3}\right) ; 109,9(\mathrm{CH}) ; 115,7$ $(\mathrm{CH}) ; 130,8(2 \times \mathrm{CH}) ; 130,8$ (2xC); 131,6 (C); 145,8 (C); 147,8 (C); 151,0 (C); 165,2 (C); $189,6(\mathrm{C})$.

Obtención de (3-amino-4-metoxifenil)(2-cloro-6-metoxipiridin-4-

\section{il)metanona}<smiles>COc1cc(C(=O)c2ccc(OC)c([N+](=O)[O-])c2)cc(Cl)n1</smiles>

$\underset{\mathrm{EtOH} / \mathrm{AcOH} / \mathrm{H}_{2} \mathrm{O}}{\longrightarrow}$<smiles>COc1cc(C(=O)c2ccc(OC)c(N)c2)cc(Cl)n1</smiles>

Se prepara una mezcla de $5 \mathrm{~mL}$ de etanol, ácido acético y agua en proporción 2:2:1 y se añade una gota de $\mathrm{HCl} 37 \%, 65 \mathrm{mg} \mathrm{(0,20} \mathrm{mmol)} \mathrm{de} \mathrm{(2-cloro-6-metoxipiridin-}$ 4-il)(4-metoxi-3-nitrofenil)metanona (32) y $87 \mathrm{mg}(1,56 \mathrm{mmol})$ de limaduras de Fe y se calienta a $100^{\circ} \mathrm{C}$ durante media hora. Posteriormente se enfría y se filtra a través de 
celita y se extrae con bicarbonato y $\mathrm{CH}_{2} \mathrm{Cl}_{2}$. Se lava con disolución saturada de $\mathrm{NaCl}$, se seca con sulfato sódico anhidro, se filtra y se evapora obteniendo $43 \mathrm{mg}(0,15$ mmol; 75\%) de (3-amino-4-metoxifenil)(2-cloro-6-metoxipiridin-4-il)metanona.

\section{(3-amino-4-metoxifenil)(2-cloro-6-metoxipiridin-4-il)metanona (34):}

$\mathrm{RMN}^{1} \mathrm{H}\left(\mathrm{CDCl}_{3}\right) \delta$ (ppm): (Espectro 34H) 3,93 (3H, s, OCH $)_{3} ; 3,98\left(3 \mathrm{H}, \mathrm{s}, \mathrm{OCH}_{3}\right) ; 6,80$ $\left(1 \mathrm{H}, \mathrm{da}, \mathrm{J}=8,2 ; \mathrm{H}_{5}\right): 6,85(1 \mathrm{H}, \mathrm{d}, \mathrm{J}=1,1 ; \mathrm{pyr}) ; 7,12(1 \mathrm{H}, \mathrm{d}, \mathrm{J}=1,1 ; \mathrm{pyr}) ; 7,17(1 \mathrm{H}, \mathrm{dd}$, $\left.J=2,2 ; J=8,2 ; H_{6}\right) ; 7,25\left(1 \mathrm{H}, \mathrm{d}, \mathrm{J}=2,2 ; \mathrm{H}_{2}\right)$.

$\mathrm{RMN}{ }^{13} \mathrm{C}\left(\mathrm{CDCl}_{3}\right) \delta(\mathrm{ppm})$ : (Espectro 34C) 54,5 $\left(\mathrm{CH}_{3}\right) ; 55,8\left(\mathrm{CH}_{3}\right) ; 109,1(\mathrm{CH}) ; 109,2$ $(\mathrm{CH}) ; 115,0(\mathrm{CH}) ; 115,6(\mathrm{CH}) ; 122,9(\mathrm{CH}) ; 128,5(\mathrm{C}) ; 136,8(\mathrm{C}) ; 148,7(\mathrm{C}) ; 151,0(\mathrm{C})$; 152,0 (C); 163,8 (C); 192,6 (C).

IR (KBr): 1445, 1515, 1544, 1594, 1655, 3373, $3472 \mathrm{~cm}^{-1}$

HRMS: Calculado $(\mathrm{M}+\mathrm{H})$ 293,0693. Obtenido $\left(\mathrm{C}_{14} \mathrm{H}_{14} \mathrm{CIN}_{2} \mathrm{O}_{3}\right) 293,0704$.

HPLC: Columna $\mathrm{C}_{18} \mathrm{t}_{\mathrm{R}}: 13,49 \mathrm{~min}$.

\section{Obtención} de (2-cloro-6-metoxipiridin-4-il)(3,5-diamino-4-

\section{metoxifenil)metanona}<smiles>COc1cc(C(=O)c2cc([N+](=O)[O-])c(OC)c([N+](=O)[O-])c2)cc(Cl)n1</smiles><smiles>CCOC(O)OCCO</smiles><smiles>COc1cc(C(=O)c2cc(N)c(OC)c(N)c2)cc(Cl)n1</smiles>

Se prepara una mezcla de $5 \mathrm{~mL}$ de etanol, ácido acético y agua en proporción 2:2:1 y se añade una gota de $\mathrm{HCl} 37 \%, 60 \mathrm{mg} \mathrm{(0,16} \mathrm{mmol)} \mathrm{de} \mathrm{(2-cloro-6-metoxipiridin-}$ 4-il)(4-metoxi-3,5-dinitrofenil)metanona (33) y $70 \mathrm{mg}(1,27 \mathrm{mmol})$ de Fe y se calienta a $100^{\circ} \mathrm{C}$ durante media hora. Posteriormente se enfría y se filtra a través de celita y se extrae con $\mathrm{CH}_{2} \mathrm{Cl}_{2}$, se lava con una disolución de $\mathrm{NaHCO}_{3} 5 \%$, con una disolución saturada de $\mathrm{NaCl}$, se seca con sulfato sódico anhidro, se filtra y se evapora obteniendo $50 \mathrm{mg}(0,16 \mathrm{mmol} ; 100 \%$ de (2-cloro-6-metoxipiridin-4-il)(3,5-diamino-4metoxifenil)metanona. 
(2-cloro-6-metoxipiridin-4-il)(3,5-diamino-4-metoxifenil)metanona (35):

$\mathrm{RMN}^{1} \mathrm{H}\left(\mathrm{CDCl}_{3}\right) \delta$ (ppm): (Espectro $\left.35 \mathrm{H}\right) 3,81\left(3 \mathrm{H}, \mathrm{s}, \mathrm{OCH}_{3}\right) ; 4,00\left(3 \mathrm{H}, \mathrm{s}, \mathrm{OCH}_{3}\right) ; 6,61$ $(2 \mathrm{H}, \mathrm{s} ; \mathrm{Ar}) ; 6,86(1 \mathrm{H}, \mathrm{s} ; \mathrm{pyr}) ; 7,13$ (1H, s; pyr).

\section{metoxifenil)metanona}<smiles>COc1ccc(C(=O)c2cc(Cl)nc(Cl)c2)cc1</smiles>

25<smiles>Nc1ccc(O)cc1</smiles>

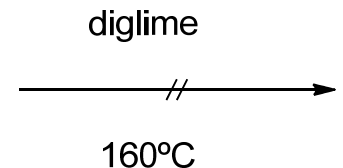

$160^{\circ} \mathrm{C}$<smiles>COc1ccc(C(=O)c2cc(Cl)nc(Nc3ccc(O)cc3)c2)cc1</smiles>

Se disuelven $417 \mathrm{mg}(1,48 \mathrm{mmol})$ de (2,6-dicloropiridin-4-il)(4metoxifenil)metanona (25), y $324 \mathrm{mg}(2,97) \mathrm{mmol})$ de $p$-aminofenol en diglime (30 mL) y se pone a reflujo durante $72 \mathrm{~h}$ a $160^{\circ} \mathrm{C}$, pero no se observa avance de la reacción.

Obtención de ácido 2-(4-hidroxifenilamino)-6-(metilsulfanil)piridina-4carboxílico<smiles>CSc1cc(C(=O)O)cc(Cl)n1</smiles><smiles>Nc1ccc(O)cc1</smiles>
3<smiles>CSc1cc(C(=O)O)cc(Nc2ccc(O)cc2)n1</smiles>

Se disuelven $118 \mathrm{mg}(0,58 \mathrm{mmol})$ de ácido 2-cloro-6-(metilsulfanil)piridina-4carboxílico (3), y $94 \mathrm{mg}(0,87 \mathrm{mmol})$ de $p$-aminofenol en DMF seca $(15 \mathrm{~mL})$ y se calienta durante $24 \mathrm{~h}$ a $120^{\circ} \mathrm{C}$ aproximadamente. Se observa cambio en CCF, pero se obtiene una mezcla compleja difícil de caracterizar. 


\section{metoxifenil)metanona}<smiles>COc1ccc(C(=O)c2cc(Cl)nc(OC)c2)cc1</smiles>

28<smiles>Nc1ccc(O)cc1</smiles>

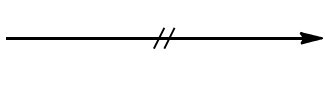<smiles>COc1ccc(C(=O)c2cc(Nc3ccc(O)cc3)nc(OC)c2)cc1</smiles>

Se disuelven $150 \mathrm{mg} \quad(0,54 \mathrm{mmol})$ de (2-cloro-6-metoxipiridin-4-il)(4metoxifenil)metanona (28) y $118 \mathrm{mg}(1,08) \mathrm{mmol})$ de $p$-aminofenol en DMF seca $(15$ $\mathrm{mL}$ ), se añaden $5 \mathrm{~mL}$ de piridina y se pone a reflujo durante $24 \mathrm{~h}$ a $100^{\circ} \mathrm{C}$, pero no se observa avance de la reacción. Se repite añadiendo carbonato sódico anhidro y cambiando la DMF seca por diglime y se aumenta la $\mathrm{T}^{\mathrm{a}}$ hasta $190^{\circ} \mathrm{C}$ durante $24 \mathrm{~h}$, no observándose avance de la reacción.

Se repite la reacción añadiendo $49 \mathrm{mg}$ de $\mathrm{NaH}(2,01 \mathrm{mmol})$ sobre $110 \mathrm{mg}$ (1 mmol) de $p$-aminofenol en THF seco sobre baño de hielo durante media hora aproximadamente, y a continuación 100 mg (0,36 mmol) de (2-cloro-6-metoxipiridin-4il)(4-metoxifenil)metanona en THF seco (28) y se deja $24 \mathrm{~h}$ en baño de hielo. Se vierte sobre $\mathrm{NH}_{4} \mathrm{Cl}$ y se extrae con agua/EtOAc, no observándose avance de la reacción por RMN ${ }^{1} \mathrm{H}$.

\section{metoxifenil)metanona}<smiles>COc1ccc(C(=O)c2cc(Nc3ccc(C)cc3)nc(OC)c2)cc1</smiles>

Se disuelven $805 \mathrm{mg} \quad(2,90 \mathrm{mmol})$ de (2-cloro-6-metoxipiridin-4-il)(4metoxifenil)metanona (28); $311 \mathrm{mg}(2,90 \mathrm{mmol})$ de $p$-toluidina; $6,5 \mathrm{mg}(0,03 \mathrm{mmol}) \mathrm{de}$ $\mathrm{Pd}(\mathrm{OAc})_{2} ; 28 \mathrm{mg}(0,06 \mathrm{mmol})$ de XPhos; 0,2 mL (1,45 mmol) de $\mathrm{Et}_{3} \mathrm{~N}$ y $456 \mathrm{mg}(4,06$ 
mmol) de $t$-BuONa en tolueno $(20-30 \mathrm{~mL})$, y se calienta a $90^{\circ} \mathrm{C}$ durante 4 horas. Posteriormente se extrae con agua y $\mathrm{CH}_{2} \mathrm{Cl}_{2}$, se añade sulfato sódico anhidro, se filtra y se evapora. No se observa avance de la reacción.

\section{Obtención de (2-cloro-6-(fenilamino)piridin-4-il)(4-metoxifenil)metanona}<smiles>COc1ccc(C(=O)c2cc(Cl)nc(Cl)c2)cc1</smiles>

25<smiles>Nc1ccccc1</smiles>

$\mathrm{Pd}(\mathrm{OAc})_{2} / \mathrm{XPhos} / \mathrm{t}-\mathrm{BuONa}$

$\mathrm{Et}_{3} \mathrm{~N} /$ tolueno<smiles>COc1ccc(C(=O)c2cc(Cl)nc(Nc3ccccc3)c2)cc1</smiles>

36

Se disuelven $100 \mathrm{mg} \quad(0,35 \mathrm{mmol})$ de (2,6-dicloropiridin-4-il)(4metoxifenil)metanona (25); 0,033 $\mathrm{mL}(0,35 \mathrm{mmol})$ de anilina; 0,785 $\mathrm{mg}(3,5 \mu \mathrm{mol}) \mathrm{de}$ $\mathrm{Pd}(\mathrm{OAc})_{2} ; 3,33 \mathrm{mg}(7 \mu \mathrm{mol})$ de XPhos; $0,0102 \mathrm{~mL}(0,14 \mathrm{mmol}) \mathrm{de}^{\mathrm{Et}} \mathrm{Et}_{3} \mathrm{~N}$ y $54,98 \mathrm{mg}$ $(0,49 \mathrm{mmol})$ de $t$-BuONa en tolueno $(10-20 \mathrm{~mL})$, y se calienta a $90^{\circ} \mathrm{C}$ durante 4 horas. Posteriormente se extrae con agua y $\mathrm{CH}_{2} \mathrm{Cl}_{2}$, se añade sulfato sódico anhidro, se filtra y se evapora. Se purifica mediante cromatografía flash, utilizando como eluyente Hexano/EtOAc (9:1) y se recogen 14 mg (0,041mmol; 12\%) de (2-cloro-6(fenilamino)piridin-4-il)(4-metoxifenil)metanona.

\section{(2-cloro-6-(fenilamino)piridin-4-il)(4-metoxifenil)metanona (36):}

$\mathrm{RMN}^{1} \mathrm{H}\left(\mathrm{CDCl}_{3}\right) \delta(\mathrm{ppm})$ : (Espectro $\left.36 \mathrm{H}\right) 3,89\left(3 \mathrm{H}, \mathrm{s}, \mathrm{OCH}_{3}\right) ; 6,90(1 \mathrm{H}, \mathrm{s} ; \mathrm{pyr}) ; 6,92$ $\left(1 \mathrm{H}, \mathrm{s} ;\right.$ pyr); 6,96 (2H, d, J=8,9; $\left.\operatorname{Ar}_{1}\right) ; 7,00-7,20\left(1 \mathrm{H}, \mathrm{m}, \mathrm{Ar}_{2}\right) ; 7,32\left(4 \mathrm{H}, \mathrm{s}, \mathrm{Ar}_{2}\right) ; 7,82(2 \mathrm{H}$, $\left.\mathrm{d}, \mathrm{J}=8,9 ; \mathrm{Ar}_{1}\right)$.

$\mathrm{RMN}{ }^{13} \mathrm{C}\left(\mathrm{CDCl}_{3}\right) \delta(\mathrm{ppm})$ : (Espectro 36C) 55,6 $\left(\mathrm{CH}_{3}\right) ; 105,3(\mathrm{CH}) ; 113,2(\mathrm{CH}) ; 114,0$ (2xCH); 121,3 (2xCH); 124,3 (CH); 128,2 (C); 129,5 (2xCH); 132,6 (2xCH); 138,7 (C); 149,6 (C); 150,2 (C); 156,2 (C); 164,2 (C); 192,5 (C).

IR (película): 1435, 1518, 1551, 1596, 1654, $3361 \mathrm{~cm}^{-1}$

HRMS: Calculado $(\mathrm{M}+\mathrm{H}) 339,0900$. Obtenido $\left(\mathrm{C}_{19} \mathrm{H}_{16} \mathrm{ClN}_{2} \mathrm{O}_{2}\right) 339,0892$.

HPLC: Columna $\mathrm{C}_{18} \mathrm{t}_{\mathrm{R}}: 22,45 \mathrm{~min}$. 


\section{metoxifenil)metanona}<smiles>COc1ccc(C(=O)c2cc(Cl)nc(Cl)c2)cc1</smiles>

25

\section{$\mathrm{Pd}(\mathrm{OAc})_{2} / \mathrm{XPhos} / \mathrm{t}-\mathrm{BuOK}$ $\mathrm{Et}_{3} \mathrm{~N} /$ tolueno}<smiles>COc1ccc(C(=O)c2cc(Cl)nc(Nc3ccc(C)cc3)c2)cc1</smiles>

37

Se disuelven $629 \mathrm{mg}(2,23 \mathrm{mmol})$ de (2,6-dicloropiridin-4-il)(4metoxifenil)metanona (25); $239 \mathrm{mg}(2,23 \mathrm{mmol})$ de $p$-toluidina; 5,006 mg (22 $\mu \mathrm{mol}) \mathrm{de}$ $\mathrm{Pd}(\mathrm{OAc})_{2} ; 21 \mathrm{mg}(44,6 \mu \mathrm{mol})$ de XPhos; 0,156 mL (1,115 mmol) de $^{2} \mathrm{Et}_{3} \mathrm{~N}$ y $350 \mathrm{mg}$ $(3,12 \mathrm{mmol})$ de $t$-BuOK en tolueno $(10-20 \mathrm{~mL})$, y se pone a $100^{\circ} \mathrm{C}$ durante 5 horas. Posteriormente se extrae con agua, $\mathrm{CH}_{2} \mathrm{Cl}_{2}$ y $\mathrm{HCl}$ y se neutraliza con $\mathrm{NaOH}$. La fase orgánica se seca con sulfato sódico anhidro, se filtra y se evapora. Se purifica mediante cromatografía flash, utilizando como eluyente Hexano/EtOAc (9:1) y se recogen $104 \mathrm{mg}(0,30 \mathrm{mmol} ; 13 \%)$ de (2-cloro-6-( $p$-toluidinamino)piridin-4-il)(4metoxifenil)metanona.

\section{(2-cloro-6-(p-toluidinamino)piridin-4-il)(4-metoxifenil)metanona (37):}

$\mathrm{RMN}^{1} \mathrm{H}\left(\mathrm{CDCl}_{3}\right) \delta(\mathrm{ppm})$ : (Espectro $\left.37 \mathrm{H}\right)$ 2,32 $\left(3 \mathrm{H}, \mathrm{s}, \mathrm{CH}_{3}\right) ; 3,89\left(3 \mathrm{H}, \mathrm{s}, \mathrm{OCH}_{3}\right) ; 6,86$ $(1 \mathrm{H}, \mathrm{s} ; \mathrm{pyr}) ; 6,87(1 \mathrm{H}, \mathrm{s} ; \mathrm{pyr}) ; 6,96\left(2 \mathrm{H}, \mathrm{d}, \mathrm{J}=8,6 ; \mathrm{Ar}_{1}\right) ; 7,14\left(2 \mathrm{H}, \mathrm{d}, \mathrm{J}=8,6 ; \mathrm{Ar}_{2}\right) ; 7,20$ $\left(2 \mathrm{H}, \mathrm{d}, \mathrm{J}=8,6 ; \mathrm{Ar}_{2}\right) ; 7,83\left(2 \mathrm{H}, \mathrm{d}, \mathrm{J}=8,6 ; \mathrm{Ar}_{1}\right)$.

$\mathrm{RMN}{ }^{13} \mathrm{C}\left(\mathrm{CDCl}_{3}\right) \delta(\mathrm{ppm})$ : (Espectro 37C) 20,9 $\left(\mathrm{CH}_{3}\right) ; 55,7\left(\mathrm{CH}_{3}\right) ; 104,9(\mathrm{CH}) ; 112,8$ (CH); 114,0 (2xCH); 122,0 (2xCH); 128,4 (C); 130,1 (2xCH); 132,7 (2xCH); 134,3 (C); 136,3 (C); 150,1 (2xC); 156,9 (C); 164,2 (C); 192,9 (C).

IR (película): 1414, 1515, 1550, 1599, 1652, $3369 \mathrm{~cm}^{-1}$

HRMS: Calculado (M+Na) 375,0876. Obtenido $\left(\mathrm{C}_{20} \mathrm{H}_{17} \mathrm{ClN}_{2} \mathrm{NaO}_{2}\right) 375,0883$.

HPLC: Columna $C_{8} \quad t_{R}: 20,33 \mathrm{~min}$. 


\section{Obtención de (2-cloro-6-(metilsulfanil)piridin-4-il)(4-metoxifenil)metanona}<smiles>CSc1cc(C(=O)O)cc(Cl)n1</smiles><smiles>CCCCCOc1ccc(Br)cc1</smiles><smiles>COc1ccc(C(=O)c2cc(Cl)nc(SC)c2)cc1</smiles>

Sobre una disolución de 2,33 $\mathrm{mL}(18,4 \mathrm{mmol})$ de 4-bromoanisol en THF seco (20-30 mL) se añaden $11,5 \mathrm{~mL}(18,4 \mathrm{mmol})$ de $n$ BuLi 1,6 $\mathrm{M}$ en hexano siguiendo el método A. Posteriormente se añade $1,5 \mathrm{~g}(7,37 \mathrm{mmol})$ de ácido 2-cloro-6metilsulfanilpiridina-4-carboxílico (3) disuelto en THF seco $(20 \mathrm{~mL})$. Se purifica mediante cromatografía flash, utilizando como eluyente Hexano/EtOAc (95:5) y se obtienen 509 mg (1,73 mmol; 24\%) de (2-cloro-6-(metilsulfanil)piridin-4-il)(4metoxifenil)metanona y 864 mg $(2,35 \mathrm{mmol} ; 32 \%) \mathrm{mg}$ de 3-(2-cloro-6(metilsulfanil)piridin-4-il)-3-hidroxi-3-(4-metoxifenil)propanoato de etilo (39).<smiles>CCOC(=O)CC(O)(c1ccc(OC)cc1)c1cc(Cl)nc(SC)c1</smiles>

\section{(2-cloro-6-(metilsulfanil)piridin-4-il)(4-metoxifenil)metanona (38)}

$\mathrm{RMN}^{1} \mathrm{H}\left(\mathrm{CDCl}_{3}\right) \delta(\mathrm{ppm}):($ Espectro $38 \mathrm{H}) 2,55\left(3 \mathrm{H}, \mathrm{s}, \mathrm{SCH}_{3}\right) ; 3,88\left(3 \mathrm{H}, \mathrm{s}, \mathrm{OCH}_{3}\right) ; 6,95$ $(2 \mathrm{H}, \mathrm{d}, \mathrm{J}=8,9 ; \mathrm{Ar}) ; 7,16(1 \mathrm{H}, \mathrm{d}, \mathrm{J}=0,7 ; \mathrm{pyr}) ; 7,26(1 \mathrm{H}, \mathrm{d}, \mathrm{J}=0,7 ; \operatorname{pyr}) ; 7,77$ (2H, d, J=8,6; Ar).

RMN ${ }^{13} \mathrm{C}\left(\mathrm{CDCl}_{3}\right) \delta$ (ppm): (Espectro 38C) 13,6 $\left(\mathrm{CH}_{3}\right) ; 55,7\left(\mathrm{CH}_{3}\right) ; 114,1(2 \mathrm{xCH}) ; 118,2$ (CH); 119,0 (CH); 128,1 (C); 132,7 (2xCH); 147,9 (C); 151,3 (C); 161,9 (C); 164,3 (C); $191,9(C)$.

IR (película): 1420, 1459, 1528, 1577, 1597, $1660 \mathrm{~cm}^{-1}$

HRMS: Calculado $(\mathrm{M}+\mathrm{H}) 294,0356$. Obtenido $\left(\mathrm{C}_{14} \mathrm{H}_{13} \mathrm{CINO}_{2} \mathrm{~S}\right) 294,0335$.

HPLC: Columna $\mathrm{C}_{18} \mathrm{t}_{\mathrm{R}}: 21,99 \mathrm{~min}$. 
3-(2-cloro-6-(metilsulfanil)piridin-4-il)-3-hidroxi-3-(4-metoxifenil)propanoato de etilo (39):

$\mathrm{RMN}^{1} \mathrm{H}\left(\mathrm{CDCl}_{3}\right) \delta$ (ppm): (Espectro 39H) 1,20 (3H, t, J=7,1; $\left.\mathrm{CH}_{3}\right) ; 2,54\left(3 \mathrm{H}, \mathrm{s}, \mathrm{SCH}_{3}\right)$; $3,09\left(1 \mathrm{H}, \mathrm{d} \mathrm{J}=16,5 ; \mathrm{CH}_{2}\right) ; 3,12\left(1 \mathrm{H}, \mathrm{d} \mathrm{J}=16,5 ; \mathrm{CH}_{2}\right) ; 3,77\left(3 \mathrm{H}, \mathrm{s}, \mathrm{OCH}_{3}\right) ; 4,12(2 \mathrm{H}, \mathrm{c}$, $\left.\mathrm{J}=7,1 ; \mathrm{CH}_{2}\right) ; 6,85(2 \mathrm{H}, \mathrm{d}, \mathrm{J}=8,9 ; \mathrm{Ar}) ; 7,03(1 \mathrm{H}, \mathrm{d}, \mathrm{J}=1,4 ; \mathrm{pyr}) ; 7,17(1 \mathrm{H}, \mathrm{d}, \mathrm{J}=1,4 ; \mathrm{pyr})$; $7,30(2 \mathrm{H}, \mathrm{d}, \mathrm{J}=8,9 ; \mathrm{Ar})$.

$\mathrm{RMN}{ }^{13} \mathrm{C}\left(\mathrm{CDCl}_{3}\right) \delta(\mathrm{ppm})$ : (Espectro 39C) 13,5 $\left(\mathrm{CH}_{3}\right) ; 14,0\left(\mathrm{CH}_{3}\right) ; 44,6\left(\mathrm{CH}_{2}\right) ; 55,3$ $\left(\mathrm{CH}_{3}\right) ; 61,4\left(\mathrm{CH}_{2}\right) ; 75,3(\mathrm{C}) ; 114,0(2 \times \mathrm{CH}) ; 116,5(\mathrm{CH}) ; 116,7(\mathrm{CH}) ; 126,7(2 \times \mathrm{CH})$; 135,9 (C); 151,2 (C); 158,1 (C); 159,1 (C); 161,1 (C); 172,3 (C).

IR (película): 1458, 1514, 1533, 1582, 1606, 1714, $3450 \mathrm{~cm}^{-1}$

HRMS: Calculado $(\mathrm{M}+\mathrm{H}) 382,0880$. Obtenido $\left(\mathrm{C}_{18} \mathrm{H}_{21} \mathrm{CINO}_{4} \mathrm{~S}\right) 382,0888$.

HPLC: Columna $\mathrm{C}_{18} \quad \mathrm{t}_{\mathrm{R}}: 20,64 \mathrm{~min}$. 
Obtención de 2-cloro-4-(1-(4-metoxifenil)vinil)-6-(metilsulfanil)piridina<smiles>COc1ccc(C(=O)c2cc(Cl)nc(SC)c2)cc1</smiles><smiles>C=C(c1ccc(OC)cc1)c1cc(Cl)nc(SC)c1</smiles>

Sobre $790 \mathrm{mg}$ (1,96 mmol) de yoduro de metiltrifenilfosfonio (19) en THF seco $(20 \mathrm{~mL}) \mathrm{a}-40^{\circ} \mathrm{C}$ y en atmósfera de argón, se añaden $0,82 \mathrm{~mL}(1,31 \mathrm{mmol})$ de $n$ BuLi $1,6 \mathrm{M}$ en hexano, siguiendo el método $\mathrm{B}$. Posteriormente se añaden $192 \mathrm{mg}(0,65$ mmol) de (2-cloro-6-(metilsulfanil)piridin-4-il)(4-metoxifenil)metanona (38) disueltos en THF seco $(10 \mathrm{~mL})$. Se purifica mediante cromatografía flash, utilizando como eluyente Hexano/EtOAc (99:1) obteniendo $65 \mathrm{mg}$ (0,22 mmol; 34\%) de 2-cloro-4-(1-(4metoxifenil)vinil)-6-(metilsulfanil)piridina.

\section{2-cloro-4-(1-(4-metoxifenil)vinil)-6-(metilsulfanil)piridina (40):}

$\mathrm{RMN}^{1} \mathrm{H}\left(\mathrm{CDCl}_{3}\right) \delta$ (ppm): (Espectro 40H) 2,56 (3H, s, $\left.\mathrm{SCH}_{3}\right) ; 3,84\left(3 \mathrm{H}, \mathrm{s}, \mathrm{OCH}_{3}\right) ; 5,47$ $\left(1 \mathrm{H}, \mathrm{s} ; \mathrm{CH}_{2}\right) ; 5,53\left(1 \mathrm{H}, \mathrm{s} ; \mathrm{CH}_{2}\right) ; 6,88(2 \mathrm{H}, \mathrm{d}, \mathrm{J}=8,6 ; \mathrm{Ar}) ; 6,95(1 \mathrm{H}, \mathrm{s}, \mathrm{pyr}) ; 7,03(1 \mathrm{H}, \mathrm{s}$, pyr); $7,20(2 \mathrm{H}, \mathrm{d}, \mathrm{J}=8,6 ; \mathrm{Ar})$.

$\mathrm{RMN}{ }^{13} \mathrm{C}\left(\mathrm{CDCl}_{3}\right) \delta$ (ppm): (Espectro 40C) 13,6 $\left(\mathrm{CH}_{3}\right) ; 55,4\left(\mathrm{CH}_{3}\right) ; 114,0(2 \times \mathrm{CH}) ; 116,4$ $\left(\mathrm{CH}_{2}\right) ; 118,6(\mathrm{CH}) ; 119,1(\mathrm{CH}) ; 129,3(2 \times \mathrm{CH}) ; 113,6(\mathrm{C}) ; 146,3(\mathrm{C}) ; 151,1(\mathrm{C}) ; 152,1$ (C); 159,9 (C); 160,9 (C).

IR (película): 1417, 1457, 1518, $1602 \mathrm{~cm}^{-1}$

HRMS: Calculado $(\mathrm{M}+\mathrm{H}) 292,0563$. Obtenido $\left(\mathrm{C}_{15} \mathrm{H}_{15} \mathrm{CINOS}\right) 292,0572$.

HPLC: Columna $\mathrm{C}_{8} \quad \mathrm{t}_{\mathrm{R}}: 21,27 \mathrm{~min}$. 
Obtención de las oximas de (2-cloro-6-(metilsulfanil)piridin-4-il)(4metoxifenil)metanona<smiles>COc1ccc(C(=O)c2cc(Cl)nc(SC)c2)cc1</smiles><smiles>CO[C@H](O)C(O)O</smiles><smiles>COc1ccc(/C(=N/O)c2cc(Cl)nc(SC)c2)cc1</smiles>

Se disuelven $97 \mathrm{mg}$ (0,33 mmol) de (2-cloro-6-(metilsulfanil)piridin-4-il)(4metoxifenil)metanona (38) en $\mathrm{MeOH}(15 \mathrm{~mL})$, y se añaden $229 \mathrm{mg}(3,30 \mathrm{mmol})$ de clorhidrato de hidroxilamina, siguiendo el método $\mathrm{E}$. Se obtienen $91 \mathrm{mg}(0,29 \mathrm{mmol}$, $89 \%$ ) de una mezcla de oximas de (2-cloro-6-(metilsulfanil)piridin-4-il)(4metoxifenil)metanona, que cristalizan en Hexano/ $\mathrm{CH}_{2} \mathrm{Cl}_{2}$ en proporción 3:7.

Oximas de (2-cloro-6-(metilsulfanil)piridin-4-il)(4-metoxifenil)metanona (41ZE):

P.f. $\left(\mathrm{Hex} / \mathrm{CH}_{2} \mathrm{Cl}_{2}\right): 100-105^{\circ} \mathrm{C}$

$\mathrm{RMN}^{1} \mathrm{H}\left(\mathrm{CDCl}_{3}\right) \delta$ (ppm): (Espectro 41ZEH) 2,58 (3H, s, SCH$) ; 3,83\left(3 \mathrm{H}, \mathrm{s}, \mathrm{OCH}_{3}\right)$; $6,87(2 \mathrm{H}, \mathrm{d}, \mathrm{J}=8,9 ; \mathrm{Ar}) ; 6,98(1 \mathrm{H}, \mathrm{d}, \mathrm{J}=1,1 ; \mathrm{pyr}) ; 6,99(2 \mathrm{H}, \mathrm{d}, \mathrm{J}=8,9 ; \mathrm{Ar}) ; 7,05(1 \mathrm{H}, \mathrm{d}$, $\mathrm{J}=1,1 ;$ pyr); $7,37(2 \mathrm{H}, \mathrm{d}, \mathrm{J}=8,9 ; \mathrm{Ar})$. Isómero $Z$.

$\mathrm{RMN}^{1} \mathrm{H}\left(\mathrm{CDCl}_{3}\right) \delta(\mathrm{ppm})$ : (Espectro 41ZEH) 2,55 (3H, s, SCH$) ; 3,87\left(3 \mathrm{H}, \mathrm{s}, \mathrm{OCH}_{3}\right)$; $6,99(2 \mathrm{H}, \mathrm{d}, \mathrm{J}=8,9 ; \mathrm{Ar}) ; 7,09(1 \mathrm{H}, \mathrm{d}, \mathrm{J}=1,2 ; \mathrm{pyr}) ; 7,14(1 \mathrm{H}, \mathrm{d}, \mathrm{J}=1,2 ; \mathrm{pyr}) ; 7,33(2 \mathrm{H}, \mathrm{d}$, $\mathrm{J}=8,9 ; \mathrm{Ar})$. Isómero $E$.

RMN ${ }^{13} \mathrm{C}\left(\mathrm{CDCl}_{3}\right) \delta(\mathrm{ppm}):\left(\right.$ Espectro 41ZEC) $13,5\left(\mathrm{CH}_{3}\right) ; 55,3\left(\mathrm{CH}_{3}\right) ; 113,9(\mathrm{CH}) ; 114,0$ (2xCH); 118,9 (CH); 119,6 (CH); 126,5 (C); 128,8 (2xCH); 130,8 (CH); 143,4 (C); 151,2 (C); 154,4 (C); 160,5 (C); 161,2 (C); 161,4 (C).

IR (KBr): 1412, 1446, 1524, 1573, 1603, $3177 \mathrm{~cm}^{-1}$

HRMS: Calculado $(\mathrm{M}+\mathrm{H}) 309,0465$. Obtenido $\left(\mathrm{C}_{14} \mathrm{H}_{14} \mathrm{CIN}_{2} \mathrm{O}_{2} \mathrm{~S}\right) 309,0438$.

HPLC: Columna $C_{18} t_{R}: 20,19$ min; $t_{R}: 20,71$ min. 
Obtención de (2-cloro-6-(dimetilamino-piridin-4-il)(4-metoxifenil)metanona<smiles>COc1ccc(C(=O)c2cc(Cl)nc(Cl)c2)cc1</smiles><smiles>CNCCCCC(C)(Br)Br</smiles><smiles>COc1ccc(C(=O)c2cc(Cl)nc(N(C)C)c2)cc1</smiles>

Se disuelven $885 \mathrm{mg} \quad(3,14 \mathrm{mmol})$ de (2,6-dicloropiridin-4-il)(4metoxifenil)metanona (25) en 0,561 $\mathrm{mL}(4,10 \mathrm{mmol})$ de una disolución de dimetilamino al $33 \%$ en $\mathrm{EtOH}$ y se calienta a $80^{\circ} \mathrm{C}$ durante 24 horas en tubo sellado. Se evapora el dimetilamino y se cromatografía en una columna sobre gel de sílice, utilizando como eluyente Hexano/EtOAc (96:4), obteniendo $351 \mathrm{mg}$ (1,21 mmol; 38\%) de (2-cloro-6(dimetilamino-piridin-4-il)(4-metoxifenil)metanona y $378 \mathrm{mg}(1,34 \mathrm{mmol} ; 43 \%) \mathrm{de}$ material de partida.

(2-cloro-6-(dimetilamino-piridin-4-il)(4-metoxifenil)metanona (42):

$\mathrm{RMN}^{1} \mathrm{H}\left(\mathrm{CDCl}_{3}\right) \delta(\mathrm{ppm})$ : (Espectro $\left.42 \mathrm{H}\right) 3,11\left(6 \mathrm{H}, \mathrm{s}, \mathrm{NMe}_{2}\right) ; 3,89\left(3 \mathrm{H}, \mathrm{s}, \mathrm{OCH}_{3}\right) ; 6,57$ $(1 \mathrm{H}, \mathrm{s}, \mathrm{pyr}) ; 6,68(1 \mathrm{H}, \mathrm{s}, \mathrm{pyr}) ; 6,95(2 \mathrm{H}, \mathrm{d}, \mathrm{J}=8,9 ; \mathrm{Ar}) ; 7,84(2 \mathrm{H}, \mathrm{d}, \mathrm{J}=8,9 ; \mathrm{Ar})$.

RMN ${ }^{13} \mathrm{C}\left(\mathrm{CDCl}_{3}\right) \delta(\mathrm{ppm})$ : (Espectro 42C) 38,0 (2xCH$) ; 55,6\left(\mathrm{CH}_{3}\right) ; 103,3(\mathrm{CH}) ; 109,4$ (CH); 113,9 (2xCH); 128,6 (C); 132,6 (2xCH); 149,3 (C); 149,6 (C); 158,9 (C); 163,9 (C); 193,4 (C).

IR (película): 1417, 1456, 1504, 1597, $1650 \mathrm{~cm}^{-1}$

HRMS: Calculado $(\mathrm{M}+\mathrm{H}) 291,0900$. Obtenido $\left(\mathrm{C}_{15} \mathrm{H}_{16} \mathrm{ClN}_{2} \mathrm{O}_{2}\right) 291,0880$.

HPLC: Columna $C_{8} \quad t_{R}: 17,96$ min. 
Obtención de 6-cloro-4-(1-(4-metoxifenil)vinil)- $N, N$-dimetilpiridin-2-amina<smiles>C=C(c1ccc(OC)cc1)c1cc(Cl)nc(N(C)C)c1</smiles>

Siguiendo el método $B$, se prepara una suspensión de $807 \mathrm{mg}(2,0 \mathrm{mmol})$ de yoduro de metiltrifenilfosfonio (19) en THF seco $(20 \mathrm{~mL})$ a $-40^{\circ} \mathrm{C}$ y se adicionan 0,85 $\mathrm{mL}(1,33 \mathrm{mmol})$ de una disolución 1,6 $\mathrm{M}$ de $n$ BuLi en hexano. Se deja 1 hora en agitación y posteriormente se adicionan $195 \mathrm{mg}(0,67 \mathrm{mmol})$ de (2-cloro-6(dimetilamino)piridin-4-il)(4-metoxifenil)metanona (42) en THF seco (10 mL). Se purifica mediante cromatografía flash usando como eluyente Hexano/EtOAc (98:2) y se obtienen $74 \mathrm{mg}(0,26 \mathrm{mmol} ; 38 \%)$ de 6-cloro-4-(1-(4-metoxifenil)vinil)- $N, N$ dimetilpiridin-2-amina.

\section{6-cloro-4-(1-(4-metoxifenil)vinil)-N,N-dimetilpiridin-2-amina (43):}

$\mathrm{RMN}^{1} \mathrm{H}\left(\mathrm{CDCl}_{3}\right) \delta(\mathrm{ppm}):($ Espectro $43 \mathrm{H}) 3,06\left(6 \mathrm{H}, \mathrm{s}, \mathrm{NMe}_{2}\right) ; 3,83\left(3 \mathrm{H}, \mathrm{s}, \mathrm{OCH}_{3}\right) ; 5,41$ $\left(1 \mathrm{H}, \mathrm{d}, \mathrm{J}=1,1 ; \mathrm{CH}_{2}\right) ; 5,47\left(1 \mathrm{H}, \mathrm{d}, \mathrm{J}=1,1 ; \mathrm{CH}_{2}\right) ; 6,29(1 \mathrm{H}, \mathrm{d}, \mathrm{J}=1,1 ; \mathrm{pyr}) ; 6,50(1 \mathrm{H}, \mathrm{d}$, $\mathrm{J}=1,1 ; p y r) ; 6,87(2 \mathrm{H}, \mathrm{d}, \mathrm{J}=8,6 ; \mathrm{Ar}) ; 7,25(2 \mathrm{H}, \mathrm{d}, \mathrm{J}=8,6 ; \mathrm{Ar})$.

$\mathrm{RMN}^{13} \mathrm{C}\left(\mathrm{CDCl}_{3}\right) \delta(\mathrm{ppm}):($ Espectro $43 \mathrm{C}) 38,1\left(2 \times \mathrm{CH}_{3}\right) ; 55,4\left(\mathrm{CH}_{3}\right) ; 103,3(\mathrm{CH}) ; 110,5$ (CH); 113,8 (2xCH); 114,8 ( $\left.\mathrm{CH}_{2}\right) ; 129,3(2 \times C H) ; 132,3$ (C); 147,6 (C); 149,5 (C); 153,3 (C); 159,3 (C); 159,7 (C).

IR (película): 1461, 1515, 1527, $1597 \mathrm{~cm}^{-1}$

HRMS: Calculado $(\mathrm{M}+\mathrm{H}) 289,1108$. Obtenido $\left(\mathrm{C}_{16} \mathrm{H}_{18} \mathrm{CIN}_{2} \mathrm{O}\right) 289,1102$.

HPLC: Columna $\mathrm{C}_{18} \mathrm{t}_{\mathrm{R}}: 26,22 \mathrm{~min}$. 
Obtención de las oximas de (2-cloro-6-(dimetilamino)piridin-4-il)(4metoxifenil)metanona<smiles>COc1ccc(C(=O)c2cc(Cl)nc(N(C)C)c2)cc1</smiles>

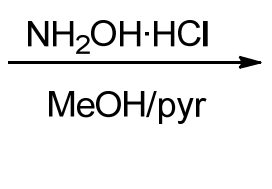<smiles>COc1ccc(/C(=N/O)c2cc(Cl)nc(N(C)C)c2)cc1</smiles>

Se disuelven $115 \mathrm{mg}$ (0,396 mmol) de (2-cloro-6-(dimetilamino)piridin-4-il)(4metoxifenil)metanona (42) en $\mathrm{MeOH}(20 \mathrm{~mL})$, y se añaden $275 \mathrm{mg}$ (3,96 mmol) de clorhidrato de hidroxilamina, siguiendo el método E. Se purifica mediante cristalización en Hexano/ $\mathrm{CH}_{2} \mathrm{Cl}_{2}$ obteniendo $34 \mathrm{mg}$ del isómero $E(0,11 \mathrm{mmol}, 28 \%)$, y $84 \mathrm{mg}$ $(0,27 \mathrm{mmol} ; 69 \%)$ de mezcla de isómeros de la oxima de (2-cloro-6(dimetilamino)piridin-4-il)(4-metoxifenil)metanona.

\section{Oxima de (E)-(2-cloro-6-(dimetilamino)piridin-4-il)(4-metoxifenil)metanona (44E):}

P.f. $\left(\mathrm{Hex} / \mathrm{CH}_{2} \mathrm{Cl}_{2}\right): 113-117^{\circ} \mathrm{C}$

$\mathrm{RMN}^{1} \mathrm{H}\left(\mathrm{CDCl}_{3}\right) \delta(\mathrm{ppm})$ : (Espectro 44EZH) 3,05 (6H, s, $\left.\mathrm{NCH}_{3}\right) ; 3,87\left(3 \mathrm{H}, \mathrm{s}, \mathrm{OCH}_{3}\right)$; 6,45 (1H, s; pyr); 6,58 (1H, s; pyr); 6,97 (2H, d, J=8,9; Ar); 7,37 (2H, d, J=8,9; Ar).

IR (KBr): 1410, 1532, $1600 \mathrm{~cm}^{-1}$

Oxima de (Z)-(2-cloro-6-(dimetilamino)piridin-4-il)(4-metoxifenil)metanona (44Z):

$\mathrm{RMN}^{1} \mathrm{H}\left(\mathrm{CDCl}_{3}\right) \delta(\mathrm{ppm})$ : (Espectro 44EZH) 3,08 (6H, s, $\left.\mathrm{NCH}_{3}\right) ; 3,81\left(3 \mathrm{H}, \mathrm{s}, \mathrm{OCH}_{3}\right)$; 6,29 (1H, s; pyr); 6,50 (1H, s; pyr); 6,85 (2H, d, J=8,9; Ar); 7,41 (2H, d, J=8,9; Ar).

Oximas de (2-cloro-6-(dimetilamino)piridin-4-il)(4-metoxifenil)metanona (44EZ):

RMN ${ }^{13} \mathrm{C}\left(\mathrm{CDCl}_{3}\right) \delta(\mathrm{ppm})$ : (Espectro 44EZC) 38,1 (2xCH$) ; 55,4\left(\mathrm{CH}_{3}\right) ; 103,0(\mathrm{CH})$; $103,4(\mathrm{CH}) ; 109,7(\mathrm{CH}) ; 110,1(\mathrm{CH}) ; 113,7(2 \times \mathrm{CH}) ; 114,0(2 \times \mathrm{CH}) ; 123,3(\mathrm{C}) ; 126,9(\mathrm{C}) ;$ $128,9(2 \times C H) ; 131,3(2 \times C H) ; 144,7$ (C); 147,9 (C); 141,7 (C); 155,8 (C); 159,1 (C); $160,4(\mathrm{C}) ; 161,1(\mathrm{C})$.

IR (película): 1469, 1515, 1532, $1602 \mathrm{~cm}^{-1}$

HRMS: Calculado $(\mathrm{M}+\mathrm{H}) 306,1009$. Obtenido $\left(\mathrm{C}_{15} \mathrm{H}_{17} \mathrm{CIN}_{3} \mathrm{O}_{2}\right) 306,0987$.

HPLC: Columna $\mathrm{C}_{18} \mathrm{t}_{\mathrm{R}}: 18,76 \mathrm{~min} ; \mathrm{t}_{\mathrm{R}}: 19,02 \mathrm{~min}$. 


\section{Obtención de (2,6-bis(metilsulfanil)piridin-4-il)(4-metoxifenil)metanona}<smiles>CSc1cc(C(=O)O)cc(SC)n1</smiles><smiles>COc1ccc(Br)cc1</smiles>

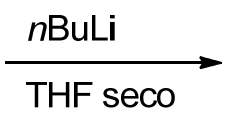<smiles>COc1ccc(C(=O)c2cc(SC)nc(SC)c2)cc1</smiles>

Sobre una disolución de 1,45 mL (11,6 mmol) de 4-bromoanisol en THF seco (20 $\mathrm{mL}$ ) se añaden $7,18 \mathrm{~mL}(11,6 \mathrm{mmol})$ de $n B u L i$ 1,6 M en hexano siguiendo el método $A$. Posteriormente se añade $1 \mathrm{~g}(4,6 \mathrm{mmol})$ de ácido 2,6-bis(metilsulfanil)piridina-4carboxílico (4) disuelto en THF seco (20 mL). Se purifica mediante cromatografía flash, utilizando como eluyente Hexano/EtOAc (95:5) y se recogen $626 \mathrm{mg}(2,1 \mathrm{mmol} ; 46 \%)$ de (2,6-bis(metilsulfanil)piridin-4-il)(4-metoxifenil)metanona, que se cristaliza en Hexano/ $\mathrm{CH}_{2} \mathrm{Cl}_{2}$, obteniendo $344 \mathrm{mg}(1,13 \mathrm{mmol} ; 25 \%)$ de cristales.

(2,6-bis(metilsulfanil)piridin-4-il)(4-metoxifenil)metanona (45):

P.f. $\left(\mathrm{Hex} / \mathrm{CH}_{2} \mathrm{Cl}_{2}\right): 103^{\circ}$

$\mathrm{RMN}^{1} \mathrm{H}\left(\mathrm{CDCl}_{3}\right) \delta$ (ppm): (Espectro 45H) 2,61 (6H, s, $\left.\mathrm{SCH}_{3}\right) ; 3,89\left(3 \mathrm{H}, \mathrm{s}, \mathrm{OCH}_{3}\right) ; 6,96$ $(2 \mathrm{H}, \mathrm{d}, \mathrm{J}=8,8 ; \mathrm{Ar}) ; 7,05$ (2H, s, pyr); 7,80 (2H, d, J=8,8; Ar).

$\mathrm{RMN}{ }^{13} \mathrm{C}\left(\mathrm{CDCl}_{3}\right) \delta(\mathrm{ppm})$ : (Espectro $\left.45 \mathrm{C}\right) 13,4\left(2 \mathrm{CCH}_{3}\right) ; 55,6\left(\mathrm{CH}_{3}\right) ; 113,9(2 \mathrm{xCH})$; 115,6 (2xCH); 128,6 (C); 132,6 (2xCH); 145,3 (C); 160,2 (2xC); 164,0 (C); 193,2 (C). IR (KBr): 1544, 1592, $1655 \mathrm{~cm}^{-1}$ HRMS: Calculado $(\mathrm{M}+\mathrm{H}) 306,0622$. Obtenido $\left(\mathrm{C}_{15} \mathrm{H}_{16} \mathrm{NO}_{2} \mathrm{~S}_{2}\right) 306,0612$. HPLC: Columna $\mathrm{C}_{18} \quad \mathrm{t}_{\mathrm{R}}: 21,55 \mathrm{~min}$. 
Obtención de 4-(1-(4-metoxifenil)vinil)-2,6-bis(metilsulfanil)piridina<smiles>C=C(c1ccc(OC)cc1)c1cc(SC)nc(SCC(=O)Oc2ccc(C(=O)c3cc(SC)nc(SC)c3)cc2)c1</smiles>

Siguiendo el método $B$, se prepara una suspensión de 1,32 $\mathrm{g}(3,27 \mathrm{mmol})$ de yoduro de metiltrifenilfosfonio (19) en THF seco $(20 \mathrm{~mL})$ a $-40^{\circ} \mathrm{C}$ y se adicionan 1,36 $\mathrm{mL}(2,18 \mathrm{mmol})$ de una disolución 1,6 M de $n$ BuLi en hexano. Se deja 1 hora en agitación y posteriormente se adicionan $333 \mathrm{mg}(1,09 \mathrm{mmol})$ de $(2,6-$ bis(metilsulfanil)piridin-4-il)(4-metoxifenil)metanona (45) en THF seco (15 mL). Se purifica mediante cromatografía flash usando como eluyente Hexano/EtOAc (97:3) y se obtienen $309 \mathrm{mg} \quad(1,02 \mathrm{mmol} ; 94 \%)$ de 4-(1-(4-metoxifenil)vinil)-2,6bis(metilsulfanil)piridina.

4-(1-(4-metoxifenil)vinil)-2,6-bis(metilsulfanil)piridina (46):

$\mathrm{RMN}^{1} \mathrm{H}\left(\mathrm{CDCl}_{3}\right) \delta(\mathrm{ppm})$ : (Espectro $\left.46 \mathrm{H}\right) 2,59\left(6 \mathrm{H}, \mathrm{s}, \mathrm{SCH}_{3}\right) ; 3,83\left(3 \mathrm{H}, \mathrm{s}, \mathrm{OCH}_{3}\right) ; 5,42$ $\left(1 \mathrm{H}, \mathrm{d}, \mathrm{J}=1,1 ; \mathrm{CH}_{2}\right) ; 5,47\left(1 \mathrm{H}, \mathrm{d}, \mathrm{J}=1,1 ; \mathrm{CH}_{2}\right) ; 6,82(2 \mathrm{H}, \mathrm{s}, \mathrm{pyr}) ; 6,86(2 \mathrm{H}, \mathrm{d}, \mathrm{J}=8,6 ; \mathrm{Ar})$; $7,21(2 \mathrm{H}, \mathrm{d}, \mathrm{J}=8,6 ; \mathrm{Ar})$.

$\mathrm{RMN}{ }^{13} \mathrm{C}\left(\mathrm{CDCl}_{3}\right) \delta$ (ppm): (Espectro 46C) 13,3 (2xCH$) ; 55,4\left(\mathrm{CH}_{3}\right) ; 113,8(2 \times \mathrm{CH})$; $115,4\left(\mathrm{CH}_{2}\right) ; 116,3(2 \times \mathrm{CH}) ; 129,3$ (2xCH); 132,1 (C); 147,1 (C); 149,4 (C); 159,3 (2xC); $159,7(C)$.

IR (película): 1523, 1593, $1654 \mathrm{~cm}^{-1}$

HRMS: Calculado $(\mathrm{M}+\mathrm{H}) 304,0830$. Obtenido $\left(\mathrm{C}_{16} \mathrm{H}_{18} \mathrm{NOS}_{2}\right) 304,0835$.

HPLC: Columna $\mathrm{C}_{18} \mathrm{t}_{\mathrm{R}}: 24,93 \mathrm{~min}$. 
Obtención de las oximas de (2,6-bis(metilsulfanil)piridin-4-il)(4metoxifenil)metanona<smiles>COc1ccc(C(=O)c2cc(SC)nc(SC)c2)cc1</smiles><smiles>COc1ccc(/C(=N/O)c2cc([Te+])nc(SC)c2)cc1</smiles>

Siguiendo el método $\mathrm{E}$, se disuelven $177 \mathrm{mg}(0,58 \mathrm{mmol})$ de (2,6bis(metilsulfanil)piridin-4-il)(4-metoxifenil)metanona (45) en $\mathrm{MeOH}(20 \mathrm{~mL}$ ) y se añaden $403 \mathrm{mg}(5,80 \mathrm{mmol})$ de clorhidrato de hidroxilamina. Por cromatografía flash, utilizando como eluyente Hexano/EtOAc (9:1) se obtienen $14 \mathrm{mg} \mathrm{(0,04} \mathrm{mmol;} \mathrm{7 \% )} \mathrm{del}$ isómero $E$ y $141 \mathrm{mg}(0,44 \mathrm{mmol} ; 76 \%)$ de mezcla de isómeros. La mezcla se cristaliza en $\mathrm{Hex} / \mathrm{CH}_{2} \mathrm{Cl}_{2}$ obteniendo mezcla de los dos isómeros (4:6).

Oxima de (E)-(2,6-bis(metilsulfanil)piridin-4-il)(4-metoxifenil)metanona (47E):

$\mathrm{RMN}^{1} \mathrm{H}\left(\mathrm{CDCl}_{3}\right) \delta(\mathrm{ppm})$ : (Espectro 47ZEH) 2,56 (6H, s, $\left.\mathrm{SCH}_{3}\right) ; 3,86\left(3 \mathrm{H}, \mathrm{s}, \mathrm{OCH}_{3}\right)$; $6,93$ (2H, s; pyr); 6,98 (2H, d, J=8,9; $\operatorname{Ar}) ; 7,36$ (2H, d, J=8,9; Ar).

$\mathrm{RMN}{ }^{13} \mathrm{C}\left(\mathrm{CDCl}_{3}\right) \delta(\mathrm{ppm})$ : (Espectro 47ZEC) 13,4 (2xCH$) ; 55,4\left(\mathrm{CH}_{3}\right) ; 113,8(2 \times \mathrm{CH})$; 115,5 (2xCH); 122,8 (C); 131,2 (2xCH); 144,1 (C); 155,6 (C); 159,9 (2xC); 160,6 (C).

Oxima de (Z)-(2,6-bis(metilsulfanil)piridin-4-il)(4-metoxifenil)metanona (47Z):

$\mathrm{RMN}^{1} \mathrm{H}\left(\mathrm{CDCl}_{3}\right) \delta(\mathrm{ppm})$ : (Espectro 47ZEH) 2,60 (6H, s, SCH$) ; 3,81\left(3 \mathrm{H}, \mathrm{s}, \mathrm{OCH}_{3}\right)$; $6,85(2 \mathrm{H}, \mathrm{d}, \mathrm{J}=8,9 ; \mathrm{Ar}) ; 6,85(2 \mathrm{H}, \mathrm{s} ; \mathrm{pyr}) ; 7,36(2 \mathrm{H}, \mathrm{d}, \mathrm{J}=8,9 ; \mathrm{Ar})$.

$\mathrm{RMN}{ }^{13} \mathrm{C}\left(\mathrm{CDCl}_{3}\right) \delta(\mathrm{ppm})$ : (Espectro 47ZEC) 13,4 (2xCH$) ; 55,4\left(\mathrm{CH}_{3}\right) ; 114,1(2 \times \mathrm{CH}) ;$ 116,3 (2xCH); 126,7 (C); 129,0 (2xCH); 140,9 (C); 155,3 (C); 159,9 (2xC); 161,2 (C).

Oximas de (2,6-bis(metilsulfanil)piridin-4-il)(4-metoxifenil)metanona (47EZ):

P.f. $\left(\mathrm{Hex} / \mathrm{CH}_{2} \mathrm{Cl}_{2}\right): 125-127^{\circ}$

IR (KBr): 1417, 1456, 1518, 1573, 1605, $3434 \mathrm{~cm}^{-1}$

HRMS: Calculado (M+Na) 343,0551. Obtenido $\left(\mathrm{C}_{15} \mathrm{H}_{16} \mathrm{~N}_{2} \mathrm{NaO}_{2} \mathrm{~S}_{2}\right) 343,0562$.

HPLC: Columna $C_{8} \quad t_{R}: 17,95$ min; $t_{R}: 18,30$ min. 
Obtención de 4-(1-(4-metoxifenil)etil)-2,6-bis(metillsulfanil)piridina<smiles>C=C(c1ccc(OC)cc1)c1cc(SC)nc(SC)c1</smiles><smiles>CCOC(C)=O</smiles><smiles>COc1ccc(C(C)c2cc(SC)nc(SC)c2)cc1</smiles>

Se disuelven $16 \mathrm{mg} \quad(0,05 \mathrm{mmol})$ de 4-(1-(4-metoxifenil)vinil)-2,6bis(metilsulfanil)piridina (46) en $5-10 \mathrm{~mL}$ de EtOAc/EtOH y se añade una punta de espátula de $\mathrm{Pd}$ sobre carbón activo y se deja en atmósfera de hidrógeno y a temperatura ambiente durante $24 \mathrm{~h}$. Cuando se observa por RMN ${ }^{1} \mathrm{H}$ que no queda material de partida, se filtra a través de sílice y se evapora el disolvente. Se purifica mediante cromatografía flash usando como eluyente Hexano/EtOAc (95:5) obteniendo $8 \mathrm{mg}$ que se cromatografían mediante CCP con Hexano/EtOAc (98:2) y se obtiene 7 $\mathrm{mg}(0,02 \mathrm{mmol} ; 45 \%)$ de 4-(1-(4-metoxifenil)etil)-2,6-bis(metillsulfanil)piridina.

\section{4-(1-(4-metoxifenil)etil)-2,6-bis(metillsulfanil)piridina (48):}

$\mathrm{RMN}^{1} \mathrm{H}\left(\mathrm{CDCl}_{3}\right) \delta$ (ppm): (Espectro 48H) 1,55 (3H, d, J=7,2; $\left.\mathrm{CH}_{3}\right) ; 2,56\left(6 \mathrm{H}, \mathrm{s}, \mathrm{SCH}_{3}\right)$; $3,79\left(3 \mathrm{H}, \mathrm{s}, \mathrm{OCH}_{3}\right) ; 3,90(1 \mathrm{H}, \mathrm{c}, \mathrm{J}=7,2 ; \mathrm{CH}) ; 6,71(2 \mathrm{H}, \mathrm{s}, \mathrm{pyr}) ; 6,83(2 \mathrm{H}, \mathrm{d}, \mathrm{J}=8,8 ; \mathrm{Ar})$; $7,06(2 \mathrm{H}, \mathrm{d}, \mathrm{J}=8,8 ; \mathrm{Ar})$.

$\mathrm{RMN}{ }^{13} \mathrm{C}\left(\mathrm{CDCl}_{3}\right) \delta(\mathrm{ppm})$ : (Espectro 48C) 13,3 $\left(2 \mathrm{xCH}_{3}\right) ; 21,2\left(\mathrm{CH}_{3}\right) ; 43,3(\mathrm{CH}) ; 55,4$ $\left(\mathrm{CH}_{3}\right) ; 113,9(2 \times \mathrm{CH}) ; 114,0(\mathrm{C}) ; 116,3(2 \times \mathrm{CH}) ; 128,6(2 \times \mathrm{CH}) ; 136,3(2 \times \mathrm{C}) ; 155,5(\mathrm{C})$; $159,0(C)$.

IR (película): 1456, 1513, 1533, 1575, $1610 \mathrm{~cm}^{-1}$

HRMS: Calculado $(\mathrm{M}+\mathrm{H}) 306,0986$. Obtenido $\left(\mathrm{C}_{16} \mathrm{H}_{20} \mathrm{NOS}_{2}\right) 306,0987$.

HPLC: Columna $C_{8} \quad t_{R}: 21,34 \mathrm{~min}$.

\section{il)metanona con $\mathrm{CH}_{3} \underline{\mathrm{SNa}}$}




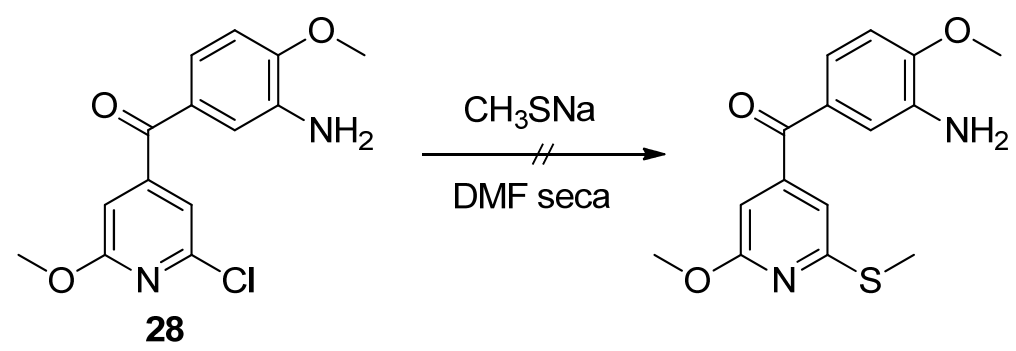

Se disuelven $43 \mathrm{mg}(0,46 \mathrm{mmol})$ de (3-amino-4-metoxifenil)(2-cloro-6metoxipiridin-4-il)metanona (28) en DMF seca $(10 \mathrm{~mL})$ y se añade exceso de $\mathrm{CH}_{3} \mathrm{SNa}$ y se pone a reflujo durante 72 horas. Se evapora la DMF y se extrae con agua y EtOAc, no observándose señales correspondientes al material de partida o al producto. 
<smiles>COc1ccc(C(=O)c2cc(OC)nc(SC)c2)cc1</smiles>

Siguiendo el método A, se prepara una disolución de 1,03 $\mathrm{mL}(8,2 \mathrm{mmol})$ de 4bromoanisol en THF seco (20-30 mL), se añaden $5 \mathrm{~mL}$ (8 mmol) de una disolución 1,6 $\mathrm{M}$ de $n$ BuLi en hexano y se deja media hora en agitación. A continuación se añaden $500 \mathrm{mg} \mathrm{(2,5} \mathrm{mmol)}$ de ácido 2-metilsulfanil-6-metoxipiridina-4-carboxílico (5) disuelto en THF seco (10-20 mL). El producto obtenido se purifica mediante cromatografía flash, utilizando como eluyente Hexano/EtOAc (9:1) y se recogen 372 mg (1,28 mmol; $51 \%$ ) de (2-metilsulfanil-6-metoxipiridin-4-il)(4-metoxifenil)metanona, que se cristalizan en $\mathrm{Hex} / \mathrm{CH}_{2} \mathrm{Cl}_{2}$ obteniendo $186 \mathrm{mg}(0,64 \mathrm{mmol} ; 26 \%)$ de cristales. Es un compuesto fluorescente.

(2-metilsulfanil-6-metoxipiridin-4-il)(4-metoxifenil)metanona (49):

P.f. $\left(\mathrm{Hex} / \mathrm{CH}_{2} \mathrm{Cl}_{2}\right): 62^{\circ}$

$\mathrm{RMN}^{1} \mathrm{H}\left(\mathrm{CDCl}_{3}\right) \delta(\mathrm{ppm}):($ Espectro $49 \mathrm{H})$ 2,59 (3H, s, $\left.\mathrm{SCH}_{3}\right) ; 3,89\left(3 \mathrm{H}, \mathrm{s}, \mathrm{OCH}_{3}\right) ; 3,99$ $\left(3 \mathrm{H}, \mathrm{s}, \mathrm{OCH}_{3}\right) ; 6,61(1 \mathrm{H}, \mathrm{d}, \mathrm{J}=1,1 ; \mathrm{pyr}) ; 6,95(2 \mathrm{H}, \mathrm{d}, \mathrm{J}=8,6 ; \mathrm{Ar}) ; 6,97(1 \mathrm{H}, \mathrm{d}, \mathrm{J}=1,1 ; \mathrm{pyr})$; $7,83(2 \mathrm{H}, \mathrm{d}, \mathrm{J}=8,6 ; \mathrm{Ar})$.

RMN ${ }^{13} \mathrm{C}\left(\mathrm{CDCl}_{3}\right) \delta(\mathrm{ppm})$ : (Espectro 49C) 13,4 $\left(\mathrm{CH}_{3}\right) ; 53,8\left(\mathrm{CH}_{3}\right) ; 55,6\left(\mathrm{CH}_{3}\right) ; 105,1$ $(\mathrm{CH}) ; 112,6(\mathrm{CH}) ; 113,9(2 \times \mathrm{CH}) ; 115,5(\mathrm{C}) ; 128,6(\mathrm{C}) ; 132,6(2 \times \mathrm{CH}) ; 148,5(\mathrm{C}) ; 158,5$ (C); $163,9(\mathrm{C}) ; 193,5(\mathrm{C})$.

IR (KBr): 1456, 1545, 1596, $1659 \mathrm{~cm}^{-1}$

HRMS: Calculado $(\mathrm{M}+\mathrm{H}) 290,0851$. Obtenido $\left(\mathrm{C}_{15} \mathrm{H}_{16} \mathrm{NO}_{3} \mathrm{~S}\right) 290,0849$.

HPLC: Columna $\mathrm{C}_{18} \mathrm{t}_{\mathrm{R}}: 22,04 \mathrm{~min}$.

\section{Obtención de 2-metilsulfanil-4-(1-(4-metoxifenil)vinil)-6-metoxipiridina}


<smiles>COc1ccc(C(=O)c2cc(OC)nc(SC)c2)cc1</smiles>

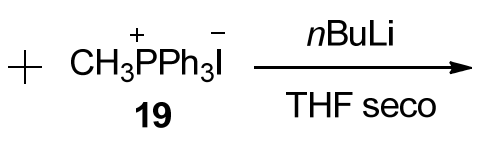<smiles>C=C(c1ccc(OC)cc1)c1cc(OC)nc(SC)c1</smiles>

A $812 \mathrm{mg}$ (2,01 mmol) de yoduro de metiltrifenilfosfonio (19) en THF seco (20 $\mathrm{mL})$ a $-40^{\circ} \mathrm{C}$ y en atmósfera de argón, se añaden $0,84 \mathrm{~mL}(1,34 \mathrm{mmol})$ de una disolución 1,6 M de $n$ BuLi en hexano según el método $\mathrm{B}$. Posteriormente se añaden $194 \mathrm{mg}(0,67 \mathrm{mmol})$ de (2-metilsulfanil-6-metoxipiridin-4-il)(4-metoxifenil)metanona (49) disueltos en THF seco $(10 \mathrm{~mL})$. Se obtienen $95 \mathrm{mg}(0,33 \mathrm{mmol} ; 49 \%)$ de 2metilsulfanil-4-(1-(4-metoxifenil)vinil)-6-metoxipiridina, que han sido purificados mediante cromatografía flash, utilizando como eluyente Hexano/EtOAc (97:3).

\section{2-metilsulfanil-4-(1-(4-metoxifenil)vinil)-6-metoxipiridina (50):}

$\mathrm{RMN}^{1} \mathrm{H}\left(\mathrm{CDCl}_{3}\right) \delta$ (ppm): (Espectro $\left.50 \mathrm{H}\right) 2,56\left(3 \mathrm{H}, \mathrm{s}, \mathrm{SCH}_{3}\right) ; 3,82\left(3 \mathrm{H}, \mathrm{s}, \mathrm{OCH}_{3}\right) ; 3,96$ $\left(3 \mathrm{H}, \mathrm{s}, \mathrm{OCH}_{3}\right) ; 5,43\left(1 \mathrm{H}, \mathrm{d}, \mathrm{J}=1,4 ; \mathrm{CH}_{2}\right) ; 5,47\left(1 \mathrm{H}, \mathrm{d}, \mathrm{J}=1,4 ; \mathrm{CH}_{2}\right) ; 6,38(1 \mathrm{H}, \mathrm{d}, \mathrm{J}=1,4$; pyr); 6,74 (1H, d, J=1,4; pyr); 6,86 (2H, d, J=8,9; Ar); 7,23 (2H, d, J=8,9; Ar).

RMN ${ }^{13} \mathrm{C}\left(\mathrm{CDCl}_{3}\right) \delta(\mathrm{ppm})$ : (Espectro 50C) 13,4 $\left(\mathrm{CH}_{3}\right) ; 53,6\left(\mathrm{CH}_{3}\right) ; 55,3\left(\mathrm{CH}_{3}\right) ; 105,0$ $(\mathrm{CH}) ; 113,4(\mathrm{CH}) ; 113,7(2 \times \mathrm{CH}) ; 115,0\left(\mathrm{CH}_{2}\right) ; 129,3(2 \times C H) ; 132,3(\mathrm{C}) ; 147,3(\mathrm{C})$; 152,5 (C); 157,1 (C); 159,6 (C); 164,1 (C).

IR (película): 1513, 1518, $1594 \mathrm{~cm}^{-1}$

HRMS: Calculado $(\mathrm{M}+\mathrm{H}) 288,1058$. Obtenido $\left(\mathrm{C}_{16} \mathrm{H}_{18} \mathrm{NO}_{2} \mathrm{~S}\right) 288,1068$.

HPLC: Columna $\mathrm{C}_{18} \mathrm{t}_{\mathrm{R}}: 23,89 \mathrm{~min}$.

Obtención de las oximas de (2-metilsulfanil-6-metoxipiridin-4-il)(4metoxifenil)metanona 
<smiles>COc1ccc(C(=O)c2cc(OC)nc(SC)c2)cc1</smiles>

Siguiendo el método $\mathrm{E}$, se disuelven $363 \mathrm{mg}(1,26 \mathrm{mmol})$ de 2-metilsulfanil-6metoxipiridin-4-il)(4-metoxifenil)metanona (49) en $\mathrm{MeOH}(20 \mathrm{~mL})$ y se añaden $90 \mathrm{mg}$ $(1,29 \mathrm{mmol})$ de clorhidrato de hidroxilamina. Por cromatografía en columna sobre gel de sílice, utilizando como eluyente Hexano/EtOAc (9:1) se obtienen 105,2 mg (0,35 $\mathrm{mmol} ; 27 \%)$ del isómero $E, 66,4 \mathrm{mg}(0,22 \mathrm{mmol} ; 17 \%)$ del isómero $Z$ y $108,1 \mathrm{mg}(0,27$ mmol; $21 \%$ ) de mezcla de oximas (1:1), que cristalizan en $\mathrm{Hex} / \mathrm{CH}_{2} \mathrm{Cl}_{2}$. En disolución $\left(\mathrm{CDCl}_{3}\right)$ se rompe formando el material de partida.

Oximas de (2-metilsulfanil-6-metoxipiridin-4-il)(4-metoxifenil)metanona (51ZE):

P.f. $\left(\mathrm{Hex} / \mathrm{CH}_{2} \mathrm{Cl}_{2}\right):$ 92-93

$\mathrm{RMN}^{1} \mathrm{H}\left(\mathrm{CDCl}_{3}\right) \delta(\mathrm{ppm})$ : (Espectro 51ZEH) 2,53 (3H, s, SCH$) ; 3,85\left(3 \mathrm{H}, \mathrm{s}, \mathrm{OCH}_{3}\right)$; $3,94\left(3 \mathrm{H}, \mathrm{s}, \mathrm{OCH}_{3}\right) ; 6,46(1 \mathrm{H}, \mathrm{d}, \mathrm{J}=1,1 ; \mathrm{pyr}) ; 6,88(1 \mathrm{H}, \mathrm{d}, \mathrm{J}=1,1 ; \mathrm{pyr}) ; 6,96(2 \mathrm{H}, \mathrm{d}$, $\mathrm{J}=8,9 ; \mathrm{Ar}) ; 7,38(2 \mathrm{H}, \mathrm{d}, \mathrm{J}=8,9 ; \mathrm{Ar})$. Isómero $E$.

$\mathrm{RMN}^{1} \mathrm{H}\left(\mathrm{CDCl}_{3}\right) \delta$ (ppm): (Espectro 51ZEH) 2,56 (3H, s, SCH$) ; 3,80\left(3 \mathrm{H}, \mathrm{s}, \mathrm{OCH}_{3}\right)$; $3,97\left(3 \mathrm{H}, \mathrm{s}, \mathrm{OCH}_{3}\right) ; 6,42(1 \mathrm{H}, \mathrm{d}, \mathrm{J}=1,1 ; \mathrm{pyr}) ; 6,75(1 \mathrm{H}, \mathrm{d}, \mathrm{J}=1,1 ; \mathrm{pyr}) ; 6,84(2 \mathrm{H}, \mathrm{d}$, $\mathrm{J}=8,9 ; \mathrm{Ar}) ; 7,38(2 \mathrm{H}, \mathrm{d}, \mathrm{J}=8,9 ; \mathrm{Ar})$. Isómero $Z$.

$\mathrm{RMN}{ }^{13} \mathrm{C}\left(\mathrm{CDCl}_{3}\right) \delta$ (ppm): (Espectro 51ZEC) 13,4 $\left(\mathrm{CH}_{3}\right) ; 53,7\left(\mathrm{CH}_{3}\right) ; 55,4\left(\mathrm{CH}_{3}\right) ; 104,8$ $(\mathrm{CH}) ; 105,5(\mathrm{CH}) ; 112,4(\mathrm{CH}) ; 113,3(\mathrm{CH}) ; 113,7(2 \times \mathrm{CH}) ; 114,0(2 \times \mathrm{CH}) ; 123,3(\mathrm{C}) ;$ $126,9(\mathrm{C}) ; 128,9(2 \times \mathrm{CH}) ; 131,2(2 \times \mathrm{CH}) ; 132,8(\mathrm{C}) ; 143,9(\mathrm{C}) ; 147,2$ (C); 155,5 (C); 155,6 (C); 157,8 (C); 158,1 (C); 160,4 (C); 161,0 (C); 163,9 (C). Mezcla de isómeros $(Z+E)$.

IR (KBr): $1411,1451,1515,1544,1598,3163,3203,3272 \mathrm{~cm}^{-1}$

HRMS: Calculado $(\mathrm{M}+\mathrm{H}) 305,0960$. Obtenido $\left(\mathrm{C}_{15} \mathrm{H}_{17} \mathrm{~N}_{2} \mathrm{O}_{3} \mathrm{~S}\right) 305,0962$.

HPLC: Columna $C_{18} \quad t_{R}: 19,89$ min; $t_{R}: 20,25$ min.

\section{Obtención de 2-metilsulfanil-4-(1-(4-metoxifenil)etil)-6-metoxipiridina}


<smiles>C=C(C)C(C)(C)C(=O)OC</smiles>

Se disuelven $46 \mathrm{mg}$ (0,16 mmol) de 2-metoxi-4-(1-(4-metoxifenil)vinil)-6(metilsulfanil)piridina (50) en 5-10 $\mathrm{mL}$ de EtOAc/EtOH y se añade una espátula de $\mathrm{Pd}$ sobre carbón activo y se deja en atmósfera de hidrógeno y a temperatura ambiente durante $24 \mathrm{~h}$. Se va controlando el avance de la reacción mediante RMN ${ }^{1} \mathrm{H}$. Al noveno día, cuando se observa que no queda material de partida, se filtra a través de sílice y se evapora el disolvente. Se purifica mediante cromatografía flash usando como eluyente Hexano/EtOAc (98:2) obteniendo $8 \mathrm{mg} \quad(0,03 \mathrm{mmol} ; 17 \%)$ de 2-metilsulfanil4-(1-(4-metoxifenil)etil)-6-metoxipiridina.

\section{2-metilsulfanil-4-(1-(4-metoxifenil)etil)-6-metoxipiridina (52):}

$\mathrm{RMN}^{1} \mathrm{H}\left(\mathrm{CDCl}_{3}\right) \delta$ (ppm): (Espectro $\left.52 \mathrm{H}\right) 1,55\left(3 \mathrm{H}, \mathrm{d}, \mathrm{J}=6,7 ; \mathrm{CH}_{3}\right) ; 2,53\left(3 \mathrm{H}, \mathrm{s}, \mathrm{SCH}_{3}\right)$; $3,79\left(3 \mathrm{H}, \mathrm{s}, \mathrm{OCH}_{3}\right) ; 3,91\left(3 \mathrm{H}, \mathrm{s}, \mathrm{OCH}_{3}\right) ; 3,95(1 \mathrm{H}, \mathrm{c}, \mathrm{J}=6,7 ; \mathrm{CH}) ; 6,26(1 \mathrm{H}, \mathrm{s} ; \mathrm{pyr}) ; 6,61$ (1H, s; pyr); 6,83 (2H, d, J=8,3; Ar); 7,11 (2H, d, J=8,3; Ar).

RMN ${ }^{13} \mathrm{C}\left(\mathrm{CDCl}_{3}\right) \delta$ (ppm): (Espectro 52C) 13,2 $\left(\mathrm{CH}_{3}\right) ; 21,1\left(\mathrm{CH}_{3}\right) ; 43,3(\mathrm{CH}) ; 53,3$ $\left(\mathrm{CH}_{3}\right) ; 55,2\left(\mathrm{CH}_{3}\right) ; 104,3(\mathrm{CH}) ; 113,4(\mathrm{CH}) ; 113,8(2 \times \mathrm{CH}) ; 114,1(\mathrm{C}) ; 128.4(2 \times \mathrm{CH}) ;$ 136,5 (C); 156,7 (C); 158,6 (C); 164,0 (C).

IR (película): 1454, 1511, 1551, $1591 \mathrm{~cm}^{-1}$

HRMS: Calculado $(\mathrm{M}+\mathrm{H}) 290,1215$. Obtenido $\left(\mathrm{C}_{16} \mathrm{H}_{20} \mathrm{NO}_{2} \mathrm{~S}\right) 290,1205$.

HPLC: Columna $C_{8} \quad t_{R}: 20,72$ min. 


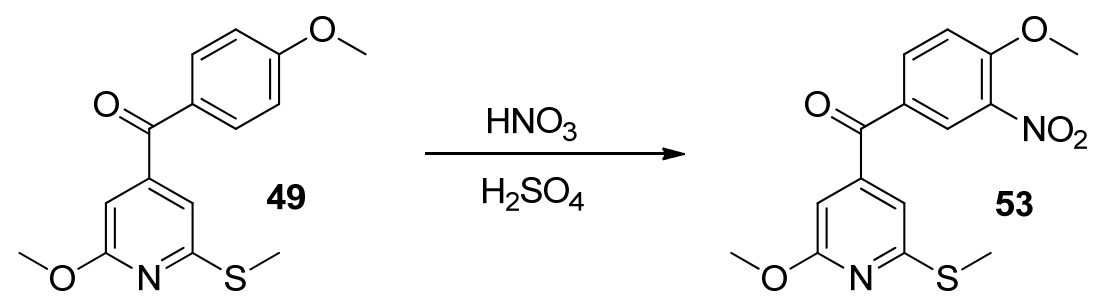

Se disuelven $328 \mathrm{~g}(1,13 \mathrm{mmol})$ de (2-metilsulfanil-6-metoxipiridin-4-il)(4metoxifenil)metanona (49) en $\mathrm{H}_{2} \mathrm{SO}_{4}(5-10 \mathrm{~mL})$ en baño de hielo, y se añade $0,43 \mathrm{~mL}$ de una dilución 1:5 de $\mathrm{HNO}_{3}$ en agua $(1,13 \mathrm{mmol})$. A los 5 minutos se vierte sobre carbonato sódico anhidro y $\mathrm{CH}_{2} \mathrm{Cl}_{2}$, se filtra y se evapora a sequedad. Se purifica mediante cromatografía flash, utilizando como eluyente Hexano/EtOAc (8:2) y se obtienen $89 \mathrm{mg}(0,27 \mathrm{mmol} ; 24 \%)$ de (4-metoxi-3-nitrofenil)(2-metilsulfanil-6metoxipiridin-4-il)metanona.

\section{(4-metoxi-3-nitrofenil)(2-metilsulfanil-6-metoxipiridin-4-il)metanona (53):}

$\mathrm{RMN}^{1} \mathrm{H}\left(\mathrm{CDCl}_{3}\right) \delta$ (ppm): (Espectro $\left.53 \mathrm{H}\right)$ 2,58 (3H, s, $\left.\mathrm{SCH}_{3}\right) ; 3,99\left(3 \mathrm{H}, \mathrm{s}, \mathrm{OCH}_{3}\right) ; 4,05$ $\left(3 \mathrm{H}, \mathrm{s}, \mathrm{OCH}_{3}\right) ; 6,56(1 \mathrm{H}, \mathrm{d}, \mathrm{J}=1,1 ; \mathrm{pyr}) ; 6,95(1 \mathrm{H}, \mathrm{d}, \mathrm{J}=1,1 ; \mathrm{pyr}) ; 7,18(1 \mathrm{H}, \mathrm{da}, \mathrm{J}=8,9$; $\left.H_{5}\right) ; 8,03\left(1 \mathrm{H}, \mathrm{dd}, \mathrm{J}=2,2 ; \mathrm{J}=8,9 ; \mathrm{H}_{6}\right) ; 8,30\left(1 \mathrm{H}, \mathrm{d}, \mathrm{J}=2,2 ; \mathrm{H}_{2}\right)$.

RMN ${ }^{13} \mathrm{C}\left(\mathrm{CDCl}_{3}\right) \delta(\mathrm{ppm})$ : (Espectro 53C) 13,5 $\left(\mathrm{CH}_{3}\right) ; 54,0\left(\mathrm{CH}_{3}\right) ; 57,1\left(\mathrm{CH}_{3}\right) ; 104,9$ $(\mathrm{CH}) ; 112,3(\mathrm{CH}) ; 113,4(\mathrm{CH}) ; 127,9(\mathrm{CH}) ; 128,3(\mathrm{C}) ; 135,9(\mathrm{CH}) ; 139,4(\mathrm{C}) ; 146,8(\mathrm{C})$; 156,6 (C); 159,4 (C); 163,9 (C); 191,8 (C).

IR (película): 1427, 1456, 1540, 1611, $1667 \mathrm{~cm}^{-1}$

HRMS: Calculado $(\mathrm{M}+\mathrm{H}) 335,0702$. Obtenido $\left(\mathrm{C}_{15} \mathrm{H}_{15} \mathrm{~N}_{2} \mathrm{O}_{5} \mathrm{~S}\right) 335,0716$.

HPLC: Columna $\mathrm{C}_{18} \mathrm{t}_{\mathrm{R}}: 20,92 \mathrm{~min}$.

Obtención de (3-amino-4-metoxifenil)(2-metilsulfanil-6-metoxipiridin-4il)metanona 


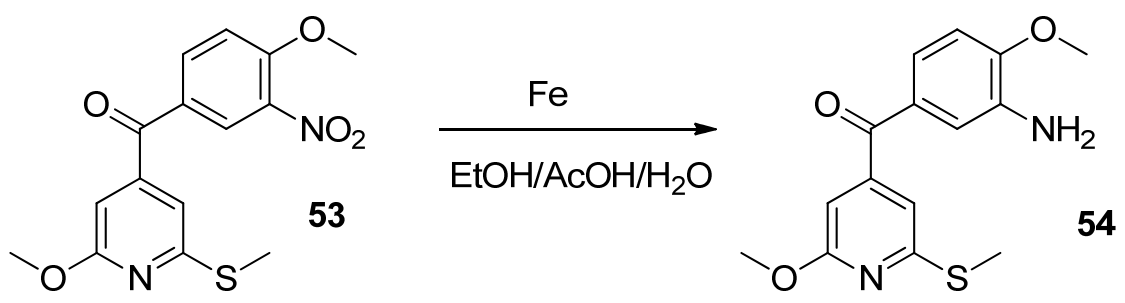

Se preparan $5 \mathrm{~mL}$ de una mezcla de etanol, ácido acético y agua en proporción 2:2:1 y se añade una gota de $\mathrm{HCl} 37 \%, 50 \mathrm{mg} \mathrm{(0,15} \mathrm{mmol)} \mathrm{de} \mathrm{(4-metoxi-3-nitrofenil)(2-}$ metilsulfanil-6-metoxipiridin-4-il)metanona (53) y $65 \mathrm{mg}(1,17 \mathrm{mmol})$ de $\mathrm{Fe}$ y se calienta a $100^{\circ} \mathrm{C}$ durante media hora. Posteriormente se enfría y se filtra a través de celita, se evapora el disolvente, se redisuelve en $\mathrm{CH}_{2} \mathrm{Cl}_{2} \mathrm{y}$ se extrae con una disolución de $\mathrm{NaHCO}_{3}$ al $5 \%$. La fase orgánica se lava con una disolución saturada de $\mathrm{NaCl}$, se seca con sulfato sódico anhidro, se filtra y se evapora obteniendo $42 \mathrm{mg}$ de crudo de reacción. Se purifica mediante cromatografía flash, utilizando como eluyente Hexano/EtOAc (9:1) y se obtienen 28 mg de un $90 \%$ de (3-amino-4-metoxifenil)(2metilsulfanil-6-metoxipiridin-4-il)metanona y un $10 \%$ de material de partida. Se realiza una CCP con $\mathrm{CH}_{2} \mathrm{Cl}_{2} /$ EtOAc (8:2) obteniendo $11 \mathrm{mg} \mathrm{(0,04} \mathrm{mmol;} \mathrm{24 \% )} \mathrm{de} \mathrm{(3-amino-4-}$ metoxifenil)(2-metilsulfanil-6-metoxipiridin-4-il)metanona.

(3-amino-4-metoxifenil)(2-metilsulfanil-6-metoxipiridin-4-il)metanona (54):

$\mathrm{RMN}^{1} \mathrm{H}\left(\mathrm{CDCl}_{3}\right) \delta$ (ppm): (Espectro $\left.54 \mathrm{H}\right) 2,58\left(3 \mathrm{H}, \mathrm{s}, \mathrm{SCH}_{3}\right) ; 3,96\left(3 \mathrm{H}, \mathrm{s}, \mathrm{OCH}_{3}\right) ; 3,99$ $\left(3 \mathrm{H}, \mathrm{s}, \mathrm{OCH}_{3}\right) ; 6,60(1 \mathrm{H}, \mathrm{d}, \mathrm{J}=1,2 ; \mathrm{pyr}) ; 6,86\left(1 \mathrm{H}, \mathrm{da}, \mathrm{J}=8,8 ; \mathrm{H}_{5}\right) ; 6,97(1 \mathrm{H}, \mathrm{d}, \mathrm{J}=1,2$; pyr); 7,36 (1H, dd, J=2,2; J=8,8; $\left.\mathrm{H}_{6}\right) ; 7,51\left(1 \mathrm{H}, \mathrm{d}, \mathrm{J}=2,2 ; \mathrm{H}_{2}\right)$.

RMN ${ }^{13} \mathrm{C}\left(\mathrm{CDCl}_{3}\right) \delta(\mathrm{ppm})$ : (Espectro $\left.54 \mathrm{C}\right)$ 13,3 $\left(\mathrm{CH}_{3}\right) ; 53,8\left(\mathrm{CH}_{3}\right) ; 55,8\left(\mathrm{CH}_{3}\right) ; 105,1$ $(\mathrm{CH}) ; 109,4(\mathrm{CH}) ; 112,6(\mathrm{CH}) ; 116,8(\mathrm{CH}) ; 124,0(\mathrm{C}) ; 124,4(\mathrm{CH}) ; 129,0(\mathrm{C}) ; 148,6(\mathrm{C})$; 152,4 (C); 158,3 (C); 163,7 (C); 193,7 (C).

IR (película): 1443, 1515, 1543, 1588, 1654, $3368 \mathrm{~cm}^{-1}$

HRMS: Calculado $(\mathrm{M}+\mathrm{H}) 305,0960$. Obtenido $\left(\mathrm{C}_{15} \mathrm{H}_{17} \mathrm{~N}_{2} \mathrm{O}_{3} \mathrm{~S}\right) 305,0961$.

HPLC: Columna $C_{8} \quad t_{R}: 14,81 \mathrm{~min}$. 
<smiles>COc1ccc(C(=O)c2cc(Cl)nc(SC)c2)cc1</smiles><smiles>CNCC1CCCCC1</smiles>

Se disuelve $400 \mathrm{mg}$ (1,36 $\mathrm{mmol})$ de (2-cloro-6-(metilsulfanil)piridin-4-il)(4 metoxifenil)metanona (38) en exceso de una disolución de dimetilamino al $33 \%$ en EtOH y se calienta a $80^{\circ} \mathrm{C}$ en atmósfera de argón durante 72 horas. Se evapora el disolvente y se purifica mediante cromatografía flash, utilizando como eluyente Hexano/EtOAc (95:5), obteniendo 266 mg (0,88 mmol; 65\%) de (2-(dimetilamino)-6(metilsulfanil)piridin-4-il)(4-metoxifenil)metanona.

\section{(2-(dimetilamino)-6-(metilsulfanil)piridin-4-il)(4-metoxifenil)metanona (55):}

P.f. ( $t$-Butilmetil éter): $76-81^{\circ} \mathrm{C}$

$\mathrm{RMN}^{1} \mathrm{H}\left(\mathrm{CDCl}_{3}\right) \delta$ (ppm): (Espectro $\left.55 \mathrm{H}\right)$ 2,55 (3H, s, $\left.\mathrm{SCH}_{3}\right) ; 3,11\left(6 \mathrm{H}, \mathrm{s}, \mathrm{NMe}_{2}\right) ; 3,88$ $\left(3 \mathrm{H}, \mathrm{s}, \mathrm{OCH}_{3}\right) ; 6,37(1 \mathrm{H}, \mathrm{s}, \mathrm{pyr}) ; 6,60(1 \mathrm{H}, \mathrm{s}, \mathrm{pyr}) ; 6,94(2 \mathrm{H}, \mathrm{d}, \mathrm{J}=8,9 ; \mathrm{Ar}) ; 7,84(2 \mathrm{H}, \mathrm{d}$, $\mathrm{J}=8,9 ; \mathrm{Ar})$.

RMN ${ }^{13} \mathrm{C}\left(\mathrm{CDCl}_{3}\right) \delta(\mathrm{ppm})$ : (Espectro 55C) 13,3 $\left(\mathrm{CH}_{3}\right) ; 38,0\left(2 \mathrm{xCH}_{3}\right) ; 55,6\left(\mathrm{CH}_{3}\right) ; 100,1$ $(\mathrm{CH}) ; 107,7(\mathrm{CH}) ; 113,8$ (2xCH); 129,2 (C); 132,7 (2xCH); 147,2 (C); 158,1 (C); 158,9 (C); 163,8 (C); 195,1 (C).

IR (KBr): 1405, 1501, 1537, 1592, 1652, $2920 \mathrm{~cm}^{-1}$

HRMS: Calculado $(\mathrm{M}+\mathrm{H}) 303,1167$. Obtenido $\left(\mathrm{C}_{16} \mathrm{H}_{19} \mathrm{~N}_{2} \mathrm{O}_{2} \mathrm{~S}\right) 303,1172$.

HPLC: Columna $\mathrm{C}_{18} \quad \mathrm{t}_{\mathrm{R}}: 22,29 \mathrm{~min}$.

Obtención de 4-(1-(4-metoxifenil)vinil)-N,N-dimetil-6-(metilsulfanil)piridin-

\section{2-amina}


<smiles>C=C(c1ccc(OC)cc1)c1cc(SC)nc(N(C)C)c1</smiles>

Siguiendo el método $B$, se prepara una suspensión de $645 \mathrm{mg}(1,6 \mathrm{mmol})$ de yoduro de metiltrifenilfosfonio (19) en THF seco $(20 \mathrm{~mL})$ a $-40^{\circ} \mathrm{C}$ y en atmósfera de argón, y posteriormente se añaden 0,67 $\mathrm{mL}(1,07 \mathrm{mmol})$ de una disolución 1,6 $\mathrm{M}$ de $n$ BuLi en hexano. A continuación se añaden $162 \mathrm{mg}(0,54 \mathrm{mmol})$ de 2-(dimetilamino)6-(metilsulfanil)piridin-4-il)(4-metoxifenil)metanona (55) disueltos en THF seco (10 mL). Se purifica mediante cromatografía flash, utilizando como eluyente Hexano/EtOAc (99:1) obteniendo $61 \mathrm{mg}(0,2 \mathrm{mmol} ; 38 \%)$ de 4-(1-(4-metoxifenil)vinil)-N,N-dimetil-6(metilsulfanil)piridin-2-amina.

\section{4-(1-(4-metoxifenil)vinil)-N,N-dimetil-6-(metilsulfanil)piridin-2-amina (56):}

$\mathrm{RMN}^{1} \mathrm{H}\left(\mathrm{CDCl}_{3}\right) \delta$ (ppm): (Espectro $\left.56 \mathrm{H}\right) 2,54\left(3 \mathrm{H}, \mathrm{s}, \mathrm{SCH}_{3}\right) ; 3,07\left(6 \mathrm{H}, \mathrm{s}, \mathrm{NCH}_{3}\right) ; 3,82$ $\left(3 \mathrm{H}, \mathrm{s}, \mathrm{OCH}_{3}\right) ; 5,38\left(1 \mathrm{H}, \mathrm{s} ; \mathrm{CH}_{2}\right) ; 5,44\left(1 \mathrm{H}, \mathrm{s} ; \mathrm{CH}_{2}\right) ; 6,11(1 \mathrm{H}, \mathrm{s}, \mathrm{pyr}) ; 6,42(1 \mathrm{H}, \mathrm{s}, \mathrm{pyr})$; $6,85(2 \mathrm{H}, \mathrm{d}, \mathrm{J}=8,6 ; \mathrm{Ar}) ; 7,26(2 \mathrm{H}, \mathrm{d}, \mathrm{J}=8,6 ; \mathrm{Ar})$.

RMN ${ }^{13} \mathrm{C}\left(\mathrm{CDCl}_{3}\right) \delta$ (ppm): (Espectro 56C) 13,3 $\left(\mathrm{CH}_{3}\right) ; 38,0\left(2 x \mathrm{CH}_{3}\right) ; 55,4\left(\mathrm{CH}_{3}\right) ; 100,7$ $(\mathrm{CH}) ; 108,7(\mathrm{CH}) ; 113,6(2 \times \mathrm{CH}) ; 114,0\left(\mathrm{CH}_{2}\right) ; 129,3(2 \times C H) ; 132,7(\mathrm{C}) ; 148,5(\mathrm{C})$; 151,0 (C); 157,2 (C); 159,2 (C); 159,5 (C).

IR (película): 1407, 1460, 1513, 1532, $1585 \mathrm{~cm}^{-1}$

HRMS: Calculado $(\mathrm{M}+\mathrm{H}) 301,1375$. Obtenido $\left(\mathrm{C}_{17} \mathrm{H}_{21} \mathrm{~N}_{2} \mathrm{OS}\right) 301,1378$.

HPLC: Columna $\mathrm{C}_{8} \quad \mathrm{t}_{\mathrm{R}}: 21,64 \mathrm{~min}$.

Obtención de las oximas de (2-(dimetilamino)-6-(metilsulfanil)piridin-4il)(4-metoxifenil)metanona 
<smiles>COc1ccc(C(=O)c2cc(SC)nc(N(C)C)c2)cc1</smiles><smiles>COC(O)C1CCCC1</smiles><smiles>COc1ccc(/C(=N/O)c2cc(SC)nc(N(C)C)c2)cc1</smiles>

Siguiendo el método $\mathrm{E}$, se disuelven $91 \mathrm{mg}(0,30 \mathrm{mmol})$ de (2-(dimetilamino)-6(metilsulfanil)piridin-4-il)(4-metoxifenil)metanona (55) en $\mathrm{MeOH} \quad(20 \mathrm{~mL})$, y posteriormente se añaden $209 \mathrm{mg}(3,01 \mathrm{mmol})$ de clorhidrato de hidroxilamina. Se obtienen 94 mg (0,30 mmol; 98\%) de una mezcla de las oximas de (2-(dimetilamino)-6(metilsulfanil)piridin-4-il)(4-metoxifenil)metanona, que cristalizan en Hexano/ $\mathrm{CH}_{2} \mathrm{Cl}_{2}$ en proporción 7:3.

Oximas de (2-(dimetilamino)-6-(metilsulfanil)piridin-4-il)(4-metoxifenil)metanona (57ZE):

P.f. $\left(\mathrm{Hex} / \mathrm{CH}_{2} \mathrm{Cl}_{2}\right): 126-140^{\circ} \mathrm{C}$

$\mathrm{RMN}^{1} \mathrm{H}\left(\mathrm{CDCl}_{3}\right) \delta(\mathrm{ppm})$ : (Espectro 57ZEH) 2,51 (3H, s, SCH $)_{3} ; 3,09\left(6 \mathrm{H}, \mathrm{s}, \mathrm{NCH}_{3}\right)$; $3,86\left(3 \mathrm{H}, \mathrm{s}, \mathrm{OCH}_{3}\right) ; 6,27(1 \mathrm{H}, \mathrm{s}, \mathrm{pyr}) ; 6,47(1 \mathrm{H}, \mathrm{s}, \mathrm{pyr}) ; 6,95(2 \mathrm{H}, \mathrm{d}, \mathrm{J}=8,6 ; \mathrm{Ar}) ; 7,43$ $(2 \mathrm{H}, \mathrm{d}, \mathrm{J}=8,6 ; \mathrm{Ar})$. Isómero $E$.

$\mathrm{RMN}^{1} \mathrm{H}\left(\mathrm{CDCl}_{3}\right) \delta$ (ppm): (Espectro 57ZEH) 2,55 (3H, s, SCH $)_{3} ; 3,17\left(6 \mathrm{H}, \mathrm{s}, \mathrm{NCH}_{3}\right)$; $3,81\left(3 \mathrm{H}, \mathrm{s}, \mathrm{OCH}_{3}\right) ; 6,09(1 \mathrm{H}, \mathrm{s}, \mathrm{pyr}) ; 6,39(1 \mathrm{H}, \mathrm{s}, \mathrm{pyr}) ; 6,84(1 \mathrm{H}, \mathrm{d}, \mathrm{J}=8,6 ; \mathrm{pyr}) ; 7,43$ $(2 \mathrm{H}, \mathrm{d}, \mathrm{J}=8,6 ; \mathrm{Ar})$. Isómero $Z$.

RMN ${ }^{13} \mathrm{C}\left(\mathrm{CDCl}_{3}\right) \delta(\mathrm{ppm})$ : (Espectro 57ZEC) 13,53 $\left(\mathrm{CH}_{3}\right) ; 37,9\left(2 \times \mathrm{CH}_{3}\right) ; 55,4\left(\mathrm{CH}_{3}\right)$; $100,2(\mathrm{CH}) ; 107,9(\mathrm{CH}) ; 113,6(\mathrm{CH}) ; 113,9(2 \times \mathrm{CH}) ; 127,3(\mathrm{C}) ; 128,9(2 \times \mathrm{CH}) ; 131,4$ $(\mathrm{CH}) ; 142,5(\mathrm{C}) ; 156,6(\mathrm{C}) ; 158,0(\mathrm{C}) ; 158,9$ (C); 160,9 (C). Mezcla de isómeros (ZE).

IR (KBr): 1412, 1457, 1511, 1540, 1588, $3243 \mathrm{~cm}^{-1}$

HRMS: Calculado $(\mathrm{M}+\mathrm{H}) 318,1276$. Obtenido $\left(\mathrm{C}_{16} \mathrm{H}_{20} \mathrm{~N}_{3} \mathrm{O}_{2} \mathrm{~S}\right) 318,1287$.

HPLC: Columna $C_{18} \quad t_{R}: 20,48$ min; $t_{R}: 20,72 \min$.

\section{metoxifenil)metanona}


<smiles>COc1cc(C(=O)O)cc(N(C)C)n1</smiles>

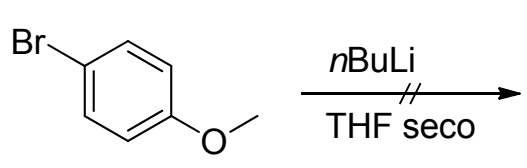<smiles>COc1ccc(C(=O)c2cc(OC)nc(N(C)C)c2)cc1</smiles>

Siguiendo el método A, se prepara una disolución de 1,36 $\mathrm{mL}(10,9 \mathrm{mmol})$ de 4bromoanisol en THF seco $(20 \mathrm{~mL})$, se añaden $6,8 \mathrm{~mL}(10,9 \mathrm{mmol})$ de una disolución $1,6 \mathrm{M}$ de $n \mathrm{BuLi}$ en hexano y se deja media hora en agitación. A continuación se añaden $855 \mathrm{mg}(4,36 \mathrm{mmol})$ de ácido 2-(dimetilamino)-6-metoxipiridina-4-carboxílico (115) disuelto en THF seco $(10-20 \mathrm{~mL})$. No se observa formación de la cetona 58 por RMN ${ }^{1} \mathrm{H}$.

\section{metoxifenil)metanona}<smiles>COc1ccc(C(=O)c2cc(Cl)nc(OC)c2)cc1</smiles><smiles>CNC1CCCC1</smiles><smiles>COc1ccc(C(=O)c2cc(OC)nc(N(C)C)c2)cc1</smiles>

Se disuelve $1 \mathrm{~g} \quad(3,6 \mathrm{mmol})$ de (2-cloro-6-metoxipiridin-4-il)(4metoxifenil)metanona (28) en exceso de una disolución de dimetilamino al 33\% en EtOH y se calienta a $80^{\circ} \mathrm{C}$ en atmósfera de argón durante 24 horas. Se controla el avance de la reacción mediante $\mathrm{RMN}{ }^{1} \mathrm{H}$ hasta la total desaparición del material de partida. Se evapora el disolvente y se purifica mediante cromatografía flash, utilizando como eluyente Hexano/EtOAc (95:5), obteniendo $655 \mathrm{mg}(2,29 \mathrm{mmol} ; 64 \%)$ de (2(dimetilamino)-6-metoxipiridin-4-il)(4-metoxifenil)metanona, que se cristaliza en $t$ Butilmetil éter.

\section{(2-(dimetilamino)-6-metoxipiridin-4-il)(4-metoxifenil)metanona (58):}

P.f. (t-Butilmetil éter): $83-85^{\circ} \mathrm{C}$ 
$\mathrm{RMN}^{1} \mathrm{H}\left(\mathrm{CDCl}_{3}\right) \delta(\mathrm{ppm}):($ Espectro $58 \mathrm{H})$ 3,09 (6H, s, NMe $)$ ); 3,88 (3H, s, $\left.\mathrm{OCH}_{3}\right) ; 3,92$ $\left(3 \mathrm{H}, \mathrm{s}, \mathrm{OCH}_{3}\right) ; 6,14(1 \mathrm{H}, \mathrm{s}, \mathrm{pyr}) ; 6,25(1 \mathrm{H}, \mathrm{s}, \mathrm{pyr}) ; 6,94(2 \mathrm{H}, \mathrm{d}, \mathrm{J}=8,9 ; \mathrm{Ar}) ; 7,88(2 \mathrm{H}, \mathrm{d}$, $\mathrm{J}=8,9 ; \mathrm{Ar})$.

$\mathrm{RMN}{ }^{13} \mathrm{C}\left(\mathrm{CDCl}_{3}\right) \delta(\mathrm{ppm}):($ Espectro $58 \mathrm{C}) 37,9\left(2 \times \mathrm{CH}_{3}\right) ; 53,3\left(\mathrm{CH}_{3}\right) ; 55,5\left(\mathrm{CH}_{3}\right) ; 95,9$ (CH); 96,6 (CH); 113,7 (2xCH); 129,3 (C); 132,7 (2xCH); 149,9 (C); 158,4 (C); 163,1 (C); 163,8 (C); 195,3 (C).

$\mathrm{IR}(\mathrm{KBr}): 1405,1507,1560,1598,1659 \mathrm{~cm}^{-1}$

HRMS: Calculado $(\mathrm{M}+\mathrm{H}) 287,1396$. Obtenido $\left(\mathrm{C}_{16} \mathrm{H}_{19} \mathrm{~N}_{2} \mathrm{O}_{3}\right) 287,1392$.

HPLC: Columna $\mathrm{C}_{18} \mathrm{t}_{\mathrm{R}}: 21,15 \mathrm{~min}$.

\section{Obtención de 6-metoxi-4-(1-(4-metoxifenil)vinil)- $N, N$-dimetilpiridin-2-amina}<smiles>COc1ccc(C(=O)c2cc(OC)nc(N(C)C)c2)cc1</smiles>

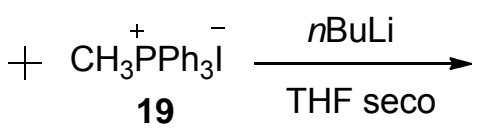

19

58<smiles>C=C(c1ccc(OC)cc1)c1cc(OC)nc(N(C)C)c1</smiles>

59

A 1,41 g (3,50 mmol) de yoduro de metiltrifenilfosfonio (19) en THF seco (30 mL) a $-40^{\circ} \mathrm{C}$ y en atmósfera de argón, se añaden $1,46 \mathrm{~mL}(2,33 \mathrm{mmol})$ de una disolución 1,6 $\mathrm{M}$ de $n$ BuLi en hexano según método $\mathrm{B}$. Posteriormente se añaden $334 \mathrm{mg}(1,17$ mmol) de (2-(dimetilamino)-6-metoxipiridin-4-il)(4-metoxifenil)metanona (58) disueltos en THF seco (10-20 mL). Se obtienen $795 \mathrm{mg}$ de crudo de reacción que se purifican mediante cromatografía flash, utilizando como eluyente Hexano/EtOAc (98:2) obteniendo $43 \mathrm{mg}$ (0,15 mmol; 13\%) de 6-metoxi-4-(1-(4-metoxifenil)vinil)- $N, N$ dimetilpiridin-2-amina y $229 \mathrm{mg}$ con un $70 \%$ de pureza que se cromatografía CCP con Hexano/EtOAc (8:2) obteniendo $14 \mathrm{mg}$ de (59).

6-metoxi-4-(1-(4-metoxifenil)vinil)- $N, N$-dimetilpiridin-2-amina (59): 
$\mathrm{RMN}^{1} \mathrm{H}\left(\mathrm{CDCl}_{3}\right) \delta$ (ppm): (Espectro $\left.59 \mathrm{H}\right) 3,05\left(6 \mathrm{H}, \mathrm{s}, \mathrm{NMe}_{2}\right) ; 3,82\left(3 \mathrm{H}, \mathrm{s}, \mathrm{OCH}_{3}\right) ; 3,89$ $\left(3 \mathrm{H}, \mathrm{s}, \mathrm{OCH}_{3}\right) ; 5,40\left(1 \mathrm{H}, \mathrm{d}, \mathrm{J}=1,1 ; \mathrm{CH}_{2}\right) ; 5,43\left(1 \mathrm{H}, \mathrm{d}, \mathrm{J}=1,1 ; \mathrm{CH}_{2}\right) ; 5,97(1 \mathrm{H}, \mathrm{s}, \mathrm{pyr}) ;$ $5,98(1 \mathrm{H}, \mathrm{s}, \mathrm{pyr}) ; 6,85(2 \mathrm{H}, \mathrm{d}, \mathrm{J}=8,9 ; \operatorname{Ar}) ; 7,28(2 \mathrm{H}, \mathrm{d}, \mathrm{J}=8,9 ; \mathrm{Ar})$.

$\mathrm{RMN}{ }^{13} \mathrm{C}\left(\mathrm{CDCl}_{3}\right) \delta(\mathrm{ppm})$ : (Espectro $\left.59 \mathrm{C}\right) 38,1\left(2 \times \mathrm{CH}_{3}\right) ; 53,2\left(\mathrm{CH}_{3}\right) ; 55,4\left(\mathrm{CH}_{3}\right) ; 96,0$ $(\mathrm{CH}) ; 97,3(\mathrm{CH}) ; 113,6(2 \times \mathrm{CH}) ; 113,6\left(\mathrm{CH}_{2}\right) ; 129,3(2 \times \mathrm{CH}) ; 132,9(\mathrm{C}) ; 148,8(\mathrm{C}) ; 153,7$ (C); 158,4 (C); 159,4 (C); 163,3 (C).

IR (película): 1447, 1508, 1555, $1601 \mathrm{~cm}^{-1}$

HRMS: Calculado $(\mathrm{M}+\mathrm{H}) 285,1603$. Obtenido $\left(\mathrm{C}_{17} \mathrm{H}_{21} \mathrm{~N}_{2} \mathrm{O}_{2}\right) 285,1598$.

HPLC: Columna $\mathrm{C}_{18} \mathrm{t}_{\mathrm{R}}: 23,88 \mathrm{~min}$.

\section{Obtención de las oximas de (2-(dimetilamino)-6-metoxipiridin-4-il)(4-} metoxifenil)metanona<smiles>COc1ccc(C(=O)c2cc(OC)nc(N(C)C)c2)cc1</smiles><smiles>CO[C@@H](Cl)O[Na]</smiles><smiles>COc1ccc(/C(=N/O)c2cc(OC)nc(N(C)C)c2)cc1</smiles>

Siguiendo el método $\mathrm{E}$, se disuelven $140 \mathrm{mg}(0,49 \mathrm{mmol})$ de (2-(dimetilamino)-6metoxipiridin-4-il)(4-metoxifenil)metanona (58) en $\mathrm{MeOH}(20 \mathrm{~mL})$ y se añaden $340 \mathrm{mg}$ $(4,89 \mathrm{mmol})$ de clorhidrato de hidroxilamina. Por cristalización en terc-butilmetiléter se obtienen $19 \mathrm{mg}(0,06 \mathrm{mmol} ; 13 \%)$ de un isómero (60a) y en las aguas madres se obtienen $113 \mathrm{mg}(0,38 \mathrm{mmol} ; 77 \%)$ de mezcla de oximas (60ZE) en proporción 6:4. El isómero aislado se isomeriza en disolución de $\mathrm{CDCl}_{3}$.

Oxima de la (2-(dimetilamino)-6-metoxipiridin-4-il)(4-metoxifenil)metanona (60a): 
P.f. (t-Butilmetil éter): $150-152^{\circ} \mathrm{C}$

RMN ${ }^{1} \mathrm{H}\left(\mathrm{CDCl}_{3}\right) \delta$ (ppm): (Espectro 60aH) 3,04 (6H, s, NMe $\left.)_{2}\right) ; 3,85\left(3 \mathrm{H}, \mathrm{s}, \mathrm{OCH}_{3}\right) ; 3,86$ $\left(3 \mathrm{H}, \mathrm{s}, \mathrm{OCH}_{3}\right) ; 5,97(1 \mathrm{H}, \mathrm{d}, \mathrm{J}=1,1 ; \mathrm{pyr}) ; 6,17(1 \mathrm{H}, \mathrm{d}, \mathrm{J}=1,1 ; \mathrm{pyr}) ; 6,95(2 \mathrm{H}, \mathrm{d}, \mathrm{J}=8,9$; pyr); 7,40 (2H, d, J=8,9; pyr). Isómero 60a (E ó Z)

$\mathrm{RMN}{ }^{13} \mathrm{C}\left(\mathrm{CDCl}_{3}\right) \delta(\mathrm{ppm})$ : (Espectro 60ZEC) 37,9 $\left(2 \mathrm{xCH}_{3}\right) ; 53,2\left(\mathrm{CH}_{3}\right) ; 55,4\left(\mathrm{CH}_{3}\right)$; 113,5 (2xCH); 113,9 (CH); 124,1 (C); 127,4 (C); 128,9 (2xCH); 131,4 (CH); 145,2 (C); 148,3 (C); 156,9 (C); 158,4 (C); 160,2 (C); 160,9 (C); 163,4 (C). Isómeros E y Z IR (KBr): 1412, 1450, 1512, 1565, $1602 \mathrm{~cm}^{-1}$ HRMS: Calculado $(\mathrm{M}+\mathrm{H}) 302,1505$. Obtenido $\left(\mathrm{C}_{16} \mathrm{H}_{20} \mathrm{~N}_{3} \mathrm{O}_{3}\right) 302,1495$. HPLC: Columna $C_{8} \quad t_{R}: 15,22 \mathrm{~min}$. 


\section{D.4.2. SÍNTESIS DE COMPUESTOS CON INDOL}

\section{Obtención de (2,6-dicloropiridin-4-il)(1-metil-1H-indol-5-il)metanona}<smiles>O=C(O)c1cc(Cl)nc(Cl)c1</smiles><smiles>Cn1ccc2cc(Br)ccc21</smiles>

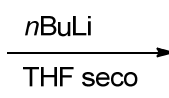<smiles>Cn1ccc2cc(C(=O)c3cc(Cl)nc(Cl)c3)ccc21</smiles><smiles>Cn1ccc2cc(-c3cc(Cl)nc(Cl)c3)ccc21</smiles>

Siguiendo el método A, se disuelven 4,10 g (19,5 mmol) de 5-bromo-1-metil- $1 \mathrm{H}$ indol (15) en THF seco (30 mL), y se añaden 12,2 $\mathrm{mL}(19,5 \mathrm{mmol})$ de una disolución 1,6 $\mathrm{M}$ de $n$ BuLi en hexano. Posteriormente se añaden $1,5 \mathrm{~g}(7,8 \mathrm{mmol})$ de ácido 2,6dicloropiridina-4-carboxílico (1) disuelto en THF seco (20 mL). Por cromatografía flash usando como eluyente Hexano/EtOAc (9:1) se obtienen $502 \mathrm{mg}(1,64 \mathrm{mmol} ; 21 \%)$ de (2,6-dicloropiridin-4-il)(1-metil-1H-indol-5-il)metanona (61) y 176 mg (0,64 mmol; 8\%) de 5-(2,6-dicloropiridin-4-il)-1-metil-1H-indol (62).

(2,6-dicloropiridin-4-il)(1-metil-1 $H$-indol-5-il)metanona (61):

P.f. (Hexano/EtOAc): $164-165^{\circ} \mathrm{C}$

$\mathrm{RMN}^{1} \mathrm{H}\left(\mathrm{CDCl}_{3}\right) \delta(\mathrm{ppm})$ : (Espectro $\left.61 \mathrm{H}\right) 3,85\left(3 \mathrm{H}, \mathrm{s}, \mathrm{NCH}_{3}\right) ; 6,61\left(1 \mathrm{H}, \mathrm{d}, \mathrm{J}=3,2 ; \mathrm{H}_{3}\right)$; 7,17 (1H, d, J=3,2; $\left.\mathrm{H}_{2}\right) ; 7,40\left(1 \mathrm{H}, \mathrm{da}, \mathrm{J}=8,8 ; \mathrm{H}_{7}\right) ; 7,49(2 \mathrm{H}, \mathrm{s}, \mathrm{pyr}) ; 7,75(1 \mathrm{H}, \mathrm{dd}, \mathrm{J}=1,6$; $\left.J=8,8 ; H_{6}\right) ; 8,01\left(1 \mathrm{H}, \mathrm{d}, \mathrm{J}=1,6 ; \mathrm{H}_{4}\right)$.

$\mathrm{RMN}{ }^{13} \mathrm{C}\left(\mathrm{CDCl}_{3}\right) \delta(\mathrm{ppm})$ : (Espectro 61C) 33,2 $\left(\mathrm{CH}_{3}\right) ; 103,5(\mathrm{CH}) ; 109,9(\mathrm{CH}) ; 122,3$ (2xCH); 123,3 (CH); 125,9 (CH); 126,7 (C); 127,9 (C); 131,2 (CH); 139,7 (C); 150,8 (2xC); 151,7 (C); 192,2 (C).

$\mathrm{IR}(\mathrm{KBr}): 1508,1530,1561,1604,1650 \mathrm{~cm}^{-1}$

HRMS: Calculado $(\mathrm{M}+\mathrm{H}) 305,0248$. Obtenido $\left(\mathrm{C}_{15} \mathrm{H}_{11} \mathrm{Cl}_{2} \mathrm{~N}_{2} \mathrm{O}\right) 305,0246$.

HPLC: Columna $\mathrm{C}_{8} \quad \mathrm{t}_{\mathrm{R}}: 18,32 \mathrm{~min}$. 


\section{5-(2,6-dicloropiridin-4-il)-1-metil-1H-indol (62):}

$\mathrm{RMN}^{1} \mathrm{H}\left(\mathrm{CDCl}_{3}\right) \delta$ (ppm): (Espectro 62H) 3,80 (3H, s, $\left.\mathrm{NCH}_{3}\right) ; 6,54\left(1 \mathrm{H}, \mathrm{d}, \mathrm{J}=2,8 ; \mathrm{H}_{3}\right)$; 7,11 (1H, d, J=2,8; $\left.\mathrm{H}_{2}\right) ; 7,37\left(1 \mathrm{H}, \mathrm{da}, \mathrm{J}=8,8 ; \mathrm{H}_{7}\right) ; 7,40\left(1 \mathrm{H}, \mathrm{da}, \mathrm{J}=8,8 ; \mathrm{H}_{6}\right) ; 7,46(2 \mathrm{H}, \mathrm{s}$, pyr); 7,82 (1H, s, $\left.\mathrm{H}_{4}\right)$.

$\mathrm{RMN}{ }^{13} \mathrm{C}\left(\mathrm{CDCl}_{3}\right) \delta(\mathrm{ppm})$ : (Espectro 62C) 33,1 $\left(\mathrm{CH}_{3}\right) ; 101,9(\mathrm{CH}) ; 110,1(2 \times \mathrm{CH}) ; 120,0$ $(\mathrm{CH}) ; 120,4(2 \times C H) ; 126,6(\mathrm{C}) ; 129,0(\mathrm{C}) ; 130,5(\mathrm{CH}) ; 137,6(\mathrm{C}) ; 150,6(2 \times \mathrm{C}) ; 155,2$ (C).

IR (KBr): 1418, 1495, 1530, $1579 \mathrm{~cm}^{-1}$

HRMS: Calculado $(\mathrm{M}+\mathrm{H}) 277,0299$. Obtenido $\left(\mathrm{C}_{14} \mathrm{H}_{11} \mathrm{Cl}_{2} \mathrm{~N}_{2}\right) 277,0295$.

HPLC: Columna $\mathrm{C}_{8} \quad \mathrm{t}_{\mathrm{R}}: 19,11 \mathrm{~min}$.

\section{Obtención de 5-(1-(2,6-dicloropiridin-4-il)vinil)-1-metil-1H-indol}

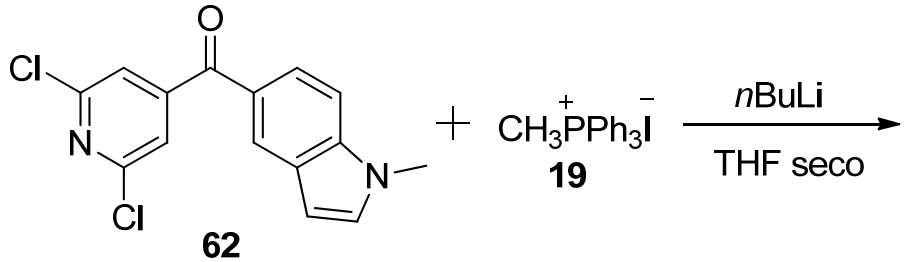<smiles>C=C(c1cc(Cl)nc(Cl)c1)c1ccc2c(ccn2C)c1</smiles>

Siguiendo el método $B$, se prepara una suspensión de $765 \mathrm{mg}(1,90 \mathrm{mmol})$ de yoduro de metiltrifenilfosfonio (19) en THF seco $(20 \mathrm{~mL})$ a $-40^{\circ} \mathrm{C}$ y se adicionan 0,80 $\mathrm{mL}(1,26 \mathrm{mmol})$ de una disolución 1,6 M de $n$ BuLi en hexano. Posteriormente se adicionan $193 \mathrm{mg}$ (0,63 mmol) de (2,6-dicloropiridin-4-il)(1-metil-1H-indol-5il)metanona (62) en THF seco (20 mL) obteniendo $461 \mathrm{mg}$ de crudo de reacción. Se purifica mediante cromatografía flash usando como eluyente Hexano/EtOAc (98:2) y se obtienen $113 \mathrm{mg}(0,37 \mathrm{mmol} ; 59 \%)$ de 5-(1-(2,6-dicloropiridin-4-il)vinil)-1-metil-1Hindol. 


\section{5-(1-(2,6-dicloropiridin-4-il)vinil)-1-metil-1H-indol (63):}

$\mathrm{RMN}^{1} \mathrm{H}\left(\mathrm{CDCl}_{3}\right) \delta$ (ppm): (Espectro 63H) 3,73 (3H, s, $\left.\mathrm{NCH}_{3}\right) ; 5,48\left(1 \mathrm{H}, \mathrm{s} ; \mathrm{CH}_{2}\right) ; 5,56$ $\left(1 \mathrm{H}, \mathrm{s} ; \mathrm{CH}_{2}\right) ; 6,41\left(1 \mathrm{H}, \mathrm{d}, \mathrm{J}=3,2 ; \mathrm{H}_{3}\right) ; 7,01\left(1 \mathrm{H}, \mathrm{d}, \mathrm{J}=3,2 ; \mathrm{H}_{2}\right) ; 7,03(2 \mathrm{H}, \mathrm{s}, \mathrm{pyr}) ; 7,03$ $\left(1 \mathrm{H}, \mathrm{dd}, \mathrm{J}=1,6 ; \mathrm{J}=8,4 ; \mathrm{H}_{6}\right) ; 7,23\left(1 \mathrm{H}, \mathrm{da}, \mathrm{J}=8,4 ; \mathrm{H}_{7}\right) ; 7,42\left(1 \mathrm{H}, \mathrm{d}, \mathrm{J}=1,6 ; \mathrm{H}_{4}\right)$.

RMN ${ }^{13} \mathrm{C}\left(\mathrm{CDCl}_{3}\right) \delta$ (ppm): (Espectro 63C) 33,0 ( $\left.\mathrm{CH}_{3}\right) ; 101,5(\mathrm{CH}) ; 109,4(\mathrm{CH}) ; 117,4$ $\left(\mathrm{CH}_{2}\right) ; 120,8(\mathrm{CH}) ; 121,8(\mathrm{CH}) ; 122,1(2 \times C H) ; 128,5(\mathrm{C}) ; 129,9(\mathrm{CH}) ; 130,1(\mathrm{C}) ; 136,7$ (C); 147,1 (C); 150,5 (2xC); 155,8 (C).

HRMS: Calculado $(\mathrm{M}+\mathrm{H}) 303,0456$. Obtenido $\left(\mathrm{C}_{16} \mathrm{H}_{13} \mathrm{Cl}_{2} \mathrm{~N}_{2}\right) 303,0450$.

HPLC: Columna $C_{8} \quad t_{R}: 20,19 \min$.

\section{Obtención de 5-(2,6-dicloropiridin-4-il)-1-metil-1H-indol-3-carbaldehído}<smiles>Cn1ccc2cc(C(=O)c3cc(Cl)nc(Cl)c3)ccc21</smiles><smiles>COC(C)(F)F</smiles><smiles>Cn1cc(C=O)c2cc(C(=O)c3cc(Cl)nc(Cl)c3)ccc21</smiles>

Siguiendo el método $\mathrm{F}$, se disuelven $0,25 \mathrm{~mL}(2,75 \mathrm{mmol})$ de $\mathrm{POCl}_{3}$ en $\mathrm{DMF}$ seca $(5 \mathrm{~mL})$, y a la media hora se añaden $140 \mathrm{mg}(0,46 \mathrm{mmol})$ de (2,6-dicloropiridin-4il)(1-metil-1H-indol-5-il)metanona (61) disueltos en $5 \mathrm{~mL}$ de DMF seca, y se deja 2 horas a $60{ }^{\circ} \mathrm{C}$. Por filtración se obtienen $137 \mathrm{mg}$ de precipitado que se purifica mediante cromatografía flash, utilizando como eluyente Hexano/EtOAc (1:1) obteniendo $129 \mathrm{mg}$ (0,39 mmol; 84\%) de 5-(2,6-dicloropiridin-4-il)-1-metil-1H-indol-3carbaldehído.

\section{5-(2,6-dicloropiridin-4-il)-1-metil-1H-indol-3-carbaldehído (64):}

$\mathrm{RMN}^{1} \mathrm{H}\left(\mathrm{CDCl}_{3}\right) \delta$ (ppm): (Espectro 64H) 3,97 (3H, s, NCH$)_{3} ; 7,50\left(1 \mathrm{H}, \mathrm{da}, \mathrm{J}=8,8 ; \mathrm{H}_{7}\right)$; 7,52 (2H, s, pyr); 7,83 (1H, s; $\left.\mathrm{H}_{2}\right) ; 7,90\left(1 \mathrm{H}, \mathrm{dd}, \mathrm{J}=1,6 ; \mathrm{J}=8,8 ; \mathrm{H}_{6}\right) ; 8,66(1 \mathrm{H}, \mathrm{d}, \mathrm{J}=1,6$; $\left.\mathrm{H}_{4}\right) ; 10,01(1 \mathrm{H}, \mathrm{s}, \mathrm{CHO})$.

RMN ${ }^{13} \mathrm{C}\left(\mathrm{CDCl}_{3}\right) \delta$ (ppm): (Espectro 64C) 34,1 $\left(\mathrm{CH}_{3}\right) ; 110,7(\mathrm{CH}) ; 119,1(\mathrm{C}) ; 122,4$ (2xCH); 124,8 (C); 125,6 (CH); 126,1 (CH); 129,9 (C); 140,7 (C); 140,8 (CH); 150,7 (C); 151,1 (2xC); 184,2 (CHO); 192,2 (C). 
IR: (película): 1531, 1573, $1659 \mathrm{~cm}^{-1}$

HRMS: Calculado $(\mathrm{M}+\mathrm{H}) 333,0199$. Obtenido $\left(\mathrm{C}_{16} \mathrm{H}_{11} \mathrm{Cl}_{2} \mathrm{~N}_{2} \mathrm{O}_{2}\right) 333,0198$.

HPLC: Columna $\mathrm{C}_{8} \quad \mathrm{t}_{\mathrm{R}}: 11,93 \mathrm{~min}$.

\section{Obtención} de 5-(1-(2,6-dicloropiridin-4-il)vinil)-1-metil-1H-indol-3-

\section{carbaldehído}<smiles>C=C(c1cc(Cl)nc(Cl)c1)c1ccc2c(ccn2C)c1</smiles><smiles>COC(C)(C)O[Na]</smiles>

63<smiles>C=C(c1cc(Cl)nc(Cl)c1)c1ccc2c(c1)c(C=O)cn2C</smiles>

Siguiendo el método $\mathrm{F}$, se disuelven $0,11 \mathrm{~mL}(1,15 \mathrm{mmol})$ de $\mathrm{POCl}_{3}$ en $\mathrm{DMF}$ seca $(5 \mathrm{~mL})$, y a la media hora se añaden $62 \mathrm{mg}(0,21 \mathrm{mmol})$ de 5-(1-(2,6dicloropiridin4-il)vinil)-1-metil-1 $H$-indol (63) disueltos en 3-5 mL de DMF seca, y se deja 2 horas a temperatura ambiente. Se obtiene un precipitado que se purifica mediante cromatografía flash, utilizando como eluyente Hexano/EtOAc (1:1) obteniendo $64 \mathrm{mg}$ (0,19 mmol; 92\%) de 5-(1-(2,6-dicloropiridin-4-il)vinil)-1-metil-1H-indol-3-carbaldehído.

\section{5-(1-(2,6-dicloropiridin-4-il)vinil)-1-metil-1H-indol-3-carbaldehído (65):}

$\mathrm{RMN}^{1} \mathrm{H}\left(\mathrm{CDCl}_{3}\right) \delta(\mathrm{ppm})$ : (Espectro $\left.65 \mathrm{H}\right)$ 3,89 (3H, s, $\left.\mathrm{NCH}_{3}\right) ; 5,65\left(1 \mathrm{H}, \mathrm{s} \mathrm{CH}_{2}\right) ; 5,68$ $\left(1 \mathrm{H}, \mathrm{s} \mathrm{CH}_{2}\right) ; 7,13\left(1 \mathrm{H}, \mathrm{dd}, \mathrm{J}=1,6 ; \mathrm{J}=8,8 ; \mathrm{H}_{6}\right) ; 7,15(2 \mathrm{H}, \mathrm{s} ; \mathrm{pyr}) ; 7,34\left(1 \mathrm{H}, \mathrm{da}, \mathrm{J}=8,8 ; \mathrm{H}_{7}\right)$; 7,73 (1H, s; $\left.\mathrm{H}_{2}\right) ; 8,24\left(1 \mathrm{H}, \mathrm{d}, \mathrm{J}=1,6 ; \mathrm{H}_{4}\right) ; 9,95(1 \mathrm{H}, \mathrm{s}, \mathrm{CHO})$.

$\mathrm{RMN}{ }^{13} \mathrm{C}\left(\mathrm{CDCl}_{3}\right) \delta$ (ppm): (Espectro 65C) 33,9 $\left(\mathrm{CH}_{3}\right) ; 110,1(\mathrm{CH}) ; 118,2(\mathrm{C}) ; 119,1$ $\left(\mathrm{CH}_{2}\right) ; 121,9(2 \times C H) ; 124,4(\mathrm{CH}) ; 125,4(\mathrm{C}) ; 133,9(\mathrm{C}) ; 137,8(\mathrm{C}) ; 140,2(\mathrm{C}) ; 146,3$ (2xC); 150,6 (CH); 155,1 (C); 184,4 (CHO).

IR: (película): 1460, 1537, $1579 \mathrm{~cm}^{-1}$

HRMS: Calculado $(\mathrm{M}+\mathrm{H}) 331,0402$. Obtenido $\left(\mathrm{C}_{17} \mathrm{H}_{13} \mathrm{Cl}_{2} \mathrm{~N}_{2} \mathrm{O}\right) 331,0405$.

HPLC: Columna $\mathrm{C}_{8} \quad \mathrm{t}_{\mathrm{R}}: 16,75 \mathrm{~min}$. 
Obtención de las oximas de 5-((2,6-dicloropiridin-4-il)(hidroximino)metil)-

\section{1-metil-1H-indol-3-carbaldehído}<smiles>Cn1cc(C=O)c2cc(C(=O)c3cc(Cl)nc(Cl)c3)ccc21</smiles><smiles>CO[C@H](O)C(O)O</smiles><smiles>Cn1cc(/C=N/O)c2cc(/C(=N\O)c3cc(Cl)nc(Cl)c3)ccc21</smiles>

Siguiendo el método $\mathrm{E}$, se disuelven $104 \mathrm{mg}$ (0,31 mmol) de 5-(2,6-dicloropiridin4-il)-1-metil-1H-indol-3-carbaldehído (64) en $\mathrm{MeOH}(20 \mathrm{~mL})$, y se añaden $217 \mathrm{mg} \mathrm{(3,12}$ $\mathrm{mmol})$ de clorhidrato de hidroxilamina. Se obtienen $100 \mathrm{mg}(0,28 \mathrm{mmol} ; 89 \%)$ de mezcla de los isómeros posibles que se utilizan sin purificar en la obtención del nitrilo 68.

Oximas de 5-((2,6-dicloropiridin-4-il)(hidroximino)metil)-1-metil-1H-indol-3carbaldehído (66):

$\mathrm{RMN}^{1} \mathrm{H}\left(\mathrm{CDCl}_{3}\right) \delta(\mathrm{ppm})$ : (Espectro $\left.66 \mathrm{H}\right) 3,80\left(3 \mathrm{H}, \mathrm{s}, \mathrm{NCH}_{3}\right) ; 3,85\left(3 \mathrm{H}, \mathrm{s}, \mathrm{NCH}_{3}\right) ; 7,14-$ $8,25(\mathrm{~m}) ; 8,56(\mathrm{~d}, \mathrm{~J}=3,6)$.

\section{Obtención de 5-((2,6-dicloropiridin-4-il)(hidroximino)metil)-1-metil-1H-} indol-3-carbonitrilo<smiles>Cn1cc(C=NO)c2cc(C(=NO)c3ccc4c(c3)c(C=NO)cn4C)ccc21</smiles>

Siguiente el método $\mathrm{J}$, se disuelven $100 \mathrm{mg}(0,28 \mathrm{mmol})$ de la mezcla de oximas del 5-((2,6-dicloropiridin-4-il)(hidroximino)metil)-1-metil-1H-indol-3-carbaldehído (66) en piridina (10-20 mL) y se añade $0,5 \mathrm{~mL}$ de anhídrido acético. Se obtienen $94 \mathrm{mg}$ que se purifican mediante cromatografía flash usando como eluyente Hexano/EtOAc (6:4) y 
se obtienen $46 \mathrm{mg}(0,12 \mathrm{mmol} ; 42 \%)$ de 5-((acetoximino)(2,6-dicloropiridin-4-il)metil)-1metil-1H-indol-3-carbonitrilo.

Se añade $1 \mathrm{~mL}$ de $\mathrm{KOH} 5 \mathrm{~N}$ y $3 \mathrm{~mL}$ de $\mathrm{MeOH}$, y se deja 72 horas a temperatura ambiente. Se evapora el $\mathrm{MeOH}$ y se redisuelve en $\mathrm{CH}_{2} \mathrm{Cl}_{2}$ y se lava la fase orgánica, hasta neutralidad, con una disolución saturada de $\mathrm{NaCl}$. Se seca con $\mathrm{Na}_{2} \mathrm{SO}_{4}$, se filtra y se evapora a sequedad. Se purifica mediante cristalización en $\mathrm{Hex} / \mathrm{CH}_{2} \mathrm{Cl}_{2}$ obteniendo $7 \mathrm{mg}(0,02 \mathrm{mmol} ; 17 \%)$ del isómero $E$ y en las aguas madres hay $27 \mathrm{mg}$ $(0,08 \mathrm{mmol} ; 65 \%)$ de la mezcla de oximas (68EZ). En disolución clorofórmica se hidroliza regenerando la cetona.

(E)-5-((2,6-dicloropiridin-4-il)(hidroximino)metil)-1-metil-1H-indol-3-carbonitrilo (68E):

RMN ${ }^{1} \mathrm{H}\left(\mathrm{CDCl}_{3}\right) \delta(\mathrm{ppm}):\left(\right.$ Espectro 68EH) $3.89\left(3 \mathrm{H}, \mathrm{s}, \mathrm{NCH}_{3}\right) ; 7,29(2 \mathrm{H}, \mathrm{s} ; \mathrm{pyr}) ; 7,41$ $\left(1 \mathrm{H}, \mathrm{da}, \mathrm{J}=8,8 ; \mathrm{H}_{7}\right) ; 7,59\left(1 \mathrm{H}, \mathrm{dd}, \mathrm{J}=1,6 ; \mathrm{J}=8,8 ; \mathrm{H}_{6}\right) ; 7,63\left(1 \mathrm{H}, \mathrm{s} ; \mathrm{H}_{2}\right) ; 7,72(1 \mathrm{H}, \mathrm{d}$, $\left.\mathrm{J}=1,6 ; \mathrm{H}_{4}\right)$.

RMN ${ }^{13} \mathrm{C}\left(\mathrm{CDCl}_{3}\right) \delta(\mathrm{ppm})$ : (Espectro 68ZEC) 33,9 $\left(\mathrm{CH}_{3}\right) ; 86,5(\mathrm{C}) ; 111,0(\mathrm{CH}) ; 115,2$ (C); 121,0 (CH); 121,1 (2xCH); 123,0 (C); 124,0 (C); 124,4 (CH); 127,7 (C); 136,7 (CH); 149,5 (C); 150,8 (2xC); 150,9 (C); 154,3 (C). Isómero E y Z

IR (KBr): 1451, 1487, 1529, 1576, 2222, $3319 \mathrm{~cm}^{-1}$

HRMS: Calculado $(\mathrm{M}+\mathrm{H}) 345,0310$. Obtenido $\left(\mathrm{C}_{16} \mathrm{H}_{11} \mathrm{Cl}_{2} \mathrm{~N}_{4} \mathrm{O}\right) 345,0315$.

HPLC: Columna $C_{8} \quad t_{R}: 11,70$ min; $t_{R}: 12,52$ min.

Obtención de las oximas de 5-(1-(2,6-dicloropiridin-4-il)vinil)-1-metil-1Hindol-3-carbaldehído<smiles>C=C(c1cc(Cl)nc(Cl)c1)c1ccc2c(c1)c(C=O)cn2C</smiles>

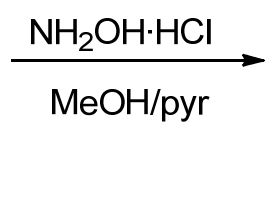<smiles>C=C(c1cc(Cl)nc(Cl)c1)c1ccc2c(c1)c(/C=N/O)cn2C</smiles> 
Siguiendo el método $\mathrm{E}$, se disuelven $38 \mathrm{mg}(0,12 \mathrm{mmol})$ de 5-(1-(2,6dicloropiridin-4-il)vinil)-1-metil-1H-indol-3-carbaldehído (65) en $\mathrm{MeOH}(10 \mathrm{~mL}$ ), y se añaden $80 \mathrm{mg}(1,15 \mathrm{mmol})$ de clorhidrato de hidroxilamina. Se obtienen $49 \mathrm{mg}(0,14$ mmol) de mezcla de oximas de 5-(1-(2,6-dicloropiridin-4-il)vinil)-1-metil-1H-indol-3carbaldehído.

Oximas de 5-(1-(2,6-dicloropiridin-4-il)vinil)-1-metil-1H-indol-3-carbaldehído (69):

$\mathrm{RMN}^{1} \mathrm{H}\left(\mathrm{CDCl}_{3}\right) \delta$ (ppm): (Espectro 69H) 4,03 (3H, s, NCH$)_{3} ; 4,06\left(3 \mathrm{H}, \mathrm{s}, \mathrm{NCH}_{3}\right) ; 5,56$ $\left(1 \mathrm{H}, \mathrm{s} ; \mathrm{CH}_{2}\right) ; 5,62\left(1 \mathrm{H}, \mathrm{s} ; \mathrm{CH}_{2}\right) ; 7,07-7,26(\mathrm{~m}) ; 7,60-7,64(\mathrm{~m}) ;$ 7,98 (d, J=1,6); 8,25 (s); $8,54(\mathrm{~d}, \mathrm{~J}=1,6)$.

\section{Obtención de 5-(1-(2,6-dicloropiridin-4-il)vinil)-1-metil-1H-indol-3-}

\section{carbonitrilo}<smiles>C=C(c1cc(Cl)nc(Cl)c1)c1ccc2c(c1)c(/C=N/O)cn2C</smiles><smiles>C=C(c1cc(Cl)nc(Cl)c1)c1ccc2c(c1)c([14O])cn2C</smiles>

Siguiendo el método $\mathrm{J}$, se disuelven $49 \mathrm{mg}(0,14 \mathrm{mmol})$ de la mezcla de oximas del 5-(1-(2,6-dicloropiridin-4-il)vinil)-1-metil-1H-indol-3-carbaldehído (69) en piridina (10 $\mathrm{mL}$ ) y se añade $0,5 \mathrm{~mL}$ de anhídrido acético. Se purifica mediante cromatografía flash, utilizando como eluyente Hexano/EtOAc (7:3) y se obtienen $9 \mathrm{mg}(0,03 \mathrm{mmol} ; 20 \%)$ de 5-(1-(2,6-dicloropiridin-4-il)vinil)-1-metil-1H-indol-3-carbonitrilo.

\section{5-(1-(2,6-dicloropiridin-4-il)vinil)-1-metil-1H-indol-3-carbonitrilo (70):}

$\mathrm{RMN}^{1} \mathrm{H}\left(\mathrm{CDCl}_{3}\right) \delta(\mathrm{ppm})$ : (Espectro $\left.70 \mathrm{H}\right) 3,83\left(3 \mathrm{H}, \mathrm{s}, \mathrm{NCH}_{3}\right) ; 5,62\left(1 \mathrm{H}, \mathrm{s}, \mathrm{CH}_{2}\right) ; 5,64$ $\left(1 \mathrm{H}, \mathrm{s}, \mathrm{CH}_{2}\right) ; 7,12\left(1 \mathrm{H}, \mathrm{dd}, \mathrm{J}=1,6 ; \mathrm{J}=8,8 ; \mathrm{H}_{6}\right) ; 7,13(2 \mathrm{H}, \mathrm{s}, \mathrm{pyr}) ; 7,34\left(1 \mathrm{H}, \mathrm{da}, \mathrm{J}=8,8 ; \mathrm{H}_{7}\right)$; $7,57\left(1 \mathrm{H}, \mathrm{s}, \mathrm{H}_{2}\right) ; 7,64\left(1 \mathrm{H}, \mathrm{d}, \mathrm{J}=1,6 ; \mathrm{H}_{4}\right)$.

RMN ${ }^{13} \mathrm{C}\left(\mathrm{CDCl}_{3}\right) \delta(\mathrm{ppm})$ : (Espectro 70C) 33,8 $\left(\mathrm{CH}_{3}\right) ; 86,0(\mathrm{C}) ; 110,5(\mathrm{CH}) ; 113,8(\mathrm{C})$; $119,0\left(\mathrm{CH}_{2}\right) ; 119,6(\mathrm{CH}) ; 121,8(2 \times \mathrm{CH}) ; 124,1(\mathrm{CH}) ; 127,9(\mathrm{C}) ; 133,2(\mathrm{C}) ; 135,9(\mathrm{C}) ;$ $136,3(\mathrm{CH}) ; 146,0(\mathrm{C}) ; 150,6(2 \times C) ; 154,7(\mathrm{C})$.

HRMS: Calculado $(\mathrm{M}+\mathrm{H}) 328,0408$. Obtenido $\left(\mathrm{C}_{17} \mathrm{H}_{12} \mathrm{Cl}_{2} \mathrm{~N}_{3}\right) 328,0409$.

HPLC: Columna $\mathrm{C}_{8} \quad \mathrm{t}_{\mathrm{R}}: 18,20 \mathrm{~min}$. 


\section{Obtención} de 5-(1-(2,6-dicloropiridin-4-il)vinil)-1-metil-1 $H$-indol-3-

\section{carboxamida}<smiles>C=C(c1cc(Cl)nc(Cl)c1)c1ccc2c(ccn2[13CH2])c1</smiles><smiles>C=C(c1cc(Cl)nc(Cl)c1)c1ccc2c(c1)c(C(N)=O)cn2C</smiles>

Siguiendo el método $K$, se disuelven $95 \mathrm{mg}(0,31 \mathrm{mmol})$ de 5-(1-(2,6dicloropiridin4-il)vinil)-1-metil-1 $\mathrm{H}$-indol (65) en 1,2-dicloroetano $(10 \mathrm{~mL})$ y se añaden 42 $\mu \mathrm{L}(0,47 \mathrm{mmol})$ de isocianato de clorosulfonilo. Se deja 24 horas a temperatura ambiente en atmósfera de argón. Se purifica mediante cromatografía flash usando como eluyente $\mathrm{CH}_{2} \mathrm{Cl}_{2} / \mathrm{MeOH}$ (98:2) y se obtienen $6 \mathrm{mg}(0,02 \mathrm{mmol} ; 6 \%)$ de 5-(1-(2,6dicloropiridin-4-il)vinil)-1-metil-1H-indol-3-carboxamida (71) y $21 \mathrm{mg}$ que se cromatografían en CCP con $\mathrm{CH}_{2} \mathrm{Cl}_{2} / \mathrm{MeOH}$ (95:5) obteniendo $13 \mathrm{mg}(0,04 \mathrm{mmol} ; 12 \%)$ de 5-(1-(2,6-dicloropiridin-4-il)vinil)-1-metil-1H-indol-3-carboxamida (71).

\section{5-(1-(2,6-dicloropiridin-4-il)vinil)-1-metil-1 $H$-indol-3-carboxamida (71):}

$\mathrm{RMN}^{1} \mathrm{H}\left(\mathrm{CDCl}_{3}\right) \delta(\mathrm{ppm})$ : (Espectro $\left.71 \mathrm{H}\right) 3,79\left(3 \mathrm{H}, \mathrm{s}, \mathrm{NCH}_{3}\right) ; 5,60(1 \mathrm{H}, \mathrm{s} \mathrm{CH}) ; 5,62$ $\left(1 \mathrm{H}, \mathrm{s} \mathrm{CH}_{2}\right) ; 5,74\left(2 \mathrm{H}, \mathrm{s}, \mathrm{NH}_{2}\right) ; 7,04\left(1 \mathrm{H}, \mathrm{dd}, \mathrm{J}=1,6 ; \mathrm{J}=8,8 ; \mathrm{H}_{6}\right) ; 7,14(2 \mathrm{H}, \mathrm{s} ; \mathrm{pyr}) ; 7,28$ $\left(1 \mathrm{H}, \mathrm{da}, \mathrm{J}=8,8 ; \mathrm{H}_{7}\right) ; 7,62\left(1 \mathrm{H}, \mathrm{s} ; \mathrm{H}_{2}\right) ; 7,96\left(1 \mathrm{H}, \mathrm{d}, \mathrm{J}=1,6 ; \mathrm{H}_{4}\right)$.

RMN ${ }^{13} \mathrm{C}\left(\mathrm{CDCl}_{3}\right) \delta(\mathrm{ppm})$ : (Espectro 71C) 33,6 $\left(\mathrm{CH}_{3}\right) ; 110,2(\mathrm{CH}) ; 118,8\left(\mathrm{CH}_{2}\right) ; 120,7$ (CH); $121,9(2 \times C H) ; 123,2(\mathrm{CH}) ; 127,1$ (C); 132,7 (C); 133,2 (C); 137,2 (C); 146,6 (C); 150,6 (CH); 155,2 (2xC); 166,7 (C).

IR: (película): 1410, 1462, 1525, 1574, 1651, 2924, $3341 \mathrm{~cm}^{-1}$

HRMS: Calculado $(\mathrm{M}+\mathrm{H}) 346,0514$. Obtenido $\left(\mathrm{C}_{17} \mathrm{H}_{14} \mathrm{Cl}_{2} \mathrm{~N}_{3} \mathrm{O}\right) 346,0511$.

HPLC: Columna $\mathrm{C}_{8} \quad \mathrm{t}_{\mathrm{R}}: 16,16 \mathrm{~min}$. 
Obtención de (2-cloro-6-(metilsulfanil)piridin-4-il)(1-metil-1H-indol-5-

\section{il)metanona}<smiles>CSc1cc(C(=O)O)cc(Cl)n1</smiles><smiles>Cn1ccc2cc(Br)ccc21</smiles>

15

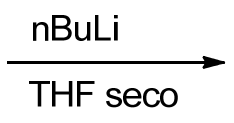

Sobre una disolución de 5,16 g (24,6 mmol) de 5-bromo- $N$-metil-1H-indol (15) en THF seco (30-40 mL) se añaden $15 \mathrm{~mL}(24,6 \mathrm{mmol})$ de una disolución 1,6 M de $n$ BuLi en hexano siguiendo el método A. Posteriormente se añade $2 \mathrm{~g}(9,8 \mathrm{mmol})$ de ácido 2cloro-6-metilsulfanilpiridina-4-carboxílico (3) disuelto en THF seco $(20 \mathrm{~mL})$. La reacción se purifica mediante cromatografía flash, utilizando como eluyente Hexano/EtOAc (9:1) y se recogen 1,09 g (3,44 mmol; 35\%) de (2-cloro-6-(metilsulfanil)piridin-4-il)(1-metil$1 H$-indol-5-il)metanona que cristaliza en Hex/EtOAc.

(2-cloro-6-(metilsulfanil)piridin-4-il)(1-metil-1H-indol-5-il)metanona (72):

P.f. (Hex/EtOAc): $116-123^{\circ} \mathrm{C}$

$\mathrm{RMN}^{1} \mathrm{H}\left(\mathrm{CDCl}_{3}\right) \delta(\mathrm{ppm}):($ Espectro $72 \mathrm{H})$ 2,60 (3H, s, $\left.\mathrm{SCH}_{3}\right) ; 3,86\left(3 \mathrm{H}, \mathrm{s}, \mathrm{NCH}_{3}\right) ; 6,63$ $\left(1 \mathrm{H}, \mathrm{d}, \mathrm{J}=2,8 ; \mathrm{H}_{3}\right) ; 7,16\left(1 \mathrm{H}, \mathrm{d}, \mathrm{J}=2,8 ; \mathrm{H}_{2}\right) ; 7,25(1 \mathrm{H}, \mathrm{s}, \operatorname{pyr}) ; 7,33(1 \mathrm{H}, \mathrm{s}, \mathrm{pyr}) ; 7,40(1 \mathrm{H}$, da, J= 8,3; $\left.\mathrm{H}_{6}\right) ; 7,79\left(1 \mathrm{H}, \mathrm{da}, \mathrm{J}=8,3 ; \mathrm{H}_{7}\right) ; 8,06\left(1 \mathrm{H}, \mathrm{s}, \mathrm{H}_{4}\right)$.

$\mathrm{RMN}{ }^{13} \mathrm{C}\left(\mathrm{CDCl}_{3}\right) \delta(\mathrm{ppm})$ : (Espectro $\left.72 \mathrm{C}\right) 13,7\left(\mathrm{CH}_{3}\right) ; 33,2\left(\mathrm{CH}_{3}\right) ; 103,5(\mathrm{CH}) ; 109,7$ $(\mathrm{CH}) ; 118,5(\mathrm{CH}) ; 119,2(\mathrm{CH}) ; 123,4(\mathrm{CH}) ; 125,9(\mathrm{CH}) ; 127,3(\mathrm{C}) ; 127,9(\mathrm{C}) ; 131,0$ $(\mathrm{CH}) ; 139,6(\mathrm{C}) ; 149,0(\mathrm{C}) ; 151,3(\mathrm{C}) ; 161,8(\mathrm{C}) ; 193,8(\mathrm{C})$.

IR (KBr): 1446, 1530, 1565, 1601, $1645 \mathrm{~cm}^{-1}$

HRMS: Calculado (M+Na) 339,0335. Obtenido $\left(\mathrm{C}_{16} \mathrm{H}_{13} \mathrm{CIN}_{2} \mathrm{NaOS}\right) 339,0316$.

HPLC: Columna $C_{8} \quad t_{R}: 21,29$ min. 
Obtención de 5-(1-(2-cloro-6-(metilsulfanil)piridin4-il)vinil)-1-metil-1H-indol<smiles>[Z2]Sc1cc(C(=O)c2ccc3c(ccn3C)c2)cc(Cl)n1</smiles>

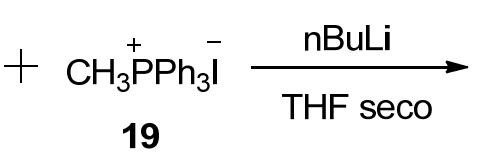<smiles>C=C(c1cc(Cl)nc(SC)c1)c1ccc2c(ccn2C)c1</smiles>

Siguiendo el método $\mathrm{B}$, a una suspensión de $3,251 \mathrm{~g}(8,07 \mathrm{mmol})$ de yoduro de metiltrifenilfosfonio (19) en THF seco $(30-40 \mathrm{~mL})$ a $-40^{\circ} \mathrm{C}$ se adicionan $3,36 \mathrm{~mL}(5,37$ $\mathrm{mmol}$ ) de una disolución 1,6 M de $n \mathrm{BuLi}$ en hexano. Posteriormente se adicionan 852 $\mathrm{mg}(2,69 \mathrm{mmol})$ de ((2-cloro-6-(metilsulfanil)piridin-4-il)(1-metil-1H-indol-5-il)metanona (72) disueltos en THF seco $(10 \mathrm{~mL})$. Se purifica mediante cromatografía flash usando como eluyente Hexano/EtOAc (98:2) y se obtienen $194 \mathrm{mg} \mathrm{(0,62} \mathrm{mmol;} 23 \%)$ de 5-(1(2-cloro-6-(metilsulfanil)piridin4-il)vinil)-1-metil-1H-indol, y $236 \mathrm{mg}$ de una mezcla (1:1) de 72 y 73.

\section{5-(1-(2-cloro-6-(metilsulfanil)piridin4-il)vinil)-1-metil-1H-indol (73):}

$\mathrm{RMN}^{1} \mathrm{H}\left(\mathrm{CDCl}_{3}\right) \delta(\mathrm{ppm}):($ Espectro $73 \mathrm{H}) 2,60\left(3 \mathrm{H}, \mathrm{s}, \mathrm{SCH}_{3}\right) ; 3,82\left(3 \mathrm{H}, \mathrm{s}, \mathrm{NCH}_{3}\right) ; 5,53$ $\left(1 \mathrm{H}, \mathrm{s}, \mathrm{CH}_{2}\right) ; 5,61\left(1 \mathrm{H}, \mathrm{s}, \mathrm{CH}_{2}\right) ; 6,50\left(1 \mathrm{H}, \mathrm{s}, \mathrm{H}_{3}\right) ; 7,01(1 \mathrm{H}, \mathrm{s}, \mathrm{pyr}) ; 7,10\left(1 \mathrm{H}, \mathrm{s}, \mathrm{H}_{2}\right) ; 7,10$ $(1 \mathrm{H}, \mathrm{s}, \mathrm{pyr}) ; 7,14\left(1 \mathrm{H}, \mathrm{da}, \mathrm{J}=8,6 ; \mathrm{H}_{6}\right) ; 7,33\left(1 \mathrm{H}, \mathrm{da}, \mathrm{J}=8,6 ; \mathrm{H}_{7}\right) ; 7,54\left(1 \mathrm{H}, \mathrm{s}, \mathrm{H}_{4}\right)$.

RMN ${ }^{13} \mathrm{C}\left(\mathrm{CDCl}_{3}\right) \delta(\mathrm{ppm})$ : (Espectro 73C) 13,7 $\left(\mathrm{CH}_{3}\right) ; 33,0\left(\mathrm{CH}_{3}\right) ; 101,6(\mathrm{CH}) ; 109,4$ $(\mathrm{CH}) ; 116,4\left(\mathrm{CH}_{2}\right) ; 118,9(\mathrm{CH}) ; 119,3(\mathrm{CH}) ; 120,9(\mathrm{CH}) ; 122,0(\mathrm{CH}) ; 128,5(\mathrm{C}) ; 129,9$ $(\mathrm{CH}) ; 130,7(\mathrm{C}) ; 136,7(\mathrm{C}) ; 147,9$ (C); 151,1 (C); 153,0 (C); 160,8 (C).

IR (película): 1422, 1442, 1492, 1519, $1576 \mathrm{~cm}^{-1}$

HRMS: Calculado $(M+H) 315,0723$. Obtenido $\left(\mathrm{C}_{17} \mathrm{H}_{16} \mathrm{CIN}_{2} \mathrm{~S}\right) 315,0723$.

HPLC: Columna $\mathrm{C}_{18} \mathrm{t}_{\mathrm{R}}: 25,16 \mathrm{~min}$. 
Obtención de las oximas de (2-cloro-6-(metilsulfanil)piridin-4-il)(1-metil-

\section{$\underline{1 H \text {-indol-5-il)metanona }}$}<smiles>[R]OSc1cc(C(=O)c2ccc3c(ccn3C)c2)cc(Cl)n1</smiles><smiles>CO[C@@H](Cl)O[Na]</smiles><smiles>CSc1cc(/C(=N/O)c2ccc3c(ccn3C)c2)cc(Cl)n1</smiles>

Se disuelven $139 \mathrm{mg}(0,43 \mathrm{mmol})$ de (2-cloro-6-(metilsulfanil)piridin-4-il)(1-metil$1 H$-indol-5-il)metanona (72) en $10 \mathrm{~mL}$ de $\mathrm{MeOH}$, y se añaden $305 \mathrm{mg}(4,39 \mathrm{mmol}) \mathrm{de}$ clorhidrato de hidroxilamina, siguiendo el método E. Cristalizan en Hexano/ $\mathrm{CH}_{2} \mathrm{Cl}_{2}$ dando $18 \mathrm{mg}(0,05 \mathrm{mmol} ; 12 \%)$ de uno de los isómeros (74a) y en las aguas madres se obtiene mezcla de oximas en proporción 4:6.

\section{Oximas de (2-cloro-6-(metilsulfanil)piridin-4-il)(1-metil-1H-indol-5-il)metanona (74ZE):}

P.f. $\left(\right.$ Hexano/ $\left.\mathrm{CH}_{2} \mathrm{Cl}_{2}\right): 176-178^{\circ} \mathrm{C}$

$\mathrm{RMN}^{1} \mathrm{H}\left(\mathrm{CDCl}_{3}\right) \delta(\mathrm{ppm}): 2,60\left(3 \mathrm{H}, \mathrm{s}, \mathrm{SCH}_{3}\right) ; 3,81\left(3 \mathrm{H}, \mathrm{s}, \mathrm{NCH}_{3}\right) ; 6,47(1 \mathrm{H}, \mathrm{d}, \mathrm{J}=3,2$; $\left.\mathrm{H}_{3}\right) ; 6,48(1 \mathrm{H}, \mathrm{s}, \mathrm{pyr}) ; 7,04(1 \mathrm{H}, \mathrm{s}, \mathrm{pyr}) ; 7,07\left(1 \mathrm{H}, \mathrm{d}, \mathrm{J}=3,2 ; \mathrm{H}_{2}\right) ; 7,30(1 \mathrm{H}, \mathrm{da}, \mathrm{J}=8,9$; $\left.\mathrm{H}_{6}\right) ; 7,47\left(1 \mathrm{H}, \mathrm{da}, \mathrm{J}=8,9 ; \mathrm{H}_{7}\right) ; 7,50\left(1 \mathrm{H}, \mathrm{s}, \mathrm{H}_{4}\right)$. Isómero 74a (E ó Z)

$\mathrm{RMN}^{1} \mathrm{H}\left(\mathrm{CDCl}_{3}\right) \delta(\mathrm{ppm})$ : (Espectro 74ZEH) 2,55 (3H, s, SCH$) ; 2,60\left(3 \mathrm{H}, \mathrm{s}, \mathrm{SCH}_{3}\right)$; $3,79\left(3 \mathrm{H}, \mathrm{s}, \mathrm{NCH}_{3}\right) ; 3,83\left(3 \mathrm{H}, \mathrm{s}, \mathrm{NCH}_{3}\right) ; 6,48(1 \mathrm{H}, \mathrm{d}, \mathrm{J}=3,2) ; 6,56(1 \mathrm{H}, \mathrm{d}, \mathrm{J}=2,9) ; 7,00-$ $7,59(\mathrm{~m}) ; 7,71(1 \mathrm{H}, \mathrm{s})$. Mezcla de isómeros $(Z$ y $E)$.

RMN ${ }^{13} \mathrm{C}\left(\mathrm{CDCl}_{3}\right) \delta(\mathrm{ppm}):\left(\right.$ Espectro 74ZEC) $13,7\left(\mathrm{CH}_{3}\right) ; 33,1\left(\mathrm{CH}_{3}\right) ; 102,0(\mathrm{CH}) ; 102,1$ $(\mathrm{CH}) ; 109,4(\mathrm{CH}) ; 109,8(\mathrm{CH}) ; 118,1(\mathrm{CH}) ; 118,7(\mathrm{CH}) ; 119,4(\mathrm{CH}) ; 119,9(\mathrm{CH}) ; 120,6$ $(\mathrm{CH}) ; 121,5(\mathrm{CH}) ; 122,6(\mathrm{CH}) ; 124,3(\mathrm{C}) ; 125,5(\mathrm{C}) ; 128,2(\mathrm{CH}) ; 130,1(\mathrm{CH}) ; 137,1(\mathrm{C})$; 137,6 (C); 144,5 (C); 147,7 (C); 151,2 (C); 155,8 (C); 156,2 (C); 161,3 (C); 161,5 (C). Mezcla de isómeros ( $Z$ y $E$ ).

IR (película): 1441, 1524, $1577 \mathrm{~cm}^{-1}$

HRMS: Calculado $(\mathrm{M}+\mathrm{H}) 332,0624$. Obtenido $\left(\mathrm{C}_{16} \mathrm{H}_{15} \mathrm{~N}_{3} \mathrm{OSCl}\right) 332,0610$.

HPLC: Columna $\mathrm{C}_{18} \mathrm{t}_{\mathrm{R}}: 20,60 \mathrm{~min} ; \mathrm{t}_{\mathrm{R}}: 21,12 \mathrm{~min}$. 
Obtención de 5-(2-cloro-6-(metilsulfanil)piridin-4-il)-1-metil-1H-indol-3-

\section{carbaldehído}<smiles>[Z20]CC(C)(C)C(=O)OC</smiles><smiles>CSc1cc(C(=O)c2ccc3c(c2)c(C=O)cn3C)cc(Cl)n1</smiles>

Se disuelven $0,35 \mathrm{~mL}(3,74 \mathrm{mmol})$ de $\mathrm{POCl}_{3}$ en DMF seca $(5 \mathrm{~mL})$, y a la media hora se añaden $200 \mathrm{mg}(0,63 \mathrm{mmol})$ de (2-cloro-6-(metilsulfanil)piridin-4-il)(1-metil-1 Hindol-5-il)metanona (72) disueltos en 5-10 mL DMF seca, y se calienta a $60^{\circ} \mathrm{C}$, siguiendo el método $\mathrm{F}$. Se obtiene un precipitado que se purifica mediante cromatografía flash, utilizando como eluyente Hexano/EtOAc (1:1). Se obtienen 140 mg (0,41 mmol; 64\%) de 5-(2-cloro-6-(metilsulfanil)piridin-4-il)-1-metil-1H-indol-3carbaldehído.

\section{5-(2-cloro-6-(metilsulfanil)piridin-4-il)-1-metil-1H-indol-3-carbaldehído (75):}

$\mathrm{RMN}^{1} \mathrm{H}\left(\mathrm{CDCl}_{3}\right) \delta(\mathrm{ppm}):($ Espectro $75 \mathrm{H})$ 2,59 (3H, s, SCH$) ; 3,95\left(3 \mathrm{H}, \mathrm{s}, \mathrm{NCH}_{3}\right) ; 7,22$ $(1 \mathrm{H}, \mathrm{s}, \mathrm{pyr}) ; 7,31(1 \mathrm{H}, \mathrm{s}, \mathrm{pyr}) ; 7,46\left(1 \mathrm{H}, \mathrm{d}, \mathrm{J}=8,6 ; \mathrm{H}_{7}\right) ; 7,81\left(1 \mathrm{H}, \mathrm{s}, \mathrm{H}_{2}\right) ; 7,85(1 \mathrm{H}, \mathrm{da}, \mathrm{J}=$ 8,6; $\left.\mathrm{H}_{6}\right) ; 8,66\left(1 \mathrm{H}, \mathrm{s}, \mathrm{H}_{4}\right) ; 9,99(1 \mathrm{H}, \mathrm{s}, \mathrm{CHO})$.

RMN ${ }^{13} \mathrm{C}\left(\mathrm{CDCl}_{3}\right) \delta(\mathrm{ppm})$ : (Espectro $\left.75 \mathrm{C}\right) 13,7\left(\mathrm{CH}_{3}\right) ; 34,1\left(\mathrm{CH}_{3}\right) ; 110,5(\mathrm{CH}) ; 118,4$ $(\mathrm{CH}) ; 119,1(\mathrm{C}) ; 119,3(\mathrm{CH}) ; 122,4(\mathrm{C}) ; 124,8(\mathrm{C}) ; 125,7(\mathrm{CH}) ; 125,9(\mathrm{CH}) ; 130,5(\mathrm{C})$; 140,7 (CH); 148,0 (C); 151,4 (C); 162,1 (C); 184,2 (CHO); 193,6 (C).

IR (película): 1466, 1530, 1607, $1658 \mathrm{~cm}^{-1}$

HRMS: Calculado $(\mathrm{M}+\mathrm{H}) 345,0465$. Obtenido $\left(\mathrm{C}_{17} \mathrm{H}_{14} \mathrm{CIN}_{2} \mathrm{O}_{2} \mathrm{~S}\right) 345,0444$.

HPLC: Columna $C_{8} \quad t_{R}: 15,78 \mathrm{~min}$. 
Obtención de 5-(1-(2-cloro-6-(metilsulfanil)piridin-4-il)vinil)-1-metil-1Hindol-3-carbaldehído<smiles>C=C(c1cc(Cl)nc(SC)c1)c1ccc2c(ccn2C)c1</smiles><smiles>C=C(c1cc(Cl)nc(SC)c1)c1ccc2c(c1)c(C=O)cn2C</smiles>

Siguiendo el método $\mathrm{F}$, se disuelven $0,16 \mathrm{~mL}(1,70 \mathrm{mmol})$ de $\mathrm{POCl}_{3}$ en $\mathrm{DMF}$ seca $(5 \mathrm{~mL})$, y a la media hora se añaden $89 \mathrm{mg}(0,28 \mathrm{mmol})$ de 5-(1-(2-cloro-6(metilsulfanil)piridin4-il)vinil)-1-metil-1H-indol (73) disueltos en 5-10 mL DMF seca, y se deja 2 horas a temperatura ambiente. Se obtienen $95 \mathrm{mg}$ un precipitado que se purifica mediante cromatografía flash, utilizando como eluyente Hex/EtOAc (4:6). Se obtienen $67 \mathrm{mg}(0,20 \mathrm{mmol} ; 70 \%)$ de 5-(1-(2-cloro-6-(metilsulfanil)piridin-4-il)vinil)-1metil-1H-indol-3-carbaldehído (76).

\section{5-(1-(2-cloro-6-(metilsulfanil)piridin-4-il)vinil)-1-metil-1H-indol-3-carbaldehído} (76):

$\mathrm{RMN}^{1} \mathrm{H}\left(\mathrm{CDCl}_{3}\right) \delta(\mathrm{ppm}):($ Espectro $76 \mathrm{H}) 2,56\left(3 \mathrm{H}, \mathrm{s}, \mathrm{SCH}_{3}\right) ; 3,92\left(3 \mathrm{H}, \mathrm{s}, \mathrm{NCH}_{3}\right) ; 5,62$ $\left(1 \mathrm{H}, \mathrm{s} ; \mathrm{CH}_{2}\right) ; 5,65\left(1 \mathrm{H}, \mathrm{s} ; \mathrm{CH}_{2}\right) ; 6,94(1 \mathrm{H}, \mathrm{d}, \mathrm{J}=1,4 ; \mathrm{pyr}) ; 7,03(1 \mathrm{H}, \mathrm{d}, \mathrm{J}=1,4 ; \mathrm{pyr}) ; 7,17$ $\left(1 \mathrm{H}, \mathrm{dd}, \mathrm{J}=1,8 ; \mathrm{J}=8,2 ; \mathrm{H}_{6}\right) ; 7,34\left(1 \mathrm{H}, \mathrm{da}, \mathrm{J}=8,2 ; \mathrm{H}_{7}\right) ; 7,73\left(1 \mathrm{H}, \mathrm{s}, \mathrm{H}_{2}\right) ; 8,29(1 \mathrm{H}, \mathrm{d}, \mathrm{J}=1,8$; $\left.\mathrm{H}_{4}\right) ; 10,0(1 \mathrm{H}, \mathrm{s}, \mathrm{CHO})$.

$\mathrm{RMN}{ }^{13} \mathrm{C}\left(\mathrm{CDCl}_{3}\right) \delta(\mathrm{ppm})$ : (Espectro $\left.76 \mathrm{C}\right)$ 13,6 $\left(\mathrm{CH}_{3}\right) ; 33,9\left(\mathrm{CH}_{3}\right) ; 110,0(\mathrm{CH}) ; 118,0$ $\left(\mathrm{CH}_{2}\right) ; 118,3(\mathrm{C}) ; 118,5(\mathrm{CH}) ; 119,0(\mathrm{CH}) ; 121,8(\mathrm{CH}) ; 124,5(\mathrm{CH}) ; 125,4(\mathrm{C}) ; 134,5$ (C); 137,8 (C); 140,2 (CH); 147,2 (C); 151,1 (C); 152,3 (C); 160,9 (C); 184,4 (CHO).

IR (película): 1528, 1577, $1657 \mathrm{~cm}^{-1}$

HRMS: Calculado $(\mathrm{M}+\mathrm{H}) 343,0672$. Obtenido $\left(\mathrm{C}_{18} \mathrm{H}_{16} \mathrm{CIN}_{2} \mathrm{OS}\right) 343,0666$.

HPLC: Columna $\mathrm{C}_{18} \mathrm{t}_{\mathrm{R}}: 21,49 \mathrm{~min}$. 
Obtención de ácido 5-(1-(2-cloro-6-(metilsulfanil)piridin-4-il)vinil)-1-metil$\underline{1 H \text {-indol-3-carboxílico }}$<smiles>C=C(c1cc(Cl)nc(SC)c1)c1ccc2c(ccn2C)c1</smiles><smiles>C=C(c1cc(Cl)nc(SC)c1)c1ccc2c(c1)c(C(=O)O)cn2C</smiles>

Se disuelven $85 \mathrm{mg}(0,27 \mathrm{mmol})$ de 5-(1-(2-cloro-6-(metilsulfanil)piridin4-il)vinil)1-metil-1H-indol (73) en $20 \mathrm{~mL}$ de $\mathrm{CH}_{2} \mathrm{Cl}_{2}$ y se añaden $186 \mu \mathrm{L}(0,35 \mathrm{mmol})$ de fosgeno al $20 \%$ en tolueno. Se controla la reacción mediante RMN ${ }^{1} \mathrm{H}$, y como a las 48 horas no ha avanzado se añaden $207 \mu \mathrm{L}(0,39 \mathrm{mmol})$ de fosgeno al $20 \%$ en tolueno. Se mantiene la reacción a temperatura ambiente durante 72 horas. Se vierte la reacción sobre agua con hielo. Se basifica el medio con $\mathrm{NaOH}$ al $5 \%$ y se extrae con EtOAc (fase orgánica A). La fase acuosa se acidifica con $\mathrm{HCl} 2 \mathrm{~N}$, y se extrae con $\mathrm{CH}_{2} \mathrm{Cl}_{2}$ (fase orgánica $B$ ). Las fases orgánicas ( $A$ y $B$ ) se neutralizan con disolución saturada de $\mathrm{NaCl}$, se secan con $\mathrm{Na}_{2} \mathrm{SO}_{4}$, se filtra y se evapora a sequedad, obteniendo $13 \mathrm{mg}$ $(0,04 \mathrm{mmol} ; 13 \%)$ de ácido 5-(1-(2-cloro-6-(metilsulfanil)piridin-4-il)vinil)-1-metil-1Hindol-3-carboxílico (77) de la fase orgánica B; y 66 mg de mezcla de 5-(1-(2-cloro-6(metilsulfanil)piridin4-il)vinil)-1-metil-1H-indol (73) y (2-cloro-6-(metilsulfanil)piridin-4il)(1-metil-1H-indol-5-il)metanona (72) en proporción 4:6 de la fase orgánica $A$.

Ácido 5-(1-(2-cloro-6-(metilsulfanil)piridin-4-il)vinil)-1-metil-1H-indol-3-carboxílico (77):

$\mathrm{RMN}^{1} \mathrm{H}\left(\mathrm{CDCl}_{3}\right) \delta(\mathrm{ppm}):($ Espectro $77 \mathrm{H}) 2,48\left(3 \mathrm{H}, \mathrm{s}, \mathrm{SCH}_{3}\right) ; 3,81\left(3 \mathrm{H}, \mathrm{s}, \mathrm{NCH}_{3}\right) ; 5,55$ $\left(1 \mathrm{H}, \mathrm{s}, \mathrm{CH}_{2}\right) ; 5,58\left(1 \mathrm{H}, \mathrm{s}, \mathrm{CH}_{2}\right) ; 6,89(1 \mathrm{H}, \mathrm{d}, \mathrm{J}=1,1 ; \mathrm{pyr}) ; 6,97(1 \mathrm{H}, \mathrm{d}, \mathrm{J}=1,1 ; \mathrm{pyr}) ; 7,05$ $\left(1 \mathrm{H}, \mathrm{da}, \mathrm{J}=8,5 ; \mathrm{H}_{6}\right) ; 7,26\left(1 \mathrm{H}, \mathrm{da}, \mathrm{J}=8,5 ; \mathrm{H}_{7}\right) ; 7,83\left(1 \mathrm{H}, \mathrm{s}, \mathrm{H}_{4}\right) ; 8,12\left(1 \mathrm{H}, \mathrm{s}, \mathrm{H}_{2}\right)$.

IR (película): 1465, 1532, 1577, 1610, $1662 \mathrm{~cm}^{-1}$

HRMS: Calculado (M+Na) 381,0440. Obtenido $\left(\mathrm{C}_{18} \mathrm{H}_{15} \mathrm{CIN}_{2} \mathrm{NaO}_{2} \mathrm{~S}\right) 381,0453$.

HPLC: Columna $\mathrm{C}_{18} \mathrm{t}_{\mathrm{R}}: 21,65 \mathrm{~min}$. 
Tratamiento de (2-cloro-6-(metilsulfanil)piridin-4-il)(1-metil-1H-indol-5il)metanona con cloruro de tionilo<smiles>[Y2]c1cc(C(=O)c2ccc3c(ccn3C)c2)cc(Cl)n1</smiles><smiles>CC(C)(C)CC(C)(C)OS(=O)(=O)O</smiles><smiles>CSc1cc(C(=O)c2ccc3c(c2)c(S(=O)(=O)O[Na])cn3C)cc(Cl)n1</smiles>

Se disuelven $40 \mathrm{mg}(0,13 \mathrm{mmol})$ de (2-cloro-6-(metilsulfanil)piridin-4-il)(1-metil$1 \mathrm{H}$-indol-5-il)metanona (72) en $\mathrm{CH}_{2} \mathrm{Cl}_{2}(5-10 \mathrm{~mL})$ a $-80^{\circ} \mathrm{C}$ y se añaden $8 \mu \mathrm{L}(0,14$ mmol) de $\mathrm{SOCl}_{2}$ disueltos en $\mathrm{CH}_{2} \mathrm{Cl}_{2}$. Se deja $24 \mathrm{~h}$ a $-80^{\circ} \mathrm{C}$. Se realiza cromatografía en capa fina, pero no se observa avance de la reacción. Se añaden $20 \mu \mathrm{L}$ de $\mathrm{SO}_{3} \mathrm{Cl}$ y la pongo en baño de hielo durante 24 horas. No se observa avance de la reacción. Se repite la reacción a temperatura ambiente y añadiendo $10 \mu \mathrm{L}$ de $\mathrm{SO}_{3} \mathrm{Cl}$. A las 24 horas se vierte sobre hielo, y se extrae con EtOAc. La fase orgánica se lava con disolución saturada de $\mathrm{NaCl}$, se seca con $\mathrm{Na}_{2} \mathrm{SO}_{4}$, se filtra y se evapora a sequedad. En RMN ${ }^{1} \mathrm{H}$ sólo se observan señales correspondientes al compuesto (72).

\section{Obtención de las oximas del 5-((2-cloro-6-(metilsulfanil)piridin-4-}

\section{il)(hidroximino)metil)-1-metil-1 $H$-indol-3-carbaldehído}<smiles>CSc1cc(C(=O)c2ccc3c(c2)c(C=O)cn3C)cc(Cl)n1</smiles><smiles>CO[Mg]C(Cl)ON</smiles><smiles>CSc1cc(/C(=N\O)c2ccc3c(c2)c(/C=N/O)cn3C)cc(Cl)n1</smiles>

Siguiendo el método $\mathrm{E}$, se disuelven $140 \mathrm{mg}(0,41 \mathrm{mmol})$ de 5-(2-cloro-6(metilsulfanil)piridin-4-il)-1-metil-1H-indol-3-carbaldehído (75) en $10 \mathrm{~mL}$ de $\mathrm{MeOH}$, y se añaden $282 \mathrm{mg}(4,06 \mathrm{mmol})$ de clorhidrato de hidroxilamina. Se obtienen $129 \mathrm{mg}$ $(0,34 \mathrm{mmol} ; 84 \%)$ de mezcla de oximas de 5-((2-cloro-6-(metilsulfanil)piridin-4il)(hidroximino)metil)-1-metil-1H-indol-3-carbaldehído. 
Oximas del 5-((2-cloro-6-(metilsulfanil)piridin-4-il)(hidroximino)metil)-1-metil-1Hindol-3-carbaldehído (78):

$\mathrm{RMN}^{1} \mathrm{H}\left(\mathrm{CDCl}_{3}\right) \delta(\mathrm{ppm}):($ Espectro $78 \mathrm{H}) 2,53\left(3 \mathrm{H}, \mathrm{s}, \mathrm{SCH}_{3}\right) ; 2,55\left(3 \mathrm{H}, \mathrm{s}, \mathrm{SCH}_{3}\right) ; 3,83$ $\left(3 \mathrm{H}, \mathrm{s}, \mathrm{NCH}_{3}\right) ; 3,88\left(3 \mathrm{H}, \mathrm{s}, \mathrm{NCH}_{3}\right) ; 7,04-7,48(\mathrm{~m}) ; 7,73-7,86(\mathrm{~m}) ; 8,1-8,3(\mathrm{~m}) ; 8,65$ (s).

\section{Obtención de 5-((2-cloro-6-(metilsulfanil)piridin-4-il)(hidroximino)metil)-1-} metil-1H-indol-3-carbonitrilo<smiles>CSc1cc(/C(=N/O)c2ccc3c(c2)c(/C=N/O)cn3C)cc(Cl)n1</smiles><smiles>COc1cc(C(=NO)c2ccc3c(c2)c(C#N)cn3C)cc(SCCO)n1</smiles><smiles>CSc1cc(/C(=N\O)c2ccc3c(c2)c(C#N)cn3C)cc(Cl)n1</smiles>

Se disuelven $129 \mathrm{mg}(0,34 \mathrm{mmol})$ de las oximas del 5-((2-cloro-6(metilsulfanil)piridin-4-il)(hidroximino)metil)-1-metil-1H-indol-3-carbaldehído (78) en piridina $(5-10 \mathrm{~mL})$ y se añade $0,5 \mathrm{~mL}$ de anhídrido acético siguiente el método $\mathrm{J}$. Se obtienen $103 \mathrm{mg} \quad(0,26 \mathrm{mmol} ; \quad 76 \%) \quad \mathrm{mg}$ de 5-((acetoximino)(2-cloro-6(metilsulfanil)piridin-4-il)metil)-1-metil-1H-indol-3-carbonitrilo (79). Se añade $1 \mathrm{~mL}$ de $\mathrm{NaOH}$ al $10 \%$ y $3 \mathrm{~mL}$ de $\mathrm{MeOH}$, y se deja 72 horas a temperatura ambiente. Se realiza extracción con $\mathrm{CH}_{2} \mathrm{Cl}_{2}$ y se lava la fase orgánica, hasta neutralidad, con una disolución saturada de $\mathrm{NaCl}$. Se seca con $\mathrm{Na}_{2} \mathrm{SO}_{4}$ anhidro, se filtra y se evapora a sequedad. Se purifica mediante cromatografía flash, utilizando como eluyente $\mathrm{CH}_{2} \mathrm{Cl}_{2} / \mathrm{EtOAc}$ (95:5), y se obtienen $45 \mathrm{mg}(0,13 \mathrm{mmol} ; 50 \%)$ de mezcla de oximas de 5-((2-cloro-6(metilsulfanil)piridin-4-il)(hidroximino)metil)-1-metil-1H-indol-3-carbonitrilo que cristalizan en $\mathrm{Hex} / \mathrm{CH}_{2} \mathrm{Cl}_{2}$ en proporción 4:6.

\section{5-((2-cloro-6-(metilsulfanil)piridin-4-il)(hidroximino)metil)-1-metil-1H-indol-3- carbonitrilo (80EZ):}

P.f. $\left(\mathrm{Hex} / \mathrm{CH}_{2} \mathrm{Cl}_{2}\right): 186-188^{\circ} \mathrm{C}$

$\mathrm{RMN}^{1} \mathrm{H}\left(\mathrm{CDCl}_{3}\right) \delta$ (ppm): (Espectro $\left.80 \mathrm{H}\right)$ 2,46 (3H, s, SCH$) ; 2,52\left(3 \mathrm{H}, \mathrm{s}, \mathrm{SCH}_{3}\right) ; 3,80$ $\left.\left(3 \mathrm{H}, \mathrm{s}, \mathrm{NCH}_{3}\right) ; 3.843 \mathrm{H}, \mathrm{s}, \mathrm{NCH}_{3}\right) ; 6,93(1 \mathrm{H}, \mathrm{s}) ; 6,99(1 \mathrm{H}, \mathrm{s}) ; 7,01(1 \mathrm{H}, \mathrm{s}) ; 7,04(1 \mathrm{H}, \mathrm{s}) ;$ 7,18 (1H, d, J=1,6); 7,22 (1H, d, J=8,6); 7,30 (1H, d, J=8,6); 7,43 (1H, d, J=8,6); 7,53 $(1 \mathrm{H}, \mathrm{s}) ; 7,58(1 \mathrm{H}, \mathrm{s}) ; 7,63(1 \mathrm{H}, \mathrm{s}) ; 7,71(1 \mathrm{H}, \mathrm{s})$. 
RMN ${ }^{13} \mathrm{C}\left(\mathrm{CDCl}_{3}\right) \delta(\mathrm{ppm})$ : (Espectro 80C) 13,5 $\left(\mathrm{CH}_{3}\right) ; 33,8\left(\mathrm{CH}_{3}\right) ; 110,7(\mathrm{CH}) ; 115,3$ (C); 117,4 (CH); 118,3 (CH); 119,0 (C); 119,7 (CH); 121,0 (CH); 123,1 (C); 124,5 (CH); 127,6 (C); 136,2 (C); 136,7 (CH); 146,6 (C); 151,2 (C); 155,1 (C); 161,6 (C); 175,8 (C). IR (película): 1428, 1448, 1527, 1574, 2219, 3316, $3338 \mathrm{~cm}^{-1}$ HRMS: Calculado (M+Na) 379,0396. Obtenido $\left(\mathrm{C}_{17} \mathrm{H}_{13} \mathrm{CIN}_{4} \mathrm{NaOS}\right) 379,0389$. HPLC: Columna $\mathrm{C}_{18} \mathrm{t}_{\mathrm{R}}: 18,13 \mathrm{~min} ; \mathrm{t}_{\mathrm{R}}: 19,32 \mathrm{~min}$.

Obtención de las oximas de 5-(1-(2-cloro-6-(metilsulfanil)piridin-4-il)vinil)1-metil-1H-indol-3-carbaldehído<smiles>C=C(c1cc(Cl)nc(SC)c1)c1ccc2c(c1)c(C=O)cn2C</smiles><smiles></smiles><smiles>C=C(c1cc(Cl)nc(SC)c1)c1ccc2c(c1)c(/C=N/O)cn2C</smiles>

Siguiendo el método E, se disuelven $160 \mathrm{mg}(0,46 \mathrm{mmol})$ de 5-(1-(2-cloro-6(metilsulfanil)piridin-4-il)vinil)-1-metil-1H-indol-3-carbaldehído (76) en $10 \mathrm{~mL}$ de $\mathrm{MeOH}$, y se añaden $324 \mathrm{mg}(4,67 \mathrm{mmol})$ de clorhidrato de hidroxilamina. Se obtienen $149 \mathrm{mg}$ $(0,42 \mathrm{mmol} ; 90 \%)$ de mezcla de oximas de 5-(1-(2-cloro-6-(metilsulfanil)piridin-4il)vinil)-1-metil-1H-indol-3-carbaldehído.

Mezcla de oximas de 5-(1-(2-cloro-6-(metilsulfanil)piridin-4-il)vinil)-1-metil-1Hindol-3-carbaldehído (81ZE):

$\mathrm{RMN}^{1} \mathrm{H}\left(\mathrm{CDCl}_{3}\right) \delta$ (ppm): (Espectro 81ZEH) 2,55 (3H, s, $\left.\mathrm{SCH}_{3}\right) ; 2,56\left(3 \mathrm{H}, \mathrm{s}, \mathrm{SCH}_{3}\right)$; $3,79\left(3 \mathrm{H}, \mathrm{s}, \mathrm{NCH}_{3}\right) ; 3,88\left(3 \mathrm{H}, \mathrm{s}, \mathrm{NCH}_{3}\right) ; 5,56\left(1 \mathrm{H}, \mathrm{s}, \mathrm{CH}_{2}\right) ; 5,59\left(1 \mathrm{H}, \mathrm{s}, \mathrm{CH}_{2}\right) ; 5,62(2 \mathrm{H}$, s, $\left.\mathrm{CH}_{2}\right) ; 6,97-7,37(\mathrm{~m}) ; 7,67(1 \mathrm{H}, \mathrm{s}, \mathrm{J}=1,2) ; 7,98(1 \mathrm{H}, \mathrm{s}) ; 7,06(1 \mathrm{H}, \mathrm{s}, \mathrm{J}=1,2) ; 8,31(2 \mathrm{H}$, s). 
Obtención de 5-(1-(2-cloro-6-(metilsulfanil)piridin-4-il)vinil)-1-metil-1Hindol-3-carbonitrilo<smiles>C=C(c1cc(Cl)nc(SC)c1)c1ccc2c(c1)c(/C=N/O)cn2C</smiles><smiles>C=C(c1cc(Cl)nc(SC)c1)c1ccc2c(c1)c(C#N)cn2C</smiles>

Se disuelven $149 \mathrm{mg}(0,42 \mathrm{mmol})$ de la mezcla de oximas de 5-(1-(2-cloro-6(metilsulfanil)piridin-4-il)vinil)-1-metil-1H-indol-3-carbaldehído (81) en piridina (5-10 mL) y se añade $0,5 \mathrm{~mL}$ de anhídrido acético siguiente el método J. Se purifica mediante cromatografía flash, utilizando como eluyente Hexano/EtOAc (7:3), y se obtienen 106 $\mathrm{mg}(0,31 \mathrm{mmol} ; 74 \%)$ de 5-(1-(2-cloro-6-(metilsulfanil)piridin-4-il)vinil)-1-metil-1H-indol3-carbonitrilo.

\section{5-(1-(2-cloro-6-(metilsulfanil)piridin-4-il)vinil)-1-metil-1H-indol-3-carbonitrilo (82):}

$\mathrm{RMN}^{1} \mathrm{H}\left(\mathrm{CDCl}_{3}\right) \delta(\mathrm{ppm}):($ Espectro $82 \mathrm{H}) 2,56\left(3 \mathrm{H}, \mathrm{s}, \mathrm{SCH}_{3}\right) ; 3,88\left(3 \mathrm{H}, \mathrm{s}, \mathrm{NCH}_{3}\right) ; 5,62$ $\left(1 \mathrm{H}, \mathrm{s}, \mathrm{CH}_{2}\right) ; 5,63\left(1 \mathrm{H}, \mathrm{s}, \mathrm{CH}_{2}\right) ; 6,93(1 \mathrm{H}, \mathrm{d}, \mathrm{J}=1,2 ; \mathrm{pyr}) ; 7,02(1 \mathrm{H}, \mathrm{d}, \mathrm{J}=1,2 ; \mathrm{pyr}) ; 7,20$ $\left(1 \mathrm{H}, \mathrm{dd}, \mathrm{J}=1,6 ; \mathrm{J}=8,6 ; \mathrm{H}_{6}\right) ; 7,37\left(1 \mathrm{H}, \mathrm{da}, \mathrm{J}=8,6 ; \mathrm{H}_{7}\right) ; 7,61\left(1 \mathrm{H}, \mathrm{s}, \mathrm{H}_{2}\right) ; 7,70\left(1 \mathrm{H}, \mathrm{s}, \mathrm{H}_{4}\right)$.

RMN ${ }^{13} \mathrm{C}\left(\mathrm{CDCl}_{3}\right) \delta(\mathrm{ppm})$ : (Espectro 82C) 13,5 $\left(\mathrm{CH}_{3}\right) ; 33,8\left(\mathrm{CH}_{3}\right) ; 86,0(\mathrm{C}) ; 110,4$ $(\mathrm{CH}) ; 117,9\left(\mathrm{CH}_{2}\right) ; 118,4(\mathrm{CH}) ; 119,0(\mathrm{CH}) ; 119,5(\mathrm{CH}) ; 124,3(\mathrm{CH}) ; 127,9(\mathrm{C}) ; 133,8$ (C); 135,9 (C); 136,3 (CH); 146,8 (C); 151,1 (C); 151,9 (C); 161,0 (C).

IR (película): 1526, 1576, $2218 \mathrm{~cm}^{-1}$

HRMS: Calculado $(\mathrm{M}+\mathrm{H}) 340,0675$. Obtenido $\left(\mathrm{C}_{18} \mathrm{H}_{15} \mathrm{CIN}_{3} \mathrm{~S}\right) 340,0673$.

HPLC: Columna $C_{8} \quad t_{R}: 19,89$ min. 
Intentos de transformación de 5-(1-(2-cloro-6-(metilsulfanil)piridin-4il)vinil)-1-metil-1 $H$-indol-3-carbonitrilo en 5-(1-(2-cloro-6-

\section{(metilsulfanil)piridin-4-il)vinil)-1-metil-1H-indol-3-carboxamida}<smiles>C=C(c1cc(Cl)nc(SC)c1)c1ccc2c(c1)c(C#N)cn2C</smiles><smiles>C=C(C)CCCCCCCC</smiles>

Se ha intentado esta reacción con las siguientes condiciones pero en ningún caso se obtuvo la amida:

- $\quad \mathrm{NaOH} 10 \%$ en $\mathrm{MeOH} . \mathrm{T}^{\mathrm{a}}$ ambiente. 24 horas.

- $\mathrm{NaOH} 10 \%$ en MeOH. Reflujo. 24 horas.

- $\quad \mathrm{NaOH} 10 \mathrm{M}$ en $\mathrm{MeOH} . \mathrm{T}^{\mathrm{a}}$ ambiente. 24 horas.

- $\mathrm{NaOH} 10 \mathrm{M}$ en MeOH. Reflujo. 24 horas.

- 4 gotas $\mathrm{HCl}$ en $\mathrm{MeOH}$. $\mathrm{T}^{\mathrm{a}}$ ambiente. 24 horas.

- 4 gotas $\mathrm{H}_{2} \mathrm{SO}_{4}$ en $\mathrm{MeOH}$. Reflujo. 24 horas.

- 3-4 mL ácido fosfórico 85\%. Reflujo. 72 horas.

- 1 espátula Triflato de zinc, $1 \mathrm{~mL}$ agua, 1 cucharadita bicarbonato sódico, $10 \mathrm{~mL}$ THF. Una semana a reflujo.

- 1 espátula isopropóxido de aluminio, 1 espátula bicarbonato sódico, $1 \mathrm{~mL}$ agua, $3 \mathrm{~mL}$ THF. Reflujo 72 horas.

Obtención de 5-(1-(2-cloro-6-(metilsulfanil)piridin-4-il)vinil)-1-metil-1Hindol-3-carboxamida

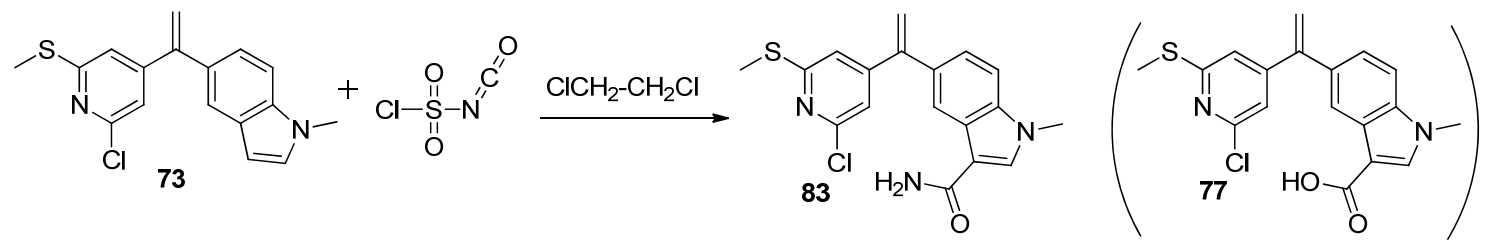


Siguiendo el método $\mathrm{K}$, se disuelven $29 \mathrm{mg}(0,09 \mathrm{mmol})$ de 5-(1-(2-cloro-6(metilsulfanil)piridin4-il)vinil)-1-metil-1H-indol (73) en 5-10 mL de 1,2-dicloroetano y se añaden $12 \mu \mathrm{L}(0,14 \mathrm{mmol})$ de isocianato de clorosulfonilo. Se deja 24 horas a temperatura. Se purifica mediante una cromatografía en CCP con $\mathrm{CH}_{2} \mathrm{Cl}_{2} / \mathrm{MeOH}$ (95:5) obteniendo $10 \mathrm{mg}$ (0,03 mmol; 31\%) de 5-(1-(2-cloro-6-(metilsulfanil)piridin-4-il)vinil)-1metil- $1 H$-indol-3-carboxamida y $12 \mathrm{mg}(0,03 \mathrm{mmol} ; 31 \%)$ del derivado de ácido 5-(1-(2cloro-6-(metilsulfanil)piridin-4-il)vinil)-1-metil-1H-indol-3-carboxílico (77).

\section{5-(1-(2-cloro-6-(metilsulfanil)piridin-4-il)vinil)-1-metil-1H-indol-3-carboxamida} (83):

$\mathrm{RMN}^{1} \mathrm{H}\left(\mathrm{CDCl}_{3}\right) \delta(\mathrm{ppm}):($ Espectro $83 \mathrm{H})$ 2,55 (3H, s, $\left.\mathrm{SCH}_{3}\right) ; 3,86\left(3 \mathrm{H}, \mathrm{s}, \mathrm{NCH}_{3}\right) ; 5,56$ $\left(2 \mathrm{H}, \mathrm{s}, \mathrm{NH}_{2}\right) ; 5,60\left(1 \mathrm{H}, \mathrm{s}, \mathrm{CH}_{2}\right) ; 5,62\left(1 \mathrm{H}, \mathrm{s}, \mathrm{CH}_{2}\right) ; 6,95(1 \mathrm{H}, \mathrm{d}, \mathrm{J}=1,2 ; \mathrm{pyr}) ; 7,03(1 \mathrm{H}, \mathrm{d}$, $J=1,2 ; p y r) ; 7,13\left(1 \mathrm{H}, \mathrm{dd}, \mathrm{J}=1,7 ; \mathrm{J}=8,6 ; \mathrm{H}_{6}\right) ; 7,33\left(1 \mathrm{H}, \mathrm{da}, \mathrm{J}=8,6 ; \mathrm{H}_{7}\right) ; 7,68\left(1 \mathrm{H}, \mathrm{s}, \mathrm{H}_{2}\right)$; $7,95\left(1 \mathrm{H}, \mathrm{d}, \mathrm{J}=1,7 ; \mathrm{H}_{4}\right)$.

RMN ${ }^{13} \mathrm{C} \delta$ (ppm): (Espectro 83C) 13,5 $\left(\mathrm{CH}_{3}\right) ; 33,5\left(\mathrm{CH}_{3}\right) ; 110,0(\mathrm{CH}) ; 110,2(\mathrm{C}) ; 117,6$ $(\mathrm{CH}) ; 118,5(\mathrm{CH}) ; 119,0(\mathrm{CH}) ; 120,4\left(\mathrm{CH}_{2}\right) ; 123,3(\mathrm{CH}) ; 125,9(\mathrm{C}) ; 133,3(\mathrm{CH}) ; 137,1$ (C); 147,4 (C); 151,1 (C); 152,3 (C); 159,5 (C); 166,6 (C).

IR: (película): 1519, 1574, 1651, 2925, $3342 \mathrm{~cm}^{-1}$

HRMS: Calculado $(\mathrm{M}+\mathrm{H}) 358,0781$. Obtenido $\left(\mathrm{C}_{18} \mathrm{H}_{17} \mathrm{CIN}_{3} \mathrm{OS}\right) 358,0780$.

HPLC: Columna $\mathrm{C}_{8} \quad \mathrm{t}_{\mathrm{R}}: 16,99 \mathrm{~min}$.

\section{Obtención de (2-metilsulfanil-6-metoxipiridin-4-il)(1-metil-1H-indol-5-}

\section{il)metanona}<smiles>COc1cc(C(=O)O)cc(SC)n1</smiles><smiles>Cn1ccc2cc(Br)ccc21</smiles><smiles>CCCCCCCCCCCC(=O)O</smiles><smiles>COc1cc(C(=O)c2ccc3c(ccn3C)c2)cc(SC)n1</smiles>

Siguiendo el método A, se prepara una disolución de 3,26 g $(15,5 \mathrm{mmol})$ de 5bromo- $N$-metil- $1 H$-indol (15) en THF seco (30 mL) y se añaden $9,7 \mathrm{~mL}(15,5 \mathrm{mmol})$ de una disolución 1,6 M de $n$ BuLi en hexano. A continuación se añade 1,18 g (5,9 mmol) de ácido 2-metilsulfanil-6-metoxipiridina-4-carboxílico (5) disuelto en THF seco (20 
$\mathrm{mL})$. Se realiza una cromatografía flash, utilizando como eluyente Hexano/EtOAc (8:2), y se recogen $911 \mathrm{mg}(2,92 \mathrm{mmol} ; 49 \%)$ de (2-metilsulfanil-6-metoxipiridin-4-il)(1-metil$1 \mathrm{H}$-indol-5-il)metanona, que se cristalizan en Hexano/ $\mathrm{CH}_{2} \mathrm{Cl}_{2}$.

(2-metilsulfanil-6-metoxipiridin-4-il)(1-metil-1H-indol-5-il)metanona (84):

P.f. $\left(\mathrm{Hex} / \mathrm{CH}_{2} \mathrm{Cl}_{2}\right): 103-104^{\circ} \mathrm{C}$

$\mathrm{RMN}^{1} \mathrm{H}\left(\mathrm{CDCl}_{3}\right) \delta(\mathrm{ppm}): 2,49\left(3 \mathrm{H}, \mathrm{s}, \mathrm{SCH}_{3}\right), 3,85\left(3 \mathrm{H}, \mathrm{s}, \mathrm{NCH}_{3}\right) ; 4,01\left(3 \mathrm{H}, \mathrm{s}, \mathrm{OCH}_{3}\right)$; $6,59\left(1 \mathrm{H}, \mathrm{d}, \mathrm{J}=2,9 ; \mathrm{H}_{3}\right) ; 6,66(1 \mathrm{H}, \mathrm{d}, \mathrm{J}=1,1 ; p y r) ; 7,02(1 \mathrm{H}, \mathrm{d}, \mathrm{J}=1,1 ; p y r) ; 7,13(1 \mathrm{H}, \mathrm{d}$, $\left.J=2,9 ; H_{2}\right) ; 7,38\left(1 \mathrm{H}, d, J=8,6 ; H_{7}\right) ; 7,81\left(1 \mathrm{H}, d d, J=1,8 ; J=8,6 ; H_{6}\right) 8,10(1 \mathrm{H}, d, J=1,8 ;$ $\mathrm{H}_{4}$ ).

$\operatorname{RMN~}{ }^{13} \mathrm{C}\left(\mathrm{CDCl}_{3}\right) \delta(\mathrm{ppm}): 13,5\left(\mathrm{CH}_{3}\right) ; 33,1\left(\mathrm{CH}_{3}\right) ; 53,9\left(\mathrm{CH}_{3}\right) ; 103,3(\mathrm{CH}) ; 105,3(\mathrm{CH})$; $109,5(\mathrm{CH}) ; 112,9(\mathrm{CH}) ; 123,4(\mathrm{CH}) ; 125,8(\mathrm{CH}) ; 127,7(\mathrm{C}) ; 128,8(\mathrm{C}) ; 130,9(\mathrm{CH}) ;$ 139,4 (C); 149,6 (C); 158,3 (C); 163,7 (C); 195,2 (C).

IR: $1545,1602,1647 \mathrm{~cm}^{-1}$

EM m/z (intensidad relativa, \%): 158 (100), $312\left(\mathrm{M}^{+}, 80\right)$

HPLC: Columna $\mathrm{C}_{18} \quad \mathrm{t}_{\mathrm{R}}: 20,85 \mathrm{~min}$.

\section{Obtención de 5-(1-(2-metilsulfanil-6-metoxipiridin-4-il)vinil)-1-metil-1H-} indol<smiles>C=C(c1cc(OC)nc(SC)c1)c1ccc2c(ccn2C)c1</smiles>

A $387 \mathrm{mg} \mathrm{(0,96} \mathrm{mmol)} \mathrm{de} \mathrm{yoduro} \mathrm{de} \mathrm{metiltrifenilfosfonio} \mathrm{(19)} \mathrm{en} \mathrm{THF} \mathrm{seco} \mathrm{(10-20}$ $\mathrm{mL})$, a $-40^{\circ} \mathrm{C}$ y en atmósfera de argón, se añaden $0,4 \mathrm{~mL}(0,64 \mathrm{mmol})$ de una disolución 1,6 M de $n \mathrm{BuLi}$ en hexano siguiendo el método $\mathrm{B}$. Posteriormente se adicionan $100 \mathrm{mg}(0,32 \mathrm{mmol})$ de (2-metilsulfanil-6-metoxipiridin-4-il)(1-metil-1H-indol5-il)metanona (84) disueltos en THF seco (10 mL). Se obtienen $441 \mathrm{mg}$ que mediante cromatografían flash, utilizando como eluyente Hexano/ $\mathrm{CH}_{2} \mathrm{Cl}_{2}(8: 2)$, da lugar a $30 \mathrm{mg}$ $(0,10 \mathrm{mmol} ; 31 \%)$ de 5-(1-(2-metilsulfanil-6-metoxipiridin-4-il)vinil)-1-metil-1H-indol (85). 


\section{5-(1-(2-metilsulfanil-6-metoxipiridin-4-il)vinil)-1-metil-1H-indol (85):}

$\mathrm{RMN}^{1} \mathrm{H}\left(\mathrm{CDCl}_{3}\right) \delta(\mathrm{ppm}): 2,56\left(3 \mathrm{H}, \mathrm{s}, \mathrm{SCH}_{3}\right) ; 3,80\left(3 \mathrm{H}, \mathrm{s}, \mathrm{NCH}_{3}\right) ; 3,96\left(3 \mathrm{H}, \mathrm{s}, \mathrm{OCH}_{3}\right)$; $5,48\left(1 \mathrm{H}, \mathrm{d}, \mathrm{J}=1,1, \mathrm{CH}_{2}\right) ; 5,54\left(1 \mathrm{H}, \mathrm{d}, \mathrm{J}=1,1, \mathrm{CH}_{2}\right) ; 6,44(1 \mathrm{H}, \mathrm{d}, \mathrm{J}=1,2, \mathrm{pyr}) ; 6,47(1 \mathrm{H}$, da, J=3,2, $\left.\mathrm{H}_{3}\right) ; 6,79(1 \mathrm{H}, \mathrm{d}, \mathrm{J}=1,2, \mathrm{pyr}) ; 7,06\left(1 \mathrm{H}, \mathrm{d}, \mathrm{J}=3,2, \mathrm{H}_{2}\right) ; 7,18(1 \mathrm{H}, \mathrm{dd}, \mathrm{J}=1,4$; $\left.J=8,9, H_{6}\right) ; 7,28\left(1 \mathrm{H}, \mathrm{d}, J=8,9, \mathrm{H}_{7}\right) ; 7,55\left(1 \mathrm{H}, \mathrm{d}, \mathrm{J}=1,4, \mathrm{H}_{4}\right)$.

$\operatorname{RMN}{ }^{13} \mathrm{C}\left(\mathrm{CDCl}_{3}\right) \delta(\mathrm{ppm}): 13,4\left(\mathrm{CH}_{3}\right) ; 33,0\left(\mathrm{CH}_{3}\right) ; 53,6\left(\mathrm{CH}_{3}\right) ; 101,4(\mathrm{CH}) ; 105,1(\mathrm{CH})$; $109,0(\mathrm{CH}) ; 113,7(\mathrm{CH}) ; 114,9\left(\mathrm{CH}_{2}\right) ; 120,8(\mathrm{CH}) ; 122,1(\mathrm{CH}) ; 128(\mathrm{C}) ; 136,6(\mathrm{CH}) ;$ 131,3 (C); 136,6 (C);148,9 (C); 153,3 (C); 156,9 (C); 164,0 (C).

IR: $1543,1593, \mathrm{~cm}^{-1}$

EM m/z (intensidad relativa, \%): $310\left(\mathrm{M}^{+}, 100\right)$.

HPLC: Columna $\mathrm{C}_{8} \quad \mathrm{t}_{\mathrm{R}}: 22,01 \mathrm{~min}$.

\section{Obtención de las oximas de (2-metilsulfanil-6-metoxipiridin-4-il)(1-metil-}

\section{$\underline{1 H \text {-indol-5-il)metanona }}$}<smiles>COc1cc(C(=O)c2ccc3c(ccn3C)c2)cc(SC)n1</smiles><smiles>COc1cc(/C(=N\O)c2ccc3c(ccn3C)c2)cc(SC)n1</smiles>

Se disuelven $312 \mathrm{mg}$ (1 mmol) de (2-metilsulfanil-6-metoxipiridin-4-il)(1-metil-1Hindol-5-il)metanona (84) en $\mathrm{MeOH}(10-20 \mathrm{~mL}$ ) según el método $\mathrm{E}$ y se añaden $660 \mathrm{mg}$ $(9,49 \mathrm{mmol})$ de clorhidrato de hidroxilamina. Por cromatografía flash, utilizando como eluyente Hexano/EtOAc (9:1), se obtienen 7,2 mg (0,02 mmol; $2 \%)$ de material de partida (84) y $228 \mathrm{mg}(0,70 \mathrm{mmol} ; 70 \%)$ del isómero $E$ que se isomeriza en disolución. Cristalizan en $\mathrm{Hex} / \mathrm{CH}_{2} \mathrm{Cl}_{2}$ formando mezcla de oximas en proporción 4:6. 
Oximas de (2-metilsulfanil-6-metoxipiridin-4-il)(1-metil-1H-indol-5-il)metanona (86EZ):

P.f. $\left(\mathrm{Hex} / \mathrm{CH}_{2} \mathrm{Cl}_{2}\right): 155-157^{\circ}$

RMN ${ }^{1} \mathrm{H}\left(\mathrm{CDCl}_{3}\right) \delta$ (ppm): (Espectro $\left.86 \mathrm{EH}\right) 2,53\left(3 \mathrm{H}, \mathrm{s}, \mathrm{SCH}_{3}\right) ; 3,83\left(3 \mathrm{H}, \mathrm{s}, \mathrm{NCH}_{3}\right)$; $3,92\left(3 \mathrm{H}, \mathrm{s}, \mathrm{OCH}_{3}\right) ; 6,48(1 \mathrm{H}, \mathrm{d}, \mathrm{J}=1,1 ; \mathrm{pyr}) ; 6,53\left(1 \mathrm{H}, \mathrm{d}, \mathrm{J}=3,2 ; \mathrm{H}_{3}\right) ; 6,93(1 \mathrm{H}, \mathrm{d}, \mathrm{J}=1,1$; pyr); 7,11 (1H, d, J=3,2; $\left.\mathrm{H}_{2}\right) ; 7,25\left(1 \mathrm{H}, \mathrm{dd}, \mathrm{J}=1,4 ; \mathrm{J}=8,3 ; \mathrm{H}_{6}\right) ; 7,39\left(1 \mathrm{H}, \mathrm{da}, \mathrm{J}=8,3 ; \mathrm{H}_{7}\right)$; $7,66\left(1 \mathrm{H}, \mathrm{d}, \mathrm{J}=1,4 ; \mathrm{H}_{4}\right)$. Isómero $E$.

RMN ${ }^{13} \mathrm{C}\left(\mathrm{CDCl}_{3}\right) \delta$ (ppm): (Espectro 86ZEC) 13,4 $\left(\mathrm{CH}_{3}\right) ; 33,0\left(\mathrm{CH}_{3}\right) ; 53,7\left(\mathrm{CH}_{3}\right) ; 101,9$ $(\mathrm{CH}) ; 102,1(\mathrm{CH}) ; 104,9(\mathrm{CH}) ; 105,6(\mathrm{CH}) ; 109,2(\mathrm{CH}) ; 109,5(\mathrm{CH}) ; 112,5(\mathrm{CH}) ; 113,5$ $(\mathrm{CH}) ; 120,5(\mathrm{CH}) ; 121,5(\mathrm{CH}) ; 122,5(\mathrm{CH}) ; 122,7(\mathrm{CH}) ; 125,8(\mathrm{C}) ; 128,2(\mathrm{C}) ; 129,8$ (CH); 136,9 (C); 137,4 (C); 144,8 (C); 147,9 (C); 157,0 (C); 157,2 (C); 157,6 (C); 157,9 (C); 163,9(C). Isómeros $E$ y $Z$.

IR: (KBr): 1456, 1515, 1544, 1589, 3227, $3272 \mathrm{~cm}^{-1}$

HRMS: Calculado (M+Na) 350,0939. Obtenido $\left(\mathrm{C}_{17} \mathrm{H}_{17} \mathrm{~N}_{3} \mathrm{NaO}_{2} \mathrm{~S}\right) 350,0953$.

HPLC: Columna $\mathrm{C}_{18} \mathrm{t}_{\mathrm{R}}: 18,39 \mathrm{~min} ; \mathrm{t}_{\mathrm{R}}: 18,90 \mathrm{~min}$.

\section{Obtención de 5-(2-metilsulfanil-6-metoxipiridin-4-il)-1-metil-1H-indol-3-} carbaldehído<smiles>COc1cc(C(=O)c2ccc3c(ccn3C)c2)cc(SC)n1</smiles>

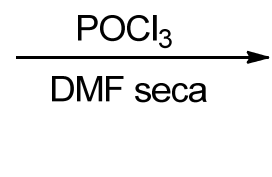<smiles>COc1cc(C(=O)c2ccc3c(c2)c(C=O)cn3C)cc(SC)n1</smiles>

Siguiendo el método $\mathrm{F}$, se disuelven $0,46 \mathrm{~mL}(5,04 \mathrm{mmol})$ de $\mathrm{POCl}_{3}$ en DMF seca $(5 \mathrm{~mL})$, y a la media hora se añaden $262 \mathrm{mg}(0,84 \mathrm{mmol})$ de (2-metilsulfanil-6metoxipiridin-4-il)(1-metil-1H-indol-5-il)metanona (84) disueltos en DMF seca (5-10 $\mathrm{mL}$ ), y se deja 2 horas a $60{ }^{\circ} \mathrm{C}$. Se obtienen $300 \mathrm{mg}$ de precipitado que se purifica mediante cromatografía flash, utilizando como eluyente Hexano/EtOAc (6:4), obteniendo $145 \mathrm{mg}(0,42 \mathrm{mmol} ; 51 \%)$ de 5-(2-metilsulfanil-6-metoxipiridin-4-il)-1-metil$1 H$-indol-3-carbaldehído. 


\section{5-(2-metilsulfanil-6-metoxipiridin-4-il)-1-metil-1H-indol-3-carbaldehído (87):}

$\mathrm{RMN}^{1} \mathrm{H}\left(\mathrm{CDCl}_{3}\right) \delta(\mathrm{ppm}):($ Espectro $87 \mathrm{H}) 2,59\left(3 \mathrm{H}, \mathrm{s}, \mathrm{SCH}_{3}\right) ; 3,93\left(3 \mathrm{H}, \mathrm{s}, \mathrm{NCH}_{3}\right) ; 4,00$ $\left(3 \mathrm{H}, \mathrm{s}, \mathrm{OCH}_{3}\right) ; 6,64(1 \mathrm{H}, \mathrm{d}, \mathrm{J}=1,1 ; \mathrm{pyr}) ; 7,03(1 \mathrm{H}, \mathrm{d}, \mathrm{J}=1,1 ; \mathrm{pyr}) ; 7,44(1 \mathrm{H}, \mathrm{da}, \mathrm{J}=8,9$; $\left.\mathrm{H}_{7}\right) ; 7,78\left(1 \mathrm{H}, \mathrm{s} ; \mathrm{H}_{2}\right) ; 7,90\left(1 \mathrm{H}, \mathrm{dd}, \mathrm{J}=1,4 ; \mathrm{J}=8,9 ; \mathrm{H}_{6}\right) ; 8,69\left(1 \mathrm{H}, \mathrm{d}, \mathrm{J}=1,4 ; \mathrm{H}_{4}\right) ; 9,99(1 \mathrm{H}$, $\mathrm{s}, \mathrm{CHO})$.

$\mathrm{RMN}{ }^{13} \mathrm{C}\left(\mathrm{CDCl}_{3}\right) \delta(\mathrm{ppm})$ : (Espectro 87C) 13,6 $\left(\mathrm{CH}_{3}\right) ; 34,0\left(\mathrm{CH}_{3}\right) ; 53,9\left(\mathrm{CH}_{3}\right) ; 105,5$ $(\mathrm{CH}) ; 110,3(\mathrm{CH}) ; 112,8(\mathrm{CH}) ; 119,0(\mathrm{C}) ; 124,6(\mathrm{C}) ; 125,8(2 \times \mathrm{CH}) ; 131,1(\mathrm{C}) ; 140,4$ (C); 140,7 (CH); 148,5 (C); 158,6 (C); 160,8 (C); 184,3 (CHO); 195,2 (C).

IR: (película): 1457, 1542, 1591, 1614, $1654 \mathrm{~cm}^{-1}$

HRMS: Calculado $(\mathrm{M}+\mathrm{H}) 341,0960$. Obtenido $\left(\mathrm{C}_{18} \mathrm{H}_{17} \mathrm{~N}_{2} \mathrm{O}_{3} \mathrm{~S}\right) 341,0959$.

HPLC: Columna $C_{8} \quad t_{R}: 15,85$ min.

\section{Obtención de ácido 5-(1-(2-metilsulfanil-6-metoxipiridin-4-il)vinil)-1-metil-} $\underline{1 H \text {-indol-3-carboxílico }}$<smiles>C=C(c1ccc2c(ccn2C)c1)c1cc(OC)cc(SC)n1</smiles><smiles>O=C(Cl)CCl</smiles><smiles>C=C(c1cc(OC)nc(SC)c1)c1ccc2c(c1)c(C(=O)O)cn2C</smiles>

Se disuelven $101 \mathrm{mg}$ (0,325 mmol) de 5-(1-(2-metilsulfanil-6-metoxipiridin-4il)vinil)-1-metil- $1 \mathrm{H}$-indol (85) en $20 \mathrm{~mL}$ de $\mathrm{CH}_{2} \mathrm{Cl}_{2}$ y se añaden $172 \mu \mathrm{L}(0,325 \mathrm{mmol}) \mathrm{de}$ fosgeno al $20 \%$ en tolueno en $\mathrm{CH}_{2} \mathrm{Cl}_{2}$. Se controla la reacción mediante $\mathrm{RMN}{ }^{1} \mathrm{H}$, y se añaden otros $172 \mu \mathrm{L}(0,325 \mathrm{mmol})$ de fosgeno al $20 \%$ en tolueno. Se mantiene la reacción a temperatura ambiente durante 72 horas. Se vierte la reacción sobre agua con hielo. Se basifica el medio con $\mathrm{NaOH}$ al $5 \%$ y se extrae con EtOAc (fase orgánica A). La fase acuosa se acidifica con $\mathrm{HCl} 2 \mathrm{~N}$, y se extrae con $\mathrm{CH}_{2} \mathrm{Cl}_{2}$ (fase orgánica $\mathrm{B}$ ). Las fases orgánicas ( $A$ y $B$ ) se neutralizan con disolución saturada de $\mathrm{NaCl}$, se secan con $\mathrm{Na}_{2} \mathrm{SO}_{4}$ anhidro, se filtra y se evapora a sequedad, obteniendo $31 \mathrm{mg}(0,087$ mmol; 27\%) de ácido 5-(1-(2-metilsulfanil-6-metoxipiridin-4-il)vinil)-1-metil-1H-indol-3carboxílico (88) de la fase orgánica B; y 73 mg de mezcla de 5-(1-(2-metilsulfanil-6metoxipiridin-4-il)vinil)-1-metil-1H-indol (85) y (2-metilsulfanil-6-metoxipiridin-4-il)(1metil-1 $H$-indol-5-il)metanona (84) de la fase orgánica $A$. 
Ácido 5-(1-(2-metilsulfanil-6-metoxipiridin-4-il)vinil)-1-metil-1H-indol-3-carboxílico (88):

$\mathrm{RMN}^{1} \mathrm{H}\left(\mathrm{CDCl}_{3}\right) \delta(\mathrm{ppm}):($ Espectro $88 \mathrm{H})$ 2,55 (3H, s, $\left.\mathrm{SCH}_{3}\right) ; 3,86\left(3 \mathrm{H}, \mathrm{s}, \mathrm{NCH}_{3}\right) ; 3,95$ $\left(3 \mathrm{H}, \mathrm{s}, \mathrm{OCH}_{3}\right) ; 5,59\left(2 \mathrm{H}, \mathrm{s}, \mathrm{CH}_{2}\right) ; 6,40(1 \mathrm{H}, \mathrm{s}, \mathrm{pyr}) ; 6,76(1 \mathrm{H}, \mathrm{s}$ pyr $) ; 7,15(1 \mathrm{H}, \mathrm{da}, \mathrm{J}=$ 8,$\left.9 ; \mathrm{H}_{6}\right) ; 7,30\left(1 \mathrm{H}, \mathrm{da}, \mathrm{J}=8,9 ; \mathrm{H}_{7}\right) ; 7,90\left(1 \mathrm{H}, \mathrm{s} ; \mathrm{H}_{2}\right) ; 8,22\left(1 \mathrm{H}, \mathrm{s} ; \mathrm{H}_{4}\right)$.

RMN ${ }^{13} \mathrm{C}\left(\mathrm{CDCl}_{3}\right) \delta(\mathrm{ppm})$ : (Espectro 88C) 13,5 $\left(\mathrm{CH}_{3}\right) ; 33,7\left(\mathrm{CH}_{3}\right) ; 53,9\left(\mathrm{CH}_{3}\right) ; 104,9$ $(\mathrm{CH}) ; 106,6(\mathrm{C}) ; 109,7(\mathrm{CH}) ; 113,4(\mathrm{CH}) ; 116,5\left(\mathrm{CH}_{2}\right) ; 121,5(\mathrm{CH}) ; 123,8(\mathrm{CH}) ; 126,9$ (C); 134,6 (C); 137,2 (CH); 148,5 (C); 152,7 (C); 157,1 (C); 164,0 (C); 170,2 (C).

IR (película): 1459, 1535, 1591, $1660 \mathrm{~cm}^{-1}$

HRMS: Calculado $(\mathrm{M}+\mathrm{H}) 355,1116$. Obtenido $\left(\mathrm{C}_{19} \mathrm{H}_{19} \mathrm{~N}_{2} \mathrm{O}_{3} \mathrm{~S}\right) 355,1113$.

HPLC: Columna $\mathrm{C}_{8} \quad \mathrm{t}_{\mathrm{R}}: 20,28 \mathrm{~min}$.

Obtención de 5-(1-(2-metilsulfanil-6-metoxipiridin-4-il)vinil)-1-metil-1Hindol-3-carbaldehído<smiles>C=C(c1cc(OC)nc(SC)c1)c1ccc2c(ccn2C)c1</smiles><smiles>COC(C)(C)CCCCO</smiles><smiles>C=C(c1cc(OC)nc(SC)c1)c1ccc2c(c1)c(C=O)cn2C</smiles>

Siguiendo el método $\mathrm{F}$, se disuelven $0,16 \mathrm{~mL}(1,71 \mathrm{mmol})$ de $\mathrm{POCl}_{3}$ en $\mathrm{DMF}$ seca $(5 \mathrm{~mL})$, y a la media hora se añaden $80 \mathrm{mg}(0,26 \mathrm{mmol})$ de 5-(1-(2-metilsulfanil6-metoxipiridin-4-il)vinil)-1-metil-1H-indol (85) disueltos en 5-10 mL de DMF seca, y se deja 2 horas a temperatura ambiente. Se obtiene un precipitado que se purifica mediante cromatografía flash utilizando como eluyente Hexano/EtOAc (6:4) y obteniendo 52 mg (0,15 mmol; 59\%) de 5-(1-(2-metilsulfanil-6-metoxipiridin-4-il)vinil)-1metil-1H-indol-3-carbaldehído. 


\section{5-(1-(2-metilsulfanil-6-metoxipiridin-4-il)vinil)-1-metil-1H-indol-3-carbaldehído} (89):

$\mathrm{RMN}{ }^{1} \mathrm{H}\left(\mathrm{CDCl}_{3}\right) \delta(\mathrm{ppm})$ : (Espectro $\left.89 \mathrm{H}\right) 2,53\left(3 \mathrm{H}, \mathrm{s}, \mathrm{SCH}_{3}\right) ; 3,85\left(3 \mathrm{H}, \mathrm{s}, \mathrm{NCH}_{3}\right) ; 3,94$ $\left(3 \mathrm{H}, \mathrm{s}, \mathrm{OCH}_{3}\right) ; 5,56\left(1 \mathrm{H}, \mathrm{s}, \mathrm{CH}_{2}\right) ; 5,57\left(1 \mathrm{H}, \mathrm{s}, \mathrm{CH}_{2}\right) ; 6,36(1 \mathrm{H}, \mathrm{d}, \mathrm{J}=1,1 ; \mathrm{pyr}) ; 6,73(1 \mathrm{H}$, d, J=1,1; pyr); 7,20 (1H, dd, J=1,4; J= 8,9; $\left.\mathrm{H}_{6}\right) ; 7,26\left(1 \mathrm{H}, \mathrm{da}, \mathrm{J}=8,9 ; \mathrm{H}_{7}\right) ; 7,66(1 \mathrm{H}, \mathrm{s}$, $\left.\mathrm{H}_{2}\right) ; 8,28\left(1 \mathrm{H}, \mathrm{d}, \mathrm{J}=1,4 ; \mathrm{H}_{4}\right) ; 9,94(1 \mathrm{H}, \mathrm{s}, \mathrm{CHO})$.

$\mathrm{RMN}{ }^{13} \mathrm{C}\left(\mathrm{CDCl}_{3}\right) \delta(\mathrm{ppm})$ : (Espectro 89C) 13,4 $\left(\mathrm{CH}_{3}\right) ; 33,8\left(\mathrm{CH}_{3}\right) ; 53,5\left(\mathrm{CH}_{3}\right) ; 104,9$ $(\mathrm{CH}) ; 109,7(\mathrm{CH}) ; 113,3(\mathrm{CH}) ; 116,2\left(\mathrm{CH}_{2}\right) ; 118,2(\mathrm{C}) ; 121,7(\mathrm{CH}) ; 124,7(\mathrm{CH}) ; 125,3$ (C); 135,3 (C); 137,7 (C); 139,9 (CH); 148,2 (C); 152,6 (C); 157,1 (C); 164,0 (C); 184,4 $(\mathrm{CHO})$.

IR: (película): 1455, 1536, 1589, $1658 \mathrm{~cm}^{-1}$

HRMS: Calculado $(\mathrm{M}+\mathrm{H}) 361,0987$. Obtenido $\left(\mathrm{C}_{19} \mathrm{H}_{18} \mathrm{~N}_{2} \mathrm{O}_{2} \mathrm{~S}\right) 361,0992$.

HPLC: Columna $C_{8} \quad t_{R}: 19,29$ min.

Intentos de obtención de 5-(2-metilsulfanil-6-metoxipiridin-4-il)-1-metil$\underline{1 H \text {-indol-3-carbonitrilo }}$<smiles>COc1cc(C(=O)O)cc(SC)n1</smiles><smiles>Cn1cc(C#N)c2cc(Br)ccc21</smiles><smiles></smiles>

Siguiendo el método A, se disuelven $1,1 \mathrm{~g}(4,71 \mathrm{mmol})$ de 5-bromo-1-metil-1Hindol-3-carbonitrilo (18) en THF seco $(20 \mathrm{~mL})$, y se añaden $3 \mathrm{~mL}(4,71 \mathrm{mmol})$ de una disolución 1,6 M de $n$ BuLi en hexano. Posteriormente se añaden $500 \mathrm{mg}(2,51 \mathrm{mmol})$ de ácido 2-metilsulfanil-6-metoxipiridina-4-carboxílico (5) disuelto en THF seco (10 $\mathrm{mL}$ ). Pasadas $24 \mathrm{~h}$ se añade formiato de etilo, EtOAc y agua. La fase orgánica se evapora parcialmente, se lava con agua saturada con $\mathrm{NaCl}$ hasta $\mathrm{pH}$ neutro, se seca con $\mathrm{Na}_{2} \mathrm{SO}_{4}$, se filtra y se evapora a sequedad. En RMN ${ }^{1} \mathrm{H}$ se observa el compuesto 18.

Se disuelven $505 \mathrm{mg}(2,15 \mathrm{mmol})$ de 5-bromo-1-metil-1H-indol-3-carbonitrilo en THF seco (10-20 mL), y se añaden $2,7 \mathrm{~mL}(4,30 \mathrm{mmol})$ de una disolución 1,6 $\mathrm{M}$ de 
$n$ BuLi en hexano. Posteriormente se añaden $214 \mathrm{mg}(1,07 \mathrm{mmol})$ de ácido 2metilsulfanil-6-metoxipiridina-4-carboxílico $(10 \mathrm{~mL})$. No se observa avance de la reacción.<smiles>COc1cc(C(=O)O)cc(SC)n1</smiles><smiles>Cn1cc(C#N)c2cc(Br)ccc21</smiles><smiles>COc1cc(C(=O)c2ccc3c(c2)c(C#N)cn3C)cc(SCC(NC(=O)O)C(F)(F)F)n1</smiles>

Sobre una suspensión de $31 \mathrm{mg}(1,29 \mathrm{mmol})$ de $\mathrm{Mg}$ en THF seco, se añade en frío unos cristales de $\mathrm{I}_{2}$ y un tercio del derivado bromado. Se deja hasta decoloración de la solución (en este caso tarda 24 horas en cambiar a color lechoso) y a continuación se añade lentamente el resto de derivado bromado (en total 158 mg (0,67 $\mathrm{mmol}$ ) de 5-bromo-1-metil-1H-indol-3-carbonitrilo) y se deja en agitación una hora. En otro matraz se prepara una suspensión de $100 \mathrm{mg}(0,50 \mathrm{mmol})$ de ácido 2metilsulfanil-6-metoxipiridina-4-carboxílico y $32 \mathrm{mg}(1,34 \mathrm{mmol})$ de $\mathrm{NaH}$ y se deja media hora en agitación en baño de hielo. Posteriormente se añade el derivado bromado sobre el ácido y se deja $24 \mathrm{~h}$ en agitación hasta alcanzar temperatura ambiente. Se añade cloruro amónico y EtOAc. La fase orgánica se evapora parcialmente, se lava con agua saturada con $\mathrm{NaCl}$ hasta $\mathrm{pH}$ neutro, se seca con $\mathrm{Na}_{2} \mathrm{SO}_{4}$, se filtra y se evapora a sequedad. No se observa avance de la reacción.

Obtención de las oximas de 5-((hidroximino-(2-metilsulfanil-6metoxipiridin-4-il)metil)-1-metil-1H-indol-3-carbaldehído<smiles>COc1cc(C(=O)c2ccc3c(c2)c(C=O)cn3C)cc(SC)n1</smiles><smiles>CO[C@H](O)C(O)O</smiles><smiles>COc1cc(/C(=N\O)c2ccc3c(c2)c(/C=N/O)cn3C)cc(SC)n1</smiles>

Siguiendo el método $\mathrm{E}$, se disuelven $68 \mathrm{mg}(0,2 \mathrm{mmol})$ de 5-(6-metilsulfanil-2metoxipiridin-4-il)-1-metil-1H-indol-3-carbaldehído (87) en $\mathrm{MeOH}(10 \mathrm{~mL})$, y se añaden $139 \mathrm{mg}$ (1,99 mmol) de clorhidrato de hidroxilamina. Se obtienen $143 \mathrm{mg}$ de mezcla de oximas que se utilizan en la siguiente reacción. 
Obtención de 5-((hidroximino)(2-metilsulfanil-6-metoxipiridin-4-il)metil)-1metil-1H-indol-3-carbonitrilo

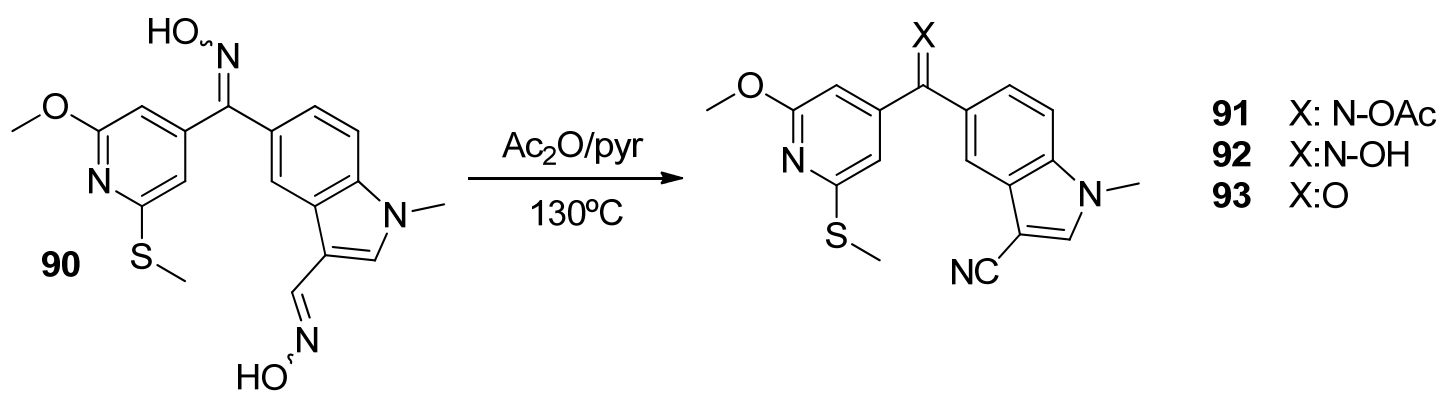

Se disuelven $143 \mathrm{mg}$ de la mezcla de oximas (90) en piridina $(5-10 \mathrm{~mL})$ y se añade $0,5 \mathrm{~mL}$ de anhídrido acético siguiendo el método J. Mediante cromatografía flash, utilizando como eluyente Hexano/EtOAc (7:3), se obtienen $10 \mathrm{mg}(0,03 \mathrm{mmol})$ de (93) y $65 \mathrm{mg}$ del derivado acetilado (91).

Se disuelven los $65 \mathrm{mg}$ del derivado acetilado (91) en $1 \mathrm{~mL}$ de $\mathrm{KOH} 5 \mathrm{~N}$ y $3 \mathrm{~mL}$ de $\mathrm{MeOH}$, durante 24 horas a temperatura ambiente. Se realiza extracción con $\mathrm{CH}_{2} \mathrm{Cl}_{2}$ y se lava la fase orgánica, hasta neutralidad, con una disolución saturada de $\mathrm{NaCl}$. Se seca con $\mathrm{Na}_{2} \mathrm{SO}_{4}$ anhidro, se filtra y se evapora a sequedad. Se purifica mediante cromatografía flash, utilizando como eluyente Hexano/EtOAc (7:3), y se obtienen $3 \mathrm{mg}$ de (93), $19 \mathrm{mg}$ de una mezcla de oximas (92) y cetona (93); y $8 \mathrm{mg}$ de la oxima (92). Se juntan las tres fracciones y se vuelven a sintetizar la oxima. Son $41 \mathrm{mg}$ de mezcla de oxima y cetona y se añade $84 \mathrm{mg}$ de clorhidrato de hidroxilamina $(1,22 \mathrm{mmol})$. Se purifica mediante cromatografía flash, utilizando como eluyente Hexano/EtOAc (7:3), y se obtienen $5 \mathrm{mg}$ del isómero $E, 5 \mathrm{mg}$ del isómero $Z$ y $9 \mathrm{mg}$ de mezcla de oximas (92EZ). En disolución clorofórmica las oximas se rompen formando la cetona.

(E)-5-((hidroximino)(2-metilsulfanil-6-metoxipiridin-4-il)metil)-1-metil-1H-indol-3carbonitrilo (92E):

$\mathrm{RMN}^{1} \mathrm{H}\left(\mathrm{CDCl}_{3}\right) \delta$ (ppm): (Espectro 92EH) 2,50 (3H, s, SCH$) ; 3,84\left(3 \mathrm{H}, \mathrm{s}, \mathrm{NCH}_{3}\right)$; $3,87\left(3 \mathrm{H}, \mathrm{s}, \mathrm{OCH}_{3}\right) ; 6,33(1 \mathrm{H}, \mathrm{d}, \mathrm{J}=1,2 ; \mathrm{pyr}) ; 6,86(1 \mathrm{H}, \mathrm{d}, \mathrm{J}=1,2 ; \mathrm{pyr}) ; 7,26(1 \mathrm{H}, \mathrm{d}$, $\left.J=8,8 ; H_{6}\right) ; 7,41\left(1 \mathrm{H}, \mathrm{d}, \mathrm{J}=8,8 ; \mathrm{H}_{7}\right) ; 7,57\left(1 \mathrm{H}, \mathrm{s}, \mathrm{H}_{2}\right) ; 7,72\left(1 \mathrm{H}, \mathrm{s}, \mathrm{H}_{4}\right)$.

IR (película): 1454, 1538, 1590, 2221, $3309 \mathrm{~cm}^{-1}$

HRMS: Calculado $(\mathrm{M}+\mathrm{H}) 353,1072$. Obtenido $\left(\mathrm{C}_{18} \mathrm{H}_{17} \mathrm{~N}_{4} \mathrm{O}_{2} \mathrm{~S}\right) 353,1069$. 
(Z)-5-((hidroximino)(2-metilsulfanil-6-metoxipiridin-4-il)metil)-1-metil-1 $\boldsymbol{H}$-indol-3carbonitrilo (92Z):

$\mathrm{RMN}^{1} \mathrm{H}\left(\mathrm{CDCl}_{3}\right) \delta$ (ppm): (Espectro 92ZH) 2,54 (3H, s, SCH$) ; 3,80\left(3 \mathrm{H}, \mathrm{s}, \mathrm{NCH}_{3}\right)$;

$3,95\left(3 \mathrm{H}, \mathrm{s}, \mathrm{OCH}_{3}\right) ; 6,34(1 \mathrm{H}, \mathrm{d}, \mathrm{J}=1,2 ; \mathrm{pyr}) ; 6,68(1 \mathrm{H}, \mathrm{s}, \mathrm{J}=1,2 ; \mathrm{pyr}) ; 7,30(1 \mathrm{H}, \mathrm{d}$, $\left.J=8,8 ; H_{6}\right) ; 7,52\left(1 \mathrm{H}, \mathrm{s}, \mathrm{H}_{2}\right) ; 7,55\left(1 \mathrm{H}, \mathrm{d}, \mathrm{J}=8,8 ; \mathrm{H}_{7}\right) ; 7,65\left(1 \mathrm{H}, \mathrm{s}, \mathrm{H}_{4}\right)$.

IR (película): 1454, 1540, 1591, 2221, $3309 \mathrm{~cm}^{-1}$

HRMS: Calculado $(\mathrm{M}+\mathrm{H}) 353,1072$. Obtenido $\left(\mathrm{C}_{18} \mathrm{H}_{17} \mathrm{~N}_{4} \mathrm{O}_{2} \mathrm{~S}\right) 353,1071$.

HPLC: Columna $C_{8} \quad t_{R}: 15,80 \mathrm{~min} ; t_{R}: 16,72$ min.

5-(2-metilsulfanil-6-(metoxi)piridin-4-il)-1-metil-1H-indol-3-carbonitrilo (93):

$\mathrm{RMN}^{1} \mathrm{H}\left(\mathrm{CDCl}_{3}\right) \delta$ (ppm): (Espectro 93H) 2,55 (3H, s, $\left.\mathrm{SCH}_{3}\right) ; 3,87\left(3 \mathrm{H}, \mathrm{s}, \mathrm{NCH}_{3}\right) ; 3,95$ $\left(3 \mathrm{H}, \mathrm{s}, \mathrm{OCH}_{3}\right) ; 6,56(1 \mathrm{H}, \mathrm{d}, \mathrm{J}=1,2 ; \mathrm{pyr}) ; 6,96(1 \mathrm{H}, \mathrm{d}, \mathrm{J}=1,2 ; \mathrm{pyr}) ; 7,43\left(1 \mathrm{H}, \mathrm{d}, \mathrm{J}=8,4 ; \mathrm{H}_{7}\right)$; $7,62\left(1 \mathrm{H}, \mathrm{s}, \mathrm{H}_{2}\right) ; 7,86\left(1 \mathrm{H}, \mathrm{dd}, \mathrm{J}=1,6 ; \mathrm{J}=8,4 ; \mathrm{H}_{6}\right) ; 8,11\left(1 \mathrm{H}, \mathrm{d}, \mathrm{J}=1,6 ; \mathrm{H}_{4}\right)$.

$\mathrm{RMN}{ }^{13} \mathrm{C}\left(\mathrm{CDCl}_{3}\right) \delta$ (ppm): (Espectro 93C) 13,4 $\left(\mathrm{CH}_{3}\right) ; 33,9\left(\mathrm{CH}_{3}\right) ; 53,8\left(\mathrm{CH}_{3}\right) ; 105,2$ $(\mathrm{CH}) ; 110,6(\mathrm{CH}) ; 112,6(\mathrm{CH}) ; 114,7(\mathrm{C}) ; 115,6(\mathrm{C}) ; 123,8(\mathrm{CH}) ; 125,5(\mathrm{CH}) ; 127,0(\mathrm{C})$; 130,5 (C); 137,3 (CH); 148,2 (C); 158,8 (C); 163,6 (C); 194,8 (C).

IR (película): 1455, 1542, 1609, 1661, $2221 \mathrm{~cm}^{-1}$

HRMS: Calculado $(\mathrm{M}+\mathrm{H}) 338,0963$. Obtenido $\left(\mathrm{C}_{18} \mathrm{H}_{16} \mathrm{~N}_{3} \mathrm{O}_{2} \mathrm{~S}\right) 338,0943$.

HPLC: Columna $\mathrm{C}_{8} \quad \mathrm{t}_{\mathrm{R}}: 17,89 \mathrm{~min}$.

Obtención de (2,6-bis(metilsulfanil)piridin-4-il)(1-metil-1H-indol-5il)metanona<smiles>CSc1cc(C(=O)O)cc(SC)n1</smiles><smiles>Cn1ccc2cc(Br)ccc21</smiles><smiles>CCCCCOC(=O)OC</smiles><smiles>CSc1cc(C(=O)c2ccc3c(ccn3C)c2)cc(SC)n1</smiles>

Siguiendo el método A, se disuelve 2,44 g (11,5 mmol) de 5-bromo-1-metil-1Hindol (15) en THF seco (20-30 mL), y se añaden 7,2 $\mathrm{mL}(11,5 \mathrm{mmol})$ de una disolución 1,6 $\mathrm{M}$ de $n \mathrm{BuLi}$ en hexano. Posteriormente se añaden $1 \mathrm{~g}(4,6 \mathrm{mmol})$ de ácido 2,6bis(metilsulfanil)piridina-4-carboxílico (4) disuelto en THF seco (10-20 mL). Mediante cromatografía flash usando como eluyente Hexano/EtOAc (9:1), se obtienen $500 \mathrm{mg}$ 
$(1,52 \mathrm{mmol} ; 33 \%)$ de (2,6-bis(metilsulfanil)piridin-4-il)(1-metil-1H-indol-5-il)metanona (94) y (2,6-bis(metilsulfanil)piridin-4-il)bis(1-metil-1H-indol-5-il)metanol (95), aislado de las fracciones polares de la columna.

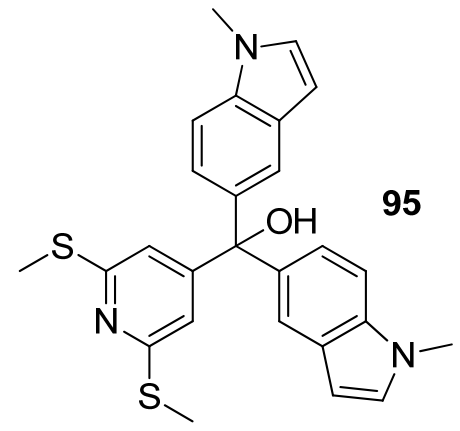

(2,6-bis(metilsulfanil)piridin-4-il)(1-metil-1H-indol-5-il)metanona (94):

$\mathrm{RMN}^{1} \mathrm{H}\left(\mathrm{CDCl}_{3}\right) \delta$ (ppm): (Espectro 94H) 2,62 (6H, s, $\left.\mathrm{SCH}_{3}\right) ; 3,85\left(3 \mathrm{H}, \mathrm{s}, \mathrm{NCH}_{3}\right) ; 6,60$ $\left(1 \mathrm{H}, \mathrm{d}, \mathrm{J}=3,2 ; \mathrm{H}_{3}\right) ; 7,10(2 \mathrm{H}, \mathrm{s}, \mathrm{pyr}) ; 7,15\left(1 \mathrm{H}, \mathrm{d}, \mathrm{J}=3,2 ; \mathrm{H}_{2}\right) ; 7,38\left(1 \mathrm{H}, \mathrm{d}, \mathrm{J}=8,8 ; \mathrm{H}_{7}\right)$; $7,80\left(1 \mathrm{H}, \mathrm{dd}, \mathrm{J}=1,8 ; \mathrm{J}=8,8 ; \mathrm{H}_{6}\right) ; 8,07\left(1 \mathrm{H}, \mathrm{d}, \mathrm{J}=1,8 ; \mathrm{H}_{4}\right)$.

$\mathrm{RMN}{ }^{13} \mathrm{C}\left(\mathrm{CDCl}_{3}\right) \delta(\mathrm{ppm})$ : (Espectro 94C) 13,5 $\left(2 \times \mathrm{CH}_{3}\right) ; 33,2\left(\mathrm{CH}_{3}\right) ; 103,4(\mathrm{CH}) ; 109,6$ $(\mathrm{CH}) ; 115,9(2 \times C H) ; 123,5(\mathrm{CH}) ; 125,8(\mathrm{CH}) ; 127,7(\mathrm{C}) ; 127,9(\mathrm{C}) ; 130,9(\mathrm{CH}) ; 139,5$ (C); 146,4 (C); 160,1 (2xC); 195,1 (C).

IR (KBr): 1526, 1565, 1603, $1652 \mathrm{~cm}^{-1}$

HRMS: Calculado $(\mathrm{M}+\mathrm{H}) 329,0782$. Obtenido $\left.\left(\mathrm{C}_{17} \mathrm{H}_{17} \mathrm{~N}_{2} \mathrm{OS}\right)_{2}\right) 329,0761$.

HPLC: Columna $\mathrm{C}_{8} \quad \mathrm{t}_{\mathrm{R}}: 20,38 \mathrm{~min}$.

(2,6-bis(metilsulfanil)piridin-4-il)bis(1-metil-1H-indol-5-il)metanol (95):

$\mathrm{RMN}^{1} \mathrm{H}\left(\mathrm{CDCl}_{3}\right) \delta(\mathrm{ppm})$ : (Espectro $\left.95 \mathrm{H}\right) 2,55\left(6 \mathrm{H}, \mathrm{s}, \mathrm{SCH}_{3}\right) ; 3,79\left(6 \mathrm{H}, \mathrm{s}, \mathrm{NCH}_{3}\right) ; 6,41$ $\left(2 \mathrm{H}, \mathrm{d}, \mathrm{J}=2,8 ; \mathrm{H}_{3}\right) ; 6,97(4 \mathrm{H}, \mathrm{s}, \mathrm{pyr}) ; 7,05\left(2 \mathrm{H}, \mathrm{d}, \mathrm{J}=2,8 ; \mathrm{H}_{2}\right) ; 7,18(2 \mathrm{H}, \mathrm{dd}, \mathrm{J}=1,8 ; \mathrm{J}=8,6$; $\left.\mathrm{H}_{6}\right) ; 7,27\left(2 \mathrm{H}, \mathrm{d}, \mathrm{J}=8,6 ; \mathrm{H}_{7}\right) ; 7,44\left(2 \mathrm{H}, \mathrm{d}, \mathrm{J}=1,8 ; \mathrm{H}_{4}\right)$.

$\mathrm{RMN}^{13} \mathrm{C}\left(\mathrm{CDCl}_{3}\right) \delta(\mathrm{ppm})$ : (Espectro 95C) 13,5 $\left(2 \mathrm{xCH}_{3}\right) ; 33,2\left(2 \mathrm{xCH}_{3}\right) ; 82,3(\mathrm{C}) ; 101,6$ (2xCH); 109,2 (2xCH); 116,6 (2xCH); 120,7 (2xCH); 122,2 (2xCH); 127,9 (2xC); 129,6 (2xCH); 136,1 (2xC); 137,6(2xC); 157,3 (C); 158,8 (2xC).

IR (película): 1439, 1489, 1529, 1571, 1728, 2925, $3510 \mathrm{~cm}^{-1}$

HRMS: Calculado (M+Na) 482,1337. Obtenido $\left(\mathrm{C}_{26} \mathrm{H}_{25} \mathrm{~N}_{3} \mathrm{NaOS}_{2}\right) 482,1301$.

HPLC: Columna $\mathrm{C}_{18} \mathrm{t}_{\mathrm{R}}: 22,69 \mathrm{~min}$. 
Obtención de 5-(1-(2,6-bis(metilsulfanil)piridin4-il)vinil)-1-metil-1H-indol

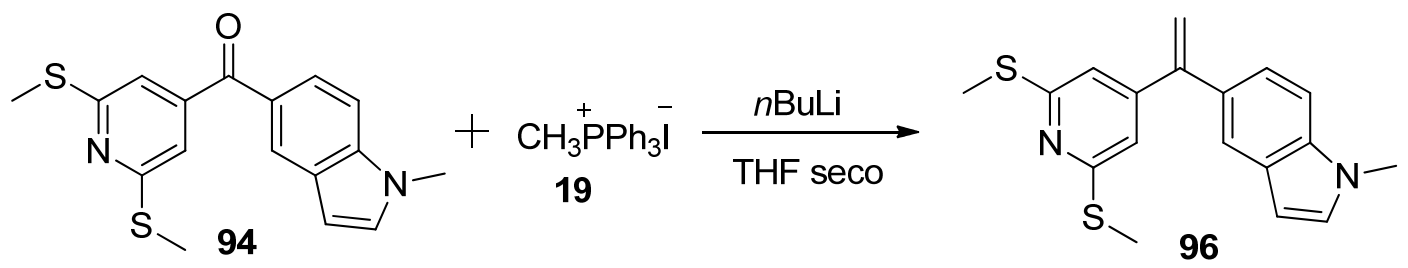

Se prepara una suspensión siguiendo el método $B$ de 1,07 g (2,65 mmol) de metiltrifenilfosfonio (19) en THF seco $(20 \mathrm{~mL})$ a $-40^{\circ} \mathrm{C}$ y se adicionan $1,1 \mathrm{~mL}(1,8$ mmol) de una disolución 1,6 M de $n$ BuLi en hexano. Posteriormente se adicionan 290 $\mathrm{mg}(0,88 \mathrm{mmol})$ de (2,6-bis(metilsulfanil)piridin-4-il)(1-metil-1H-indol-5-il)metanona (94) disueltos en THF seco $(10 \mathrm{~mL})$, obteniendo $545 \mathrm{mg}$. Mediante cromatografía en columna, usando como eluyente Hexano/EtOAc (95:5), se obtienen $134 \mathrm{mg}$ (0,41 mmol; 47 \%) de 5-(1-(2,6-bis(metilsulfanil)piridin4-il)vinil)-1-metil-1H-indol.

\section{5-(1-(2,6-bis(metilsulfanil)piridin-4-il)vinil)-1-metil-1H-indol (96):}

$\mathrm{RMN}^{1} \mathrm{H}\left(\mathrm{CDCl}_{3}\right) \delta$ (ppm): (Espectro 96H) 2,63 (6H, s, $\left.\mathrm{SCH}_{3}\right) ; 3,81\left(3 \mathrm{H}, \mathrm{s}, \mathrm{NCH}_{3}\right) ; 5,51$ $\left(1 \mathrm{H}, \mathrm{d}, \mathrm{J}=1,1 ; \mathrm{CH}_{2}\right) ; 5,59\left(1 \mathrm{H}, \mathrm{d}, \mathrm{J}=1,1 ; \mathrm{CH}_{2}\right) ; 6,50\left(1 \mathrm{H}, \mathrm{d}, \mathrm{J}=3,2 ; \mathrm{H}_{3}\right) ; 6,94(2 \mathrm{H}, \mathrm{s}, \mathrm{pyr})$; $7,09\left(1 \mathrm{H}, \mathrm{d}, \mathrm{J}=3,2 ; \mathrm{H}_{2}\right) ; 7,20\left(1 \mathrm{H}, \mathrm{dd}, \mathrm{J}=1,8 ; \mathrm{J}=8,8 ; \mathrm{H}_{6}\right) ; 7,31\left(1 \mathrm{H}, \mathrm{d}, \mathrm{J}=8,8 ; \mathrm{H}_{7}\right) ; 7,58$ $\left(1 \mathrm{H}, \mathrm{d}, \mathrm{J}=1,8 ; \mathrm{H}_{4}\right)$.

RMN ${ }^{13} \mathrm{C}\left(\mathrm{CDCl}_{3}\right) \delta(\mathrm{ppm})$ : (Espectro 96C) 13,4 (2xCH$) ; 33,0\left(\mathrm{CH}_{3}\right) ; 101,5(\mathrm{CH}) ; 109,2$ $(\mathrm{CH}) ; 115,4\left(\mathrm{CH}_{2}\right) ; 116,5(2 \times C H) ; 120,9(\mathrm{CH}) ; 122,1(\mathrm{CH}) ; 128,4(\mathrm{C}) ; 129,7(\mathrm{CH}) ; 131,2$ (C); 136,6 (C); 148,7 (C); 150,3 (C);159,2 (2xC).

IR (película): 1517, 1571, $1607 \mathrm{~cm}^{-1}$

HRMS: Calculado $(\mathrm{M}+\mathrm{H}) 327,0990$. Obtenido $\left(\mathrm{C}_{18} \mathrm{H}_{19} \mathrm{~N}_{2} \mathrm{~S}_{2}\right) 327,1031$.

HPLC: Columna $\mathrm{C}_{18} \quad \mathrm{t}_{\mathrm{R}}: 24,78 \mathrm{~min}$. 
Obtención de las oximas de (2,6-bis(metilsulfanil)piridin-4-il)(1-metil-1Hindol-5-il)metanona<smiles>CSc1cc(C(=O)c2ccc3c(ccn3C)c2)cc(SC)n1</smiles><smiles>CSc1cc(/C(=N\O)c2ccc3c(ccn3C)c2)cc(SC)n1</smiles>

Se disuelven $134 \mathrm{mg}(0,41 \mathrm{mmol})$ de (2,6-bis(metilsulfanil)piridin-4-il)(1-metil- $1 \mathrm{H}$-indol5-il)metanona (94) en $\mathrm{MeOH}(10-20 \mathrm{~mL})$ y, siguiento el método $\mathrm{E}$, se añaden $284 \mathrm{mg}$ $(4,08 \mathrm{mmol})$ de clorhidrato de hidroxilamina . Para separar las dos oximas se hace una cromatografía flash, utilizando como eluyente Hexano/EtOAc (9:1) obteniendo $48 \mathrm{mg}$ $(0,14 \mathrm{mmol} ; 34 \%)$ del isómero $E, 21 \mathrm{mg}(0,06 \mathrm{mmol} ; 15 \%)$ del isómero $Z$ y $52 \mathrm{mg}(0,15$ mmol; 37\%) de mezcla de oximas.

\section{Oximas de (2,6-bis(metilsulfanil)piridin-4-il)(1-metil-1H-indol-5-il)metanona (97EZ):}

$\mathrm{RMN}^{1} \mathrm{H}\left(\mathrm{CDCl}_{3}\right) \delta$ (ppm): (Espectro 97ZEH) 2,56 (6H, s, SCH$)_{3} ; 3,84\left(3 \mathrm{H}, \mathrm{s}, \mathrm{NCH}_{3}\right)$; $6,54\left(1 \mathrm{H}, \mathrm{d}, \mathrm{J}=3,2 ; \mathrm{H}_{3}\right) ; 6,98(2 \mathrm{H}, \mathrm{s}, \mathrm{pyr}) ; 7,12\left(1 \mathrm{H}, \mathrm{d}, \mathrm{J}=3,2 ; \mathrm{H}_{2}\right) ; 7,24(1 \mathrm{H}, \mathrm{dd}, \mathrm{J}=1,8$; $\left.J=8,6 ; H_{6}\right) ; 7,40\left(1 \mathrm{H}, \mathrm{d}, \mathrm{J}=8,6 ; \mathrm{H}_{7}\right) ; 7,68\left(1 \mathrm{H}, \mathrm{d}, \mathrm{J}=1,8 ; \mathrm{H}_{4}\right)$. Isómero $E$.

$\mathrm{RMN}^{1} \mathrm{H}\left(\mathrm{CDCl}_{3}\right) \delta$ (ppm): (Espectro 97ZEH) 2,61 (6H, s, $\left.\mathrm{SCH}_{3}\right) ; 3,80\left(3 \mathrm{H}, \mathrm{s}, \mathrm{NCH}_{3}\right)$; $6,46\left(1 \mathrm{H}, \mathrm{d}, \mathrm{J}=3,2 ; \mathrm{H}_{3}\right) ; 6,90(2 \mathrm{H}, \mathrm{s}, \mathrm{pyr}) ; 7,06\left(1 \mathrm{H}, \mathrm{d}, \mathrm{J}=3,2 ; \mathrm{H}_{2}\right) ; 7,29(1 \mathrm{H}, \mathrm{d}, \mathrm{J}=8,6$; $\left.\mathrm{H}_{7}\right) ; 7,49\left(1 \mathrm{H}, \mathrm{dd}, \mathrm{J}=1,8 ; \mathrm{J}=8,6 ; \mathrm{H}_{6}\right) ; 7,51\left(1 \mathrm{H}, \mathrm{d}, \mathrm{J}=1,8 ; \mathrm{H}_{4}\right)$. Isómero $Z$.

RMN ${ }^{13} \mathrm{C}\left(\mathrm{CDCl}_{3}\right) \delta$ (ppm): (Espectro 97ZC) 13,3 (2xCH$) ; 32,9\left(\mathrm{CH}_{3}\right) ; 102,0(\mathrm{CH})$; 109,4 (CH); 116,5 (2xCH); 120,6 (CH); 121,6 (CH); 125,5 (C); 128,1 (C); 129,8 (CH); 137,5 (C); 141,5 (C); 156,9 (C); 159,7 (2xC). Isómero Z.

IR (película): 1435, 1517, 1571, $3214 \mathrm{~cm}^{-1}$

HRMS: Calculado $(\mathrm{M}+\mathrm{H}) 344,0891$. Obtenido $\left(\mathrm{C}_{17} \mathrm{H}_{18} \mathrm{~N}_{3} \mathrm{OS}{ }_{2}\right) 344,0870$.

HPLC: Columna $C_{18} \quad t_{R}: 21,22 \mathrm{~min} ; t_{R}: 21,67$ min. 
Obtención de 5-(2,6-bis(metilsulfanil)piridin-4-il)-1-metil-1H-indol-3-

\section{carbaldehído}<smiles>CSc1cc(C(=O)c2ccc3c(ccn3C)c2)cc(SC)n1</smiles><smiles>COC(C)(F)F</smiles><smiles>CSc1cc(C(=O)c2ccc3c(c2)c(C=O)cn3C)cc(SC)n1</smiles>

Siguiendo el método $\mathrm{F}$, se disuelven $0,15 \mathrm{~mL}(1,64 \mathrm{mmol})$ de $\mathrm{POCl}_{3}$ en $\mathrm{DMF}$ seca $(5 \mathrm{~mL})$ en tamiz molecular, y a la media hora se añaden $96 \mathrm{mg}(0,29 \mathrm{mmol}) \mathrm{de}$ (2,6-bis(metilsulfanil)piridin-4-il)(1-metil-1H-indol-5-il)metanona (94) disueltos en DMF seca $(5-10 \mathrm{~mL})$, y se deja 2 horas a $60^{\circ} \mathrm{C}$. Se obtienen $62 \mathrm{mg}$ de precipitado que se purifica mediante cromatografía flash, utilizando como eluyente Hexano/EtOAc (1:1) obteniendo $45 \mathrm{mg}(0,13 \mathrm{mmol} ; 44 \%)$ de 5-(2,6-bis(metilsulfanil)piridin-4-il)-1-metil-1Hindol-3-carbaldehído.

\section{5-(2,6-bis(metilsulfanil)piridin-4-il)-1-metil-1H-indol-3-carbaldehído (98):}

$\mathrm{RMN}^{1} \mathrm{H}\left(\mathrm{CDCl}_{3}\right) \delta$ (ppm): (Espectro 98H) 2,62 (6H, s, $\left.\mathrm{SCH}_{3}\right) ; 3,94\left(3 \mathrm{H}, \mathrm{s}, \mathrm{NCH}_{3}\right) ; 7,10$ $(2 \mathrm{H}, \mathrm{s}, \mathrm{pyr}) ; 7,44\left(1 \mathrm{H}, \mathrm{d}, \mathrm{J}=8,4 ; \mathrm{H}_{7}\right) ; 7,79\left(1 \mathrm{H}, \mathrm{s} ; \mathrm{H}_{2}\right) ; 7,88\left(1 \mathrm{H}, \mathrm{dd}, \mathrm{J}=1,8 ; \mathrm{J}=8,4 ; \mathrm{H}_{6}\right)$; $8,69\left(1 \mathrm{H}, \mathrm{d}, \mathrm{J}=1,8 ; \mathrm{H}_{4}\right) ; 10,02(1 \mathrm{H}, \mathrm{s}, \mathrm{CHO})$.

RMN ${ }^{13} \mathrm{C}\left(\mathrm{CDCl}_{3}\right) \delta(\mathrm{ppm})$ : (Espectro 98C) 13,4 (2xCH$) ; 33,9\left(\mathrm{CH}_{3}\right) ; 110,2(\mathrm{CH}) ; 115,8$ $(2 \times C H) ; 119,1(\mathrm{C}) ; 124,7(\mathrm{C}) ; 125,6(\mathrm{CH}) ; 125,7(\mathrm{CH}) ; 130,9(\mathrm{C}) ; 140,2(\mathrm{CH}) ; 145,3$ (C); 160,3 (2xC); 184,1 (CH); 194,9 (C).

IR: (película): 1457, 1529, 1568, 1610, $1658 \mathrm{~cm}^{-1}$

HRMS: Calculado $(\mathrm{M}+\mathrm{H}) 357,0731$. Obtenido $\left(\mathrm{C}_{18} \mathrm{H}_{17} \mathrm{~N}_{2} \mathrm{O}_{2} \mathrm{~S}_{2}\right) 357,0792$.

HPLC: Columna $\mathrm{C}_{8} \quad \mathrm{t}_{\mathrm{R}}: 17,23 \mathrm{~min}$. 
Obtención de 5-(1-(2,6-bis(metilsulfanil)piridin-4-il)vinil)-1-metil-1H-indol-3carbaldehído<smiles>C=C(c1ccc2[nH]ccc2c1)c1cc(SC)cc(SC)n1</smiles><smiles>COC(C)(F)F</smiles><smiles>C=C(c1ccc2c(c1)c(C=O)cn2C)c1cc(SC)cc(SC)n1</smiles>

Siguiendo el método $\mathrm{F}$, se disuelven $0,3 \mathrm{~mL}(3,38 \mathrm{mmol})$ de $\mathrm{POCl}_{3}$ en DMF seca $(5 \mathrm{~mL})$ en tamiz molecular, y a la media hora se añaden $184 \mathrm{mg}(0,56 \mathrm{mmol})$ de 5-(1(2,6-bis(metilsulfanil)piridin-4-il)vinil)-1-metil-1H-indol (96) disueltos en DMF seca (5-10 $\mathrm{mL}$ ), y se deja 2 horas a temperatura ambiente. Se obtiene un precipitado que se purifica mediante cromatografía flash, utilizando como eluyente Hexano/EtOAc (6:4), obteniendo $183 \mathrm{mg}$ (0,51 mmol; 92\%) de 5-(1-(2,6-bis(metilsulfanil)piridin-4-il)vinil)-1metil-1H-indol-3-carbaldehído.

\section{5-(1-(2,6-bis(metilsulfanil)piridin-4-il)vinil)-1-metil-1H-indol-3-carbaldehído (99):}

$\mathrm{RMN}^{1} \mathrm{H}\left(\mathrm{CDCl}_{3}\right) \delta$ (ppm): (Espectro 99H) 2,57 (6H, s, $\left.\mathrm{SCH}_{3}\right) ; 3,88\left(3 \mathrm{H}, \mathrm{s}, \mathrm{NCH}_{3}\right) ; 5,56$ $\left(1 \mathrm{H}, \mathrm{s} ; \mathrm{CH}_{2}\right) ; 5,60\left(1 \mathrm{H}, \mathrm{s} ; \mathrm{CH}_{2}\right) ; 6,82(2 \mathrm{H}, \mathrm{s}, \mathrm{pyr}) ; 7,17\left(1 \mathrm{H}, \mathrm{d} ; \mathrm{J}=8,6 ; \mathrm{H}_{7}\right) ; 7,32(1 \mathrm{H}, \mathrm{d}$, $\left.\mathrm{J}=8,6 ; \mathrm{H}_{6}\right) ; 7,70\left(1 \mathrm{H}, \mathrm{s} ; \mathrm{H}_{2}\right) ; 8,29\left(1 \mathrm{H}, \mathrm{s} ; \mathrm{H}_{4}\right) ; 9,98(1 \mathrm{H}, \mathrm{s}, \mathrm{CHO})$.

$\mathrm{RMN}{ }^{13} \mathrm{C}\left(\mathrm{CDCl}_{3}\right) \delta$ (ppm): (Espectro 99C) 13,3 $\left(2 \mathrm{xCH}_{3}\right) ; 33,8\left(\mathrm{CH}_{3}\right) ; 109,9(\mathrm{CH}) ; 116,1$ (2xCH); 116,9 $\left(\mathrm{CH}_{2}\right) ; 118,2(\mathrm{C}) ; 121,6(\mathrm{CH}) ; 124,5(\mathrm{CH}) ; 125,3(\mathrm{C}) ; 134,9(\mathrm{C}) ; 137,7$ (C); 140,2 (CH); 148,0 (C); 149,5 (C); 159,3 (2xC); 184,3 (CHO).

IR: (película): 1456, 1481, 1524, 1572, 1652, $2918 \mathrm{~cm}^{-1}$

HRMS: Calculado $(\mathrm{M}+\mathrm{H}) 355,0937$. Obtenido $\left.\left(\mathrm{C}_{19} \mathrm{H}_{19} \mathrm{~N}_{2} \mathrm{OS}\right)_{2}\right) 355,0939$.

HPLC: Columna $\mathrm{C}_{18} \mathrm{t}_{\mathrm{R}}: 25,07 \mathrm{~min}$. 
Intentos de obtención de ácido 5-(2,6-bis(metilsulfanil)piridin-4-il)-1-metil-

\section{$\underline{1 H \text {-indol-3-carboxílico }}$}

a) Por oxidación del aldehído 98

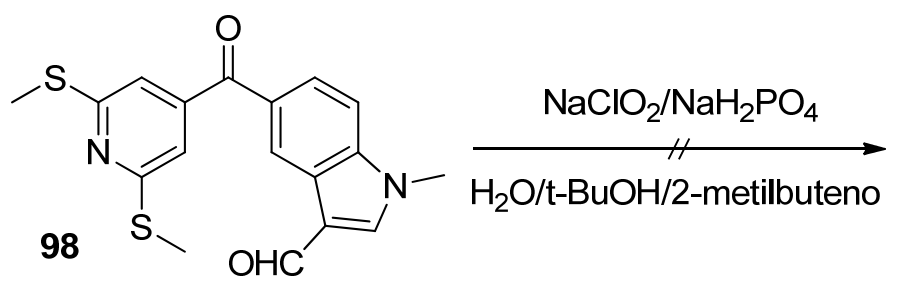<smiles>CSc1cc(C(=O)c2ccc3c(c2)c(C(=O)O)cn3C)cc(SC)n1</smiles>

Se disuelven $40 \mathrm{mg}(0,11 \mathrm{mmol})$ de 5-(2,6-bis(metilsulfanil)piridin-4-il)-1-metil-1H-indol3-carbaldehído (98) en una mezcla de $1,5 \mathrm{~mL}$ de $t$-BuOH, y 2,5 mL de 2-metilbuteno. A continuación se añaden $290 \mathrm{mg}(3,2 \mathrm{mmol})$ de $\mathrm{NaClO}_{2}$, y $326 \mathrm{mg}(2,36 \mathrm{mmol})$ de $\mathrm{NaH}_{2} \mathrm{PO}_{4}$ en $1,5 \mathrm{~mL}$ de $\mathrm{H}_{2} \mathrm{O}$ y se pone en agitación en baño de hielo. Se controla mediante CCF. Se realiza extracción con $\mathrm{CH}_{2} \mathrm{Cl}_{2}$ y se lava la fase orgánica, hasta neutralidad, con una disolución saturada de $\mathrm{NaCl}$. Se seca con $\mathrm{Na}_{2} \mathrm{SO}_{4}$ anhidro, se filtra y se evapora a sequedad. Se obtienen $100 \mathrm{mg}$ de una mezcla compleja difícil de caracterizar.

b) Por cloroacilación de la olefina 94<smiles>CSc1cc(C(=O)c2ccc3c(ccn3C)c2)cc(SC)n1</smiles>

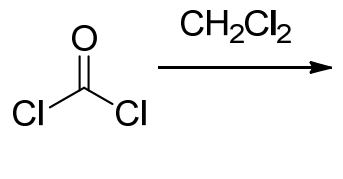<smiles>CSc1cc(C(=O)c2ccc3c(c2)c(C(=O)O)cn3C)cc(SC)n1</smiles>

Se disuelven 79 mg (0,22 mmol) de (2,6-bis(metilsulfanil)piridin-4-il)(1-metil-1H-indol-5il)metanona (94) en $\mathrm{CH}_{2} \mathrm{Cl}_{2}$ y se añade $0,15 \mathrm{~mL}(0,28 \mathrm{~mol})$ de fosgeno al $20 \%$ en tolueno y se deja $24 \mathrm{~h}$ en agitación a temperatura ambiente. No se observa avance de la reacción en $\mathrm{RMN}{ }^{1} \mathrm{H}$. Se añaden 6 equivalentes de fosgeno al $20 \%$ en tolueno y se calienta a $80^{\circ} \mathrm{C}$. No se observa avance de la reacción en $\mathrm{RMN}{ }^{1} \mathrm{H}$. Se disuelve la cetona en tolueno, se añaden $0,6 \mathrm{~mL}(1,13 \mathrm{mmol})$ de fosgeno al $20 \%$ en tolueno y se calienta a $120{ }^{\circ} \mathrm{C}$. Se obtiene mezcla compleja dificil de caracterizar. Se realiza extracción con $\mathrm{CH}_{2} \mathrm{Cl}_{2}$ y se lava la fase orgánica, hasta neutralidad, con una disolución saturada de $\mathrm{NaCl}$. Se seca con $\mathrm{Na}_{2} \mathrm{SO}_{4}$ anhidro, se filtra y se evapora a sequedad. No se observa avance de la reacción en $\mathrm{RMN}^{1} \mathrm{H}$. 
Obtención de ácido 5-(1-(2,6-bis(metilsulfanil)piridin-4-il)vinil)-1-metil-1Hindol-3-carboxílico<smiles>C=C(c1cc(SC)nc(SC)c1)c1cc(SC)nc(SCC(=O)c2ccc3c(ccn3C)c2)c1</smiles>

Se disuelven $79 \mathrm{mg}(0,24 \mathrm{mmol})$ de 5-(1-(2,6-bis(metilsulfanil)piridin-4-il)vinil)-1metil-1H-indol (95) en $\mathrm{CH}_{2} \mathrm{Cl}_{2}(10 \mathrm{~mL})$ y se añade $0,13 \mathrm{~mL}(0,24 \mathrm{~mol})$ de fosgeno al $20 \%$ en tolueno y se deja $24 \mathrm{~h}$ en agitación a temperatura ambiente. Se vierte la reacción sobre agua con hielo. Se basifica el medio con $\mathrm{NaOH}$ al $5 \%$ y se hace extrae con EtOAc (fase orgánica A). La fase acuosa se acidifica con $\mathrm{HCl} 2 \mathrm{~N}$, y se extrae con $\mathrm{CH}_{2} \mathrm{Cl}_{2}$ (fase orgánica $\mathrm{B}$ ). Las fases orgánicas ( $\mathrm{A}$ y $B$ ) se neutralizan con disolución saturada de $\mathrm{NaCl}$, se secan con $\mathrm{Na}_{2} \mathrm{SO}_{4}$ anhidro, se filtra y se evapora a sequedad, obteniendo $22 \mathrm{mg}(0,06 \mathrm{mmol} ; 25 \%)$ de ácido 5-(1-(2,6-bis(metilsulfanil)piridin-4il)vinil)-1-metil-1H-indol-3-carboxílico (100) de la fase orgánica $B$; y $52 \mathrm{mg}$ de mezcla de material de partida (96) y de derivado de fenstatina (94) de la fase orgánica A.

Ácido 5-(1-(2,6-bis(metilsulfanil)piridin-4-il)vinil)-1-metil-1H-indol-3-carboxílico (100):

$\mathrm{RMN}^{1} \mathrm{H}\left(\mathrm{CDCl}_{3}\right) \delta$ (ppm): (Espectro $\left.100 \mathrm{H}\right) 2,58\left(6 \mathrm{H}, \mathrm{s}, \mathrm{SCH}_{3}\right) ; 3,88\left(3 \mathrm{H}, \mathrm{s}, \mathrm{NCH}_{3}\right)$; 5,58 (1H, s, $\left.\mathrm{CH}_{2}\right) ; 5,61\left(1 \mathrm{H}, \mathrm{s}, \mathrm{CH}_{2}\right) ; 6,84(2 \mathrm{H}, \mathrm{s}, \mathrm{pyr}) ; 7,12\left(1 \mathrm{H}, \mathrm{da}, \mathrm{J}=8,9 ; \mathrm{H}_{6}\right) ; 7,31$ $\left(1 \mathrm{H}, \mathrm{da}, \mathrm{J}=8,9 ; \mathrm{H}_{7}\right) ; 7,90\left(1 \mathrm{H}, \mathrm{s} ; \mathrm{H}_{2}\right) ; 8,22\left(1 \mathrm{H}, \mathrm{s} ; \mathrm{H}_{4}\right)$.

RMN ${ }^{13} \mathrm{C}$ (DMSO-d) $\delta$ (ppm): (Espectro 100C) 12,7 (2xCH$) ; 33,1\left(\mathrm{CH}_{3}\right) ; 106,5$ (C); $110,9(\mathrm{CH}) ; 115,3(2 \times \mathrm{CH}) ; 117,1\left(\mathrm{CH}_{2}\right) ; 120,2(\mathrm{CH}) ; 122,4(\mathrm{CH}) ; 126,4(\mathrm{C}) ; 132,7(\mathrm{C}) ;$ $136,9(\mathrm{CH}) ; 147,4(\mathrm{C}) ; 149,6(\mathrm{C}) ; 159,2$ (2xC); 165,5 (C).

IR (KBr): 1422, 1482, 1523, 1573, 1615, $1656 \mathrm{~cm}^{-1}$

HRMS: Calculado $(\mathrm{M}+\mathrm{H}) 371,0888$. Obtenido $\left(\mathrm{C}_{19} \mathrm{H}_{19} \mathrm{~N}_{2} \mathrm{O}_{2} \mathrm{~S}_{2}\right) 371,0886$.

HPLC: Columna $\mathrm{C}_{8} \quad \mathrm{t}_{\mathrm{R}}: 21,86 \mathrm{~min}$. 
Intento de obtención de 5-(2,6-bis(metilsulfanil)piridin-4-il)-1-metil-1Hindol-3-carbonitrilo<smiles>CSc1cc(C(=O)O)cc(SC)n1</smiles><smiles></smiles>

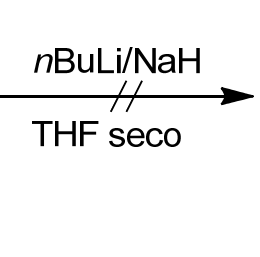<smiles>CSc1cc(C(=O)c2ccc3c(c2)c(C#N)cn3C)cc(SC)n1</smiles>

Siguiendo el método A, se disuelven $750 \mathrm{mg} \mathrm{(3,19} \mathrm{mmol)} \mathrm{de} \mathrm{5-bromo-1-metil-1H-}$ indol-3-carbonitrilo (18) en THF seco $(10-20 \mathrm{~mL})$ a $-40^{\circ} \mathrm{C}$, y se añaden $2,2 \mathrm{~mL}(3,51$ $\mathrm{mmol})$ de una disolución 1,6 M de $n$ BuLi en hexano. Sobre $687 \mathrm{mg}(3,19 \mathrm{mmol})$ de ácido 2,6-bis(metilsulfanil)piridina-4-carboxílico (4) disuelto en THF seco (10 mL) a $0^{\circ} \mathrm{C}$, se añaden $84 \mathrm{mg}(3,5 \mathrm{mmol})$ de $\mathrm{NaH}$. Una hora después se añade el indol sobre la sal del ácido y se deja subir la temperatura hasta la temperatura ambiente. A las 24 horas se añade formiato de etilo y EtOAc y se evapora parcialmente la fase orgánica. Se extrae con EtOAc, y se lava la fase orgánica, hasta neutralidad, con una disolución saturada de $\mathrm{NaCl}$. Se seca con $\mathrm{Na}_{2} \mathrm{SO}_{4}$, se filtra y se evapora a sequedad, obteniendo $83 \mathrm{mg}$ de crudo de reacción. En RMN ${ }^{1} \mathrm{H}$ solo se observan señales del indol de partida (18).

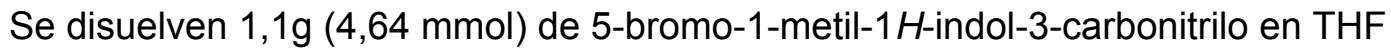
seco a $-40^{\circ} \mathrm{C}$, y se añaden $2,9 \mathrm{~mL}(4,64 \mathrm{mmol})$ de $\mathrm{nBuli}$. A la media hora se añade 500 $\mathrm{mg}(2,32 \mathrm{mmol})$ de ácido 2,6-bis(metilsulfanil)piridina-4-carboxílico disuelto en THF seco sobre el indol, y se deja subir la temperatura hasta la temperatura ambiente. Se realiza $\mathrm{RMN}{ }^{1} \mathrm{H}$ pero solo se observan señales de material de partida.

Obtención de las oximas del 5-(1-(2,6-bis(metilsulfanil)piridin-4-il)vinil)-1metil-1H-indol-3-carbaldehído<smiles>C=C(c1cc(SC)nc(SC)c1)c1ccc2c(c1)c(C=O)cn2C</smiles><smiles>C=C(c1cc(SC)nc(SC)c1)c1ccc2c(c1)c(/C=N/O)cn2C</smiles> 
Siguiendo el método $\mathrm{E}$, se disuelven $138 \mathrm{mg}(0,39 \mathrm{mmol})$ de 5-(1-(2,6bis(metilsulfanil)piridin-4-il)vinil)-1-metil-1H-indol-3-carbaldehído (99) en $\mathrm{MeOH}$ (10-20 $\mathrm{mL})$, y se añaden $271 \mathrm{mg}(3,89 \mathrm{mmol})$ de clorhidrato de hidroxilamina. Se obtienen $138 \mathrm{mg}(0,37 \mathrm{mmol} ; 95 \%)$ de mezcla de oximas de 5-(1-(2,6-bis(metilsulfanil)piridin-4il)vinil)-1-metil-1H-indol-3-carbaldehído que se utilizan directamente en la síntesis del compuesto 102.

Oximas de 5-(1-(2,6-bis(metilsulfanil)piridin-4-il)vinil)-1-metil-1H-indol-3carbaldehído (101):

$\mathrm{RMN}^{1} \mathrm{H}\left(\mathrm{CDCl}_{3}\right) \delta(\mathrm{ppm})$ : (Espectro $\left.101 \mathrm{H}\right)$ 2,50 (6H, s, SCH$) ; 2,52\left(6 \mathrm{H}, \mathrm{s}, \mathrm{SCH}_{3}\right) ; 3,74$ $\left(3 \mathrm{H}, \mathrm{s}, \mathrm{NCH}_{3}\right) ; 3,79\left(3 \mathrm{H}, \mathrm{s}, \mathrm{NCH}_{3}\right) ; 5,45\left(1 \mathrm{H}, \mathrm{d}, \mathrm{J}=0,8 ; \mathrm{CH}_{2}\right) ; 5,47\left(1 \mathrm{H}, \mathrm{d}, \mathrm{J}=0,8 ; \mathrm{CH}_{2}\right)$; $5,50\left(1 \mathrm{H}, \mathrm{d}, \mathrm{J}=0,8 ; \mathrm{CH}_{2}\right) ; 5,51\left(1 \mathrm{H}, \mathrm{d}, \mathrm{J}=0,8 ; \mathrm{CH}_{2}\right) ; 6,78(\mathrm{~s}) ; 7,06-8,57(\mathrm{~m})$.

Obtención de 5-(1-(2,6-bis(metilsulfanil)piridin-4-il)vinil)-1-metil-1H-indol-3carbonitrilo<smiles>C=C(c1cc(SC)nc(SC)c1)c1ccc2c(c1)c(/C=N/O)cn2C</smiles><smiles>C=C(c1cc(SC)nc(SC)c1)c1ccc2c(c1)c(C#N)cn2C</smiles>

Siguiente el método $\mathrm{J}$, se disuelven $138 \mathrm{mg}(0,37 \mathrm{mmol})$ de la mezcla de oximas de 5-(1-(2,6-bis(metilsulfanil)piridin-4-il)vinil)-1-metil-1H-indol-3-carbaldehído (101) en piridina $(5-10 \mathrm{~mL})$ y se añade $0,5 \mathrm{~mL}$ de anhídrido acético. Mediante cromatografía flash, utilizando como eluyente Hexano/EtOAc (75:25), se obtienen $51 \mathrm{mg}$ (0,15 mmol; $39 \%) \mathrm{mg}$ de 5-(1-(2,6-bis(metilsulfanil)piridin-4-il)vinil)-1-metil-1H-indol-3-carbonitrilo. 
5-(1-(2,6-bis(metilsulfanil)piridin-4-il)vinil)-1-metil-1H-indol-3-carbonitrilo (102):

$\mathrm{RMN}^{1} \mathrm{H}\left(\mathrm{CDCl}_{3}\right) \delta(\mathrm{ppm}):($ Espectro $102 \mathrm{H}) 2,55\left(6 \mathrm{H}, \mathrm{s}, \mathrm{SCH}_{3}\right) ; 3,77\left(3 \mathrm{H}, \mathrm{s}, \mathrm{NCH}_{3}\right)$; $5,48\left(1 \mathrm{H}, \mathrm{s}, \mathrm{CH}_{2}\right) ; 5,49\left(1 \mathrm{H}, \mathrm{s}, \mathrm{CH}_{2}\right) ; 6,72(2 \mathrm{H}, \mathrm{s} ; \mathrm{pyr}) ; 7,13\left(1 \mathrm{H}, \mathrm{d}, \mathrm{J}=8,8 ; \mathrm{H}_{6}\right) ; 7,26(1 \mathrm{H}$, d, J=8,8; $\left.\mathrm{H}_{7}\right) ; 7,50\left(1 \mathrm{H}, \mathrm{s}, \mathrm{H}_{2}\right) ; 7,60\left(1 \mathrm{H}, \mathrm{s}, \mathrm{H}_{4}\right)$.

$\mathrm{RMN}{ }^{13} \mathrm{C}\left(\mathrm{CDCl}_{3}\right) \delta(\mathrm{ppm})$ : (Espectro 102C) 13,6 (2xCH$) ; 34,2\left(\mathrm{CH}_{3}\right) ; 110,7(\mathrm{CH})$; $116,1(\mathrm{C}) ; 116,5(2 \times \mathrm{CH}) ; 117,3\left(\mathrm{CH}_{2}\right) ; 119,8(\mathrm{CH}) ; 124,8(\mathrm{CH}) ; 128,2(\mathrm{C}) ; 134,7(\mathrm{C})$; 136,2 (C); 136,6 (CH); 148,0 (C); 159,6 (C); 159,7 (2xC).

IR (película): 1484, 1527, 1573, $2218 \mathrm{~cm}^{-1}$

HRMS: Calculado $(\mathrm{M}+\mathrm{H}) 352,0942$. Obtenido $\left(\mathrm{C}_{19} \mathrm{H}_{18} \mathrm{~N}_{3} \mathrm{~S}_{2}\right) 352,0939$.

HPLC: Columna $\mathrm{C}_{8} \quad \mathrm{t}_{\mathrm{R}}: 20,85 \mathrm{~min}$. 
Obtención de 5-(1-(2,6-bis(metilsulfanil)piridin-4-il)vinil)-1-metil-1H-indol-3-

\section{carboxamida}<smiles>C=C(c1cc(SC)nc(SC)c1)c1cc(SC)nc(SCC(=O)N=C(CCl)C(=O)c2ccc3c(ccn3C)c2)c1</smiles>

Siguiendo el método $\mathrm{K}$, se disuelven $70 \mathrm{mg}(0,21 \mathrm{mmol})$ de 5-(1-(2,6bis(metilsulfanil)piridin4-il)vinil)-1-metil-1H-indol (96) en $10 \mathrm{~mL}$ de 1,2-dicloroetano y se añaden $29 \mu \mathrm{L}(0,32 \mathrm{mmol})$ de isocianato de clorosulfonilo. Mediante cromatografía en columna sobre gel de sílice usando como eluyente $\mathrm{CH}_{2} \mathrm{Cl}_{2} / \mathrm{MeOH}$ (99:1), se obtienen $24 \mathrm{mg}(0,06 \mathrm{mmol} ; 31 \%)$ de 5-(1-(2,6-bis(metilsulfanil)piridin-4-il)vinil)-1-metil-1 $H$-indol3-carboxamida.

5-(1-(2,6-bis(metilsulfanil)piridin-4-il)vinil)-1-metil-1H-indol-3-carboxamida (103):

RMN ${ }^{1} \mathrm{H}\left(\mathrm{CDCl}_{3}\right) \delta$ (ppm): (Espectro 103H) 2,51 (6H, s, $\left.\mathrm{SCH}_{3}\right) ; 3,78\left(3 \mathrm{H}, \mathrm{s}, \mathrm{NCH}_{3}\right)$; $5,50\left(1 \mathrm{H}, \mathrm{s}, \mathrm{CH}_{2}\right) ; 5,51\left(1 \mathrm{H}, \mathrm{s}, \mathrm{CH}_{2}\right) ; 5,66\left(2 \mathrm{H}, \mathrm{s}, \mathrm{NH}_{2}\right) ; 6,76(2 \mathrm{H}, \mathrm{s} ; \mathrm{pyr}) ; 7,08(1 \mathrm{H}, \mathrm{dd}$, $\left.J=1,6 ; J=8,6 ; H_{6}\right) ; 7,24\left(1 \mathrm{H}, d, J=8,6 ; H_{7}\right) ; 7,63\left(1 \mathrm{H}, \mathrm{s} ; \mathrm{H}_{2}\right) ; 7,86\left(1 \mathrm{H}, \mathrm{d}, \mathrm{J}=1,6 ; \mathrm{H}_{4}\right)$.

RMN ${ }^{13} \mathrm{C}\left(\mathrm{CDCl}_{3}\right) \delta(\mathrm{ppm})$ : (Espectro 103C) 13,3 (2xCH$) ; 33,5\left(\mathrm{CH}_{3}\right) ; 110,0(\mathrm{CH})$; $110,1(\mathrm{C}) ; 116,2(2 \times \mathrm{C}) ; 120,1\left(\mathrm{CH}_{2}\right) ; 123,4(\mathrm{CH}) ; 125,6(\mathrm{C}) ; 133,6(\mathrm{C}) ; 133,8(\mathrm{CH}) ;$ $137,1(\mathrm{C}) ; 148,1(\mathrm{C}) ; 149,5$ (C); 159,2 (2xC); 166,7 (C).

IR: (película): 1462, 1519, 1573, 1651, 2924, $3341 \mathrm{~cm}^{-1}$

HRMS: Calculado $(\mathrm{M}+\mathrm{H}) 370,1048$. Obtenido $\left.\left(\mathrm{C}_{19} \mathrm{H}_{20} \mathrm{~N}_{3} \mathrm{OS}\right)_{2}\right) 370,1051$.

HPLC: Columna $\mathrm{C}_{8} \quad \mathrm{t}_{\mathrm{R}}: 18,14 \mathrm{~min}$. 
Obtención de (2-(dimetilamino)-6-(metilsulfanil)piridin-4-il)(1-metil-1Hindol-5-il)metanona<smiles>[Z20]Sc1cc(C(=O)c2ccc3c(ccn3C)c2)cc(Cl)n1</smiles><smiles>CNC(C)CO</smiles><smiles>CSc1cc(C(=O)c2ccc3c(ccn3C)c2)cc(N(C)C)n1</smiles>

Sobre 1,295 g (4,09 mmol) de (2-cloro-6-(metilsulfanil)piridin-4-il)(1-metil-1Hindol-5-il)metanona (72) se añade dimetilamina en EtOH al 33\% en exceso y se pone a reflujo durante 48 horas. Se evapora y se purifica mediante cromatografía flash, utilizando como eluyente Hexano/EtOAc (9:1), recogiéndose $631 \mathrm{mg}$ (1,94 mmol, 47\%) de (2-(dimetilamino)-6-(metilsulfanil)piridin-4-il)(1-metil-1H-indol-5-il)metanona y 673 $\mathrm{mg}(2,12 \mathrm{mmol} ; 52 \%)$ de compuesto 72 sin reaccionar.

(2-(dimetilamino)-6-(metilsulfanil)piridin-4-il)(1-metil-1H-indol-5-il)metanona (104): $\mathrm{RMN}^{1} \mathrm{H}\left(\mathrm{CDCl}_{3}\right) \delta$ (ppm): (Espectro 104H) 2,57 (3H, s, $\left.\mathrm{SCH}_{3}\right) ; 3,13$ (6H, s, $\left.\mathrm{NMe}_{2}\right) ; 3,85$ $\left(3 \mathrm{H}, \mathrm{s}, \mathrm{NCH}_{3}\right) ; 6,44(1 \mathrm{H}, \mathrm{s}, \mathrm{pyr}) ; 6,59\left(1 \mathrm{H}, \mathrm{d}, \mathrm{J}=2,8 ; \mathrm{H}_{3}\right) ; 6,67(1 \mathrm{H}, \mathrm{s}, \mathrm{pyr}) ; 7,14(1 \mathrm{H}, \mathrm{d}$, $\left.J=2,8 ; H_{2}\right) ; 7,38\left(1 \mathrm{H}, \mathrm{da}, J=8,6 ; \mathrm{H}_{6}\right) ; 7,84\left(1 \mathrm{H}, \mathrm{da}, J=8,6 ; \mathrm{H}_{7}\right) ; 8,14\left(1 \mathrm{H}, \mathrm{s} ; \mathrm{H}_{4}\right)$.

$\mathrm{RMN}{ }^{13} \mathrm{C}\left(\mathrm{CDCl}_{3}\right) \delta(\mathrm{ppm})$ : (Espectro $\left.104 \mathrm{C}\right) 13,7\left(\mathrm{CH}_{3}\right) ; 33,1\left(\mathrm{CH}_{3}\right) ; 37,9\left(2 \times \mathrm{CH}_{3}\right)$; 100,3 (CH); 103,4 (CH); 107,8 (CH); 109,5 (CH); 123,5 (CH); 125,8 (CH); 127,8 (C); 128,2 (C); 130,7 (CH); 139,3 (C); 148,1 (C); 157,9 (C); 158,8 (C); 196,7 (C).

IR (película): 1448, 1500, 1532, 1589, 1651, $2924 \mathrm{~cm}^{-1}$

HRMS: Calculado $(\mathrm{M}+\mathrm{H}) 326,1327$. Obtenido $\left(\mathrm{C}_{18} \mathrm{H}_{20} \mathrm{~N}_{3} \mathrm{OS}\right) 326,1309$.

HPLC: Columna $C_{8} \quad t_{R}: 19,79$ min. 
de $N, N$-dimetil-4-(1-(1-metil-1H-indol-5-il)vinil)-6-

(metilsulfanil)piridin-2-amina<smiles>CSc1cc(C(=O)c2ccc3c(ccn3C)c2)cc(N(C)C)n1</smiles><smiles>C=C(c1cc(SC)nc(N(C)C)c1)c1ccc2c(ccn2C)c1</smiles>

Siguiendo el método B, se prepara una suspensión de 1,96 g $(4,85 \mathrm{mmol})$ de yoduro de metiltrifenilfosfonio (19) en THF seco $(20 \mathrm{~mL})$ a $-40^{\circ} \mathrm{C}$ y se adicionan 2,02 $\mathrm{mL}(3,23 \mathrm{mmol})$ de una disolución 1,6 M de $n$ BuLi en hexano. Posteriormente se añaden $526 \mathrm{mg}$ (1,62 mmol) de (2-(dimetilamino)-6-(metilsulfanil)piridin-4-il)(1-metil$1 \mathrm{H}$-indol-5-il)metanona (104) disueltos en THF seco $(10 \mathrm{~mL})$. Se purifica mediante cromatografía flash usando como eluyente Hexano/EtOAc (98:2) y se obtienen $418 \mathrm{mg}$ $(1,29$ mmol; $80 \quad \%)$ de $\quad N, N$-dimetil-4-(1-(1-metil-1H-indol-5-il)vinil)-6(metilsulfanil)piridin-2-amina.

\section{N,N-dimetil-4-(1-(1-metil-1H-indol-5-il)vinil)-6-(metilsulfanil)piridin-2-amina (105):}

$\mathrm{RMN}^{1} \mathrm{H}\left(\mathrm{CDCl}_{3}\right) \delta$ (ppm): (Espectro 105H) 2,56 (3H, s, SCH$) ; 3,08\left(6 \mathrm{H}, \mathrm{s}, \mathrm{NMe}_{2}\right) ; 3,81$ $\left(3 \mathrm{H}, \mathrm{s}, \mathrm{NCH}_{3}\right) ; 5,45\left(1 \mathrm{H}, \mathrm{s}, \mathrm{CH}_{2}\right) ; 5,53\left(1 \mathrm{H}, \mathrm{s}, \mathrm{CH}_{2}\right) ; 6,21(1 \mathrm{H}, \mathrm{s}, \mathrm{pyr}) ; 6,48(1 \mathrm{H}, \mathrm{d}$, $\left.\mathrm{J}=3,2 ; \mathrm{H}_{3}\right) ; 6,52(1 \mathrm{H}, \mathrm{s}, \mathrm{pyr}) ; 7,07\left(1 \mathrm{H}, \mathrm{d}, \mathrm{J}=3,2 ; \mathrm{H}_{2}\right) ; 7,25\left(1 \mathrm{H}, \mathrm{da}, \mathrm{J}=8,9 ; \mathrm{H}_{6}\right) ; 7,25$ $\left(1 \mathrm{H}, \mathrm{da}, \mathrm{J}=8,9 ; \mathrm{H}_{7}\right) ; 7,61\left(1 \mathrm{H}, \mathrm{s}, \mathrm{H}_{4}\right)$.

RMN ${ }^{13} \mathrm{C}\left(\mathrm{CDCl}_{3}\right) \delta(\mathrm{ppm})$ : (Espectro $\left.105 \mathrm{C}\right)$ 13,4 $\left(\mathrm{CH}_{3}\right) ; 33,0\left(\mathrm{CH}_{3}\right) ; 38,1\left(2 \times \mathrm{CH}_{3}\right)$; $101,0(\mathrm{CH}) ; 101,5(\mathrm{CH}) ; 109,0(2 \times \mathrm{CH}) ; 114,0\left(\mathrm{CH}_{2}\right) ; 120,9(\mathrm{CH}) ; 122,2(\mathrm{CH}) ; 128,5(\mathrm{C}) ;$ 129,6 (CH); 131,9 (C); 136,7 (C); 150,2 (C); 152,0 (C); 157,2 (C); 159,3 (C).

IR (película): 1405, 1494, 1532, $1583 \mathrm{~cm}^{-1}$

HRMS: Calculado $(\mathrm{M}+\mathrm{H}) 324,1534$. Obtenido $\left(\mathrm{C}_{19} \mathrm{H}_{22} \mathrm{~N}_{3} \mathrm{~S}\right) 324,1521$.

HPLC: Columna $\mathrm{C}_{18} \mathrm{t}_{\mathrm{R}}: 25,06 \mathrm{~min}$. 
Obtención de las oximas de (2-dimetilamino)-6-(metilsulfanil)piridin-4-il)(1metil-1H-indol-5 il)metanona<smiles>CSc1cc(C(=O)c2ccc3c(ccn3C)c2)cc(N(C)c2cc(/C(=N\O)c3ccc4c(ccn4C)c3)cc(SC)n2)n1</smiles>

Siguiendo el método $\mathrm{E}$, se disuelven $76 \mathrm{mg}(0,23 \mathrm{mmol})$ de (2-(dimetilamino)-6(metilsulfanil)piridin-4-il)(1-metil-1H-indol-5-il)metanona (104) en $10 \mathrm{~mL}$ de $\mathrm{MeOH}$ y se añaden $162 \mathrm{mg}(2,33 \mathrm{mmol})$ de clorhidrato de hidroxilamina. Se obtienen $70 \mathrm{mg}(0,21$ mmol; $89 \%)$ de una mezcla de oximas de (2-dimetilamino)-6-(metilsulfanil)piridin-4il)(1-metil-1H-indol-5-il)metanona en proporción 3:7.

Oximas de (2-dimetilamino)-6-(metilsulfanil)piridin-4-il)(1-metil-1H-indol-5i)metanona (106ZE):

$\mathrm{RMN}^{1} \mathrm{H}\left(\mathrm{CDCl}_{3}\right) \delta$ (ppm): (Espectro 106ZEH) 2,46 (3H, s, SCH$) ; 2,51\left(3 \mathrm{H}, \mathrm{s}, \mathrm{SCH}_{3}\right)$; $3,10\left(6 \mathrm{H}, \mathrm{s}, \mathrm{NMe}_{2}\right) ; 3,11\left(6 \mathrm{H}, \mathrm{s}, \mathrm{NMe}_{2}\right) ; 3,79\left(3 \mathrm{H}, \mathrm{s}, \mathrm{NCH}_{3}\right) ; 3,82\left(3 \mathrm{H}, \mathrm{s}, \mathrm{NCH}_{3}\right) ; 6,20$ $(1 \mathrm{H}, \mathrm{s}, \mathrm{pyr}) ; 6,3-6,6(\mathrm{~m}) ; 6,99-7,55(\mathrm{~m})$.

RMN ${ }^{13} \mathrm{C}\left(\mathrm{CDCl}_{3}\right) \delta(\mathrm{ppm})$ : (Espectro 106ZEC) 13,3 $\left(\mathrm{CH}_{3}\right) ; 33,0\left(\mathrm{CH}_{3}\right) ; 38,0\left(2 \times \mathrm{CH}_{3}\right)$; $100,1(\mathrm{CH}) ; 100,5(\mathrm{CH}) ; 101,9(\mathrm{CH}) ; 102,1(\mathrm{CH}) ; 108,2(\mathrm{CH}) ; 109,0(\mathrm{CH}) ; 109,4(\mathrm{CH}) ;$ 120,5 (CH); 121,6 (CH); 122,8 (CH); 125,9 (C); 126,2 (C); 128,2 (C); 129,8 (CH); 137,4 (C); 143,4 (C); 157,6 (C); 157,9 (C); 158,1 (C); 158,9 (C).

IR (película): 1408, 1533, $1589 \mathrm{~cm}^{-1}$

HRMS: Calculado $(\mathrm{M}+\mathrm{H}) 341,1436$. Obtenido $\left(\mathrm{C}_{18} \mathrm{H}_{21} \mathrm{~N}_{4} \mathrm{OS}\right) 341,1414$.

HPLC: Columna $C_{18} t_{R}: 19,17$ min; $t_{R}: 20,29$ min.

Obtención de 5-(2-(dimetilamino)-6-(metilsulfanil)piridin-4-il)-1-metil-1Hindol-3-carbaldehído<smiles>CSc1cc(C(=O)c2ccc3c(ccn3C)c2)cc(N(C)C)n1</smiles><smiles>COc1ccccc1</smiles><smiles>CSc1cc(C(=O)c2ccc3c(c2)c(C=O)cn3C)cc(N(C)C)n1</smiles> 
a) Con exceso de $\mathrm{POCl}_{3}$

Siguiendo el método $\mathrm{F}$, se disuelven $0,23 \mathrm{~mL}(2,4 \mathrm{mmol})$ de $\mathrm{POCl}_{3}$ en DMF seca (5 mL), y a la media hora se añaden $134 \mathrm{mg}(0,41 \mathrm{mmol})$ de (2-(dimetilamino)-6(metilsulfanil)piridin-4-il)(1-metil-1H-indol-5-il)metanona (104) disueltos en 5-10 mL de DMF seca, y se deja 2 horas a $60^{\circ} \mathrm{C}$. Se obtiene un precipitado que se purifica mediante cromatografía flash, utilizando como eluyente Hex/EtOAc (2:8). Se obtienen $52 \mathrm{mg}(0,14 \mathrm{mmol} ; 34 \%)$ de 5-(2-(dimetilamino)-3-formil-6-(metilsulfanil)piridin-4-il)-1metil-1H-indol-3-carbaldehído (108):<smiles>CSc1cc(C(=O)c2ccc3c(c2)c(C=O)cn3C)c(C=O)c(N(C)C)n1</smiles>

b) Con 1,5 moles de $\mathrm{POCl}_{3}$ por mol de indol

Siguiendo el método $\mathrm{F}, \quad 50 \mathrm{mg}$ (0,15 mmol) de (2-(dimetilamino)-6(metilsulfanil)piridin-4-il)(1-metil-1H-indol-5-il)metanona (104) disueltos en 5-10 mL de DMF seca se hacen reaccionar con $21 \mu \mathrm{L}(0,23 \mathrm{mmol})$ de $\mathrm{POCl}_{3}$. Se obtiene un precipitado que se purifica mediante cromatografía flash, utilizando como eluyente Hex/EtOAc (1:1). Se obtienen 25 mg (0,07 mmol; 47\%) de 5-(2-(dimetilamino)-6(metilsulfanil)piridin-4-il)-1-metil-1H-indol-3-carbaldehído (107), en forma de aceite amarillo que es fluorescente al irradiarlo con luz U.V.

\section{5-(2-(dimetilamino)-6-(metilsulfanil)piridin-4-il)-1-metil-1H-indol-3-carbaldehído} (107):

RMN ${ }^{1} \mathrm{H}\left(\mathrm{CDCl}_{3}\right) \delta$ (ppm): (Espectro $\left.107 \mathrm{H}\right) 2,56\left(3 \mathrm{H}, \mathrm{s}, \mathrm{SCH}_{3}\right) ; 3,12\left(6 \mathrm{H}, \mathrm{s}, \mathrm{NCH}_{3}\right)$; $3,94\left(3 \mathrm{H}, \mathrm{s}, \mathrm{NCH}_{3}\right) ; 6,44(1 \mathrm{H}, \mathrm{s} ; \mathrm{pyr}) ; 6,67(1 \mathrm{H}, \mathrm{s} ; \mathrm{pyr}) ; 7,45\left(1 \mathrm{H}, \mathrm{d} ; \mathrm{J}=9,2 ; \mathrm{H}_{7}\right) ; 7,78$ $\left(1 \mathrm{H}, \mathrm{s}, \mathrm{H}_{2}\right) ; 7,94\left(1 \mathrm{H}, \mathrm{d}, \mathrm{J}=9,2 ; \mathrm{H}_{6}\right) ; 8,76\left(1 \mathrm{H}, \mathrm{s} ; \mathrm{H}_{4}\right) ; 10,03(1 \mathrm{H}, \mathrm{s}, \mathrm{CHO})$.

RMN ${ }^{13} \mathrm{C}\left(\mathrm{CDCl}_{3}\right) \delta(\mathrm{ppm})$ : (Espectro 107C) 13,3 $\left(\mathrm{CH}_{3}\right) ; 33,9\left(\mathrm{CH}_{3}\right) ; 38,1\left(2 \times \mathrm{CH}_{3}\right)$; 100,5 (CH); 107,9 (CH); 109,8 (C); 110,0 (CH); 119,1 (C); 124,6 (C); 125,7 (CH); 125,9 (CH); 131,5 (C); 140,2 CH); 146,9 (C); 158,2 (C); 158,8 (C); 184,1 (CH); 196,4 (C).

IR (película): 1405, 1457, 1535, 1590, $1663 \mathrm{~cm}^{-1}$

HRMS: Calculado $(\mathrm{M}+\mathrm{H}) 354,1276$. Obtenido $\left(\mathrm{C}_{19} \mathrm{H}_{20} \mathrm{~N}_{3} \mathrm{O}_{2} \mathrm{~S}\right) 354,1281$.

HPLC: Columna $\mathrm{C}_{18} \mathrm{t}_{\mathrm{R}}: 19,28 \mathrm{~min}$. 


\section{5-(2-(dimetilamino)-3-formil-6-(metilsulfanil)piridin-4-il)-1-metil-1H-indol-3- carbaldehído (108):}

RMN ${ }^{1} \mathrm{H}\left(\mathrm{CDCl}_{3}\right) \delta$ (ppm): (Espectro $\left.108 \mathrm{H}\right)$ 2,61 (3H, s, $\left.\mathrm{SCH}_{3}\right) ; 3,23\left(3 \mathrm{H}, \mathrm{s}, \mathrm{NCH}_{3}\right)$; $3,25\left(3 \mathrm{H}, \mathrm{s}, \mathrm{NCH}_{3}\right) ; 3,91\left(3 \mathrm{H}, \mathrm{s}, \mathrm{NCH}_{3}\right) ; 6,16(1 \mathrm{H}, \mathrm{s} ; \mathrm{pyr}) ; 7,45\left(1 \mathrm{H}, \mathrm{d} ; \mathrm{J}=8,8 ; \mathrm{H}_{7}\right) ; 7,75$ $\left(1 \mathrm{H}, \mathrm{sa} ; \mathrm{H}_{2}\right) ; 8,06\left(1 \mathrm{H}, \mathrm{da} ; \mathrm{J}=8,8 ; \mathrm{H}_{6}\right) ; 8,57\left(1 \mathrm{H}, \mathrm{sa}, \mathrm{H}_{4}\right) ; 9,96(1 \mathrm{H}, \mathrm{s}, \mathrm{CHO}): 9.97(1 \mathrm{H}$, $\mathrm{s}, \mathrm{CHO})$.

IR (película): 1458, 1535, 1574, 1659, $1743 \mathrm{~cm}^{-1}$

HRMS: Calculado $(\mathrm{M}+\mathrm{H}) 382,1225$. Obtenido $\left(\mathrm{C}_{20} \mathrm{H}_{20} \mathrm{~N}_{3} \mathrm{O}_{3} \mathrm{~S}\right) 382,1221$.

HPLC: Columna $\mathrm{C}_{8} \quad \mathrm{t}_{\mathrm{R}}: 8,39 \mathrm{~min}$.

\section{Obtención de 5-(1-(2-(dimetilamino)-6-(metilsulfanil)piridin-4-il)vinil)-1-} metil-1H-indol-3-carbaldehído<smiles>C=C(c1cc(SC)nc(N(C)C)c1)c1ccc2[nH]ccc2c1</smiles><smiles>COC(C)(F)F</smiles><smiles>C=C(c1ccc2c(c1)c(C=O)cn2C)c1cc(SC)cc(N(C)C)n1</smiles>

a) Siguiendo el método $\mathrm{F}$, se disuelven $114 \mu \mathrm{L}(1,2 \mathrm{mmol})$ de $\mathrm{POCl}_{3}$ en DMF seca $(5 \mathrm{~mL})$, y a la media hora se añaden $134 \mathrm{mg}(0,4 \mathrm{mmol})$ de $\mathrm{N}, \mathrm{N}$-dimetil-4-(1-(1metil-1H-indol-5-il)vinil)-6-(metilsulfanil)piridin-2-amina (105) disueltos en 5-10 $\mathrm{mL}$ de DMF seca, y se deja 2 horas a $60^{\circ} \mathrm{C}$. Se obtiene $89 \mathrm{mg}$ de un precipitado que se purifica mediante cromatografía flash, utilizando como eluyente Hex/EtOAc (1:1) y se obtienen 28 mg (0,08 mmol; 21\%) de 5-(1-(2cloro-6-(dimetilamino)piridin-4-il)vinil)-1-metil-1H-indol-3-carbaldehído (110).<smiles>C=C(c1cc(Cl)nc(N(C)C)c1)c1ccc2c(c1)c(C=O)cn2C</smiles>

b) Se disuelven $151 \mu \mathrm{L}(1,6 \mathrm{mmol})$ de $\mathrm{POCl}_{3}$ en DMF seca $(5 \mathrm{~mL})$ siguiendo el método $\mathrm{F}$, y a la media hora se añaden $89 \mathrm{mg}(0,28 \mathrm{mmol})$ de $N, N$-dimetil-4-(1(1-metil-1H-indol-5-il)vinil)-6-(metilsulfanil)piridin-2-amina (105) disueltos en 5- 
$10 \mathrm{~mL}$ de DMF seca. Una hora después la reacción se vuelve de color marrón oscuro. Se obtienen $85 \mathrm{mg}$ de un precipitado que se purifica mediante cromatografía flash, utilizando como eluyente Hexano/EtOAc (4:6) y se obtienen $24 \mathrm{mg}(0,06 \mathrm{mmol} ; 28 \%)$ de 5-(1-(6-(dimetilamino)-3-formil-2(metilsulfanil)piridin-4-il)vinil)-1-metil-1H-indol-3-carbaldehído (111).<smiles>CSc1nc(N(C)C)cc(C(=O)c2ccc3c(c2)c(C=O)cn3C)c1C=O</smiles>

c) A $134 \mathrm{mg}(0,41 \mathrm{mmol})$ de $N, N$-dimetil-4-(1-(1-metil-1H-indol-5-il)vinil)-6(metilsulfanil)piridin-2-amina (105) disueltos en 5-10 mL de DMF seca, se añaden $114 \mu \mathrm{L}(1,24 \mathrm{mmol})$ de $\mathrm{POCl}_{3}$ siguiendo el método $\mathrm{F}$, y se pone 2 horas a reflujo de $60{ }^{\circ} \mathrm{C}$. Se obtiene un precipitado que se purifica mediante cromatografía flash, utilizando como eluyente Hexano/EtOAc (1:1), obteniendo $78 \mathrm{mg} \quad(0,22 \mathrm{mmol} ; 54 \%)$ de 5-(1-(2-(dimetilamino)-6-(metilsulfanil)piridin-4il)vinil)-1-metil- $1 H$-indol-3-carbaldehído (109).

\section{5-(1-(2-(dimetilamino)-6-(metilsulfanil)piridin-4-il)vinil)-1-metil-1H-indol-3- carbaldehído (109):}

$\mathrm{RMN}^{1} \mathrm{H}\left(\mathrm{CDCl}_{3}\right) \delta$ (ppm): (Espectro 109H) 2,51 (3H, s, SCH$) ; 3,03\left(6 \mathrm{H}, \mathrm{s}, \mathrm{NMe}_{2}\right) ; 3,83$ $\left(3 \mathrm{H}, \mathrm{s}, \mathrm{NCH}_{3}\right) ; 5,51\left(1 \mathrm{H}, \mathrm{d}, \mathrm{J}=1,0 ; \mathrm{CH}_{2}\right) ; 5,54\left(1 \mathrm{H}, \mathrm{d}, \mathrm{J}=1,0 ; \mathrm{CH}_{2}\right) ; 6,11(1 \mathrm{H}, \mathrm{d}, \mathrm{J}=1,2$; pyr); 6,41 (1H, d, J=1,2; pyr); 7,20 (1H, d, J=7,6; $\left.\mathrm{H}_{7}\right) ; 7,25\left(1 \mathrm{H}, \mathrm{d}, \mathrm{J}=7,6 ; \mathrm{H}_{6}\right) ; 7,65(1 \mathrm{H}$, $\left.\mathrm{s}, \mathrm{H}_{2}\right) ; 8,32\left(1 \mathrm{H}, \mathrm{s}, \mathrm{H}_{4}\right) ; 9,93(1 \mathrm{H}, \mathrm{s}, \mathrm{CHO})$.

RMN ${ }^{13} \mathrm{C}\left(\mathrm{CDCl}_{3}\right) \delta(\mathrm{ppm})$ : (Espectro 109C) 13,6 $\left(\mathrm{CH}_{3}\right) ; 34,2\left(\mathrm{CH}_{3}\right) ; 38,4\left(2 \times \mathrm{CH}_{3}\right)$; $101,1(\mathrm{CH}) ; 109,0(\mathrm{CH}) ; 109,9(\mathrm{CH}) ; 116,0\left(\mathrm{CH}_{2}\right) ; 121,9(\mathrm{CH}) ; 125,2(2 \times \mathrm{CH}) ; 125,7(\mathrm{C}) ;$ 136,2 (C); 138,0 (C); 140,2 (C); 149,7 (C); 151,5 (C); 157,5 (C); 159,5 (C); 184,8 $(\mathrm{CHO})$.

IR (película): 1456, 1483, 1533, 1584, $1658 \mathrm{~cm}^{-1}$

HRMS: Calculado $(\mathrm{M}+\mathrm{H}) 352,1484$. Obtenido $\left(\mathrm{C}_{20} \mathrm{H}_{22} \mathrm{~N}_{3} \mathrm{OS}\right) 352,1477$.

HPLC: Columna $C_{8} \quad t_{R}: 19,14$ min. 


\section{5-(1-(2-cloro-6-(dimetilamino)piridin-4-il)vinil)-1-metil-1H-indol-3-carbaldehído}

(110):

RMN ${ }^{1} \mathrm{H}\left(\mathrm{CDCl}_{3}\right) \delta(\mathrm{ppm})$ : (Espectro $\left.110 \mathrm{H}\right) 3,03\left(6 \mathrm{H}, \mathrm{s}, \mathrm{NMe}_{2}\right) ; 3,88\left(3 \mathrm{H}, \mathrm{s}, \mathrm{NCH}_{3}\right)$; 5,48 $\left(1 \mathrm{H}, \mathrm{s}, \mathrm{CH}_{2}\right) ; 5,51\left(1 \mathrm{H}, \mathrm{s}, \mathrm{CH}_{2}\right) ; 6,23(1 \mathrm{H}, \mathrm{s}, \mathrm{pyr}) ; 6,41(1 \mathrm{H}, \mathrm{s}, \mathrm{pyr}) ; 7,13-7,24(2 \mathrm{H}$, $\left.\mathrm{m} ; \mathrm{H}_{7}, \mathrm{H}_{6}\right) ; 7,62\left(1 \mathrm{H}, \mathrm{s}, \mathrm{H}_{2}\right) ; 8,25\left(1 \mathrm{H}, \mathrm{s}, \mathrm{H}_{4}\right) ; 9,90(1 \mathrm{H}, \mathrm{s}, \mathrm{CHO})$.

RMN ${ }^{13} \mathrm{C}\left(\mathrm{CDCl}_{3}\right) \delta(\mathrm{ppm})$ : (Espectro 110C) 33,3 $\left(\mathrm{CH}_{3}\right) ; 37,6\left(2 \mathrm{xCH}_{3}\right) ; 102,8(\mathrm{CH})$; 109,1 (CH); 109,8 (CH); 115,9 ( $\left.\mathrm{CH}_{2}\right) ; 117,8(\mathrm{C}) ; 121,1(\mathrm{CH}) ; 124,2(\mathrm{CH}) ; 124,8(\mathrm{C}) ;$ 134,8 (C); 137,2 (C); 139,3 (CH); 147,9 (C); 148,9 (C); 152,8 (C); 158,7 (C); 183,8 $(\mathrm{CHO})$.

IR (película): 1403, 1452, 1491, 1529, 1592, $1654 \mathrm{~cm}^{-1}$

HRMS: Calculado $(\mathrm{M}+\mathrm{H}) 340,1217$. Obtenido $\left(\mathrm{C}_{19} \mathrm{H}_{19} \mathrm{~N}_{3} \mathrm{OCl}\right) 340,1204$.

HPLC: Columna $\mathrm{C}_{18} \mathrm{t}_{\mathrm{R}}: 22,95 \mathrm{~min}$.

5-(1-(6-(dimetilamino)-3-formil-2-(metilsulfanil)piridin-4-il)vinil)-1-metil-1H-indol-3carbaldehído (111):

$\mathrm{RMN}^{1} \mathrm{H}\left(\mathrm{CDCl}_{3}\right) \delta$ (ppm): (Espectro 111H) 2,44 (3H, s, SCH$\left.)_{3}\right) ; 3,15\left(6 \mathrm{H}, \mathrm{s}, \mathrm{NMe}_{2}\right) ; 3,76$ $\left(3 \mathrm{H}, \mathrm{s}, \mathrm{NCH}_{3}\right) ; 5,22\left(1 \mathrm{H}, \mathrm{d}, \mathrm{J}=1,2 ; \mathrm{CH}_{2}\right) ; 5,86(1 \mathrm{H}, \mathrm{s}, \mathrm{pyr}) ; 6,09\left(1 \mathrm{H}, \mathrm{d}, \mathrm{J}=1,2 ; \mathrm{CH}_{2}\right)$; 7,15 (2H, m); 7,58 (1H, s, $\left.\mathrm{H}_{2}\right) ; 8,24\left(1 \mathrm{H}, \mathrm{s}, \mathrm{H}_{4}\right) ; 9,76(1 \mathrm{H}, \mathrm{s}, \mathrm{CHO}) ; 9,85(1 \mathrm{H}, \mathrm{s}, \mathrm{CHO})$.

$\mathrm{RMN}{ }^{13} \mathrm{C}\left(\mathrm{CDCl}_{3}\right) \delta(\mathrm{ppm})$ : (Espectro $\left.111 \mathrm{C}\right)$ 13,7 $\left(\mathrm{CH}_{3}\right) ; 33,7\left(\mathrm{CH}_{3}\right) ; 37,9\left(2 \times \mathrm{CH}_{3}\right)$; $101,7(\mathrm{CH}) ; 110,0(\mathrm{CH}) ; 116,0(\mathrm{C}) ; 116,4\left(\mathrm{CH}_{2}\right) ; 118,3(\mathrm{C}) ; 119,8(\mathrm{CH}) ; 123,3(\mathrm{CH}) ;$ 125,5 (C); 135,2 (C); 137,7 (C); 140,0 (CH); 146,5 (C); 156,6 (C); 158,5 (C); 164,0 (C); 184,3 (CHO); 188,6 (CHO).

IR (película): 1400, 1457, 1565, $1658 \mathrm{~cm}^{-1}$

HRMS: Calculado $(\mathrm{M}+\mathrm{H}) 380,1433$. Obtenido $\left(\mathrm{C}_{21} \mathrm{H}_{22} \mathrm{~N}_{3} \mathrm{O}_{2} \mathrm{~S}\right) 380,1419$.

HPLC: Columna $\mathrm{C}_{18} \mathrm{t}_{\mathrm{R}}: 20,69 \mathrm{~min}$. 
Obtención de ácido 5-(1-(2-(dimetilamino)-6-(metilsulfanil)piridin-4-il)vinil)1-metil-1H-indol-3-carboxílico<smiles>C=C(c1ccc2[nH]ccc2c1)c1cc(SC)cc(N(C)C)n1</smiles><smiles>CCCCC(=O)Cl</smiles><smiles>C=C(c1cc(SC)nc(N(C)C)c1)c1ccc2c(c1)c(C(=O)O)cn2C</smiles>

Se disuelven $71 \mathrm{mg}(0,22 \mathrm{mmol})$ de $N, N$-dimetil-4-(1-(1-metil-1H-indol-5-il)vinil)6-(metilsulfanil)piridin-2-amina (105) en $20 \mathrm{~mL}$ de $\mathrm{CH}_{2} \mathrm{Cl}_{2}$ y se añaden $151 \mu \mathrm{L}(0,29$ $\mathrm{mmol})$ de fosgeno al $20 \%$ en tolueno. A las 48 horas se añaden $170 \mu \mathrm{L}(0,32 \mathrm{mmol}) \mathrm{de}$ fosgeno al $20 \%$ en tolueno. Se mantiene la reacción a temperatura ambiente durante 72 horas. Se vierte la reacción sobre agua con hielo. Se basifica el medio con $\mathrm{NaOH}$ al $5 \%$ y se hace extrae con EtOAc (fase orgánica $A$ ). La fase acuosa se acidifica con $\mathrm{HCl}$ $2 \mathrm{~N}$, y se extrae con $\mathrm{CH}_{2} \mathrm{Cl}_{2}$ (fase orgánica $\mathrm{B}$ ). Las fases orgánicas ( $A$ y $B$ ) se neutralizan con disolución saturada de $\mathrm{NaCl}$, se secan con $\mathrm{Na}_{2} \mathrm{SO}_{4}$ anhidro, se filtra y se evapora a sequedad, obteniendo $4 \mathrm{mg}(0,01 \mathrm{mmol} ; 5 \%)$ de ácido 5-(1-(2(dimetilamino)-6-(metilsulfanil)piridin-4-il)vinil)-1-metil-1H-indol-3-carboxílico (112) en la fase orgánica B; y 55 mg de mezcla de material de partida (105) y fenstatina (104).

Ácido 5-(1-(2-(dimetilamino)-6-(metilsulfanil)piridin-4-il)vinil)-1-metil-1H-indol-3carboxílico (112):

$\mathrm{RMN}^{1} \mathrm{H}\left(\mathrm{CDCl}_{3}\right) \delta$ (ppm): (Espectro 112H) 2,54 (3H, s, SCH$) ; 3,07\left(6 \mathrm{H}, \mathrm{s}, \mathrm{NMe}_{2}\right) ; 3,88$ $\left(3 \mathrm{H}, \mathrm{s}, \mathrm{NCH}_{3}\right) ; 5,54\left(1 \mathrm{H}, \mathrm{s}, \mathrm{CH}_{2}\right) ; 5,57\left(1 \mathrm{H}, \mathrm{s}, \mathrm{CH}_{2}\right) ; 6,15(1 \mathrm{H}, \mathrm{s}, \mathrm{pyr}) ; 6,46(1 \mathrm{H}, \mathrm{s}, \mathrm{pyr}) ;$ 7,18 (1H, d, J=8,6; $\left.\mathrm{H}_{6}\right) ; 7,29\left(1 \mathrm{H}, \mathrm{d}, \mathrm{J}=8,6 ; \mathrm{H}_{7}\right) ; 7,89\left(1 \mathrm{H}, \mathrm{s}, \mathrm{H}_{2}\right) ; 8,26\left(1 \mathrm{H}, \mathrm{s}, \mathrm{H}_{4}\right)$.

IR (película): 1406, 1468, 1534, 1584, $1663 \mathrm{~cm}^{-1}$

HRMS: Calculado $(\mathrm{M}+\mathrm{H}) 368,1433$. Obtenido $\left(\mathrm{C}_{20} \mathrm{H}_{22} \mathrm{~N}_{3} \mathrm{O}_{2} \mathrm{~S}\right) 368,1431$.

HPLC: Columna $\mathrm{C}_{8} \quad \mathrm{t}_{\mathrm{R}}: 20,26 \mathrm{~min}$. 
Obtención de las oximas del 5-((2-(dimetilamino)-6-(metilsulfanil)piridin-4il)(hidroximino)metil)-1-metil-1H-indol-3-carbaldehído<smiles>CSc1cc(C(=O)c2ccc3c(c2)c(C=O)cn3C)cc(N(C)[18O])n1</smiles><smiles>CO[Mg]C(O)O</smiles><smiles>CSc1cc(/C(=N\O)c2ccc3c(c2)c(/C=N/O)cn3C)cc(N(C)C)n1</smiles>

Siguiendo el método $\mathrm{E}$, se disuelven $200 \mathrm{mg}$ (0,56 mmol) de 5-(2-(dimetilamino)6-(metilsulfanil)piridin-4-il)-1-metil-1H-indol-3-carbaldehído (107) en $\mathrm{MeOH}$ (10-20 mL), y se añaden $393 \mathrm{mg} \mathrm{(5,66} \mathrm{mmol)} \mathrm{de} \mathrm{clorhidrato} \mathrm{de} \mathrm{hidroxilamina.} \mathrm{Se} \mathrm{obtienen} 214 \mathrm{mg}$ $(0,56 \mathrm{mmol} ; 100 \%)$ de crudo de reacción (Espectro $113 \mathrm{H})$ que se usa directamente en la siguiente reacción.

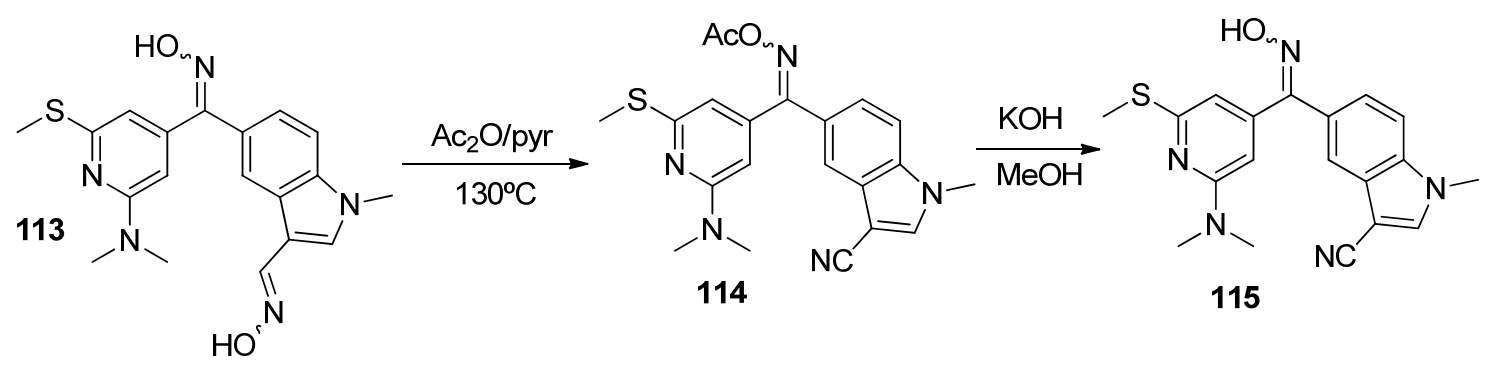

Siguiendo el método J, se disuelven $214 \mathrm{mg}(0,56 \mathrm{mmol})$ de las oximas del 5-((2(dimetilamino)-6-(metilsulfanil)piridin-4-il)(hidroximino)metil)-1-metil-1H-indol-3carbaldehído (113) en piridina $(10 \mathrm{~mL})$ y se añade $0,5 \mathrm{~mL}$ de anhídrido acético. Se obtienen $225 \mathrm{mg}(0,55 \mathrm{mmol} ; 98 \%) \mathrm{mg}$ de crudo de reacción. Se añade $1 \mathrm{~mL}$ de $\mathrm{KOH}$ $5 \mathrm{~N}$ y $3 \mathrm{~mL}$ de $\mathrm{MeOH}$, y se deja 24 horas a temperatura ambiente. Se extrae con $\mathrm{CH}_{2} \mathrm{Cl}_{2}$ y se lava la fase orgánica, hasta neutralidad, con una disolución saturada de $\mathrm{NaCl}$. Se seca con $\mathrm{Na}_{2} \mathrm{SO}_{4}$, se filtra y se evapora a sequedad. Se purifica mediante cromatografía flash, utilizando como eluyente Hexano/EtOAc (6:4), y se obtienen 171 $\mathrm{mg}(0,47 \mathrm{mmol} ; 85 \%)$ de mezcla de oximas de 5-((2-(dimetilamino)-6(metilsulfanil)piridin-4-il)(hidroximino)metil)-1-metil-1H-indol-3-carbonitrilo 
proporción 7:3. Cristaliza en $\mathrm{Hex} / \mathrm{CH}_{2} \mathrm{Cl}_{2}$ una sola oxima, pero se isomeriza en disolución.

\section{5-((2-(dimetilamino)-6-(metilsulfanil)piridin-4-il)(hidroximino)metil)-1-metil-1H- indol-3-carbonitrilo (115EZ):}

P.f. $\left(\mathrm{Hex} / \mathrm{CH}_{2} \mathrm{Cl}_{2}\right): 208-210^{\circ} \mathrm{C}$

$\mathrm{RMN}^{1} \mathrm{H}\left(\mathrm{CDCl}_{3}\right) \delta$ (ppm): (Espectro 115ZEH) 2,44 (3H, s, $\left.\mathrm{SCH}_{3}\right) ; 2,49\left(3 \mathrm{H}, \mathrm{s}, \mathrm{SCH}_{3}\right)$; 2,98 $\left(6 \mathrm{H}, \mathrm{s}, \mathrm{NMe}_{2}\right) ; 3,04\left(6 \mathrm{H}, \mathrm{s}, \mathrm{NMe}_{2}\right) ; 3,79\left(3 \mathrm{H}, \mathrm{s}, \mathrm{NCH}_{3}\right) ; 3.83\left(3 \mathrm{H}, \mathrm{s}, \mathrm{NCH}_{3}\right) ; 6,04$ (s); 6,24 (d); 6,34 (s); 6,42 (m); 7,28-7,77 (m).

RMN ${ }^{13} \mathrm{C}\left(\mathrm{CDCl}_{3}\right) \delta(\mathrm{ppm})$ : (Espectro 115ZEC) 13,1 $\left(\mathrm{CH}_{3}\right) ; 37,8\left(\mathrm{CH}_{3}\right) ; 38,0\left(2 \times \mathrm{CH}_{3}\right)$; $86,1(\mathrm{C}) ; 110,1(\mathrm{CH}): 102,6(\mathrm{C}) ; 107,8(\mathrm{CH}) ; 109,3(\mathrm{C}) ; 110,2(\mathrm{C}) ; 110,4(\mathrm{CH}) ; 115,5$ (C); 119,7 (CH); 121,1 (C); 123,0 (CH); 125,0 (C); 125,1 (C); 127,4 (C); 129,5 (C); $136,6(\mathrm{CH}) ; 142,3(\mathrm{C}) ; 156,0(\mathrm{C}) ; 157,1(\mathrm{C}) ; 158,0(\mathrm{C}) ; 158,8(\mathrm{C}) ; 159,0(\mathrm{C})$.

IR (película): 1408, 1451, 1533, 1590, 2220, $2925 \mathrm{~cm}^{-1}$

HRMS: Calculado $(\mathrm{M}+\mathrm{H}) 366,1389$. Obtenido $\left(\mathrm{C}_{19} \mathrm{H}_{20} \mathrm{~N}_{5} \mathrm{OS}\right) 366,1386$.

HPLC: Columna $C_{8} \quad t_{R}: 14,77 \mathrm{~min} ; t_{R}: 15,16$ min.

\section{Obtención de las oximas del 5-(1-(2-(dimetilamino)-6-(metilsulfanil)piridin-}

\section{4-il)vinil)-1-metil-1 $H$-indol-3-carbaldehído}<smiles>C=C(c1cc(SC)nc(N(C)C)c1)c1ccc2c(c1)c(C=O)cn2C</smiles><smiles>COC(O)C1CCCCC1</smiles><smiles>C=C(c1cc(SC)nc(N(C)C)c1)c1ccc2c(c1)c(/C=N/O)cn2C</smiles>

Siguiendo el método $\mathrm{E}$, se disuelven $69 \mathrm{mg}(0,19 \mathrm{mmol})$ de 5-(1-(2(dimetilamino)-6-(metilsulfanil)piridin-4-il)vinil)-1-metil-1H-indol-3-carbaldehído (109) en $10 \mathrm{~mL}$ de $\mathrm{MeOH}$, y se añaden 64,8 $\mathrm{mg}$ (1,96 mmol) de clorhidrato de hidroxilamina. Se obtienen $74 \mathrm{mg}(0,20 \mathrm{mmol})$ de mezcla de oximas de 5-(1-(2-(dimetilamino)-6(metilsulfanil)piridin-4-il)vinil)-1-metil-1H-indol-3-carbaldehído en proporción 1:1. 
Oximas de 5-(1-(2-(dimetilamino)-6-(metilsulfanil)piridin-4-il)vinil)-1-metil-1Hindol-3-carbaldehído (116):

$\mathrm{RMN}^{1} \mathrm{H}\left(\mathrm{CDCl}_{3}\right) \delta$ (ppm): (Espectro 116H) 2,46 (3H, s, SCH$) ; 2,47\left(3 \mathrm{H}, \mathrm{s}, \mathrm{SCH}_{3}\right) ; 2,98$ $\left(6 \mathrm{H}, \mathrm{s}, \mathrm{NMe}_{2}\right) ; 2,99\left(6 \mathrm{H}, \mathrm{s}, \mathrm{NMe}_{2}\right) ; 3,74\left(3 \mathrm{H}, \mathrm{s}, \mathrm{NCH}_{3}\right) ; 3,78\left(3 \mathrm{H}, \mathrm{s}, \mathrm{NCH}_{3}\right) ; 5,42(1 \mathrm{H}, \mathrm{s}$; $\left.\mathrm{CH}_{2}\right) ; 5,43\left(1 \mathrm{H}, \mathrm{s} ; \mathrm{CH}_{2}\right) ; 5,46\left(1 \mathrm{H}, \mathrm{s} ; \mathrm{CH}_{2}\right) ; 5,47\left(1 \mathrm{H}, \mathrm{s} ; \mathrm{CH}_{2}\right) ; 6,09(1 \mathrm{H}, \mathrm{d}, \mathrm{J}=1,2) ; 6,41$ $(1 \mathrm{H}, \mathrm{d}, \mathrm{J}=1,2) ; 7,14-7,25(\mathrm{~m}) ; 7,66-7.68(\mathrm{~m}) ; 8,06(1 \mathrm{H}, \mathrm{d}, \mathrm{J}=1,6) ; 8,16(1 \mathrm{H}, \mathrm{s}) ; 8,25(1 \mathrm{H}$, $\mathrm{d}, \mathrm{J}=1,2) ; 8,57(1 \mathrm{H}, \mathrm{d}, \mathrm{J}=1,2)$.

Obtención de 5-(1-(2-(dimetilamino)-6-(metilsulfanil)piridin-4-il)vinil)-1metil-1H-indol-3-carbonitrilo<smiles>C=C(c1cc(SC)nc(N(C)C)c1)c1ccc2c(c1)c(/C=N/O)cn2C</smiles>

Siguiendo el método J, se disuelven $74 \mathrm{mg}(0,20 \mathrm{mmol})$ de las oximas del 5-(1(2-(dimetilamino)-6-(metilsulfanil)piridin-4-il)vinil)-1-metil-1H-indol-3-carbaldehído (116) en (5-10 mL) piridina y se añade $0,5 \mathrm{~mL}$ de anhídrido acético. Se purifica mediante cromatografía flash, utilizando como eluyente Hexano/EtOAc (8:2), y se obtienen 19 mg (0,5 mmol; 27\%) de 5-(1-(2-(dimetilamino)-6-(metilsulfanil)piridin-4-il)vinil)-1-metil$1 H$-indol-3-carbonitrilo; y $14 \mathrm{mg}(0,03 \mathrm{mmol} ; 15 \%)$ de un derivado acetilado (118), que se degrada en disolución. 


\section{5-(1-(2-(dimetilamino)-6-(metilsulfanil)piridin-4-il)vinil)-1-metil-1H-indol-3- carbonitrilo (117):}

$\mathrm{RMN}^{1} \mathrm{H}\left(\mathrm{CDCl}_{3}\right) \delta$ (ppm): (Espectro 117H) 2,47 (3H, s, SCH$\left.)_{3}\right) ; 2,99\left(6 \mathrm{H}, \mathrm{s}, \mathrm{NMe}_{2}\right) ; 3,79$ $\left(3 \mathrm{H}, \mathrm{s}, \mathrm{NCH}_{3}\right) ; 5,45\left(1 \mathrm{H}, \mathrm{d}, \mathrm{J}=1,2 ; \mathrm{CH}_{2}\right) ; 5,47\left(1 \mathrm{H}, \mathrm{d}, \mathrm{J}=1,2 ; \mathrm{CH}_{2}\right) ; 6,04(1 \mathrm{H}, \mathrm{d}, \mathrm{J}=1,2$; pyr); $6,34\left(1 \mathrm{H}, \mathrm{d}, \mathrm{J}=1,2 ;\right.$ pyr); 7,22 (1H, d, J=8,8; $\left.\mathrm{H}_{7}\right) ; 7,24\left(1 \mathrm{H}, \mathrm{dd}, \mathrm{J}=0,8 ; \mathrm{J}=8,8 ; \mathrm{H}_{6}\right)$; $7,51\left(1 \mathrm{H}, \mathrm{s}, \mathrm{H}_{2}\right) ; 7,68\left(1 \mathrm{H}, \mathrm{d}, \mathrm{J}=0,8 ; \mathrm{H}_{4}\right)$.

$\mathrm{RMN}{ }^{13} \mathrm{C}\left(\mathrm{CDCl}_{3}\right) \delta(\mathrm{ppm})$ : (Espectro 117C) 13,2 $\left(\mathrm{CH}_{3}\right) ; 33,7\left(\mathrm{CH}_{3}\right) ; 37,9\left(2 \times \mathrm{CH}_{3}\right) ; 85,8$ (C); 100,5 (CH); 108,6 (CH); 110,0 (CH); 115,8 $\left(\mathrm{CH}_{2}\right) ; 119,3(\mathrm{CH}) ; 124,5(\mathrm{CH}) ; 127,8$ (C); 134,9 (C); 135,7 (C); 136,0 (CH); 149,0 (C); 150,8 (C); 157,2 (C); 159,1 (C).

IR (película): 1405, 1534, 1584, 2218, $2917 \mathrm{~cm}^{-1}$

HRMS: Calculado $(\mathrm{M}+\mathrm{H}) 349,1487$. Obtenido $\left(\mathrm{C}_{20} \mathrm{H}_{21} \mathrm{~N}_{4} \mathrm{~S}\right) 349,1477$.

HPLC: Columna $\mathrm{C}_{8} \quad \mathrm{t}_{\mathrm{R}}: 20,39 \mathrm{~min}$.

Acetil oxima del 5-(1-(2-(dimetilamino)-6-(metilsulfanil)piridin-4-il)vinil)-1-metil$1 H$-indol-3-carbaldehído (118):

$\mathrm{RMN}^{1} \mathrm{H}\left(\mathrm{CDCl}_{3}\right) \delta$ (ppm): (Espectro 118H) 2,21 (3H, s, $\left.\mathrm{CH}_{3}\right) ; 2,52\left(3 \mathrm{H}, \mathrm{s}, \mathrm{SCH}_{3}\right) ; 3,05$ $\left(6 \mathrm{H}, \mathrm{s}, \mathrm{NMe}_{2}\right) ; 3,83\left(3 \mathrm{H}, \mathrm{s}, \mathrm{NCH}_{3}\right) ; 5,47\left(1 \mathrm{H}, \mathrm{d}, \mathrm{J}=1,2 ; \mathrm{CH}_{2}\right) ; 5,56\left(1 \mathrm{H}, \mathrm{d}, \mathrm{J}=1,2 ; \mathrm{CH}_{2}\right)$; $6,13(1 \mathrm{H}, \mathrm{d}, \mathrm{J}=0,8 ; p y r) ; 6,43(1 \mathrm{H}, \mathrm{d}, \mathrm{J}=0,8 ; p y r) ; 7,23\left(1 \mathrm{H}, \mathrm{d}, \mathrm{J}=9,0 ; \mathrm{H}_{6}\right) ; 7,26(1 \mathrm{H}, \mathrm{d}$, $\left.J=9,0 ; H_{7}\right) ; 8,10\left(1 \mathrm{H}, \mathrm{s}, \mathrm{H}_{2}\right) ; 8,50\left(1 \mathrm{H}, \mathrm{s}, \mathrm{H}_{4}\right)$.

IR (película): 1405, 1534, 1588, 1756, 2219, $2927 \mathrm{~cm}^{-1}$

HRMS: Calculado $(\mathrm{M}+\mathrm{H}) 409,1698$. Obtenido $\left(\mathrm{C}_{22} \mathrm{H}_{25} \mathrm{~N}_{4} \mathrm{O}_{2} \mathrm{~S}\right) 409,1665$.

HPLC: Columna $\mathrm{C}_{8} \quad \mathrm{t}_{\mathrm{R}}: 20,34 \mathrm{~min}$. 
Obtención de 5-(1-(2-(dimetilamino)-6-(metilsulfanil)piridin-4-il)vinil)-1metil-1 $H$-indol-3-carboxamida<smiles>C=C(c1cc(SC)nc(N(C)C)c1)c1cc(C(=C)c2ccc3c(ccn3C)c2)nc(N(C)CC(=O)NS(=O)(=O)Cl)c1</smiles>

Siguiendo el método $\mathrm{K}$, se disuelven $33 \mathrm{mg}(0,10 \mathrm{mmol})$ de $\mathrm{N}, \mathrm{N}$-dimetil-4-(1-(1metil-1H-indol-5-il)vinil)-6-(metilsulfanil)piridin-2-amina (105) en $10 \mathrm{~mL}$ de 1,2dicloroetano y se añaden $14 \mu \mathrm{L}(0,15 \mathrm{mmol})$ de isocianato de clorosulfonilo. Se deja 24 horas a temperatura ambiente. Se purifica mediante CCP con $\mathrm{CH}_{2} \mathrm{Cl}_{2} / \mathrm{MeOH}$ (95:5) obteniendo $8 \mathrm{mg}(0,02 \mathrm{mmol} ; 22 \%)$ de 5-(1-(2-(dimetilamino)-6-(metilsulfanil)piridin-4il)vinil)-1-metil-1 $H$-indol-3-carboxamida.

\section{5-(1-(2-(dimetilamino)-6-(metilsulfanil)piridin-4-il)vinil)-1-metil-1H-indol-3- carboxamida (119):}

RMN ${ }^{1} \mathrm{H}\left(\mathrm{CDCl}_{3}\right) \delta(\mathrm{ppm})$ : (Espectro $\left.119 \mathrm{H}\right) 2,52\left(3 \mathrm{H}, \mathrm{s}, \mathrm{SCH}_{3}\right) ; 3,06\left(6 \mathrm{H}, \mathrm{s}, \mathrm{NCH}_{3}\right)$; $3,85\left(3 \mathrm{H}, \mathrm{s}, \mathrm{NCH}_{3}\right) ; 5,52\left(1 \mathrm{H}, \mathrm{s} \mathrm{CH}_{2}\right) ; 5,53\left(1 \mathrm{H}, \mathrm{s} \mathrm{CH} \mathrm{CH}_{2}\right) ; 6,13(1 \mathrm{H}, \mathrm{d}, \mathrm{J}=0,8 ; \mathrm{pyr}) ; 6,44$ $(1 \mathrm{H}, \mathrm{d}, \mathrm{J}=0,8 ;$ pyr $) ; 7,22\left(1 \mathrm{H}, \mathrm{dd}, \mathrm{J}=1,2 ; \mathrm{J}=8,6 ; \mathrm{H}_{6}\right) ; 7,30\left(1 \mathrm{H}, \mathrm{da}, \mathrm{J}=8,6 ; \mathrm{H}_{7}\right) ; 7,72(1 \mathrm{H}$, $\left.\mathrm{s} ; \mathrm{H}_{2}\right) ; 7,91\left(1 \mathrm{H}, \mathrm{d}, \mathrm{J}=1,2 ; \mathrm{H}_{4}\right)$.

RMN ${ }^{13} \mathrm{C} \delta$ (ppm): (Espectro $\left.119 \mathrm{C}\right) 13,2\left(\mathrm{CH}_{3}\right) ; 29,7\left(\mathrm{CH}_{3}\right) ; 38,0\left(\mathrm{CH}_{3}\right)$ 100,6 (CH); $108,6(\mathrm{CH}) ; 109,8(\mathrm{CH}) ; 115,3(\mathrm{CH}) ; 119,8(\mathrm{CH}) ; 123,5\left(\mathrm{CH}_{2}\right) ; 133,8(\mathrm{CH}) ; 149,5(\mathrm{C}) ;$ 151,1 (C); 152,2 (C); 153,5 (C); 159,1 (C); 166,7 (C).

IR: (película): 1401, 1462, 1532, 1584, 1644, 2851, 2923, $3341 \mathrm{~cm}^{-1}$

HRMS: Calculado (M+Na) 389,1412. Obtenido $\left(\mathrm{C}_{20} \mathrm{H}_{22} \mathrm{~N}_{4} \mathrm{NaOS}\right) 389,1412$.

HPLC: Columna $\mathrm{C}_{8} \quad \mathrm{t}_{\mathrm{R}}: 17,68 \mathrm{~min}$. 
Obtención de (2-cloro-6-(dimetilamino)piridin-4-il)(1-metil-1H-indol-5-

\section{il)metanona}<smiles>Cn1ccc2cc(C(=O)c3cc(Cl)nc(Cl)c3)ccc21</smiles><smiles>CNCCCCCC(C)(Br)Br</smiles><smiles>CN(C)c1cc(C(=O)c2ccc3c(ccn3C)c2)cc(Cl)n1</smiles>

Se disuelve $1 \mathrm{~g}$ (3,28 mmol) de (2,6-dicloropiridin-4-il)(1-metil-1H-indol-5-il)metanona (61) en $0,76 \mathrm{~mL}(4,25 \mathrm{mmol})$ de una disolución de dimetilamino al $33 \%$ en EtOH y se calienta a $80^{\circ} \mathrm{C}$ durante 24 horas en tubo sellado. Se evapora el dimetilamino y se cromatografía en una columna sobre gel de sílice, utilizando como eluyente Hexano/EtOAc (96:4), obteniendo $401 \mathrm{mg}$ (1,28 mmol; 39\%) de (2-cloro-6(dimetilamino)piridin-4-il)(1-metil-1H-indol-5-il)metanona, que cristalizan en $t$ butilmetiléter.

(2-cloro-6-(dimetilamino)piridin-4-il)(1-metil-1H-indol-5-il)metanona (120):

$\mathrm{RMN}^{1} \mathrm{H}\left(\mathrm{CDCl}_{3}\right) \delta$ (ppm): (Espectro $\left.120 \mathrm{H}\right) 3,09\left(6 \mathrm{H}, \mathrm{s}, \mathrm{NMe}_{2}\right) ; 3,81\left(3 \mathrm{H}, \mathrm{s}, \mathrm{NCH}_{3}\right)$; $6,59(1 \mathrm{H}, \mathrm{s}, \mathrm{pyr}) ; 6,59(1 \mathrm{H}, \mathrm{s}, \mathrm{pyr}) ; 6,74\left(1 \mathrm{H}, \mathrm{s}, \mathrm{H}_{3}\right) ; 7,13\left(1 \mathrm{H}, \mathrm{s}, \mathrm{H}_{2}\right) ; 7,35(1 \mathrm{H}, \mathrm{d}, \mathrm{J}=8,6$; $\left.\mathrm{H}_{7}\right) ; 7,80\left(1 \mathrm{H}, \mathrm{d}, \mathrm{J}=8,6 ; \mathrm{H}_{6}\right) ; 8,12\left(1 \mathrm{H}, \mathrm{s}, \mathrm{H}_{4}\right)$.

RMN ${ }^{13} \mathrm{C}\left(\mathrm{CDCl}_{3}\right) \delta(\mathrm{ppm})$ : (Espectro 120C) 33,2 $\left(\mathrm{CH}_{3}\right) ; 38,1\left(2 \mathrm{xCH}_{3}\right) ; 103,3(\mathrm{CH})$; $103,5(\mathrm{CH}) ; 109,5(\mathrm{CH}) ; 109,8(\mathrm{CH}) ; 123,5(\mathrm{CH}) ; 125,8(\mathrm{CH}) ; 127,7(\mathrm{C}) ; 127,8$ (C);130,9 (CH); 139,5 (C); 149,5 (C); 150,4 (C); 160,0 (C); 195,3 (C).

IR (película): 1532, 1600, $1649 \mathrm{~cm}^{-1}$

HRMS: Calculado $(\mathrm{M}+\mathrm{Na}) 336,0880$. Obtenido $\left(\mathrm{C}_{17} \mathrm{H}_{16} \mathrm{CIN}_{3} \mathrm{NaO}\right) 336,0882$.

HPLC: Columna $C_{8} \quad t_{R}: 18,71 \mathrm{~min}$. 
Obtención de 6-cloro- $N, N$-dimetil-4-(1-(1-metil-1H-indol-5-il)vinil)piridin-2-amina<smiles>CN(C)c1cc(C(=O)c2ccc3c(ccn3C)c2)cc(Cl)n1</smiles>

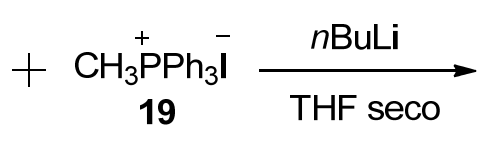<smiles>C=C(c1cc(Cl)nc(N(C)C)c1)c1ccc2c(ccn2C)c1</smiles>

Siguiendo el método $B$, se prepara una suspensión de 1,16 g $(2,87 \mathrm{mmol})$ de yoduro de metiltrifenilfosfonio (19) en THF seco $(20 \mathrm{~mL})$ a $-40^{\circ} \mathrm{C}$ y se adicionan $1,2 \mathrm{~mL}$ $(1,92 \mathrm{mmol})$ de una disolución $1,6 \mathrm{M}$ de $n$ BuLi. Se deja 1 hora en agitación y posteriormente se adicionan $300 \mathrm{mg}(0,96 \mathrm{mmol})$ de (2-cloro-6-(dimetilamino)piridin-4il)(1-metil-1H-indol-5-il)metanona (120) disueltos en THF seco $(10 \mathrm{~mL})$. Se purifica mediante cromatografía flash usando como eluyente Hexano/EtOAc (98:2) y se obtienen 112 mg (0,36 mmol; $37 \%)$ de 6-cloro- $N, N$-dimetil-4-(1-(1-metil-1H-indol-5il)vinil)piridin-2-amina.

\section{6-cloro- $N, N$-dimetil-4-(1-(1-metil-1H-indol-5-il)vinil)piridin-2-amina (121):}

RMN ${ }^{1} \mathrm{H}\left(\mathrm{CDCl}_{3}\right) \delta(\mathrm{ppm})$ : (Espectro $\left.121 \mathrm{H}\right) 3,05\left(6 \mathrm{H}, \mathrm{s}, \mathrm{NMe}_{2}\right) ; 3,81\left(3 \mathrm{H}, \mathrm{s}, \mathrm{NCH}_{3}\right)$; $5,46\left(1 \mathrm{H}, \mathrm{s}, \mathrm{CH}_{2}\right) ; 5,54\left(1 \mathrm{H}, \mathrm{s}, \mathrm{CH}_{2}\right) ; 6,36(1 \mathrm{H}, \mathrm{s}, \mathrm{pyr}) ; 6,48\left(1 \mathrm{H}, \mathrm{d}, \mathrm{J}=3,2 ; \mathrm{H}_{3}\right) ; 6,56(1 \mathrm{H}$, s, pyr); 7,08 (1H, d, J=3,2; $\left.\mathrm{H}_{2}\right) ; 7,20\left(1 \mathrm{H}, \mathrm{d} ; \mathrm{J}=8,9 ; \mathrm{H}_{6}\right) ; 7,28\left(1 \mathrm{H}, \mathrm{d}, \mathrm{J}=8,9 ; \mathrm{H}_{7}\right) ; 7,57$ $\left(1 \mathrm{H}, \mathrm{s} ; \mathrm{H}_{4}\right)$.

RMN ${ }^{13} \mathrm{C}\left(\mathrm{CDCl}_{3}\right) \delta(\mathrm{ppm})$ : (Espectro 121C) 33,0 $\left(\mathrm{CH}_{3}\right) ; 38,2\left(2 \times \mathrm{CH}_{3}\right) ; 101,4(\mathrm{CH})$; 103,6 (CH); 109,0 (CH); 110,7 (CH); 114,7 $\left(\mathrm{CH}_{2}\right) ; 116,5(\mathrm{C}) ; 120,8(\mathrm{CH}) ; 122,1(\mathrm{CH})$; 128,3 (C); 129,6 (CH); 131,4 (C); 136,6 (C); 149,4 (C).

IR (película): 1525, 1591, $2924 \mathrm{~cm}^{-1}$

HRMS: Calculado $(\mathrm{M}+\mathrm{H}) 312,1268$. Obtenido $\left(\mathrm{C}_{18} \mathrm{H}_{19} \mathrm{CIN}_{3}\right) 312,1262$.

HPLC: Columna $\mathrm{C}_{18} \mathrm{t}_{\mathrm{R}}: 26,85 \mathrm{~min}$. 
Obtención de las oximas de 5-(1-(2-cloro-6-(dimetilamino)piridin-4-il)vinil)-

\section{1-metil-1H-indol-3-carbaldehído}<smiles>C=C(c1cc(Cl)nc(N(C)C)c1)c1ccc2c(c1)c(C=O)cn2C</smiles><smiles>CO[Mg]NOC(O)Cl</smiles><smiles>C=C(c1cc(Cl)nc(N(C)C)c1)c1ccc2c(c1)c(/C=N/O)cn2C</smiles>

Siguiendo el método $\mathrm{E}$, se disuelven $64 \mathrm{mg}(0,19 \mathrm{mmol})$ de 5-(1-(2-cloro-6(dimetilamino)piridin-4-il)vinil)-1-metil-1H-indol-3-carbaldehído (110) en $10 \mathrm{~mL}$ de $\mathrm{MeOH}$, y se añaden $62 \mathrm{mg}(1,9 \mathrm{mmol})$ de clorhidrato de hidroxilamina. Se obtienen 76 $\mathrm{mg}(0,21 \mathrm{mmol})$ de mezcla de oximas del 5-(1-(2-cloro-6-(dimetilamino)piridin-4-il)vinil)1-metil-1H-indol-3-carbaldehído en proporción 1:1.

Oximas del 5-(1-(2-cloro-6-(dimetilamino)piridin-4-il)vinil)- 1-metil-1H-indol-3carbaldehído (122):

$\mathrm{RMN}^{1} \mathrm{H}\left(\mathrm{CDCl}_{3}\right) \delta$ (ppm): (Espectro 122H) 2,97 (6H, s, NMe $)$; 2,98 (6H, s, NMe $)_{2} ; 3,74$ $\left(3 \mathrm{H}, \mathrm{s}, \mathrm{NCH}_{3}\right) ; 3,76\left(3 \mathrm{H}, \mathrm{s}, \mathrm{NCH}_{3}\right) ; 5,44\left(1 \mathrm{H}, \mathrm{s} ; \mathrm{CH}_{2}\right) ; 5,46\left(1 \mathrm{H}, \mathrm{s} ; \mathrm{CH}_{2}\right) ; 550(2 \mathrm{H}, \mathrm{s} ;$ $\left.\mathrm{CH}_{2}\right) ; 6,26(2 \mathrm{H}, \mathrm{s}) ; 6,46(1 \mathrm{H}, \mathrm{d}, \mathrm{J}=1,8) ; 7,14-$

7,24 (m); 7,60-7,67 (m); 8,04 (1H, s); 8,14 (1H, s); 8,24 (2H, s); 8,55 (2H, d, J=3,6).

\section{Obtención de 5-(1-(2-cloro-6-(dimetilamino)piridin-4-il)vinil)-1-metil-1H-} indol-3-carbonitrilo<smiles>C=C(c1cc(Cl)nc(N(C)C)c1)c1ccc2c(c1)c(/C=N/O)cn2C</smiles>

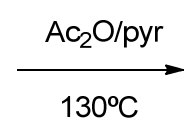<smiles>C=C(c1cc(Cl)nc(N(C)C)c1)c1ccc2c(c1)c(C#N)cn2C</smiles>

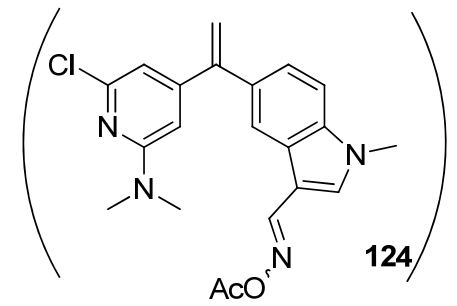

Siguiendo el método J, se disuelven $76 \mathrm{mg}(0,21 \mathrm{mmol})$ de las oximas del 5-(1(2-cloro-6-(dimetilamino)piridin-4-il)vinil)-1-metil-1H-indol-3-carbaldehído (122) en piridina $(5-10 \mathrm{~mL})$ y se añade $0,5 \mathrm{~mL}$ de anhídrido acético. Se purifica mediante 
cromatografía flash, utilizando como eluyente Hexano/EtOAc (7:3) y se obtienen $15 \mathrm{mg}$ $(0,4 \mathrm{mmol} ; 21 \%)$ de 5-(1-(2-cloro-6-(dimetilamino)piridin-4-il)vinil)-1-metil-1H-indol-3carbonitrilo y $4 \mathrm{mg}(0,01 \mathrm{mmol} ; 5 \%)$ de derivado acetilado (124).

\section{5-(1-(2-cloro-6-(dimetilamino)piridin-4-il)vinil)-1-metil-1H-indol-3-carbonitrilo} (123):

$\mathrm{RMN}^{1} \mathrm{H}\left(\mathrm{CDCl}_{3}\right) \delta(\mathrm{ppm})$ : (Espectro $\left.123 \mathrm{H}\right) 2,98\left(6 \mathrm{H}, \mathrm{s}, \mathrm{NMe}_{2}\right) ; 3,80\left(3 \mathrm{H}, \mathrm{s}, \mathrm{NCH}_{3}\right)$; $5,49\left(1 \mathrm{H}, \mathrm{s}, \mathrm{CH}_{2}\right) ; 5,51\left(1 \mathrm{H}, \mathrm{s}, \mathrm{CH}_{2}\right) ; 6,22(1 \mathrm{H}, \mathrm{s}, \mathrm{pyr}) ; 6,41(1 \mathrm{H}, \mathrm{s}, \mathrm{pyr}) ; 7,19(1 \mathrm{H}, \mathrm{d}$, $\left.J=8,4 ; H_{6}\right) ; 7,28\left(1 \mathrm{H}, \mathrm{d}, \mathrm{J}=8,4 ; \mathrm{H}_{7}\right) ; 7,52\left(1 \mathrm{H}, \mathrm{s}, \mathrm{H}_{2}\right) ; 7,66\left(1 \mathrm{H}, \mathrm{s}, \mathrm{H}_{4}\right)$.

$\mathrm{RMN}{ }^{13} \mathrm{C}\left(\mathrm{CDCl}_{3}\right) \delta(\mathrm{ppm})$ : (Espectro 123C) 29,8 $\left(\mathrm{CH}_{3}\right) ; 38,1\left(2 \times \mathrm{CH}_{3}\right) ; 86,0(\mathrm{C}) ; 103,2$ $(\mathrm{CH}) ; 110,1(\mathrm{CH}) ; 110,3(\mathrm{CH}) ; 115,6(\mathrm{C}) ; 116,3\left(\mathrm{CH}_{2}\right) ; 119,4(\mathrm{CH}) ; 124,4(\mathrm{CH}) ; 127,8$ (C); 132,1 (C); 134,5 (C); 136,1 (CH); 148,2 (C); 153,1 (C); 153,5 (C).

IR (película): 1407, 1451, 1530, 1594, 2217, $2931 \mathrm{~cm}^{-1}$

HRMS: Calculado $(\mathrm{M}+\mathrm{H}) 337,1220$. Obtenido $\left(\mathrm{C}_{19} \mathrm{H}_{18} \mathrm{CIN}_{4}\right) 337,1215$.

HPLC: Columna $C_{8} \quad t_{R}: 19,53$ min.

Acetil oxima del 5-(1-(2-cloro-6-(dimetilamino)piridin-4-il)vinil)-1-metil-1H-indol-3carbaldehído (124):

$\mathrm{RMN}^{1} \mathrm{H}\left(\mathrm{CDCl}_{3}\right) \delta$ (ppm): (Espectro 124H) 2,16 (3H, s, $\left.\mathrm{CH}_{3}\right) ; 2,98\left(6 \mathrm{H}, \mathrm{s}, \mathrm{NMe}_{2}\right) ; 3,77$ $\left(3 \mathrm{H}, \mathrm{s}, \mathrm{NCH}_{3}\right) ; 5,45\left(1 \mathrm{H}, \mathrm{s}, \mathrm{CH}_{2}\right) ; 5,54\left(1 \mathrm{H}, \mathrm{s}, \mathrm{CH}_{2}\right) ; 6,25(1 \mathrm{H}, \mathrm{s} ; \mathrm{pyr}) ; 6,44(1 \mathrm{H}, \mathrm{s} ; \mathrm{pyr}) ;$ 7,15 (1H, da, J=8,8; $\left.\mathrm{H}_{6}\right) ; 7,22\left(1 \mathrm{H}, \mathrm{da}, \mathrm{J}=8,8 ; \mathrm{H}_{7}\right) ; 8,05\left(1 \mathrm{H}, \mathrm{s}, \mathrm{H}_{4}\right) ; 8,44\left(1 \mathrm{H}, \mathrm{s}, \mathrm{H}_{2}\right)$.

IR (película): 1409, 1532, 1593, $1756 \mathrm{~cm}^{-1}$

HRMS: Calculado $(\mathrm{M}+\mathrm{H}) 397,1431$. Obtenido $\left(\mathrm{C}_{21} \mathrm{H}_{22} \mathrm{CIN}_{4} \mathrm{O}_{2}\right) 397,1419$.

HPLC: Columna $\mathrm{C}_{8} \quad \mathrm{t}_{\mathrm{R}}: 19,55 \mathrm{~min}$. 
Obtención de (2-metilsulfinil-6-metoxipiridin-4-il)(1-metil-1H-indol-5-

\section{il)metanona}<smiles>COc1cc(C(=O)c2ccc3c(ccn3C)c2)cc(SC)n1</smiles><smiles>CCCCCCCC</smiles><smiles>COc1cc(C(=O)c2ccc3c(ccn3C)c2)cc(S(C)=O)n1</smiles>

A una disolución de $325 \mathrm{mg}(1,04 \mathrm{mmol})$ de (2-metilsulfanil-6-metoxipiridin-4il)(1-metil-1H-indol-5-il)metanona (84) en $\mathrm{CH}_{2} \mathrm{Cl}_{2}(10-20 \mathrm{~mL})$, se le añade $180 \mathrm{mg}(1,04$ $\mathrm{mmol}$ ) de AMCPB y se deja en agitación $24 \mathrm{~h}$ en baño de hielo. Posteriormente se añade bisulfito sódico, se disuelve en $\mathrm{CH}_{2} \mathrm{Cl}_{2}$, y se extrae con bicarbonato sódico. Se lava la fase orgánica con agua saturada en $\mathrm{NaCl}$, se añade $\mathrm{Na}_{2} \mathrm{SO}_{4}$, se filtra y se evapora. El producto obtenido se purifica mediante cromatografía en columna sobre gel de sílice, utilizando como eluyente Hexano/EtOAc 1\% trietilamina, y se obtienen 48 $\mathrm{mg}(0,146 \mathrm{mmol}, \quad 14 \%)$ de (2-metilsulfinil-6-metoxipiridin-4-il)(1-metil-1H-indol-5il)metanona.

\section{(2-metilsulfinil-6-metoxipiridin-4-il)(1-metil-1H-indol-5-il)metanona (125):}

$\mathrm{RMN}^{1} \mathrm{H}\left(\mathrm{CDCl}_{3}\right) \delta(\mathrm{ppm})$ : (Espectro $\left.125 \mathrm{H}\right) 2,90\left(3 \mathrm{H}, \mathrm{s}, \mathrm{SCH}_{3}\right) ; 3,85\left(3 \mathrm{H}, \mathrm{s}, \mathrm{NCH}_{3}\right)$; 4,00 $\left(3 \mathrm{H}, \mathrm{s}, \mathrm{OCH}_{3}\right) ; 6,59\left(1 \mathrm{H}, \mathrm{d}, \mathrm{J}=3, \mathrm{H}_{3}\right) ; 7,07(1 \mathrm{H}, \mathrm{d}, \mathrm{J}=1,2 ; p y r) ; 7,15(1 \mathrm{H}, \mathrm{d}, \mathrm{J}=3$, $\left.\mathrm{H}_{2}\right) ; 7,39\left(1 \mathrm{H}, \mathrm{da}, \mathrm{J}=8,6 ; \mathrm{H}_{7}\right) ; 7,82\left(1 \mathrm{H}, \mathrm{dd}, \mathrm{J}=1,8 ; \mathrm{J}=8,6 ; \mathrm{H}_{6}\right) ; 7,82(1 \mathrm{H}, \mathrm{d}, \mathrm{J}=1,2 ; p y r)$; $8,08\left(1 \mathrm{H}, \mathrm{d}, \mathrm{J}=1,8 ; \mathrm{H}_{4}\right)$.

RMN ${ }^{13} \mathrm{C}\left(\mathrm{CDCl}_{3}\right) \delta(\mathrm{ppm}):($ Espectro $125 \mathrm{C}) 33,2\left(\mathrm{CH}_{3}\right) ; 40,8\left(\mathrm{CH}_{3}\right) ; 54,4\left(\mathrm{CH}_{3}\right) ; 103,5$ $(\mathrm{CH}) ; 109,7(\mathrm{CH}) ; 111,9(\mathrm{CH}) ; 112,4(\mathrm{CH}) ; 123,5(\mathrm{CH}) ; 125,9(\mathrm{CH}) ; 127,2(\mathrm{C}) ; 127,9$ (C); 131,0 (CH); 139,6 (C); 151,2 (C); 163,3 (C); 164,2 (C); 194,5 (C).

IR (película): 1543, 1602, $1656 \mathrm{~cm}^{-1}$

HRMS: Calculado $(\mathrm{M}+\mathrm{H}) 329,0960$. Obtenido $\left(\mathrm{C}_{17} \mathrm{H}_{17} \mathrm{~N}_{2} \mathrm{O}_{3} \mathrm{~S}\right) 329,0968$.

HPLC: Columna $\mathrm{C}_{18} \mathrm{t}_{\mathrm{R}}: 15,62 \mathrm{~min}$. 
Obtención de 5-(1-(2-metilsulfinil-6-metoxipiridin-4-il)vinil)-1-metil-1H-indol<smiles>C=C(c1cc(OC)nc(S(C)=O)c1)c1ccc2c(ccn2C)c1</smiles>

Siguiendo el método $B$, se disuelven $157 \mathrm{mg}(0,39 \mathrm{mmol})$ de yoduro de metiltrifenilfosfonio (19) en THF seco $(10 \mathrm{~mL})$ a $-40^{\circ} \mathrm{C}$ y se añaden $0,18 \mathrm{~mL}(0,29$ mmol) de una disolución 1,6 M de nBuLi en hexano y se deja una hora en agitación. Posteriormente se añade $32 \mathrm{mg}(0,09 \mathrm{mmol})$ de (2-metilsulfinil-6-metoxipiridin-4-il)(1metil-1H-indol-5-il)metanona (125) en THF seco (5-10 mL). Se recupera el material de partida sin reaccionar.

Obtención de (2-metilsulfonil-6-metoxipiridin-4-il)(1-metil-1H-indol-5il)metanona<smiles>COc1cc(C(=O)c2ccc3c(ccn3C)c2)cc(SC)n1</smiles><smiles>COc1cc(C(=O)c2ccc3c(ccn3C)c2)cc(S(C)(=O)=O)n1</smiles>

A una disolución de $224 \mathrm{mg}(0,72 \mathrm{mmol})$ de (2-metilsulfanil-6-metoxipiridin-4il)(1-metil-1H-indol-5-il)metanona (84) en $\mathrm{CH}_{2} \mathrm{Cl}_{2}(10-20 \mathrm{~mL})$ se añaden $185 \mathrm{mg}(1,07$ mmol) de AMCPB y se deja en agitación $1 \mathrm{~h}$ en baño de hielo. Posteriormente se añaden $100 \mathrm{mg}(0,58)$ de AMCPB y se deja en agitación durante $72 \mathrm{~h}$. Se añade bisulfito sódico, se disuelve en $\mathrm{CH}_{2} \mathrm{Cl}_{2}$, y se extrae con bicarbonato sódico. Se lava la fase orgánica varias veces con agua saturada en $\mathrm{NaCl}$, se añade $\mathrm{Na}_{2} \mathrm{SO}_{4}$, se filtra y se evapora obteniendo $175 \mathrm{mg}$ de crudo de reacción. Se realiza una cromatografía en columna sobre gel de sílice, utilizando como eluyente $\mathrm{CH}_{2} \mathrm{Cl}_{2} / \mathrm{EtOAc} 9: 1$, obteniendo 8 mg (0,02 mmol; 3,2 \%) de (2-metilsulfonil-6-metoxipiridin-4-il)(1-metil-1H-indol-5il)metanona. 
(2-metilsulfonil-6-metoxipiridin-4-il)(1-metil-1 $H$-indol-5-il)metanona (126):

RMN ${ }^{1} \mathrm{H}\left(\mathrm{CDCl}_{3}\right) \delta(\mathrm{ppm}): 3,24\left(3 \mathrm{H}, \mathrm{s}, \mathrm{SCH}_{3}\right), 3,85\left(3 \mathrm{H}, \mathrm{s}, \mathrm{NCH}_{3}\right) ; 4,07\left(3 \mathrm{H}, \mathrm{s}, \mathrm{OCH}_{3}\right)$; $6,60\left(1 \mathrm{H}, \mathrm{d}, \mathrm{J}=3,2, \mathrm{H}_{3}\right) ; 7,16\left(1 \mathrm{H}, \mathrm{d}, \mathrm{J}=3,2 ; \mathrm{H}_{2}\right) ; 7,25(1 \mathrm{H}, \mathrm{d}, \mathrm{J}=1,1, \mathrm{pyr}) ; 7,42(1 \mathrm{H}, \mathrm{d}$, $\left.J=8,6, H_{7}\right) ; 7,79\left(1 \mathrm{H}, d d, J=1,8 ; J=8,6 ; H_{6}\right) ; 7,93(1 \mathrm{H}, d, J=1,1, p y r) ; 8,05(1 \mathrm{H}, d, J=1,8$; $\mathrm{H}_{4}$ ).

RMN ${ }^{13} \mathrm{C}\left(\mathrm{CDCl}_{3}\right) \delta(\mathrm{ppm}): 33,1\left(\mathrm{CH}_{3}\right) ; 39,8\left(\mathrm{CH}_{3}\right) ; 54,6\left(\mathrm{CH}_{3}\right) ; 103,5(\mathrm{CH}) ; 109,7(\mathrm{CH})$; $113,7(\mathrm{CH}) ; 115,6(\mathrm{CH}) ; 123,3(\mathrm{CH}) ; 125,9(\mathrm{CH}) ; 126,9(\mathrm{C}) ; 127,9(\mathrm{C}) ; 131,0(\mathrm{CH}) ;$ 139,6 (C); 151,2 (C); 155,1 (C); 164,3 (C); 193,2 (C).

IR (película): 1543, 1604, $1658 \mathrm{~cm}^{-1}$

EM m/z (intensidad relativa, \%): 158 (100), $344\left(\mathrm{M}^{+}, 29\right)$.

HPLC: Columna $\mathrm{C}_{18} \mathrm{t}_{\mathrm{R}}: 10,57 \mathrm{~min}$. 


\section{D.4.3. SÍNTESIS DE COMPUESTOS CON NAFTALENO}

\section{Obtención de (2-metilsulfanil-6-metoxipiridin-4-il)(naftalen-2-il)metanona}<smiles>COc1cc(C(=O)O)cc(SC)n1</smiles><smiles>Brc1ccc2ccccc2c1</smiles><smiles>CCCCCCCCC(C)C</smiles><smiles>COc1cc(C(=O)c2ccc3ccccc3c2)cc(SC)n1</smiles>

Siguiendo el método $\mathrm{A}$, se disuelven 2,48 g (11,9 mmol) de 2-bromonaftaleno en THF seco (20-30 mL) y se añaden 7,5 mL de una disolución 1,6 M de $n$ BuLi en hexano (12 mmol), apareciendo una coloración amarillenta. Transcurrida $1 \mathrm{~h}$ se añaden lentamente $909 \mathrm{mg}(4,5 \mathrm{mmol})$ de ácido 2-metilsulfanil-6-metoxipiridina-4-carboxílico (5) disueltos en THF seco $(10-20 \mathrm{~mL})$. Se realiza una cromatografía flash, utilizando como eluyente hexano/ $\mathrm{CH}_{2} \mathrm{Cl}_{2}$ 8:2; obteniendo $329 \mathrm{mg}(1,1 \mathrm{mmol} ; 24 \%)$ de (2metilsulfanil-6-metoxipiridin-4-il)(naftalen-2-il)metanona, que se cristaliza en dietiléter.

\section{(2-metilsulfanil-6-metoxipiridin-4-il)(naftalen-2-il)metanona (127):}

P.f. $\left(\mathrm{Et}_{2} \mathrm{O}\right): 76-77^{\circ} \mathrm{C}$

$\mathrm{RMN}^{1} \mathrm{H}\left(\mathrm{CDCl}_{3}\right) \delta(\mathrm{ppm}): 2,61\left(3 \mathrm{H}, \mathrm{s}, \mathrm{SCH}_{3}\right) ; 4,02\left(3 \mathrm{H}, \mathrm{s}, \mathrm{OCH}_{3}\right) ; 6,70(1 \mathrm{H}, \mathrm{d}, \mathrm{J}=1,1$, pyr); 7,08 (1H, d, J=1,1, pyr); 7,5-7,7 (3H, m); 7,8-8,0 (3H, m); 8,2 (1H, sa, $\left.\mathrm{H}_{1}\right)$.

$\operatorname{RMN}{ }^{13} \mathrm{C}\left(\mathrm{CDCl}_{3}\right) \delta(\mathrm{ppm}): 13,6\left(\mathrm{CH}_{3}\right), 53,9\left(\mathrm{CH}_{3}\right) ; 105,5(\mathrm{CH}) ; 112,9(\mathrm{CH}) ; 125,2(\mathrm{CH})$; $126,0(\mathrm{CH}) ; 127,9(\mathrm{CH}) ; 128,5(\mathrm{CH}) ; 129,0(\mathrm{CH}) ; 129,7(\mathrm{CH}) ; 132,2(\mathrm{C}) ; 133,3(\mathrm{C})$; 132,7 (CH); 136,7 (C); 148,1 (C); 158,8 (C); 163,9 (C); 195,0 (C).

$\mathrm{IR}(\mathrm{KBr}):$ 1589, $1657 \mathrm{~cm}^{-1}$

EM m/z (intensidad relativa, \%): 127 (100), $309\left(\mathrm{M}^{+}, 85\right)$

HPLC: Columna $C_{8} \quad t_{R}: 21,79$ min.

Columna $\mathrm{C}_{18} \mathrm{t}_{\mathrm{R}}: 23,58 \mathrm{~min}$. 
Obtención de (2-metilsulfinil-6-metoxipiridin-4-il)(naftalen-2-il)metanona y de (2-metilsulfonil-6-metoxipiridin-4-il)(naftalen-2-il)metanona

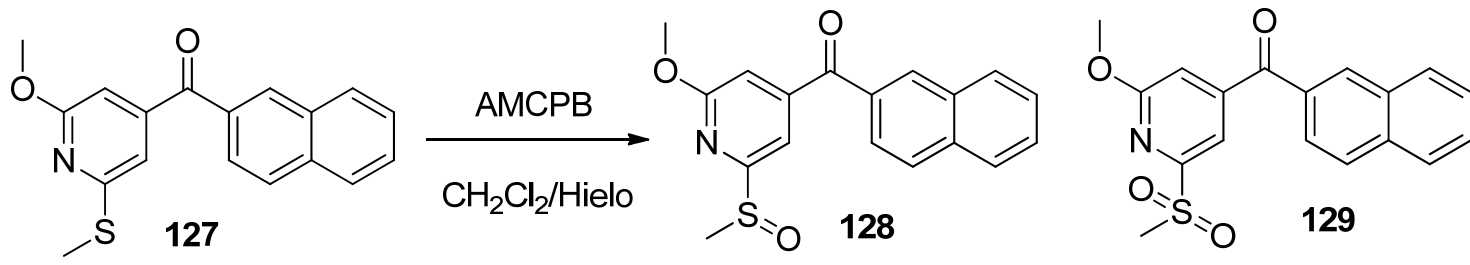

Se disuelven $175 \mathrm{mg}(0,57 \mathrm{mmol})$ de (2-metilsulfanil-6-metoxipiridin-4il)(naftalen-2-il)metanona (127) en $10 \mathrm{~mL}$ de $\mathrm{CH}_{2} \mathrm{Cl}_{2}$ y se añaden $97 \mathrm{mg}(0,57 \mathrm{mmol})$ de AMCPB y se deja $24 \mathrm{~h}$ en agitación sobre baño de hielo. Se añade bisulfito de sodio y se extrae en EtOAc, lavando con agua y una disolución de bicarbonato sódico al $5 \%$. La fase orgánica se seca con $\mathrm{Na}_{2} \mathrm{SO}_{4}$, se filtra y se evapora obteniendo $148 \mathrm{mg}$ de mezcla compleja. Se realiza una cromatografía de columna en gel de sílice, utilizando como eluyente Hexano/EtOAc 6:4, y se obtienen $19 \mathrm{mg}(0,06 \mathrm{mmol} ; 10,5 \%)$ de (2-metilsulfonil-6-metoxipiridin-4-il)(naftalen-2-il)metanona (129) y 49 mg (0,15 mmol; 26,3\%) de (2-metilsulfinil-6-metoxipiridin-4-il)(naftalen-2-il)metanona (128) y 31 $\mathrm{mg}(0,10 \mathrm{mmol})$ de (2,6-dimetoxipiridin-4-il)(naftalen-2-il)metanona (130):<smiles>COc1cc(C(=O)c2ccc3ccccc3c2)cc(OC)n1</smiles>

(2-metilsulfinil-6-metoxipiridin-4-il)(naftalen-2-il)metanona (128):

$\mathrm{RMN}^{1} \mathrm{H}\left(\mathrm{CDCl}_{3}\right) \delta(\mathrm{ppm}): 2,91\left(3 \mathrm{H}, \mathrm{s}, \mathrm{SCH}_{3}\right) ; 4,02\left(3 \mathrm{H}, \mathrm{s}, \mathrm{OCH}_{3}\right) ; 7,12(1 \mathrm{H}, \mathrm{d}, \mathrm{J}=1,4$, pyr); 7,5-7,7 (3H, m); 7,87 (1H, d, J=1,4, pyr ); 7,9-8,0 (3H, m); 8,25 (1H, sa, $\left.\mathrm{H}_{1}\right)$.

$\mathrm{RMN}{ }^{13} \mathrm{C}\left(\mathrm{CDCl}_{3}\right) \delta(\mathrm{ppm}): 40,8\left(\mathrm{CH}_{3}\right), 54,5\left(\mathrm{CH}_{3}\right) ; 112,4(\mathrm{CH}) ; 112,6(\mathrm{CH}) ; 124,9(\mathrm{CH}) ;$ $127,1(\mathrm{CH}) ; 127,9(\mathrm{CH}) ; 129,1(\mathrm{CH}) ; 129,2(\mathrm{CH}) ; 129,8(\mathrm{CH}) ; 132,2(2 \times \mathrm{C}) ; 132,7(\mathrm{CH}) ;$ 135,8 (C); 149,6 (C); 163,9 (C); 164,3 (C); 193,9 (C).

IR (película): 1543, 1600, $1665 \mathrm{~cm}^{-1}$

EM m/z (intensidad relativa, \%): 127 (100), $325\left(\mathrm{M}^{+}, 23\right)$.

HPLC: Columna $\mathrm{C}_{18} \mathrm{t}_{\mathrm{R}}: 16,39 \mathrm{~min}$. 
(2-metilsulfonil-6-metoxipiridin-4-il)(naftalen-2-il)metanona (129):

$\mathrm{RMN}^{1} \mathrm{H}\left(\mathrm{CDCl}_{3}\right) \delta(\mathrm{ppm}): 3,26\left(3 \mathrm{H}, \mathrm{s}, \mathrm{SCH}_{3}\right) ; 4,09\left(3 \mathrm{H}, \mathrm{s}, \mathrm{OCH}_{3}\right) ; 7,29(1 \mathrm{H}, \mathrm{d}, \mathrm{J}=1,2$, pyr); 7,5-7,7 (3H, m); 7,98 (1H, d, J=1,2, pyr); 7,9-8,0 (3H, m); 8,22 (1H, sa, $\left.\mathrm{H}_{1}\right)$.

$\mathrm{RMN}{ }^{13} \mathrm{C}\left(\mathrm{CDCl}_{3}\right) \delta(\mathrm{ppm}): 39,8\left(\mathrm{CH}_{3}\right) ; 54,8\left(\mathrm{CH}_{3}\right) ; 113,5(\mathrm{CH}) ; 115,9(\mathrm{CH}) ; 124,7(\mathrm{CH}) ;$ $127,3(\mathrm{CH}) ; 127,9(\mathrm{CH}) ; 129,1(\mathrm{CH}) ; 129,3(\mathrm{CH}) ; 129,8(\mathrm{CH}) ; 132,1(\mathrm{C}) ; 132,4(\mathrm{C}) ;$ 132,8 (CH); 135,8 (C); 149,7 (C); 155,6 (C); 164,5 (C); 193,1 (C).

IR (película): 1546, 1603, 1625, $1665 \mathrm{~cm}^{-1}$

EM m/z (intensidad relativa, \%): 155 (100), $341\left(\mathrm{M}^{+}, 42\right)$.

HPLC: Columna $\mathrm{C}_{18} \mathrm{t}_{\mathrm{R}}: 16,81 \mathrm{~min}$.

(2,6-dimetoxipiridin-4-il)(naftalen-2-il)metanona (130):

$\mathrm{RMN}^{1} \mathrm{H}\left(\mathrm{CDCl}_{3}\right) \delta(\mathrm{ppm}): 4,00\left(6 \mathrm{H}, \mathrm{s}, \mathrm{OCH}_{3}\right) ; 6,62(2 \mathrm{H}, \mathrm{s}, \mathrm{Ar}) ; 7,5-7,7(3 \mathrm{H}, \mathrm{m}) ; 7,9-8,0$ $(3 \mathrm{H}, \mathrm{m}) ; 8,29\left(1 \mathrm{H}, \mathrm{sa}, \mathrm{H}_{1}\right)$.

RMN ${ }^{13} \mathrm{C}\left(\mathrm{CDCl}_{3}\right) \delta$ (ppm): 53,9 (2xCH$) ; 101,1(2 \times \mathrm{CH}) ; 125,1(\mathrm{CH}) ; 126,9(\mathrm{CH}) ; 127,8$ $(\mathrm{CH}) ; 128,5(\mathrm{CH}) ; 128,8(\mathrm{CH}) ; 129,6(\mathrm{CH}) ; 132,1(\mathrm{C}) ; 132,6(\mathrm{CH}) ; 133,3(\mathrm{C}) ; 135,6(\mathrm{C})$; 150,5 (C); 163,4 (2xC); 195,2 (C).

IR (película): 1522, 1562, 1608, $1662 \mathrm{~cm}^{-1}$

EM m/z (intensidad relativa, \%): 127(100); $293\left(\mathrm{M}^{+}, 86\right)$

HPLC: Columna $\mathrm{C}_{18} \mathrm{t}_{\mathrm{R}}: 23,61 \mathrm{~min}$. 


\section{Obtención de (2,6-bis(metilsulfanil)piridin-4-il)(naftalen-2-il)metanona}<smiles>CSc1cc(C(=O)O)cc(SC)n1</smiles>

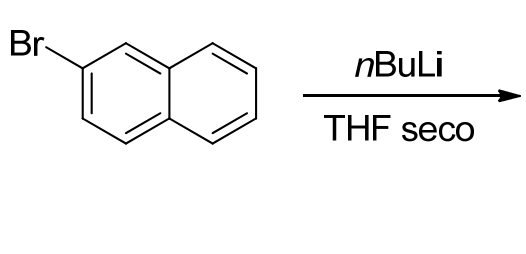<smiles>CSc1cc(C(=O)c2ccc3ccccc3c2)cc(SC)n1</smiles>

Siguiendo el método A, se disuelven 2,41 g (11,5 mmol) de 2-bromonaftaleno en THF seco (20-30 mL), y se añaden 7,2 $\mathrm{mL}(11,5 \mathrm{mmol})$ de una disolución 1,6 $\mathrm{M}$ de $n$ BuLi en hexano. Posteriormente se adiciona $1 \mathrm{~g}(4,6 \mathrm{mmol})$ de ácido 2,6bis(metilsulfanil)piridina-4-carboxílico (4) disuelto en THF seco (10-20 mL). Se purifica mediante cromatografía flash usando como eluyente Hexano/EtOAc (95:5) y se obtienen $709 \mathrm{mg}(2,18 \mathrm{mmol} ; 47 \%)$ de (2,6-bis(metilsulfanil)piridin-4-il)(naftalen-2il)metanona

\section{(2,6-bis(metilsulfanil)piridin-4-il)(naftalen-2-il)metanona (131):}

$\mathrm{RMN}^{1} \mathrm{H}\left(\mathrm{CDCl}_{3}\right) \delta(\mathrm{ppm})$ : (Espectro $\left.131 \mathrm{H}\right)$ 2,61 (6H, s, $\left.\mathrm{SCH}_{3}\right) ; 7,17(2 \mathrm{H}, \mathrm{s}, \mathrm{pyr}) ; 7,4-$ 7,6 (m); 7,9-8,3 (m).

$\mathrm{RMN}{ }^{13} \mathrm{C}\left(\mathrm{CDCl}_{3}\right) \delta(\mathrm{ppm})$ : (Espectro 131C) 13,5 (2xCH$) ; 116,2(2 \times \mathrm{CH}) ; 124,3(\mathrm{CH})$; $125,5(\mathrm{CH}) ; 126,8(\mathrm{CH}) ; 128,0(\mathrm{CH}) ; 128,6(\mathrm{CH}) ; 129,5(\mathrm{CH}) ; 132,9(\mathrm{CH}) ; 130,8(\mathrm{C}) ;$ 133,8 (C); 134,1 (C); 145,1 (C); 160,8 (2xC); 196,4 (C).

IR: (película): 1529, 1570, $1665 \mathrm{~cm}^{-1}$

HPLC: Columna $\mathrm{C}_{18} \mathrm{t}_{\mathrm{R}}: 24,23 \mathrm{~min}$. 
Obtención de 2,6-bis(metilsulfanil)-4-(1-(naftalen-2-il)vinil)-piridina

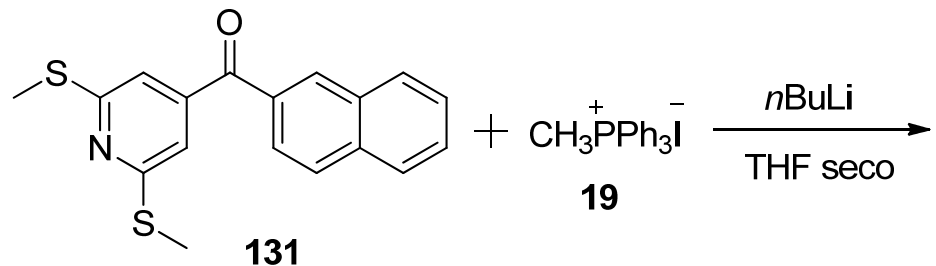<smiles>C=C(c1cc(SC)nc(SC)c1)c1ccc2ccccc2c1</smiles>

Siguiendo el método $B$, se prepara una suspensión de $1,85 \mathrm{~g}(5,49 \mathrm{mmol}) \mathrm{de}$ yoduro de metiltrifenilfosfonio (19) en THF seco $(20-30 \mathrm{~mL})$ a $-40^{\circ} \mathrm{C}$ y se adicionan 1,9 $\mathrm{mL}(3,1 \mathrm{mmol})$ de una disolución 1,6 M de $n$ BuLi en hexano. Se deja 1 hora en agitación y posteriormente se adicionan $497 \mathrm{mg}(1,53 \mathrm{mmol})$ de $(2,6-$ bis(metilsulfanil)piridin-4-il)(naftalen-2-il)metanona (131) disueltos en THF seco (10 $\mathrm{mL}$ ). Se purifica mediante cromatografía flash usando como eluyente Hexano/EtOAc (97:3) y se obtienen $293 \mathrm{mg}(0,91 \mathrm{mmol} ; 59$ \%) de 2,6-bis(metilsulfanil)-4-(1-(naftalen2-il)vinil)-piridina.

\section{2,6-bis(metilsulfanil)-4-(1-(naftalen-2-il)vinil)-piridina (132):}

RMN ${ }^{1} \mathrm{H}\left(\mathrm{CDCl}_{3}\right) \delta$ (ppm): (Espectro 132H) 2,56 (6H, s, $\left.\mathrm{SCH}_{3}\right) ; 5,53(1 \mathrm{H}, \mathrm{d}, \mathrm{J}=1,1$; $\left.\mathrm{CH}_{2}\right) ; 6,08\left(1 \mathrm{H}, \mathrm{d}, \mathrm{J}=1,1 ; \mathrm{CH}_{2}\right) ; 6,81(2 \mathrm{H}, \mathrm{s}, \mathrm{pyr}), 7,2-7,7(7 \mathrm{H}, \mathrm{m})$.

$\mathrm{RMN}{ }^{13} \mathrm{C}\left(\mathrm{CDCl}_{3}\right) \delta(\mathrm{ppm})$ : (Espectro 132C) 13,4 (2xCH$) ; 114,7(2 \times \mathrm{CH}) ; 120,0\left(\mathrm{CH}_{2}\right)$; $125,5(\mathrm{CH}) ; 126,1(2 \times \mathrm{CH}) ; 126,4(\mathrm{CH}) ; 127,6(\mathrm{CH}) ; 128,5(\mathrm{CH}) ; 128,7(\mathrm{CH}) ; 131,6(\mathrm{C}) ;$ 133,8 (C); 138,0 (C); 146,2 (C); 148,5 (C); 159,6 (2xC).

IR: (película): 1519, $1570 \mathrm{~cm}^{-1}$

HRMS: Calculado $(\mathrm{M}+\mathrm{H}) 324,0881$. Obtenido $\left(\mathrm{C}_{19} \mathrm{H}_{18} \mathrm{NS}_{2}\right) 324,0893$.

HPLC: Columna $\mathrm{C}_{18} \mathrm{t}_{\mathrm{R}}: 25,47 \mathrm{~min}$. 
Obtención de las oximas de (2,6-bis(metilsulfanil)piridin-4-il)(naftalen-2il)metanona<smiles>CSc1cc(C(=O)c2ccc3ccccc3c2)cc(SC)n1</smiles><smiles>CSc1cc(/C(=N\O)c2ccc3ccccc3c2)cc(SC)n1</smiles>

Siguiendo el método $\mathrm{E}$, se disuelven $93 \mathrm{mg}(0,29 \mathrm{mmol})$ de (2,6bis(metilsulfanil)piridin-4-il)(naftalen-2-il)metanona (131) en $\mathrm{MeOH}(10 \mathrm{~mL}$ ) y se añaden $199 \mathrm{mg}(2,86 \mathrm{mmol})$ de clorhidrato de hidroxilamina. Por cromatografía flash, utilizando como eluyente Hexano/EtOAc (95:5), se obtienen $49 \mathrm{mg}(0,14 \mathrm{mmol} ; 50 \%)$ del isómero $Z, 31 \mathrm{mg}(9 \mathrm{mmol} ; 31 \%)$ del isómero $E$ y $68 \mathrm{mg}(0,20 \mathrm{mmol} ; 68 \%)$ de mezcla de oximas.

Oxima de (Z)-(2,6-bis(metilsulfanil)piridin-4-il)(naftalen-2-il)metanona (133Z):

$\mathrm{RMN}^{1} \mathrm{H}\left(\mathrm{CDCl}_{3}\right) \delta$ (ppm): (Espectro 133ZEH) 2,53 (6H, s, SCH $)_{3} ; 6,95(2 \mathrm{H}, \mathrm{s}, \mathrm{pyr}), 7,2-$ $8,0(7 \mathrm{H}, \mathrm{m}, \mathrm{Ar})$.

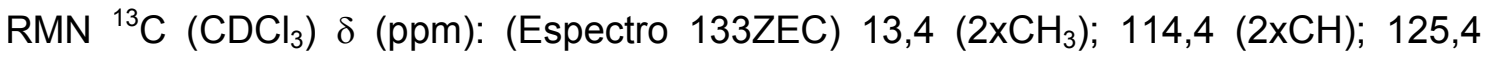
(2xCH); 126,3 (CH); 126,5 (CH); 127,0 (CH); 128,7 (CH); 127,3 (C); 129,8 (CH); 130,2 (C); 133,6 (C); 143,3 (C); 155,6 (C); 159,9 (2xC).

Oxima de (E)-(2,6-bis(metilsulfanil)piridin-4-il)(naftalen-2-il)metanona (133E):

$\mathrm{RMN}^{1} \mathrm{H}\left(\mathrm{CDCl}_{3}\right) \delta$ (ppm): (Espectro 133ZEH) 2,55 (6H, s, SCH $)_{3} ; 7,01(2 \mathrm{H}, \mathrm{s}, \mathrm{pyr}) ; 7,4-$ $8,0(7 \mathrm{H}, \mathrm{m}, \mathrm{Ar})$.

RMN ${ }^{13} \mathrm{C}\left(\mathrm{CDCl}_{3}\right) \delta(\mathrm{ppm})$ : (Espectro 133ZEH) 13,4 (2xCH$) ; 114,4(\mathrm{CH}) ; 116,8(\mathrm{CH})$; $125,4(2 \times C H) ; 126,5(\mathrm{CH}) ; 127,0(\mathrm{CH}) ; 128,5(\mathrm{CH}) ; 129,7(\mathrm{CH}) ; 130,2(\mathrm{CH}) ; 131,5(\mathrm{C})$; 133,9 (C); 140,6 (C); 143,4 (C); 154,8 (C); 155,5 (C); 159,8 (2xC).

Oximas de (2,6-bis(metilsulfanil)piridin-4-il)(naftalen-2-il)metanona (133EZ):

IR: (película): 1435, 1522, 1571, 3271, $3295 \mathrm{~cm}^{-1}$

HRMS: Calculado $(\mathrm{M}+\mathrm{H}) 341,0782$. Obtenido $\left.\left(\mathrm{C}_{18} \mathrm{H}_{17} \mathrm{~N}_{2} \mathrm{OS}\right)_{2}\right) 341,0792$.

HPLC: Columna $C_{18} \quad t_{R}: 25,12$ min; $t_{R}: 25,36$ min. 


\section{D.4.4. SÍNTESIS DE COMPUESTOS CON DIMETILAMINOFENIL}

Obtención

de

(2,6-bis(metilsulfanil)piridin-4-il)(3-

(dimetilamino)fenil)metanona<smiles>CSc1cc(C(=O)O)cc(SC)n1</smiles><smiles>CN(C)c1cccc(Br)c1</smiles><smiles>CSc1cc(C(=O)c2cccc(N(C)C)c2)cc(SC)n1</smiles>

Sobre una disolución de 1,29 $\mathrm{mL}(8,75 \mathrm{mmol})$ de 3-bromo- $\mathrm{N}, \mathrm{N}$-dimetilanilina en THF seco se añaden $5,47 \mathrm{~mL}(8,75 \mathrm{mmol})$ de una disolución 1,6 $\mathrm{M}$ de $n$ BuLi en hexano siguiendo el método A. Posteriormente se añaden $754 \mathrm{mg}(3,5 \mathrm{mmol})$ de ácido 2,6-bis(metilsulfanil)piridina-4-carboxílico (4) disuelto en THF seco. Se purifica mediante cromatografía flash, utilizando como eluyente Hexano/EtOAc (95:5) y se recogen $590 \mathrm{mg} \quad(1,85 \mathrm{mmol} ; 53 \%)$ de (2,6-bis(metilsulfanil)piridin-4-il)(3(dimetilamino)fenil)metanona que cristalizan en $\mathrm{Hex} / \mathrm{CH}_{2} \mathrm{Cl}_{2}$.

(2,6-bis(metilsulfanil)piridin-4-il)(3-(dimetilamino)fenil)metanona (134)

P.f. $\left(\mathrm{Hex} / \mathrm{CH}_{2} \mathrm{Cl}_{2}\right): 114-116^{\circ}$

$\mathrm{RMN}^{1} \mathrm{H}\left(\mathrm{CDCl}_{3}\right) \delta$ (ppm): (Espectro 134H) 2,61 (6H, s, SCH$) ; 3,00\left(6 \mathrm{H}, \mathrm{s}, \mathrm{NMe}_{2}\right) ; 6,96$ $\left(1 \mathrm{H}, \mathrm{dd}, \mathrm{H}=1,7 ; \mathrm{J}=7,6 ; \mathrm{H}_{4}\right) ; 7,02\left(1 \mathrm{H}, \mathrm{dd}, \mathrm{J}=7,6 ; \mathrm{H}_{6}\right) ; 7,15(2 \mathrm{H}, \mathrm{s}, \mathrm{pyr}) ; 7,16(1 \mathrm{H}, \mathrm{d}$, $\left.\mathrm{J}=1,7 ; \mathrm{H}_{2}\right) ; 7,31\left(1 \mathrm{H}, \mathrm{t}, \mathrm{J}=7,9 ; \mathrm{H}_{5}\right)$.

$\mathrm{RMN}{ }^{13} \mathrm{C}\left(\mathrm{CDCl}_{3}\right) \delta(\mathrm{ppm})$ : (Espectro 134C) 13,3 $\left(2 \mathrm{xCH}_{3}\right) ; 40,5\left(2 \times \mathrm{CH}_{3}\right) ; 112,6(\mathrm{CH})$; $115,4(2 \times C H) ; 117,3(\mathrm{CH}) ; 118,7(\mathrm{CH}) ; 129,0(\mathrm{CH}) ; 136,6(\mathrm{C}) ; 144,9(\mathrm{C}) ; 150,4(\mathrm{C}) ;$ $160,1(2 \times C) ; 195,5(C)$.

IR (KBr): 1436, 1496, 1525, 1568, 1596, $1656 \mathrm{~cm}^{-1}$

HRMS: Calculado $(\mathrm{M}+\mathrm{H}) 319,0939$. Obtenido $\left.\left(\mathrm{C}_{16} \mathrm{H}_{19} \mathrm{~N}_{2} \mathrm{OS}\right)_{2}\right) 319,0938$.

HPLC: Columna $\mathrm{C}_{8} \quad \mathrm{t}_{\mathrm{R}}: 21,58 \mathrm{~min}$.

Columna $\mathrm{C}_{18} \mathrm{t}_{\mathrm{R}}: 27,17 \mathrm{~min}$. 
Obtención de 3-(1-(2,6-bis(metilsulfanil)piridin-4-il)vinil)- $N, N$-dimetilanilina<smiles>C=C(c1cccc(N(C)C)c1)c1cc(SC)nc(SC)c1</smiles>

Siguiendo el método $B$, se prepara una suspensión de $1,18 \mathrm{~g}(2,93 \mathrm{mmol}) \mathrm{de}$ yoduro de metiltrifenilfosfonio (19) en THF seco $(20-30 \mathrm{~mL})$ a $-40^{\circ} \mathrm{C}$ y se adicionan 1,2 $\mathrm{mL}(1,95 \mathrm{mmol})$ de una disolución 1,6 M de $n$ BuLi en hexano. Se deja 1 hora en agitación y posteriormente se adicionan $312 \mathrm{mg}(0,98 \mathrm{mmol})$ de $(2,6-$ bis(metilsulfanil)piridin-4-il)(3-(dimetilamino)fenil)metanona (134) disueltos en THF seco $(10 \mathrm{~mL})$. Se purifica mediante cromatografía flash usando como eluyente Hexano/EtOAc (97:3) y se obtienen $112 \mathrm{mg}(0,35 \mathrm{mmol} ; 36 \%)$ de 3-(1-(2,6bis(metilsulfanil)piridin-4-il)vinil)- $N, N$-dimetilanilina.

\section{3-(1-(2,6-bis(metilsulfanil)piridin-4-il)vinil)-N,N-dimetilanilina (135):}

$\mathrm{RMN}^{1} \mathrm{H}\left(\mathrm{CDCl}_{3}\right) \delta$ (ppm): (Espectro 135H) 2,59 (6H, s, SCH$\left.)_{3}\right) ; 2,94\left(6 \mathrm{H}, \mathrm{s}, \mathrm{NMe}_{2}\right) ; 5,52$ $\left(1 \mathrm{H}, \mathrm{d}, \mathrm{J}=1,2 ; \mathrm{CH}_{2}\right) ; 5,54\left(1 \mathrm{H}, \mathrm{d}, \mathrm{J}=1,2 ; \mathrm{CH}_{2}\right) ; 6,62(1 \mathrm{H}, \mathrm{da}, \mathrm{J}=8,1) ; 6,65(1 \mathrm{H}, \mathrm{m}) ; 6,73$ $(1 \mathrm{H}, \mathrm{da}, \mathrm{J}=8,1) ; 6,85(2 \mathrm{H}, \mathrm{s}, \mathrm{pyr}) ; 7,21\left(1 \mathrm{H}, \mathrm{t}, \mathrm{J}=8,1 ; \mathrm{H}_{5}\right)$.

RMN ${ }^{13} \mathrm{C}\left(\mathrm{CDCl}_{3}\right) \delta(\mathrm{ppm})$ : (Espectro 135C) 13,4 (2xCH$) ; 40,7\left(2 \times \mathrm{CH}_{3}\right) ; 112,4(\mathrm{CH}) ;$ $112,5(\mathrm{CH}) ; 116,3(2 \times C H) ; 116,5\left(\mathrm{CH}_{2}\right) ; 116,8(\mathrm{CH}) ; 129,1(\mathrm{CH}) ; 140,6(\mathrm{C}) ; 148,4(\mathrm{C})$; 149,2 (C); 150,5 (C); 159,2 (2xC).

IR (película): 1432, 1517, 1571, $1596 \mathrm{~cm}^{-1}$

HRMS: Calculado (M+Na) 339,0966. Obtenido $\left(\mathrm{C}_{17} \mathrm{H}_{20} \mathrm{~N}_{2} \mathrm{NaS}_{2}\right) 339,0959$.

HPLC: Columna $\mathrm{C}_{18} \mathrm{t}_{\mathrm{R}}: 25,95 \mathrm{~min}$. 
Obtención de las oximas de (2,6-bis(metilsulfanil)piridin-4-il)(3(dimetilamino)fenil)metanona<smiles>CSc1cc(C(=O)c2cccc(N(C)C)c2)cc(C(=NO)c2cc(SC)nc(SC)c2)c1</smiles>

Siguiendo el método $\mathrm{E}$, se disuelven $213 \mathrm{mg}(0,67 \mathrm{mmol})$ de (2,6bis(metilsulfanil)piridin-4-il)(3-(dimetilamino)fenil)metanona (134) en $\mathrm{MeOH}(10-20 \mathrm{~mL}$ ) y se añaden $465 \mathrm{mg}(6,69 \mathrm{mmol})$ de clorhidrato de hidroxilamina. Por cromatografía flash, utilizando como eluyente Hexano/EtOAc (9:1) se obtienen 19 mg (0,06 mmol; $8,5 \%)$ del isómero $E$ y $163 \mathrm{mg}(0,49 \mathrm{mmol} ; 73 \%)$ de mezcla de oximas $(E+Z)$ en proporción 4:6.

Oxima de (E)-(2,6-bis(metilsulfanil)piridin-4-il)(3-(dimetilamino)fenil)metanona (136E):

$\mathrm{RMN}^{1} \mathrm{H}\left(\mathrm{CDCl}_{3}\right) \delta$ (ppm): (Espectro 136EH) 2,57 (6H, s, $\left.\mathrm{SCH}_{3}\right) ; 2,96\left(6 \mathrm{H}, \mathrm{s}, \mathrm{NMe}_{2}\right)$; $6,59\left(1 \mathrm{H}, \mathrm{d}, \mathrm{J}=1,6 ; \mathrm{H}_{2}\right) ; 6,59(1 \mathrm{H}, \mathrm{m}) ; 6,61(1 \mathrm{H}, \mathrm{da}, \mathrm{J}=8,2) ; 6,80(1 \mathrm{H}, \mathrm{da}, \mathrm{J}=8,2) ; 6,98$ $(2 \mathrm{H}, \mathrm{s}, \mathrm{pyr}) ; 7,33\left(1 \mathrm{H}, \mathrm{t}, \mathrm{J}=8,2 ; \mathrm{H}_{5}\right)$.

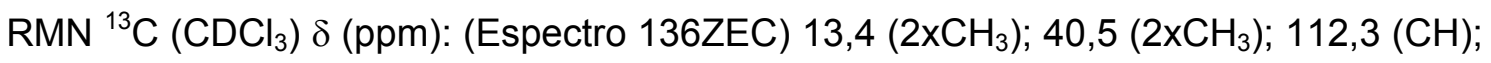
$113,5(\mathrm{CH}) ; 115,1(2 \times \mathrm{CH}) ; 116,6(\mathrm{CH}) ; 129,3(\mathrm{CH}) ; 131,7(\mathrm{C}) ; 143,7(\mathrm{C}) ; 150,4(\mathrm{C}) ;$ $156,9(\mathrm{C}) ; 159,6(2 \times C)$.

IR (película): 1432, 1521, 1572, 1597, 2921, $3265 \mathrm{~cm}^{-1}$

HRMS: Calculado $(\mathrm{M}+\mathrm{H}) 334,1048$. Obtenido $\left.\left(\mathrm{C}_{16} \mathrm{H}_{20} \mathrm{~N}_{3} \mathrm{OS}\right)_{2}\right) 334,1042$.

Oxima de (Z)-(2,6-bis(metilsulfanil)piridin-4-il)(3-(dimetilamino)fenil)metanona (136Z):

$\mathrm{RMN}^{1} \mathrm{H}\left(\mathrm{CDCl}_{3}\right) \delta$ (ppm): 2,59 (6H, s, $\left.\mathrm{SCH}_{3}\right) ; 2,92\left(6 \mathrm{H}, \mathrm{s}, \mathrm{NMe}_{2}\right) ; 6,61(1 \mathrm{H}, \mathrm{da}, \mathrm{J}=7,9)$; $6,63(1 \mathrm{H}, \mathrm{m}) ; 6,77(1 \mathrm{H}, \mathrm{da}, \mathrm{J}=7,9) ; 6,87(2 \mathrm{H}, \mathrm{s}, \mathrm{pyr}) ; 7,18\left(1 \mathrm{H}, \mathrm{t}, \mathrm{J}=7,9 ; \mathrm{H}_{5}\right)$.

$\mathrm{RMN}{ }^{13} \mathrm{C}\left(\mathrm{CDCl}_{3}\right) \delta(\mathrm{ppm}):\left(\right.$ Espectro 136ZEC) 13,4 $\left(2 \times \mathrm{CH}_{3}\right) ; 40,7\left(2 \times \mathrm{CH}_{3}\right) ; 111,2(\mathrm{CH})$; $112,6(\mathrm{CH}) ; 114,5(\mathrm{CH}) ; 116,5(2 \times \mathrm{CH}) ; 129,3(\mathrm{CH}) ; 135,2(\mathrm{C}) ; 141,0(\mathrm{C}) ; 150,5(\mathrm{C}) ;$ $156,2(\mathrm{C}) ; 159,7(2 \times C)$.

HPLC: Columna $\mathrm{C}_{18} \quad \mathrm{t}_{\mathrm{R}}: 21,98 \mathrm{~min} ; \mathrm{t}_{\mathrm{R}}: 22,23 \mathrm{~min}$. 
Obtención de (4-(dimetilamino)fenil)(2-metilsulfanil-6-metoxipiridin-4il)metanona<smiles>COc1cc(C(=O)O)cc(SC)n1</smiles><smiles>CN(C)c1ccc(Br)cc1</smiles>

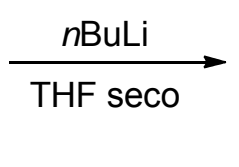<smiles>COc1cc(C(=O)c2ccc(N(C)C)cc2)cc(SC)n1</smiles>

Siguiendo el método A, se prepara una disolución de 2,95 g (14,75 mmol) de 4bromo- $N, N$-dimetilanilina en THF seco (20-30 mL), se añaden $9,2 \mathrm{~mL}(14,72 \mathrm{mmol}) \mathrm{de}$ una disolución $1,6 \mathrm{M}$ de $n \mathrm{BuLi}$ en hexano y se deja media hora en agitación. A continuación se añade 1,174 g (5,90 mmol) de ácido 2-metilsulfanil-6-metoxipiridina-4carboxílico (5) disuelto en THF seco $(10-20 \mathrm{~mL})$. El producto obtenido se purifica mediante una cromatografía flash, utilizando como eluyente Hexano/EtOAc (95:5) y se recogen $723 \mathrm{mg}(2,39 \mathrm{mmol} ; 41 \%)$ de (4-(dimetilamino)fenil)(2-metilsulfanil-6metoxipiridin-4-il)metanona.

\section{(4-(dimetilamino)fenil)(2-metilsulfanil-6-metoxipiridin-4-il)metanona (137):}

$\mathrm{RMN}^{1} \mathrm{H}\left(\mathrm{CDCl}_{3}\right) \delta$ (ppm): (Espectro 137H) 2,58 (3H, s, SCH$) ; 3,09\left(6 \mathrm{H}, \mathrm{s}, \mathrm{NMe}_{2}\right) ; 3,98$ $\left(3 \mathrm{H}, \mathrm{s}, \mathrm{OCH}_{3}\right) ; 6,59(1 \mathrm{H}, \mathrm{d}, \mathrm{J}=1,1 ; \mathrm{pyr}) ; 6,67(2 \mathrm{H}, \mathrm{d}, \mathrm{J}=9,1 ; \mathrm{Ar}) ; 6,95(1 \mathrm{H}, \mathrm{d}, \mathrm{J}=1,1 ; \mathrm{pyr})$; $7,77(2 \mathrm{H}, \mathrm{d}, \mathrm{J}=9,1 ; \mathrm{Ar})$.

RMN ${ }^{13} \mathrm{C}\left(\mathrm{CDCl}_{3}\right) \delta(\mathrm{ppm})$ : (Espectro $\left.137 \mathrm{C}\right)$ 13,5 $\left(\mathrm{CH}_{3}\right) ; 40,1\left(2 \times \mathrm{CH}_{3}\right) ; 53,8\left(\mathrm{CH}_{3}\right)$; $104,9(\mathrm{CH}) ; 110,6$ (2xCH); 115,6 (CH); 123,2 (C); 132,7 (2xCH); 149,8 (C); 153,8 (C); 158,1 (C); 163,7 (C); 192,8 (C).

IR (KBr): 1449, 1478, 1543, 1592, $1644 \mathrm{~cm}^{-1}$

HRMS: Calculado $(\mathrm{M}+\mathrm{H}) 303,1167$. Obtenido $\left(\mathrm{C}_{16} \mathrm{H}_{19} \mathrm{~N}_{2} \mathrm{O}_{2} \mathrm{~S}\right) 303,1154$.

HPLC: Columna $\mathrm{C}_{8} \quad \mathrm{t}_{\mathrm{R}}: 19,04 \mathrm{~min}$. 


\section{dimetilanilina}<smiles>C=C(c1ccc(N(C)C)cc1)c1cc(OC)nc(SC)c1</smiles>

Siguiendo el método $B$, se prepara una suspensión de 1,3 g $(3,23 \mathrm{mmol})$ de yoduro de metiltrifenilfosfonio (19) en THF seco $(20-30 \mathrm{~mL})$ a $-40^{\circ} \mathrm{C}$ y se adicionan 1,4 $\mathrm{mL}(2,29 \mathrm{mmol})$ de una disolución $1,6 \mathrm{M}$ de $n \mathrm{BuLi}$ en hexano. Se deja 1 hora en agitación y posteriormente se adicionan $276 \mathrm{mg}(0,91 \mathrm{mmol})$ de (4(dimetilamino)fenil)(2-metilsulfanil-6-metoxipiridin-4-il)metanona (137) disueltos en 10$20 \mathrm{~mL}$ de THF seco. Se purifica mediante cromatografía flash usando como eluyente Hexano/EtOAc (98:2) y se obtienen 90 mg (0,30 mmol; $33 \%)$ de 4-(1-(2-metilsulfanil6-metoxipiridin-4-il)vinil)- $N, N$-dimetilanilina.

\section{4-(1-(2-metilsulfanil-6-metoxipiridin-4-il)vinil)-N,N-dimetilanilina (138):}

$\mathrm{RMN}^{1} \mathrm{H}\left(\mathrm{CDCl}_{3}\right) \delta$ (ppm): (Espectro 138H) 2,56 (3H, s, SCH$) ; 2,98\left(6 \mathrm{H}, \mathrm{s}, \mathrm{NMe}_{2}\right) ; 3,95$ $\left(3 \mathrm{H}, \mathrm{s}, \mathrm{OCH}_{3}\right) ; 5,32\left(1 \mathrm{H}, \mathrm{d}, \mathrm{J}=1,1 ; \mathrm{CH}_{2}\right) ; 5,44\left(1 \mathrm{H}, \mathrm{d}, \mathrm{J}=1,1 ; \mathrm{CH}_{2}\right) ; 6,40(1 \mathrm{H}, \mathrm{d}, \mathrm{J}=1,1$; pyr); 6,72 (2H, d, J=8,9; Ar); 6,76 (1H, d, J=1,1; pyr); 7,19 (2H, d, J=8,9; Ar).

RMN ${ }^{13} \mathrm{C}\left(\mathrm{CDCl}_{3}\right) \delta(\mathrm{ppm})$ : (Espectro $\left.138 \mathrm{C}\right)$ 13,5 $\left(\mathrm{CH}_{3}\right) ; 40,5\left(2 \times \mathrm{CH}_{3}\right) ; 53,6\left(\mathrm{CH}_{3}\right)$; $105,1(\mathrm{CH}) ; 110,6(\mathrm{CH}) ; 112,1(2 \times \mathrm{CH}) ; 113,9\left(\mathrm{CH}_{2}\right) ; 128,8(2 \times \mathrm{CH}) ; 132,8(\mathrm{C}) ; 147,7$ (C); 150,3 (C); 153,1 (C); 156,9 (C); 164,0 (C).

IR (película): 1449, 1532, $1592 \mathrm{~cm}^{-1}$

HRMS: Calculado $(\mathrm{M}+\mathrm{H}) 301,1375$. Obtenido $\left(\mathrm{C}_{17} \mathrm{H}_{21} \mathrm{~N}_{2} \mathrm{OS}\right) 301,1351$.

HPLC: Columna $\mathrm{C}_{8} \quad \mathrm{t}_{\mathrm{R}}: 22,3 \mathrm{~min}$. 
Obtención de las oximas de (4-(dimetilamino)fenil)(2-metilsulfanil-6metoxipiridin-4-il) metanona<smiles>COc1cc(C(=O)c2ccc(N(C)C)cc2)cc(SC)n1</smiles>

Siguiendo el método $E$, se disuelven $133 \mathrm{mg}(0,44 \mathrm{mmol})$ de (4(dimetilamino)fenil)(2-metilsulfanil-6-metoxipiridin-4-il) metanona (137) en $\mathrm{MeOH}$ (10 $\mathrm{mL})$ y se añaden $305 \mathrm{mg}(4,39 \mathrm{mmol})$ de clorhidrato de hidroxilamina. Se purifica mediante cromatografía flash, utilizando como eluyente Hexano/EtOAc (8:2) obteniendo $97 \mathrm{mg}$ de $(0,31 \mathrm{mmol} ; 70 \%)$ de mezcla de oximas $(Z+E)$ que cristalizan en $\mathrm{Hex} / \mathrm{CH}_{2} \mathrm{Cl}_{2}$ en proporción 1:1.

Oximas de ((4-(dimetilamino)fenil)(2-metilsulfanil-6-metoxipiridin-4-il)metanona (139ZE):

P.f. $\left(\mathrm{Hex} / \mathrm{CH}_{2} \mathrm{Cl}_{2}\right): 142-144^{\circ} \mathrm{C}$

$\mathrm{RMN}^{1} \mathrm{H}\left(\mathrm{CDCl}_{3}\right) \delta$ (ppm): (Espectro 139ZEH) 2,58 (3H, s, $\left.\mathrm{SCH}_{3}\right) ; 2,99\left(6 \mathrm{H}, \mathrm{s}, \mathrm{NMe}_{2}\right)$; $3,98\left(3 \mathrm{H}, \mathrm{s}, \mathrm{OCH}_{3}\right) ; 6,40(1 \mathrm{H}, \mathrm{d}, \mathrm{J}=1,1 ; \mathrm{pyr}) ; 6,69(2 \mathrm{H}, \mathrm{d}, \mathrm{J}=8,8 ; \mathrm{Ar}) ; 6,91(1 \mathrm{H}, \mathrm{d}, \mathrm{J}=1,1$; pyr); $7,39(2 \mathrm{H}, \mathrm{d}, \mathrm{J}=8,8 ; \mathrm{Ar})$. Isómero $Z$.

RMN ${ }^{1} \mathrm{H}\left(\mathrm{CDCl}_{3}\right) \delta(\mathrm{ppm}):\left(\right.$ Espectro 139ZEH) 2,55 (3H, s, $\left.\mathrm{SCH}_{3}\right) ; 3,03\left(6 \mathrm{H}, \mathrm{s}, \mathrm{NCH}_{3}\right)$; $3,94\left(3 \mathrm{H}, \mathrm{s}, \mathrm{OCH}_{3}\right) ; 6,47(1 \mathrm{H}, \mathrm{d}, \mathrm{J}=1,1 ; \mathrm{pyr}) ; 6,83(2 \mathrm{H}, \mathrm{d}, \mathrm{J}=8,8 ; \mathrm{Ar}) ; 6,95(1 \mathrm{H}, \mathrm{d}, \mathrm{J}=1,1$; pyr); $7,35(2 \mathrm{H}, \mathrm{d}, \mathrm{J}=8,8 ; \mathrm{Ar})$. Isómero $E$.

RMN ${ }^{13} \mathrm{C}\left(\mathrm{CDCl}_{3}\right) \delta(\mathrm{ppm})$ : (Espectro 139ZEC) 13,5 $\left(\mathrm{CH}_{3}\right) ; 40,3\left(2 \times \mathrm{CH}_{3}\right) ; 53,7\left(\mathrm{CH}_{3}\right)$; 105,2 (CH); 111,3 (2xCH); 111,8 (2xCH); 112,9 (CH); 113,4 (CH); 118,3 (C); 121,9 (C); $128,6(2 \times C H) ; 131,3(2 \times C H) ; 144,6(C) ; 148,0$ (C); 151,0 (C); 155,8 (C); 157,6 (C); $163,8(C)$. Isómeros $Z+E$

IR (pastilla): 1449, 1540, 1602, 3267, $3364 \mathrm{~cm}^{-1}$

HRMS: Calculado $(\mathrm{M}+\mathrm{H}) 318,1276$. Obtenido $\left(\mathrm{C}_{16} \mathrm{H}_{20} \mathrm{~N}_{3} \mathrm{O}_{2} \mathrm{~S}\right) 318,1283$.

HPLC: Columna $C_{8} \quad t_{R}: 17,85$ min; $t_{R}: 18,20$ min. 
Intento de obtención de 2-(dimetilamino)-5-(2-metilsulfanil-6-metoxipiridin-

\section{4-il)benzaldehído}<smiles>COc1cc(C(=O)c2ccc(N(C)C)cc2)cc(SC)n1</smiles>

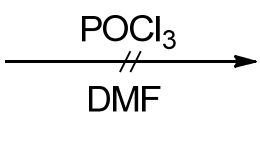<smiles>COc1cc(C(=O)c2ccc(N(C)C)c(C=O)c2)cc(SC)n1</smiles>

Siguiendo el método $\mathrm{F}$, se disuelven $0,2 \mathrm{~mL}(2,2 \mathrm{mmol})$ de $\mathrm{POCl}_{3}$ en $5 \mathrm{~mL}$ de $\mathrm{DMF}$, y a la media hora se añaden $60 \mathrm{mg}(0,20 \mathrm{mmol})$ de (4-(dimetilamino)fenil)(2-metilsulfanil6-metoxipiridin-4-il)metanona (137) disueltos en $5 \mathrm{~mL}$ de DMF seca, y se deja 2 horas a $80^{\circ} \mathrm{C}$. Se obtiene una mezcla compleja difícil de caracterizar.

\section{(dimetilamino)fenil)metanona}
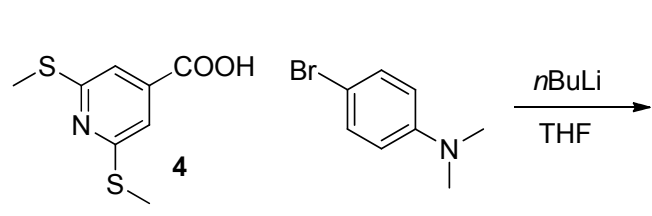<smiles>CSc1cc(C(=O)c2ccc(N(C)C)cc2)cc(SC)n1</smiles><smiles>CCSc1cc(SC)cc(C(O)(c2ccc(N(C)C)cc2)c2ccc(N(C)C)cc2)c1</smiles>

Sobre una disolución de 2,32 g (11,6 mmol) de 4-bromo- $N, N$-dimetilanilina en THF seco (20-30 mL) se añaden 7,3 mL (11,6 mmol) de una disolución 1,6 M de $n$ BuLi en hexano siguiendo el método A. Posteriormente se añade $1 \mathrm{~g}(4,6 \mathrm{mmol})$ de ácido 2,6-bis(metilsulfanil)piridina-4-carboxílico (4) disuelto en THF seco (20 mL). Se purifica mediante cromatografía flash, utilizando como eluyente Hexano/EtOAc (98:2) y se recogen $669 \mathrm{mg} \quad(2,1 \mathrm{mmol} ; \quad 45,7 \%)$ de (2,6-bis(metilsulfanil)piridin-4-il)(4(dimetilamino)fenil)metanona, que cristaliza en Hex/EtOAc, y $81 \mathrm{mg}(0,18 \mathrm{mmol} ; 4 \%)$ de (2,6-bis(metilsulfanil)piridin-4-il)bis(4-(dimetillamino)fenil)metanol (141). 


\section{(2,6-bis(metilsulfanil)piridin-4-il)(4-(dimetilamino)fenil)metanona (140):}

P.f. (Hex/EtOAc): 103-105

$\mathrm{RMN}^{1} \mathrm{H}\left(\mathrm{CDCl}_{3}\right) \delta$ (ppm): (Espectro 140H) 2,61 (6H, s, SCH$)_{3} ; 3,09\left(6 \mathrm{H}, \mathrm{s}, \mathrm{NMe}_{2}\right) ; 6,67$ $(2 \mathrm{H}, \mathrm{d}, \mathrm{J}=9,2 ; \mathrm{Ar}) ; 7,04$ (2H, s, pyr); 7,75 (2H, d, J=9,2; Ar).

$\mathrm{RMN}^{13} \mathrm{C}\left(\mathrm{CDCl}_{3}\right) \delta$ (ppm): (Espectro 140C) 13,3 $\left(2 \mathrm{xCH}_{3}\right) ; 40,1\left(2 \mathrm{xCH}_{3}\right) ; 110,7(2 \mathrm{xCH})$; 115,6 (2xCH); 123,4 (C); 132,6 (2xCH); 146,5 (C); 153,7 (C); 159,8 (2xC); 192,6 (C).

IR (KBr): $1435,1523,1591,1639 \mathrm{~cm}^{-1}$

HRMS: Calculado $(\mathrm{M}+\mathrm{H}) 319,0939$. Obtenido $\left(\mathrm{C}_{16} \mathrm{H}_{19} \mathrm{~N}_{2} \mathrm{OS}{ }_{2}\right) 319,1221$.

HPLC: Columna $C_{8} \quad t_{R}: 20,29$ min.

Columna $\mathrm{C}_{18} \mathrm{t}_{\mathrm{R}}: 25,52 \mathrm{~min}$.

(2,6-bis(metilsulfanil)pridin-4-il)bis(4-(dimetilamino)fenil)metanol (141):

$\mathrm{RMN}^{1} \mathrm{H}\left(\mathrm{CDCl}_{3}\right) \delta$ (ppm): (Espectro $\left.141 \mathrm{H}\right) 2,55\left(6 \mathrm{H}, \mathrm{s}, \mathrm{SCH}_{3}\right) ; 2,94\left(12 \mathrm{H}, \mathrm{s}, \mathrm{NMe}_{2}\right)$; $6,66(4 \mathrm{H}, \mathrm{d}, \mathrm{J}=8,8 ; \mathrm{Ar}) ; 6,91$ (2H, s, pyr); 7,09 (4H, d, J=8,8; Ar).

RMN ${ }^{13} \mathrm{C}\left(\mathrm{CDCl}_{3}\right) \delta(\mathrm{ppm})$ : (Espectro 141C) 13,2 (2xCH 3$) ; 40,4\left(4 \mathrm{xCH}_{3}\right) ; 80,7$ (C); 111,7 (4xCH); 115,9 (2xCH); 128,6 (4xCH); 133,6 (2xC); 149,7 (2xC); 156,5 (C); 158,6 $(2 \times C)$.

IR (KBr): 1442, 1480, 1522, 1576, 1608, 2921, $3432 \mathrm{~cm}^{-1}$

HRMS: Calculado $(\mathrm{M}+\mathrm{H}) 440,1830$. Obtenido $\left.\left(\mathrm{C}_{24} \mathrm{H}_{30} \mathrm{~N}_{3} \mathrm{OS}\right)_{2}\right) 440,1838$.

HPLC: Columna $\mathrm{C}_{8} \quad \mathrm{t}_{\mathrm{R}}: 20,87 \mathrm{~min}$. 
Obtención de 4-(1-(2,6-bis(metilsulfanil)piridin-4-il)vinil)- $N, N$-dimetilanilina

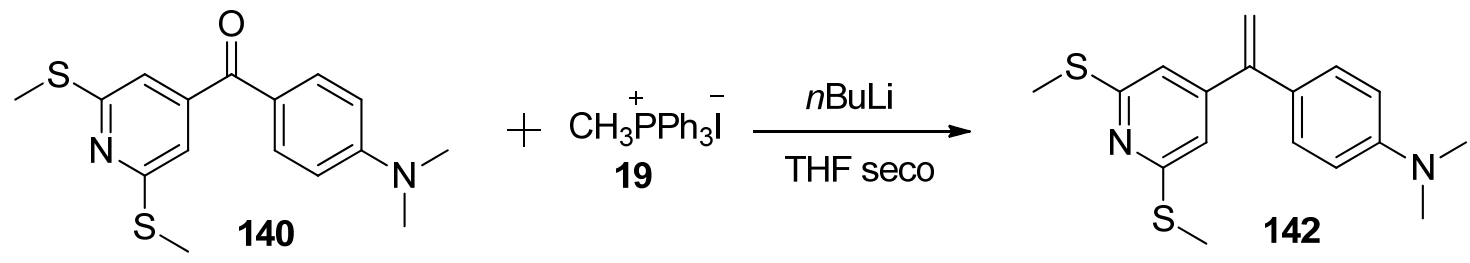

Siguiendo el método $B$, se prepara una suspensión de $1,33 \mathrm{~g}(3,30 \mathrm{mmol})$ de yoduro de metiltrifenilfosfonio (19) en THF seco $(20 \mathrm{~mL})$ a $-40^{\circ} \mathrm{C}$ y se adicionan 1,48 $\mathrm{mL}(2,37 \mathrm{mmol})$ de una disolución 1,6 M de $n$ BuLi en hexano. Se deja 1 hora en agitación y posteriormente se adicionan $302 \mathrm{mg}(0,95 \mathrm{mmol})$ de (2,6bis(metilsulfanil)piridin-4-il)(4-(dimetilamino)fenil)metanona (140) disueltos en THF seco $(10 \mathrm{~mL})$. Se purifica mediante cromatografía flash usando como eluyente Hexano/EtOAc (97:3) y se obtienen $118 \mathrm{mg}(0,37 \mathrm{mmol} ; 39 \%)$ de 4-(1-(2,6bis(metilsulfanil)piridin-4-il)vinil)- $N, N$-dimetilanilina.

\section{4-(1-(2,6-bis(metilsulfanil)piridin-4-il)vinil)- $N, N$-dimetilanilina (142):}

$\mathrm{RMN}^{1} \mathrm{H}\left(\mathrm{CDCl}_{3}\right) \delta$ (ppm): (Espectro 142H) 2,59 (6H, s, SCH$)_{3} ; 2,99\left(6 \mathrm{H}, \mathrm{s}, \mathrm{NMe}_{2}\right) ; 5,31$ $\left(1 \mathrm{H}, \mathrm{d}, \mathrm{J}=1,0 ; \mathrm{CH}_{2}\right) ; 5,45\left(1 \mathrm{H}, \mathrm{d}, \mathrm{J}=1,0 ; \mathrm{CH}_{2}\right) ; 6,69(2 \mathrm{H}, \mathrm{d}, \mathrm{J}=9,2 ; \mathrm{Ar}) ; 6,86(2 \mathrm{H}, \mathrm{s}, \mathrm{pyr})$; $7,18(2 \mathrm{H}, \mathrm{d}, \mathrm{J}=9,2 ; \mathrm{Ar})$.

$\mathrm{RMN}{ }^{13} \mathrm{C}\left(\mathrm{CDCl}_{3}\right) \delta$ (ppm): (Espectro 142C) 13,2 (2xCH$) ; 40,4\left(2 \mathrm{xCH}_{3}\right) ; 111,7(2 \times \mathrm{CH})$; $113,5\left(\mathrm{CH}_{2}\right) ; 116,4(2 \times \mathrm{CH}) ; 127,5(\mathrm{C}) ; 128,8(2 \times \mathrm{CH}) ; 147,3(\mathrm{C}) ; 149,9$ (C); 150,3 (C); $159,0(2 \times C)$.

IR (película): 1436, 1484, 1519, 1572, $1606 \mathrm{~cm}^{-1}$

HRMS: Calculado $(\mathrm{M}+\mathrm{H}) 317,1146$. Obtenido $\left(\mathrm{C}_{17} \mathrm{H}_{21} \mathrm{~N}_{2} \mathrm{~S}_{2}\right) 317,1142$.

HPLC: Columna $\mathrm{C}_{18} \mathrm{t}_{\mathrm{R}}: 25,27 \mathrm{~min}$. 
Obtención de las oximas de (2,6-bis(metilsulfanil)piridin-4-il)(4(dimetilamino)fenil)metanona<smiles>CSc1cc(C(=O)c2ccc(N(C)C)cc2)cc(SC)n1</smiles>

Siguiendo el método $\mathrm{E}$, se disuelven $198 \mathrm{mg}(0,62 \mathrm{mmol})$ de (2,6bis(metilsulfanil)piridin-4-il)(4-(dimetilamino)fenil)metanona (140) en $\mathrm{MeOH}(10-20 \mathrm{~mL}$ ) y se añaden $432 \mathrm{mg}(6,22 \mathrm{mmol})$ de clorhidrato de hidroxilamina. Por cromatografía flash, utilizando como eluyente Hexano/EtOAc (9:1), se obtienen $121 \mathrm{mg}(0,36 \mathrm{mmol}$; $59 \%)$ de mezcla de oximas $(Z+E)$ y $20 \mathrm{mg}(0,06 \mathrm{mmol} ; 10 \%)$ del isómero $Z$ que se isomeriza en solución clorofórmica.

Oxima de (Z)-(2,6-bis(metilsulfanil)piridin-4-il)(4-(dimetilamino)fenil)metanona (143Z):

$\mathrm{RMN}^{1} \mathrm{H}\left(\mathrm{CDCl}_{3}\right) \delta$ (ppm): (Espectro 143ZEH) 2,59 (6H, s, $\left.\mathrm{SCH}_{3}\right) ; 2,99\left(6 \mathrm{H}, \mathrm{s}, \mathrm{NMe}_{2}\right)$; $6,62(2 \mathrm{H}, \mathrm{d}, \mathrm{J}=9,0 ; \mathrm{Ar}) ; 6,83(2 \mathrm{H}, \mathrm{s} ; \mathrm{pyr}) ; 7,30(2 \mathrm{H}, \mathrm{d}, \mathrm{J}=9,0 ; \mathrm{Ar})$.

RMN ${ }^{13} \mathrm{C}\left(\mathrm{CDCl}_{3}\right) \delta(\mathrm{ppm})$ : (Espectro 143ZEC) 13,2 (2xCH$) ; 40,2\left(2 \mathrm{xCH}_{3}\right) ; 111,7$ (2xCH); 116,4 (2xCH); 128,4 (C); 128,4 (2xCH); 137,8 (C); 151,3 (C); 155,7 (C); 159,6 $(2 \times C)$.

Oxima de (E)-(2,6-bis(metilsulfanil)piridin-4-il)(4-(dimetilamino)fenil)metanona (143E):

$\mathrm{RMN}^{1} \mathrm{H}\left(\mathrm{CDCl}_{3}\right) \delta$ (ppm): (Espectro 143ZEH) 2,57 (6H, s, $\left.\mathrm{SCH}_{3}\right) ; 3,02\left(6 \mathrm{H}, \mathrm{s}, \mathrm{NMe}_{2}\right)$; $6,72(2 \mathrm{H}, \mathrm{d}, \mathrm{J}=8,9 ; \mathrm{Ar}) ; 6,96(2 \mathrm{H}, \mathrm{s} ; \mathrm{pyr}) ; 7,36(2 \mathrm{H}, \mathrm{d}, \mathrm{J}=8,9 ; \mathrm{Ar})$.

RMN ${ }^{13} \mathrm{C}\left(\mathrm{CDCl}_{3}\right) \delta$ (ppm): (Espectro 143ZEC) $13,3\left(2 \mathrm{xCH}_{3}\right) ; 40,1\left(2 \mathrm{xCH}_{3}\right) ; 111,2$ (2xCH); 115,9 (2xCH); 118,0 (C); 121,7 (C); 131,1 (2xCH); 150,9 (C); 155,6 (C); 159,5 $(2 \times C)$.

IR (KBr): 1441, 1482, 1524, 1574, 1605, 3246, $3273 \mathrm{~cm}^{-1}$

HRMS: Calculado (M+Na) 356,0867. Obtenido $\left(\mathrm{C}_{16} \mathrm{H}_{19} \mathrm{~N}_{3} \mathrm{NaOS}_{2}\right) 356,1157$.

HPLC: Columna $C_{18} \quad t_{R}: 21,83$ min; $t_{R}: 22,28 \min$. 
Intento de obtención de 5-(2,6-bis(metilsulfanil)piridin-4-il)-2-

\section{(dimetilamino)benzaldehido}<smiles>CSc1cc(C(=O)c2ccc(N(C)C)cc2)cc(SCC(=O)c2cc(SC)nc(C(=O)c3ccc(N(C)C)c(C=O)c3)c2)n1</smiles>

Siguiendo el método $\mathrm{F}$, se disuelven $0,096 \mathrm{~mL}(1,05 \mathrm{mmol})$ de $\mathrm{POCl}_{3}$ en $5 \mathrm{~mL}$ de DMF, y a la media hora se añaden $56 \mathrm{mg}(0,18 \mathrm{mmol})$ de (2,6-bis(metilsulfanil)piridin4-il)(4-(dimetilamino)fenil)metanona (140) disueltos en $5 \mathrm{~mL}$ de DMF seca y se deja 2 horas a $80^{\circ} \mathrm{C}$. Se obtienen $44 \mathrm{mg}$ de material de partida sin reaccionar.

\section{Obtención de (2,6-bis(metilsulfanil)piridin-4-il)(6-(dimetilamino)piridin-3-} il)metanona<smiles>CSc1cc(C(=O)O)cc(SC)n1</smiles>

Se prepara una disolución de 1,167 g $(5,80 \mathrm{mmol})$ de 5-bromo- $N, N$-dimetilpiridin2-amina en THF seco (20-30 mL), y se añaden 3,6 $\mathrm{mL}(5,8 \mathrm{mmol})$ de una disolución 1,6 $\mathrm{M}$ de $n$ BuLi en hexano y se deja 1 hora en agitación a $-40^{\circ} \mathrm{C}$ y en atmósfera de argón. Se prepara otra disolución de 1,498 g (6,97 mmol) de ácido 2-metilsulfanil-6metoxipiridina-4-carboxílico (4) disuelto en THF seco (10-20 mL), y se añade $215 \mathrm{mg}$ $(8,96 \mathrm{mmol})$ de $\mathrm{NaH}$ y se deja 1 hora en baño de hielo y atmósfera de argón. $\mathrm{A}$ continuación se añade la disolución del bromoderivado sobre el ácido y se deja en agitación en baño de hielo durante 24 horas. El producto obtenido se purifica mediante cromatografía flash, utilizando como eluyente Hexano/EtOAc (8:2) y se recogen $97 \mathrm{mg}$ $(0,30 \mathrm{mmol} ; \quad 5,2 \%)$ de (2,6-bis(metilsulfanil)piridin-4-il)(6-(dimetilamino)piridin-3il)metanona (144) y $71 \mathrm{mg}(0,16 \mathrm{mmol} ; 2,8 \%)$ de (2,6-bis(metilsulfanil)piridin-4-il)bis(6(dimetilamino)piridin-3-il)metanol (145). 
(2,6-bis(metilsulfanil)piridin-4-il)(6-(dimetilamino)piridin-3-il)metanona (144):

$\mathrm{RMN}^{1} \mathrm{H}\left(\mathrm{CDCl}_{3}\right) \delta$ (ppm): (Espectro 144H) 2,61 (6H, s, SCH$)_{3} ; 3,21\left(6 \mathrm{H}, \mathrm{s}, \mathrm{NMe}_{2}\right) ; 6,55$ $\left(1 \mathrm{H}, \mathrm{d}, \mathrm{J}=9,2 ; \mathrm{H}_{5}\right) ; 7,04(2 \mathrm{H}, \mathrm{s}, \mathrm{pyr}) ; 7,98\left(1 \mathrm{H}, \mathrm{dd}, \mathrm{J}=2,2 ; \mathrm{J}=9,2 ; \mathrm{H}_{4}\right) ; 8,57(1 \mathrm{H}, \mathrm{d}, \mathrm{J}=2,2$; $\mathrm{H}_{2}$ ).

$\mathrm{RMN}{ }^{13} \mathrm{C}\left(\mathrm{CDCl}_{3}\right) \delta(\mathrm{ppm})$ : (Espectro 144C) 13,4 (2xCH$) ; 38,1\left(2 \times \mathrm{CH}_{3}\right) ; 105,3(\mathrm{CH})$; $115,5(2 \times C H) ; 119,9(\mathrm{C}) ; 138,3(\mathrm{CH}) ; 145,5(\mathrm{C}) ; 153,1(\mathrm{CH}) ; 160,2(2 \times \mathrm{C}) ; 160,7(\mathrm{C})$; $191,8(C)$.

IR (KBr): 1524, 1593, $1645 \mathrm{~cm}^{-1}$

HRMS: Calculado $(\mathrm{M}+\mathrm{H}) 320,0891$. Obtenido $\left(\mathrm{C}_{15} \mathrm{H}_{18} \mathrm{~N}_{3} \mathrm{OS} \mathrm{S}_{2}\right) 320,0901$.

HPLC: Columna $\mathrm{C}_{8} \quad \mathrm{t}_{\mathrm{R}}: 18,14 \mathrm{~min}$.

(2,6-bis(metilsulfanil)piridin-4-il)bis(6-(dimetilamino)piridin-3-il)metanol (145):

P.f. $\left(\mathrm{Hex} / \mathrm{CH}_{2} \mathrm{Cl}_{2}\right): 175-177^{\circ}$

$\mathrm{RMN}^{1} \mathrm{H}\left(\mathrm{CDCl}_{3}\right) \delta$ (ppm): (Espectro $\left.145 \mathrm{H}\right) 2,55\left(6 \mathrm{H}, \mathrm{s}, \mathrm{SCH}_{3}\right) ; 3,09\left(12 \mathrm{H}, \mathrm{s}, \mathrm{NMe}_{2}\right)$; $6,45\left(2 \mathrm{H}, \mathrm{da}, \mathrm{J}=8,8 ; \mathrm{H}_{5}\right) ; 6,86(2 \mathrm{H}, \mathrm{s}, \mathrm{pyr}) ; 7,36\left(2 \mathrm{H}, \mathrm{dd}, \mathrm{J}=2,4 ; \mathrm{J}=8,8 ; \mathrm{H}_{4}\right) ; 7,95(2 \mathrm{H}, \mathrm{d}$, $\left.\mathrm{J}=2,4 ; \mathrm{H}_{2}\right)$.

$\mathrm{RMN}{ }^{13} \mathrm{C}\left(\mathrm{CDCl}_{3}\right) \delta(\mathrm{ppm})$ : (Espectro $\left.145 \mathrm{C}\right) 13,3\left(2 \times \mathrm{CH}_{3}\right) ; 38,2\left(4 \mathrm{xCH}_{3}\right) ; 78,2$ (C); $105,5(2 \times C H) ; 115,6(2 \times C H) ; 128,1(2 \times C) ; 137,2(2 \times C H) ; 146,9(2 \times C H) ; 155,3(\mathrm{C}) ;$ $158,4(2 \times C) ; 159,2(2 \times C)$.

IR (KBr): 1432, 1515, 1568, 1605, $2924 \mathrm{~cm}^{-1}$

HRMS: Calculado $(\mathrm{M}+\mathrm{H}) 442,1735$. Obtenido $\left(\mathrm{C}_{22} \mathrm{H}_{28} \mathrm{~N}_{5} \mathrm{OS}{ }_{2}\right) 442,1722$.

HPLC: Columna $\mathrm{C}_{8} \quad \mathrm{t}_{\mathrm{R}}: 17,99 \mathrm{~min}$. 


\section{D.5. SÍNTESIS DE COMPUESTOS CON MÁS DE UN ÁTOMO EN EL PUENTE}

\section{D.5.1. SÍNTESIS DE COMBRETASTATINAS}

\section{Obtención de 4-(4-metoxiestiril)-2,6-bis(metilsulfanil)piridina}

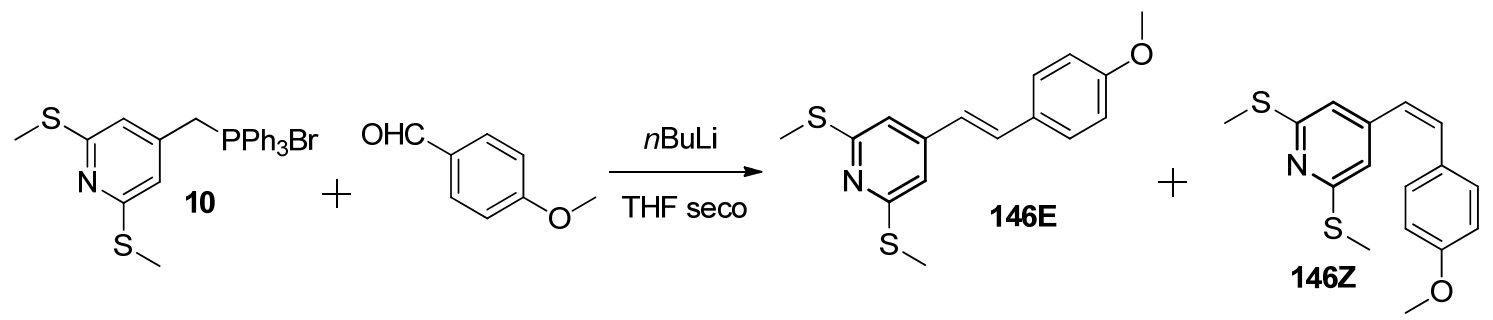

Se prepara una suspensión de $189 \mathrm{mg}$ (0,36 mmol) de bromuro de (2,6bis(metilsulfanil)piridin-4-il)metiltrifenilfosfonio (10) en THF seco $(10-20 \mathrm{~mL}$ ) y se añaden $0,25 \mathrm{~mL}(0,40 \mathrm{mmol})$ de una disolución $1,6 \mathrm{M}$ de $n \mathrm{BuLi}$ en hexano, siguiendo el método $B$. Una hora después se añade $0,13 \mathrm{~mL}(1,10 \mathrm{mmol})$ de 4metoxibenzaldehído disuelto en THF seco $(5-10 \mathrm{~mL})$. Se cromatografía en columna sobre gel de sílice, utilizando como eluyente Hexano/EtOAc (98:2), y posteriormente mediante CCP con Hexano/EtOAc (97:3), obteniendo $19 \mathrm{mg}(0,06 \mathrm{mmol} ; 17 \%)$ de $(E)$ 4-(4-metoxiestiril)-2,6-bis(metilsulfanil)piridina y $59 \mathrm{mg}(0,19 \mathrm{mmol} ; 54 \%)$ de (Z)-4-(4metoxiestiril)-2,6-bis(metilsulfanil)piridina.

(E)-4-(4-metoxiestiril)-2,6-bis(metilsulfanil)piridina (146E):

$\mathrm{RMN}^{1} \mathrm{H}\left(\mathrm{CDCl}_{3}\right) \delta$ (ppm): (Espectro 146EH) 2,61 (6H, s, SCH$)_{3} ; 3,84\left(3 \mathrm{H}, \mathrm{s}, \mathrm{OCH}_{3}\right)$; 6,73 (1H, d, J=16; CH); 6,91 (2H, d, J=8,6; Ar); 6,94 (2H, s, pyr); 7,18 (1H, d, J=16; $\mathrm{CH}) ; 7,45(2 \mathrm{H}, \mathrm{d}, \mathrm{J}=8,6 ; \mathrm{Ar})$.

$\mathrm{RMN}{ }^{13} \mathrm{C}\left(\mathrm{CDCl}_{3}\right) \delta(\mathrm{ppm})$ : (Espectro 146EC) 13,4 $\left(2 \mathrm{xCH}_{3}\right) ; 55,4\left(\mathrm{CH}_{3}\right) ; 114,0(2 \mathrm{xCH})$; $114,3(2 \times C H) ; 123,3(\mathrm{CH}) ; 128,4(2 \times C H) ; 128,9(\mathrm{C}) ; 132,8(\mathrm{C}) ; 132,9(\mathrm{CH}) ; 159,4$ $(3 \times C)$.

IR (KBr): 1433, 1457, 1517, 1571, $1604 \mathrm{~cm}^{-1}$

HPLC: Columna $C_{8} \quad t_{R}: 21,13 \mathrm{~min}$. 
(Z)-4-(4-metoxiestiril)-2,6-bis(metilsulfanil)piridina (146Z):

$\mathrm{RMN}^{1} \mathrm{H}\left(\mathrm{CDCl}_{3}\right) \delta(\mathrm{ppm})$ : (Espectro 146ZH) 2,49 (6H, s, SCH$) ; 3,79\left(3 \mathrm{H}, \mathrm{s}, \mathrm{OCH}_{3}\right)$; $6,25(1 \mathrm{H}, \mathrm{d}, \mathrm{J}=12 ; \mathrm{CH}) ; 6,65(1 \mathrm{H}, \mathrm{d}, \mathrm{J}=12 ; \mathrm{CH}) ; 6,73(2 \mathrm{H}, \mathrm{s}, \mathrm{pyr}) ; 6,78(2 \mathrm{H}, \mathrm{d}, \mathrm{J}=8,2$; $\operatorname{Ar}) ; 7,16(2 \mathrm{H}, \mathrm{d}, \mathrm{J}=8,2 ; \mathrm{Ar})$.

$\mathrm{RMN}{ }^{13} \mathrm{C}\left(\mathrm{CDCl}_{3}\right) \delta(\mathrm{ppm})$ : (Espectro 146ZC) 13,3 $\left(2 \mathrm{xCH}_{3}\right) ; 55,3\left(\mathrm{CH}_{3}\right) ; 113,8(2 \times \mathrm{CH})$; $116,3(2 \times C H) ; 125,5(\mathrm{CH}) ; 128,4(\mathrm{C}) ; 130,3(2 \times C H) ; 132,8(\mathrm{C}) ; 133,6(\mathrm{CH}) ; 145,5(\mathrm{C})$; $159,4(2 \times C)$.

IR (KBr): 1427, 1457, 1512, 1566, $1604 \mathrm{~cm}^{-1}$

HRMS: Calculado $(\mathrm{M}+\mathrm{H}) 304,0830$. Obtenido $\left(\mathrm{C}_{16} \mathrm{H}_{18} \mathrm{NOS}_{2}\right) 304,0823$.

HPLC: Columna $C_{8} \quad t_{R}: 21,15$ min. 


\section{Obtención de 5-(2,6-bis(metilsulfanil)piridin-4-il)vinil)-1-metil-1H-indol}<smiles>CSc1cc(C[Pb])cc(SC)n1</smiles>

Se prepara una suspensión de $139 \mathrm{mg}(0,26 \mathrm{mmol})$ de bromuro de $(2,6-$ bis(metilsulfanil)piridin-4-il)metiltrifenilfosfonio (10) en THF seco $(10-20 \mathrm{~mL})$ y se añade $0,4 \mathrm{~mL}(0,64 \mathrm{mmol})$ de una disolución 1,6 M de $n$ BuLi en hexano, siguiendo el método B. Una hora después se añade $252 \mathrm{mg}(1,58 \mathrm{mmol})$ de 1-metil-1H-indol-5calbaldehído (15) disuelto en THF seco (5-10 mL). Se cromatografía en columna sobre gel de sílice utilizando como eluyente Hexano/EtOAc (98:2), obteniendo 11,6 mg (0,04 mmol; 14\%) de (Z)-5-(2,6-bis(metilsulfanil)piridin-4-il)vinil)-1-metil-1H-indol y 22 mg $(0,07 \mathrm{mmol} ; 26 \%)$ de mezcla de $Z$ y $E$ en proporción $1: 1$.

\section{(Z)-5-(2,6-bis(metilsulfanil)piridin-4-il)vinil)-1-metil-1H-indol (147Z):}

RMN ${ }^{1} \mathrm{H}\left(\mathrm{CDCl}_{3}\right) \delta(\mathrm{ppm})$ : (Espectro $\left.147 \mathrm{ZH}\right) 2,45\left(6 \mathrm{H}, \mathrm{s}, \mathrm{SCH}_{3}\right) ; 3,77\left(3 \mathrm{H}, \mathrm{s}, \mathrm{NCH}_{3}\right)$; $6,26(1 \mathrm{H}, \mathrm{d}, \mathrm{J}=12 ; \mathrm{CH}) ; 6,43\left(1 \mathrm{H}, \mathrm{d}, \mathrm{J}=3,2 ; \mathrm{H}_{3}\right) ; 6,78(2 \mathrm{H}, \mathrm{s}, \mathrm{pyr}) ; 6,86(1 \mathrm{H}, \mathrm{d}, \mathrm{J}=12$; $\mathrm{CH}) ; 7,03\left(1 \mathrm{H}, \mathrm{d}, \mathrm{J}=3,2 ; \mathrm{H}_{2}\right) ; 7,12\left(1 \mathrm{H}, \mathrm{da}, \mathrm{J}=8,6 ; \mathrm{H}_{7}\right) ; 7,12\left(1 \mathrm{H}, \mathrm{da}, \mathrm{J}=8,6 ; \mathrm{H}_{6}\right) ; 7,52$ $\left(1 \mathrm{H}, \mathrm{s} ; \mathrm{H}_{4}\right)$.

$\mathrm{RMN}{ }^{13} \mathrm{C}\left(\mathrm{CDCl}_{3}\right) \delta$ (ppm): (Espectro 147ZC) 13,4 (2xCH$) ; 33,1\left(\mathrm{CH}_{3}\right) ; 101,7(\mathrm{CH})$; 109,7 (CH); 114,0 (2xCH); 120,5 (CH); 120,8 (CH); 122,5 (CH); 124,7 (C); 127,8 (C); 128,8 (C); 129,8 (CH); 134,9 (CH); 145,5 (C); 159,3 (2xC).

IR (película): 1422, 1488, 1521, 1571, 1608, $1626 \mathrm{~cm}^{-1}$

HRMS: Calculado $(\mathrm{M}+\mathrm{H}) 327,0990$. Obtenido $\left(\mathrm{C}_{18} \mathrm{H}_{19} \mathrm{~N}_{2} \mathrm{~S}_{2}\right) 327,1001$.

HPLC: Columna $C_{18} \quad t_{R}: 24,57$ min; $t_{R}: 25,72$ min. 


\section{Obtención de 2-metoxi-4-(4-metoxiestiril)-6-(metilsulfanil)piridina}

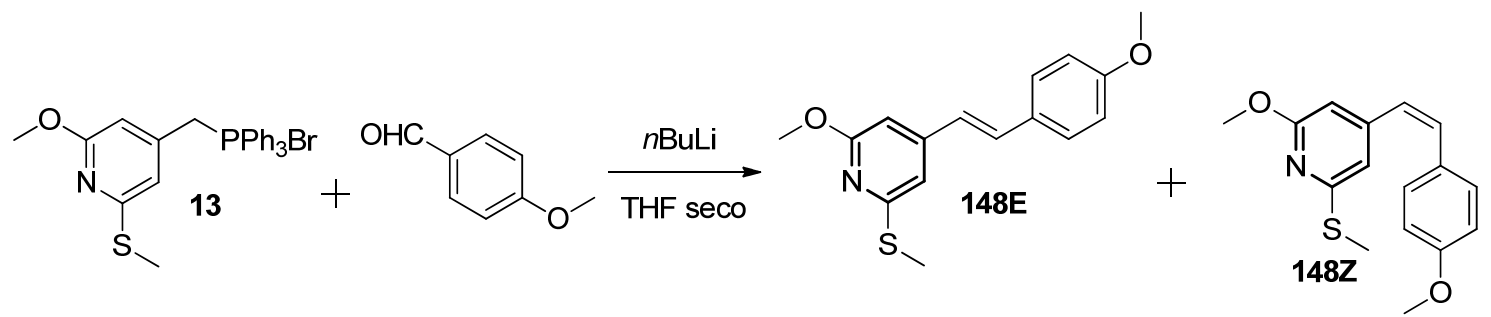

Se prepara una suspensión de $191 \mathrm{mg}(0,37 \mathrm{mmol})$ de bromuro de (2metilsulfanil-6-metoxipiridin-4-il)metiltrifenilfosfonio (13) en THF seco $(10-20 \mathrm{~mL})$ y se añade $0,25 \mathrm{~mL}(0,40 \mathrm{mmol})$ de una disolución $1,6 \mathrm{M}$ de $n \mathrm{BuLi}$ en hexano, siguiendo el método $B$. Una hora después se añade $0,19 \mathrm{~mL}(1,52 \mathrm{mmol})$ de 4metoxibenzaldehído disuelto en THF seco $(5-10 \mathrm{~mL})$. Mediante cromatografía flash utilizando como eluyente Hexano/EtOAc (99:1), se obtienen $11 \mathrm{mg}(0,04 \mathrm{mmol} ; 10 \%)$ de (Z)-2-metoxi-4-(4-metoxiestiril)-6-(metilsulfanil)piridina y $43 \mathrm{mg}(0,15 \mathrm{mmol} ; 40 \%) \mathrm{de}$ una mezcla de $Z$ y $E$ aproximadamente al $50 \%$.

\section{(Z)-2-metoxi-4-(4-metoxiestiril)-6-(metilsulfanil)piridina (148Z):}

$\mathrm{RMN}^{1} \mathrm{H}\left(\mathrm{CDCl}_{3}\right) \delta$ (ppm): (Espectro 148ZH) 2,45 (3H, s, $\left.\mathrm{SCH}_{3}\right) ; 3,79\left(3 \mathrm{H}, \mathrm{s}, \mathrm{NCH}_{3}\right)$; $3,89\left(3 \mathrm{H}, \mathrm{s}, \mathrm{OCH}_{3}\right), 6,28(1 \mathrm{H}, \mathrm{d}, \mathrm{J}=12 ; \mathrm{CH}) ; 6,29(1 \mathrm{H}, \mathrm{s}, \mathrm{pyr}) ; 6,62(1 \mathrm{H}, \mathrm{d}, \mathrm{J}=12 ; \mathrm{CH})$; 6,63 (1H, s, pyr); 6,77 (2H, d, J=8,9; Ar); 7,17 (2H, d, J=8,9; Ar).

HPLC: Columna $\mathrm{C}_{8} \quad \mathrm{t}_{\mathrm{R}}: 20,74 \mathrm{~min}$.

(ZE)-2-metoxi-4-(4-metoxiestiril)-6-(metilsulfanil)piridina (148ZE):

RMN ${ }^{13} \mathrm{C}\left(\mathrm{CDCl}_{3}\right) \delta(\mathrm{ppm})$ : (Espectro 148ZEC) 13,4 $\left(\mathrm{CH}_{3}\right) ; 53,5\left(\mathrm{CH}_{3}\right) ; 55,4\left(\mathrm{CH}_{3}\right)$; 102,6 $(\mathrm{CH}) ; 105,0(\mathrm{CH}) ; 111,0(\mathrm{CH}) ; 113,4(\mathrm{CH}) ; 113,8(2 \times \mathrm{CH}) ; 114,3(2 \times \mathrm{CH}) ; 123,8$ $(\mathrm{CH}) ; 125,9(\mathrm{CH}) ; 128,4(2 \times \mathrm{CH}) ; 129,0(\mathrm{C}) ; 130,3(2 \times \mathrm{CH}) ; 132,5(\mathrm{CH}) ; 133,2(\mathrm{CH}) ;$ 148,0 (C); 148,5 (C); 157,4 (C); 159,2 (C); 160,1 (C); 164,4 (C).

IR (película): 1453, 1515, 1538, $1587 \mathrm{~cm}^{-1}$

HRMS: Calculado (M+Na) 310,0878. Obtenido $\left(\mathrm{C}_{16} \mathrm{H}_{17} \mathrm{NNaO}_{2} \mathrm{~S}\right) 310,0874$. 
Obtención de 5-(2-(2-metilsulfanil-6-metoxipiridin-4-il)vinil)-1-metil-1Hindol<smiles>COc1cc(C[Pb])cc(SC)n1</smiles>

Sobre una suspensión de $169 \mathrm{mg}(0,33 \mathrm{mmol})$ de bromuro de (2-metilsulfanil-6metoxipiridin-4-il)metiltrifenilfosfonio (13) en THF seco (10-20 mL), se añade $0,2 \mathrm{~mL}$ $(0,36 \mathrm{mmol})$ de una disolución $1,6 \mathrm{M}$ de $n \mathrm{BuLi}$ en hexano, siguiendo el método $\mathrm{B}$. Una hora después se añade $211 \mathrm{mg}(1,33 \mathrm{mmol})$ de 1-metil-1H-indol-5-calbaldehído (15) disuelto en THF seco (5-10 mL). Se cromatografía en columna sobre gel de sílice utilizando como eluyente Hexano/EtOAc (98:2). Se obtienen 4,5 mg (0,01 mmol; 4\%) de (Z)-5-(2-(2-metilsulfanil-6-metoxipiridin-4-il)vinil)-1-metil-1H-indol; y $17 \mathrm{mg} \quad(0,05$ mmol; $16 \%$ ) de una mezcla de $Z$ y $E$ aproximadamente al $50 \%$.

\section{(Z)-5-(2-(2-metilsulfanil-6-metoxipiridin-4-il)vinil)-1-metil-1H-indol (149Z):}

$\mathrm{RMN}^{1} \mathrm{H}\left(\mathrm{CDCl}_{3}\right) \delta$ (ppm): (Espectro 149ZH) 2,41 (3H, s, $\left.\mathrm{SCH}_{3}\right) ; 3,77\left(3 \mathrm{H}, \mathrm{s}, \mathrm{NCH}_{3}\right)$; $3,87\left(3 \mathrm{H}, \mathrm{s}, \mathrm{OCH}_{3}\right) ; 6,30(1 \mathrm{H}, \mathrm{d}, \mathrm{J}=12 ; \mathrm{CH}) ; 6,41\left(1 \mathrm{H}, \mathrm{d}, \mathrm{J}=3,2 ; \mathrm{H}_{3}\right) ; 6,69(1 \mathrm{H}, \mathrm{s}, \mathrm{pyr}) ;$ $6,78(1 \mathrm{H}, \mathrm{s}, \mathrm{pyr}) ; 6,84(1 \mathrm{H}, \mathrm{d}, \mathrm{J}=12 ; \mathrm{CH}) ; 7,02\left(1 \mathrm{H}, \mathrm{d}, \mathrm{J}=3,2 ; \mathrm{H}_{2}\right) ; 7,15(1 \mathrm{H}, \mathrm{d}, \mathrm{J}=8,6$; $\left.\mathrm{H}_{7}\right) ; 7,17\left(1 \mathrm{H}, \mathrm{d}, \mathrm{J}=8,6 ; \mathrm{H}_{6}\right) ; 7,53\left(1 \mathrm{H}, \mathrm{s} ; \mathrm{H}_{4}\right)$.

HPLC: Columna $\mathrm{C}_{18} \mathrm{t}_{\mathrm{R}}: 24,04 \mathrm{~min}$.

(ZE)-5-(2-(2-metilsulfanil-6-metoxipiridin-4-il)vinil)-1-metil-1H-indol (149ZE):

RMN ${ }^{13} \mathrm{C}\left(\mathrm{CDCl}_{3}\right) \delta$ (ppm): (Espectro 149ZEC) 13,3 $\left(\mathrm{CH}_{3}\right) ; 32,0\left(\mathrm{CH}_{3}\right) ; 53,4\left(\mathrm{CH}_{3}\right)$; 101,4 (CH); 101,6 (CH); 102,4 (CH); 103,5 (CH); 105,1 (CH); 108,9 (CH); 109,5 (CH); $111,0(\mathrm{CH}) ; 111,81(\mathrm{CH}) ; 113,5(\mathrm{CH}) ; 120,4(\mathrm{CH}) ; 120,6(\mathrm{CH}) ; 121,7(\mathrm{CH}) ; 122,7(\mathrm{CH}) ;$ $122,9(\mathrm{CH}) ; 125,0(\mathrm{CH}) ; 127,3(\mathrm{C}) ; 127,8(\mathrm{C}) ; 128,7(\mathrm{C}) ; 129,3(\mathrm{CH}) ; 129,6(\mathrm{CH}) ; 134,4$ $(\mathrm{CH}) ; 135,1(\mathrm{CH}) ; 148,4(\mathrm{C}) ; 164,0(\mathrm{C}) ; 164,3(\mathrm{C})$.

IR (película): 1451, 1488, 1541, $1587 \mathrm{~cm}^{-1}$

HRMS: Calculado $(\mathrm{M}+\mathrm{H}) 311,1218$. Obtenido $\left(\mathrm{C}_{18} \mathrm{H}_{19} \mathrm{~N}_{2} \mathrm{OS}\right) 311,1206$. 


\section{D.5.1. SÍNTESIS DE OXADIAZOLINAS}

Obtención de 1-(2-(4-(dimetilamino)fenil)-5-(2-metilsulfanil-6-metoxipiridin4-il)-1,3,4-oxadiazol-3(2H)-il)etanona<smiles>COc1cc(C(=O)N/N=C/c2ccc(N(C)C)cc2)cc(SC)n1</smiles>

Siguiendo el método D, se disuelven $232 \mathrm{mg}(0,67 \mathrm{mmol})$ de $N^{\prime}-(4-$ (dimetilamino)benciliden)-2-metilsulfanil-6-metoxipiridinahidrazida (22) en $4 \mathrm{~mL}$ de anhídrido acético. Mediante cromatografía flash utilizando como eluyente Hexano/EtOAc (9:1), se obtienen $82 \mathrm{mg} \quad(0,21 \mathrm{mmol} ; 32 \%)$ de 1-(2-(4(dimetilamino)fenil)-5-(2-metilsulfanil-6-metoxipiridin-4-il)-1,3,4-oxadiazol-3(2H)il)etanona.

1-(2-(4-(dimetilamino)fenil)-5-(2-metilsulfanil-6-metoxipiridin-4-il)-1,3,4-oxadiazol$3(2 H)$-il)etanona (150):

$\mathrm{RMN}{ }^{1} \mathrm{H}\left(\mathrm{CDCl}_{3}\right) \delta(\mathrm{ppm})$ : (Espectro $\left.150 \mathrm{H}\right)$ 2,34 (3H, s, $\left.\mathrm{CH}_{3} \mathrm{CO}\right) ; 2,57\left(3 \mathrm{H}, \mathrm{s}, \mathrm{SCH}_{3}\right)$; 2,96 (6H, s, NMe $)$; 3,97 (3H, s, OCH $) ; 6,69(2 \mathrm{H}, \mathrm{d}, \mathrm{J}=8,6 ; \mathrm{Ar}) ; 6,82(1 \mathrm{H}, \mathrm{d}, \mathrm{J}=0,7$; pyr); 7,00 (1H, s, CH); 7,20 (1H, d, J=0,7; pyr); 7,29 (2H, d, J=8,6; Ar).

RMN ${ }^{13} \mathrm{C}\left(\mathrm{CDCl}_{3}\right) \delta$ (ppm): (Espectro 150C) 13,4 $\left(\mathrm{CH}_{3}\right) ; 21,6\left(\mathrm{CH}_{3}\right) ; 40,4\left(2 \mathrm{xCH}_{3}\right) ; 53,9$ $\left(\mathrm{CH}_{3}\right) ; 93,6(\mathrm{CH}) ; 102,8(\mathrm{CH}) ; 110,5(\mathrm{CH}) ; 112,2(2 \times \mathrm{CH}) ; 123,2(\mathrm{C}) ; 127,7(2 \times \mathrm{CH})$; 135,1 (C); 151,6 (C); 153,8 (C); 158,8 (C); 164,1 (C); 167,8 (C).

IR (película): 1452, 1550, $1603 \mathrm{~cm}^{-1}$

HRMS: Calculado (M+Na) 409,1310. Obtenido $\left(\mathrm{C}_{19} \mathrm{H}_{22} \mathrm{~N}_{4} \mathrm{NaO}_{3} \mathrm{~S}\right) 409,1320$.

HPLC: Columna $\mathrm{C}_{8} \quad \mathrm{t}_{\mathrm{R}}: 4,032 \mathrm{~min}$. 
Obtención de 1-(5-(2-metilsulfanil-6-metoxipiridin-4-il)-2-(metoxifenil)-

\section{1,3,4-oxadiazol-3(2H)-il)etanona}<smiles>COc1ccc(/C=N/NC(=O)c2cc(OC)nc(SC)c2)cc1</smiles>

Siguiendo el método $D$, se disuelven $109 \mathrm{mg}(0,33 \mathrm{mmol})$ de 2-metoxi- $\mathrm{N}^{\prime}$-(4metoxibenciliden)-6-(metilsulfanil)piridinahidrazida (23) en $2 \mathrm{~mL}$ de anhídrido acético. Se purifica mediante cromatografía flash, utilizando como eluyente Hexano/EtOAc (9:1) y se obtienen $118 \mathrm{mg}(0,32 \mathrm{mmol} ; 96 \%)$ de 1-(5-(2-metilsulfanil-6-metoxipiridin-4il)-2-(metoxifenil)-1,3,4-oxadiazol-3(2H)-il)etanona.

\section{1-(5-(2-metilsulfanil-6-metoxipiridin-4-il)-2-(metoxifenil)-1,3,4-oxadiazol-3(2H)- il)etanona (151):}

$\mathrm{RMN}^{1} \mathrm{H}\left(\mathrm{CDCl}_{3}\right) \delta$ (ppm): (Espectro 151H) 2,34 (3H, s, $\left.\mathrm{CH}_{3} \mathrm{CO}\right) ; 2,57\left(3 \mathrm{H}, \mathrm{s}, \mathrm{SCH}_{3}\right)$; $3,79\left(3 \mathrm{H}, \mathrm{s}, \mathrm{OCH}_{3}\right) ; 3,97\left(3 \mathrm{H}, \mathrm{s}, \mathrm{OCH}_{3}\right) ; 6,81(1 \mathrm{H}, \mathrm{d}, \mathrm{J}=1,1 ; \mathrm{pyr}) ; 6,90(2 \mathrm{H}, \mathrm{d}, \mathrm{J}=8,6$; $\operatorname{Ar}) ; 7,02(1 \mathrm{H}, \mathrm{s}, \mathrm{CH}) ; 7,19(1 \mathrm{H}, \mathrm{d}, \mathrm{J}=1,1 ; \mathrm{pyr}) ; 7,37$ (2H, d, J=8,6; Ar).

$\mathrm{RMN}{ }^{13} \mathrm{C}\left(\mathrm{CDCl}_{3}\right) \delta(\mathrm{ppm})$ : (Espectro 151C) 13,4 $\left(\mathrm{CH}_{3}\right) ; 21,5\left(\mathrm{CH}_{3}\right) ; 53,9\left(\mathrm{CH}_{3}\right) ; 55,4$ $\left(\mathrm{CH}_{3}\right) ; 93,0(\mathrm{CH}) ; 102,8(\mathrm{CH}) ; 110,4(\mathrm{CH}) ; 114,3(2 \times \mathrm{CH}) ; 128,1(2 \times \mathrm{CH}) ; 128,3(\mathrm{C})$; 134,9 (C); 153,8 (C); 158,9 (C); 160,9 (C); 164,1 (C); 167,9 (C).

$\mathrm{IR}(\mathrm{KBr}): 1458,1519,1551,1610,1665 \mathrm{~cm}^{-1}$

HRMS: Calculado (M+Na) 396,0994. Obtenido $\left(\mathrm{C}_{18} \mathrm{H}_{19} \mathrm{~N}_{3} \mathrm{NaO}_{4} \mathrm{~S}\right) 396,0987$.

HPLC: Columna $\mathrm{C}_{8} \quad \mathrm{t}_{\mathrm{R}}: 20,59 \mathrm{~min}$. 
Obtención de 1-(5-(2-metilsulfanil-6-metoxipiridin-4-il)-2-(1-metil-1H-indol5-il)-1,3,4-oxadiazol-3(2H)-il)etanona<smiles>COc1cc(C(C)=O)cc(C(=O)N/N=C/c2ccc3c(ccn3C)c2)c1</smiles>

Siguiendo el método $D$ se disuelven $259 \mathrm{mg}(0,73 \mathrm{mmol})$ de 2-metoxi- $\mathrm{N}^{\prime}-((1-$ metil-1H-indol-5-il)metileno)-6-(metilsulfanil)piridinahidrazida (24) en $4 \mathrm{~mL}$ de anhídrido acético. Se purifica mediante cromatografía flash, utilizando como eluyente Hexano/EtOAc (9:1) y se obtienen $133 \mathrm{mg} \mathrm{(0,34} \mathrm{mmol;} \mathrm{46 \% )} \mathrm{de} \mathrm{1-(5-(2-metilsulfanil-6-}$ metoxipiridin-4-il)-2-(1-metil-1H-indol-5-il)-1,3,4-oxadiazol-3(2H)-il)etanona.

1-(5-(2-metilsulfanil-6-metoxipiridin-4-il)-2-(1-metil-1H-indol-5-il)-1,3,4-oxadiazol$3(2 H)$-il)etanona (152):

$\mathrm{RMN}^{1} \mathrm{H}\left(\mathrm{CDCl}_{3}\right) \delta$ (ppm): (Espectro 152H) 2,38 (3H, s, $\left.\mathrm{CH}_{3} \mathrm{CO}\right) ; 2,58\left(3 \mathrm{H}, \mathrm{s}, \mathrm{SCH}_{3}\right)$; $3,76\left(3 \mathrm{H}, \mathrm{s}, \mathrm{NCH}_{3}\right) ; 3,97\left(3 \mathrm{H}, \mathrm{s}, \mathrm{OCH}_{3}\right) ; 6,49\left(1 \mathrm{H}, \mathrm{d}, \mathrm{J}=3,2, \mathrm{H}_{3}\right) ; 6,85(1 \mathrm{H}, \mathrm{s} ; \mathrm{pyr}) ; 7,07$ $\left(1 \mathrm{H}, \mathrm{d}, \mathrm{J}=3,2, \mathrm{H}_{2}\right) ; 7,19(1 \mathrm{H}, \mathrm{s}, \mathrm{CH}) ; 7,23(1 \mathrm{H}, \mathrm{s} ; \mathrm{pyr}) ; 7,30\left(1 \mathrm{H}, \mathrm{d}, \mathrm{H}_{7}\right) ; 7,30(1 \mathrm{H}, \mathrm{d}$, $\left.\mathrm{H}_{6}\right) ; 7,72\left(1 \mathrm{H}, \mathrm{s} ; \mathrm{H}_{4}\right)$.

RMN ${ }^{13} \mathrm{C}\left(\mathrm{CDCl}_{3}\right) \delta(\mathrm{ppm})$ : (Espectro 152C) 13,4 $\left(\mathrm{CH}_{3}\right) ; 21,6\left(\mathrm{CH}_{3}\right) ; 32,9\left(\mathrm{CH}_{3}\right) ; 53,9$ $\left(\mathrm{CH}_{3}\right) ; 94,3(\mathrm{CH}) ; 101,7(\mathrm{CH}) ; 102,8(\mathrm{CH}) ; 109,8(\mathrm{CH}) ; 110,5(\mathrm{CH}) ; 119,8(2 \times \mathrm{CH})$; 127,1 (C); 128,4 (C); 130,0 (CH); 135,1 (C); 137,6 (C); 153,8 (C); 158,9 (C); 164,1 (C); $167,8(C)$.

IR (película): 1456, 1549, 1596, 1625, $1672 \mathrm{~cm}^{-1}$

HRMS: Calculado (M+Na) 419,1154. Obtenido $\left(\mathrm{C}_{20} \mathrm{H}_{20} \mathrm{~N}_{4} \mathrm{NaO}_{3} \mathrm{~S}\right) 419,1160$.

HPLC: Columna $\mathrm{C}_{8} \quad \mathrm{t}_{\mathrm{R}}: 21,04 \mathrm{~min}$.

Columna $\mathrm{C}_{18} \mathrm{t}_{\mathrm{R}}: 22,60 \mathrm{~min}$. 


\section{D.6. ACTIVIDAD BIOLÓGICA}

\section{D.6.1. ENSAYOS DE INHIBICIÓN DE POLIMERIZACIÓN DE TUBULINA}

El procedimiento experimental seguido en la realización de los ensayos de inhibición de polimerización de tubulina se puede dividir en tres apartados:

- Aislamiento de la proteína microtubular a partir de cerebros de ternero.

- Ensayos de inhibición de polimerización de tubulina, en el cual se hace un cribado con el fin de seleccionar los compuestos que den mejores resultados.

- Determinación de la $\mathbf{I C}_{50}$, de los compuestos seleccionados en el apartado anterior.

\section{D.6.1.1. AISLAMIENTO DE LA PROTEÍNA MICROTUBULAR}

El aislamiento de la proteína se lleva a cabo utilizando el método de Shelanski ${ }^{62}$ con modificaciones, mediante dos ciclos de polimerización/despolimerización a $37^{\circ} \mathrm{C}$ y $0{ }^{\circ} \mathrm{C}$ respectivamente, tal y como se describe a continuación.

Se parte de 4 cerebros de ternero recién sacrificados, se enfrían a $0{ }^{\circ} \mathrm{C}$ en un tampón de transporte (que contiene sacarosa y EDTA) y se llevan a una cámara fría donde se eliminan manualmente las meninges y los coágulos. La parte superficial del córtex se corta tomando la sustancia gris y evitando, en lo posible, coger la sustancia blanca. Se obtienen aproximadamente 300 gramos de tejido.

\footnotetext{
${ }^{62}$ Shelanski, M. L.; Gaskin, F.; Cantor, C. R. Microtubule assembly in the absence of added nucleotides. Proc. Nat. Acad. Sci. 1973, 70, 765-768.
} 
Por cada gramo de córtex obtenido se añade $1 \mathrm{~mL}$ de tampón de extracción (que contiene sacarosa y EGTA). A continuación se homogeniza en varias etapas con un homogeneizador potter. Del homogenizado obtenido se utilizan unos $400 \mathrm{~mL}$ que tienen un aspecto rosa uniforme, y se centrifugan a $4^{\circ} \mathrm{C}$ y $31000 \mathrm{rpm}$ durante una hora.

Al sobrenadante, $240 \mathrm{~mL}$ aproximadamente, se añade tampón 10XAB (1/10 del volumen del sobrenadante), glicerol (hasta concentración 3,5 M), GTP (hasta concentración 0,5 M) y PMSF (hasta concentración $1 \mathrm{mM}$ ). Los $335 \mathrm{~mL}$ (aproximadamente) resultantes se incuban a $37^{\circ} \mathrm{C}$ durante 45 minutos y después se somete a centrifugación a $37^{\circ} \mathrm{C}$ durante 90 minutos a $31000 \mathrm{rpm}$.

El precipitado obtenido (primer ciclo de proteína polimerizada) se resuspende en $12 \mathrm{~mL}$ de tampón 1 XAB y $1 \mathrm{mM}$ GTP y se homogeniza la muestra. La suspensión se enfría en hielo durante 30 minutos, y posteriormente se centrifuga a $32000 \mathrm{rpm}$ durante 30 minutos a $4{ }^{\circ} \mathrm{C}$. Al sobrenadante obtenido (primer ciclo de polimerización/despolimerización de tubulina), se le añade GTP (hasta 0,5 mM) y PMSF (hasta $1 \mathrm{mM}$ ) y la mezcla se incuba a $37{ }^{\circ} \mathrm{C}$ durante 30 minutos. Después se centrifuga a $32000 \mathrm{rpm}$ durante 45 minutos y a $37^{\circ} \mathrm{C}$. Se recoge el precipitado y se enfría en hielo durante 5 minutos (segunda polimerización). El precipitado se resuspende con $2 \mathrm{~mL}$ de tampón 1 XAB y $10 \mu \mathrm{l}$ de GTP $(0,5 \mathrm{mM})$.

Las muestras se alicuotan en volúmenes de $250 \mu$ (obteniendo un volumen total entre 2,5 y $3,0 \mathrm{~mL}$ ), y se almacenan a $-80^{\circ} \mathrm{C}$, previa congelación rápida con nitrógeno líquido, hasta su posterior uso.

El rendimiento promedio de cada purificación (utilizando como material de partida $300 \mathrm{~g}$ de tejido) fue de 0,3-0,5 $\mathrm{mg}$ de proteína microtubular (MTP) por gramo de tejido. 


\section{D.6.1.2. ENSAYO DE INHIBICIÓN DE POLIMERIZACIÓN DE TUBULINA}

Las alícuotas de proteína microtubular (MTP) se descongelan rápidamente en un baño de agua a $20^{\circ} \mathrm{C}$ y se resuspenden en $1 \mathrm{~mL}$ de tampón $1 \mathrm{XAB}$ por alícuota. Se somete la suspensión a agitación magnética cuidadosamente en hielo durante 30 minutos, se centrifuga 30 minutos a $4{ }^{\circ} \mathrm{C}$ y $50000 \mathrm{rpm}$ (segundo ciclo completo de polimerización/despolimerización). Se recoge el sobrenadante y se realiza el ensayo de Bradford para determinar la concentración de proteína total. El valor de concentración medio por preparación es de $4,0 \mathrm{mg} / \mathrm{mL}$. Para esta concentración de proteína, se toman $125 \mu \mathrm{l}$ de MTP (para una concentración de proteína de 1,0 mg/mL), 1,25 $\mu \mathrm{l}$ de disolución $2 \mathrm{mM}$ de los ligandos en DMSO (para una concentración de compuesto $5 \mu \mathrm{M}$ ), 18,75 $\mu \mathrm{l}$ de DMSO y $355 \mu \mathrm{l}$ de tampón (1XAB y 1,5 mM GTP), hasta completar los $500 \mu \mathrm{l}$ de volumen final.

Las muestras se incuban a $20^{\circ} \mathrm{C}$ durante 30 minutos, permitiendo la interacción de los ligandos con la proteína microtubular. A continuación, se enfrían en un baño de hielo durante 10 minutos y se introducen en el espectrofotómetro. Tras un periodo de estabilización a $4{ }^{\circ} \mathrm{C}$ durante aproximadamente 10 minutos, la temperatura se eleva a $37{ }^{\circ} \mathrm{C}$ registrándose la absorbancia a $450 \mathrm{~nm}$ durante todo el proceso. Cuando la absorbancia se estabiliza, cerca de los 45 minutos, se vuelve a cambiar la temperatura a $4{ }^{\circ} \mathrm{C}$ y la absorbancia vuelve a disminuir. 


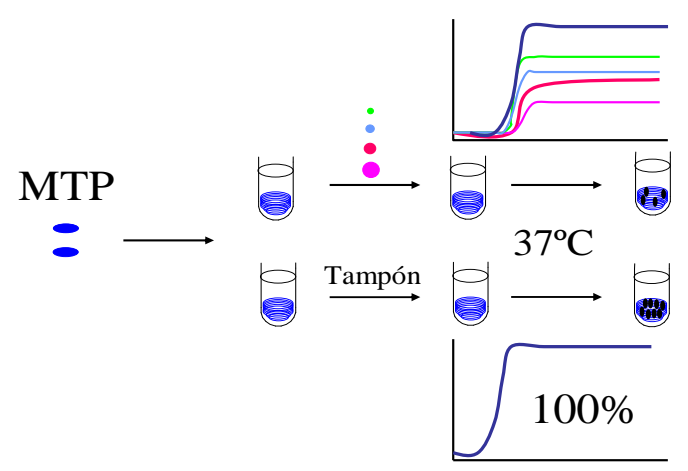

Figura 67. Esquema de ensayo de inhibición de polimerización de tubulina. Cada cubeta contiene proteína microtubular en tampón a concentración de $1 \mathrm{mg} / \mathrm{mL}$, y DMSO (4\%). En cada cubeta se añade el compuesto que se quiere ensayar, a la concentración elegida, exceptuando la cubeta de referencia. A continuación, se aumenta la temperatura $\left(37^{\circ} \mathrm{C}\right)$ y se mide la turbidez generada. La diferencia entre la absorbancia presentada por la muestra de referencia (línea azul oscura, valor considerado como el 100\% de polimerización) y cada una de las muestras que contienen compuesto (resto de líneas de colores) se corresponde con la inhibición que ejerce ese compuesto (\%) a la concentración ensayada.

Inicialmente, la mayoría de los compuestos se prueban a una concentración 5 $\mu \mathrm{M}$ y posteriormente, aquellos que se ha visto que inhiben (más de un $45 \%$ ) la polimerización de tubulina se ensayan a diversas concentraciones a partir de las cuales se puede calcular el valor de $\mathrm{IC}_{50}$.

En la tabla siguiente se resumen los ensayos de inhibición de polimerización de tubulina y se indica la concentración probada y el porcentaje de inhibición producida. Todos los resultados son para una concentración final de proteína de $1 \mathrm{mg} / \mathrm{mL}$. 


\begin{tabular}{|c|c|c|c|c|c|c|c|c|}
\hline COMP & $\begin{array}{l}\text { CONC } \\
(\mu \mathrm{M})\end{array}$ & \% INHIB & COMP & $\begin{array}{l}\text { CONC } \\
(\mu \mathrm{M})\end{array}$ & $\begin{array}{c}\% \\
\text { INHIB }\end{array}$ & COMP & $\begin{array}{l}\text { CONC } \\
(\mu \mathrm{M})\end{array}$ & $\begin{array}{c}\% \\
\text { INHIB }\end{array}$ \\
\hline 25 & 5 & 0 & 65 & 5 & 44 & 115 & 5 & 89 \\
\hline 26 & 5 & 25 & 68 & 5 & 63 & 117 & 5 & 75 \\
\hline 27 & 5 & 31 & 70 & 5 & 92 & 118 & 6 & 26 \\
\hline 28 & 5 & 0 & 71 & 5 & 63 & 119 & 5 & 45 \\
\hline 29 & 5 & 22 & 72 & 5 & 79 & 120 & 6 & 41 \\
\hline 30 & 5 & 22 & 73 & 5 & 100 & 121 & 5 & 91 \\
\hline 31 & 5 & 0 & 74 & 5 & 0 & 123 & 5 & 86 \\
\hline 32 & 20 & 56 & 75 & 5 & 14 & 124 & 5 & 33 \\
\hline 34 & 5 & 74 & 76 & 5 & 100 & 125 & 5 & 0 \\
\hline 36 & 5 & 11 & 77 & 5 & 33 & 126 & 10 & 27 \\
\hline 37 & 5 & 40 & 80 & 5 & 92 & 127 & 20 & 0 \\
\hline 38 & 6 & 21 & 82 & 5 & 90 & 128 & 10 & 18 \\
\hline 39 & 5 & 39 & 83 & 5 & 87 & 129 & 10 & 4 \\
\hline 40 & 5 & 100 & 84 & 5 & 7 & 130 & 10 & 0 \\
\hline 41 & 5 & 83 & 85 & 5 & 31 & 131 & 10 & 18 \\
\hline 42 & 5 & 34 & 86 & 5 & 100 & 132 & 20 & 4 \\
\hline 43 & 5 & 100 & 87 & 5 & 0 & 133 & 10 & 26 \\
\hline 44 & 5 & 35 & 88 & 5 & 30 & 134 & 5 & 20 \\
\hline 45 & 5 & 39 & 89 & 5 & 80 & 135 & 5 & 0 \\
\hline 46 & 5 & 86 & 93 & 5 & 76 & 136 & 5 & 9 \\
\hline 47 & 5 & 80 & 94 & 5 & 58 & 137 & 5 & 11 \\
\hline 48 & 5 & 6 & 95 & 5 & 44 & 139 & 5 & 11 \\
\hline 49 & 5 & 21 & 96 & 5 & 100 & 140 & 5 & 0 \\
\hline 50 & 5 & 48 & 97 & 5 & 49 & 141 & 5 & 20 \\
\hline 51 & 5 & 89 & 98 & 5 & 13 & 142 & 5 & 89 \\
\hline 52 & 5 & 1 & 99 & 5 & 95 & 143 & 5 & 95 \\
\hline 53 & 5 & 0 & 100 & 5 & 95 & 144 & 5 & 0 \\
\hline 54 & 4 & 100 & 102 & 5 & 82 & 145 & 5 & 3 \\
\hline 55 & 6 & 18 & 103 & 5 & 79 & $146 z$ & 5 & 70 \\
\hline 56 & 5 & 97 & 104 & 5 & 94 & $146 \mathrm{e}$ & 5 & 24 \\
\hline 57 & 5 & 32 & 105 & 5 & 100 & $147 z$ & 5 & 43 \\
\hline 58 & 5 & 2 & 106 & 5 & 27 & $148 z$ & 5 & 70 \\
\hline 59 & 5 & 98 & 107 & 5 & 0 & $149 z$ & 5 & 80 \\
\hline 60 & 5 & 2 & 108 & 5 & 7 & 150 & 10 & 4 \\
\hline 61 & 5 & 46 & 109 & 5 & 89 & 151 & 10 & 0 \\
\hline 62 & 5 & 11 & 110 & 5 & 100 & 152 & 10 & 8 \\
\hline 63 & 5 & 100 & 111 & 5 & 98 & & & \\
\hline 64 & 5 & 0 & 112 & 5 & 14 & & & \\
\hline
\end{tabular}

Tabla 20. Inhibición (\%) de los compuestos ensayados a 5, 6, 10 ó $20 \mu \mathrm{M}$. En negrita se resaltan aquellos compuestos que presentan un valor de IPT mayor del $45 \%$ para la concentración de prueba $(5 \mu \mathrm{M})$. 


\section{D.6.1.3. DETERMINACIÓN DE LA IC I $_{50}$ DE INHIBICIÓN DE POLIMERIZACIÓN DE TUBULINA}

La $I_{50}$ es la concentración a la cual el compuesto inhibe el $50 \%$ de la polimerización. La determinación se lleva a cabo realizando un ajuste a una exponencial con el programa Origin ${ }^{\circledR}$.

Los compuestos seleccionados para la determinación de la $\mathrm{IC}_{50}$ fueron aquellos que a una concentración de $5 \mu \mathrm{M}$ presentan una inhibición de la polimerización de la tubulina superior al $45 \%$ (marcados en negrita en la tabla).

El procedimiento seguido es exactamente igual al explicado anteriormente, pero se mide la inhibición de polimerización de tubulina a varias concentraciones de ligando (generalmente se utilizan al menos las concentraciones 5, 4, 2 y $1 \mu \mathrm{M}$, aunque varían en función del comportamiento de cada compuesto).

Los valores de $\mathrm{IC}_{50}$ de los compuestos seleccionados se muestran en la siguiente tabla: 


\begin{tabular}{cc|cc|cc} 
COMP & $\mathrm{IC}_{50}(\boldsymbol{\mu M})$ & $\mathbf{C O M P}$ & $\mathrm{IC}_{50}(\boldsymbol{\mu M})$ & $\mathbf{C O M P}$ & $\mathrm{IC}_{50}(\boldsymbol{\mu M})$ \\
\hline $\mathbf{3 4}$ & 2,5 & $\mathbf{7 2}$ & 2,4 & $\mathbf{1 0 4}$ & 2,4 \\
\hline $\mathbf{4 0}$ & 1,5 & $\mathbf{7 3}$ & 0,3 & $\mathbf{1 0 5}$ & 0,7 \\
\hline $\mathbf{4 1}$ & 4,6 & $\mathbf{7 6}$ & 1,6 & $\mathbf{1 0 9}$ & 2,4 \\
\hline $\mathbf{4 3}$ & 1,1 & $\mathbf{8 0}$ & 0,2 & $\mathbf{1 1 0}$ & 1,6 \\
\hline $\mathbf{4 6}$ & 2,0 & $\mathbf{8 2}$ & 0,6 & $\mathbf{1 1 1}$ & 3,2 \\
\hline $\mathbf{4 7}$ & 3,4 & $\mathbf{8 3}$ & 2,3 & $\mathbf{1 1 5}$ & 1,4 \\
\hline $\mathbf{5 0}$ & 4,1 & $\mathbf{8 6}$ & 1,6 & $\mathbf{1 1 7}$ & 1,0 \\
\hline $\mathbf{5 1}$ & 1,3 & $\mathbf{8 9}$ & 2,9 & $\mathbf{1 1 9}$ & 4,8 \\
\hline $\mathbf{5 4}$ & 0,9 & $\mathbf{9 3}$ & 2,9 & $\mathbf{1 2 1}$ & 1,9 \\
\hline $\mathbf{5 6}$ & 0,6 & $\mathbf{9 4}$ & 1,7 & $\mathbf{1 2 3}$ & 1,6 \\
\hline $\mathbf{5 9}$ & 1,4 & $\mathbf{9 6}$ & 1,1 & $\mathbf{1 4 2}$ & 3,8 \\
\hline $\mathbf{6 1}$ & 4,9 & $\mathbf{9 7}$ & 0,9 & $\mathbf{1 4 3}$ & 2,1 \\
\hline $\mathbf{6 3}$ & 0,9 & $\mathbf{9 9}$ & 1,2 & $\mathbf{1 4 6 z}$ & 3,8 \\
\hline $\mathbf{6 8}$ & 4 & $\mathbf{1 0 0}$ & 4,7 & $\mathbf{1 4 8 z}$ & 4,1 \\
\hline $\mathbf{7 0}$ & 2,5 & $\mathbf{1 0 2}$ & 0,4 & $\mathbf{1 4 9 z}$ & 1,0 \\
\hline $\mathbf{7 1}$ & 3,4 & $\mathbf{1 0 3}$ & 2,4 & & \\
& & & & &
\end{tabular}

Tabla 21. Valores de $I C_{50}$ de los compuestos seleccionados (aquellos que a una concentración $5 \mu \mathrm{M}$ presentan una inhibición de la polimerización de la tubulina superior al $45 \%$ ). 


\section{D.6.2. ENSAYOS DE CITOTOXICIDAD}

El procedimiento experimental seguido en la realización de los ensayos de citotoxicidad se puede dividir en tres apartados:

- Cultivo de células tumorales.

- Ensayos de citotoxidad, en el cual se hace un cribado con el fin de seleccionar los compuestos que den mejores resultados.

Determinación de $\mathbf{l a} \mathbf{I C}_{50}$, de los compuestos seleccionados en el apartado anterior.

\section{D.6.2.1. CULTIVO DE CÉLULAS TUMORALES}

Los ensayos de citotoxicidad se llevaron a cabo en las líneas celulares derivadas de carcinoma humano de cervix HeLa, de adenocarcinoma humano de colon HT29, todas ellas crecidas en monocapa adherente, y en la de leucemia promielocítica humana HL60 crecida en suspensión.

Las líneas celulares, conservadas a $-80^{\circ} \mathrm{C}$ en suero fetal bovino FBS con un $10 \%$ de DMSO, se descongelaron rápidamente por inmersión durante 1-2 minutos en baño a $37^{\circ} \mathrm{C}$, se lavan con medio de cultivo y posterior centrifugado durante 10 minutos a $1200 \mathrm{rpm}$ para eliminar el DMSO; seguidamente se crecen en estufa de $\mathrm{CO}_{2}$ a $37{ }^{\circ} \mathrm{C}$, con un $5 \%$ de $\mathrm{CO}_{2}$ y en ambiente húmedo. Los medios de cultivo utilizados fueron Dulbecco (DMEM) para la línea celular HeLa y RPMI para las restantes (HT29 y HL60), suplementados con glutamina (200 mM), penicilina-estreptomicina $(10000 \mathrm{u} / 100 \mathrm{ml}$ y $10 \mathrm{mg} / 100 \mathrm{ml})$ y suero fetal bovino $(10 \%)$. El mantenimiento de las líneas celulares se llevó a cabo por subcultivo a medio fresco de igual composición. 


\section{D.6.2.2. ENSAYOS DE CITOTOXIDAD}

El efecto ejercido por los distintos compuestos en el crecimiento celular se monitorizó con el test de viabilidad XTT. Para ello las líneas celulares HeLa y HT29 en crecimiento exponencial se sembraron en placas de titulación estériles de 96 pocillos de fondo plano a una densidad de $1,5 \times 10^{3}$ células por pocillo $(100 \mu \mathrm{l})$ las primeras y a $3,0 \times 10^{3}$ las segundas. Los cultivos se mantuvieron en las condiciones de cultivo arriba descritas durante $24 \mathrm{~h}$ para permitir que las células se adhirieran a las placas. Las células HL60 se sembraron a una densidad de $5,0 \times 10^{3}$ por pocillo en el momento de efectuar los ensayos de citotoxicidad.

Las células se incubaron en presencia de los diferentes compuestos a $37^{\circ} \mathrm{C}$ bajo una atmósfera de $\mathrm{CO}_{2}$ al $5 \%$ durante 72 horas. Las concentraciones ensayadas de los compuestos $\left(10^{-5}, 10^{-6}, 10^{-7}, 10^{-8}, 10^{-9} \mathrm{M}\right)$ se prepararon mediante diluciones seriadas $\mathrm{y}$ por triplicado a partir de una disolución del compuesto en agua estéril y DMSO, siendo la concentración de DMSO en cada pocillo de 0,15\%. La proliferación celular se cuantificó $^{63}$ por el kit de proliferación celular XTT (sal sódica de 2,3-bis(2-metoxi-4nitro-5-sulfofenil)-5-((fenilamino)-carbonil)-2 $\mathrm{H}$-tetrazolio) de acuerdo con las instrucciones del fabricante (Roche Molecular Biochemicals, Mannheim, Alemania). Se añade a cada pocillo $50 \mu \mathrm{l}$ de la mezcla de reacción XTT preparada fresca que contenía la sal anterior $(49 \mu \mathrm{l})$ y $1 \mu \mathrm{l}$ del agente acoplador de electrones $N$ metildibenzopirazina metil sulfato. Las placas se incubaron durante 4 horas adicionales en atmósfera húmeda $\left(37^{\circ} \mathrm{C}, 5 \%\right.$ de $\left.\mathrm{CO}_{2}\right)$ y la absorbancia del formazán generado en la reacción se midió en un lector de placas a $450 \mathrm{~nm}$ usando como longitud de onda de referencia $620 \mathrm{~nm}$.

Inicialmente se prueban todos los compuestos o ligandos a concentraciones de $10^{-5}, 10^{-6}, 10^{-7}, 10^{-8}, 10^{-9} \mathrm{M}$; y posteriormente, aquellos que se ha visto que inhiben el

\footnotetext{
${ }^{63}$ Scudiero, D. A., Shoemaker, R. H., Paull, K. D., Monks, A., Tierney, S., Nofziger, T. H., et al. Evaluation of a soluble tetrazolium/formazan assay for cell growth and drug sensitivity in culture using human and other tumor cell lines. Cancer Research, 1988, 48, 4827-4833.
} 
crecimiento a una concentración de $10^{-6} \mathrm{M}$, son seleccionados para repetir el ensayo con el fin de calcular el valor de $\mathrm{IC}_{50}$.

En la siguiente tabla se muestran los compuestos que no han sido seleccionados en ninguna de las líneas tumorales para el cálculo del valor de $\mathrm{IC}_{50}$.

\begin{tabular}{|c|c|c|c|c|c|c|c|}
\hline COMP & $\begin{array}{c}\mathrm{IC}_{50} \text { Hela } \\
\left(10^{-6} \mathrm{M}\right)\end{array}$ & $\begin{array}{c}\mathrm{IC}_{50} \mathrm{HL60} \\
\left(10^{-6} \mathrm{M}\right)\end{array}$ & $\begin{array}{c}\text { IC }_{50} \text { HT29 } \\
\left(10^{-6} \mathrm{M}\right)\end{array}$ & COMP & $\begin{array}{c}\mathrm{IC}_{50} \text { Hela } \\
\left(10^{-6} \mathrm{M}\right)\end{array}$ & $\begin{array}{c}\text { IC }_{50} \text { HL60 } \\
\left(10^{-6} \mathrm{M}\right)\end{array}$ & $\begin{array}{c}\mathrm{IC}_{50} \text { HT29 } \\
\left(10^{-6} \mathrm{M}\right)\end{array}$ \\
\hline 25 & $\geq 1$ & $\geq 1$ & $\geq 1$ & 95 & $\geq 1$ & $\geq 1$ & $\geq 1$ \\
\hline 27 & $\geq 1$ & $\geq 1$ & $\geq 1$ & 98 & $\geq 1$ & $\geq 1$ & $\geq 1$ \\
\hline 28 & $\geq 1$ & $\geq 1$ & $\geq 1$ & 100 & $\geq 1$ & $\geq 1$ & $\geq 1$ \\
\hline 29 & $\geq 1$ & $\geq 1$ & $\geq 1$ & 107 & $\geq 1$ & $\geq 1$ & $\geq 1$ \\
\hline 30 & $\geq 1$ & $\geq 1$ & $\geq 1$ & 120 & $\geq 1$ & $\geq 1$ & $\geq 1$ \\
\hline 31 & $\geq 1$ & $\geq 1$ & $\geq 1$ & 125 & $\geq 1$ & $\geq 1$ & $\geq 1$ \\
\hline 32 & $\geq 1$ & $\geq 1$ & $\geq 1$ & 126 & $\geq 1$ & $\geq 1$ & $\geq 1$ \\
\hline 36 & $\geq 1$ & $\geq 1$ & $\geq 1$ & 128 & $\geq 1$ & $\geq 1$ & $\geq 1$ \\
\hline 37 & $\geq 1$ & $\geq 1$ & $\geq 1$ & 129 & $\geq 1$ & $\geq 1$ & $\geq 1$ \\
\hline 38 & $\geq 1$ & $\geq 1$ & $\geq 1$ & 130 & $\geq 1$ & $\geq 1$ & $\geq 1$ \\
\hline 39 & $\geq 1$ & $\geq 1$ & $\geq 1$ & 131 & $\geq 1$ & $\geq 1$ & $\geq 1$ \\
\hline 45 & $\geq 1$ & $\geq 1$ & $\geq 1$ & 132 & $\geq 1$ & $\geq 1$ & $\geq 1$ \\
\hline 48 & $\geq 1$ & $\geq 1$ & $\geq 1$ & 133 & $\geq 1$ & $\geq 1$ & $\geq 1$ \\
\hline 49 & $\geq 1$ & $\geq 1$ & $\geq 1$ & 134 & $\geq 1$ & $\geq 1$ & $\geq 1$ \\
\hline 52 & $\geq 1$ & $\geq 1$ & $\geq 1$ & 135 & $\geq 1$ & $\geq 1$ & $\geq 1$ \\
\hline 53 & $\geq 1$ & $\geq 1$ & $\geq 1$ & 136 & $\geq 1$ & $\geq 1$ & $\geq 1$ \\
\hline 55 & $\geq 1$ & $\geq 1$ & $\geq 1$ & 141 & $\geq 1$ & $\geq 1$ & $\geq 1$ \\
\hline 58 & $\geq 1$ & $\geq 1$ & $\geq 1$ & 144 & $\geq 1$ & $\geq 1$ & $\geq 1$ \\
\hline 62 & $\geq 1$ & $\geq 1$ & $\geq 1$ & 145 & $\geq 1$ & $\geq 1$ & $\geq 1$ \\
\hline 64 & $\geq 1$ & $\geq 1$ & $\geq 1$ & $146 z$ & $\geq 1$ & $\geq 1$ & $\geq 1$ \\
\hline 75 & $\geq 1$ & $\geq 1$ & $\geq 1$ & $148 z$ & $\geq 1$ & $\geq 1$ & $\geq 1$ \\
\hline 77 & $\geq 1$ & $\geq 1$ & $\geq 1$ & 150 & $\geq 1$ & $\geq 1$ & $\geq 1$ \\
\hline 87 & $\geq 1$ & $\geq 1$ & $\geq 1$ & 151 & $\geq 1$ & $\geq 1$ & $\geq 1$ \\
\hline 88 & $\geq 1$ & $\geq 1$ & $\geq 1$ & 152 & $\geq 1$ & $\geq 1$ & $\geq 1$ \\
\hline
\end{tabular}

Tabla 22. Valores de citotoxicidad de los compuestos que no han sido seleccionados para calcular el valor de $\mathrm{IC}_{50}$. 


\section{D.6.2.3. DETERMINACIÓN DE LA IC ${ }_{50}$ DE CITOTOXICIDAD}

La $I C_{50}$ es la concentración a la cual el compuesto produce el $50 \%$ de muerte celular. Los compuestos que se seleccionan para la determinación de la $\mathrm{IC}_{50}$ son aquellos que producen muerte celular a una concentración igual o menor de $10^{-6} \mathrm{M}$. Para calcular la $\mathrm{IC}_{50}$ se repite por triplicado el ensayo de citotoxicidad de cada compuesto a las mismas concentraciones, y se realiza un ajuste sigmoidal a una curva dosis-respuesta mediante el complemento Solver de Excel囚. Posteriormente se realiza la media de las medidas obteniendo el valor de $\mathrm{IC}_{50}$ para cada compuesto y su error estándar. En algunos compuestos se calcula la $\mathrm{IC}_{50}$ en alguna de las tres líneas, pero no en todas debido a que es menos sensible y no produce muerte celular a $10^{-6} \mathrm{M}$.

Los compuestos que han sido seleccionados para determinar el valor de $I_{50}$ se muestra a continuación, junto al valor de su error estándar. 


\begin{tabular}{|c|c|c|c|c|c|c|c|}
\hline COMP & $\begin{array}{c}\mathrm{IC}_{50} \text { Hela } \\
\left(10^{-6} \mathrm{M}\right)\end{array}$ & $\begin{array}{c}\mathrm{IC}_{50} \mathrm{HL60} \\
\left(10^{-6} \mathrm{M}\right)\end{array}$ & $\begin{array}{c}\mathrm{IC}_{50} \mathrm{HT} 29 \\
\left(10^{-6} \mathrm{M}\right)\end{array}$ & COMP & $\begin{array}{c}\mathrm{IC}_{50} \text { Hela } \\
\left(10^{-6} \mathrm{M}\right)\end{array}$ & $\begin{array}{c}\mathrm{IC}_{50} \mathrm{HL60} \\
\left(10^{-6} \mathrm{M}\right)\end{array}$ & $\begin{array}{c}\mathrm{IC}_{50} \mathrm{HT} 29 \\
\left(10^{-6} \mathrm{M}\right)\end{array}$ \\
\hline 26 & $0,4 \pm 0,09$ & $0,6 \pm 0,2$ & $\geq 1$ & 86 & $0,2 \pm 0,04$ & $0,2 \pm 0,03$ & $\geq 1$ \\
\hline 34 & $0,03 \pm 0,004$ & $0,2 \pm 0,01$ & $\geq 1$ & 89 & $0,4 \pm 0,01$ & $0,1 \pm 0,005$ & $0,7 \pm 0,07$ \\
\hline 40 & $0,4 \pm 0,09$ & $0,4 \pm 0,06$ & $0,4 \pm 0,1$ & 93 & $0,8 \pm 0,005$ & $0,2 \pm 0,02$ & $\geq 1$ \\
\hline 41 & $0,5 \pm 0,03$ & $0,7 \pm 0,2$ & $\geq 1$ & 94 & $0,2 \pm 0,08$ & $0,2 \pm 0,06$ & $0,5 \pm 0,07$ \\
\hline 42 & $0,9 \pm 0,04$ & $\geq 1$ & $\geq 1$ & 96 & $0,5 \pm 0,1$ & $0,7 \pm 0,07$ & $0,2 \pm 0,03$ \\
\hline 43 & $0,3 \pm 0,02$ & $0,3 \pm 0,02$ & $0,2 \pm 0,04$ & 97 & $0,5 \pm 0,2$ & $0,2 \pm 0,07$ & $0,7 \pm 0,1$ \\
\hline 44 & $0,4 \pm 0,1$ & $\geq 1$ & $\geq 1$ & 99 & $0,1 \pm 0,02$ & $0,3 \pm 0,006$ & $0,5 \pm 0,1$ \\
\hline 46 & $0,4 \pm 0,1$ & $0,3 \pm 0,1$ & $0,5 \pm 0,2$ & 102 & $0,6 \pm 0,001$ & $0,6 \pm 0,1$ & $0,5 \pm 0,2$ \\
\hline 47 & $0,4 \pm 0,1$ & $0,3 \pm 0,1$ & $0,2 \pm 0,08$ & 103 & $0,6 \pm 0,2$ & $0,2 \pm 0,04$ & $0,2 \pm 0,06$ \\
\hline 50 & $0,5 \pm 0,1$ & $0,3 \pm 0,01$ & $\geq 1$ & 104 & $0,5 \pm 0,1$ & $0,3 \pm 0,1$ & $0,7 \pm 0,05$ \\
\hline 51 & $0,2 \pm 0,05$ & $0,3 \pm 0,03$ & $0,2 \pm 0,005$ & 105 & $0,2 \pm 0,03$ & $0,3 \pm 0,01$ & $0,5 \pm 0,1$ \\
\hline 54 & $0,07 \pm 0,01$ & $0,06 \pm 0,02$ & $0,5 \pm 0,01$ & 106 & $0,6 \pm 0,08$ & $0,6 \pm 0,1$ & $\geq 1$ \\
\hline 56 & $0,3 \pm 0,05$ & $0,2 \pm 0,04$ & $0,3 \pm 0,02$ & 109 & $0,3 \pm 0,04$ & $0,9 \pm 0,08$ & $0,4 \pm 0,2$ \\
\hline 57 & $0,5 \pm 0,1$ & $\geq 1$ & $\geq 1$ & 110 & $\geq 1$ & $0,1, \pm 0,008$ & $\geq 1$ \\
\hline 59 & $0,4 \pm 0,006$ & $0,4 \pm 0,1$ & $0,3 \pm 0,03$ & 111 & $0,3 \pm 0,07$ & $0,2 \pm 0,008$ & $0,6 \pm 0,2$ \\
\hline 60 & $0,6 \pm 0,1$ & $\geq 1$ & $\geq 1$ & 112 & $0,7 \pm 0,1$ & $\geq 1$ & $\geq 1$ \\
\hline 61 & $0,8 \pm 0,02$ & $0,7 \pm 0,2$ & $\geq 1$ & 115 & $0,3 \pm 0,03$ & $0,5 \pm 0,1$ & $0,5 \pm 0,1$ \\
\hline 63 & $0,04 \pm 0,01$ & $0,08 \pm 0,007$ & $0,4 \pm 0,12$ & 117 & $0,6 \pm 0,07$ & $0,7 \pm 0,08$ & $0,6 \pm 0,1$ \\
\hline 65 & $0,2 \pm 0,06$ & $0,2 \pm 0,06$ & $\geq 1$ & 119 & $0,6 \pm 0,08$ & $0,3 \pm 0,05$ & $0,4 \pm 0,1$ \\
\hline 68 & $0,3 \pm 0,2$ & $0,07 \pm 0,02$ & $0,9 \pm 0,2$ & 121 & $0,1 \pm 0,04$ & $0,3 \pm 0,1$ & $0,7 \pm 0,06$ \\
\hline 70 & $0,08 \pm 0,01$ & $0,07 \pm 0,0004$ & $0,1 \pm 0,01$ & 123 & $0,6 \pm 0,1$ & $0,7 \pm 0,1$ & $0,4 \pm 0,09$ \\
\hline 71 & $0,05 \pm 0,02$ & $0,074 \pm 0,003$ & $0,09 \pm 0,01$ & 127 & $0,7 \pm 0,08$ & $\geq 1$ & $\geq 1$ \\
\hline 72 & $0,3 \pm 0,1$ & $0,4 \pm 0,09$ & $\geq 1$ & 137 & $0,6 \pm 0,2$ & $0,5 \pm 0,2$ & $\geq 1$ \\
\hline 73 & $0,1 \pm 0,02$ & $0,4 \pm 0,1$ & $0,5 \pm 0,2$ & 138 & $0,5 \pm 0,2$ & $0,30 \pm 0,02$ & $\geq 1$ \\
\hline 74 & $0,3 \pm 0,007$ & $0,2 \pm 0,03$ & $\geq 1$ & 139 & $0,6 \pm 0,2$ & $0,3 \pm 0,1$ & $\geq 1$ \\
\hline 76 & $0,07 \pm 0,01$ & $0,04 \pm 0,001$ & $0,8 \pm 0,04$ & 140 & $0,6 \pm 0,021$ & $0,4 \pm 0,2$ & $0,8 \pm 0,03$ \\
\hline 80 & $0,06 \pm 0,01$ & $0,09 \pm 0,001$ & $0,1 \pm 0,002$ & 142 & $0,3 \pm 0,08$ & $0,4 \pm 0,2$ & $0,94 \pm 0,05$ \\
\hline 82 & $0,1 \pm 0,05$ & $0,07 \pm 0,002$ & $0,3 \pm 0,1$ & 143 & $0,2 \pm 0,03$ & $0,2 \pm 0,07$ & $0,8 \pm 0,1$ \\
\hline 83 & $0,08 \pm 0,003$ & $0,04 \pm 0,01$ & $0,3 \pm 0,008$ & $147 z$ & $\geq 1$ & $\geq 1$ & $0,6 \pm 0,2$ \\
\hline 84 & $0,2 \pm 0,03$ & $0,6 \pm 0,04$ & $\geq 1$ & $149 z$ & $0,3 \pm 0,09$ & $0,4 \pm 0,3$ & $0,4 \pm 0,03$ \\
\hline 85 & $0,6 \pm 0,1$ & $0,3 \pm 0,1$ & $0,7 \pm 0,1$ & & & & \\
\hline
\end{tabular}

Tabla 23. Valores de $\mathrm{IC}_{50}$ de los compuestos seleccionados (aquellos que producen muerte celular a una concentración igual o menor de $10^{-6} \mathrm{M}$ ) 


\section{D.7. DETERMINACIÓN DE LA SOLUBILIDAD ACUOSA}

El ensayo de solubilidad acuosa de los compuestos que han sido sintetizados se ha llevado a cabo en un tampón fosfato a $\mathrm{pH} 7$, ya que es el $\mathrm{pH}$ fisiológico y son las condiciones en las que se realizan los ensayos biológicos de estos compuestos.

La solubilidad acuosa se ha determinado espectrofotométricamente, comparando la absorbancia de la muestra problema con la absorbancia de una recta patrón o recta de calibrado.

La metodología seguida ha sido la siguiente:

1) Determinación de las longitudes de onda de absorción máxima para cada compuesto.

2) Realización de la recta de calibrado a partir de disoluciones de concentración conocida. Estas disoluciones se preparan a partir de un stock del compuesto con una concentración $2 \mathrm{mM}$ en DMSO, y las medidas se realizan en una mezcla DMSO/tampón pH 7 en relación 9/1.

3) Preparación de las muestras problema. Se pesa entre 1 y $2 \mathrm{mg}$ de compuesto a lo que se añaden $300 \mu \mathrm{L}$ de tampón $\mathrm{NaPi} 10 \mathrm{mM}$ a $\mathrm{pH}=7$, que se mantienen un mínimo de 48 horas agitando para después filtrar el contenido a través de un filtro de $22 \mu \mathrm{m}$, de manera que se retira todo el compuesto que no se haya solubilizado en el tampón y queda el filtrado que contiene la cantidad de compuesto que se ha solubilizado. Se preparan tres cubetas con $30 \mu \mathrm{L}$ del filtrado y $270 \mu \mathrm{L}$ de DMSO y se mide la absorbancia a la longitud de onda escogida, obteniendo de esta maneras tres valores de solubilidad, con los que se hace la media aritmética. 
Se ha determinado la solubilidad de varios compuestos sintetizados, según la cantidad disponible de la sustancia, el grado de pureza y la relevancia de su estructura. De esta manera se han obtenido los siguientes resultados:

\begin{tabular}{|c|c|c|c|}
\hline COMP & $\begin{array}{c}\text { SOLUBILIDAD } \\
(\mu \mathrm{g} / \mathrm{mL})\end{array}$ & COMP & $\begin{array}{c}\text { SOLUBILIDAD } \\
(\mu \mathrm{g} / \mathrm{mL})\end{array}$ \\
\hline 25 & 10,4 & 88 & 151,9 \\
\hline 27 & 29,5 & 93 & 14,9 \\
\hline 34 & 56,2 & 98 & 230,2 \\
\hline 37 & 2,2 & 99 & 7,6 \\
\hline 40 & 48,9 & 100 & 102,7 \\
\hline 41 & 41,7 & 102 & 46,3 \\
\hline 42 & 10,7 & 104 & 8,2 \\
\hline 43 & 18,0 & 105 & 0 \\
\hline 45 & 1,5 & 108 & 47,6 \\
\hline 46 & 35,7 & 115 & 5,3 \\
\hline 49 & 17,0 & 123 & 6,0 \\
\hline 50 & 10,9 & 128 & 34,5 \\
\hline 54 & 37,3 & 132 & 1,9 \\
\hline 55 & 7,4 & 134 & 1,3 \\
\hline 56 & 7,5 & 135 & 2,4 \\
\hline 57 & 4,5 & 136 & 14,7 \\
\hline 58 & 6,9 & 138 & 43,8 \\
\hline 59 & 22,9 & 139 & 4,6 \\
\hline 73 & 12,3 & 140 & 1,0 \\
\hline 74 & 14,8 & 142 & 6,9 \\
\hline 76 & 6,3 & 143 & 1,1 \\
\hline 80 & 5,1 & 144 & 47,1 \\
\hline 82 & 3,2 & $149 z$ & 19,1 \\
\hline 86 & 0 & 151 & 9,8 \\
\hline 87 & 15,5 & 152 & 12,8 \\
\hline
\end{tabular}

Tabla 24. Valores de solubilidad en un tampón $\mathrm{NaPi} 10 \mathrm{mM}, \mathrm{pH}=7$ de los compuestos seleccionados. 



\section{E CONCLVSIONES}



En este trabajo de tesis doctoral se ha llevado a cabo la síntesis y evaluación de nuevos agentes antimitóticos con estructura de fenstatinas e isocombretastatinas basados en piridina, y a la vista de los resultados se pueden sacar las siguientes conclusiones:

> La metodología empleada para la síntesis de fenstatinas e isocombretastatinas es la adecuada, obteniéndose los compuestos deseados con altos niveles de pureza y buenos rendimientos en la mayoría de los casos.

La sustitución del anillo de trimetoxifenilo por un anillo de piridina disustituido conduce a compuestos que mantienen la actividad, e incluso en algún caso la mejoran, por lo que este sistema ya no debe ser considerado imprescindible para la actividad de este tipo de compuestos.

> La introducción de sistemas aromáticos unidos en la posición 6 del anillo de piridina, con la intención de que se coloquen en la zona 3 del dominio de la colchicina, conduce a compuestos que pierden la actividad. Se han sintetizado pocos compuestos de este tipo, por lo que es necesario realizar más pruebas.

- Se han realizado combinaciones del anillo de piridina disustituido con varios sistemas aromáticos en el anillo B (indol, $p$-metoxifenilo, naftilo,...) obteniendo como resultado que los compuestos con mayor actividad son los que tienen un anillo de indol con o sin sustituyentes en posición 3 de dicho anillo. También se 
obtienen buenos resultados con anillos de $p$-metoxifenilo con grupos amino en posición 3. Los compuestos con agrupaciones naftaleno, piridina, y dimetilaminofenilo como anillo $\mathrm{B}$ conducen a pérdida de actividad.

$>$ A igualdad de elementos estructurales en el anillo A y B, las isocombretastatinas son más potentes que las fenstatinas. En el caso de las oximas, en algunos casos son mejores que las isocombretastatinas, pero por lo general son peores.

> Se han sintetizado compuestos con más de un átomo en el puente, combretastatinas y oxadiazolinas. Las primeras presentan actividad dependiendo de los demás elementos estructurales, pero las oxadiazolinas carecen de actividad.

> Los compuestos que presentan actividad inhibitoria sobre la polimerización de la tubulina tienen actividad citotóxica, por lo que el mecanismo por el que producen muerte celular puede ser la inhibición de la polimerización. Sin embargo, algunos de los compuestos que presentan actividad citotóxica tienen baja actividad en IPT, por lo que el mecanismo por el que producen muerte celular puede ser otro diferente.

> Se ha evaluado la solubilidad acuosa de algunos de los compuestos sintetizados y son más solubles que el compuesto de referencia CA-4. Esto es debido a la introducción de grupos que pueden establecer enlaces de hidrógeno con el agua.

Las modificaciones estructurales introducidas en este trabajo son adecuadas para producir agentes citotóxicos potentes frente a líneas celulares cancerosas y como inhibidores de la polimerización de la tubulina, que además presentan un incremento de la solubilidad acuosa, por lo que se abre una nueva línea de estudio en los agentes antimitóticos que se unen en el sitio de la colchicina.

La estructura de piridina 2,6-disustituida es muy versátil y abre el camino al estudio de nuevos agentes que puedan ocupar las tres zonas de unión en dicho sitio. 
$\mathrm{F} \sim \mathrm{ESPECTR} \odot \mathrm{S}$ 



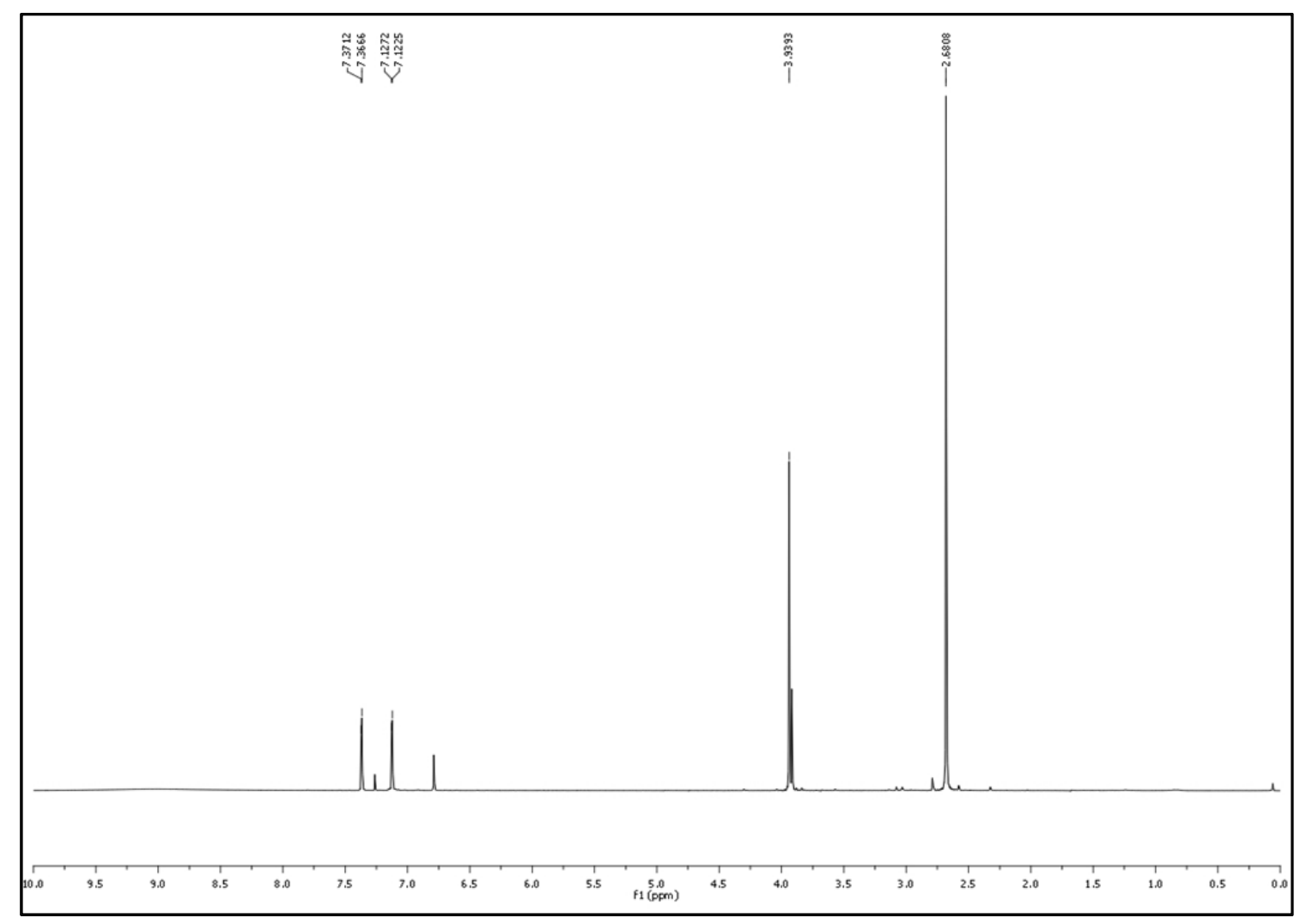

Espectro 7H 


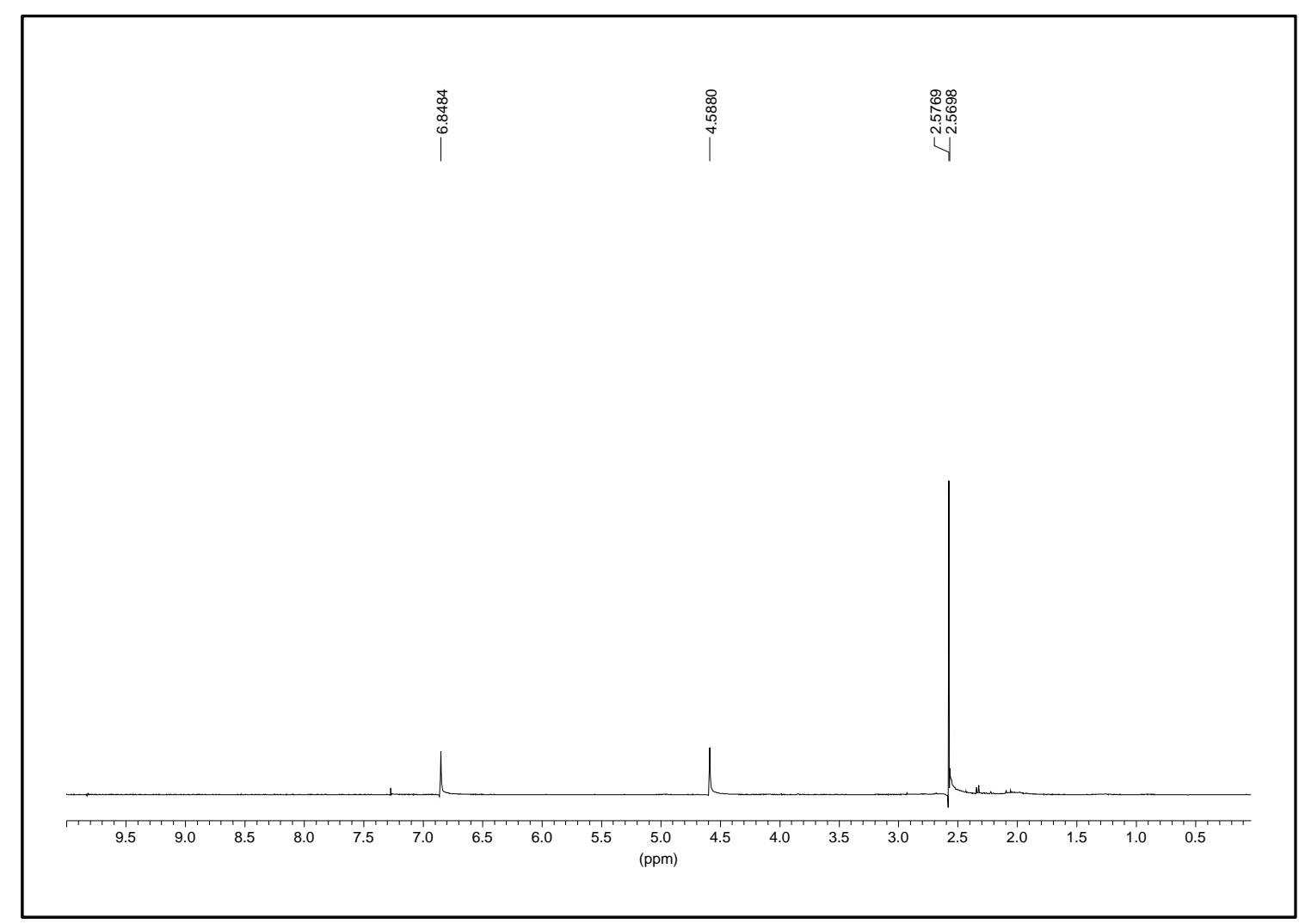

\section{Espectro 8H}

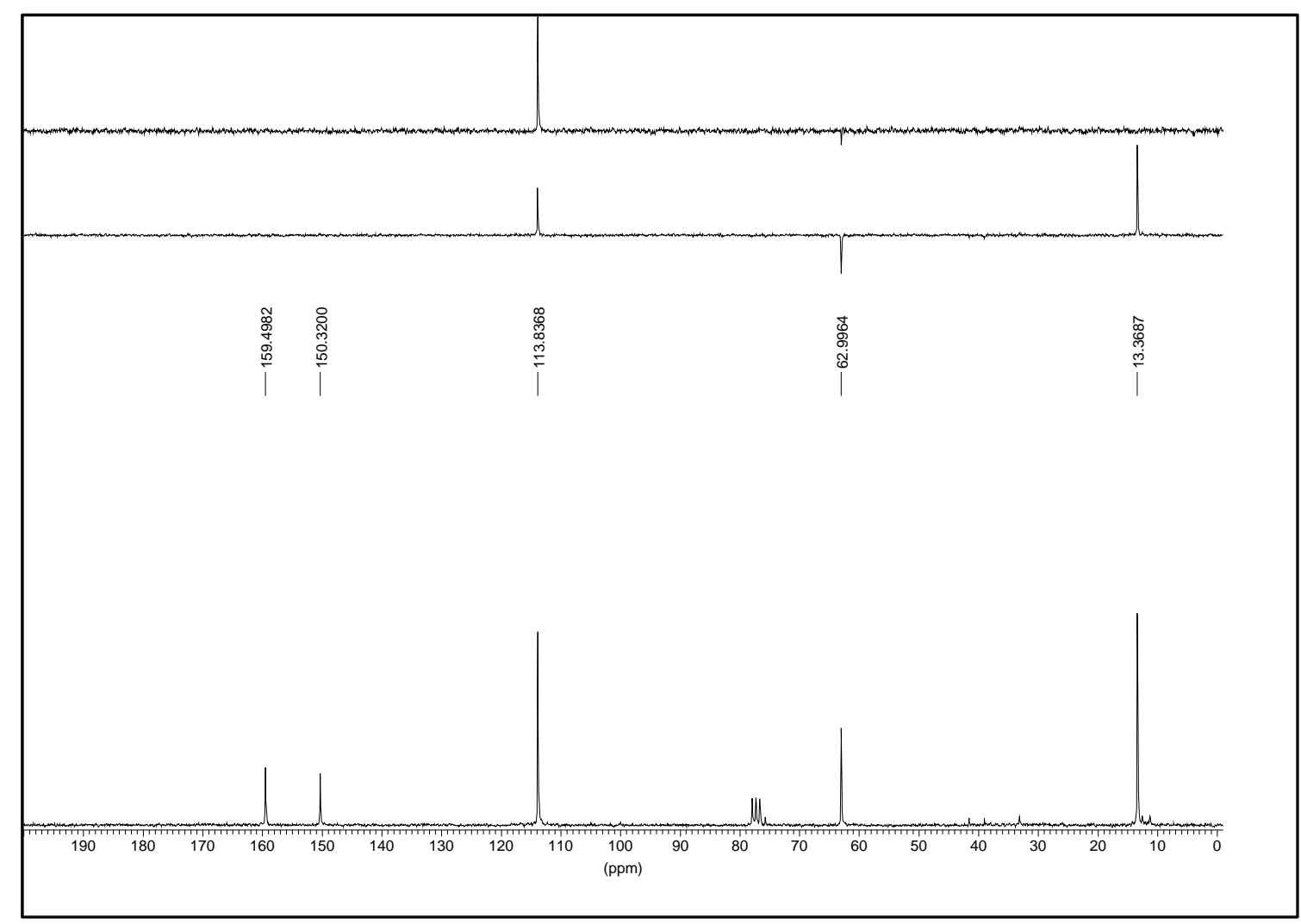

Espectro 8C 


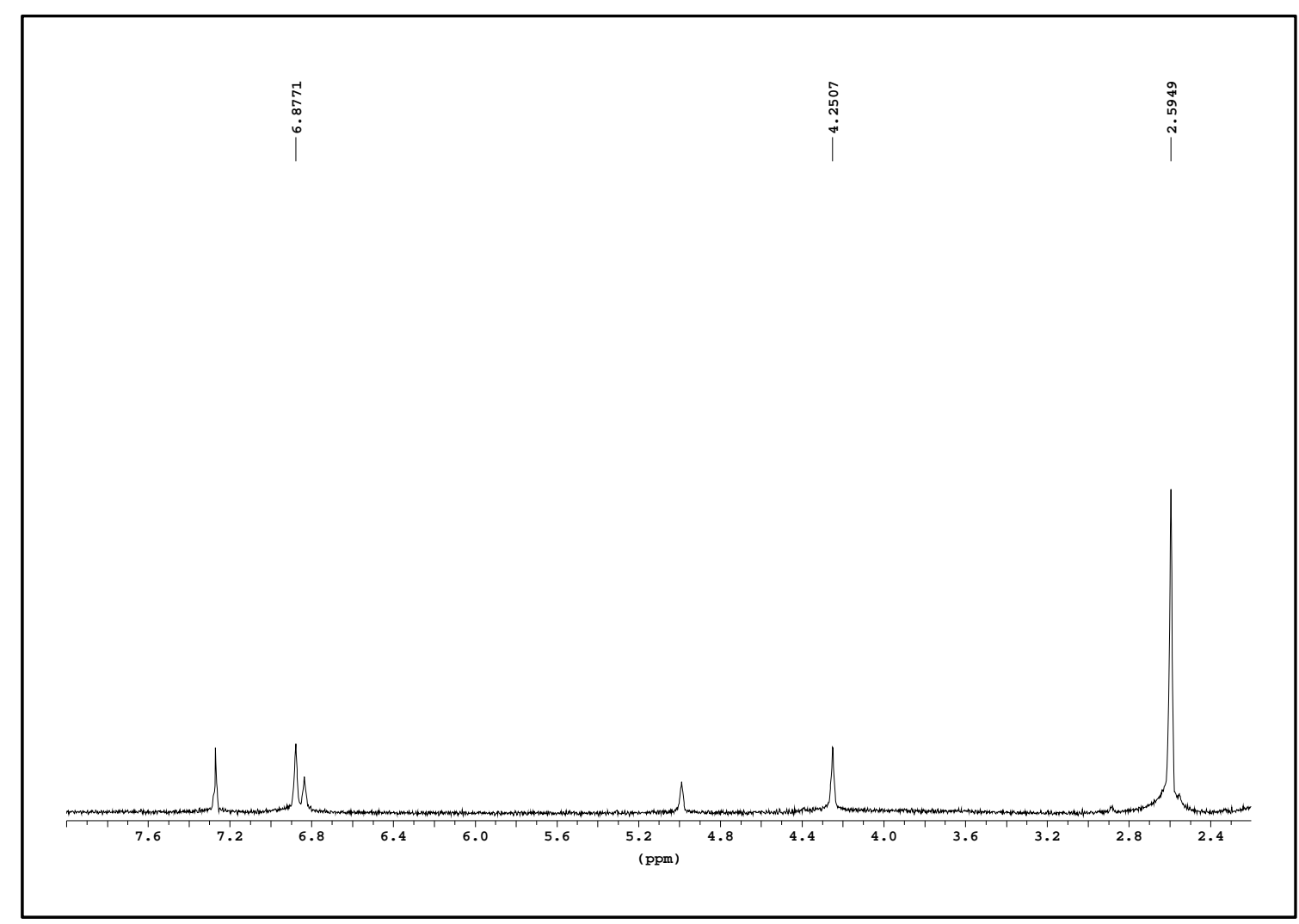

\section{Espectro 9H}

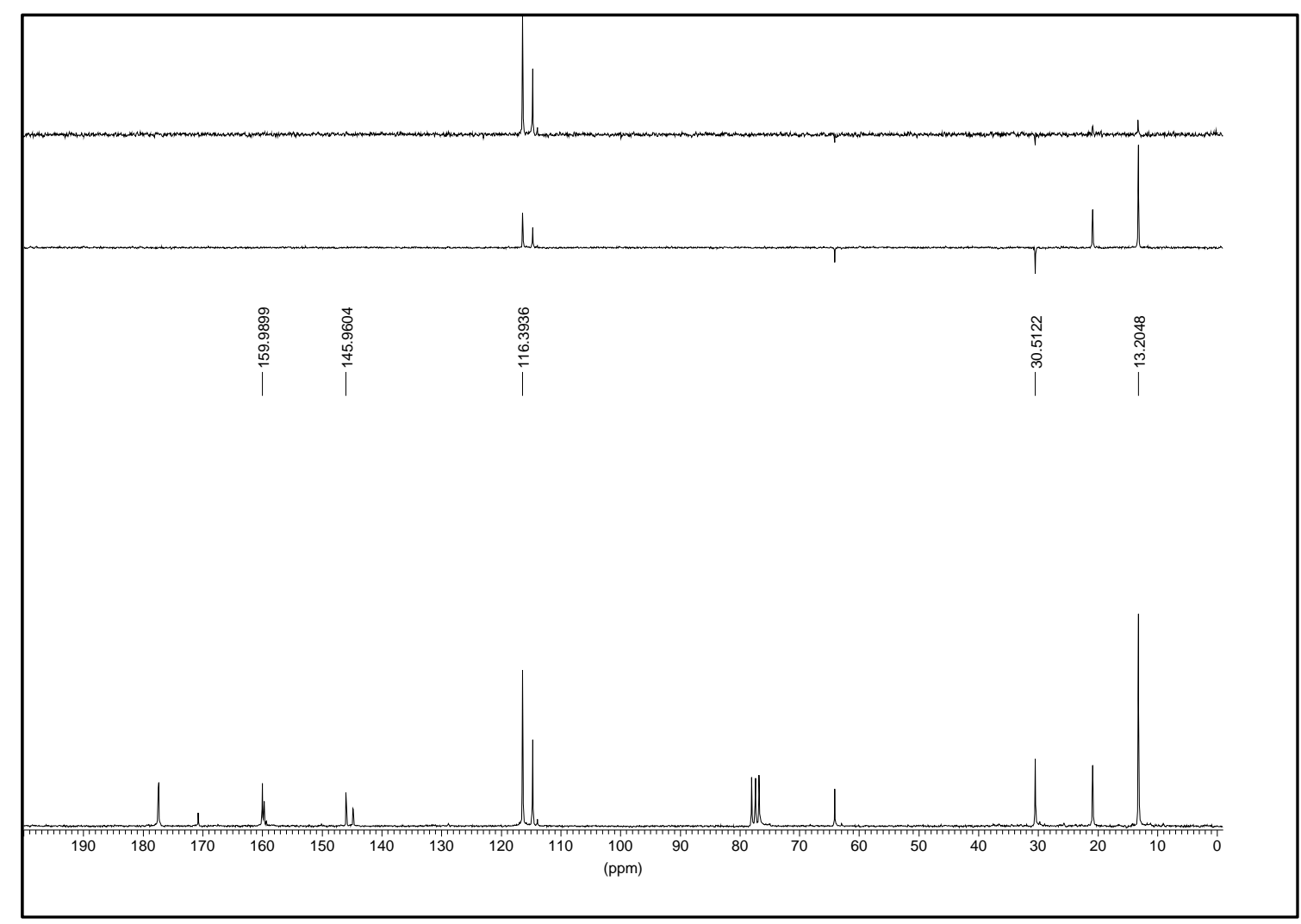

Espectro 9C 


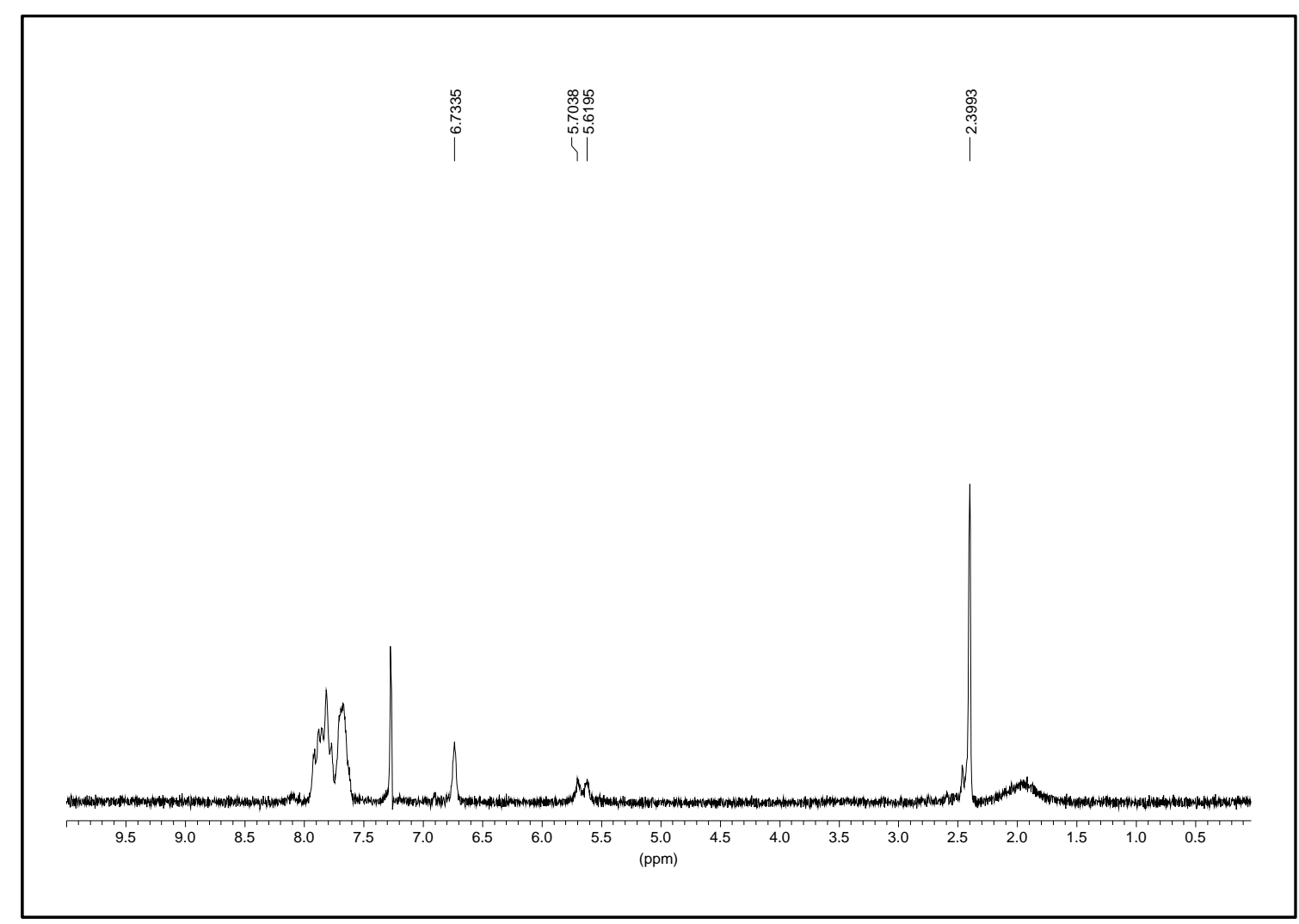

Espectro $10 \mathrm{H}$ 


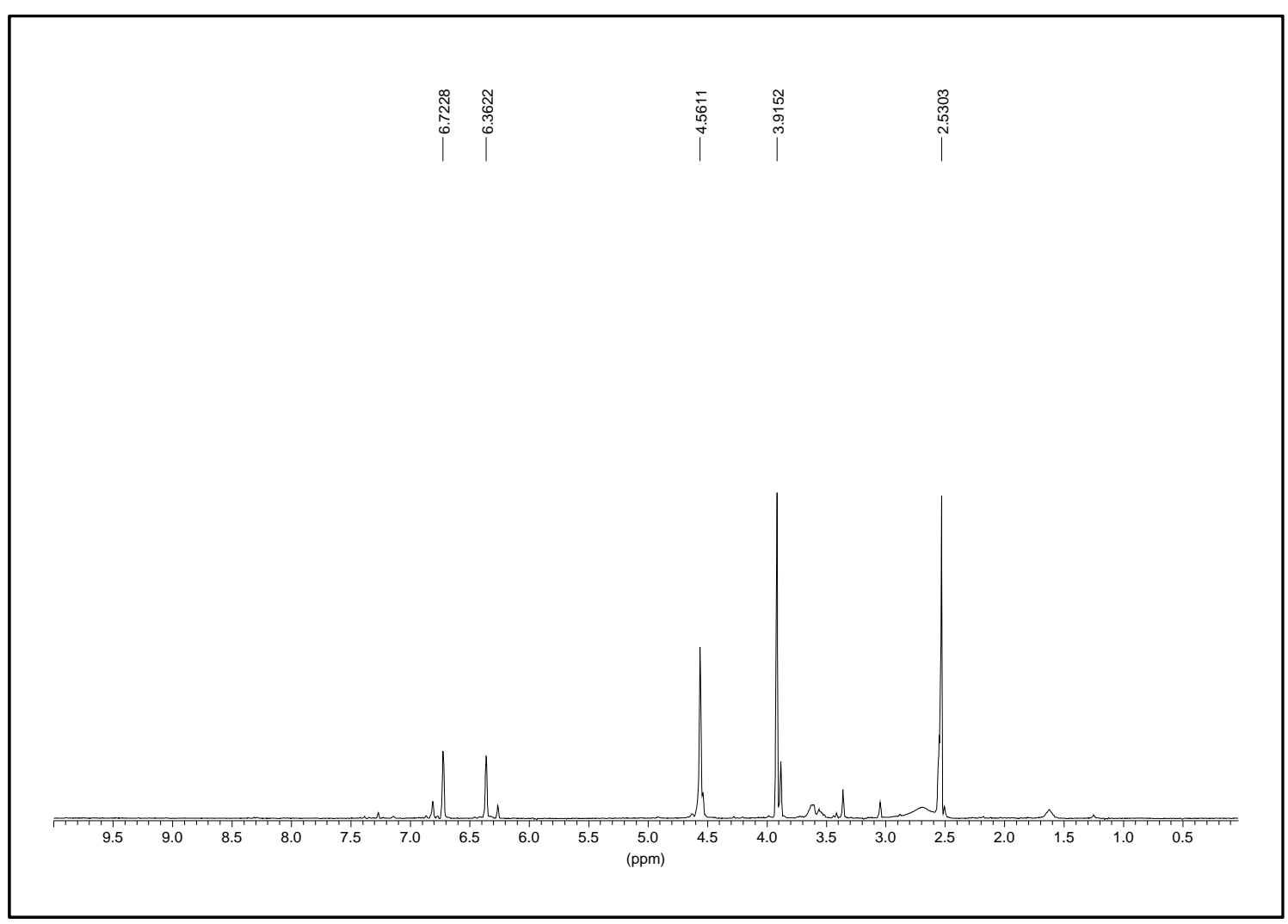

\section{Espectro $11 \mathrm{H}$}

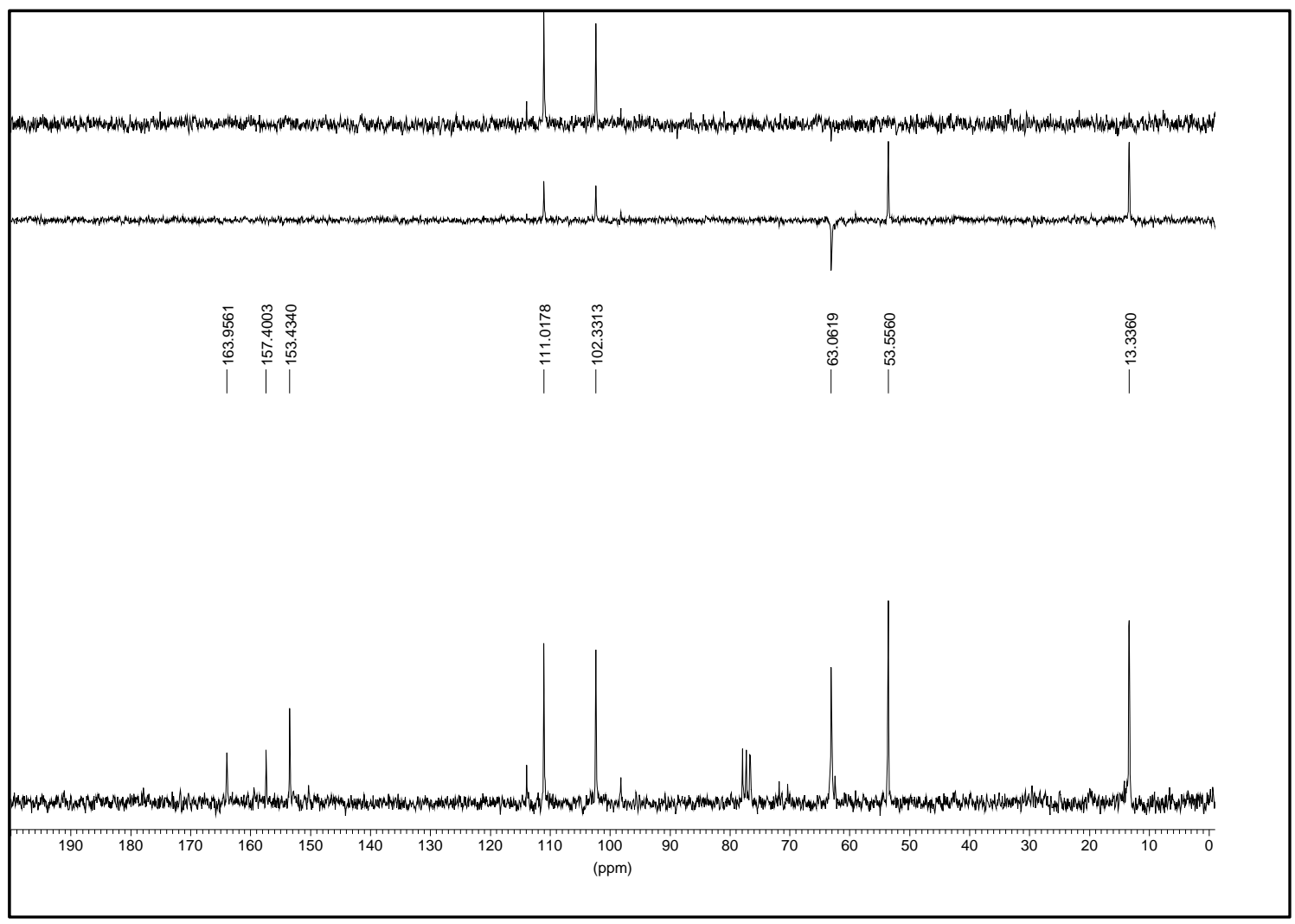

Espectro 11C 


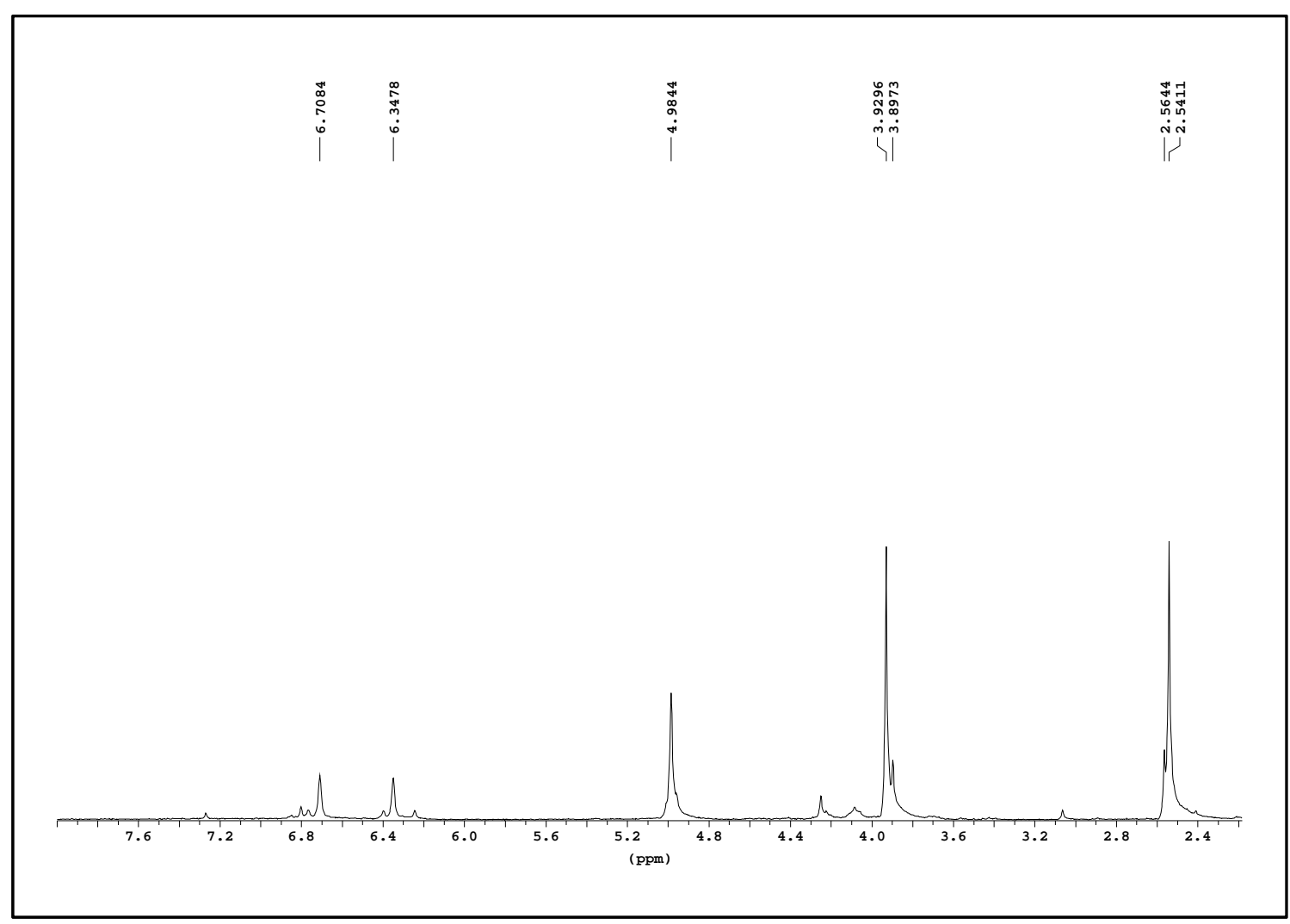

Espectro $12 \mathrm{H}$

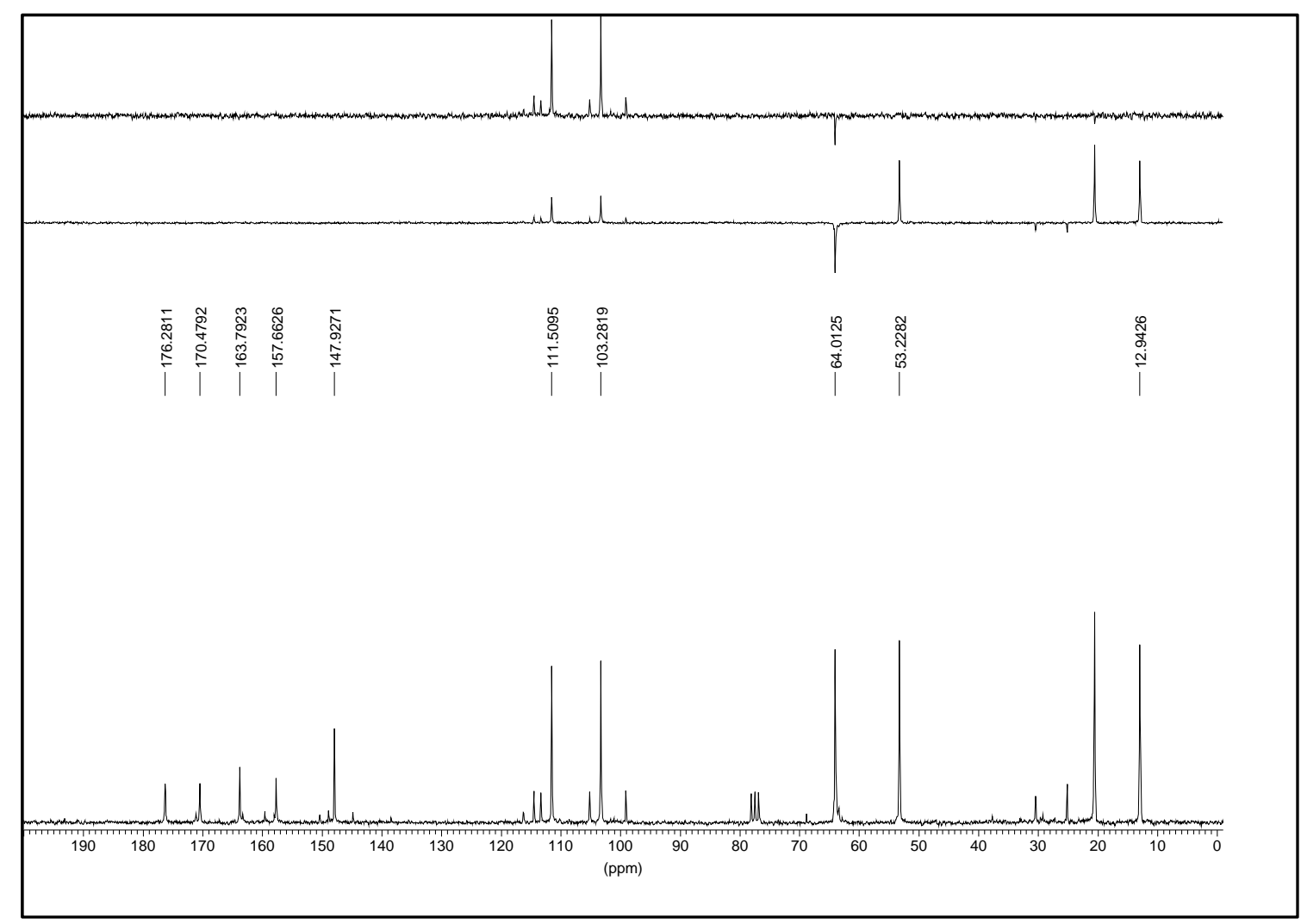

Espectro 12C 


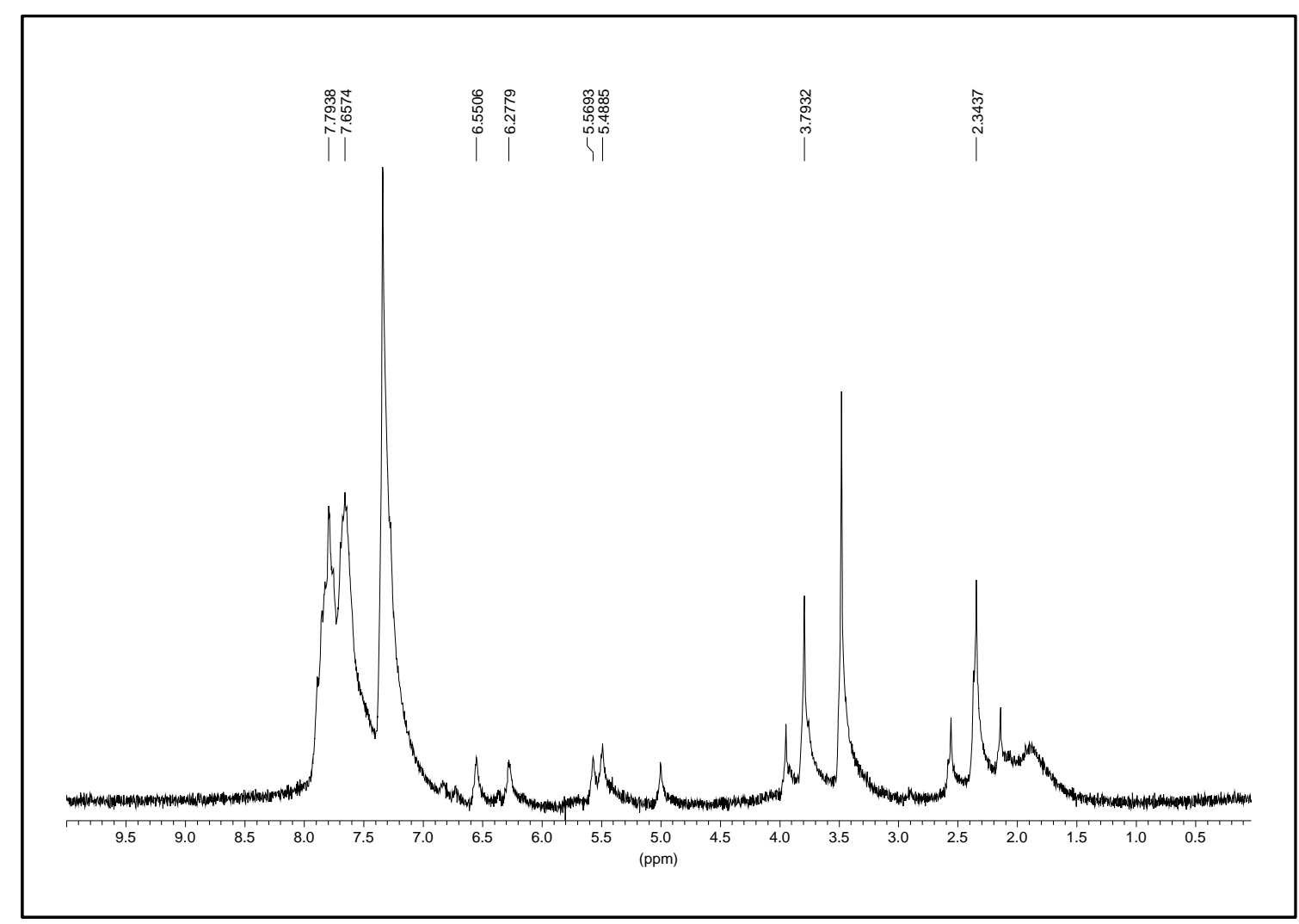

Espectro $13 \mathrm{H}$ 


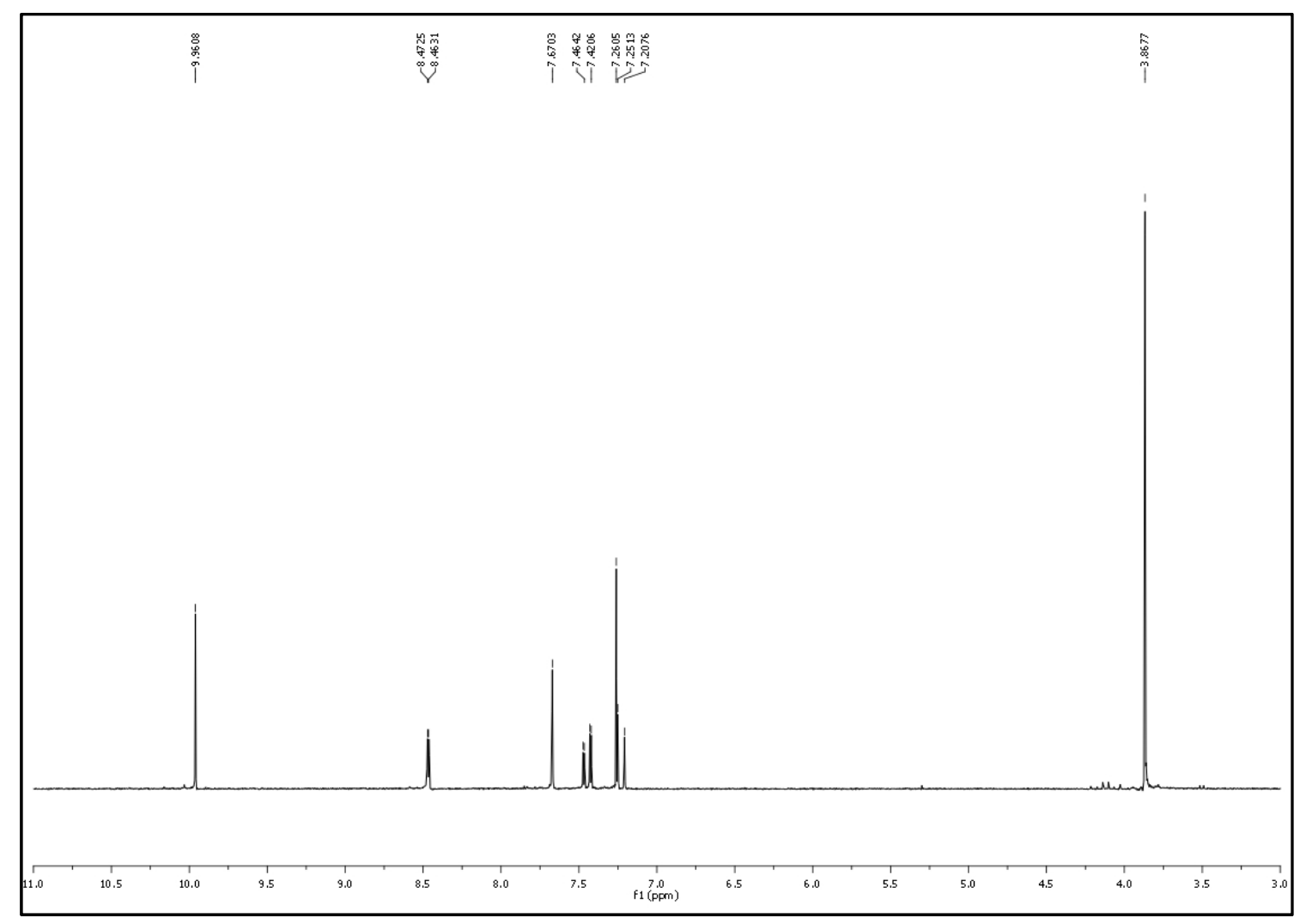

Espectro $16 \mathrm{H}$ 


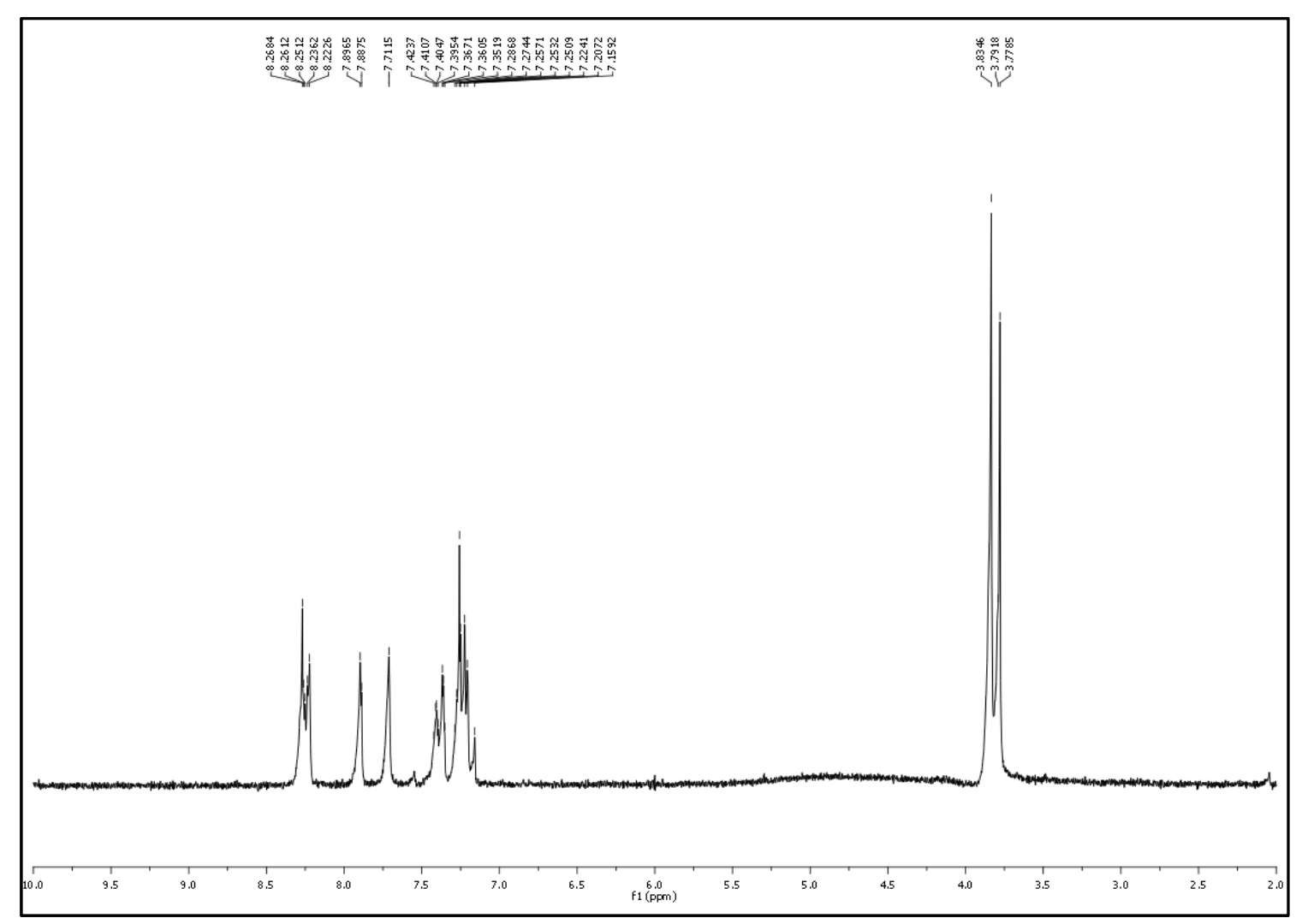

Espectro 17H. 


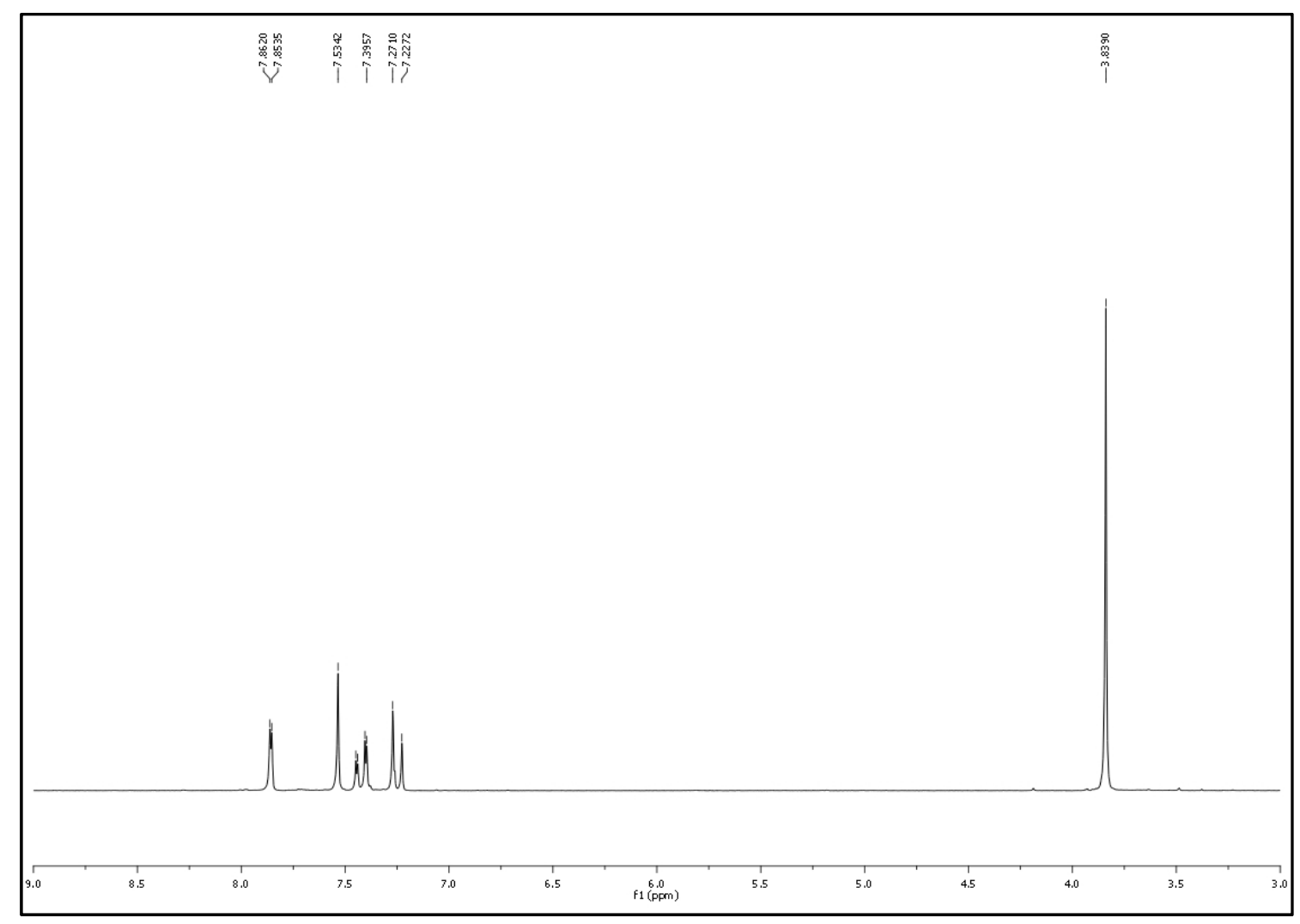

Espectro $18 \mathrm{H}$ 


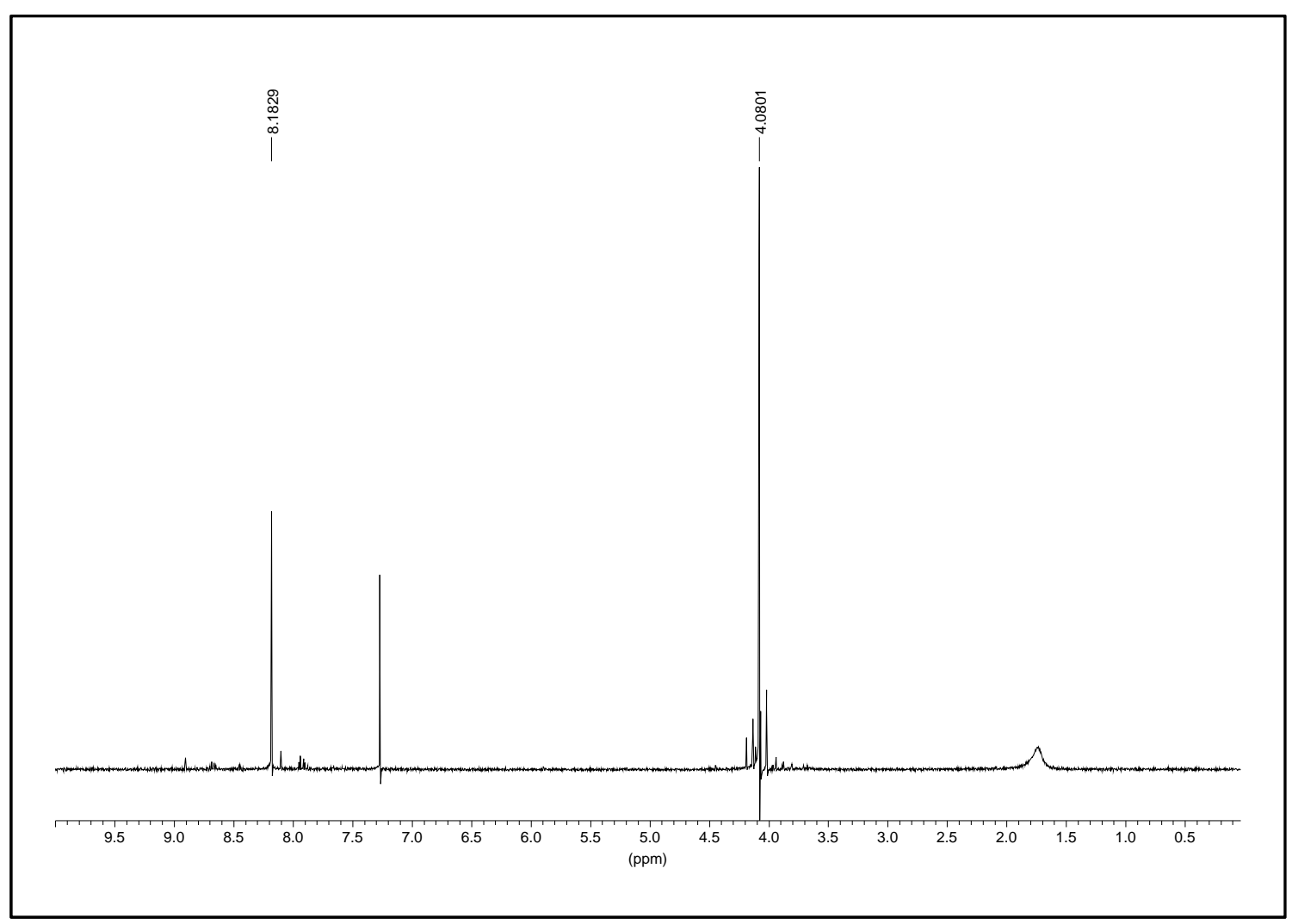

\section{Espectro $20 \mathrm{H}$}

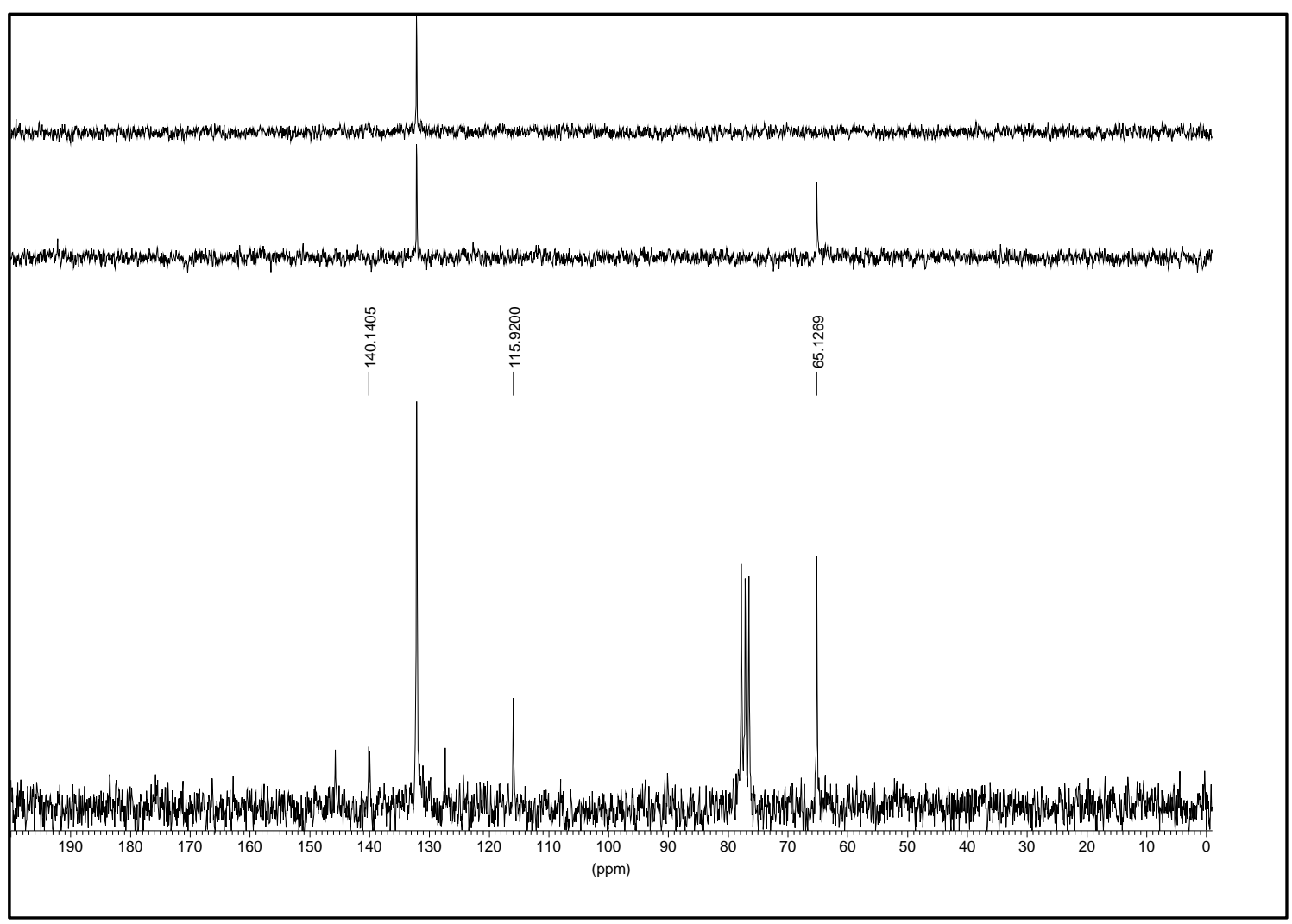

Espectro 20C 


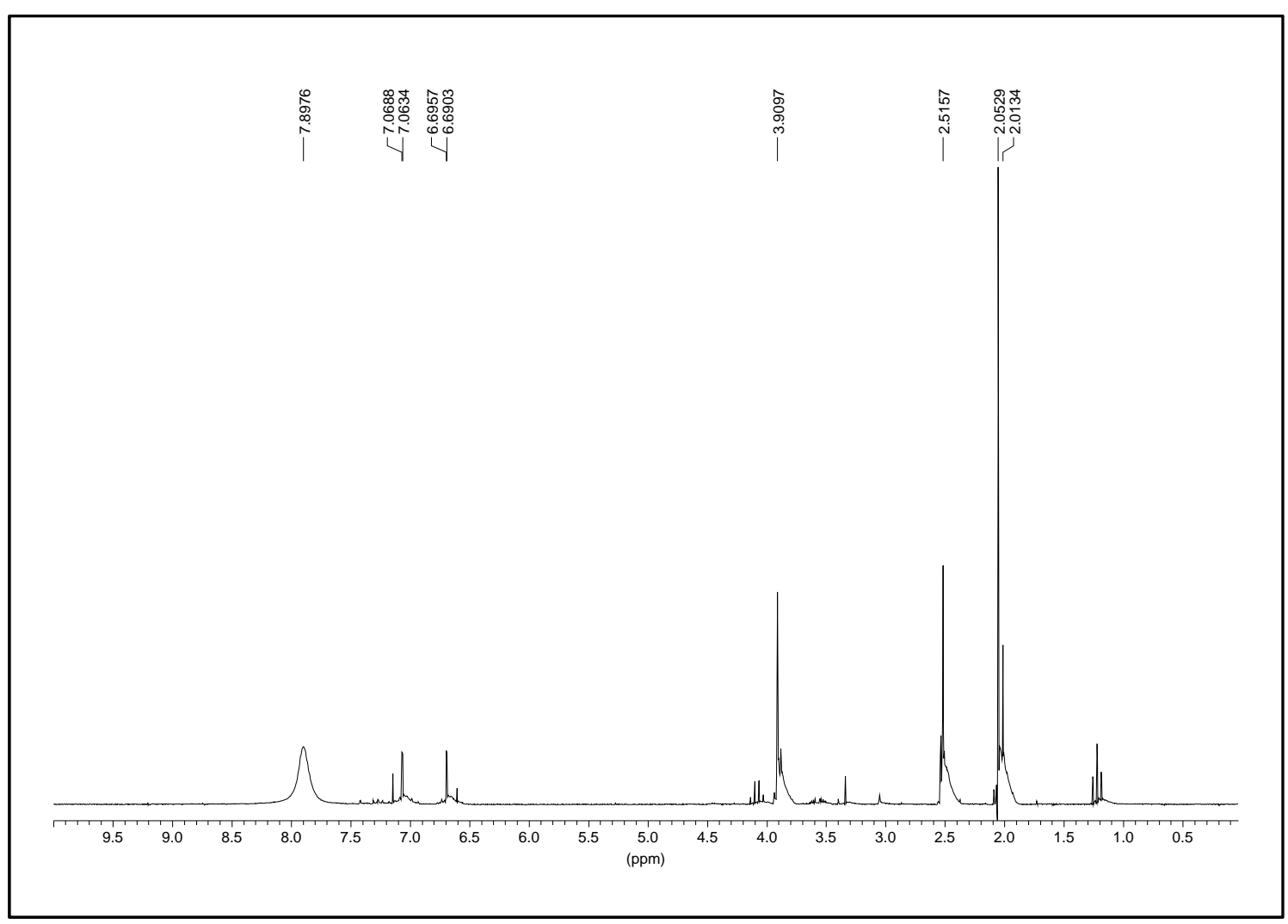

\section{Espectro $21 \mathrm{H}$}

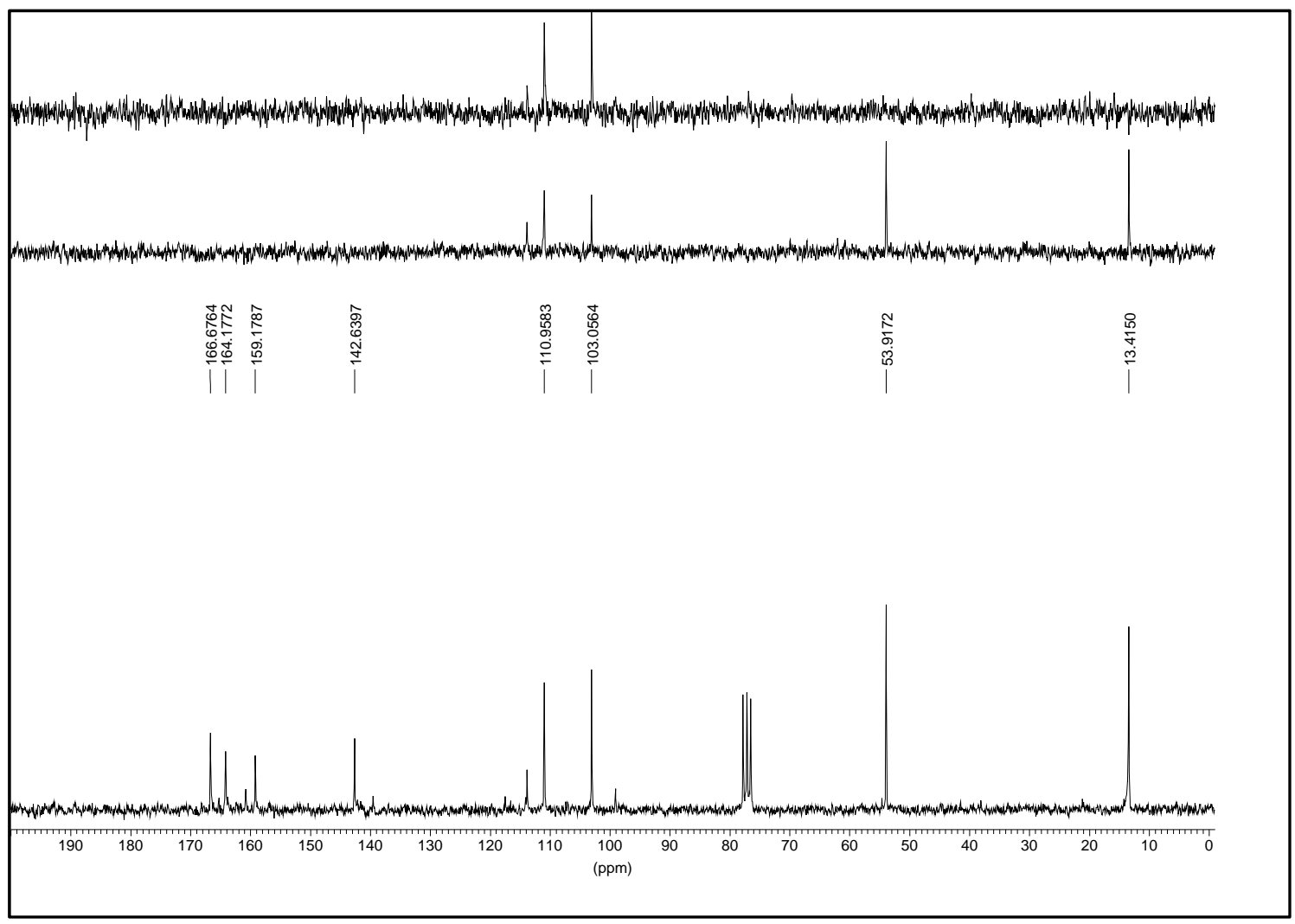

Espectro 21C 


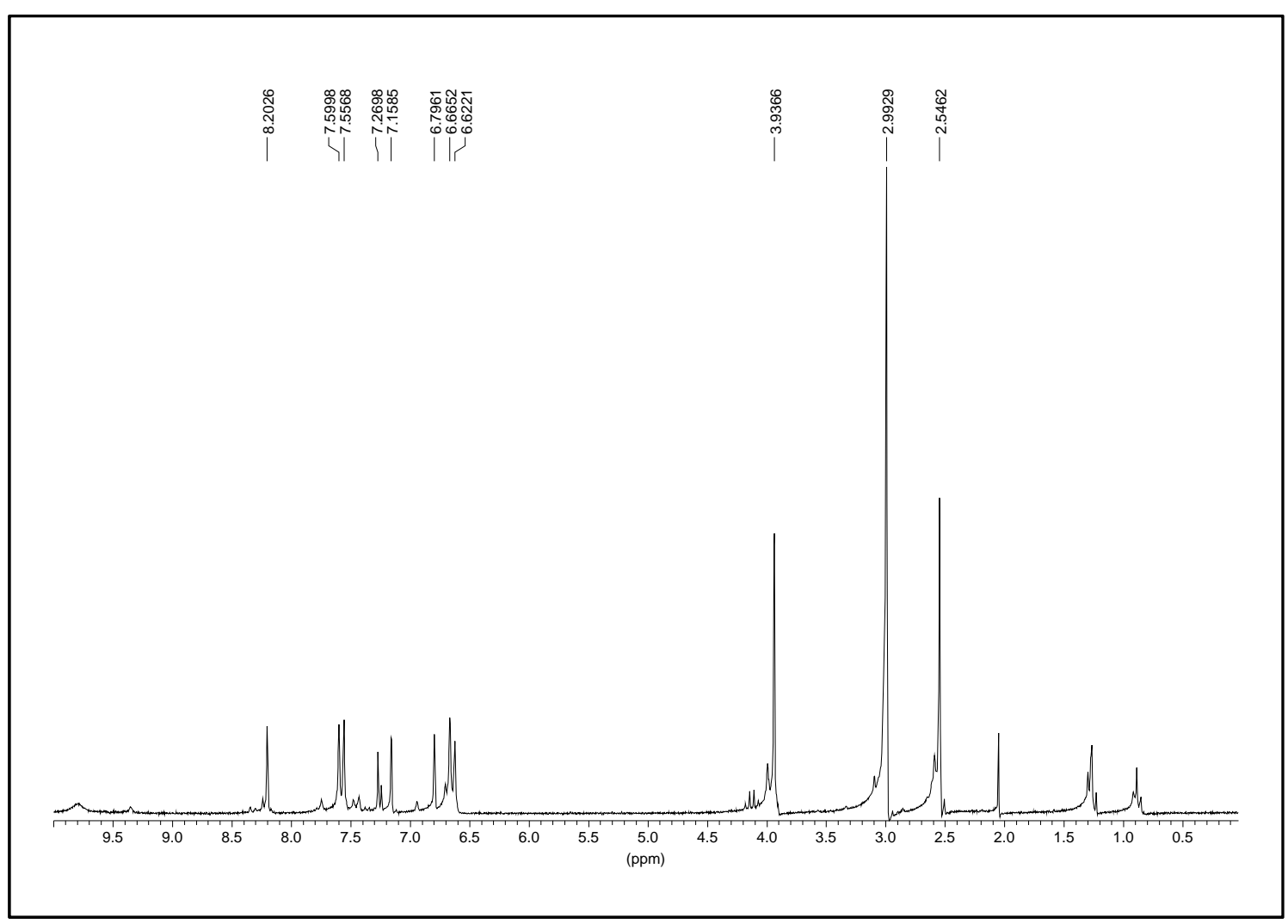

Espectro 22H

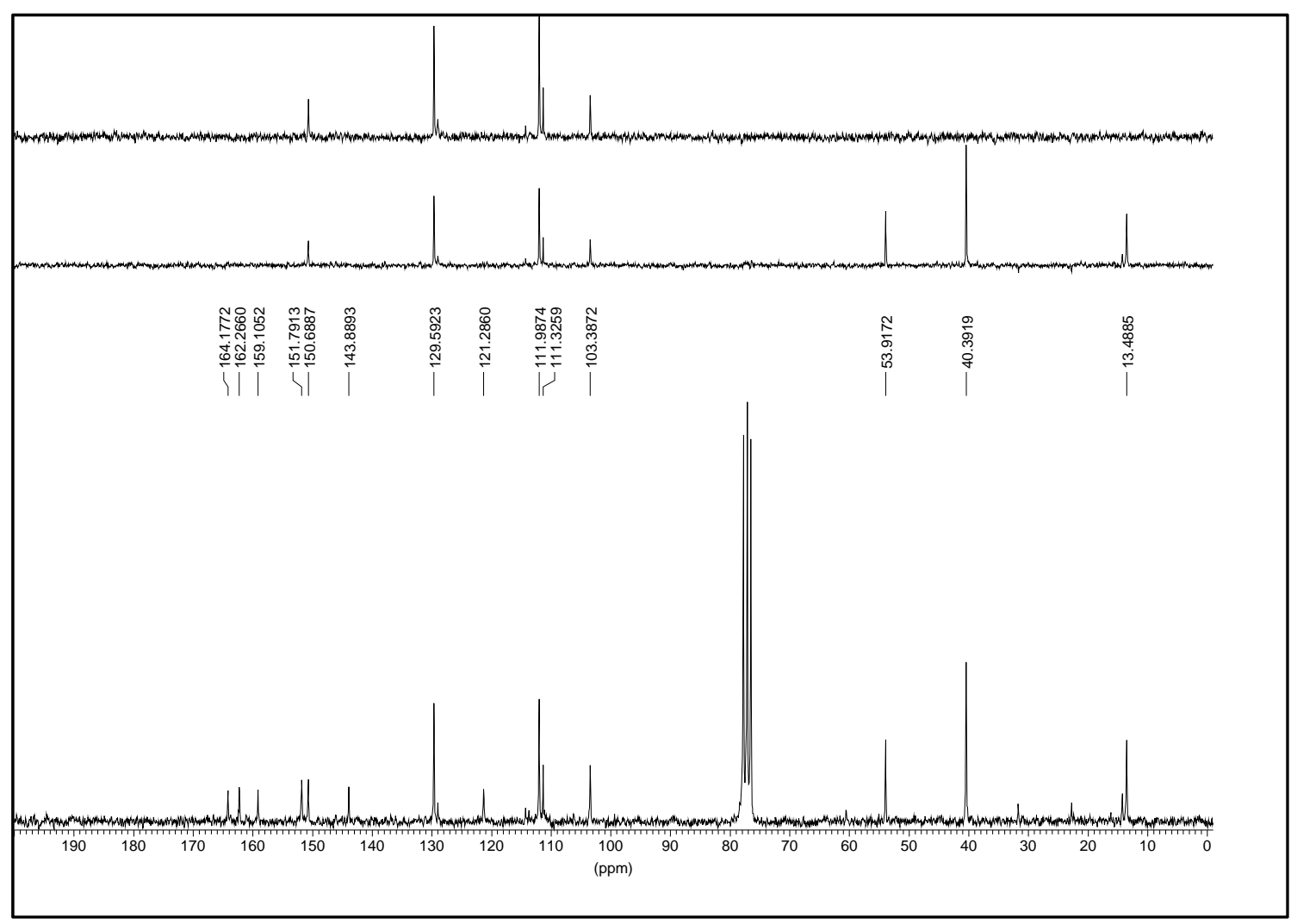

Espectro 22C 


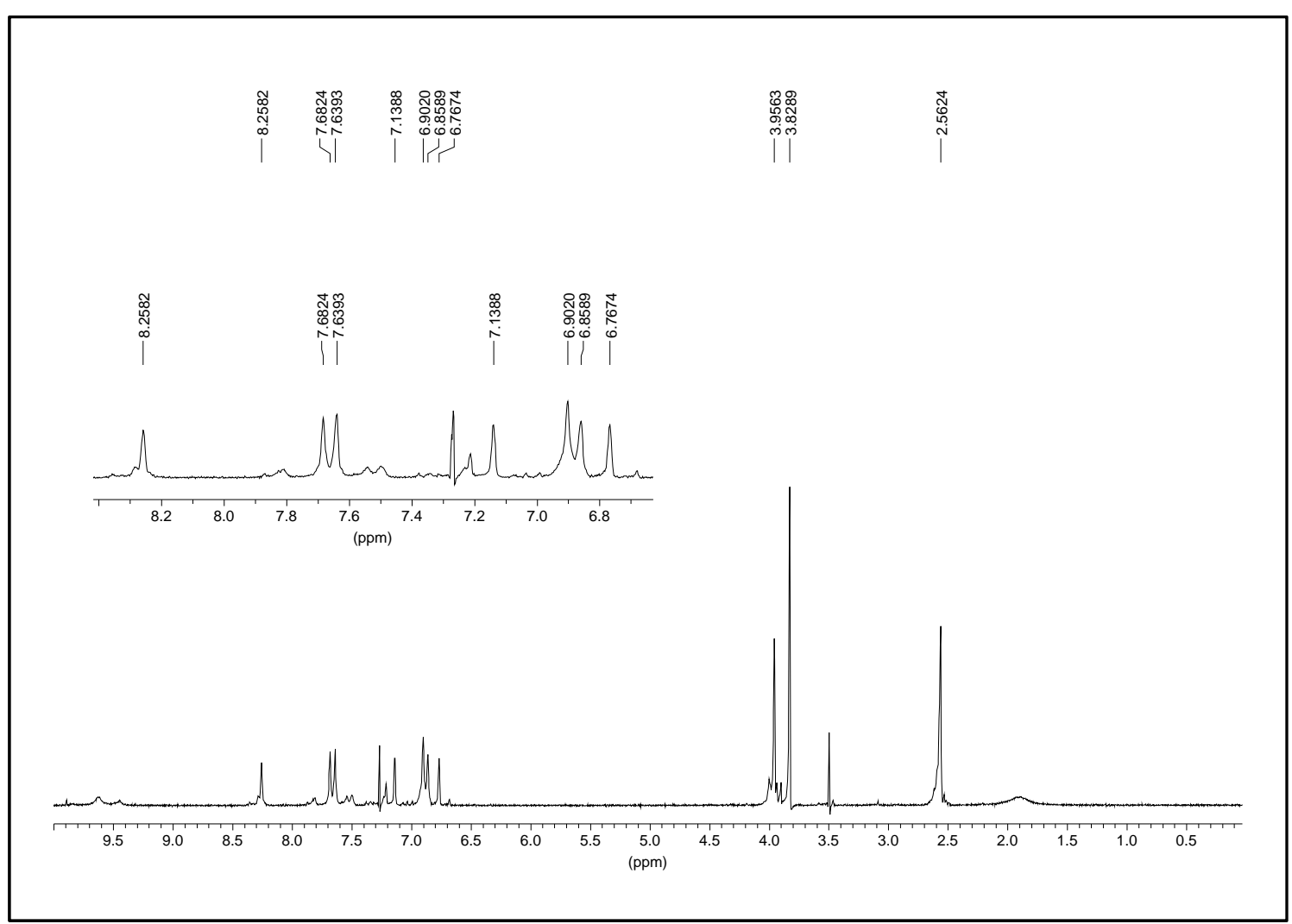

\section{Espectro 23H}

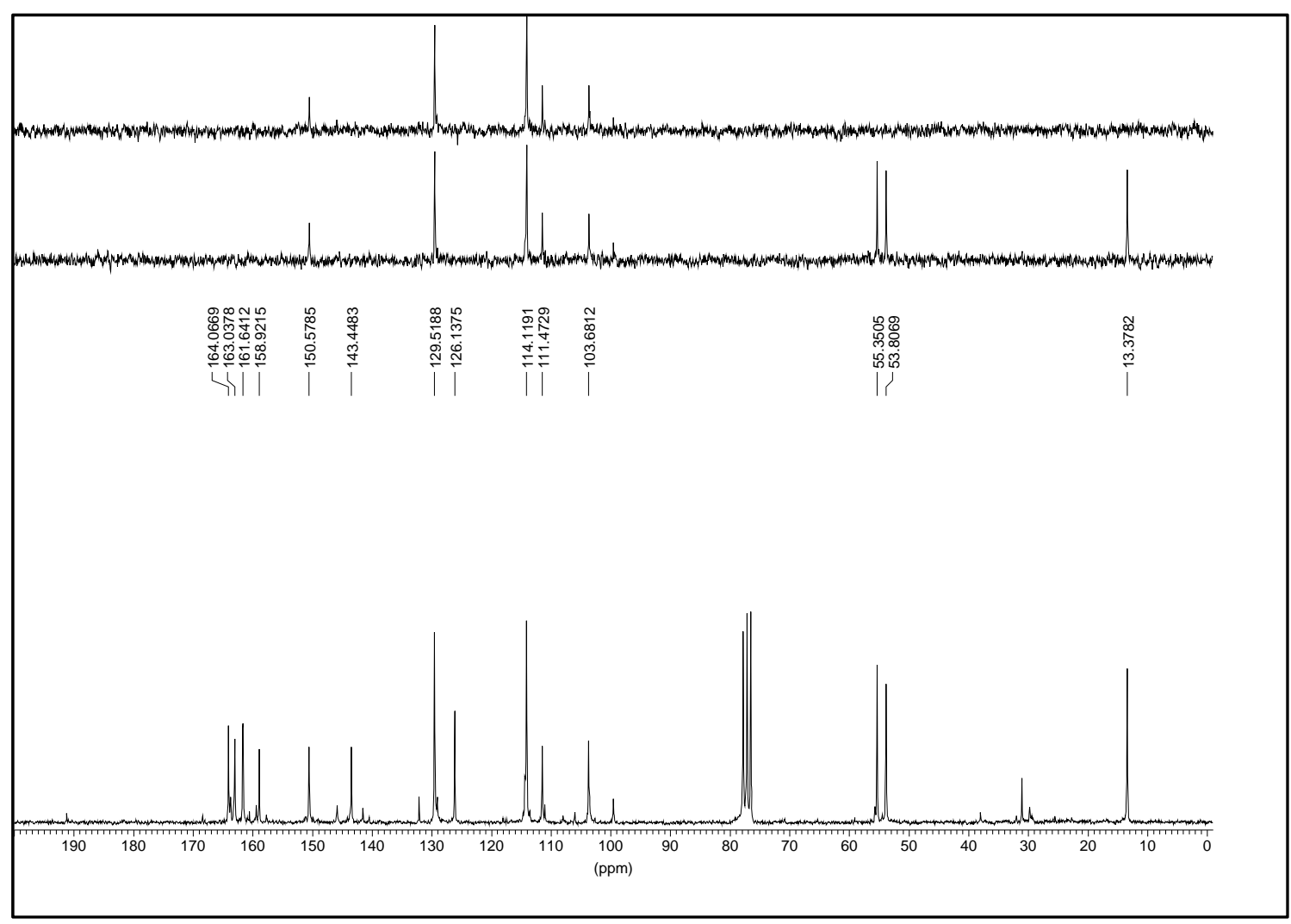

Espectro 23C 


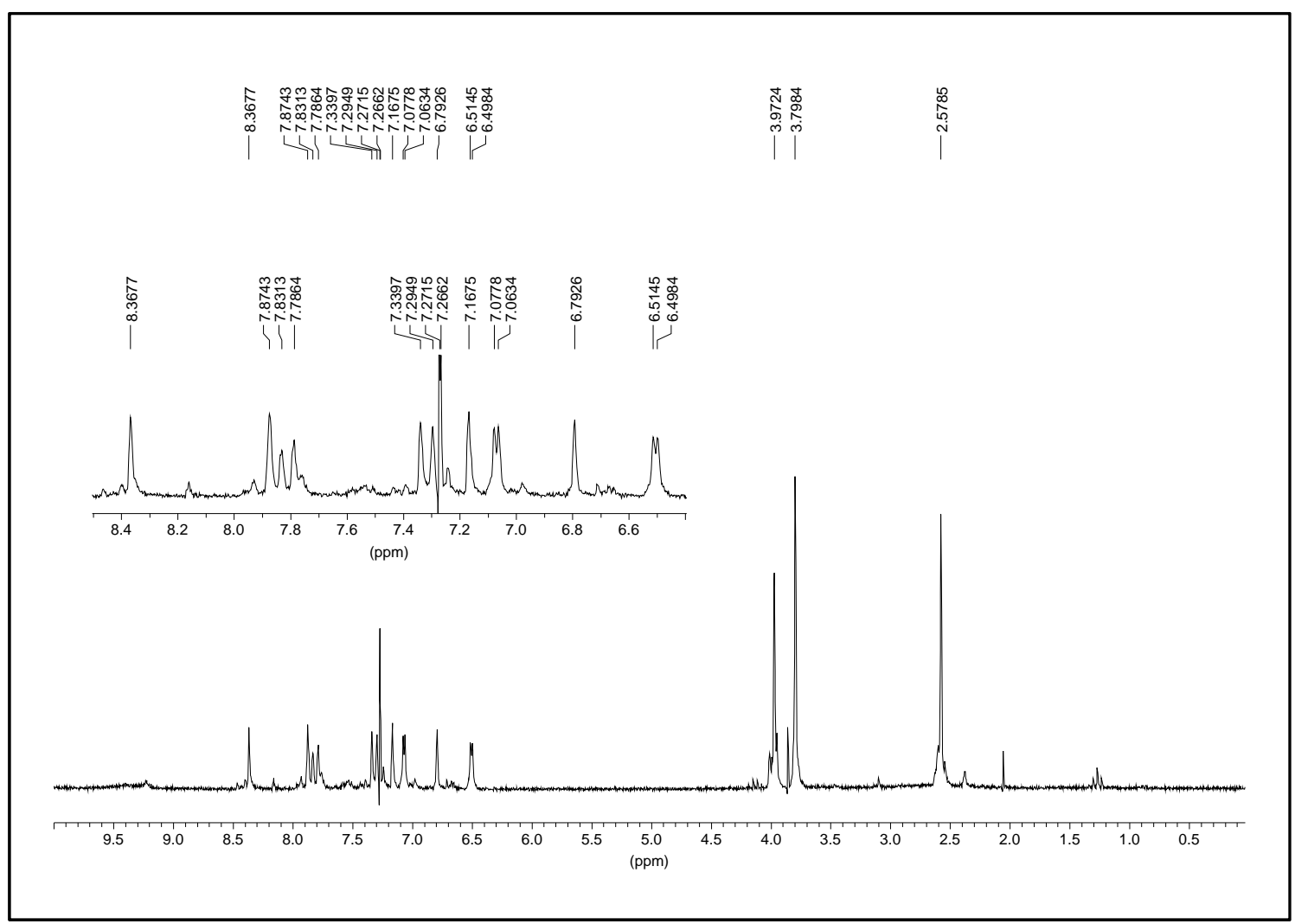

\section{Espectro 24H}

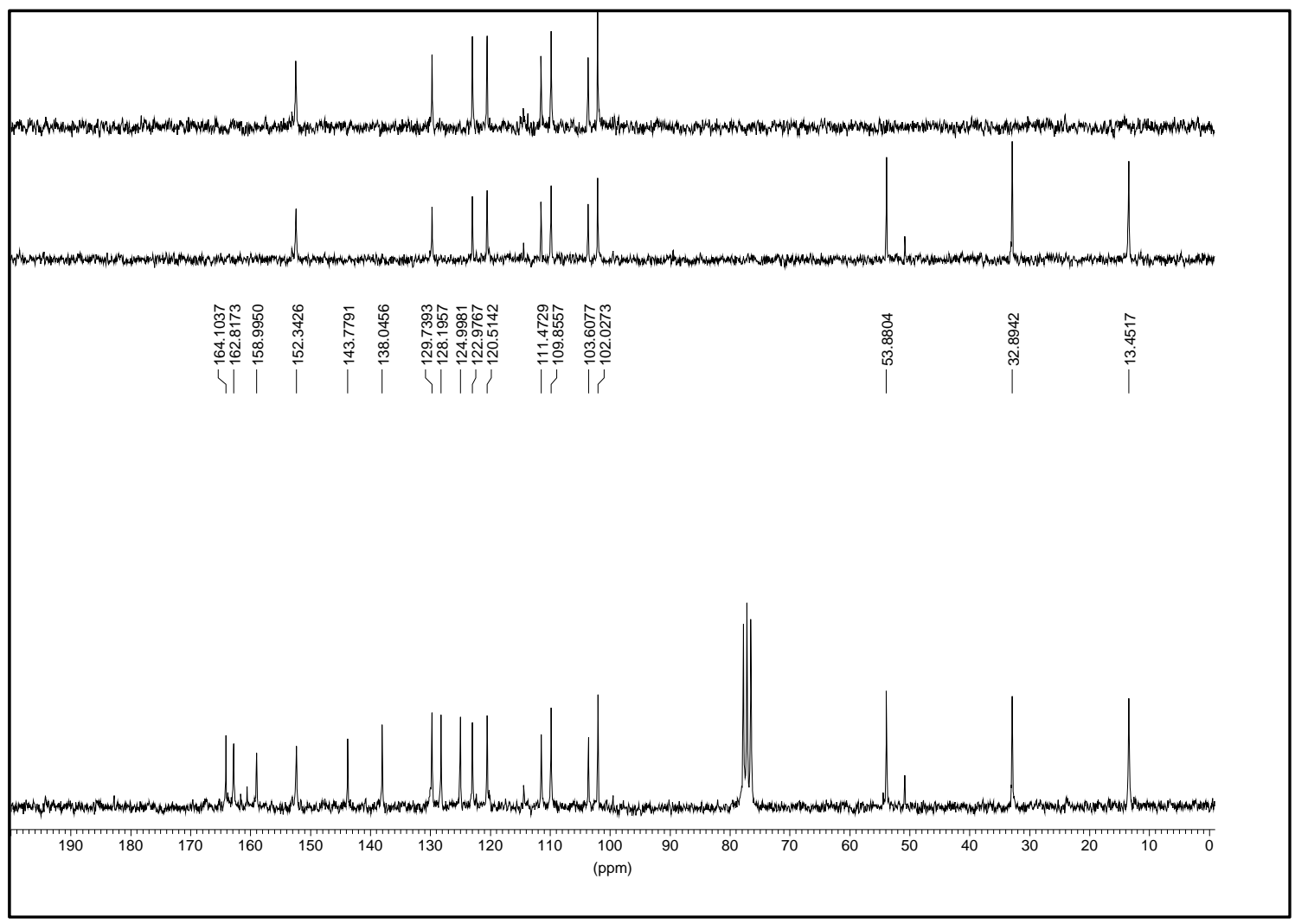

Espectro 24C 


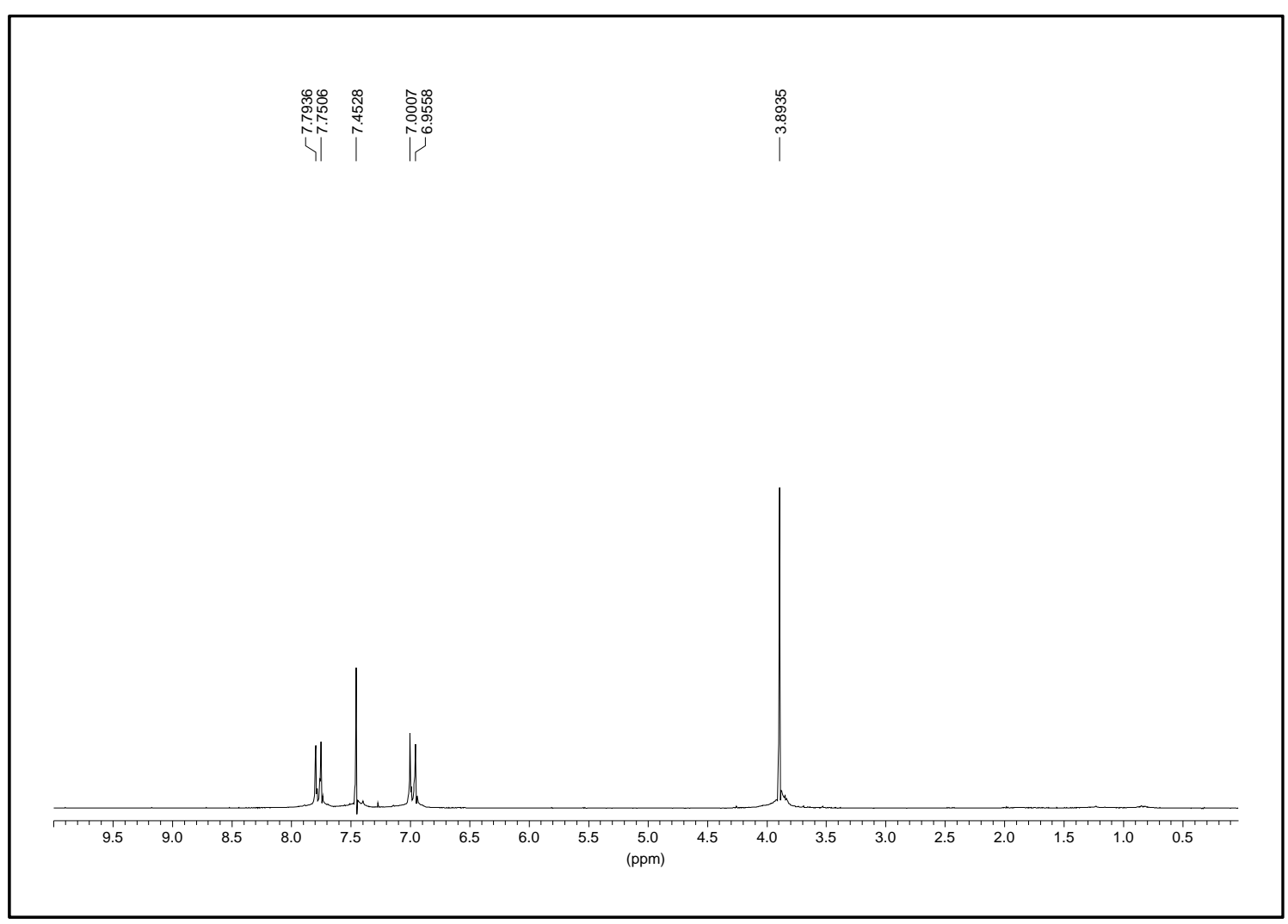

Espectro $25 \mathrm{H}$

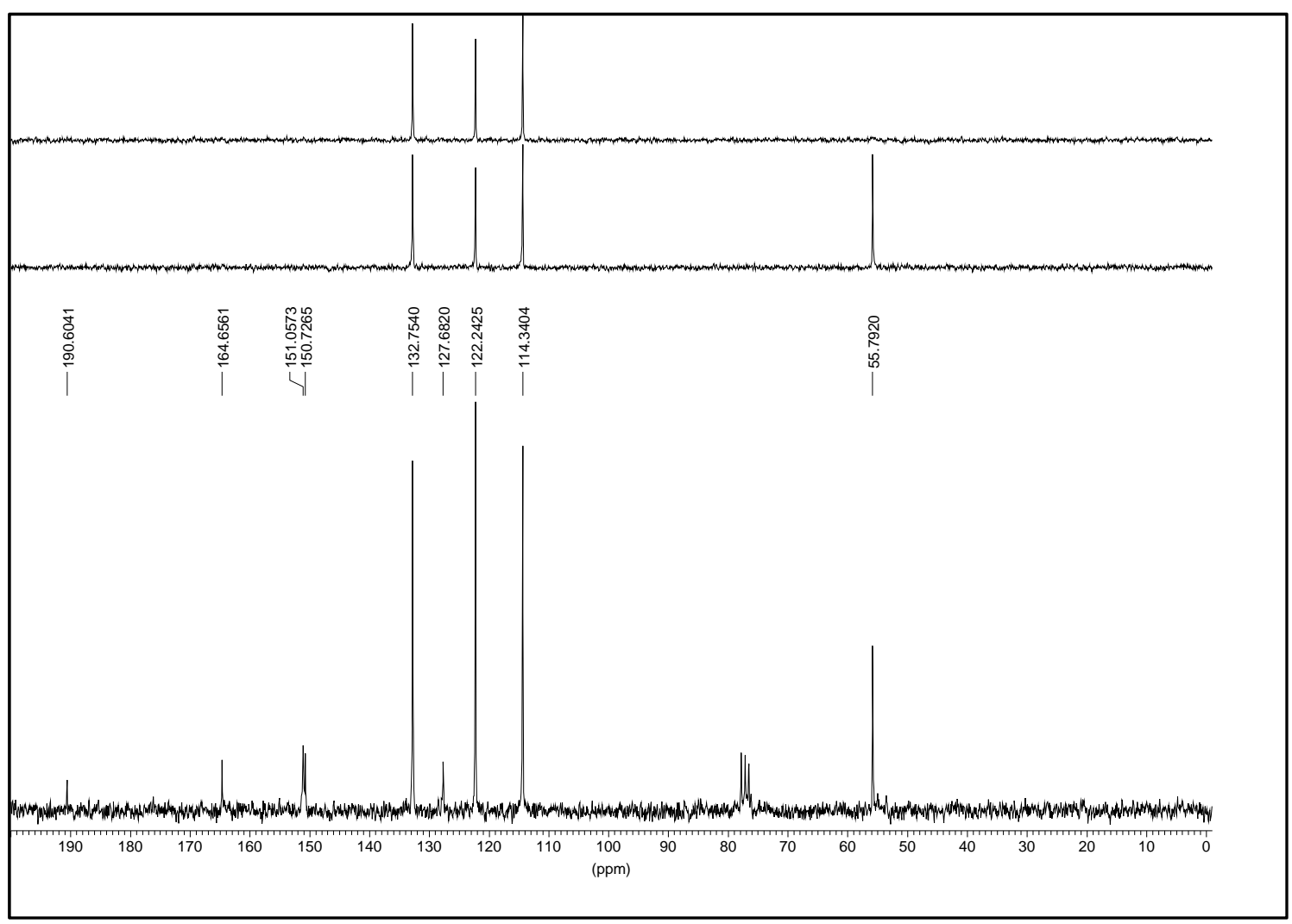

Espectro 25C 


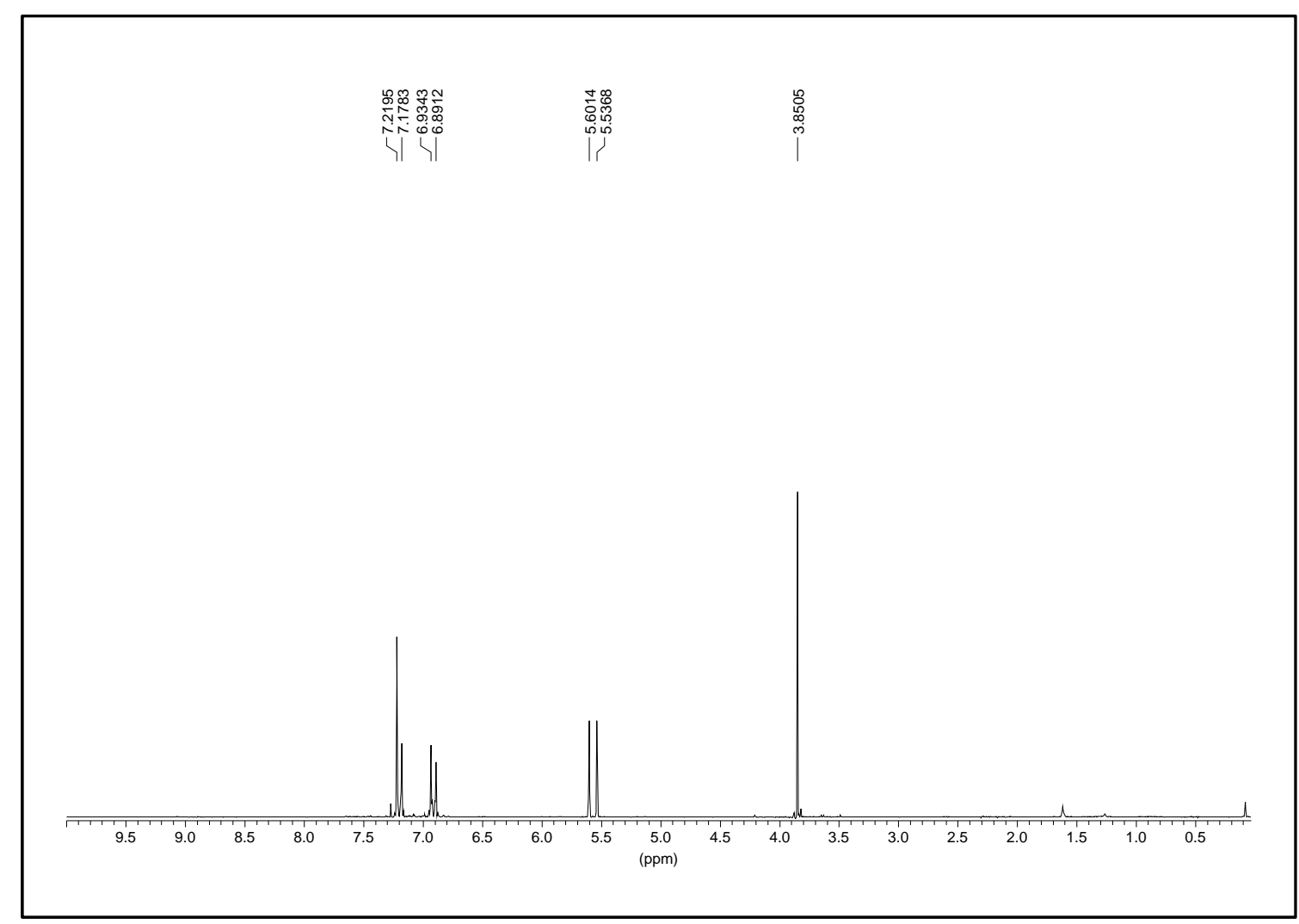

Espectro $26 \mathrm{H}$

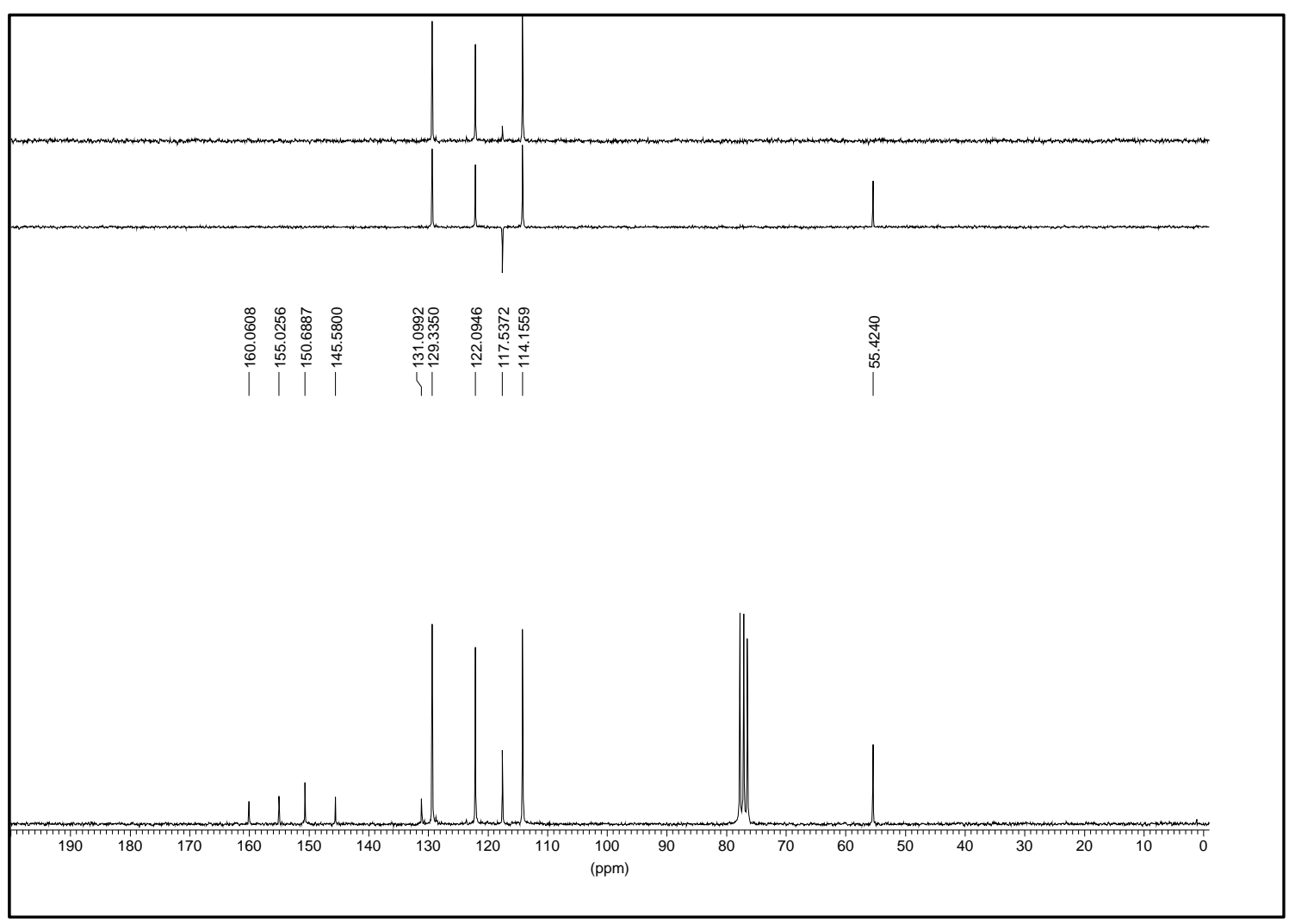

Espectro 26C 


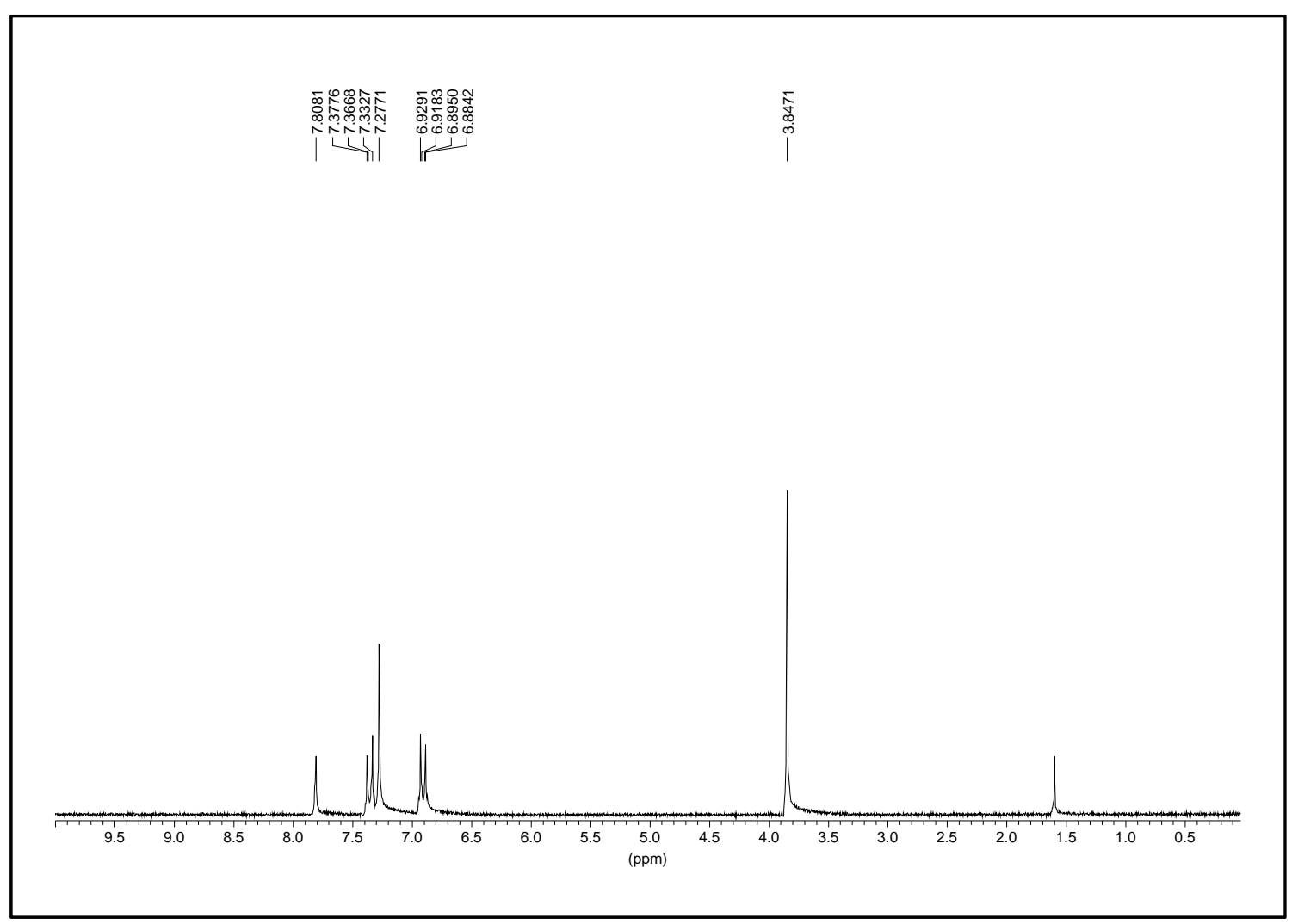

\section{Espectro 27ZH}

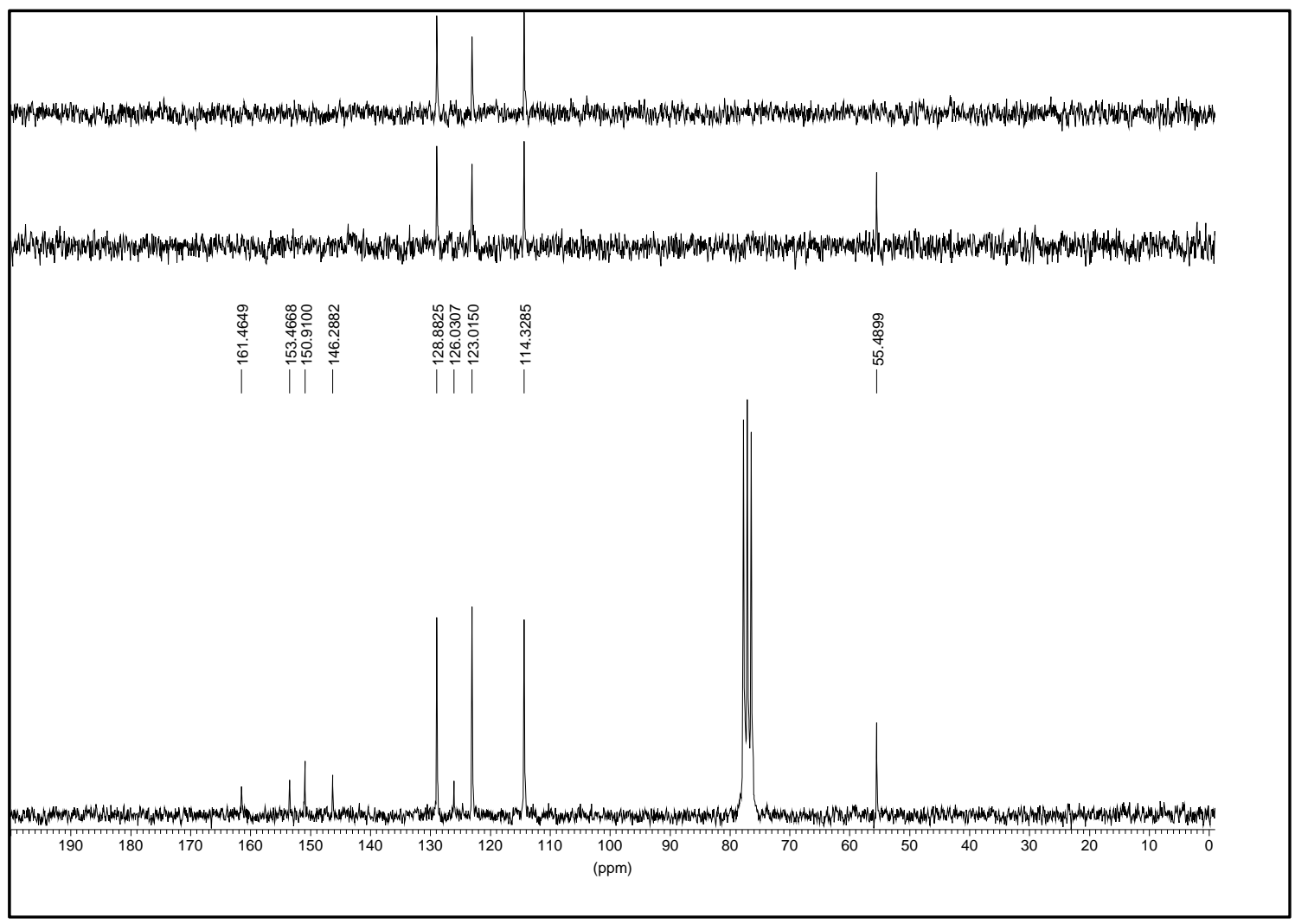

Espectro 27ZC 


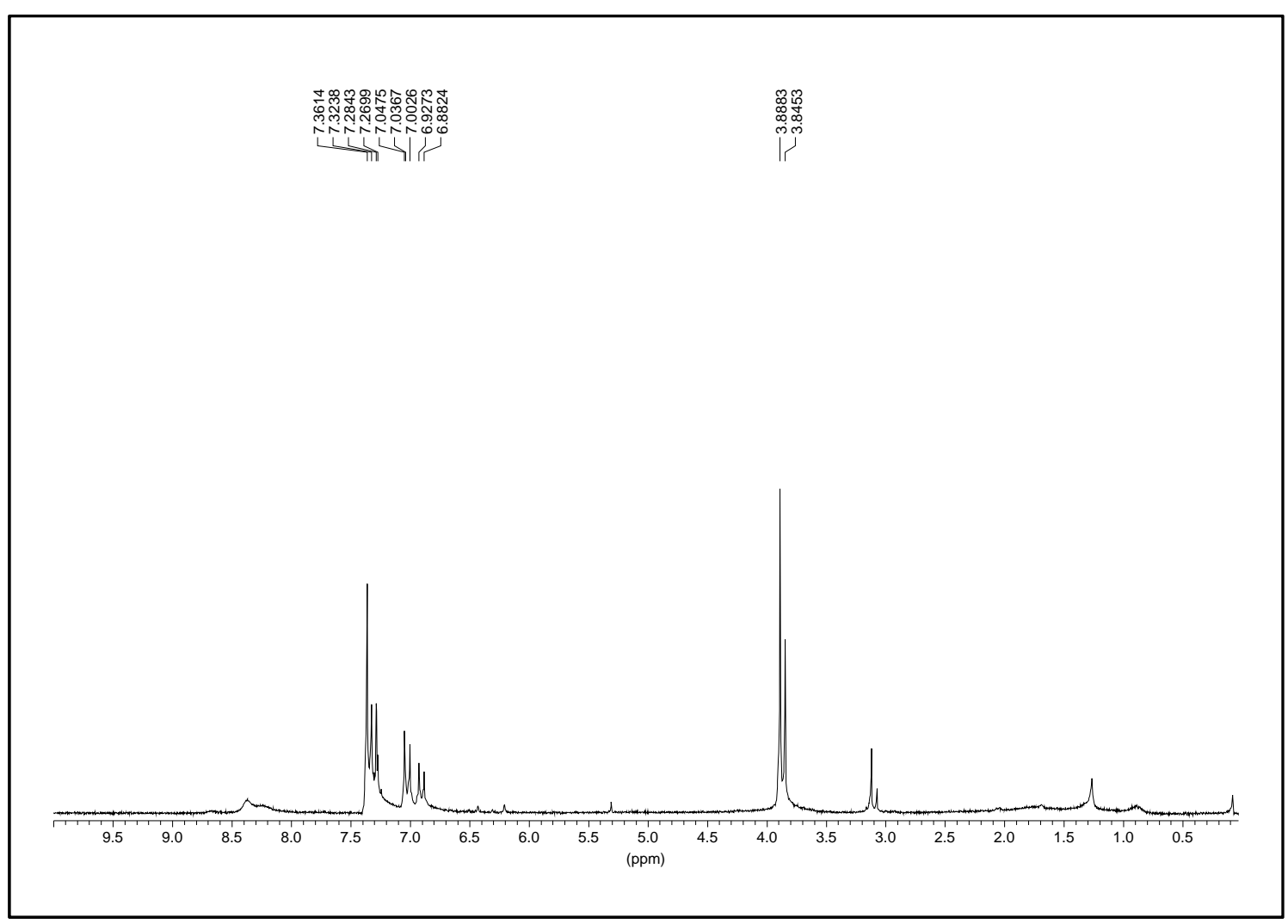

\section{Espectro 27ZEH}

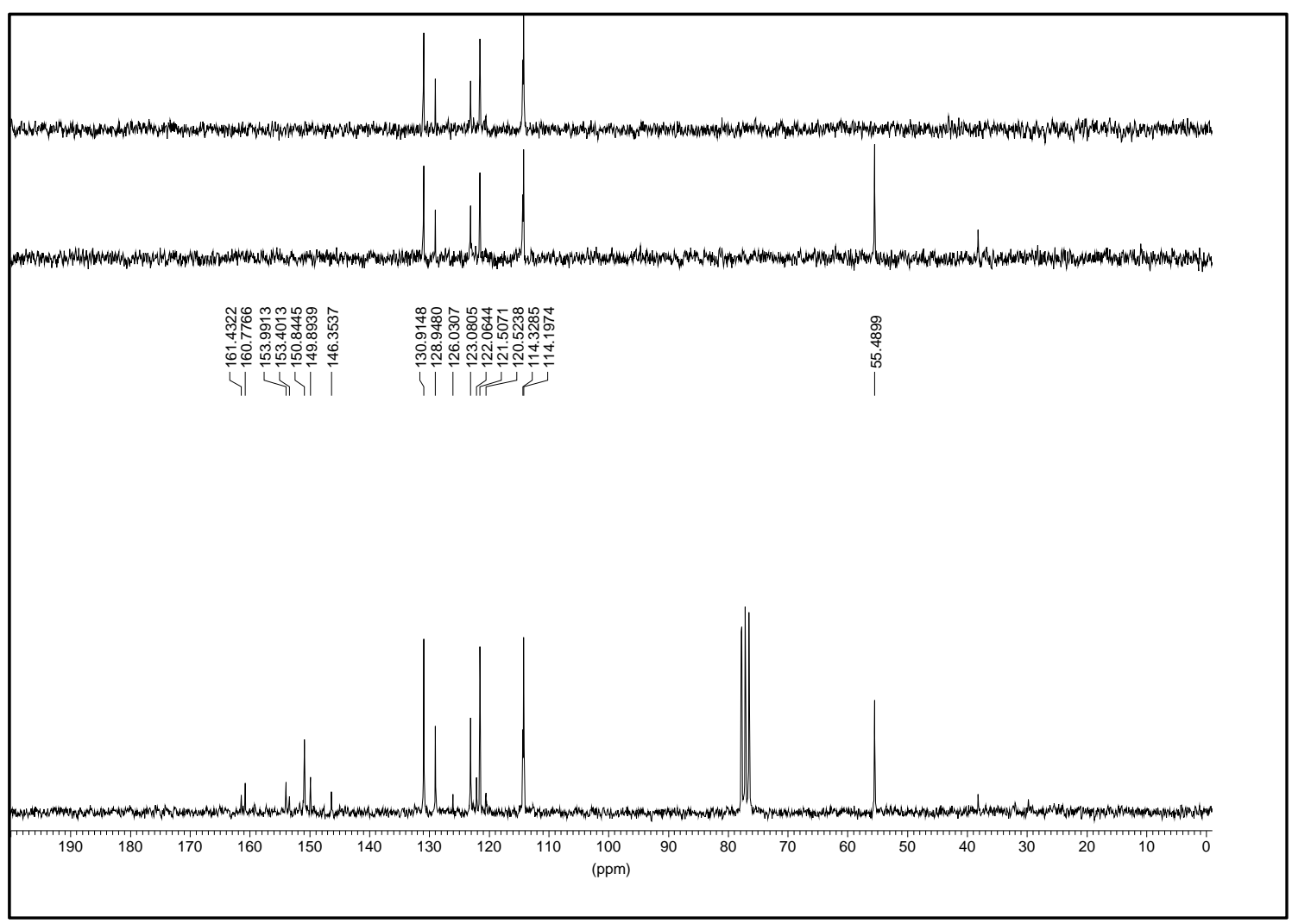

Espectro 27ZEH 


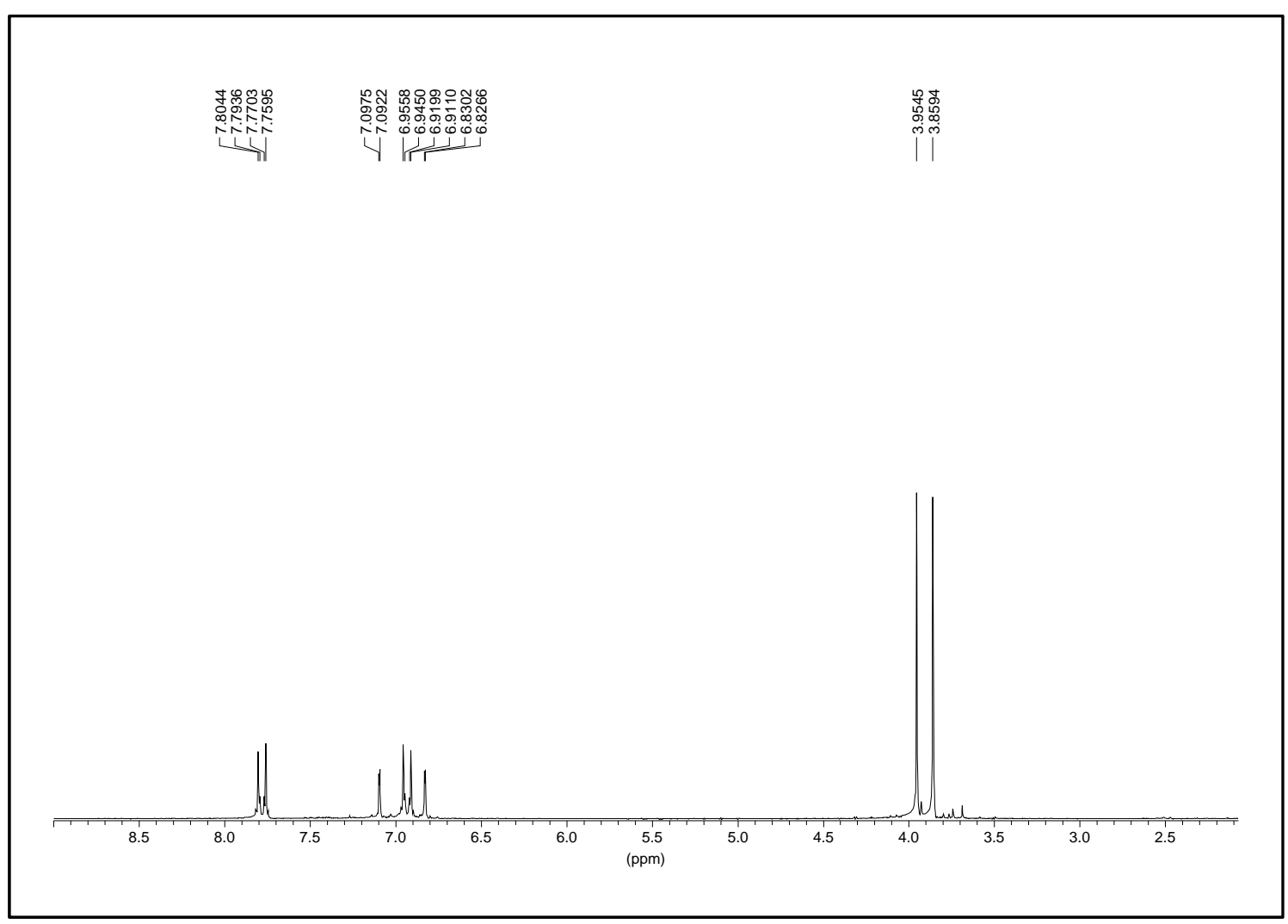

\section{Espectro $\mathbf{2 8} \mathrm{H}$}

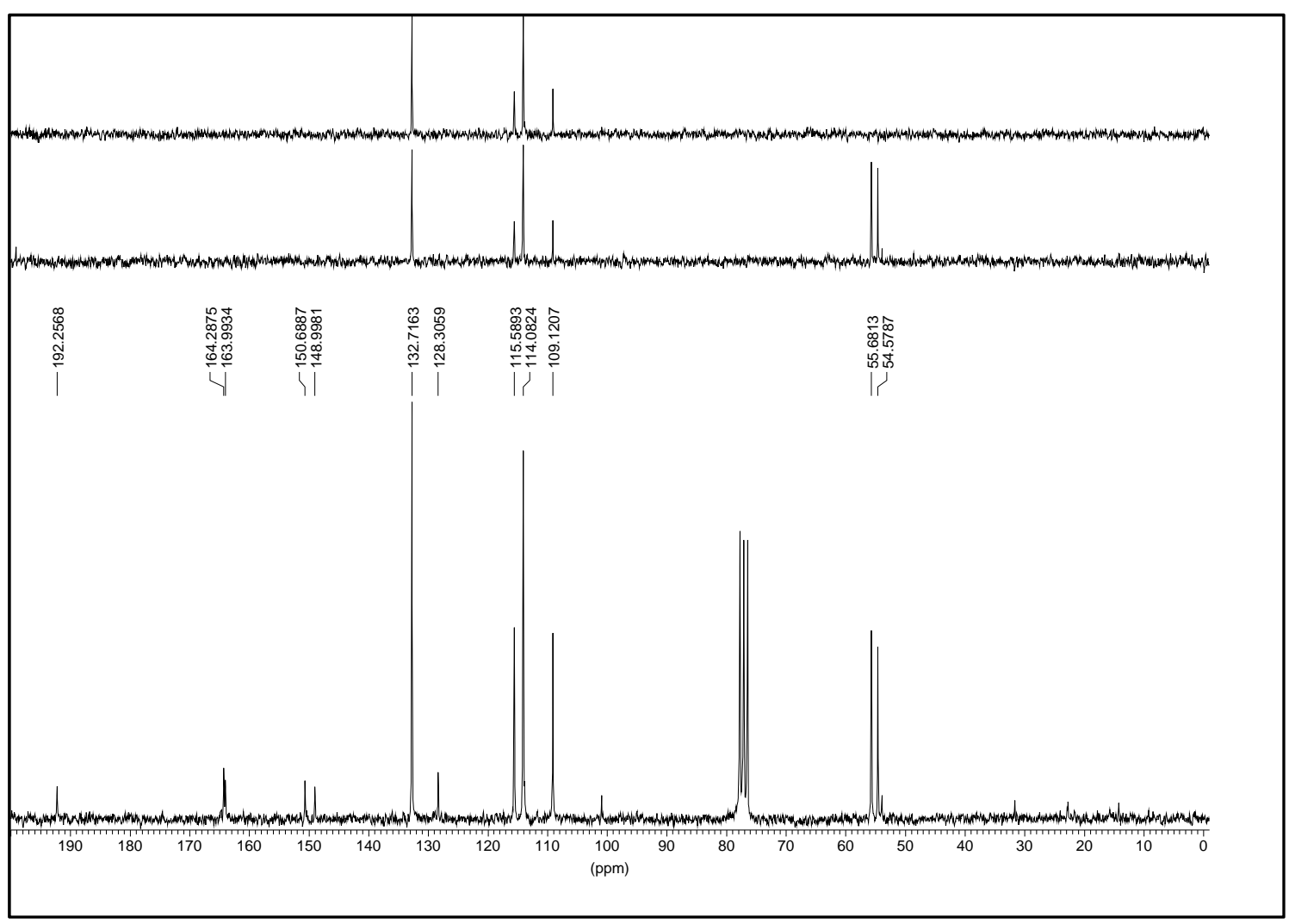

Espectro 28C 


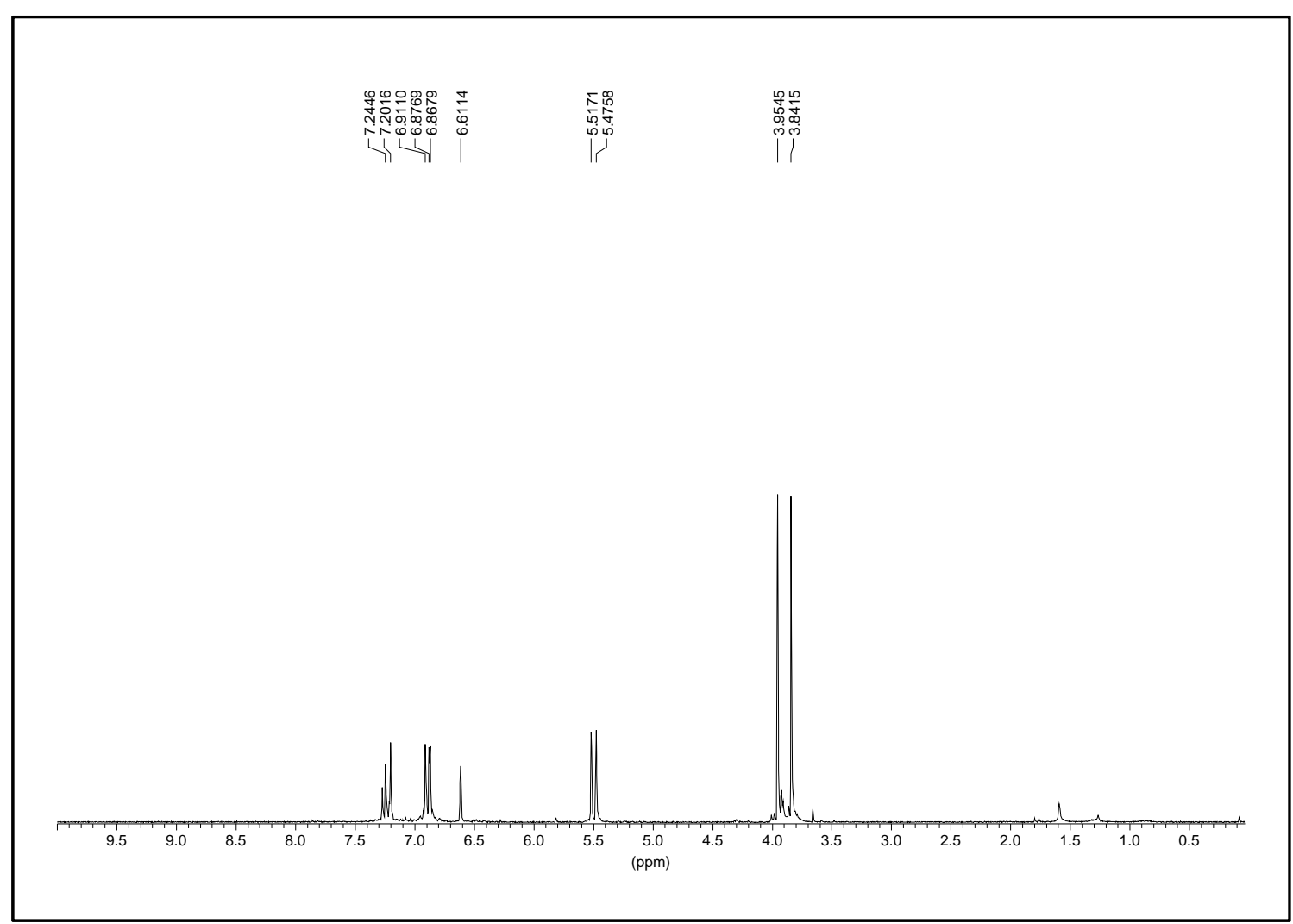

Espectro $29 \mathrm{H}$

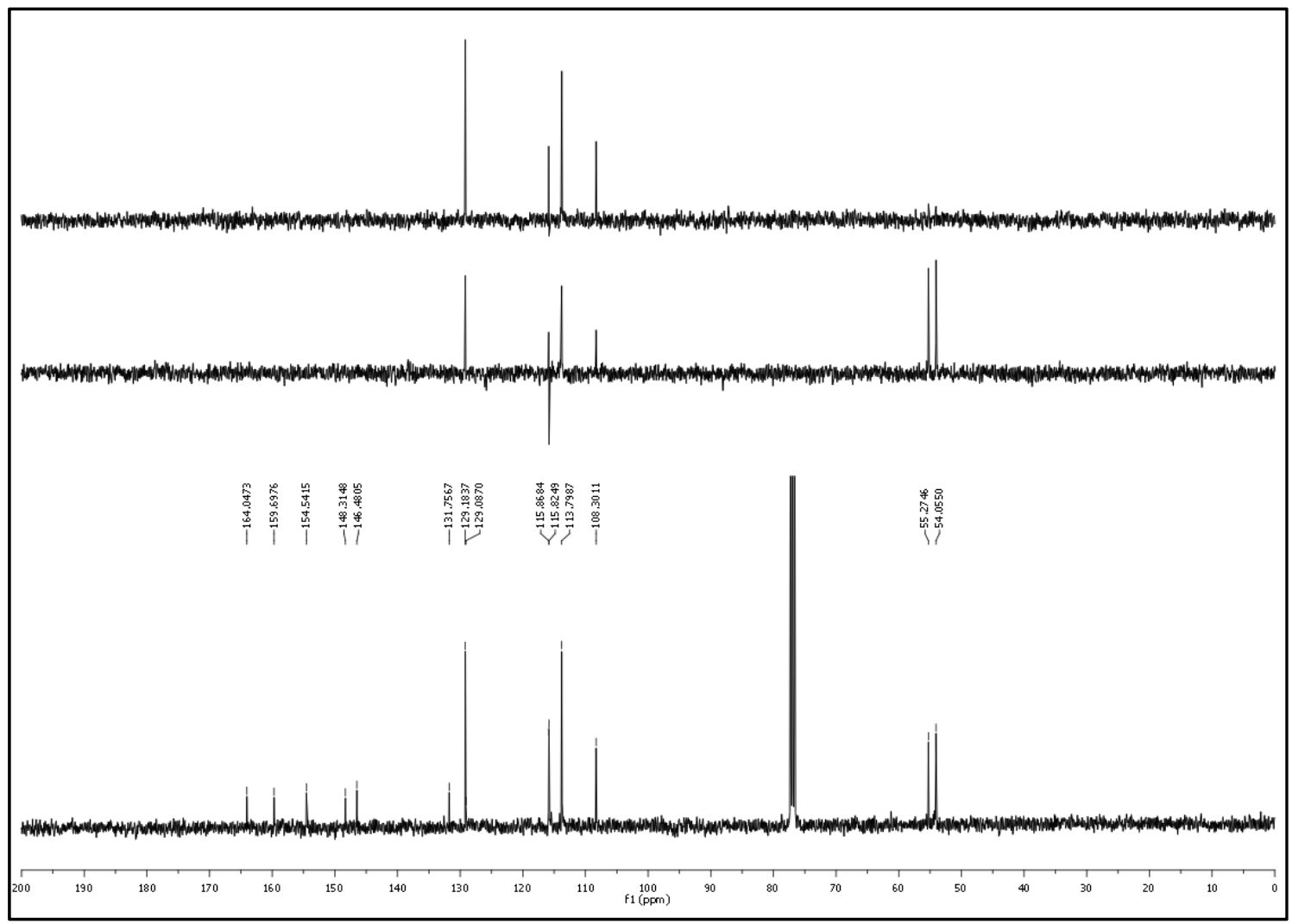

Espectro 29C 


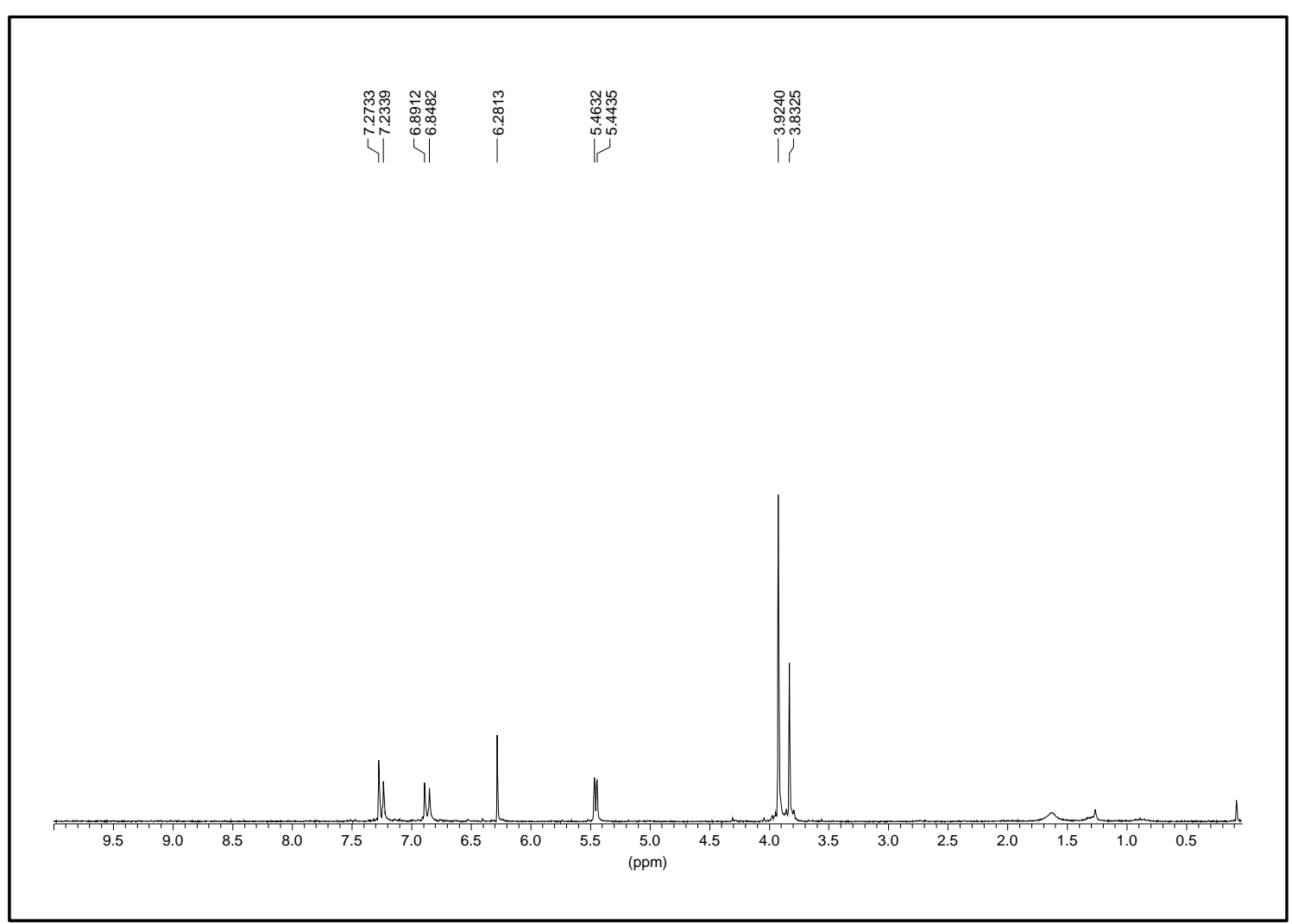

Espectro $\mathbf{3 0 H}$

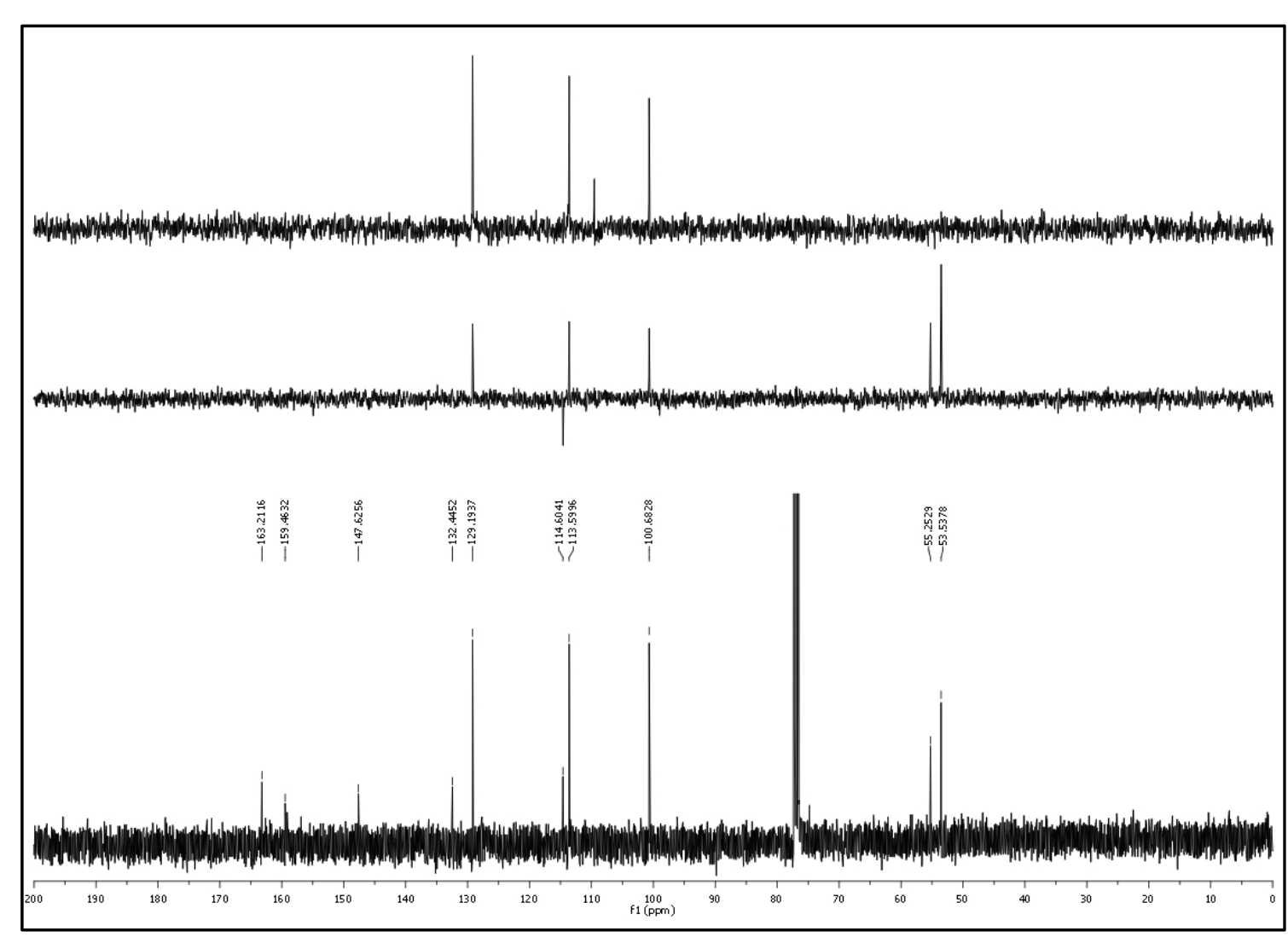

Espectro 30C 


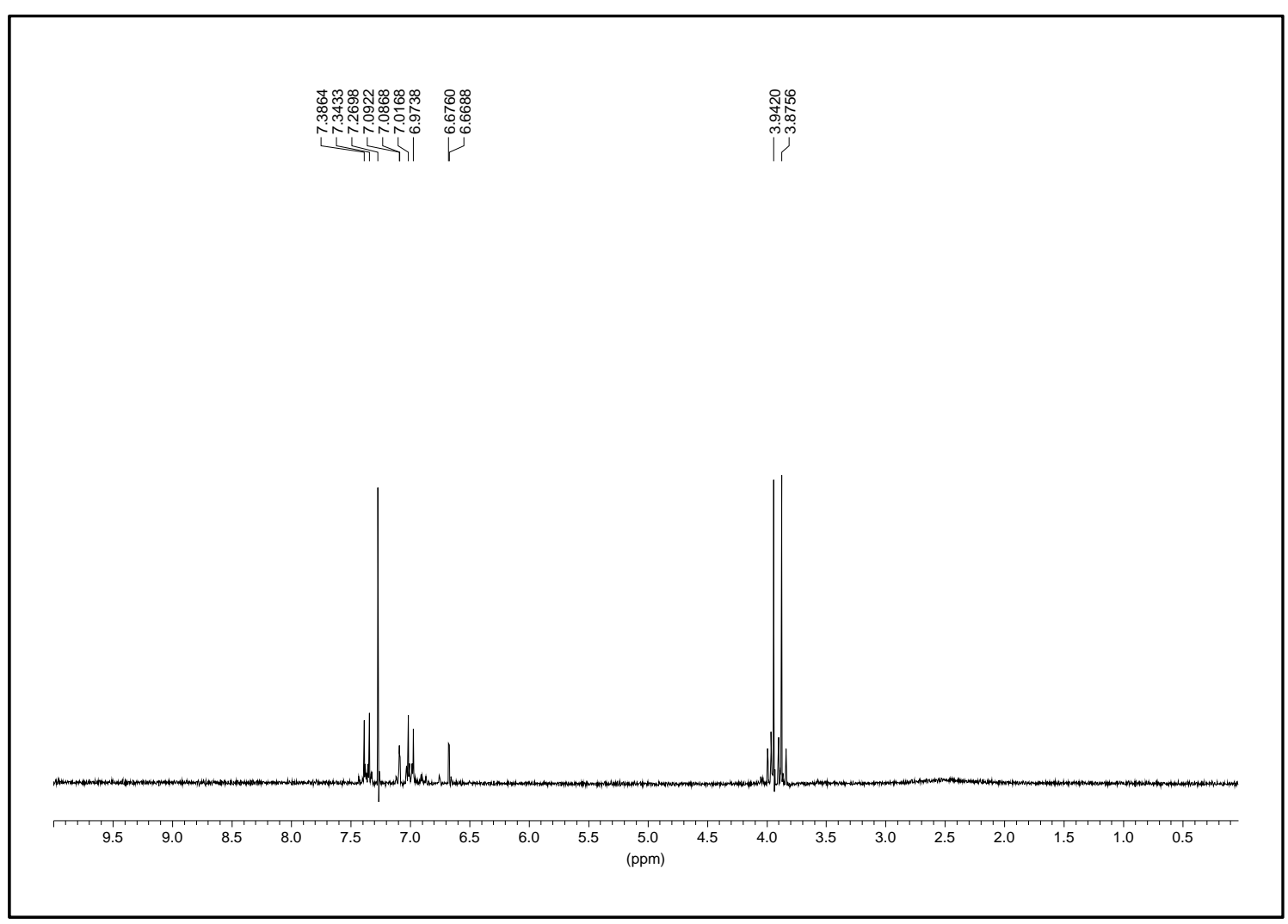

\section{Espectro 31EH}

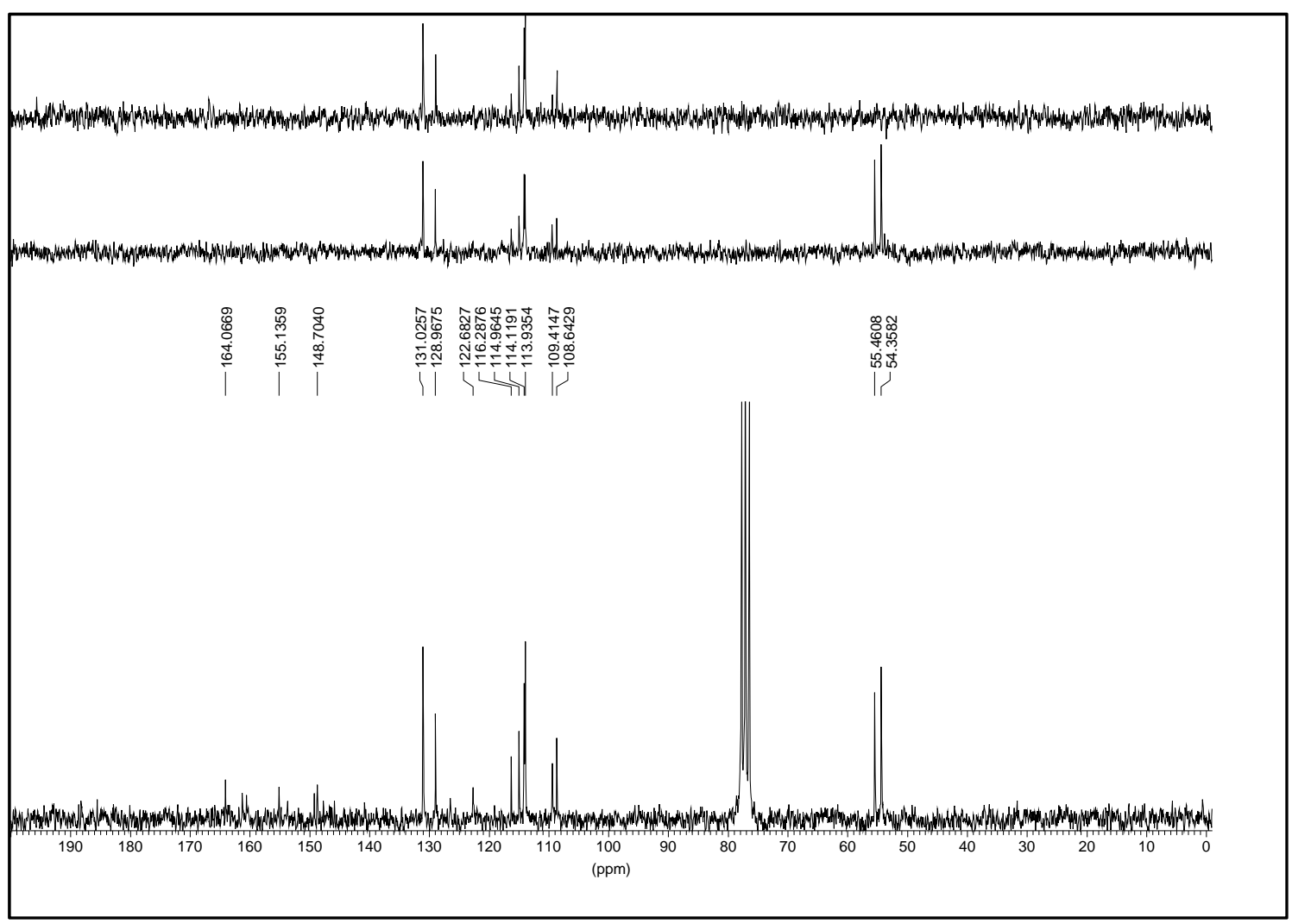

Espectro 31 ZEC 


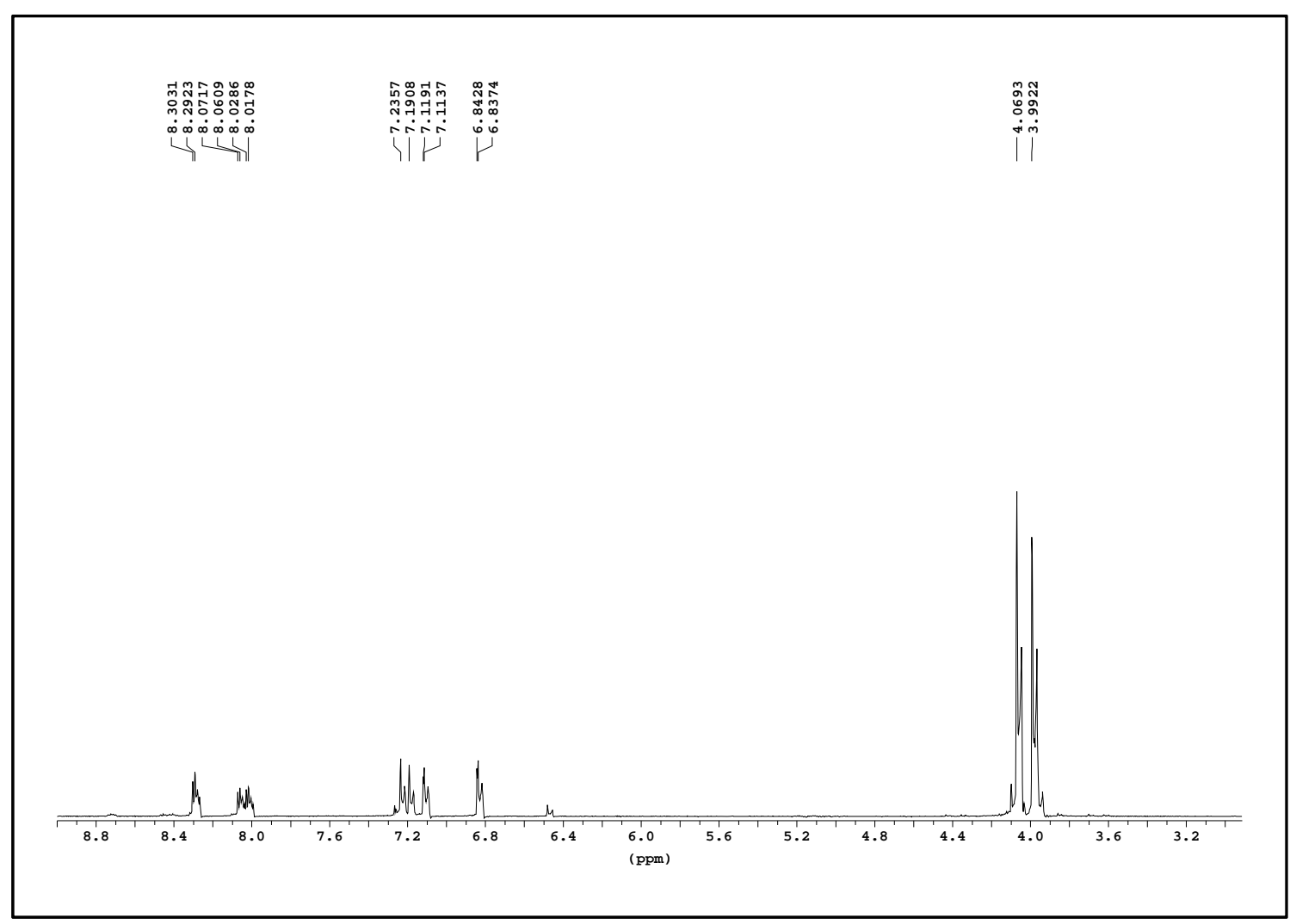

Espectro $32 \mathrm{H}$

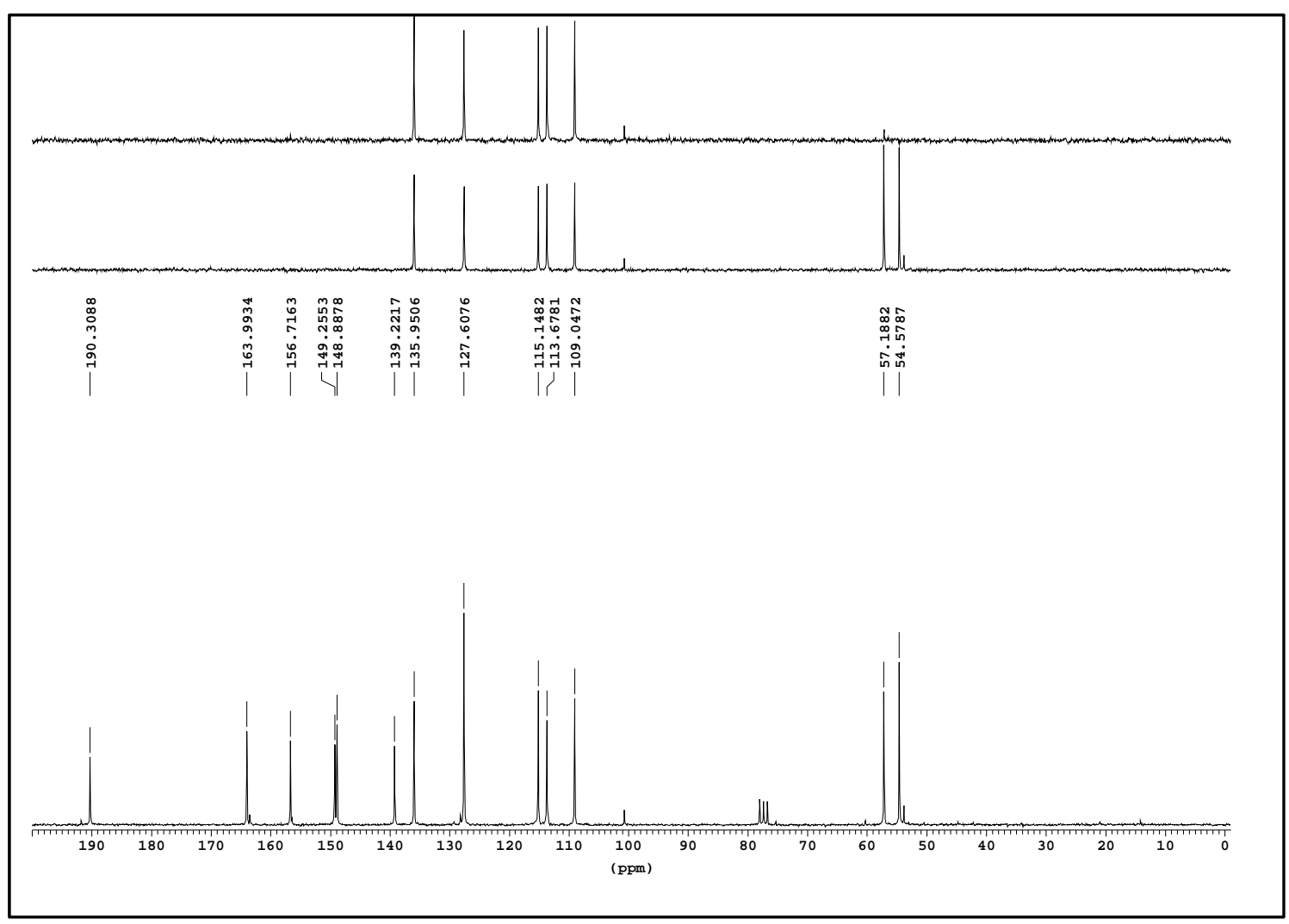

Espectro 32C 


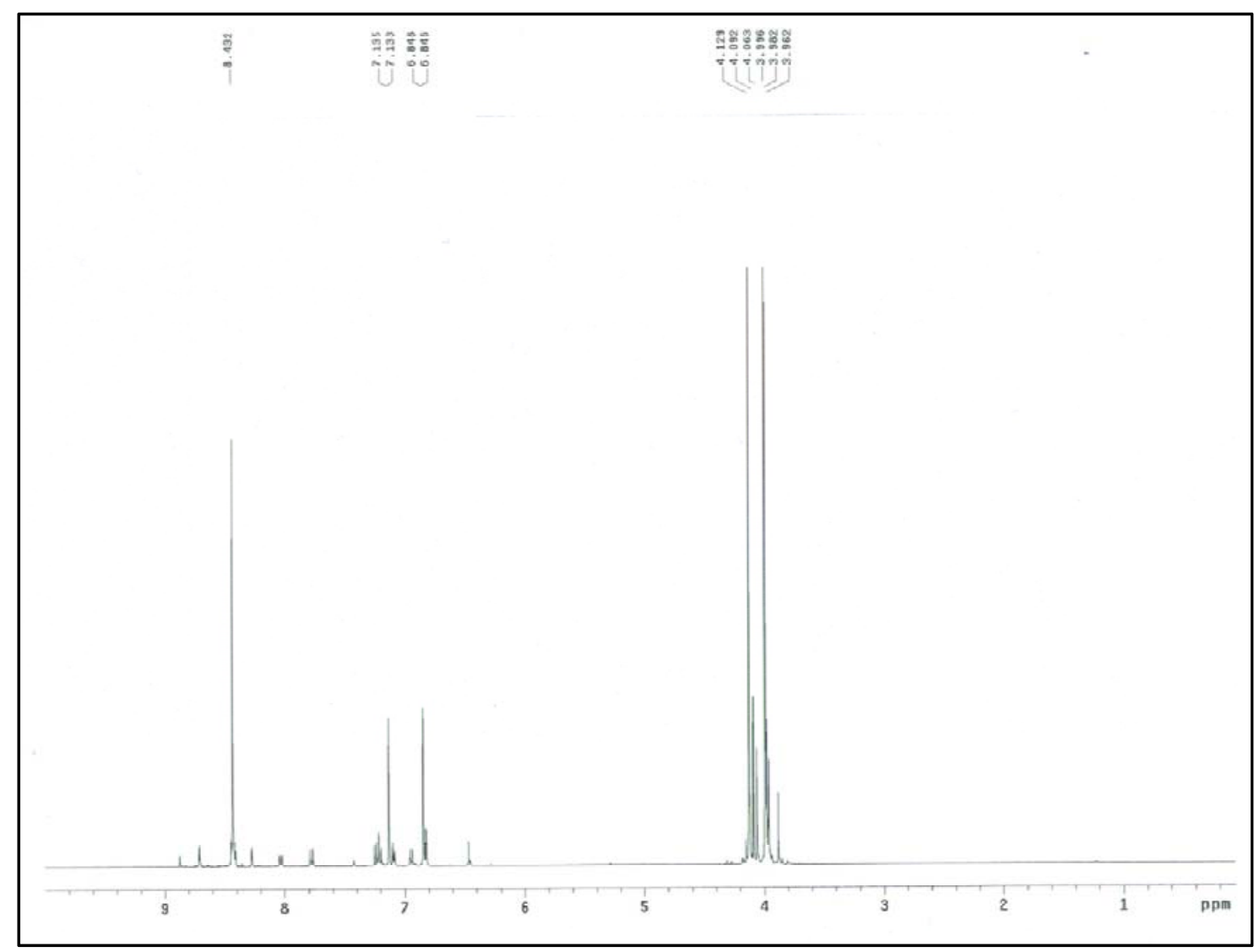

Espectro $33 \mathrm{H}$

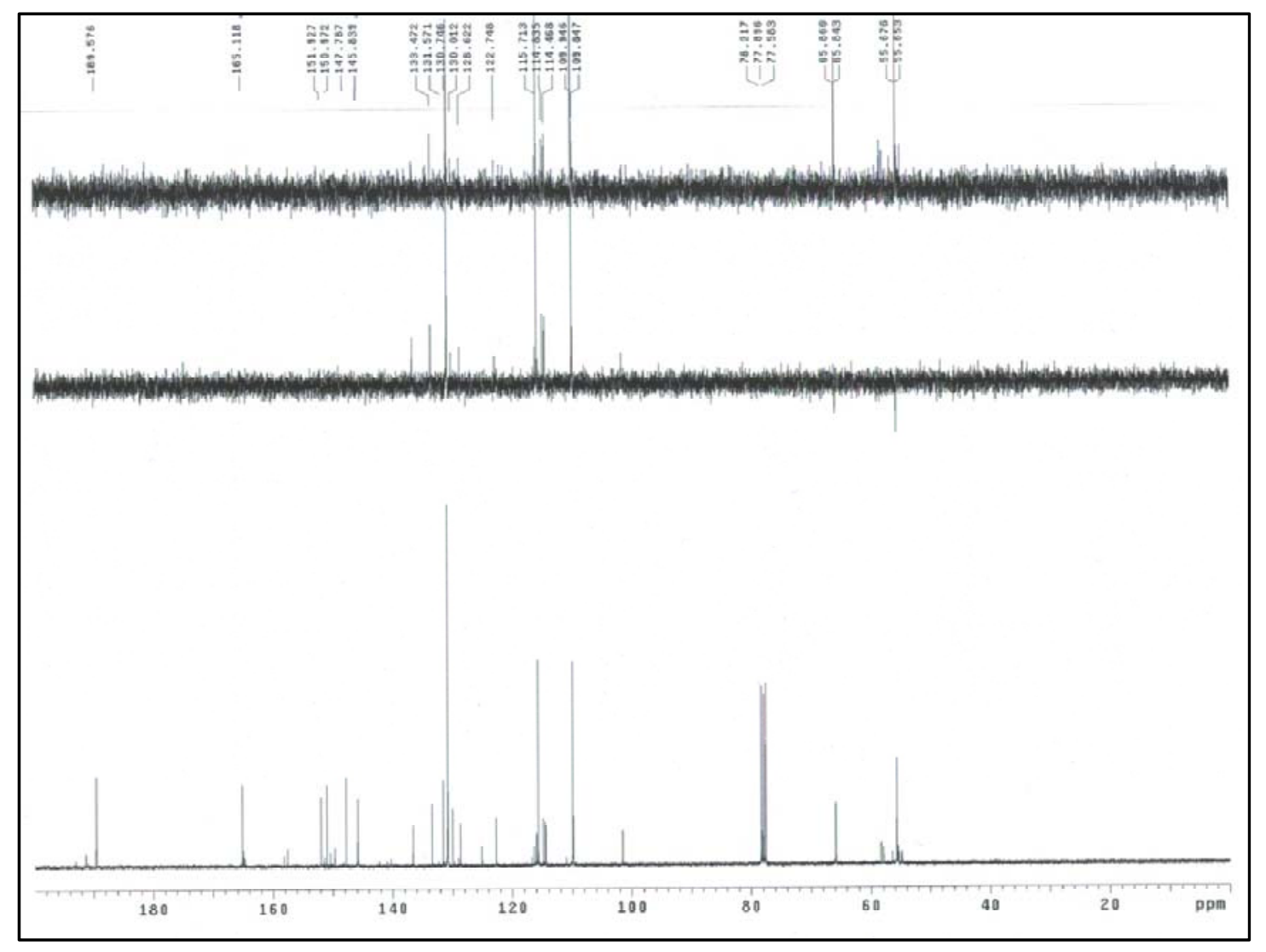

Espectro 33C 


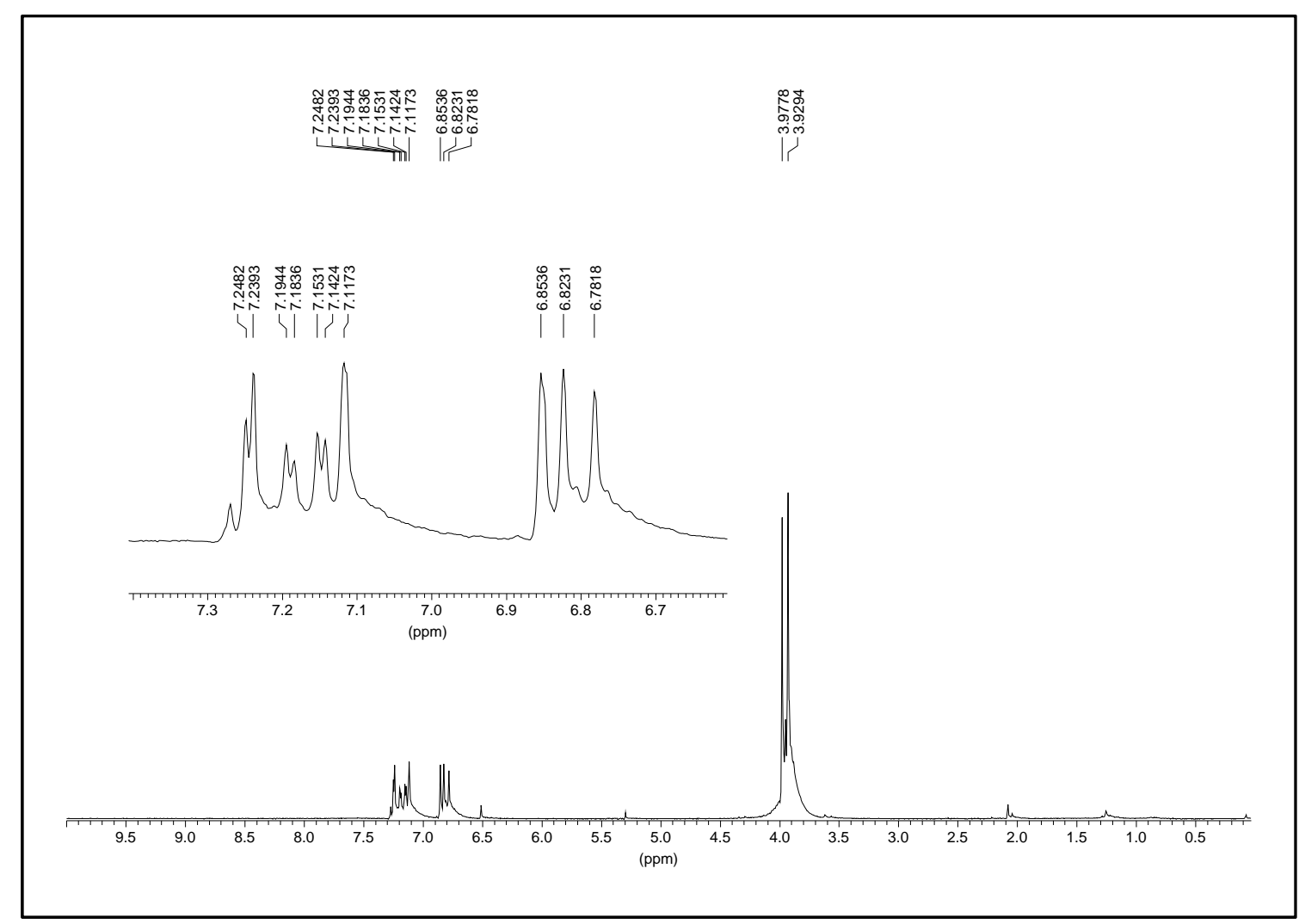

Espectro $34 \mathrm{H}$

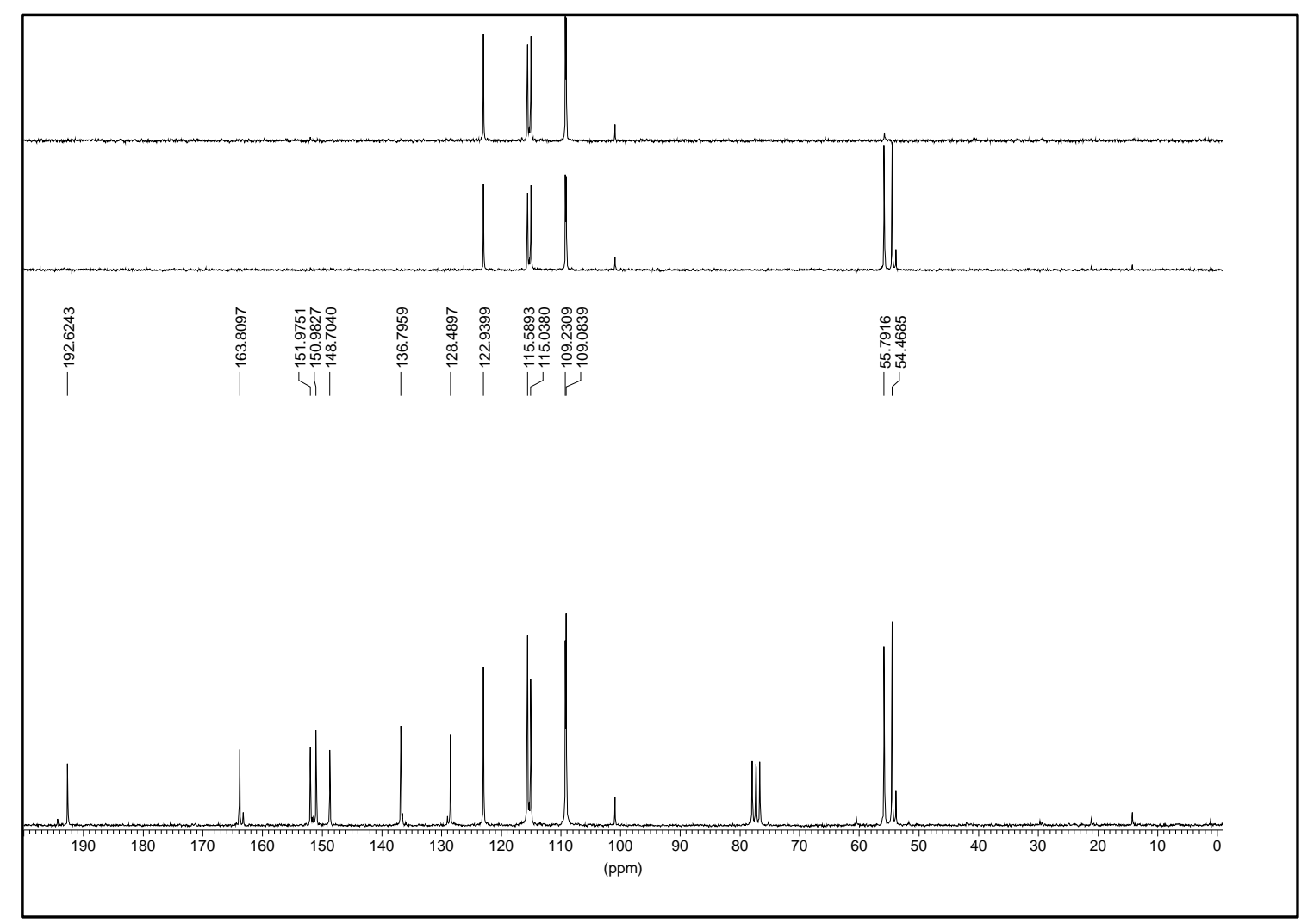

Espectro 34C 


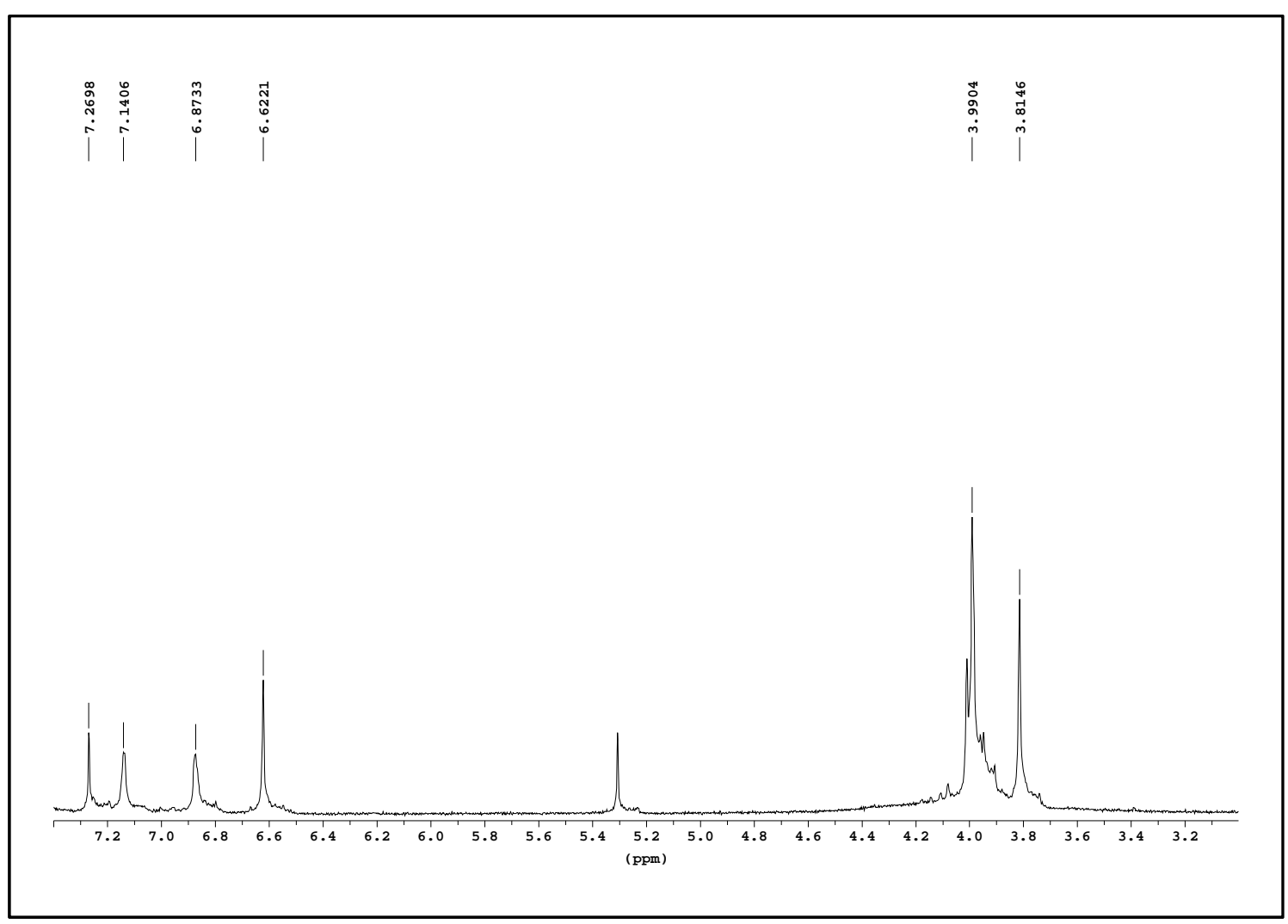

Espectro $35 \mathrm{H}$ 


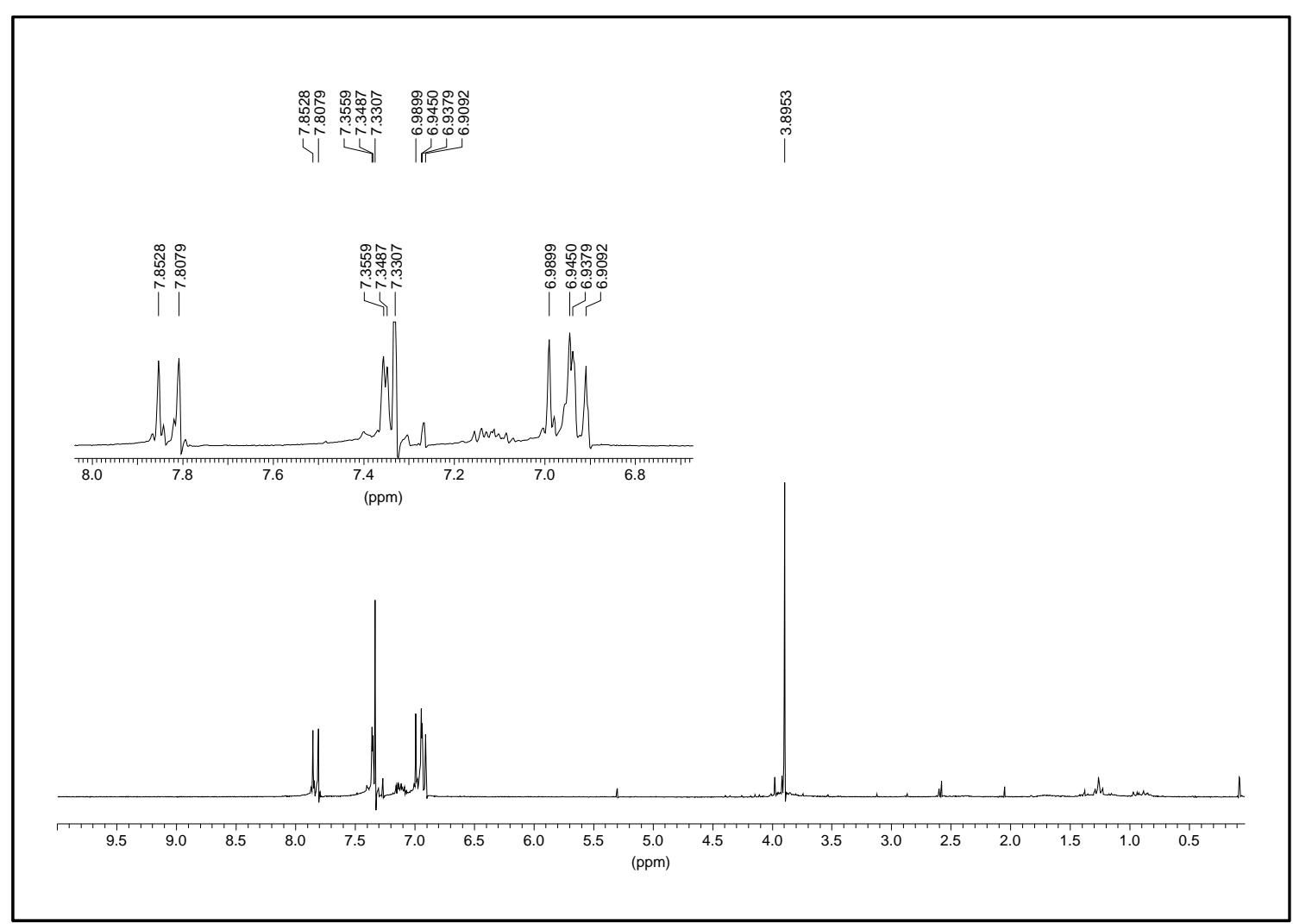

Espectro $36 \mathrm{H}$

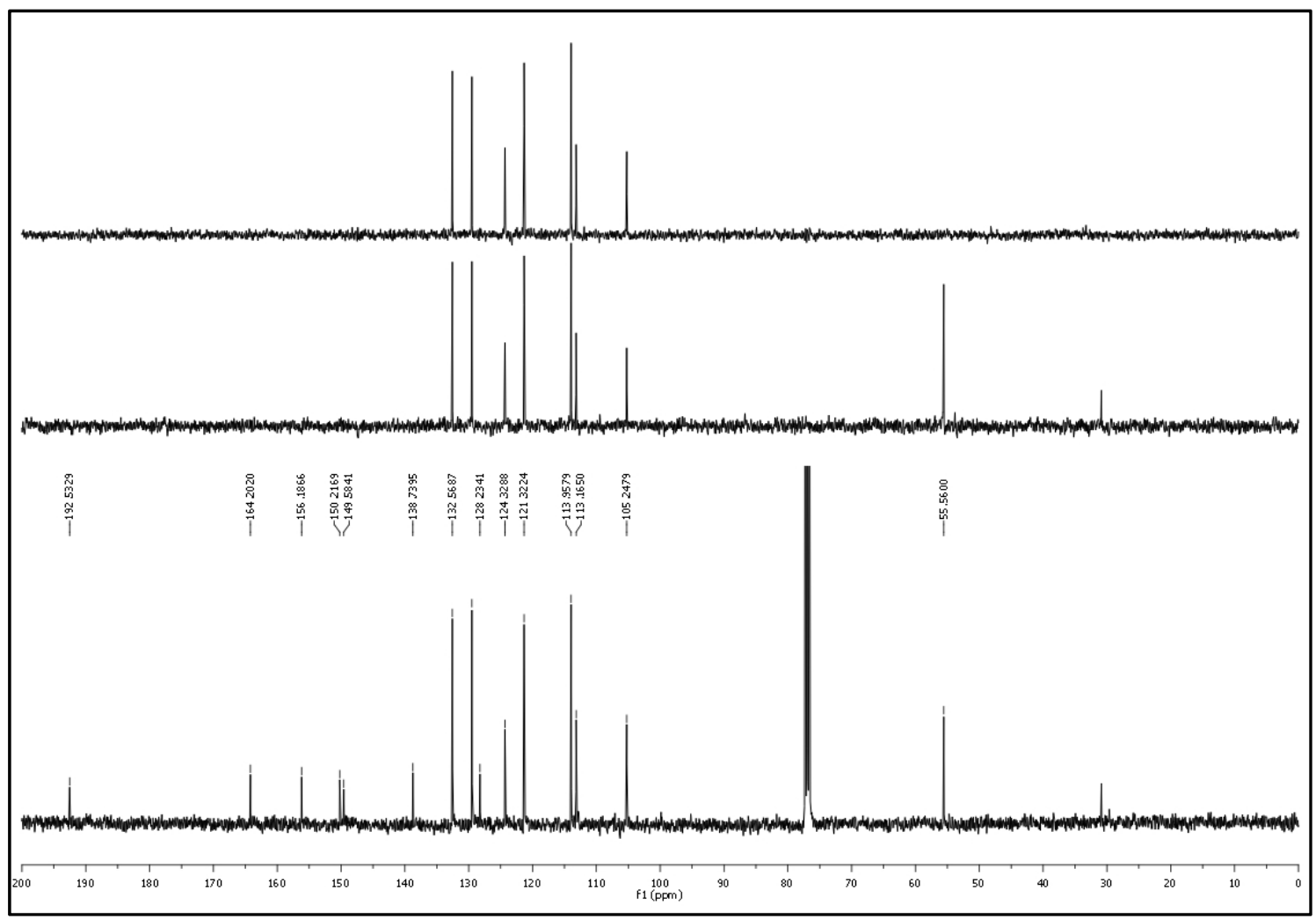

Espectro 36C 


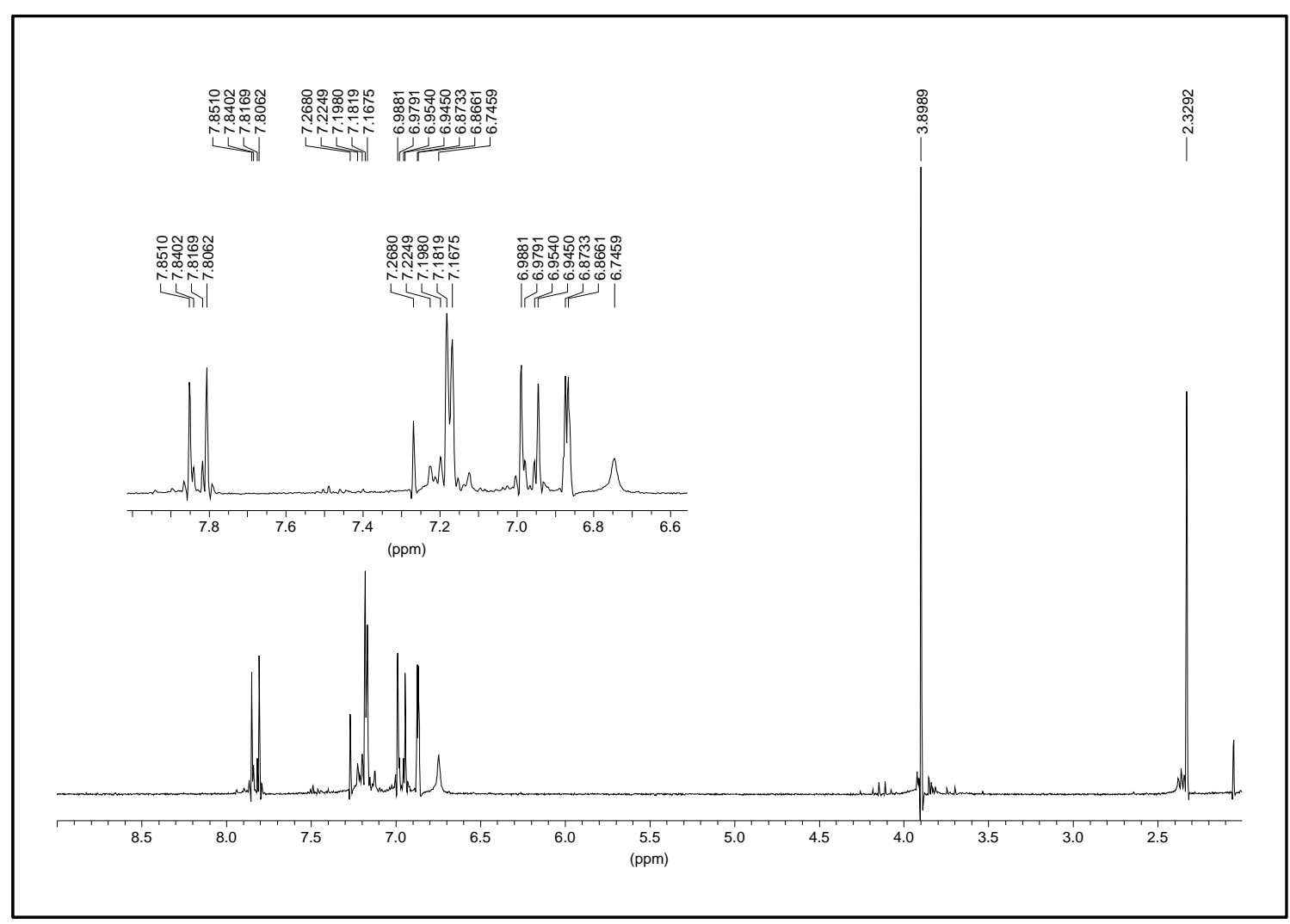

\section{Espectro $37 \mathrm{H}$}

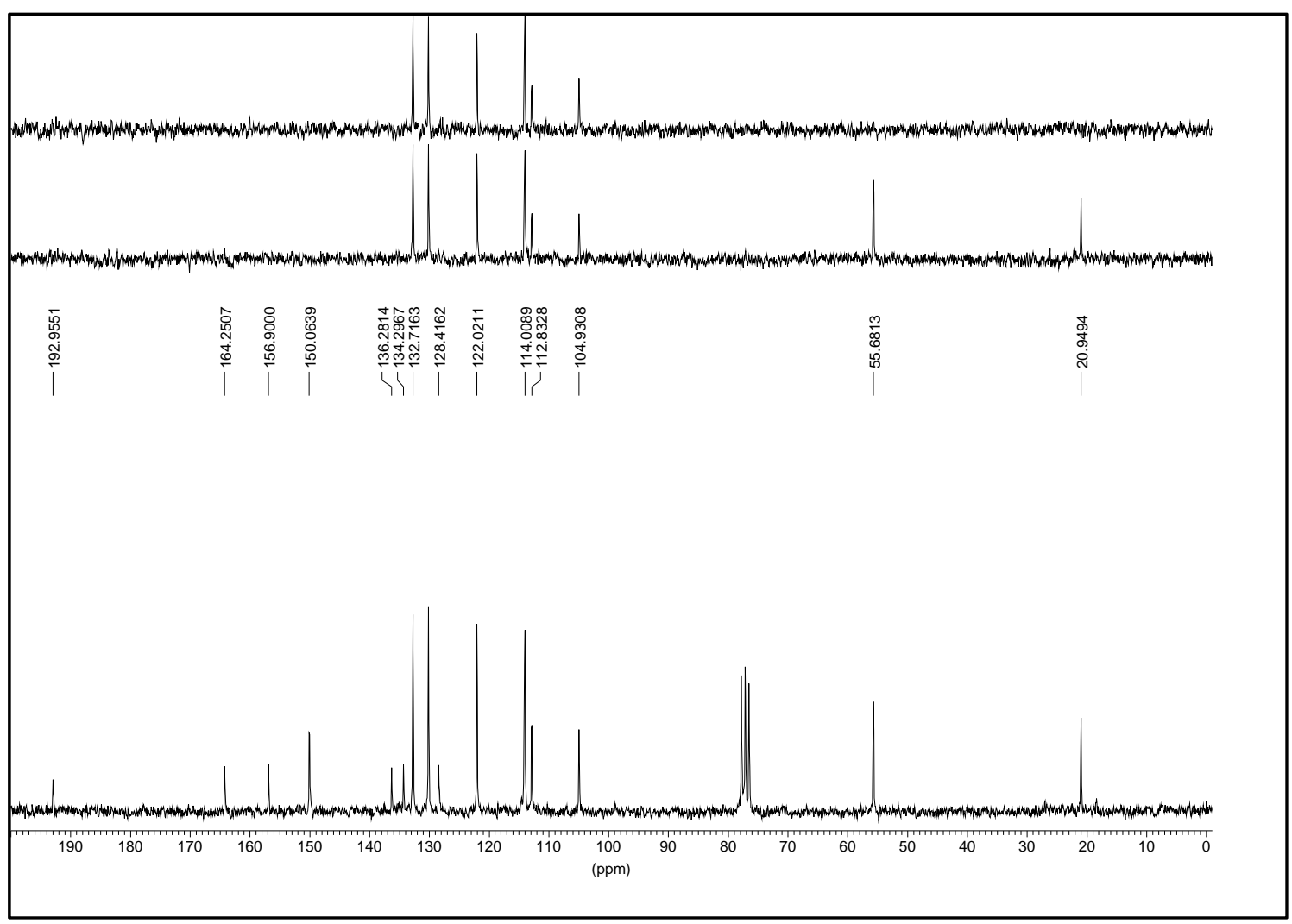

Espectro 37C 


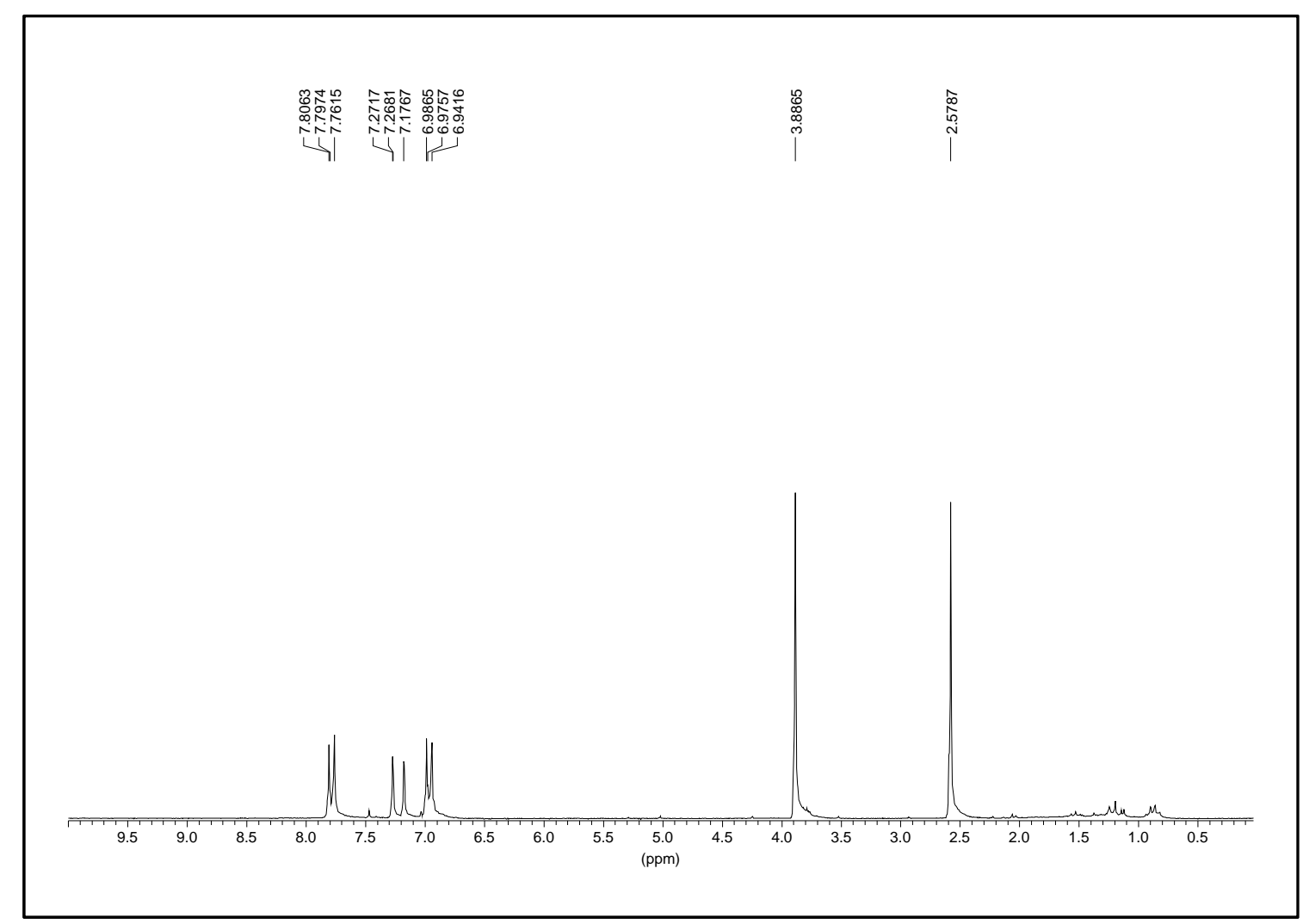

Espectro $\mathbf{3 8 H}$

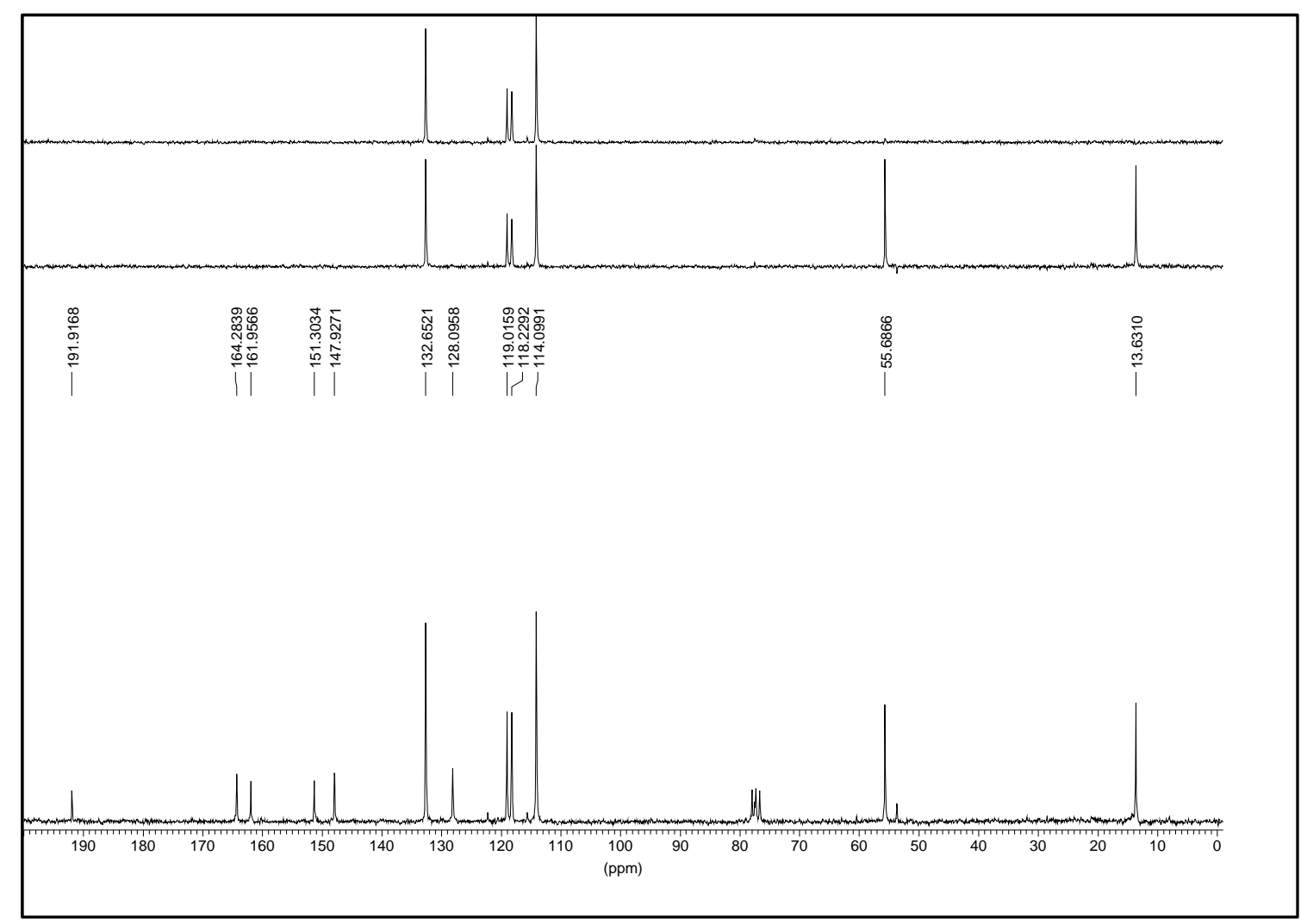

Espectro 38C 


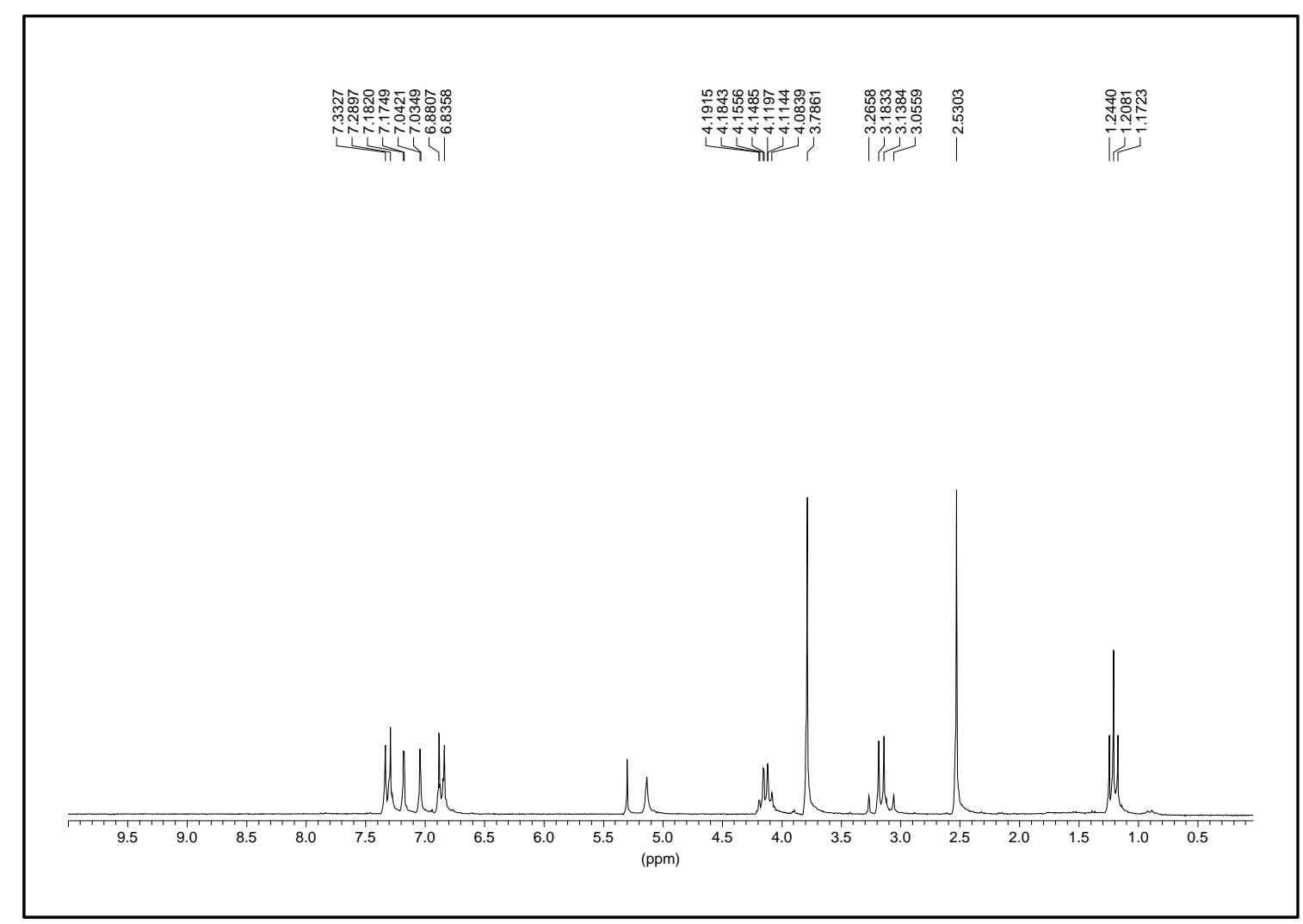

\section{Espectro $39 \mathrm{H}$}

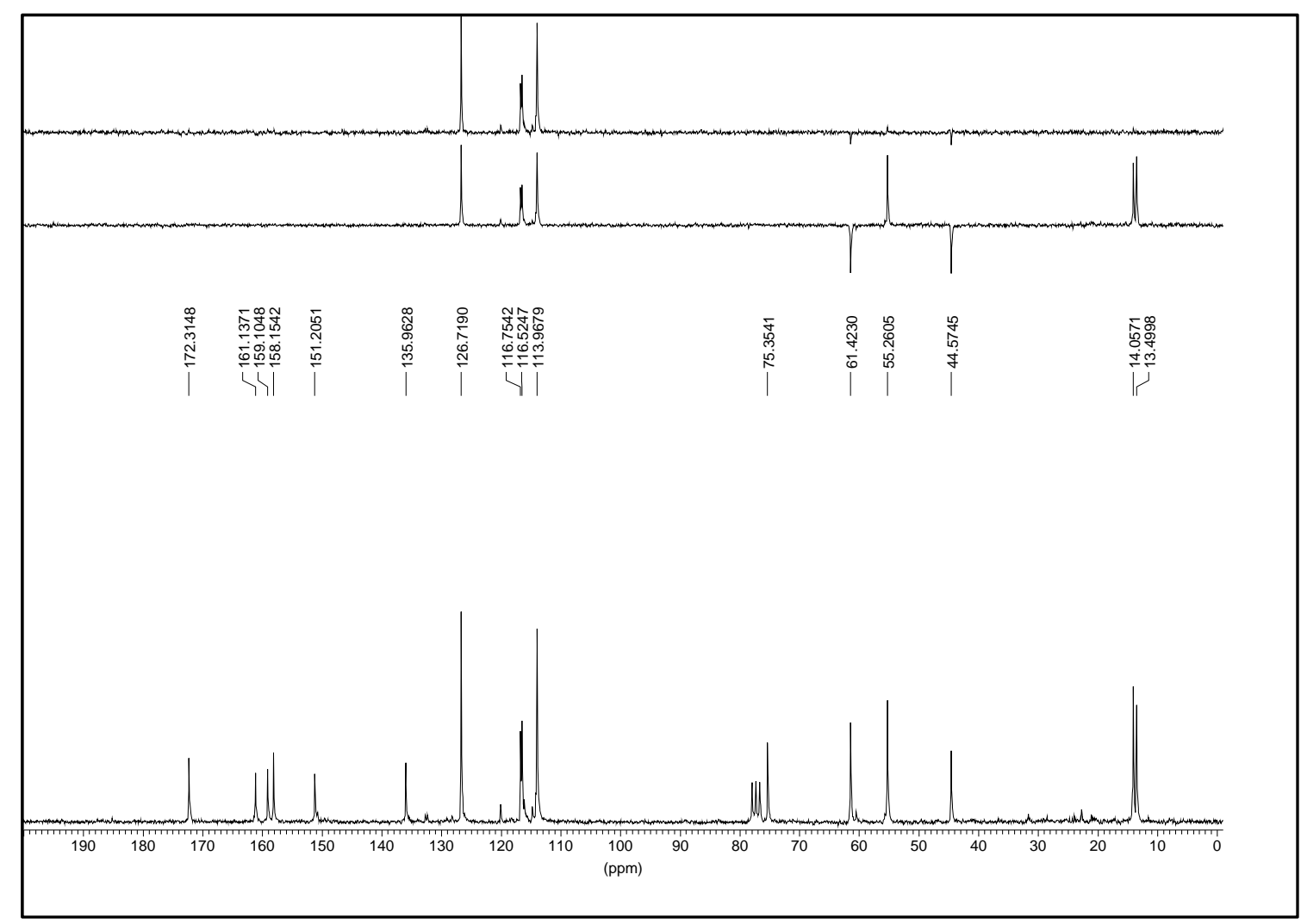

Espectro 39C 


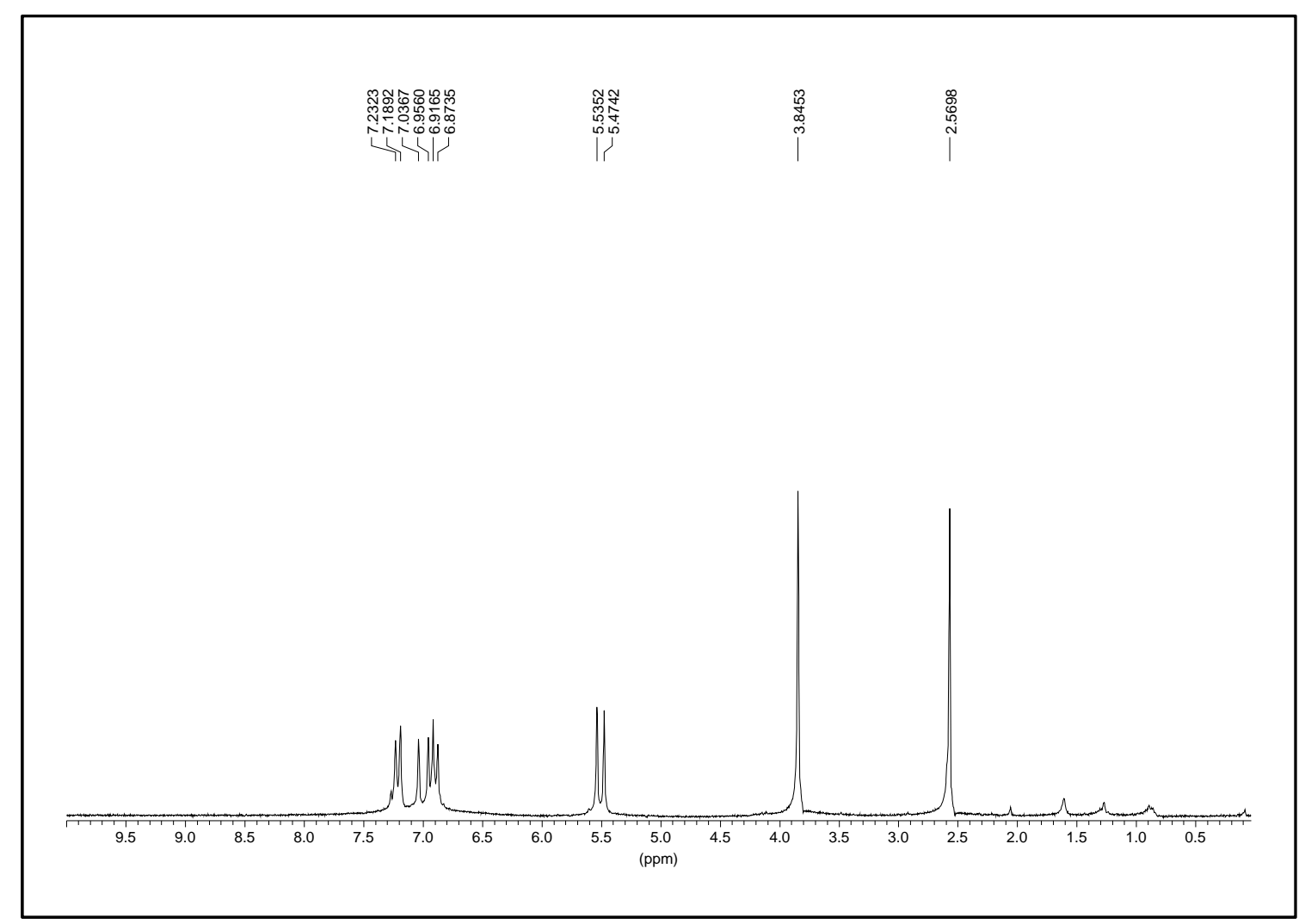

\section{Espectro 40H}

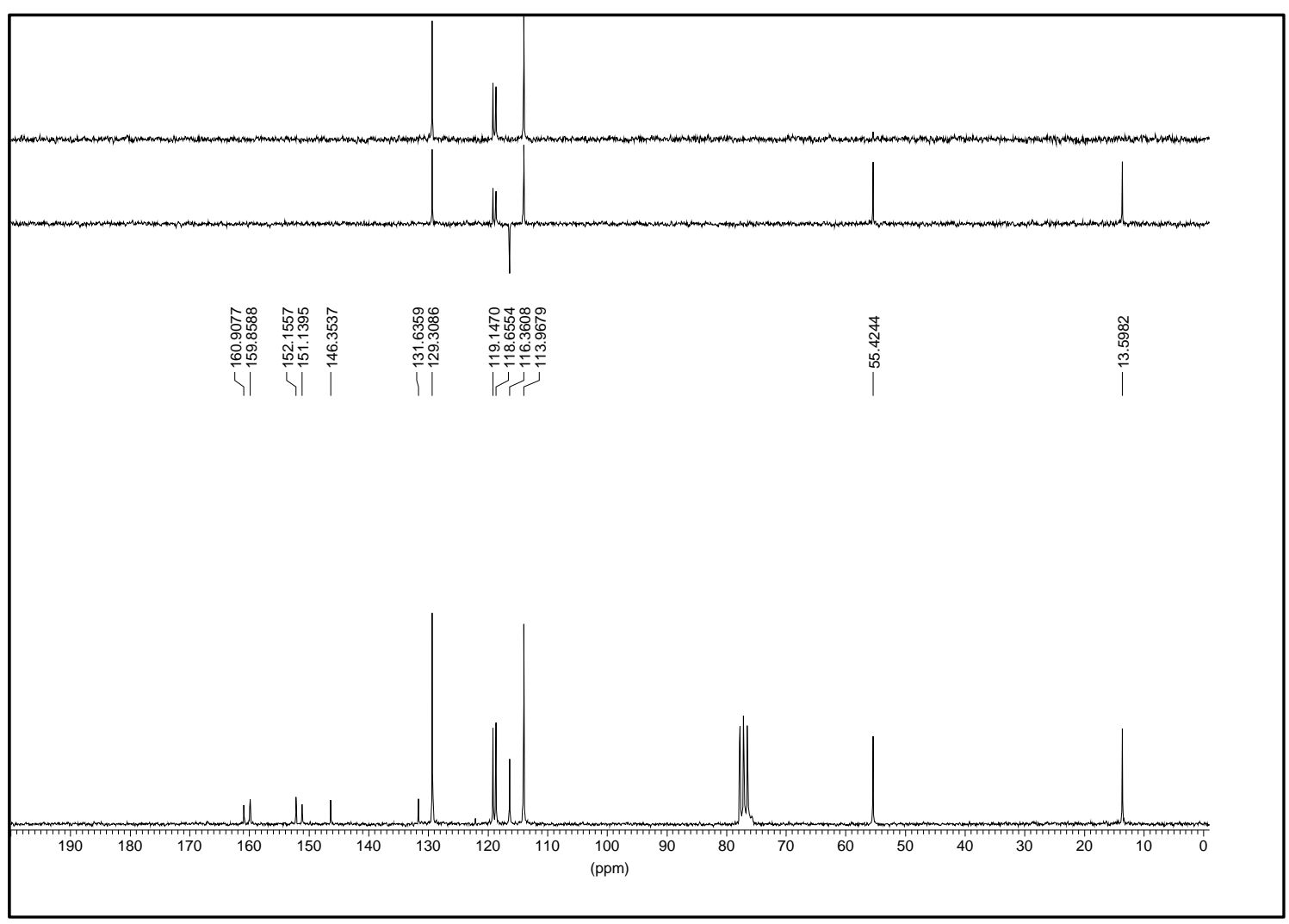

Espectro 40C 


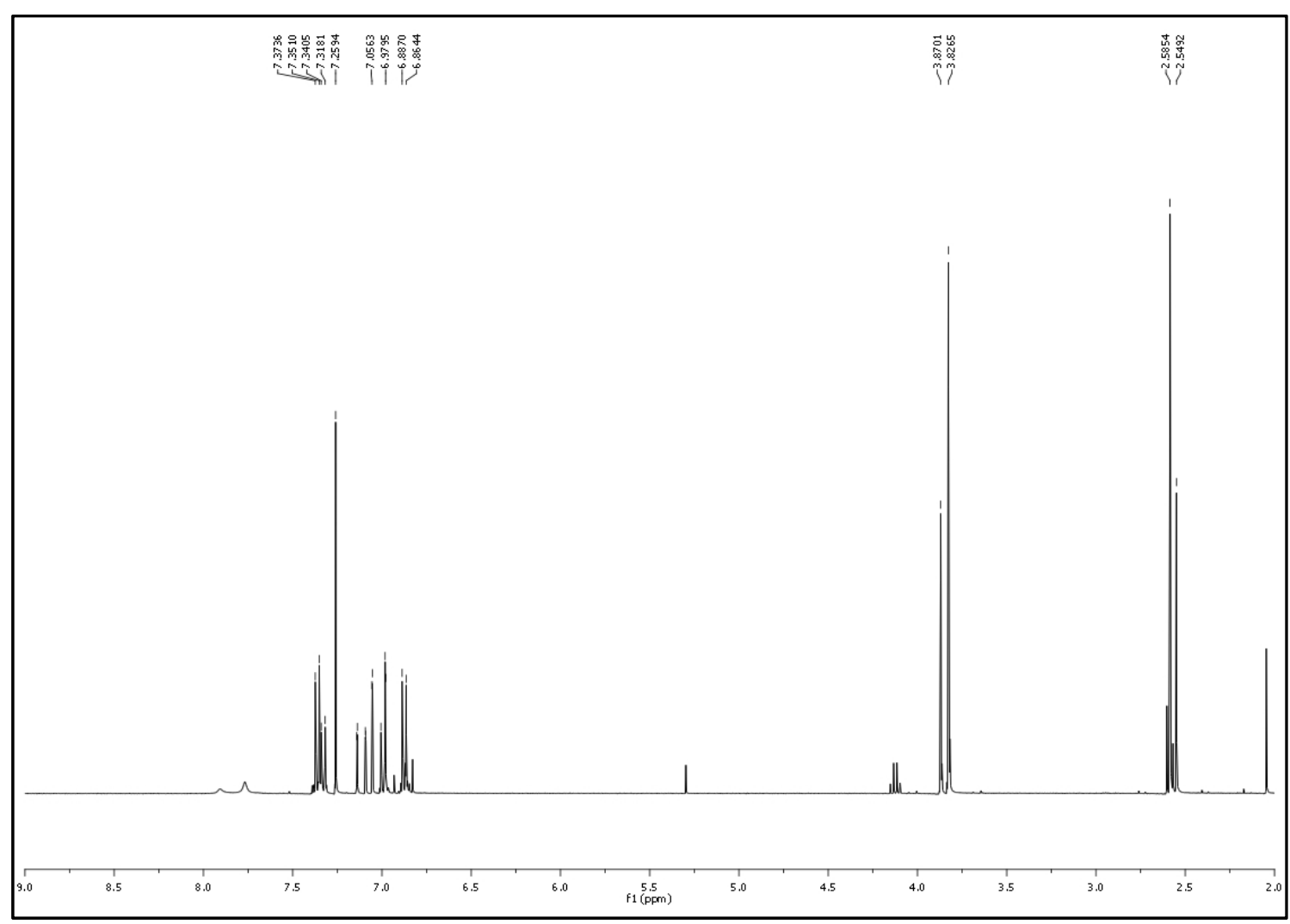

\section{Espectro 41ZEH}

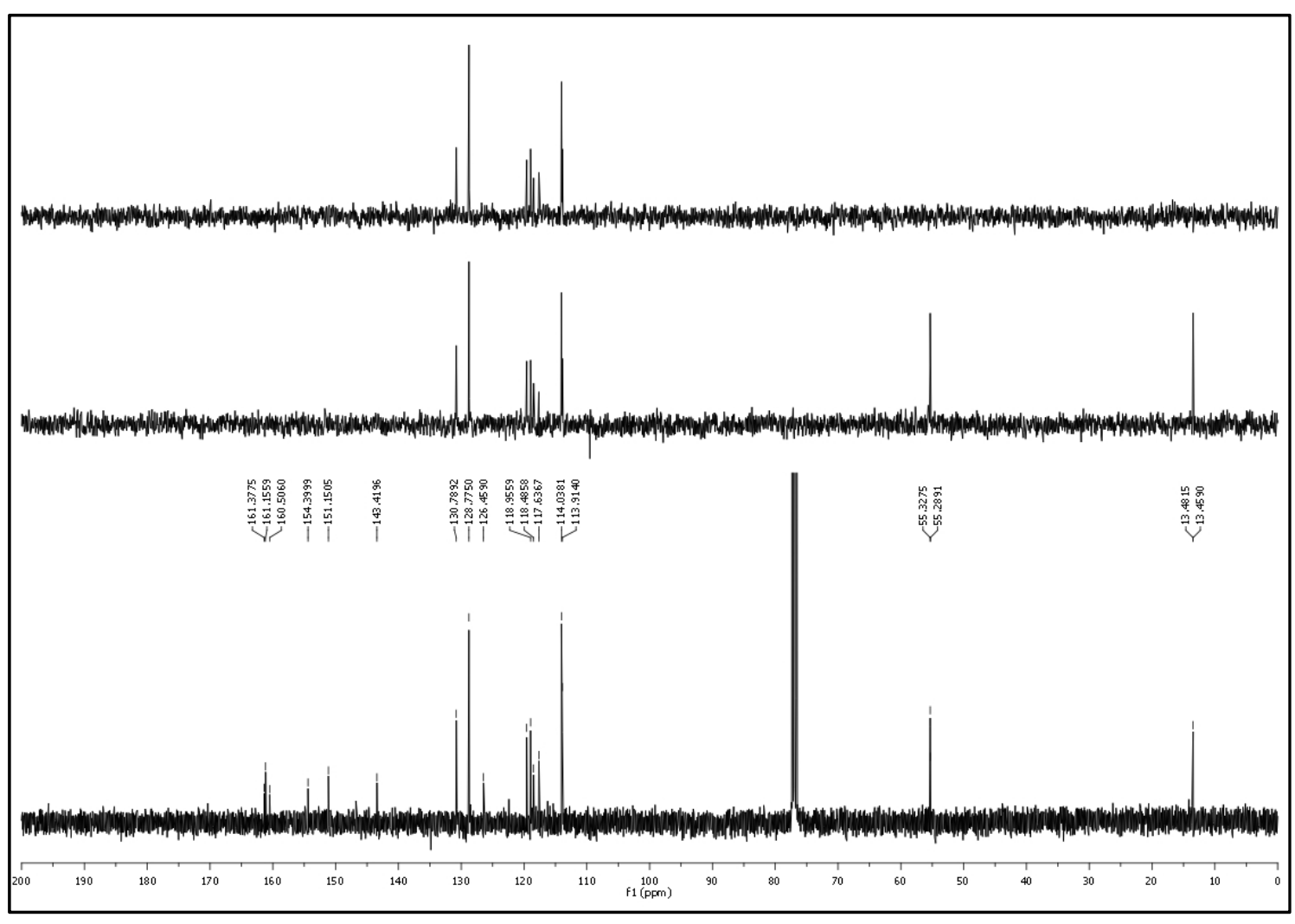

Espectro 41ZEC 


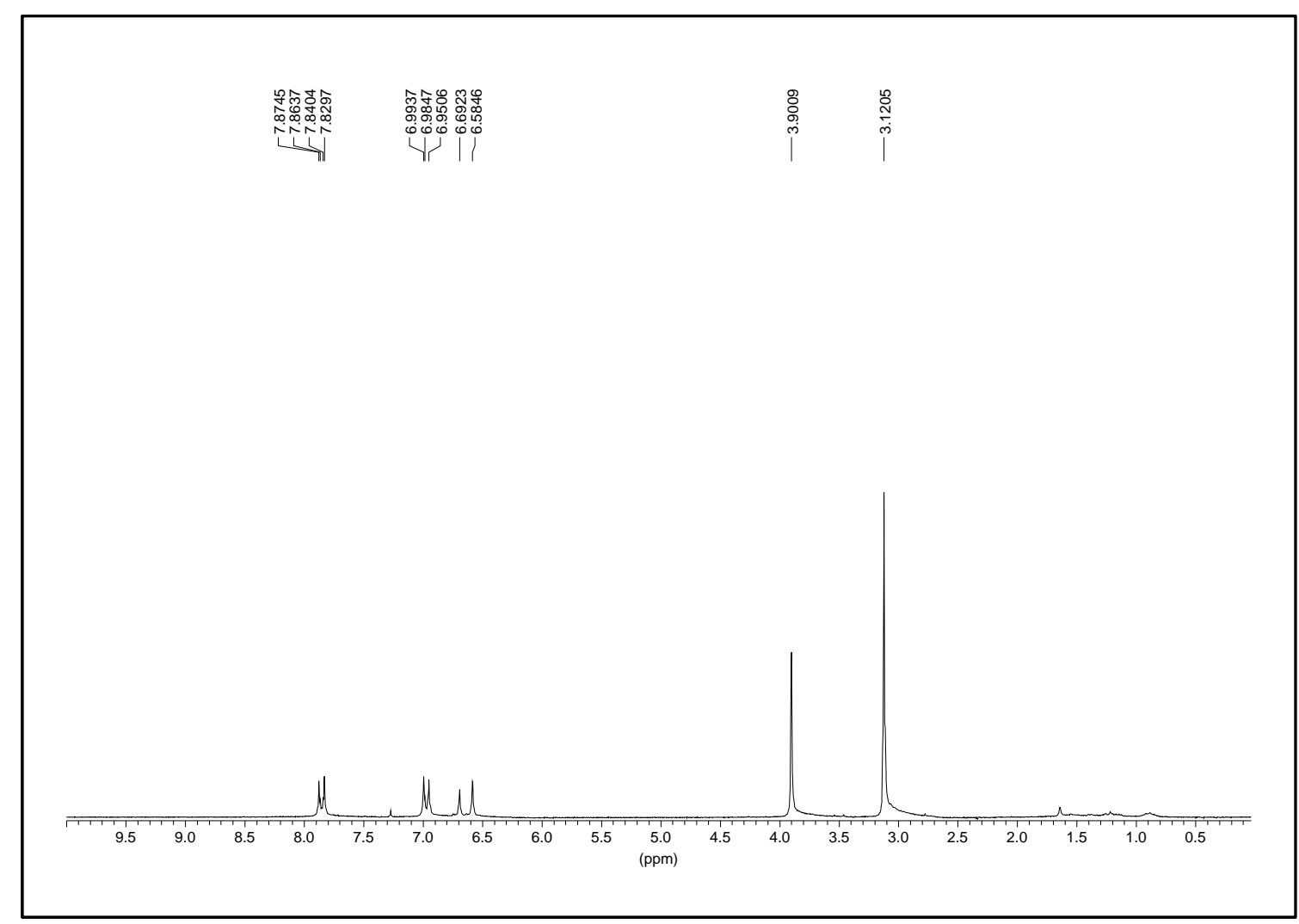

Espectro 42H

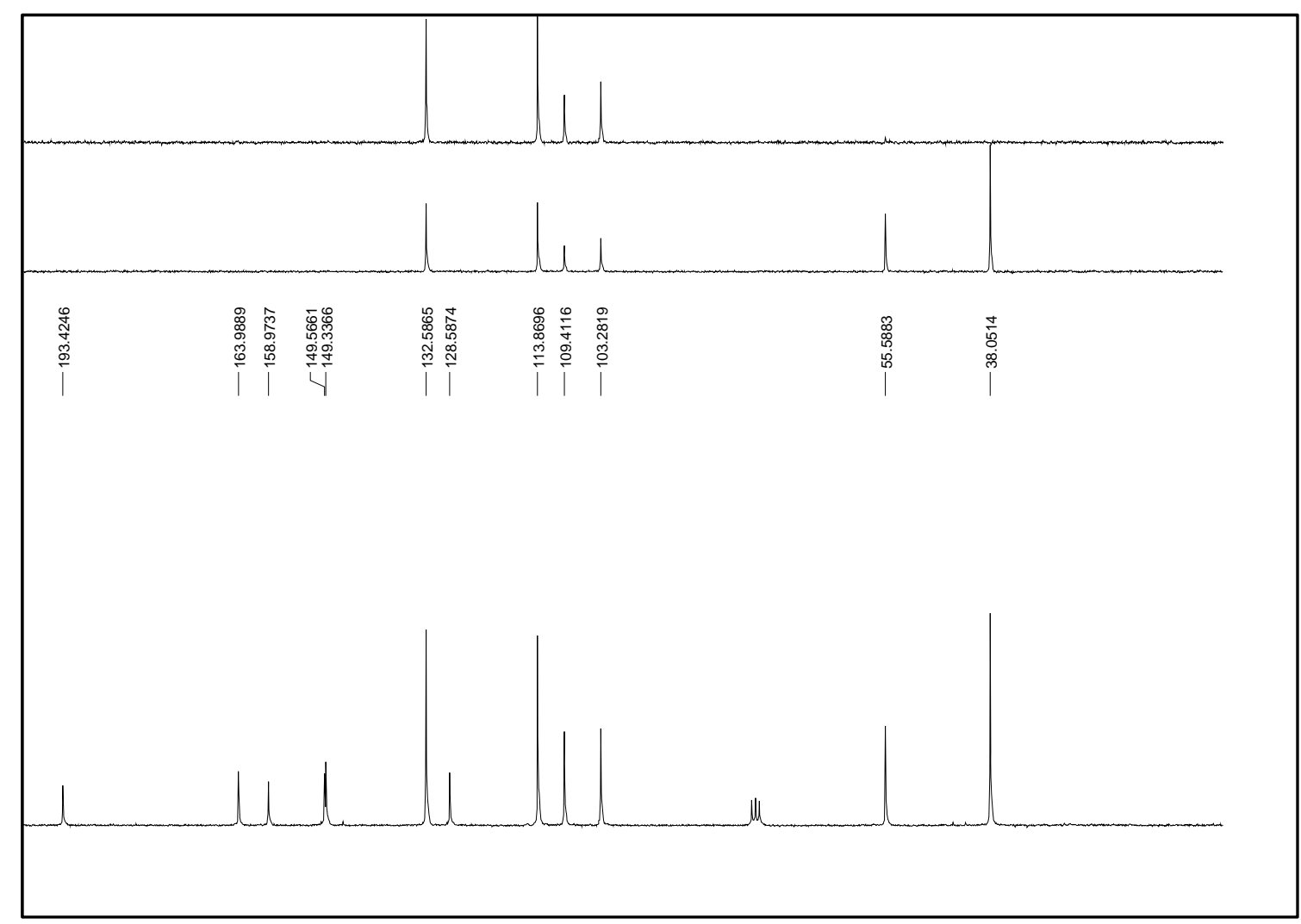

Espectro 42C 


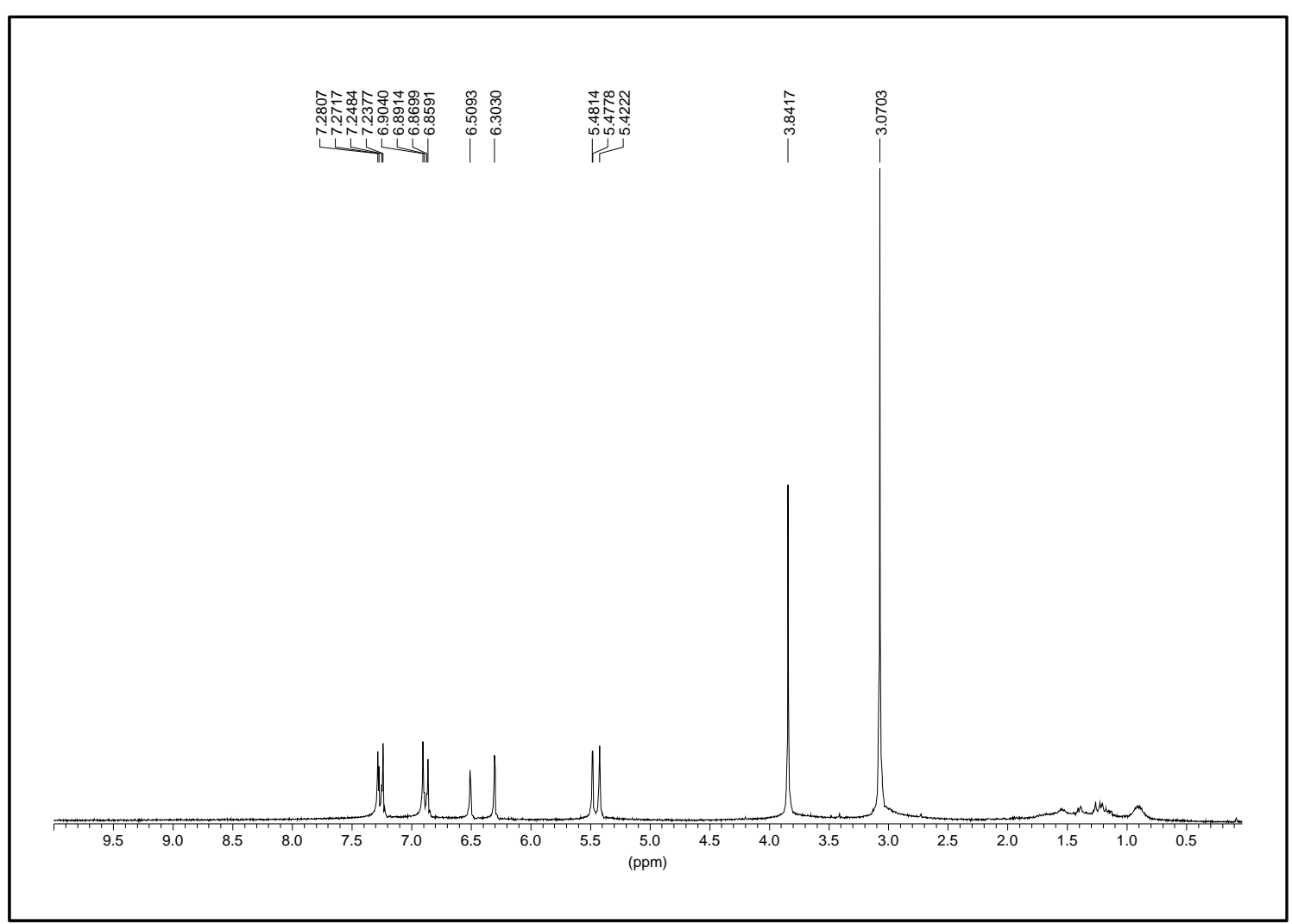

Espectro 43H

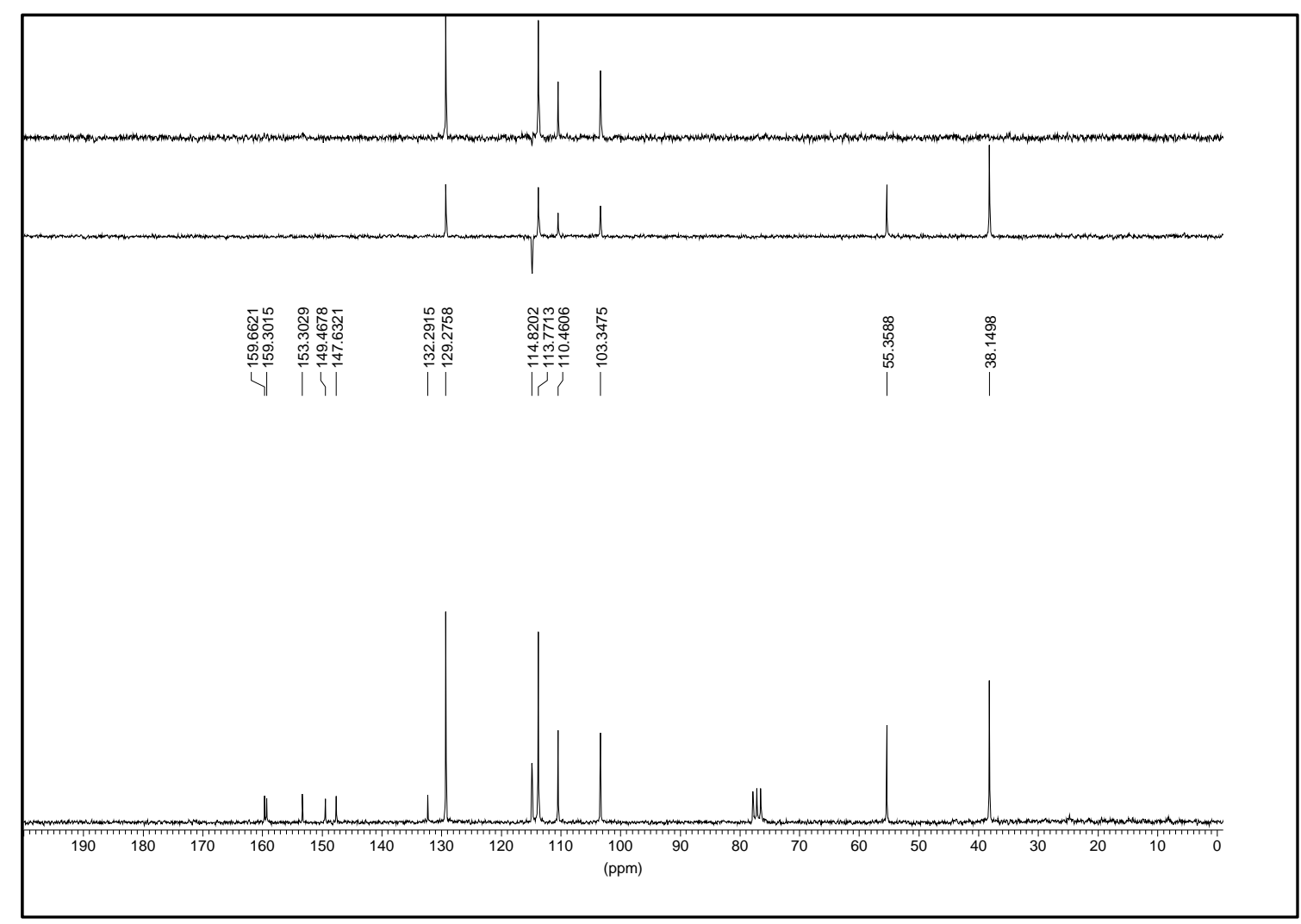

Espectro 43C 


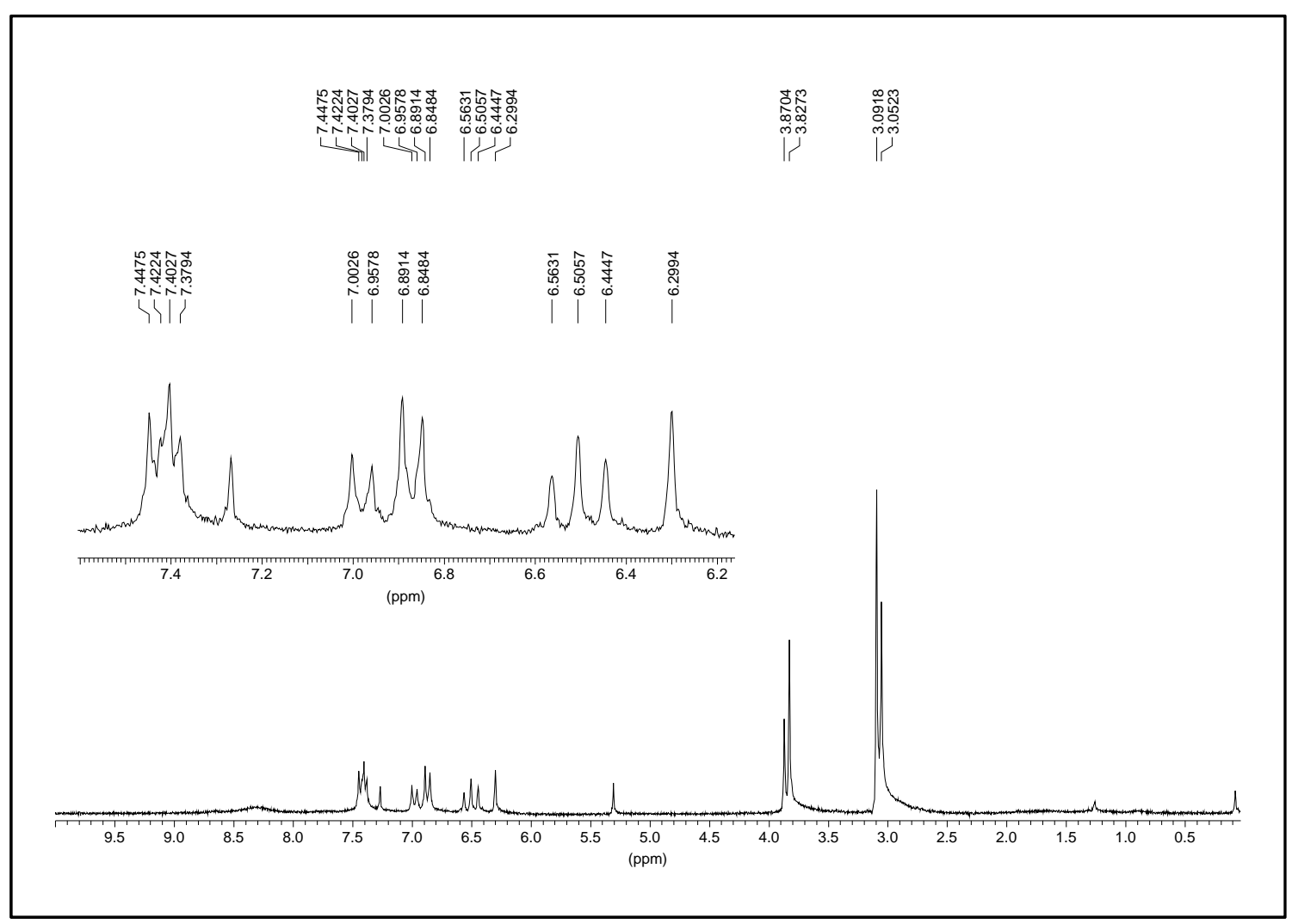

\section{Espectro 44EZH}

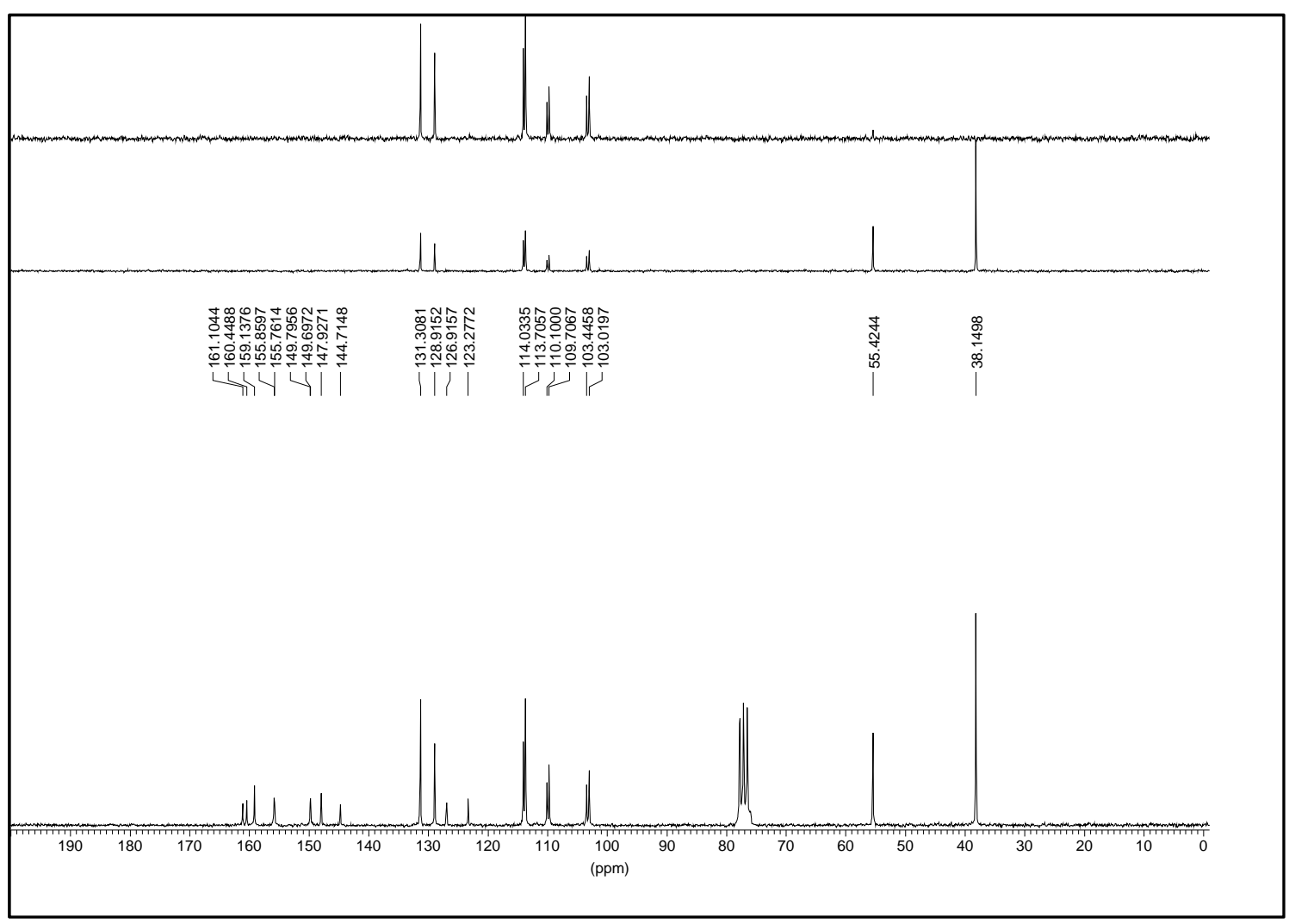

Espectro 44EZC 


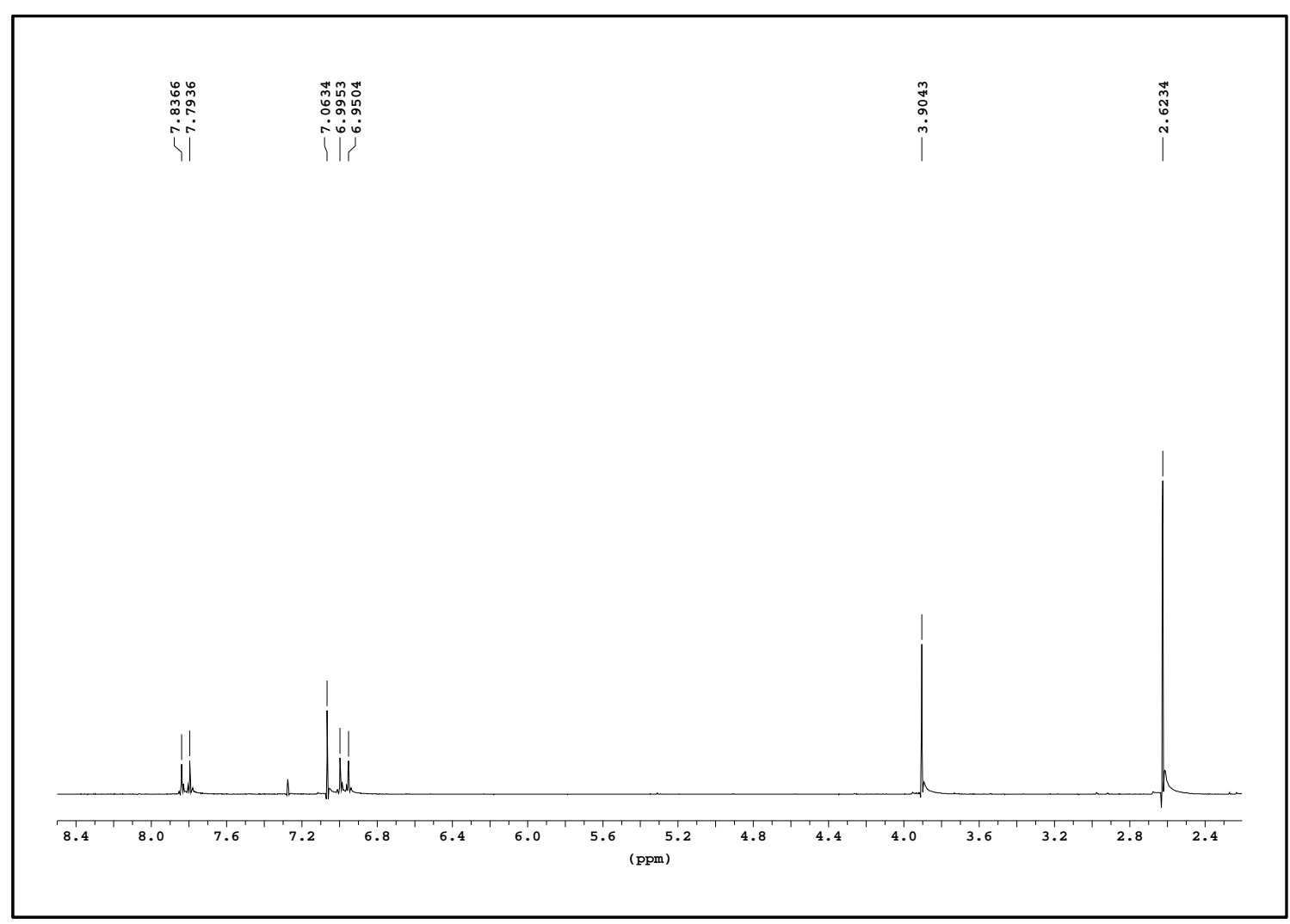

\section{Espectro 45H}

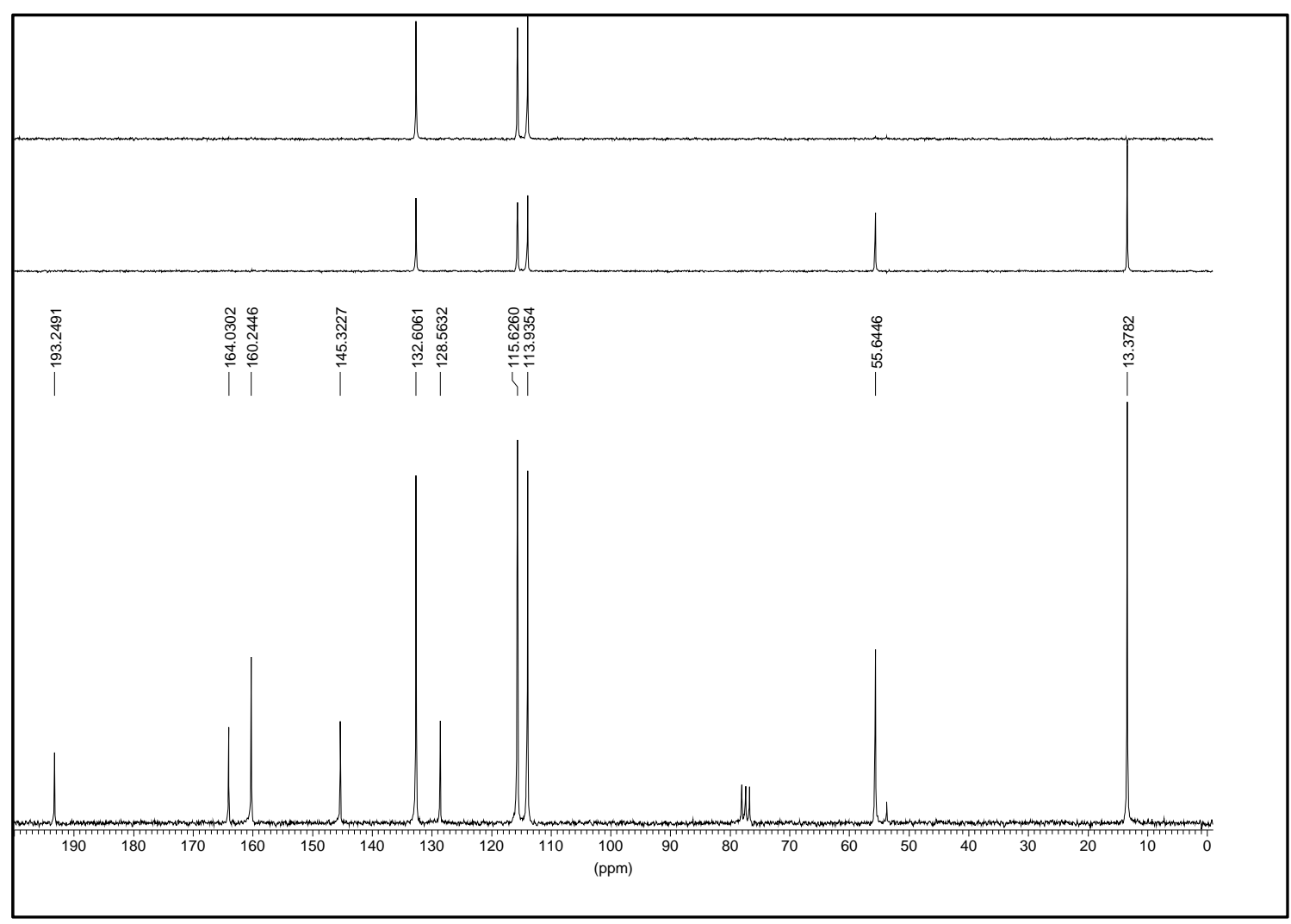

Espectro 45C 


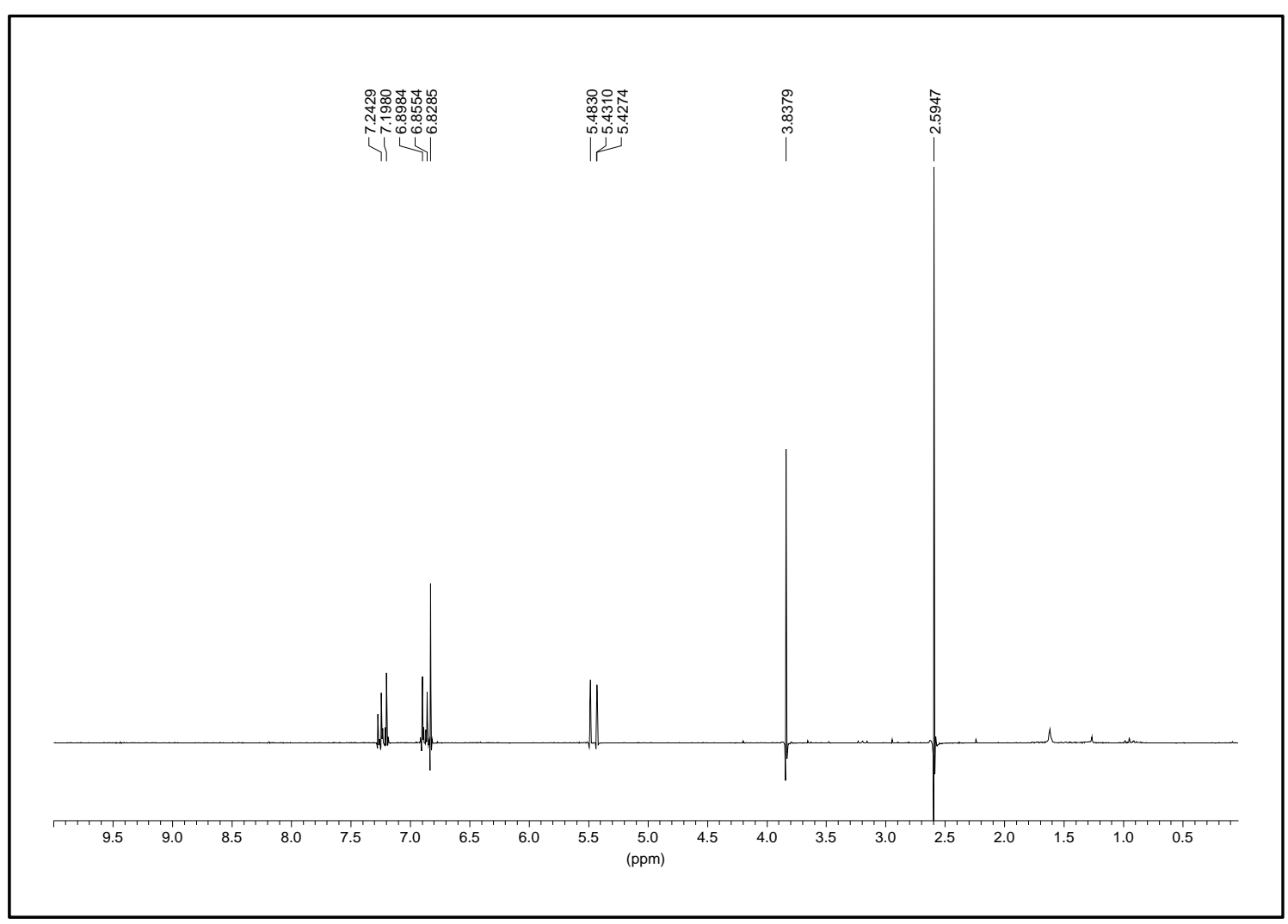

\section{Espectro 46H}

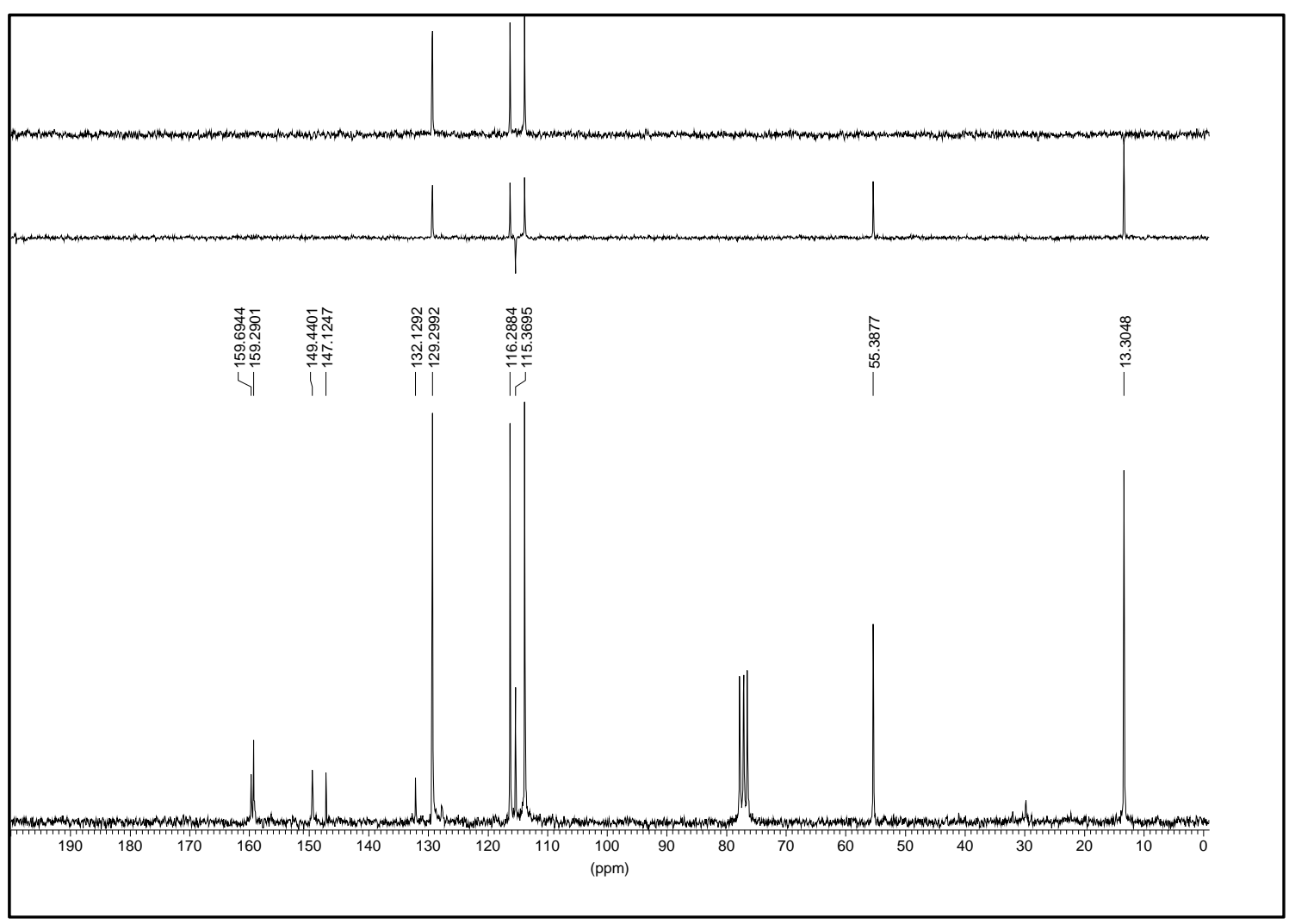

Espectro 46C 


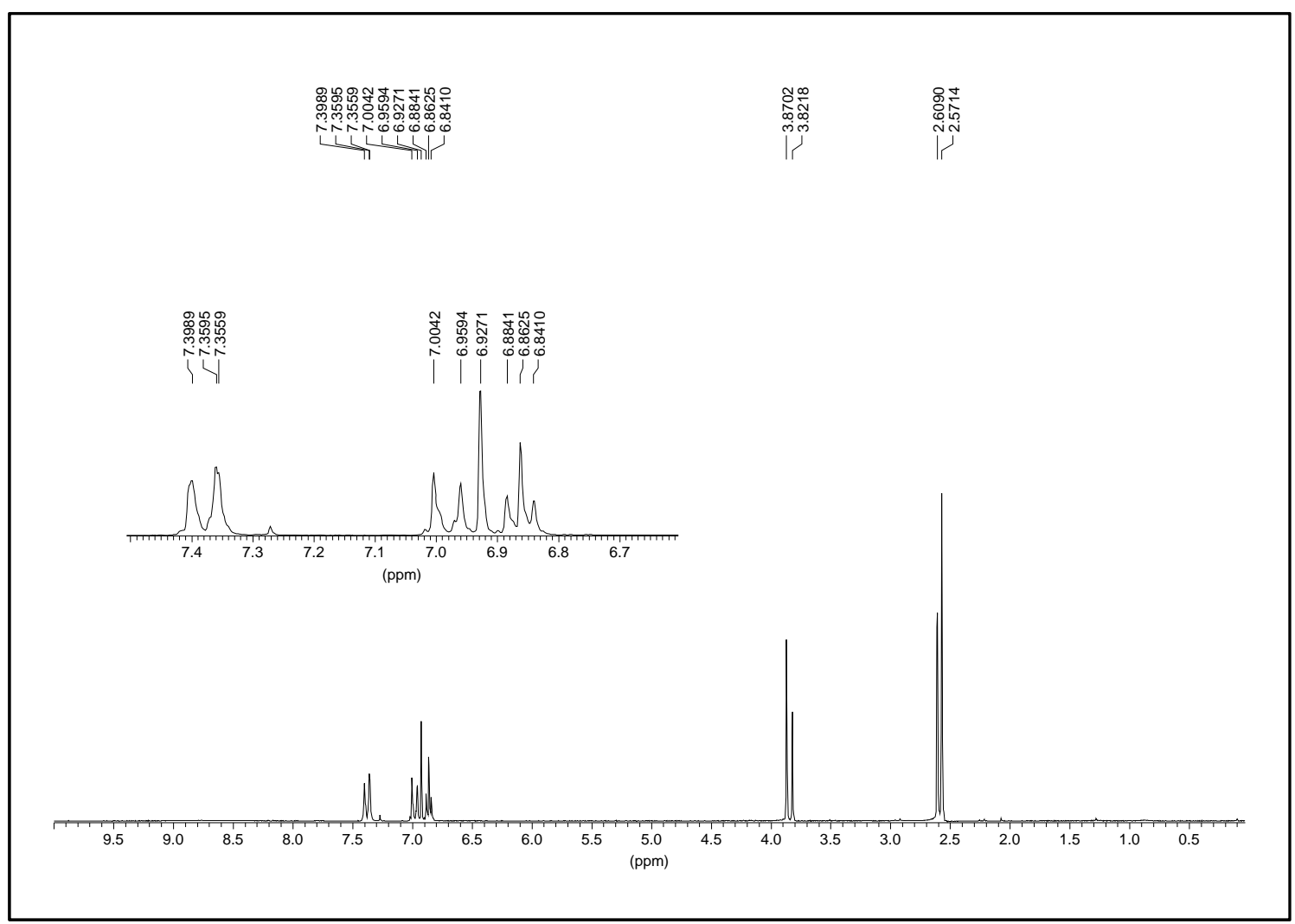

\section{Espectro 47ZEH}

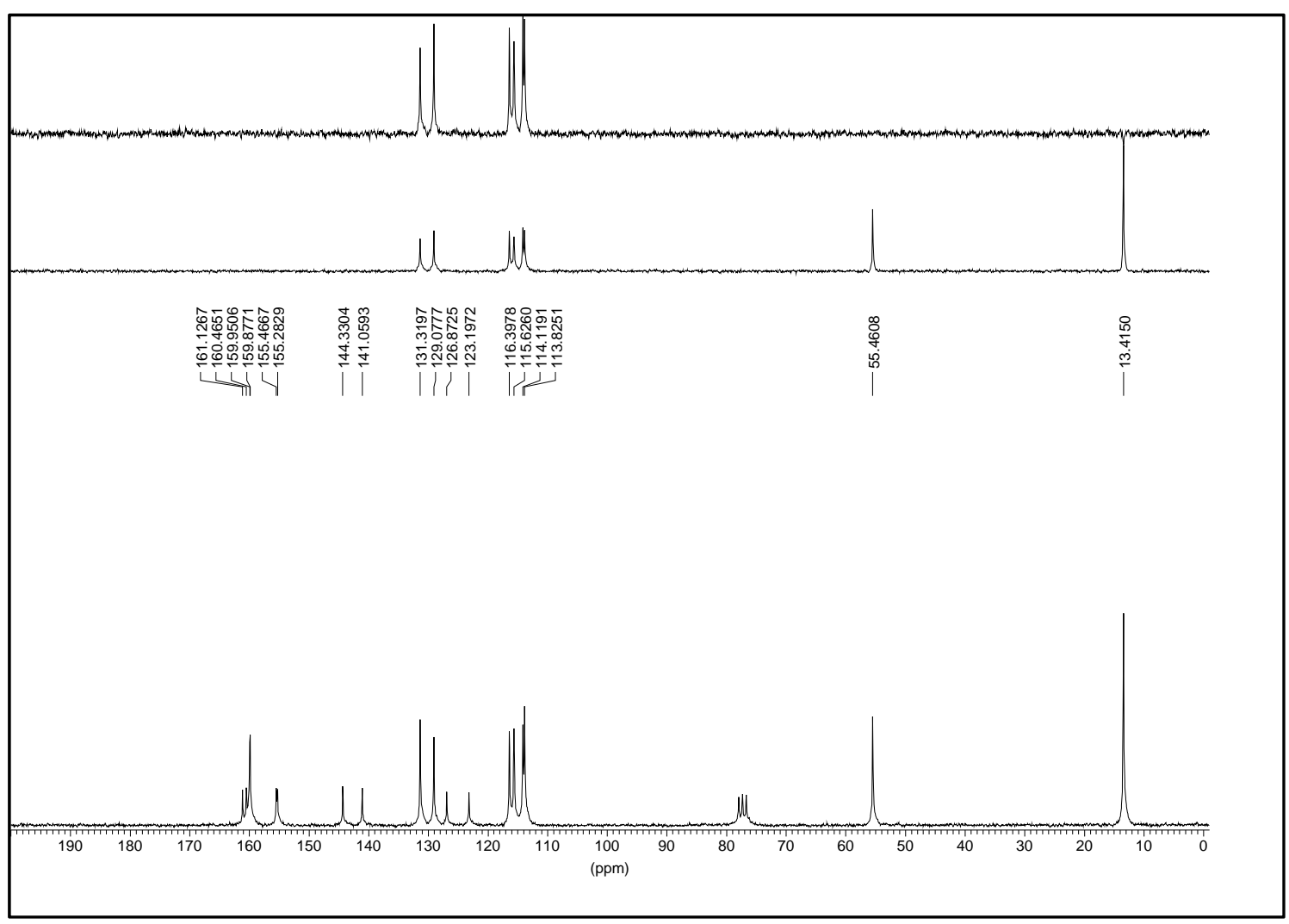

Espectro 47ZEC 


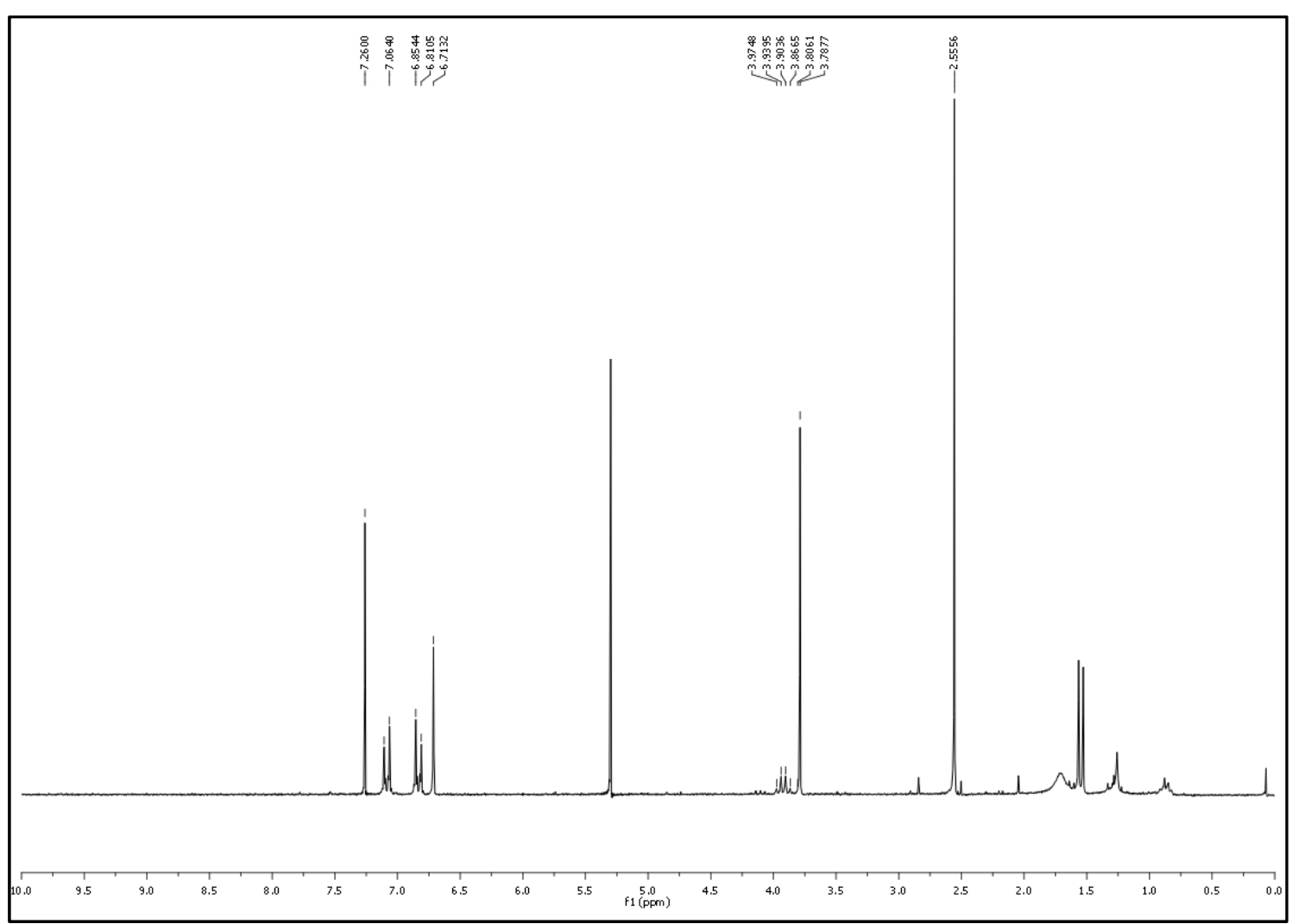

\section{Espectro 48H}

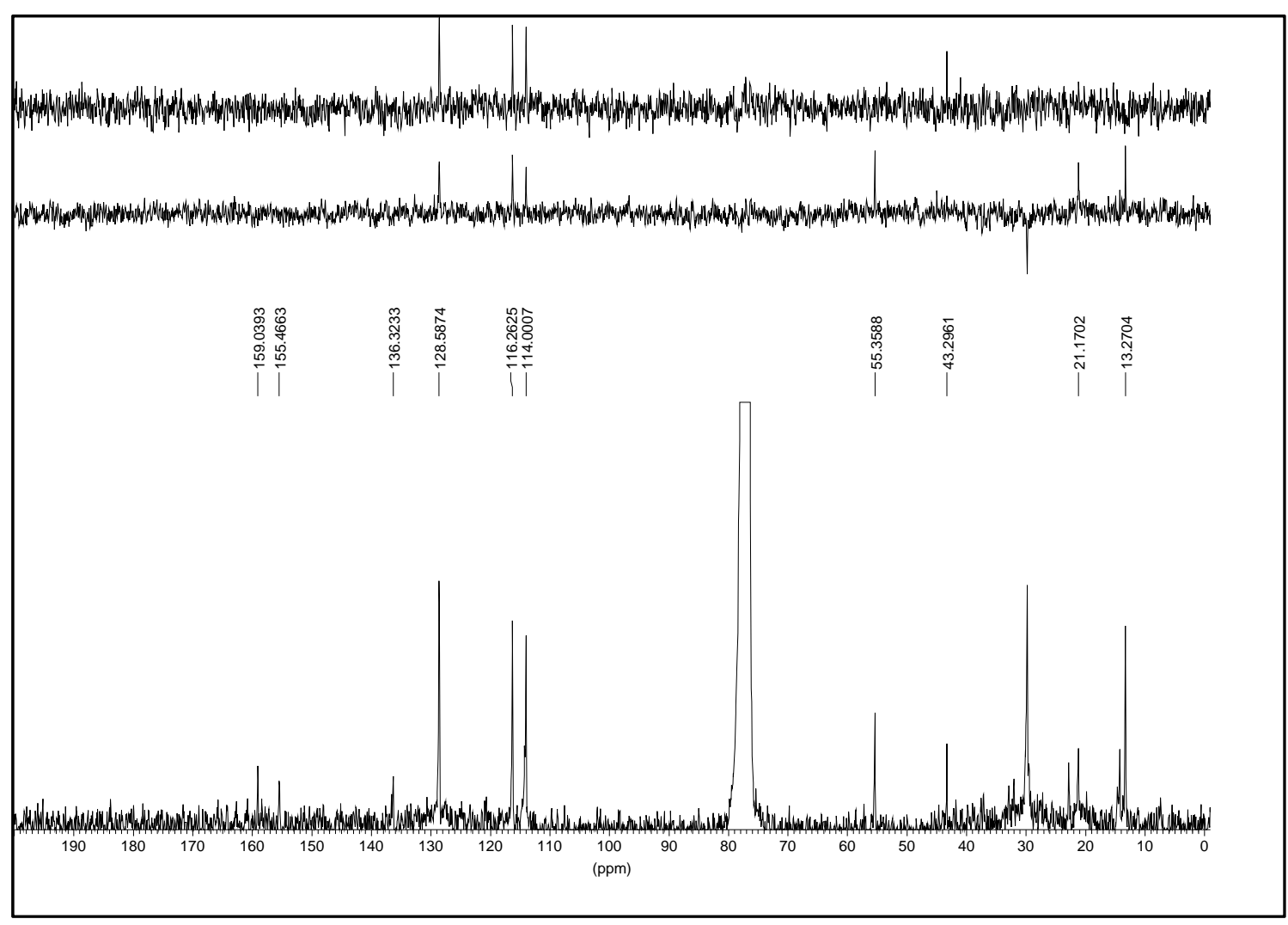

Espectro 48C 


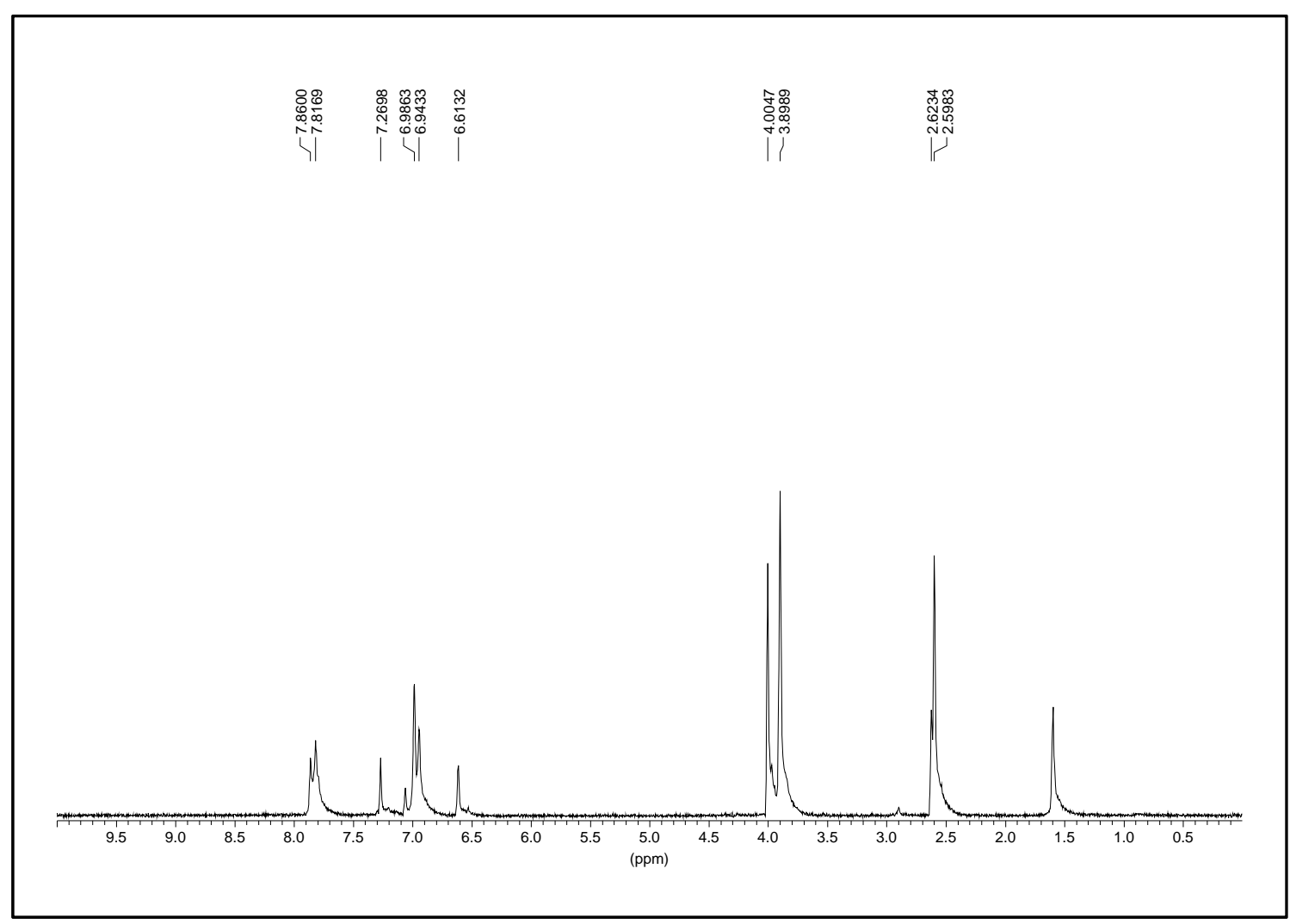

\section{Espectro $49 \mathrm{H}$}

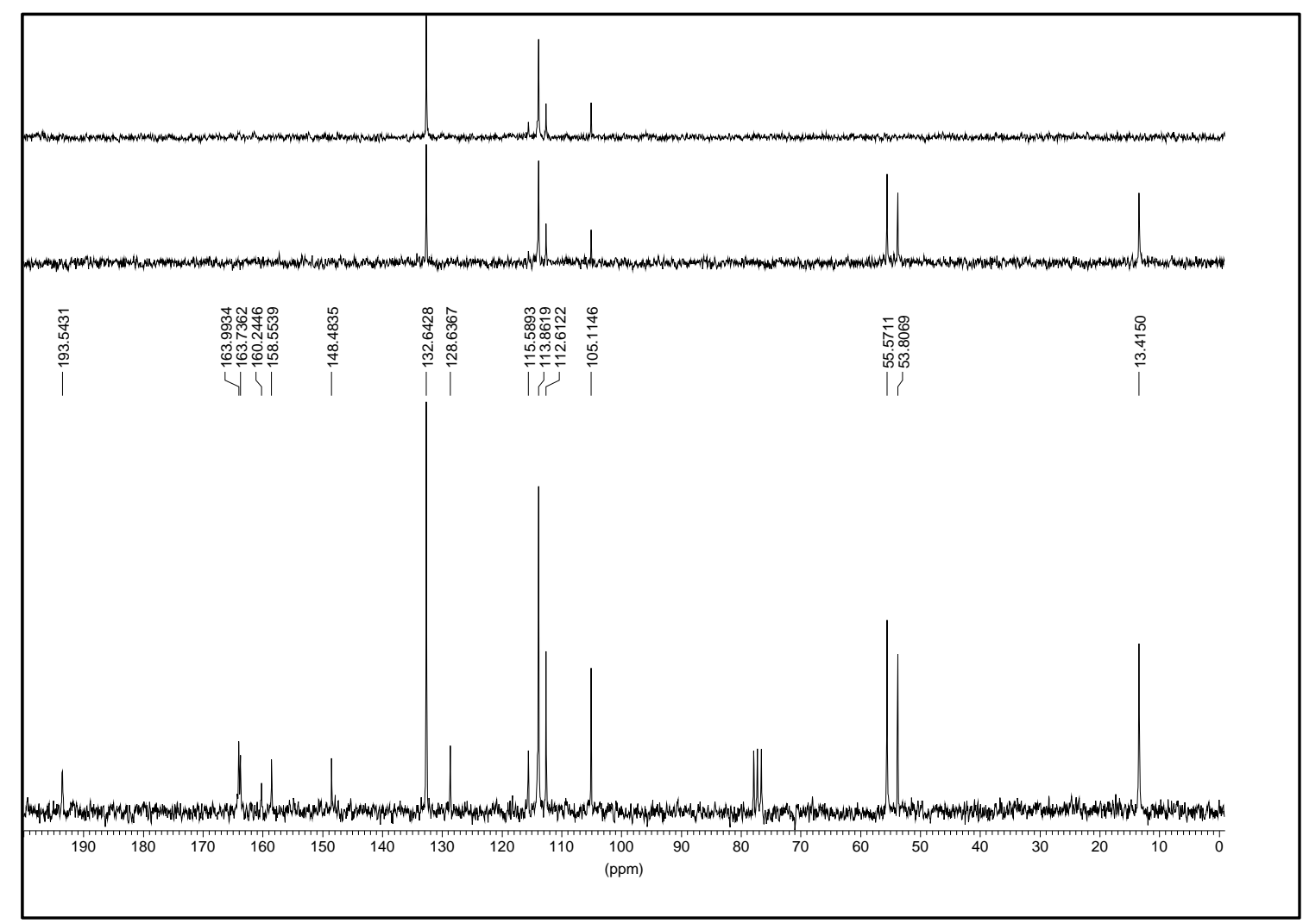

Espectro 49C 


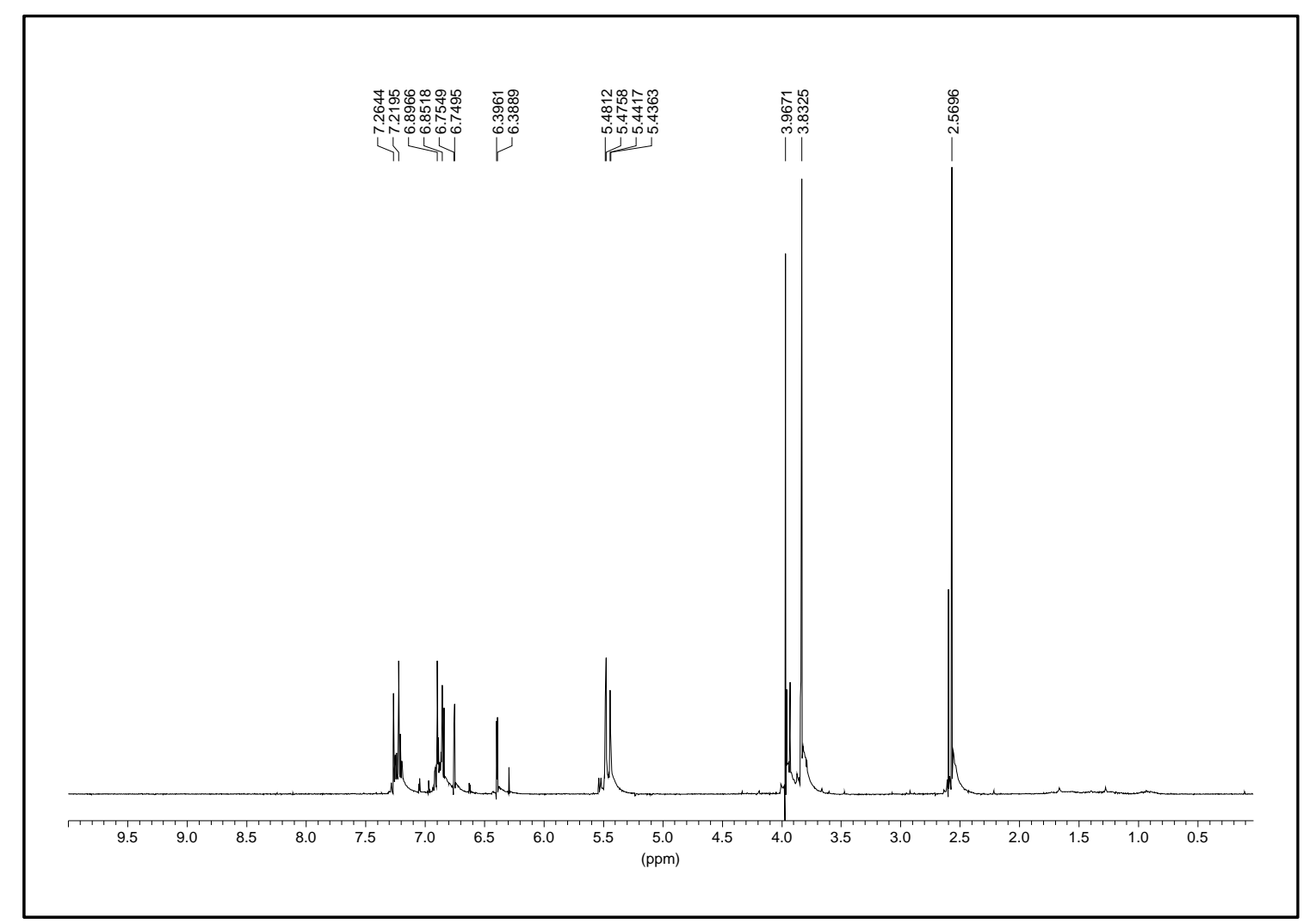

\section{Espectro $50 \mathrm{H}$}

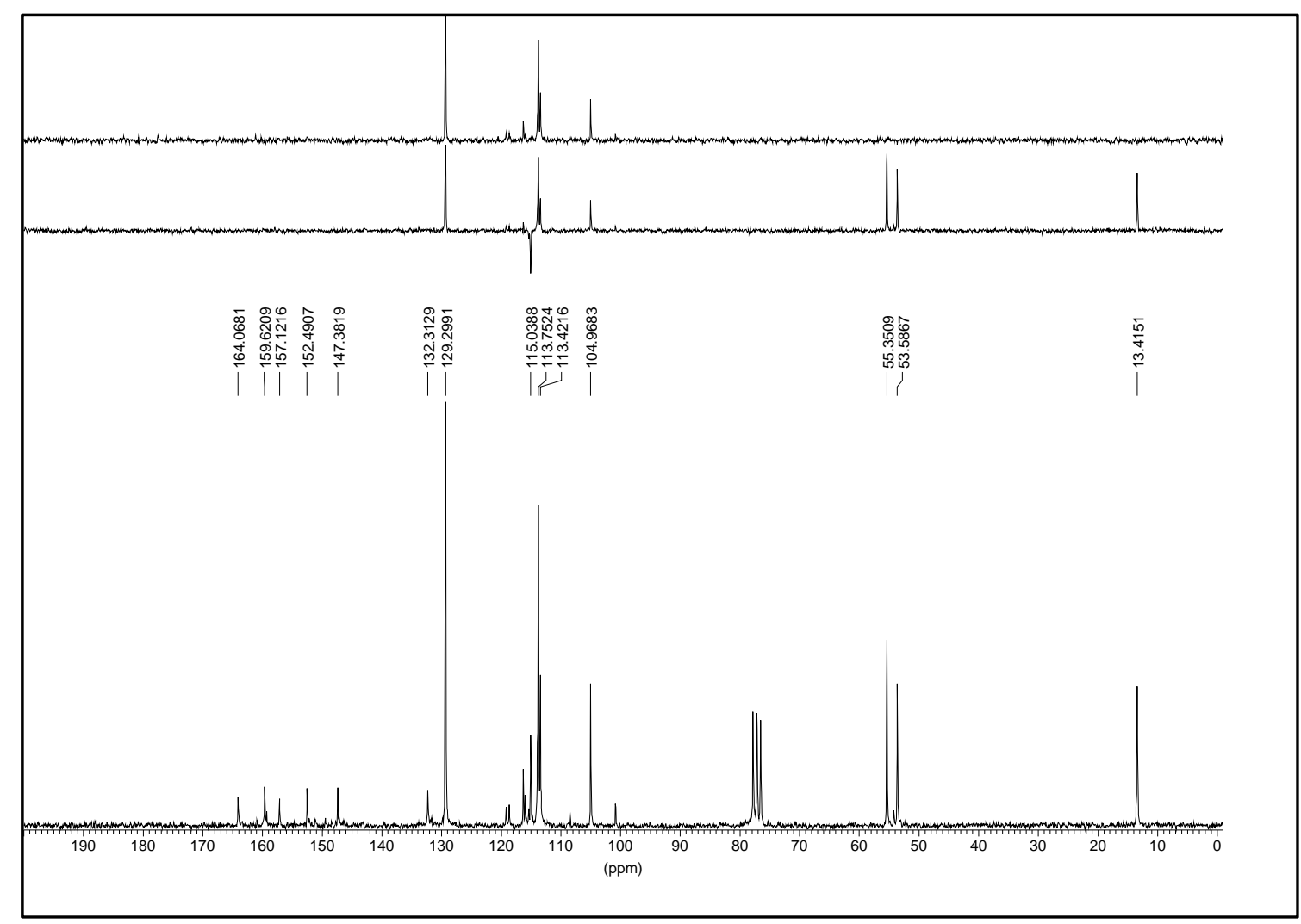

Espectro 50C 


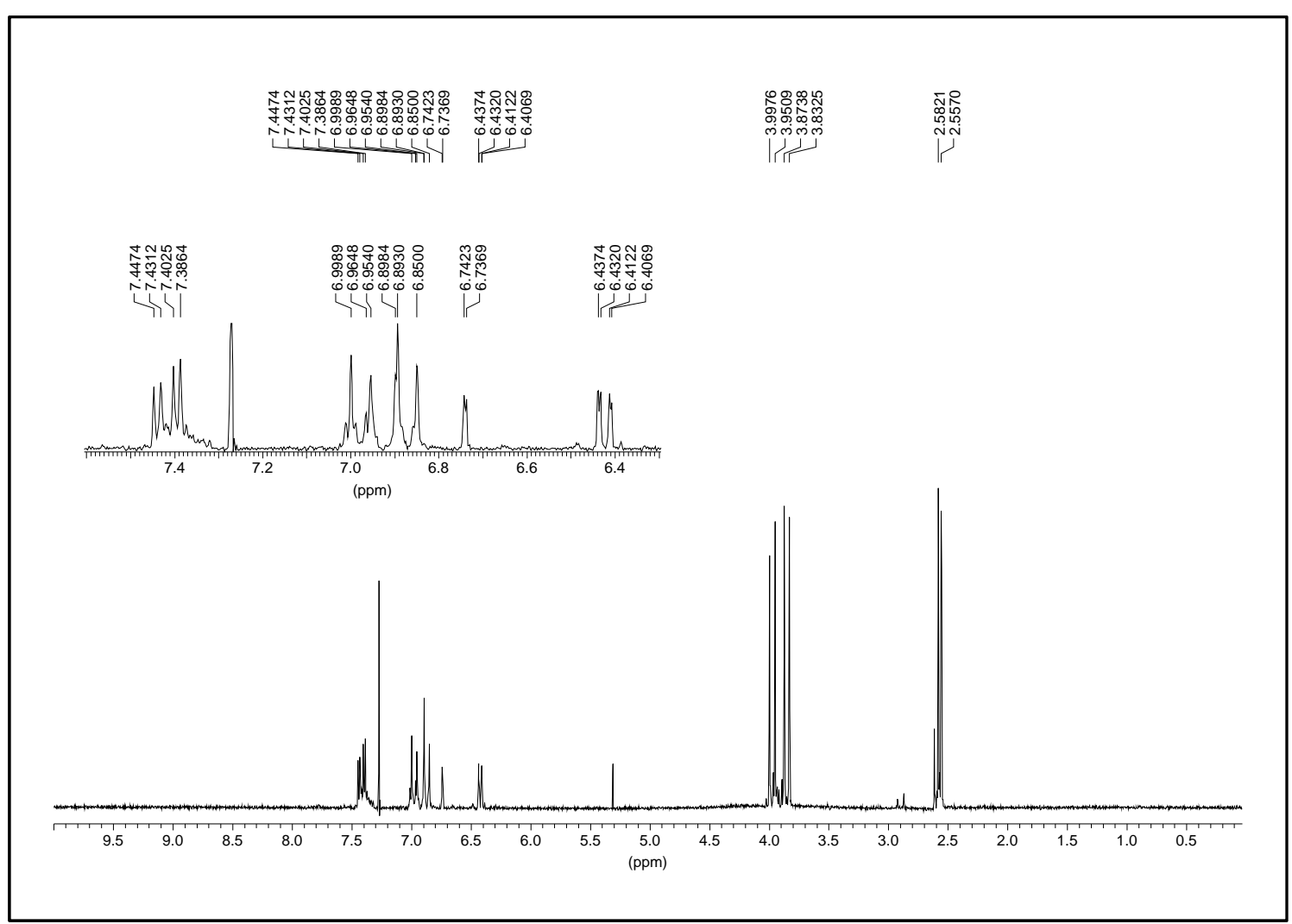

\section{Espectro 51ZEH}

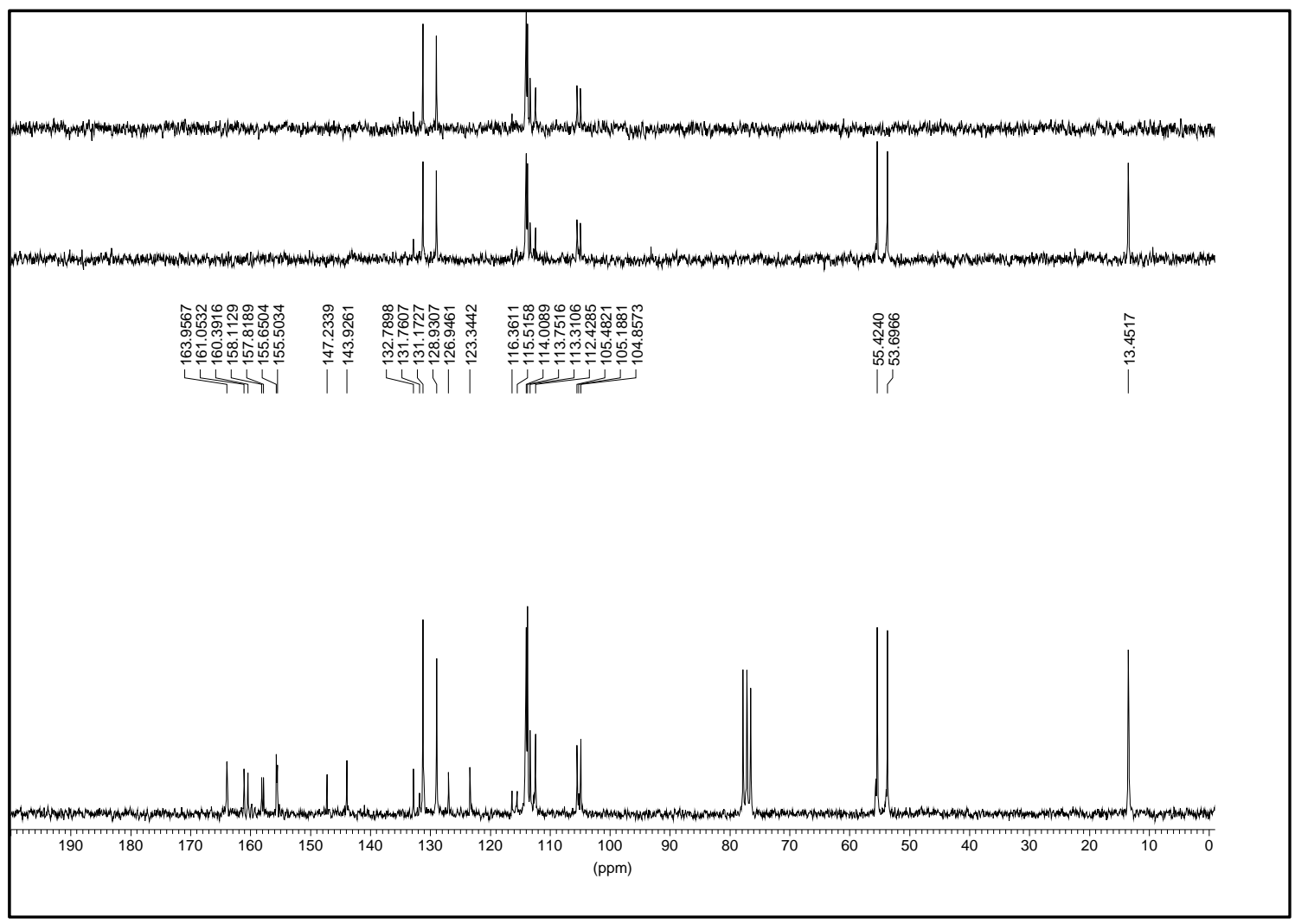

Espectro 51ZEC 


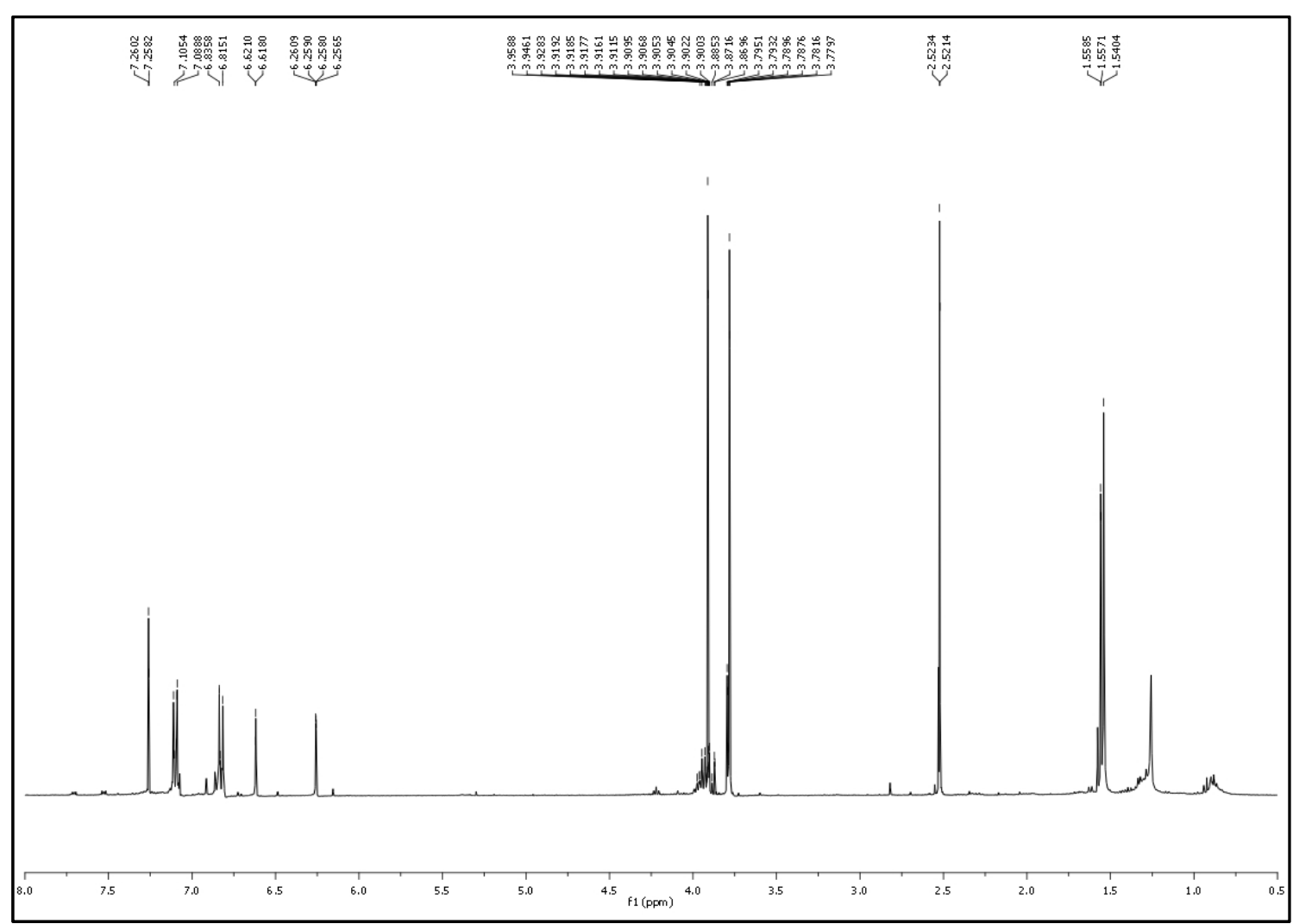

Espectro $52 \mathrm{H}$

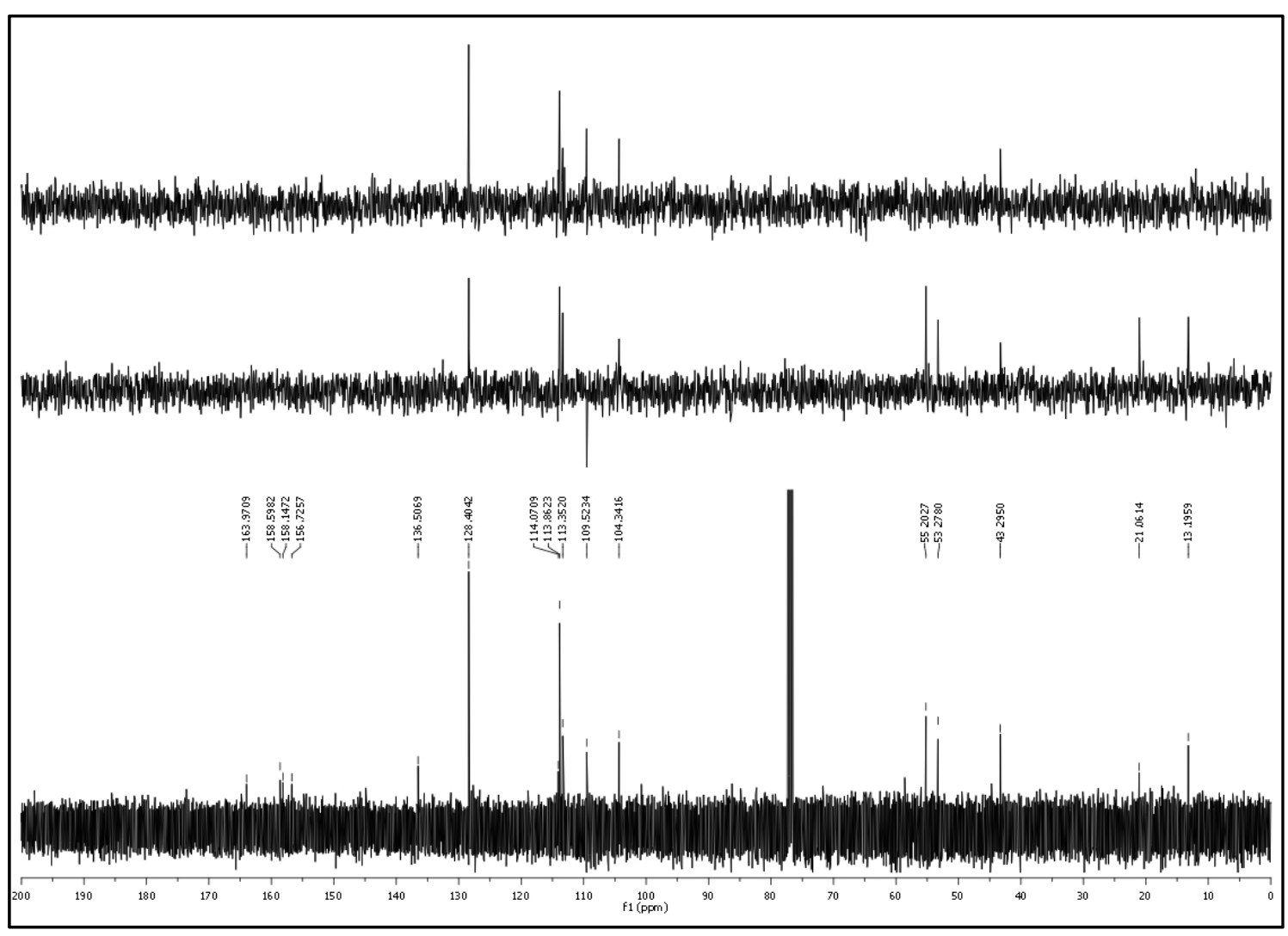

Espectro 52C 


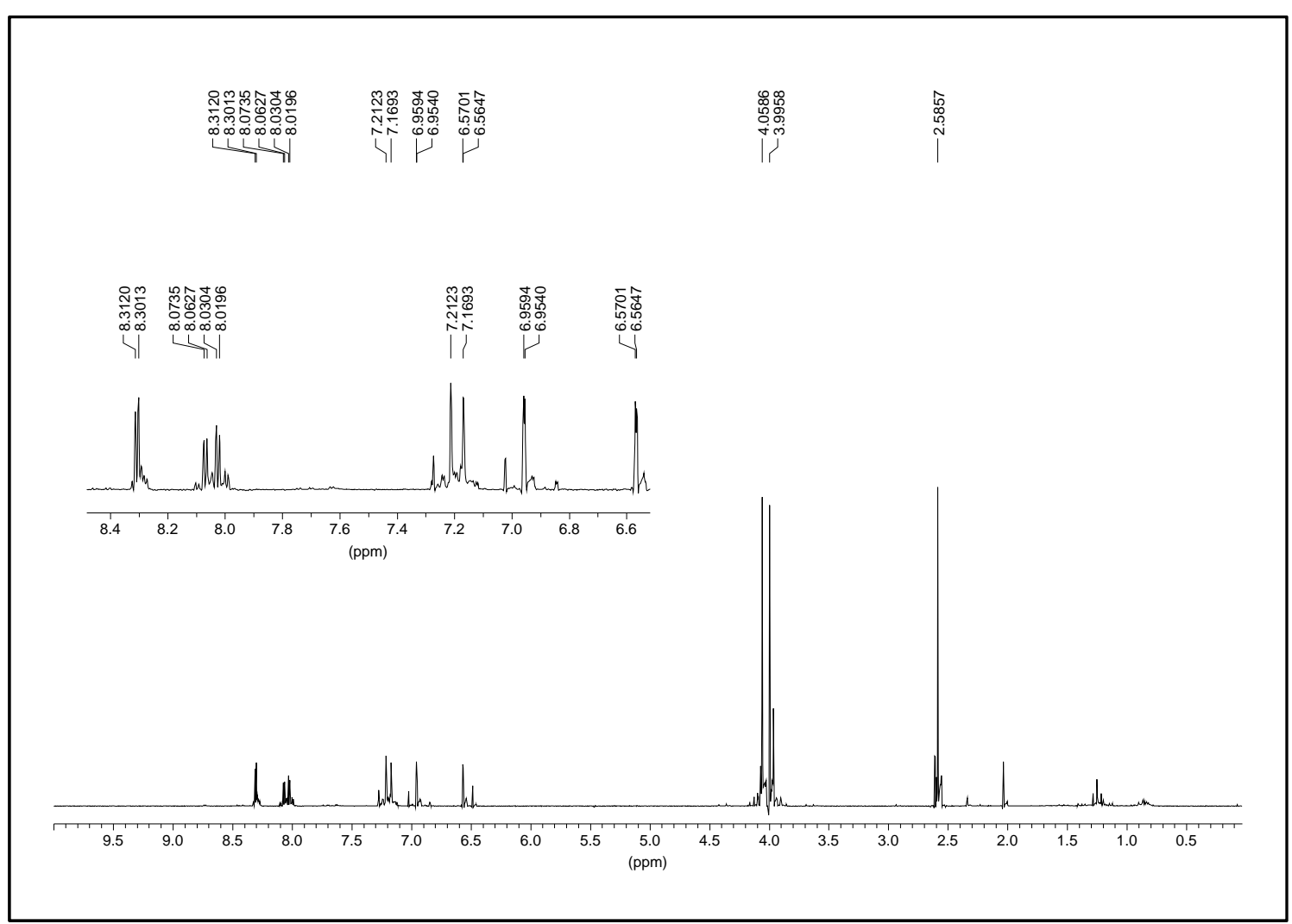

\section{Espectro $53 \mathrm{H}$}

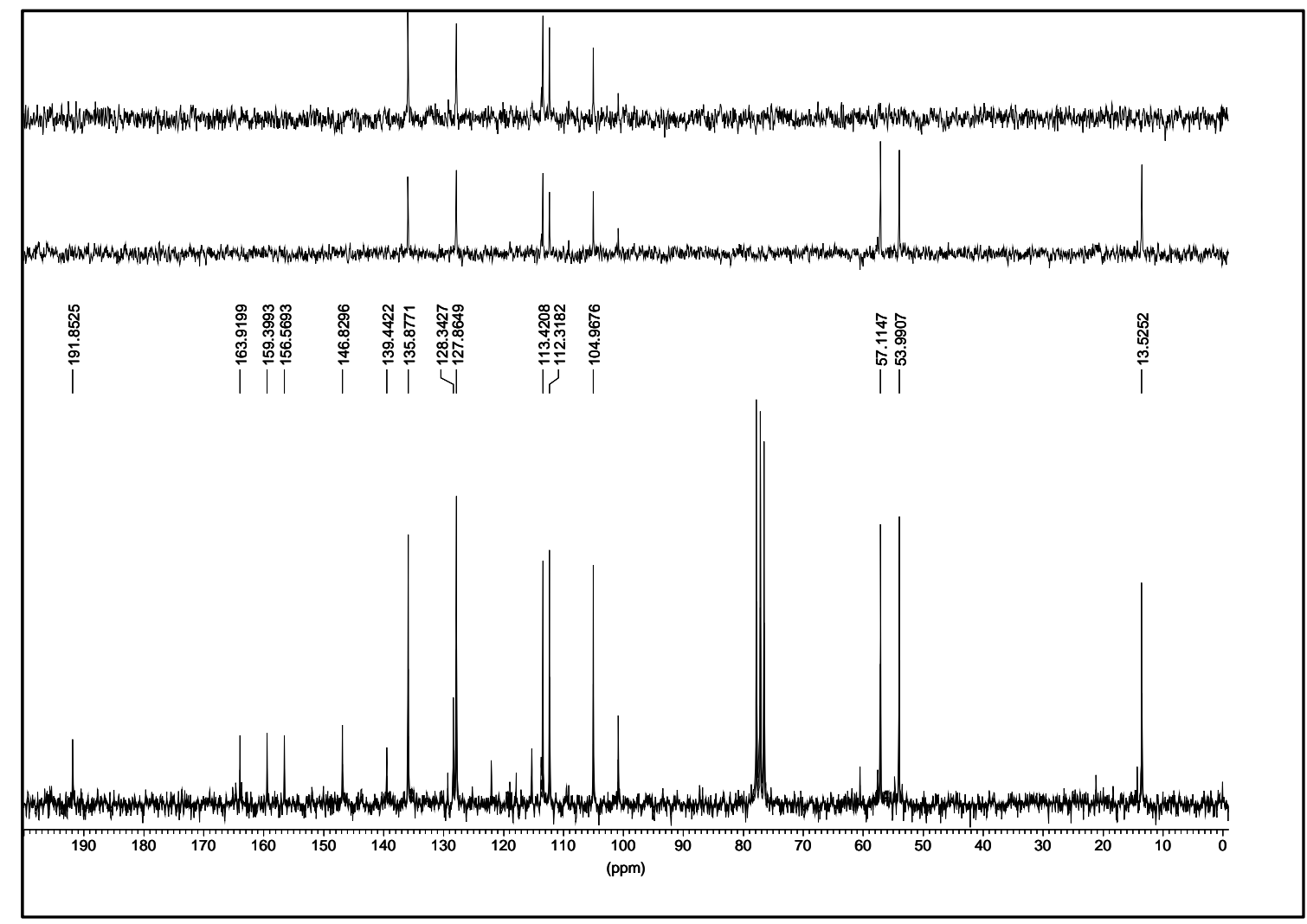

Espectro 53C 


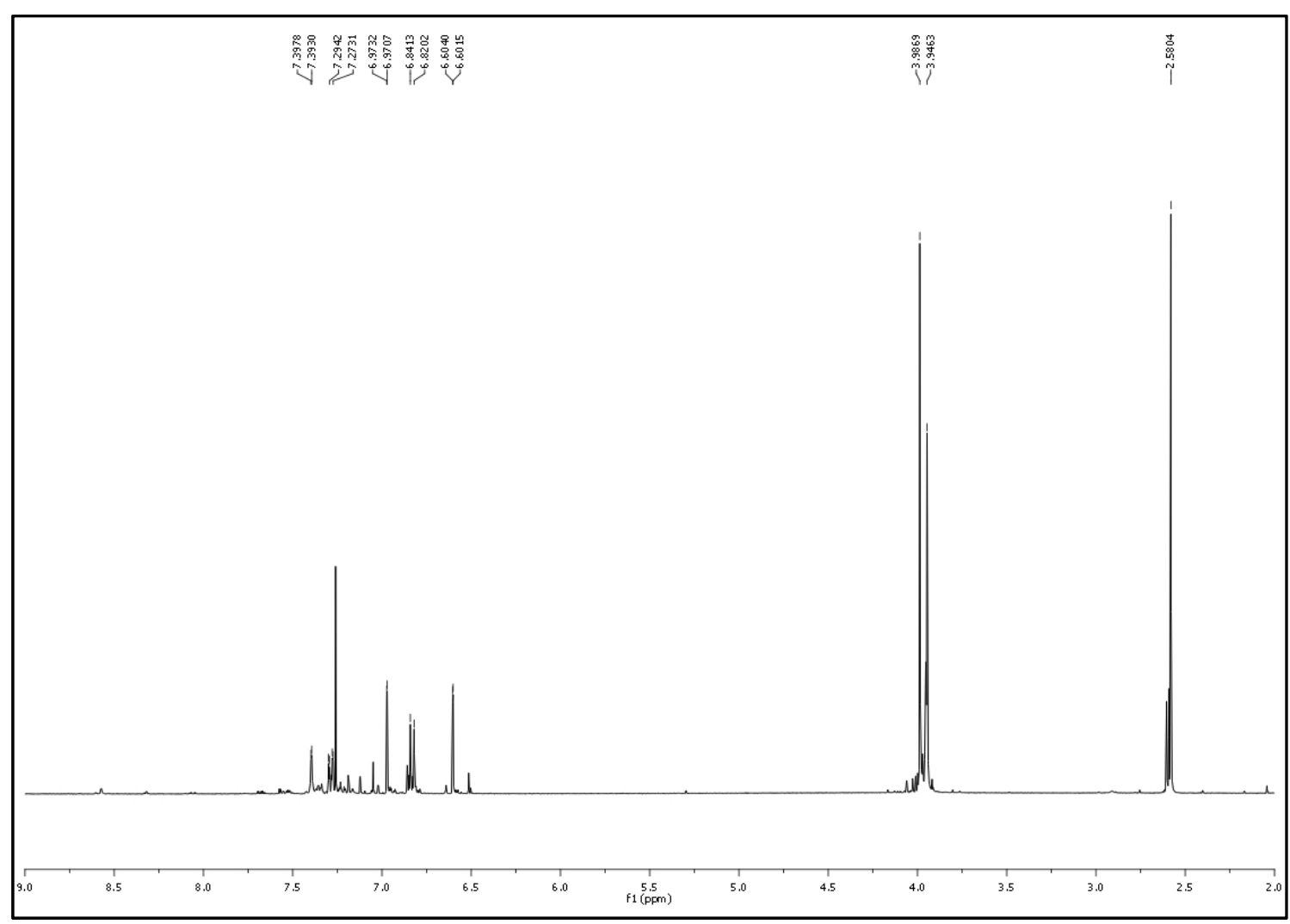

Espectro 54H

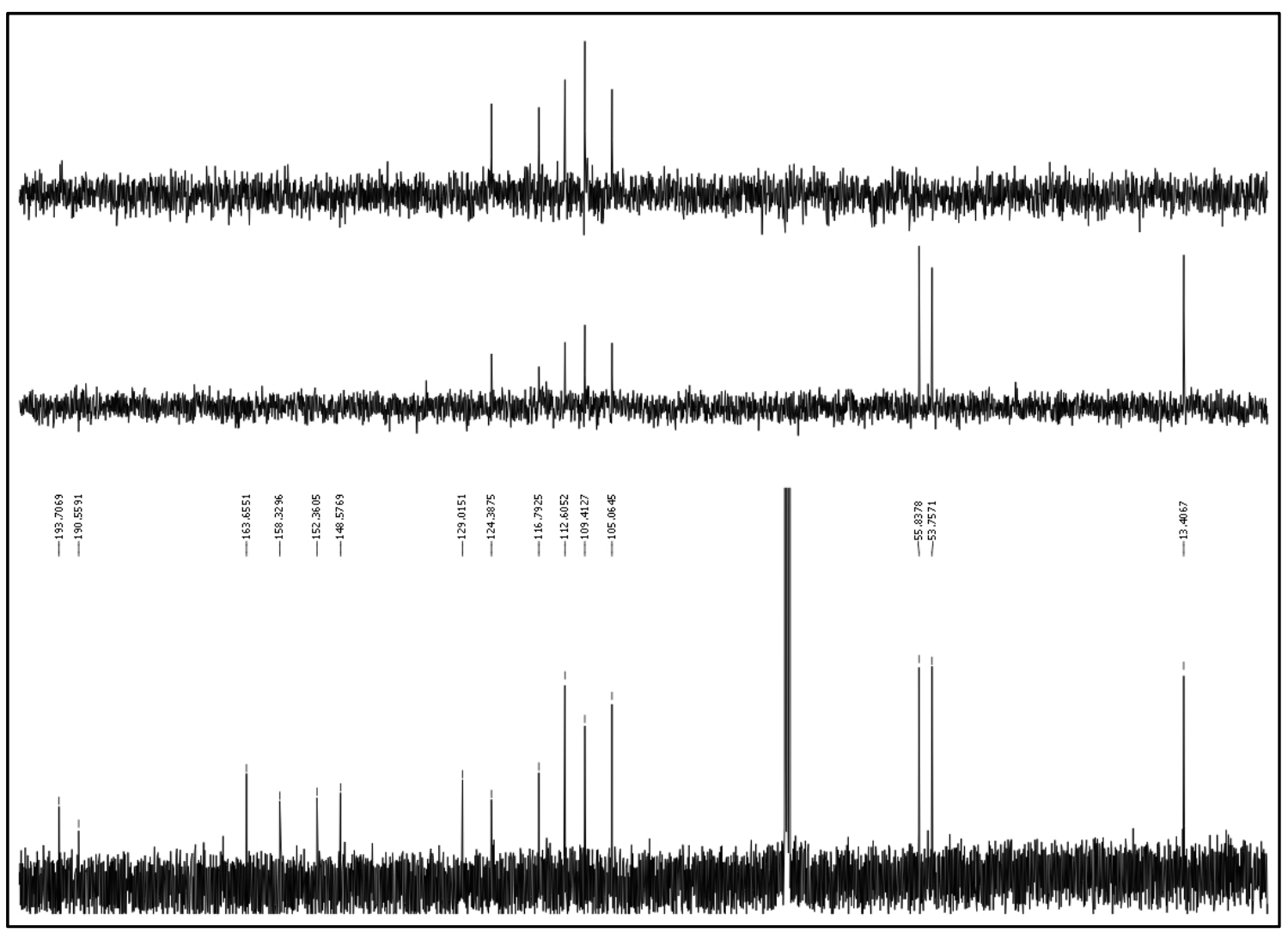

Espectro 54C 


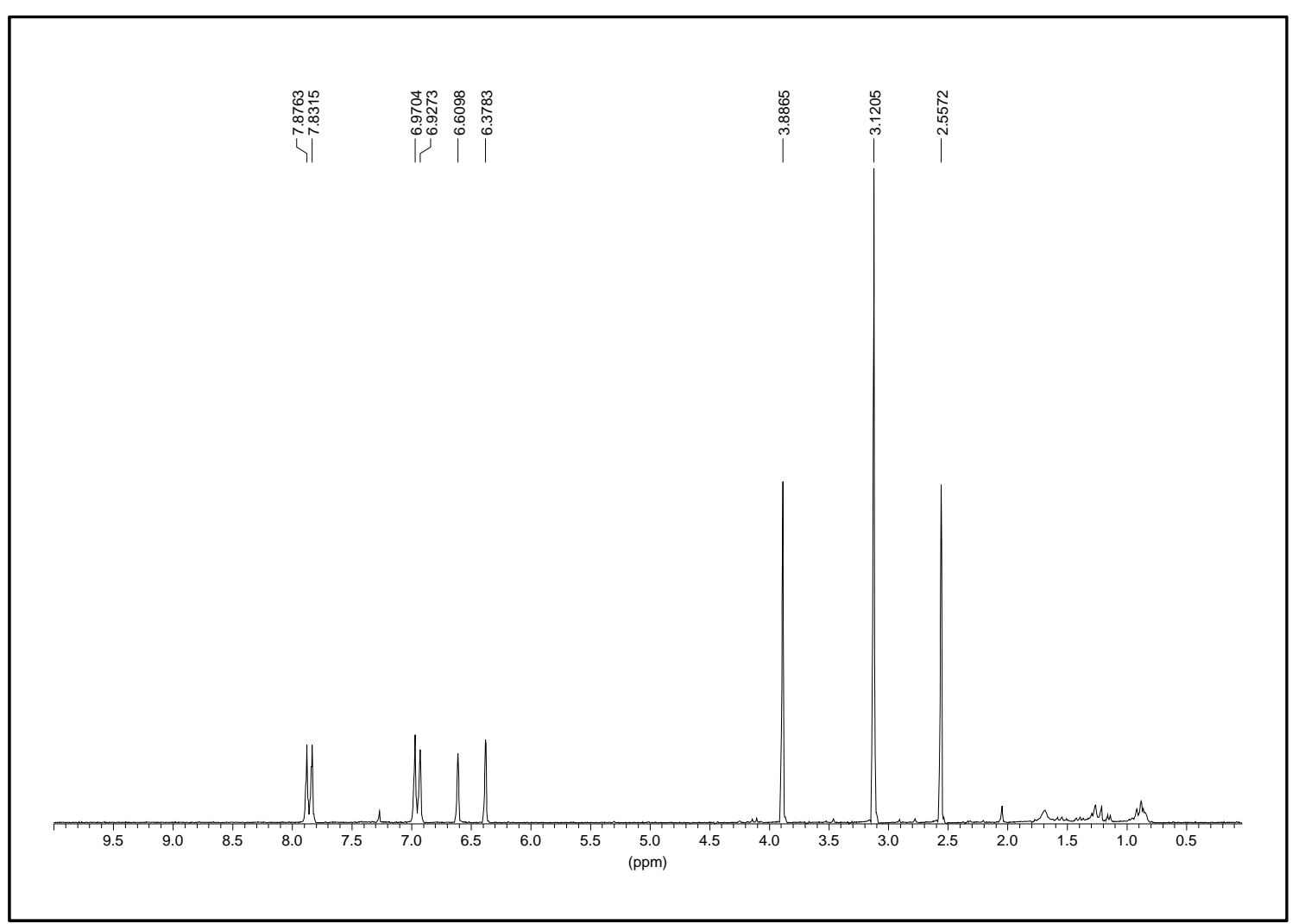

\section{Espectro $55 \mathrm{H}$}

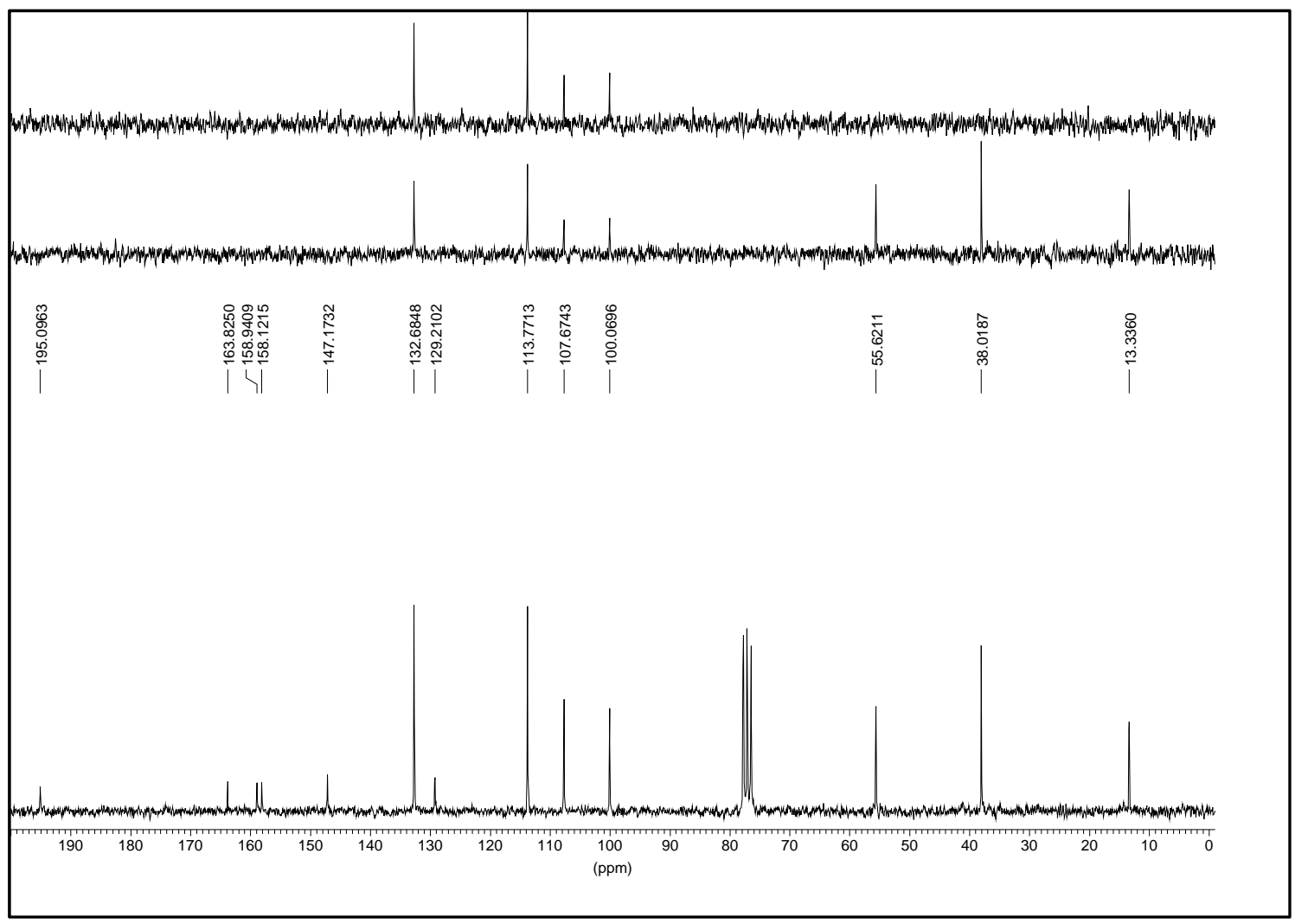

Espectro 55C 


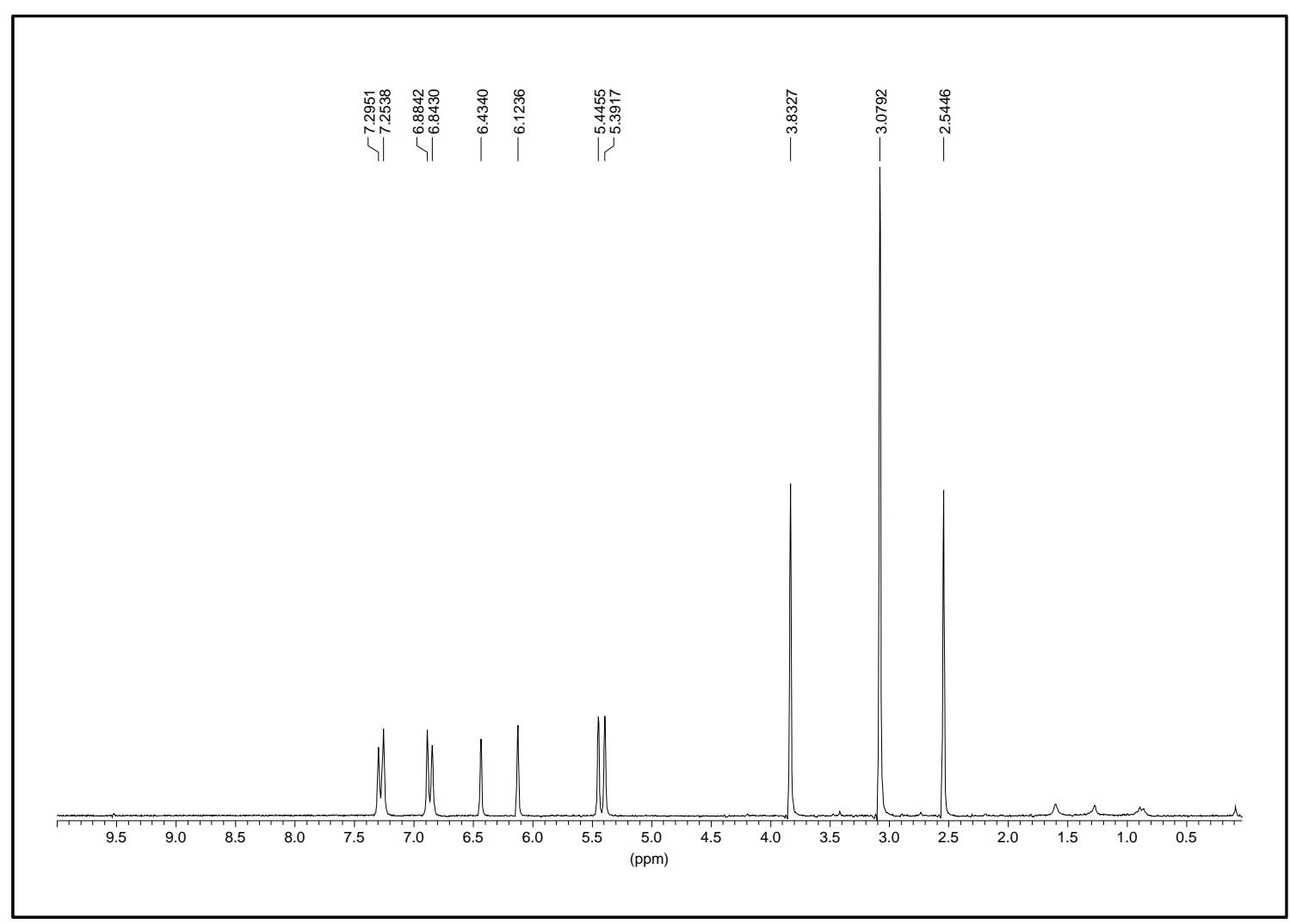

Espectro $56 \mathrm{H}$

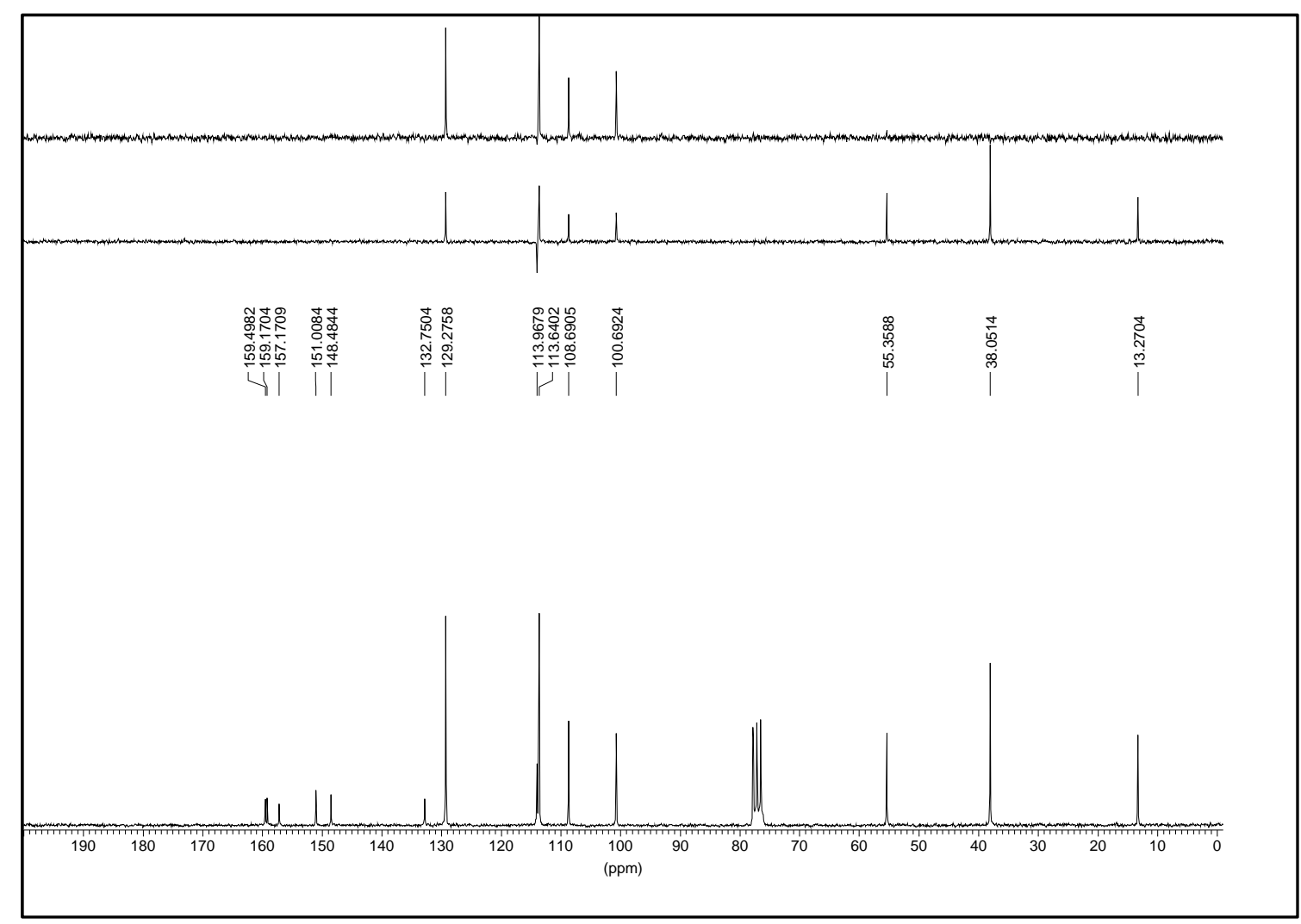

Espectro 56C 


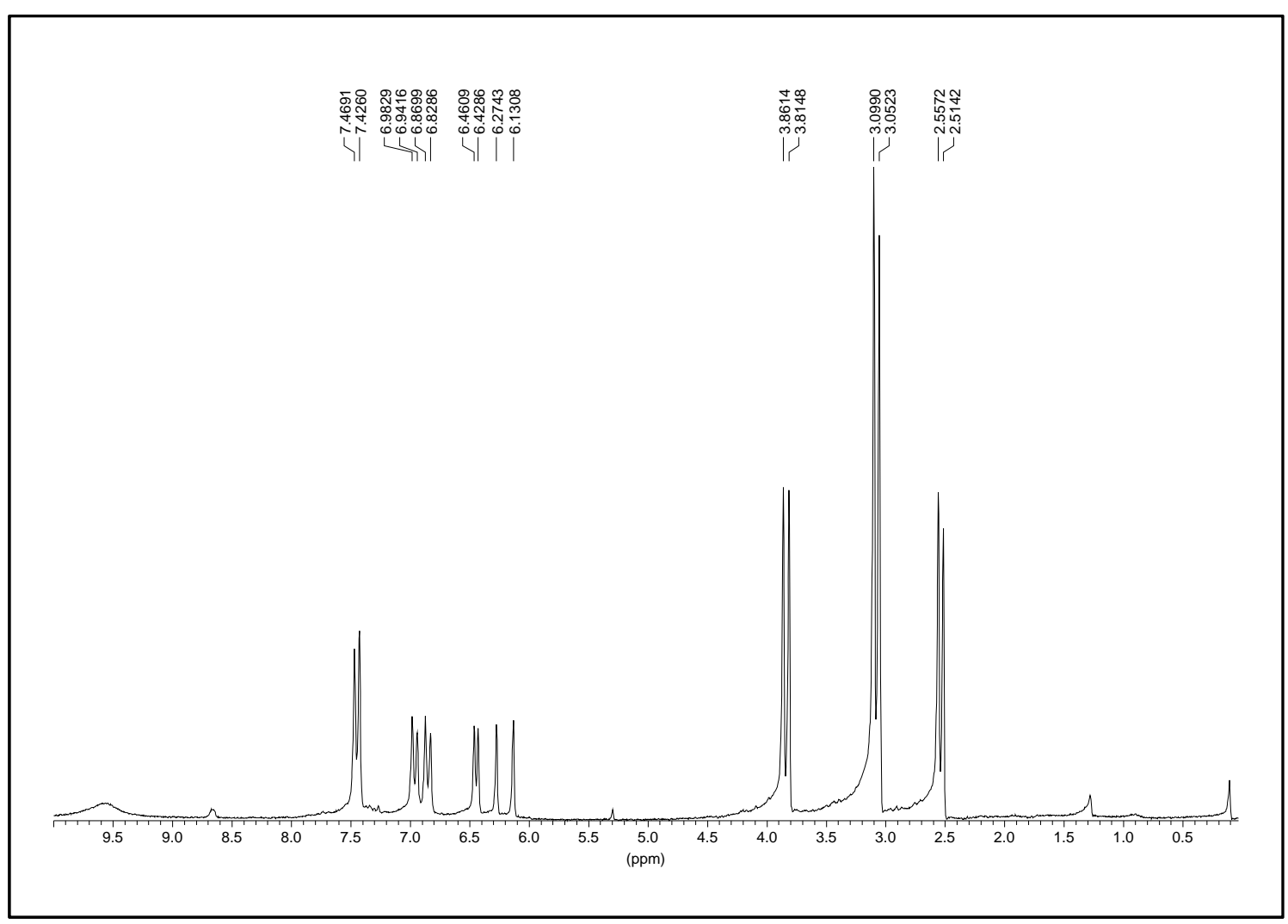

\section{Espectro 57ZEH}

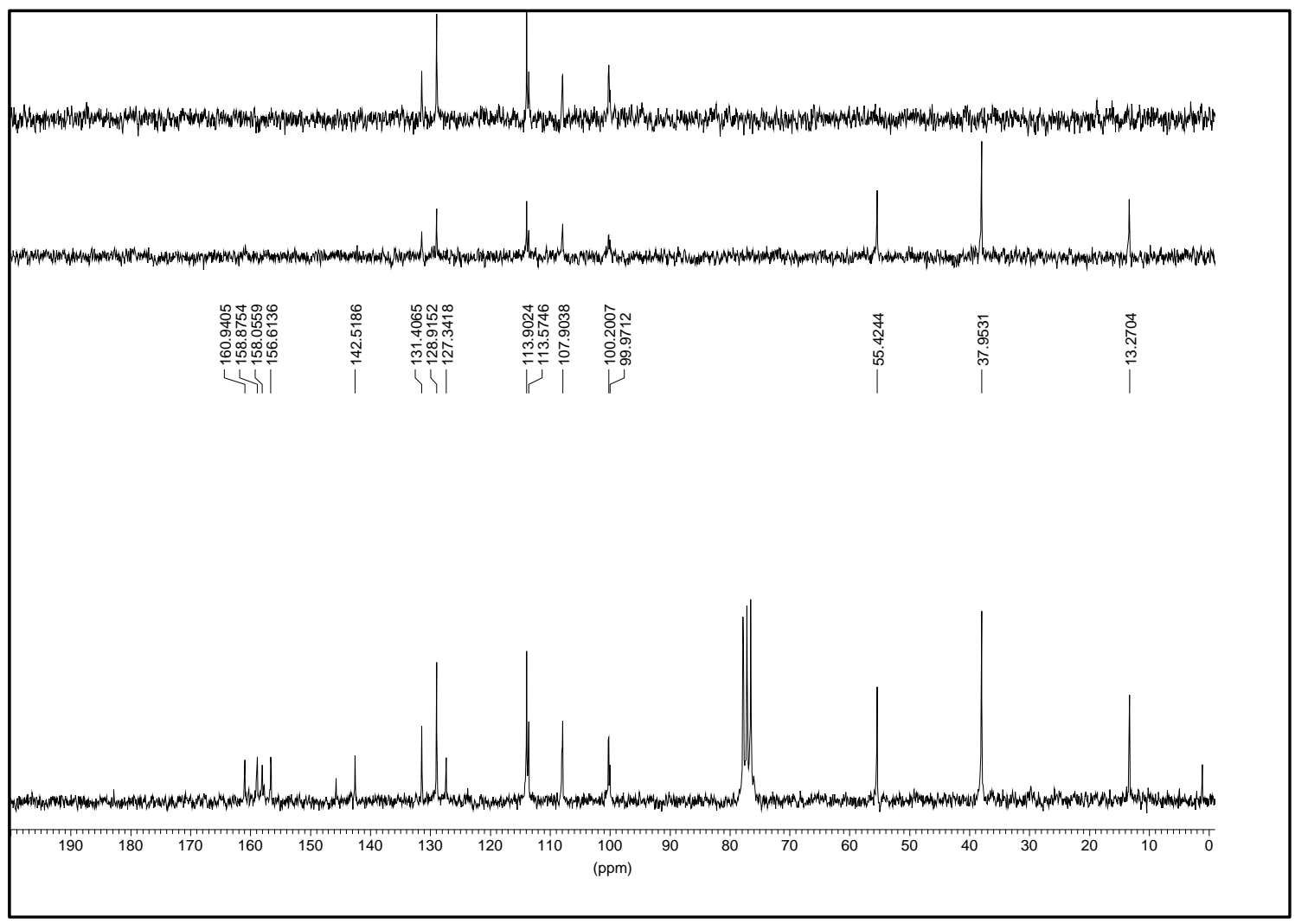

Espectro 57ZEC 


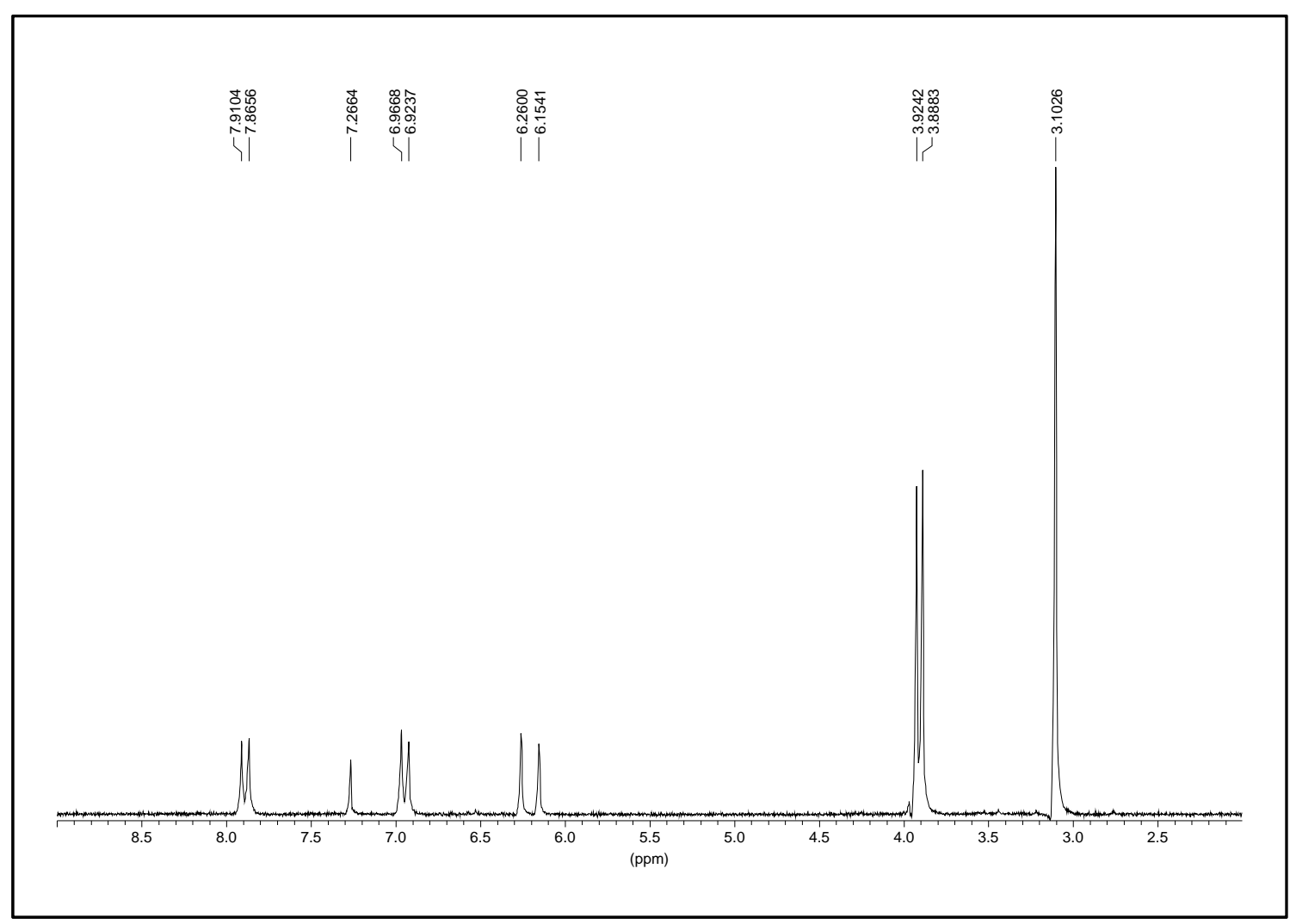

Espectro $58 \mathrm{H}$

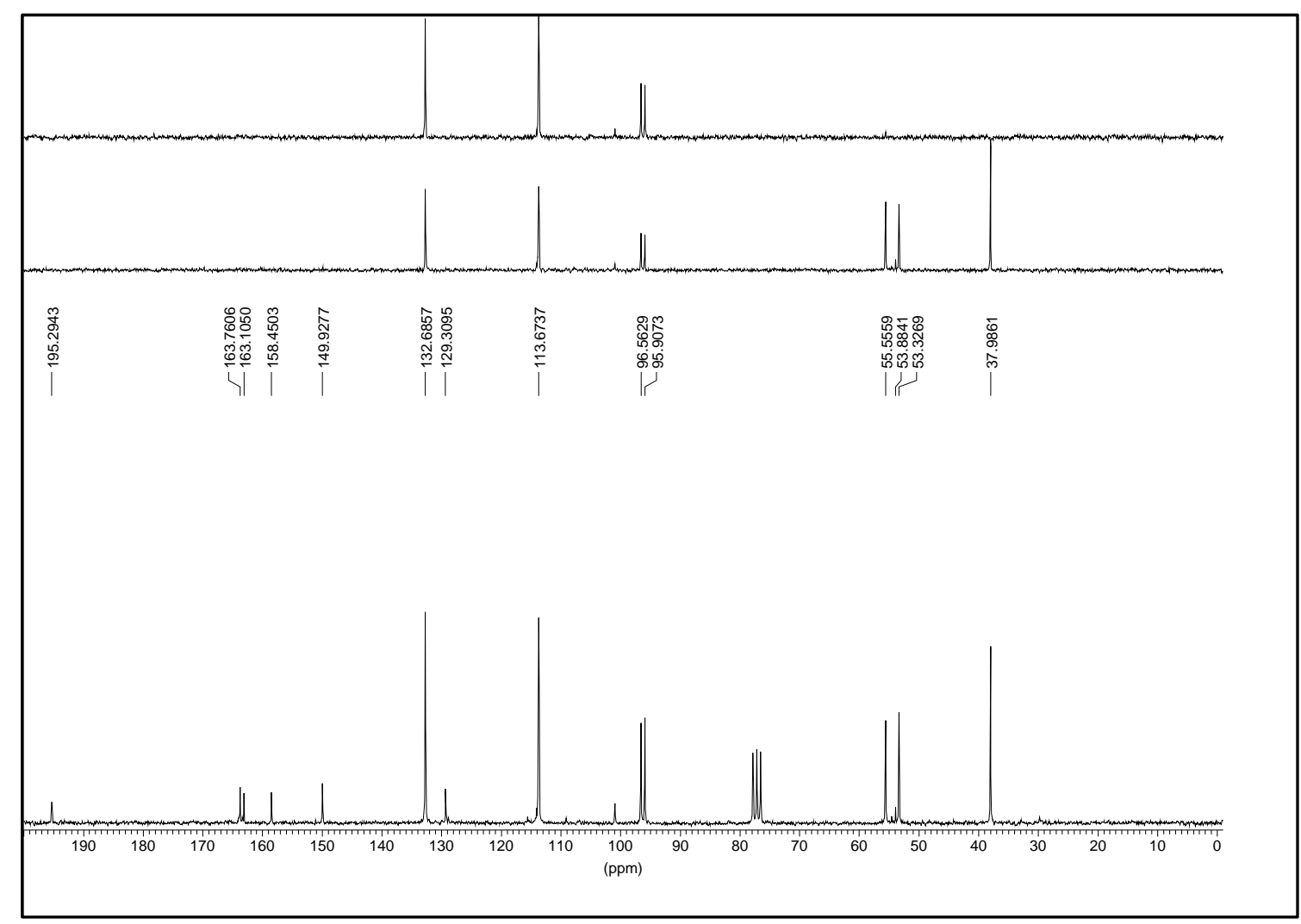

Espectro 58C 


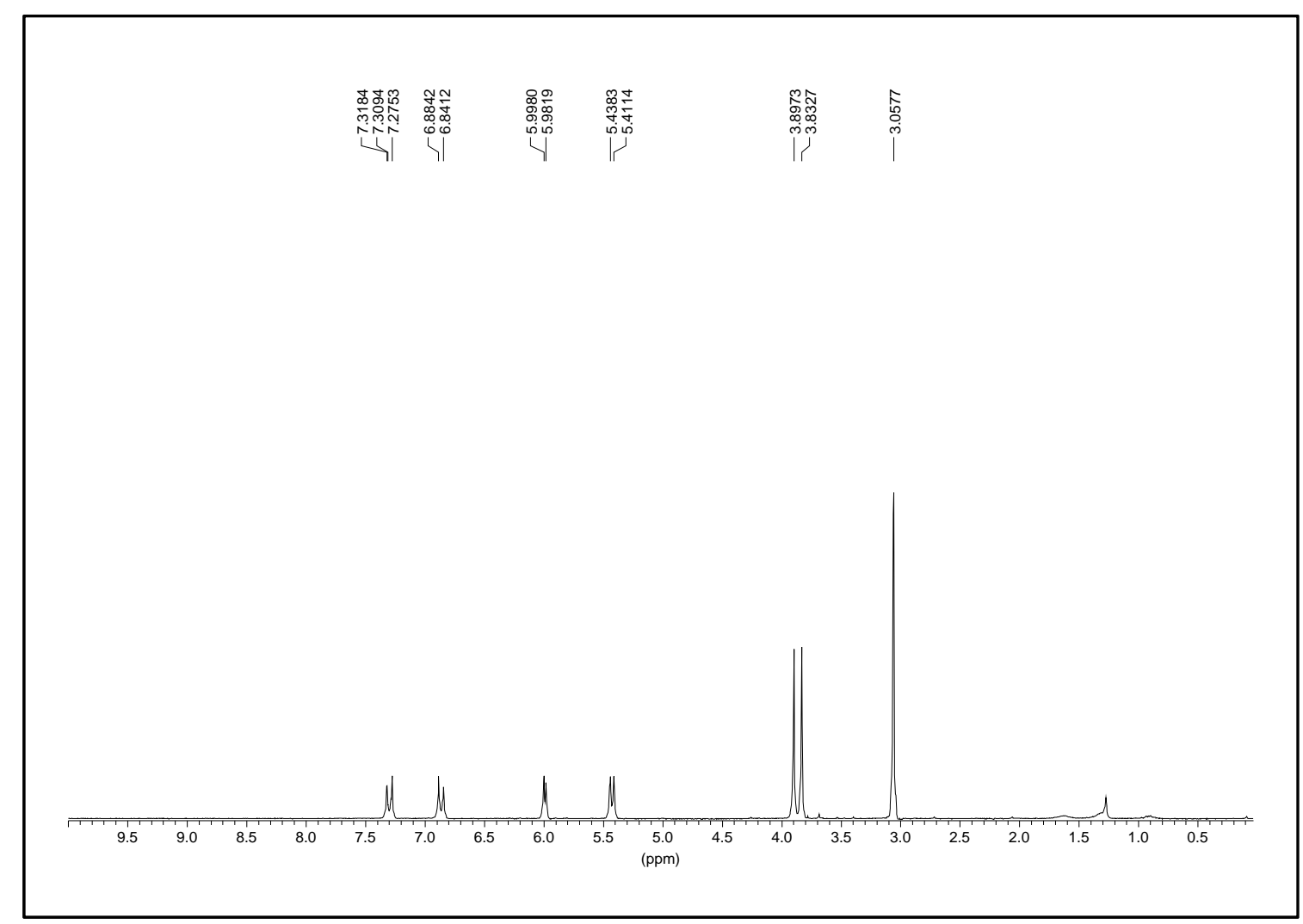

\section{Espectro $59 \mathrm{H}$}

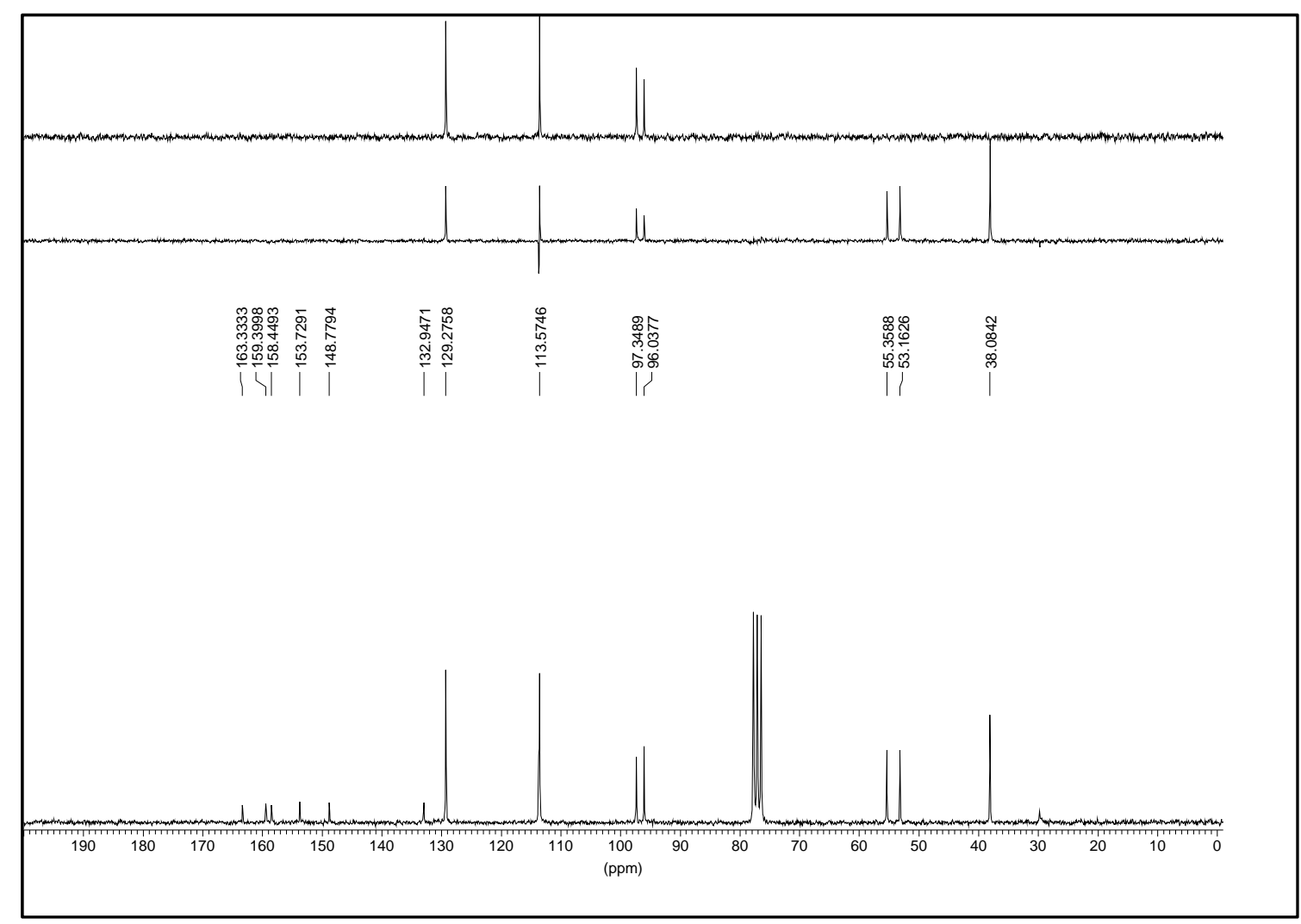

Espectro 59C 


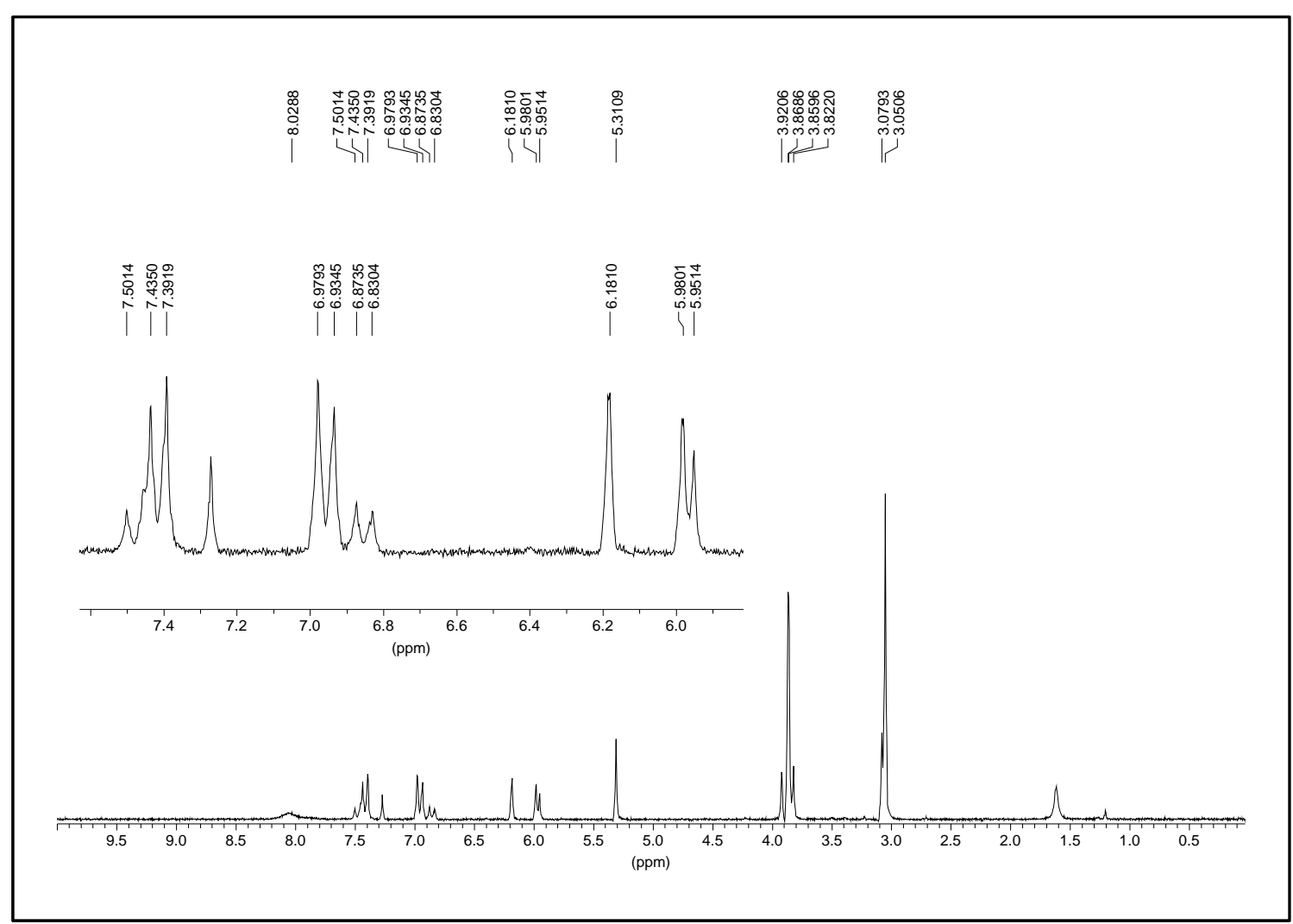

\section{Espectro 60aH}

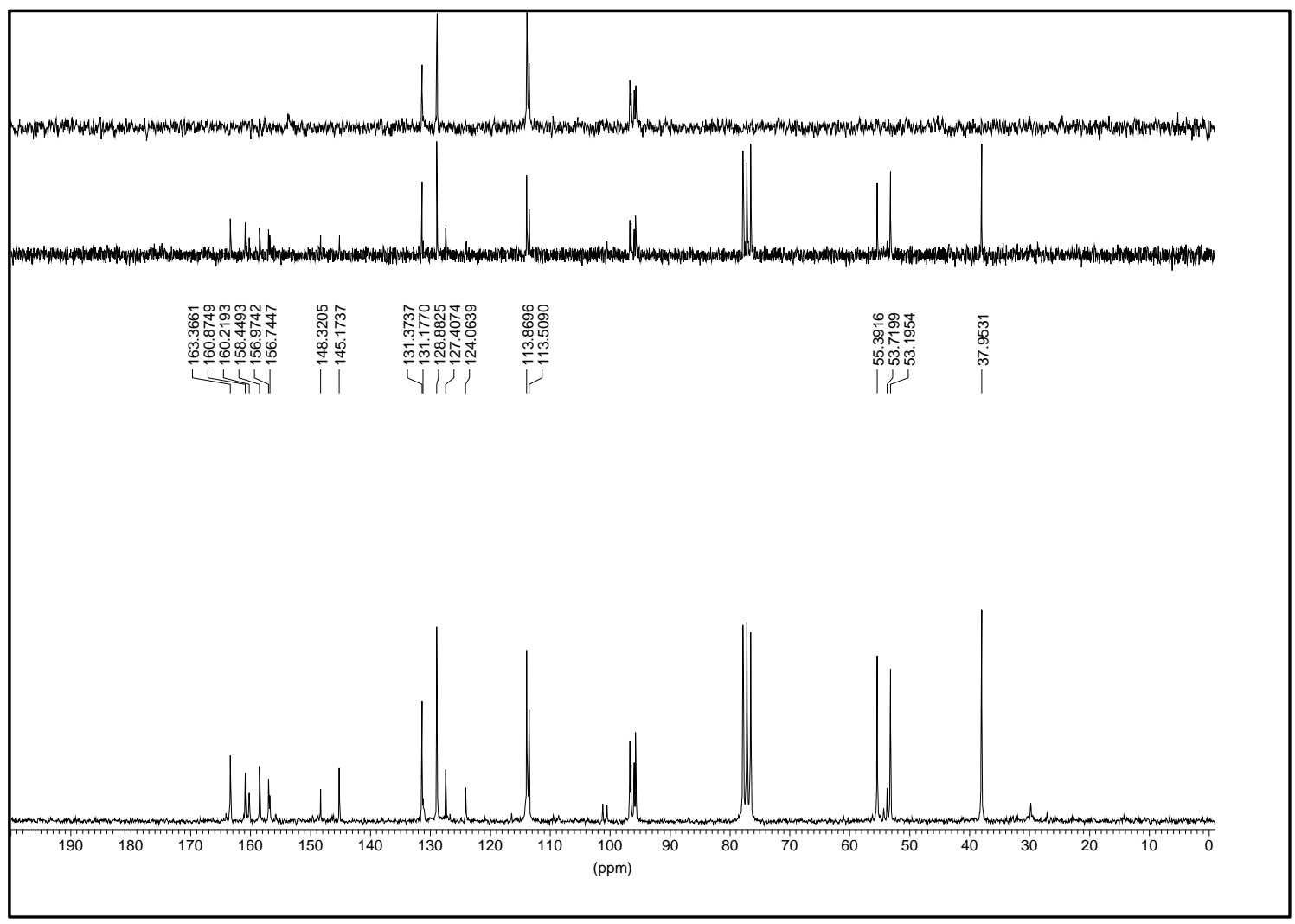

Espectro 60ZEC 


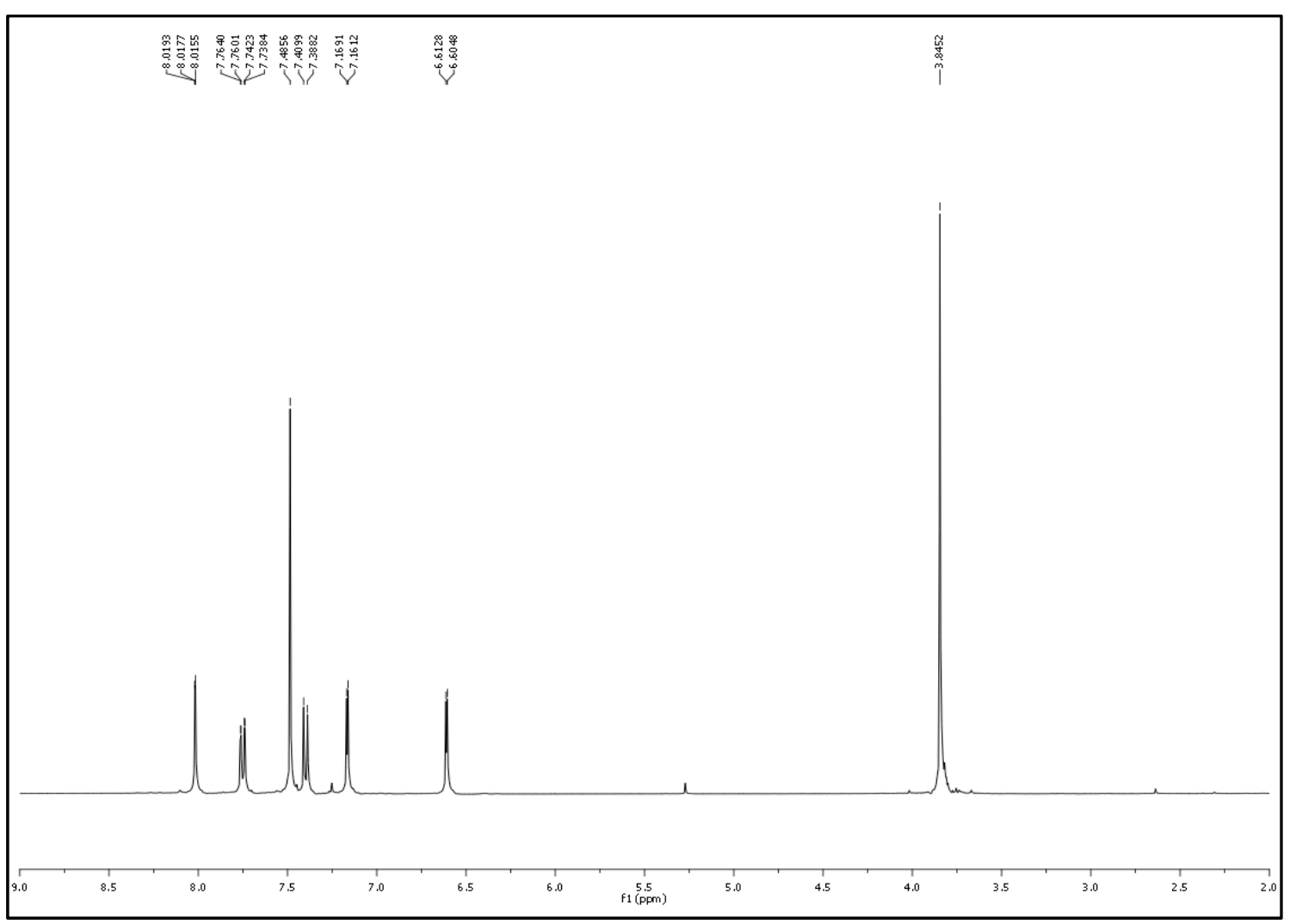

Espectro $61 \mathrm{H}$

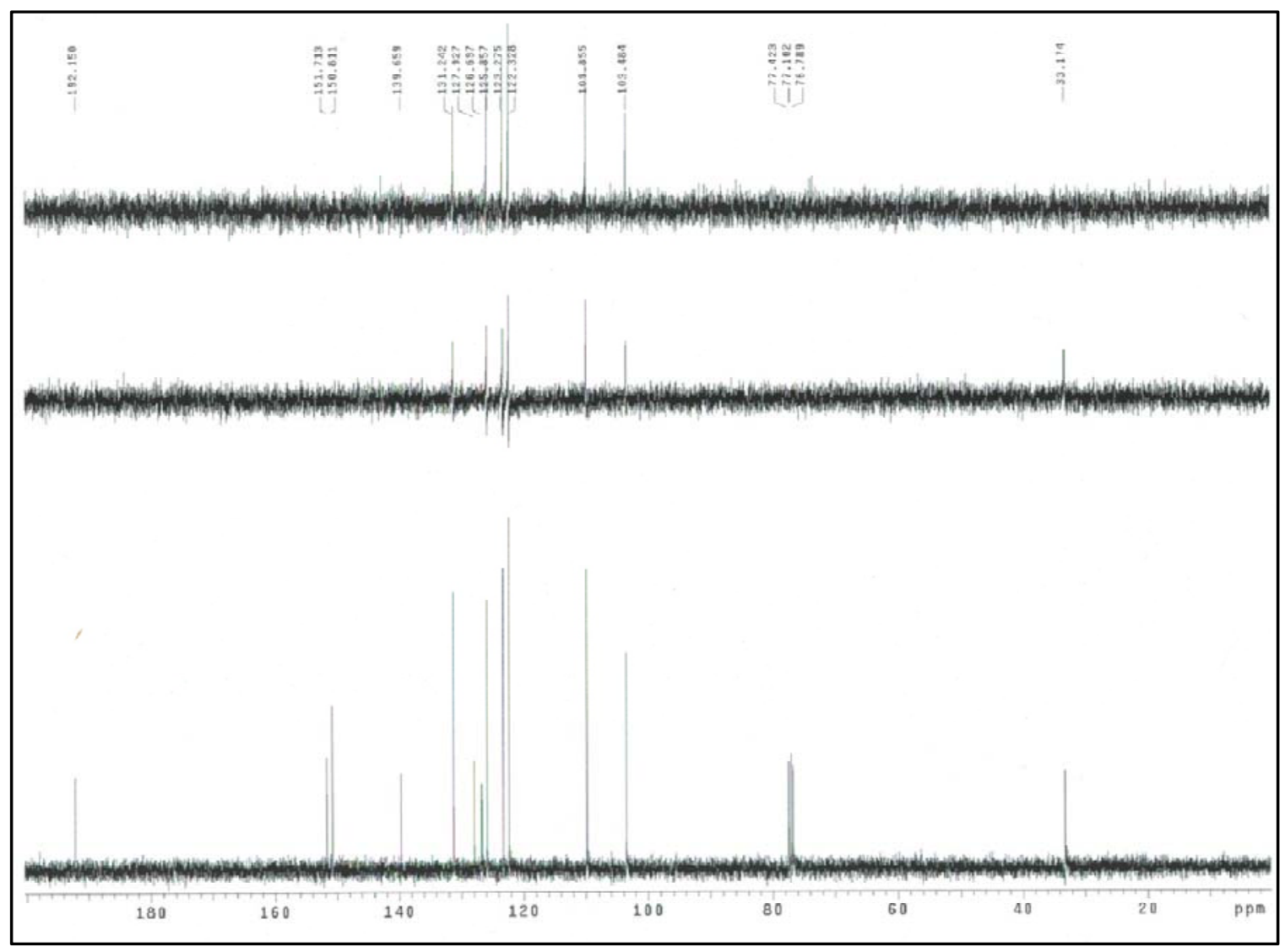

Espectro 61C 


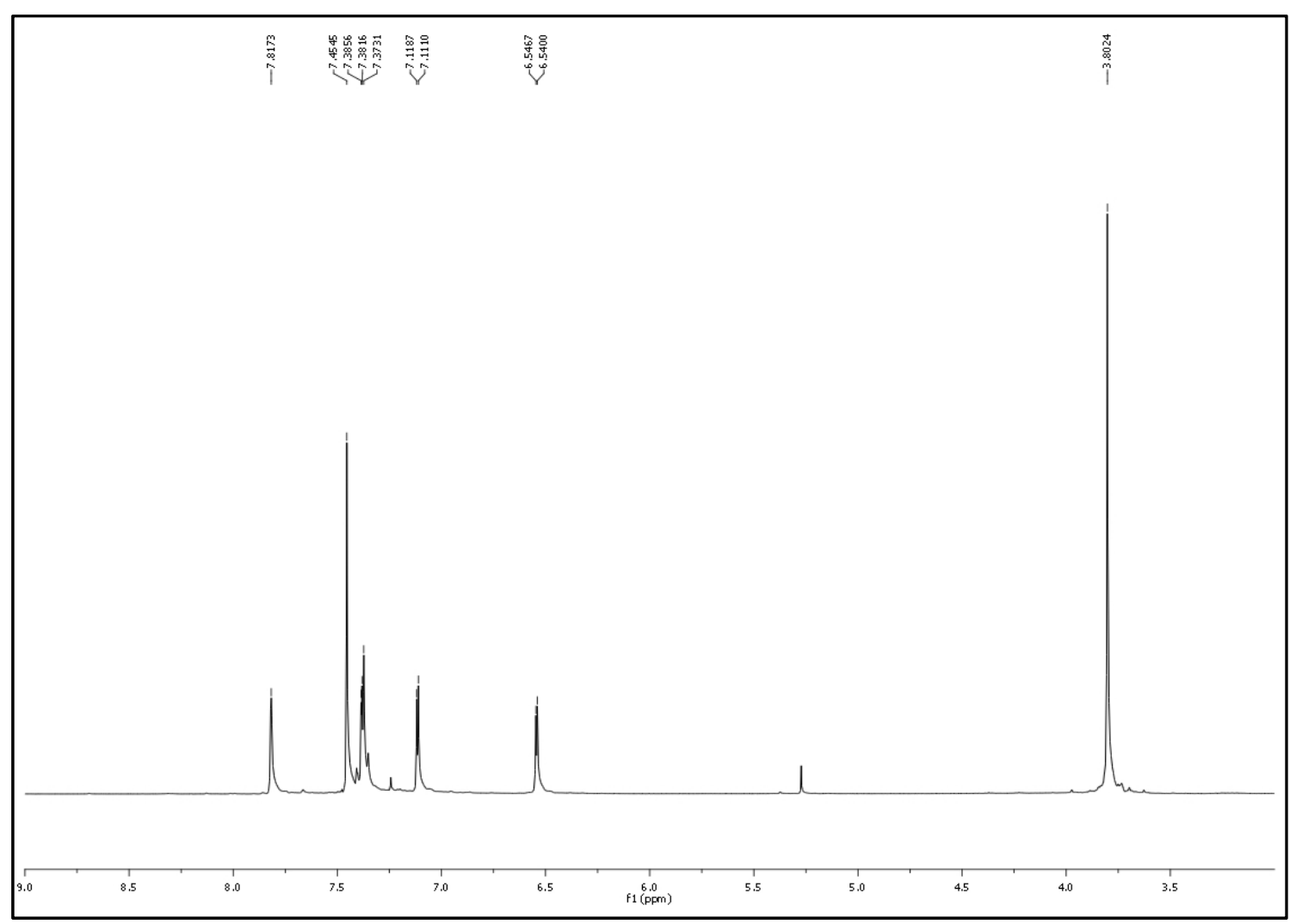

Espectro $62 \mathrm{H}$

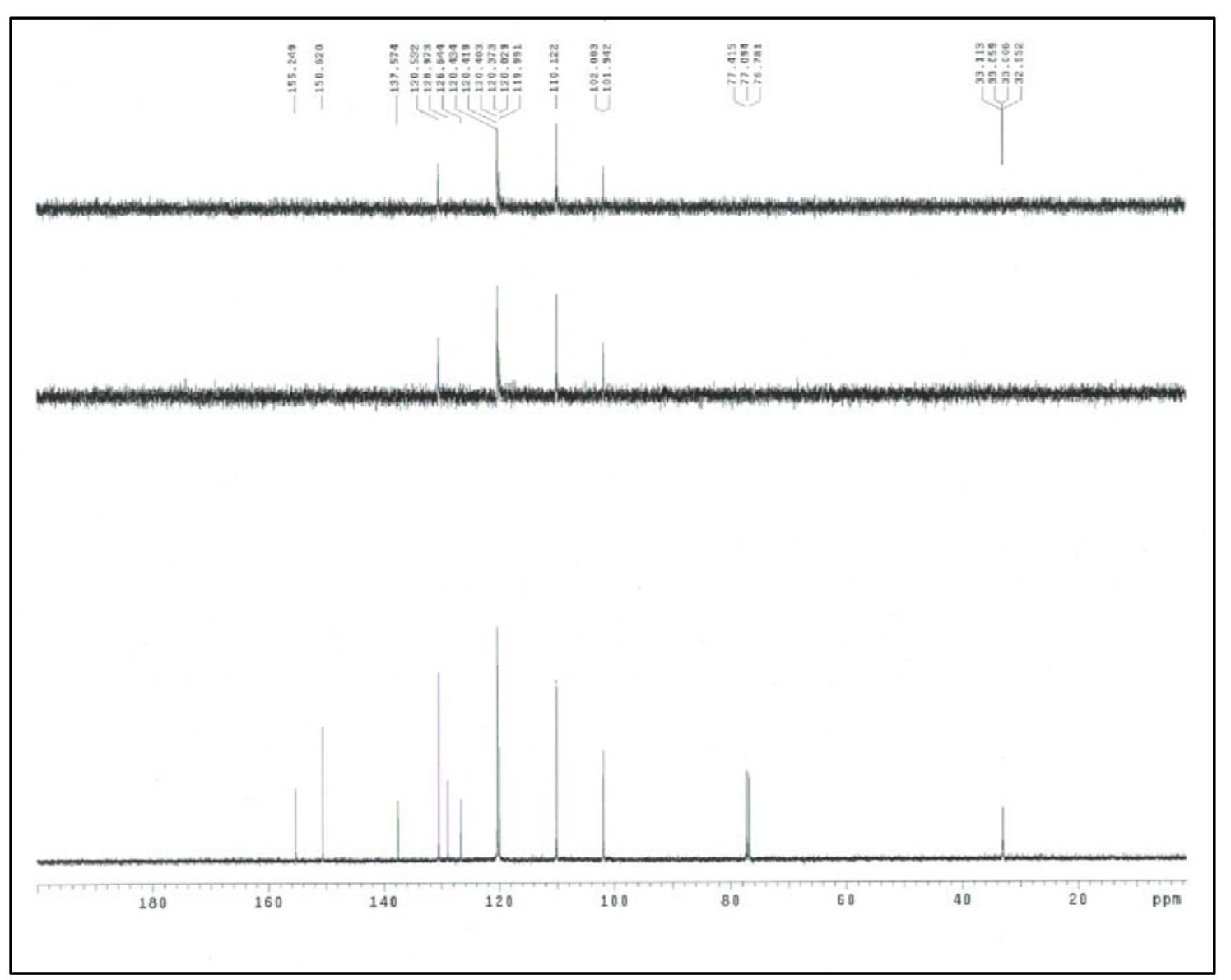

Espectro 62C 


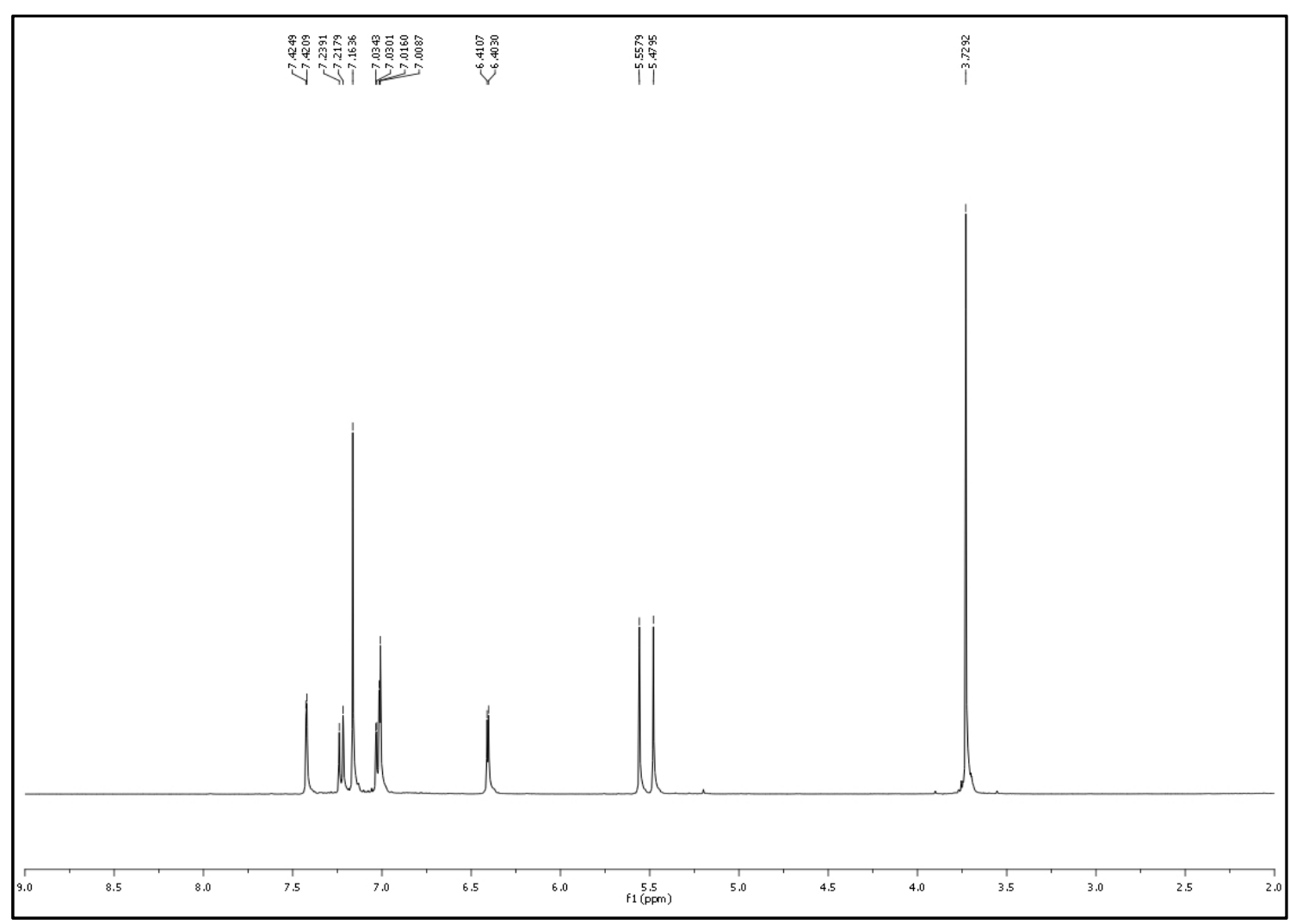

Espectro 63H

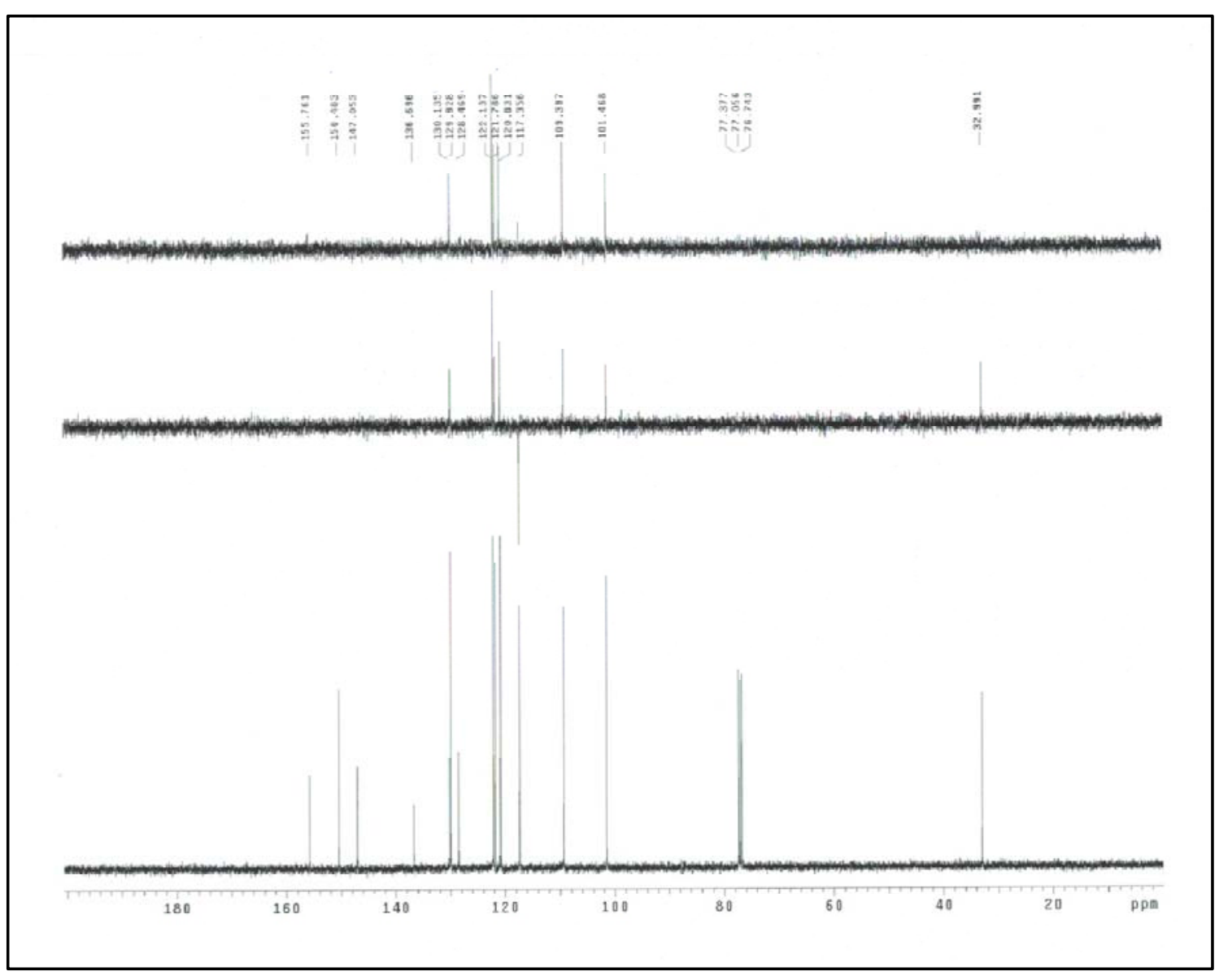

Espectro 63C 


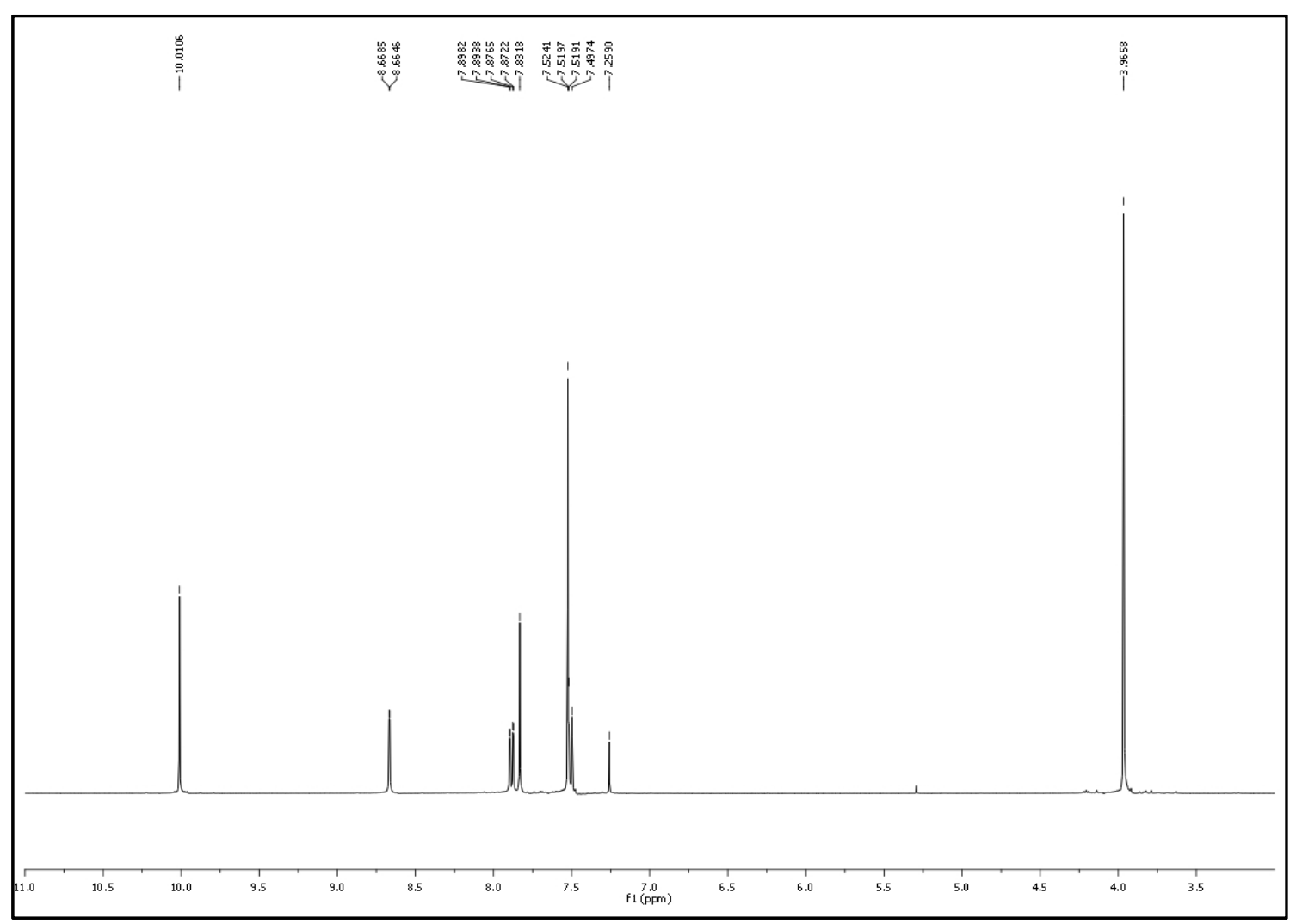

Espectro 64H

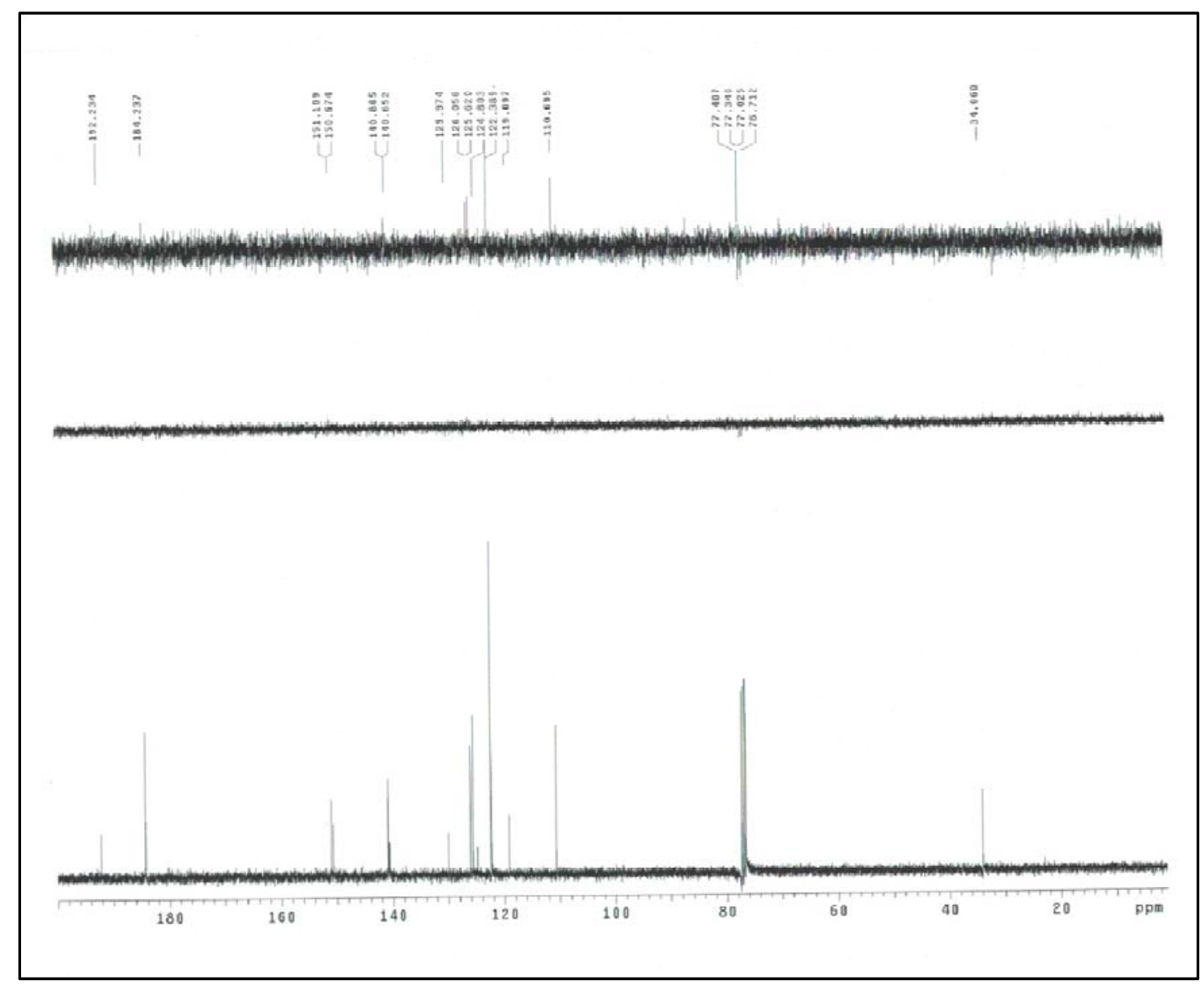

Espectro 64C 


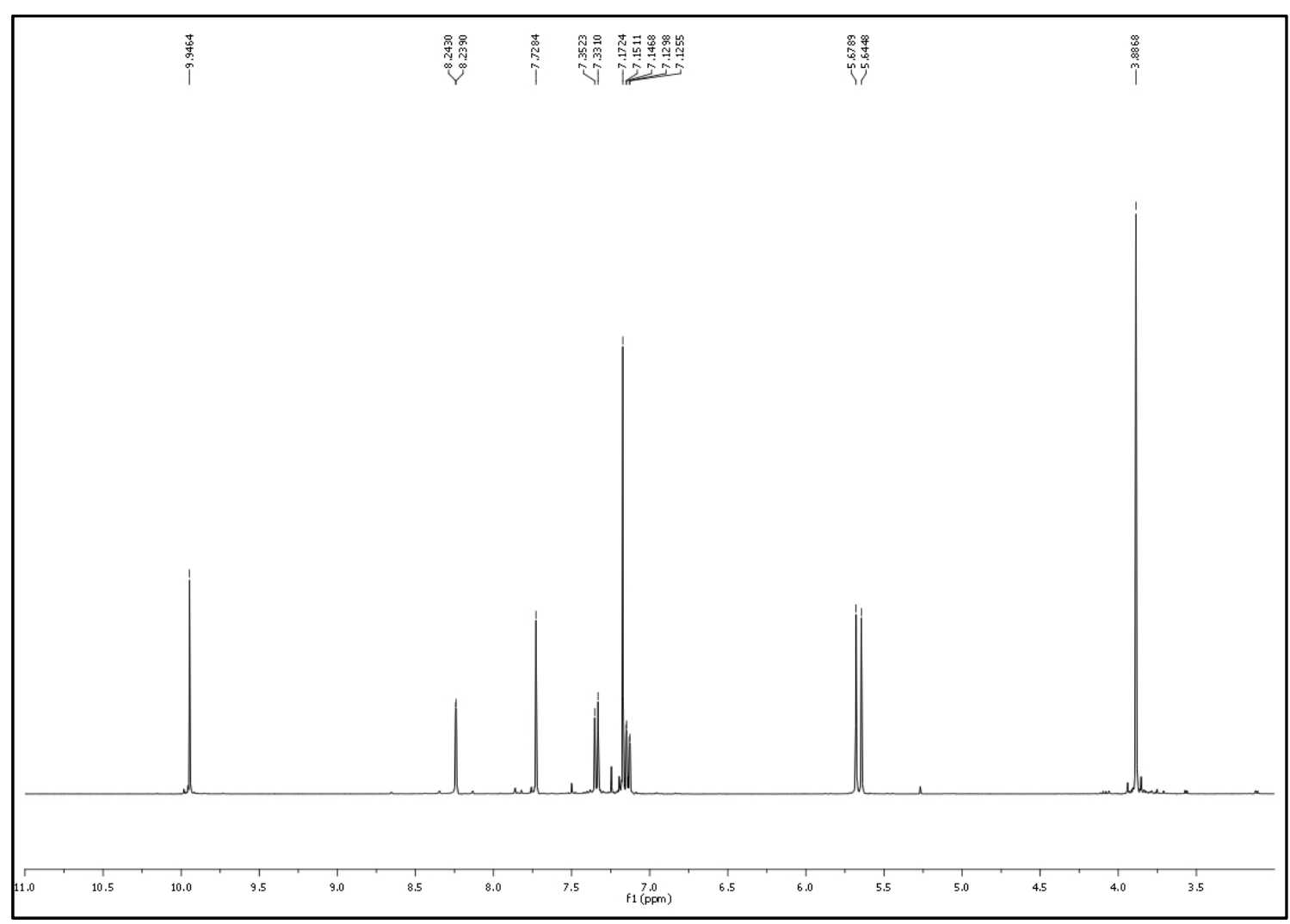

Espectro 65H

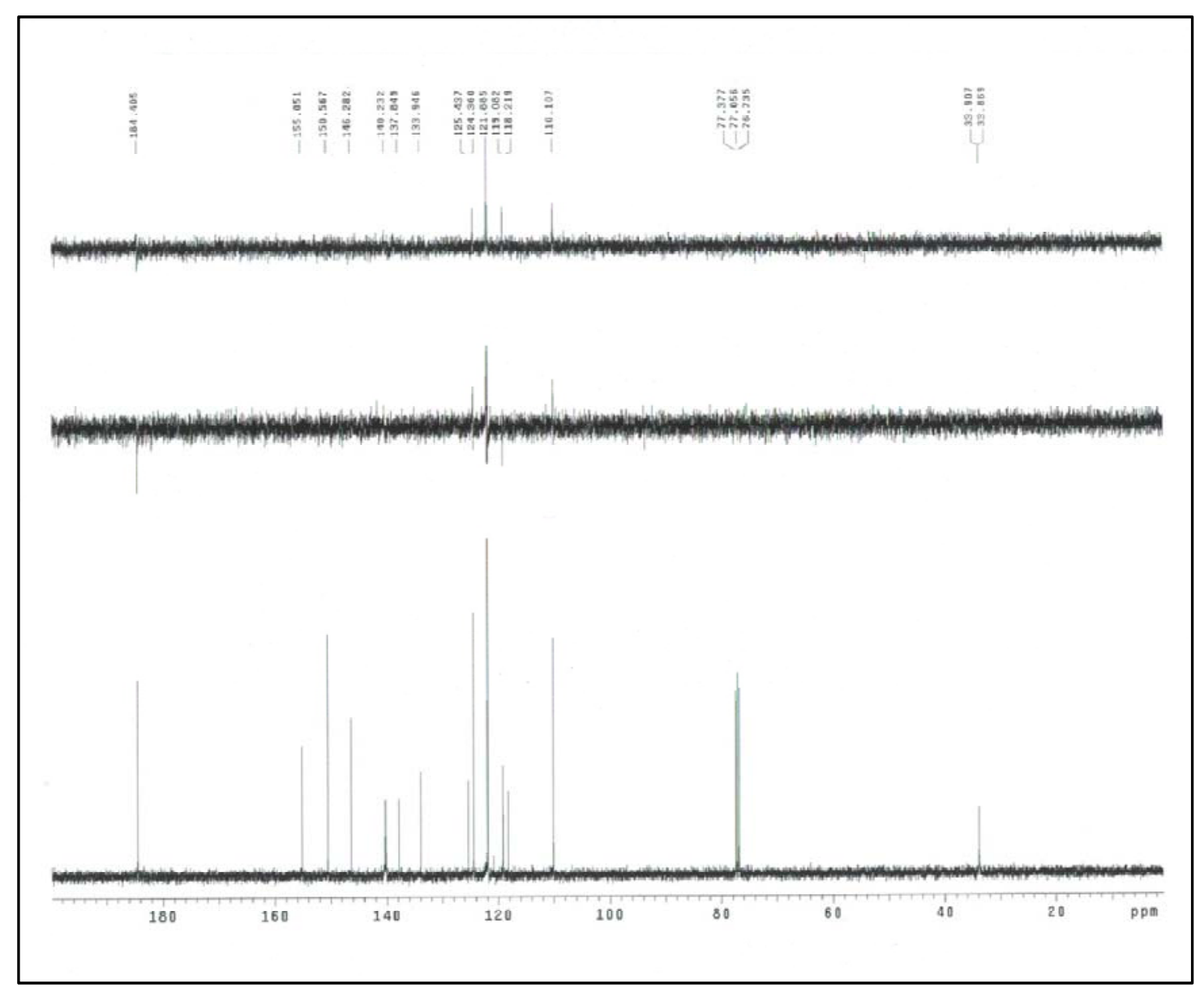

Espectro 65C 


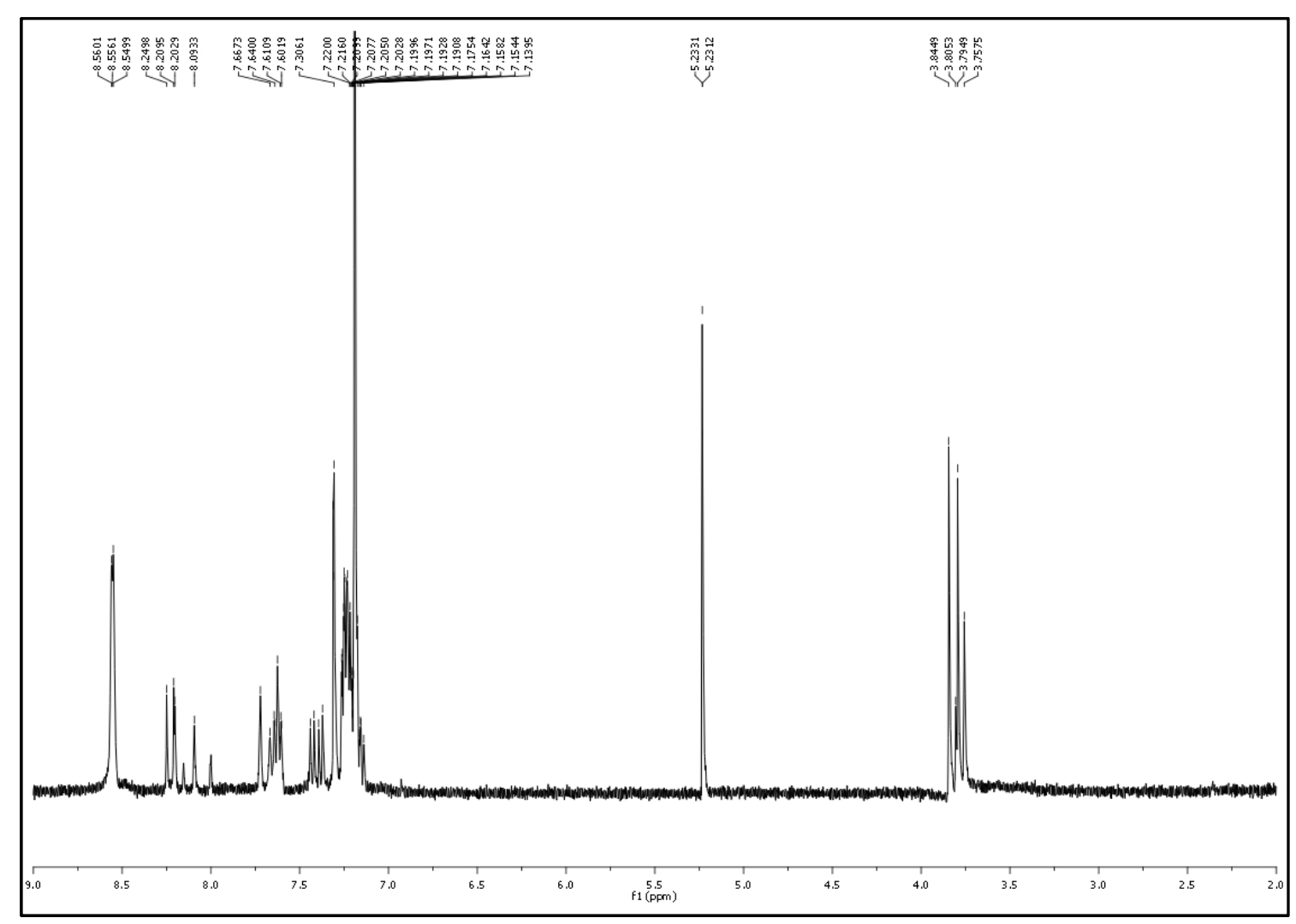

Espectro $66 \mathrm{H}$ 


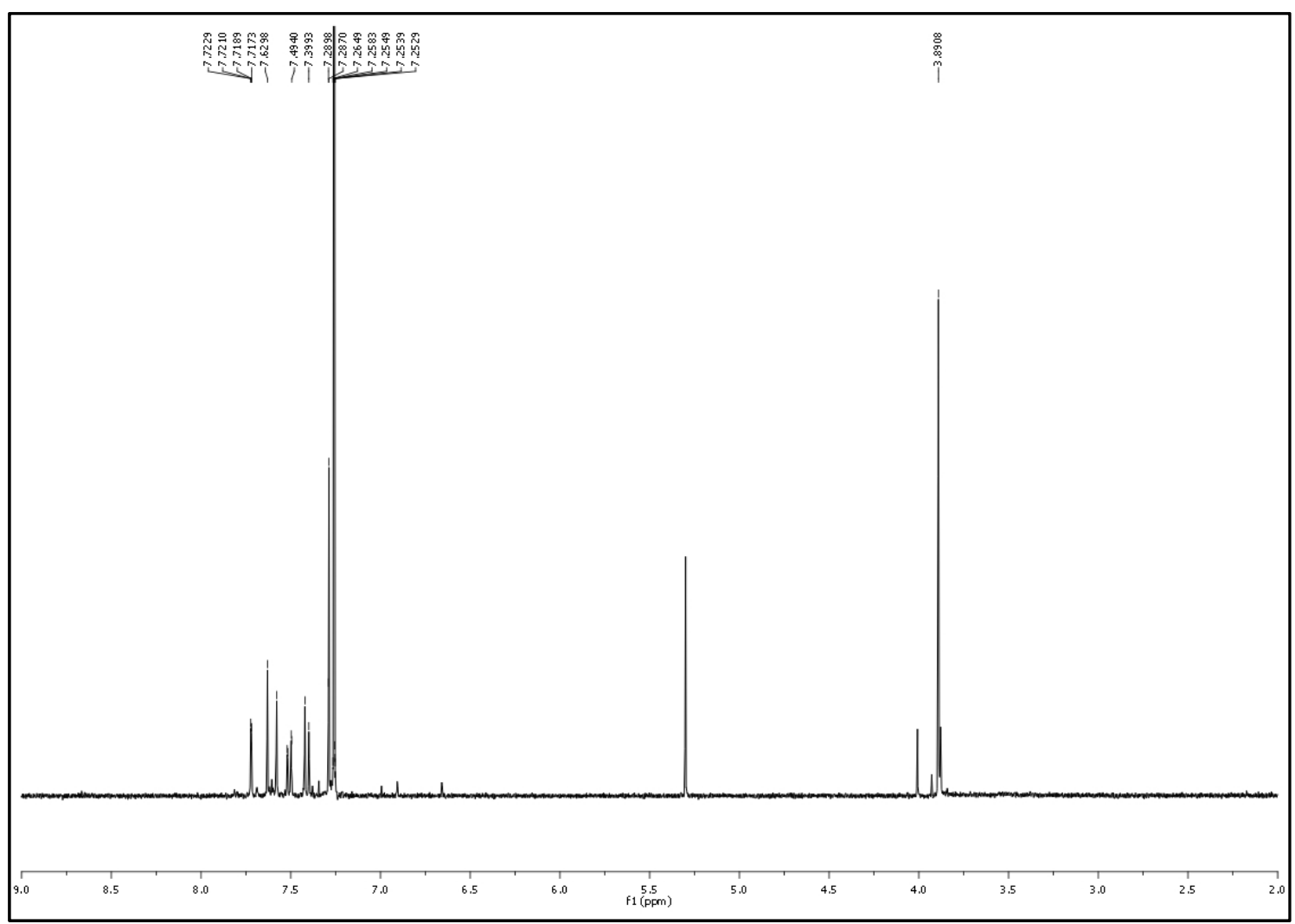

\section{Espectro 68EH}

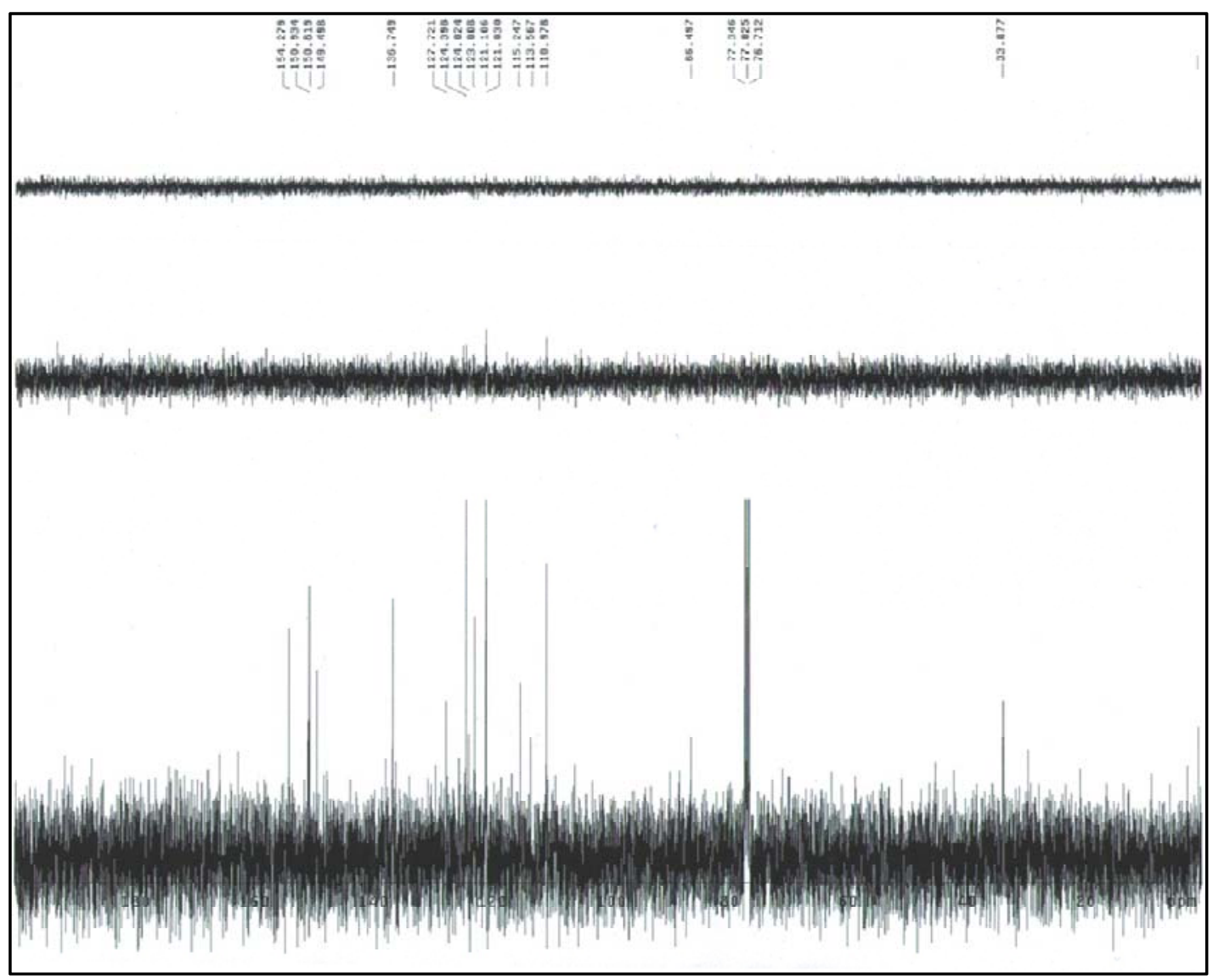

Espectro 68ZEC 


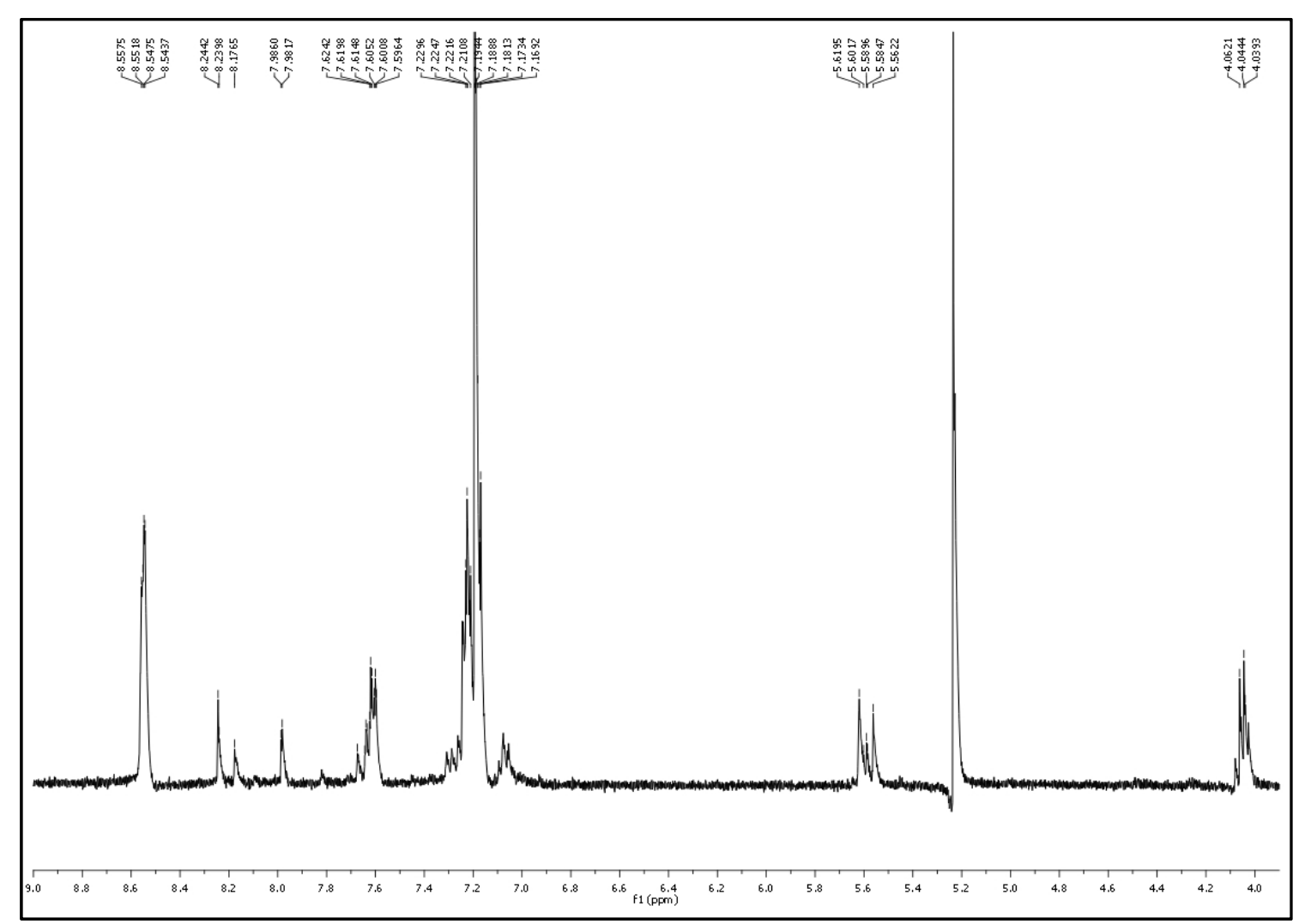

Espectro $69 \mathrm{H}$ 


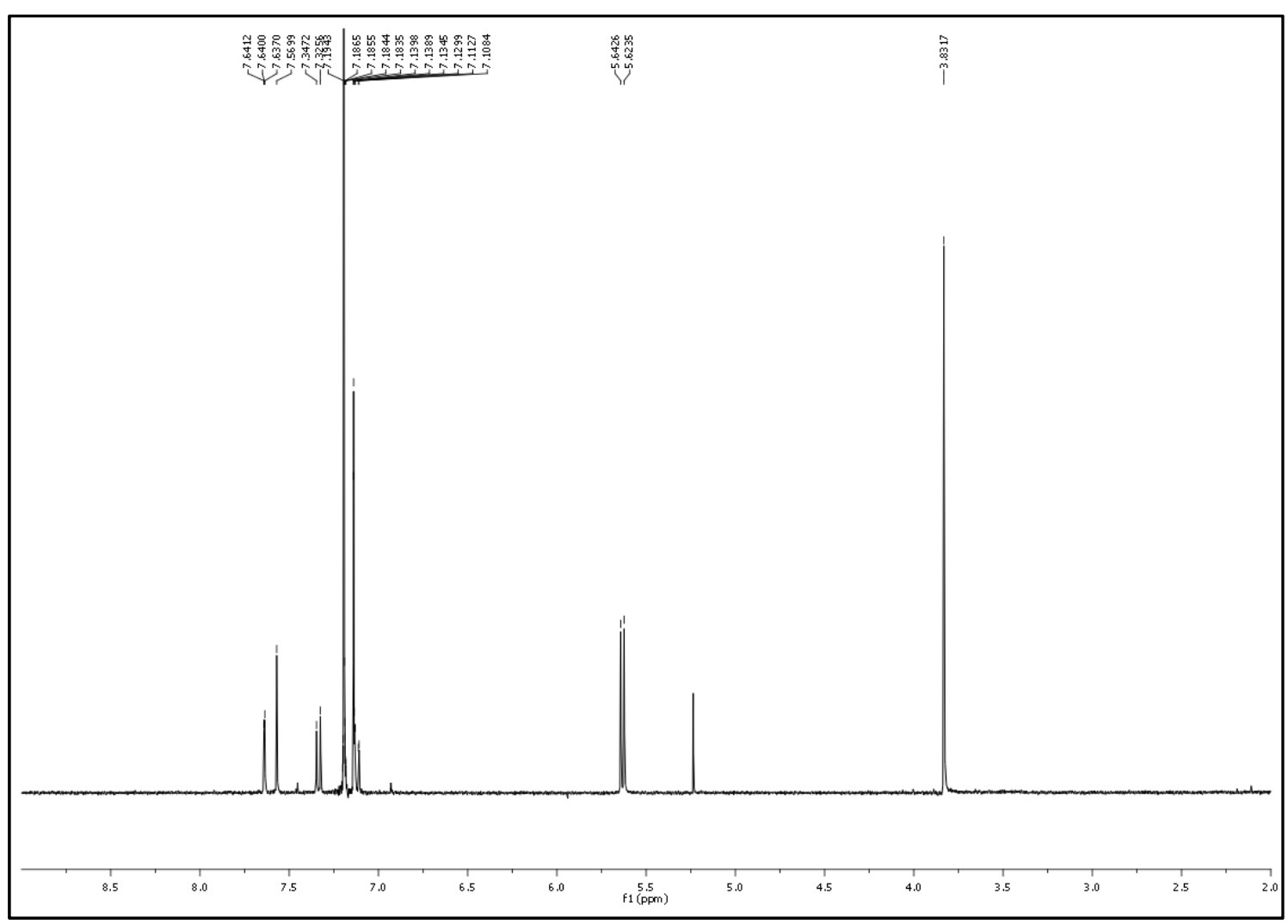

Espectro $70 \mathrm{H}$

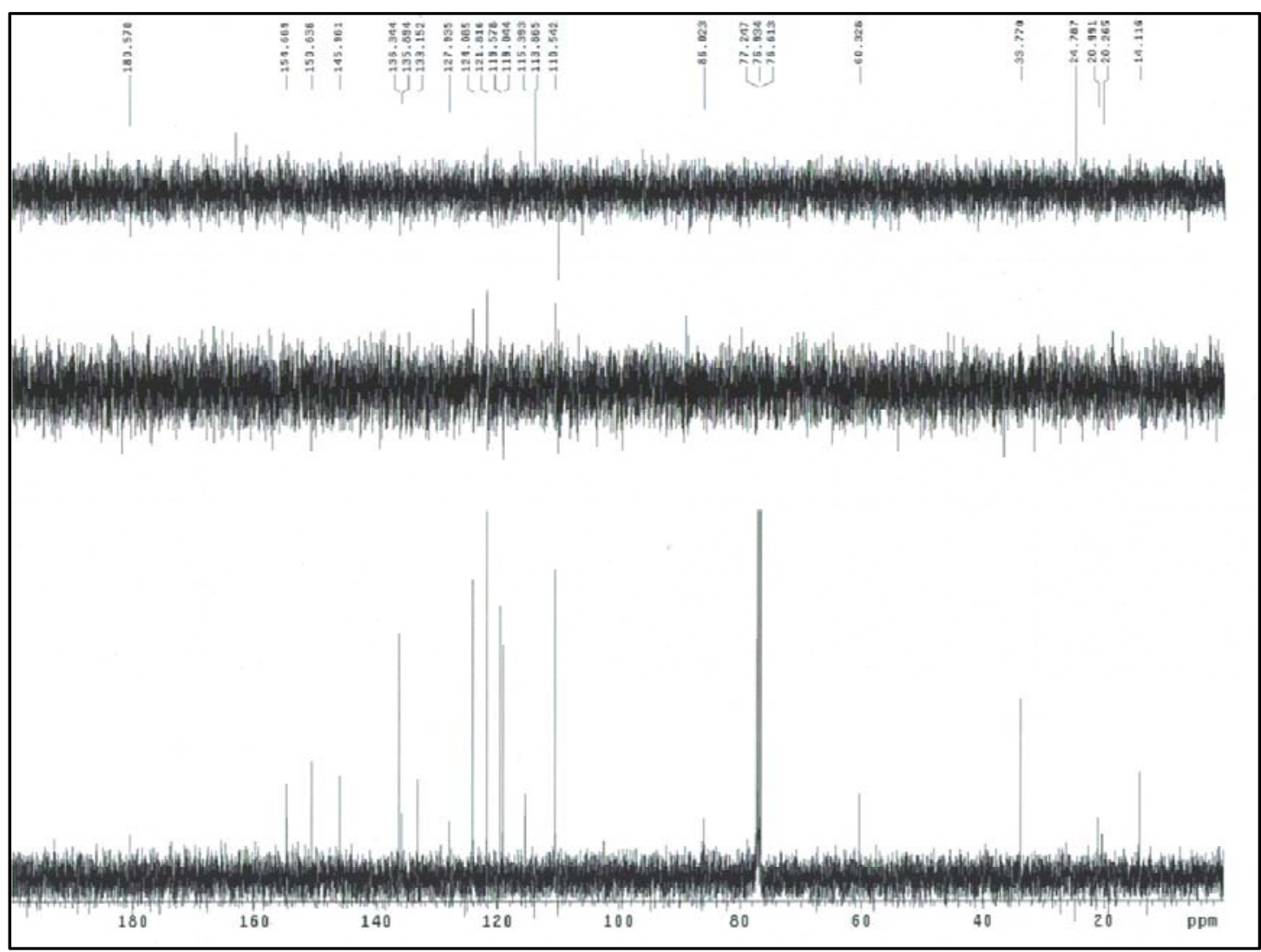

Espectro 70C 


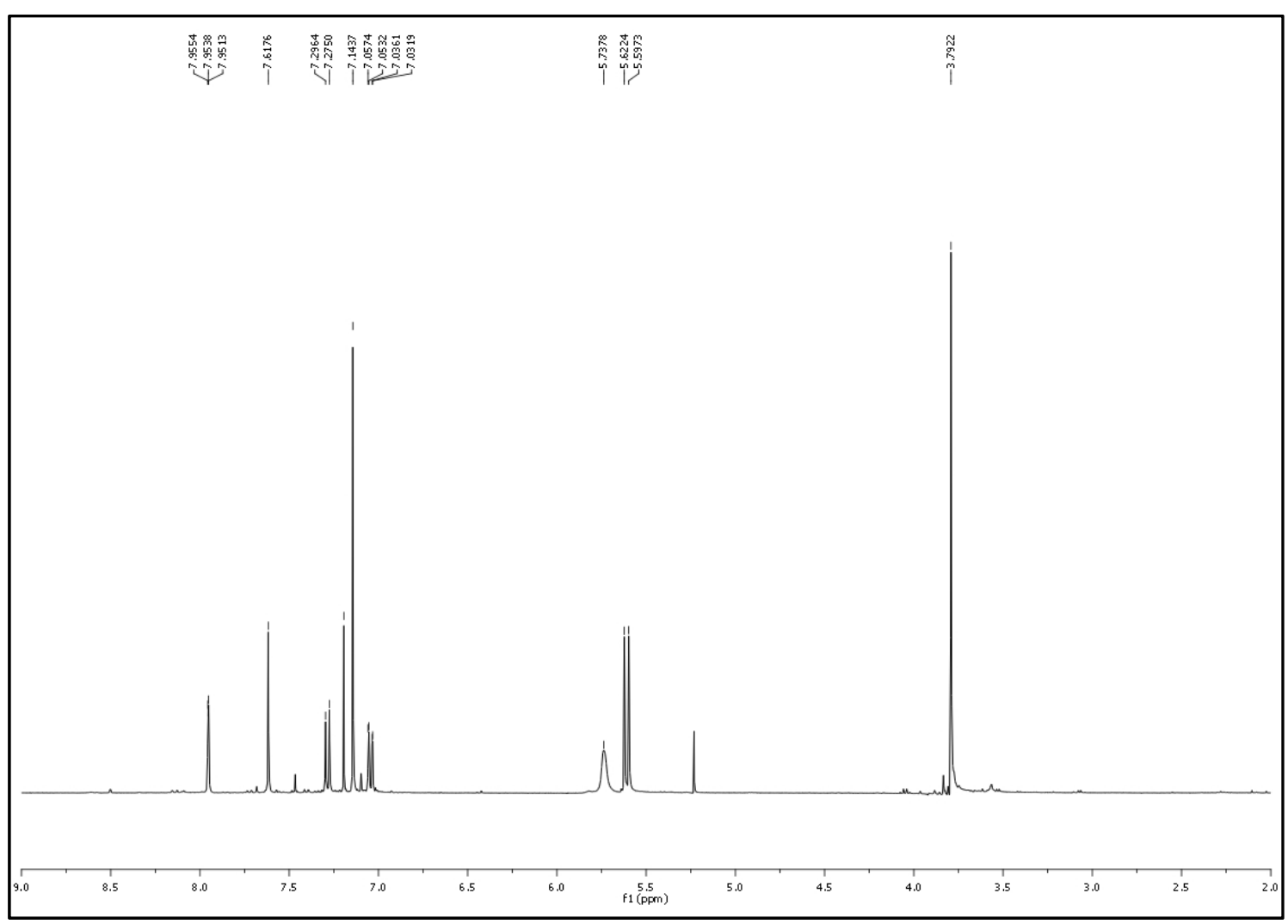

Espectro $71 \mathrm{H}$

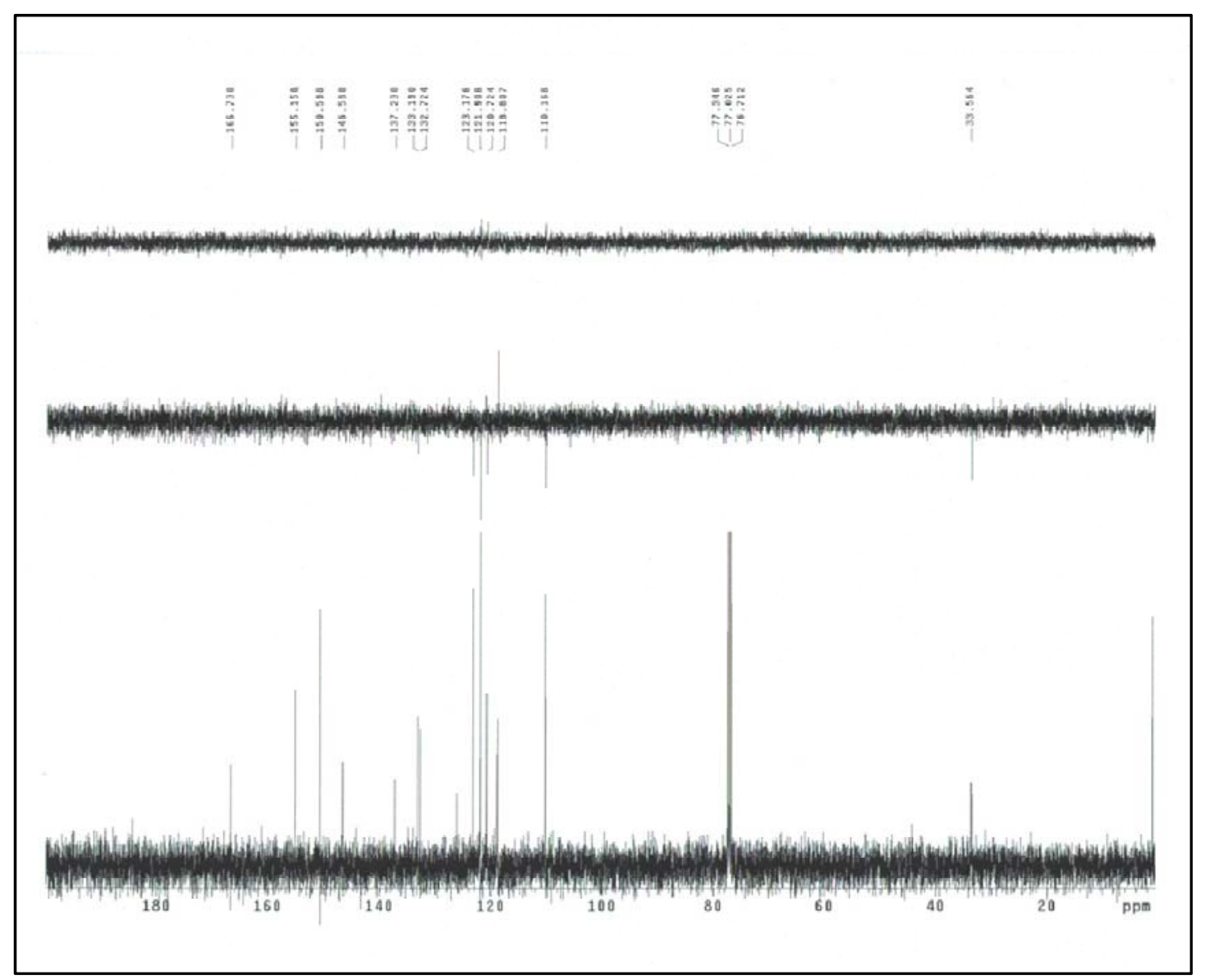

Espectro 71C 


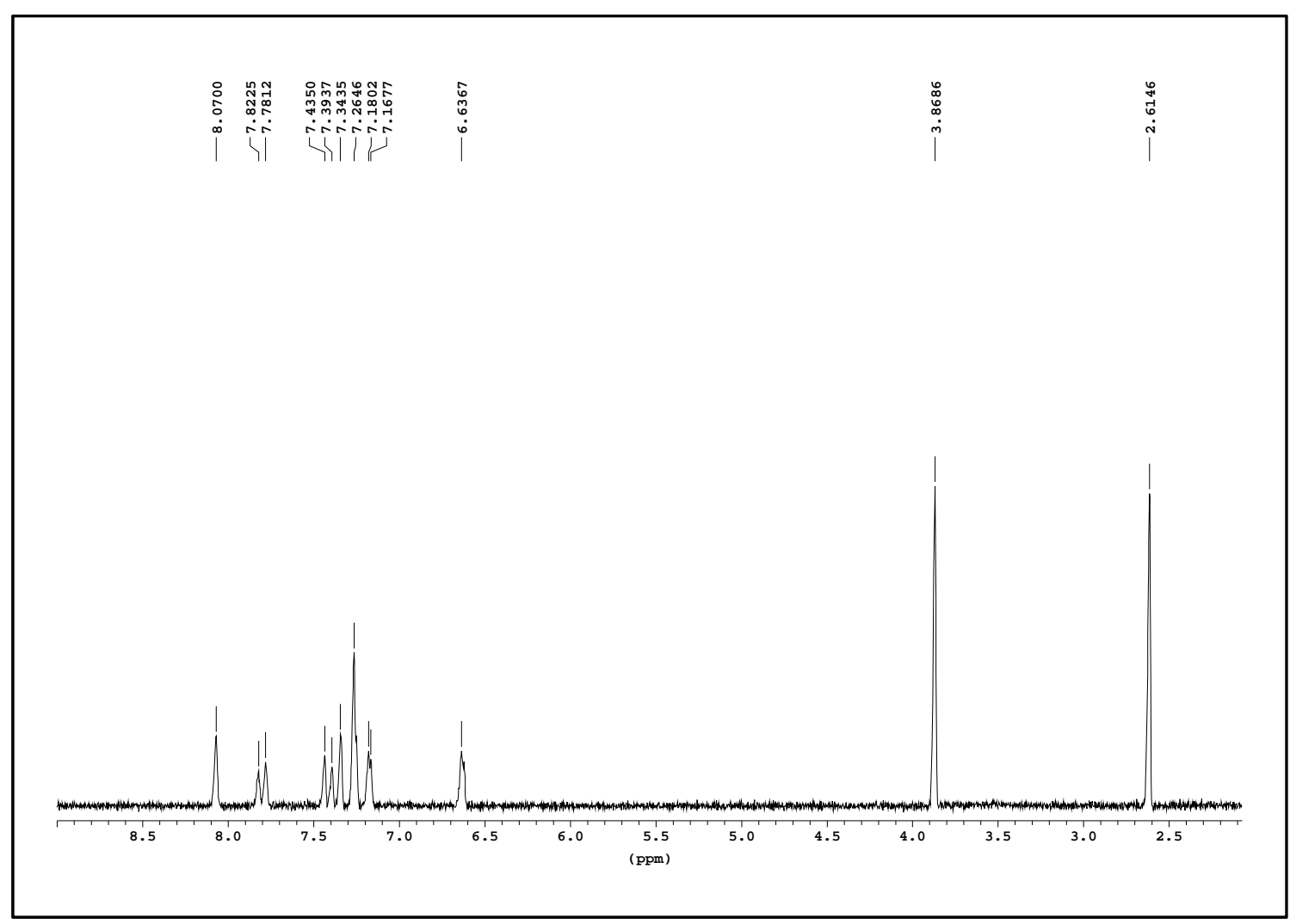

\section{Espectro $72 \mathrm{H}$}

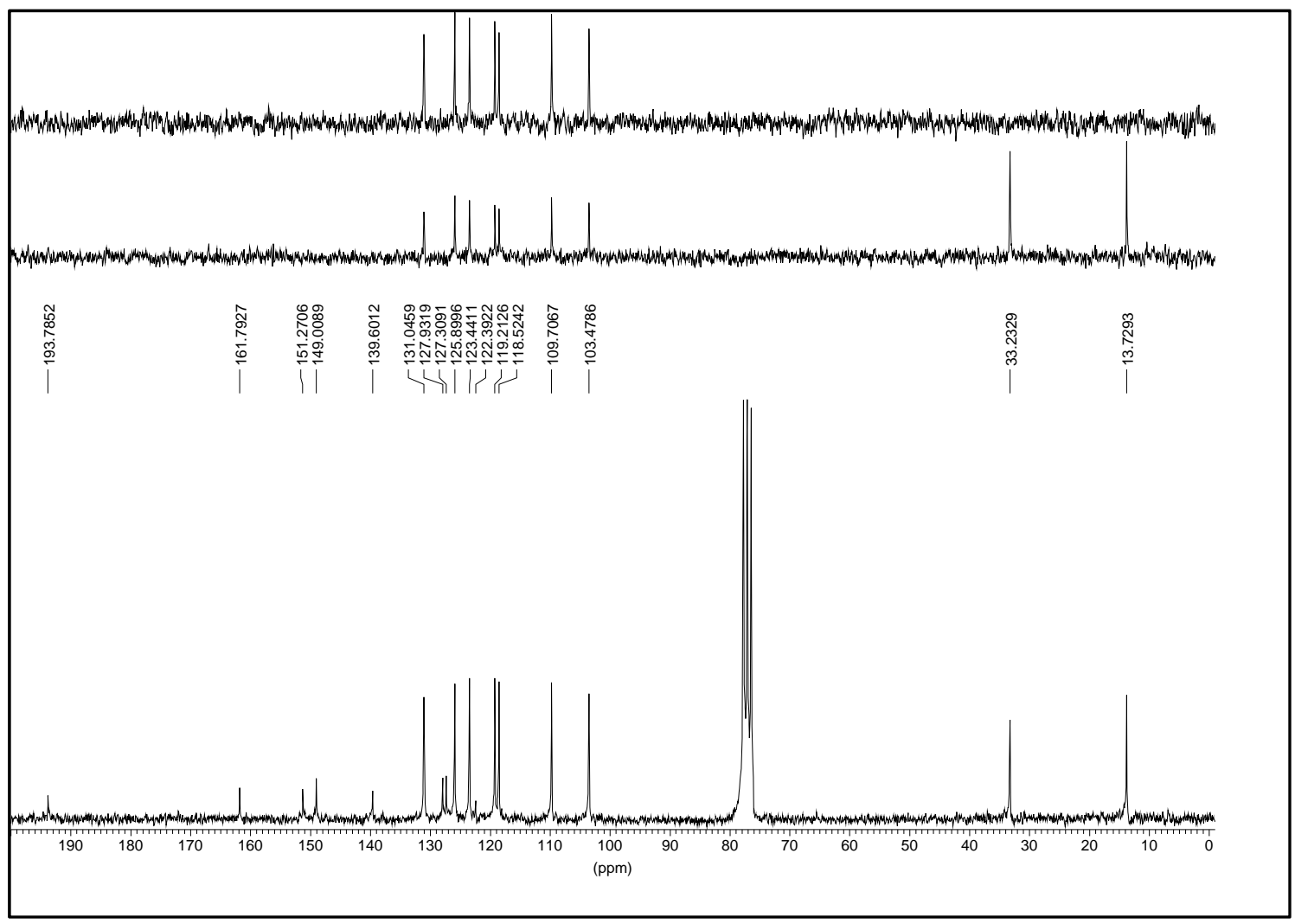

Espectro 72C 


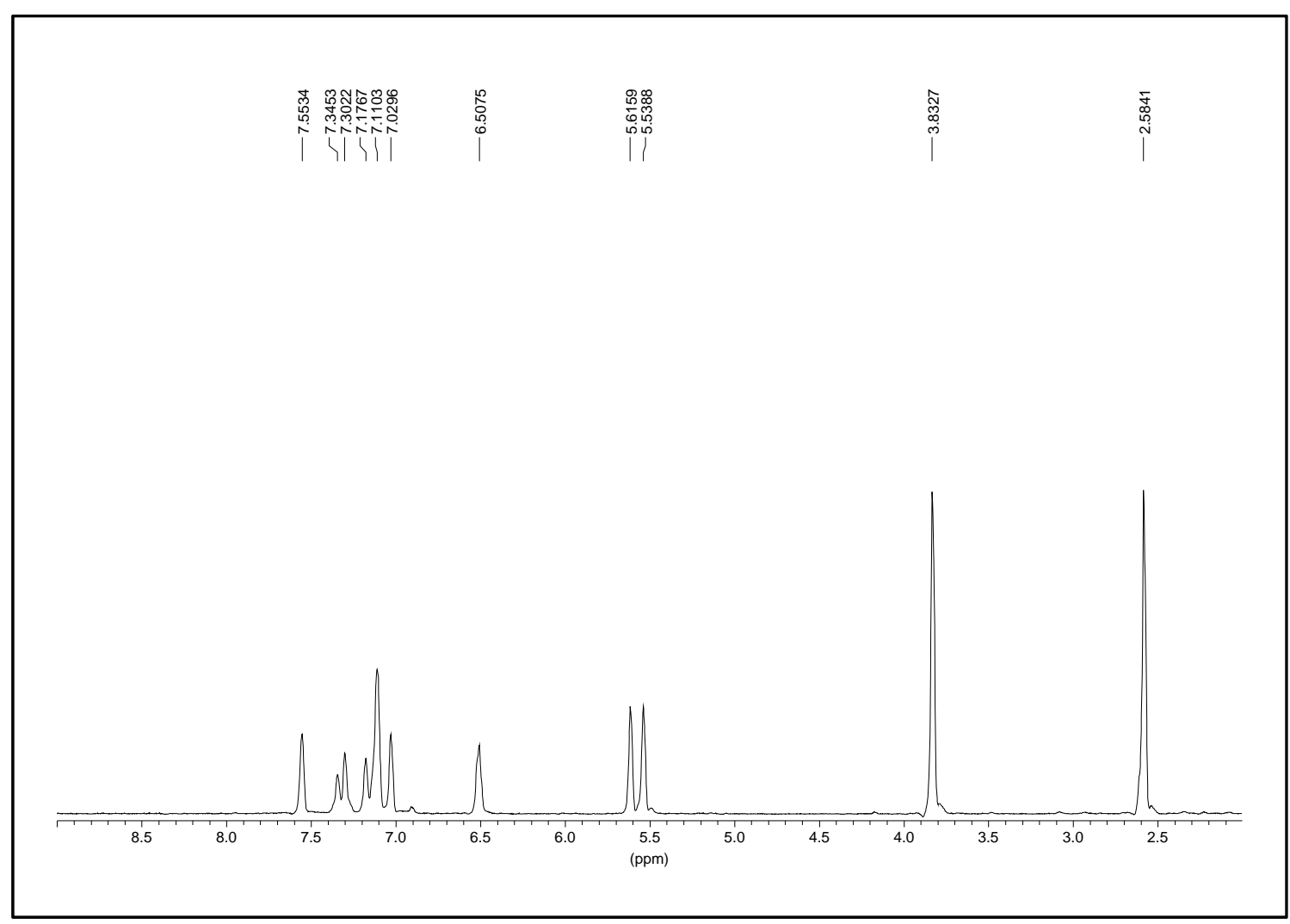

\section{Espectro $73 \mathrm{H}$}

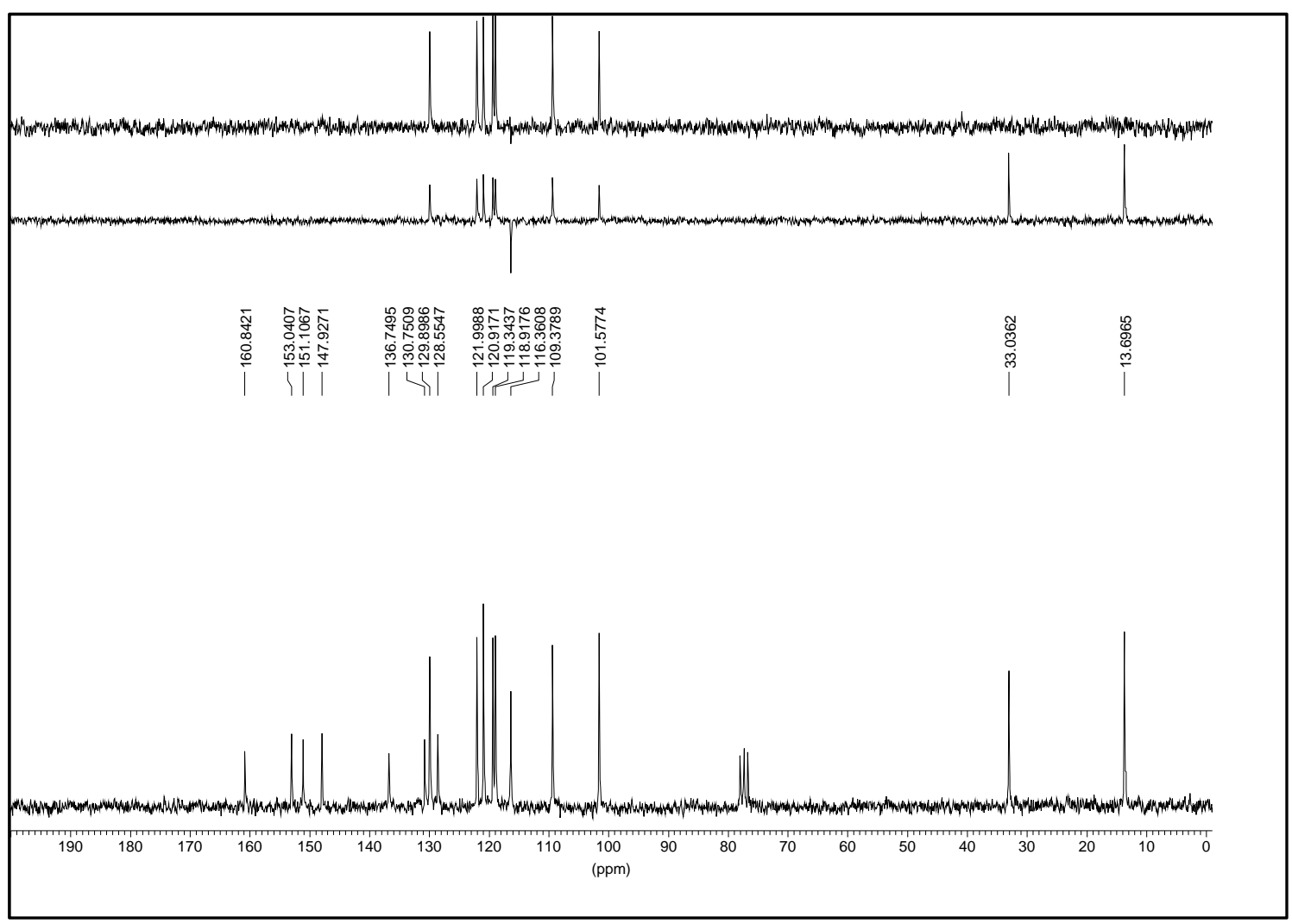

Espectro 73C 


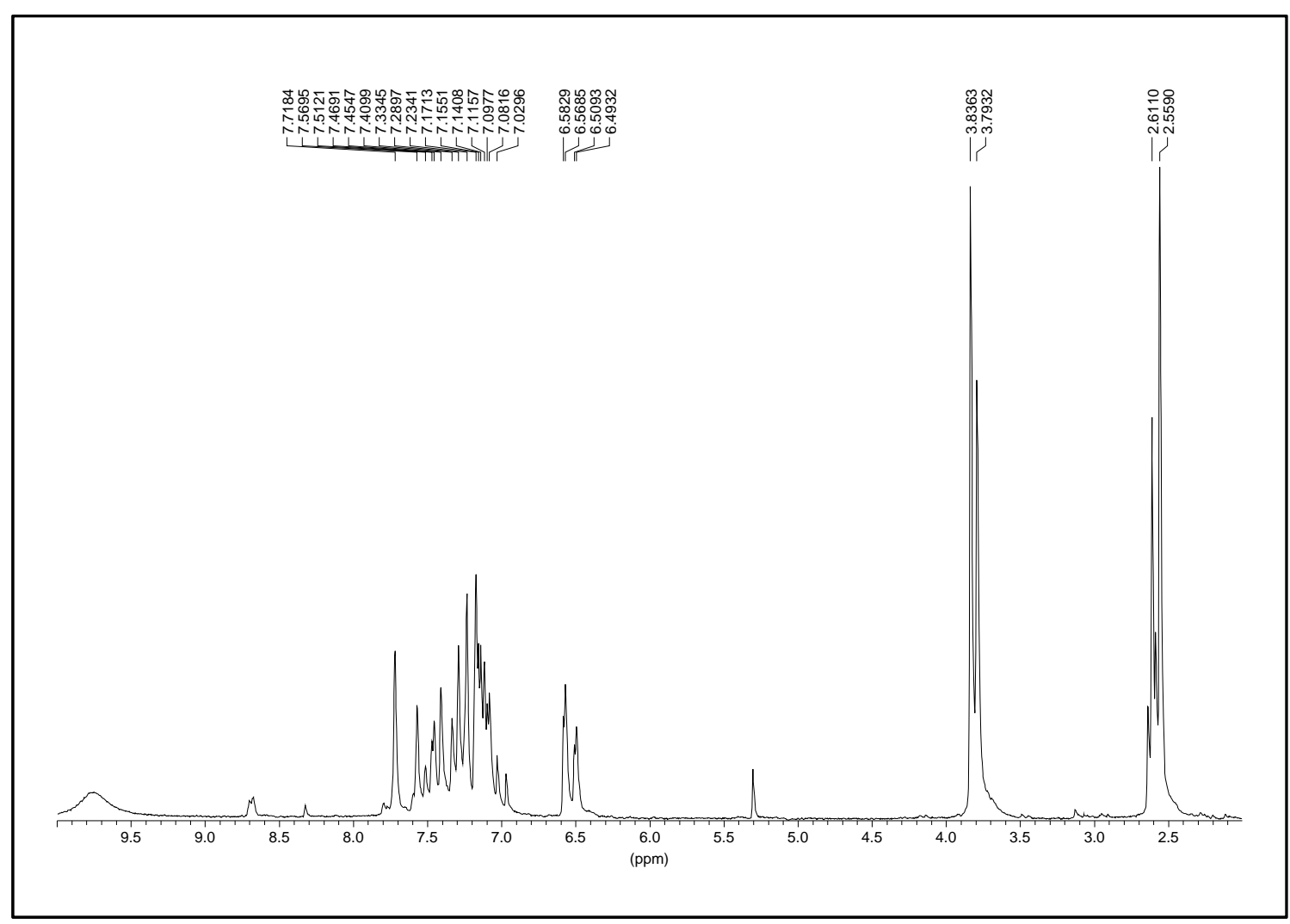

\section{Espectro 74ZEH}

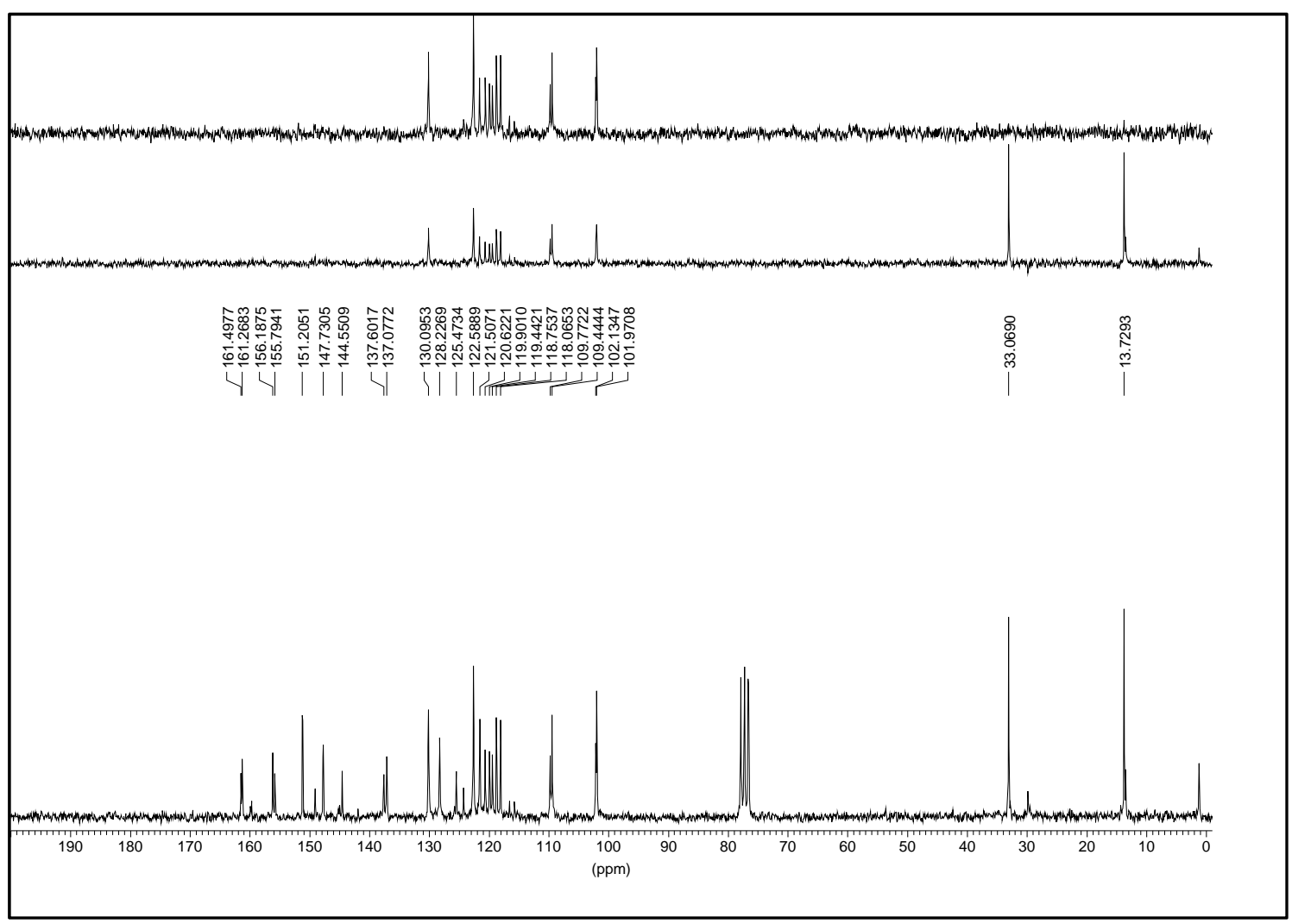

Espectro 74ZEC 


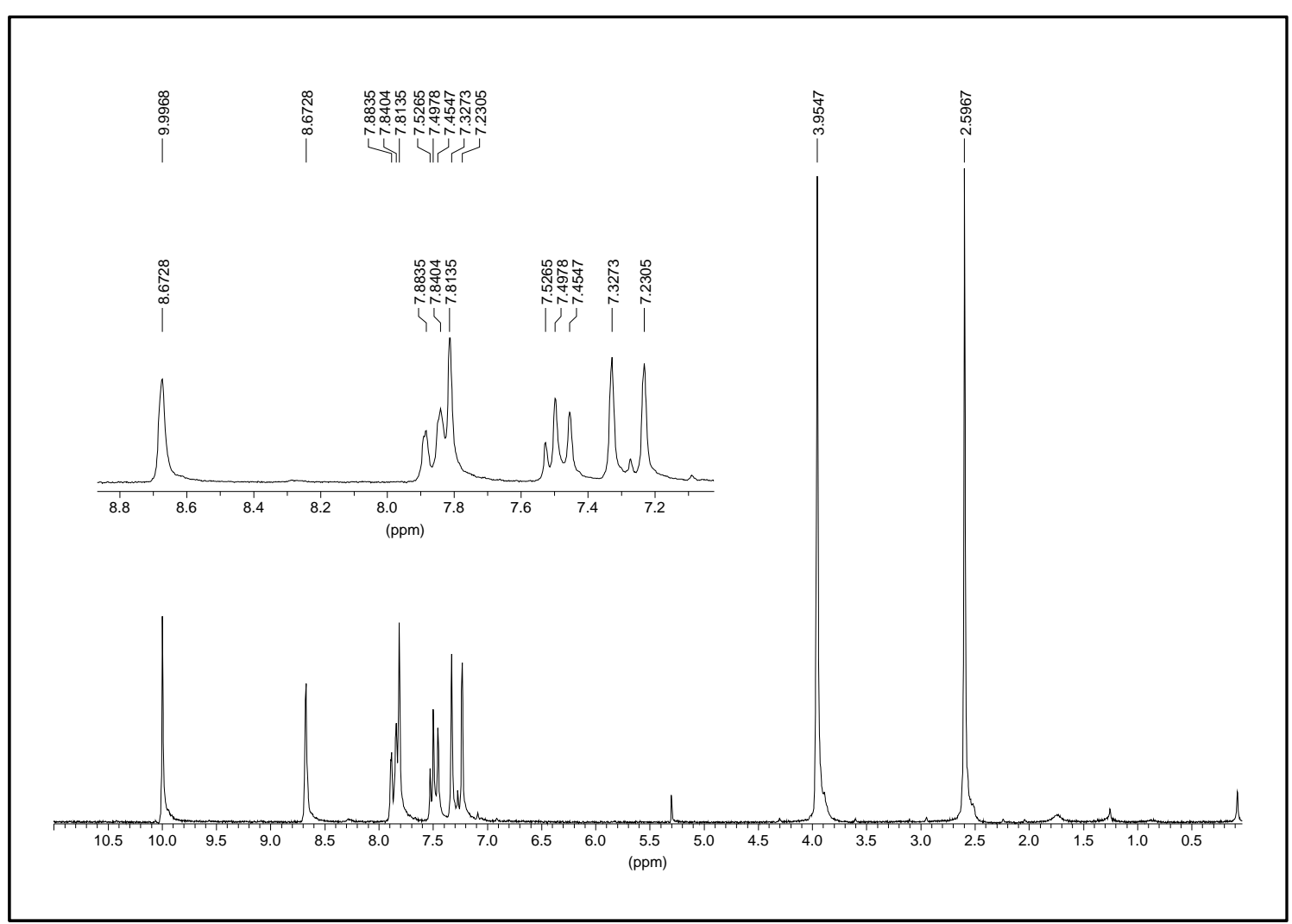

\section{Espectro $75 \mathrm{H}$}

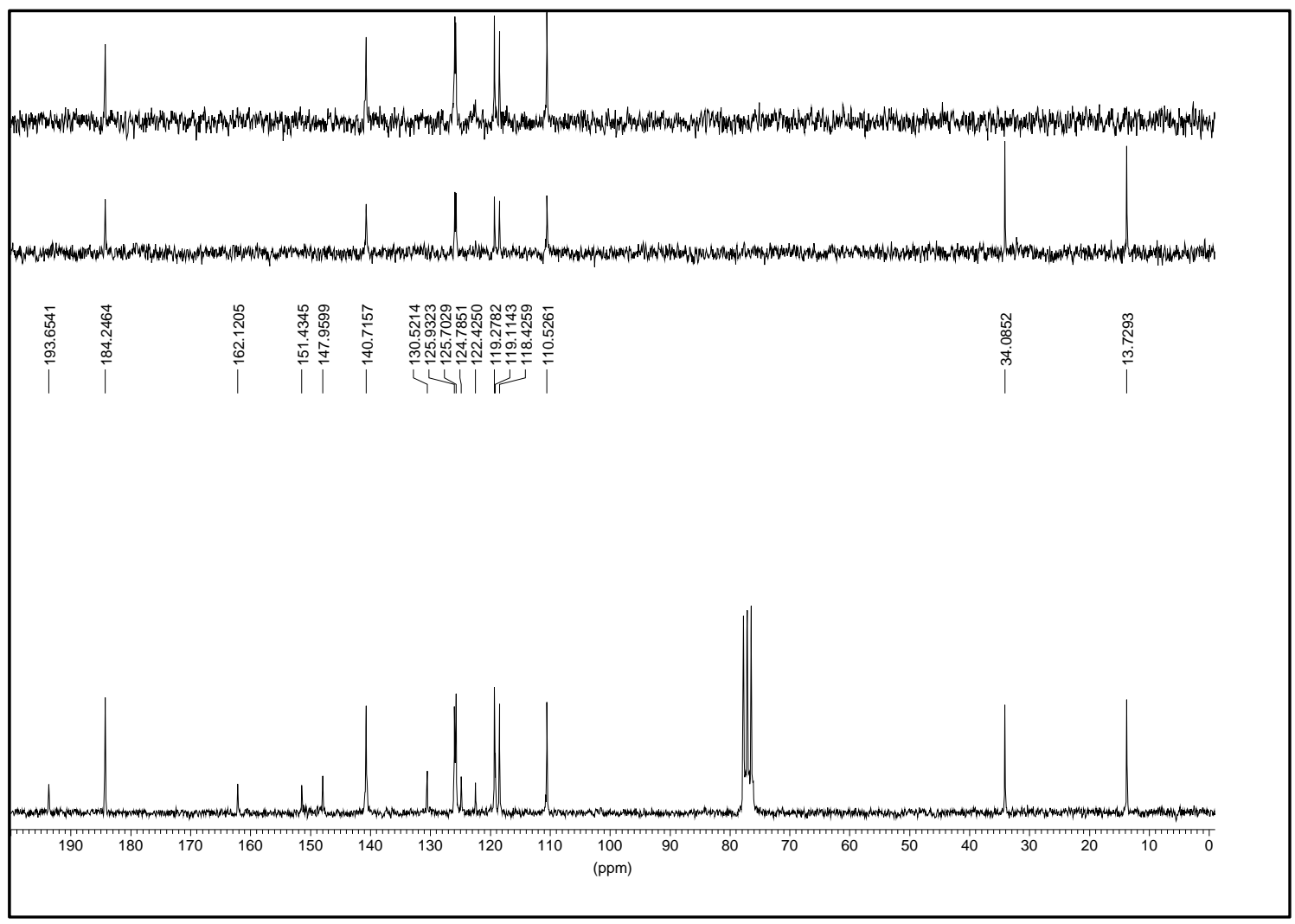

Espectro 75C 


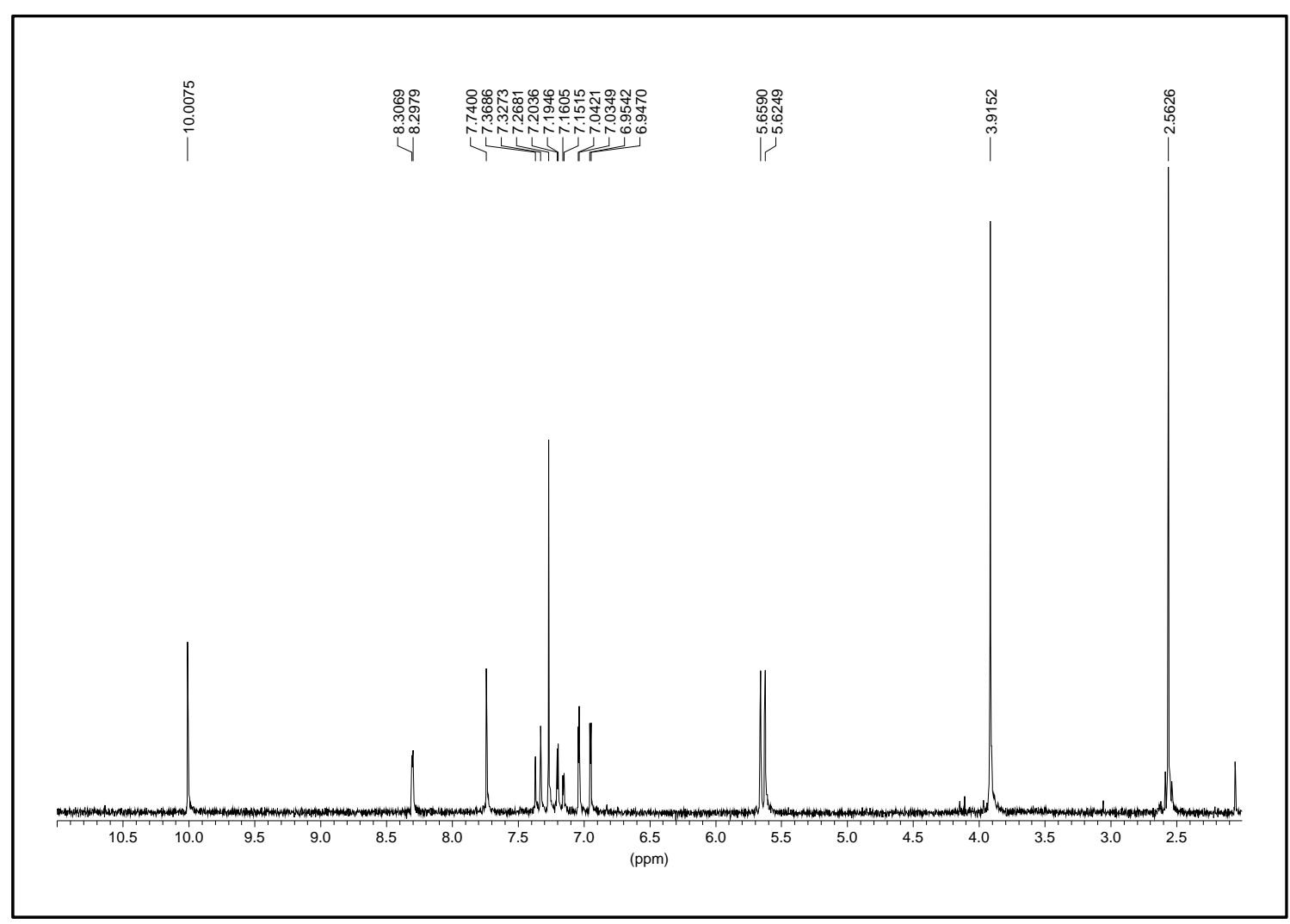

\section{Espectro $76 \mathrm{H}$}

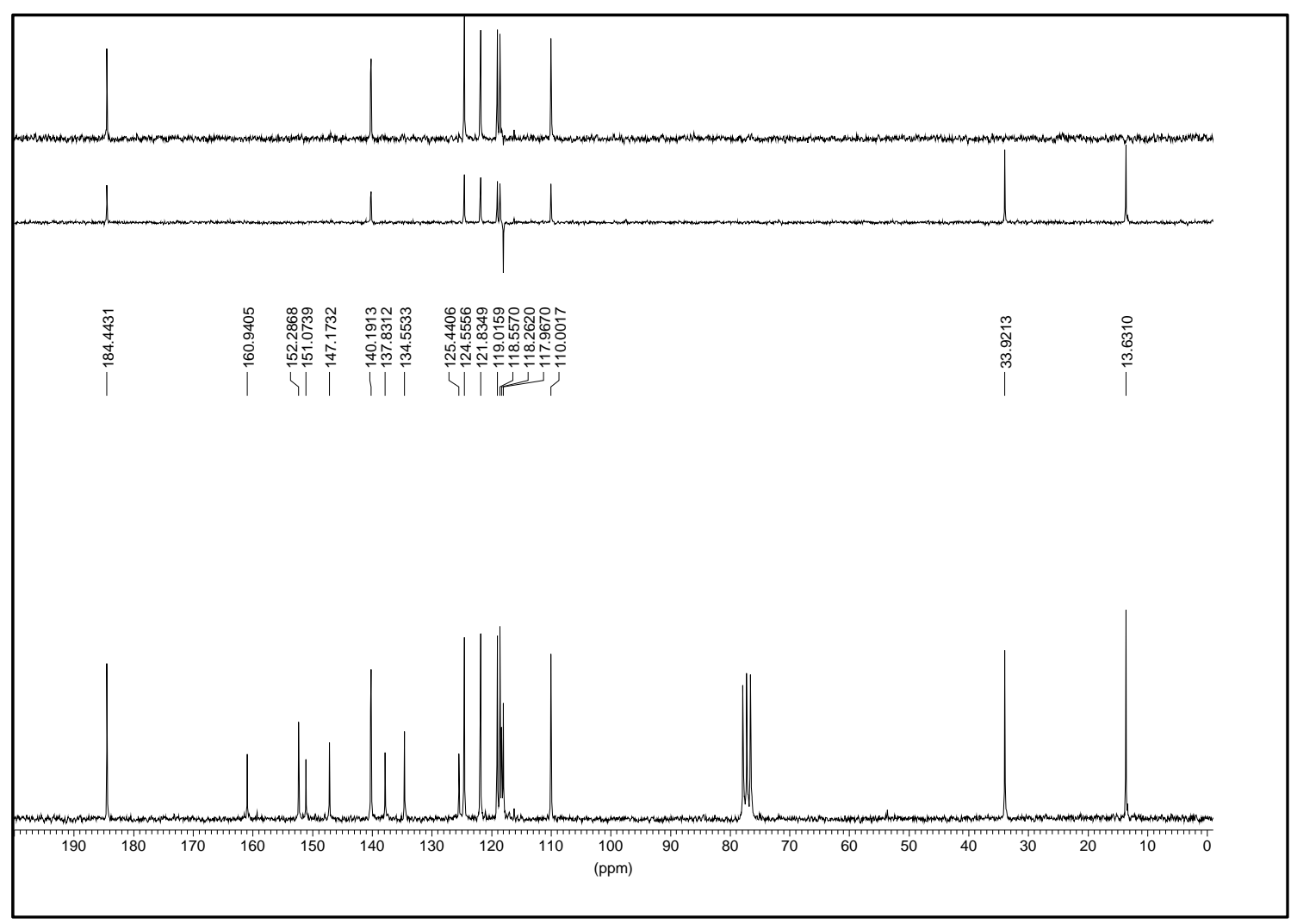

Espectro 76C 


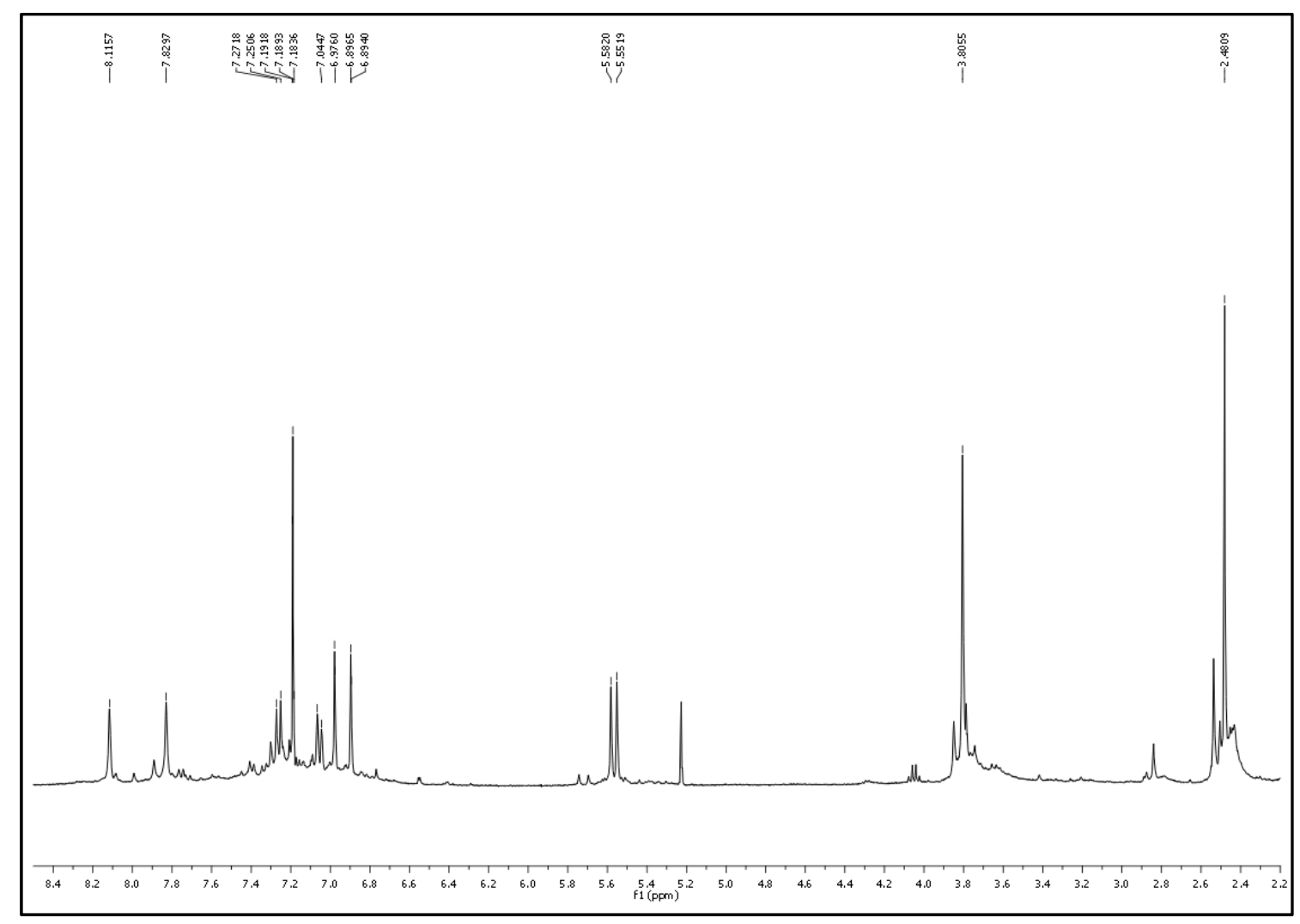

Espectro $77 \mathrm{H}$ 


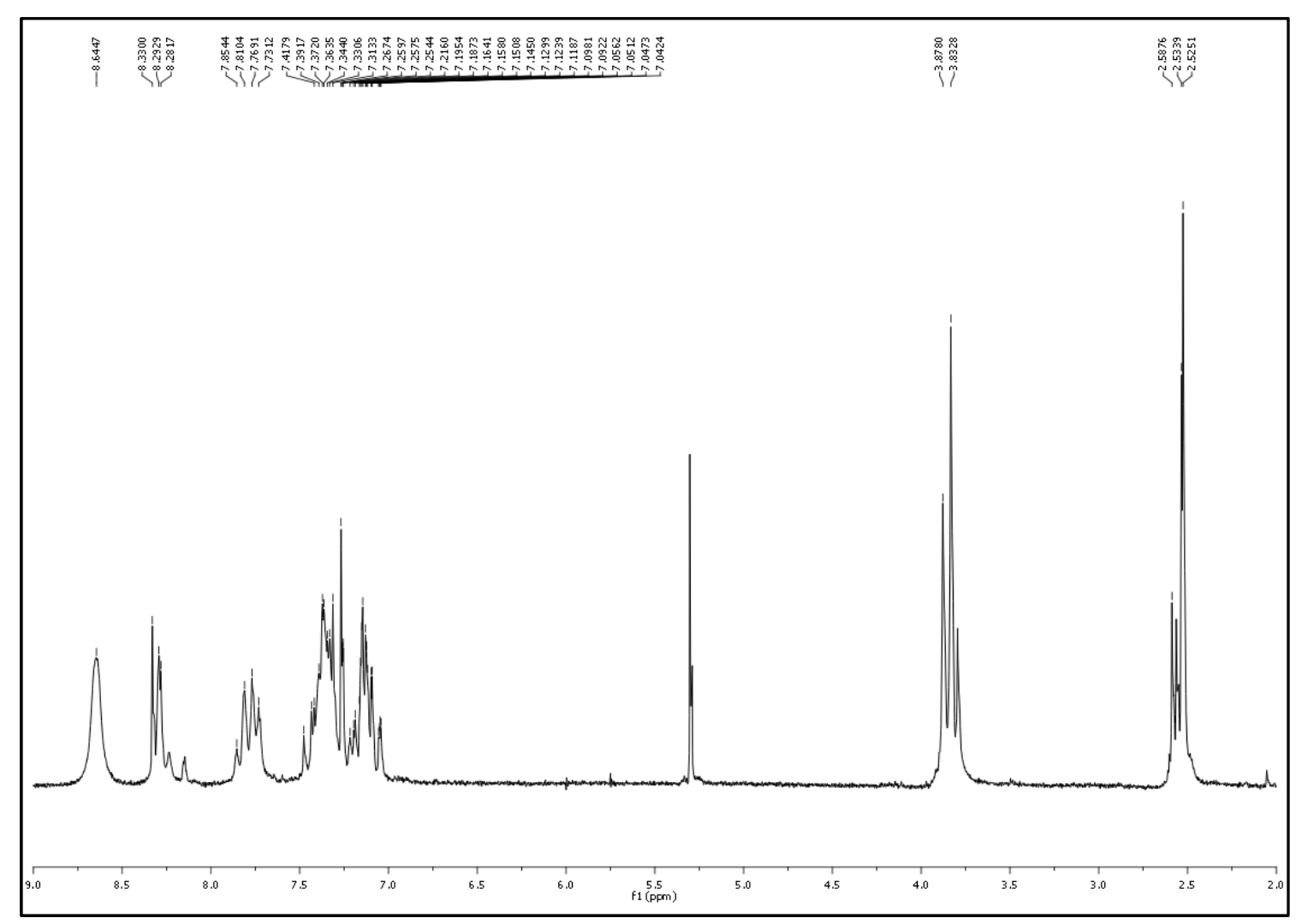

Espectro $78 \mathrm{H}$ 


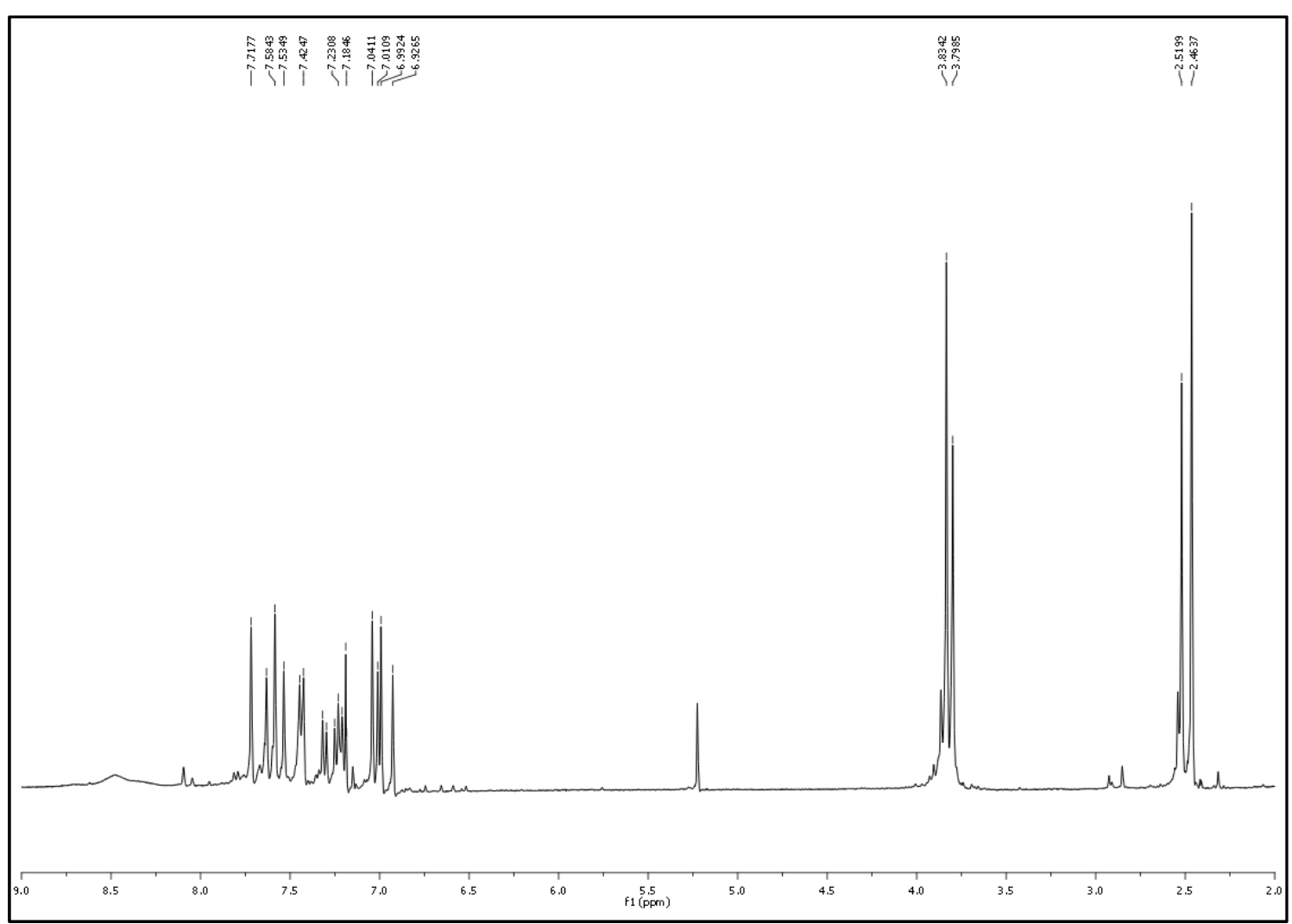

Espectro $\mathbf{8 0 H}$

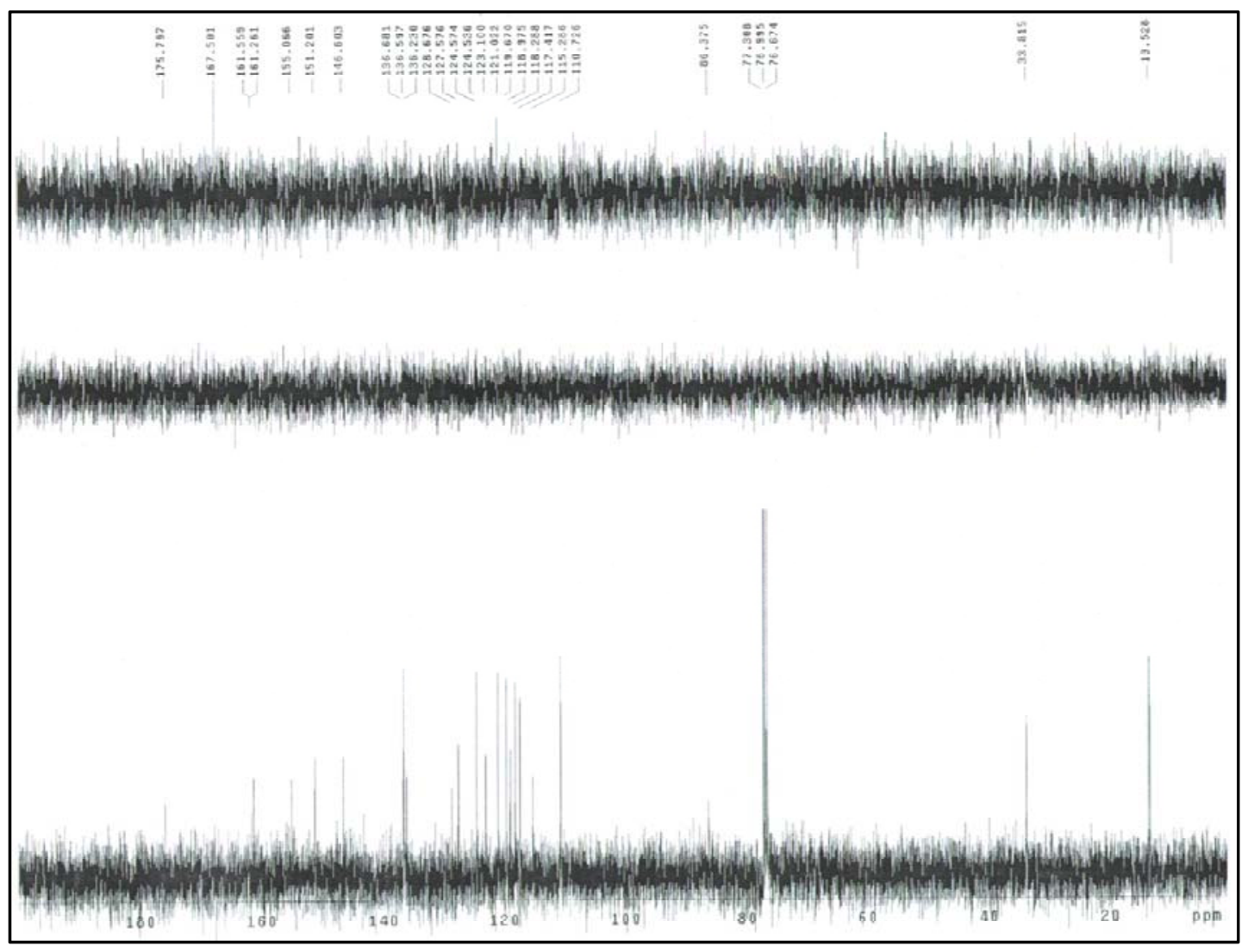

Espectro 80C 


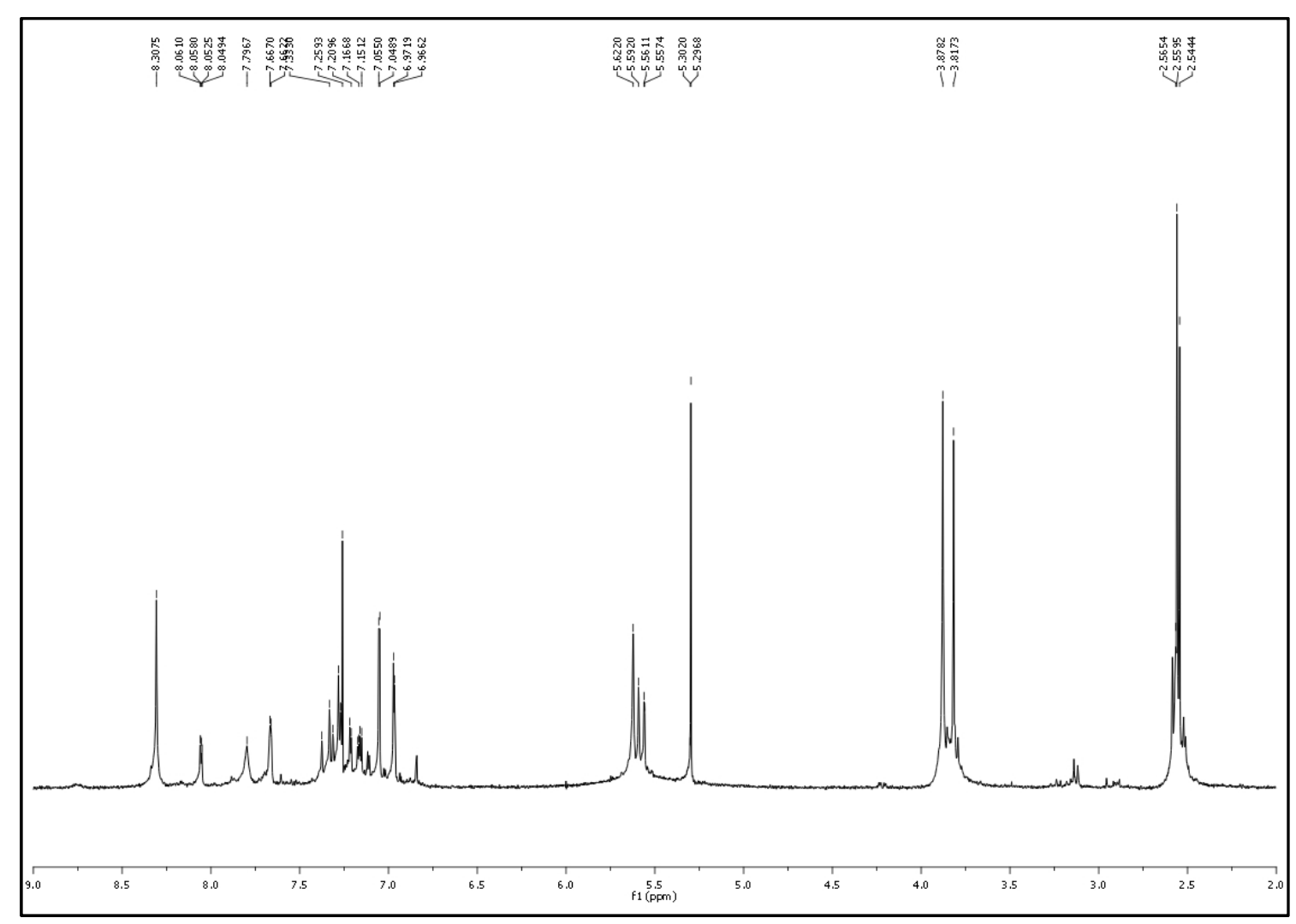

Espectro 81ZEH 


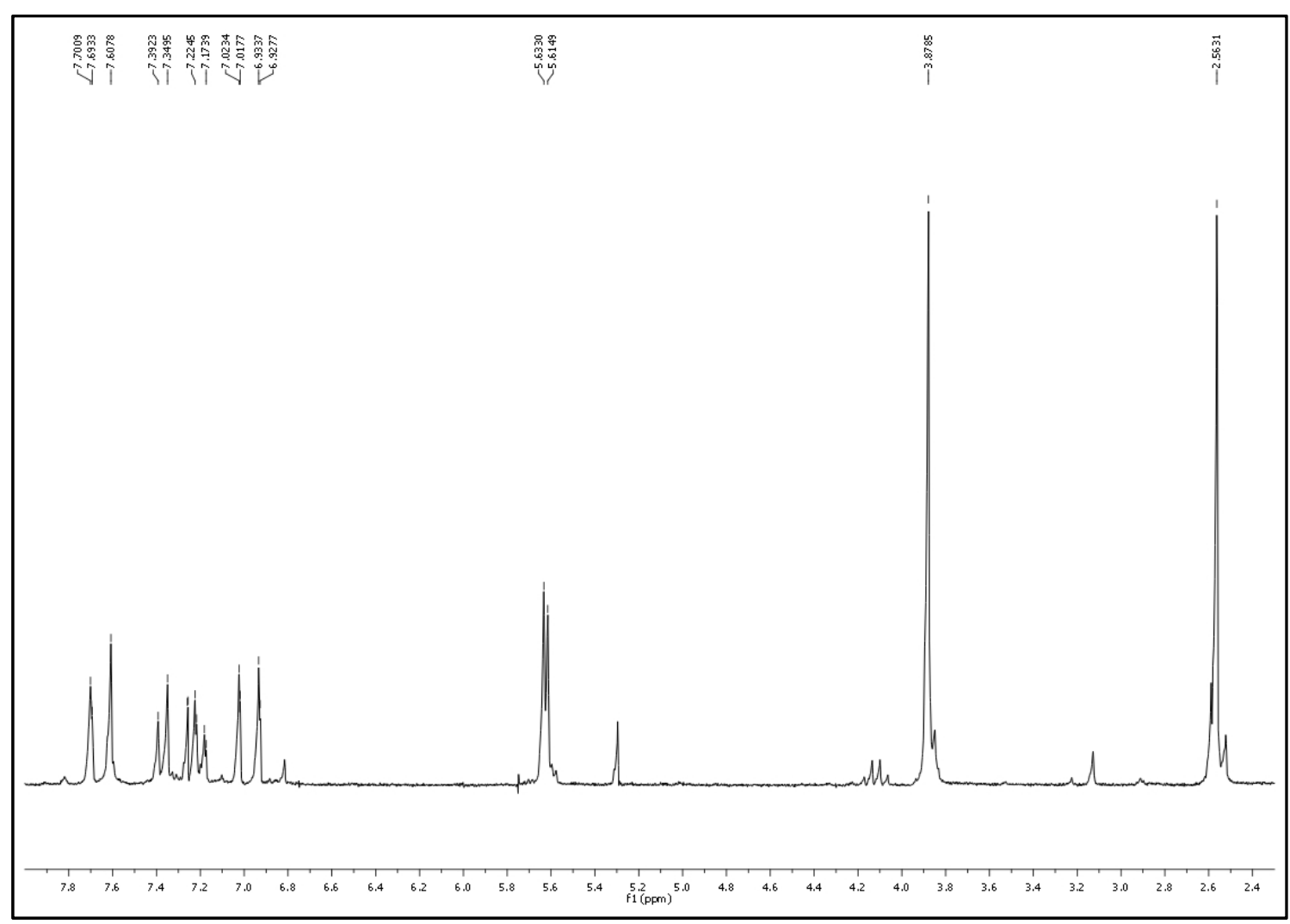

Espectro 82H

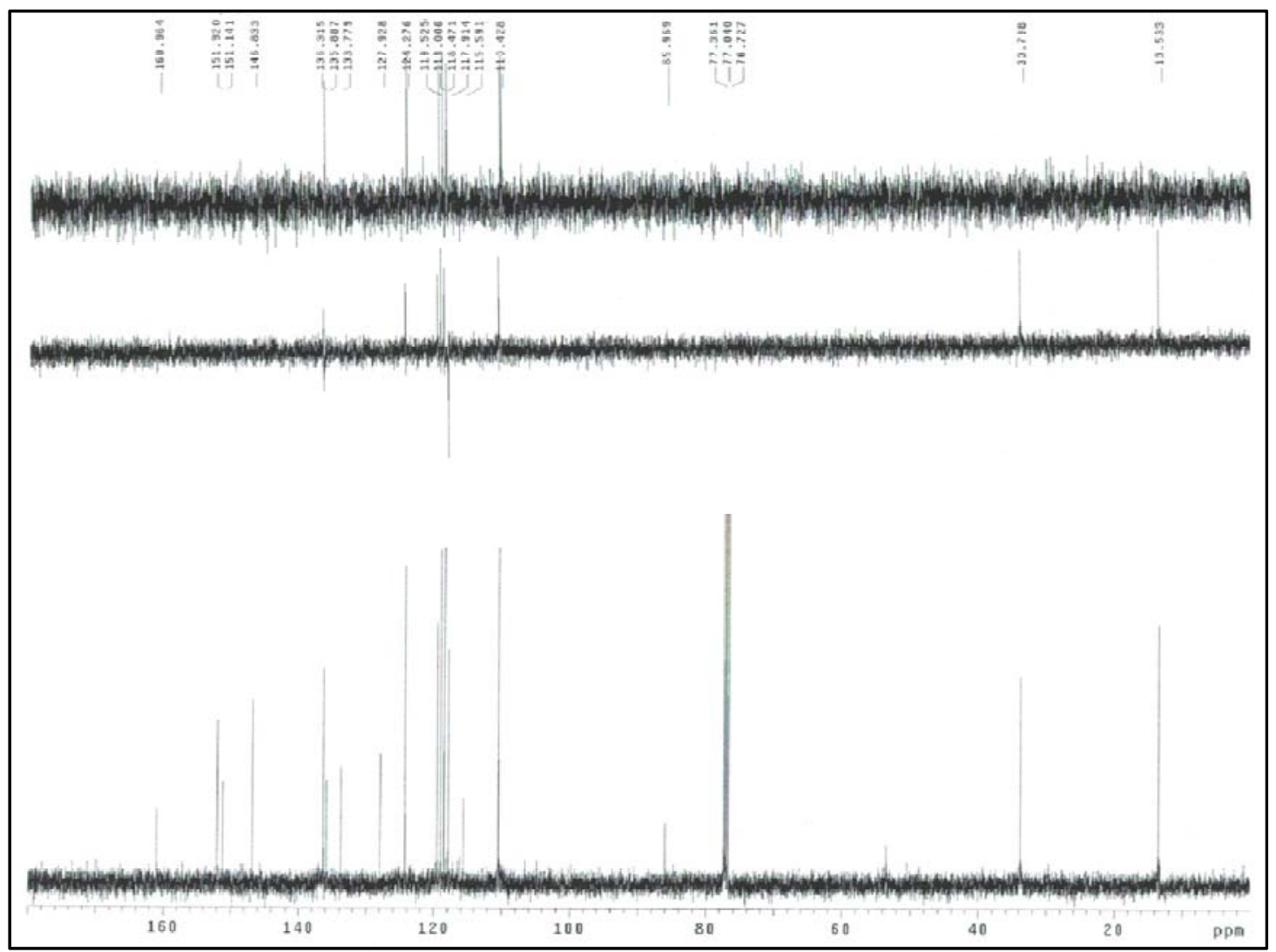

Espectro 82C 


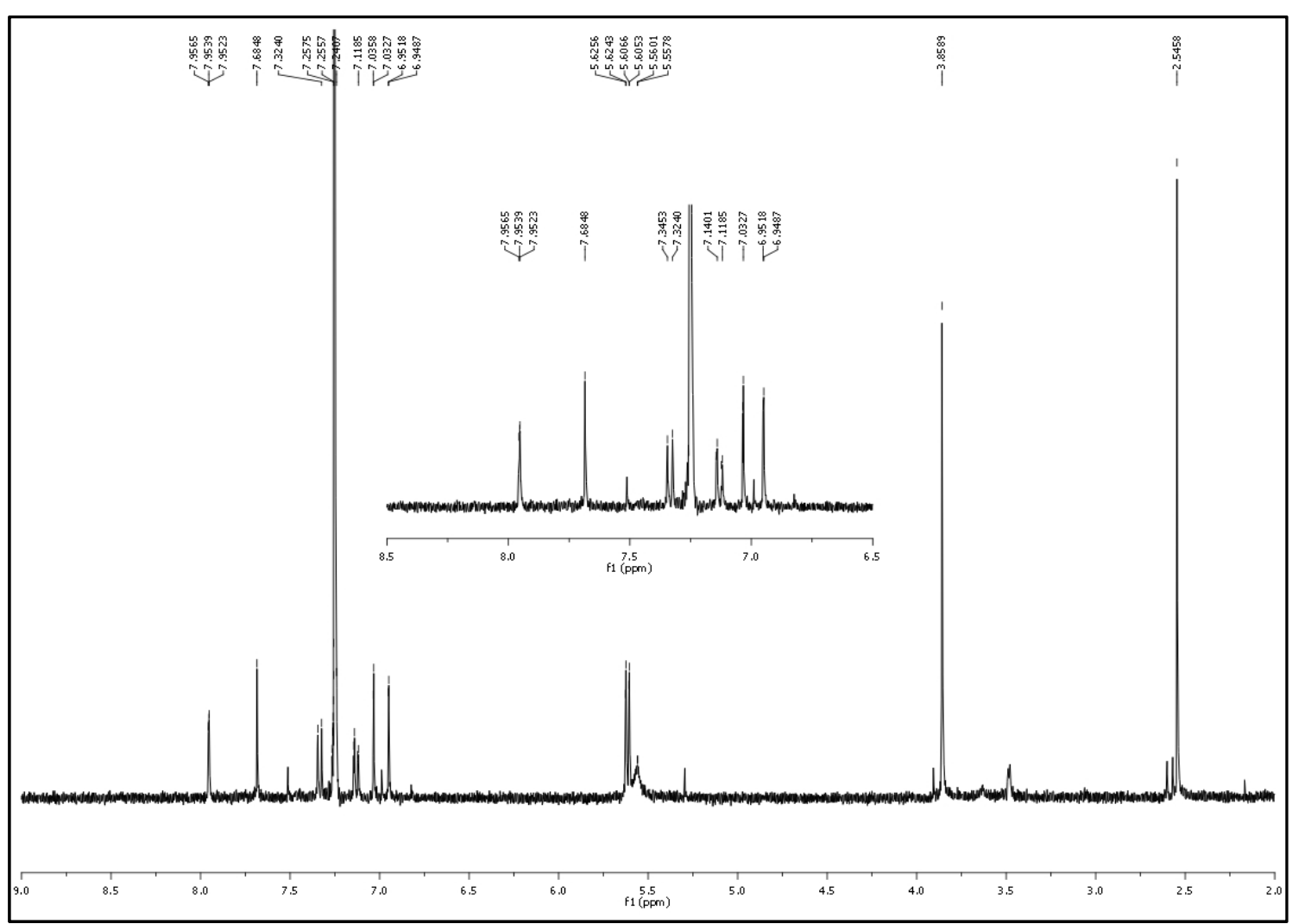

Espectro $\mathbf{8 3 H}$

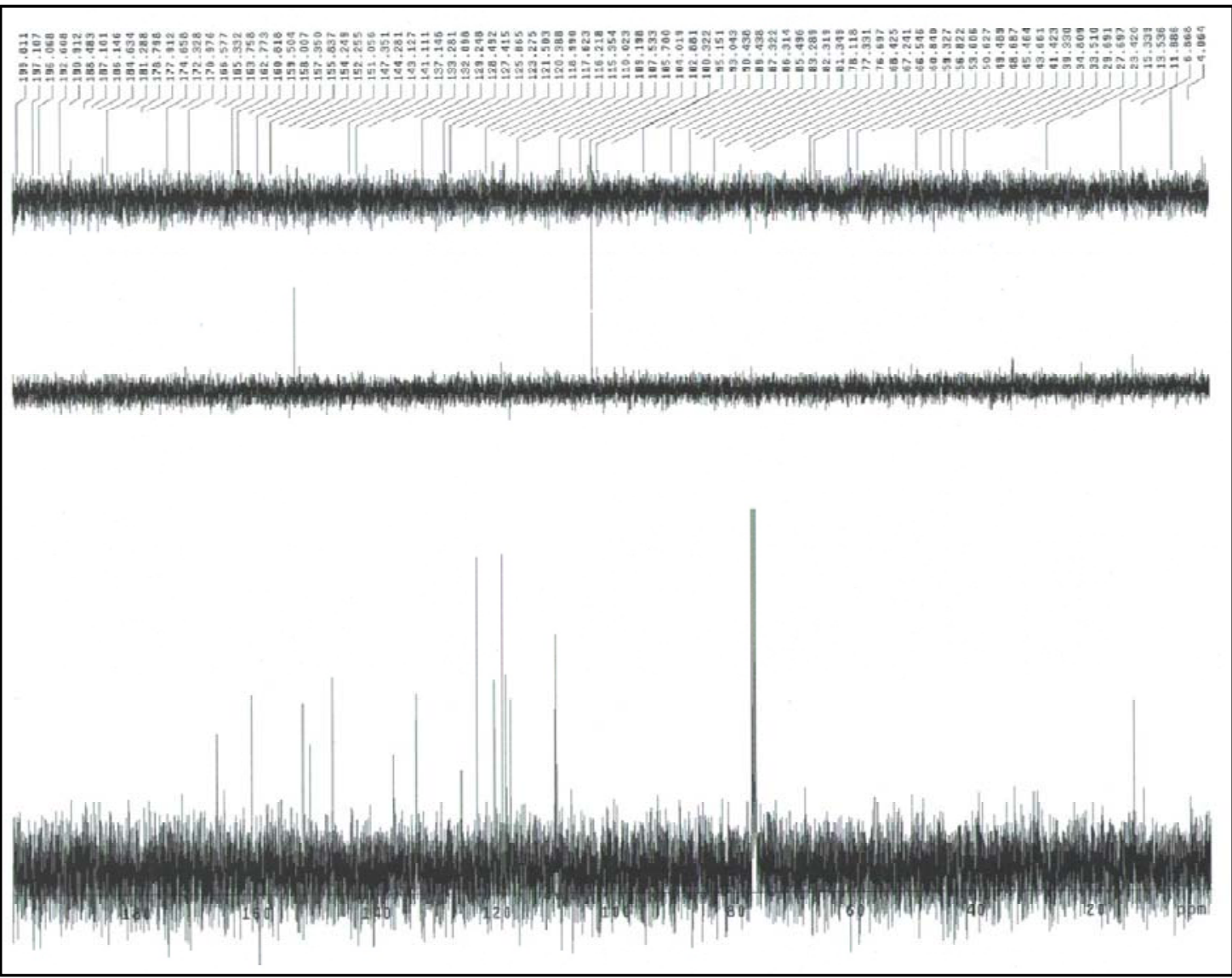

Espectro 83C 


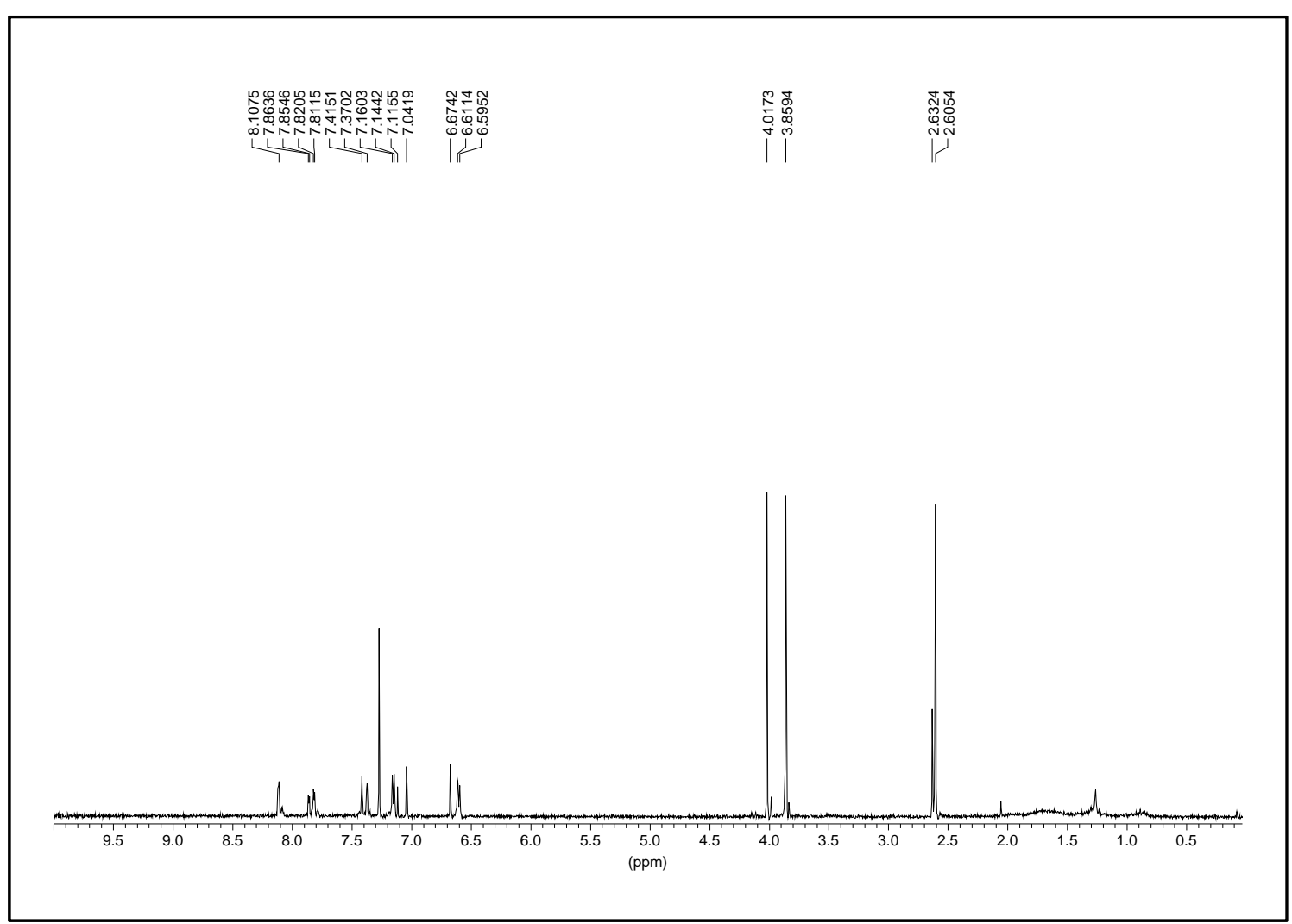

\section{Espectro 86EH}

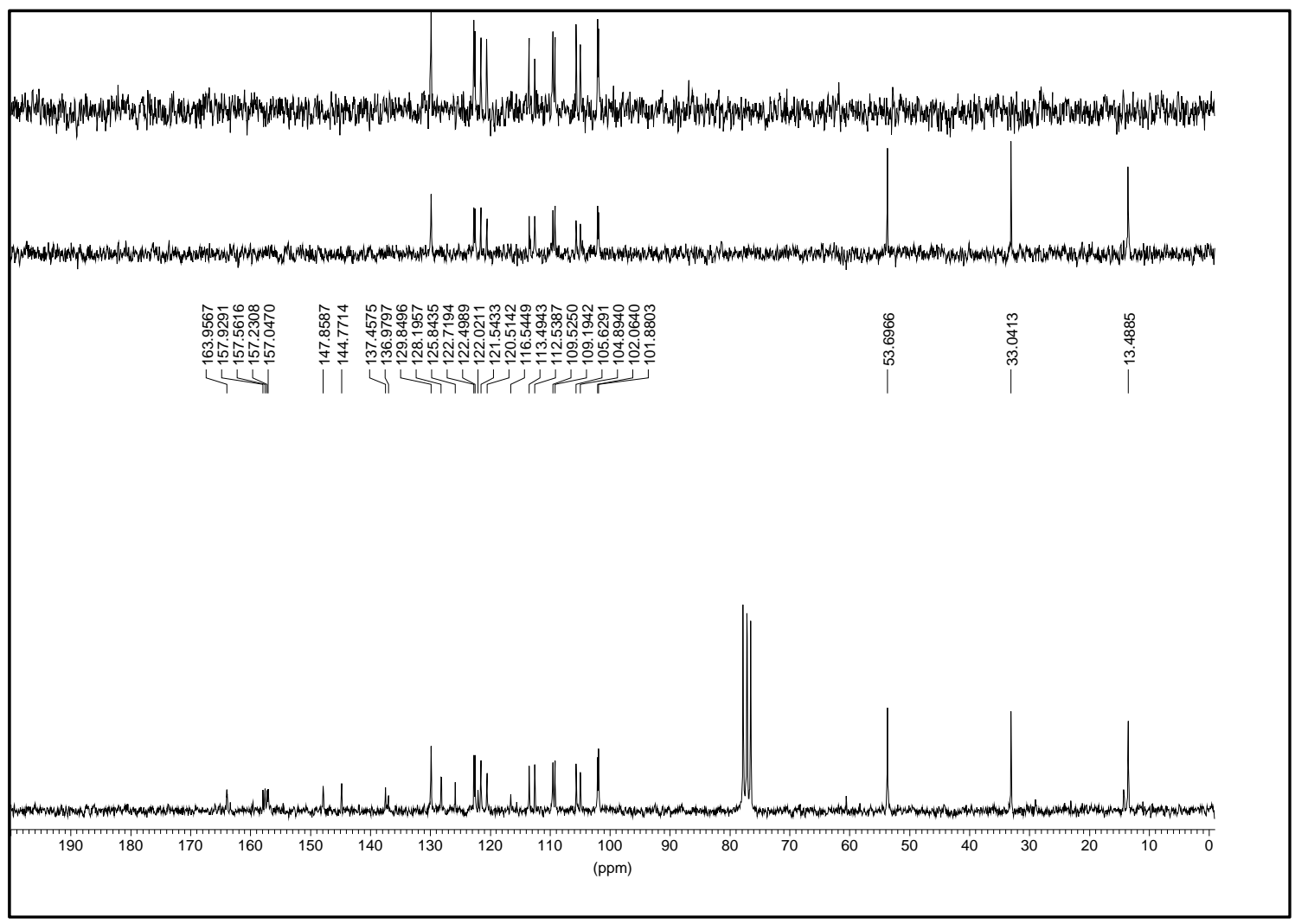

Espectro 86ZEC 


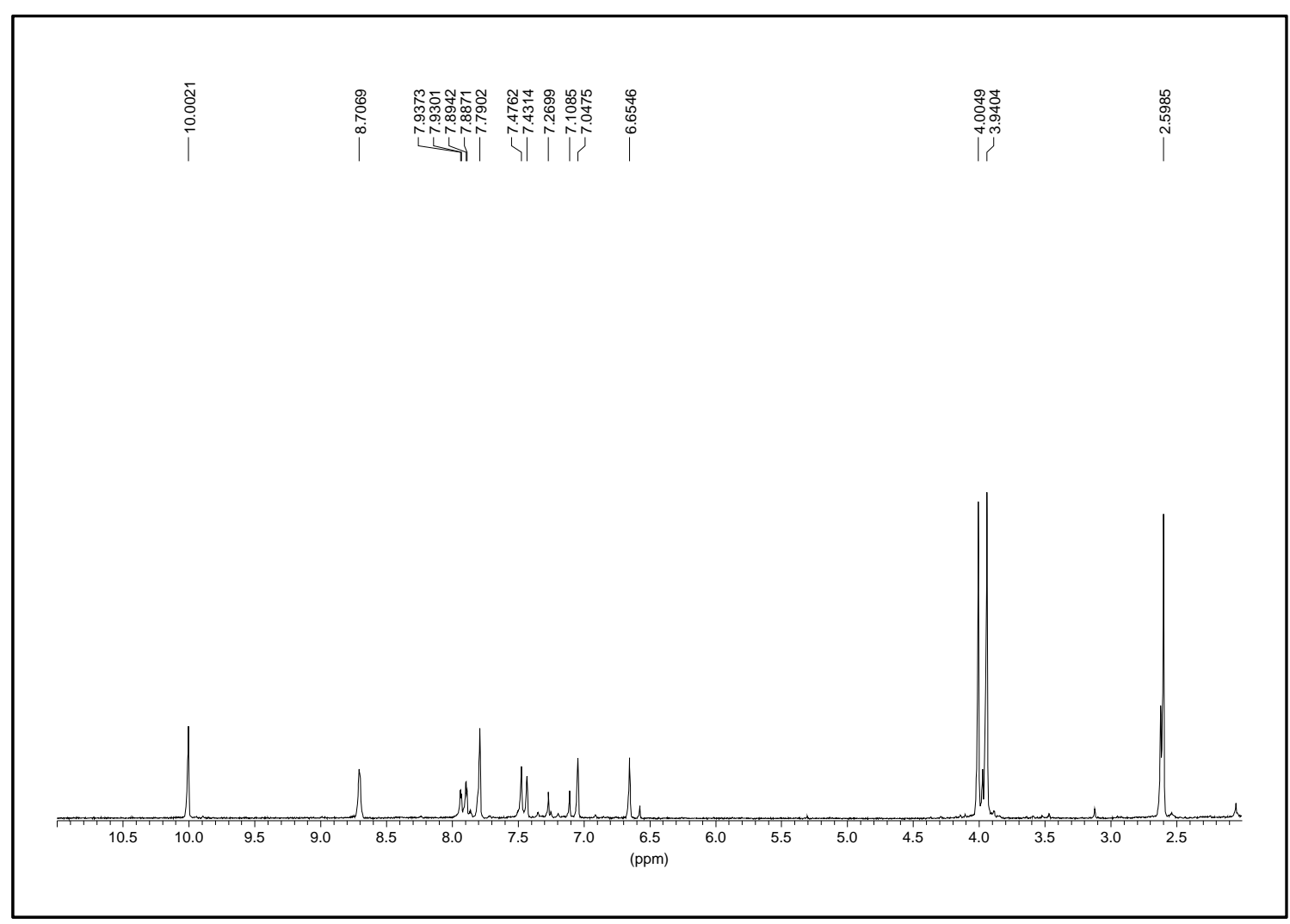

\section{Espectro 87H}

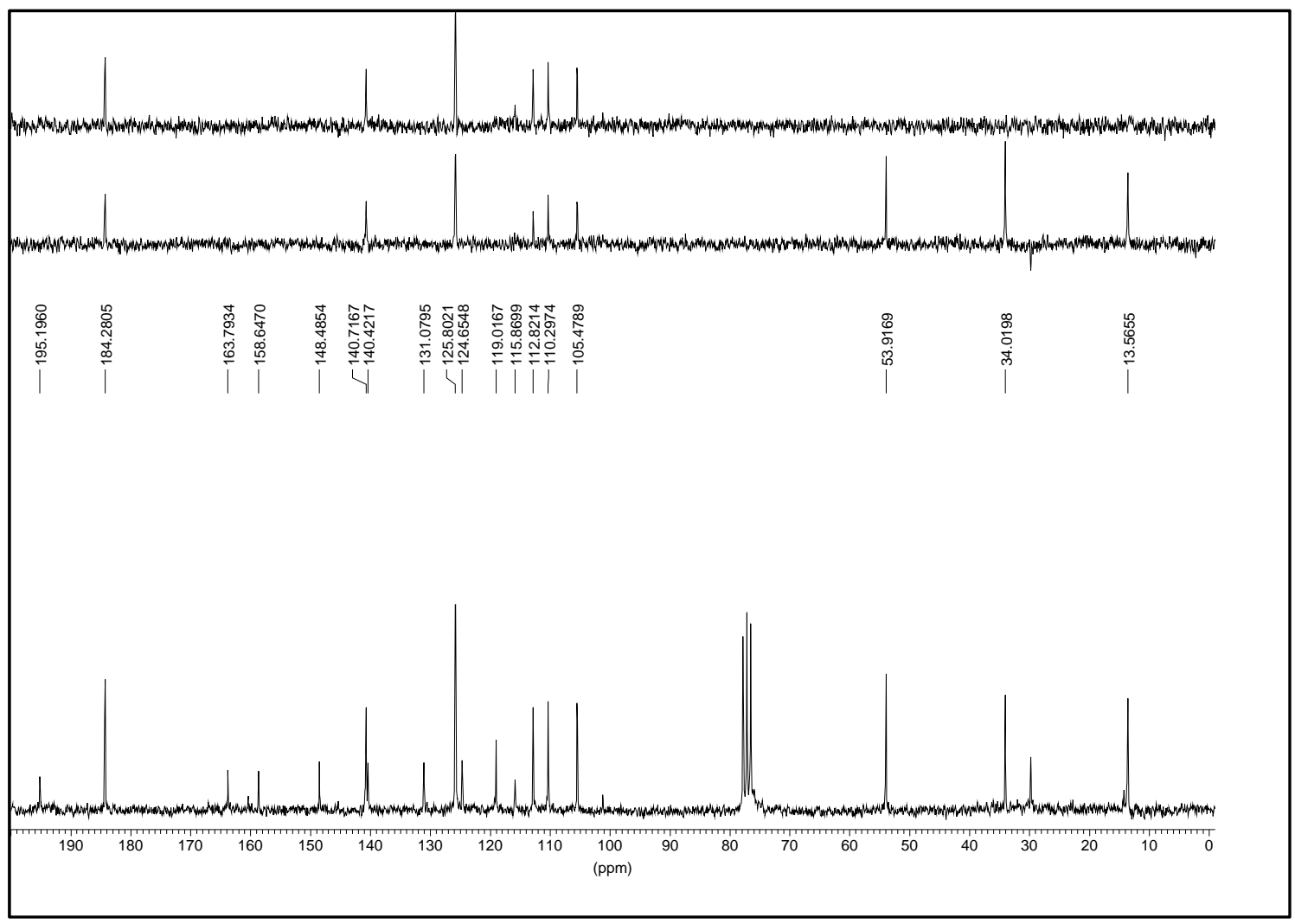

Espectro 87C 


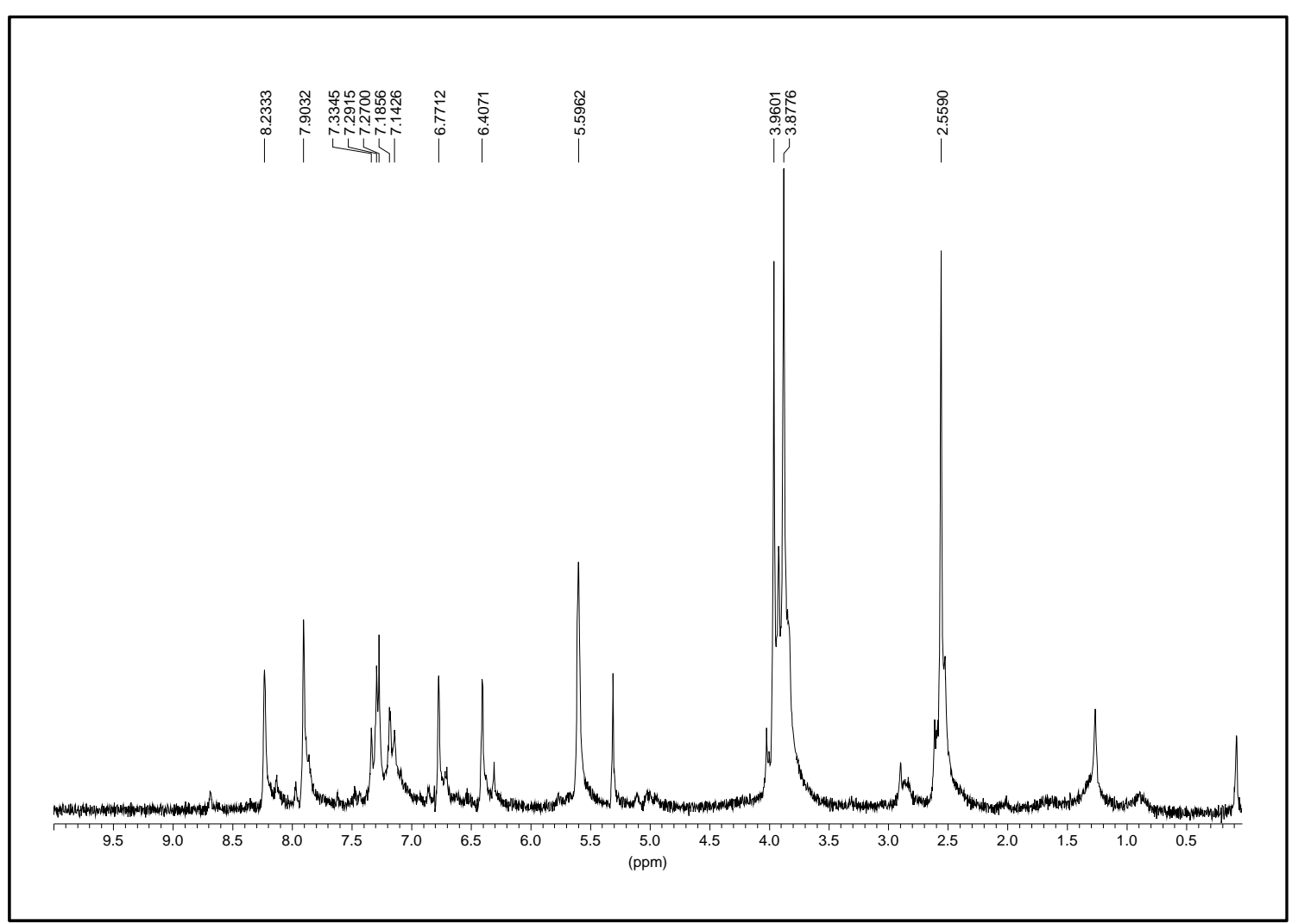

\section{Espectro $\mathbf{8 8} \mathrm{H}$}

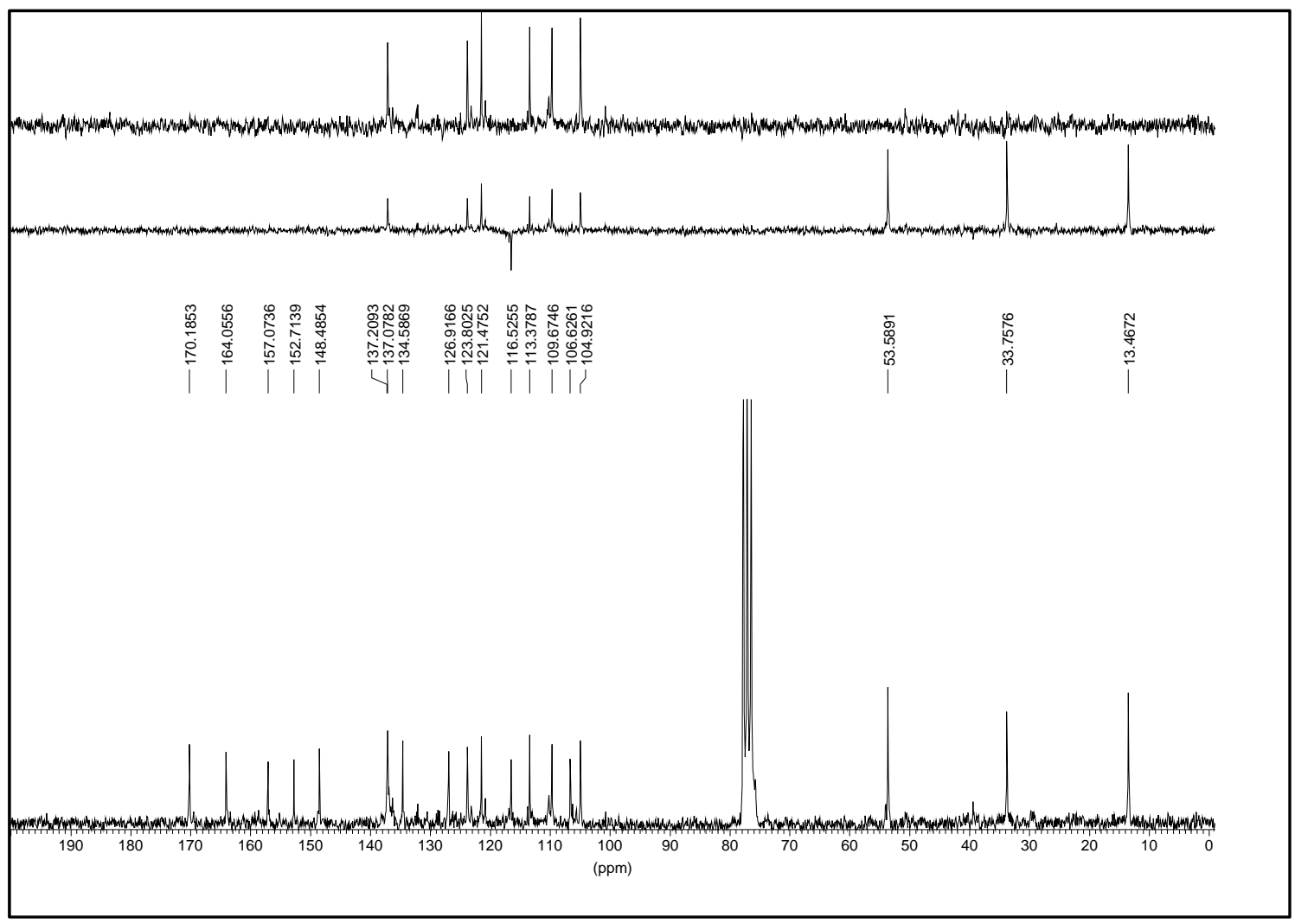

Espectro 88C 


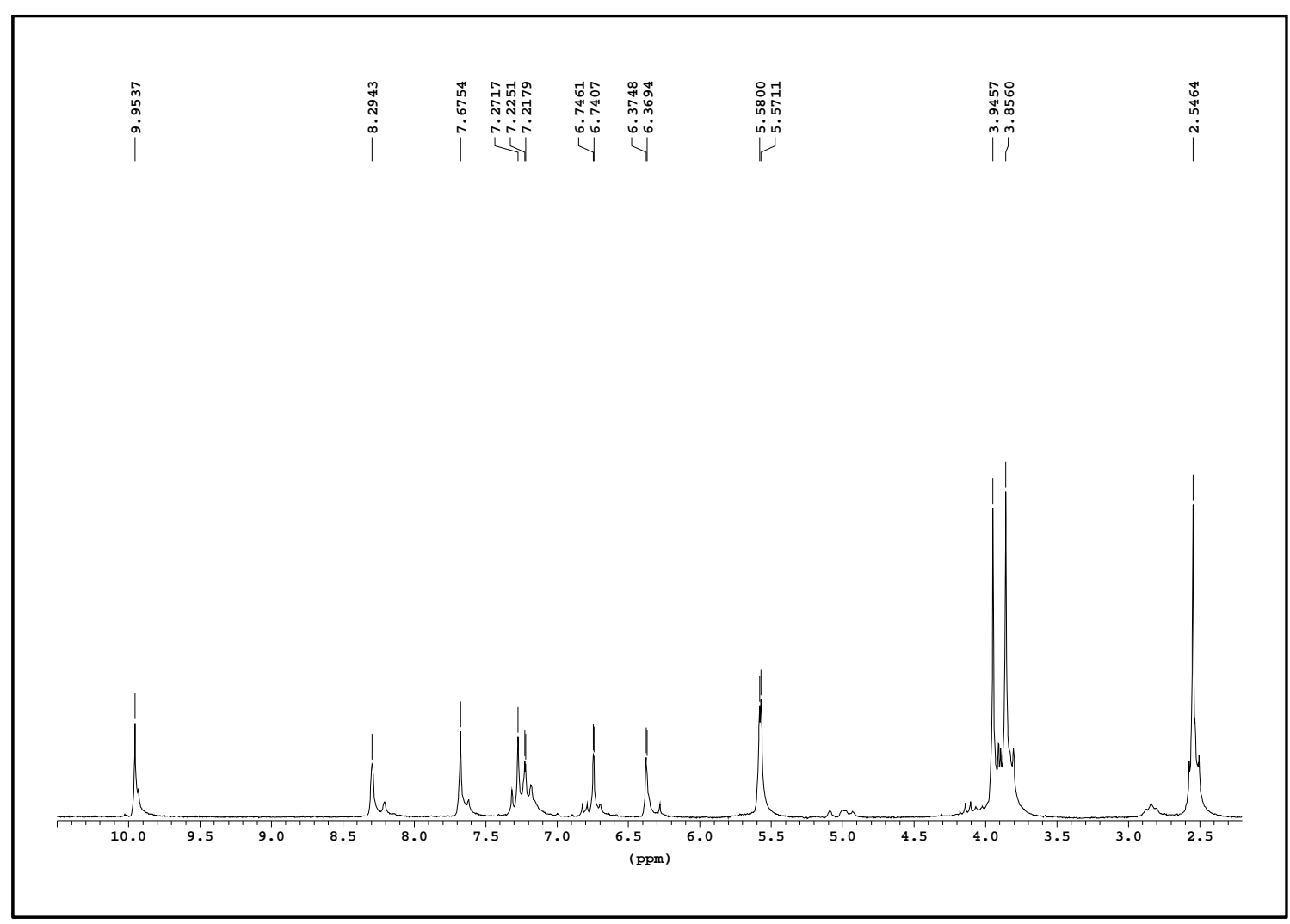

\section{Espectro 89H}

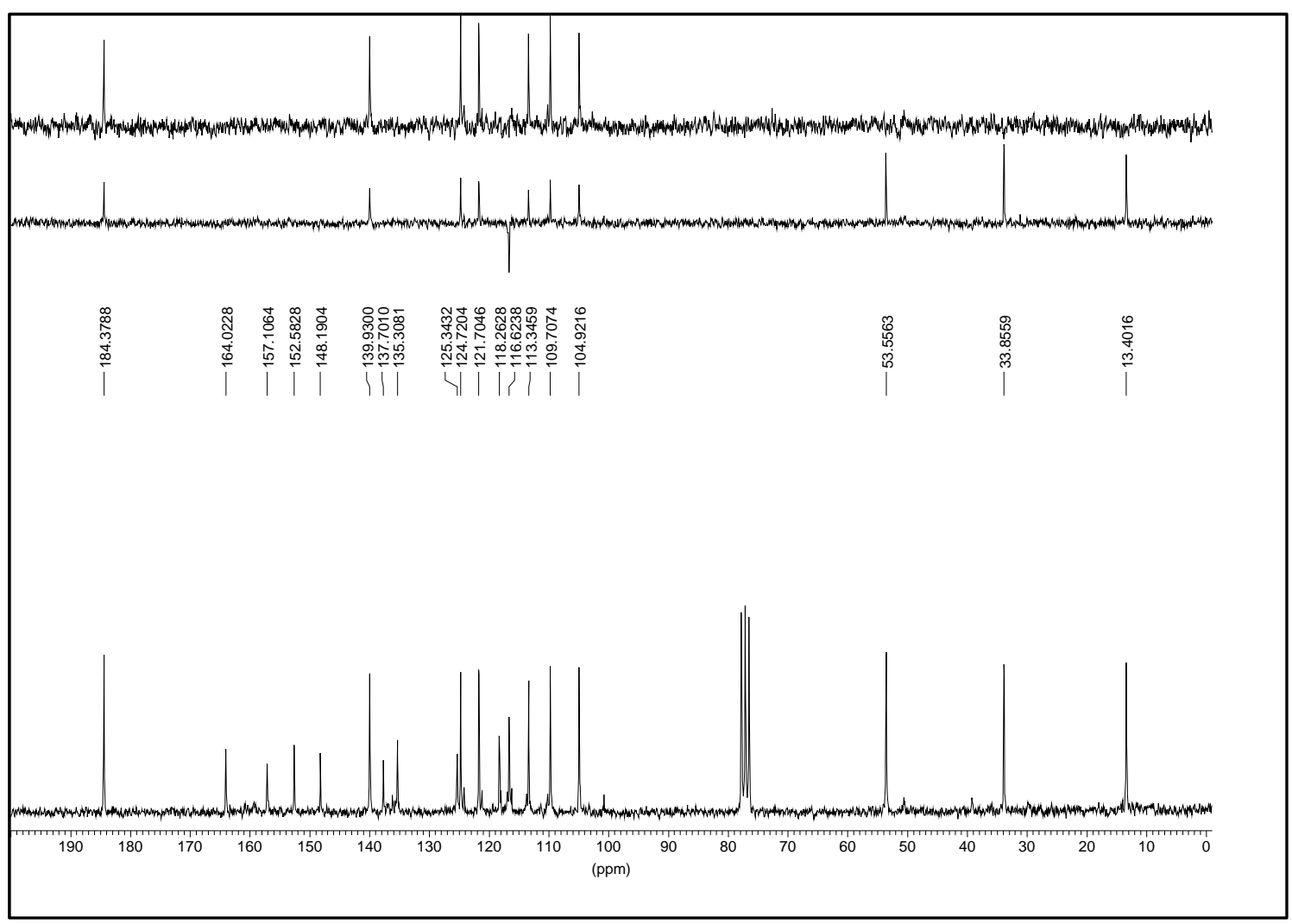

Espectro 89C 


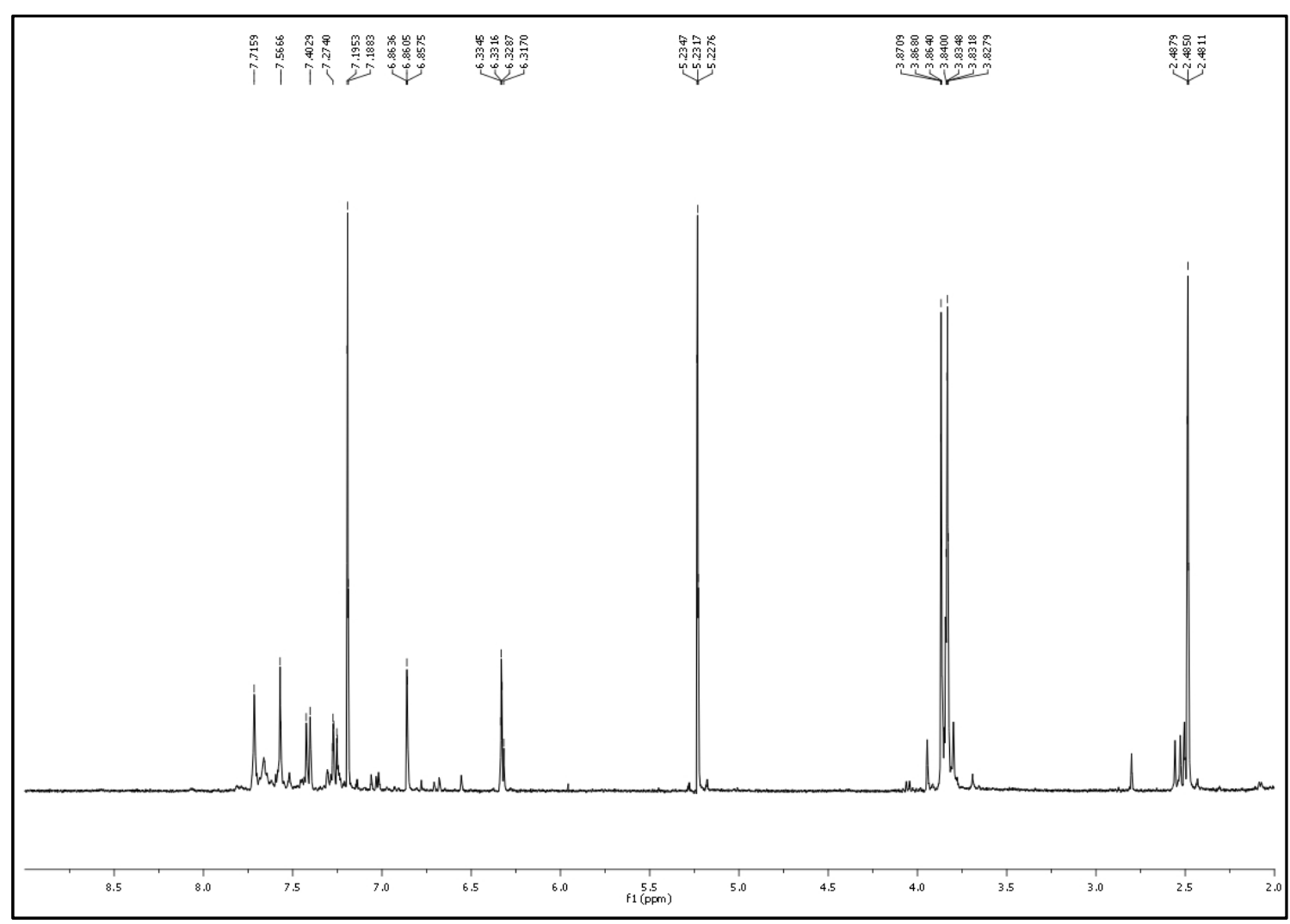

Espectro 92EH

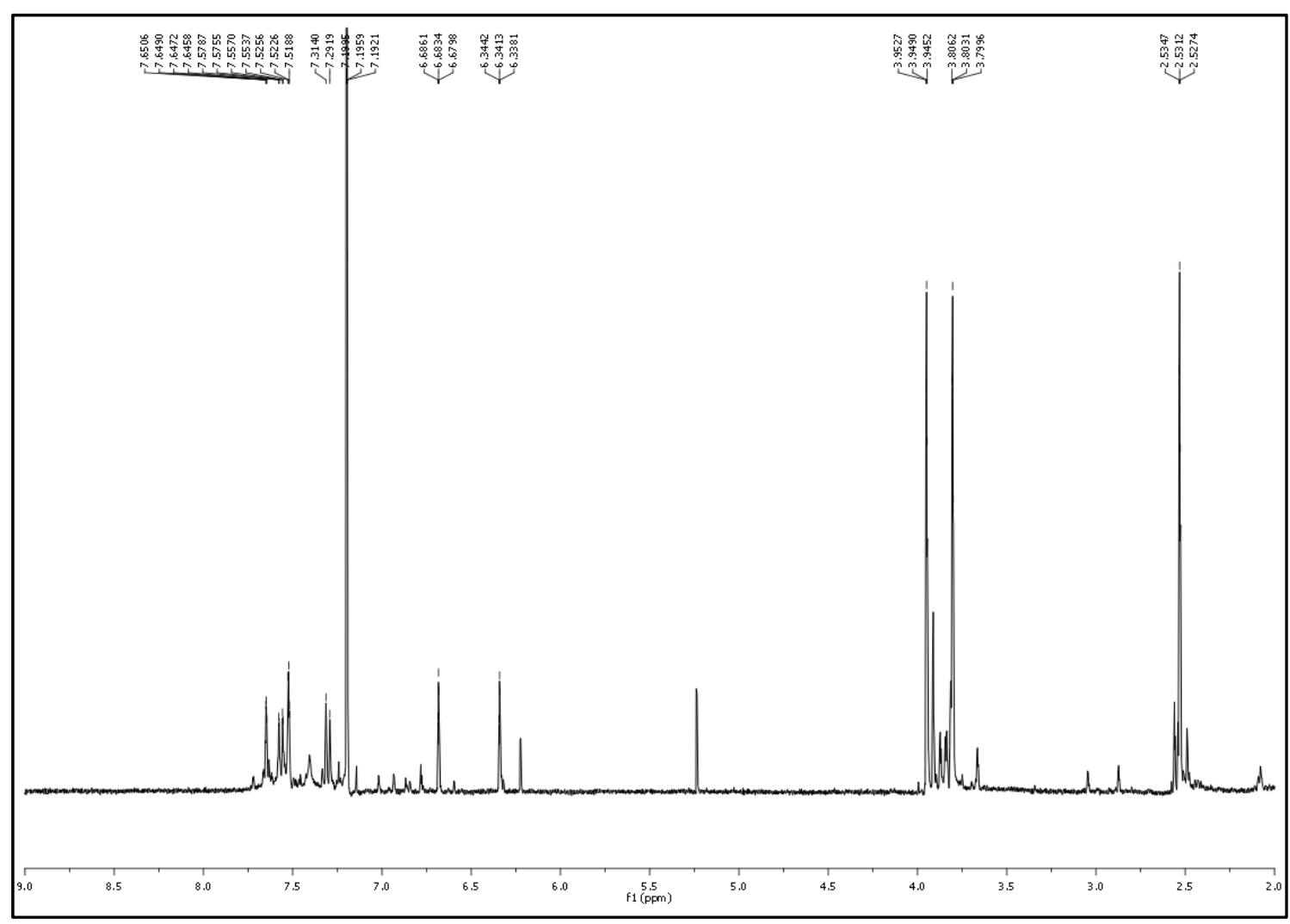

Espectro 92ZH 


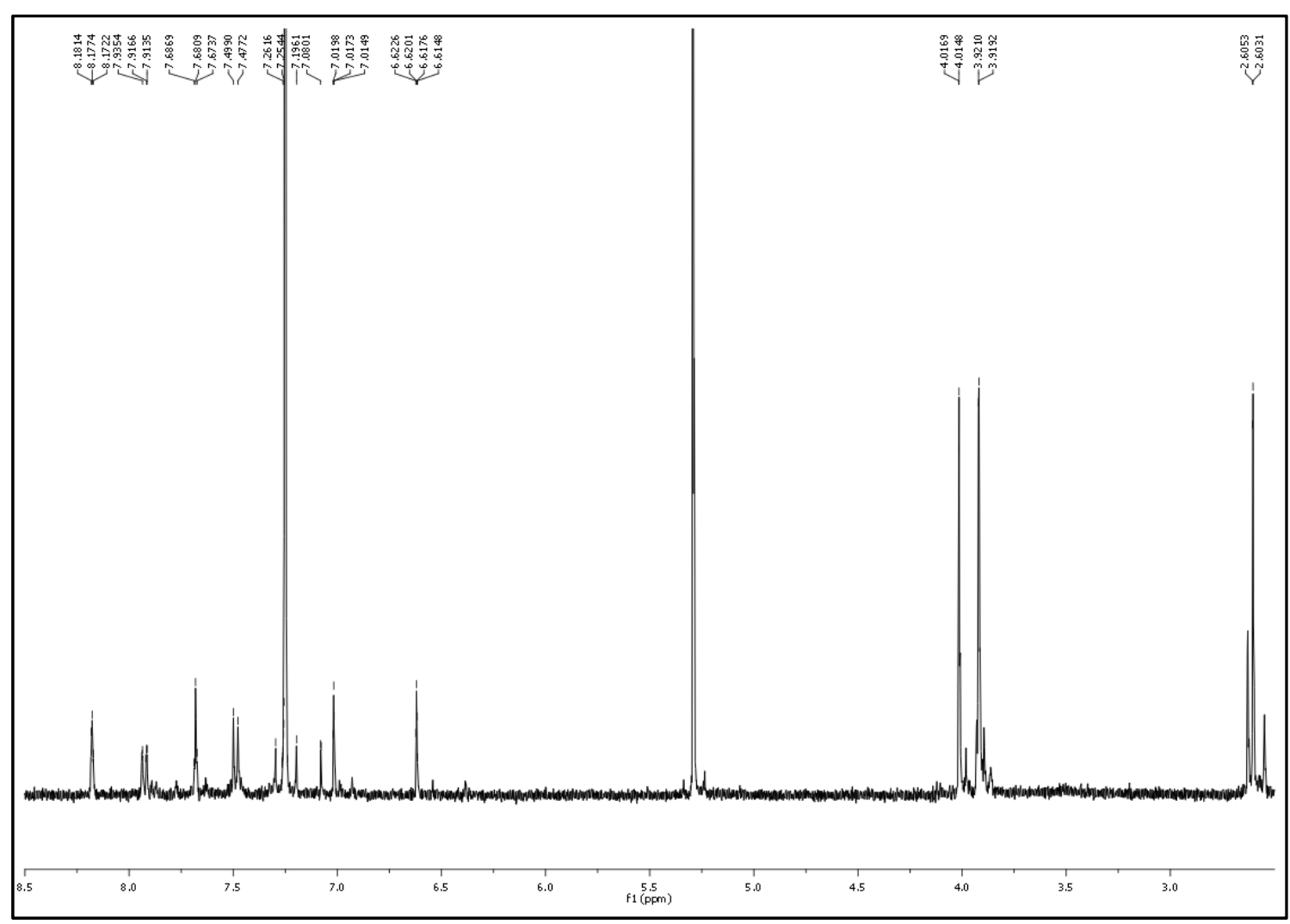

Espectro 93H

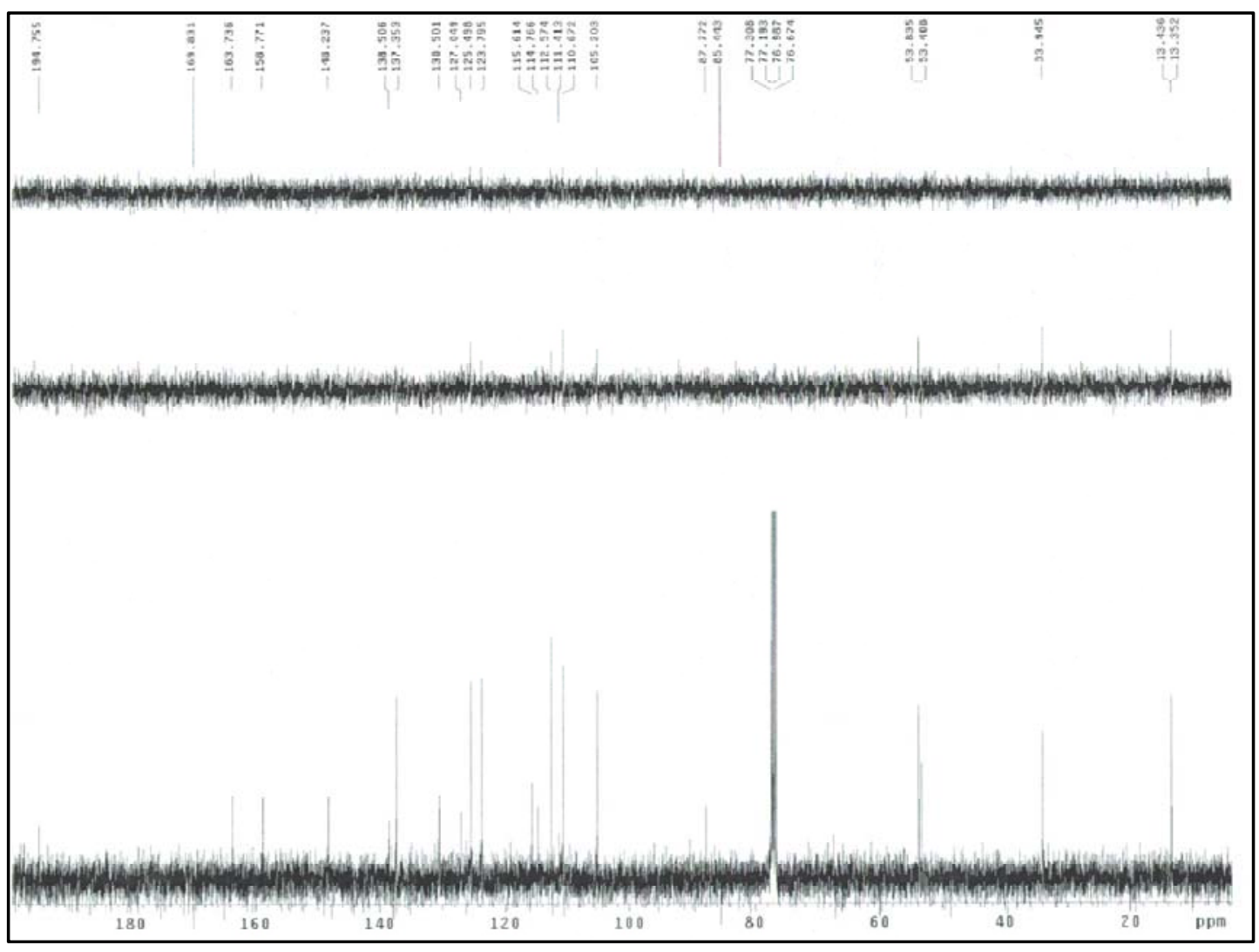

Espectro 93C 


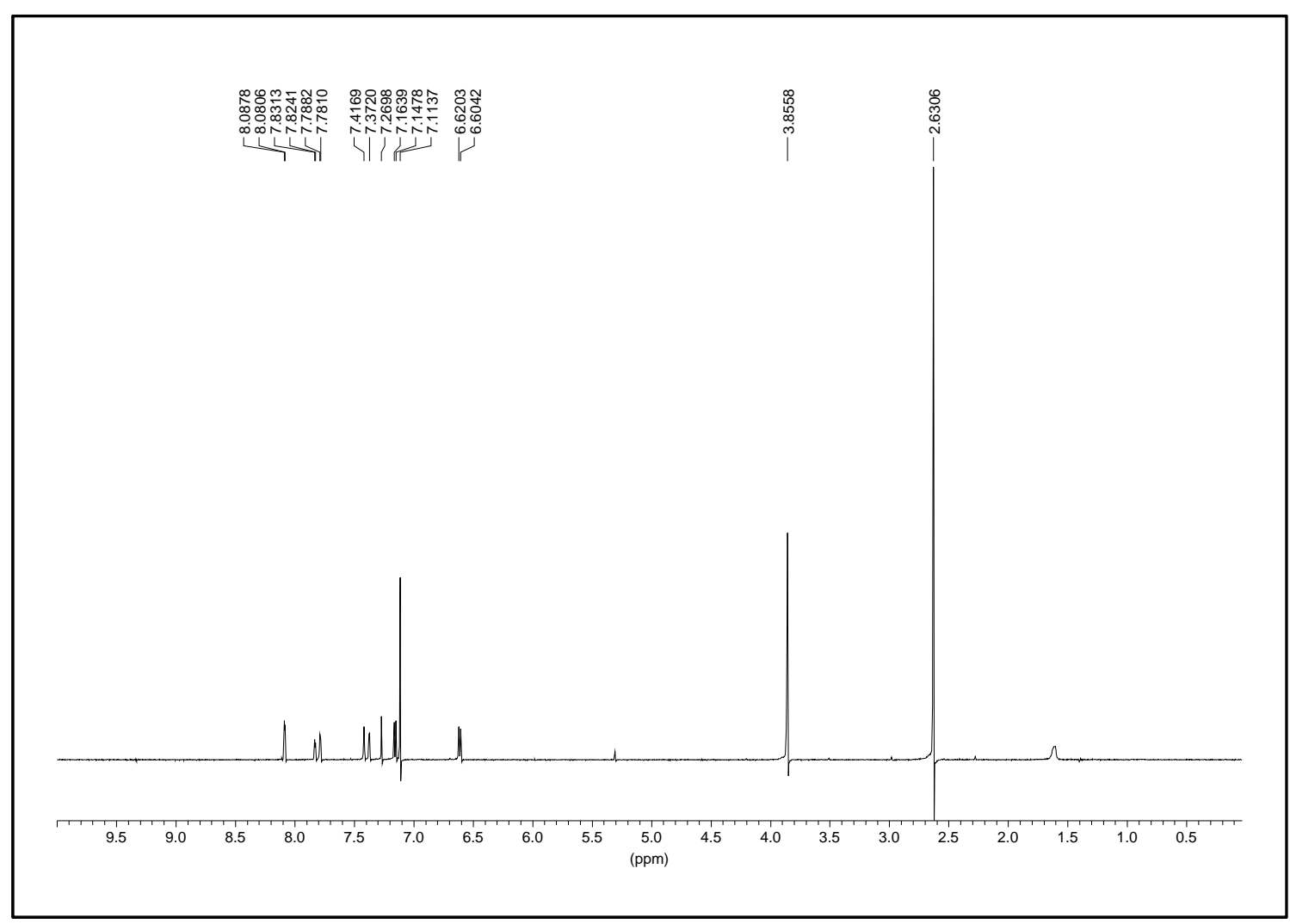

\section{Espectro 94H}

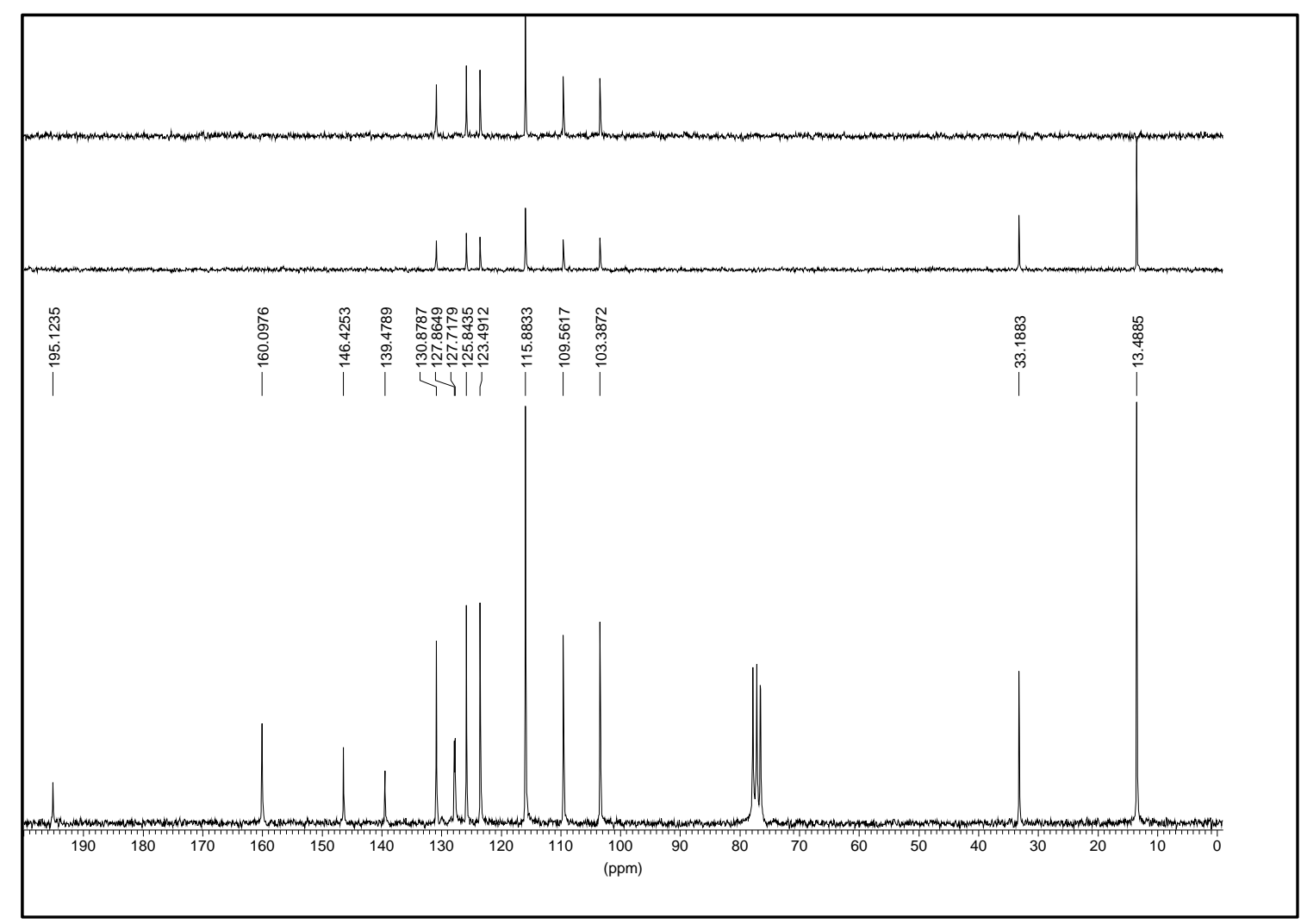

Espectro 94C 


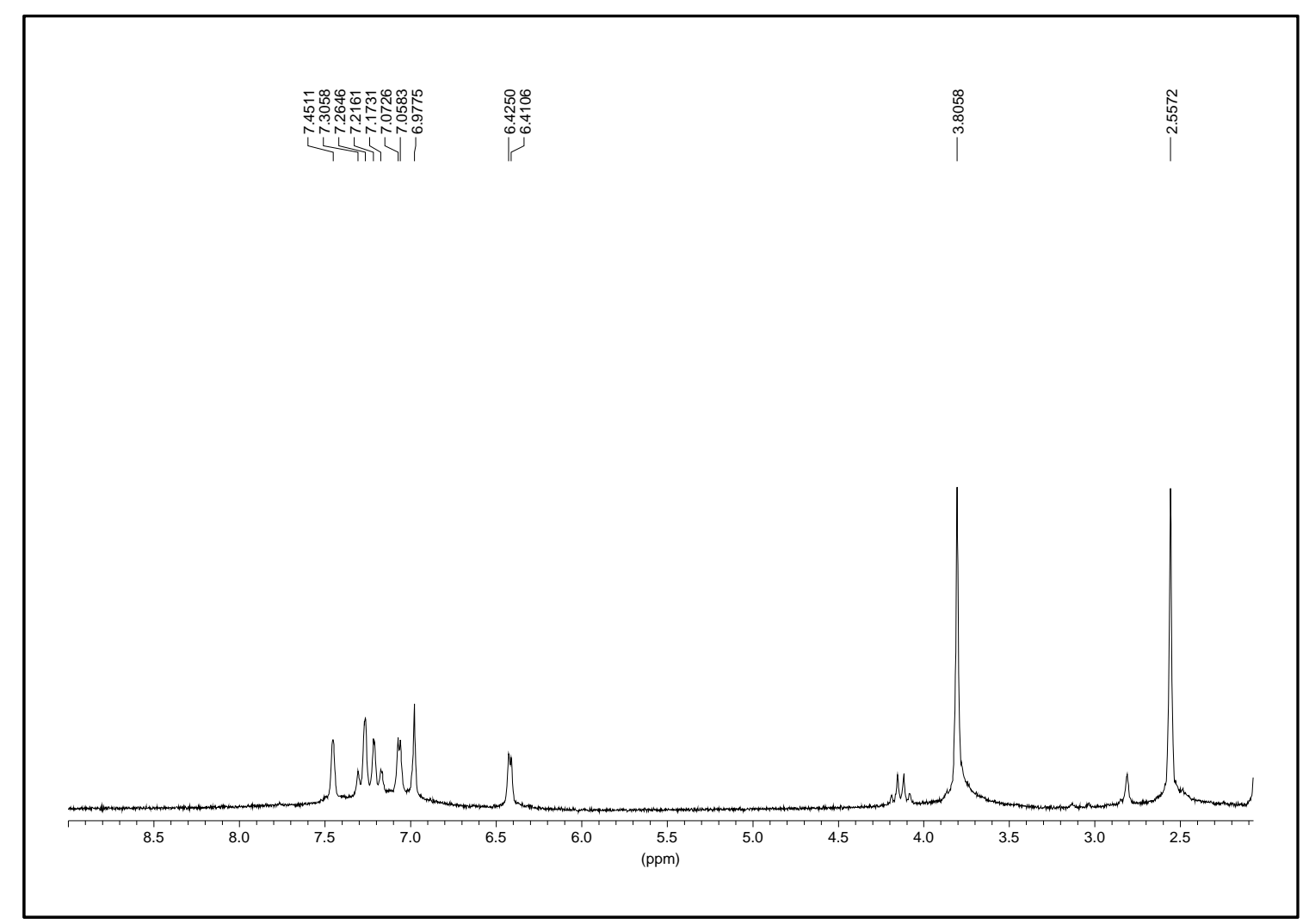

\section{Espectro 95H}

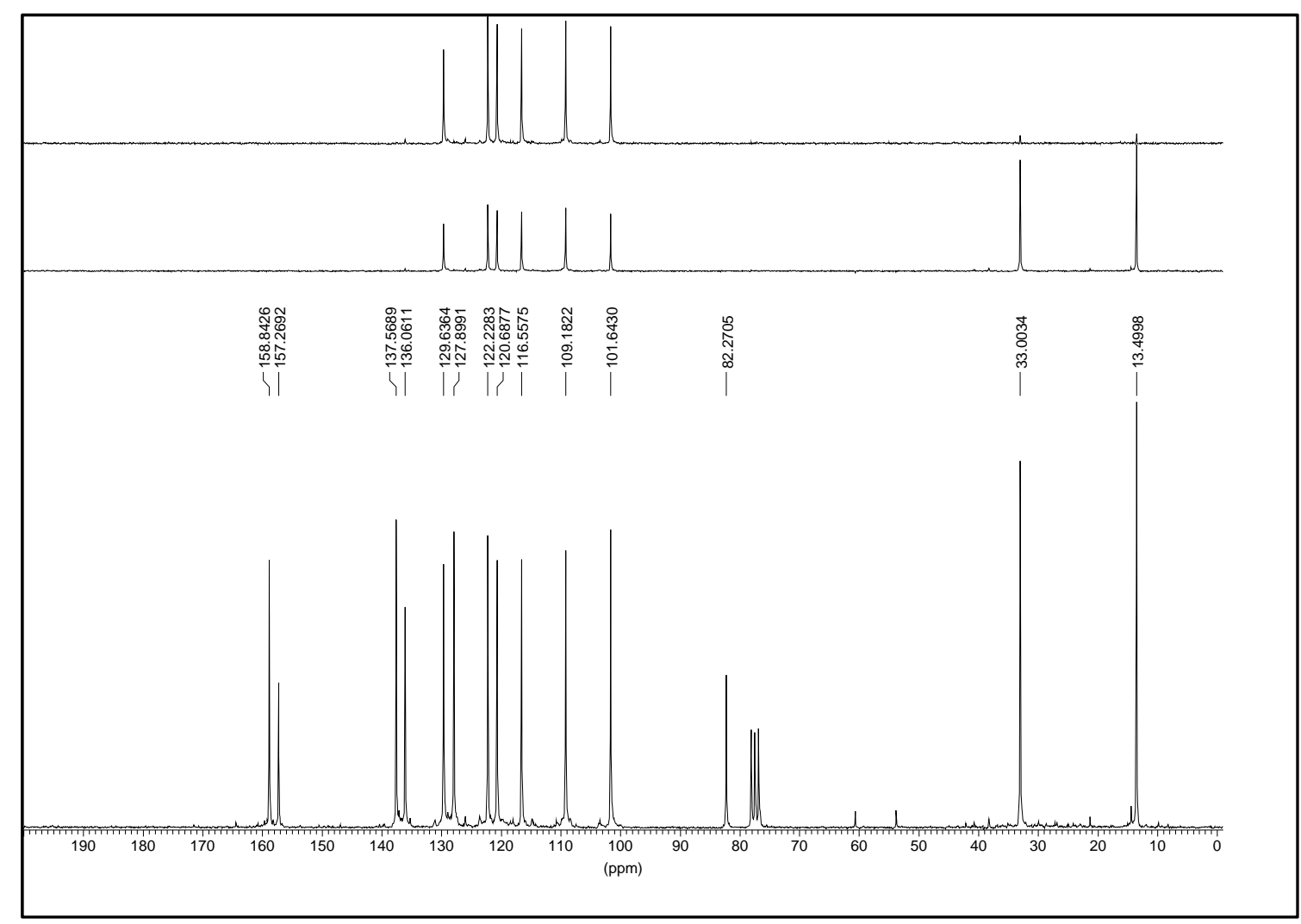

Espectro 95C 


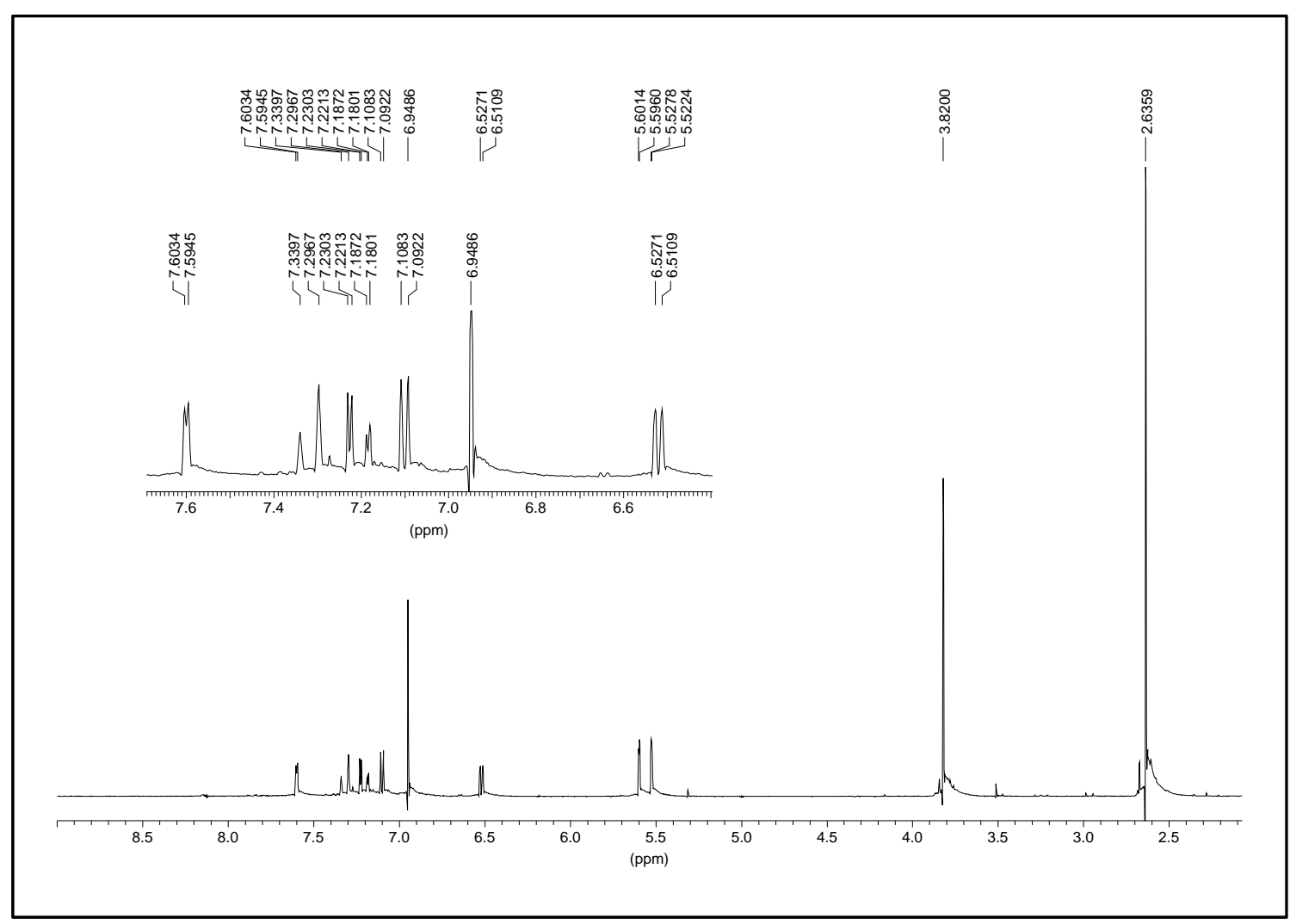

\section{Espectro 96H}

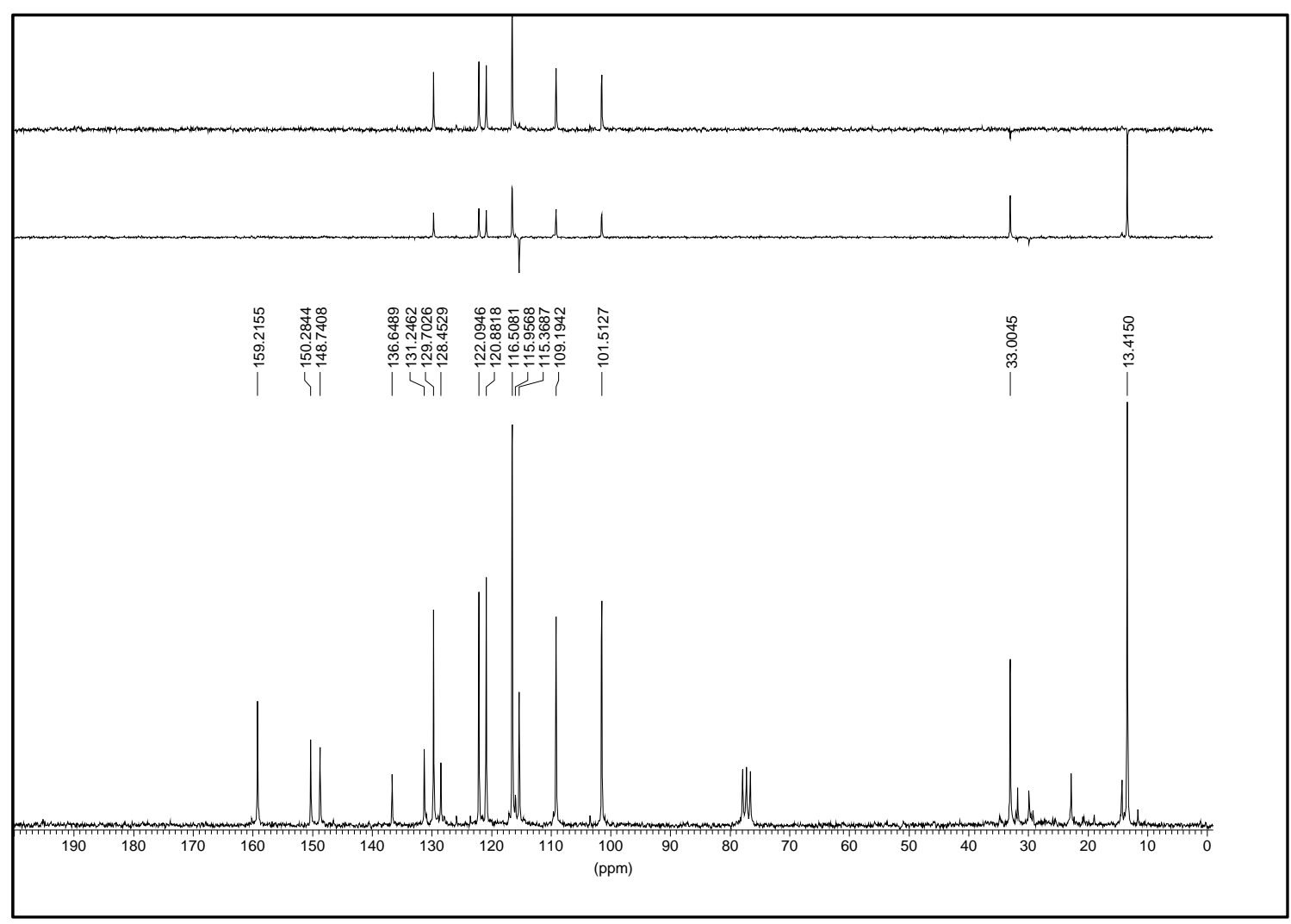

Espectro 96C 


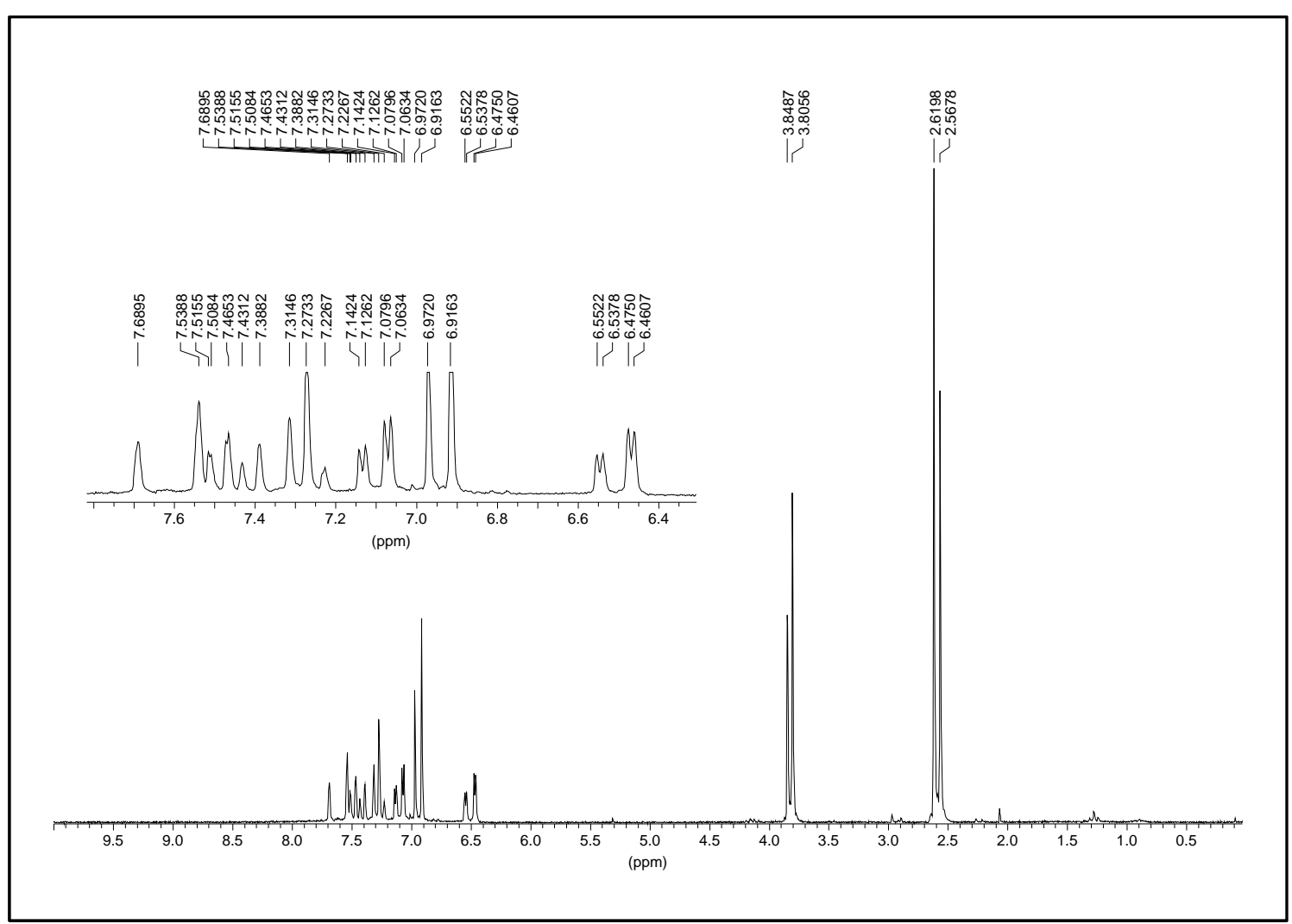

\section{Espectro 97ZEH}

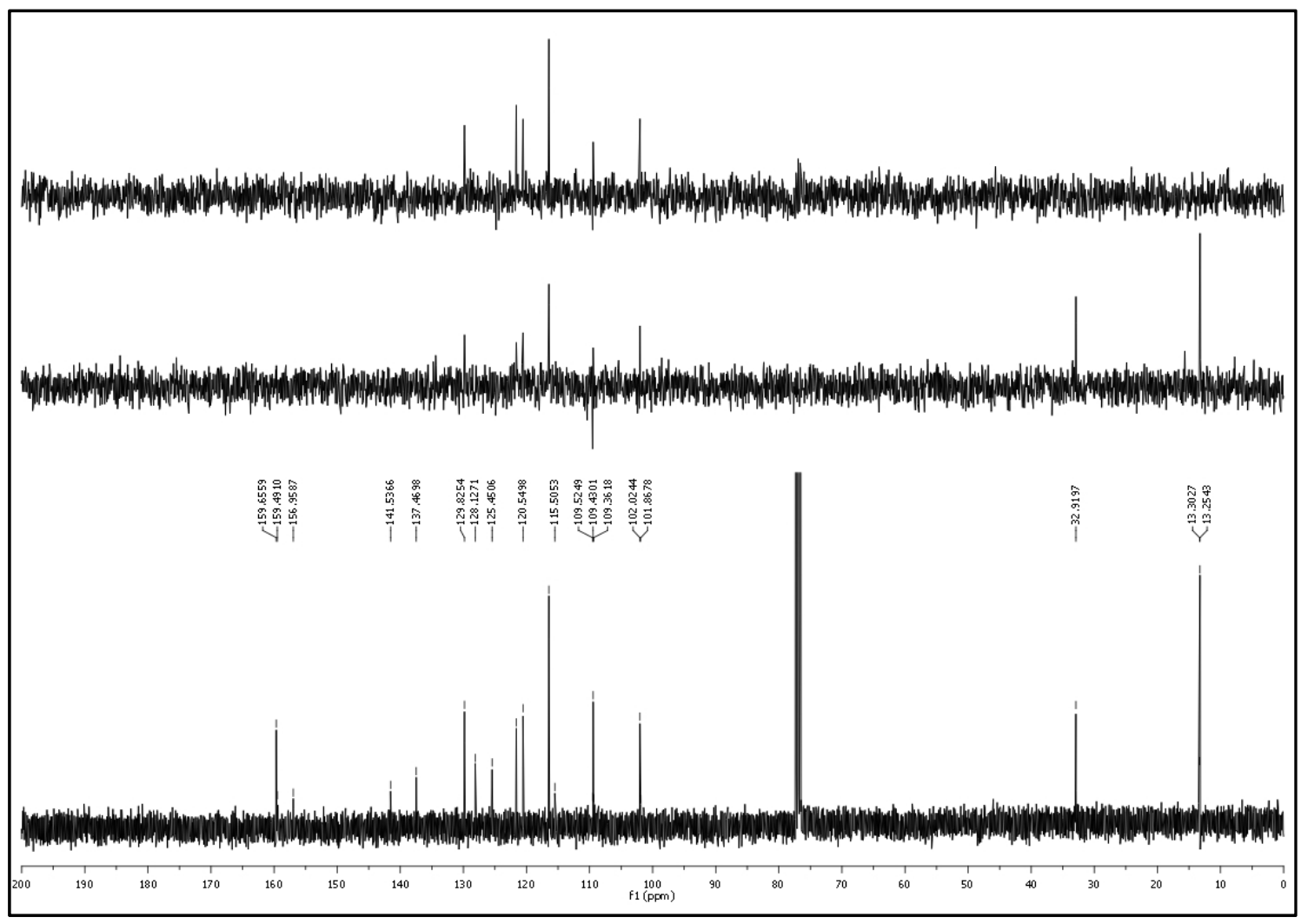

Espectro 97ZC 


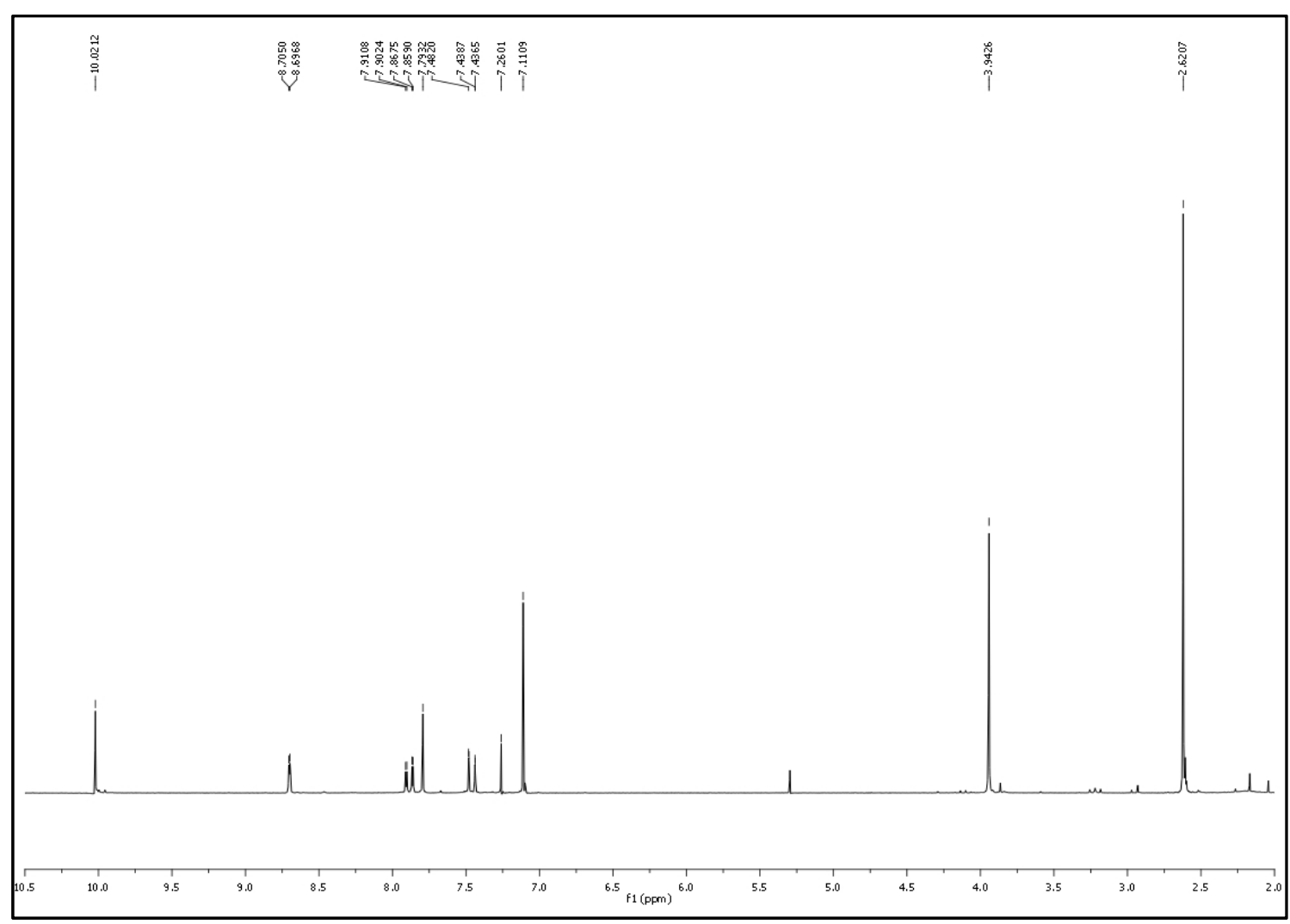

Espectro 98H

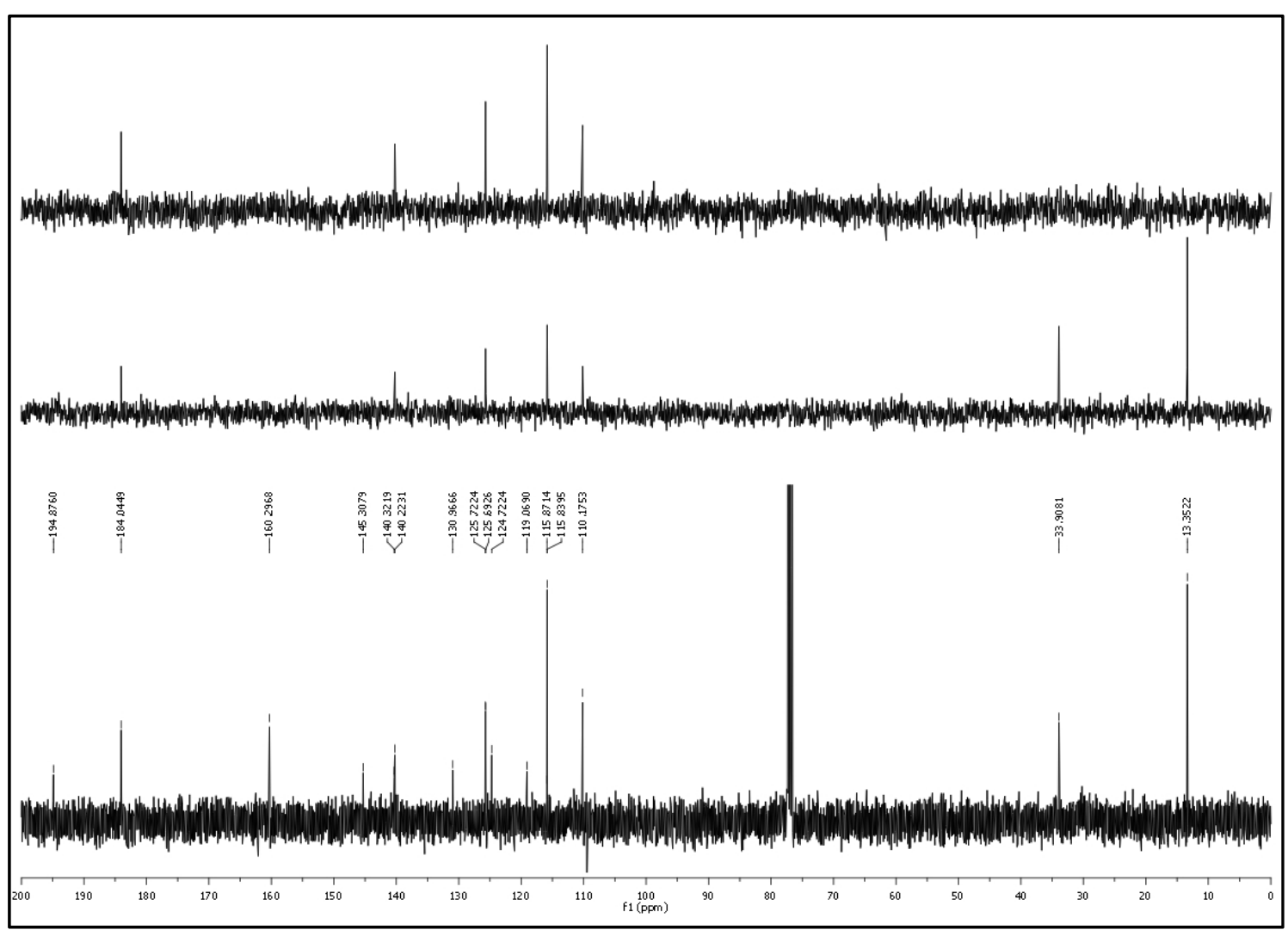

Espectro 98C 


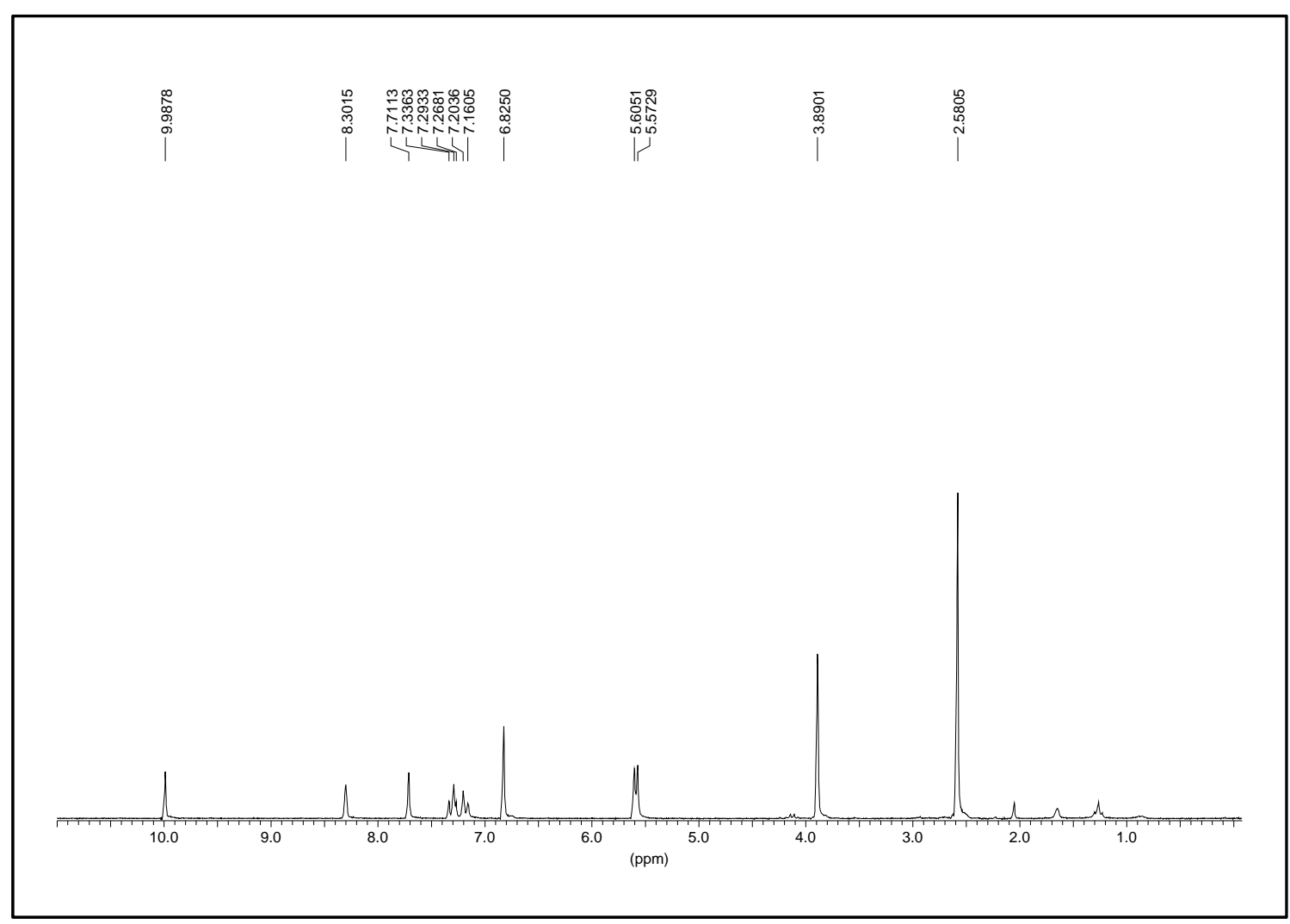

\section{Espectro 99H}

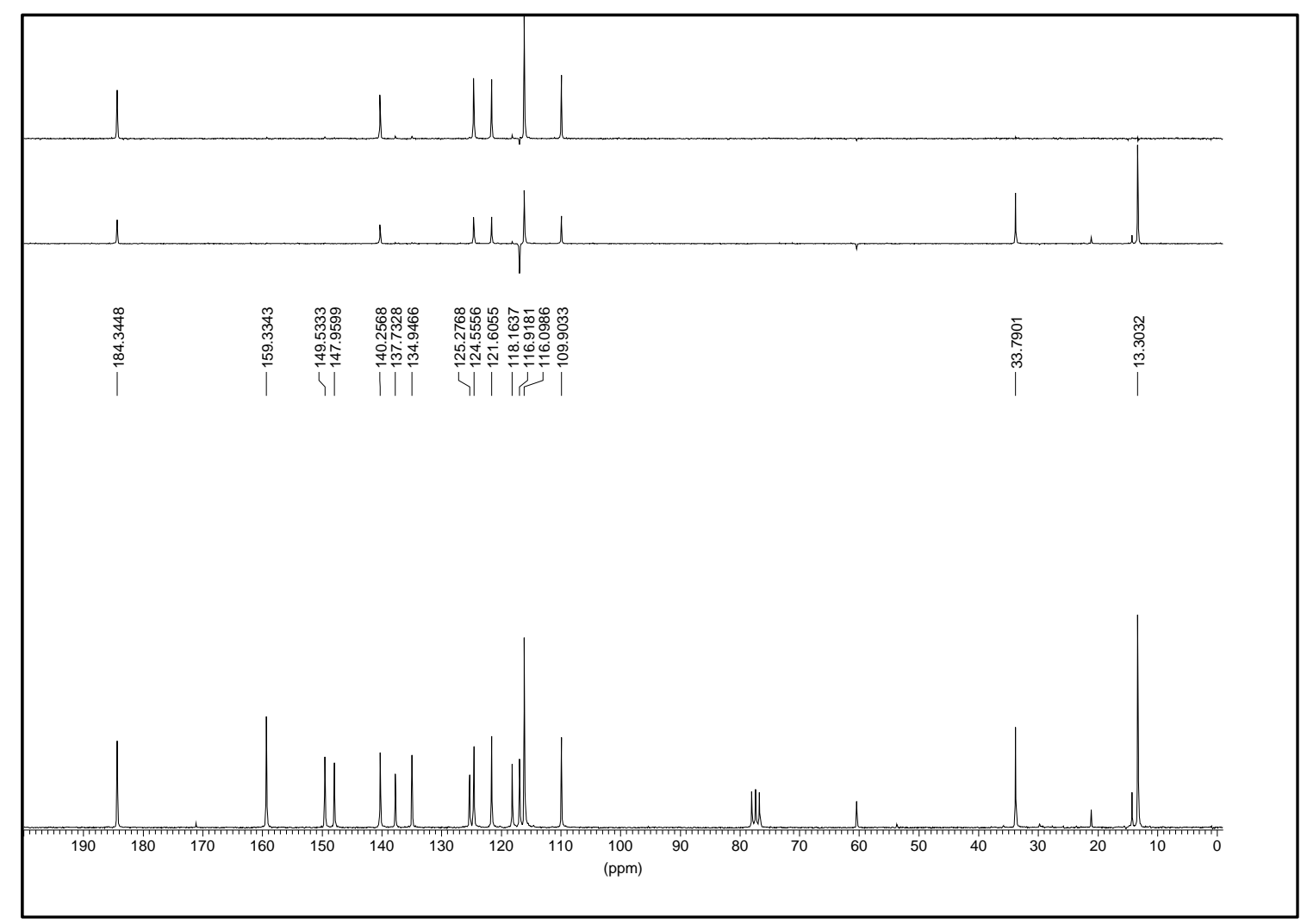

Espectro 99C 


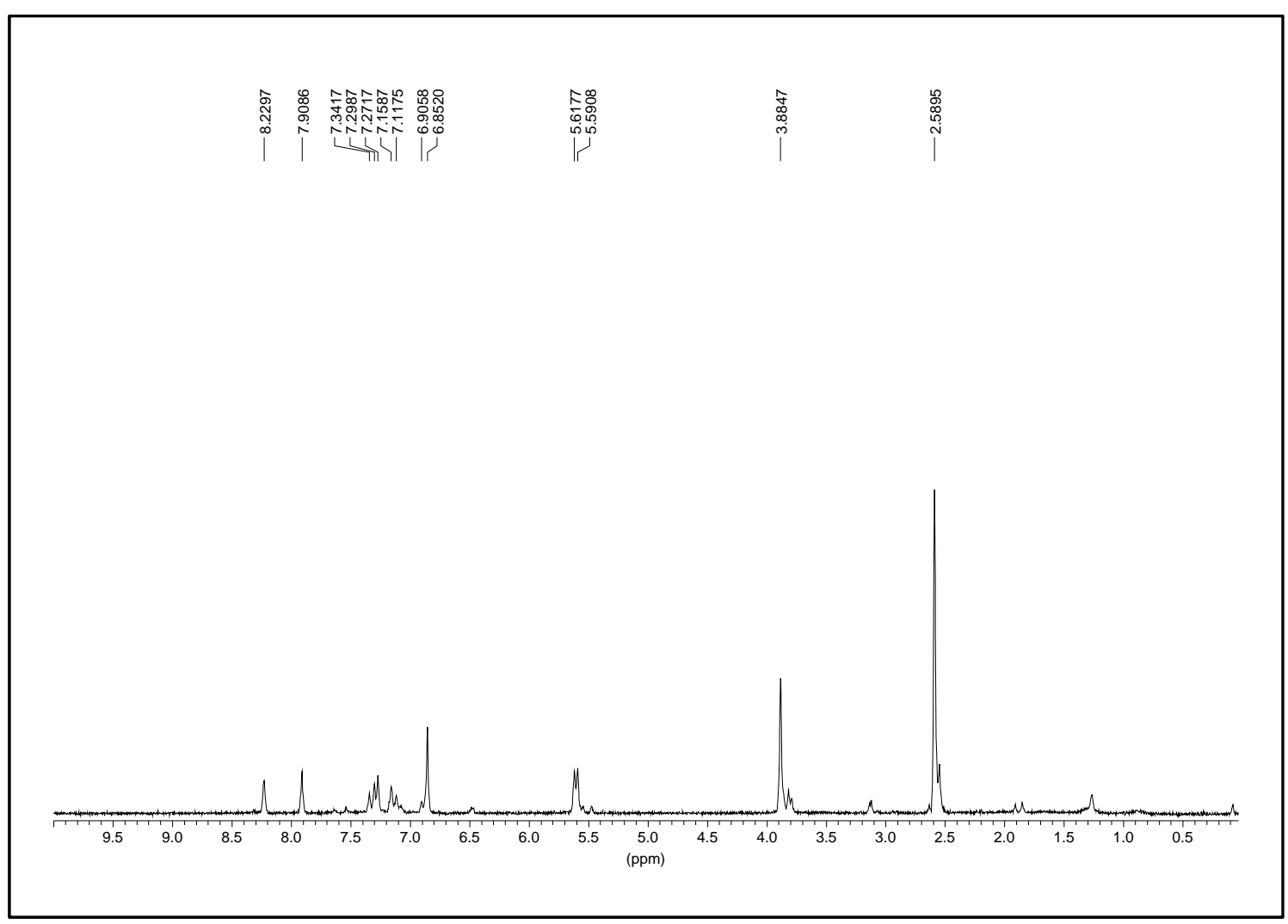

Espectro $100 \mathrm{H}$

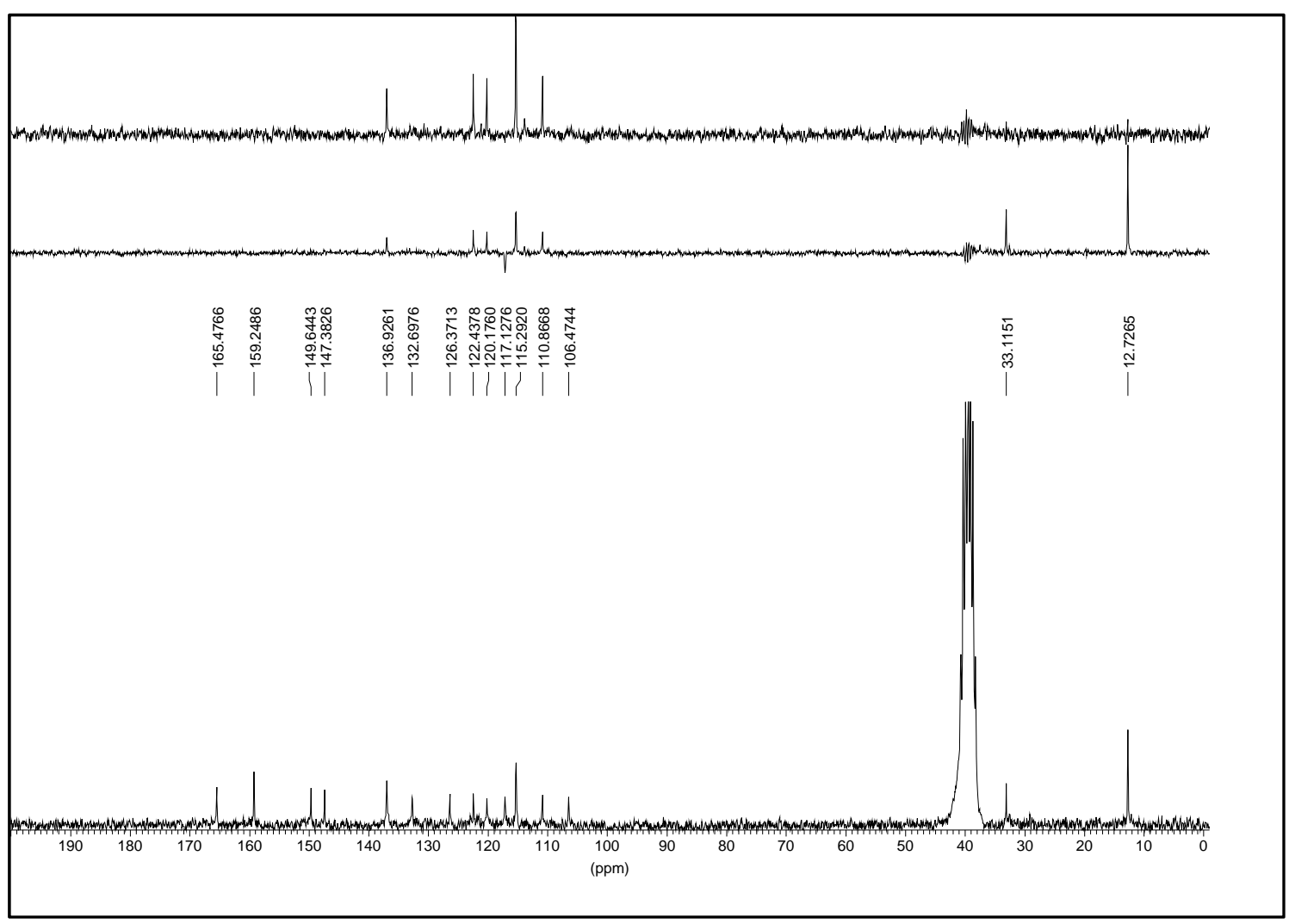

Espectro $100 \mathrm{C}$ en DMSO-d 


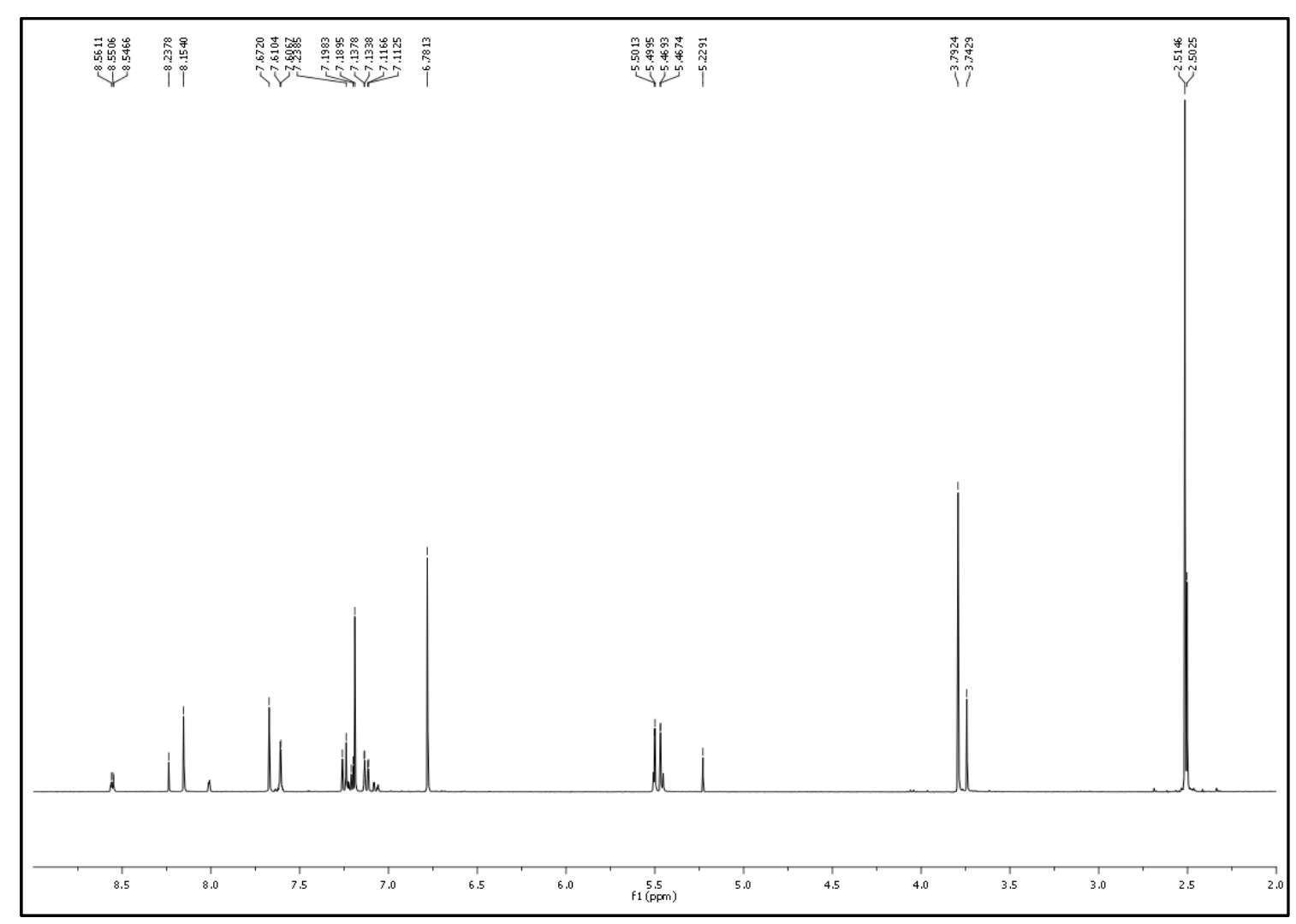

Espectro $101 \mathrm{H}$ 


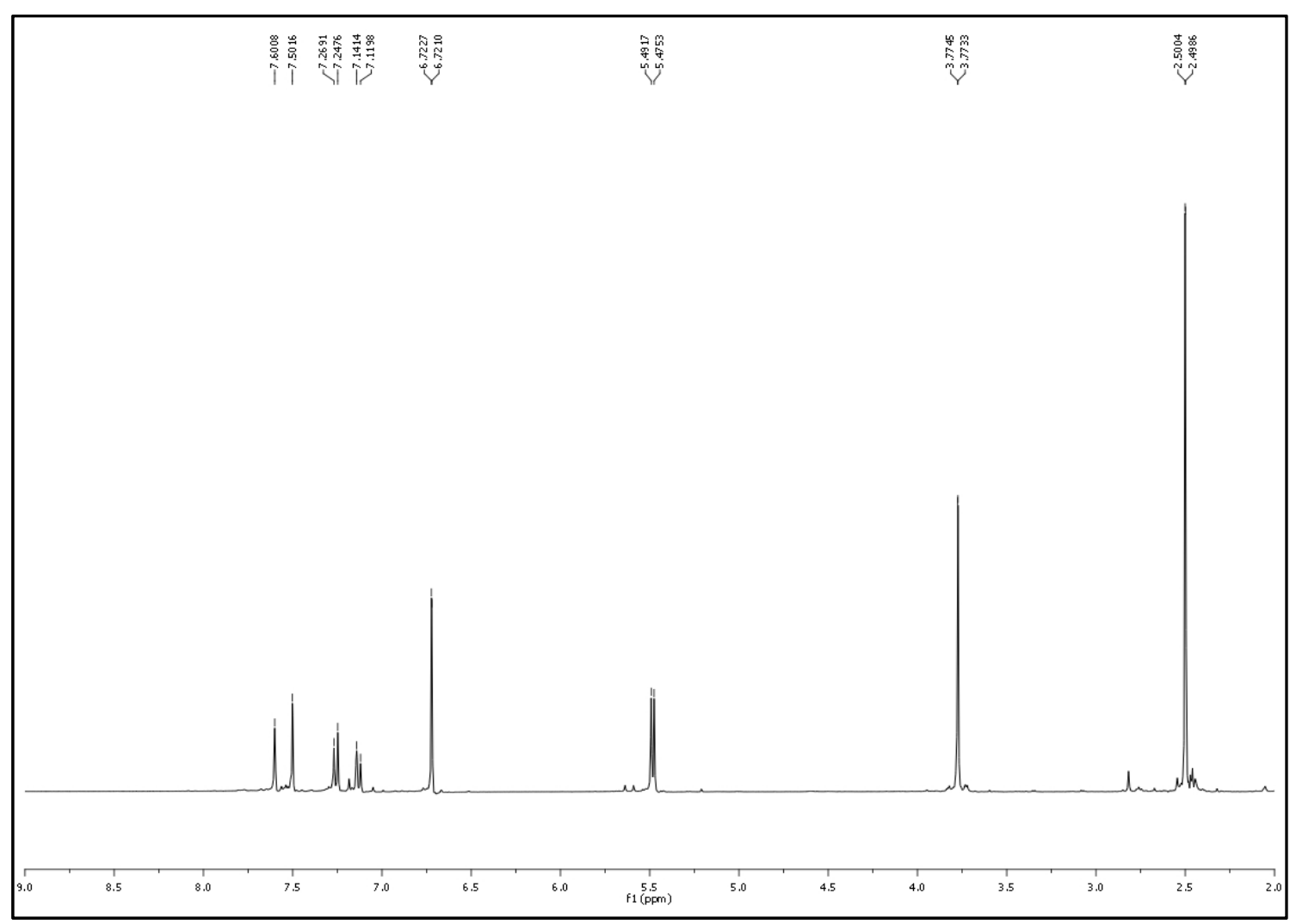

Espectro 102H

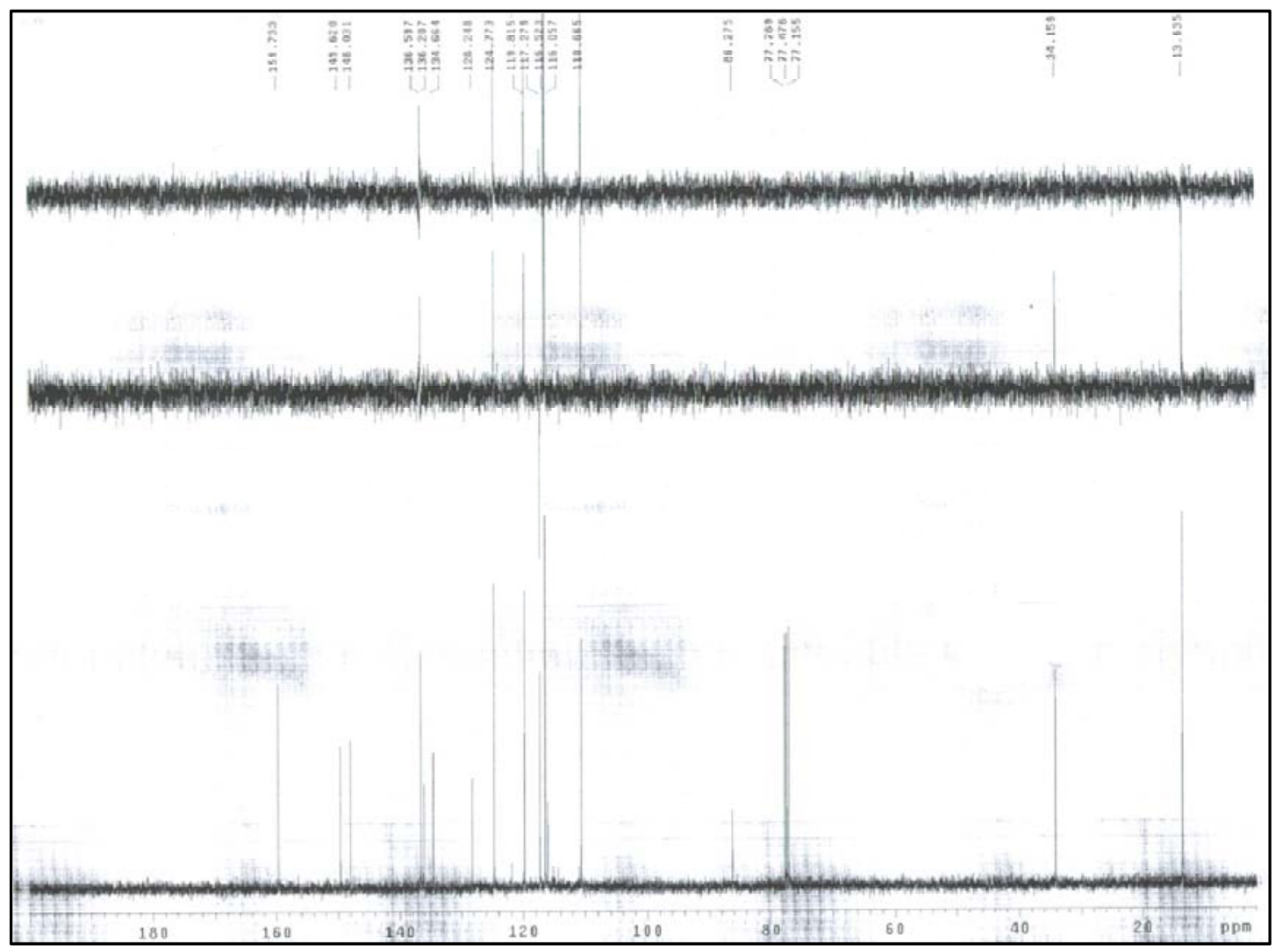

Espectro 102C 


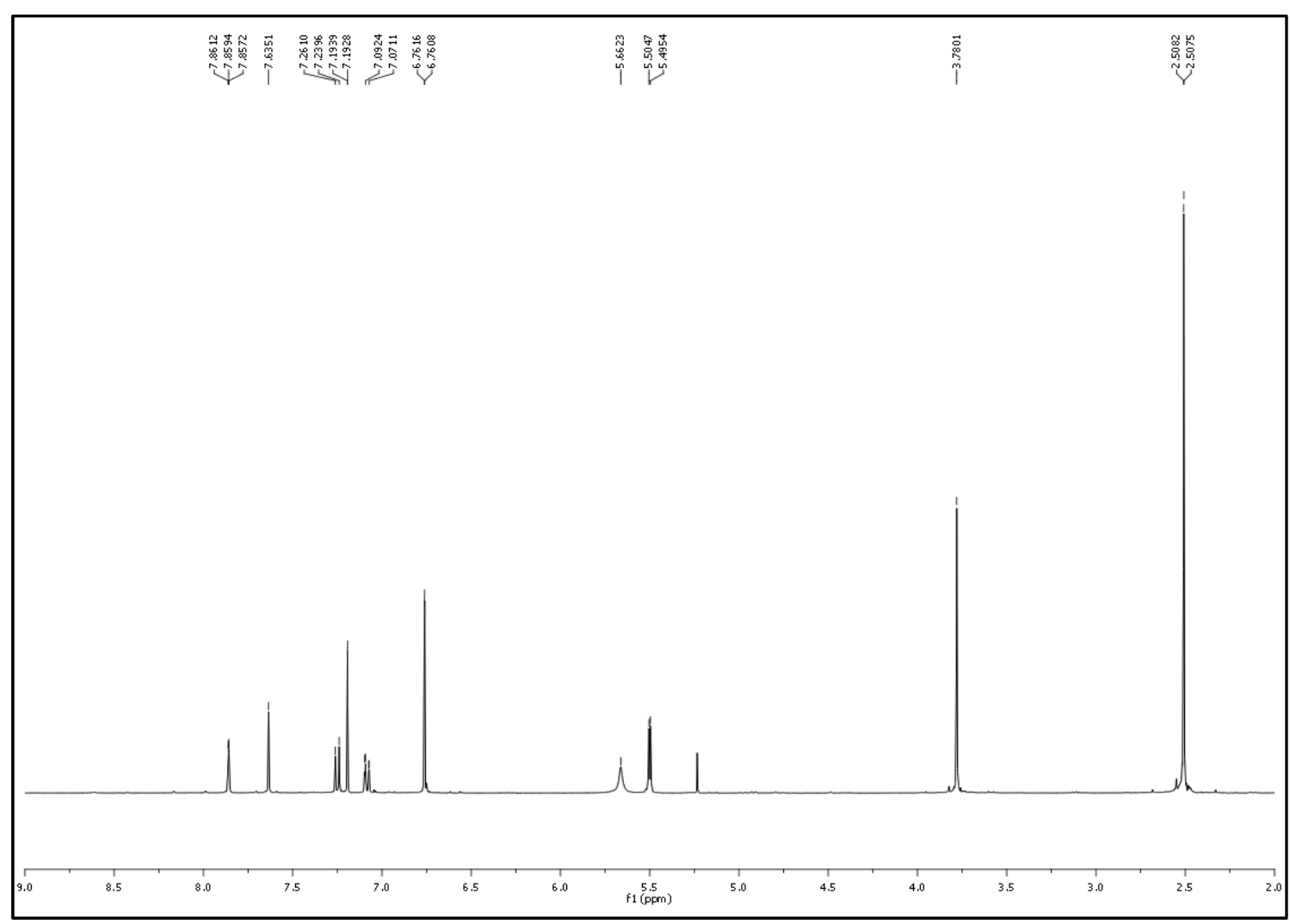

Espectro $103 \mathrm{H}$

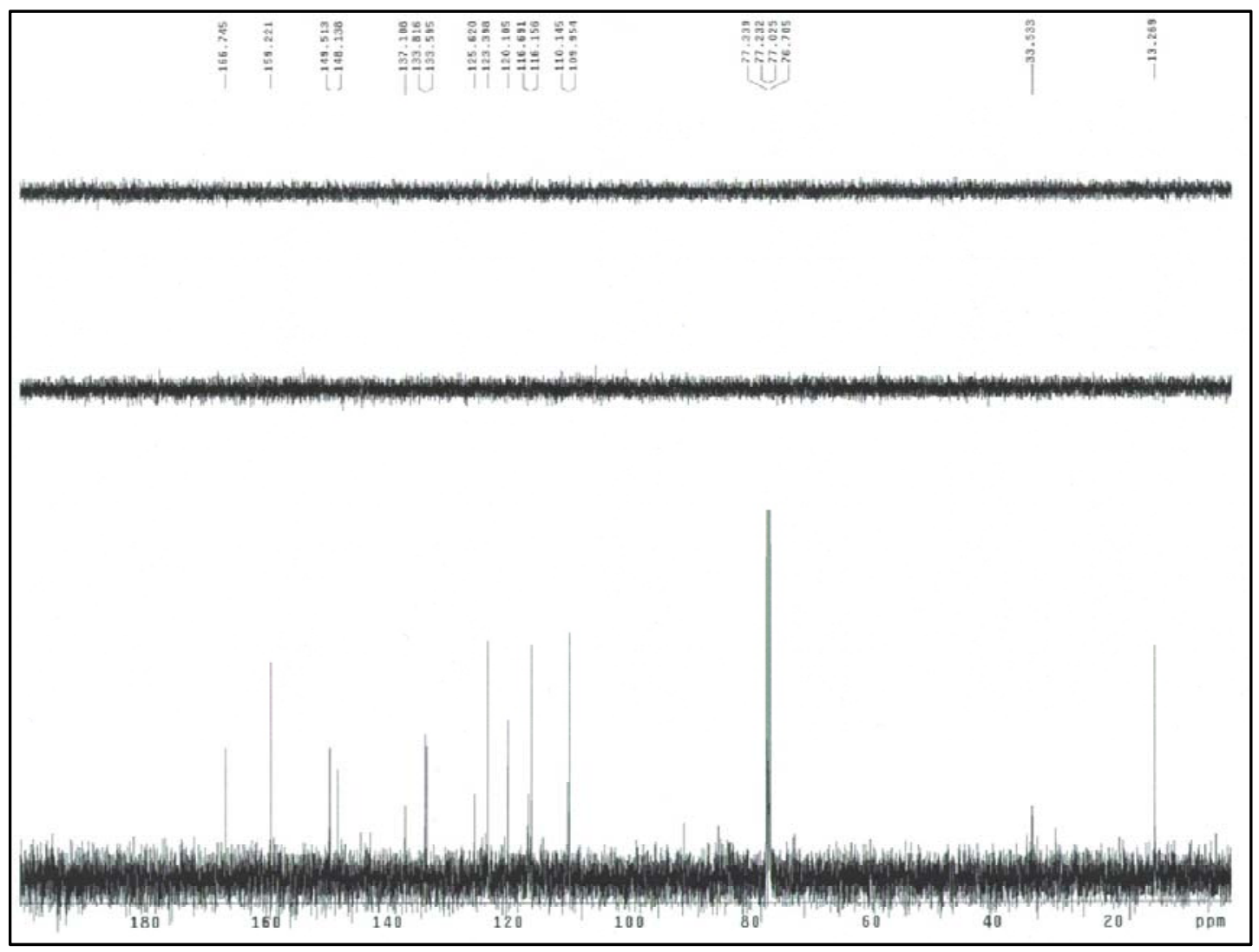

Espectro 103C 


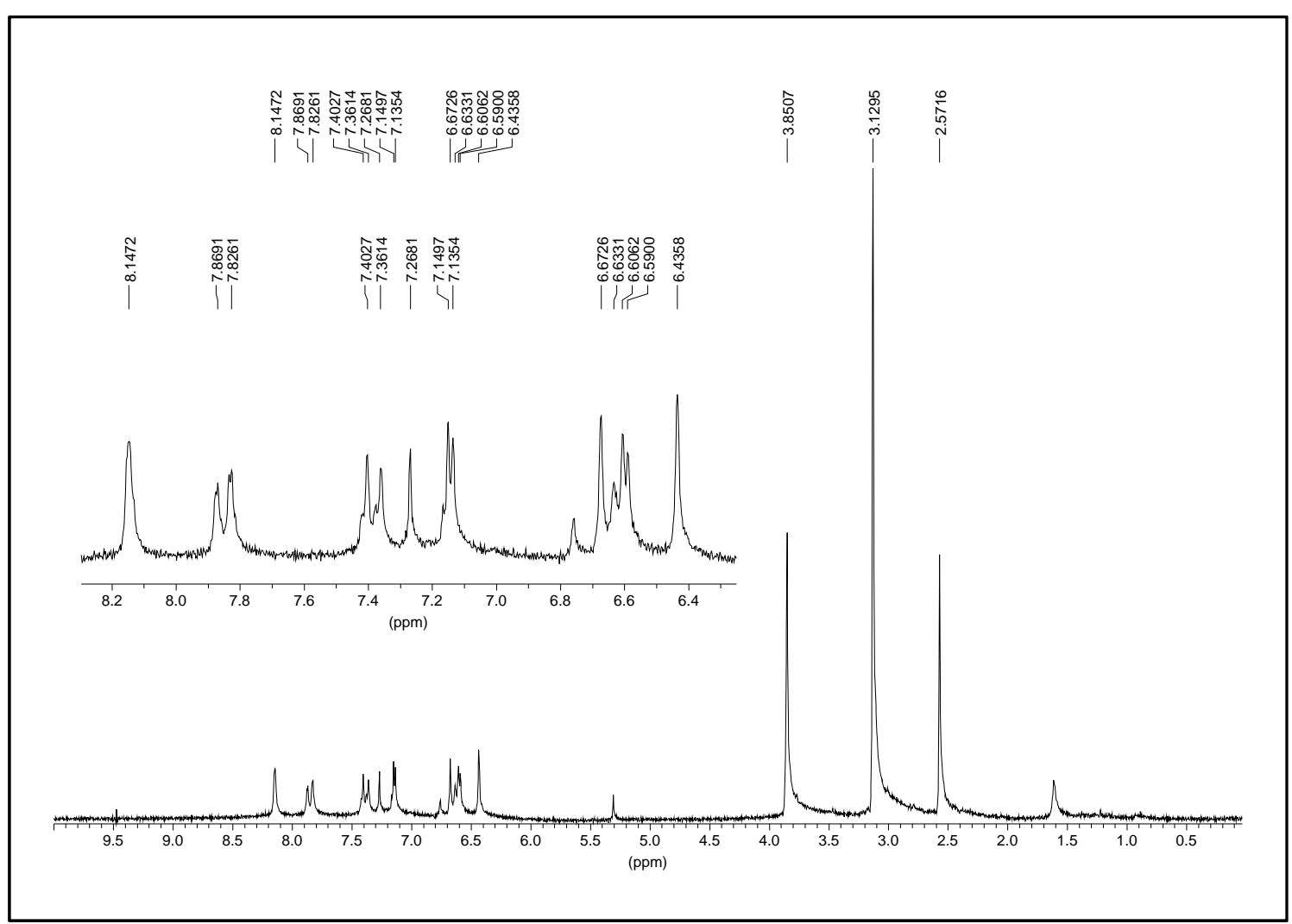

Espectro $104 \mathrm{H}$

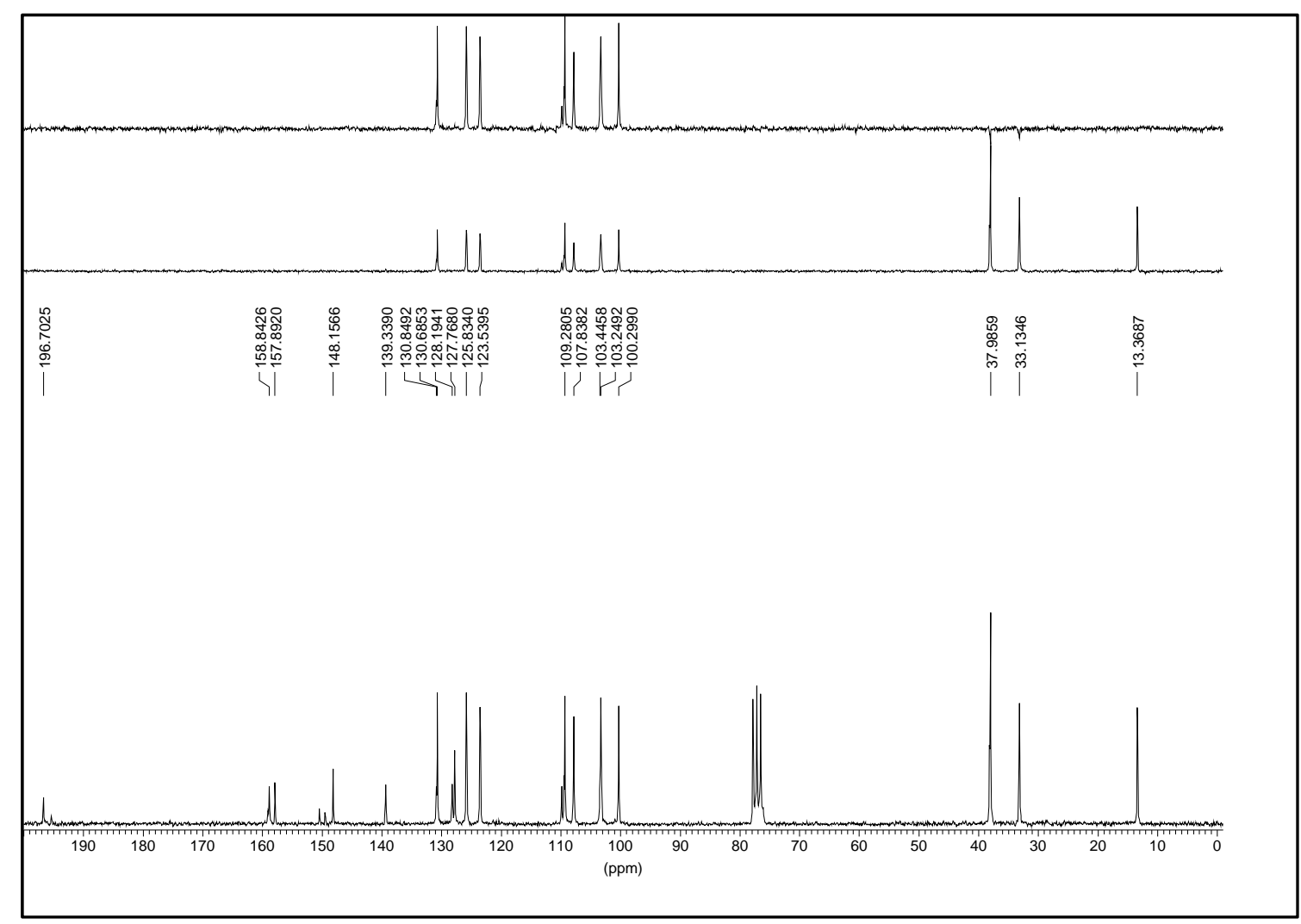

Espectro 104C 


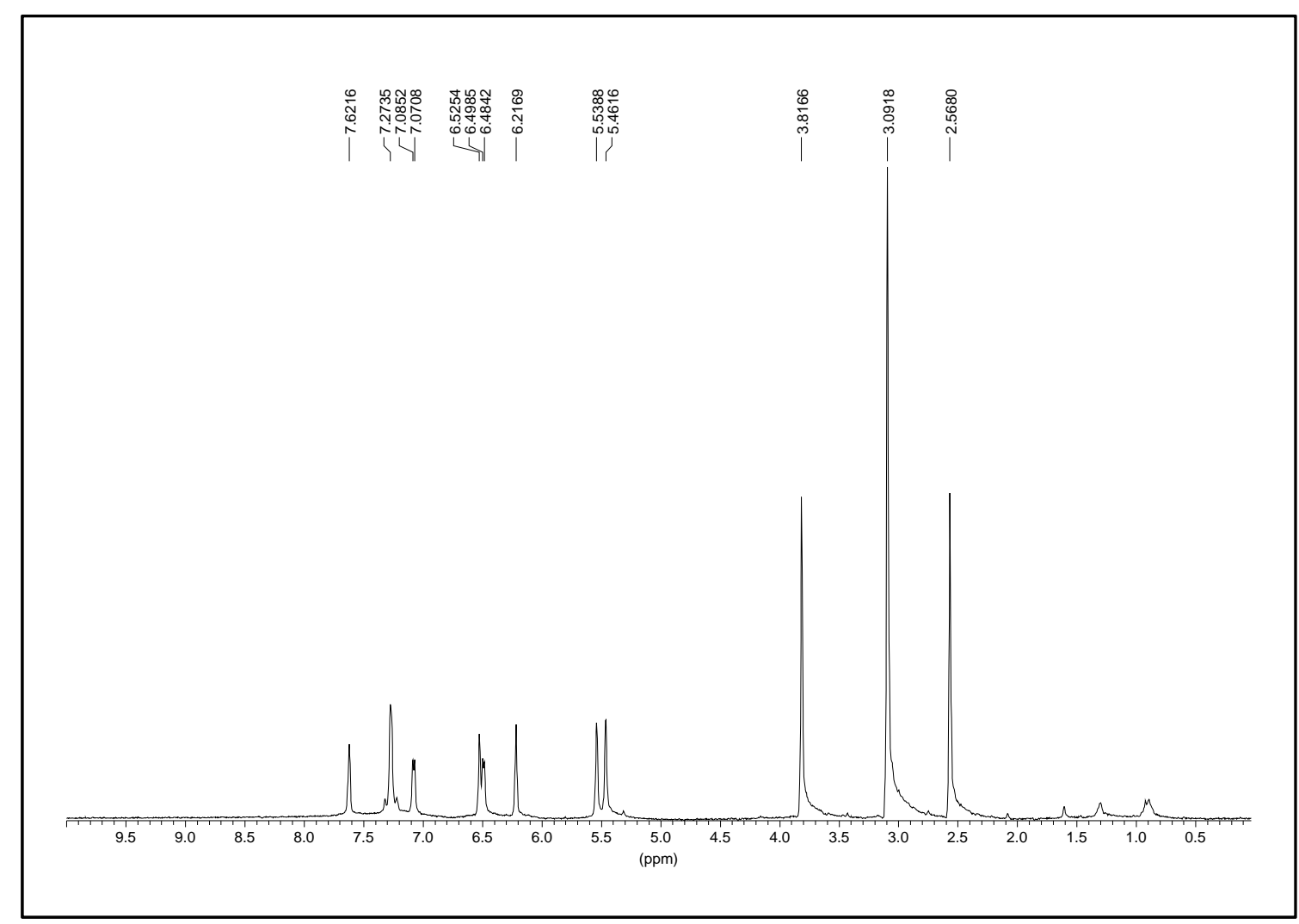

Espectro $105 \mathrm{H}$

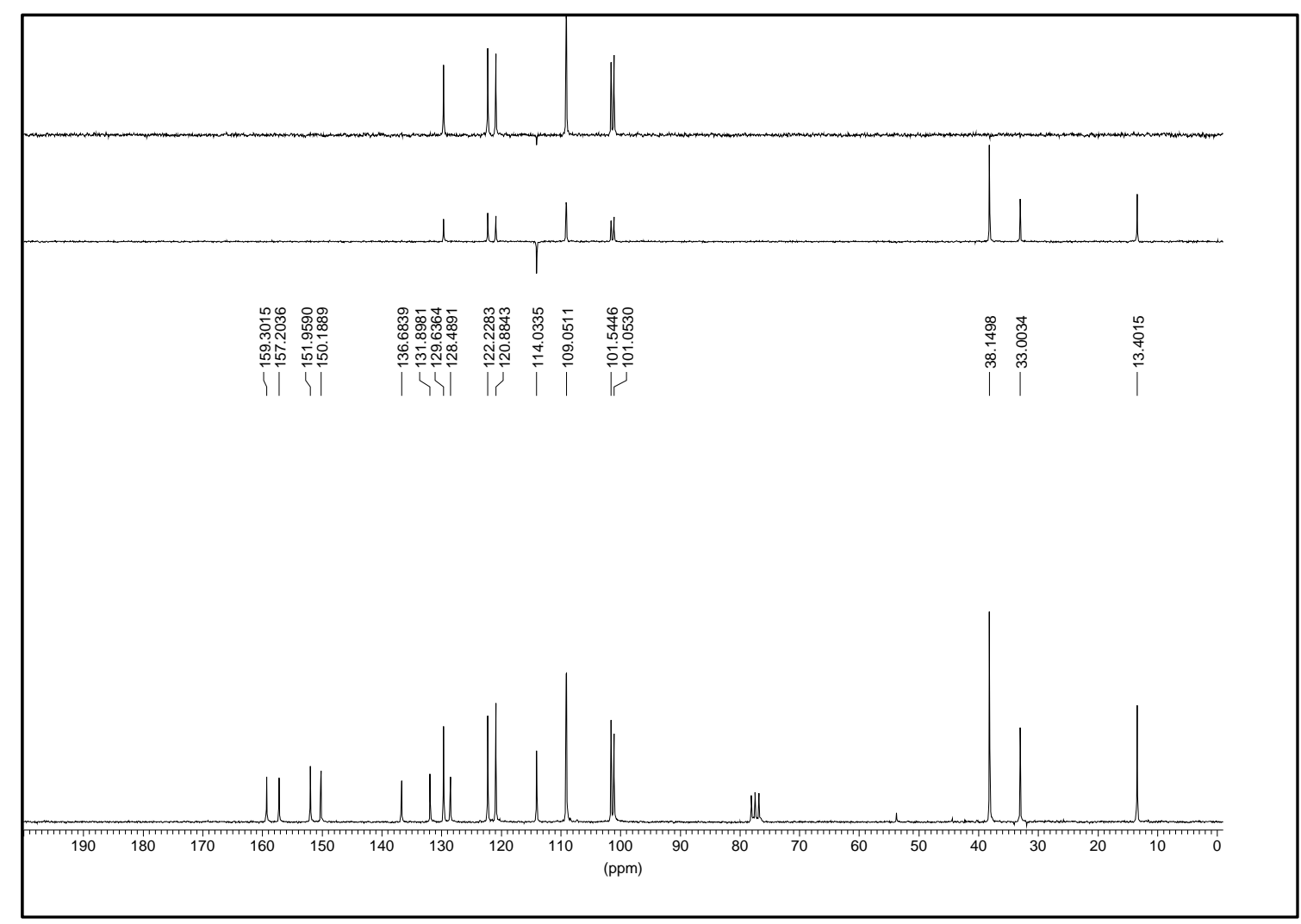

Espectro 105C 


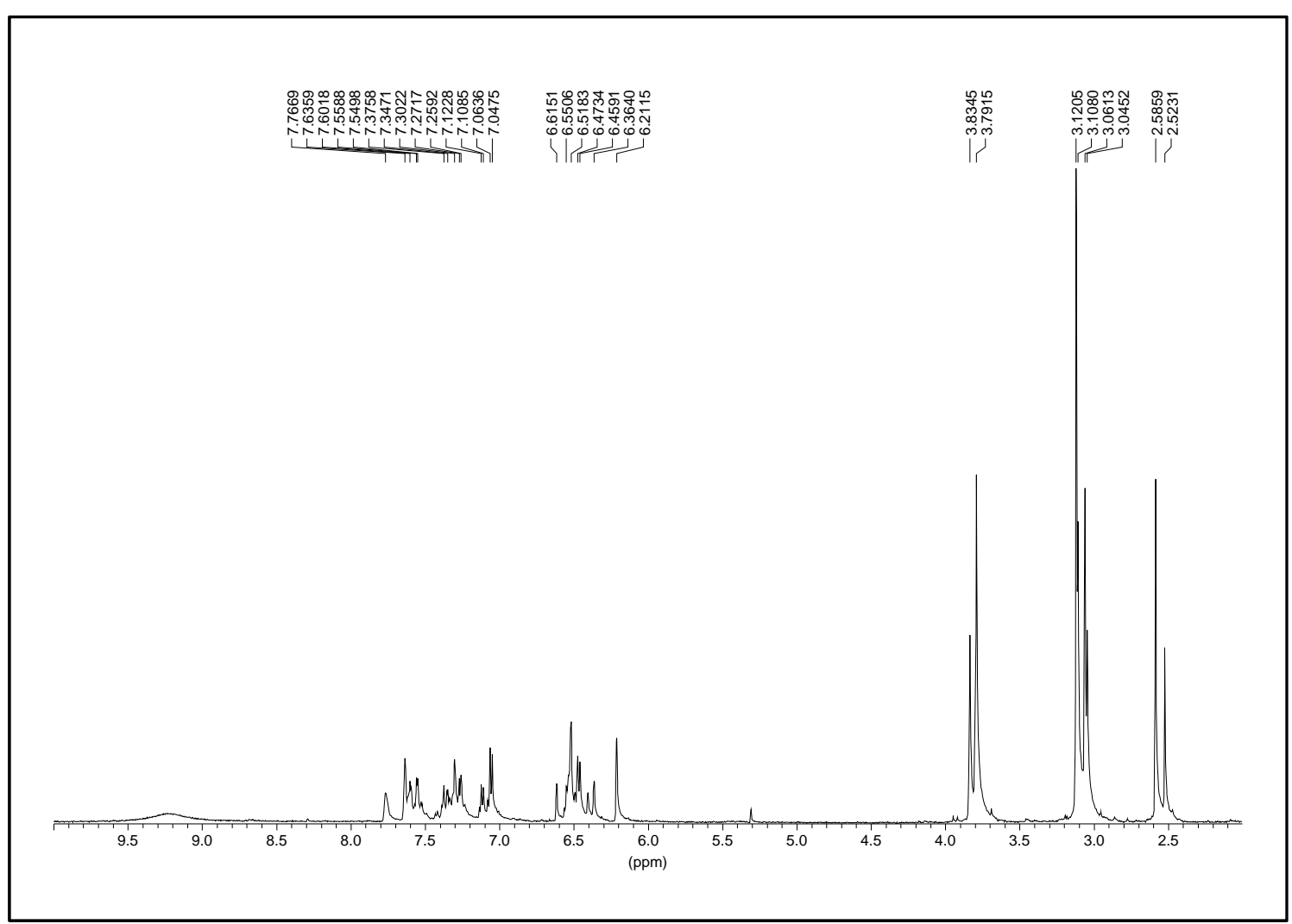

\section{Espectro 106ZEH}

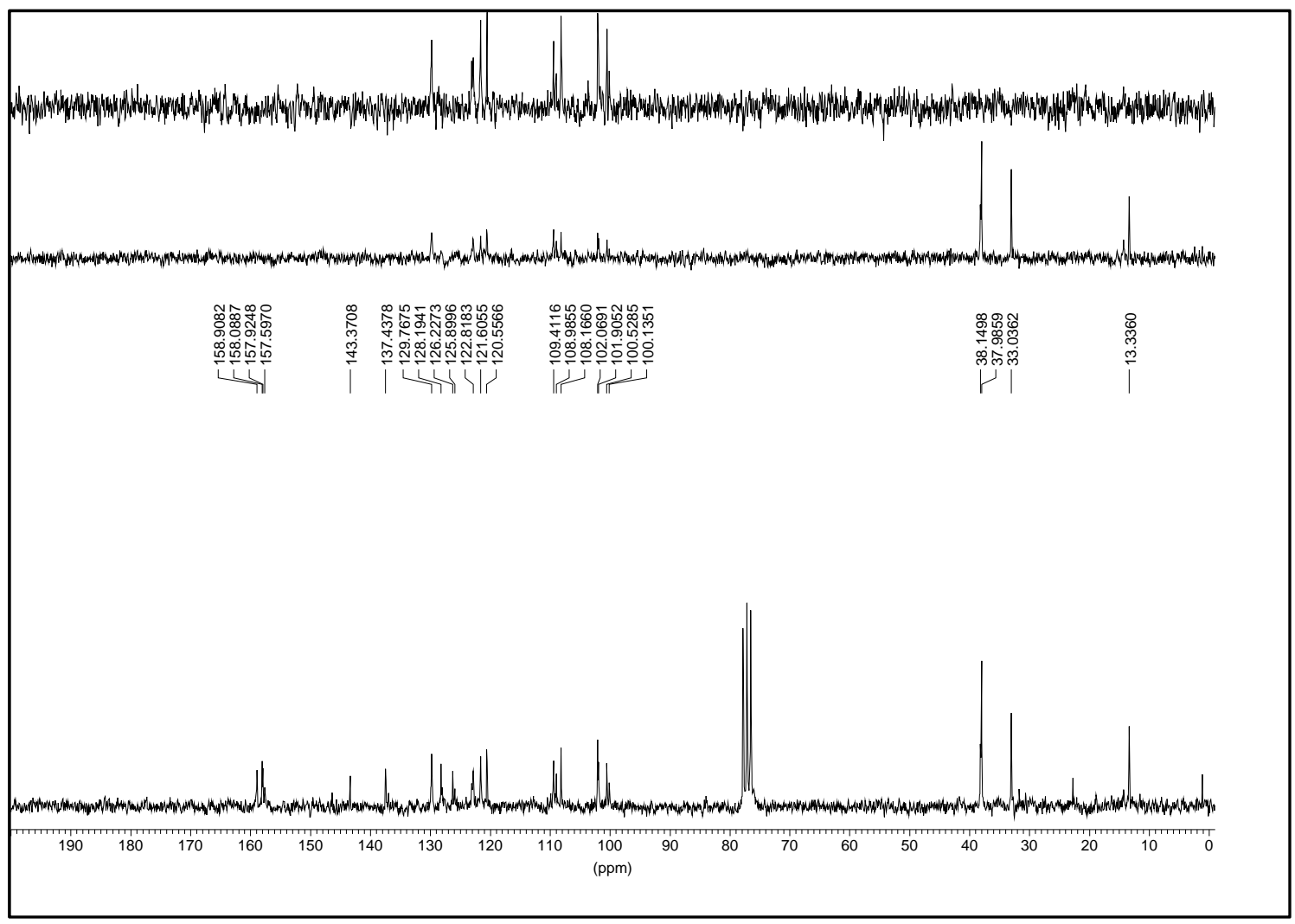

Espectro 106ZEC 


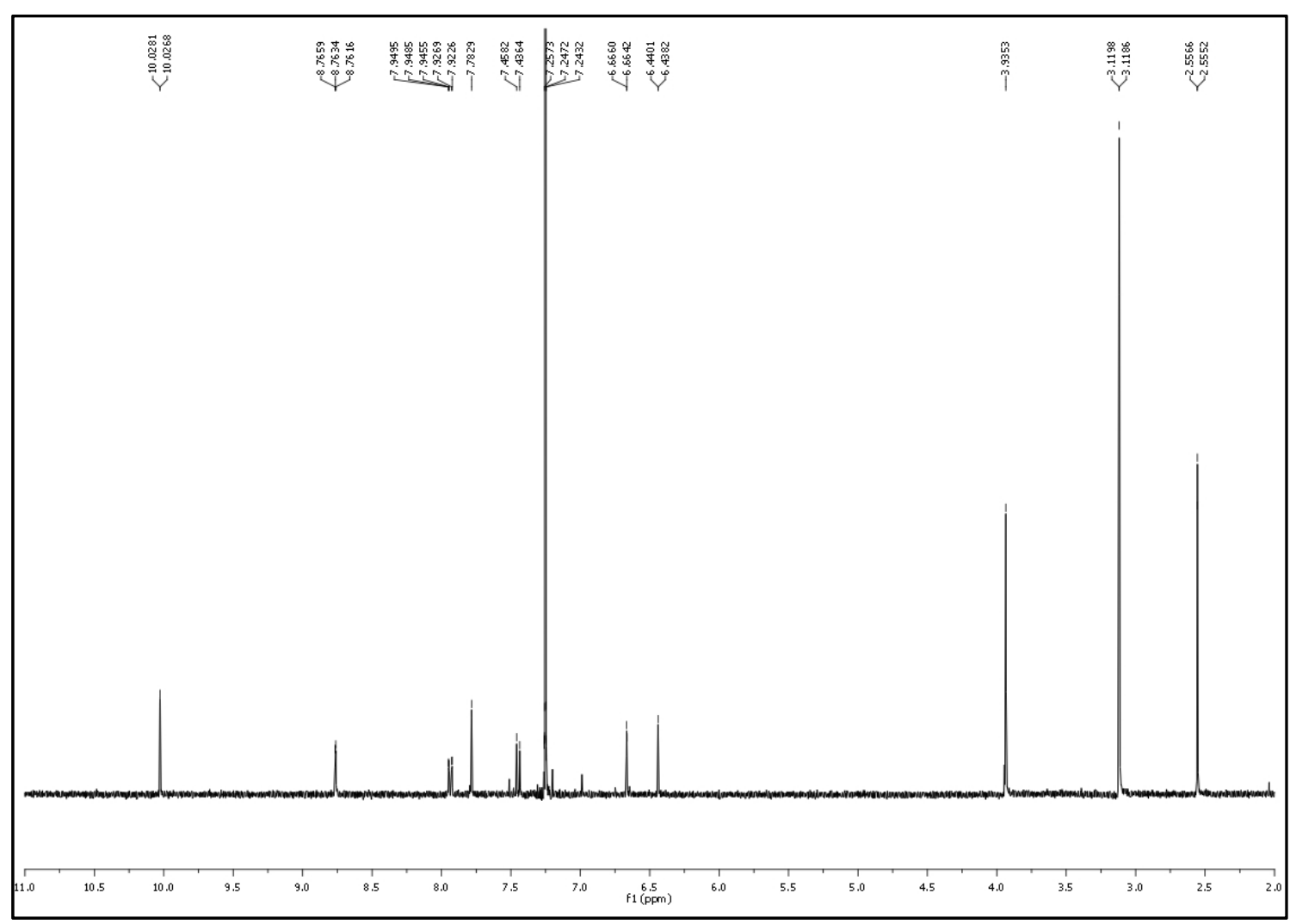

Espectro 107H

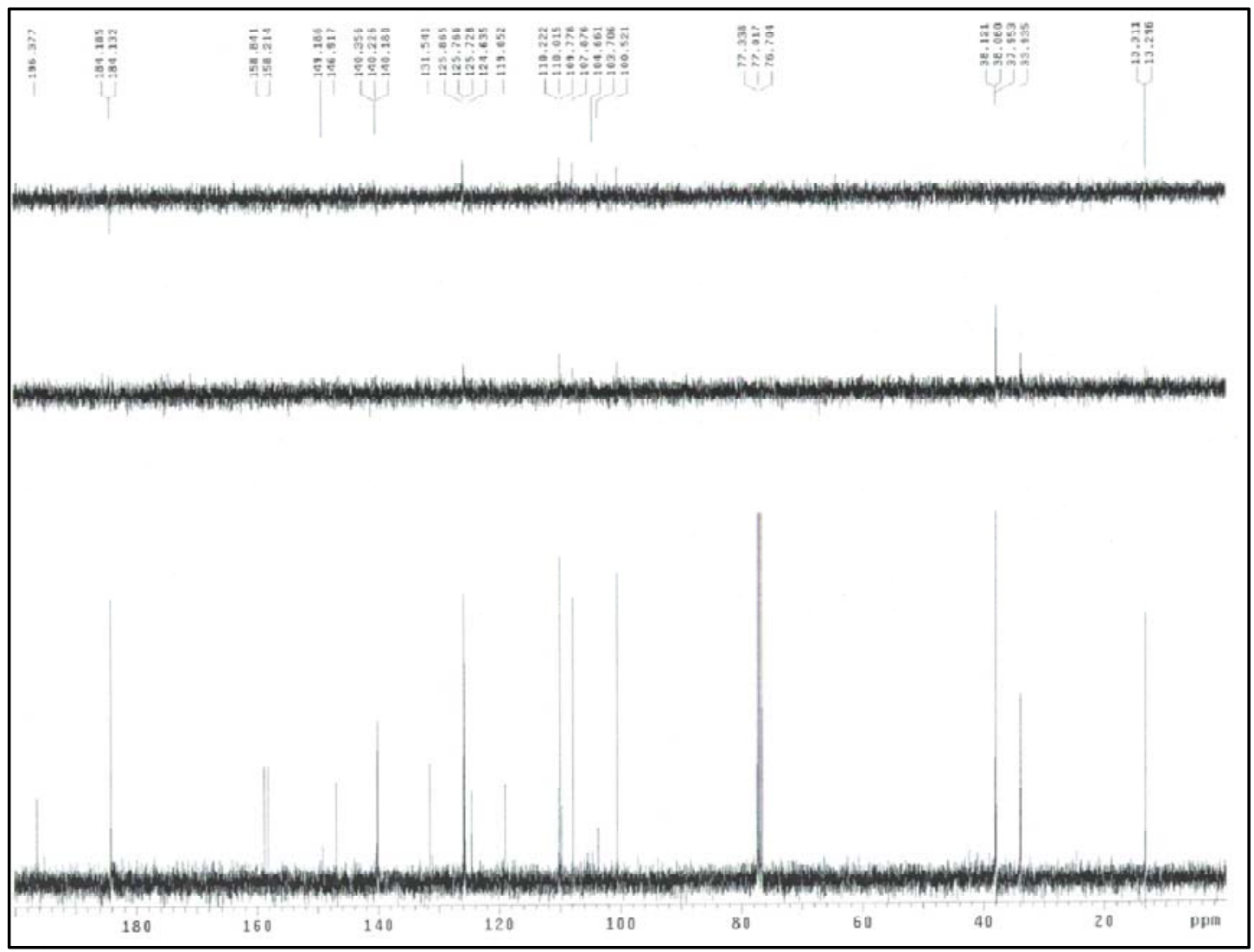

Espectro 107C 


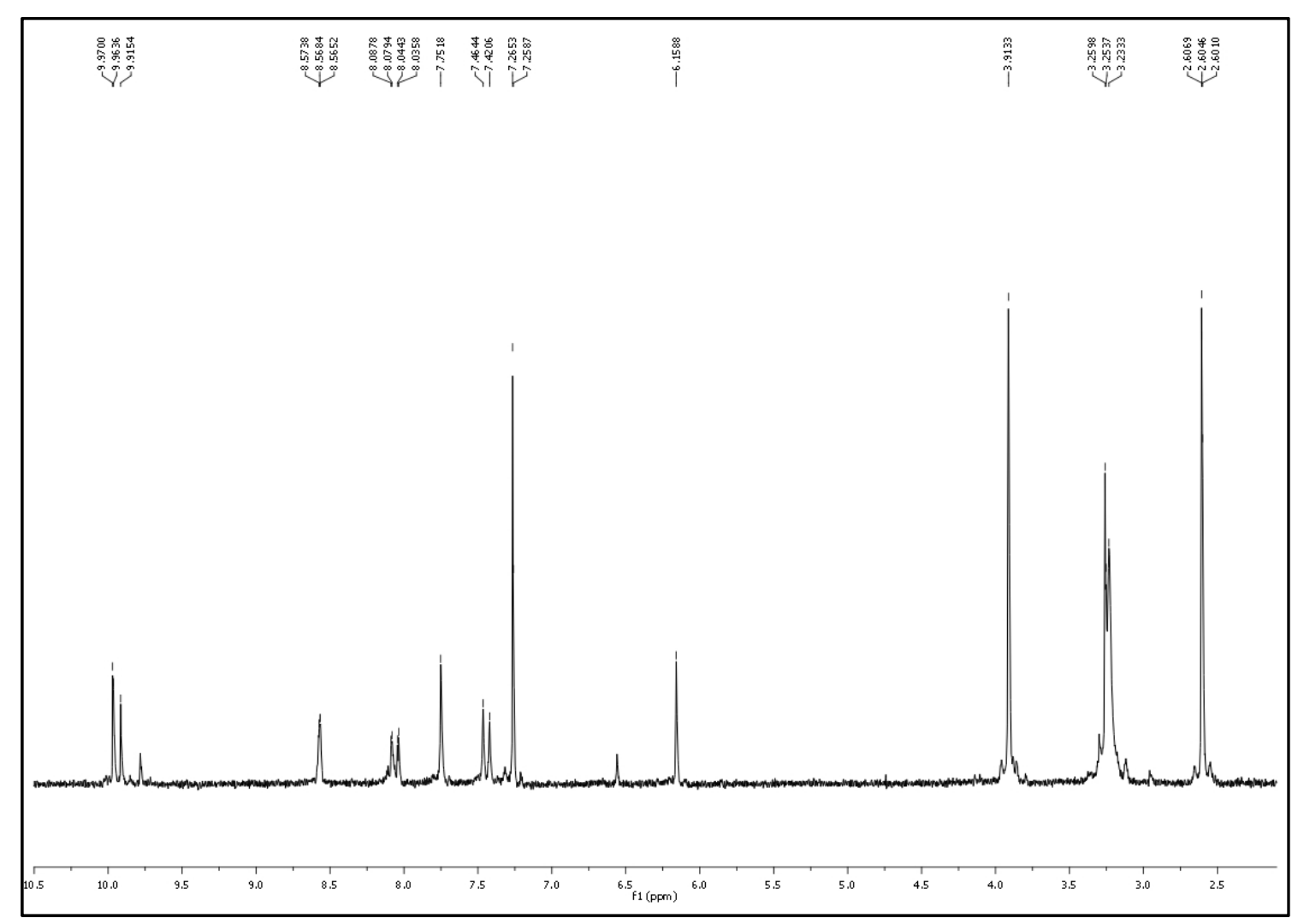

Espectro $108 \mathrm{H}$ 


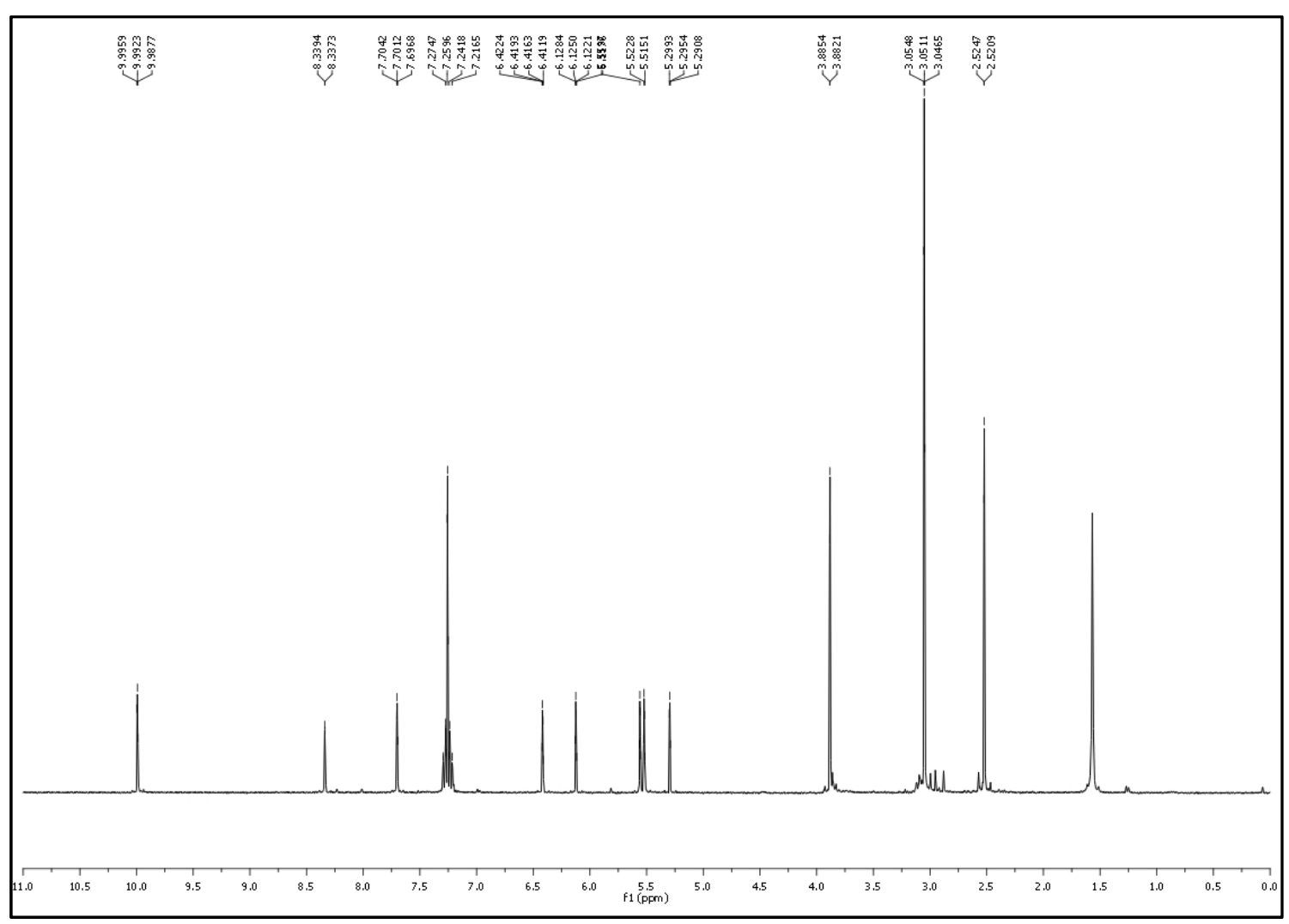

Espectro109H

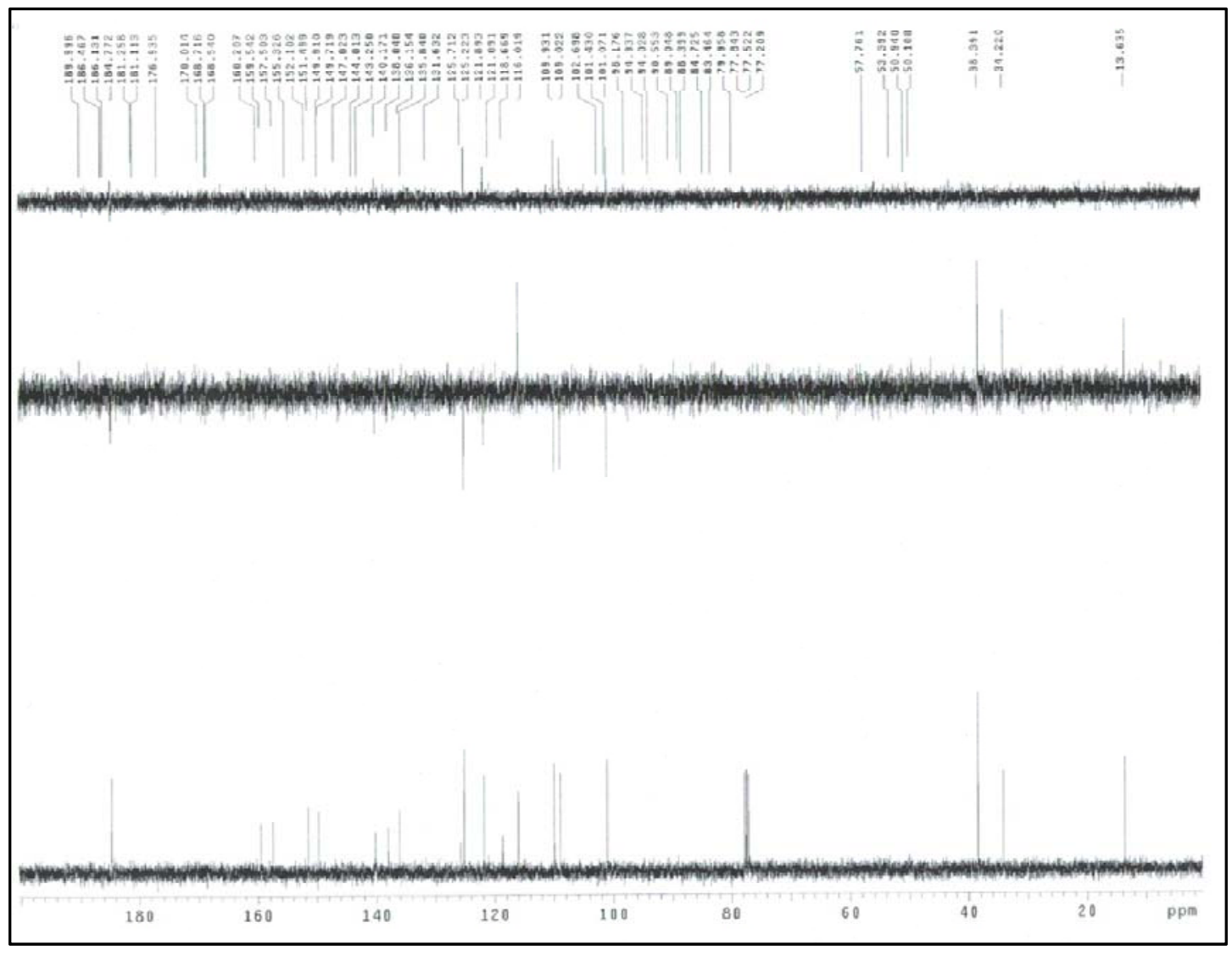

Espectro109C 


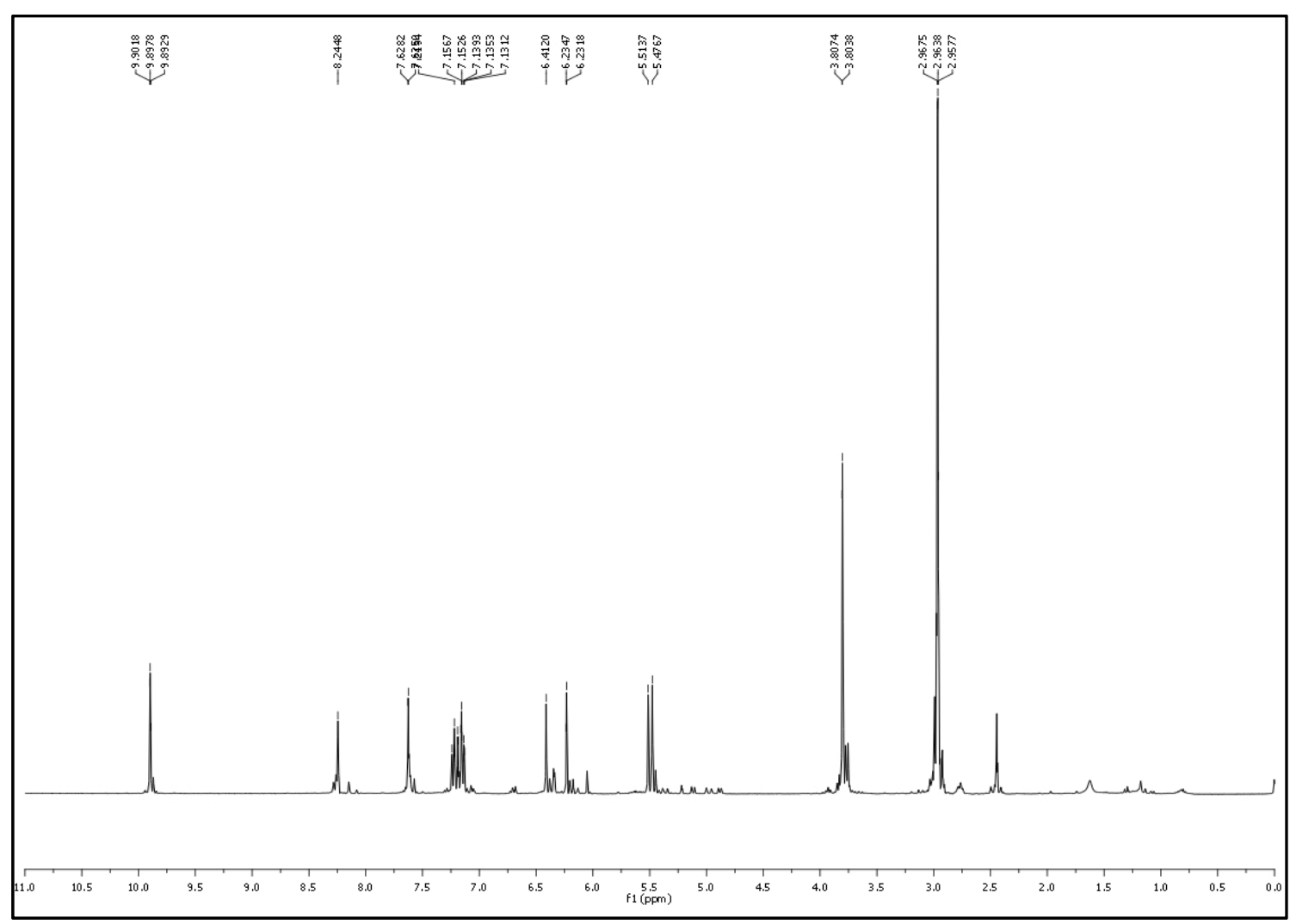

Espectro $110 \mathrm{H}$

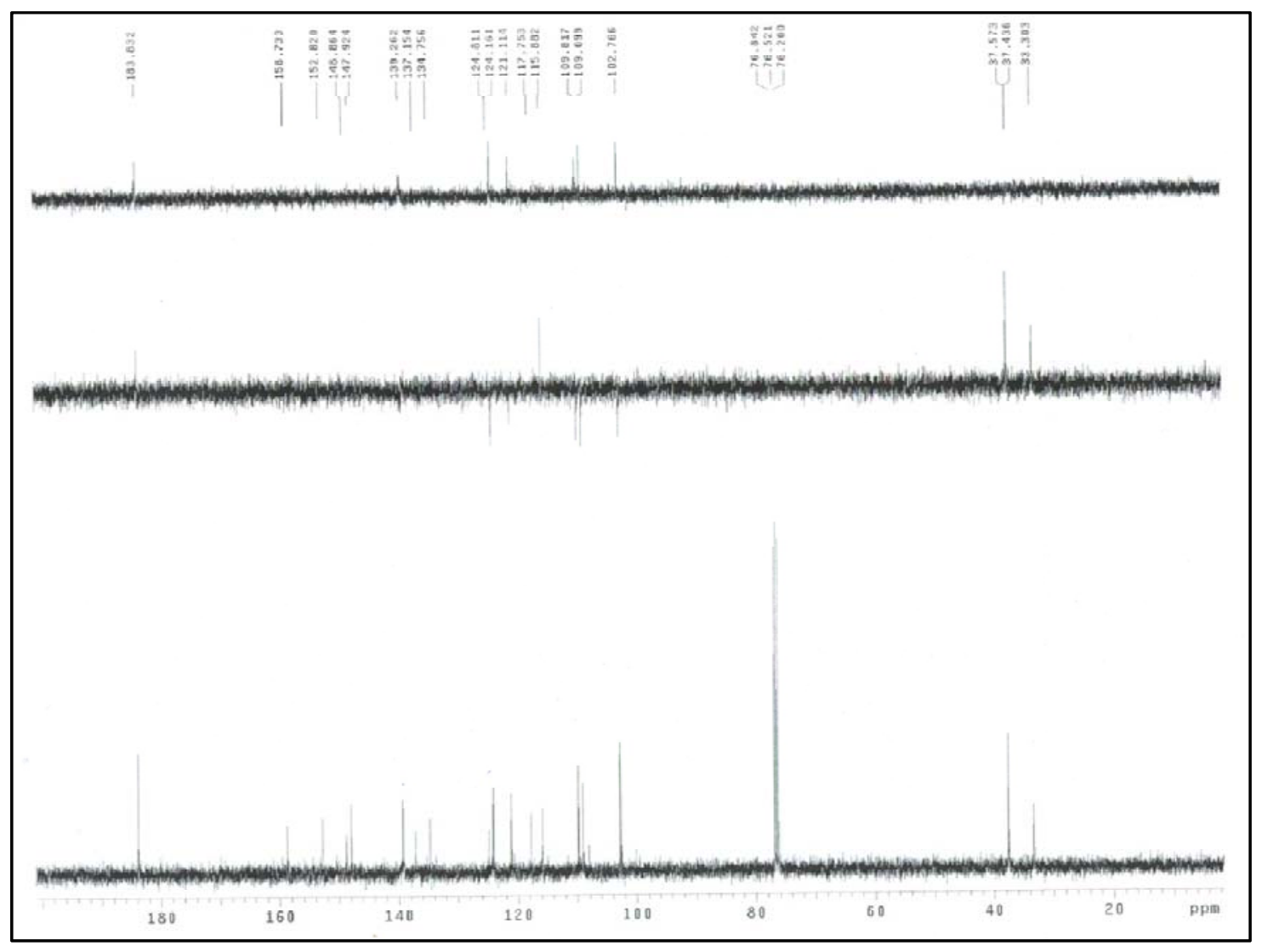

Espectro 110C 


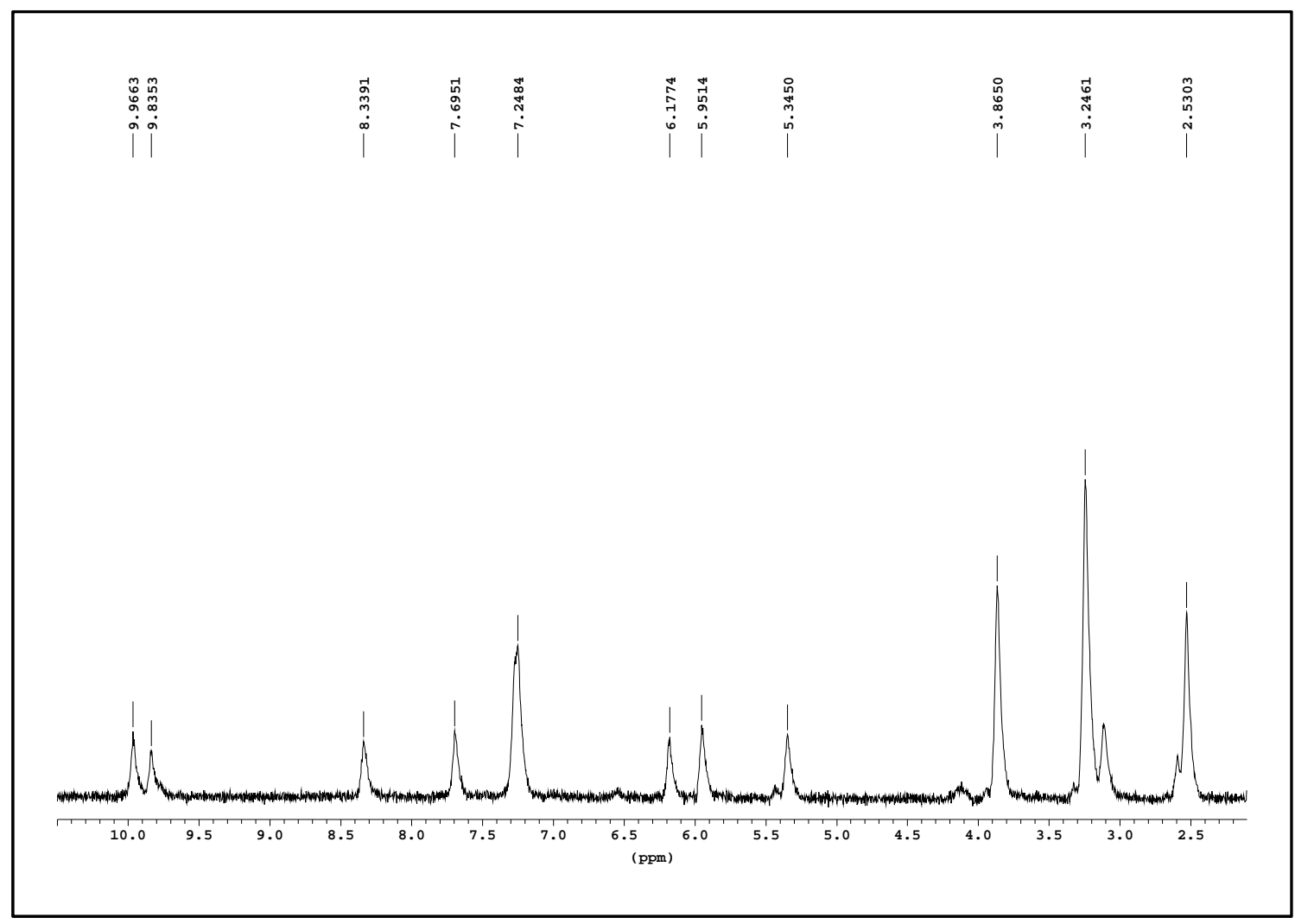

Espectro $111 \mathrm{H}$

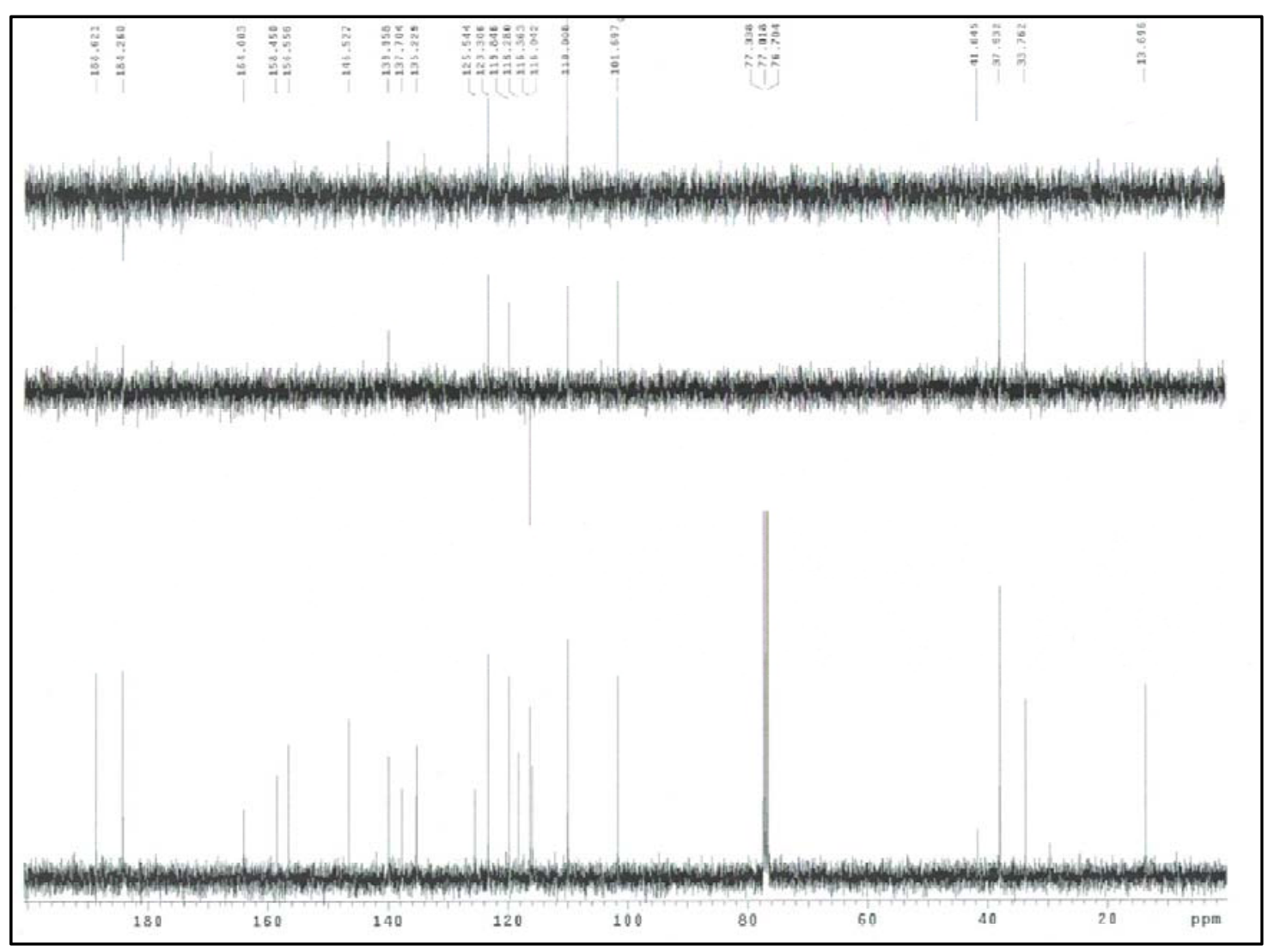

Espectro 111C 


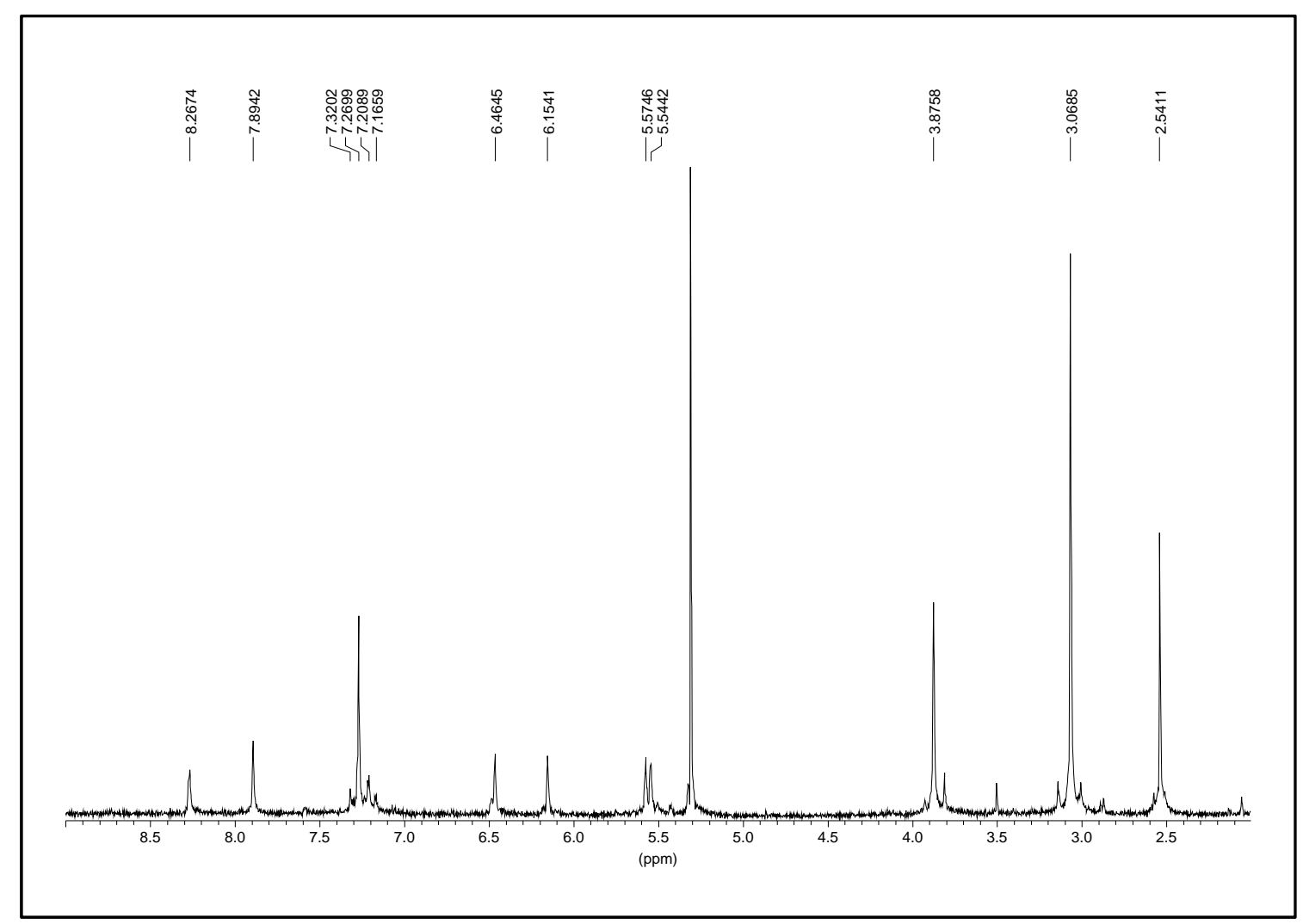

Espectro $112 \mathrm{H}$ 


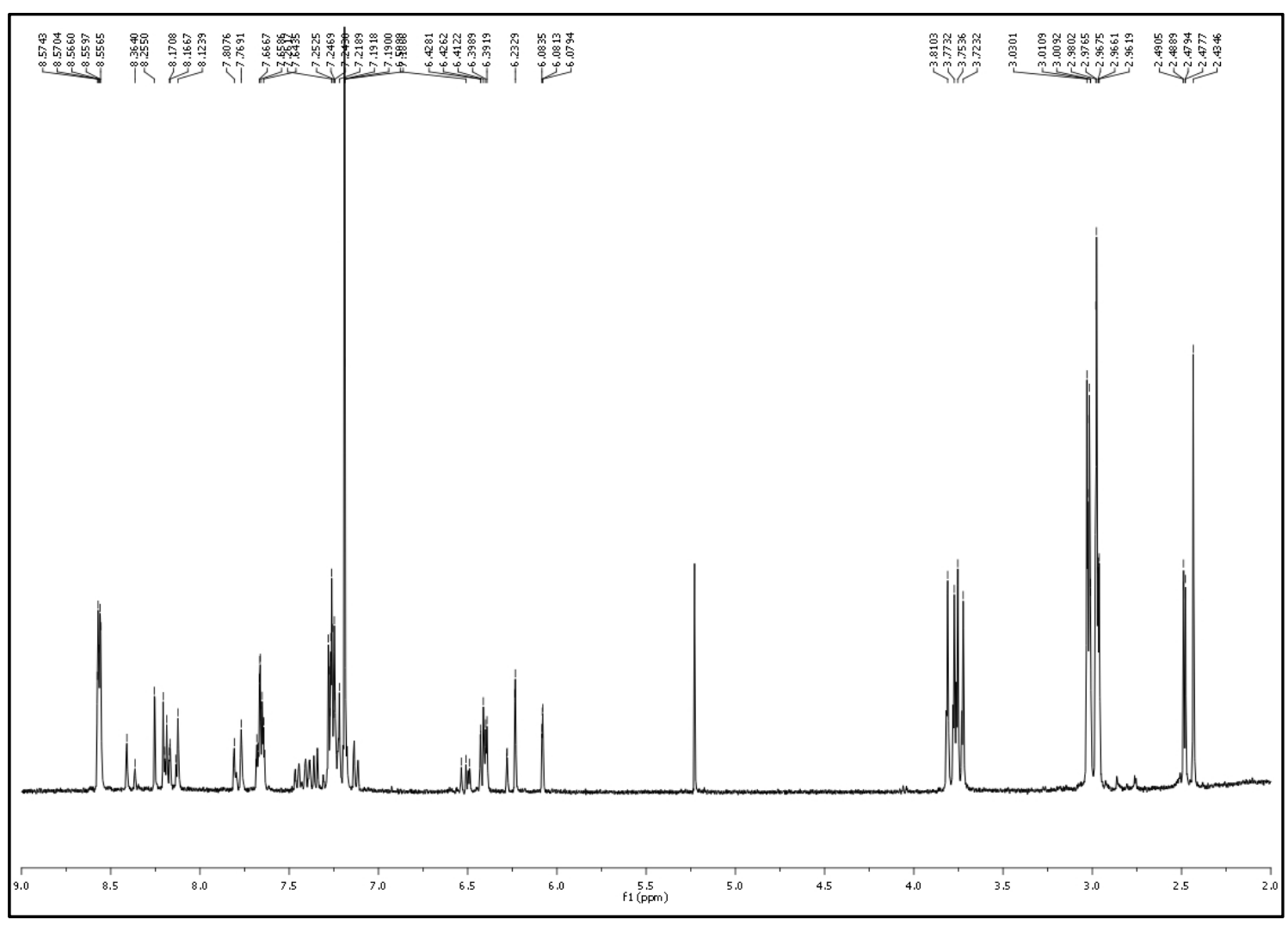

Espectro 113H 


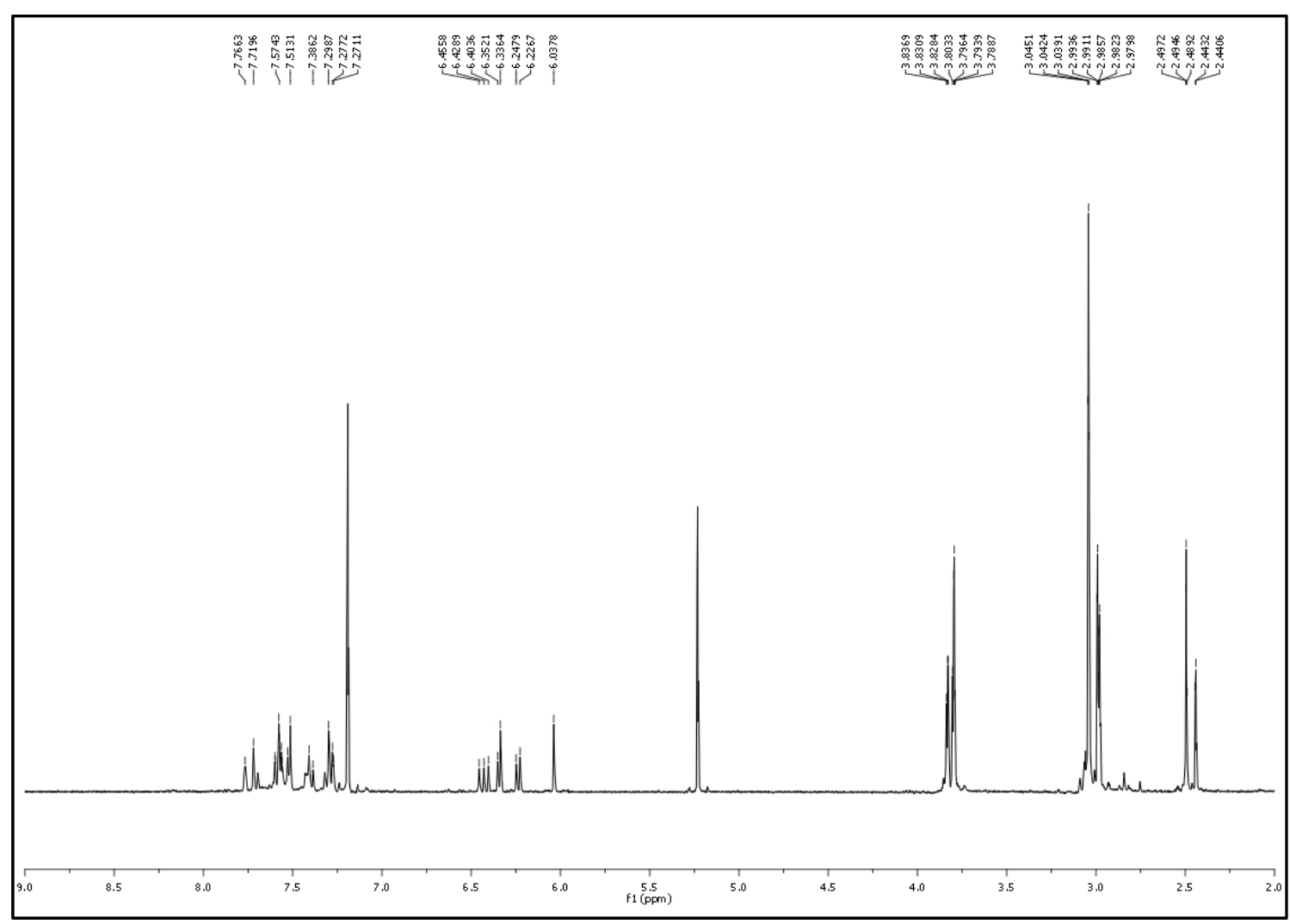

Espectro 115ZEH

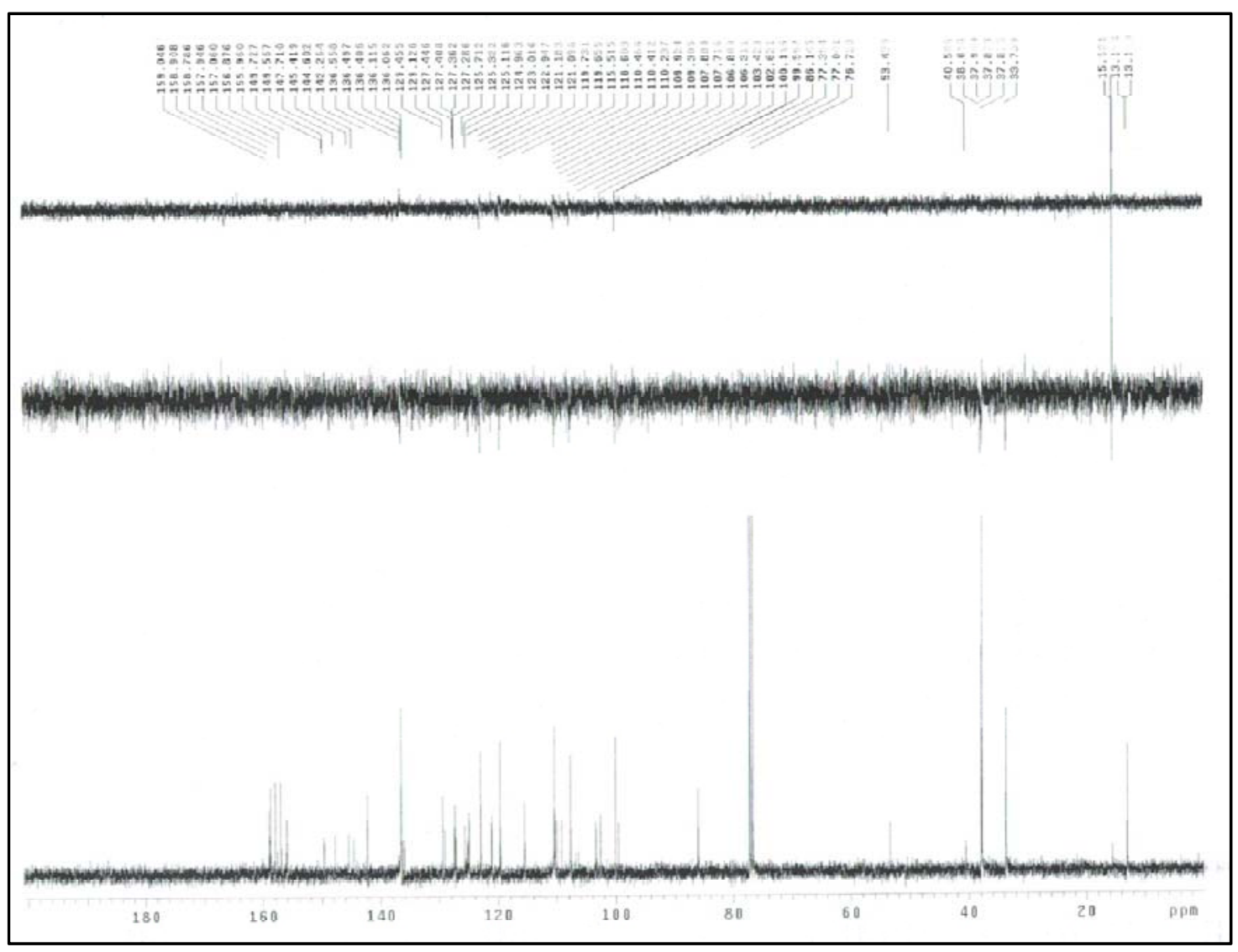

Espectro 115ZEC 


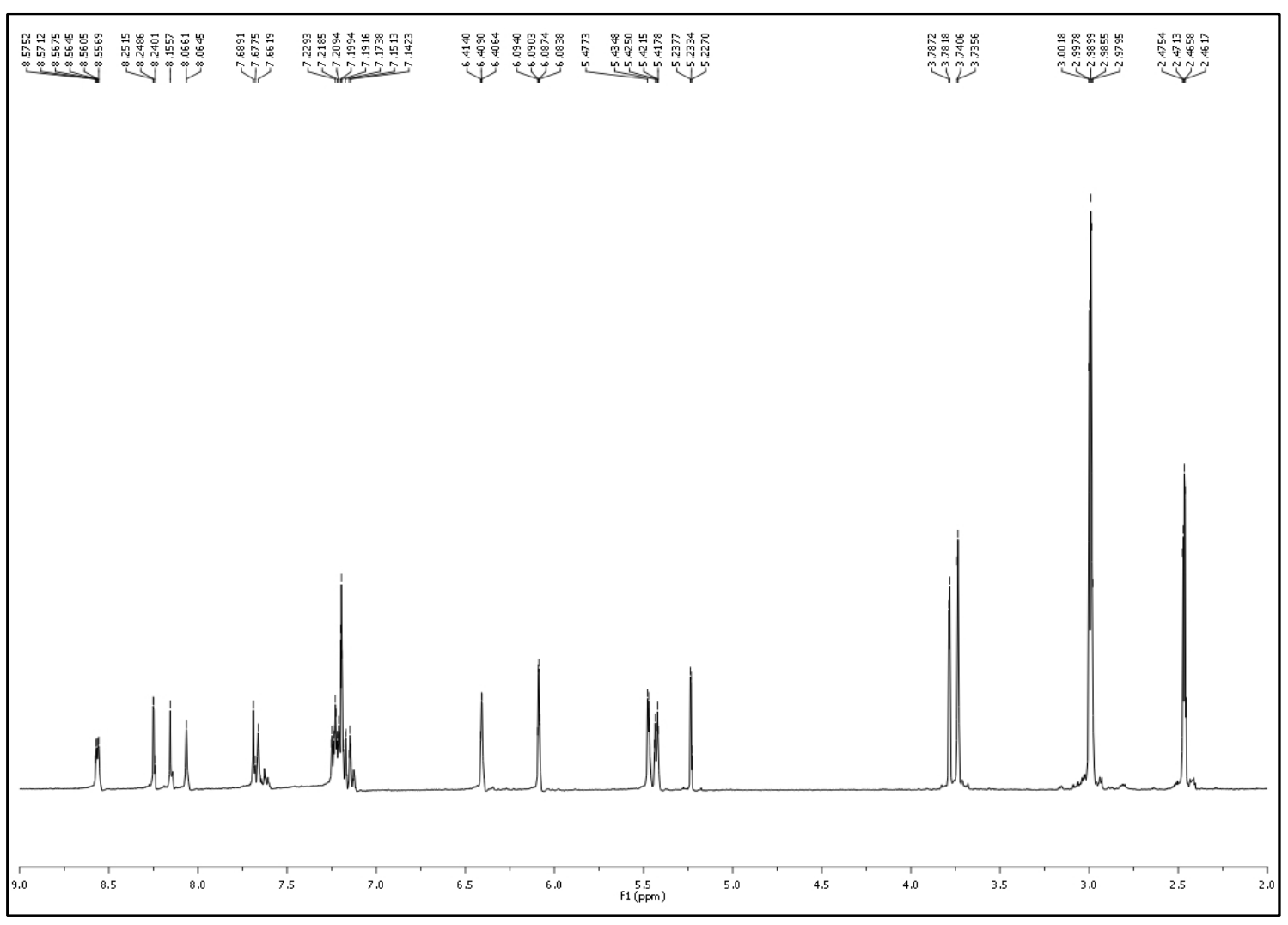

Espectro 116H 


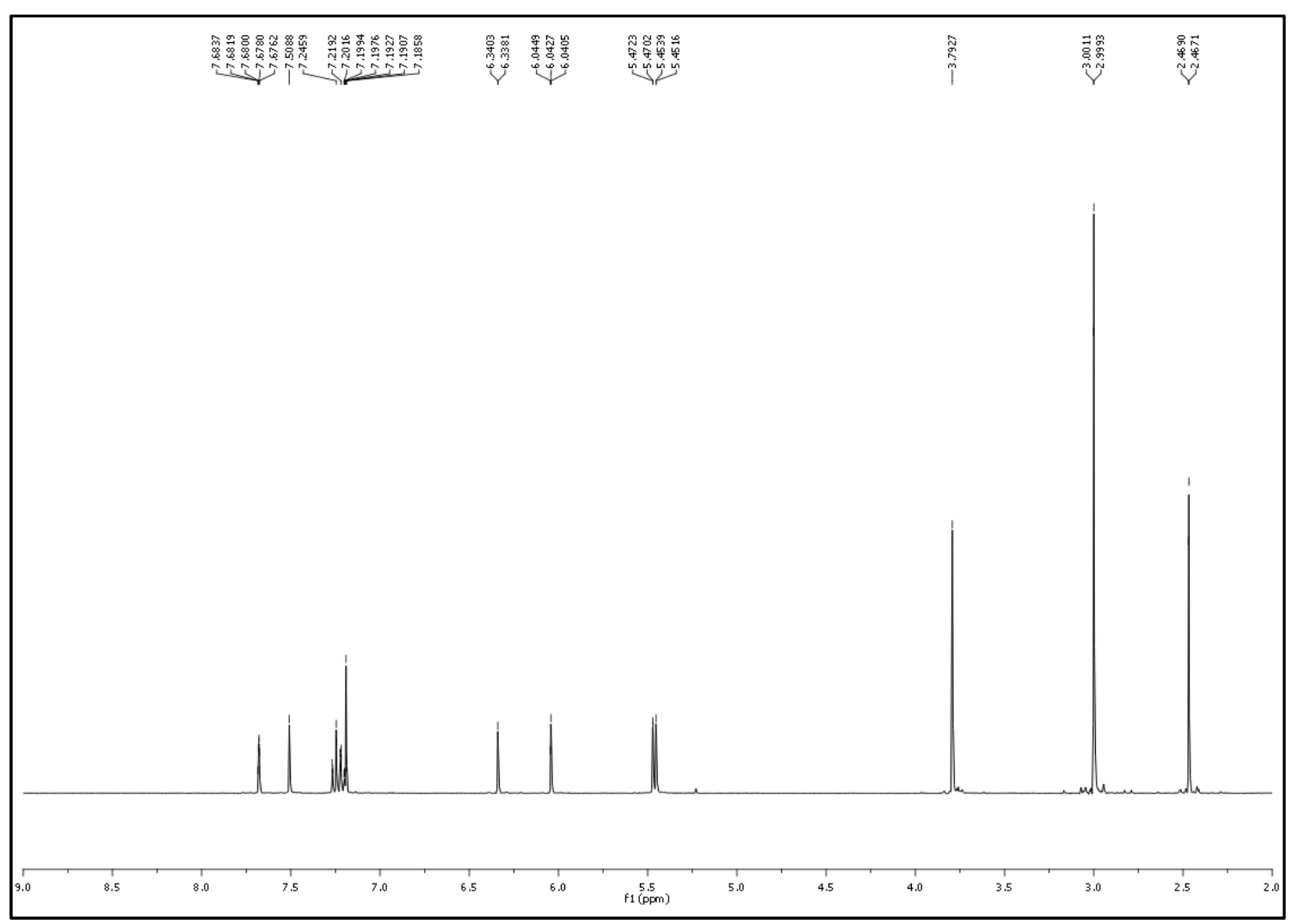

Espectro 117H

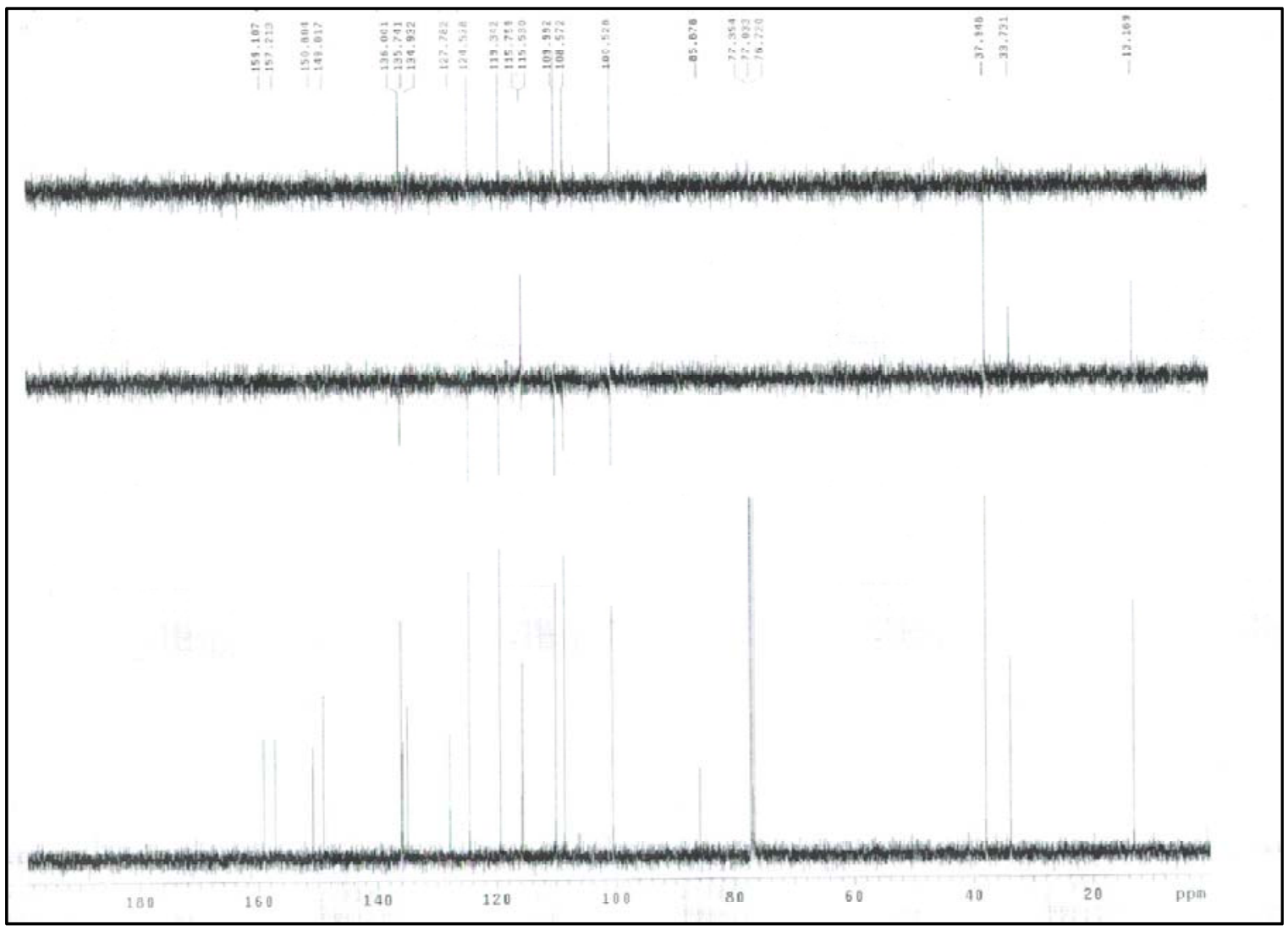

Espectro 117C 


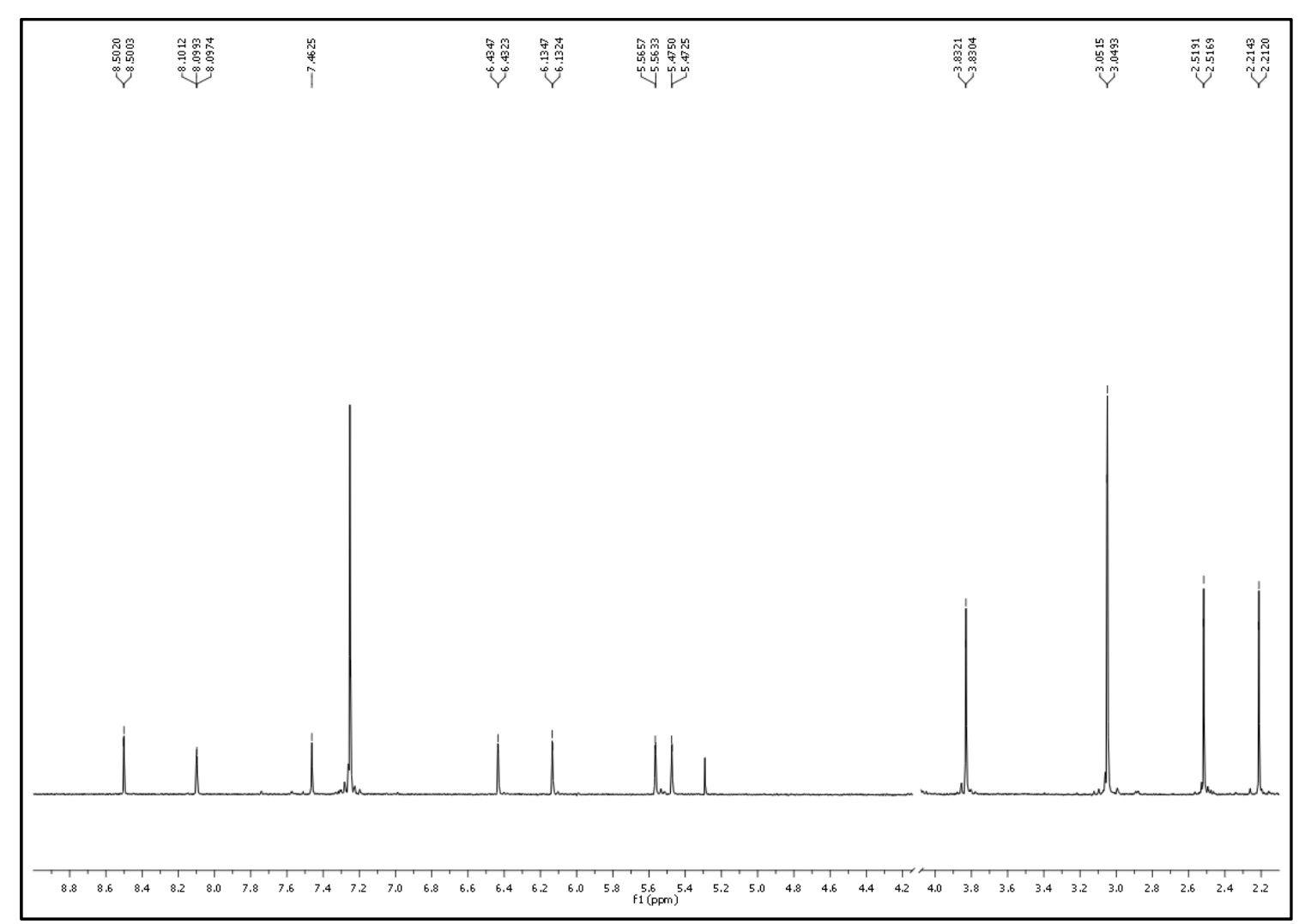

Espectro $118 \mathrm{H}$ 


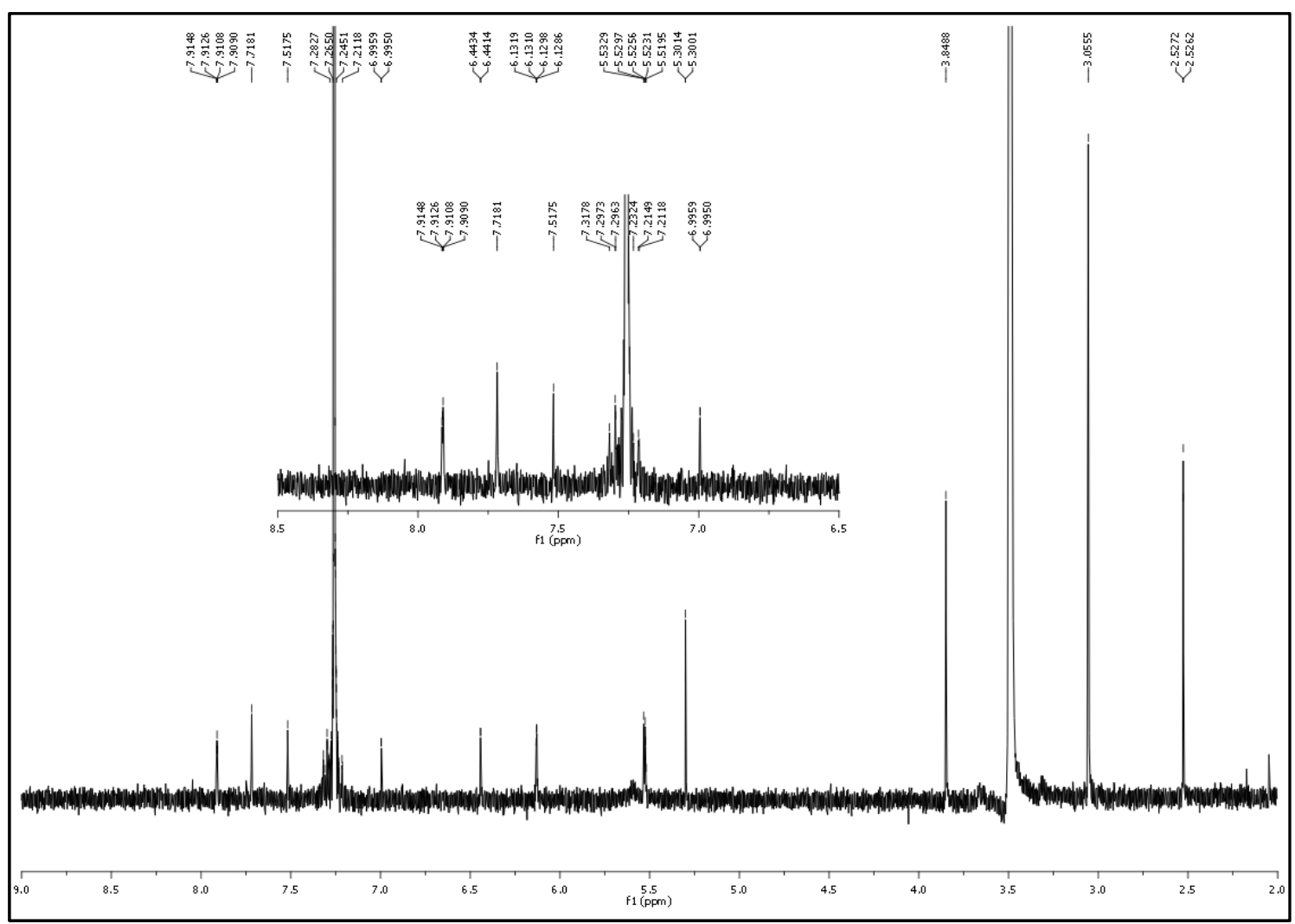

Espectro 119H

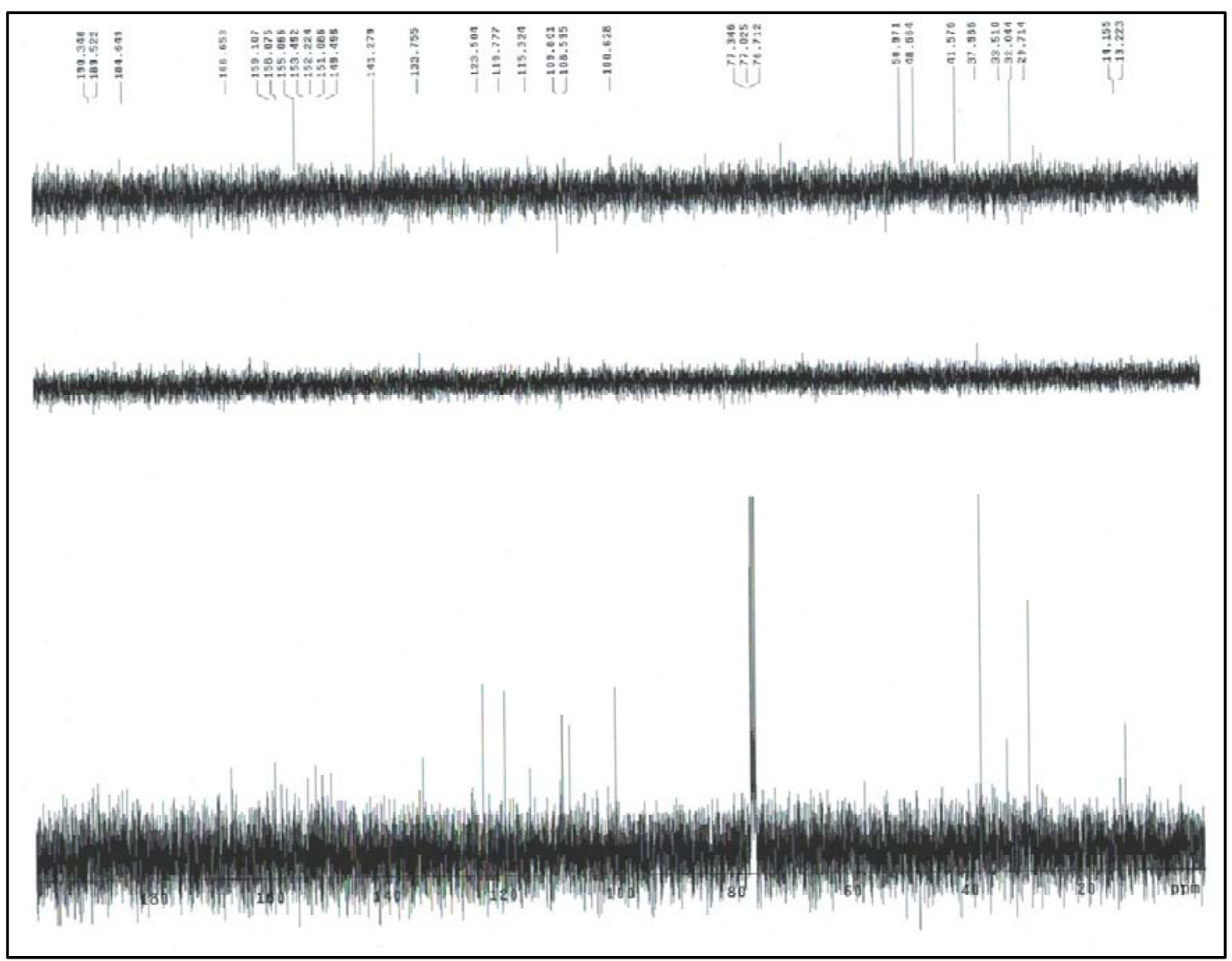

Espectro 119C 


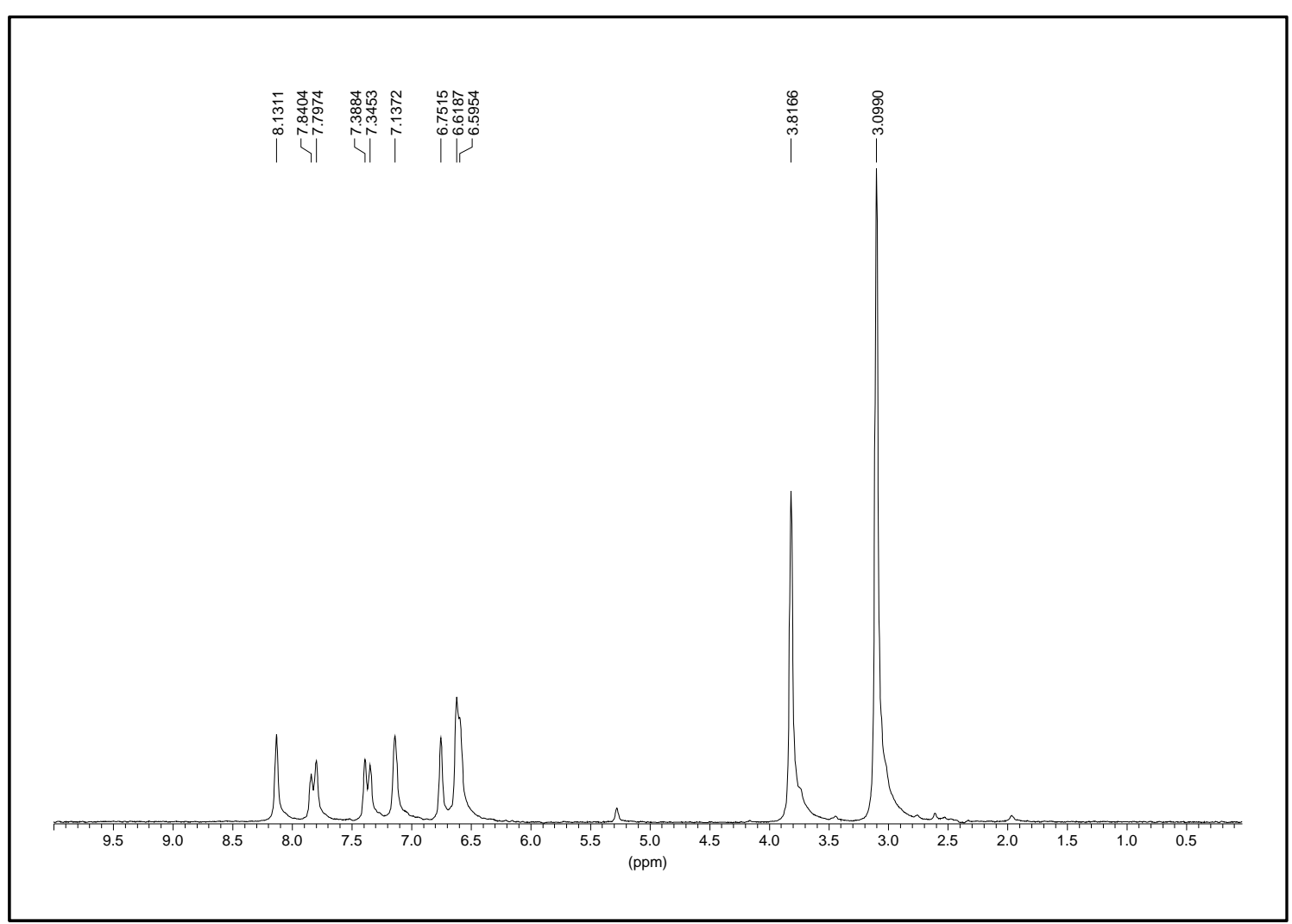

Espectro $\mathbf{1 2 0 \mathrm { H }}$

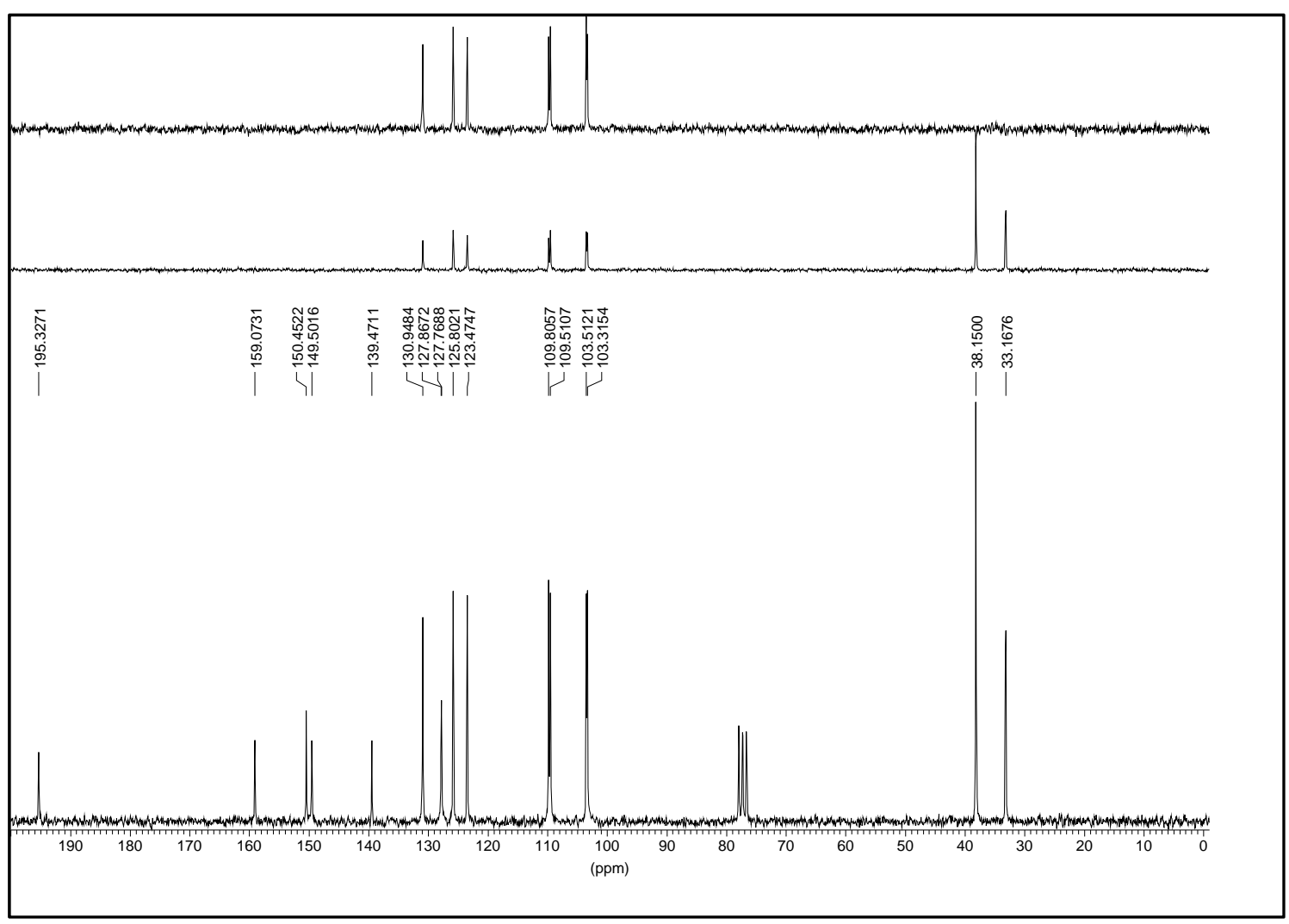

Espectro 120C 


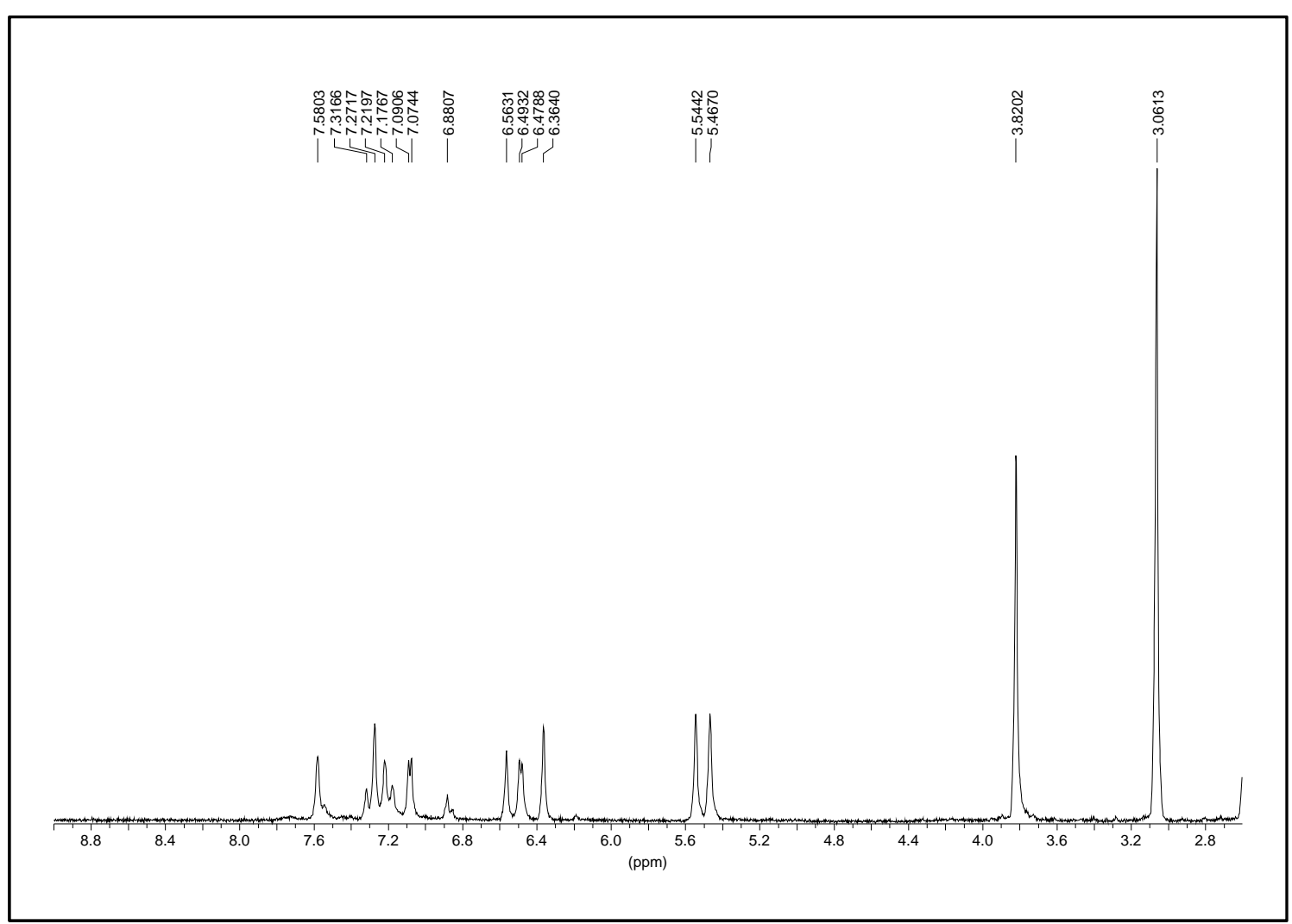

\section{Espectro $121 \mathrm{H}$}

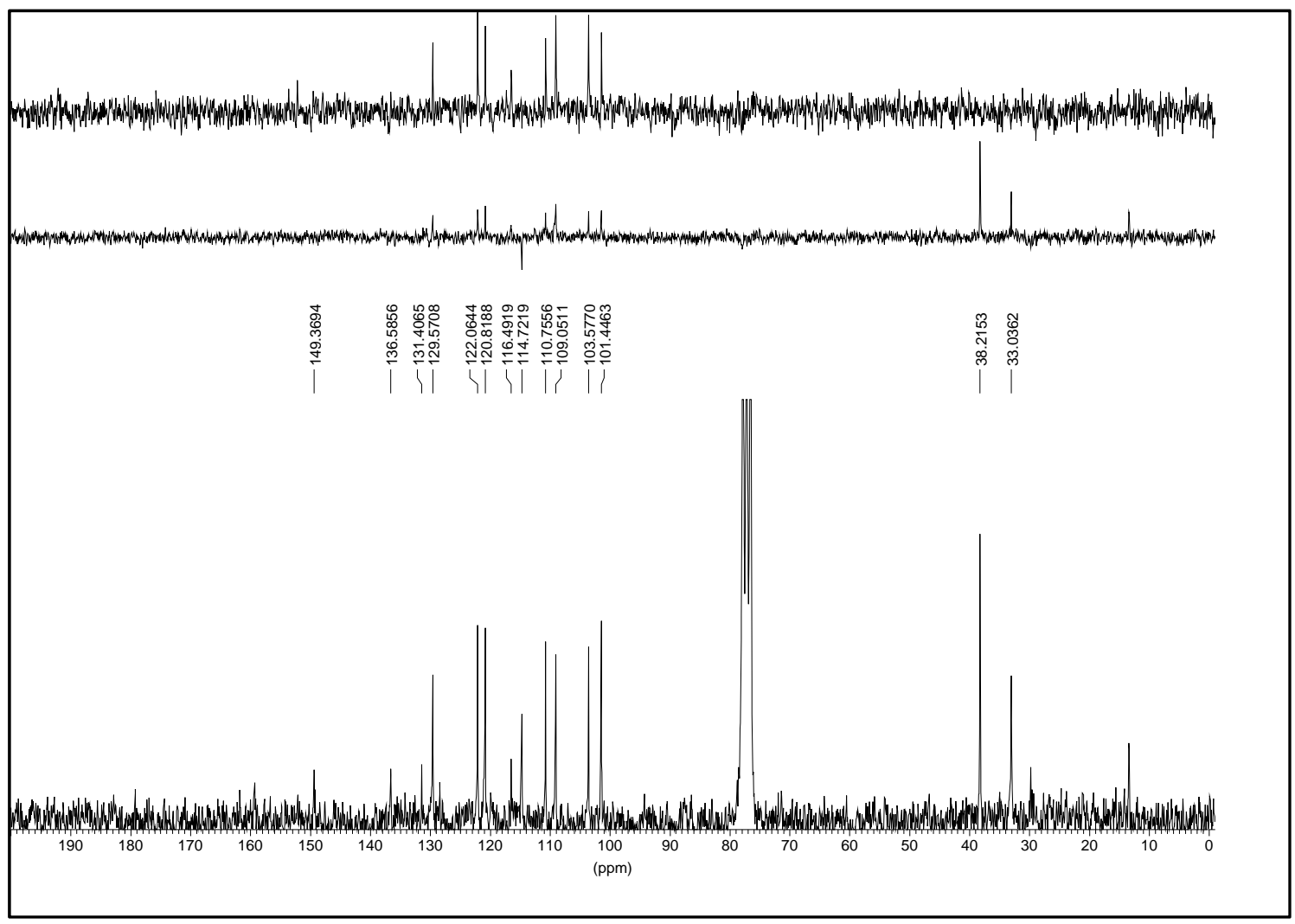

Espectro 121C 


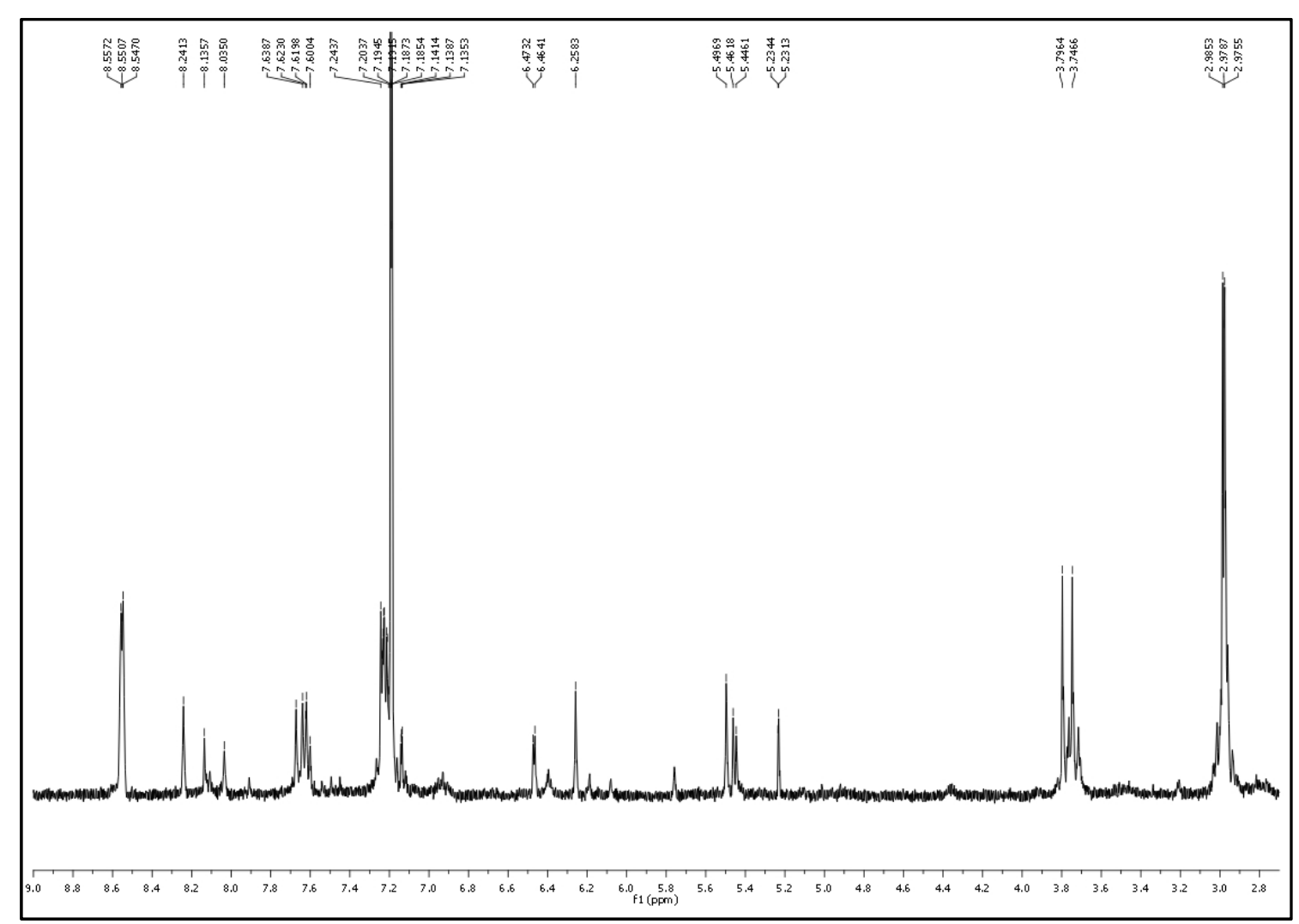

Espectro $122 \mathrm{H}$ 


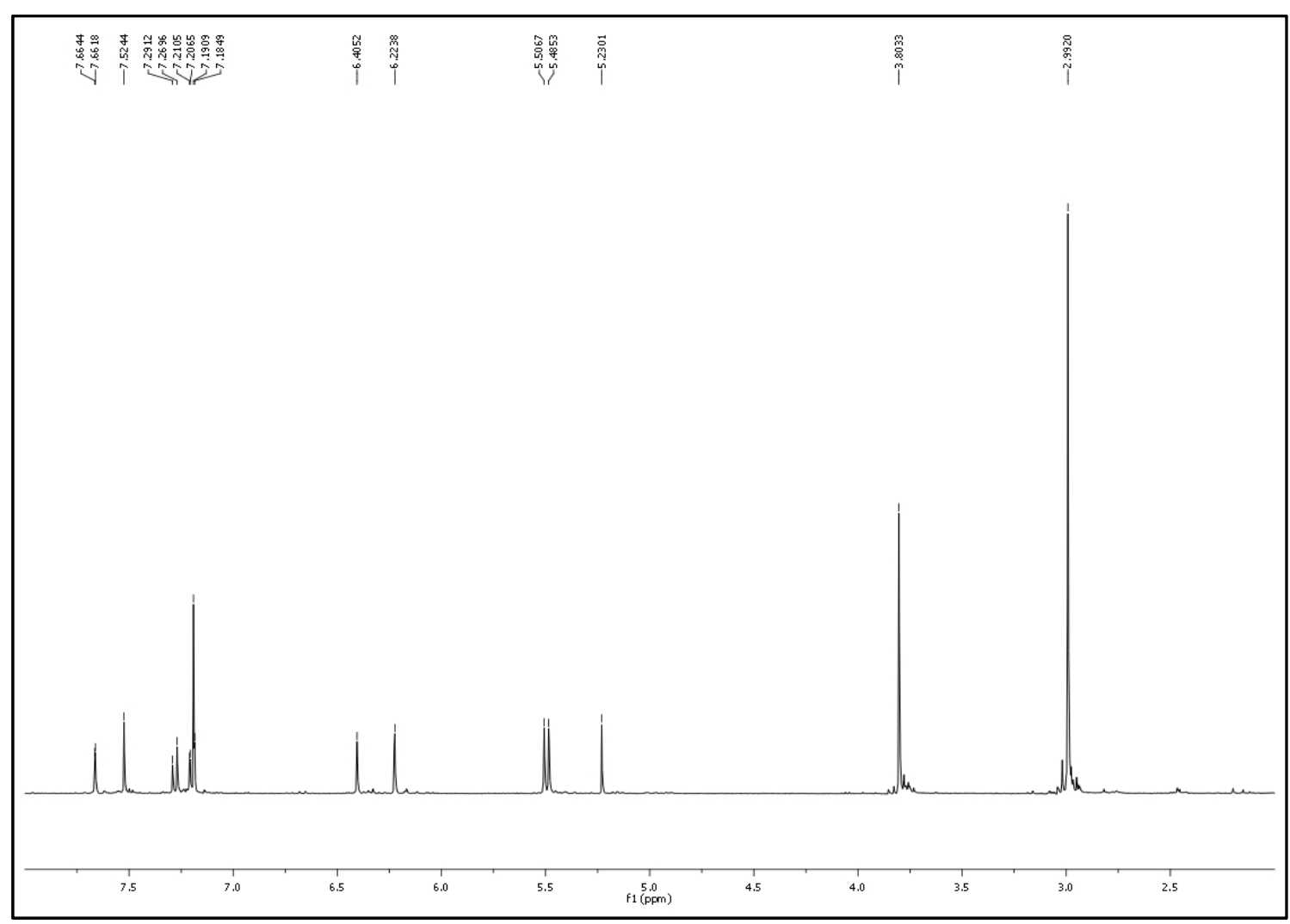

Espectro 123H

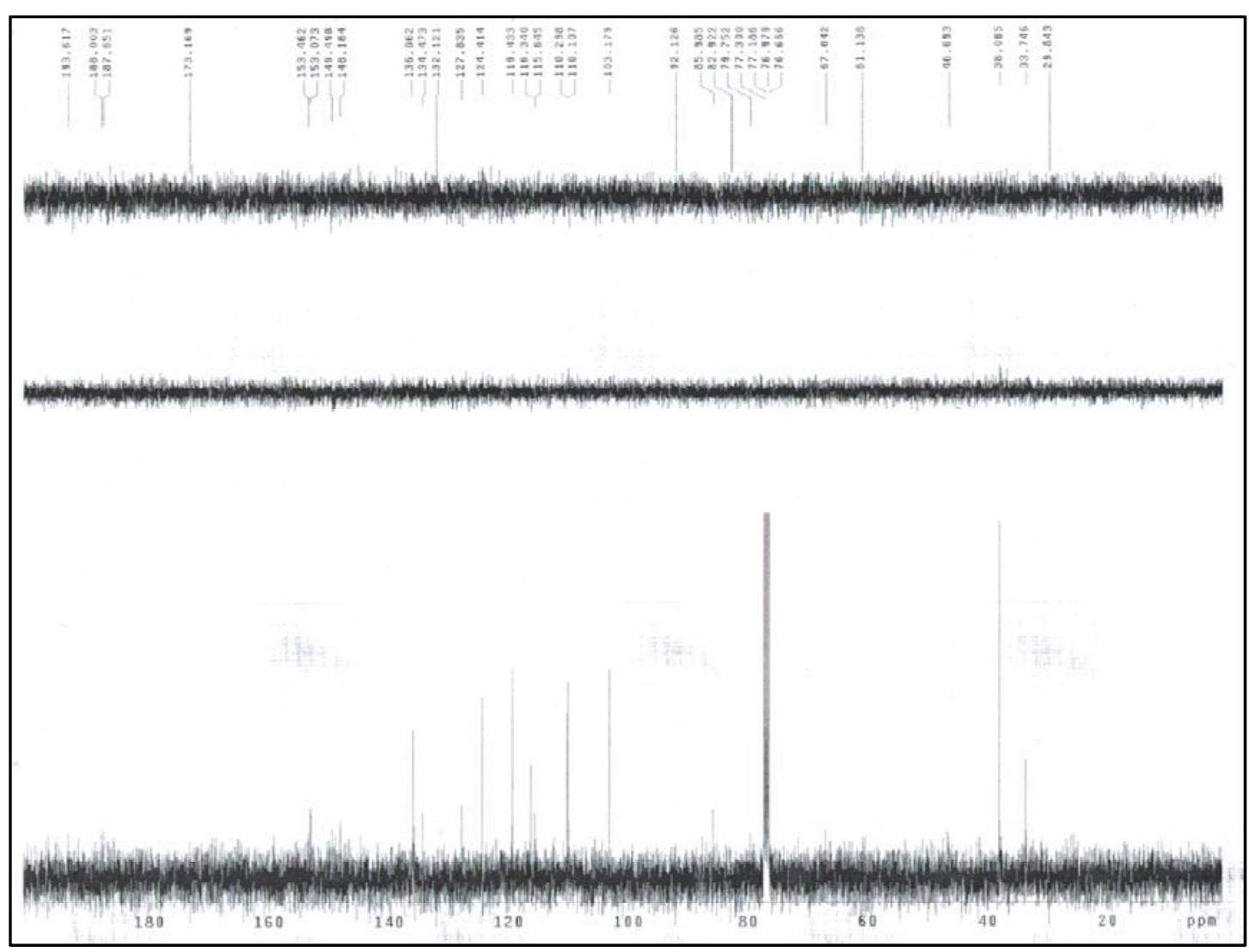

Espectro 123C 


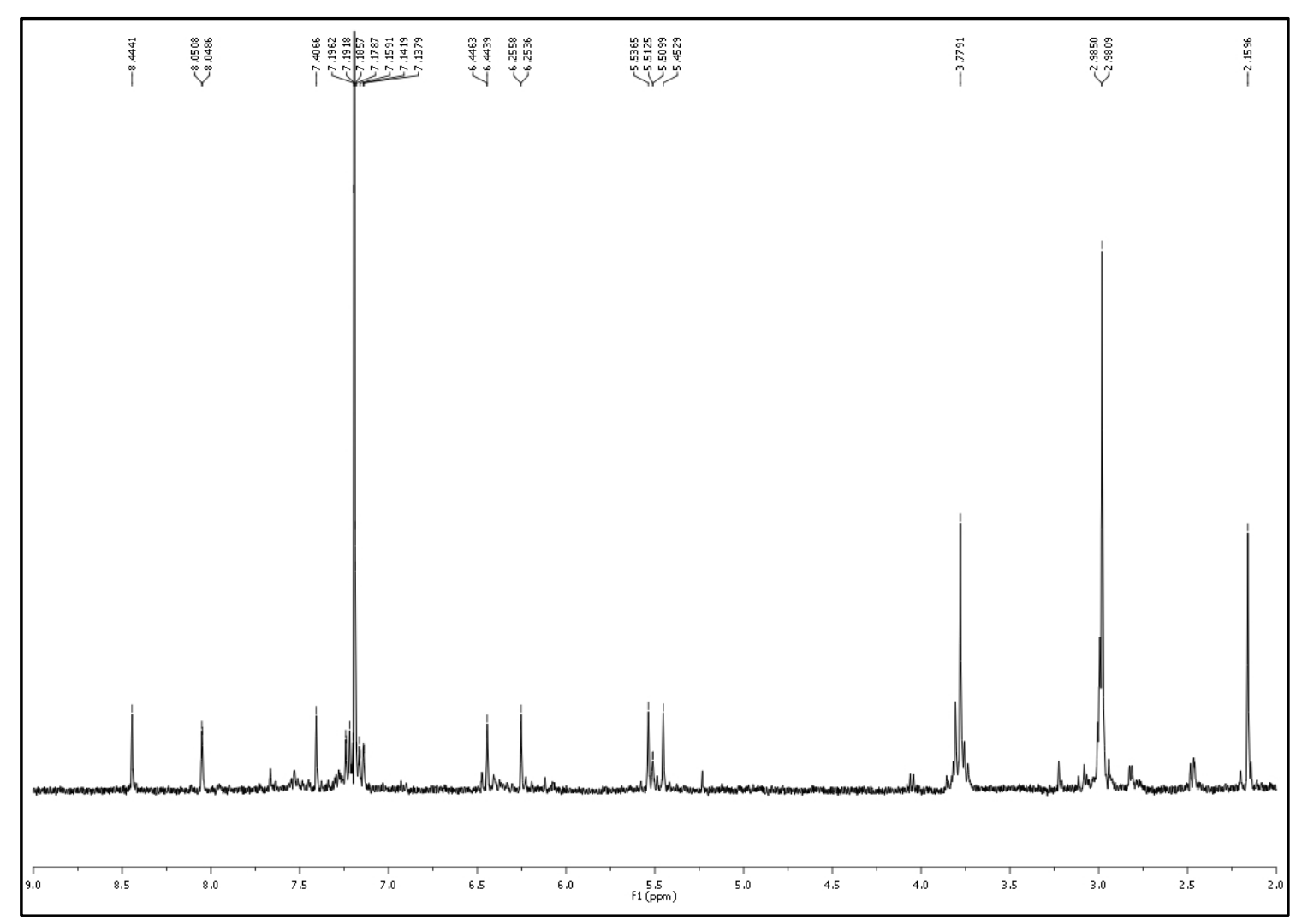

Espectro $124 \mathrm{H}$ 


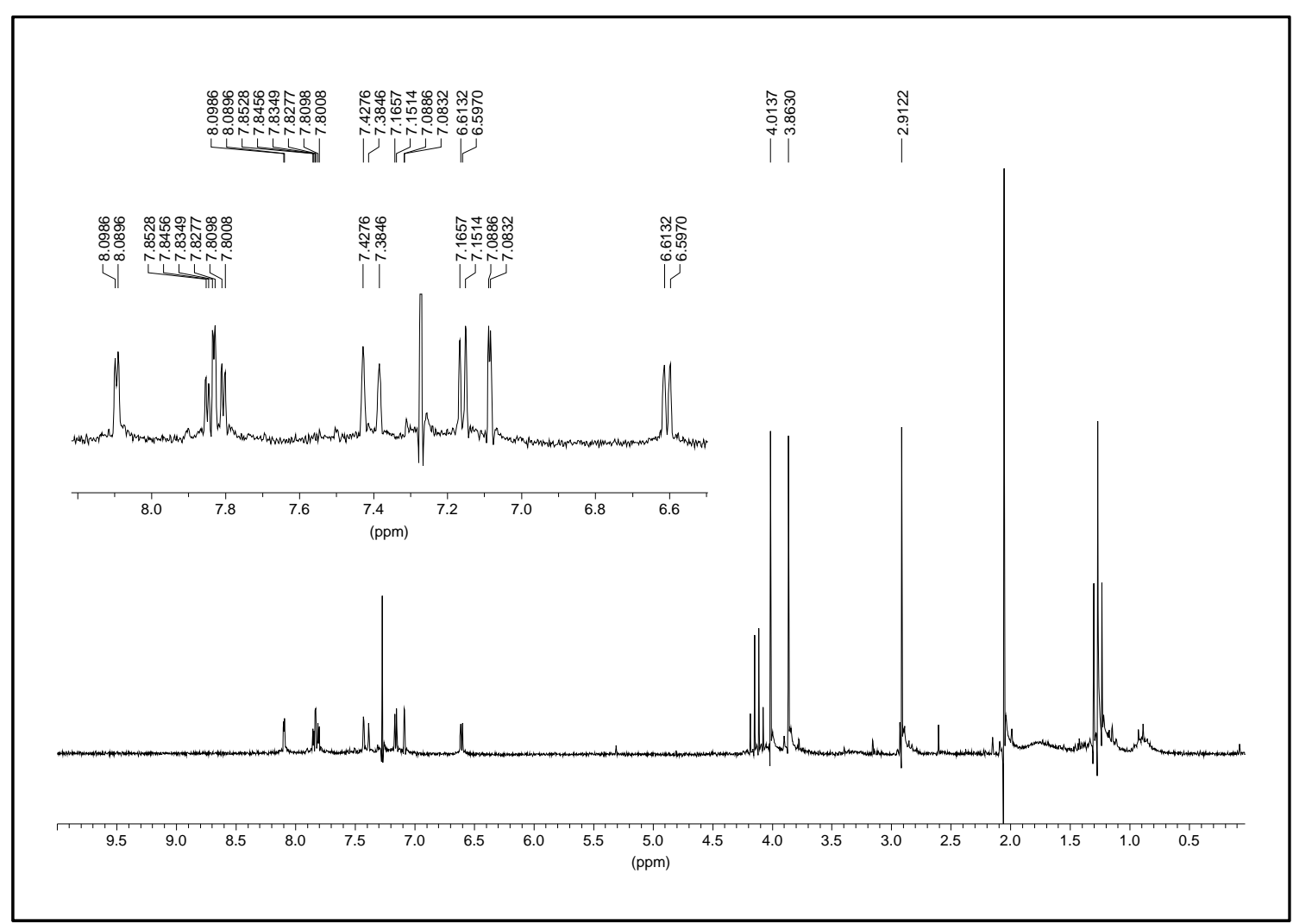

\section{Espectro $125 \mathrm{H}$}

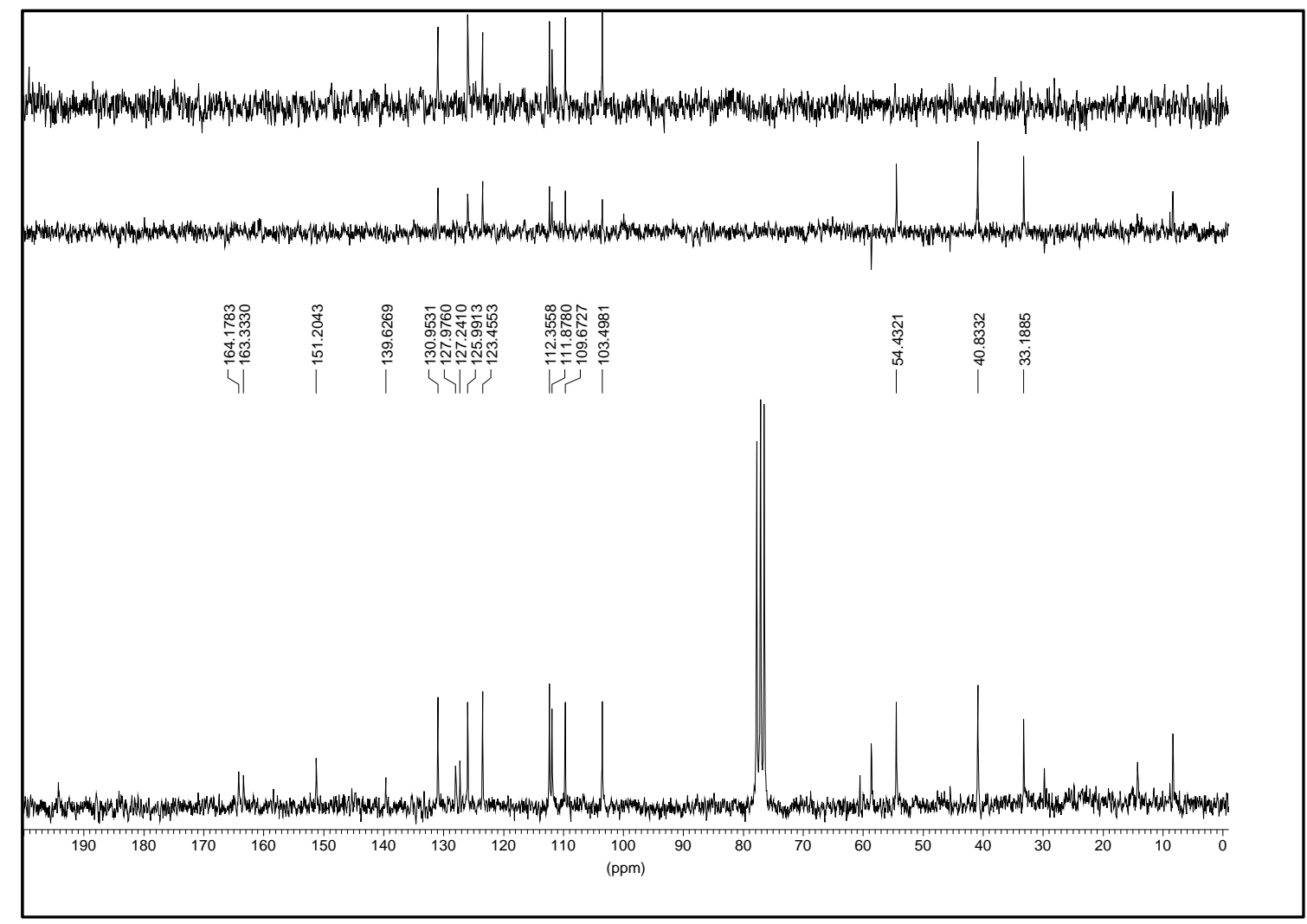

Espectro 125C 


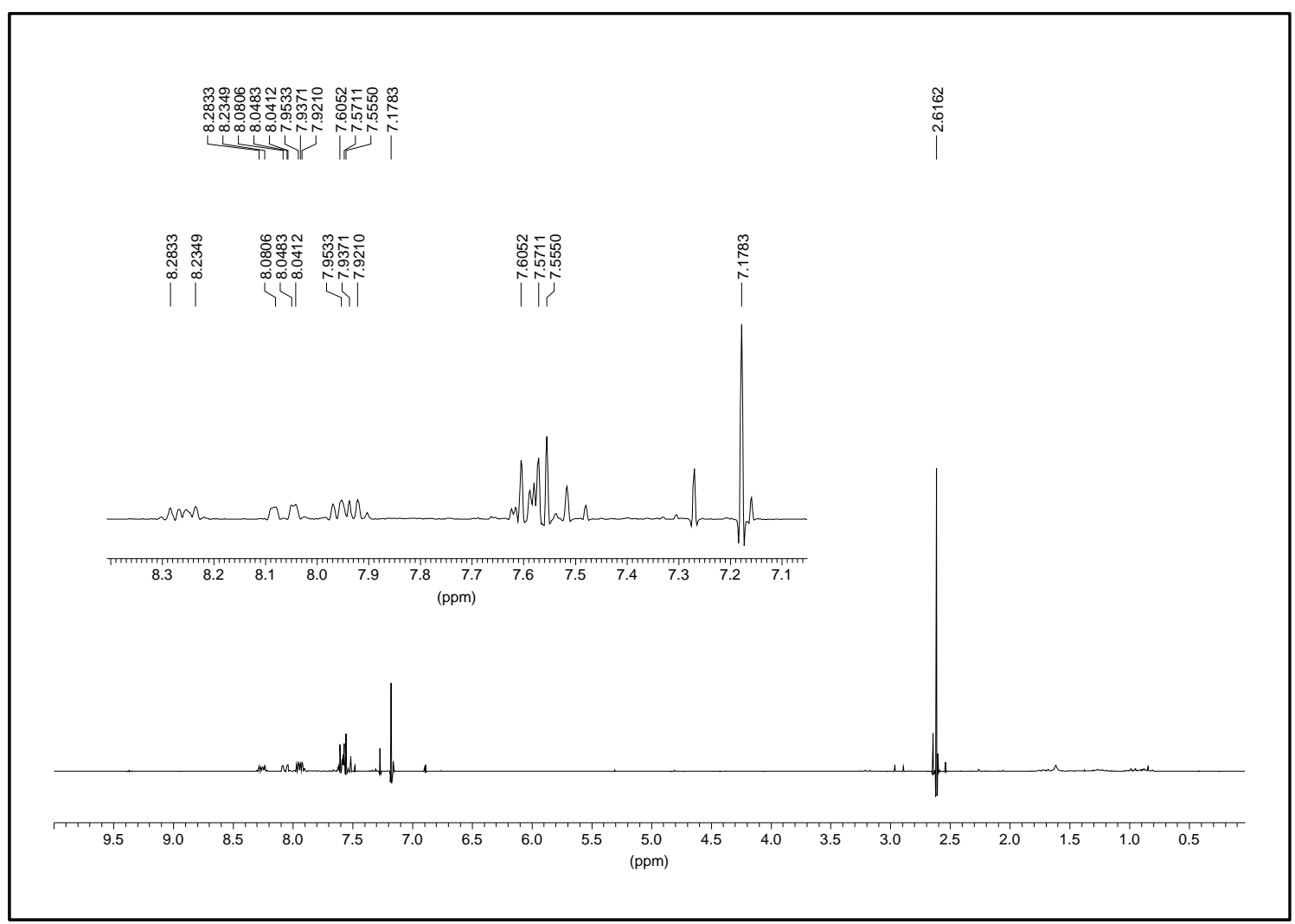

\section{Espectro $131 \mathrm{H}$}

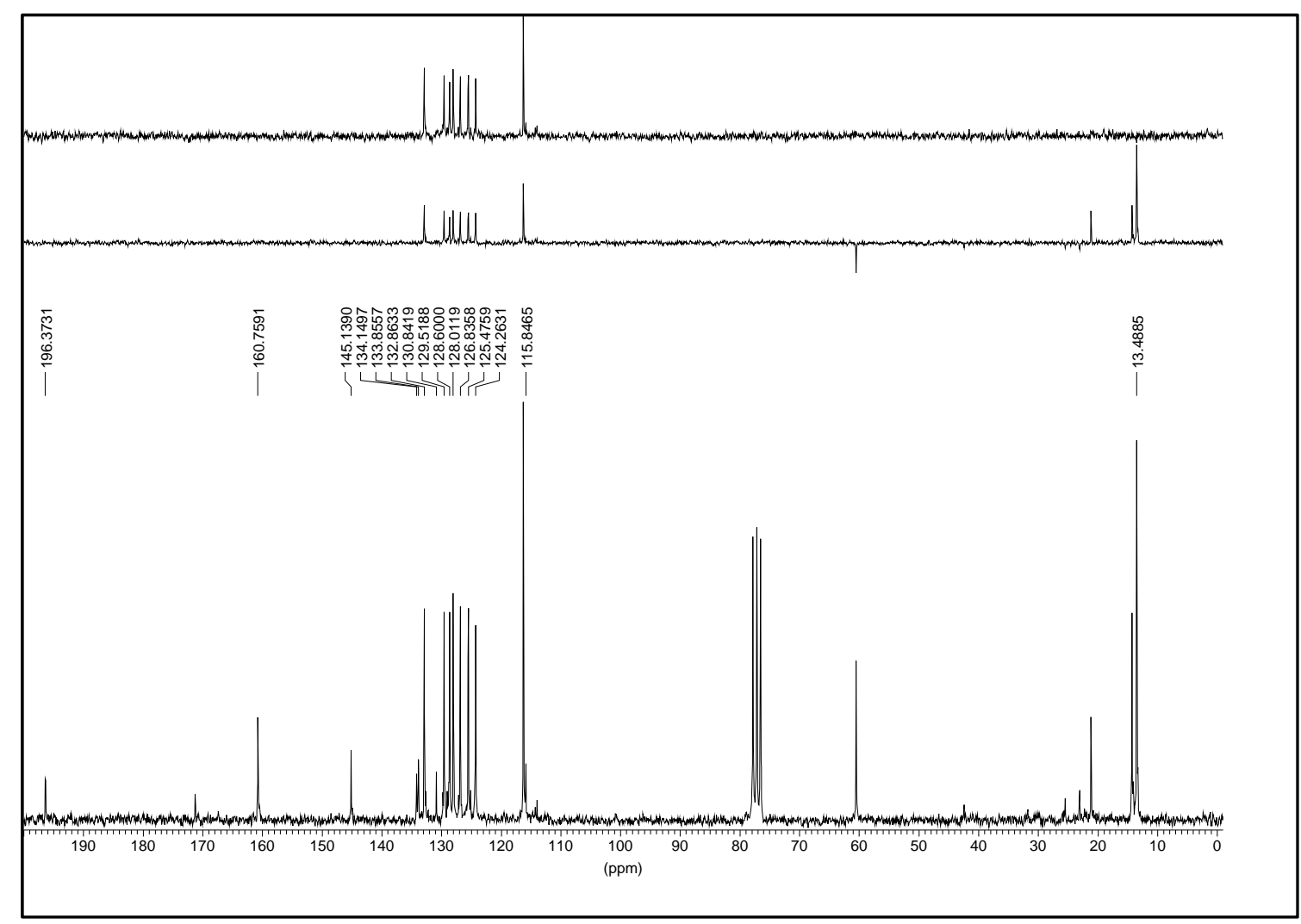

Espectro 131C 


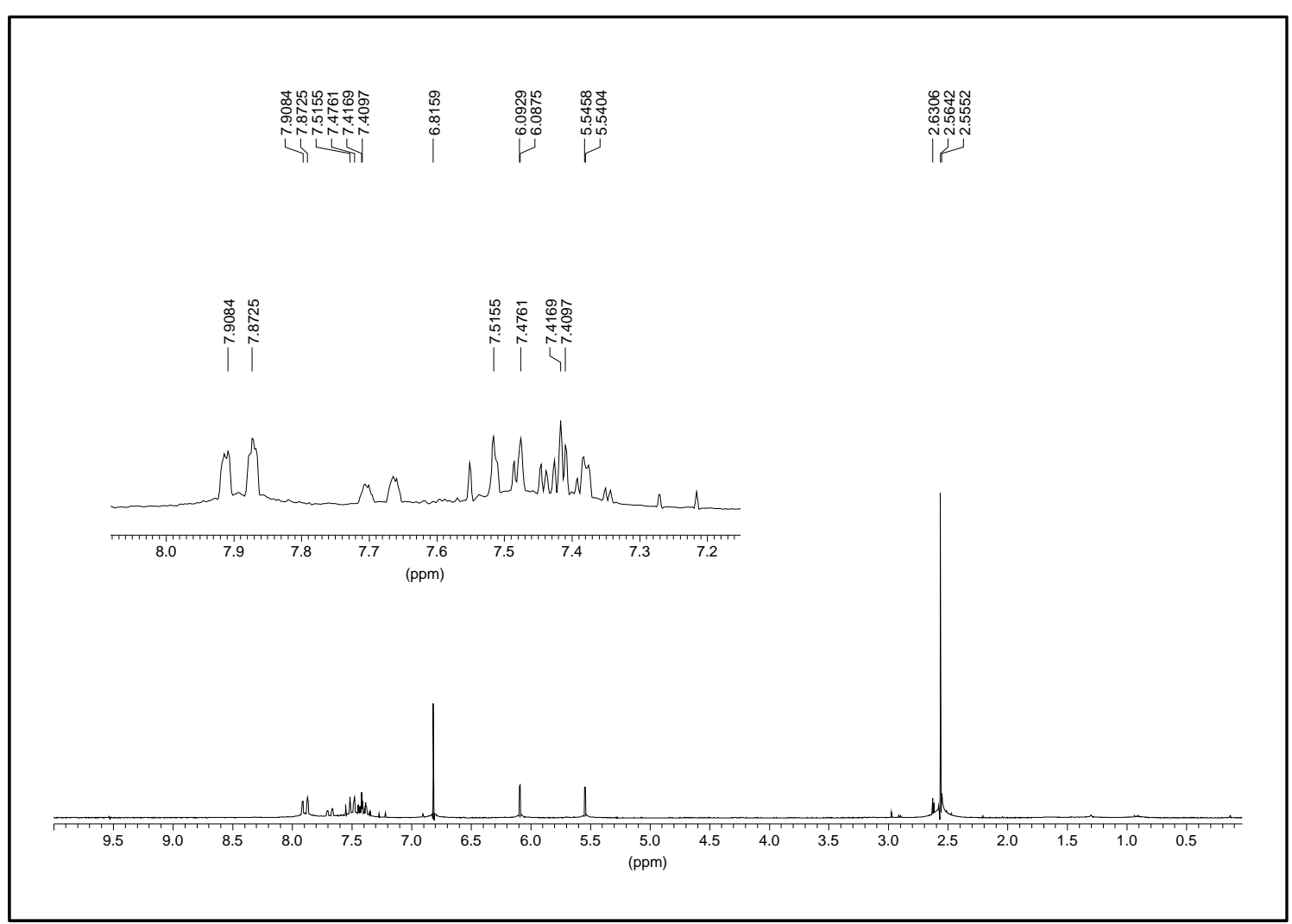

Espectro $132 \mathrm{H}$

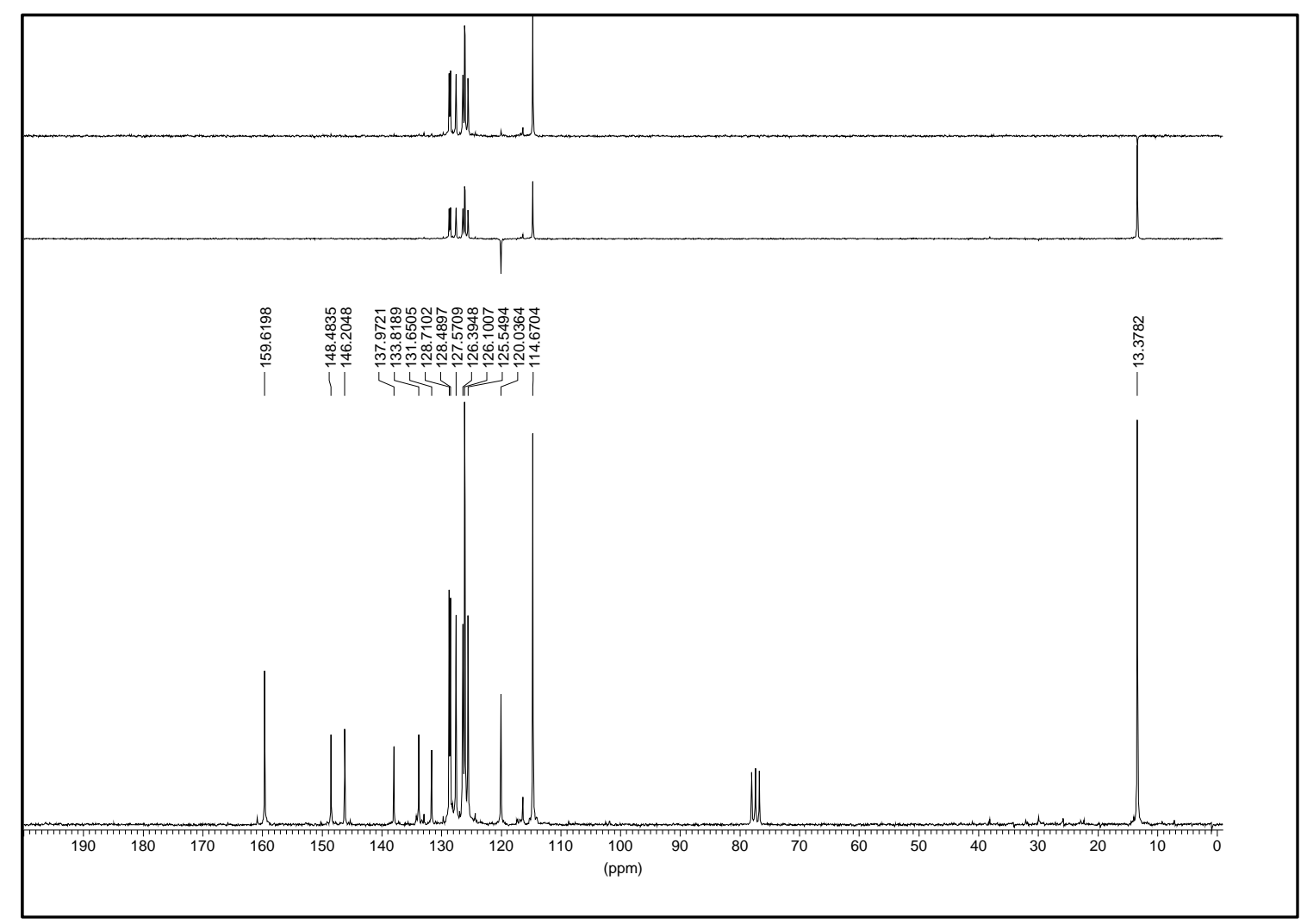

Espectro 132C 


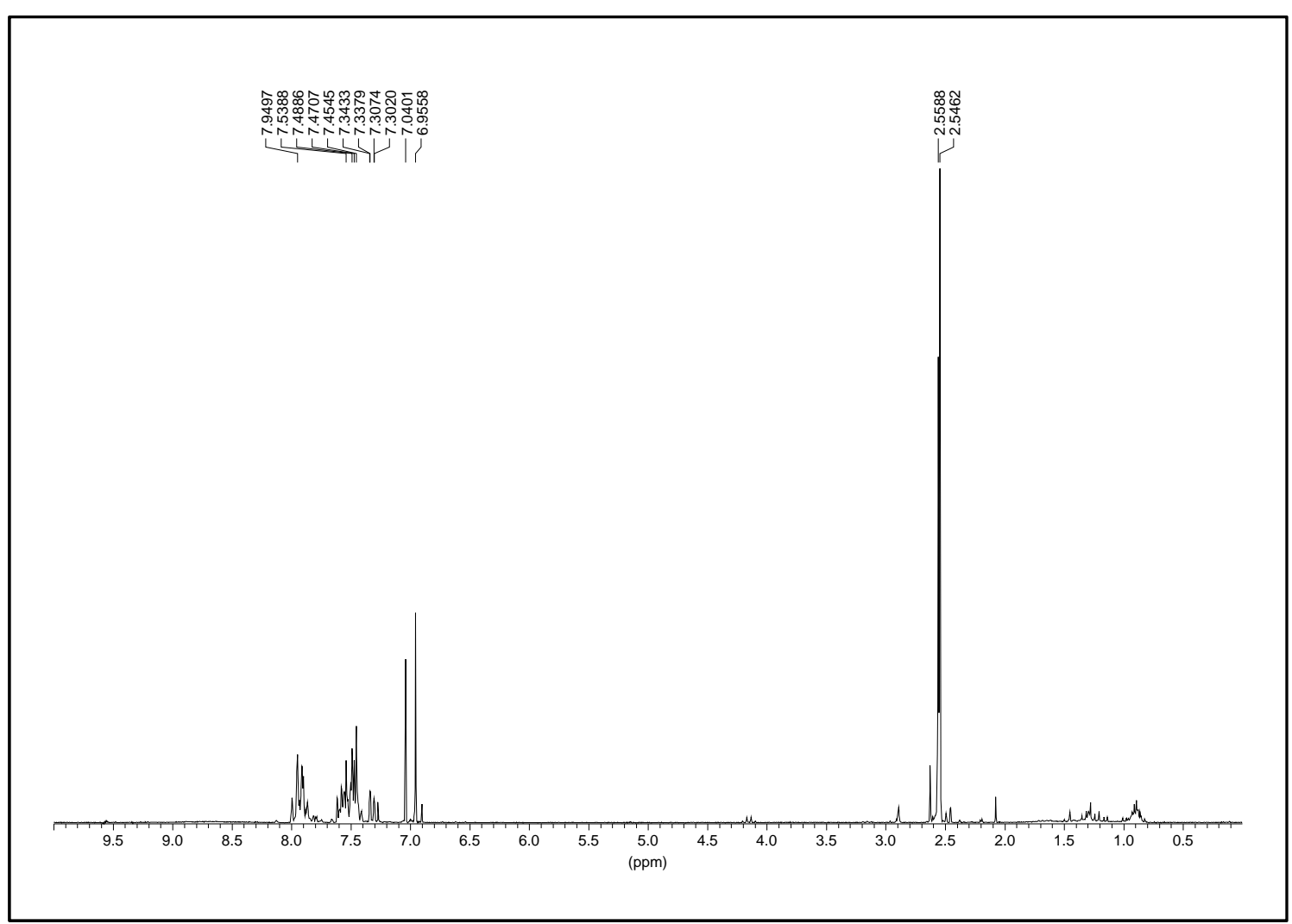

\section{Espectro 133ZEH}

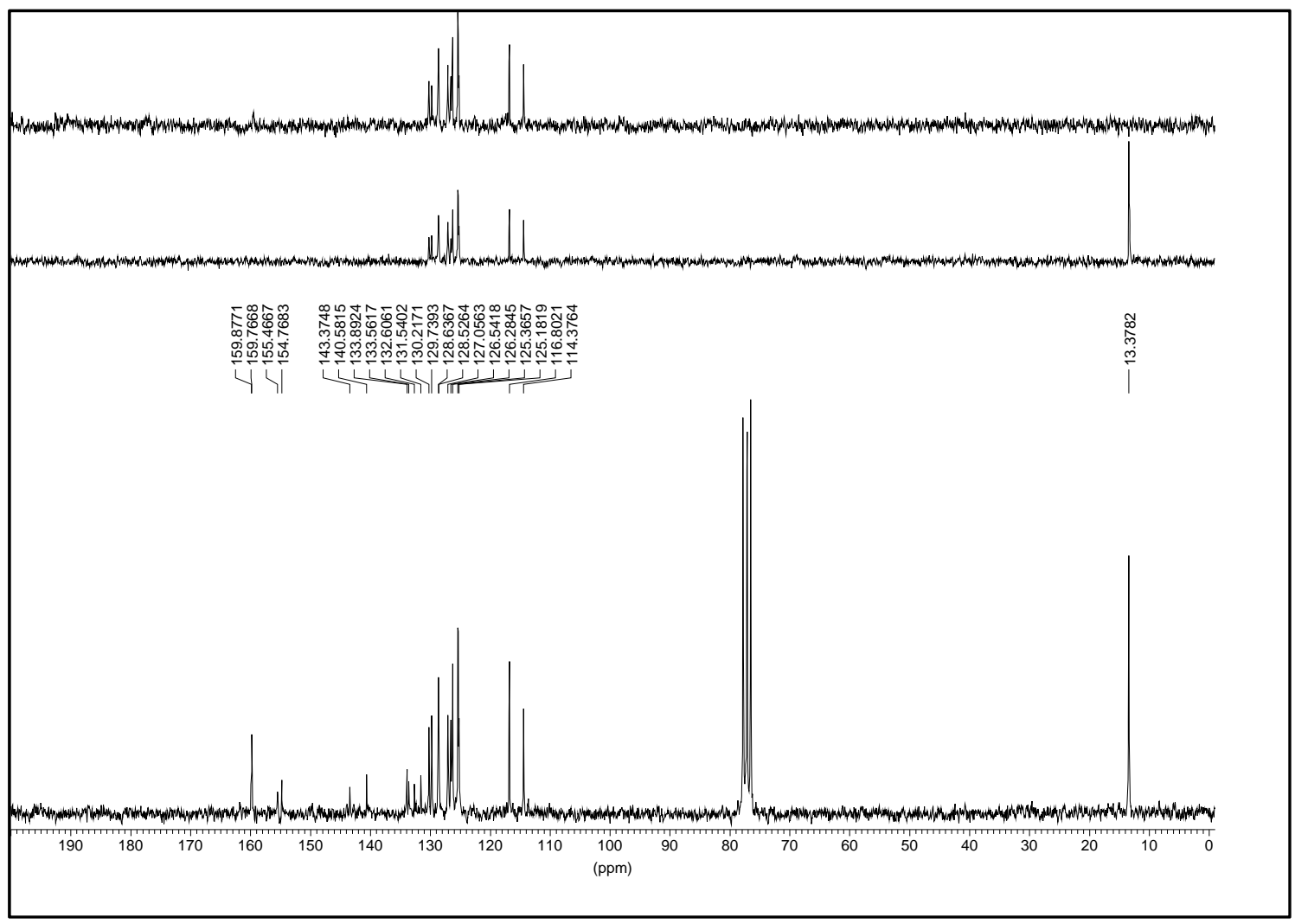

Espectro 133ZEC 


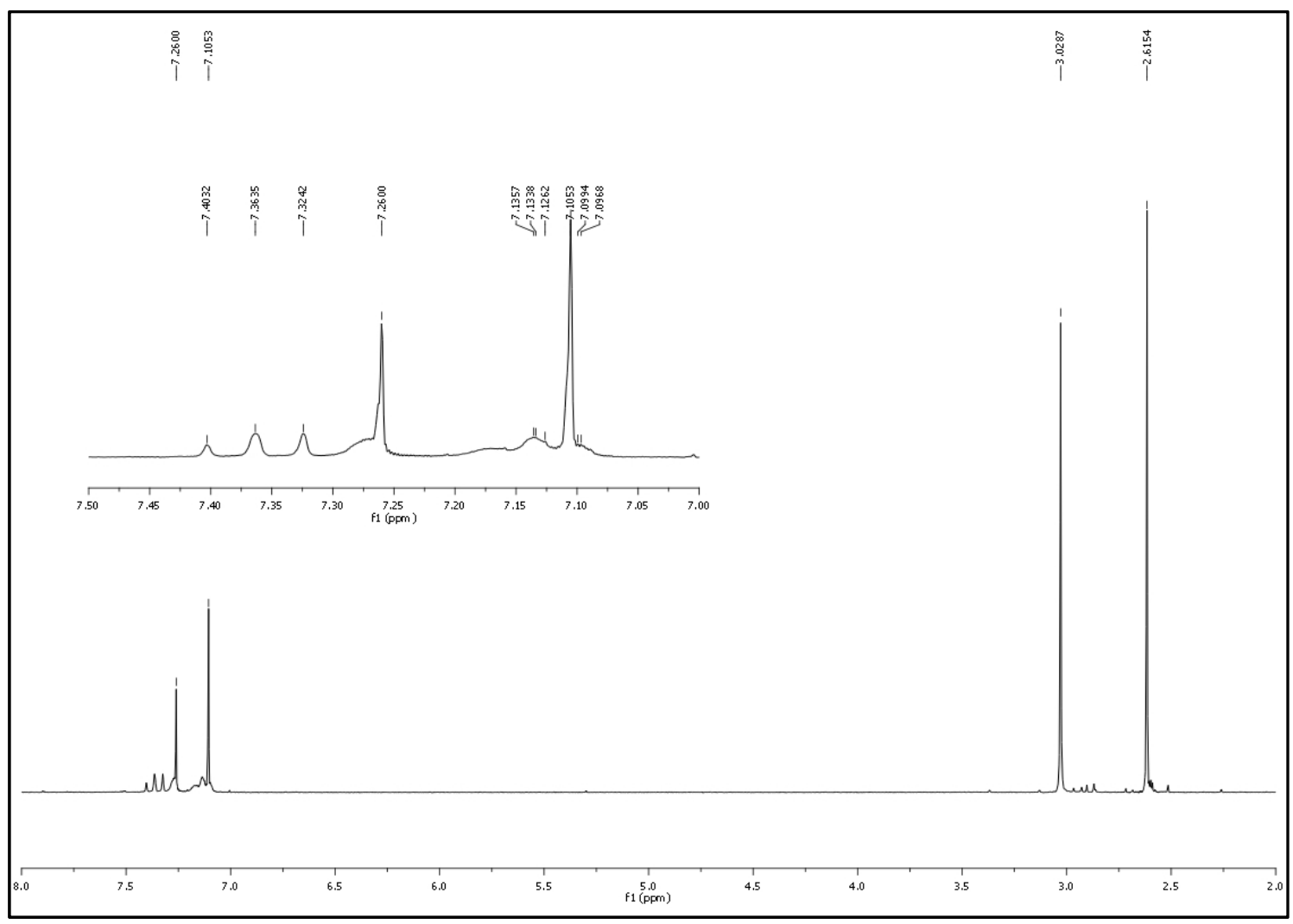

Espectro $134 \mathrm{H}$

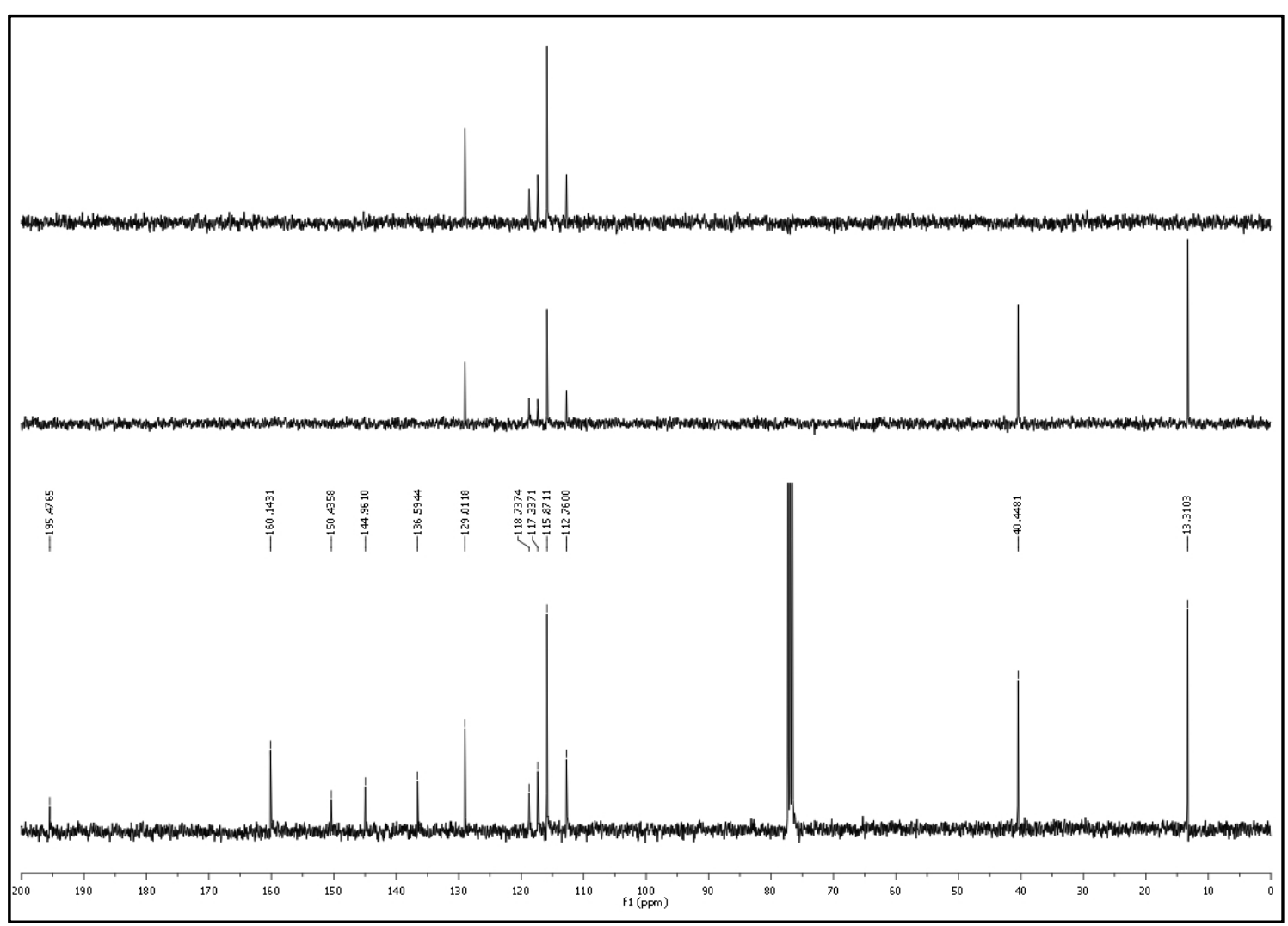

Espectro 134C 


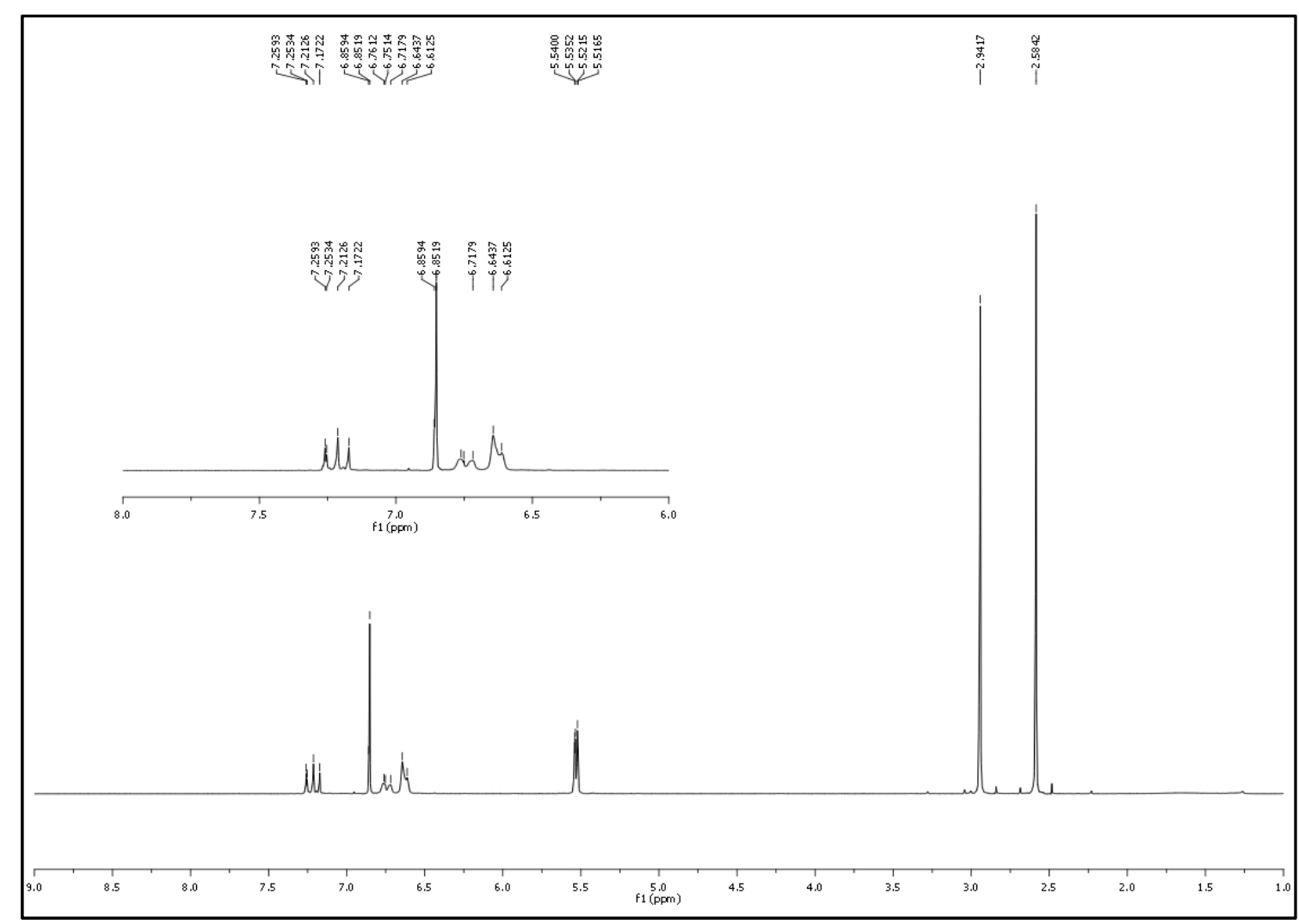

Espectro $135 \mathrm{H}$

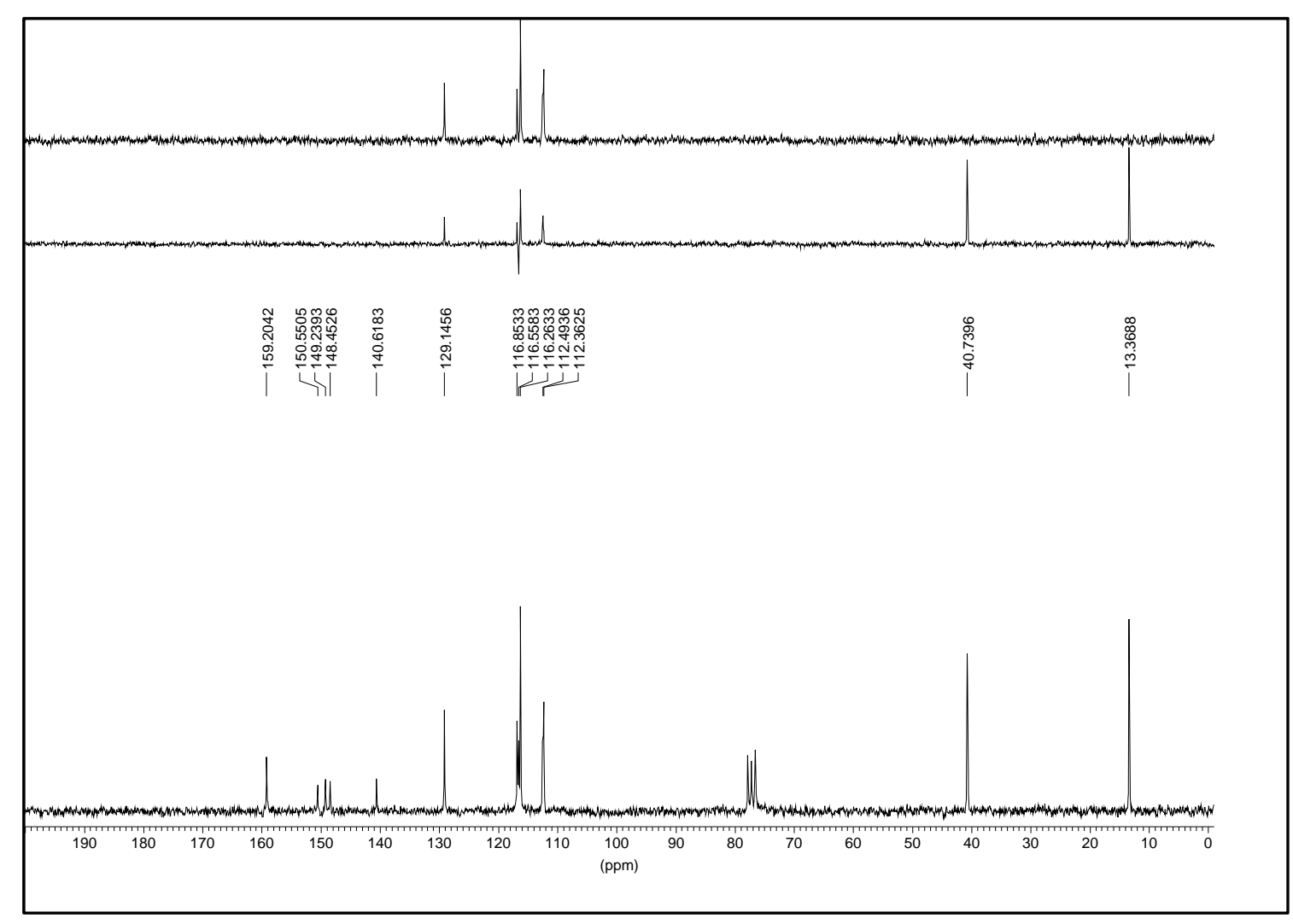

Espectro 135C 


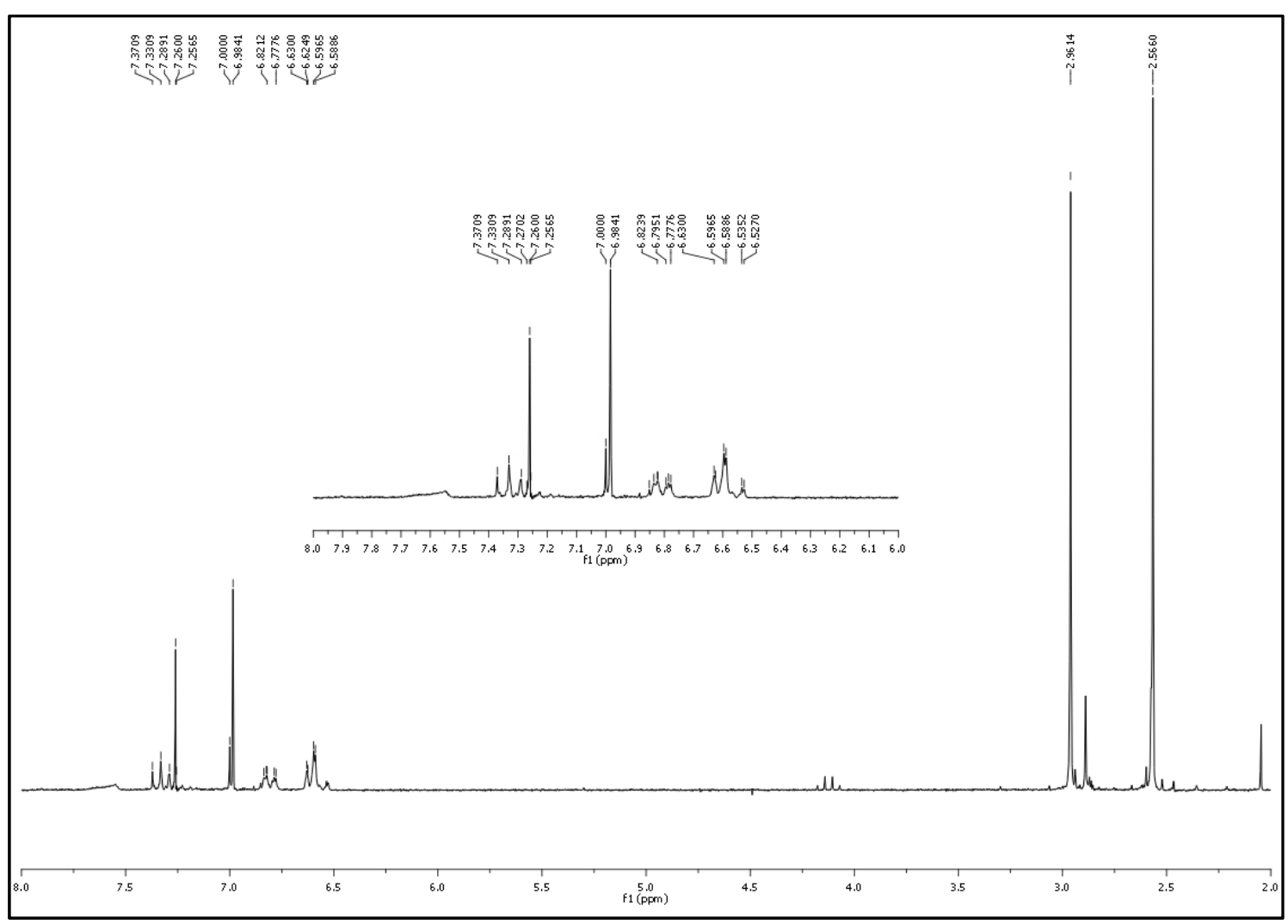

Espectro 136EH

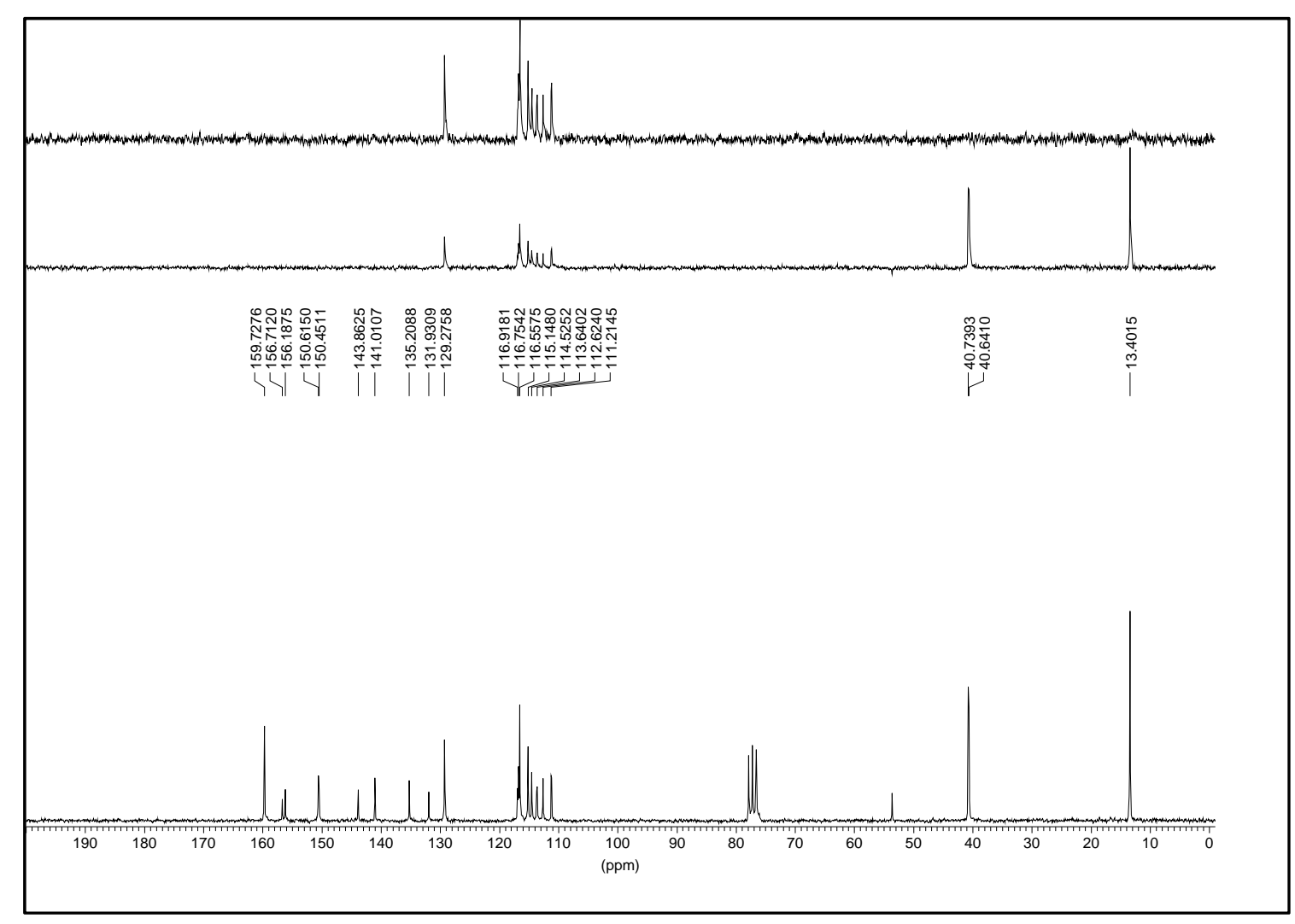

Espectro 136ZEC 


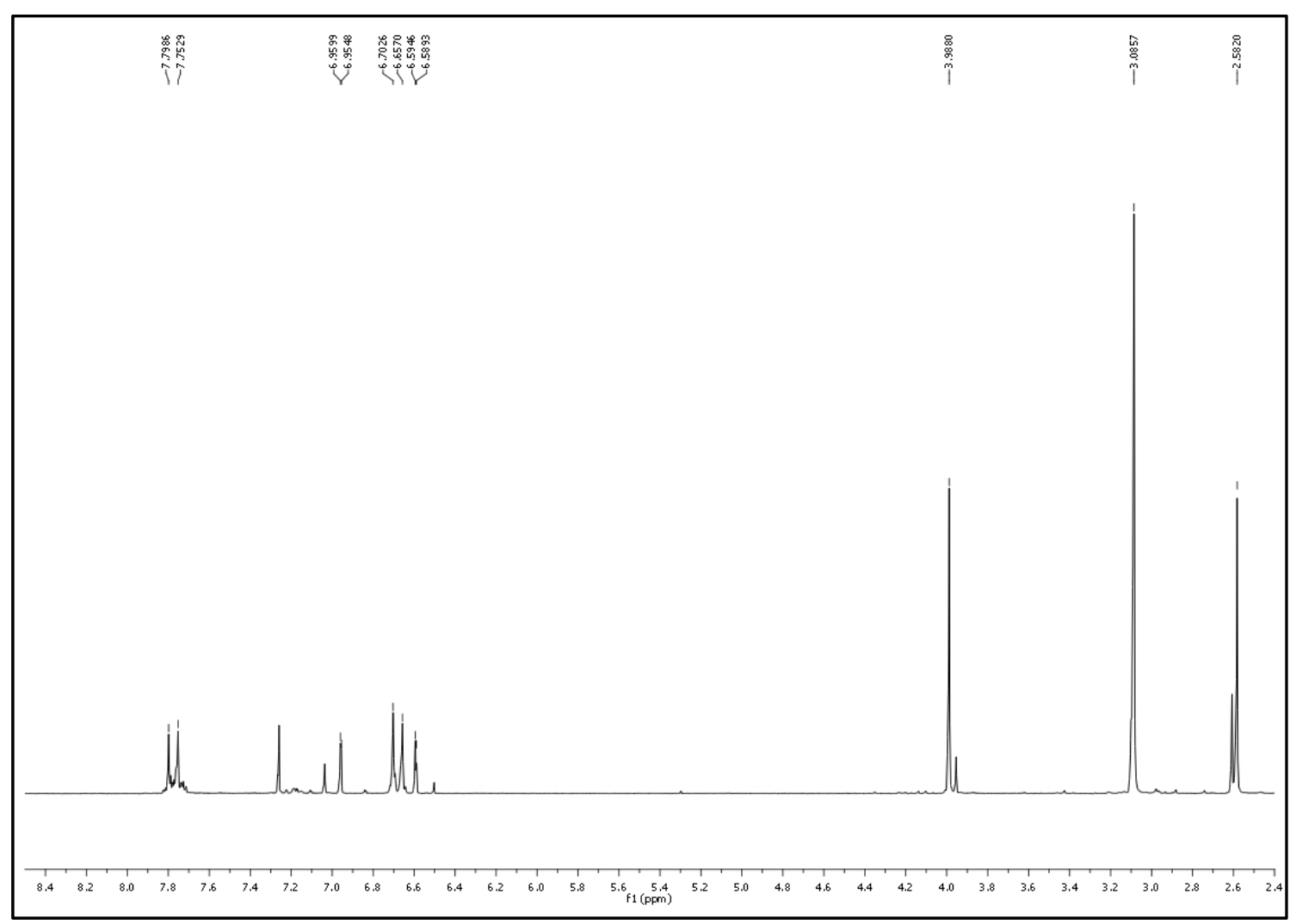

Espectro 137H

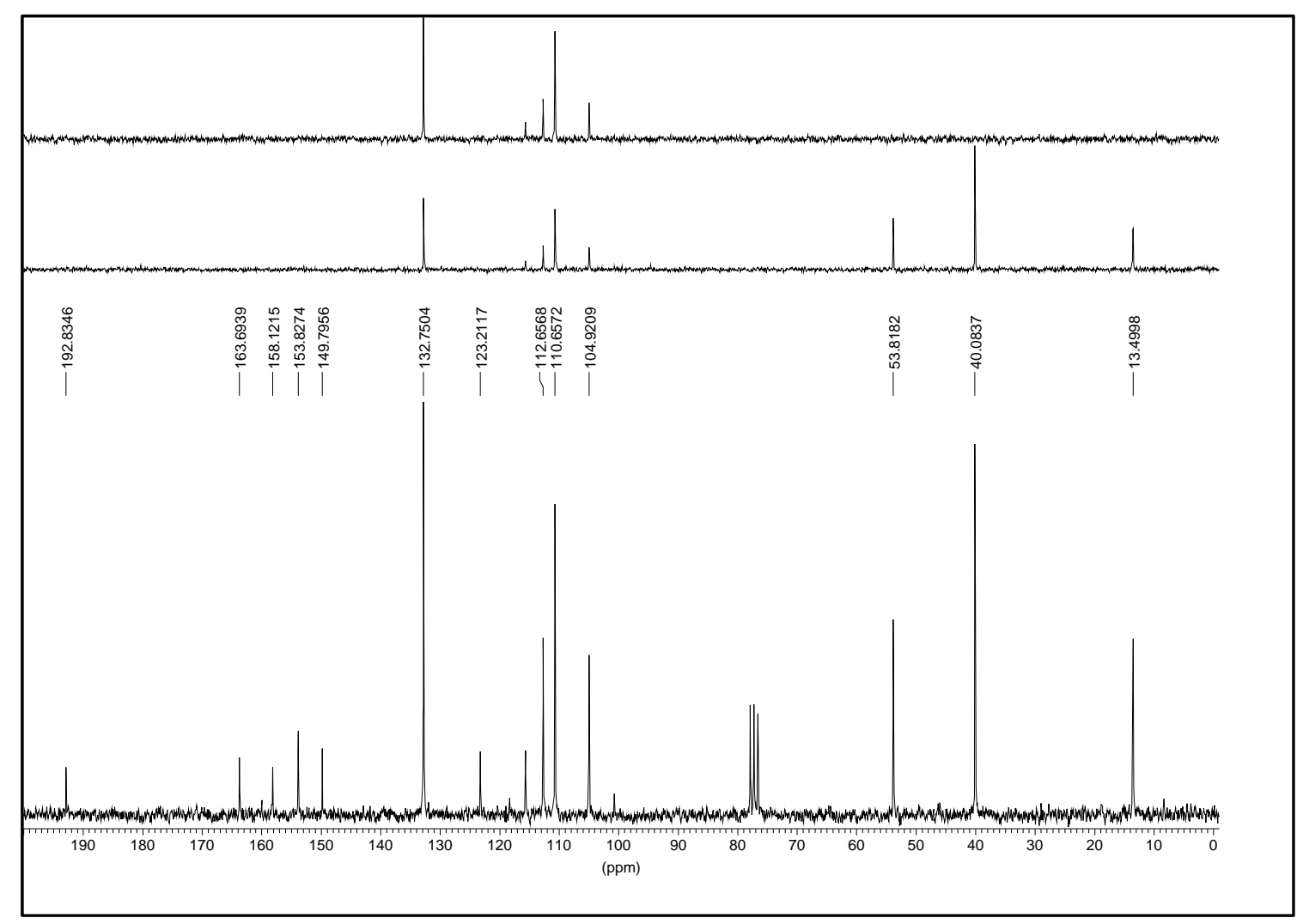

Espectro 137C 


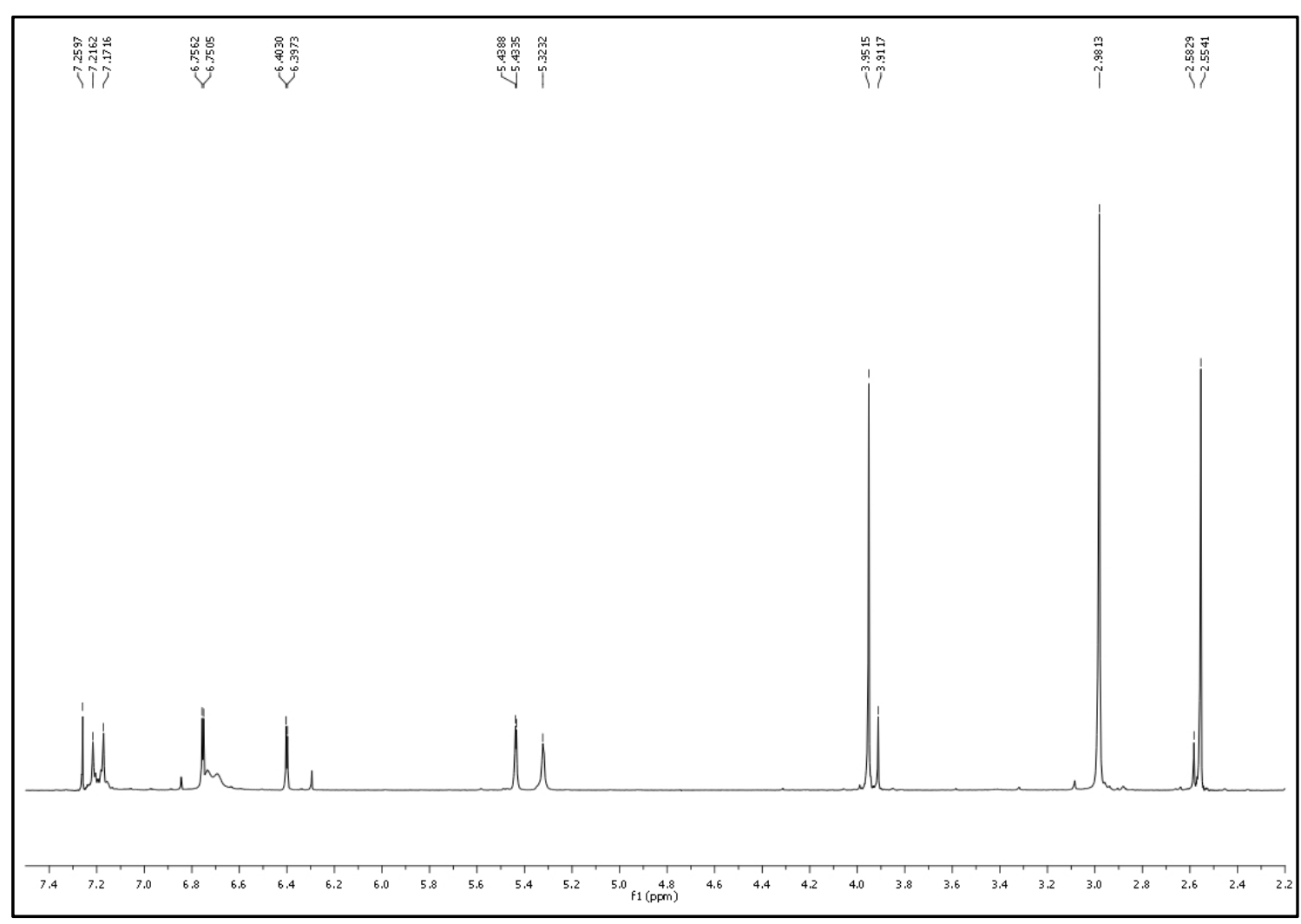

\section{Espectro $138 \mathrm{H}$}

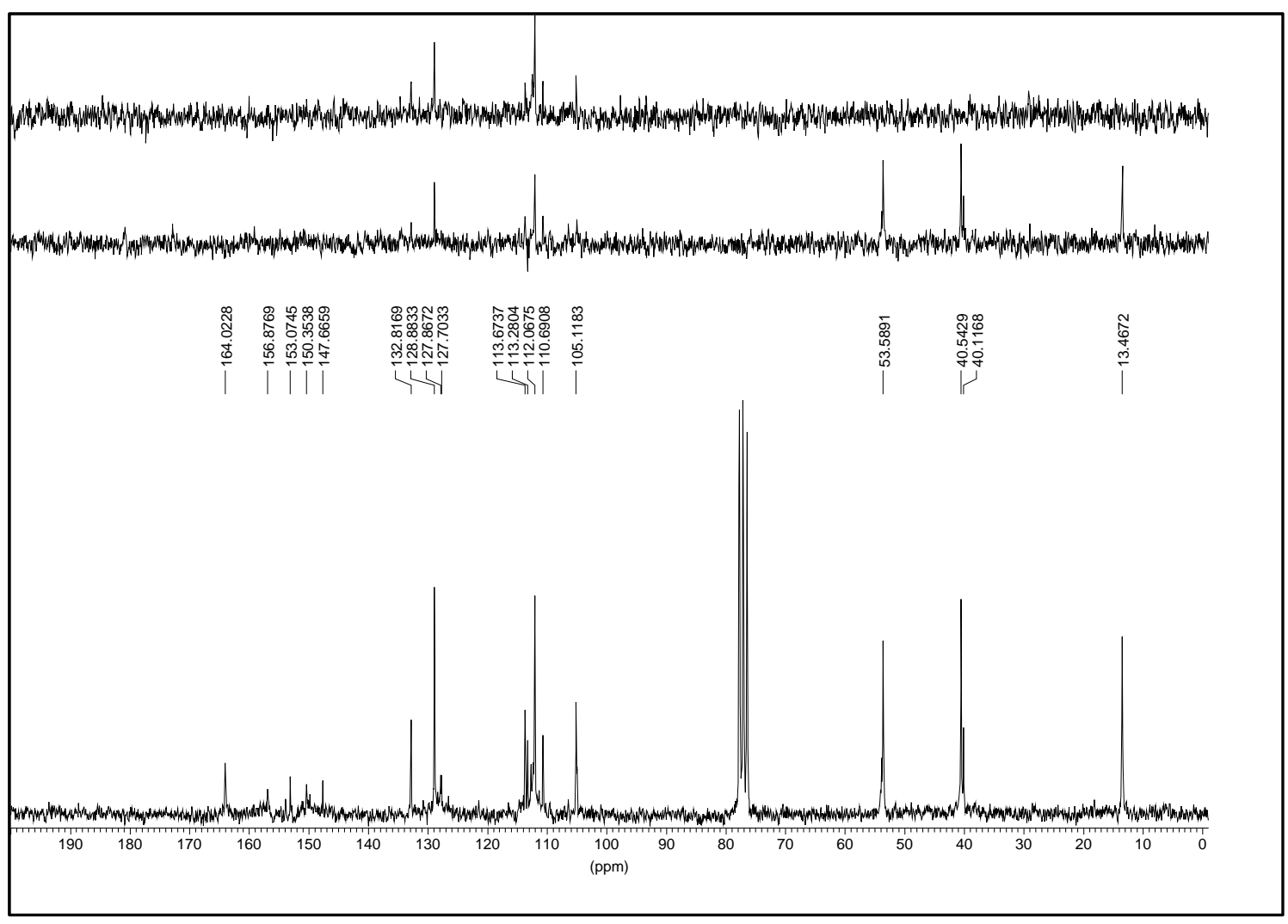

Espectro 138C 


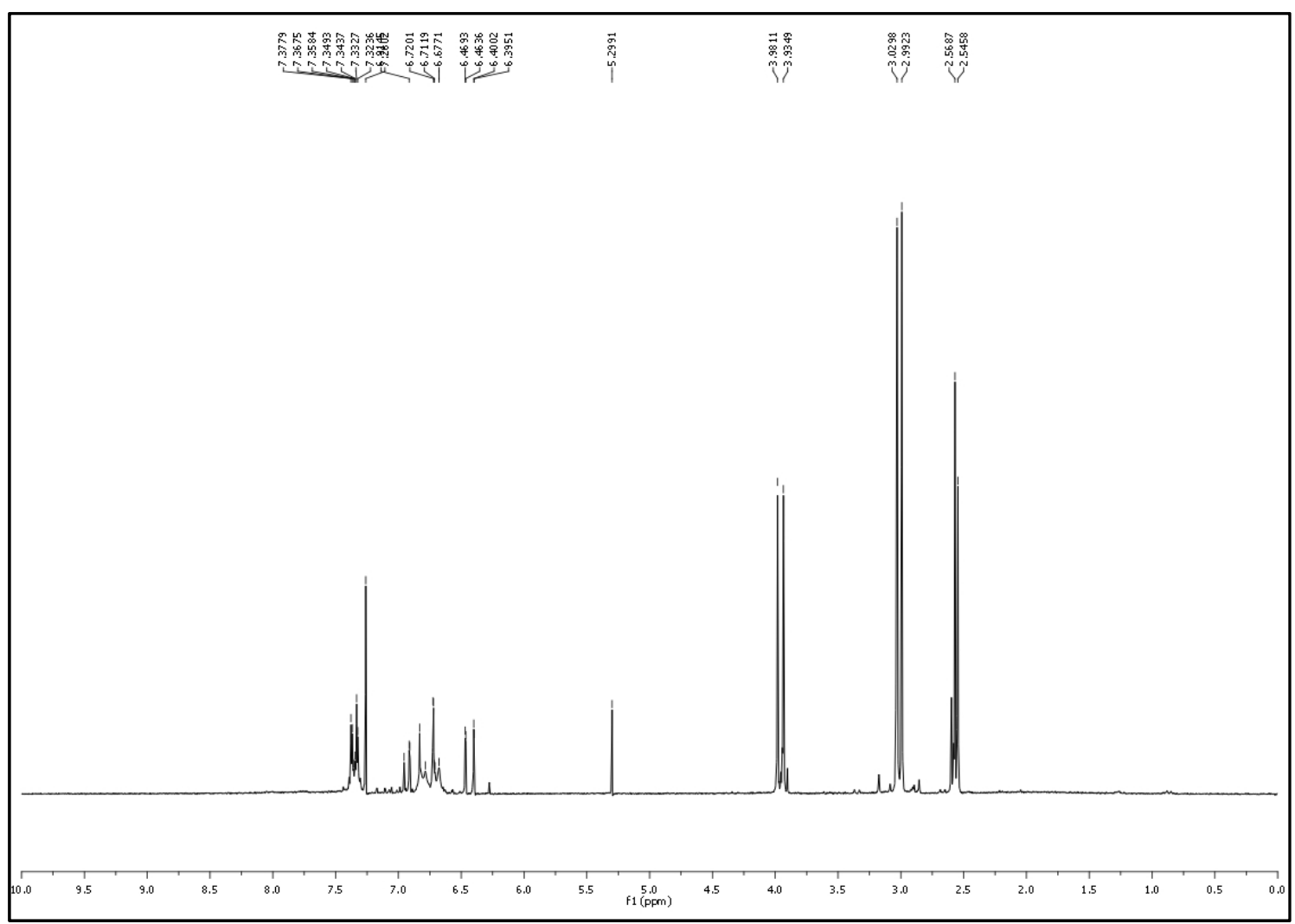

\section{Espectro 139ZEH}

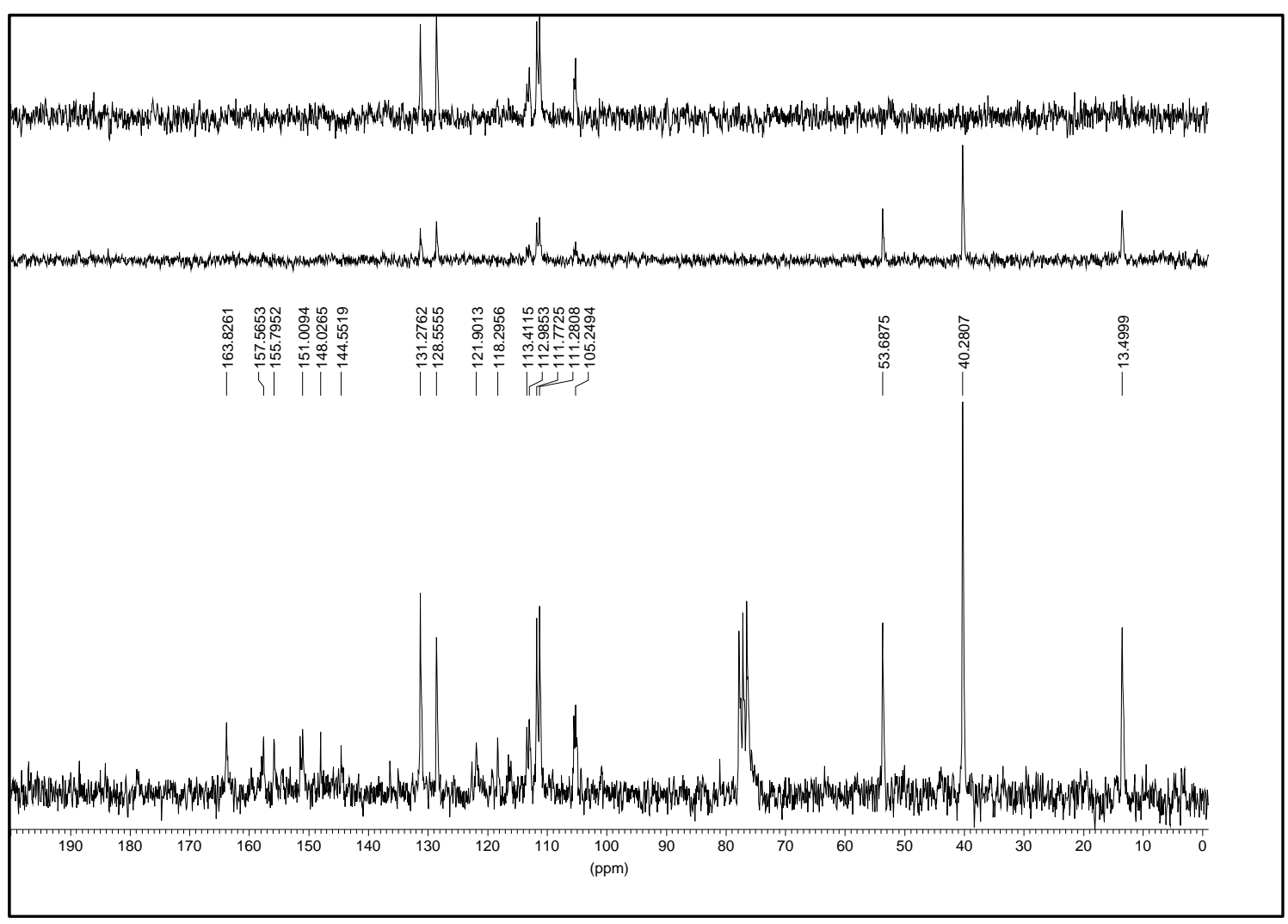

\section{Espectro 139ZEC}




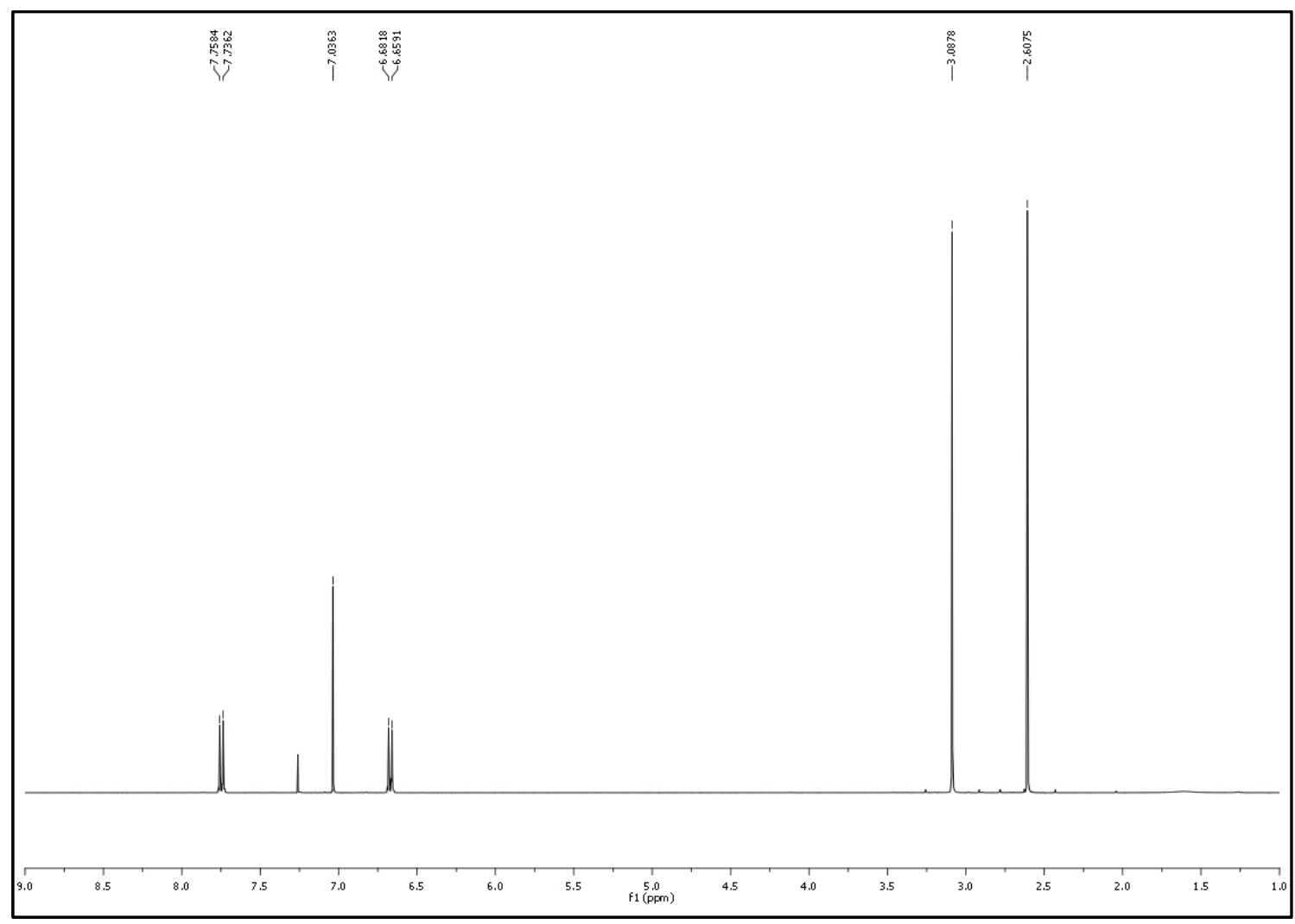

Espectro $140 \mathrm{H}$

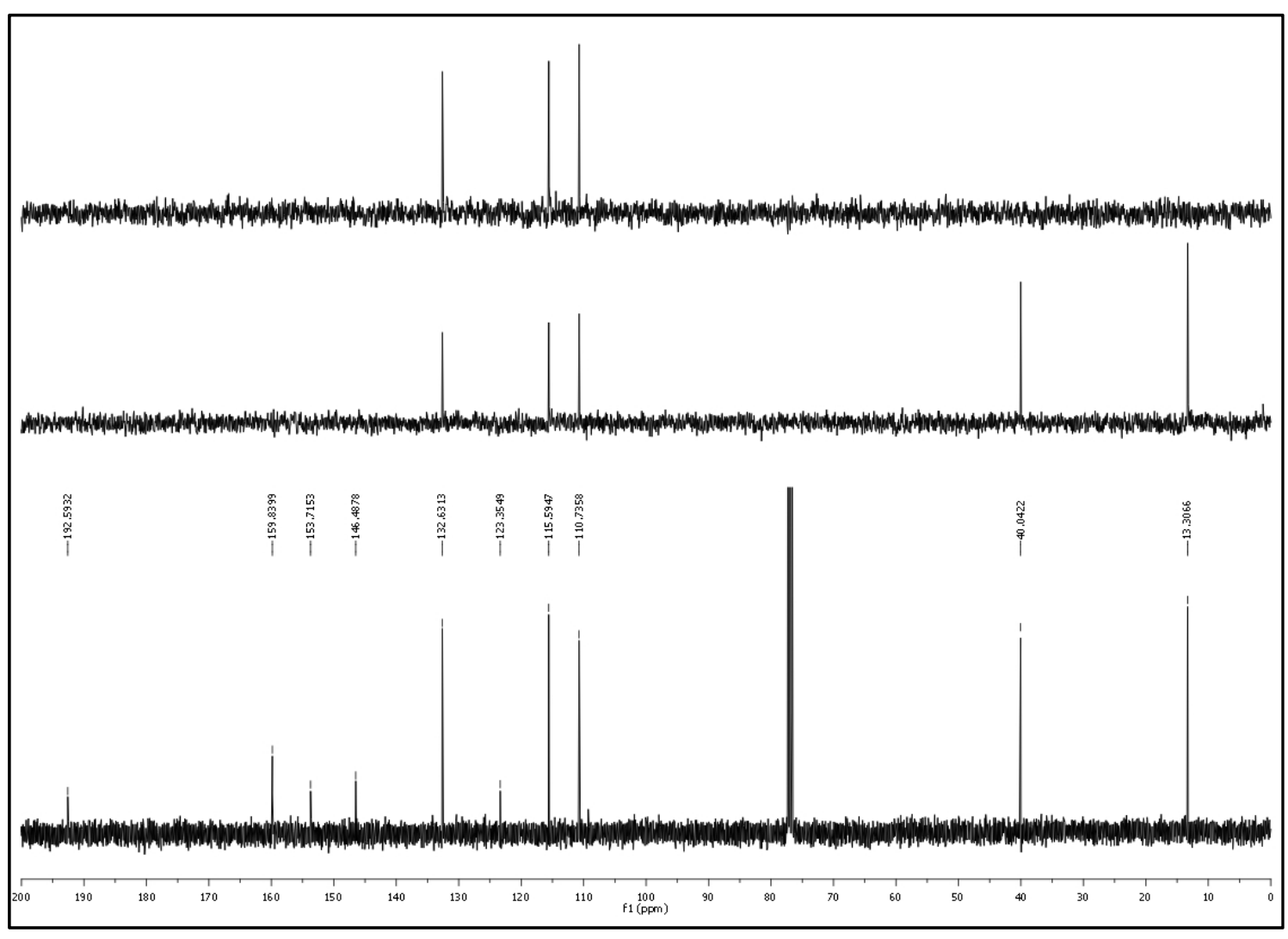

Espectro 140C 


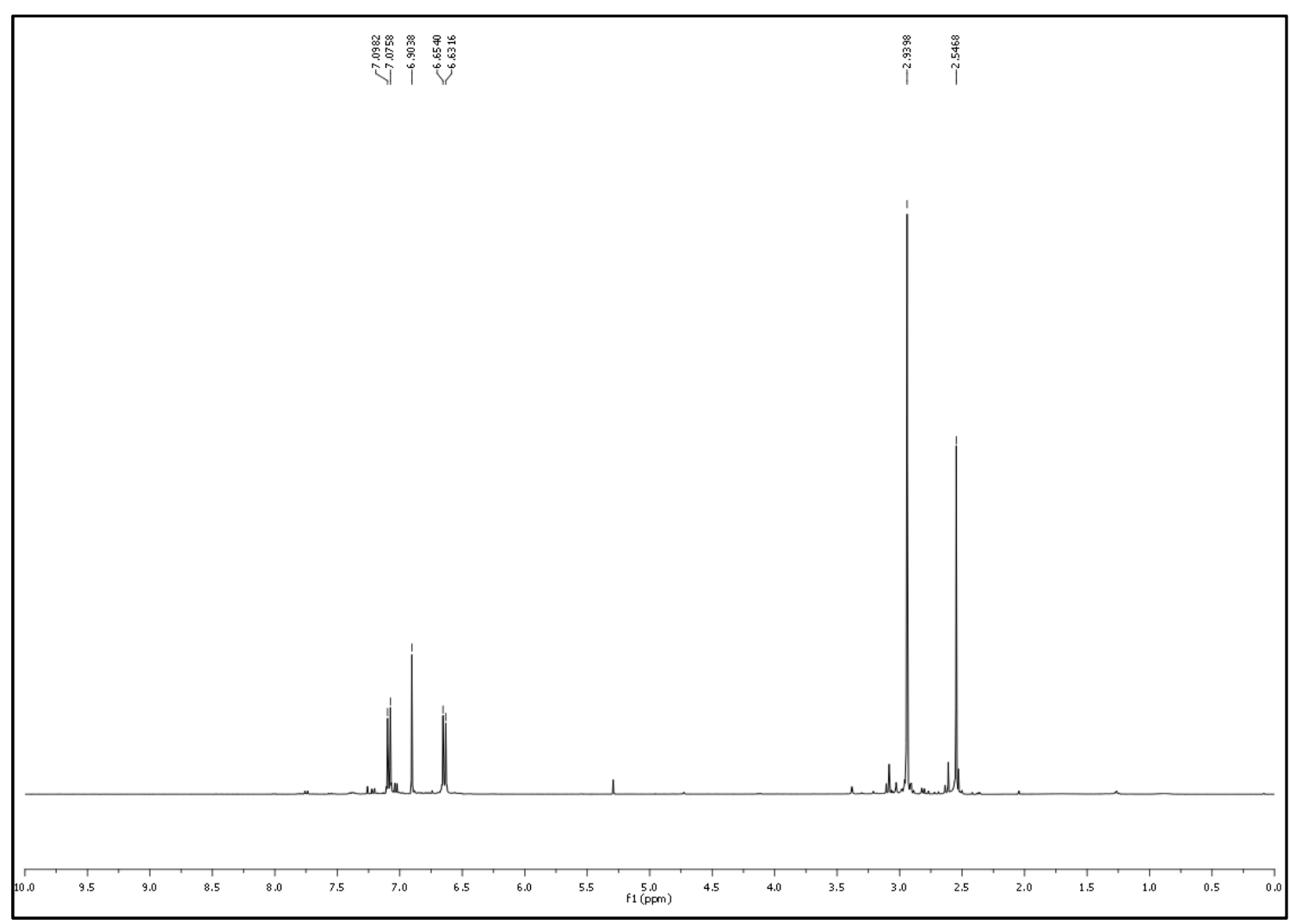

Espectro $141 \mathrm{H}$

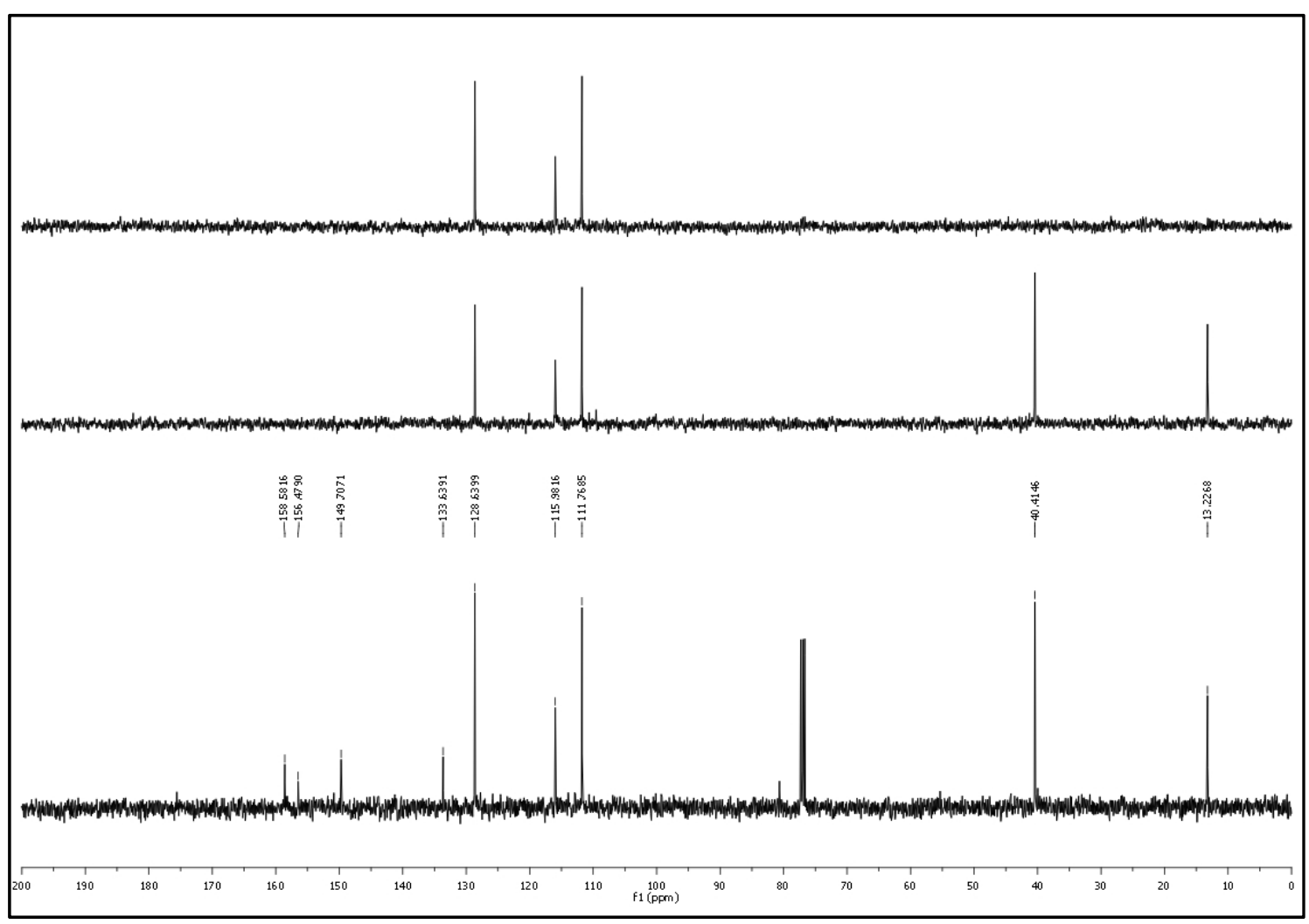

Espectro 141C 


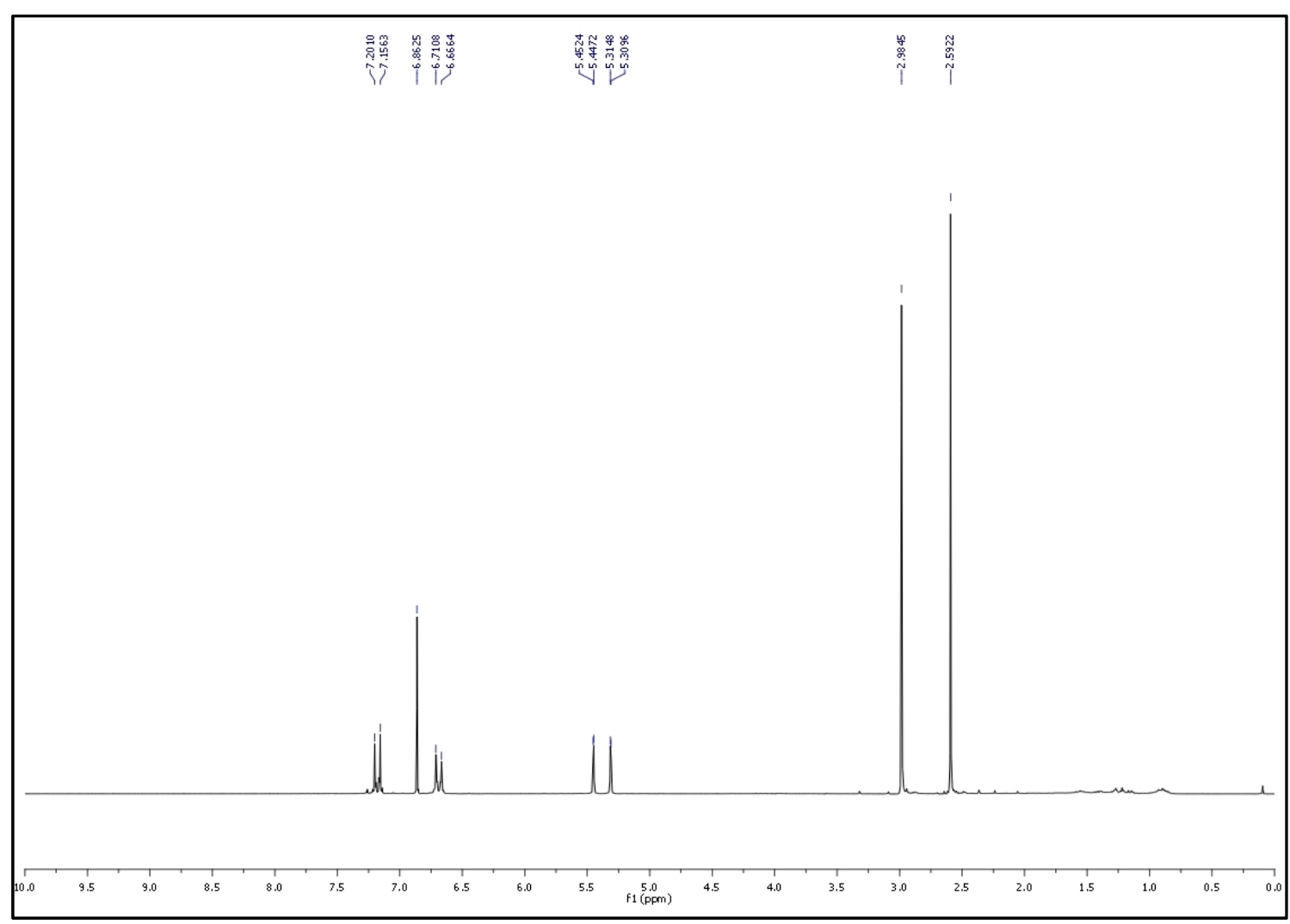

Espectro $142 \mathrm{H}$

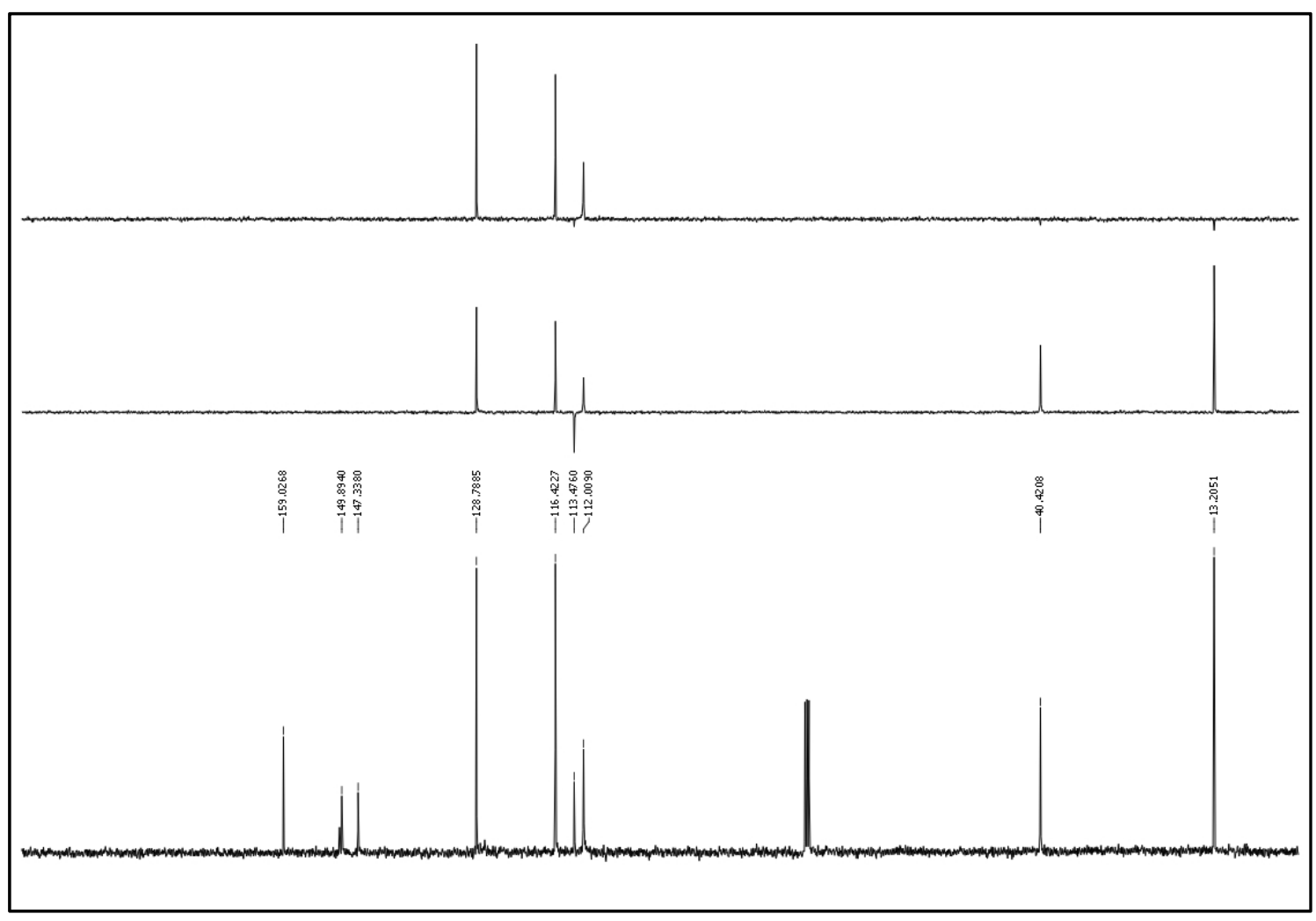

Espectro 142C 


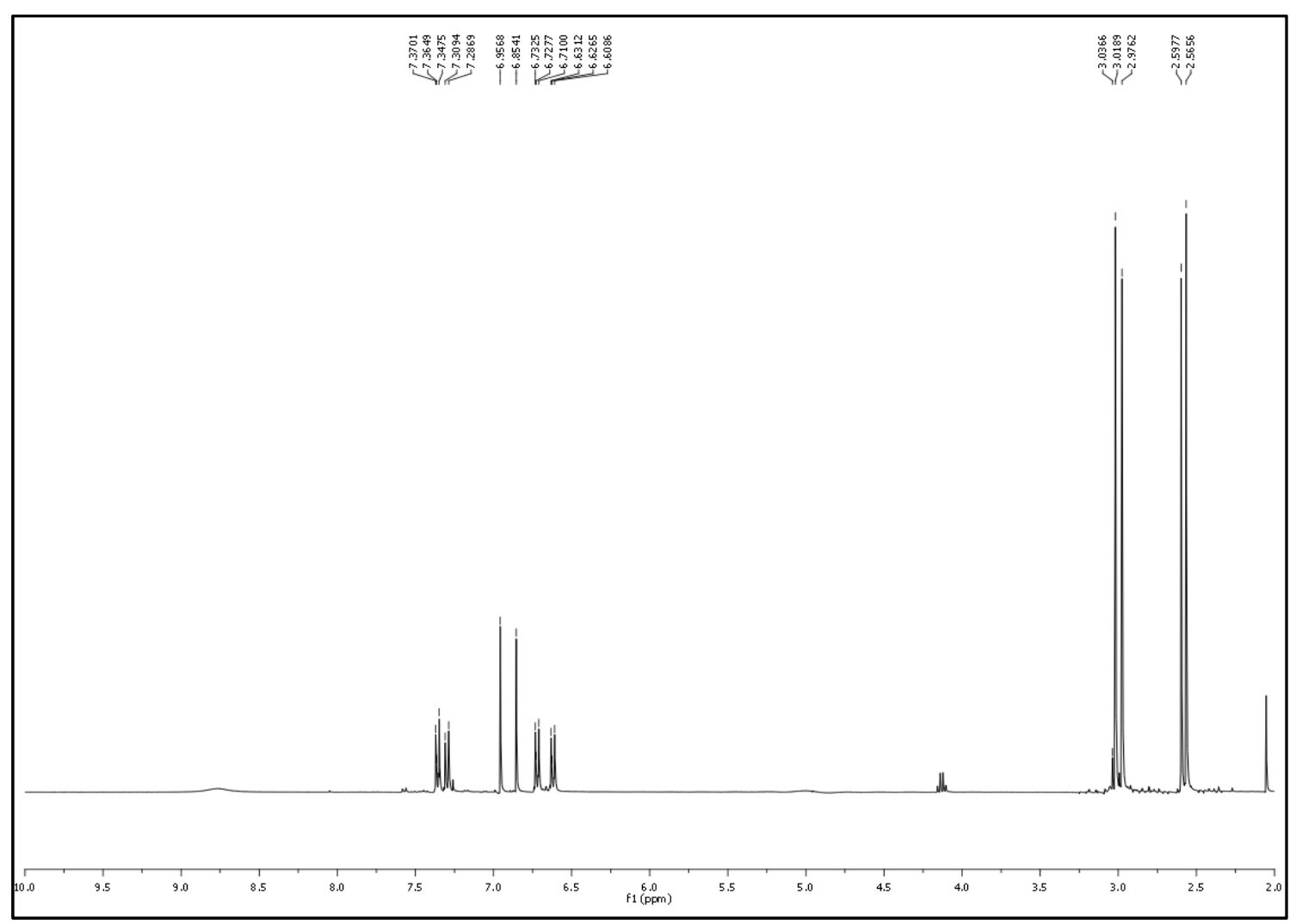

Espectro 143ZEH

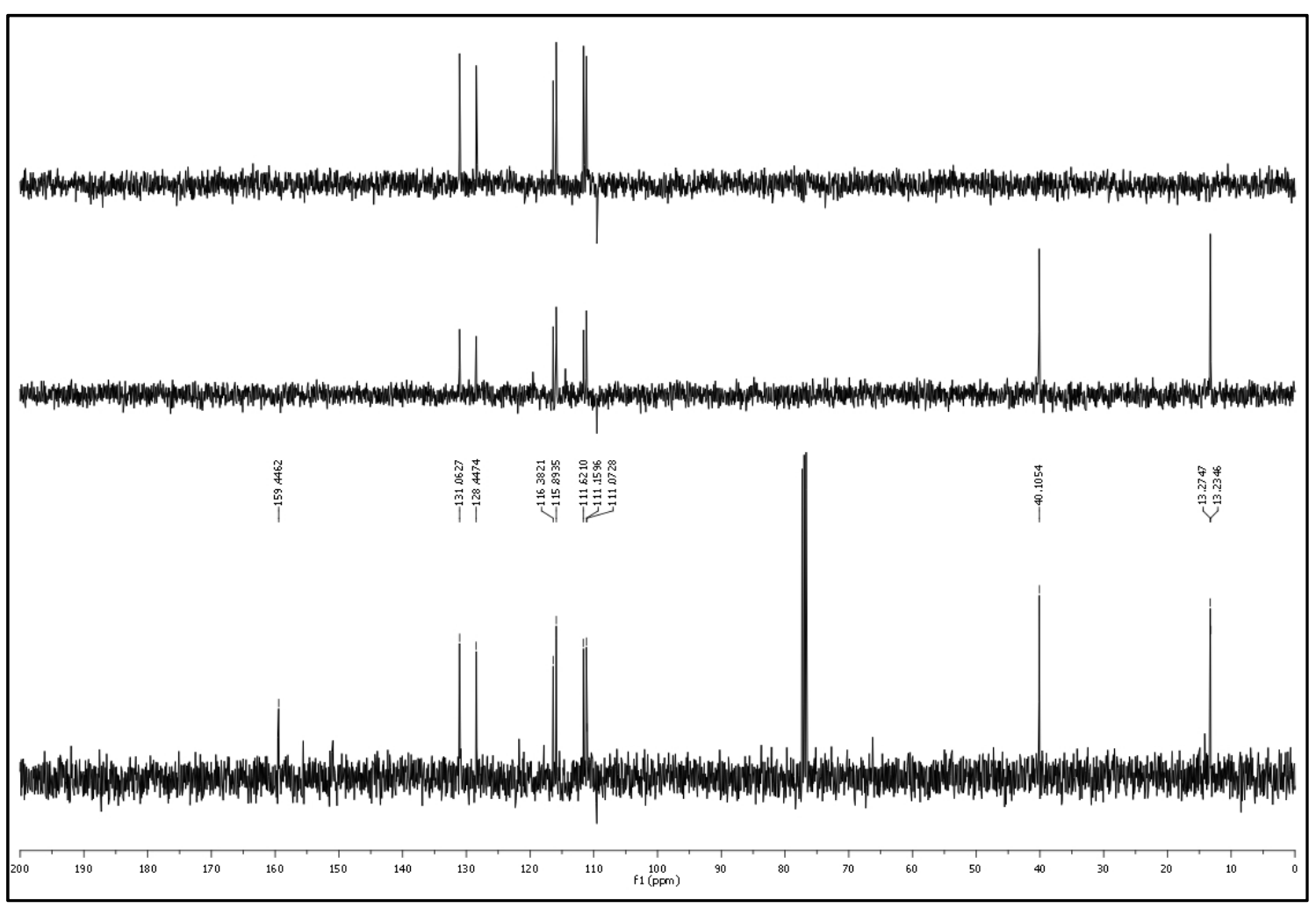

Espectro 143ZEC 
Espectros

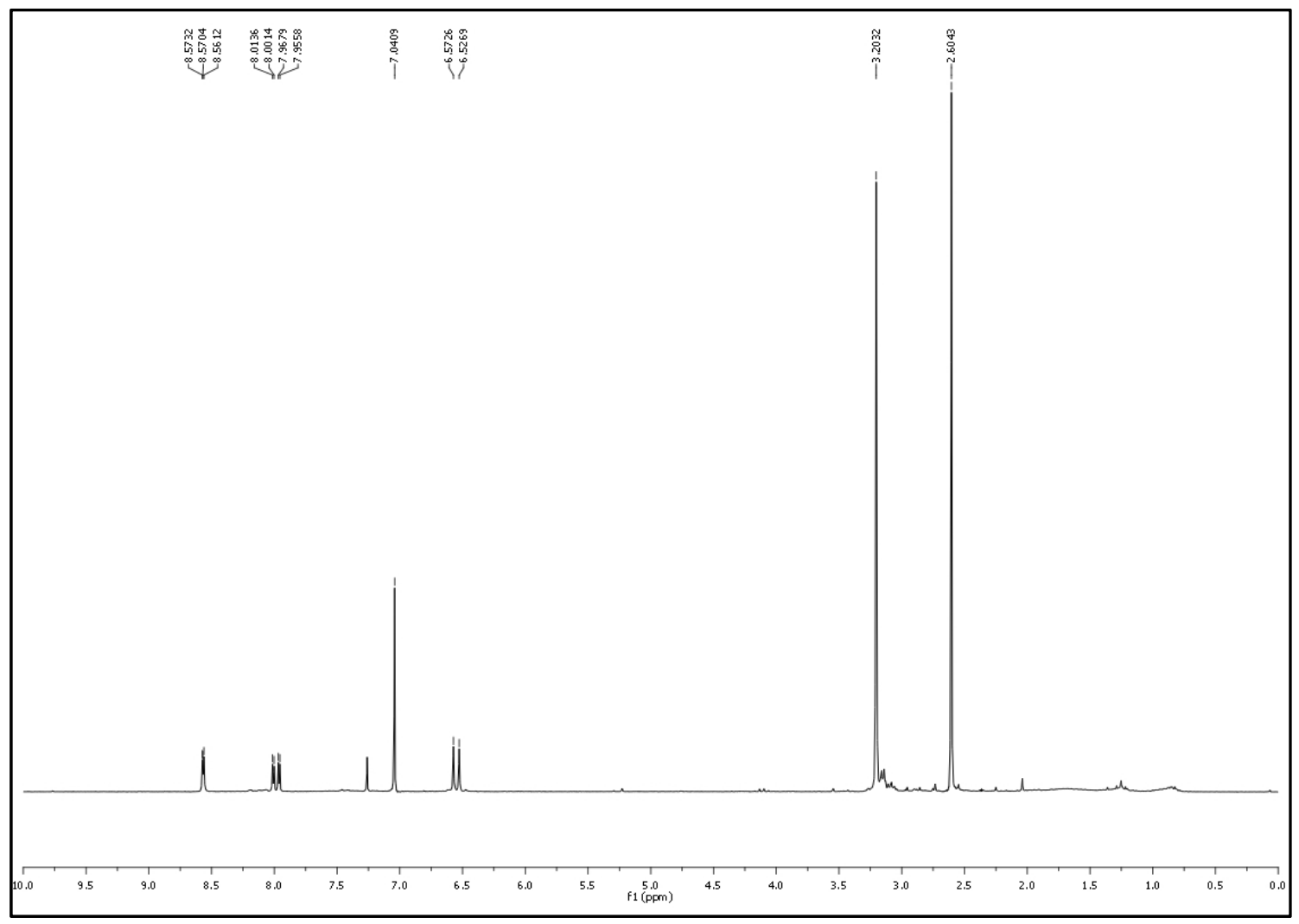

Espectro144H

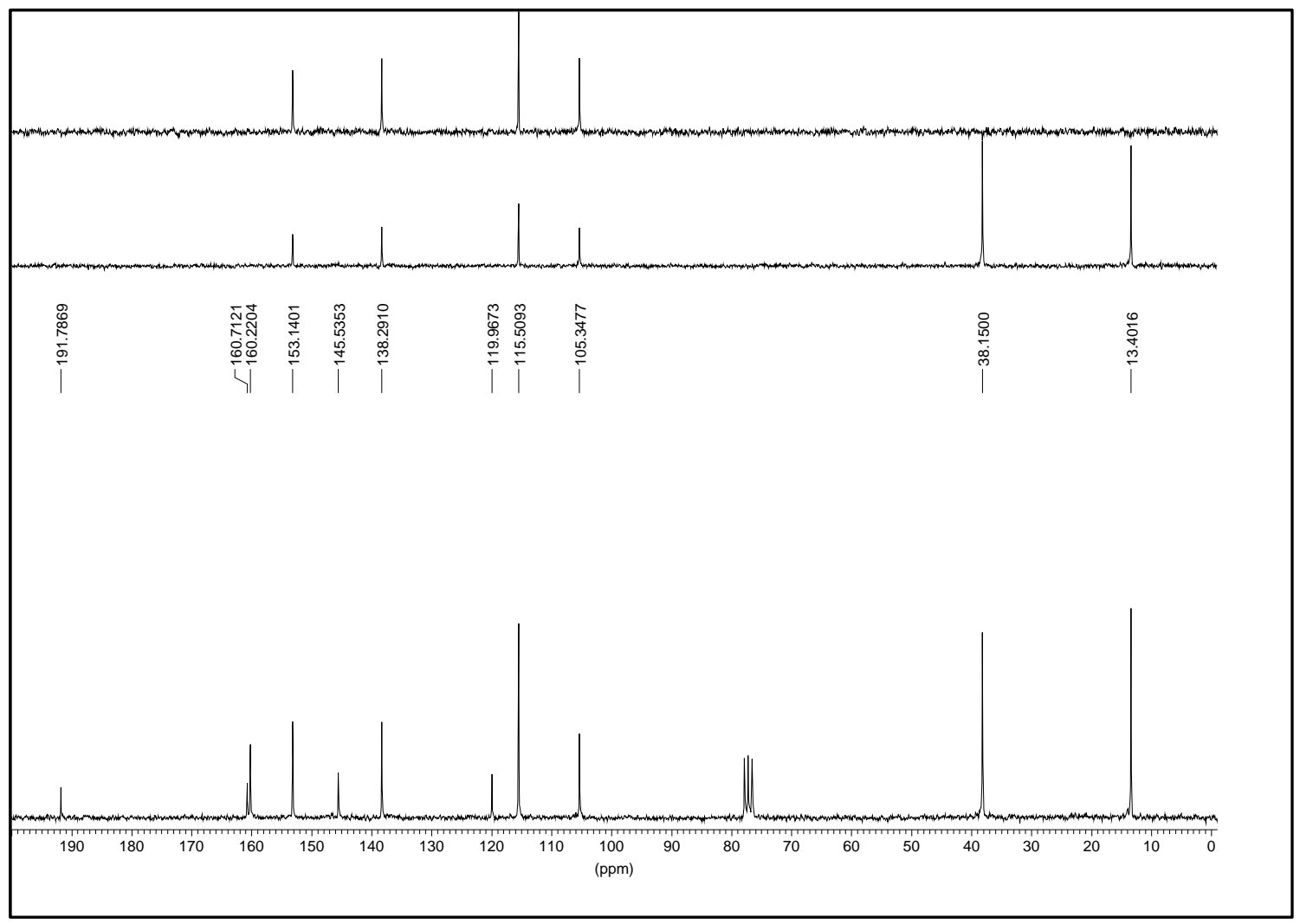

Espectro 144C

416 


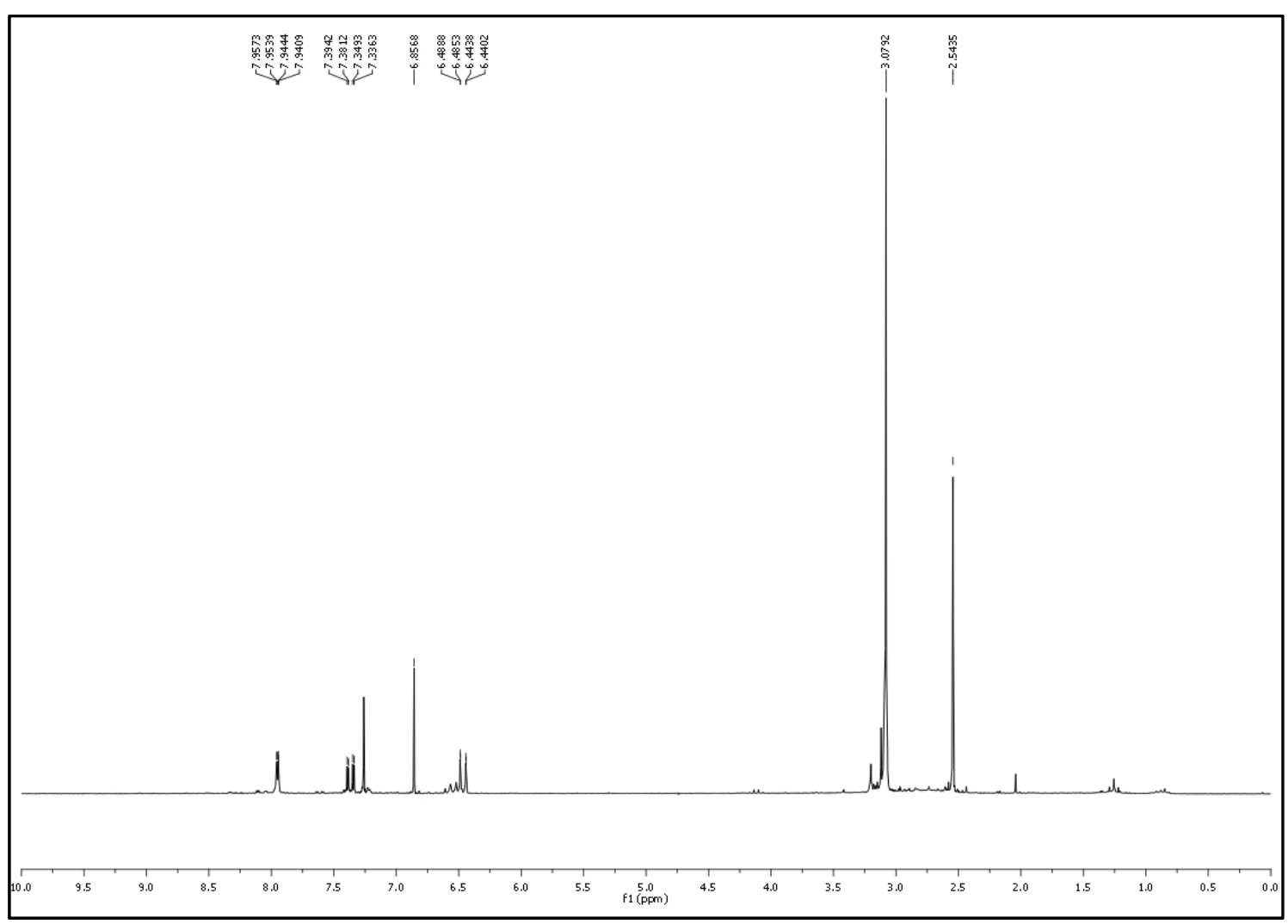

Espectro $145 \mathrm{H}$

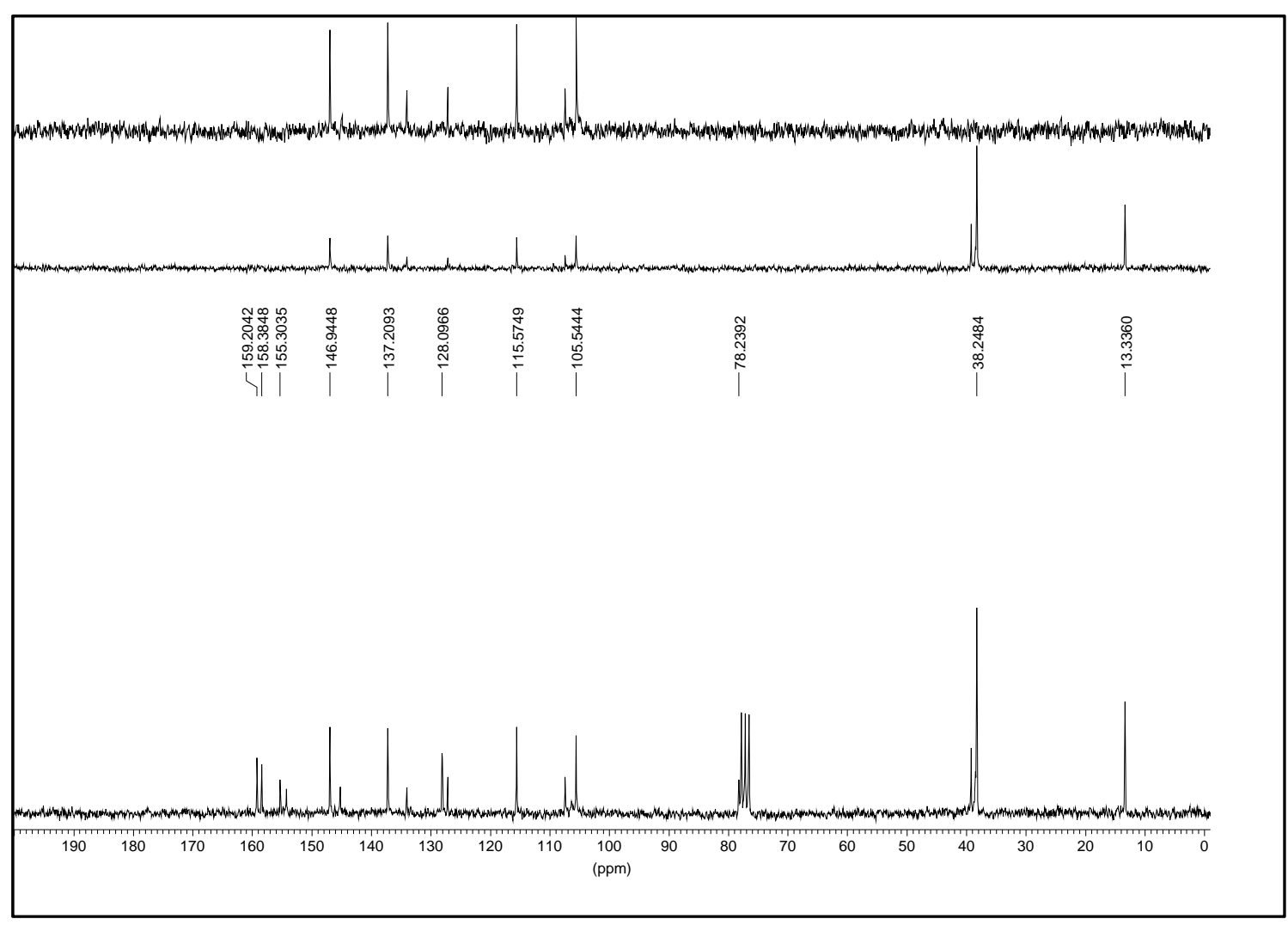

Espectro 145C 


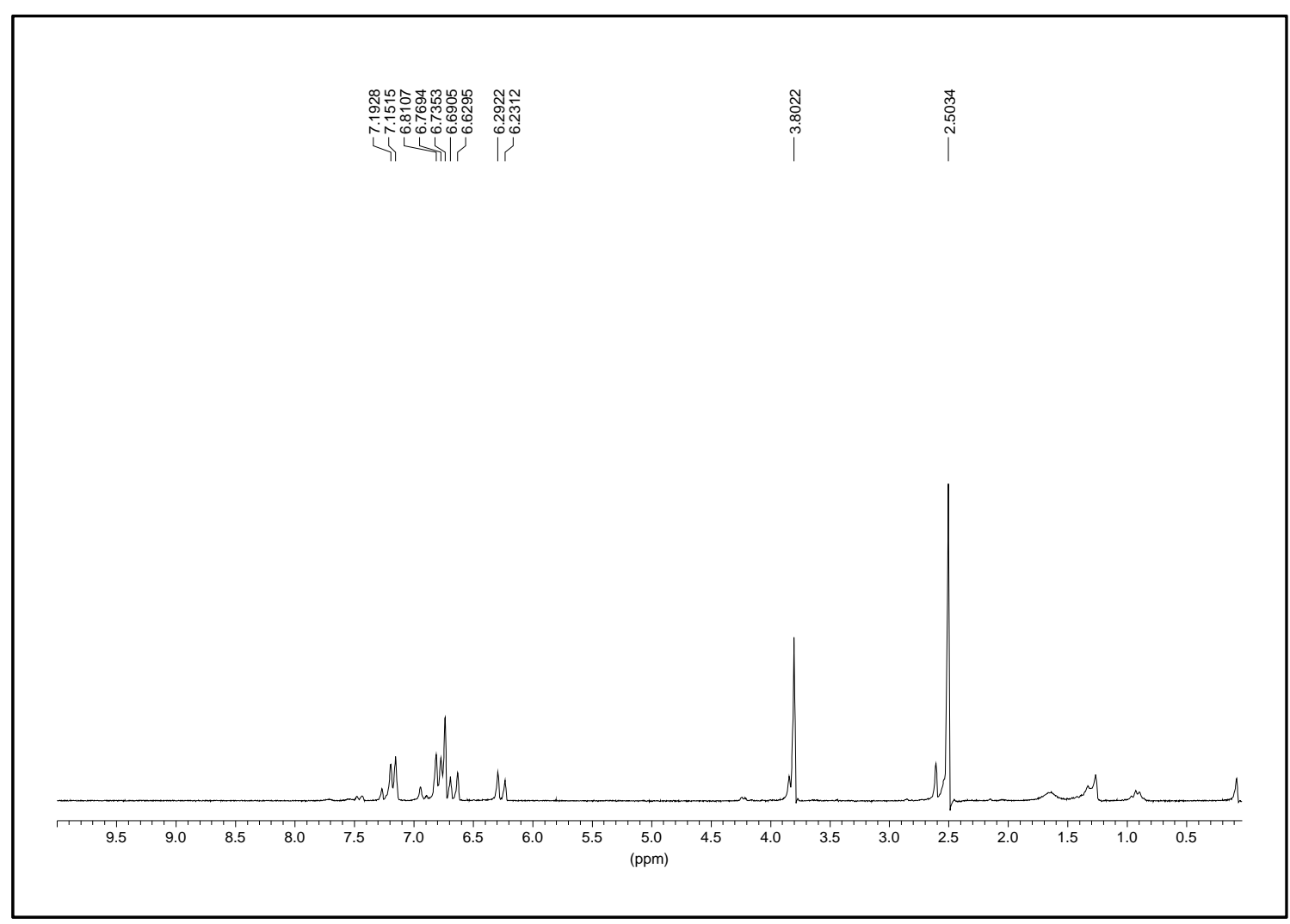

Espectro 146ZH

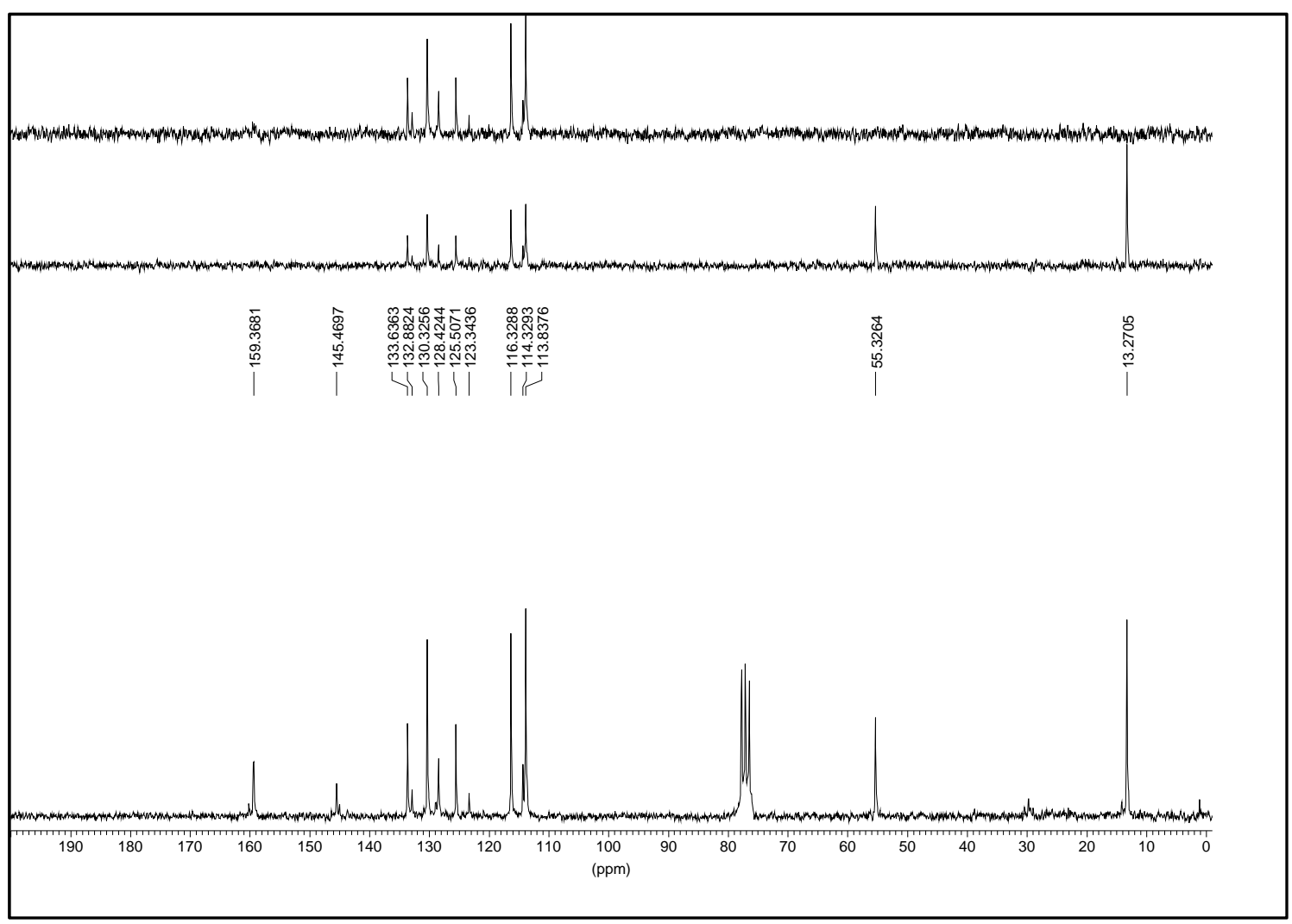

Espectro 146ZC 


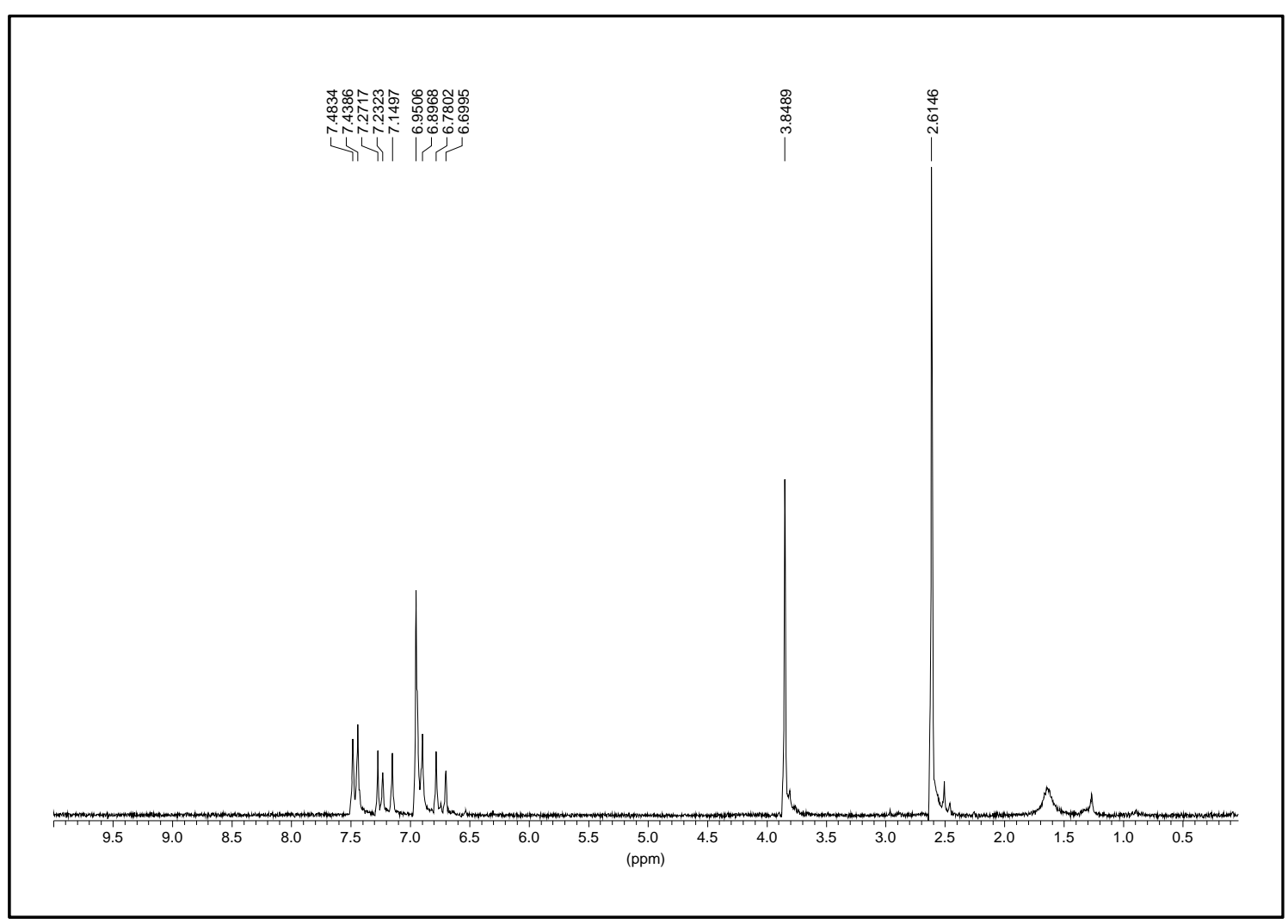

\section{Espectro 146EH}

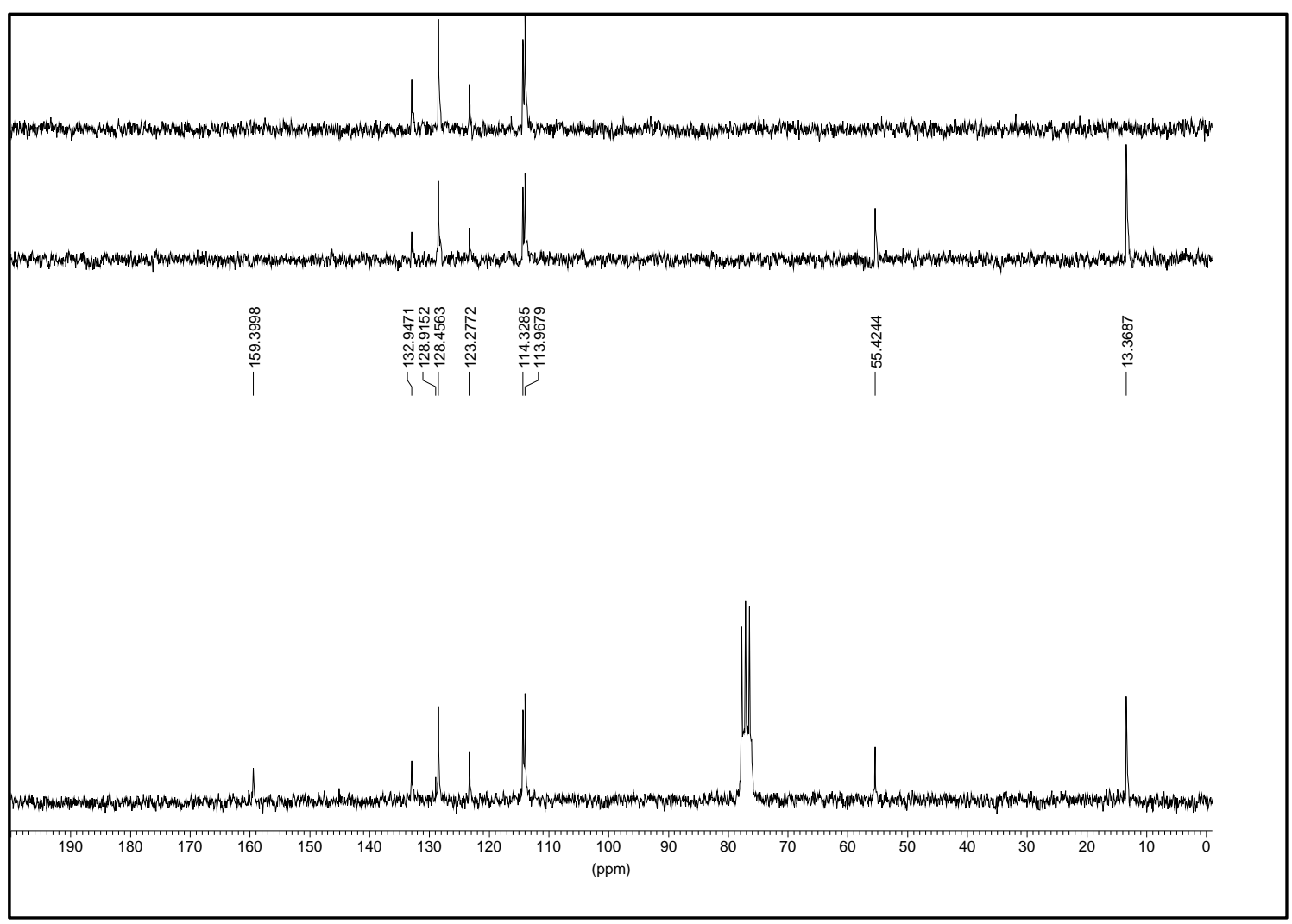

Espectro 146EC 


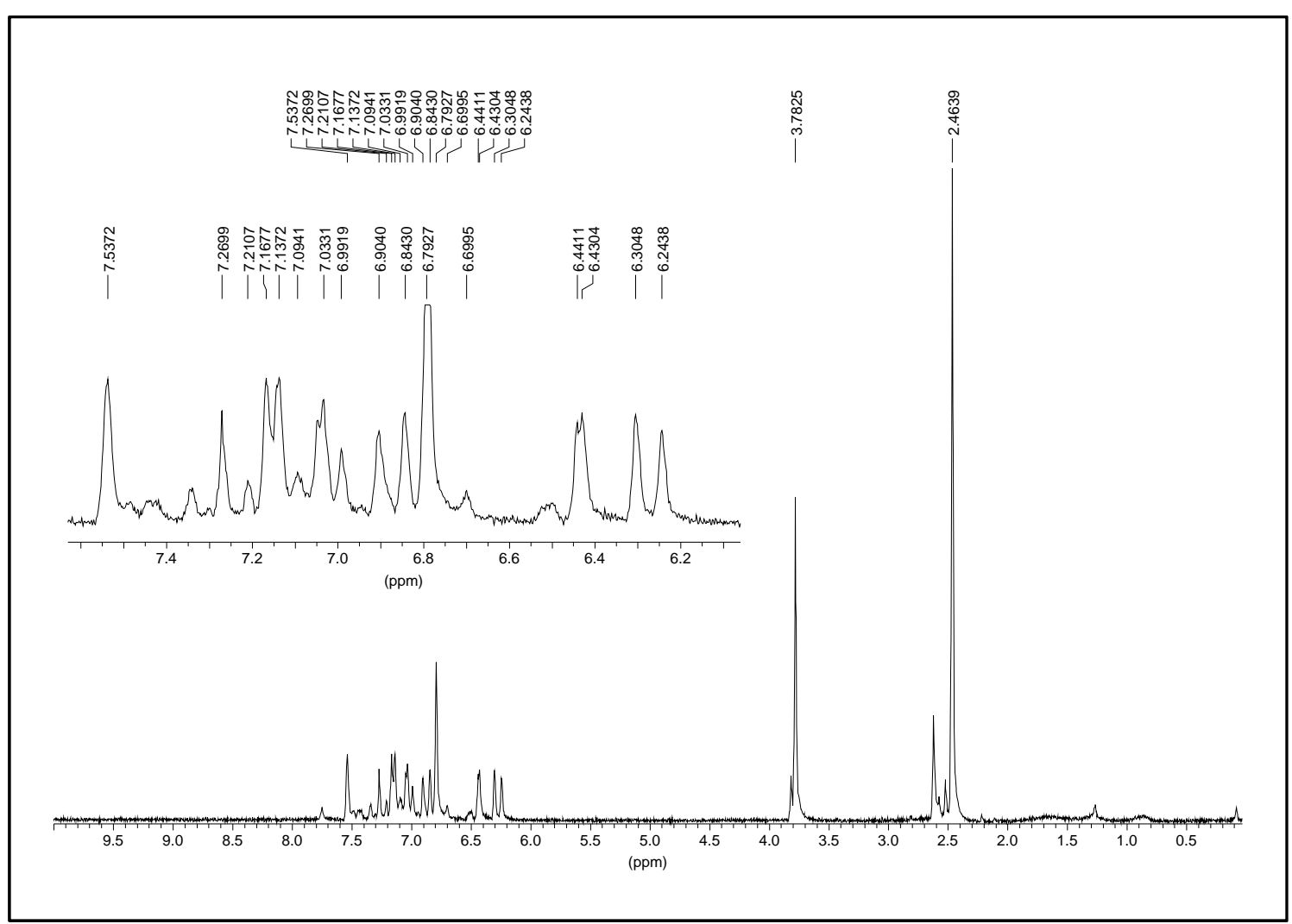

\section{Espectro 147ZH}

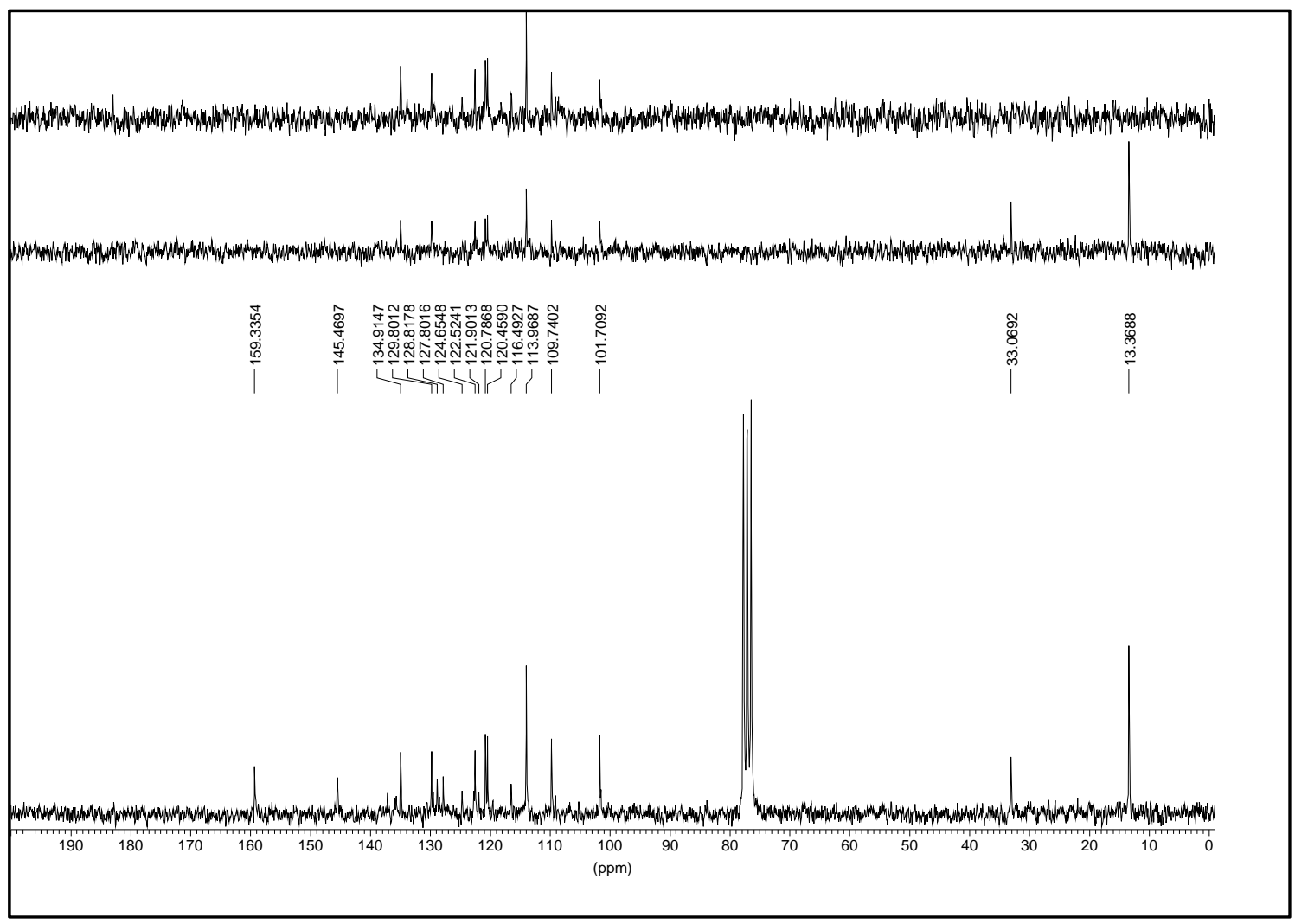

Espectro 147ZC 


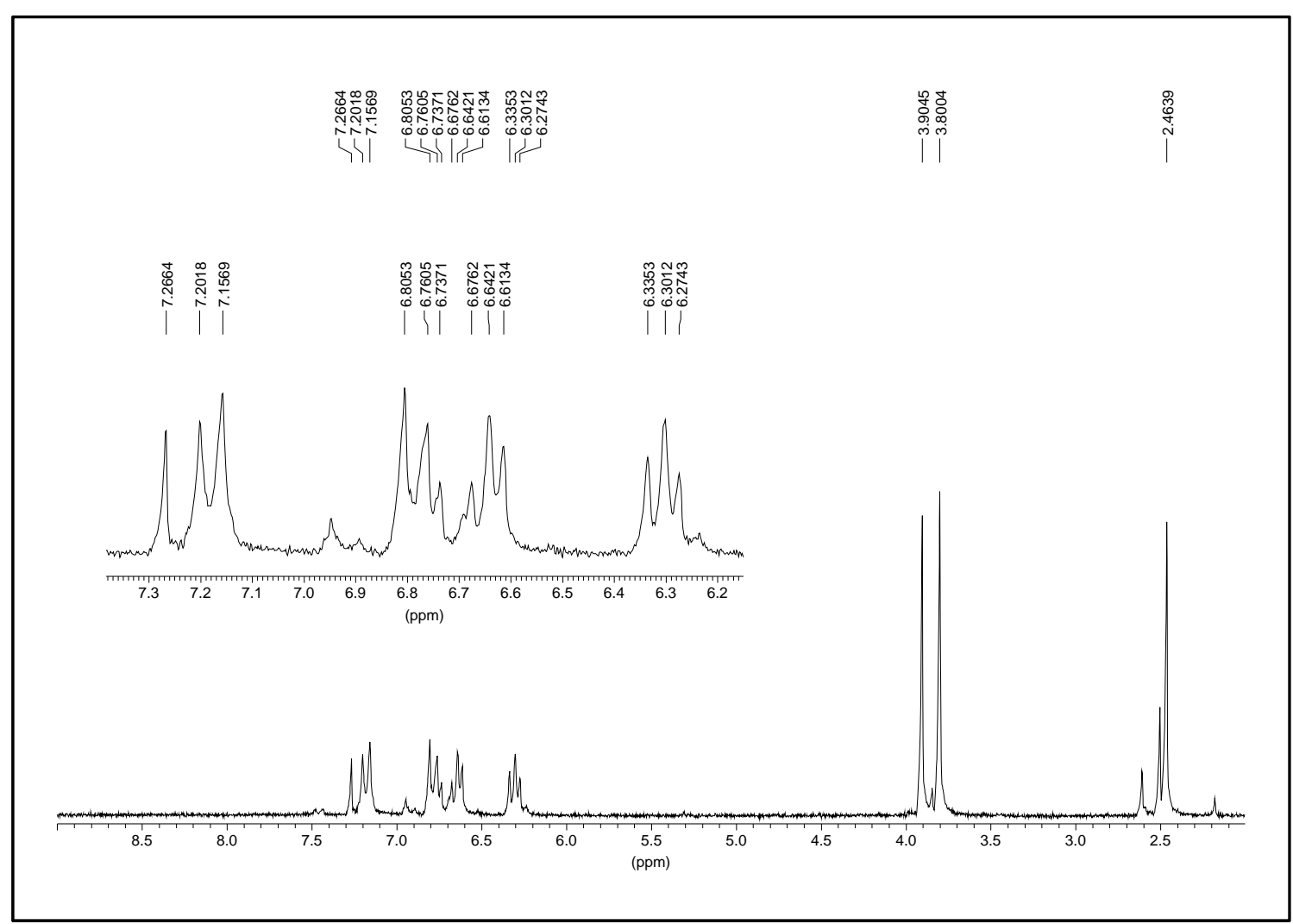

\section{Espectro 148ZH}

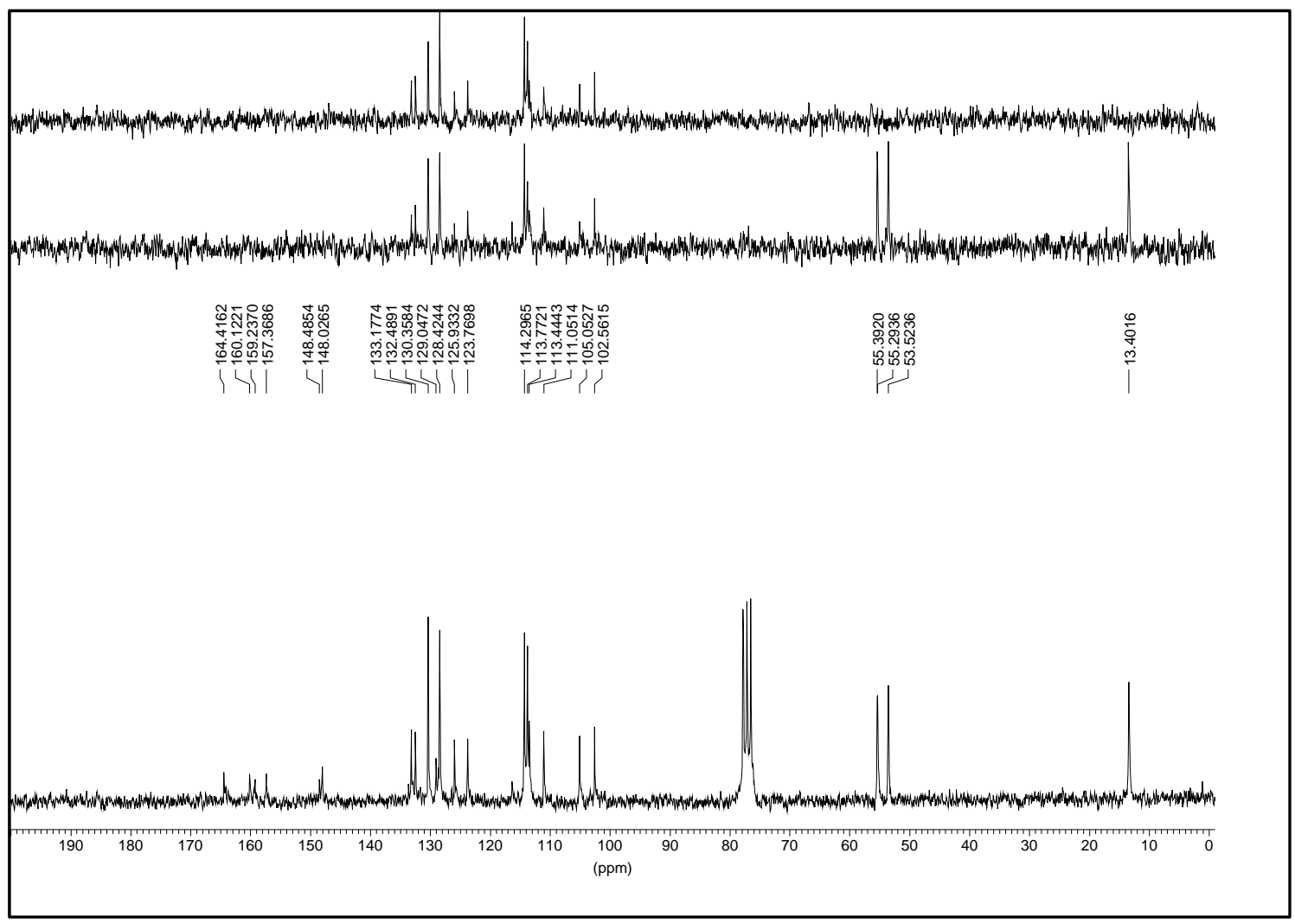

Espectro 148ZEC 


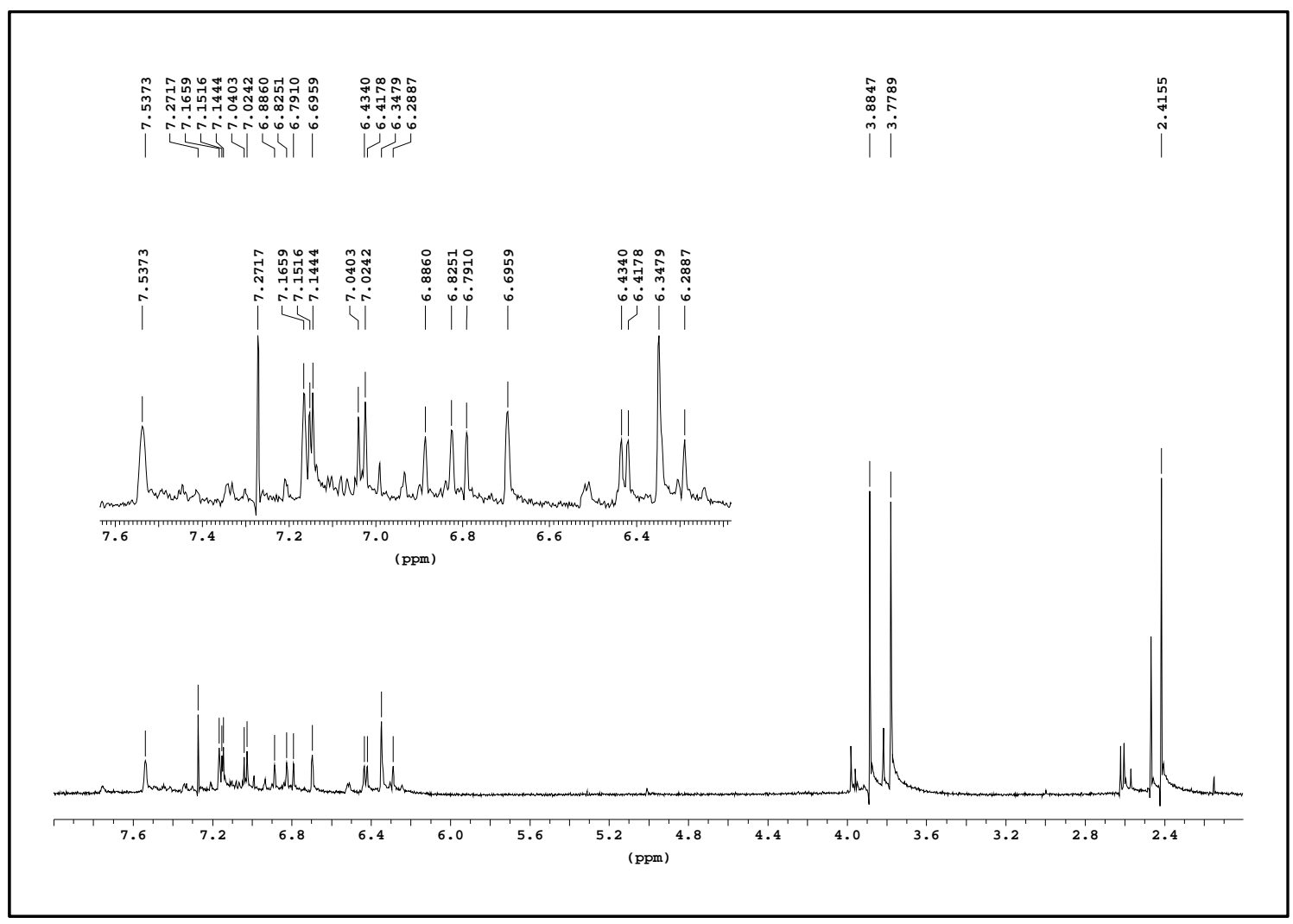

Espectro 149ZH

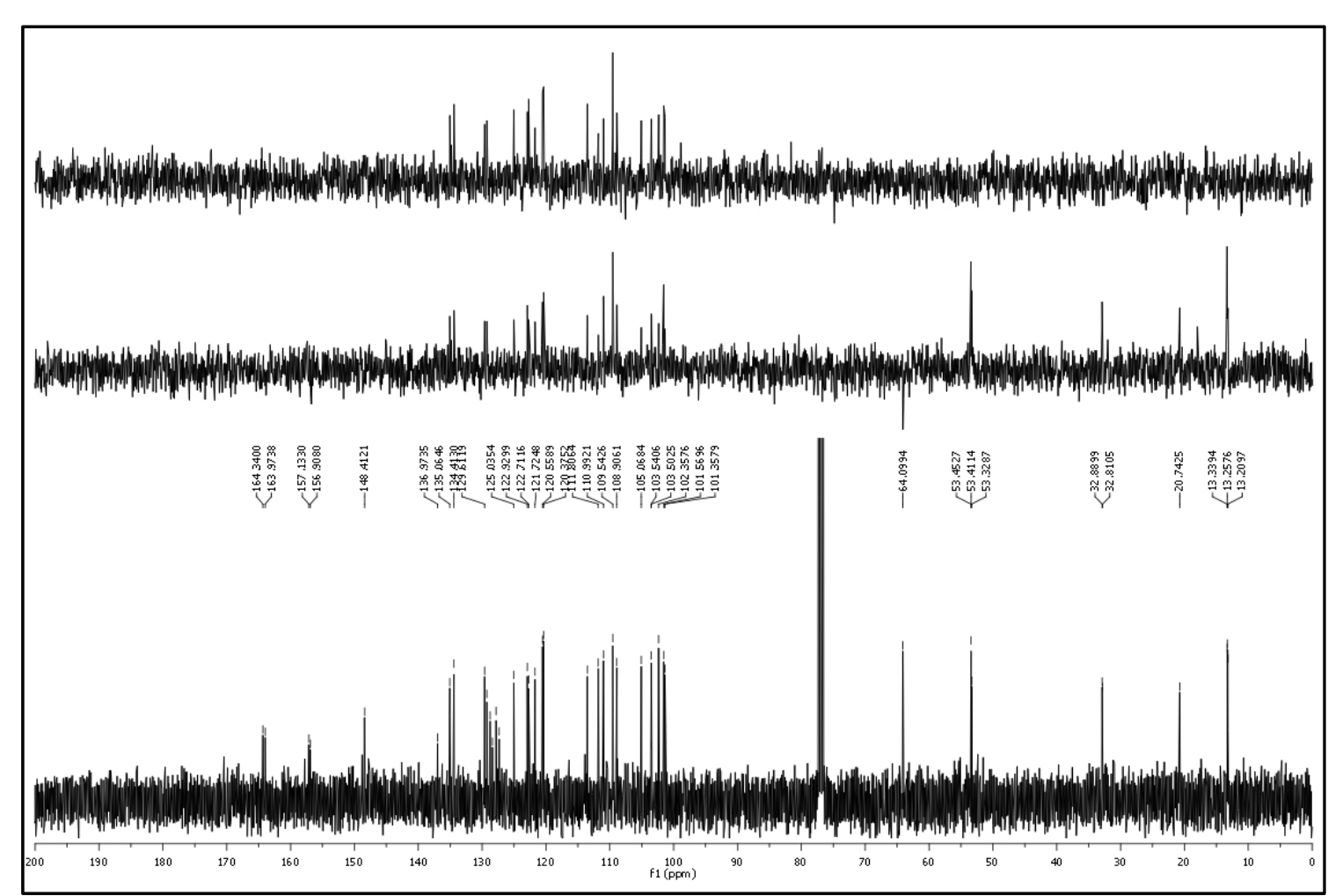

Espectro 149ZEC 


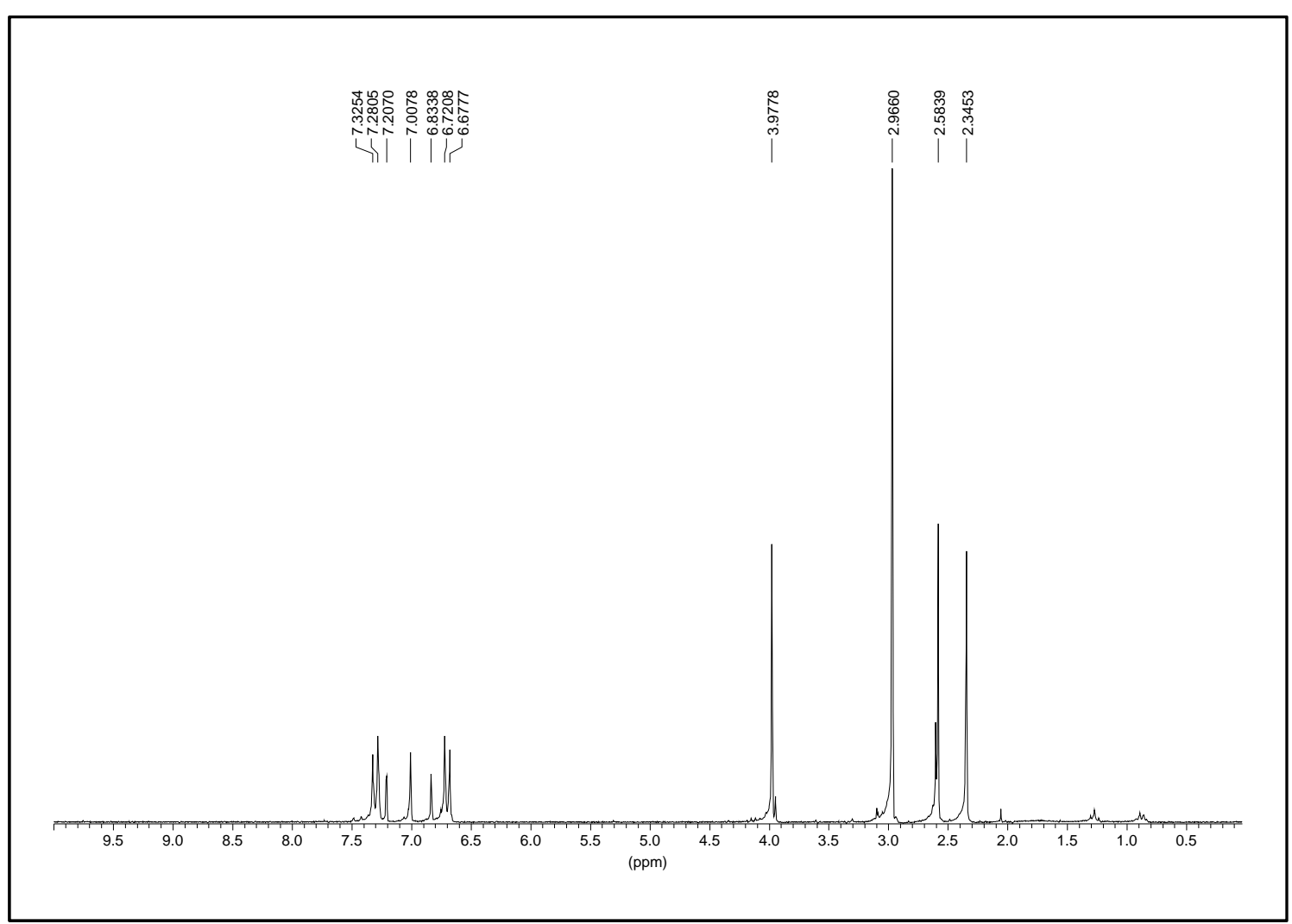

\section{Espectro $150 \mathrm{H}$}

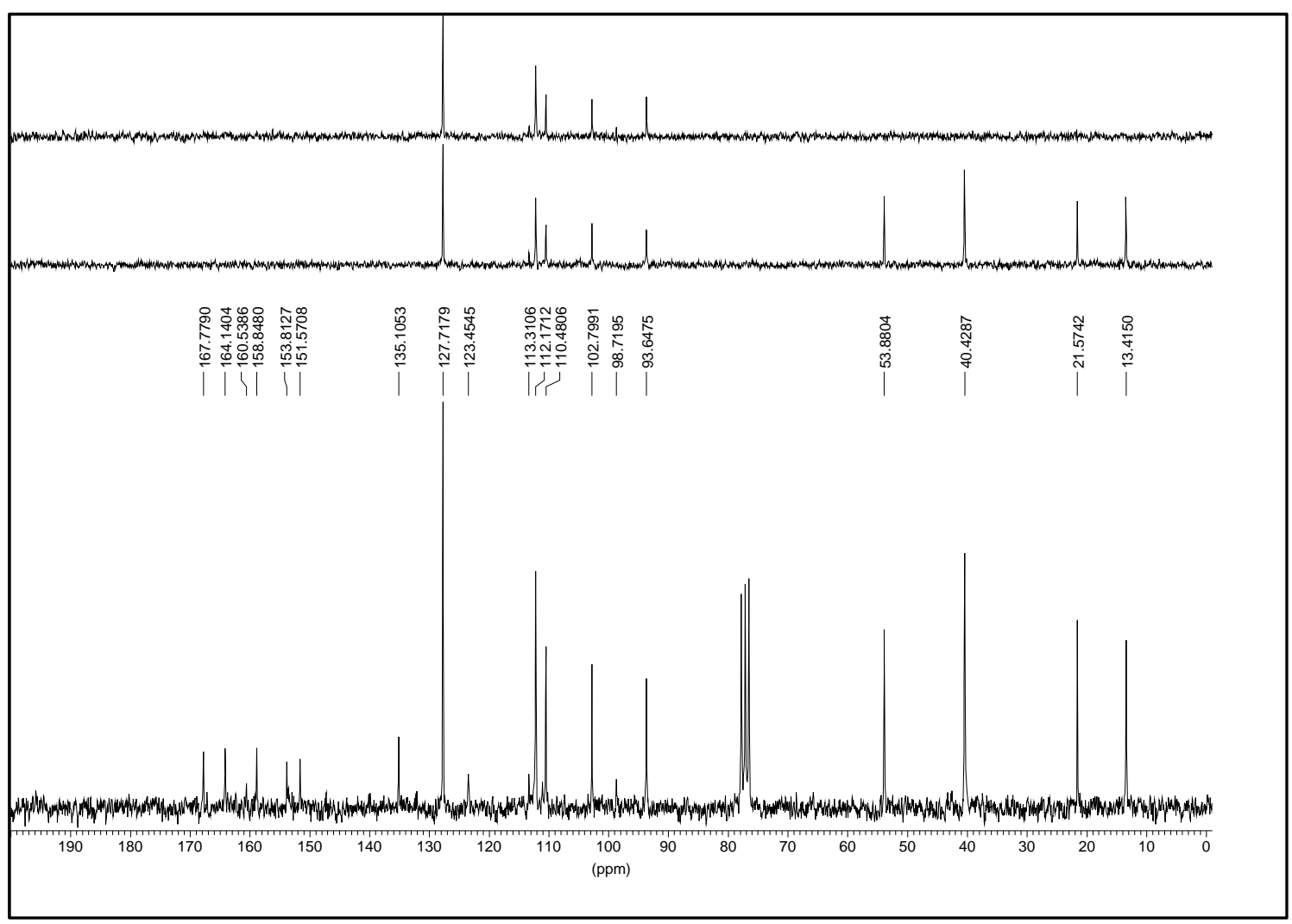

Espectro 150C 


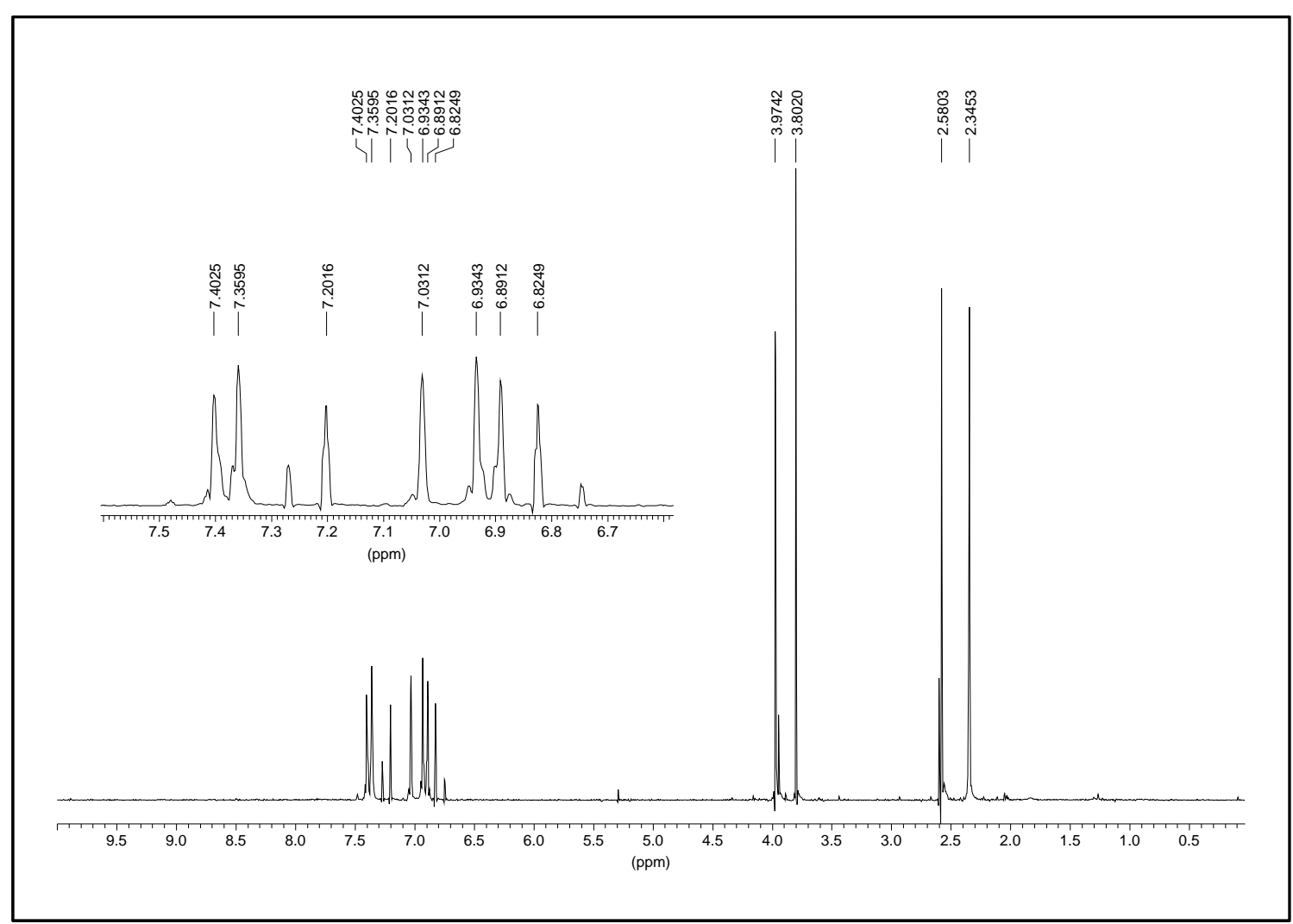

Espectro $151 \mathrm{H}$

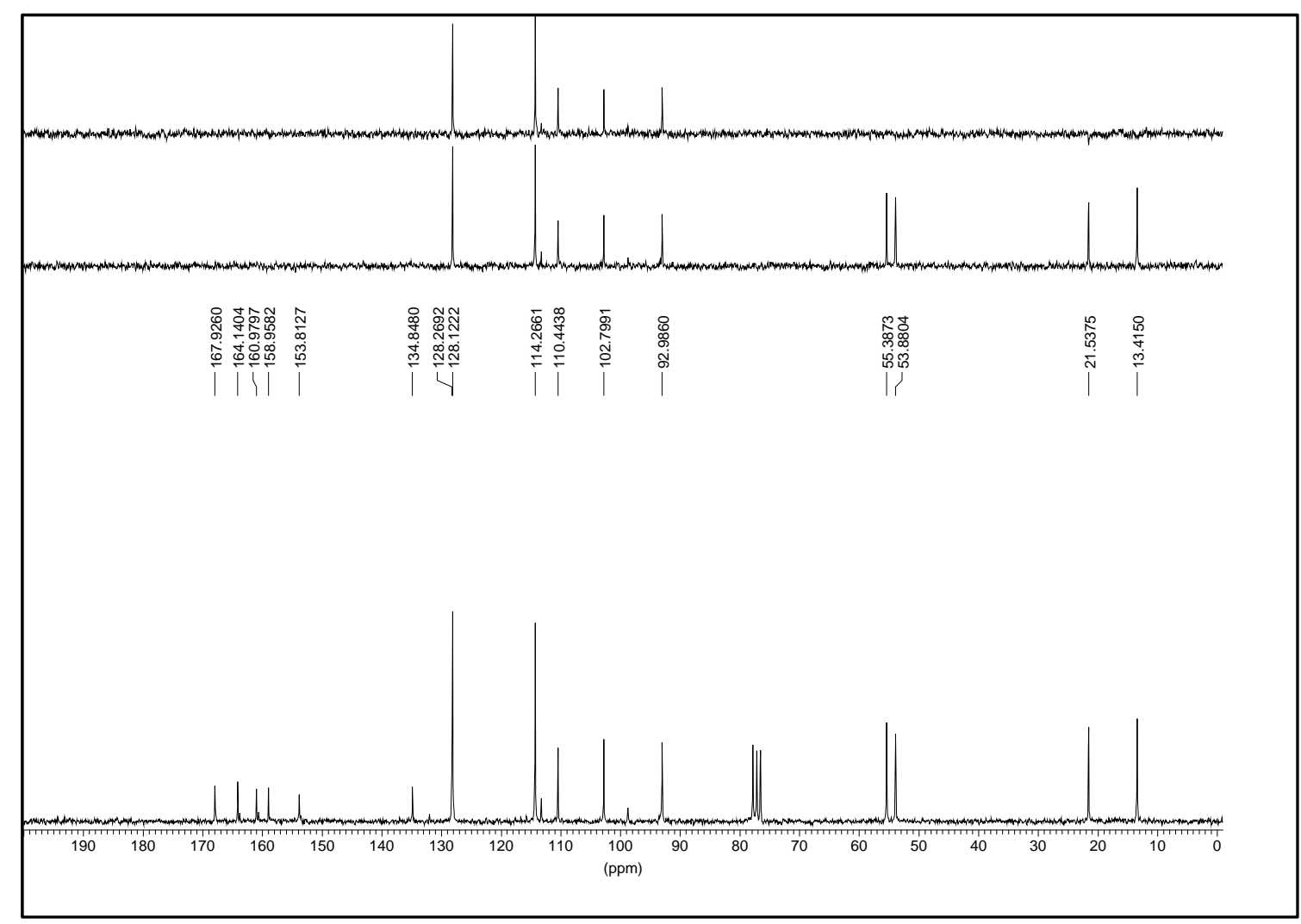

Espectro 151C 


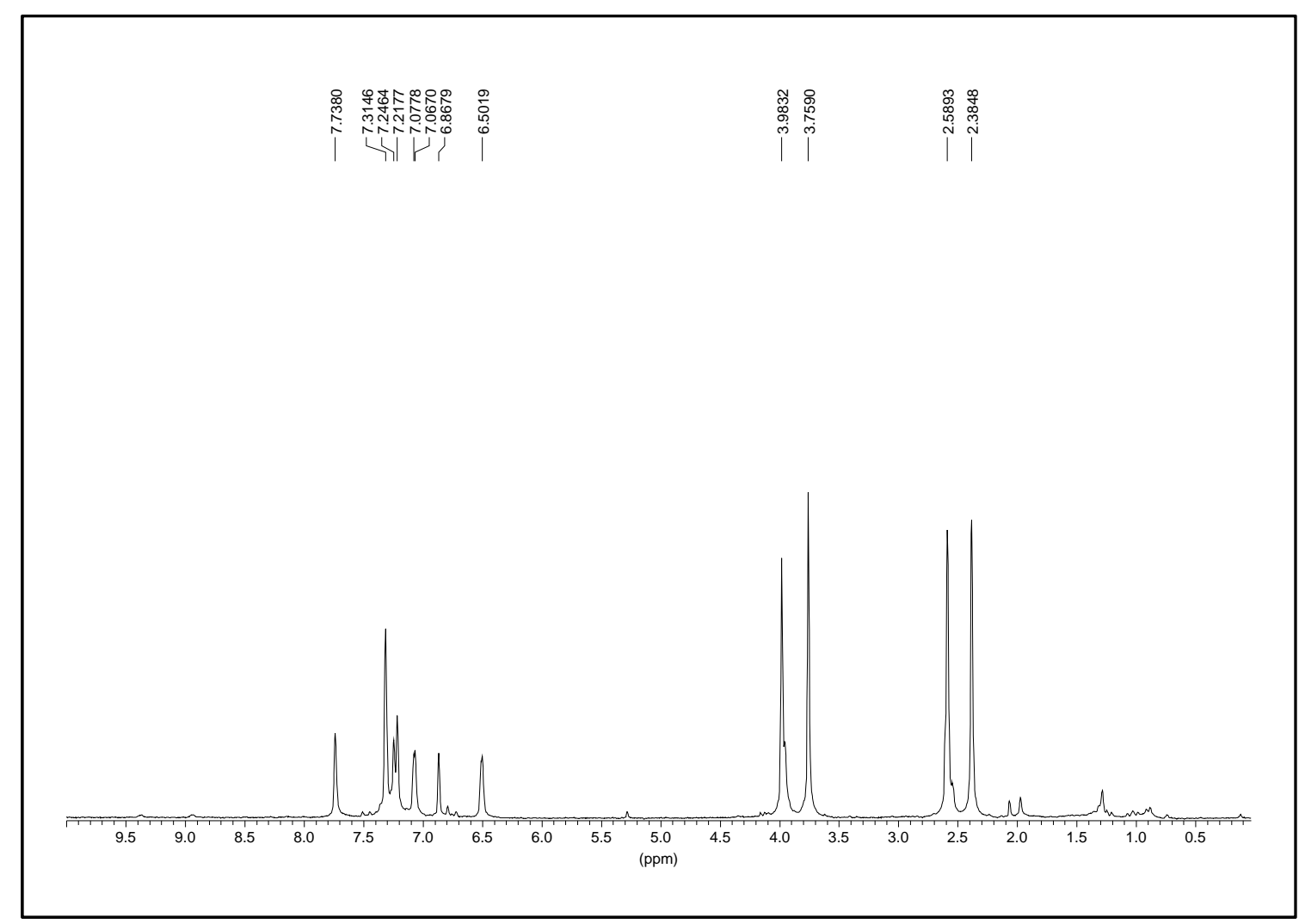

Espectro $152 \mathrm{H}$

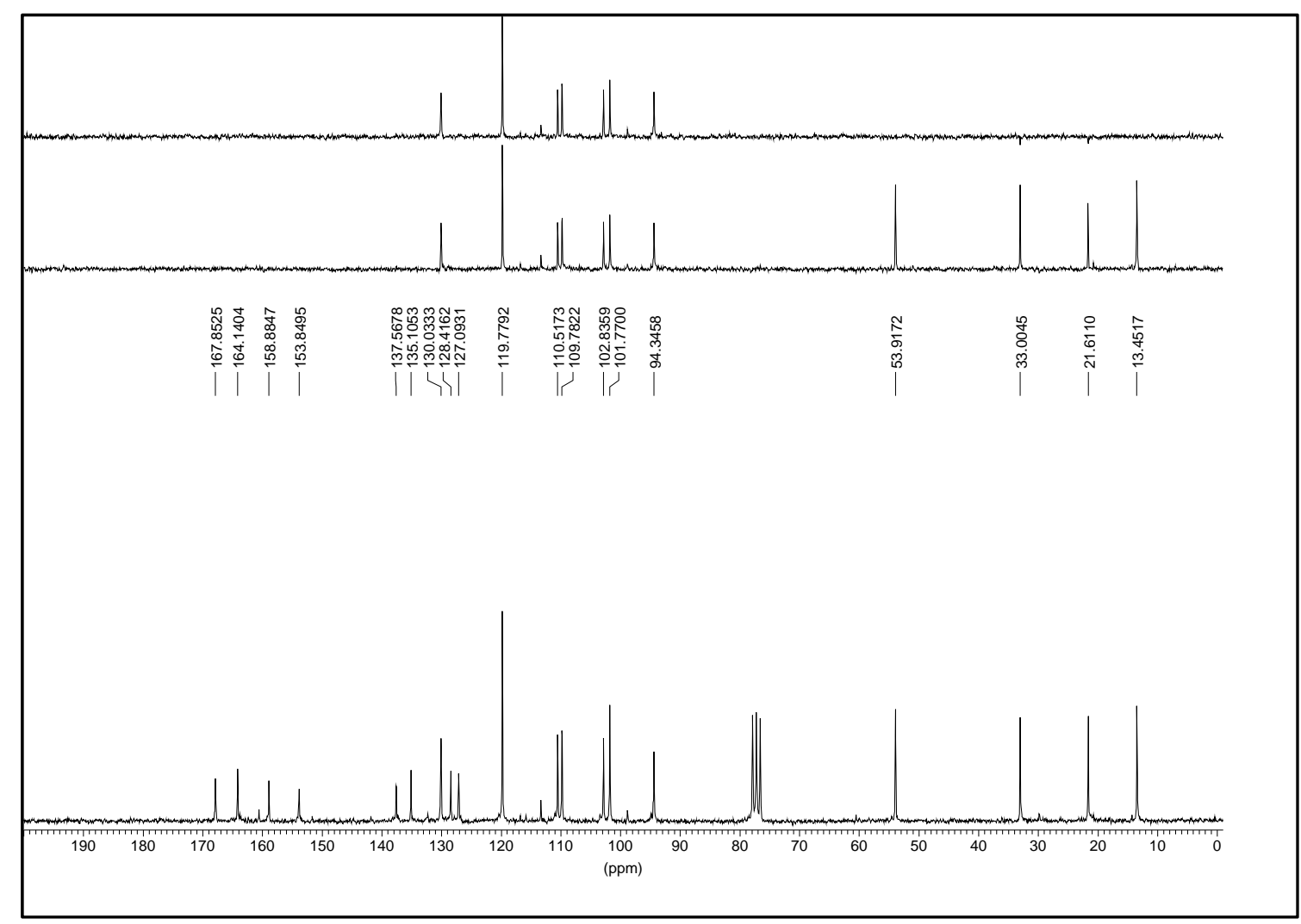

Espectro 152C 

G ENGLISH SVMMARY 



\title{
VNIVERSITYY OF SALAMANCA
}

\author{
FACVLTY OF PHAR MACY
}

DEPARTMENT OF MEDICINAL CHEMISTRY

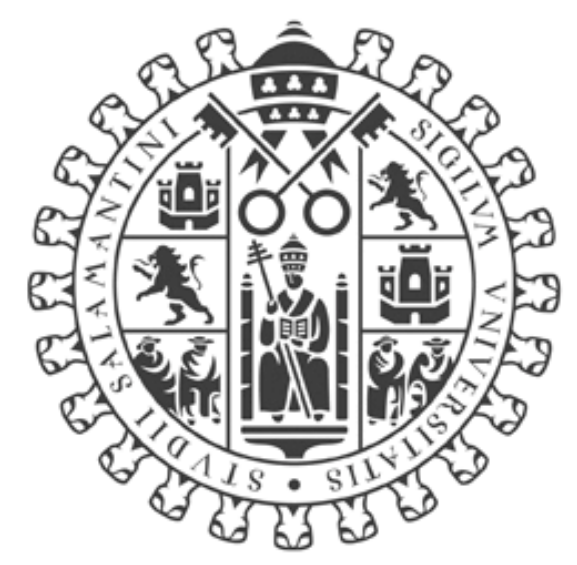

PYRIDINE BASED ANALOGUES OF PHENSTATINS AND ISOCOMBRETASTATINS

DOCTORAL THESIS: ENGLISH SUMMARY

LAURA ARAMBURU VILLAR

DECEMBER 2014 



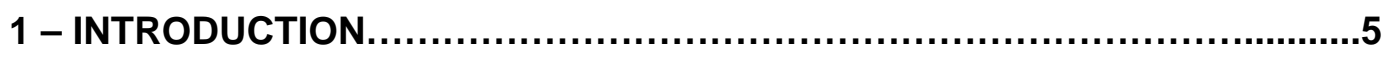

1.1 Pharmacophore and Structure Activity Relationship (SAR) ..........

1.1.1 A Ring modifications...................................

1.1.2 B Ring modifications......................................

1.1.3 Bridge modifications....................................... 9

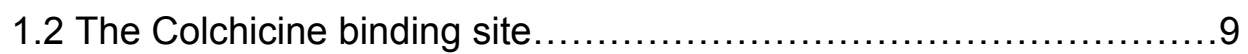

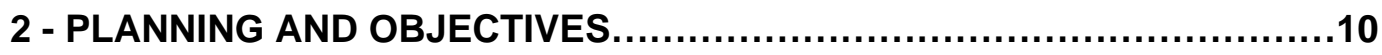

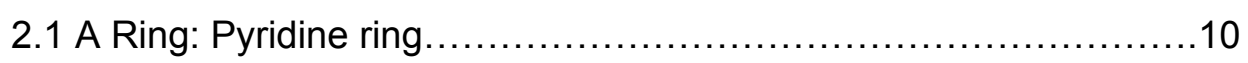

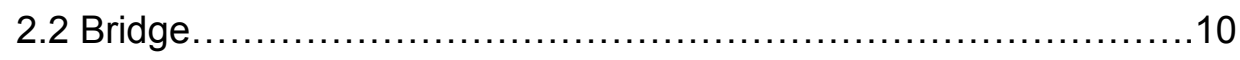

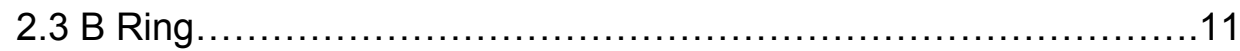

2.4 Objectives....................................................... 12

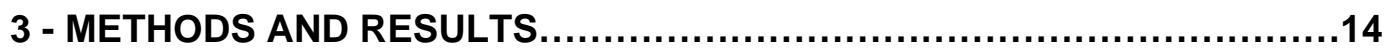

3.1 Synthesis of Phenstatins........................................ 14

3.1.1 Synthesis of starting materials .........................15

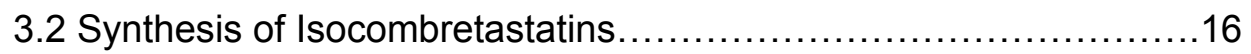

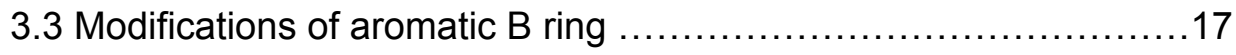

3.3.1 Modification of the phenyl ring..........................17

3.3.2 Modifications at the position 3 of the indole ring...........17

3.3.2.1 Formylations.................................... 18

3.3.2.2 Introduction of carboxylic acids..................18

3.3.2.3 Formation of carbonitriles.......................18

3.3.2.4 Synthesis of amides.............................19

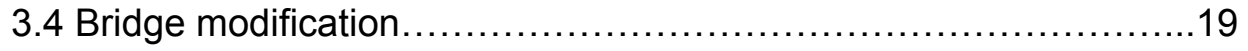

3.5 Synthesis of Combretastatins...................................20

3.5.1 Preparation of phosphonium salts from isonicotinic acid...20

3.6 Synthesis of oxadiazolines.......................................21

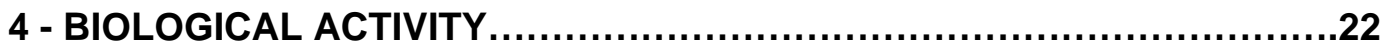

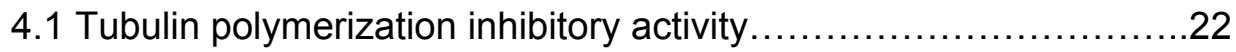

4.1.1 Tubulin isolation.......................................... 22

4.1.2 Tubulin assembly inhibitory activity of the compounds....23

4.1.3 Determination of the $\mathrm{IC}_{50}$ of tubulin assembly inhibitory activity of the selected compounds..........................23

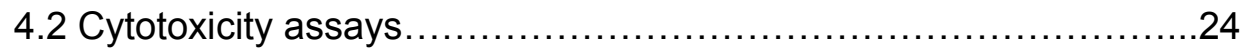

4.3 Discussion of the results of biological activity....................27

4.3.1 Compounds with $p$-methoxyphenyl as $\mathrm{B}$ ring $\ldots \ldots \ldots \ldots \ldots 27$ 
4.3.2 Compounds with $N$-methylindole as B ring.

4.3.3 Compounds with other aromatic systems as $B$ ring........28

4.3.4 Compounds with more than bridging atom................28

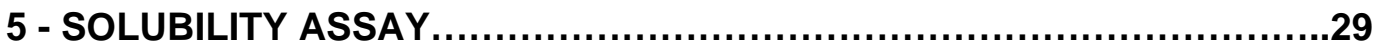

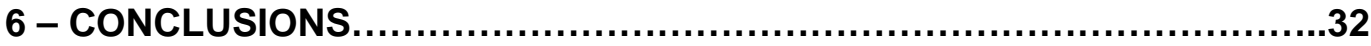




\section{1 - INTRODUCTION}

Cancer is a group of diseases characterized by an uncontrolled cell proliferation and tissue invasiveness causing metastasis. According to $\mathrm{WHO}$, cancer is one of the leading causes of death worldwide.

Chemotherapy drugs that affect cell division are frequently used in the treatment of cancer. Microtubules ${ }^{1}$ are one of the most important targets of anticancer drugs, because of their significant role in many cellular processes. Microtubules are protein polymers composed by heterodimers of $\alpha$-tubulin and $\beta$-tubulin. These tubulin ${ }^{2}$ dimers present multiple drug-binding sites: Taxol, colchicine, vinca alkaloids, laulimalide and peloruside A. Colchicine site ligands produce depolymerization of microtubules. During the last years, our research group has been working on the design, synthesis and activity assays of compounds that bind to this site.

There is a wide structural variety of natural and synthetic compounds that bind to tubulin at the colchicine site $^{3}$, such as quinolones, lignans, benzophenones (phenstatins), combretastatins, sulfonamides, isocombretastatins, etc; however, none

1 Jordan MA, Wilson L. Microtubules as a target for anticancer drugs. Nat Rev Cancer, 2004, 4 , 253-265.

2 Jordan A, Hadfield JA, Lawrence NJ, McGown AT. Tubulin as a target for anticancer drugs: agents which interact with the mitotic spindle. Med Res Rev, 1998,18, 259-296.

${ }^{3}$ a) Massarotti A, Coluccia A, Silvestri R, Sorba G, Brancale A. The tubulin colchicine domain: a molecular modeling perspective. ChemMedChem, 2012, 7, 33-42. b) Lu Y, Chen J, Xiao M, Li W, Miller DD. An overview of tubulin inhibitors that interact with the colchicine binding site. Pharm Res, 2012, 29, 2943-2971. 
of them is currently being used for the clinical treatment of cancer. Nevertheless, there are several compounds that are in advanced clinical trials, including sulfonamide ABT$751^{4}$ (Phase II) and combretastatin ${ }^{5}$ phosphates (CA4P y CA1P).<smiles>COc1cc2c(c(OC)c1OC)-c1ccc(OC)c(=O)cc1[C@H](N)CC2</smiles>

Colchicine<smiles>COc1ccc(/C=C\c2cc(OC)c(OC)c(OC)c2)cc1O</smiles>

$\mathrm{CA}-4$<smiles>COc1ccc(S(=O)(=O)Nc2cccnc2Nc2ccc(O)cc2)cc1</smiles>

ABT-751

Fig 1: Compounds that bind at the colchicine binding site.

During the last years, our research group has focused on the synthesis of colchicines analogues (mostly Phenstatins and Combretastatins) in an attempt to improve the pharmacokinetic properties and the potency of these compounds.

\footnotetext{
${ }^{4}$ Mauer AM, Cohen EE, Ma PC, Kozloff MF, Schwartzberg L, Coates Al, et al. A phase II study of ABT-751 in patients with advanced non-small cell lung cancer. $J$ Thorac Oncol, 2008, 3, 631636. b) Hande KR, Hagey A, Berlin J, Cai Y, Meek K, Kobayashi H, et al. The pharmacokinetics and safety of ABT-751, a novel, orally bioavailable sulfonamide antimitotic agent: results of a phase 1 study. Clin Cancer Res, 2006, 12, 2834-2840.

${ }^{5}$ a) Study of Combretastatin and Paclitaxel/carboplatin in the treatment of Anaplastic Thyroid Cancer, US National Institutes of Health, http://clinicaltrials.gov/show/NCT00507429. Last updating 2012 January. b) Zweifel M, Jayson GC, Reed NS, Osborne R, Hassan B, Ledermann $\mathrm{J}$, et al. Phase II trial of combretastatin A4 phosphate, carboplatin, and paclitaxel in patients with platinum-resistant ovarian cancer. Ann Oncol, 2011, 22, 2036-2041.
} 


\subsection{PHARMACOPHORE AND STRUCTURE ACTIVITY RELATIONSHIP (SAR).}

Combretastatins are compounds with simple structures that bind to the colchicine site, and they have a high cytotoxic potency. However, they have some disadvantages such a low aqueous solubility and the instability of the cis double bond. Phenstatins are analogues of combretastatins without the double bond instability. Other analogues that have been synthesized are isocombretastatins (combretastatins positional isomers).<smiles>COc1ccc(/C=C\c2ccc(OC)c(OC)c2)cc1OC</smiles>

Combretastatin A4<smiles>COc1ccc(C(=O)c2cc(OC)c(OC)c(OC)c2)cc1O</smiles>

Phenstatin<smiles>C=C(c1ccc(OC)c(O)c1)c1ccc(OC)c(OC)c1</smiles>

Isocombretastatin

Fig 2: Structure of combretastatin A-4, phenstatin and isocombretastatin

In order to understand the structure activity relationship of these compounds we focus on the pharmacophore model described by Nguyen $^{6}$ et al. In this model, the pharmacophore consists of seven points on two different planes arranged with an angle of $45^{\circ}$. These seven points are: three hydrogen bond acceptors (A1, A2, A3), a hydrogen bond donor (D1), two hydrophobic centers $(H 1, H 2)$, and one flat group (R1).

\footnotetext{
${ }^{6}$ Nguyen TL, McGrath C, Hermone AR, Burnett JC, Zaharevitz DW, Day BW, et al. A common pharmacophore for a diverse set of colchicine site inhibitors using a structure-based approach. J Med Chem, 2005, 48, 6107-16.
} 
<smiles>COc1cc(C(=O)c2ccc(OCC(=O)O)c(O)c2)cc(OC)c1OC</smiles>

Phenstatins<smiles>C=C(c1ccc(OCC(=O)O)c(O)c1)c1cc(OC)c(OC)c(OC)c1</smiles>

Isocombretastatins

A1 A2 A3 D1 H1 H2 R1

Figure 3: Structure of phenstatins and isocombretastatins with pharmacophore points of Nguyen et al.

Different modifications have been performed on the structure of the compounds leading to changes in activity, and the most significant are detailed below.

\subsubsection{A RING MODIFICATIONS}

A 3,4,5-trimethoxyphenyl A ring was traditionally considered essential for high cytotoxic and tubulin polymerization inhibitory effects. However, new active compounds have been developed introducing modifications at the A ring or even lacking this ring. One of these compounds is ABT-751, a sulfonamide that is currently in clinical trials with a pyridine ring in substitution of the trimethoxyphenyl ring.

\subsubsection{B RING MODIFICATIONS}

The B Ring of combretastatin A-4 accepts many modifications. In our research group we have synthesized numerous analogues during the last years with different structural variations in this ring. The best results were obtained with the $\mathrm{N}$-methyl indol ring showing high potency in isocombretastatin and phenstatin derivatives. In addition, this ring allows the incorporation of functional groups at position 3 , such as carboxylic acids, carbonitriles, amides and aldehydes in order to increase the aqueous solubility of the compounds. 


\subsubsection{BRIDGE MODIFICATIONS}

The bridge between the two aromatic rings must allow a non coplanar position with an angle of about $45^{\circ}$. In this context, there are many inhibitors of tubulin polymerization with different lengths on the bridge (0-4 atoms of carbon).

\subsection{THE COLCHICINE BINDING SITE}

The colchicine binding domain ${ }^{7}$ is located at the interface between the alpha and beta subunits of the tubulin heterodimer. Three different interaction zones ${ }^{8}$ and a spacer have been described taking in consideration the X-ray structures of tubulin with several ligands. Colchicine occupies only zones 1 (seven membered ring) and 2 (trimethoxyphenyl ring), while compounds such as sulfonamide ABT-751 also occupies zone 3 with small aromatic rings.

\footnotetext{
${ }^{7}$ Massarotti A, Coluccia A, Silvestri R, Sorba G, Brancale A. The tubulin colchicine domain: a molecular modeling perspective. ChemMedChem, 2012, 7, 33-42.

${ }^{8}$ Álvarez R, Peláez R, Medarde M. Current Topics Med Chem, 2014, 0000.
} 


\section{2 - PLANNING AND OBJECTIVES}

The main objective of this work is the synthesis and biological evaluation of novel tubulin ligands that enhance cytotoxic potency and increase the aqueous solubility, combining the following structural features: a pyridine moiety (A ring), different length bridges and an aromatic system of one or two rings (B ring).

\subsection{A RING: PYRIDINE RING}

Trimethoxyphenyl ring has traditionally been considered essential for activity. However, new compounds carrying a smaller pyridine ring have been able to display similar activity (for example ABT-751). In this work, we have selected a pyridine moiety with different substituents at the 2 and 6 positions as a replacement of the 3,4,5trimethoxyphenyl ring.

\subsection{BRIDGE}

The bridge between the two rings can be from zero to four carbon atoms of lenght. In this doctoral work, it has been planned to synthesize compounds with one- 
atom (phenstatin and isocombretastatin), two-atoms (combretastatin) and three atoms bridges (oxadiazoline).

Combretastatins have the disadvantage of the double bond isomerization, therefore, phenstatins ${ }^{9}$ will be synthesized because of their capacity to maintain the activity with the same substitution patterns on $A$ and $B$ rings.

Isocombretastatins will also be synthesized. These compounds are obtained by replacing the carbonyl by a methylene group, a change that leads to a large increase in potency. ${ }^{10}$

\subsection{B RING}

Because indole systems have proved to be good substitutes of the guaiacol moiety as $\mathrm{B}$ ring in both combretastatins and phenstatins, the $\mathrm{N}$-methyl-5-indolyl system has been selected in this work as a structural basis for further modifications. Other aromatic rings such as naphthalene, and dimethylaminophenyl, are also going to be introduced as $B$ ring in order to compare their activity with the known analogues that carry a trimethoxyphenyl ring.

\footnotetext{
${ }^{9}$ Liou JP, Chang CW, Song JS, Yang YN, Yeh CF, Tseng HY, et al. Synthesis and structureactivity relationship of 2-aminobenzophenone derivatives as antimitotic agents. J Med Chem, 2002, 45, 2556-62.

${ }^{10}$ a) Álvarez R, Puebla P, Díaz JF, Bento AC, García-Navas R, de la Iglesia-Vicente J, et al. Endowing indole-based tubulin inhibitors with an anchor for derivatization: Highly potent 3substituted indolephenstatins and indoleisocombretastatins. J Med Chem, 2013, 56, 2813-27.
} 


\subsection{OBJECTIVES}

After this general planning, the specific objectives that have been set for this Ph.D. work are the following:

- First objective: Synthesis of pyridine-4-carboxylic acids with different substituents at the 2 and 6 positions as starting materials for the synthesis of phenstatins and isocombretastatins.

- Second objective: Synthesis of phenstatins and isocombretastatins with a pyridine moiety as A ring and a 4-methoxyphenyl as B ring. Nitro and amino groups are going to be introduced at position 3 , as well as other modifications on the bridge.

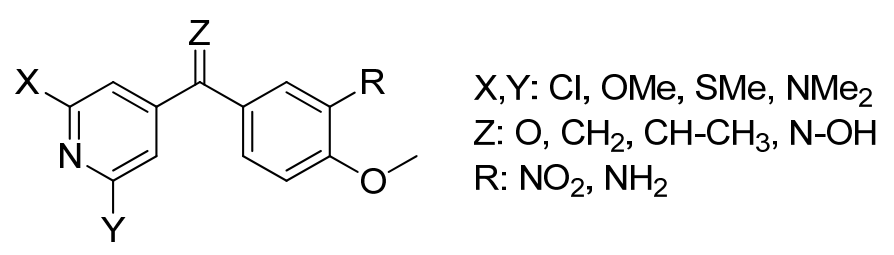

To explore the zone 3 of the colchicine binding domain, compounds with additional aromatic ring at the 6 position of the pyridine will be synthesized.<smiles>[R][X]CC</smiles>

- Third objective: Synthesis of phenstatins and isocombretastatins based on the 5-indolyl moiety as B ring, with or without substituents at the C-3 position.<smiles>[X]c1cc(C(=[Z])c2ccc3c(c2)c([R])cn3C)cc([X])n1</smiles>

$\mathrm{X}, \mathrm{Y}: \mathrm{Cl}, \mathrm{OMe}, \mathrm{SMe}, \mathrm{NMe}_{2}, \mathrm{SOMe}, \mathrm{SO}_{2} \mathrm{Me}$

$\mathrm{Z}: \mathrm{O}, \mathrm{CH}_{2},-\mathrm{CH}_{3}, \mathrm{~N}-\mathrm{OH}$

R: $\mathrm{CHO}, \mathrm{COOH}, \mathrm{CONH}_{2}, \mathrm{CN}$ 
- Fourth objective: Synthesis of phenstatins and isocombretastatins with other aromatic rings (naphthalene, dimethylaminophenyl or pyridine) as B ring.<smiles>[X]c1cc(C([Z])c2ccc3ccccc3c2)cc([X])n1</smiles><smiles>[X]c1cc(C([Z])c2ccc(N(C)C)c([Y])n2)cc([X])n1</smiles>

$\mathrm{X}, \mathrm{Y}: \mathrm{OMe}, \mathrm{SMe}$ $\mathrm{Z}: \mathrm{O}, \mathrm{CH}_{2}, \mathrm{~N}-\mathrm{OH}$ $\mathrm{R}: \mathrm{CH}, \mathrm{N}$

- Fifth objective: Additionally to the synthesis of compounds with one carbon atom bridge, the synthesis of compounds with bridges of two (combretastatins) or three (oxadiazoline) atoms length will be carried out.

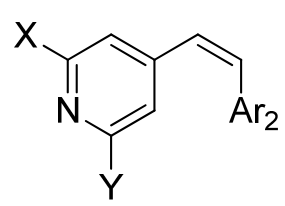<smiles>[X]c1cc(C2=NN(C(C)=O)C([Y16])O2)cc([X])n1</smiles>

- Sixth objective: Perform inhibition of tubulin polymerization assays for all the synthesized derivatives. The most potent compounds will be selected to determine the $\mathrm{IC}_{50}$ values.

- Seventh objective: Perform cytotoxicity assays on tumoral cell cultures (HeLa, HT29, HL60). The best compounds will be selected to determine the $\mathrm{IC}_{50}$ value against the three tumoral cell lines.

- Eighth objective: Determine the aqueous solubility of the compounds. 


\section{3 - METHODS AND RESULTS}

As planned in the previous section, the compounds to be synthesized are:

$\checkmark$ One-atom bridged compounds: Phenstatins

$\checkmark$ One-atom bridged compounds: Isocombretastatins

$\checkmark$ Two-atom bridged compounds: Combretastatins

$\checkmark$ Three-atom bridged compounds: Oxadiazolines

\subsection{SYNTHESIS OF PHENSTATINS}

The method used for the synthesis of phenstatin analogues consist in the preparation of an organolithium derivative, by treating the bromo derivative with $n$ BuLi. The organolithium derivative reacts with a carboxylic acid giving the phenstatins directly.

$$
\mathrm{Ar}_{2}-\mathrm{Br} \underset{\text { dry THF }}{\stackrel{n \mathrm{BuLi}}{\longrightarrow}} \mathrm{Ar}_{2}-\mathrm{Li} \stackrel{\mathrm{Ar}_{1}-\mathrm{COOH}}{\longrightarrow} \mathrm{Ar}_{1} \stackrel{\mathrm{O}}{\mathrm{Ar}_{2}}
$$

Scheme 1: Synthetic scheme for phenstatins

\footnotetext{
${ }^{*} \mathrm{Ar}_{1}$ : A Ring

$\mathrm{Ar}_{2}$ : B Ring
} 
Organolithium derivatives are formed by the slow addition of $n \mathrm{BuLi}$ over the halogen derivative previously dissolved in dry THF at $-40^{\circ} \mathrm{C}$, in a $1: 1$ ratio. Isomerization products are not observed at the low temperatures employed.

The next step is the slow addition of the carboxylic acid dissolved in dry THF. In this reaction, two equivalents of organolithium derivatives are consumed for each equivalent of acid, unless the potassium salt of the carboxylic acid is previously prepared. One equivalent reacts with the acidic proton and the other one is added to the carboxylate anion.

\subsubsection{SYNTHESIS OF STARTING MATERIALS}

The first step in this work is the synthesis of pyridines with a carboxilic acid at position 4, and two different substituents at 2 and 6 positions. The synthesis starts from citrazinic acid, which is a cheap commercial product.

From citrazinic acid, using phosphorus oxychloride and tetramethyl ammonium chloride as catalyst, the 2,6-dichlorocitrazinic acid was synthesized. The purpose of this step is to facilitate the entry of different substituents at the 2 and 6 positions. From the dichloro derivative, numerous substituents can be sequentially introduced using different nucleophilic agents and reaction conditions.

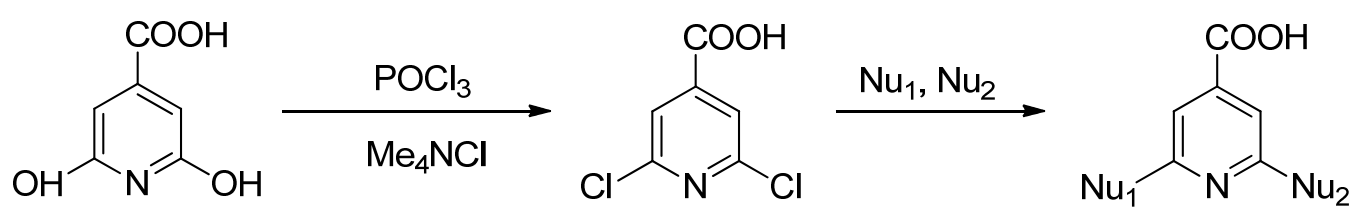

Scheme 2: Synthetic scheme of disubstituted pyridine ring 
Synthesized pyridine compounds are summarized in the following figure:<smiles>[X]c1cc(C(=O)O)cc([Y])n1</smiles>

\begin{tabular}{c|cc}
$\mathbf{n} \boldsymbol{0}$ & $\mathbf{X}$ & $\mathbf{Y}$ \\
\hline $\mathbf{1}$ & $\mathrm{Cl}$ & $\mathrm{Cl}$ \\
\hline $\mathbf{2}$ & $\mathrm{Cl}$ & $\mathrm{OMe}$ \\
\hline $\mathbf{3}$ & $\mathrm{Cl}$ & $\mathrm{SMe}$ \\
\hline $\mathbf{4}$ & $\mathrm{SMe}$ & $\mathrm{SMe}$ \\
\hline $\mathbf{5}$ & $\mathrm{SMe}$ & $\mathrm{OMe}$ \\
\hline $\mathbf{6}$ & $\mathrm{OMe}$ & $\mathrm{OMe}$ \\
\hline $\mathbf{7}$ & $\mathrm{OMe}$ & $\mathrm{NMe}_{2}$
\end{tabular}

Table 1: Synthesized pyridine carboxylic acids.

\subsection{SYNTHESIS OF ISOCOMBRETASTATINS}

Isocombretastatin synthesis is performed by Wittig reaction from corresponding phenstatins and a phosphonium salt.

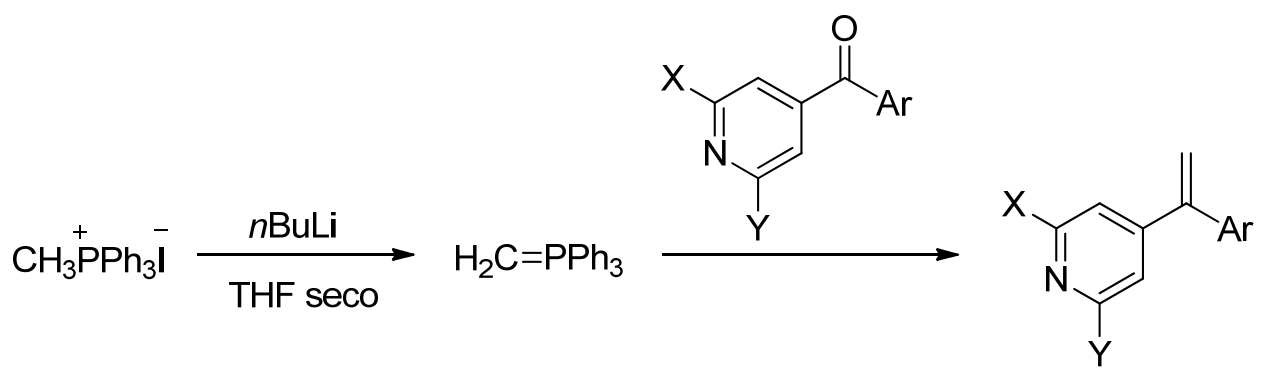

Scheme 3: Synthetic scheme for Isocombretastatins.

The first step is the preparation at $-40^{\circ} \mathrm{C}$ of the phosphorus ylide by treatment of the phosphonium salt with a strong base such as nBuLi. The final step is the addition of the ketone previously dissolved in dry THF.

The reaction product is purified by flash chromatography and the yields range from $20-95 \%$. 


\subsection{MODIFICATIONS OF AROMATIC B RING}

Once the phenstatins and isocombretastatins were obtained, modifications of these products were undertaken.

\subsubsection{MODIFICATION OF THE PHENYL RING}

In an attempt to increase the solubility of the compounds, an amino group was introduced at 3 position.

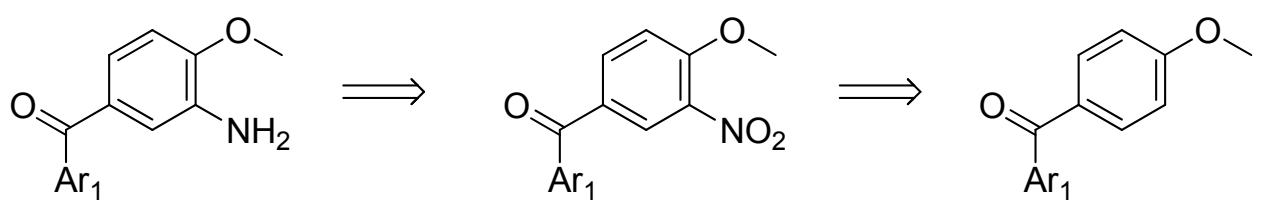

Scheme 4: Methodology planned for the introduction of amino groups on the $p$-methoxyphenyl ring.

For the reduction of the nitrophenstatins ${ }^{11}$, Fe in methanol/water/acetic acid was used to avoid the reduction of the bridge.

\subsubsection{MODIFICATIONS AT THE POSITION 3 OF THE INDOLE RING}

In our research group numerous compounds with $N$-methylindole systems have been synthesized ${ }^{12}$, and modifications at the 3 position were introduced in order to improve the aqueous solubility of these compounds. In this way, several functional groups such as carboxylic acids, aldehydes, carbonitriles and amides were introduced.

\footnotetext{
${ }^{11}$ Liou JP, Chang CW, Song JS, Yang YN, Yeh CF, Tseng HY, et al. Synthesis and structureactivity relationship of 2-aminobenzophenone derivatives as antimitotic agents. J Med Chem, 2002, 45, 2556-2562.

12 Alvarez R, Puebla P, Diaz JF, Bento AC, Garcia-Navas R, de la Iglesia-Vicente J, et al. Endowing indole-based tubulin inhibitors with an anchor for derivatization: highly potent 3substituted indolephenstatins and indoleisocombretastatins. J Med Chem, 2013, 56, 2813-2827
} 


\subsubsection{Formylations}

The formylation of the indole compounds was carried out by Vilsmeier-Haack reaction and the resulting compounds were used as starting materials for the preparation of carbonitriles, amides, etc.

The reaction takes place using an excess of dimethylformamide in presence of 6 $\mathrm{mmol}$ of $\mathrm{POCl}_{3} / \mathrm{mmol}$ of compound at $60{ }^{\circ} \mathrm{C}$ (phenstatin as starting materials) or at room temperature (isocombretastatin as starting materials) for two hours.

\subsubsection{Introduction of carboxylic acids}

$20 \%$ phosgene in toluene is used to introduce carboxilic groups using $\mathrm{CH}_{2} \mathrm{Cl}_{2}$ as solvent. The acid chloride derivative in contact with water is transformed into the carboxylic acid.

\subsubsection{Formation of carbonitriles}

Synthesis of phenstatins and isocombretastatins with a carbonitrile at the 3 position of the indole was carried out in two steps from the aldehyde. First, oxime derivatives were formed and then,treatment with acetic anhydride resulted in the formation of the carbonitriles.
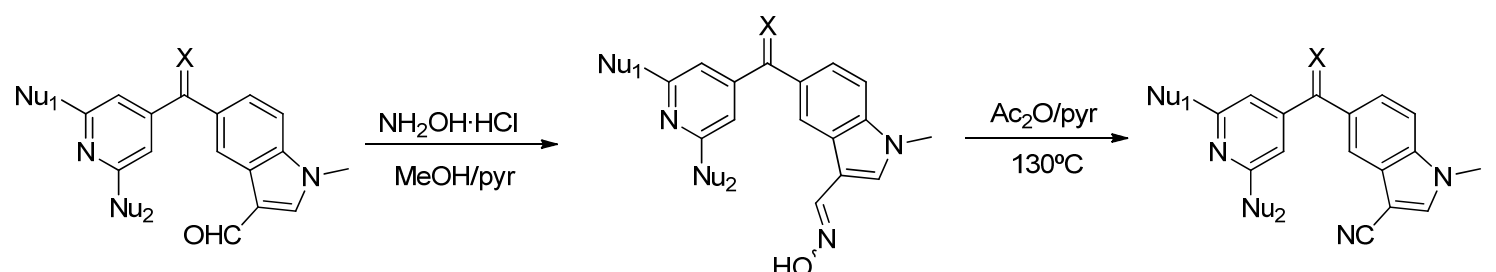

Scheme 5: Synthetic scheme for the preparation of carbonitriles 


\subsubsection{Synthesis of amides}

The conditions described by Kim et al were used for the synthesis of amide derivatives. Reaction of 1.5 equivalents of chlorosulfonyl isocyanate in 1,2dichloroethane as solvent for 24 hours at room temperature, with yields from 6 to $31 \%$.

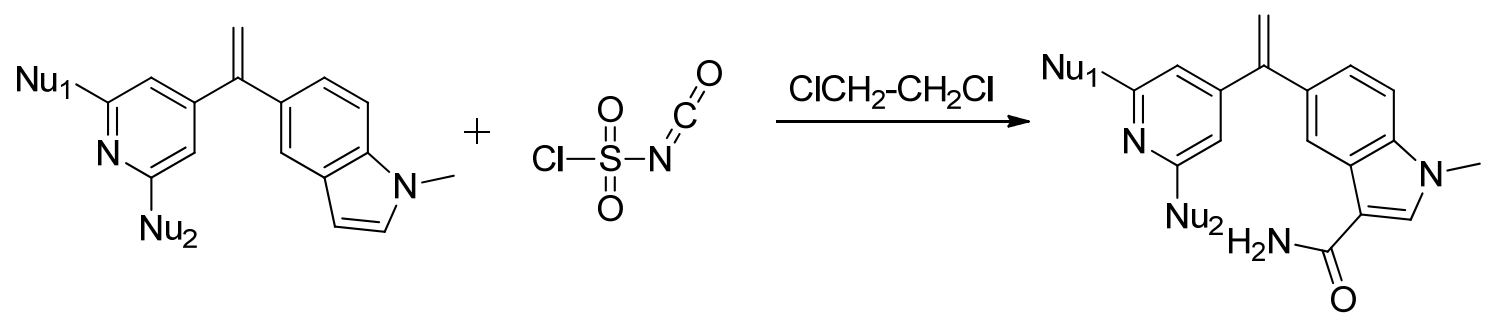

Scheme 6. Synthetic scheme for the preparation of amides at 3 positionof indole ring.

\subsubsection{BRIDGE MODIFICATION}

We have previously ${ }^{13}$ introduced oximes thus maintaining the $\mathrm{sp}^{2}$ hybridization resulting in compounds with high cytotoxic potency. The introduction of this group increases the probability of establishing hydrogen bonds, thus increasing the aqueous solubility of these compounds. Furthermore, the synthesis is simple and good yields were obtained. The usual procedure is carried out by dissolving the phenstatin in methanol and adding an excess of hydroxylamine hydrochloride with 4 drops of pyridine.

\footnotetext{
13 Alvarez C, Alvarez R, Corchete P, Lopez JL, Perez-Melero C, Pelaez R, et al. Diarylmethyloxime and hydrazone derivatives with 5-indolyl moieties as potent inhibitors of tubulin polymerization. Bioorg Med Chem, 2008, 16, 5952-5961.
} 


\subsection{SYNTHESIS OF COMBRETASTATINS}

With the aim of comparing some combretastatins with the phenstatins and isocombretastatins synthesized in this work, the preparation of some derivatives with the same combination of aromatic rings was undertaken. For this study it was decided to maintain the $p$-methoxyphenyl ring or the $N$-methylindole as $\mathrm{B}$ ring.

Combretastatin synthesis is performed using Wittig reaction between the ylide from disubstituted pyridine phosphonium bromides and the corresponding carbaldehydes, producing mixtures of $E$ and $Z$ isomers.

Reaction products were separated by flash chromatography and $Z$ and $E$ isomers were characterized according to these differences:

- The coupling constant of bridge protons has a value of $12 \mathrm{~Hz}$ for the cis isomer, and $16 \mathrm{~Hz}$ for the trans isomer.

- The chemical shifts of the bridge protons are larger for trans than for cis isomers.

\subsubsection{PREPARATION OF PHOSPHONIUM SALTS FROM ISONICOTINIC ACID}

Phosphonium salts of the pyridine derivatives are not commercial, and were prepared from the isonicotinic acids by the following scheme:

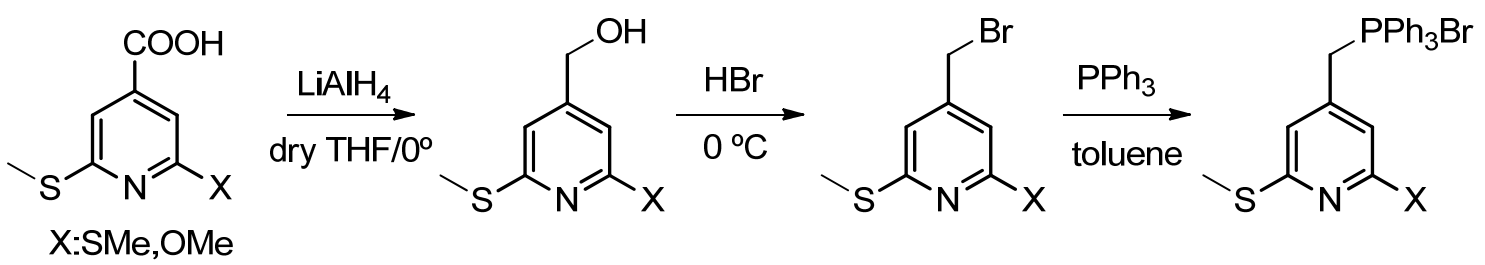

Scheme 7: Preparation of the phosphonium salts. 


\subsection{SYNTHESIS OF OXADIAZOLINES}

Oxadiazolines are colchicine analogues with a three-atom bridge. The synthesis of these compounds was performed in three steps outlined in the following scheme:

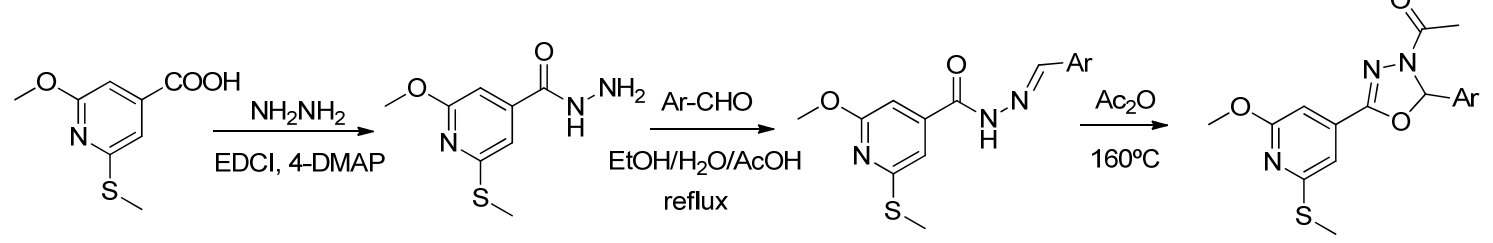

Scheme 8: General scheme for the synthesis of oxadiazolines.

The first step involves the synthesis of the hydrazide, which subsequently reacts with an aldehyde to give a carbohydrazide. The last step is a cyclization where the oxadiazoline is obtained. 


\section{4 - BIOLOGICAL ACTIVITY}

The compounds synthesized in this work are designed to bind to tubulin at the colchicine site and therefore, the effect produced on the protein can be assessed by measuring their effect on cell viability. With this aim, two different biological assays were carried out:

- Tubulin polymerization inhibitory activity (TPI).

- Cytotoxicity assay on different cell lines.

\subsection{TUBULIN POLYMERIZATION INHIBITORY ACTIVITY}

\subsubsection{TUBULIN ISOLATION}

Calf brain microtubule protein (MTP) was purified by two cycles of temperaturedependent assembly/disassembly, according to a modification of the method of Shelanski ${ }^{14}$. The MTP solution was stored at $-80{ }^{\circ} \mathrm{C}$. Protein concentrations were determined by the Bradford's method, using BSA as standard.

${ }^{14}$ Shelanski ML, Gaskin F, Cantor CR. Microtubule assembly in the absence of added nucleotides. Proc. Nat. Acad. Sci. 1973, 70, 765-768. 


\subsubsection{TUBULIN ASSEMBLY INHIBITORY ACTIVITY OF THE COMPOUNDS}

In vitro tubulin self-assembly was turbidimetrically monitored at $450 \mathrm{~nm}$. The ligands were dissolved in DMSO and the final amount of DMSO in the assays was kept at $4 \%$, which has been reported not to interfere with the assembly process. The increase in turbidity was simultaneously followed in a batch of six cuvettes (containing $1.0 \mathrm{mg} / \mathrm{mL}$ MTP in $0.1 \mathrm{M}$ MED buffer, $1 \mathrm{mM}$ EGTA, $1 \mathrm{mM} \mathrm{MgCl}, 1 \mathrm{mM} \beta$ mercaptoethanol, $1.5 \mathrm{mM} \mathrm{GTP}, \mathrm{pH}=6.7$, and the measured ligand concentration), with a control (with no ligand) being always included.

The samples were preincubated for $30 \mathrm{~min}$ at $20^{\circ} \mathrm{C}$ in order to allow ligand binding, and were cooled on ice for $10 \mathrm{~min}$. The cuvettes were then placed in the spectrophotometer at $4{ }^{\circ} \mathrm{C}$. The assembly process was initiated by a shift in the temperature to $37^{\circ} \mathrm{C}$ and the percentage of inhibition (with respect to a sample with no drug) of tubulin polymerization at a single concentration (tipically $5 \mu \mathrm{M}$ ) was determined in at least two independent experiments for each compound. Compounds which inhibit tubulin polymerization more than $50 \%$ at $5 \mu \mathrm{M}$ (with expected $\mathrm{IC}_{50}$ lower than $5 \mu \mathrm{M}$ ) were selected for the determination of their $\mathrm{IC}_{50}$.

\subsubsection{DETERMINATION OF THE IC $_{50}$ OF TUBULIN ASSEMBLY INHIBITORY ACTIVITY OF THE SELECTED COMPOUNDS}

The $\mathrm{IC}_{50}$ was calculated as the concentration of drug causing $50 \%$ inhibition of polymerization after $20 \mathrm{~min}$ of incubation and was analytically determined. The following table shows the obtained results: 


\begin{tabular}{|c|c|c|c|c|c|}
\hline COMP & $I^{\prime} C_{50}(\mu \mathrm{M})$ & COMP & $\mathrm{IC}_{50}(\mu \mathrm{M})$ & COMP & $\mathrm{IC}_{50}(\mu \mathrm{M})$ \\
\hline 34 & 2,5 & 72 & 2,4 & 104 & 2,4 \\
\hline 40 & 1,5 & 73 & 0,3 & 105 & 0,7 \\
\hline 41 & 4,6 & 76 & 1,6 & 109 & 2,4 \\
\hline 43 & 1,1 & 80 & 0,2 & 110 & 1,6 \\
\hline 46 & 2,0 & 82 & 0,6 & 111 & 3,2 \\
\hline 47 & 3,4 & 83 & 2,3 & 115 & 1,4 \\
\hline 50 & 4,1 & 86 & 1,6 & 117 & 1,0 \\
\hline 51 & 1,3 & 89 & 2,9 & 119 & 4,8 \\
\hline 54 & 0,9 & 93 & 2,9 & 121 & 1,9 \\
\hline 56 & 0,6 & 94 & 1,7 & 123 & 1,6 \\
\hline 59 & 1,4 & 96 & 1,1 & 142 & 3,8 \\
\hline 61 & 4,9 & 97 & 0,9 & 143 & 2,1 \\
\hline 63 & 0,9 & 99 & 1,2 & $146 z$ & 3,8 \\
\hline 68 & 4 & 100 & 4,7 & $148 z$ & 4,1 \\
\hline 70 & 2,5 & 102 & 0,4 & $149 z$ & 1,0 \\
\hline 71 & 3,4 & 103 & 2,4 & CA-4 & 3 \\
\hline
\end{tabular}

Table 2: $I_{50}$ values of tubulin assembly inhibitory activity of selected compounds. 


\subsection{CYTOTOXICITY ASSAYS}

The toxicity against cancer cell lines of the synthesized compounds in this work was carried out using the XTT Roche ${ }^{\circledR}$ viability tests. This method was first used by Scudiero ${ }^{15}$ et al, for the spectrophotometric quantification of cell growth and viability. This test consists in the determination of mitochondrial activity of the cells by adding a tetrazolium salt which is transformed in formazan into living cells, a soluble and orangereddish coloured compound whose absorbance can be related to the amount of live cells.

The compounds were tested against different cell lines for cytotoxicity. For this purpose, these types of cells were used:

- HL-60: Human myeloid leukemia.

- HeLa: Human cervical carcinoma.

- HT-29: Human colon carcinoma.

Cells in exponential growth phase were cultivated in 96-well plates with appropriate cell line concentration and, after incubating for 72 hours with compounds, XTT is added and incubated for 4-24 hours. The absorbance measurements were carried out in an ELISA microwell plate reader. In this test a positive control is formed by cells without compounds at $72 \mathrm{~h}$, and a negative control is formed by cells without compound at 0 hours of incubation. Absorbance was measured and the growth percentage is calculated in relation to the positive control. With these values at different concentrations, the $\mathrm{IC}_{50}$ value is calculated.

The $\mathrm{IC}_{50}$ values calculated are shown below:

\footnotetext{
${ }^{15}$ Scudiero DA, Shoemaker RH, Paull KD, Monks A, Tierney S, Nofziger TH, et al. Evaluation of a soluble tetrazolium/formazan assay for cell growth and drug sensitivity in culture using human and other tumor cell lines. Cancer Research, 1988, 48, 4827-4833. b) Skehan P, Storeng R, Scudiero D, Monks A, McMahon J, Vistica D, Warren JT, Bokesch H, Kenney S, Boyd MR. New colorimetric cytotoxicity assay for anticancer-drug screening. J. Natl. Cancer Inst. 1990, 82, 1107-1112.
} 


\begin{tabular}{|c|c|c|c|c|c|c|c|}
\hline COMP & $\begin{array}{c}\mathrm{IC}_{50} \text { Hela } \\
\left(10^{-6} \mathrm{M}\right)\end{array}$ & $\begin{array}{c}\mathrm{IC}_{50} \mathrm{HL60} \\
\left(10^{-6} \mathrm{M}\right)\end{array}$ & $\begin{array}{c}\mathrm{IC}_{50} \mathrm{HT} 29 \\
\left(10^{-6} \mathrm{M}\right)\end{array}$ & COMP & $\begin{array}{c}\mathrm{IC}_{50} \text { Hela } \\
\left(10^{-6} \mathrm{M}\right)\end{array}$ & $\begin{array}{c}\mathrm{IC}_{50} \mathrm{HL60} \\
\left(10^{-6} \mathrm{M}\right)\end{array}$ & $\begin{array}{c}\mathrm{IC}_{50} \mathrm{HT} 29 \\
\left(10^{-6} \mathrm{M}\right)\end{array}$ \\
\hline 25 & $\geq 1$ & $\geq 1$ & $\geq 1$ & 88 & $\geq 1$ & $\geq 1$ & $\geq 1$ \\
\hline 26 & $0,4 \pm 0,09$ & $0,6 \pm 0,2$ & $\geq 1$ & 89 & $0,4 \pm 0,01$ & $0,1 \pm 0,005$ & $0,7 \pm 0,07$ \\
\hline 27 & $\geq 1$ & $\geq 1$ & $\geq 1$ & 93 & $0,8 \pm 0,005$ & $0,2 \pm 0,02$ & $\geq 1$ \\
\hline 28 & $\geq 1$ & $\geq 1$ & $\geq 1$ & 94 & $0,2 \pm 0,08$ & $0,2 \pm 0,06$ & $0,5 \pm 0,07$ \\
\hline 29 & $\geq 1$ & $\geq 1$ & $\geq 1$ & 95 & $\geq 1$ & $\geq 1$ & $\geq 1$ \\
\hline 30 & $\geq 1$ & $\geq 1$ & $\geq 1$ & 96 & $0,5 \pm 0,1$ & $0,7 \pm 0,07$ & $0,2 \pm 0,03$ \\
\hline 31 & $\geq 1$ & $\geq 1$ & $\geq 1$ & 97 & $0,5 \pm 0,2$ & $0,2 \pm 0,07$ & $0,7 \pm 0,1$ \\
\hline 32 & $\geq 1$ & $\geq 1$ & $\geq 1$ & 98 & $\geq 1$ & $\geq 1$ & $\geq 1$ \\
\hline 34 & $0,03 \pm 0,004$ & $0,2 \pm 0,01$ & $\geq 1$ & 99 & $0,1 \pm 0,02$ & $0,3 \pm 0,006$ & $0,5 \pm 0,1$ \\
\hline 36 & $\geq 1$ & $\geq 1$ & $\geq 1$ & 100 & $\geq 1$ & $\geq 1$ & $\geq 1$ \\
\hline 37 & $\geq 1$ & $\geq 1$ & $\geq 1$ & 102 & $0,6 \pm 0,001$ & $0,6 \pm 0,1$ & $0,5 \pm 0,2$ \\
\hline 38 & $\geq 1$ & $\geq 1$ & $\geq 1$ & 103 & $0,6 \pm 0,2$ & $0,2 \pm 0,04$ & $0,2 \pm 0,06$ \\
\hline 39 & $\geq 1$ & $\geq 1$ & $\geq 1$ & 104 & $0,5 \pm 0,1$ & $0,3 \pm 0,1$ & $0,7 \pm 0,05$ \\
\hline 40 & $0,4 \pm 0,09$ & $0,4 \pm 0,06$ & $0,4 \pm 0,1$ & 105 & $0,2 \pm 0,03$ & $0,3 \pm 0,01$ & $0,5 \pm 0,1$ \\
\hline 41 & $0,5 \pm 0,03$ & $0,7 \pm 0,2$ & $\geq 1$ & 106 & $0,6 \pm 0,08$ & $0,6 \pm 0,1$ & $\geq 1$ \\
\hline 42 & $0,9 \pm 0,04$ & $\geq 1$ & $\geq 1$ & 107 & $\geq 1$ & $\geq 1$ & $\geq 1$ \\
\hline 43 & $0,3 \pm 0,02$ & $0,3 \pm 0,02$ & $0,2 \pm 0,04$ & 109 & $0,3 \pm 0,04$ & $0,9 \pm 0,08$ & $0,4 \pm 0,2$ \\
\hline 44 & $0,4 \pm 0,1$ & $\geq 1$ & $\geq 1$ & 110 & $\geq 1$ & $0,1, \pm 0,008$ & $\geq 1$ \\
\hline 45 & $\geq 1$ & $\geq 1$ & $\geq 1$ & 111 & $0,3 \pm 0,07$ & $0,2 \pm 0,008$ & $0,6 \pm 0,2$ \\
\hline 46 & $0,4 \pm 0,1$ & $0,3 \pm 0,1$ & $0,5 \pm 0,2$ & 112 & $0,7 \pm 0,1$ & $\geq 1$ & $\geq 1$ \\
\hline 47 & $0,4 \pm 0,1$ & $0,3 \pm 0,1$ & $0,2 \pm 0,08$ & 115 & $0,3 \pm 0,03$ & $0,5 \pm 0,1$ & $0,5 \pm 0,1$ \\
\hline 48 & $\geq 1$ & $\geq 1$ & $\geq 1$ & 117 & $0,6 \pm 0,07$ & $0,7 \pm 0,08$ & $0,6 \pm 0,1$ \\
\hline 49 & $\geq 1$ & $\geq 1$ & $\geq 1$ & 119 & $0,6 \pm 0,08$ & $0,3 \pm 0,05$ & $0,4 \pm 0,1$ \\
\hline 50 & $0,5 \pm 0,1$ & $0,3 \pm 0,01$ & $\geq 1$ & 120 & $\geq 1$ & $\geq 1$ & $\geq 1$ \\
\hline 51 & $0,2 \pm 0,05$ & $0,3 \pm 0,03$ & $0,2 \pm 0,005$ & 121 & $0,1 \pm 0,04$ & $0,3 \pm 0,1$ & $0,7 \pm 0,06$ \\
\hline 52 & $\geq 1$ & $\geq 1$ & $\geq 1$ & 123 & $0,6 \pm 0,1$ & $0,7 \pm 0,1$ & $0,4 \pm 0,09$ \\
\hline 53 & $\geq 1$ & $\geq 1$ & $\geq 1$ & 125 & $\geq 1$ & $\geq 1$ & $\geq 1$ \\
\hline 54 & $0,07 \pm 0,01$ & $0,06 \pm 0,02$ & $0,5 \pm 0,01$ & 126 & $\geq 1$ & $\geq 1$ & $\geq 1$ \\
\hline 55 & $\geq 1$ & $\geq 1$ & $\geq 1$ & 127 & $0,7 \pm 0,08$ & $\geq 1$ & $\geq 1$ \\
\hline 56 & $0,3 \pm 0,05$ & $0,2 \pm 0,04$ & $0,3 \pm 0,02$ & 128 & $\geq 1$ & $\geq 1$ & $\geq 1$ \\
\hline 57 & $0,5 \pm 0,1$ & $\geq 1$ & $\geq 1$ & 129 & $\geq 1$ & $\geq 1$ & $\geq 1$ \\
\hline 58 & $\geq 1$ & $\geq 1$ & $\geq 1$ & 130 & $\geq 1$ & $\geq 1$ & $\geq 1$ \\
\hline 59 & $0,4 \pm 0,006$ & $0,4 \pm 0,1$ & $0,3 \pm 0,03$ & 131 & $\geq 1$ & $\geq 1$ & $\geq 1$ \\
\hline 60 & $0,6 \pm 0,1$ & $\geq 1$ & $\geq 1$ & 132 & $\geq 1$ & $\geq 1$ & $\geq 1$ \\
\hline 61 & $0,8 \pm 0,02$ & $0,7 \pm 0,2$ & $\geq 1$ & 133 & $\geq 1$ & $\geq 1$ & $\geq 1$ \\
\hline 62 & $\geq 1$ & $\geq 1$ & $\geq 1$ & 134 & $\geq 1$ & $\geq 1$ & $\geq 1$ \\
\hline 63 & $0,04 \pm 0,01$ & $0,08 \pm 0,007$ & $0,4 \pm 0,12$ & 135 & $\geq 1$ & $\geq 1$ & $\geq 1$ \\
\hline 64 & $\geq 1$ & $\geq 1$ & $\geq 1$ & 136 & $\geq 1$ & $\geq 1$ & $\geq 1$ \\
\hline 65 & $0,2 \pm 0,06$ & $0,2 \pm 0,06$ & $\geq 1$ & 137 & $0,6 \pm 0,2$ & $0,5 \pm 0,2$ & $\geq 1$ \\
\hline 68 & $0,3 \pm 0,2$ & $0,07 \pm 0,02$ & $0,9 \pm 0,2$ & 138 & $0,5 \pm 0,2$ & $0,30 \pm 0,02$ & $\geq 1$ \\
\hline 70 & $0,08 \pm 0,01$ & $0,07 \pm 0,0004$ & $0,1 \pm 0,01$ & 139 & $0,6 \pm 0,2$ & $0,3 \pm 0,1$ & $\geq 1$ \\
\hline 71 & $0,05 \pm 0,02$ & $0,074 \pm 0,003$ & $0,09 \pm 0,01$ & 140 & $0,6 \pm 0,021$ & $0,4 \pm 0,2$ & $0,8 \pm 0,03$ \\
\hline
\end{tabular}




\begin{tabular}{cccc|cccc}
$\mathbf{7 2}$ & $0,3 \pm 0,1$ & $0,4 \pm 0,09$ & $\geq 1$ & $\mathbf{1 4 1}$ & $\geq 1$ & $\geq 1$ & $\geq 1$ \\
\hline $\mathbf{7 3}$ & $0,1 \pm 0,02$ & $0,4 \pm 0,1$ & $0,5 \pm 0,2$ & $\mathbf{1 4 2}$ & $0,3 \pm 0,08$ & $0,4 \pm 0,2$ & $0,94 \pm 0,05$ \\
\hline $\mathbf{7 4}$ & $0,3 \pm 0,007$ & $0,2 \pm 0,03$ & $\geq 1$ & $\mathbf{1 4 3}$ & $0,2 \pm 0,03$ & $0,2 \pm 0,07$ & $0,8 \pm 0,1$ \\
\hline $\mathbf{7 5}$ & $\geq 1$ & $\geq 1$ & $\geq 1$ & $\mathbf{1 4 4}$ & $\geq 1$ & $\geq 1$ & $\geq 1$ \\
\hline $\mathbf{7 6}$ & $0,07 \pm 0,01$ & $0,04 \pm 0,001$ & $0,8 \pm 0,04$ & $\mathbf{1 4 5}$ & $\geq 1$ & $\geq 1$ & $\geq 1$ \\
\hline $\mathbf{7 7}$ & $\geq 1$ & $\geq 1$ & $\geq 1$ & $\mathbf{1 4 6 z}$ & $\geq 1$ & $\geq 1$ & $\geq 1$ \\
\hline $\mathbf{8 0}$ & $0,06 \pm 0,01$ & $0,09 \pm 0,001$ & $0,1 \pm 0,002$ & $\mathbf{1 4 7 z}$ & $\geq 1$ & $\geq 1$ & $0,6 \pm 0,2$ \\
\hline $\mathbf{8 2}$ & $0,1 \pm 0,05$ & $0,07 \pm 0,002$ & $0,3 \pm 0,1$ & $\mathbf{1 4 8 z}$ & $\geq 1$ & $\geq 1$ & $\geq 1$ \\
\hline $\mathbf{8 3}$ & $0,08 \pm 0,003$ & $0,04 \pm 0,01$ & $0,3 \pm 0,008$ & $\mathbf{1 4 9 z}$ & $0,3 \pm 0,09$ & $0,4 \pm 0,3$ & $0,4 \pm 0,03$ \\
\hline $\mathbf{8 4}$ & $0,2 \pm 0,03$ & $0,6 \pm 0,04$ & $\geq 1$ & $\mathbf{1 5 0}$ & $\geq 1$ & $\geq 1$ & $\geq 1$ \\
\hline $\mathbf{8 5}$ & $0,6 \pm 0,1$ & $0,3 \pm 0,1$ & $0,7 \pm 0,1$ & $\mathbf{1 5 1}$ & $\geq 1$ & $\geq 1$ & $\geq 1$ \\
\hline $\mathbf{8 6}$ & $0,2 \pm 0,04$ & $0,2 \pm 0,03$ & $\geq 1$ & $\mathbf{1 5 2}$ & $\geq 1$ & $\geq 1$ & $\geq 1$
\end{tabular}

Table 3: Results obtained in cytotoxicity assays of the 109 prepared compounds.

\subsection{DISCUSSION OF THE BIOLOGICAL ACTIVITY RESULTS}

\subsubsection{COMPOUNDS WITH $p$-METHOXYPHENYL AS B RING}

36 compounds with p-methoxyphenyl system as B ring have been synthesized and assayed, 16 of them showing $\mathrm{IC}_{50}$ values lower than $1 \mathrm{uM}$ in the Cytotoxicity assay. 11 out of these 16 compounds have an IC $\mathrm{I}_{50}$ value in TPI lower than $5 \mu \mathrm{M}$. showing a correlation between TPI and Cytotoxicity values.

The best results in activity have been observed for compounds with an amino group at 3 position. Also, with respect to the bridge between the two rings, the isocombretastatins are the most potent compounds compared to phenstatins and oximes. 


\subsubsection{COMPOUNDS WITH N-METHYLINDOLE AS B RING}

51 compounds have been synthesized with $N$-methylindole system as $\mathrm{B}$ ring, and 36 have an $\mathrm{IC}_{50}$ value below $1 \mu \mathrm{M}$ in cytotoxicity assay. 30 out of these 36 compounds have an $\mathrm{IC}_{50}$ value in TPI lower than $5 \mu \mathrm{M}$.

Compounds with high potency in cytotoxicity have a good profile in TPI; however, some families do not match this tendency, such as isocombretastatinas with carboxamide at 3 position.

Compounds with $\mathrm{N}$-methylindole are the most potent synthesized compounds in this work in both biological activity assays. The introduction of functional groups at 3 position leads in some cases to an increase in comparison to hydrogen. Furthermore, the most potent compounds have a methylene group in the bridge. Compounds with an oxime bridge have also great activity profile.

Due to the variability in the activity results, it is difficult to draw a pattern for the substituents on the ring $A$.

\subsubsection{COMPOUNDS WITH OTHER AROMATIC SYSTEMS AS B RING}

Compounds having a naphthalene, a 3-dimethylaminophenyl, or a pyridine moiety as $B$ ring do not improve the activity with respect to reference combretastatins. However, compounds with 4-dimethylaminophenyl ring have good activity profile in TPI and cytotoxicity.

\subsubsection{COMPOUNDS WITH MORE THAN ONE BRIDGING ATOM}

Oxadiazolines do not maintain the activity of the reference compounds. However, combretastatins have a good profile in TPI activity and cytotoxicity. 


\section{5 - SOLUBILITY ASSAY}

Solubility test were carried out to measure the amount of drug that is dissolved in a pH 7 in phosphate buffer (physiological pH) after 48 hours under continuous stirring. Then, the buffer is filtered to remove the drug that has not been dissolved and the amount of drug that is dissolved in the buffer is determined spectrophotometrically at a particular wavelength for each compound.

The results obtained are shown below: 
<smiles>[X]c1cc(C([Z])[R18])cc([Y])n1</smiles>

\begin{tabular}{|c|c|c|c|c|c|c|c|c|c|c|c|c|c|}
\hline no & $x$ & $Y$ & z & B Ring & $\mathbf{R}$ & $\begin{array}{c}S \\
(\mu \mathrm{g} / \mathrm{ml})\end{array}$ & no & $x$ & $Y$ & z & B Ring & $\mathbf{R}$ & $\underset{(\mu \mathrm{g} / \mathrm{ml})}{S}$ \\
\hline 25 & $\mathrm{Cl}$ & $\mathrm{Cl}$ & 0 & 4-MeO-Ph & $\mathrm{H}$ & 10,4 & 88 & SMe & OMe & $\mathrm{CH}_{2}$ & NMeIND & $\mathrm{COOH}$ & 151,9 \\
\hline 27 & $\mathrm{Cl}$ & $\mathrm{Cl}$ & $\mathrm{NOH}$ & 4-MeO-Ph & $\mathrm{H}$ & 29,5 & 93 & SMe & OMe & 0 & NMeIND & $\mathrm{CN}$ & 14,9 \\
\hline 34 & $\mathrm{Cl}$ & OMe & 0 & 4-MeO-Ph & $\mathrm{NH}_{2}$ & 56,2 & 98 & $\mathrm{SMe}$ & SMe & 0 & NMeIND & $\mathrm{CHO}$ & 230,2 \\
\hline 37 & $\mathrm{Cl}$ & MePh-NH & 0 & 4-MeO-Ph & $\mathrm{H}$ & 2,2 & 99 & SMe & SMe & $\mathrm{CH}_{2}$ & NMeIND & $\mathrm{CHO}$ & 7,6 \\
\hline 40 & $\mathrm{Cl}$ & SMe & $\mathrm{CH}_{2}$ & 4-MeO-Ph & $\mathrm{H}$ & 48,9 & 100 & $\mathrm{SMe}$ & SMe & $\mathrm{CH}_{2}$ & NMeIND & $\mathrm{COOH}$ & 102,7 \\
\hline 41 & $\mathrm{Cl}$ & SMe & $\mathrm{NOH}$ & 4-MeO-Ph & $\mathrm{H}$ & 41,7 & 102 & SMe & SMe & $\mathrm{CH}_{2}$ & NMeIND & $\mathrm{CN}$ & 46,3 \\
\hline 42 & $\mathrm{Cl}$ & $\mathrm{NMe}_{2}$ & 0 & 4-MeO-Ph & $\mathrm{H}$ & 10,7 & 104 & SMe & $\mathrm{NMe}_{2}$ & 0 & NMeIND & $\mathrm{H}$ & 8,2 \\
\hline 43 & $\mathrm{Cl}$ & $\mathrm{NMe}_{2}$ & $\mathrm{CH}_{2}$ & 4-MeO-Ph & $\mathrm{H}$ & 18,0 & 105 & SMe & $\mathrm{NMe}_{2}$ & $\mathrm{CH}_{2}$ & NMeIND & $\mathrm{H}$ & 0 \\
\hline 45 & SMe & SMe & 0 & 4-MeO-Ph & $\mathrm{H}$ & 1,5 & 108 & SMe & $\mathrm{NMe}_{2}$ & 0 & NMeIND & $\mathrm{CHO}$ & 47,6 \\
\hline 46 & SMe & SMe & $\mathrm{CH}_{2}$ & 4-MeO-Ph & $\mathrm{H}$ & 35,7 & 115 & SMe & $\mathrm{NMe}_{2}$ & $\mathrm{NOH}$ & NMeIND & $\mathrm{CN}$ & 5,3 \\
\hline 49 & SMe & OMe & 0 & 4-MeO-Ph & $\mathrm{H}$ & 17,0 & 123 & $\mathrm{Cl}$ & $\mathrm{NMe}_{2}$ & $\mathrm{CH}_{2}$ & NMeIND & $\mathrm{CN}$ & 6,0 \\
\hline 50 & SMe & OMe & $\mathrm{CH}_{2}$ & 4-MeO-Ph & $\mathrm{H}$ & 10,9 & 128 & SOMe & OMe & 0 & 2-Naft & $\mathrm{H}$ & 34,5 \\
\hline 54 & SMe & OMe & 0 & 4-MeO-Ph & $\mathrm{NH}_{2}$ & 37,3 & 132 & SMe & SMe & $\mathrm{CH}_{2}$ & 2-Naft & $\mathrm{H}$ & 1,9 \\
\hline 55 & SMe & $\mathrm{NMe}_{2}$ & 0 & 4-MeO-Ph & $\mathrm{H}$ & 7,4 & 134 & SMe & SMe & 0 & 3-NMe ${ }_{2} \mathrm{Ph}$ & $\mathrm{H}$ & 1,3 \\
\hline 56 & SMe & $\mathrm{NMe}_{2}$ & $\mathrm{CH}_{2}$ & 4-MeO-Ph & $\mathrm{H}$ & 7,5 & 135 & SMe & SMe & $\mathrm{CH}_{2}$ & $3-\mathrm{NMe}_{2} \mathrm{Ph}$ & $\mathrm{H}$ & 2,4 \\
\hline 57 & SMe & $\mathrm{NMe}_{2}$ & $\mathrm{NOH}$ & 4-MeO-Ph & $\mathrm{H}$ & 4,5 & 136 & SMe & SMe & $\mathrm{NOH}$ & 3-NMe ${ }_{2} \mathrm{Ph}$ & $\mathrm{H}$ & 14,7 \\
\hline 58 & OMe & $\mathrm{NMe}_{2}$ & 0 & 4-MeO-Ph & $\mathrm{H}$ & 6,9 & 138 & SMe & OMe & $\mathrm{CH}_{2}$ & $4-\mathrm{NMe}_{2} \mathrm{Ph}$ & $\mathrm{H}$ & 43,8 \\
\hline 59 & OMe & $\mathrm{NMe}_{2}$ & $\mathrm{CH}_{2}$ & 4-MeO-Ph & $\mathrm{H}$ & 22,9 & 139 & $\mathrm{SMe}$ & OMe & $\mathrm{NOH}$ & $4-\mathrm{NMe}_{2} \mathrm{Ph}$ & $\mathrm{H}$ & 4,6 \\
\hline 73 & $\mathrm{Cl}$ & SMe & $\mathrm{CH}_{2}$ & NMeIND & $\mathrm{H}$ & 12,3 & 140 & SMe & SMe & 0 & $4-\mathrm{NMe}_{2} \mathrm{Ph}$ & $\mathrm{H}$ & 1,0 \\
\hline 74 & $\mathrm{Cl}$ & SMe & $\mathrm{NOH}$ & NMeIND & $\mathrm{H}$ & 14,8 & 142 & SMe & SMe & $\mathrm{CH}_{2}$ & $4-\mathrm{NMe}_{2} \mathrm{Ph}$ & $\mathrm{H}$ & 6,9 \\
\hline 76 & $\mathrm{Cl}$ & SMe & $\mathrm{CH}_{2}$ & NMeIND & $\mathrm{CHO}$ & 6,3 & 143 & SMe & SMe & $\mathrm{NOH}$ & 4- $\mathrm{NMe}_{2} \mathrm{Ph}$ & $\mathrm{H}$ & 1,1 \\
\hline 80 & $\mathrm{Cl}$ & SMe & $\mathrm{NOH}$ & NMeIND & $\mathrm{CN}$ & 5,1 & 144 & SMe & SMe & 0 & Pyr & $\mathrm{H}$ & 47,1 \\
\hline 82 & $\mathrm{Cl}$ & SMe & $\mathrm{CH}_{2}$ & NMeIND & $\mathrm{CN}$ & 3,2 & $149 z$ & SMe & Ome & Combre & NMeIND & $\mathrm{H}$ & 19,1 \\
\hline 86 & SMe & OMe & $\mathrm{NOH}$ & NMeIND & $\mathrm{H}$ & 0 & 151 & SMe & Ome & Oxadiazo & 4-MeO-Ph & $\mathrm{H}$ & 9,8 \\
\hline 87 & SMe & OMe & 0 & NMeIND & $\mathrm{CHO}$ & 15,5 & 152 & SMe & Ome & Oxadiazo & NMeIND & $\mathrm{H}$ & 12,8 \\
\hline $\mathrm{CA}-4^{16}$ & & & & & & 1 & & & & & & & \\
\hline
\end{tabular}

Table 4: Solubility values of the compounds assayed.

\footnotetext{
${ }^{16}$ Chen J, Wang Z, Li CM, Lu Y, Vaddady PK, Meibohm B, et al. Discovery of novel 2-aryl-4benzoyl-imidazoles targeting the colchicines binding site in tubulin as potential anticancer agents. J Med Chem, 2010, 53, 7414-7427.
} 
Most of the compounds that have been tested have a greater value than the Combretastatin A-4, being in the 88, 98 and $\mathbf{1 0 0}$ compounds hundred times higher. The best results have been obtained for compounds with aldehydes and carboxylic acids at the indole 3 position. Good results were also obtained for compounds with amino group at 3 position of the $p$-methoxyphenyl ring. 


\section{6 - CONCLUSIONS}

In this work the synthesis and evaluation of new antimitotic agents related to phenstatins and isocombretastatins based on pyridine has been carried out. From the obtained results, it is possible to infer the following conclusions:

- The employed synthetic methodology for the synthesis of phenstatins and isocombretastatins is appropriate to obtain the desired compounds in high levels of purity and good yields in most cases.

- The substitution of trimethoxyphenyl ring by a disubstituted pyridine ring produce compounds which maintain or, in some cases, improve the activity. Because of that, this system is not anymore considered essential to the activity of the compounds.

- The synthesized compounds with aromatic rings at the 6 position of the pyridine ring leads to a lack of activity.

- Combinations of disubstituted pyridine ring with several aromatic B rings (indole, p-methoxyphenyl, naphthyl, ...) were performed. The best results were obtained for compounds with indole ring with or without substituents at 3 position of the ring, and also for compounds with $p$-methoxyphenyl rings with amino groups at 3 position. 
Compounds with naphthalene, pyridine, and dimethylaminophenyl moieties lead to a loss of activity.

- Isocombretastatins are more potent than phenstatins with the same structural elements in both $A$ and $B$ rings. In some cases the oximes are better than corresponding isocombretastatin, but generally they are worse.

- Compounds with more than one bridging atom have been synthesized (combretastatins and oxadiazolines). The first ones have activity depending on the other structural elements, and the second ones produce a lack of activity.

- Aqueous solubility of some compounds has been determined and most of them are more soluble than the reference compound $\mathrm{CA}-4$, being in some cases hundred times higher. This may be due to the introduction of groups with capacity to establish hydrogen bonds with water. 